
Natural History Museum Library 
. 
72 I

q

S. 
Dott. F E D E R I CO SACCO

Pıof, di Paleontologia e libero docente di Geologia nella R. Universiti di Torino

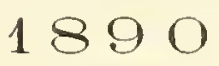

\section{IL BACINO TERZIARIO E QUATERNARIO DEL PIEMONTE}

Dopo circa 10 anni di studio venne ora condotta a termine e pubblicata la descrizizione del Bacino terziario e quaternario del Piemonte; questo Bacino, gia ben famoso paleontologicamente per la ricchezza in fossili terziari, specialmente di quelli tongriani dell'Appennino settentrionale, di quelli elveziani dei colli di Tolino, di quelli tortoniani delle vicinanze di Tortona, di quelli astiani dell'Astigiana, ece., diventera ora, dopo questo lavoro, un bacino pure affatto tipico dal lato geologico, presentando esso completa, graduale, bellissima la serie dei diversi orizzonti geologici, quasi tutti fossiliferi, lall'Eocene al Quaternario.

ll volume, di 940 pagine, è diviso in quattro parti, cioè:

Parte 1. - HBa da un indice alfabetico) di oltre 600 opere trattanti, esclusivamente o parzialmente, della geologia o della paleontologia del Bacino terziario del Pienonte.

Parte Il. - meologia purar. - Contiene la descrizione geologica del Bacino piemontese ell è divisa nei seguenti capitoli : Cerchia pleterziaria, Suessoniano e Parisinno, Iiguriano, Formazioni ofiolitiche del Liguriano, Bartoniano, Sestiano, Tongriano, stanpiano, Aquitaniano, Han= ghiano, Elveziano, Tortoniazo, Ressiniano, Piacenziano, Astiano, Fossaniano, Villafranchiano, Sahariano (Diluvium, Terreno morenico), Terrazziano (Alluvioni recenti), Paleoetnologia.

Ciascun capitolo è a sila volta suldiviso nei segrenti paragrafi:

Studi anteriori, Generalità, Caratteri paleontologici, Distribuzione geografica, Tetlonica, Potensa, Altimetria, Rapporto coi terreni solto e somirastanti, Localita fossizifere, Descrizione geologica regionale, Riassunto.

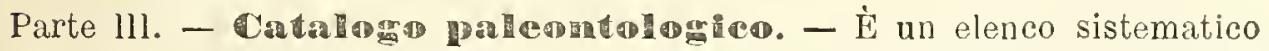
di circa 5500 forme terziar ie, di ciascuna delle quali è indicato il preciso orizzonte geologico di ritrovamento. Tale catalogo è diviso in tre parti, cioè: Paleoichologia, Paleofitologia e Paleozoologia; esso" termina con un Indice generale dei generi e dei sottogeneri.

Parte IV. - Geologia applieata. - In quest'ultima parte si tratta della geologia terziaria e quaternaria del bacino piemontese in rapporto colla Orografia, coll'Idrografia (sia superficiale che sotterranea), coll'Agricoltura, coll'Industria, Igiene, ecc. Riguardo a ciascuna di queste pirti, costituenti altrettanti capitoli, è esaminato singolarmente ognuno degli orizzonti geologici descritti nella parte 11. 
Al lavoro vanno unite diverse carte geologiche, cioè: $1^{\circ}$, Carta geo= logica del Baciuo tcrziario del Piemonte (scala di $1: 100.000$, dimensioni centim. $100 \times 120$, con 16 colori, legata su tela, entro astuccio); - $2^{\circ}$ Carta geologica del Bacino quaternario del Piemonte (scala di $1: 500.000) ;-3^{\circ}$, Carta geologica applicata (scala di 1:500.000); - 4' 19 Carte geologiche, in grinde scala, delle piu interessanti regioni del Bacino terziario, cioè: ad l:50.000, Spigno Monferrato, Voltaggin. Ovada, Ceva e Garessio, Cairo Montenotte; arl $1: 25.000$, Serravalle Scrivia, Gavi, Villalvernia e Garbagna, Anfiteatro morenico di Rivoli (centim. $110 \times 100$ ), Acqui, Capriata d'Orba, Fossano, Nizza Monferrato e Sezzè, Mombercelli e Canelli, Canale e Monteu Roero, Calamandralla, Costigliole d'Asti, I Colli torinesi (centim. $110 \times 100$, 12 colori), Cherasco e Cervere.

$N$. B. Numerose altre carte speciali del Bacino piemontese vanno unite a speciali lavori, recenti, indicati nella Bibliografia.

PREZZ 1 :

Il Volume (legato in tela) colle 3 prime carte geologiche: in $-4^{\circ}$ L. 40 ; in- $8^{\circ}$ L. 30

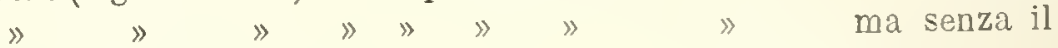

Catalogo paleontologico (pubblicato nel Boll. Soc. geol. it.), in- $8^{\circ}$ L. 20 Le 19 carte geol. in graude scala L. 30 ; ciascuna (eccetto 2 gr.) L. 1,50-2,50 La sola $1^{\text {a }}$ Carta geolonica del Bacino terziario (leg. in tela, entro astuccio) L. 10

\section{MOLLUSGHI}

dei terreni Terziarii del Piemonte e della Liguria

Questa opera grandiosa, ben nota ai Paleontologi, venne iniziata nel 1872 dal Prof. Luigi Bellardi che ne pubblico le prime 5 parti, comprendenti i Cefalopodi, gli Eteropodi, i Pteropodi e dei Gasteropodi le seguenti famiglie: Muricidae, Tritonidae, Pleurotomidae, Buccinidae, Cyclopsidae, Purpuridae, Coralliophilidae, Olividae, Fasciolaridae, Turbinellidae e Iilridae.

Il Prof. Sacco, allievo ed amico del Bellardi, dietro incarico aruto dalla R. Accademia delle Scienze di Torino, condusse a termine la parte 6’, giả iniziata dal Bellardi, e quindi intraprese la continuazione dell'opera, che ora trovasi a questo punto:

Parte VI. - Wolntidne, Maroginellidae e Columbellidae con 140 figure.

Parte VII. - Hianpidae e Cassididae - con 120 fig.

Parte VIll. - Eadoliidae, Dolidae, Ficuldac e Vaticidae con oltre $200 \mathrm{fig}$.

Parte IX. - Sentaroildae (in corso di stampa).

Parte $X$. - Terebridac, Dusionellidac, Pyramidellidae,

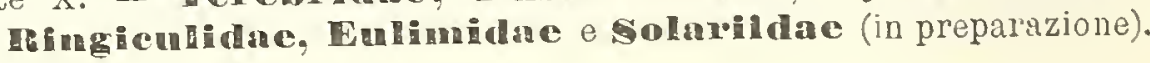


OPERE DELLO STESSO AUTORE

in deposito presso la Libreria LoescheR (C. Clausen) - Torino

\section{G E O L O G I A}

1. L'alta Valle Padana durante l'epoca delle terrazze in relazione col contemporaneo sollevamento della circ. cat. alpino-apenninica (l cart. geol.).

2. Nuove caverne ossifere e uon ossifere nelle Alpi marit. ed osservazioni ceol. fatte durante un'ascensione al Mongioie (2 tav. ed l carta geol.).

3. Sull'origine delle vallate e dei laghi alpini in rapporto coi sollevannenti delle Alpi e coi terreni pliocenici e quaternari della Valle Padana (1 cart. geol.).

4. Sopra alcuni fenomeni stratigrafici osservati nei terreni pliocenici dell'alta Valle Padana (1 tav.).

5. Massima elevazione del Pliocene al piede delle Alpi (l carta geol.).

6. Studio geo-paleontologico del territorio di Bene-Vigienna (l gr. carta geol.).

7.

8. Massima elevazione dell"Eocene nelle Alpi occ. italiane (1 carta geol.).

9. Sulla costituzione geolica degli altipiani isolati di Fossano, Salmour $\theta$ Banale (l grande carta geol).

10. 11 piano Messiniano nel Piemonte. Parte I.

11. 》 》 》 $\gg$ II (1 tav.).

12. Des phénomènes altimétriques observès dans l'intérieur des continents.

13. Il Villafranchiano al piede delle A!pi (l tav.).

14. 11 terlazzamento dei littorali e delle vallate (l tav.).

15. I Bacini torbiferi di Trana e di Avigliana (1 carta geol.).

16. Le Fossanien: nouvel étage du Plicéne d'ltalie.

17. I terreni terziari del Piemonte e della Liguria (foglietto d'annunzio).

18. I terreni quaternari della collina di Torino (l grande carta geol.).

19. I terren terziari e quaternari del Biellese (1 grande carta geol.).

20. Le tremblement de terre du 23 février 1887.

21. 1 Colli torinesi (foglietto esplicativo).

22. Studio geologico dei dintorni li Voltaggio (1 carta geol.).

23. On the origin of the Great Alpine Lakes.

24. L'anfiteatro morenico di Rivoli (1 carta geol.).

25. Studio guologico dei dintorni di Guarene d'Alba (1 carta geol.).

26. 11 passaggio tra il Liguriano ed il Tongriano (1 grande carta geol).

27. Classification des terrains tertiaires conforme à leur facies.

28. Sur l'origine du Loess en Piémont.

29. 11 cono di deiezione della Stura di Lanzo (1 carta geol.).

30. Studio geologico delle colline di Cherasco e della Morra in Piemonte (1 grande curta geol.).

31. Il Pliocene entroalpino di Valsesia (l grande carta geol.).

32. Les terrains tertiaires de la Suisse.

33. I Colli braidesi (l grande carta geol.).

34. Le Ligurien.

35. Sopra due tracciati per un tronco della linea Torino-Chieri-Piovà-Casale.

36. Sopra un progetto di serbatoio in Valle Usseglia.

37. Un coin intéressant du tertiaire d'ltalie (l grande carta geol.).

38. I Col!i monregalesi (I grande cirta geol.).

39. 11 seno terziario di Moncalvo (l calta geol.).

40. Les conglonérats du Flysch (2 tav.).

41. La conca terziaria di Varzi-S. Sebastiano (l grande carta geol.).

42. La caverna ossifera del Bandito in Val Gesso (l tav.).

43. Relazione geologica sopra un progetto di derivazione d'acqua dal torrente Giandone (1 carta geol.). 
44. Sur la position stratigraphique les charbons fossiles du Piẻmont.

45. La géotectonique de li Haute ltalie septentrionale (l carta geol).

46. 1l Bacino terzlario e quaternario del Piemonte (Bibliourafia - Geolologia pura - Paleontologia - Geologial applicata). Volume di 940 pagine (3 grancli carte geol.).

47. Con M. Baretti - 11 Margozzoln (2 carte geol. e 3 tar.).

\section{PALEON T OLO G I}

48. Nuove specie di Mollus shi lacustri e terrestri del Piemonte (l tav.).

49. Fauna nacologica delle alluvioni plioc. clel Piemonte (2 tav.).

50. Nuove specie terziarie di Molluschi terrestri, dacqua dolce e salmastra del Piemonte (2 tav.).

51. Stullo geo-paleontologico sul Lias"dell"alta Valle della Stura di Cuneo.

52. Sopra una nuova specie di Discohelix Dunker (1 tav.).

53. Sur quelques restes fossiles du Pliocene du Piémont (con fig.).

54. Rivisti della Fauna malacologica fossile terrestre, lacustre e salmastra del Piemonte.

55. Aggiunte alla Fauna malacologica estranarina fossile del Piemonte e dellir Liguria (2 tav.).

56. Sovra alcuni Polamides del Bacino terziario del Piemonte (4 tav.).

57. Note di Paleoicuologia italiana (2 grandi tar.).

58. I Cheloni astiani del Piemonte (2 tiv.).

59. Soprit una mandibola di Balaenoplera dell'Astigiana (l tav.).

60. 1 Molluschi dei terreni terziari del Piemonte e della Liguria. Parte VII (Harpidae e Cassididae.) - (Nota preventiva).

61. I Molluschi dei terreni terziari del Piemonte e della Liguria. Parte VlI (Harpirlae e Cassididae (120 figure).

62. I Molluschi dei terreni terziari del Piemonte e della Liguria. Parte V1lI (Galeodoliidae. Doliidae, Ficulidae e Nalicidae). - (Notil preventira).

63. I Molluschi dei terreni terziari del Piemonte e della Lignria. Parte VIII (Galeodoliidae, Doliidae, Ficulidae e Naticidae) - (oltre 20n figure).

64. I Molluschi dei terreni telziari del Piemonte e della Liguria. Parte 1X (Scalaridae) - (in corso di stampa).

65. I Molluschi dei terreni terzinri del Piemonte e della Liguria. Parte X (Terebridae, Pusionellidae, Pyramidellirlae, Ringiculidae, Eulimidae e Solariadae - (in preparazione).

66. Con L. Bellardi - 1 Molluschi dei terreni terziari del Piemonte e della Liguria. Parte Vl (Volulidae, Colmmbellidae e Narginellidae) - (con 1 to tigule).

\section{CARTE GEOLOGICHE.}

Alla scaln di $1: 50.000:-67$. Spigno Monferrato $\rightarrow 68$. Voltaggio N. - 69. Orada N. - J0. Ceva. S e Garessio N. tril. Cairo Montenotte O. Alla scala di 1 : 25.000 - 72. Serravalle Serivia - 73. Gavi - j. Villavernia e Garbagna 0. - 50. Acqui - 36. Capriata d. Orba - 7. Fossano - 78. Nizzi Monfelrato e Sezzè Q. - 79. Mombercelli e Canelli N. - 80. Canale e Monteu Roero E. - 81. Calamandrina - \&2. Costigliole d'Asti - \$3. Cherasco e Ceryere - 84 . Colli torinesi (12 colori ; diametro centim. $100 \times 110$ ) -85 . Anfiteatro morenico di Rivoli (diametro centim. $100 \times 110)$.

\section{BIOGRAFIE.}

86. Luigi Bellardi (Biografia di) - (con ritratto).

87. Louis Bellardi (Biographie de) - (con ritratto).

\section{ZOOLOGIA.}

88. Sulla presenza dello spelerpes fuscus (Bonap.) in Piemonte. 

$72 . I$.

q.

(hap.6.18) 


\section{IL}

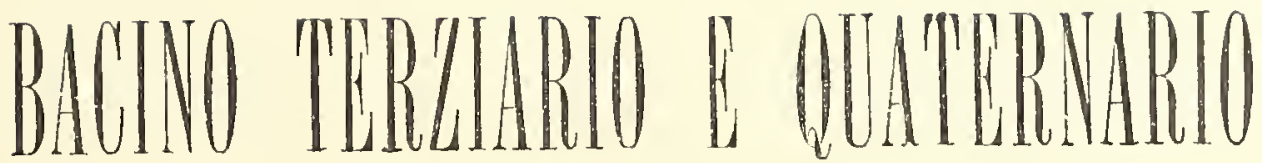

DEL

\section{PIEMONTE}

Bibliografia - Geologia pntra - Paleoulologia - Geologia applicata

CON TRE CARTE GEOLOGICHE

I. Bacino terziario (scala di 1:100,000). - II. Bacino quaternario (scala di 1:500,000).

III. Geologia applicata (scala di $1: 500,000$ )

$$
\begin{aligned}
& \text { STUDIO } \\
& \text { del Dotture }
\end{aligned}
$$

\section{FEDERICO SACCO}

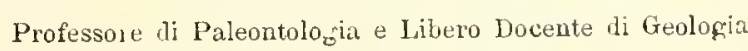

nella $R$. Universita di Torino.

$1889-1890$ 
M I M D R E

QUESTO FRUTTO DELLA MIA GIOVINEZZA

CONSACRO 

II

\section{BACINO TERZIARIO}

DEL

\section{PIE MONTE}

STUDIO DEL

Dott. FEDERICO SACCO

PROFESSORE DI PALEONTOLOGIA E LIBERO DOCENTE DI GEOLOGIA NELLA R. UNIVERSTÀ HI TORINO.

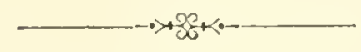

MILANO

TIP. BERNARDONI DI C. REBESCHINI E C.

1889. 


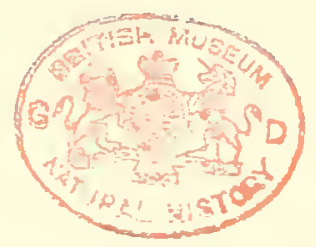




\section{INTRODUZIONE.}

I terreni terziari del Piemonte, tanto famosi per aver fornito stupende raccolte di fossili ad una gran parte dei Musei paleontologici del mondo, dal lato geologico invece sono stati finora sempre molto negletti, tanto che fino al giorno d'oggi non ne esisteva che una carta geologica, in piccolissima scala, redattic dal prof. A. Sismonda, il quale vi aveva approssimativamente segnate le divisioni di eocene, miocene e pliocene.

Allorquando incominciai ad occuparmi di questi terreni terziari nell'alta valle padana, m'accorsi bentosto she, se abbondantissimi vi si trovano i fossili, come già da lungo tempo è noto, stupendamente regolare vi si presenta pure la serie stratigrafica, per modo che incoraggiato dai primi risultati ottenuti, allargando ogni anno l'area di studio e continuamente raccogliendo $i$ fossili clre incontravo in tale lavoro, giunsi poco a poco alla conoscenza geo-paleontologica dell'intiero bacino; ed ora che ho compiuto il lavoro prefissomi credo opportuno di pubblicarlo affinchè ognuno possa convincersi doversi considerare il bacino terziario del Piemonte come un bacino tipo, nor solo 
paleontologicamente, ma eziandio stratigraficamente e non essere quindi esso per nulla inferiore ai già famosi bacini terziari di Parigi, di Vienna, di Magonza, ecc., giacchè, se l'eocene del Piemonte, per essere generalmente di tipo alpino, non presenta tutte quelle numerose suddivisioni che esistono per esempio nel bacino parigino, il miocene ed il pliocene invece offrono una serie cosi tipica, cosi completa e cosi regolare di caratteristici orizzonti, quale difficilmente si può osservare altrove.

Fra le più recenti classificazioni dei terreni terziari che mi si pararono innanzi allorchè intrapresi lo studio in questione, non mi decisi a fare la scelta che allorquando il laroro minuto di rilevamento sul terreno mi persuase essere senza dubbio a preferirsi la classificazione del mio amico prof. Karl Nayer Eymar, il quale d'altronde è il geologo che più profondamente di qualunque altro ebbe già ad occuparsi della geologia terziaria del Piemonte e della Liguria.

In seguito però alle personali osservazioni fatte sul terreno ebbi a convincermi che, se esistono e sono abbastanza distinguibili i piani geologici indicati dal Mayer, in generale invece i sottopiani segnati da questo autore o non esistono affatto in natura, oppure corrispondono a fenomeni talmente locali che non parmi nè utile, nè opportuno di considerarli come orizzonti speciali e tanto meno poi di indicarli sulle carte geologiche, essendone la delimitazione incertissima e troppo arbitraria.

La serie di piani geologici che potei osservare e nettamente distinguere nel bacino del Piemonte sono, nel loro ordine naturale di sovrapposizione, $\mathrm{i}$ seguenti :

$$
\begin{aligned}
\text { Quaternario } & \left\{\begin{array}{l}
\text { Terrazziano } \\
\text { Sahariano }
\end{array}\right. \\
\text { Terziario } & \left\{\begin{array}{l}
\text { Villafrancliano } \\
\text { Fossaniano } \\
\text { Astiano } \\
\text { Piacentino } \\
\text { Messiniano }
\end{array}\right.
\end{aligned}
$$




Teratario $\left\{\begin{array}{l}\text { Tortoniano } \\ \text { Elveziano } \\ \text { Langliano } \\ \text { Aquitaniano } \\ \text { Stanıiano } \\ \text { Tongriano } \\ \text { Gassiniano (Bartoniano?) } \\ \text { Liguriano } \\ \text { Parisiano }\end{array}\right.$

Volendosi poi far rientrare queste suddivisioni nelle grandi divisioni del Lyell (eocene, miocene e pliocene) si troverebbero difficoltì abbastanza grandi; cosi ad esempio se si volesse dividere il miocene dal pliocene, a causa dell'orizzonte Messiniano clie è incertce sedis, costituendo esso un passaggio fra l'un terreno e l'altro. Nella regione in esame sarebbe poi ancor meno accettabile la distinzione, altrove forse pratica e necessaria, dell'oligocene comprendente Aquitaniano, Stampiano e Tongriano, poichè in quasi tutto il Piemonte l'Aquitaniano, sotto il triplice aspetto della paleontologia, della stratigrafia e della litologia, costituisce graduatissimo passaggio al sovrastante Langhiano, ed inoltre sono queste formazioni ambidue marine, quantunque generalmente una di mare profondo e l'altra di littorale. Ma d'altronde sono queste semplici questioni di parole per cui quindi è inutile insistervi.

Se però si volesse ad ogni modo far rientrare i sovradetti piani geologici nelle antiche divisioni del Terziario, si potrebbe adottare la presente interpretazione:

Pliocene (Villafranchiano, Fossaniano, Astiano, Piacentino)

Miocene (Messiniano, Tortoniano, Elveziano, Langhiano)

Oligocene (Aquitaniano, Stampiano, Tongriano)

Eocene (Gassiniano, Liguriano, Parisiano).

Il rileramento geologico fu fatto sulle recenti carte topografiche alla scala di 1:25000, a linee curve e coll'equidistanza di 5 o di 10 metri secondo le regioni; fin dal 1886 incominciai 
a pubulicare le carte geologiche in grande scala delle regioni più iuteressanti, specialmente delle falde settentrionali della catena alpino-appeninica, estendendomi poscia poco a poco alle recioni dell'Astigiano, del Monférrato e dei colli Torino-Valenza.

Quanto al lavoro litografico di tali carte, se esso non appaga la vista di chi le osserva, ciò dipende specialmente, oltre che da questioni di economia, dall'aver voluto sovrapporre le diverse tinte al già complicato lavoro topografico a curve, desiderando che, anche a svantaggio dell' estetica, si raggiungesse maggior precisione nella delimitazione dei terreni; accudii quindi piuttosto la sostanza che non la forma di queste carte geologiche, clie si devono d'altronde considerare come semplici carte di campagna da cui si possono trarre delle nitide carte in scala minore.

Noto ancora in riguardo a queste carte geologiche in grande scala come, trattandosi di orizzonti terziari che fanno generalmente gradualissimo passaggio gli uni agli altri, i loro limiti di separazione potranno forse parere sul terreno alquanto arbitrari e varianti da luogo a luogo. Ma è a notarsi anzitutto come sia affatto naturale che esistano tali incertezze, le quali provano appunto la regolarità stratigrafica del bacino in esame (e nel corso del lavoro avrò cura di sempre farle risaltare), ed in secondo luogo che le varianti che si possono osservare nella delimitazione dei diversi orizzonti geologici tra le varie regioni dipendono specialmente da varianti locali che alterano più 0 meno profondamente la facies caratteristica di un dato orizzonte, specialmente nella parte inferiore e superiore.

Si comprende infatti facilmente come sovente la delimitazione di due piani sia sul terreno assai dificile, o, a dir meglio, alquanto arbitraria, talora veriticandosi a questo riguardo delle oscillazioni di diversi metri tra regione e regione, tanto più là dove certi banchi speciali, che si possono seguire per tratti lunglissimi e che ci servono come di guida per l'indicata delimitazione, vengono a mancarc, o, come più comunemente si verifica, perdono poco a poco i loro caratteri differenziali, cunfondendosi quindi affatto coi terreni dell'orizzonte sopra o sottostante; in tal caso, 
cangiandosi colla natura litologica anche il carattere paleontologico di questi banchi, si è obbligati di ricorrere ad altri strati a facies un po' spiccata per proseguire la suddetta delimitazione. Ne deriva quiudi che nel passaggio tra due orizzonti geologici in regioni fra di loro distanti non siano sempre gli stessi banchi quelli che sono posti alla base od all' apice di un dato piano, ma che esista, a questo riguardo, una specie di oscillazione, in rapporto colle diversità di condizione in cui si trovarono le varie parti del bacino in esame in uno stesso momento geologico.

Questo modo d'intendere le delimitazioni dei diversi orizzonti geologici, se pare erroneo al geologo di tavolino, sembrerà però certamente logico a cli fa uno studio geologico minuto sul terreno in queste regioni terziarie; in tal caso infatti si vede che se si volesse assumere sempre uno stesso banco come limite di due orizzonti, anzitutto dovrebbesi fare una scelta affatto convenzionale ed arbitraria di questo banco delinitativo, in seguito, anche che tale banco in altre regioni non venisse a scomparire, come quasi sempre invece accade, lo si vedrebbe mutare più o meno presto nei caratteri litologici e paleontologici, assumendo esso cioè quelli dell'orizzonte superiore od inferiore; e quindi per poter seguire tale banco occorrerebbe che esso fosse sempre visibile in una sezione continua, ciò che in verità non si verifica.

Credo quindi che nella delimitazione degli orizzonti geologici sia necessario adattarsi alle piccole oscillazioni che tra regione e regione verificansi rispetto al momento, non sempre ovunque contemporaneo, in cui avvenne il mutamento di facies da un orizzonte a quello sopra o sottostante.

I fatti ora accennati si possono specialmente osservare in modo assai chiaro nel passaggio tra Langhiano ed Elveziano, a causa della facies cosi diversa, in generale, di questi due orizzonti geologici.

Quanto al piano adottato nella presente Memoria, cercai sovratutto che ci fosse dell'ordine, e che non vi esistessero inutili ripetizioni, per modo che chi consulta questo lavoro possa facil- 
mente trovare le parti che lo interessano, donde la divisione che ho fatta dell'intiero studio in diversi capitoli e sottocapitoli.

Rispetto alla Bibliografia geo-paleontologica del bacino in esame, era dapprima mia intenzione di dare di ciascun laroro un brere riassunto, ma abbandonai in seguito tale idea non solo per la considererole mole di laroro che ne sarebbe risultata, ma anche perchè dubitai alquanto della sua utilità, giacchè mentre il contenuto dei singoli larori è già generalmente indicato dal suo titolo, è naturale che chi roglia consultarli non si contenti certamente di un semplice riassunto in cui manca talora un accenno di quei fatti appunto che egli desidera sapere.

Cercai invece di rendere il catalogo bibliografico completo il più che possibile, ed affinchè fosse facile il prendersi un'idea del graduale progresso dello studio geo-paleontologico fattosi sino ad oggi, rispetto al bacino terziario del Piemonte, ordinai tale catalogo dapprima secondo l'epoca di pubblicazione dei singoli larori e poscia alfabeticamente secondo il nome dei dirersi autori, in modo che non solo fosse facile il rintracciare le memorie di ciascun geologo o paleontologo, ma eziandio risultasse nettamente lo sviluppo di rita scientifica di ciascun autore, rispetto al bacino terziario del Piemonte.

Considerando la ricchezza bibliografica del bacino terziario del Piemonte, parrebbe che dopo tanti larori poco ci sia a dire di nuoro; facendone però una seria analisi trorasi che in massima parte essi sono paleontologici, moltissimi trattano di sorgenti minerali, di materiali utili, ecc., ed inrece ben pochi si occupano di geologia vera; inoltre di questi ultimi la massima parte considera i terreni terziari solo dal punto di rista della classificazione di Lyell, e quei pochissimi infine che ne trattano colle idee moderne si riferiscono solo ad aree ristrette e si tengono sulle linee generali.

Premessa la bibliografia geo-paleontologica si sarebbero potuti fare alcuni cenni generali sulla topografia, oroidrografia, clima, ecc., del bacino da studiarsi, ma trattandosi di un laroro esclusiramente geologico, e corredato di buone carte topografiche 
colorate geologicamente, ho creduto dover incominciare senz'altro colla descrizione dei singoli terreni; per questa descrizione dovendo continuamente accennare a nomi locali ho creduto opportuno di adoperare a quest'uopo unicamente i nomi segnati sulle recenti carte topografiche a curve orizzontali, anche quando conoscevo essere falsi o poco esatti, giacchè in tal modo si potrà avere una sicura base di confronto clıe, meglio di qualınque altra, si avvicini al vero.

In generale, divisi il lavoro in quattro parti, cioè: parte I, Bibliografia; parte II, Geologia purce in cui sono descritti i vari terreni, senza trattare dei loro rapporti coll'uomo; parte III, Paleontologia, la quale non è altro che un catalogo dei fossili finora trovati nei terreni terziari del Piemonte e della Liguria settentrionale, non volendo fare in questo lavoro un vero studio paleontologico, sia perchè in parte questo venne già fatto da E. Sismonda, Michelotti, Bellardi, ecc., sia perchè esso avrebbe richiesto la pubblicazione di moltissime specie nuove e quindi di numerose tavole. Mi limitai perciò, su tale riguardo, quasi solo a raccogliere ciò che si era fatto finora su questo proposito, riferendo però i fossili ai diversi orizzonti geologici che descrissi nel lavoro e distinsi sulle carte.

Questo minuto catalogamento che si fa qui per la prima volta, pei fossili piemontesi, secondo i vari orizzonti geologici, quantunque talora lasci dei dubbi per certe forme di cui è ignoto il preciso punto di ritrovanento, credo però che sia interessante perchè ora si vanno abbandonando le anticlıe divisioni di eocene, miocene e pliocene. Infatti a queste antiche suddivisioni quasi soltanto si riferirono gli studiosi della Paleontologia piemontese, ver modo che in avvenire i loro lavori rimarrebbero in parte non più utilizzabili senza il suddetto catalogamento stratigrafico più particolareggiato.

Ebbi poi cura d'indicare, nella descrizione d'ogni orizzonte geologico, le località ove più comunemente rinvenni resti fossili, sperando così di essere utile ai paleontologi e quindi alla Paleontologia in generale. 
La parte IV del lavoro tratta della Geologia applicuta; in essa sono indicati di ogui orizzonte geologico i materiali in qualunque modo utili all'uomo, ed i rapporti che ogni formazione ha coll'Agricoltura, l'Igiene, l'Industria, ecc.

Trattandosi di descrivere, geologicamente un area tanto grande (circa 13000 kilom. q.) quale è il bacino terziario del Piemonte, due metodi principali mi si presentarono innanzi, cioè o fare una particolare descrizione per ciascuna delle regioni segnate dai limiti di provincia o di circondario o dalle antiche denominazioni di Langhe, Astigiana, Monferrato, Tortonese, ecc., oppure descrivere particolarmente ciascun terreno seguendolo nel suo sviluppo attraverso l'intiero bacino.

Adottai senza esitazione quest' ultimo metodo, non solo perchè sembrani assai più logico e naturale rispetto all'unità del hacino da esaminare, ma eziandio perchè risparmia inutili ripetiziuni; d'altronde chi vuol conoscere la costituzione di una data regione, osservando sulla carta geologica gli orizzonti che vi si presentano, può facilmente trovarne la descrizione a suo posto in ciascuno dei capitoli che trattano di tali orizzonti; mentre viceversa chi ad esempio vorra solo prendere conoscenza del modo di presentarsi di un dato piano geologico potrà raggiungere rapidamente il suo scopo tralasciando tutta la descrizione regionale, e così via. 
I.

\section{BIBLIOGRAFIA}

\section{ELENCO CRONOLOGICO.}

1553. 1. Savonarola, Guainerio, Mengo, Viotti da Clivoli, ecc., De balneis, omnia quæ extant apud Græcos, Iatinos et Arabes. Venezia.

1606. 2. Teveroni, 'Trattato dei bagni d'Acqui in Monferrato, ecc.

1687. 3. Ravetti e Campeggio, Analyse des eaux thermales.

1727. 4. Fantoni G., De aquis ad fanum Sancti Genesii. Ginevra.

1747. 5. Fantoni, Commentariolum de quibusdam aquis medicatis. Angustæ Taurinorum.

1757. 6. Allionius C., Oryctographiæ pedemontanæe specimen, exhibens corpora fossilia terræ adventitia. Parisiis.

178. 7. Malacarue, Trattato delle R. Terme d'Acqui. Torino.

1786. S. Nicolis de Robilant, Essai géographique, suivi d'une topographie souterraine, minéralogique et d'une docimasie des États de S. M. en terre ferme. Mem. R. Acc. Sc. di Torino. Serie I. Vol. VI.

1787. 9. Dana, De aquis ad fanum Sancti Genesii.

1786-87. 10. Argentero di Bersezio (De Brezé), Analyse des eaux minérales de Castelletto Adorno et de Saint-Génis. Mem. R. Acc. Sc. di Torino, Serie I, VIII.

1787. 11. Benevelli C., Sopra il terremoto d'Alba. Asti.

1788-89. 12. Argentero di Bersezio (De Brezé), Analyse de l'eau sulfureuse de Iu en Mtonferrat.

1790-91. 13. Vasco et Morozzo, Sur les prétendus prodiges de la baguette divinatrice pour la découverte des courants d'eau souterrains et des mines. Mem. R. Acc. Sc. di Torino, Seric I, X.

1793. 14. Levis (de), La Pirenta di Murisengo. Carmagnola.

1794. 15. Levis (de), Sulla Pirenta murisenghina. Torino.

1795. 16. Levis (de), Descrizione della grotta metereologica di Murjsengo. Casale.

1796-1804. 17. De Saussure H. C. B., Voyages dans les Alpes précédé d'un essai sur l'histoire raturelle des environs de Genève. Neuchâtel. 
1800. 1S. Borson S., Ad Oryctographiam pedemontanam auctarium Mem. R. Acc. Sc. di Torino, Serie 1, XI.

1803. 19. Michelotti I. T., Essayo hydrografico do Piemonte. Traducido pello P. Francisco Furtado de ilendœa. Roma.

1806. 20. Cambiaso G. M., Rapporto sulla purificazione del Carbon fossile di Cadibona. Memoria dell'Istituto ligure. - Genova.

21. Cuvier, Annales du Muséum. VII. Paris.

1805-08. 22. Vassalli-Eandi, Notices géologiques de diffèrentes parties du Piémont. Mem. R. Acc. Sc. di Torino, Serie I, XVI.

23. Vassalli-Eandi, Observations sur les puits de la forteresse de Verrue. Mem. R. Acc. Sc. di 'Torino, Serie I, XVI.

1808. 24. Amoretti C., Su un dente e parte di mandibola d'un Mastodonte trovato presso la Rocchetta nel dipartimento di 'Tanaro. Mem. di St. Naz. Ital., II. Parte 2. Bologna.

25. Majon (f., Analyse des eaux sulphureuses et thermales d'Acqui. Genova.

1810. 26. Bonillon de la Grange, Essai sur les eaux minérales naturelles et artificielles. Paris.

1814. 27. Brocehi G., Conchiologia fossile subappenina con osservazioni geologiche sugli Appennini e sul suolo adiacente. Milano.

1816. 2S. Vagnone, Observations minéralogiques et lithologiques sur la vallée de Brozzo, arec des remarques minéralogiques et géologiques sur le gypse de Montcucco. Mem. R. Acc. Sr. di Torino, Serie I, XXII.

1817. 29. Brocchi G. B., Catalogo ragionato d'una raccolta di roccie disposte con ordine geografico per servire alla geognosia d'Italia. I. e R. Stamperia. Milano.

1818. 30. Canobbio, Solfato di magnesia nelle montagne presso Acqui. Mem. R. Acc. Sc. di Torino, Serie I, XXIII.

31. Lichenthal P., Notizie compendiate delle acque medicinali ed Istituti balneari d'Europa. Novara.

32. IIarmora (della), Combustibili fossili in Piemonte. Programma di quesito. Nem. R. Acc. Sc. di Torino, Serie I, XXIII.

1819. 33. Borson S., Sur des machoires et des dents de Mastodonte dit Mammouth trouvées fossiles en Piémont. Mem. R. Acc. Sc. di Torino, Serie I, Vol. XXIV.

34. Ragazzoni R., Dei combustibili fossili del Piemonte. Novara.

1820. 35. Borson S., Saggio di Orittografia piemontese. Parte 1. ${ }^{\mathrm{a}} \mathrm{M}$ em. R. Acc Sc. di Torino, Serie I, XXV.

36. Brouguiart A., Sur le gisement ou sur la position relative des ophiolites, euphotides, jaspes, etc., dans quelques parties des Apennins. Bull. Soc. phyloemat. Paris. (Abregé dans la biblio. ital. Tom. XXIV, 1821. Milano.) 
1820. 37. Canobbio G. B., Ricerche mineralogiche nella Provincia d'Acqui. Mem. R. Acc. Sc. di Torino, Serie I, XXV.

35. Marmora (della), Combustibili fossili in Piemonte. Risposte al quesito, ecc. Mem. R. Acc. Sc. di Torino, Serie I, XXV.

1821. 39. Bertini B., Idrologia minerale degli Stati Sardi, ossia descrizione di tutte le sorgenti d'acque minerali note sinora negli Stati di S. M. il Re di Sardegna, ecc. Torino.

40. Borson S., Continuazione del saggio di Orittografia piemontese. Mem. R. Acc. Sc. di Torino, Serie I, XXVI.

1821-24. 41. Cuvier G., Récherches sur les ossements fossiles. Paris.

1822. 42. Bourdet, Bulletin de la Soc. philomatique.

43. Bertini B., Idrologia minerale. 1.a edizione.

1323. 44. Borson S., Continuazione del Søggio di Orittografia Piemontese. Mem. R. Acc. di Torino, Serie I, XXIX.

45. Borson S., Note sur les dents du grand Mastodonte trouvées en Piémont et sur des machôires et dents fossiles prises dans la mine de houille de Cadibone près Savone. Mem. R. Acc. Sc. di Torino. Serie I, XXVII.

46. Brongniart A., Sur les terrains de sédiment supérieur calcareo-trappéens du Vicentin et sur quelques terrains d'Itaìe, etc., qui peuvent se rapporter à la même époque. Levrault Édit. Paris.

47. Cantì G. L., Saggio medico-chimico sull'acqua solfureo-salina di Castelnuovo d'Asti. Alessandria.

48. Amoretti C., Viaggio da Milano ai tre laghi. Milano.

49. Chabrol di Volvie, Statistique des Provinces de Savone, d'Oneille, d'Acqui et d'une partie de la Province de Mondovi, formant l'ancien département de Montenotte. Didot. Paris.

1825. 50. Borson S., Ossa fossili in Val d'Andona credute falsamente di scheletro umano. Mem. R. Acc. Sc. di Torino, Serie I, XXX.

51. Bronn H. G., Ueber die Versteinerungen und ueber verschiedene Felsarten in Piemont. Zeitschrift v. Leonard, I.

52. Cantù G. L., Sull' esistenza dell' Iodio nelle acque minerali sulfuree e particolarmente in quelle di Castelnuovo d'Asti. Annali di St. Nat., VI, Paris, e Mem. R. Acc. Sc. di Torino, Vol. XXIX.

1826. 53. Alibert, Précis historique sur les eaux minérales les plus nsitées en médécine. Paris.

1827. 54. Inonimo (L. Pareto), Descrizione della cava di combustibile fossile nelle vicinanze di Cadibona. Giorn. Isigust. di Sc. Lett. ed Arti. Anno I, Fase. I. Genova. 
1827. 0.ग. Paganini P., Lotizia compendiata di tutte le acque minerali e bagni d'Italia. Milano.

56. Pareto L., Di alcune relazioni che esistono tra la costituzione geognostica dell'Appennino ligure e quella delle Alpi della Savoia. Giornale ligustico di Scienze Lett. ed Arti. Anno II, Fase. 11. Genova.

1828. 57. Bronn H. G., Briefe aus der Schweiz, Italien und Sudfranclreich im Sommer 1824. Heidelberg und Leipzig.

1829. 5S. Anonimo, Acque minerali negli Stati di Terraferma di S. I. Calendario generale.

1830. 59. Borson S., Catalogue raisonné de la collection minéralogique de l'Université de Turin. Corps organisés fossiles. Turin.

1S31. 60. Beaumont (de) E.g Némoire sur la direction et l'âge relatif des montagnes serpentineuses de la Ligurie. Bull. Soc. géol. Franc. Tom. I.

61. Bronn H., ltalien Tertiaer-Gebilde und deren organische Emschlïsse. Heidellberg.

1832-33. 62. Beaumont (de) E., Cavité qui avant l'epoque tertiaire dut séparer les Alpes des Appennins. Bull. Soc. Géol. Franc. Serie I, Tom. III.

1832. 63. Jan G., Catalogus rerum naturalium in Museo Josephi De Cristofori et Giorgii Jan extantium. Sec. 2.", fasc. 2. ${ }^{\circ}$, 8. ${ }^{\circ}$ Parmæ.

64. Marmora (della) A., Note sur la géologie du Piémont. Bull. Soc. Géol. de France. Serie I, Tome II.

1832-83. 65. Pareto L., Note sur les Alpes de la Ligurie, voisinage du Col de Tenda. Bull. Soc. Géol. France. Serie I, Tom. I.

1833. 66. Borson S., Mémoire sur quelques ossements fossiles trourés en Piémont. Mem. R. Acc. Sc. di Torino. Serie I, XXXYI.

67. Della Chiesa di Benevello C., Delle sorgenti artesie e delle Società che vollero introdurne l'uso in Piemonte. Torino.

is. Pareto L., Note sur le gypse du Tortonais. Mem. Soc. géol. France. Serie I, Tom. I.

(i9. Viviani, Lettre à II. Pareto sur les restes de plantes fossiles trouvés dans les gypses tertiaires de Stradella, près Pavie. Niem. Soc. géol. France. Serie I, Tom. I.

70. Larini G., Analyse de l'eau de Saint-Genis. Mem. R. Acc. Sc. di Torino. Vol. XXXVI.

1833-5̃. 71. Casalis G., Dizionario geografico-storico, statistico-commerciale degli Stati di S. M. il re di Sardegna. $8^{\circ}$, Torino.

1834. i2. Anonimo, Escursione geologica fatta in Piemonte. Sollevamento del Colle di Superga, Bibl. Stat. Vol. Lxxvi.

73. Me-Rolandis, Monografia dell' acqua di Calliano. Alessandria. 
1834-35. 74. Beaumont (de), Opinion sur l'âge des serpentines de Cadibona et de celles de Gênes. Bull. Soc. géol. de France. Seric I, Tom. VI.

7... Bertrand-Geslin, Mémoire sur les pouddingues ว̀ lignites dc Cadibona. Bull. Soc. géol. France. Serie I, Tom. VI.

76. Parcto L., Calcaire à Nummulites des environs de Turin rangé à tort dans le grés vert par M. de la Marmora, tandis qu'il doit être regardé comme tertiaire, ainsi que le prouverait une dent de squale qu'on a trouvé. Bull. Soc. Géol. France. Tom. VT, Série I.

1835. 77. Barelli F., Cenni di statistica mineralogica degli Stati di S. M. il re di Sardegna, ovvero catalogo ragionato della facoltà formatasi presso l'azienda generale dell' interno. Tip. Fodratti. Torino.

78. Barocchini, Cenni sulle acque del R. Stabilimento dei bagni salutari d'Aqui.

79. Bertrand-Geslin, De Beaumont et Verlet. Bulletin de la Sociêté Gé llogique le France. Vol. VI, Séance dı 1 Juin.

80. Giordano A., Analyse chimique de l'eau sulphureuse dit la Pirenta de Calliano (Piémont). Journal de Chim. Medic. I. Paris.

81. Lavini G., Découverte du sulfate de Magnésie dans la chaux sulfatée de Piobesi en Piémont. Mem. R. Acc. Sc. di Toriuo. Serie I, Vol. XXXIX.

\$ะ. Pareto L., Lettera ai direttori della Biblioteca italiana. Bibl. ital. Tomo LXXVI (Gite geologiche in Piemonte e Liguria). Milano. Bull. Soc. Géol. Frauce. Série I, 'Tom. IV, Append. pag. LXI-LXV.

S3. Ragazzoni R., T)ei vantaggi che ricavar si potrebbero per l'agricoltura da molte acque minerali del Piemonte. Mem. R. Śoc. li agric. Tomo XI.

84. Znecagna-0rlandini A., Corografia fisica, storica e statistica dell' Italia e delle sue isole. Firenze.

1835-36. S5. Sismonda A., Notizie intorno a due fossili trovati sui colli di S. Stefano Roero. Mem. R. Acc. Sc. di Torino. Serie II, Vol. I. Et: Deux mots sur ces mêmes fossiles dans le Bull. Soc. géol. France. Tome VII, Série I.

1835-4: 86. Lamarck, Histoire naturelle des animaux sans Vertèbres. 2. edit. revue et aug. par Deshayes et Milne-Edwards. Vol. I-Xl. Paris.

1836. S\%. Collegno (Provana di) G., Éssai géologique sur les collines de Superga. Compte rendu de l'Acc. Sc. de Paris. Vol. 2. (1 s m.). Paris. 
1836-37. \$s. Pareto L., Indication de la carte géologique de la Ligurie et des observations geologiques par lui faites dans le Comté de Nice et de Piémont. Bull. Soc. Géol. France. T. VIII, Série I.

1836-39. 89. Brnio G. D., Illustrazione di un nuovo cetaceo fossile, Mfem. R. Acc. Sc. di Torino. Serie II, Vol. I.

1837. 90. Dujardin P., Mémoire sur les conches du sol en Touraine. Ilem. Soc. géol, de France. Tome 2.0

91. Bourdon I., Guide aux eaux minerales etc. 2a edition, Paris.

1538. 92. Bellardi L., Sur le genre Borsonia. Lettre au Président de la Soc. Géol. de France. Bull. Soc. géol. France. Série I, Vol. X.

93. Collegno (Provana di) G., Sur les terrains tertiaires du XordOvest de l'Italie. Compte rendu Acc. Sc. de Paris. Vol. IV.

94. Micluclotti G., Specimen Zoopbytologiæ diluvianæ. Auguste Taurinorum.

1\%. Michclotti G., Geognosticl-Zoologische Ansicht neber die Tertiären bildungen Piemonts. Neues Jahrb. f. Min. Geol. und Palæontologie.

1839. 96. Floris G., Sulle conchiglie ed i terreni di Lessona, Cossato, Ce. retto e Valdengo nella I'rov. di Biella. Giorn. Il Subalpino, Riv. italiana. Torino.

97. Nichclotti G., Valves de Thécides trouvées dans le terrain tertiaire moyen de la colline de Turin. Bull. Soc. géol. France. Série I, Tom. X.

95. Michelotti G., Malacological and Conchyological Magazine. (Planche isolée dessinée par Sowerby).

99. Michelotti G., Brevi cenni di alcuni resti delle classi Brachiopodi, Lamellibranchi, ecc. Ann. Sc. Lomb. Ven.

100. Barocchini G., Cenni sulle acque termali del R. Stabilimento delle terme d'Acqui. Acqui.

1839-40. 101. Studer, Notice sur quelques phénomènes de l'ẻpoque diluvienne. Bull. Soc. géol. France. Tome XI, Série I.

1539-43. 102. Osauna P., Physikalisch-medicinische Darstellung der hekannten Heilquellen der vorzüglichsten Länder Europas. 2a edizione, $8^{\circ}$, Berlino.

1839-61. 10\%. Blaiuville A., Ostéographie ou description iconographique complete des mammiferes récents et fossiles. Atlas, 4 Tol. fol. Paris.

1S40. 104. Bellardi L. e Michelotti G., Saggio orittugrafico sulla classe dei Gasteropodi fossili dei ter. terz. del l'iemonte. MIem. Ii. Acc. Sc. di Torino. Serie II, Tomo III.

105. Cantraiue F., Malacologie méditerranc̀eme et litorale $(\mathrm{Ou}$ vrage servant de faune malacologique italienne et à complénent 
à la Conchiologia fossile subappenina del Brocehi. Mem. Aco. R. di Bruxelles. 'T. XIII.

1840. 106. Michelotti $\mathrm{H}_{0}$, Indice ragionato di alcuni 'Teš́ncei di Cefalopodi fossili in Italia, in Savoia e nel Contado di Nizza. Ann. Sc. R. Lomb. Ven. Bimestrc III-TV.

107. Miehelotti *., Rivista di alcune specic fossili della famiglia dei Gasteropodi. Ann. Sc. R. Lomb. Ven. Bimestre III-IV.

1840-47. 108. M chelin H., Iconographie Zoophytologique, description par localites et terrains de Polypiers tossiles de la France et pays environnants. Bertrand Edit. Paris.

1840. 109. Pareto L., Relazione d'escursione fatta a Gassino. Atti della seconda riunione degli scienziati italiani a Torino.

110. Sismouda A., Osservazioni mineralogiche e geologiche per servire alla formazione della Carta geologica del Piemonte. R. Acc. Sc. di Torino. Serie II, Vol. II.

1841. 111. Ratti P. S., Lc regie terme acquesi (Piemonte). Milano.

112. Bellardi L., Description des Cancellaires fossiles des terrains tertiaires du Piémont. Mem. Acc. Sc. Torino. Serie II, Tomo II.

113. Michelotti G., Munografia del genere Murex, ossia enumerazione delle principali specie dei terreni sopracretacei dell' Italia, 4." Vicenza.

114. Michelotti G., De Solariis in Supracretaceis Italiæe stratis repertis. 4. ${ }^{\circ}$ Trans. of the Roy Soc. of. Edimburg. Vol. XV, Part. I.

115. Michelotti G., Monografia degli Echinidi fossili del Piemonte proposta dal Dott. E. Sismonda. Giorn. Sc. Med. Fasc. Luglio. 'lorino.

116. Michelo ti G., Saggio storico dei Rizopodi carattcristici dei terreni sopracretacei. 4..$^{\circ}$ Mem. Soc. Ital. Sc. res. in Modena. Vol. XXIl.

117. Michelotti A., Brevi cenni sullo studio della zoologia fossile. 8.० Estr. Gionale: I'Eridano, I Luglio 1841. Torino.

118. 0nbigny ( $\left.\mathbf{m}^{\%}\right)$, Sur deux genres nouveaux de Cephalopodes fossiles (les Conôtheutis et Spirulirostra). 8. ${ }^{\circ}$ Ann. Sc. nat., Série II, Zoologie, Tome XVII. Paris.

119. Sismonda E., Monografia degli Echinidi fossili del Piemonte. Nem. R. Acc. Sc. di Torino. Serie II, Vol. IV.

120. Sismonda A., Osservazioni geologiche sulle Alpi Marittime c sugli Appennini liguri. Carta geol. del golfo della Spezia e profili della stessa regione. Mem. R. Acc. Sc. Torino. Serie II, T. IV.

1842. 121. Moulius (des) Cl., Révision de quelques éspères de Pleurotomes. 8.0 Actes Soc. lininéeme. Bordeaux. 
1842. 122. Sismonda A., Osservazion geologiche sui terreni delle formazioni terziaria e cretacea in Piemonte. Mem, R. Acc. Sc. di Torino. Serie II, Vol. V.

123. Sismonda E., Synopsis methodica animalium invertebratorum $\mathrm{Pe}$ demontii fossilium qua in collectione Comitis Cesaris S. Martino della Motta per maxima parte extant - Augustæ Taurinorum.

124. Sismonda E., Appendice alla monografia degli Echinidi fossili del Piemonte. 4. Mem. R. Acc. Sc. Torino, Serie II, T. IV.

125. Sismonda A., Osservazioni geologiche sulle Alpi Marittime e sugli Appennini liguri. Mem. R. Acc. Sc. di Torino. Serie II, Vol. IV.

1843. 126. Bertini B., Idrologia minerale degli Stati Sardi, ecc. 2. ${ }^{\mathrm{a}}$ ediz. Torino.

127. Collegno (di) G., Sur les terrains secondaires du revers méridional des Alpes. Compte rendu Acc. Sc. de Paris. Vol. XVII, 2.0 semestre.

128. Pareto L., Sopra alcune alternative di strati marini e fluviatili nei terreni di sedimento superiore dei colli subappennini. Estr. Gior. Tosc. Sc. Med. e Nat. Tomo I, n. ${ }^{\circ} 4$.

1844. 129. Amoretti C., Viaggio da Milano ai tre Laghi.

130. Collegno (di), Carte de l'Italie coloriée géologiquement, comprenent les terrains siluriens, carboniferes, jurassiques, cétacés, tertiaires et les roches eruptives. Observations de MII. d'Omalius d'Halloy, V. Raulin, D'Archiac, Dufrenoy, Deshayes et Al. D'Orbigny. Bull. Soc. Géol. France. Tol. I.

131. Colleguo (di), Essai d'une carte géologique de l'Italie. Compte rendu de l'Acc. Sc. de Paris. Vol. XVIII (1.0 semestre).

132. Collegno (di), Sur les terrains diluviens du revers méridional des Alpes. Compte rendu Accad. des Sc. de Paris. Vol. XVIII (1.0 semestre).

133. Gastaldi B., Lettre au Sécrétaire de la Soc. Géol. de France annonçunt la découverte de fragments de tige de Pentacrinite dans les terrains miocéniques de la collıne de Turin. Bull. Soc. Géol. de France. Série II, Vol. II.

134. Michelin et De Verucuil, Observations sur la carte géologique des états Sardes, Bull. Soc. Géol France. 'Tome I.

13. Sismonda A., Cenni geologici sul Piemonte - Annali Geografici del Ranuzzi.

136. Sismonda A., Carte géologique des états Sardes, avec quelques considérations sur le soulévement du sol des Alpes et du Piémont, sur l'état métamorphique des terrains stratifiés et sur les terrains crétacé et tertiaire de ces contrées. Bull. Soc. Géol. France. Tome I. 
1S44-45, 1:5 Kigno (de) A., Pentacrinites dans le terrain tertiairc de la colline de Turin. Bull. Soc. Géol. France. Vol. II, Série 11.

1845-54. 138. Biainville (Ie), Ostéographie des cinq classes d'animaux récents et fossiles. A. Bertrand. Paris.

1845. 139. Collegno (di) G., Esquisse Génlorique de l'Ttalie, avec indication de l'âge du Calcaire rouge. Observations de M. Elie de Beaumont. Bull. Soc. Géol. France. Série 1I, Vol. II.

140. GistaIIi B., Lettre pour répondre aux doutes soulevés à propos de la dćcouverte des Pentacrinites dans la colline de Turil. Bull. Soc. Géol. France. Série II.

141. Pomel, Anthracotherium de Cadibona. Bull. Soc. Géol. France. Série Il, T. III.

142. Saluzzo A., Ie Alpi che cingono l'Italia, considerate militarmente così nell'antica come nella presente condizione. Parte I, Vol. I. Torino.

1816. 143. Bianconi G. G., De mare olim occupante planities et colles Italiæ, Græciæ, Asiæ minoris, etc. Bononiæ.

144. Collegno (di) G., Ésquisse d'une carte géologique d'Italie à l'échelle de $3 / 2000000^{.}$Paris.

145. Grastaldi B., Remarques de MM. d'Archiac et Agassiz. Bull. Soc. Géol. France. Série II, Vol. III.

146. Michelotti G., Introduzione allo studio della Geologia, positiva. Torino.

147. Pareto I., Descrizione di Genova e del Genovesato. Vol. II, Topno. Idrog. e Geol. 8. con Carta Geologica. Carta Idrografica e fig. nel testo. Tip. Ferrando. Genova.

148. Sismonda E., Descrizione dei pesci e crostacei fossili del Piemonte. Mem. Acc. Sc. di Toriuo. Seri II, Vol. X.

149. Sismonda A., Carta geologica del Biellese. Torino.

150. Sismonda A., Maus H. e Sobrero A., Sopra un nuovo forno fumivoro e sull'impiego dei carboni fossili del Pienonte (ligniti di Nocelo e Cadibona). Torino.

(Vi c̀ pure un' edizione simile in lingua francese.)

1847. 151. Bellardi L., Nonografia delle Pleurotome fosili del Pienonte. $4^{\circ}$ Mem. R. Acc. S:. di Torino. Serie II, T. IX.

152. Michēlotti G., Comhustibili minerali; cenni sulla lignite e sulla torba. Torino.

153. MicheIotti G., Précis de la faune miocène de la haute Italie. Mem. Soc. Holl. de Sc. à Harlem.

154. Michelotti G., Description des fossiles des terrains miocènes de l'Italic septentrionale. 4. ${ }^{\circ}$ Naturk. Verandel. v. d. Holl. Maatschap d. Wctensch. t. Haarlem Tweedc verz. (come sopra). 
1547. 15.. Manganotti 1., Sulla descrizione dei pesci e crostacei fossili del Dott. Eugenio Sismonda. Atti Accad. Agric. art. e Comm. Vol. XXIII.

156. Brey G., Statistica delle acque minerali delle sorgenti più frequentate d'Italia. Milano.

15\%. Pareto L., Della posizione rispettiva della Serpentina e del Gabbro. Verbale della riunione del 23 Settembre (Sezione geologico-mineralogica). Atti 8. ${ }^{\mathrm{a}}$ riunione Scienz. Ital. Genova.

15S. Sismonda A., Sul gesso delle formazioni terziarie in Piemonte. Antologia Italiana. Torino.

159. Sismonda E., Synopsis methodica animalium invertebratorum Pedemontii fossilium (exceptis speciebus ineditis). Éditio altera, accuratior, et aucta. Aug. Taur. $80^{\circ}$

1848. 160. Bellardi L., Monografia delle Columbelle fossili del Piemonte. Mem. R. Acc. Sc. Torino. Serie II, Tomo X.

161. Coquand H., Observations sur les dénominations de terrains de macigno et d'alberese, sur l'âge du Calcaire à fucoïdes de l'Italie, et sur la véritable position du calcaire rouge ammonifère de la même contrée. Bull. Soc. Géol. France. Serie II, Vol. V.

162. Pomel, Sus leptodon de Cadibona. Archiv. Sc. phis. et Nat. 'Tonie VIII. Genève.

163. Sismonla A., Notizie e schiarimenti sulla costituzione delle Alpi Piemontesi. Mem. R. Acc. Sc. Torino. Serie II, Tol. IX.

1849. 164. Borsarelli P. A., Nota sulla fornıazione contemporanea di massi arenacei a cemento calcareo nella collina di Torino. Mem. $\mathrm{R}$. Acc. Sc. Cii Torino, Serie II, Vol. X.

165. Coquaud H., Établissement du sinchronisme: 1.॰ Des terrains tertiaires et crétacés des bassins de la Gironde, de la Méditerranée et de Paris; $2 .^{\circ}$ des terrains tertiaires du Piémont, de la Toscane, des Legations et du Midi de la France. Annonce de la decouverte du terrain nummulitique du pourtour de la Méditerranée, dans les Carphates, la Syrie, la Perse et le sind (Inde). Observations de MM. D'Archiac, De Roys et Pomel. Bull. Soc. Géol. France. Série II, Vol. T].

166. Targioni-Tozzetti, Analisi chimica delle acque minerali e termali dei bagni d'Acqui. Gazzetta Tosc. delle Sc. mediche.

1849.52. 167. Statistica delle acque minerali dei Regii Stati Sardi di Terraferma. Torino.

1850. 16S. Bellardi L., Monografia delle Mitre fossili del Pienınte. Mem. R. Acc. Sc. Torino. Serie II, Tomo XI.

169. Gastaldi et Martins Ch., Essai sur les terrains superficiels de la vallée du Po, cuvirons de Turin, comparés à ceux de la plaine 
suisse. Observations de Min. Favre, de Wegmann, C. Prévost et Ėlie de Beaumont. Bull. Soc. Géol. France. Tol. VII

1850. 170. Luppi E., Sul valore degli argomenti ai quali dal Relatore del Consiglio superiore di sanità di Torino si affidava la sentenza: non fosse da prendersi in considerazione la proposta di studiare tutte le acque minerali sarde, presentata al Ministro degli $I_{11-}$ terni. Modena.

1850-51. 171. Orbigny (1)'), Prodrome de Paléontologie stratigraphique universelle. $16 .^{\circ} 3$ Fols en 4 parties. Paris.

1850. 172. Sismonda A.g Lettre sur la découverte du Mastodonte de Dusino. Bull. Soc. Géol. France. Série II, Tome VII.

173. Sismonda A., Proceedings of the Geological Society of London. Tom. VI.

1851. 174. James Cog Guide pratique aux principales eaut minérales de France, de Belgique, d'Allemagne, de Suisse, de Savoie et a'Italie. Paris,

(Vi furono molte edizioni di questo lavoro sino al 1875.)

1851-70. 175. Hïrnes M., Die fossilen mollusken des Tertiær-Beckens von Wien. 4. Vol. I, II. Herausggb, voln. k, k. Geol. Reichsan. stalt. Wien.

1851. 176. Manganotti A., Estratto del rapporto sulla descrizione dei pesci e crostacei fossili del Piemonte del Dott. E. Sismonda. Nuovi Ann. di Sc. Nat. Vol. III.

177. Sismonda A., Osteografia di un Mastodonte angustidente. Mem. R. Acc. Sc. Torino. Serie II, Vol. XII.

1852. 178. Bellardi L., Catalogue raisonné des fossiles nummulitiques dn Comté de Nice avec la collaboration de M. E. Sismonda (Echinodermes), de D'Archiac (Foraminifères) et de M. Hajme (Polypiers), $40^{\circ}$

179. Davet de Beaurepaire, Histoire et description des sources minérales du Royaume de Sardaigne et des contrées voisines. Paris.

180. Michelotti G., Lettre sur le terrain tertiaire de la vallée de la Bormida (Piémont). Bull، Soc。 Géol. France, Série II, Tome IX.

181. Pareto L., Della posizione delle roccie eruttive e pirogene dei periodi terziari, quaternario ed attuale in Ilalia. 8. $\mathrm{Tip}$ Sordo-Muti. Genova.

182. Sismonda A., Classificazione dei terreni stratificati delle Alpi tra il Monte Bianco e la Contea di Nizza. Mem. R. Acc. Sc. di Torino. Serie II, Tom, XII.

1853. 183. Archiac (D') et Haime I., Description des animaux fossiles de l'Inde (Monographie des Nummulites). 4. ${ }^{\circ}$ Paris.

184. Mayer Ch., Versuch einer Classification der tertiacr Gebilde Fu- 
ropa's. Vern. d. Schweiz, naturforsch. Gesellsch. Trogen, Ap. penzel.

1853. 15. Pictet F. I., Traité de Paléontologie. 4 Vols. Paris.

156. Sismouda E., Note sur le dépôt à nummulites du Piémont. Bull. Soc. Géol. France. Série 1I, Vol. I.

187. Sismonda A., Carta geologica degli stati di S. M. il Re di Sardegna: in terraferma.

185. Stefani G., Rivista delle acque salubri degli Stati Sardi. Torino. 1..$^{\circ}$ ix; $20^{\circ}$ Acqui; $3 .^{\circ}$ Vinadis; 4. Courmayeur. 11 Cimento III, IV.

1854. 159. Capsoni G., Guida alle acque minerali d'Acqui in Piemonte, Aix les bains in Savoia, ecc. Milano.

190. Stefani G., Guida alle acque salutari degli Stati Sardi. Torino.

1855. 191. Bayle E., Note sur le système dentaire de l'Anthracotherium magnum. Bull. Soc. Géol. France. Série II, Tom. XI.

192. Brocchi G. B., Conchiologia fossile subappennina con osservazioni geolngiche sugli Apennini ecc. $2 \mathrm{Vol}$. in-16. Silvestri. Milano.

1855-58. 193. Desor E., Synopsis des Echinides fossiles. 4. Reintwald Édit. Paris.

194. Pareto L., Note sur le terrain nummulitique du pied des Apennins. Bull. Soc. Gẻol. France. Série II, Toine XlI.

1855.59. 195. Paglia, Sugli strati del terreno sottoposto al letto attuale del Po. Atti Soc. Ital. Sc. Nat. Vol. I. Milano.

1855. 196. Sismonda E., Lettre à M. Élie de Beaumont sur les deux formations nummulitiques du Piémont. Compte rendu Acc. Sc. Vol. XL.

197. Sismonda E., Note sur le terrain nummulitique supérieur de Dego, Carcare, etc. Mem. R. Acc. Sc. To1ino. Série II, Vol. XVI.

195. Zigno (de) A., Sulle ossa fossili di Rinoceronte trovate in Italia. Atti dell'Imp. R. Ist. Ven. di Sc. Lett. ed Arti. 8.

1856-57. 199. Gastaldi B., Sur l'Anthracotherium magnum de Cadibone. Bull. Soc. Géol. France.

1856. 200. Righini G., Acque minerali del Piemonte. Farmacopea popolare. Torino.

1857. 901. Cocchi G., Carte géologique de l'Italie supérieure et centrale à l'échelle de 1:600000.

1857. 202. Mayer C., Description de coquilles nouvelles des étages supérieurs des terrains tertiaires. 8. Journal de Conchyl. Tome VI. Paris.

20:. Maycr C., Essai d'un tableau synchronistique des terrains tertiaires d'Eurore. Zurich.

1558. 901. Despine, Notice slatistique sur l'industrie minérale des Ftâts Sardes. Turin. 
1858. 205. Gastaldi B., Cenni sui vertebrati fossili del Piemonte. Mem. R. Acc. Sc. Torino. Serie II, Tomo XIX.

206 Gaudin C. T. e Strozzi C., Mémoire sur quelques gisements de feuilles fossiles de la Toscane. 4. ${ }^{\circ}$ Tav. I-XIII. Zurich.

207. Mayer C., Description de coquilles nouvelles des etages supérieurs des terrains tertiares. $80^{\circ}$ Journ. Conchyl. Tom. VII. Paris.

20S. Mayer C., Versuch einer neuen klassification der Tertiär-Gebilde r uropa's.

1858-59. 209. Peters K. F., Beiträge zur kenntniss der Schildkrötenreste aus den Oesterreichischen Tertiaerablagerungen. $40^{\circ}$ in Fr. v. Hauer: Beiträge zur Paleontographie Bd. I, 2. Heft. Wien.

1859-62. 210. Gaudin Th. e Strozzi C., Contributions à la flore fossilc Italienne. Soc, helv, de Sc. Nat.

1859. 211. Bossi A., Intorno alle argille, agli altri minerali ed ai fossili di Maggiora. Atti Soc. Ital. di Sc. Nat. Vol. I.

212. Sismonda E., Prodrome d'une flore tertiaire du Piémont. Mem. R. Acc. Sc. Torino. Serie II, Vol. XVIII.

1860. 213. Gastaldi B., Su alcune ossa di Mammiferi fossili del Piemonte. Lettera al Prof. Cornalia. Atti Soc. Ital. Sc. Nat. Milano.

214. Mayer C., Description de coquilles nouvelles des étages supérieurs des terrains tertiaires. $8{ }^{{ }^{\circ}}$ Journ Conchyl. Tome VIII. Paris.

21.5. Parola, Cenno sulle sorgenti minerali solforose, ferruginose ed alcaline testè scoperte in Vico di Mondovì. Turino.

216. Gastaldi B., Frammenti di Geologia del Piemonte. Sugli elementi che compongono i conglomerati miocenici del Piemonte. Mem. R. Acc. Sc. Torino. Serie II, Tomo XX.

1861. 217. Crosse H., Catalogue des espèces fossiles actuellement connues du genre Cancellaria. 8. Journ. Conchyl. Tome IX. Paris.

218. Mayer C., Description de coquilles nouvelles des étages supérieurs des terrains tertiaires. $80^{\circ}$ Journ. Conchyl. 'Tome IX. Paris.

219. Mayer C., Description des coquilles fossiles des terrains tertiaires inférieurs, 8. Journ. Conchyl. Tome IX. Paris.

290. Michelotti G., Études sur le Miocène inférieur de l'Itaiie Septentrionale. 4. Mem. Soc. Holl. Sc. Haarlem.

221. Michelotti G., Description de quelques nouveaux fossiles du terrain Hiocéne de la colline de Turin. $8^{\circ}$ Revue et Magasin de Zoologîe, Août.

Q22. Pareto L., Coupes à travers l'Apennin des bords de la Méditerranée à la vallée dı Po, depuis Livourne jusqu'à Nice. Bull. ¿voc. Géol. France. Série II, Tom. XIX. Paris.

298. Semper 0., Palæontologische Untersuchungen. 8. Neubrandenburg. l'lusieurs articles de la Kieler Schulzeitung en 1856 
et de l'Archiv des Vereins der Freunde der Naturgeschicht de Mlecklemburg en 1\$61, réimprimés dans la brochure éditée à Neubrandenburg.

1861. 224. Sismonda E., Appendice alla descrizione dei Pesci e Crostacei fossili del Piemonte. Mem. R. Acc. Sc. di Torino. Serie II, Vol. XIX.

22.5. Sisuronda E., Prodrome d'une flore tertiaire du Piémont. Mem. R. Acc. Sc. 'Turin. Serie II, Vol. XVIII.

1862 296. Cratveri F., Terremoto a Bra. Atti Soc. It. Sc. Nat. Tol. IV. Milano.

227. Doderlein P., Cenni geologici intorno alla giacitura dei terreni miocenici superiori dell'Italia Centrale. 4. ${ }^{\circ}$ Atti del X Congresso Sc. Ital, tenuto in Siena.

22S. Fournet I., Aperçus relatifs à la carte gẻologique de la Sávoie, du Piémont et de la Ligurie par M. A. Sismonda. Bull. Soc. Géol. France. Série II, Vol. XX.

229. (xastaldi B., Composizione dei conglomerati miocenici del Piemonte. Atti Soc. Ital. Sc. Nat. Milano.

230. Mayer C., Description de coquilles nouvelles des étages supérieurs des terrains tertiaires. $80^{\circ}$ Journ. Conchyl. X. Paris.

231. Sismonda A., Carta geologica di Savoia, Piemonte e Liguria. Torino.

932. Stefanelli e Sestini, Sommario degli studi di chimica.

1863. 9:3. Costa 0. G., Descrizıone di alcuni fossili delle colline di Torino. Arın. di Acc. d'aspir, nat. Vol. III. Napoli.

234. Craveri F., Idrografia sotterranea della città di Bra. Bra.

235. Giastaldi B., Antracoterio di Agnano, Balenottera di Ca-Lunga presso S. Damiano, Mastodonte di Mongrosso. Lettcra al Prof. E. Cornalia. 8. Atti Soc. Ital. Sc. Nat. Vol. V. JIilano.

236. Gastalli et Mortillet, Sur la théorie de l'affouillement glaciaire. Atti Soc. Ital. Sc. Nat. Vol. V.

237. Gastaldi B., Sulla escavazione dei bacini lacustri compresi negli anfiteatri morenici. Atti Soc. Ital. Sc. Nat. Vol. V.

235. Mayer C., Description de coquilles fossiles des terrains tertiaires inférieurs. 8.0 Journ. Conchyl. Tome XI. Paris.

:39. Mortillet (de) (*., Sur l'affouillement des anciens glaciers. Atti Soc. Sc. Nat. Vol. V. Milano.

240. Omboni G., Azioue riescavatrice esercitata dagli antichi ghiacciai sul fondo delle valli alpine. Milano.

\#1. Omboni Gr., Sull' azione riescavatrice esercitata dagli antichi ghiarciai nel fondo delle valli alpine. Atti Soc. Sc. Nat. Vol. I. Milano. 
1863. 24. (karelli 1)., Delle acque mincrali d'Italia e delle loro applicazioni terapentiche. 'Torino.

1864. 243. Costa 0. G., Sopra alcuni fossili di Gassino in Piemonte. Lettera al D. Garbiglietti. Boll. Soc. Ital. Mat. Soc. Sc. Lett. Arti 11. 7. 8. Napoli.

244. Mayer C., Description de coquilles nouvelles des étages supéricurs des terrains tertiaires. $80^{\circ}$ Journ. Conchyl. Tome XII. Paris.

245. Mayer C., Description des coquilles fossiles des terrains tertiaires inférieurs. 8. Journ. Conchyl. Tome XII. Paris.

946. Mortillet (de) G.o. Terrains du versant italien des Alpes comparés à ceux du versant français.

247. Mortillet (de) G., L'époque quaternaire dans la vallée du Po. Bull. Soc. Géol. France. Serie II, Vol. XXII.

1864-65. 948. Mortillet (de) G., Note additionelle sur la valléc du Po. Bull. Soc. Géol. France. Série II, Tome XXII.

1864. 249. Rotureau A., Des priucipales caux minérales de l'Europe. Paris.

250. Sella Q., Sulla costiızione geologica e sull'ińdustria del Biellesc. Biella.

1865-67. 251. Costa 0. (4., Sui pesci fossili di Bra in Piemonte. Parte I e II. Napoli.

1865 25. Costa 0. G., Bra ed i Sig. Craveri. Boll. d'Ass. Ital. Mut. Soc. Sc. Nat. Lett. Art. Napoli.

953. Gastaldi B., Intorno ad alcuni fossili della Toscana e del Piemonte. $8 .^{\circ}$ Atti R. Acc. Sc. Torino. Vol. I.

854. Gastaldi B., Sull' esistenza del Serpentiuo in posto nelle colline del Monferrato. Atti R. Acc. Sc. Torino. Vol. I.

855. Gastaldi B., Nuove osservazioni sull'origine dei bacini lacustri. Atti R. Acc. Sc. di Torino. Vol. I.

256. Gastaldi B., Sulla riescavazione dei bacini lacustri per opera degli antichi ghiacciai. Mem. Soc. Ital. Sc. Nat. Vol. I.

9.77 Hébert E., Sur le terrain nummulitique de l'Italie septentrionale. Compte rendu de l'Acc. de Sc. de Paris. Vol. LXI.

258. Mayer C., Tableau syncronistique des terrains tertiaires d'Enrope. Zurich.

1865-66. 259. Hébert E., Sur le terrain nummulitique de l'Italie septentrionale et des Alpes, et sur l'Oligocène d'Allemagne. Bull. Soc. Géol. France. Série II, Tome XXIII.

1865. 260. Pareto L., Note sur les subdivisions que l'on pourrait établir dans les terraius tertiaires de l'Apennin septentrional. Bull. Soc. Géol. France. Série II, Tome XXIr.

961. Sismonda F., Matériaux pour servir à la Paléontologie du ter- 
tiaire đù Piẻmont. I Partie: Végétaux. M[em, R. Acc. Sc. di Torino. Série II, Vol. XXII.

1865. 262. Tournouer R., Sur le calcaire à astéries et sur ses rapports a avec certains terrains tertiaires de l'Italie septentrionale. Comptc rendu de l'Acc. de Sc. Paris. Vol. LXI.

1866. 263. Costa 0. (H., Nuove osservazioni intorno ai fossili di Gassino ed illustrazione di alcune nuove specie. $80^{\circ}$ Ant. Cons. Tip. Napoli.

264. Gastaldi B., Sunto di una Memoria Intomo ad alcuni fossili della Toscana e della Lombardia. Atti R. Acc. Se. di Torino. Vol I.

265. Hébert E., Sur le terrain nummulitique de l'Italie et des Alpes. Note en réponse à une réclamation de MI.r Dellhos. Vol. LXI. Compte rendu Acc. Sc. Paris. Vol. LXII (1 semes're).

266. Mayer C., Description de coquilles nouvelles des étages supérieurs des terrains tertiaires. $80^{\circ}$ Journ. Conchyl. Tome XIV. Paris.

967. Segu'nza G., Intorno ai brachiopodi miocenici delle provincie piemontesi. Lettera al Sig. Cav. Rovasenda. Ann. dell'Acc. di aspir. 1at. Serie III, Vol. XI. Napoli.

1867-68-70. 268. Mnyer C., Catalogue systématique et descriptif des fossiles des terrains tertiaires qui se trouvent au Musée fédéral de Zurich. $80^{\circ}$ Journ. trim. Soc. Sc. Nat. Zurich.

1868. 269. Achiardi (d') A., Studio comparativo fra i coralli dei terreni terziari del Piemonte e delle Alpi Venete. $4 .^{\circ}$ Ann. Unir. di Pisa. Amo X. Pisa.

270. Falconer H., On tlıe spècies of Mastodon and Elephant occurring in the fossil state in Great Britain. 8. ${ }^{\circ}$ Quart Journ. Geol. Soc. of London. 1857-1860. Paleontological memoirs and notes. Vol. II. London.

271. Falconer H., Notes on Rhinoceros. VIII. Description of remains of Rhinoceros leptorhinus in Muséum of Nat. Hist. at Turin. April 1861. Paleontological Memoirs and notes. 8. ${ }^{\circ}$ Vol. II. London.

272. Mayer C., Description de coquilles nouvelles des étages supérieurs des terrains tertiaires. $80^{\circ}$ Jouru. Conchyl. Tome XVI. Paris.

273. Mayer C., Tableau syncronistique des terrains tertiaires supérieurs. Zurich.

274. Tissandier, Sur l'eau minérale de Villa Salice près de Voghera. Jouru. Pharm. et Chim. Tome VII.

1869. 275. Mayer C., Description de coquilles nouvelles, des étages supérieurs des terrains tertiaires inférieurs. $8 .^{\circ}$ Journ. Conchỵl. Tome XVII. Paris. 
1S69. 976. Mayer C., Description de coquilles fossiles des terrains tertiaires inférieurs. 8. Journ. Conchyl. Tome XVII. Paris.

277. Waya C., Tablean syncronistique des terrains tertiaires inferieurs.

978. Manzoni, Briozoi fossili italiani. 8.0 1869. Sitzb. d. k. Ak. d. Wissens. in Wien. I Abtl. $1^{\text {a }}$ contrib. in B. LIX. Januar. Heft 1869. 2. ${ }^{a}$ Contrib. in B. IIX April. Heft. 1869. 3. ${ }^{a}$ Contrib. in B. LX. December. Heft. 1869.

279. Onboni G., Geologia dell'Italia. Maisner. Milano.

980. Statistica del Regno d'Italia (Acque minerali). Firenze.

1870. 281. Davidson Th., On italian tertiary Brachiopoda. Geol. Magazine. N. $74-75-76$. L.ondon.

98. Mayer C., Description de coquilles fossiles des terrains tertiaires. 8. Journ Conchyl. Tome XVIII. Paris.

98:. Perone A., Dizionario universale topografico, storico, fisico, chimico, terapeutico delle acque minerali di tutte le provincie italiane. Napoli.

284. Marieni L., Geografia medica dell' Italia (Acque minerali). Milano.

98.5. Siguorile G., Te calci idrauliclie ed i cementi della Liguria. Effem. Soc. Lett. e Conv. Scient. di Genova. Anno I, Vol. I. Genova.

1870-75. 296. Sandberger F., I.and und Süsswasser conchylien der Worwelt. Wiesbaden.

1870. 287. Stampa cchia G., La nuova teoria del calorico applicata alla fisiologia ed alla terapia, con alquanti ricordi sulle sorgenti termali d'Acqui e delle acque sulfuree di S. Cesaria, ancora ignote all'Ttalia. Torino.

1871. 288. Bruno C., Cenno sulla costituzione del terreno e sul clima del circondario di Mondovì. - Mondovì.

299. Gastaldi B., Studi geologici sulle Alpi occidentali. Mem. P. Com. Geol. Ital. Parte I.

990. Gastaldi B., Iconografia di alcuni oggetti d'alta antichita rinvenuti in Italia. Mem. R. Acc Sc. di Torino, Vol. XVI, Se. rie 11.

1871-72. 291. Mastaldi B., Intorno ad alcuri resti fossili di Arctomys e di Ursus Spclaus. Atti R. Acc. Sc. Torino. Vol, VII.

1871. 992. Mayer C., Découverte de couches à Congéries dans le bassin du Rhône.

293. Mayer C., Description de coquilles nouvelles des étages supérieurs des terrains tertiaires. $80^{\circ} \mathrm{J} n$ mrn. Conchyl. Tome XIX. Paris 
1871. 294. Schirardi, Nnora analisi dell'acqua minerale d'Acqui esegnita dal Prof. Bunsen. Amnali Fol. LIII.

295. Sismonda E., Matériaux pour servir à la Paléontologie du terrain tertiaire du Piémont. Partie II. Protozaires et Célentéres. Ourrage reru et angmenté par I. Wichelotti. Mem. Acc. Sc. Torino. Serie II, Vol. SXV.

1871-72. 296. Tardy, Aperçu sur les collines de Turin. Bull. Soc. Géol. France. Sẻrie II, Tome XXIX.

997. Tardy, Esquisse des périodes miocène, pliocéne et quaternaire dans la hante Italie. Bull. Soc. Géol. France. Série II, T. XXIX.

1872 295. Brandt I. F., Ueber die Reste eines in Italien bei fcqui in den unteren Schichten des mitteren miocän entdeckten jungen Sqnalodons Bull. Acc. Imp. Sc. S. Petersbonrg. T. XXIII.

299. Bellardi L., I Jollnschi dei terreni terziari del Piemonte e della Liguria. Parte I. Cefalopodi, Eteropodi, Pteropodi, Gasteropodi Afuricidi, Tritonidi). 4. ${ }^{\circ}$ Mem. R. Acc. Sc. Torino. Serie II, T. XXVII.

300. Gastaldi B. e Lessona M., Relazione intorno ad una Memoria di L. Bellardi intitolata: I Molnuschi dei terreni terzinri del Piemonte e della Lombardia. Atti R. Acc. Sc. di Torino. Vol. VII.

1872-73. 301. Gastaldi B., Appunti snlla memoria del Sig. Geikie F, R. $S \mathrm{E}$. On changes of climate during the glacial epoch. Atti R. Acc. Sc. di Torino. Tol. VIII.

1872. 302 Gerrais P., Coup d'œil sur les mammifères fossiles d'Italie. Journ. de Zool. Vol. I, et Bull. Soc. Géol. France. Serie II, Tome XIIX.

303 Gastaldi B., Cenni sulla costituzione geologica del Piemonte. Boll. R. Com. Geol. d'Italia Vol. VIII.

304. Nayer C., Description de coqnilles nourelles des étages snpérieurs des terrains tertiaires. $80^{\circ}$ Journ. Conchrl. Tome XX. Paris.

35. Sigunrile (F., Stndi sulle giaciture cuprifere e magnesifere della Liguria e sulle roccie che le racchitdono, seguiti da alcune norme per la loro ricerca, con raggnagli sulla natura della serpentina e suoi affini. Atti R. Acc. Sc. di Torino. Tol. VII.

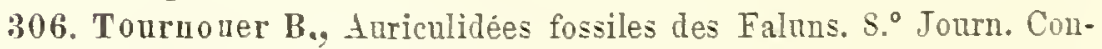
chỹ. Série III, Tome XII.

1873. 307. Brandt I. F., Untersuchngen neber die fossilen und subfossilen Cetaceen Europa's, mit Beiträgen ron Cornalia, Gastaldi, ecc. 4. ${ }^{\circ}$ Hem. R. Acc. Sc. St Petersbourg. Serie VII, T. XX, n ${ }^{\circ}$ I.

33s. Ierris ( $x .$, I tesori sotterranei d'Italia. Parto I Regione delle Alpi. Torino. 
1873. 309. Mayer C., Description de coquilles nouvelles des étages supérieurs des terrains tertiaires. $8 .^{\circ}$ Journ. Conchyl. Tome XXI. Paris.

310. Stoppani A., Corso di Geologia. 8.0 Nilano.

1874. 311. Brandt I. F., Ergänzungen zu den Fossilen Cetacen Europa's. 4. ${ }^{0}$ Mem. Acc. Imp. Sc. St. Petersbourg. Série VII, T. XXI.

312. Bruno C., Intorno all'origine delle fontane con speciale riguardo alla Idrografia sotterranea di Mondovi. - Mondovi.

313. Bellardi L., Monografia delle Nuculidi trovate finora nei terreni terziari del Piemonte e della Liguria. Annuario del R. liceo Gioberti.

314. Desor L., Die Beziehungen des Eiszeit in den Alpen zur pliocaen Formation von Ober Italien. Verhandl. d. Schw. Natur. Gesch.

315. Gastaldi B. e Lessona M., Relazione intorno ad una memoria del Prof. L. Bellardi intitolata: I Molluschi dei terreni terziari del Piemonte e della Liguria. Parte II. Atti R. Acc. Sc. Torino. Vol. IX.

316. Gastaldi 13., Studi geologici sulle Alpi occidentali. Parte II. Mem. Com. Geol. d'Italia.

317. Issel A., Sullopera di L. Bellardi intorno ai Molluschi dei terreni terziari del Piemonte e della Liguria. Effem. Soc. Lett. Conv. Scientif. Genova.

318. Iervis G., I tesori sotterranei dell'Italia. Parte II. Regione dell'Appemino e vulcani attivi e spenti dipendentivi. Torino.

319. Macagno e Bertoni, Sulla composizione chimica delle acque di Asti. R. Stazione enol. sperim. Asti.

320. Mayer C., Description de coquilles nouvelles des étages supérieurs des terrains tertiaires. $8 .^{n}$ Journ. Conchyl. Tome XXII. Paris.

321. Mayer C., Natürliche, gleichmässige und practische Classification der Sediment-Gebilde. Zïrich.

187t-78. 322. Stoppani A., Geologia d'Italia. L' Italia sotto l'aspetto fisico, ecc. Milano.

1875. 323. Bellardi L., Novæ Pleurotomidarum Pedemontii et Liguriæ fossilium dispositionis prodromus. 8. ${ }^{0}$ Boll. Soc. Malac. Ital. Vol. I. Pisa.

1875-80. 324. Beneden (Van) et Gervais, Ostéographie des Cétacés vivants et fossiles. 4 Livr. 1-17.

1875. 325. Bianconi G. A., Prove della contemporancità dell'epoca glaciale col periodo pliocenico. Bologna.

326. Brouno L., Sull'anfiteatro glaciale d'Ivrea. 8. Ivrea.

327. Cavalli G., Note sul bacino del Po in Piemonte. Torino. 
1875-96. 3.2. C. Caralli G., Note sul bacino del $P_{0}$ in Piernonte concernenti la disposizione geologica dello strato di puddinga sotto il quale fu trorata nello scaro d'un pozzo della Casa del Barone Ca. sana, una daga di rame primitiro, e sulle abbondanti acque provenienti dalle grandi masse dei ghiacciai alpini che scorrono sotto tale strato. Atti R. Acc. di Torino. Vol II.

1075 . 399. Desor E., Le passage morainique, son origine glaciaire et ses rapport arec les formations pliocènes d'Italie. Arch. Sc. Nat. LIV. Geuère.

330. Gastaldi B., Cemi sulla giacitura del Cerus euriceros. Atti R. Acc. Lincei. Serie Il, Tomo II. Roma.

331. Gastaldi B., Sur les glaciers pliocèniques de Mr. E. Désor. Atti R. Acc. Sc. Torino Tol. X.

392. Gastaldi B., Uno scheletro di balena a Montafia. Appendice (3 mumeri) della Gazz. Piem. 1875. Estratto 16." Farale Edit Torino.

333. Harpe (De la) Ph., Note sur les Tummulites des Alpes Occidentales. $8^{\circ}$. Actes de la $60^{e}$ session d. 1. Soc. Helr. Sc. Nat. Bex.

834. Lawler R., Monografia del genere Notidanus. $8^{\circ}$ Firenze.

335. Haser C., Osservazioni geologiche sulla Liguria, il Tortonese e l'alto Monferrato Atti. R. Acc I incei. Serie II, Yol. II. Roma.

936. Mayer C, Description de coquilles nourelles des étages supérieurs des terrains tertiaires. Journ. Conchyl. Tnme XXIII Paris.

333. Marer C., Vue panoramique prise du Chateau de Serraralle Scrivia.

33:5. Riitinerer L, Weitere beiträge zur Benrtheilung der Pferde der Quaternär-Epoch. 4. Abhandl. d. Schw. palæont. Ges. Tol. II.

339. Tounover L., Obserrations sur la comunication de LI. Harer: Ball. Soc. Géol. France. Tome IV, Série IIl.

1076. : $: 40$. Bellardi L., Descrizione di un moro genere della famiglia delle Bullidi fossili del terreno pliocenico inferiore del Piemonte e della Liguria. Boll. Soc. JIalac. Ital. Vol. JII. fasc. 3̋. Pisa.

341 Mager C., La rérité sur la mer Glaciale an pied des Alpes. Bull. Soc. Géol. France. Série III, Tome IV.

342. Nayer C., Description de coquilles nourelles des étages supérieurs des terrains tertiaires. Journ. Conchyl. Tome XXIT. Paris.

343. Omboni G., Come si è fatta l'Italia. Sagogio di Geologia popolare.

:3. Riitimeyer L., Ueber pliocæu und eisperoide ans beiden seiten der Alpen. Genère. 
1876. 345. Seguenza (H, Cenni intorno alle Verticordie fossili del Pliocene italiano. 4. ${ }^{\circ}$ Rendiconto R. Acc. Sc. fis. e natur. di Napoli. Fase. 6 .

346. Stefani (De) C., Molluschi continentali fino ad ora notati in Italia nei terreni pliocenici. 8. Atti Soc. Tosc. di Sc. Nat. Vol. II. Pisa.

1877. 347. Bellardi L., I Molluschi dei terreni terziari del Piemonte e della Liguria. Parte II Gasteropodi (Pleurotomidi). Mem. R. Acc. Sc. Torino. Serie II, Tomo XXIX.

348. Buretti M., Studi geologici del gruppo del Gran Paradiso. Mem. R. Acc. dei Lincei. Serie III, Vol. I.

349. Bruno $\mathbf{L}$., I terreni costituenti l'antiteatro allo sbocco della Dora Baltea.

350. Garelli G., La cura termale d'Acqui. Torino.

351. Hébert E., Observations sur les terrains tertiaires du Piémont. Bull Soc. Géol. France. Série III, Vol. V (e risposta di Noguès, Mayer e Toumonër).

352. Issel A., Appunti paleontologici - II. Cenni sui Myliobates fos sili dei terreni terziari italiani. $80^{\circ}$ Ann. IIus. Civ. St. Nat. Vol. X. Genova.

3ə3. Mayer C., Studi geologici sulla Liguria centrale. Boll. R. Com. Geol. N. ${ }^{\circ}$ 11-12. Roma.

354. Mayer C., Sur la carte géologique de la Ligurie centrale. Bull. Soc. Géol. France. Serie III, Tome V.

3əə. H ayer C, Description de coquilles nouvelles des étages supérieurs des terrains tertiaires. $80^{\circ}$ Journ. Conchyl. Tome XXV. Paris.

3 ä6 Mayer C., Schizzo geologico d' una parte della Liguria e dell'alto Monferrato, Soc. Lett. Conver. Scient. I. Genova.

35̃. Stoppani A., Del carattere marino degli anfiteatri morenici. L'Ttalia sotto l'aspetto fisico, ecc. Milano.

3és Taramelli C, Osservazioni stratigrafiche sulla Provincia di Pavia.

359. Vasehetti, Cenni sull'acqua salso-bromo-iodica di Vignale MLonferrato Torino.

360. Val rio G., Sull'opuscolo del D.r Vaschetti: Cemi sull'acqua salso-bromo-iodica di Vignale Dionferrato. Giom. della R. Acc. di ILed. Serie III, Vol. XXI.

1878. 361. Bell. rdi L., Descrizione di una nuova specie di Zeidora trovata nelle marue del Pliocene inferiore delli Liguria. Atti $\mathrm{R}$. Acc. Sc. Torino. Vol. XIII.

362. Fuclıs Th., Studien neber die Glicderung der jüngeren Tertiär- 
bildungen Ober-Italiens, gesammelt auf einer Reise im Frưlihnge $18778^{\circ}$. Sitzb. d. k. Akad. d. Wissensch. za Wien. Band i7. I Abth.

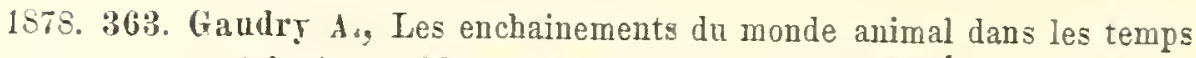
géologiques. Mammifères tertiaires. 8." Sary Édit. Paris.

364. Issel A., Appnnti paleontologici, III, Ritroramento del genere Machcerodus sugli Appennini liguri. S.0 Estr. Ann. Ins. Cir. Sc. Nat, XII. Genora.

36. Mayer C., Description de coquilles nourelles des étages supérieurs des terrains tertiaires. 8.0 Journ. Conchyl. Tome XXVI. Paris.

366. Mayer C., Ueber die Nummuliten Gebilde ober Italiens.

367. Narer C., Zur Geologie des mittleren Ligurien. Viertljhrschft. d. Zuirich. Naturs. Ges. XIII. Band. I Heft. Zürich.

36S. Morlet L., Monographie du genre Ringicula Deshayes, et description de quelques éspèces nourelles. Fartie II; liste des éspèces fossiles. Journ. Conchrl. Vol. XXVI (Série III, Tome XVIII). Paris.

369. Taramelli F., Del granito nella formazione serpentinosa.

370. Taramelli T., Sulla formazione serpentinosa dell'Apennino parese. 4. ${ }^{\circ}$ Iem. R. Acc. Lincei. Serie II, Vol. II. Roma.

33. Zigno (de) d., Sopra un nuovo Sirenio fossile scoperto nelle colline di Bra in Piemonte. 4. ${ }^{\circ}$ Mem. R. Acc. Lincei. Serie III, Vol. II. Roma.

1879. 372. Alessandrini (de) I., Acqui, le sne terme ed i suoi dintorni. Acqui.

333. Bonney T. G., Note sopra alcune serpentine della Liguria e della Toscana. Boll. F. Com. Geol. 1..09-10 (du Geol. Mag. T." 182). Roma.

3it. Harpe (de la) Ch., Étude sur les Nummnlites dn Comté de Xice, stirie d"une Échelle des Nummulites. Bull. Soc. Vand. Sc. Nat. Vol. XYI, N.o 82.

3i.3. Iervis G., I combustibili minerali d'Italia. 8.0 Torino.

3i6. Omboni G., Le nostre Aipi e la piamura del Po. s.o Hilano.

3i. Parona C. F., Il Pliocene d'oltre Po parese. Atti Soc. Ital. Sc. Nat.

3is. Portis A., Di alcuni fossili terziari del Piemonte e della Ljguria appartenenti all'ordine dei Cheloni. Hem. R. Acc. Sc. di Torino. Serie II, Yol. XXXII.

379. Portis A., Intormo ad alcne impronte eoceniche di Vertebrati recentemente scoperti in Piemonte. Atti R. Acc. Sc. Torino. Tol. XV. 
1880. 380. Baretti $\mathbf{M}$., Sui resti fossili di Rinoceronte nel territorio di Dusino. Atti R Acc. Sc. Torino. Vol. XV. (I e II Comunicaziones)

381. Giordano S., Acqua minerale (acido ferruginoso di Veglia). L'idrologia medica II.

382. Issel A., Conclusionl di nno studio sui terreni serpentinosi nella Liguria Orientale. Bull. R Com. Geol. Roma.

383. Issel A., Osservazioni intorno a certe roccie amfiboliche della Ligurla, a proposito d'una nota del Prof. Bonney concernente alcune serpentine della Liguria e della Toscana. Boll. $R$. Com. Geol ${ }^{2}$ Roma.

384. Iampani (\%., L'Italia sotto l'aspetto idrografico, fisico, storico, ecc. Parte I. Roma.

38.ّ. Morlet L., Supplément à la monographie du genre Ringicula Deshayes, Journ. Conchyl. Vol. XXVIII (Série III, Tom. XX).

BS6 Pajssa P., Brevi cenni sulla fonte e sull'acqua salso-bromoiodio-solforata di S. Genesio. Torino.

387. Stoppani A., Era neozoica. 4. Tip. Vallardi. Milano.

1881. 388. Baretti M., Resti fossili di Mastodonte nel territorio d'Asti (Valle Andona, Cà dei Boschi). Atti R. Acc. Sc. Torino. Vol. XVI.

389. Com. Geol. Ital., Carta geologica d'Italir. Scala 1:111111. Roma.

390. Cauda V., Calce idraulica di Lauriano.

391. Cossa, Su alcune roccie serpentinose dell'Appenuino bobbiese.

392. Issel A. e Mazznoli L., Relazione degli studi fatti per un rilievo delle masse ofiolitiche nella riviera di Levante. Boll. $R$. Com. Geol. Ital.

993. Jervis G., I tesori sotterranei d'Italia. Parte III. Regione delle isole ed addenda. Torino.

394. Portis A., Sui terreni stratificati di Argentera. Mem. R. Acc. Sc. Torino. Serie II, Vol. XXXIV.

395. Seguenza G., Le Ringicule terziarie degli strati italiani. Mem. R. Acc. Lincei. Serie III. Roma.

1882.396. Bellardi I., I Molluschi dei terreni terziari del Piemonte e della l.iguria. Parte III. Gasteropodi (Buccinidi, Ciclopsidi, Purpuridi, Coralliofillidi, Olividi). Mem. R. Acc. Sc. Torino. Serie II, Vol. XXIV.

397. Bruno I., Rapporto del terreno pliocenico col glaciale. $8 .^{\circ}$ Ivrea 398. Capellini G., Del Tursiops Cortesii e del Delfino fossile di Mombercelli nell'Astigiano.

399. Taramelli T., Osservazioni geologiche fatte nel raccogliere alcuni campioni di serpentine. Boll. Soc. Geol. Ital. Vol. I. 
1882. 400. Taramelli T., Sopra đue giacimenti nummulitici nell'Appennino pavese.

1883 401. Bonardi E., Esame chimico di alcune argille glaciali e plioceniche dell'Alta Italia. Boll. Soc. Geol. Ital. Vol. III.

402. Bruno Is, L'êra lacustre nell'anfiteatro delia Dora Baltea. Boll. Club Alpino ital Vol L.

403. Parona C. F., Esame comparativo della fauna dei vari lembi pliocenici lombardi. Rendiconto R. Istituto Lombardo.

404. Parona C. F., Sopra i lembi pliocenici sitnati tra il bacino del lago d'Orta e la Val Sesia. Boll. Soc. Geol. Ital. Vol. I.

405. Portis A., Nuovi studi sulle traccie attribuite all'uomo pliocenico. Mem. R. Acc. Sc. di Turino. Serie II, Vol. XXXV.

406. Portis A., Nuovi cheloni fossili del Piemonte. Mem. R. Acc. Sc. Torino. Serie II, Vol. XXXV.

40\%. Taramelli T., Descrizione geologica della Prov. di Paria.

1884. 40s. Bellardi L., I Hollnschi dei terreni terziari del Piemonte e della Liguria. Parte IV (Fasciolaridi, Turbineilidi). Mem. R. Acc. Sc. Torino. Serie III, T. XXXVIr.

409. Issel A., Note sulla zona di coincidenza delle formazioni ofiolitiche, eoceniche e triassiche delia Liguria occidentale. Boll. R. Com. Geol. d'Italia. Serie II, Tomo V.

410. Issel A., Dell'esistenza di una zoua ofiolitica terziaria a Rivara Canavese.

411. Issel A., Bibliografia scientifica della Liguria 8. Genova.

412. Mazzuoli L., Le formazioni ofiolitiche della Valle del Penna nell'Apennino ligure.

413. Nayer C., Tableau synchronistique des terrains tertiaires conforme à l'équivalence des perihelies et des etages. Zürich.

414. Porlis A., Coutribuzione all' Ornitolitologia Ital. Hem. R. Acc. Sc. Torino. Serie II, Vol. XXXVI.

41.5. Portis A, Breve cenno sulle condizioni geologiche della collina di Superga. 16\%. Torino.

416. Relazione sui larori della Galleria dei Giori. Societa di Letture e colversazioni scientifiche. Fasc. Marzo-Aprile. Genora.

417. Sacco F., Nuove specie fossili di Mollnschi lacustri e terrestri in Fiemonte. Atti R. Acc. delle Sc. di Torino. Vol. XIX.

415. Sisceo F., L'alta valle padana durante l'epoca delle terrazze, in relazione col contemporaneo sollevamento deila catena alpinoappenniuica. Atti R. Acc. Sc. Torino. Yol. XIX.

1855. 419. Baretti II. e Saceo F., Il Hargozzolo Boll del Chub Alpino Italiano. N. ${ }^{\circ} 51$.

420. Fuchs Th., Die Versuche einer gliederung des unteren Neogen 
BACINO LRKZLARBO DEL, PIEMONTE.

in gebiete des Mittlmeers-Zeitschr. d. Deutsch. Geol. Ges. Bd XXXVII. Berlin.

18×5. 421. Issel A., La liguria ed i suoi abitanti nei tempi primordiali. Discorso inangurale dell' Univer stà. di Genova.

429. Issel $\mathbf{\Lambda}$., Note intomo al rilevamento geologico del territorio compreso nei fogli di Cairo Montenotte e Varazze. Boll. R. Com Geol. Ital. Serie II, Vol. VI.

423. Portis A., Catalogo descrittivo dei Talassoteri rinvenuti nei terreni terziari del Piemonte e della Liguria. Mem. R. Acc. Sc. di Toŕino. Scrie II, Vol. XXXVII.

424. Sacco F., Sopra alcuni fenomeni stratigrafici osservati nei terreni pliocenici dell'alta valle padana. Atti R. Acc. Sc. di Torino. Vol. XX.

425. Sacco $\mathbf{F}$., Des phénomènes altimétriques observés dans l'intérieur des continents. Bull. Soc. Géol. France Série III, T. XIV.

426 acco F', Sull'origine delle vallate e dei laghi alpini in rapporto coi sollevamenti delle Alpi e coi terreni pliocenici della valle padana. Atti R. Acc. Sc. Torino. Vol. XX.

40\%. Sacco F., Massima elevazione del Pliocene marino al piede delle Alpi. Atti R. Acc. Sc. Torino Vol. XX.

42S. Sacco F., Fama malacologica delle alluvioni plioceniche del Piemonte. Mem. R Acc. Sc. Torino. Serie II, Tome XXXVII.

429. Sacco F., Studio geo-paleontologico del territorio di Bene-Vagienna. $4^{\circ}$. Savigliano.

430. Sacco $\mathbf{E}$, Il terrazzamento dei littorali e delle vallate. Atti della R Acc. d'Agric. di Torino. Vol. XXVIII.

431. 'I'aramelli T'., Note geologiche sul Bacino idrografico del fiume Ticino. Boll. Soc. Geol. Ital. Vol. IV.

432. 'Irabuceo "., I fossili e la fossilizzazione. 8.0 Genova.

4:33. Cavara F., Le sabbie marnose plioceniche di Mongardino ed i loro fossili. Acc Sc. Ist. Bologna.

1886 434. Fornasini C., Foraminiferi illustrati da Soldani e citati dagli antori. Boll. Soc. Geol. Ital. V. Roma.

435. Issel A., Cenno sull'acqnisto del Museo Perrando. $8^{\circ}$. Soc. di Lett. e Conv. Scient. Fasc. Marzo 1886. Genova.

436. Mayer C., Description des coquilles fossiles des terrains tertiaires supérieurs. Journ. Conchyl. Série III, Tome XXVI.

437. Parona C. F., Valsesia e Lago d'Orta. Atti Soc. Ital. Sc. Nat. Vol XXXIX.

4:38. Pantanelii 10., Monografia sugli strati ponlici del Miocene superiore dell'Italia Settentrionale e Centrale. Mem. R. Acc. Sc. Lett. cl Arti di Modena. Serie II, T! IV. Modena. 
1886. 4:39. Pantanclli D., Melannpsis fossili e virenti d'Italia. Boll. Soc. Jalac. Ital. Vol. XII. Modena.

440. Portis A., Sulla vera posizione del Calcare di Gassino. Boll. R. Com. Geol Ital. Serie II, Tomo XVII.

441. Ristori, I Crostacei brachiuri ed anomuri del Pliocene Italiano. Boll. Soc. Geol. Ital. Anno $\nabla$.

442. Sacco F., Nuove specie terziarie di Molluschi terrestri, d'acqua dolce e salmastra del Piemonte. Atti Soc. Ital. di Sc. Nat. Vol. XXIX.

443. Sacco F., Intorno ad alcune impronte organiche dei terreni terziari del Piemonte. Atti R. Acc. Sc. di Torino. Vol, XXI.

444. Sacco F., Il Villafranchiano al piede delle Alpi. Boll. del R. Com. Geol. Ital.

445. Sacco F., Le Fossanien, nourel étage du Pliocène d'Italie Bull. Soc. Géol. de France. Série III, Tome XV.

446. Sacco F, La valle della Stura di Cuneo dal Ponte dell'olla a Bra e Cherasco. Atti Soc. Ital. Se. Nat. Vol. XXIX.

447. Sacco F., Sur quelques restes fossiles de Poissons du Pliocène du Piémont. Bull. Soc. Géol de France. Série III, T. XIV.

448. Saceo F., Il Piano Jiessiniano nel Piemonte. Parte I (MIondoriGuarene), Boll. Soc. Geol. Ital. Vol. V.

449. Saceo F, Sopra una nuova specie di Discohelix Dunker. Boll. dei MIusei di Zool. ed Anat. comp. di Torino. Vol. I.

450. Sacco F., I terreni terziari del Piemonte e della Liguria settentriouale (Anuunzio dell' inizio di pubblicazione).

451. Saceo F., Carta geologica di Serravalle Scrivia. Scala di $3 / 25000^{\circ}$ Torino.

452. Saceo F., icala geologica di Villalvernia e Garbagna Orest. Scala di $1 / 25000^{\circ}$ Torino.

45̃3. Sacco F., Hrassima elevazione dell'Eocene nelle Alpi occidentali italiane. Boll. del Club Alp. Ital. N ${ }^{0}{ }^{5} 52$.

4ə̌t. Saceo F., Sulla costituzione degli altipiani isolati di Fossano, Salmour e Banale. Atti R Acc. d'Agric. di Torino. Vol. XXIX.

45. Vasseur et Carez, Carte géologique de la France au ${ }^{2 / 500000}$ (Feuille IX. S. E. et Feuille XII. N. E.).

1887. 456. Baretti M., Sulle condizioni geologiche dei terreni attraversati dalla Galleria succursale dei Giovi. 4. ${ }^{\circ}$ Torino.

457. Baretti M., Appendice alla relazione sulle condizioni geologiche dei terreni attraversati, ecc. $4 .^{\circ}$ Torino.

458. Baretti II, Ancora della Galleria succursale dei Giori. MIonitore delle Strade Ferrate. N. 1?.

459. Bcllardi L., I JIolluschi dei terreni terziari del Piemonte e della 
Liguria. Parte V (Mitridi pars). Mein. R. Acc. Sc. Torino. Serie II, Tomo XXXVIII.

1887. 460. De Stefani, l'Appennino fra il Colle dell'Altare e la Polcevera. Boll. Soc. Geol. Ital. Vol. VI.

461. Gioldano F. G., Lanino e Saluoiraghi P., Linea succursale dei Giovi. Galleria Ronco. Memoria tecnica. 4. ${ }^{\circ}$ (30 marzo 1887). Roma.

462. Issel A., Nazzuoli L. e Zaceagna D., Carta geologica delle Riviere Liguri e delle Alpi Marittime, pubblicazione fatta dal Club. Alp. Ital. (Sez. ligure), un foglio grande in litografia. Fratelli Armanino. Genova.

463. Issel A, La nuova carta geologica delle Riviere liguri e delle Alpi IIarittime. Boll. Soc. Geol. Ital. Vol. VI.

464. Mayer C., Description des coquilles fossiles des terrains tertiaires supérieurs. Journ. Conchyl. Série III, Tome XXXVIJ.。

46.5. Mattirolo E., Sugli schisti argillosi della nuova Galleria dei Giovi, lettera all'Ispettore Capo delle Miniere. Boll. R. Com. Geol. Anno 1887. Roma.

466. Mariani E., Descrizione dei terreni miocenici fra la Scrivia e la Staffora. Boll Soc. Geol. Ital. Vol. V.

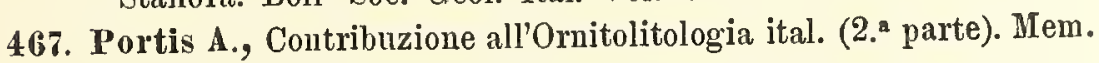
R. Acc. Sc. Torino. Serie II, Tomo XXXVIII.

46S. Sacco F., I terreni quaternari della collina di Torino. Atti Soc. Ital. Sc. Nat. Vol. XXX.

469. Sacco F., Il Piano Messiniano nel Piemonte. Parte II (GuareneTortona). Boll. Soc. Geol. Ital.

470. Saceo $\mathbb{F}$., Studio geologico dei dintorni di Voltaggio. Atti R. Acc. Sc. di Torino. Vol. XXII.

471 Sacco F., Rivista della fauna malacologica fossile, terrestre, lacustre e salmastra del Piemonte. Boll. Soc. Malac. Ital. Vol. XII.

472. Saceo F., Le tremblement de terre du 23 Férrier 1887 en Italie. Bull. Soc. Belge de Géologie. Tome I.

473. Sacco F., Sul passaggio tra il Liguriano ed il Tongriano. Boll. Soc. Geol. it. Vol, VI.

474. Sacco F., Carta geologica di Gavi, alla scala di $1 / 25000^{\circ}$ Torino.

475. Sacco F., Carta geologica di Capriata d'Orba, alla scala di $1 / 25000^{\circ}$ Torino.

476. Sacco $\mathbf{F}$., Carta geologica d'Acqui, alla scala di $1 / 25000^{\circ}$ Torino.

477. Sacco F., Carta geologica di Calamandrana, alla scala_di $1 / 25000^{\circ}$ Torino.

478. Sacco F., Carta geologica di Nizza Mronferrato e Sezzè Est, alla scala di $1 / 25000$. Torino. 
1587. 479. Sacco F., Carta geologica di Costigliole d’Asti, alla scala di ${ }^{1}{ }_{25000^{\circ}}$ Torino.

450. Sacco F., Carta geologica di Canale e Monteu Roero Est, alla scala di $1 / 4, \operatorname{sino}^{\circ}$ Torino.

451. Sacco F., Carta geologica di Mombercelli e Canelli Nord, alla scala di $1 / 25000^{\circ}$ Torino.

452. Sacco F., Carta geologica di Fossano, alla scala di ${ }^{1} / 25000^{\circ}{ } T_{0}-$ rino.

45: Sacco F., Carta geologica dei Colli torinesi, alla scala di "2,500" Torino.

484. Sacco F., Carta geologica di Orada Nord, alla scala di ${ }^{1}{ }_{50000}$ Torino.

45.). Sacco F., Carta geologica di Spigno Monferrato, alla scala di $1 / 50000^{\circ}$ Torino.

4S6. Sacco F., Carta geologica di Voltaggio Nord, alla scala di ${ }^{1} / 50000^{*}$ Torino.

4S7. Sacco F., Carta geologica di Cairo Montenotte Est, alla scala di ${ }^{1 / 50000}$. Torino.

45s. Śacco F., Carta geologica di Cera Sud e Garessio Nord, alla scala di "', ${ }_{50000}$ 'Toliuo.

459. Sacco F., Comunicazioni al Congresso Geologico Italiano in Sarona. Boll. Soc. Geol. Ital. Vol. VI.

190. Sacco F., I Colli torinesi (Foglietto esplicativo della carta geologica). \&.० Torino.

491. Sacco F., Classification des terrains t itiaires conforme a leurs facies. Bull. Soc. belge de Géologie. Tome I.

492. Sacco F., On the Origin of the Great Alpine Lakes. Proceedings of the Rojal Society of Ediuburgh. Vol. XIV.

493. Sacco F., Studio geologico dei dintorni di Guarene d'Alba. Atti R. Ace. Sc. di Torino. Vol. XXIII.

194. Sacco F, L'anfiteatro morenico di Riroli. Boll. R. Comit. Geol. Italiano.

495. Squinabol S., Contribuzione alla flora fossile dei terreni terziari della Liguria. Fucoidi ed Elimintoidi. Boll. Soc. Geol. Ital. Vol. VI.

1885. 496. Bellardi L., I Molluschi dei terreni terziari del Piemonte e della Liguria. Parte T. Mitridi (fine). Mem. R. Acc. Sc di Torino. Serie II. Vol. XXXIX.

497. Comitato geologico d'Italia. Carta geologica d'Italia. Scala di $1 / 1000900^{\circ}$ Roma.

198. Issel 1. Il terremoto del 1887 in Liguria. Boll R. Com Geol. Italiano. 
388s. 499. Mazzuoli $\mathbf{L}$, Sul modo di formazione dei conglomerati miocenici dell'Appennino ligure. Boll. R. Com. Geol. Ital.

500. Mayer C'., Tablean des terrains de sédiment. Zürich.

501. Mayer C., Description des coqnilles fossiles des terrains tertiaires inférieurs. Journ. Conchyl. Série IIT.

502. P'ortis A., Sui terreni attraversati dal confine franco-italiano nelle Alpi Marittime. Boll. R. Com Geol. Ital.

503 Portis A., Sul modo di formazione dei conglomerati miocenici delle colline di Torino. Boll. R. Com. Geol. d'Italia.

504. Sacco F., Carta geologica di Cherasco e Cervere. Scala di $1 / 25000$. Torino.

505. Sacco F., Sopra alcuni Potamides del Bacino terziario del Piemonte. Boll. Soc. Malac. Ital. Vol. XIIT.

506. Saceo F., Aggiunte alla fauna malacologica cstramarina fossile del Piemonte e della Liguria. Mem. R. Acc. Sc. di Torino.

507. Saceo F., Note di Paleoienologia italiana. Atti Soc. Ital. Sc. Nat. Vol. XXXI.

508. Sacco F., Stndio geologico delle colline di Cherasco e della Morra in Piemonte. Boll. R. Com. Geol. Ital.

509. Saceo F., Il cono di deiezione della Stura di Lanzo. Boll. Soc. Geol. Ital. Vol. VII.

510. Saceo F., I terreni terziari e quaternari del Biellese. Pnbblicazione della sezione biellese del Club. Alp. Ital. $4^{\circ}$. Torino.

511. Sacco F., I colli braidesi. Atti R. Acc. Agric. di Torino. Vol. XXXI.

512. Sacco F., Il Pliocene entroalpino di Valsesia. Boll R. Comit. Geol. Italiano.

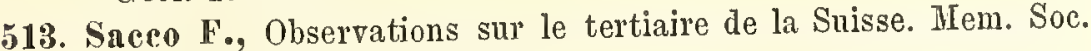
belge de Géologie. Tome II.

514. Sacco F., Un coin intéressant du tertiaire d'Italie. Mrem. Soc. belge de Géologie.

515. Sacco F., Les conglomérats dn Flysch.

516. Sacco F., Carta geologica del Bacino terziario del Piemonte. Scala di 1/100000. Torino.

517. Tellini A., Le Nummulitidee terziarie dell'Alta Italia occidentale. Boll. Soc. Geol. Ital. Vol. VII.

518. Uzielli ${ }^{\prime} x_{0}$, Gita geologica nella Liguria orientale. Torino.

519. Zaceagna G., Sulla geologia delle Alpi occidentali. Boll. Com Geol. Ital. Roma. 
Achiardi (D') A., 1863.

Archiac (D'), 1855.

Alessandrini (de), 1879.

Alibert, 1826.

Allioni, 1757.

Amoretti, 1803, 1824, 1844.

Anonimo, 1827, 1834, 1829.

Argentero di Bersezio (JIarquis de Brezé), 178f, 1787, 1788, 1789.

Barelli V., 1835.

Baretti JI., 1880, 1881, 1885, 1887.

Barocchini, 1835.

Bayle, 1855, 1876.

Beaumont (de) Élie, 1831, 1832, 1833, $1834,1835$.

Bellardi L., 1838, 1840, 1841, 1847, $1848,1850,1852,1872,1873,1874$, $1875,1876,1877,1878,1881,1882$, 1881, 1887, 1888.

Benteden (Van), 1875, 1880.

Benevelli, 1787.

Bertini B., 1821, 1843.

Bertoni, 1872.

Bertrand Geslin, 1831, 1835.

Bianconi G. G, 1846.

Bianconi G. A., 1875.

Blainville A., 1839, 1845, 1854, 1864.

Bonardi E., 1883.

Bcnney 'T. G., 1879.

Borsarelli. 1849.
| Borson S., 1800, 1819, 1820, 1821, 1822, 1823, 1825, 1830, 1833.

Bossi A., 1859.

Bouillon de la Grange, 1810.

Bourdet, 1822.

Brandt I. F., 1872, 187 ì, 1874.

Brocchi G, 1814, 1855.

Brongniart A., 1820 (1821), 1823.

Bronn H., 1825, 1828, 1831.

Bruno G, 1871, 1874.

Bruno G. D., 1836, 1839.

Bruno L, 1875, 1877, 1882, 1883.

Cambiaso G. II., 1806,

Campeggio., 1687.

Canobbio G. B., 1820, 1818.

Cantraine F. 1840.

Cantù G. L., 1823, 1825.

Capellini G., 1882.

Capsoni C., 1854, 1871.

Carez, 1856.

Cauda V., 1881.

Cavalli G., 1875, 1876.

Cavara F., 1886.

Chabrol de Volvie, 1824.

Cocchi G., 1857.

Collegno (di) G., 1836, 1838, 1843, 1844, 1845, 1846.

Com. Geol. Ital., 1881, 1888.

Coquand H., 1845, 1849.

Cossa, 1881. 
Costa O. G.', 1863, 1861, 1865, 1866, James G., 1851.

1867.

Craveri F., 1862, 1863.

Crosse G., 1861 .

Cuvier G., 1806, 1821, 1822, 1824.

Davet de Beaupaire, 1852.

Davidson 'Th., 1870.

De Blainville, 1845, 1854.

De-Cristofori, 1832.

Della Chiesa di Beuevello, 1833.

De-Rolandis, 1834.

De Saussure H. B., 1796, 1804.

Desor E., 1855, 1858, 1874, 1875.

Despine, 1858.

Di Collegno G. P., 1852.

Doderlein F., 1862.

Dujardin F., 1837.

Falconer H., 1857, 1860, 1861, 1868.

Fantoni, 1747.

Floris G., 1839.

Fornasini C., 1886.

Fournet I., 186:.

Fuchs 'Th., 1878, 1885.

Garelli G., 1861, 1877.

Gastaldi B., 1844, 1845, 184fi, 1849 , $1850,1855,1856,1857,1858,1860$, $1861,1862,1863,1865,1866,1871$, $1872,1873,1874,1875$.

Gaudin e Strozzi, 1858, 185?, 1862.

Gaudry A., 1878.

Gervais P., 1872, $1875,1880$.

Giordano A., 1835.

Giordano S., 1880.

Giordano P., 1887.

Halpe (de la) Pl., 1875, 1879.

Hebert E., 1865, 1866, $187 \bar{\imath}$.

Hörnes MI, 1S51-1870.

Issel A., 1874, 1877, 1878, 1880, $1881,1884,1885,1886,1887,1888$.
Jan G., 1832.

Jervis G., 1873, 1874, 1879, 1881.

Lamarck, 1835, 1845.

Lampani G., 1880.

Lanino G., 1887.

Lavini, 1835 .

Lawley R.; 1875.

Levis (de), 1754, 1795.

Lichenthal P., 1818.

Luppi E, 1850.

Macagno, 1874.

Majon G., 1808.

Malacarne, 1778.

Manganotti A., 1847, 1831

Manzoni, 1869.

Mariani E., 1387.

Marieni Is, 1870.

Marmora (della) 1818, 1820, 1832.

Martins Ch., 1849.

Miatlirolo E., 1886.

Mazzuoli, 1884, 1888.

Mayel C., 385.3, 1857, 1858, 1860, $1861,1862,1863,1864,1865,1866$, $1867,1868,1869,1870,1871,1872$, $1873,1874,1875,1876,1877,1878$, 1884, 1886, 1887, 1888.

Michelin H., 1840, 1844, 1847.

Michelotti G., 1838, 1839, 1810, 1811, $1816,1847,1852,1861,1871$.

Miclielotti I. 'T., 1803.

Morlet L., 1878, 1880.

Morozzo, 1790, 1791.

Mortillet (de) G., 1863, 1864, 1865.

Moulins (Des) Ch., 1842.

Nicolis de Robilant, 1786.

Omboni S., 1863, 1869, 1876, 1879.

Orbigny (d') A., 1841, $1850,1851$.

- Paganini, 18:7. 
Paglia, 1855, 1859.

Paissa P., 1880.

Pantanelli D., 1886.

Pareto L., 1827, 1832, 1853, 1834, Sismonda E., 1842, 1846, 1847, 1853, $1835,1836,1837,1840,1841,1843, \quad 1855,1859,1861,1865,1871$.

$1846,1817,1852,1855,1861,1865$. Squinabol S., 1857.

Parola, 1860.

Parona C. F., 1879, 1883, 1886.

Perone A., 1370.

Peters K. F., 1858, 1859.

Pictet F. I., 1553, 1857.

Pomel, 1845, 1818, 1854.

Portis A., 1579, 1881, 1883, I881, $1855,1886,1857,1888$.

Ragazzoni R., 1819, 1835?

Ratti P. I., 1811.

Ravetti, 1687.

Righini G., 185 .

Ristori, 1856.

Rotureau A, 1864.

Rütimejer L., 1875, 1876.

śacco F., 1884, 1885, 1886, 1887 . 1888.

Salmoiraghi F., 1887.

Saluzzo A., 1845.

Sandberger F., 1S70-1S75.

Schivardi, 1871.

Segnenza G., 1866, 1876, 1881.

Sella Q., 1864.

Semper 0, 1855, 1861 .

Signorile G., 1870, 1372, 1834.
Sismonda A., 1835, 1836, 1840, 1811 , $1842,1844,1846,1847$, IS48, 1850 , $1851,1852,1853,1862$.

Stampacchia, 1870 .

Stefani G., 1853, 1854.

Stefani (de) G., 1S76, 1887.

Stoppaui A., 1873, 1874, 1877, 1873, 1880.

Strozzi e Gaudin, 1858, 1859, 1862.

Studer B., 1\$39. 1540.

Taramelli T., 1577, 1878, 1882, 1883, 1885.

Tardy, 1871, 1872.

Tellini A., 1888.

Tissandier, $186 \mathrm{~s}$.

Tomrnomer R. 1865, 1872, $1575,1876$.

Trabucco G.. 1855.

Tzielli G., 1888.

Tagnone, 1816.

Valerio G., $187 \bar{i}$.

Vaschetti, 1877.

Vasco, 1790, 1791.

Tassalli-Eandi, $1805,1808$.

Vassenr, 1S86.

Viviani, 1833.

Zaccagna, 1857, 1588.

Zigno (de) A., 1S44, 1815, 1855, 187S.

Zuccagni-Orlandini A., 18335. 
II.

\section{GEOLOGIA PURA.}

Nella descrizione geologica del bacino terziario del Piemonte credo opportuno e naturale di incominciare dai terreni più antichi risalendo poco a poco sino ai più giovani; di ciascun terreno, dopo avere brevemente accennate le anteriori osservazioni dei vari antori, indicherò le generalità più importanti specialmente riguardo alla sua costituzione ed ai suoi caratteri paleontologici; accennerò quindi alla sua distribuzione geografica ed alla sua tettonica nel bacino in esame; poscia, dopo averue indicato la potenza, l'altimetria e le località più ricche in fossili, passerò alla descrizione regionale colle relative osservazioni $d \dot{i}$ dettaglio, terminando con un rapido riassunto dei fatti esposti. Quanto alla descrizione regionale seguirò sempre, per quanto è possibile, il seguente ordine: Langhe, Monferrato subappenino, Tortonese, Colline Valenza-Toriuo, Astigiana.

Quantunque il presente lavoro riguardi specialmente i terreni terziari, stimo però conveniente di dare eziandio alcuni cenni sia sui terreni preterziari che più o meno direttamente costituiscono l'imbasamento del bacino terziario, sia sui terreni quaternari che in gran parte circondano e per larghe aree anche ricoprono concordantemente o discordantemente $i$ terreni terziarî del bacino in esame, costituendone per tal modo il naturale complemento. 


\section{CAPITOLO I.}

\section{CERChIA PRETERZIaRIA.}

Se si considera complessivamente la regione piemontese sotto il punto di rista geologico, essa si presenta essenzialmente costituita di due grandi bacini od anfiteatri, di cui uno interno, cioè il bacino terziario, oggetto di questo laroro, ed uno esterno preterziario, cioè la cerchia alpino-appenninica. È noterole come cronologicamente tra questi due bacini esista in generale un hiatus enorme in causa della mancanza quasi completa di terreni secondarî tra il bacino terziario interno e la racchiudente catena alpina costituita quasi esclusiramente di terreni primarî.

Malgrado l'accennata inclusione d'un bacino dentro l'altro, in gran parte però essi sono l'uno dall'altro isolati, apparentemente almeno, per mezzo d'un ampio ed abbastanza potente deposito di terreno quaternario, sotto al quale tuttaria, alle falde meridionali delle Alpi, spuntano ancora qua e là alcuni lembi dei più giorani orizzonti terziarî. Ė solo nella parte meridionale della conca del Piemonte che i terreni dei due sorraccennati bacini vengono per lungo tratto direttamente a contatto ed è quindi specialmente su queste regioni che dorremo dare alcuni cenni particolari sul Preterziario.

Considerando nel suo assieme la cerchia preterziaria in cui sta incluso il bacino terziario piemontese, rediamo come essa è essenzialmente costituita di varie e più o meno regolari pieghe di terreni prepaleozoici, nelle cui conche o sulle cui testate posano lembi più o meno estesi degli ultimi orizzonti della serie primaria od anche terreni secondari. Troriamo infatti dapprima in ordine cronologico diversi nuclei od elissoidi di solleraniento rappresentati da Gneiss, Gneiss ghiandone o Gneiss centrale con passaggi, inferiormente per lo più a Granito ed a Protogino, cioè terreni riferibili al Lauren 
I terreni laurenziani della regione alpina in questione formano in complesso due grandi rughe concentriche, una interna forse suddivisibile a sua volta, in parte ripiegata o ribaltata verso la pianura padana e rappresentata dai nuclei gneissicogranitici di M. Rosa, Gran Paradiso, Val Dora, Val Varaita, ed una esterna rappresentata dalle elissoidi di M. Bianco, Gran Pelvoux, Catena Belledonne e Mercantour.

Attorno e sopra a questi nuclei centrali si adagia la potentissima serie delle roccie verdi o zona dei Micaschisti, Calcoschisti e Gnciss tabulari, con lenti più o meno importanti di Calcari cristallini, Quarziti, Graniti, Sieniti, Porfidi e con potentissimi ammassi di roccie serpcntinose, eufotidichc, cloritiche, diabasiche, dioritiche ed amfiboliche; terreni che rappresentano l'Hurouiano, largamente inteso.

A tali formazioni prepaleozoiche (nella cui parte superiore può forse essere racchiuso alcuno dei più anticli orizzonti paleozoici molto metamorfosati) si appoggiano più 0 meno irregolarmente i terreni paleozoici, rappresentati essenzialmente dal Carbonifero e dal Permiano, che costituiscono una specie di fascia attorno al grande allineamento prepaleozoico interno che più ci interessa in questo lavoro. Tale fascia, abbastanza ben conservata e quasi continua verso l'esterno della conca padana, dalle Alpi Pennine sin presso Savona, è invece verso l'interno soltanto visibile in pochi punti come alle falde alpine tra Val Stura di Lanzo e Val Dora Baltea, sviluppandosi però più ampiamente verso Est, ma fuori della regione piemontese, dove invece tal fascia è in massima parte sepolta sotto ai terreni terziari e quaternari.

I terreni secondarî che prendono parte alla costituzione della catena alpina sono rappresentati specialmente dal Trias, che, più o meno interrotto, ma con sviluppo abbastanza notevole, accompagna la zona permo-carbonifera sorraccennata non solo nel suo percorso all'esterno del gran nuc'eo prepaleozoico, ma anche nei suoi indicati affioramenti interni, cosi nel Canavese e nel Biellese. 
Quanto agli altri terreni secondarî, Lias, Giurese e Cretaceo, essi hanno ben poca importanza, almeno rispetto al Piemonte, nella costituzione della cerchia alpina in esame, essendo anche essi per lo più profondamente sepolti sotto alie formazioni terziarie.

Notiamo infine come nelle Alpi Marittime ai terreni secondarî si sovrappongano pure depositi eocenici, di cui non mi occupo specialmente in questa nota perchè già molto conosciuti, ma la cui costituzione è abbastanza semplice ed uniforme, essendo essi infatti rappresentati essenzialmente nella parte inferiore da banchi nummulitici, specialmente del Parisiano, nella parte media da areuarie o MIacigno e nella parte superiore da argilloschisti o Flysch, corrispondendo, questi due ultimi orizzonti, al piano (o meglio faciez) Liguriano.

Premesse queste cousiderazioni generali sulla costituzione della cerchia alpina, in cui è racchiuso il bacino terziario piemontese, pare opportuno di dare ancora un accenno, un po'più particolareggiato, delle roccie preterziarie che nella parte meridionale di detto bacino sostengono direttamente le formazioni terziarie. Quanto alle roccie preterziarie (prepaleozoiche, primarie e secondarie) che costituiscono le falde meridionali delle Alpi centrali, da Val Ticino a Val Dora Riparia, ed a cui spesso appoggiansi lembi pliocenici, basterà fare poche osservazioni trattando di questi ultimi terreni.

Alle falde settentrionali delle Alpi Marittime, tra Cuneo e Mondori, là dove $\mathrm{i}$ depositi terziarî cominciano ad appoggiarsi sui terreni più antichi, questi sono specialnıente costituiti da Talcoschisti, Serpentine e Quarsiti, a stratificazione generalmente assai contorta, ricoperte qua e là da Calcari spesso assai ricchi in Giroporelle.

Le località dove meglio si possono osservare le sovraccennate roccie sono, per le Quarziti specialmente presso lit Chiusa di Pesio, pei Tulcoschisti la Valle Andei, per le Serpentine le prealpi a Sud di Pianfei (R. Cintarana, Poggio Pelato, ecc.), e per i terreni calcari le vicinanze di Villanuora Mondovì (MI. Cal- 
vario). Queste formazioni ci rappresentano rispettivamente gli orizzonti più recenti (Permiano) dell'era primaria ed i più antichi (Trias) dell'era secondaria.

Spesso queste roccie, specialmente i Talcoschisti, si presentano profondissimamente alterate dagli agenti esterni a cui sono esposte da tempo remotissimo, carattere d'altronde comune a pressochè tutte le roccie delle falde alpine.

Ad Est di Mondovì verso Ceva, Bagnasco, Millesimo, Cairo Montenotte, ecc., vediamo ad un dipresso gli stessi fatti che tra Cuneo e Mondovì, essendo quasi sempre la stessa fascia rocciosa, più o meno complessa, quella su cui si appoggiano i terreni terziarî; solo che, siccome questi ultimi non solo si applicano, ma talora eziandio si estendono assai sui terreni preterziarî, risulta talora un po' difficile il delimitare i varî orizzonti di tali formazioni antiche che appaiono spesso solo qua e là al fondo delle valli per fenomeni di erosione, oppure costituiscono, fra i circostanti terreni terziarî, delle specie di isole corrispondenti ai più alti rilievi delle antiche creste rocciose ora in gran parte sepolte.

Noto però clie oltre alle roccie già prima menzionate compaiono eziandio bene sviluppate lungo le falde alpine ad Est di Mondovi, le Appenniniti e le Anageniti assieme a roccie svariatissime, specialmente Calceschisti, Quarziteschisti, Steaschisti, Micaschisti e Cloritoschisti.

Non essendo qui affatto il caso di trattare di questi terreni antichi mi limiterò specialmente ad indicare con pochi cenni gli isolotti di terreni primari o secondari che spuntano sotto al terziario, essendo anch' essi molto interessanti riguardo al tema principale di questo lavoro, come quelli che ci spiegano fenomeni statigrafici, altrimenti incomprensibili, che osservansi nei terreni terziari.

Già in Val Gniera presso Monastero di Vasco si può osservare una larga ed irregolarmente oblunga massa di Calcare triassico che appare sotto ai conglomerati ed alle sabbie marnose mioceniche, ma più interessante riesce un piccolissimo spun- 
tone di Quaraite che venne messo a giorno dall'erosione del T. Ermena, al fondo della ralle omonima (poco a monte dello sbocco del T. Armetta), non che un piccolo isolotto ancora di Calcare triassico che osservasi nel letto dello stesso torrente Ermena, poco ad Ovest di C. Rocca. Tale Calcare è anclie notevole per essere qua e là traforato dai Molluschi litofagi. Altri due piccoli spuntoni calcarei veggonsi al fondo della valletta Groglio a Sud e ad Orest di Fontana Candia.

E pure a rilevarsi il grande sviluppo rerso Ford che presentano i terreni antichi nelle vicinanze di Mombasiglio (dove appaiono bellissime Serpentine fra i Talcoschisti), Scagnello, Battifollo, Nucetto, Malpotremo e Molare (dove vedesi il Talcosctisto coperto da una piccola placca di Culcare frammentario) mentre trovansi potenti placche di terreno terziario molto più a Sud delle sorraccennate regioni.

Nella valle di Campetto, a Sud di Priero, presso C. Scuse, appare una zona preterziaria abbastanza lunga costituita specialmente di Tulcoschisti ricoperti ancl' essi, verso settentrione, da Calcari triassici (he talora, anche solo per 2 o 3 metri, ricompaiono ancora qua e là al fondo delle vallette, sotto ai terreni terziarî, a Nord e Nord Est di C. Scuse.

Più verso Oriente notiamo, ad Est di Castelnuovo, il grande addentrarsi della zona triassica calcarca fra i depositi terziarî in valle Zemola, come pure il considerevole sviluppo verso Nord della zona essenzialmente talcoschistosa di hoccavignale e Millesimo, presso il quale ultimo paese però sono pure assai sviluppati i Calcari che talora, come presso il Molino, si presentano traforati dai Mollusclii litofagi.

Nella grande valle della Bormid'; siccome i terreni terziarî sono generalmente assai poco inclinati e spesso formano solo una specie di velo sulle formazioni antiche, è naturale che queste vengano soventi a giorno frammezzo ai primi. Così in valle Auta, ad Orest di Carcare, sotto la C. Tapol, appare una massa rocciosa costituita essenzialmente di Talcoschisto, anclie in questo caso coperto ad Orest da una zona di Calcarc. Lo stesso ve- 
desi nella vicina valle di Cosseria, presso il Casello 22 della Ferrovia, quivi essendovi pure un complesso di banchi calcarei che copre una stretta zona di Talcosclisto, il quale però riappare poco più a valle, mezzo chilometro circa a Est del Casello 22 ; più ad Est ancora, nella valle stessa, a Sud-Ovest di C. Malsano, ma solo nel letto del torrente, osservai alcuni Calcari frantumati (ed in parte eziandio traforati da Litodomi) che paionmi rappresentare roccia in posto, la quale d'altronde appare poco a Nord potentemente sviluppata presso Cairo Montenotte.

Ad Est, in complesso, della valle della Bormida di Spigno si estende una grande zona ofiolitica rappresentata però oltre che da Serpentina eziandio da Eufotide, Diabase, Diorite ed Amfibolite. Tale formazione che già compare in diversi punti presso Spigno sotto i terreni terziarî, e che viene avviluppata ad Ovest e Nord da questi terreni, sopporta inoltre qua e là placche più o meno estese di questi stessi terreni terziarî; oltre che presso Spigno è nelle vicinanze di Mojola, Malvicino, Cartosio, Ponzone, Grognardo, Cassinelle, Molare, Belforte e Voltaggio che veggonsi spuntare, spesso irregolarissimamente, sotto ai depositi terziarî queste roccie ofiolitiche che più a Sud costituiscono una estesissima regione aspra, quasi deserta, a facies affatto alpina.

Esaminando questa zona preterziaria più minutamente possiamo osservare che, a cominciare da Cairo Montenotte ad un dipresso, coi Talcoschisti, talora passanti a roccie appenninitiche, trovansi assai sovente associate formazioni serpentinose che talora anzi vengono da sole a costituire l'intiera zona preterziaria.

Vediamo infatti sviluppatissime le Serpentine tra Cairo e Rocclietta Cairo, e se invece presso Degi) ricompaiono potenti.le roccie talcoschistose (di cui sono a notarsi due piccolissimi spuntoni, l'uno alle falde Nord-Ovest del Bric-Ridotta e l'altro al fondo della valletta di Carpez presso il suo termine), nuovamente veggonsi poco a Sud di Piana Crixia assai potenti, quantunque non sole, le Serpentine quivi formanti una lunga zona di terreno antico avviluppato d'ogni parte dal terziario.

In causa del grande allargarsi dei depositi terziarî sopra 
quelli antichi, a Nord-Est di Dego, avrenne che in Val Bormida, per la potente erosione acquea, diversi lembi di terreno preterziario, (specialmente punte e creste di queste formazioni antiche sepolte sotto alle più recenti) vennero messe a giorno in molti punti ed anche per aree molto estese.

Così presso Merana, sulla sponda sinistra della Bormida, ad un dipresso tra il Casello 18 e 19 della Ferroria, esiste un piccolo spuntone roccioso di forma irregolare e più a Nord se ne trovano altri più sviluppati presso i Casali Pian del Gallo e specialmente poco a Sud di N.S. di Casato.

Importantissimo è il grande rilievo serpentinoso di Bric Calına che si estende colle sue estreme propaggini sin presso i Franzini a Sud, i Colombi ad Ovest, Spigno a Nord e C. Gallarei ad Est. Presso Spigno esistono ancora due piccoli spuntoni di Serpentina a Nord e Sud del paese, ma talora coperti in parte dalle acque della Bormida.

Infine un'ultima comparsa della formazione serpentinosa nella valle Bormida esiste, sotto forma, direi, di largo scudo dorsale di tartaruga sepolta nei terreni terziarî, sulla destra sponda della Bormida, presso la strada nazionale, di fronte quasi a Mombaldone alle falde S. O. del Monte Castello.

Nell' ampia valle percorsa dal T. Valla, tributario di destra della Bormida, veggonsi pure numerosi affioramenti di terreni rocciosi antichi fra il terziario, cosi nella valletta di Sorba mostransi in due punti le Serpentine, ed anzi, presso il termine della valle, appare anche una placca calcarea; altro spuntone roccioso osservasi lungo il rio di Cascina dei Santi, subito a Nord del T. Sorba; infine per oltre un chilometro affiora, al fondo della valle Rabbioso, la roccia antica.

Volgendo ad Est trovansi altri simili afforamenti serpentinosi al fondo della valle dei Giuliani (Nord-Est di Pareto) e della valle dei Bergiavelli (Nord di Miojola.)

Nell'ampia valle dell'Erro, in cui sono sviluppatissime specialmente le serpentine ed i talcoschisti, vedesi la formazione serpentinosa avanzarsi molto verso Nord, cioè sin presso a Cartosio, 
offrendo ancora un ampio affioramento al fondo della vallata di Saquanna.

Interessantissimi per il loro isolamento sono, a Nord-Est di Cavatore, un piccolo spuntone serpentinoso che esiste rell' alta valle Ravanasco presso C. Ferri ed un altro ancor minore che osservasi all'incirca dove il rio discendente da C. Scuti si unisce con qiello di Cavatore.

In Val Visone, nei dintorni di Caldasio, Morbello, ecc., le Serpentine si associano frequentemente a Quarziti e Talcoschisti, per lo più profondissimamente alterati, e si spingono sino a Grognardo, affiorando anzi ancora per breve tratto a Nord di questo paese.

Ma lo spuntone preterziario più settentrionale di tutta la linea di contatto tra terziario e preterziario da Spigno a Voltaggio è il Bric Marzapiede presso Prasco, rilievo serpentinoso molto allungato da Ovest ad Est, diviso per breve tratto in due porzioni per mezzo di una striscia di terreno terziario, e corrispondente senza dubbio ad una cresta assai elevata della sepolta catena preterziaria.

In Val Veirera ed in Valle Stura le formazioni serpentinose e talcoschistose si spingono molto a settentrione, rispettivamente sin presso Molare e Belforte, ed inoltre un piccolo affioramento preterziario appare eziandio al fondo della valletta di Requaglia, sotto C. Lanza.

Da Belforte sin presso Voltaggio la sovrapposizione dei terreni terziarî alla formazione antica, essenzialmente serpentinosa, è abbastanza regolare nel suo assieme, quantunque irregolarissima nei particolari; nei dintorni di Toltaggio vengono a scomparire $\mathrm{i}$ terreni antichi sotto al velo delle formazioni terziarie.

La formazione serpentinosa spesso profondamente alterata, producente alla superficie del terreno una specie di mantello terroso di color bruno rossastro o giallastro, colla sua tipica facies di regione arida, aspra, a creste acute, a profondi e tortuosi burroni, ecc., viene a terminare nel rio di Acquastriata presso la Casciná omonima e nel rio Lavezze alle falde Nord- 
Ovest del M. Lagoscuro; ma più a Nord, come presso al Castello di Voltaggio e molto più ampiamente nel rio Frasso, appaiono Calcari dolomitici grigiastri, frammentari, che per l'aspetto e la composizione chimica, quantunque non vi siano stati finora rinvenuti fossili di sorta, sono probabilmente da riferirsi al Trias.

Notiamo infine come in queste regioni trovandosi spesso vicinissime le Serpentine terziarie a quelle antiche, non siano sempre facili e sicure le distinzioni che si possono fare fra di esse.

Ora siccome nei dintorni di Voltaggio, come fu detto, i terreni antichi vengono quasi del tutto a scomparire pel fatto che l'avviluppo terziario, facendo un rapido giro si risvolta verso Sud per modo da estendersi sin presso Genova, e siccone ad Est di Voltaggio, in tutta la restante area del bacino in studio non vengono più affatto a giorno terreni preterziarî (se però non deve attribuirsi al Cretaceo una parte del Flysch della Liguria), così di questi non avremo quindi più ad occuparci che incidentalmente trattando dei singoli depositi terziari che appoggiansi direttamente in qualche punto sulle roccie antiche.

\section{CAPITOLO II.}

\section{Suessoniano e Parisiano.}

Nel bacino terziario del Piemonte l'orizzonte Suessoniano è ridotto a pochi bancli calcarei grigiastri, i quali contengono solo per lo più resti di Alghe; tali banchi di poclii metri di spessore si incontrano nelle Alpi Marittime, specialmente nell'alta valle di Stura, tra i calcari del Senoniano superiore, ed i calcari arenacei del Parisiano.

Molto interessante, quantunque poco potente, è la zona arenaceo-calcarea che rappresenta il Parisiano nelle Alpi marittime del Piemonte; essa infatti si presenta molto fossilifera, e ricca specialmente in Cerithium, Natica, Turitclla, Trochus, Ostraza, 
Trochocyathus, ecc.; ma ciò che caratterizza specialmente questa formazione eocenica è l'abbondanza straordinaria in Nummuliti, cioè N. Brogniarti var., N. lucasana, N. perforata, N. striata, N. Ramondi, N. Portisi, N. Biarritzensis, ecc.; vi si incontrano pure Assiline e numerosissimi altri foraminiferi.

Questo orizzonte, sollevato talora ad oltre $2500 \mathrm{~m}$. di altezza, come al M. Enchastraye in Val Stura, è in Piemonte limitato (almeno colla sua facies tipica) a lembi più o meno ampi nelle Alpi Marittime; è quasi sempre rappresentato da banchi calcareo-arenacei brunastri, alternati con calceschisti ed argilloschisti; raggiurge solo pochi metri di potenza. Non ne faccio uno studio speciale perchè maggiori dettagli su questa formazione si possono avere in lavori riguardanti la geologia alpina del Piemonte.

Accenno però come il fatto, che esamineremo in seguito, che si trovino qua e là nel Liguriano straterelli con Nummuliti molto analoghe a quelle del Parisiano, ci prova che il Flysch liguriano non è che un deposito speciale racchiudibile ancora nel piano Parisiano (largamente inteso).

\section{CAPITOLO III.}

\section{Liguriano.}

\section{Studî anteriori.}

Mentre che molto ampiamente venne già trattato da vari geologi dei terreni liguriani che affiorano per tratti estesissimi nel Tenovesato e nel Parmigiano, generalmente invece poco studiati furono questi terreni nel Piemonte, specialmente a causa di esservi essi assai meno sviluppati.

Però del Liguriano che compare nella parte Sud-Est del Piemonte, e che non è altro che la continuazione di quello tanto esteso della Liguria, ebbero già a trattare con scopo special- 
F. SACCO,

mente scientifico il Pareto, il Nayer, l'Issel, ecc., e con scopo applicativo il Sismonda, il Baretti, il Mazzuoli, il Giordano, ecc. a causa della perforazione delle gallerie ferroviarie dei Giovi. Invece del Liguriano che costituisce in parte assai noterole $\mathrm{i}$ colli tortonesi e che affiora in più punti nelle colline Torino- $\mathrm{Va}$ lenza, vennero finora fatti solo alcuni pochi cenni specialmente dal Sismonda.

Quanto a carte geologiche, senza discendere a dettagli inutili, basterà che si confrontino quelle unite al presente laroro con quelle antecedenti del Sismonda (1862) e del Comitato geologico (1881) per conoscere le grandi differenze che esistono.

Riguardo alle proposte fatte da Issel, Mazzuoli e Zaccagna nella spiegazione della loro carta geologica della Liguria, di appellare infraliguriano il complesso di banchi eocenici che racchiudono gli ammassi ofiolitici, se si considera come tali banchi (e ciò specialmente si vede bene nei dintorni di Voltaggio) hanno specialmente l'aspetto del Flysch alpino sino a prova paleontologica in contrario, pare debbansi ancora includere $\mathrm{i}$ banchi sovraccennati nel vero Liguriano e, per quanto sembra, nella sua parte inferiore; tanto più che per me il Liguriano di Mayer non rappresenta altro che una facies speciale del Parisiano (largamente inteso), se pure non si estende anche al Cretaceo in qualche punto dell'Appennino ligure.

Il Pareto distinse il piano Liguriano di Mayer in un orizzonte inferiore, o Liguriano propriamente detto, rappresentato specialmente dal macigno e dagli argilloschisti talcosi, ed in un orizzonte superiore o Mlodenese caratterizzato dalla prevalenza dei banchi calcarei, delle argille scagliose e dei galestri. Nei terreni eocenici superiori del bacino terziario del Piemonte ebbi bensì a constatare in più punti, come farò osservare in seguito, tale successione stratigrafica assai regolare, almeno in complesso; ma in causa delle ripetute alternanze delle varie formazioni non nii pare per ora conveniente di adottare la distinzione proposta dal Pareto, tanto più trattandosi di pochi lembi come è il caso pel bacino terziario del Piemonte. Tolendosi però fare tale diri- 
sione si potrebbe dire in generale clie costituirebbero il Liguriano propriamente detto gli argilloschisti talcosi con parte dei banchi calcarei di Val Lemno e Val Scrivia e spetterebbero invece al Modeniano la massima parte degli affioramenti eocenici di Val Sisola-Borbera, delle colline tortonesi e vogheresi (parte settentrionale) e delle colline Torino-Valenza.

$\mathrm{Ma}$ in verità tali distinzioni hanno un valore molto relativo, se si tien conto che tanto il Liguriano quanto il Modeniano, come intesi dai loro autori, non rappresentano che una facies speciale, per quanto caratteristica e potente, del gran piano Parisiano, almeno nella regione in esame.

\section{Generalitì.}

Molte ed assai diverse süno le fucies con cui si presenta il Liguriano nelle varie parti del bacino piemontese, ma considerandole in complesso possonsi ridurre a due principali; cioè: nella regione appenninica argilloschisti talcosi alternati con banchi ofiolitici inferiormente e con banchi arenacei e calcarei superiormente, e nella regione subappenninica argille scagliose e galestri alternati con banchi calcarei (Alberese) ed arenacei ( $M a-$ cigno), ed inglobanti pure lenti ofiolitiche.

Oltre a queste facies più importanti dobbiamo notare, nelle vicinanze di Voltaggio, la comparsa di potenti calceschisti, oficalci, ecc. e nelle colline torinesi e tortonesi di conglomerati cementatissimi ad elementi sia appenninici che alpini, nonchè, di conglomerati-breccie di forma affatto particolare.

Generalmente le argille scagliose suno di colore brunastro; i galestri invece presentano delle tinte svariatissime, specialmente violacee, verdastre e rossastre, talora solo dovute ad alterazioni chimiche più o meno superficiali; in alcune regioni poi i terreni liguriani sono rappresentati da marne grigiastre e da marne sabbiose grigio-giallastre che ricordano assai bene certi banchi del Miocene. 
Sono specialmente le argille scagliose brune o verdastre o rossiccie che fanno il passaggio alle assise del Gassiniano (Bartoniano).

\section{Caratteri paleontologici.}

11 Liguriano del bacino terziario del Piemonte appartenendo al tipo alpino, poco è a dirsi intorno ai suoi fossili, essendo nota a tutti la loro scarsità e la loro uniformità in questa facies speciale dell'eocene; è però importante il notare che, per quanto pochi, tali fossili sono affatto caratteristici e quindi assai utili per la determinazione cronologica dei banchi che li racchiudono.

Possiamo quindi limitarci ad accennare come i dati paleontologici del Liguriano delle regioni accennate siano specialmente rappresentati da impronte di Helminthoidea labyrinthica Heer, che osservasi talora nell'eocene appenninico, e da numerosi resti di Chondrites e di altre Fucoidi che si trovano nei calcari alberesi, nonchè da numerose impronte, più o meno determinabili, d'origine sia animale che vegetale ed anche inorganica, che osservansi alla superficie degli strati arenacei. Assai rari sono i resti di Nummuliti, Assiline (A. mamillata), Orbitoidi (Orbitoides stella ecc.), ma importanti perchè ci provano la relativa antichiti del Liguriano.

\section{Distribuzione geografica.}

Lasciando per ora in disparte i terreni liguriani che appaiono in Junga zona, talora però interrotta, nelle Alpi Marittime dall'alta valle della Stura di Cuneo al mare, tra Ventimiglia ed Albenga, indichiamo solo come nel bacino terziario del Piemonte appare questo orizzonte al piede degli Appennini settentrionali nelle vicinanze di Voltaggio, appoggiandosi quivi direttamente sui terreni preterziari; si sviluppa quindi tosto stra- 
ordinariamente per modo da costituire quasi completamente la Valle Scrivia sino a Pietrabissara, solo venendo coperto qua e là da lembi tongriani.

Sempre sviluppatissimo vediamo il Liguriano, inmergentesi sotto i depositi tongriani a Nord, ma quasi completamente libero verso Sud, raggiungere la Valle della Sisola e la Valle Borbora costituendone da solo tutta la parte orientale.

Verso settentrione il Liguriano scompare sotto il potentissimo ammanto dei terreni miocenici, specialmente tongriani, per ricomparire però non molto lungi verso Nord, costituendo allora una lunga zona estendentesi dalla Valle del Curone a Spinetta, zona che potremo appellare Brignano-Spinetta e che a mio parere è assai importante come quella che limita, in certo qual modo, il vero bacino terziario del Piemonte, giacchè i terreni miocenici e pliocenici che compaiono a Nord di questa zona lignriano paionmi appartenere ad un altro bacino; che potrebbe appellarsi bacino terziario padano, formato essenzialmente dai depositi terziarî che costituiscono le falde appenniniche da Tortona verso Est, quantunque debba anmettere come questi si colleghino assai bene coi contemporanei terreni della collina Torino-Valenza.

Un ampio ed importante affioramento liguriano si osserva ancora in Val Curone tra Volpedo e Giarella, presentando quivi diversi spuntoni ofiolitici ed inoltre potenti banchi conglomeratici.

Tanto la zona liguriana Brignano-Spinetta come quella di Val Curone si collegano assai bene per mezzo di diramazioni, libere dal mantello miocenico, con quelle dei colli di Tortona che sono pure in massima parte costituiti di terreno liguriano.

Nelle colline Torino-Valenza esiste una ventina di affioramenti liguriani di forma e distribuzione assai varia ed irregolare; e quantunque il Liguriano quivi affiori solo qua e là per lembi più () meno estesi, presumibilmente però questo terreno costituisce il vero imbasamento delle colline Torino-Valenza ed in generale di tutto il bacino terziario del Piemonte. 
F. SACCO,

Notiamo che secondo l'Issel esisterebbe una zona di Liguviano presso Rivara Canarese.

\section{Tettonica.}

In generale la stratigrafia dei terreni liguriani è molto confusa, giacchè per le potenti pressioni laterali e dal basso all'alto che essi subirono in diverse epoche dopo la loro deposizione, per lo più i banchi (in complesso poco resistenti) che li costituiscono furono in gran parte svariatissimamente pieghettati, rotti, sconquassati per modo che riesce ora soventi assai difficile il rintracciarne la vera direzione ed inclinazione.

Nei dintorni di Voltaggio il Liguriano, che si appoggia direttamente sui terreni preterziarî, ha in generale una stratificazione abbastanza netta, sia perchè non vi esistono grandi contorcimenti, sia perchè i banchi che lo compongono sono piuttosto resistenti; orbene, in questa regione veggonsi gli strati liguriani, diretti generalmente da Nord-Orest a Sud-Est, pendere abbastanza regolarmente verso il Nord-Est, ma con un grado di inclinazione svariatissimo, per lo più assai forte, tanto anzi che talora i banchi sono rizzati persino alla verticale od anche alquanto rovesciati ciò che si può osservare specialmente assai bene nella valle del Lemno e nelle vallette confluenti di sinistra.

Non mancano però anche in queste regioni le pieghettature, ma spesso solo in piccola scala.

Dalla valle del Lemno a quella della Scrivia si osservano non poche ripiegature negli strati, ma in generale questi, talora anche verticali ma per lo più con inclinazione varia tra gli $80^{\circ}$ ed i $20^{\circ}$, pendono verso l'Est all'incirca.

Nella valle della Scrivia l'inclinazione degli strati liguriani dalle vicinanze di Busalla sin presso ad Isola del Cantone, quantunque molto variabile di grado, da $20^{\circ}$ a $50^{\circ}$ circa, è però abbastanza regolare dapprima verso il Nord-Est, poscia verso il Nord circa; nelle vicinanze di Isola del Cantone osservansi inclina- 
zioni assai diverse, forse attribuibili ad una grande curva. Infine presso Pietrabissara gli strati liguriani, spesso inclinati di oltre $80^{\circ}$ e talora stupendamente contorti, pendono decisamente verso il Sud-Ovest, quasi l'opposto cioè di quello cle vedemmo nelle vicinanze di Voltaggio. Quindi, considerando in complesso i fatti ora enunciati, troviamo che il Liguriamo di queste regioni costituisce stratigraficamente una specie di ampio semicerchio dentro al quale vennero a depositarsi i terreni tongriani il cui andanento stratigrafico, molto diverso nei particolari da quello del Liguriano, gli è però concordante nelle linee generali.

Procedendo verso Nord nell' esame stratigrafico del Liguriano vediamo che siccome agli argilloschisti ed ai banchi calcarei si sono sostituite le argille scagliose, i cui strati sono per lo più contorti e spezzati, la tettonica è assai difficile a ricostruirsi; tuttavia esaminando quei banchi che veggonsi ancora qua e là abbastanza ben conservati ed in posizione regolare, si può dire che anche in queste regioni dalla valle Scrivia a quella di Roccaforte, a quella di Borbera, ecc., l'andamento stratigrafico del Liguriano in complesso accompagna abbastanza bene la curra che quivi fanno i sovrastanti terreni miocenici, giacchè in diversi punti, specialmente presso Rocchetta, Cantalupo e Colonne ebbi ad osservare straterelli calcareo-arenacei inclinati assai regolarmente di circa $50^{\circ}$ verso l'Ovest, inclinazione e direzione che combina appunto abbastanza bene con quella del sovrastante Tongriano (e talora anche Gassiniano [Bartoniano]).

A Nord della conca tongriana di S. Sebastiano Curone troviamo la grande zona liguriana Brignano-Spinetta la quale per essere costituita essenzialmente di argille scagliose non presenta che assai raramente una stratificazione netta; tuttavia da una serie di osservazioni fatte su questo proposito, benchè non tutte concordanti, mi risultò che in complesso i banchi liguriani di questa zona pendono di circa $45^{\circ}$ verso il Sud, non tenendo conto delle notevoli contorsioni e variazioni stratigrafiche clie talora si allontanano dall' audamento stratigrafico sovraesposto, sia per la direzione che per l'inclinazione. 
Una delle località in cui meglio si può osservare la stratificazione del Liguriano è il lato settentrionale del rilievo di Magrassa, giacchè salendo a questa borgata da Isola Grue si vede il Liguriano superiore, costituito di argille scagliose nerastre ripetutamente alternate con banchi calcarei e con letti sabbiosi, pendere assai regolarmente di circa $45^{\circ}$ rerso Sud-Est, inclinazione abbastanza concordante con quelle dei sovragiacenti banchi del Tongriano.

Orbene, anche rispetto a questa vastix zona liguriana essendosi potuto osservare come il suo andamento stratigrafico concordi in complesso assai bene con quello dei terreni miocenici che gli si appoggiano a Sud, ne consegue che da Voltaggio a Spinetta, per Rocchetta ligure, si è potuto constatare una vera conca nou solo apparente ma reale, ciò̀ stratigrafica, conca Tigurima che ricevette nel suo interno i terreni miocenici e che in certo qual modo chiude assai bene a Sud-Est il bacino terziario del Piemonte.

Nel grande affioramento liguriano di Volpedo-Giarella in Tal Curone evvi un importante fenomeno stratigrafico; esiste cioè nel rilievo di Ca di Bruno una specie di centro di solleramento da cui pendono all'intorno i binchi liguriani che immergonsi ¿ Sud, Orest e Nord sotto i terreni oligocenici. Siccome in questa regione riappaiono assai sviluppati i grossi bancli calcarei alteruati cogli argilloschisti, si può in cliversi punti, specialmente presso il Molino del Bove, osservare nettamente la tettonica dell'orizzonte liguriuno i cui strati sono quiri inclinati di circa $60^{\circ}$ verso Sud-Sud-Est; invece dal lato settentrionale delle colline di Reguardia veggonsi i banchi marnoso-argillosi e calcarei pendere di una trentina di gradi verso Sud-Sud-Ovest; nelle vicinanze di Poggio essi inclinano piuttosto all' Ovest, finchè rer'so Volpedo assumono una peudenza abbastanza regolare a Nord, sempre però naturalmente con numerose eccezioni che non paionmi tuttavia infirmare l'andamento stratigrafico generale sorraindicato.

Nelle colline di Tortoma a causa della predominanza. Antlo 
argille scagliose a stratificazione, come di solito, confusa, e dei rari e poco profondi tagli naturali, ma specialmente a motivo del grande svilıppo dell'agricoltura, riesce difficile rendersi conto esatto della stratigrafia liguriana la quale non sembra però presentare quivi fatti importanti; in generale pare che in queste colline i banchi eocenici pendano verso l'Ovest all' incirca na con delle numerose varianti verso Nord e Sud.

Il vedere $\mathrm{i}$ depositi miocenici e pliocenici disposti molto variamente sul Liguriano di queste colline di Tortona e talora addentrati alquanto nelle attuali vallate, come ad esempio in valle Ossona oltre Villaromagnano, ci rende avvertiti clie già durante il Miocene ed il Pliocene era in parte abbozzata l'orografia di queste regioni, sia per gli agenti esterni che per le ripiegature degli strati liguriani.

Le stesse difficoltà che incontransi nello studiare la tettonica del Liguriano delle colline tortonesi esistono pure, e per le stesse cause, per la maggior parte degli affioramenti di questo terreno nelle colline Torino-Valenza.

Infatti nella parte più orientale di queste colline là dove appaiono i terreni liguriani, spesso per tratti assai poco estesi, essi ci si presentano solo sotto forma di depositi molto tormentati, infranti ed a stratificazione aftatto indistinguibile; tuttavia dall'andamento degli affioramenti liguriani possiamo dedurre che quelli più orientali hanno direzione ad un dipresso da Nord a Sud mentre quelli di tutta la restante parte delle colline Torino-Valenza sono piuttosto diretti da Orest-Nord-Ovest ad EstSud-Est.

Persino nella grande zona liguriana di Casale, per quanto siano numerose le escavazioni fattesi per estrazione del calcare, non trovansi che raramente dei banchi a stratificazione un po' attendibile. In alcuni punti però, come ad esempio presso la Torre Gajona, il Torcello, ecc. è possibile osservare la tettonica di questa zona liguriana e dedurne come in generale i suoi strati pendano piuttosto verso il Sud e solo presso la piauura padana inclinino a Nord. In questa regione sono spesso 
molto evidenti le ripetute ripiegature degli strati; cosi per esempio salendo da Villa Sardi a C. Ragazzina, si veggono gli strati liguriani, costituiti da un' alternanza di arenarie giallastre, di sabbie e di argille brune e grigiastre, inclinare dapprima di circa $60^{\circ}$ verso Nord, poscia sopra Torcello con ripetute contorsioni assumere l'inclinazione opposta:

L'affioramento liguriano di Cuccaro, alquanto distante dall'allineamento solito di questi terreni, è probabilmente dovuto ad un corrugamento laterale però quasi parallelo a quello principale di cui vediano diversi lembi irregolarmente elissoidali da Lu a Camagna.

Nello spuntone liguriano di Ottiglio; ma ancor più chiaramente in quello di Cortenova-Montalero, veggonsi banchi eocenici fortemente sollevati e diretti ad un dipresso da Nord-Orest a Sud-Est, cioè parallelaniente circa all'asse orografico della collina.

Gli afforamenti liguriani sulla sinistra del Po mostrano i loro banchi quasi verticali e diretti da $0 . \mathrm{N}$ : O. ad E. S. E. circa.

Anche nei vastissimi affioramenti liguriani di Verrua e di Lauriano possonsi raccogliere pochi dati sulla tettonica di questo orizzonte, ma per quel poco che potè essere osservato pare che essa sia in complesso abbastanza concordante con quella dei sovrastanti terreni tongriani e bartoniani; in alcuni punti possonsi osservare stupende ripiegature negli strati marnosoarenacei-calcarei, come per esempio alla Fornace di Monticelli Verrua, dove essi costituiscono un rero arco colla convessità rivolta a Nord-Est, e con pendenza verso il Sud-Orest circa.

Nell' esaminare le rotture e gli spostamenti di questi straterelli di varia natura fortemente ripiegati si conırende facilmente perchè di solito nelle zone liguriane siano solo più ridotti a frammenti sparsi i banchi calcarei ad arenacei che si alternano colle argille scagliose; ben sapendosi come questi terreni abbiano generalmente subite potenti pressioni e quindi numerose contorsioni.

Nel ric di S. Fede a Sud di Caragnolo sotto C. Gallardo 
veggonsi i banchi calcareo-arenacei del Liguriano drizzati quasi alla verticale e diretti da Orest-Nord-Ovest ad Est-Sud-Est, cioè concordanti coi depositi bartoniani che vi si appoggiano sopra.

Fenomeni consimili, quantunque con locali na abbastanza notevoli varianti, osservansi nella valle di Monteu da Po, nelle cave di Lauriano, nelle vicinanze di Berilacqua, ecc. per modo che si può conchiudere che, se in complesso la direzione dei banchi liguriani è abbastanza concordante con quella dell' asse maggiore della collina, sonvi però così svariate contorsioni, più o meno ampie, che esse, nell'esame particolare dei fatti, spesso paiono opporsi alla veduta generale che ho sopraccennato.

Possiamo infine notare come nell' affioramento liguriano di Cocconato i banchi eocenici siano generalmente inclinati di $40^{\circ}$, $50^{\circ}$ e più, e diretti da Ovest-Sud-Ovest ad Est-Nord-Est, ed inoltre che, mentre dal lato settentrionale di questa zona liguriana gli strati pendono specialmente verso Nord, dal lato opposto invece inclinano per lo più a Sud circa, cioè in modo da concordare alquanto, in complesso, coi terreni oligocenici circostanti; pare quindi che questo affioramento corrisponda solo ad una specie di ruga laterale secondaria.

\section{Potenza.}

In causa dei ripetuti contorcimenti e dello svariatissimo andamento stratigrafico dei terreni liguriani, oltre che pel fatto che spesso solo appaiono in lembi ristretti, è sorente impossibile limitarne la potenza; tuttavia limitandomi alle regioni dove per più lungo tratto si può seguire in un dato senso una regolare stratificazione, così nella valle Scrivia tra Isolabuona ed Isola del Cantone e nella valle del Curone attorno al nucleo di sollevamento di Ca di Bruno, credo poter affermare che il Liguriano raggiunge talora la potenza di circa 2000 metri; noto però come da osservazioni che ebbi occasione di fatre al- 
l'infuori del bacino terziario in esame, ma però solo nelle vicine Alpi Marittime, sembrami poter dedurre cle in alcuni hoghi la pila dei banchi liguriani, anche tenendo conto dei loro ripiegamenti, raggiunge forse i 3000 metri in spessore. Ciò ci prova sempre più che il Liguriano rappresenta solo una facies del gran piano Parisiano, e forse anche talora da parte del Cretaceo.

\section{Altimetria.}

Ha poca importanza, nello studio del bacino terziario del Piemonte, l'esame della massima altezza cle vi raggiunge il Liguriano, giacchè quivi essa è molto minore di quella che lo stesso terreno raggiunge altrove, sia nella catena appenninica, sia nelle Alpi Marittime dove, al M. Encastraye per esempio, lo si vede sollevarsi sin quasi a 3000 metri sul livello marino.

Ad ogni modo se esaminiamo sotto questo punto di vista il Liguriano della regione in studio vediamo che nelle vicinanze di Toltaggio esso arriva in alcuni punti a 700 ed 800 metri (I. Cavetti 815$)$; altitudini simili, ed anzi generalmente minori, tocca tra la valle della Scrivia e quella della Borbera, sollevandosi invece verso Est sin oltre i 1700 , come al M. Ebro, e poi va gradatamente abbassandosi verso Tolpedo e Tortona sino ad immergersi sotto la pianura.

Quanto agli afforamenti liguriani dei colli Torino-Talenza essi spesso si sollevano solo a circa 200 metri, tuttavia in alcuni punti nei colli di Casale, essi arrivano quasi ai 300 metri e quelli di Terrua, di Lauriano e di Cocconato spesso si sollevano sopra questa quota raggiungendo anche i 355 metri come alla Cappella di S. Michele, ad Est del paese di Piazzo, toccando anzi persino i 410 metri presso la borgata Pareglio. 


\section{Rupporto coi terreni sotto e soprastanti.}

In tutto il bacino terziario del Piemonte è solo nelle Alpi Marittime che si possono osservare i rapporti del Liguriano coi terreni sottostanti. Infatti nei dintorni di Voltaggio vediamo i banchi inferiori di questo orizzonte poggiare direttamente e con assoluta discordanza stratigrafica sui terreni preterziarî ed in seguito nella valle della Scrivia, del Borbera, del Curone e nelle colline tortonesi $\mathrm{i}$ banchi liguriani più o meno ripiegati e contorti non presentano mai passaggi ai terreni inferiori.

Invece in molte regioni delle Alpi Marittime, specialmente in Val Stura, si può vedere come i banchi arenaceo-calcari e gli argilloschisti (cioè il Flyseh) liguviani passano graduatissimamente ai banchi calcarei nummulitiferi del Parisiano e poscia insensibilmente al Cretaceo.

Questa transizione graduatissima tra piano e piano l'osserveremo d'ora in avanti fra tutti gli orizzonti terziarî, per modo che si può dire giustamente che in Piemonte è possibile passare senza salti, attraverso tutta la serie terziaria, dal Secondario al Quaternario.

Quanto ai rapporti del Liguriano coi terreni sorrastanti, siccome ebbi già a trattarne in un lavoro speciale, così mi limiterò qui a pochi cenni riassuntivi.

In generale, tra il Liguriano ed il Tongriano esiste un hyatus piuttosto notevole che corrisponde a tutto il Bartoniano; esso è molto evidente nei dintorni di Voltaggio, in Val Scrivia, ecc., sin nella Valle Borbera dove il Liguriano assume la facies di argille seagliose nerastre, che ne rappresentano la parte superiore. Orbene, dalla Valle Borbera risalendo alla borgata Merlazzina, vediamo che tra queste tipiche argille scagliose liguriane ed i conglomerati tongriani appaiono e si sviluppano poco a poco da Sud a Nord banchi marnoso-argillosi che hanno in parte la facies tongriana e in parte quella liguriana; ciò specialmente a causa dell'intcrporsi fra i banchi marnoso-arenacei, certamente 
tongriani, ed i banchi conglomeratici dello stesso piano geologico, un complesso di marne argillose nerastre, senza evidente stratificazione, che ricordano quasi perfettamente quelle del $\mathrm{Li}$ guriano superiore tanto più che raccliudono eziandio straterelli di calcare simile alquanto a quello alberese dell'eocene.

A questo riguardo una sezione bellissima, che riportai nel sovraccennato lavoro, si può osservare salendo dalla borgata Merlazzina $(500 \mathrm{~m}$.$) al M. Rivarossa (910 \mathrm{~m}$.). Noto poi che secondo recenti osservazioni sembranmi doversi inglobare nel $\mathrm{Li}$ guriano superiore (passante per facies al Bartoniano) le marne scagliose ed i banchi arenacei di Serra-Brignano-Pallauzona, che credetti dapprima ancora inscrivibili al Tongriano inferiore, appunto per la loro facies speciale; tale incertezza di riferimento dipende precisamente dal fatto che in queste regioni, se non esiste un graduale passaggio tra Tongriano e Liguriano, quest'ultimo orizzonte presenta però quivi i suoi banchi superiori (fatto assai raro in generale), i quali hanno caratteri che li fanno rassomigliare di molto ai banchi del Tongriano inferiore.

Noto qui come le arenarie a Nummulites vascu, N. Boucheri var., ecc., di Griara (alta Valle Museglia), ma specialmente le marne ed i calcari, pure a $N$. vasca e $N$. Boucheri var. di M. Rivarossa, nonchè le marne grigio-verdastre di Giarella, S. Giorgio-Casasco (V. Curone), ecc., rappresentano già ia formazione di passaggio (Sestiano) tra Tongriano e Bartoniano, ed anzi in parte debbonsi già includere nel Bartoniano, per modo che la transizione dal Tongriano al Liguriano in queste regioni è spesso molto graduale.

Nelle restanti parti dei colli tortonesi non possiamo più osservare generalmente graduali passaggi tra $\mathrm{i}$ due terreni in questione, anzi spesso si nota un'assoluta discordanza tra il Liguriano ed i terreni oligocenici che gli si appoggiano direttamente.

La stessa cosa ad un dipresso deve ripetersi per le colline Torino-Valenza, dove generalmente il Liguriano è direttamente coperto dal Tongriano, ma con un evidente lacuna fra questi due orizzonti geologici. 
Però nelle colline torinesi tale lacuna è soventi riempita dalla comparsa del Bartoniano il quale, mentre superiormente si collega insensibilmente col Tongriano per mezzo di banchi riferibili al Sestiano, inferiormente passa gradatissimamente al Liguriano per mezzo di marne rossastre, o di marne argillose verdiccie o rossiccie inglobanti già lenti di arenaria (pseudomacigno) di calcare (pseudoalberese) nonchè enti arenaceo-puddingoidi con Nummulitidee, per modo che soventi riesce impossibile decidere se certi banchi sono già da riferirsi al Liguriano od ancora al Bartoniano.

Questi fatti si possono osservare specialmente bene al margine esterno della zona bartoniana tra le colline di Verrua Savoia e l'alta Valle Caservalle, nonchè in alcuni punti di Vaì Trincavenna nelle colline di Brozolo, ma nel modo più chiaro nelle colline ed al fondo dei valloni tra Lauriano ed il vallone di S. Fede, dove osserviamo:

Elveziano - Marne, sabbie ed arenarie, grigie e grigio-giallastre

Langhiano - Marne grigiastre, dure scagliose

Aquitaniano $\left\{\begin{array}{l}\text { Banchi marnosi ed arenacei } \\ \text { Marne grigiastre e bleuastre } \\ \text { Banchi arenacei grigio-bruni }\end{array}\right.$

Stampiano - Marne grigiastre, friabili

Tongriano $\left\{\begin{array}{l}\text { Arenarie straterellate } \\ \text { Marne grigiastre friabili }\end{array}\right.$

Sestiano - Arenarie straterellate con Nummuliti Bartoniano $\left\{\begin{array}{c}\text { Marne grigio-verdastre con strati calcarei } \\ \text { Marne argillose rossiccie o verdastre con lenti } \\ \text { arenacee e calcaree }\end{array}\right.$

Marne argillose grigio-verdastre o rossastre, con lenti di calcarc alberese e di Macigno

Liguriano e banchi breccioso-conglomeratici

Banchi conglomeratici

Argille scagliose, banchi di calcarc alberese, di Macigno, ecc. 


\section{Localita fossilifere.}

Siccome le poche forme fossili del Liguriano sono variamente sparse in quasi tutti i banchi che lo costituiscouo, così è difficile indicare località ove esse più abbondantemente si possano raccogliere: si può invece notare che le impronte di Hetminthoidea sono assai comuni negli schisti argillosi-calcarei della Valle della Scrivia, cosi presso Villavecchia, mentre i resti di fucoidi arborescenti riscontransi specialmente, e talora in quantità straordinaria, in certi speciali orizzonti dei calcari biancastri che stanno frammezzo alle argille scagliose, come, per esempio, nelle col line Torino-Talenza presso Casale, Villadeati, Brozolo, Brusasco, Lauriano, ecc. Per rintracciare tali resti fossili è specialmente utile l'esplorar'e gli scavi fatti per l'estrazione del calcare ed i materiali, sia utili che inutili come pietra da calce, che trovansi sparsi nelle vicinanze di tali care; notisi inoltre che incontrando in un dato luogo o strato un esemplare dei fossili sopra indicati è utile il proseguire pazientemente ed accuratamente le ricerche in quella stessa località perchè essi trovansi per lo più in grandissimo numero nello stesso banco. Le nummuliti e le orbitoidi incontransi rarissimamente qua e là fra le arenarie delle colline tortonesi e pavesi; nelle colline di Casale trovansi banchi a numerose Nummulitidee nell'affioramento $l_{i}$ guriano lungo il Po, quasi di fronte a Trino; nelle colline torinesi trovansi pure Nummulitidee in speciali banchi calcarei breccioso-conglomeratici del Liguriano superiore passante ai Bartoniano, specialmente nelle vallette di Monteu da Po e di S. Fede, nonchẻ presso il Bricco di Marmito in dirersi punti.

\section{Descrizione geclogica regionale.}

Il Liguriano delle Alpi Marittime è gia noto per altri studi.

Del Liguriano dei dintorni di Toltaggio, dore questo terreno comincia ad apparire nel bacino terziario in esame, mi 
limiterò a pochi cenni principali avendone già trattato abbastanza ampiamente in altro lavoro.

Ritenendo triassici i calcari dolomitici escavati come pietra da calce nel rio Frasso e sotto al Castello di Voltaggio, e che io, pur riconoscendone la fisionomia triassica, avero dapprima dubitato rappresentassero una facies speciale del Liguriano, e lasciando ad un esame successivo i banchi ofiolitici, l' eocene di queste regioni si può dire consti essenzialmente di Calcoschisti e di argilloschisti talcosi, per lo più fortenente sollevati, che rappresentano il vero Flysch alpino.

I calcoschisti a stratificazione nettissima, spesso assai compatti, talora passanti ad Ipoftaniti, sono specialmente sviluppati nella parte inferione del Liguriano di queste regioni e veggonsi assai bene in Val Lemna anche solo percorrendo la strada da Voltaggio ai Molini di Voltaggio.

Molto più estesamente sviluppati e più potenti sono gli argilloschisti talcosi (clie però passano talora gradatamente ai sovraccennati calcoschisti) con lenti incluse o interstrati o arenacei, quaraitici o calcarei e con una tinta generale grigio-plumbea o grigia argentina assai caratteristica. Talora invece questi talcoschisti assumono un color giallo-verdastro o rosso-vinato, come si osserva per vaste ragioni, specialmente tra la Val Lemna e la Val Traversa; ciò dipende in parte da alterazione chimica, wa in parte eziandio da materiali accessori la cui presenza è forse in qualche relazione coi fenomeni che accompagnarono la formazione dei banchi ofiolitici generalmente non molto lontani.

Nella Valle Scrivia veggonsi sviluppatissimi gli argilloschisti talcosi in cui vennero scavate le due gallerie ferroviarie dei Giovi, incontrandosi in ciò, come è noto, gravi difficoltà a causa del rapido alterarsi ed idratarsi di questi terreni chc, per essere spesso poco omogenei cd alquanto frantumati, cedono facilmente alle poderose spinte delle masse circostanti.

Ma a Nord di Ronco Scrivia agli indicati banchi schistosi grigio-plumbei, con lenti quarzose e calcaree bianche pieghettate, succedono per sorrapposizione banchi calcarei grigiastri, 
alternati però ancora con argilloschisti brunastri lucenti; questo complesso di strati, che vediamo comparire ancora con aspetto quasi eguale nelle colline di Rocchetta Ligure e Volpedo, ci rappresenta la formazione del calcare alberese a frattura concoide, che però colla sua facies tipica compare poi specialmente più a Nord assieme alle argille scaglioss.

Per esaminare minutamente la costituzione del Liguriano di queste regioni è utilissimo anclie solo il percorrere attentamente la strada nazionale che passa in fondo di Val Scrivia, esistendovi numerosi tagli naturali ed artificiali che mettono a nudo l'intiera serie stratigrafica di questa ampia zona eocenica.

Dalla Valle Scrivia portandoci verso Roccaforte possiamo vedere che nel Liguriano affiorante sotto al velo spesso interrotto dei terreni tongriani (come già in alcuni punti sopra il paesello di Mereta, ma specialmente verso le borgate di La Riva, La Barca, ecc.), con i banclii di vero Flysch, cioè con gli argilloschisti interstratisicati a banchi arenacei e calcarei grigiastri, si alternano e poscia loro si sostituiscono gradualmente bancli argilloso-marnosi di color bruno con inclusi straterelli di calcare biancastro e di arenaria grigio-giallognola; ma generalmente questi sono infranti e ridotti a frammenti sparsi irregolarmente nella massa argillosa; si passa cioè in queste regioni alla notissima facies delle argille scagliose e dei galestri dell'Appennino, facies clie prende poi l'assoluta predominanza nella restante parte del bacino terziario del Piemonte.

Infatti da Roccaforte a Roccletta Ligure, Cantalupo, Colonne, ecc., sino allo espandimento tongriano di S. Sebastiano Curone, vediamo sviluppatissime le argille scagliose ed i galestri con forme però svariatissime per maggior o minor sviluppo dei banchi calcari ed arenacei, pel colore diverso che presentano le marne argillose che, generalmente nerastre, passano spesso, o per alterazione o per sfumature naturali, al rossastro, al violaceo, al verdiccio, ecc.

Fra le regioni più istruttive, almeno nei limiti di questo lavoro, per osservare il passaggio tra il Liguriano inferiore a 
facies alpino-appenninica e quello superiore a facies appenninica e subappenuinica, è da indicarsi il Vallone Spinti dal M. Lerta sin dove l'eocene vien coperto dal Tongriano. Infatti, risalendo questa valle, si può vedere la graduale transizione tra i terreni che il Pareto pose nel suo Modenese e quelli che incluse nel Liguriano in senso stretto; anzi la maggior parte della formazione eocenica quivi visibile è già da attribuirsi al vero Liguriano, essendo costituita di strati calcarei grigiastri, frammentari, e di strati arenacei. Questi però sono spesso alternati con argille scagliose, le quali alla loro volta formano quivi già un passaggio agli argillosclisti che sono tanto sviluppati nell'Appenino Ligure.

A Sud della borgata Cafiorenga si inizia poi il tipico Liguriano con potenti banchi di calcare alberese, di Flych ad Helminthoidea, con argilloschisti talcosi ecc., talora però ancora con qualche strato di argille scagliose nerastre intercluse.

In tutta questa serie stratigrafica la tettonica è poco regolare; osservansi nunerosi ripieganenti e contorcimenti (come per esempio, tra M. Eremita e M. Langonio) ed inclinazioni spesso fra di loro contrarie in punti vicinissimi. Ma in Val Sisola, a valle di Sisola, l'andamento stratigrafico diventa più regolare e veggonsi $\mathrm{i}$ banchi inclinare di $30^{\circ}$ a $50^{\circ}$ circa verso il Nord-Ovest o l' Orest, almeno in linea generale, come si può osservare benissimo ad esempio nei dintorni di borgata Pagliaro, Rocchetta, Arborelle, Bregni, Montacuto, ecc. In queste regioni hanno un'assoluta prevalenza nella costituzione del Liguriano le argille nerastre con cui, oltre a banchi frammentari di arenarie, si alternano spesso potenti banchi di calcare alberese, come, per citare un esempio, si può osservare nei dintorni di segnale Bregni.

Tra le borgate di Montacuto e di Costa troviamo un fatto assai interessante, che avremo ancora occasione di osservare altrove, cioè la comparsa di potentissime lenti conglomeratiche, che a primo aspetto parrebbero lembi staccati di Tongriano inferiore, ma che credo invece assolutamente includibili nel $L_{i}$ guriano superiore. 
Infatti ridiscendendo la ralle Museglia rediamo $i$ banchi arenacei e calcarei, alternati colle argille scagliose neristre, presentare una nettissima inclinazione, variante, da $30^{\circ}$ a $60^{\circ}$, rerso il YordNord-Orest; sotto Montacuto a questi banchi tipici del Liguriano si sovrappongono direttamente e concordemente grossi bancli conglomeratici, ricoperti ancora da argille scagliose nerastre con calcare alberese; su tutto ciò poi si appoggia, poco a Nord, il Tongriano inferiore (forse anche il Scstiano) costituito da arenarie grigio-chiare, da conglomerati, ecc., e stratigraficamente abbastanza concordante col Liguriano, da cui però credo sia separato per un forte hyatus corrispondente a tutto il Bartoniano.

Ad un dipresso la stessa successione stratigrafica osservasi ancora verso Est sino a borgata Costa. Crli elementi di questi conglomerati sono talora di oltre un metro, però più comunemente di solo 15 o 20 centin. di diametro, quasi sempre fortemente cementati fra di loro, spesso profondamente improntati, di natura prevalentemente arenacea o calcarea o diasproide; ciò che ci indica come questo conglomerato si è formato specialmente alle spese delle più antiche formazioni liguriune. I banchi conglomeratici in questione si presentano spesso sollerati quasi alla rerticale od anche leggermente rovesciati, come nel vallone di C. del Ferro.

In Tal Staffora, specialmente nella sua parte più bassa, osservansi sviluppatissime le argille scagliose per lo più nerastre, ma anclie spesso violacescenti, con zone qua e là di color rosso, cioè colla tipica facies del Liguriano superiore (Modeniano) appenninico. Le argille galestrine a tinte variegate sono attraversate da zone più o meno regolari di calcari e di arenarie frantumate, cosi, ad esempio, tra Bagnaria e Coriola, tra borgata Crocetta e Rio Frascata, ecc. Tali zone, per la direzione abbastanza costante clue talora presentano, come appunto nell'ultimo caso accennato, servono assai bene ad indicarci landamento stratigrafico della formazione eocenica, ciò che difficilmente si potrebbe conoscere in altro modo. 
Ad un dipresso colla medesima fucies vediamo presentarsi il Liguriano sia nella zona Brignano-Spinetta, sia nelle colline tortonesi; quivi infatti qua e là fra le argille scagliose brune compaiono aree di argille verdastre $o$, più comunemente, rossastre ed anche gialle e grigie, tinte clie possonsi, ad esempio, osservare nel rio incassato a Nor-Est del paese di Montebello dove gli strati sono ora rizzati alla verticale, ora inclinati solo di $30^{\circ}$ o $40^{\circ}$ con evidenti ripiegature; così pure argille rossastre veggonsi assai sviluppate qua e là nelle colline presso Tortona, specialmente nei rilievi a Nord di Vho.

Talora invece le argille scagliose assumono un color nerastro così intenso che certi banchi simulano di lontano depositi lignitici, come ad esempio si può osservare nel Rio Cornigliasca dove gli strati argillosi neri sono alternati più o meno regolarmente con strati calcareo-marnosi compatti di color grigiastro o giallognolo.

Molto interessante è il Liguriano superiore dal M. Vallassa alla borgata Pallanzona poichè quivi esso presenta in parte una facies sabbioso-arenacea che lo fa rassomigliare molto al Tongriano inferiore, tanto che in una nota sul passaggio tra il Liguriano e Tongriano sredetti di poter già includere i suddetti banchi nel Tonyriano basale, mentre che ora invece credo piuttosto doverli ancora attribuire al Liguviano superiore passante al Bartoniano; ciò in causa di una potente formazione di argille galestrine violacescenti che li dividono dal rero Tongriano.

Lo studio dettagliato di questa zona speciale fu già fatto nella sovraccennata nota, basta quindi indicare ora cone la costituzione della zona del Liguriano superiore in esame sia rappresentata dalla seguente serie stratigrafica: 
Tongriano - Arenarie, sabbie e conglomerati (appoggiantesi, con hyatus, sul Liguriano).

Argille galestrine bruno-riolacee (pila potente) e Marne e subbie grigiastre regolarmente stratifi-

Liguriano cate (psendo-bartoniane).

superiore

Banchi calcareo-arenacei, alternati con marne grigiastre; spesso ridotti in frantumi.

Argille scagliose nerastre con bancli frammentati di calcare alberese e di arenaria.

Nella parte settentrionale delle colline tortonesi il Liguriano, per quanto lascia scorgere la sviluppatissima coltura del terreno, pare si presenti alquanto arenaceo. Quanto ai banchi calcarei, quasi sempre ridotti in frammenti e commisti ai banchi arenacei, essi trovansi sparsi quasi ovunque, specialmente presso Brignano, tra Casasco e Magrassa, nei dintorni delle Tassere, tra Pallanzona e Montebello, presso Alpicella e Montale, nelle colline di Spinetto attorno alla C. Roncrasio, da C. Bellaria al Rio Pso, fra argille nerastre e verdiccie, alla C. Daviceo ed a S. Bartolomeo in val Grue, presso la C. Bruciata, a Sud di Vho e nelle colline di C. Bellameglio presso Tortona, dore i banchi di calcare veggonsi spesso commisti ad argille verdastre; generalmente però questi afíoramenti calcarei non vennero ancora utilizzati cone pietra da calce.

Fra le argille scagliose sopra la C. Roncrasio, ad Orest di Bersano ebbi a riscontrare uno stupendo esemplare di quelle concrezioni, conosciute col nome di septarie, clie sono tanto comuni in certe località dell'Appennino fra terreni cousimili.

La facie's arenacea è assai ridotta in. queste regioni, tuttaria è notevole come nella valle Grue, e precisanente tra C. Daviceo e C. Campoltrone, trovinsi assai potenti banchi, ripieghettati ed infranti, di argilloschisti arenacei che ci ricordano molto bene il Flysch delle Alpi Marittime. E inoltre importante l'osserrare come in questa stessa località da ambo i lati di Val Grue, assieme o meglio sul lato settentrionale dei sorrindicati banchi 
di Flysch, stanno arenarie grossolane passanti talora a durissimi conglomerati; questi sono per lo più a piccoli elementi (calcarei od arenacei) cementatissimi, ma talora anche ad elementi abbastanza voluminosi ( $8-10$ centim.). Tali conglomerati, passanti talora localmente a breccie, quantunque per lit loro posizione possa sorgere il dubbio che siansi da attribuire ad un lembo oligocenico conservatosi per la sua durezza, tuttavia per l'assieme dei caratteri sembrami debbansi ancora riferire al $L_{i}$ guriano; questi banchi, utilizzati come materiale da costruzione, sono sollevati quasi alla verticale, con direzione ad un dipresso da Sud ad Ovest.

Esaminando la larga zona d'affioramento di Liguviano di Val Curone a Sud di Volpedo è a notarsi che nella sua parte periferica, la quale va ad immergersi sotto ai terreni oligocenici e miocenici, si presenta sviluppata la fucics delle argille scagliose, commiste a banchi calcarei, specialmente sopra a C. Premarone, nella parte alta del Rio del Brolio, attorno al Poggio, a Sud di Monleale, ecc.; invece verso la parte più interna di questa zona, che già dicemmo presentare una specie di centro di sollevamento nel rilievo di Cà di Bruno, assieme alle argille scagliose, racchiudenti frammenti di calcare alberese, si sviluppano molto le arenarie, sia in banchi regolari alternati con argilloschisti talcosi e con calcari, come vedesi stupendamente hene presso il Molino del Bove (facies simile a quella di Val Scrivia presso Pietrabissara), sia ridotte a frammenti irregolari o commiste a sabbie e marne sabbiose giallastre o grigio-verdastre, che si possono specialmente osservare lungo la strada e nell'alveo del Curone, sotto Montalto.

Anche in questa regione sotto le assise or ora indicate apparono, ed assai sviluppati, i conglomerati cementatissimi, a ciottoli improntati in modo straordiuario e che credo riferibili al Liguriano; questi conglomerati ad elementi poco voluminosi (raramente di 20 centim. di diametro), formati specialmente di calcare alberese e di arenarie che paiono provenire dal Lignviano inferiore, costituiscono in massima parte il Montalto con 
inclinazione specialmente pronunciata verso il Sud, mentre i banchi sabbioso-arenacei, che ne formano il fianco settentrionale, pendono già verso il Nord.

Al M. Cugrosso incontriamo ancora durissimi banchi arenacei, spesso frantumati, a cui si uniscono grosse lenti conglomeratiche, cementatissime, ad elementi per lo più piccoli, ma talora anche di vitie 10 centim. di diametro; questi ciottoli, di natura specialmente arenacea, calcarea o diasproide, si presentano talrolta notevolmente schiacciati e sconquassáti.

Assieme a questi conglomerati, specialmente sul lato settentrionale di Montalto, si sviluppano potenti banchi sabbiosi ed arenacei, di color giallastro, che hanno molto la facies di terreni miocenici.

E poi notevole che questa formazione arenaceo-conglomeratica non trovasi già qui nella parte superiore del Liguriano come verificasi altrove, ma ad un dipresso nella sua parte niedia; giacchè attorno al suo punto di affioramento i sovraincombenti e tipici terreni eocenici (costituiti di marne grigiastre scagliose alternate con banchi di calcare alberese e di Flysch) pendono irradialmente verso l'esterno in modo abbastanza regolare, di un $40^{\circ}$ in media, come si può vedere molto bene specialmente nella parte inferiore del Vallone del Brolio.

Quindi dalla Giarella alle vicinanze del Bric Montalto noi troviamo un'interessantissima serie stratigrafica che si può indicare in questo modo: 
Tongriano - VIII. Arenarie e conglomerati in banchi potenti.

Bartoniano - VII. Marne farinose grigio-verdiccie.

VI. Argille scagliose nerastre con qualche strato frantumato di calcare alberese e di arenarie.

V. Potente complesso di banchi arenacei (Macigno) e calcarei (Alberese) alternati con marne argillose grigio-nerastre ed argilloschisti talcosi (Flysch).

IV. Marne sabbiose grigio-giallastre con strati frantumati di arenaria e di calLiguriano care, con passaggi talora ad argille scagliose.

III. Arenarie e conglomerati a ciottoli improntati; sabbie giallastre e giallo-verdastre.

II. Argille ed arenarie fra cui sono sparsi irregolarissimamente ciottoli e frammenti irregolari (a superficie spesso lucente) di Calcare, Serpentina, ecc.

I. Affioramenti ofiolitici.

Notiamo infine come nelle colline di Cà di Bruıo, attorno agli spuntoni ofiolitici, che esamineremo in seguito, veggonsi, come di solito in tali casi, depositi breccioso-conglomeratici a struttura caotica in cui, franmezzo ad un arenaria giallastra, sono mescolati gli elementi serpentinosi con quelli arenacei e calcarei con rilegature di varia natura, tanto che riesce talora difficile il distinguere quivi con una certa chiarezza i diversi terreni.

Nei numerosi, quantunque spesso assai ristretti, affioramenti di Liguriano delle colline Torino-Valenza, questo terreno si presenta quasi esclusivamente colla facies di argille scagliose con banchi per lo più infranti d'arenaria e di calcare alberese.

Il Liguriano di Pietramarazzi, per quel poco che la coltivazione 
permette di osservare; appare per brevissimo tratto alle falde meridionali del Bric Mariano colla facics di argille bruno-rossastre.

I'affioramento liguriano di Bric Mariano-C. Cardenas è molto più importante raggiungendo uno sviluppo di oltre 5 chilom., quantunque talora ridotto solo ad una striscia di un centinaio di metri di larghezza; talvolta invece esso è ampio quasi un chilometro; anche qui predominano le argille scagliose di color bruno, fra cui trovansi sparsi dei frammenti di arenarje e di calcari arenacei: non è neppur raro l'osservare argille di color rossastro, come per esempio, sulla cresta del Bric Cantoniere, e ad Est di C. Deamici, oppure di color verdiccio, come al Sud di C. Villa.

Sono quivi numerosi i frammenti di calcare alberese specialmente alle falde occidentali di Bric Castellar e sul fianco orientale di Bric Oliva. Trattasi qui di un corrugamento eocenico diretto allincirca da Nord a Sud (cioè contrario a quellu clie osserrasi generalmente nella restante parte dei colli Casale-Torino) e clie portò a giorno i terreni tongriani, alterando molto landamento di quelli miocenici.

Quanto agli affioramenti liguriani a Nord di Lu, quello minore, a Sud di M. Torre, appare solo pel colore nerastro del terreno che costituisce il fondo della vallata; l'altro, pure assai piccolo, di C. dei Bersani è ben evidente per i frammenti arenacei e calcarei commisti alle argille scagliose brune; il mag: giore, con uno sviluppo in lungliezza di oltre 3 Chilom, ed in certi punti con 1 Chilom. circa di larghezza, benchè quasi diviso in due dalla placca miocenica di Montalberto, presenta in più punti ben visibili le solite argille brune, ma commiste piuttosto a banchi frantumati arenacei che non a banchi calcarei.

J'allungato affioramento liguriuno di Conzano-Camagna, col massimo diametro di tre chilom. e mezzo e colla larghezza di circa 500 metri, è importante industrialmente pel fatto che colle sue argille scagliose sono commisti abbastanza comunemente banchi o frammenti di banchi di calcare duro, scaglioso, utiliz- 
zato in più punti come pietra da calce, ciò specialmente presso la C. Pellegrini e la C. Rivarolo, quantunque sviluppatissime sieno pure le marne calcaree biancastre tra C. della Madonna e la Cappella di S. Rocco.

Dal Molino di Camagna in val Grana sin oltre C. Serra, presso Camagna, esiste un largo affioramento di argille scagliose brune liguriane coi soliti buncli infranti di arenarie e di calcare alberese; l'inclinazione di tali banchi pare sia prevalentemente verso Nord-Est.

Ad Ovest di Camagna, presso C. Barbotta, appare eziandio un affioramento liguriano, continuazione dell'ultimo accennato.

Una bella lente di questo terreno possiamo poi ancora osservare in val Grana, tra Cuccaro e la C. Nuova, dove le argille scagliose presentano pure i caratteristici banchi infranti di arenarie e di calcari; questo afforamento è forse da attribuirsi ad un corrugamento secondario, direi, dell'eocene, corrugamento parallelo però a quello principale dell'asse della collina.

La ben conosciuta zona liguriana di Casale, per quanto rasta, avendo uno sviluppo di circa 8 chilom. in lungliezza per 5 in larghezza, si presenta però abbastanza uniforme nella sua costituzione; come di solito vi predominano in modo assoluto le argille scagliose, specialmente nerastre, con sparsi quasi ovunque banchi di marna calcarea dura, biancastra, a frattura concoide e scagliosa e banchi di calcare alberese, grigio, rosso, biancastro o giallognolo; sonvi pure bancli di arenarie più o meno frantumate; talvolta compaiono anche marne argillose biancastre (come ad esempio sotto la torre Gaiona, presso la C. Serra, ecc.), che ricordano alquanto quelle mioceniche; qua e là veggonsi strati sabbioso-arenacei alternati colie tenacissime argille. In complesso però abbiamo una sola fucies litologica in questa graude zona eocenica cioè la facies appenninica, direi, del Liguriano. In generale si nota che le argille scagliose nerastre sono assai ricche in banchi calcarei, mentre quelle grigiastre presentano piuttosto comunemente banchi o frammenti arenacei.

La continuazione, verso Orest, della grande zona liguriance 
di Casale osservasi nelle colline di Canino, quasi di fronte a Trino, ed anzi essa serve assai bene a collegare il Liguriano dei colli casalesi con quello dei colli della Verrua e di Brusasco; questo affioramento, lungo quasi 3 chilometri, coperto a Sud dai terreni eocenici ed oligocenici ed in gran parte mascherato a Nord dalle alluvioni del Po, consta essenzialmente delle solite argille scagliose brune con arenarie e calcari. È però assai interessante l'osservare clie poco a Nord di Zizano e verso lo sbocco del vallone che esiste ad Est di Brusaschetto, appare nel Liguriano medio o medio inferiore una serie assai regolare di banchi arenacei, fortemente inclinati a Sud o Sud-Sud-Orest, e clie a diversi livelli presentano numerose piccole Nummuliti ed Orbitoidi (Orbitoides stella; O. temicostata, ecc.). Tale località è molto importante pel paleontologo che raramente può incoutrare altrove Nummulitidee liguriane; cioè nel F/ysch.

Il Liguriano (a marne grigie e rossastre con calcari, arenarie, concrezioni a Septaria, ecc.); affiora per lunghi tratti sulla sinistra del Po tra Palazzolo e S. Silvestro.

L'affioramento liguriano di Ottiglio, lungo quasi 2 chilom., presenta interessanti rapporti di sottoposizione col vicino spuntone bartoniano; fra le argille scagliose nerastre clie lo costituiscono assieme ai soliti frammenti calcarei ed arenacei ebbi a rinvenire, benissimo conservata; una di quelle caratteristiche concrezioni che ricevettero il nome di Septaria; tra la C. Spinosa alta ed il rilievo bartoniano è assai netta la zona liguriana con arenarie e calcari in frammenti; presso C. Preus; raccolsi alla superficie del terreno dei frammenti di arenarie inglobanti piccole nummuliti, frammenti che forse provengono dallo stesso terreno liguriano.

Presso la borgata Starola; ad Est di Ponzano, appaiono per breve tratto le marne argillose nere del Lignuiano coi soliti frammenti arenacei e calcarei.

Lo spuntone fusiforme di Liguriano; lungo circa un chilonetro, cle osservasi ad Orest di Ponzano serve assai bene a guidarei sull'andamento della ruga eocenica di cui possiamo solo 
rintracciare qua e là pocli brani, quando denudati dai sovrincombenti terreni oligocenici; come di solito tale zona è costituita da argille scagliose brunastre o bleuastre con frammenti di arenarie e di calcare alberese.

E interessante il piccolo affioramento liguriano del Cimitero di Fabiano, giacchè esso ci spiega il corrugamento oligocenico di Mombello.

In Val Stura vedesi ricomparire il Liguriano ben caratteristico nella valletta che discende da Piancerreto a C. Scaldino, giacchè quivi le argille scagliose nerastre presentano spesso degli affioramenti di banchi calcarei ed arenacei, ridotti come di solito a semplici frammenti argillosi; sul lato sinistro di Valle Stura il Liguriano è assai meno appariscente e lo si può quasi solo constatare per alcuni frammenti di calcare alberese sotto C. Perosio.

Continuando verso occidente troviamo che, prima di giungere alla grande zona liguriana di Verrua, affiora già in alcuni punti questo terreno colla solita sua facies di argille scagliose nerastre e rossiccie; così per pochi metri quadrati al fondo di Val Bosco sotto C. Rossi presso Oddalengo grande, e con uno sviluppo poco maggiore presso S. Antonio Vechio (parte alta del rio della Marca verso Sud) dove le marne argillose, clie qua e là presentano resti calcarei ed arenacei, hanno un color bruno violaceo o bruno bleuastro assai spiccato.

Nella parte alta di Val Caservalle affiorano per un certo tratto le argille bruno-bleuastre del Liguriano, che inoltre innalzandosi verso il Cimitero di Cortiglione prolungansi sino alla parte alta di rio della Marca, col solito corteo di calcari alberesi ecc.

I prolungamenti più orientali della zona liguriana di Verrua in Val Caservalle osservansi sotto Castella colla facies di argille nero-azzurrognole fra cui incontransi talora frammenti calcareo-biancastri ma più conunemente arenacei grigio-bruni.

Nelle vicinanze delle borgate Valeisa, Castella, Vignali, Casaretto, Piaj, ecc., le argille scagliose liguriane, spesso rossiccie o verdastre, sono molto ricche in frammenti di arenarie e talora 
anche di calcare alberese; esse appaiono specialmente in fondo delle valli e nei bassi colli fra $\mathrm{i}$ più resistenti banchi oligocenici; è poi talora difficile il delimitare gli affioramenti liguriani, sia per il loro apparire specialmente nella parte bassa delle valli e quindi per lo più sotto depositi alluvionali, sia perchè le sovragiacenti marne oligoceniche rassomigliano talrolta alquanto a quelle eoceniche quando non si possono osservare che in piccolo spazio, come sovente è il caso.

In Val Jiaj possonsi esaminare molto bene sotto C. Cerruti, per mezzo di profondissimi tagli naturali, le argille scagliose bruno-azzurrastre i cui banchi calcareo-arenacei intermedi facilmente si infrangono oppure, se già infranti, si disaggregano quando messi allo scoperto, per modo che i loro frammenti reggonsi numerosi alle falde dei pendii scoscesi.

Nelle vicinanze di Brozolo i bancli calcarei o marnoso-calcarei duri, scagliosi, biancastri si presentano molto sviluppati (ad esempio presso C. del Gallo) ed assai ricchi in bellissime fucoidi; d'altronde banchi calcarei, più o meno ben conservati, trovansi assai comunemente oltre che presso Brozolo anche in Val Trincavenna, nei dintorni di C. Mogol, presso S. Orsola, nel Rio Quarlasco, sotto Monticelli Verrua, ecc.

Le argille scagliose rosse o verdiccie appaiono talora framnnezzo a quelle brune, così sotto Piazzone di Brozolo, a C. Visca, al Bric delle Pessere, ecc.

Talvolta colle argille, colle arenarie e coi calcari si alternano letti sabbiosi, oppure tutti questi terreni ridotti a straterelli si alternano ripetutaniente fra diloro, come al esempio, si può benissimo osservare per tagli artificiali nella stupenda curva che formano gli strati liguriani sotto Monticelli Verrua.

Debbo poi infine notare come presso C. Castellazzo, nelle ricinanze di C. Nuova di Marcorengo e nell'alta Talle Quarlasco, poco a Nord di C. Forno, esistono dei depositi conglomeratici, a ciottoli profondissimamente improntati e che, per quanto abbiano l'apparenza di placche tongriane sull'eocene, paionmi piuttosto far parte del Liguriano stesso, corrispondendo probabil- 
mente ad un dipresso ai conglomerati che, in questo orizzonte, già osservammo in più punti dei colli tortonesi; osservo però cle i ciottoli stupendamente improntati sorraccennati sono in parte costituiti di calcare clie generalmente somiglia molto a quello alberese, per cui, se tali conglomerati sono eocenici, come credo, essi si sono formati alle spese dei banchi di calcare alberese che abbiamo già visto rappresentare una parte assai importante nel Liguriano inferiore: d'altronde la profondità delle impressioni che presentano questi ciottoli potrebbe forse attribuirsi oltre che alle azioni fisico-chimiche anche alla poca durezza che essi dovevano avere allorquando vennero ad essere riuniti assieme.

Oltre ai ciottoli calcarei sonvi pure ciottoli diasproidi, quarzitici, porfirici, granitici, serpentinosi, ecc., generalmente molto alterati e rilegati da una sabbia o da un'arenaria calcarea spesso profondamente decomposta. I ciottoli sono generalmente poco voluminosi, ma talora però presentano un diametro di anche 20 centim., talora anzi persino di oltre 50 centim., come osservasi presso C. Castellazzo.

Lq grande zona liguriana irregolarmente triangolare di Lauriano, oltre al' solite argille scagliose giallo-brune o nerastre o bruno-bleuastre, presenta qua e là delle argille verdastre o rossiccie come in Talle di Ponte presso C. Colombaro e Beviiacqua, a Sud di borgata La Pietra, ecc.; abbondantissimi quasi ovunque sono i hanchi di calcare allerese, escavati su vasta scala nei luoglii più comodi all'uopo.

Fra le argille scagliose notansi talora, come in Valle S. Fede, presso C. Scarrone, in Val Monteu a Nord-Est di borgata Novarese, nelle cave dell'alta Val Mezzana, e nelle cave di Lauriano, delle vere breccie calcaree ridotte talora solo più a monoliti irregolari, ma che dovevano costituire primitivamente una specie di banco quasi continuo, ed anche strati breccioso-conglomeratici inglobanti molte Nummulitidee.

Per l'esame delle argille scagliose è specialmente utile il risalire la Valle di S. Fede, dove esse sono caratteristiche, bene 
sviluppate e, direi, colanti in tempo di pioggia seco trascinando caoticamente sparsi i frammenti scagliosi di arenarie, calcari, ecc., cioè col tipico aspetto del Liguriano appenninico.

Nelle colline e nei valloni tra Lauriano e Val S. Fede si può esaminare in tutti i suoi più minnti dettagli il passaggio graduatissimo tra il Liguriano ed il Bartoniano inferiore.

E poi interessante l'osservare in val Monteu sotto borgata Novarese un potentissimo complesso di bancli conglomeratici ed arenacei soventi potentemente cementati, sollevati spesso alia verticale e con direzione variante tra Nord-Sud e Nord-EstSud-Ovest; questo conglomerato, di cui troviamo poi ancora dei lembi nelle cave di Lauriano presso C. Boggetto (dove è però poco cementato ed in parte anzi quasi ridotto a gliaie) e dei frammenti in diversi punti fra le argille scagliose, (nonclıè dei ciottoli nei conglomerati tongriani), credo doversi ancora riferire al Liguriano come quelli già sopramenzionati. Gli elementi di questi conglomerati, generalmente di 4 o 5 centim. di diametro (talora però anche di 20, 30 centim. e raramente persino di 1 metro di diametro), quantunque alquanto diversi a seconda le localitì ed i banchi in cui si osservano, sono specialmente di Serpentina, Granito, Quarzite, Porfido, Sienite, Micaschisto, Diaspro e Calcare; questi ultimi presentansi spesso fortemente improntati.

L'età liguriana di questi conglomerati è indicata, oltre che dalla loro cementazione, dalla loro facies, dalla loro stratificazione e dalla loro posizione fra le argille scagliose, anclie perchè si possono talora osservare, per esempio nelle care di Lauriano, fra questi conglomerati alcuni arnioni irregolari di argille scagliose verdiccie e rossastre, al tutto somiglianti a quelle liguriane; d'altronde le sovraccennate breccic certamente eoceniche, costituite di elementi calcarei derivanti probabilmente dallo sfacelo degli stessi banchi liguriani più antichi, ci spingono ad ammettere come dello stesso periodo anche i suddetti conglomerati. In conclusione dall'esame del Liguriano di Val Monteu risulta che sotto alle argille scagliose con banchi di calcare al- 
bcresc e di breccie calcaree compaiono potenti banchi conglomeratici ed arenacei, 'iò che s'accorda con quanto già osservammo di simile nei conglomerati liguriani delle colline tortonesi.

Interessantissima per spiegarci il curioso affioramento tongriano laterale di Villadeati-Penango è la zona liguriana che osservasi in fondo a val Stura presso Murisengo; essa è in gran parte costituita da marne calcaree dure, scagliose, e da marne brunastre con banchi calcarei a grosse Fucoidi (Chondrites affinis, ecc.), come si può vedere specialmente presso C. Cerro, C. Candido e borgata Ferrero; l'inclinazione di questi banchi liguriani è specialmente verso il Nord-Ovest.

Accenno ancora all' afforamento liguriano di Cocconato-Marmorito il quale, oltre alle solite argille scagliose brune ed anche verde-rossiccie, presenta qua e là i noti frammenti di banchi calcarei biancastri ed arenacei grigio-nerastri; specialmente tipici sono gli strati biancastri sotto C. Pessina. Oltre a ciò in fondo di Val Freddo osservansi almeno tre affioramenti di un'arenaria stratificata giallo-grigia che si può benissimo qualificare come tipico Macigno e che presenta varia inclinazione nelle diverse località, conservando però una direzione abbastanza regolare da Est ad Ovest allo incirca. Nei banchi di passaggio al Bartoniano, in Val Fabiasco e presso Curone, arenarie e puddinghe con Nummuliti, Orbitoidi ed Assiline.

Indico infine come frammezzo all' affioramento bartoniano di Gassino, specialmente nel vallone poco sotto C. Defilippi e nella Valle Maggiore sotto la C. Donaudi, si veggono spuntare quelle marne argillose rossiccie che formano il passaggio tra il Bartoniano ed il Liguriano.

L'ipotesi dell'Issel sulla zona liguriana di Rivara Canavese. necessita ulteriori studi prima di essere confermata.

\section{Riassunto.}

Da tutto ciò che si è osservato intorno ai terreni liguriani della regione in esame possiamo dunque concludere che questi 
terreni costituiscono, per dir così, l'imbasamento di gran parte del bacino terziario del Piemonte, cessando però probabilmente a Sud della linea Toltaggio-Torino, poichè si può presumere che lungo questa linea all'incirca avrenga la sovrapposizione del Liguriano alle roccie preterziarie, ad un dipresso come si osserva tra Cornegliano e Voltaggio.

L'andamento dei terreni liguriani, per quanto svariato nei particolari, se considerato in complesso è abbastanza concordante con quello dei sovrastanti terreni eocenici ed oligocenici, appoggiandosi essi alle roccie antiche dalle vicinanze di Genora a Toltaggio con direzione ad un dipresso Nord-Sud ed inclinazione verso Est, poscia curvandosi poco a poco a senicerchio con inclinazione verso il Nord, il Nord-Orest, l'Orest e poi persino verso il Sud, raccogliendo, per dir cosi, nella parte interna i terreni miocenici.

Il Liguriano mostra in val Curone a Sud di Volpedo una specie di centro di sollevanento da cui dipendono ancora i banchi liguriani dei colli tortonesi; si presenta poi nelle colline Torino-Talenza sotto forma specialmente di anticlinali, allineati ad un dipresso secondo il clinale orografico delle colline stesse, e talora anche ripetuti lateralmente come corruganenti secondarî, generalmente però quasi paralleli a quello principale.

Il Liguriano consta nella parte inferiore specialmente di argilloschisti talcosi grigio-plumbei che in alto si alternano ripetutamente con banchi calcarei i quali prendono poscia la prevalenza; nella parte superiore è costituito essenzialmente di argille scagliose e di galestri di color nerastro passante talora all'azzurrognolo, al violaceo, o, più frequentemente, al verdiccio ed al rossastro; con tutto ciò alternansi frequenti banchi di arenarie e di calcari alberesi per lo piu ridotti a frantumi angolosi sparsi fra le argille. Compaiono inoltre talora, specialmente nella parte superiore del Liguriano, sabbie, breccie e conglomerati, disposti in banchi più o meno interrotti.

Il Lignriano del bacino piemontese è quindi da considerarsi in massima come veramente di tipo appenninico sia litologica- 
mente che paleontologicamente, eccetto che negli appennini liguri dove assume piuttosto la facies del Flysch alpino. Riguardo ai fossili il Liguriano presenta quasi solo le note impronte di Helminthoidea e di Fucoidi e rarissimamente invece resti di Nummulitidee; in potenza questo terreno pare che sia talora superiore ai 2000 metri, forse anzi raggiungendo i 3000 in alcune regioni limitrofe a quella studiata. Quanto all'elevazione che presenta il Liguriano ora esaminato essa è assai piccola, per lo più inferiore ai 400 metri; notiamo però come in alcuni punti degli Appennini questo terreno s'innalzi oltre i 1000 metri e come anzi nelle vicine Alpi Marittime si spinga sin quasi ai 3000 metri.

Si è notato infine come le argille scagliose brunastre o variegate del Liguriano superiore passino talora gradatissimamente ai banchi inferiori del Bartoniano.

\section{CAPITOLO IV.}

\section{Forimazion ofiomtiche del Liguriano.}

Per quanto le formazion: clse passerò ora ad esaminare facciano parte, a mio parere, del piano Liguriano, pure per i loro caratteri così spiccati e per le questioni varie che loro si collegano credetti opportuno di descriverle in un capitolo speciale. Avverto però subito che trattandosi di lenti pochissimo estese nel bacino terziario del Piemonte e quindi poco importanti per la sua costituzione, mi limiterò a pochi cenni a loro riguardo senza entrare in un minuto dettaglio sulla loro natura e sulla loro origine.

D'altronde, a dire il vero, le formazioni ofiolitiche della regione in esame sono talmente simili a quelle dell'Appennino, e di queste si è già tanto e da tanti autori e da tanto tempo trattato che io credo inutile di fare ora lunghe considerazioni a loro riguardo. 
Delle Serpentine e roccie affini clie appaiono nei dintorni di Voltaggio ebbero già ad occuparsi l'Issel, lo Zaccagna, il Taramelli ed io stesso, risultandone idee abbastanza conformi, solo che come già ebbi ad osservare, non credo accettabile la deno. minazione di Infraliguriano all'orizzonte geologico che comprende le roccie ofiolitiche, e ciò per le ragioni sovraesposte, tanto più che lo stesso appellativo liguriano è piuttosto da attribuirsi ad una facies speciale di orizzonti diversi, che non ad un vero piano geologico generale. Alle formazioni serpentinose del Tortonese già accennò in un suo lavoro ii Taramelli.

Quanto alle ofioliti dei colli Torino-Valenza, già il Pareto accennò vagamente, e più nettamente il Gastaldi, a quelle che affiorano presso Piancerreto; nessuno finora conobbe quelle di rio Freddo sotto Albugnano.

Giova osservare che la distribuzione geografica dei quattro principali affioramenti ofiolitici del bacino terziario del Piemonte sembra accompagnare l'andamento generale a conca del Liguriano piemontese, per modo che si può presumere che queste formazioni trovinsi, nelle varie località, a livelli non molto diversi rispetto alla serie stratigrafica del Liguriano e forse nella sua parte medio-inferiore, quantunque la comparsa sporadica degli affioramenti ofiolitici delle colline Torino-Valenza, senza che se ne possano constatare i rapporti colle formazioni liguriane circostanti, renda impossibile una sicura affermazione a questo proposito.

Quanto ai rapporti che presentano gli affioramenti serpentinosi coi terreni circostanti, essi sono specialmente interessanti e chiari nei dintorni di Voltaggio, dove si può osserrare molto bene che $\mathrm{i}$ banchi ofiolitici sono interstratificati cogli argilloschisti talcosi e colle altre formazioni del Flysch, fatto assai importante come quello clie delimita nettamente l'età di queste lenti rocciose, abbattendo completamente l'opinione che esse appartengano ad orizzonti preterziarî. Tuttaria là dore queste ofioliti liguriane appoggiansi a quelle antiche rimangono talrolta ancora dei dubbi nella loro delimitazione. 
Degli afforamenti ofiolitici (già esaminati in un precedente lavoro) che appaiono presso Voltaggio nel Liguriano, alcuni hanno uno sviluppo assai considerevole, come ad esempio quello clie dal M. Lagoscuro pare continuarsi più o meno potente ed irregolarmente suddiviso sin alla Valle Frasco, e quello che, con forma assai irregolare, compare in Val di Lemno, nelle vicinanze dello sbocco del torrente di Acquastriata; questi affioramenti sono per lo più interstratificati a banchi fortissimamente rialzati, durissimi e di natura alquanto diversa da quella del Flysch tipico. Altri affioramenti invece costituiscono solo delle piccole lenti, talora appena segnabili sulle carte; così ad esempio: quella che trovasi sulla cresta tra C. Uogo e la Val Lemno a Nord di Voltaggio; i due spuntoni serpentinosi esistenti verso la parte terminale di Val Morsone presso lo stabilimento di bagni e sotto lo stradone che conduce a Carrosio; più sviluppata è la zona ofiolitica del Rio rirasso, che è separata dal calcare triassico per inezzo di pochi straterelli di argilloschisti talcoso-arenacei; pure notevoli sono gli affioramenti lentiformi di Serpentina che si osservano presso Voltaggio, cioè uno nell'alveo del T. Lemno e due lungo la strada che sale a Castagnola; più sviluppato è il banco ofiolitico che appare sulla destra di Val Lemno ad Est di M. Lagoscuro; osservai poi ancora di recente fra gli argilloschisti talcosi un piccolo affioramento di Serpentina (di un bellissimo color verde-erba) in Val Paganino, precisamente là dove il Tongriano appoggiasi sul $\mathrm{Li}$ guriano. Un afforamento simile esiste pure mezzo chilometro ad Ovest di C. Scietti; inoltre notai in Rio Morsone alle falde delle cave di calcare triassico, un piccolo spuntone ofiolitico, che pare però avvolto da calceschisti ed argilloschisti arenacei, fortemente contorti, del Liguriano; noto per ultimo uno spuntone ofiolitico assai spiccato, quantunque piccolo, che osservasi fra gli argilloschisti liguriani, ma assai distante dal descritto allineamento delle ofioliti di Toltaggio, cioè sulla destra di Val Traversa ad Est di C. Rivera.

In complesso le accenmate ofioliti liguriane delle vicinanze 
di Voltaggio offrono, come carattere generale, una lucentezza alquanto grassa, un colore verde erba assai bello, specialmente nelle piccole lenti affioranti fra gli argilloschisti talcosi grigioplumbei a Sud-Est di Voltaggio (ma negli altri casi passante ad un verde scuro ed a varie sfumature indefinibili); presentano sovente una frattura abbastanza facile e che dà origine generalmente a scaglie piuttosto che non a frammenti irregolari; inoltre una relativa ricchezza in minerali di rame e di ferro, specialmente pirite, calcopirite, magnetite, ecc. La minor durezza e compattezza delle serpentine liguriane, rispetto a quelle preterziarie, è una delle cause per cui quelle formano dei rilievi molto meno elevati di queste.

Oltre alle vere ofioliti nei dintorni di Voltaggio osservansi, specialmente in Val Lemno verso i Molini, delle oficalci e delle roccie pseudo-cristalline svariatissime, le quali paiono collegarsi alle Serpentine e clie dall' Issel e dal Mazzuoli sono appellate anfimorfiche.

Nelle colline tortonesi il Liguriano manca assolutaniente di affioramenti ofiolitici, almeno nelle regioni in esame, sino in Val Curone a Sud di Volpedo; quivi, nella parte interna di quella specie di centro di sollevamento a cui ebbi già più volte ad accennare, frammezzo alle argille scagliose, a banchi calcarei ed arenacei ed a conglomerati-breccie di varia natura, e con completo disordine stratigrafico, vedonsi affiorare in diversi punti alla destra della valle, sotto Cà di Bruno e presso C. de! Tasso, poco anpi spuntoni ofiolitici. Questi lanno una facies alquanto diversa da quella delle ofioliti di Voltaggio ed invece affatto simile a quella che offrono generalmente gli afforamenti serpentinosi dell'Appennino, sia per la distribuzione che per la costituzione, non presentandosi essi in veri banchi, ma piuttosto in lenti irregolarissime, ed essendo costituiti, nou solo da vera Serpentina con superficie lucente, come di solito, ma eziandio da Diabasi più o meno profondamente alterate (Gabbro) e da roccie eufotidiclie spesso talmente decomposte ed alterate da essere difficilmente definibili; in questi spuntoni ofiolitici, quan- 
tunque per lo più di color verde, si osserva in più punti, specialmente nel Gabbro, un color rosso vino assai spiccato e caratteristico (il ben noto Gabbro rosso dei geologi toscani).

Dei sette piccoli affioramenti ofiolitici di Volpedo, il maggiore non raggiunge un chilometro di sviluppo, ed è quello clie da sotto Ca di Bruno si protende sino al fondo di Rio della Serena, ed è, come di solito, circondato da roccie anfimorficlie e pseudo-conglomeraticlie.

In tutta l'ampia regione collinosa Torino-Valenza, for'se per la generale ristrettezza delle zone liguriane, veggonsi in due sole località affioramenti ofiolitici, con caratteri simili piuttosto a quelli di Volpedo che non a quelli di Voltaggio.

Nelle colline di Casale, sulla destra in Tal Stura, a Sud di borgata Cerrina, e più precisamente sul lato settentrionale della strada che dalla borgata Piancerreto conduce al colle di C. Ramengo, frammezzo a potenti conglomerati, arenarie e marne tongriane, osservansi due lunghe e strette lenti di Serpentina bastitica di un color verde-scuro con rilegatura a pasta pure serpentinosa, ma di color verde-erba e costituente un intreccio, una reticolatura molto irregolare, tanto che talora la roccia appare come una vera breccia.

Parrebbe a primo tratto abbastanza curioso e difficile a spiegarsi la comparsa di roccie serpentinose frammezzo ai depositi oligocenici, tanto che il Gastaldi ritenendole molto antiche le paragonò a quelle preterziarie delle Alpi e dell'Appennino Ligure, dove esse sono pure direttamente coperte dai terreni tongriani.

Ma osservando un po' più in complesso i due accennati afforamenti serpentinosi fusiformi, vediamo anzitutto cle sono tra loro vicinissimi ed ambedue diretti ad un dipresso da NordOvest a Sud-Est, per modo che probabilmente tolto il sottile velo di terreno tongriano che li separa, essi costituirebbero una lente sola della lunghezza di quasi 800 metri, con una larghezza di circa 50 metri; ma oltre a questo ciò clie riesce assai importante è che, se prolunghiamo idealmente questa lente serpentinosa secondo il suo asse, incontriamo verso Nord-Ovest, 
dopo appena 300 metri circa, Je tipiche argille scagliose $7 i$ guriane di Cortenova, e verso Sud-Est, dopo poco più di un kilon., l'affioramento lentiforme delle argille scagliose liguriane di Ponzano, anch'esse dirette da Nord-Orest a Sud-Est.

Da tutto ciò io credo poter concludere che gli affioramenti serpentinosi di Piancerreto sono certamente da riferirsi al Liguriano e che il trovarsi essi attualmente distaccati in apparenza dalle argille scagliose eoceniche, di cui realmente fanno parte essendone inglobati, ed il presentarsi essi ora completamente ravolti da depositi tongriani dipende specialmente dalla loro resistenza molto maggiore a quella delle argille liguriane.

In complesso poi risulta anche assai nettamente che le lenti ofiolitiche del Liguriano dei colli Torino-Talenza stratigraficamente sono abbastanza concordanti coll'andamento stratigrafico dell'eocene e quindi, probabilmente sono, od erano originariamente, interstratificati ai bancli liguriani.

L'altra località, più ad Ovest, clıe presenta lenti ofiolitiche è la valle di Rio Freddo fra Albugnano, Marmorito e Cocconato. Quivi, in fondo alla valle presso l'alveo del rio trovasi dapprima, immediatamente a Sud del Molino di Rio Freddo, allo sbocco di un torrentello confluente di destra, una lente, della lunghezza di pochi metri (tanto da parere quasi solo un ammasso di grossi massi erratici) di una roccia diabasica, a struttura spesso brecciosa, in generale profondanente alterata $\left(G a b b r^{\circ}\right)$ e quindi di color rosso-vinato, come già si osservò per le ofioliti di Volpedo. Duecento metri circa più a Sud si incontra una seconda piccolissima lente ofiolitica rappresentata pure specialmente da Diabase alterata a struttura brecciosa, ma quivi, meglio che nello spuntone sovraccennato, osservasi talora la massa diabasica passare ad una roccia ofiolitica.

Infine, circa 700 metri a Sud del Molino di Rio Freddo, pure presso l'alveo del rio, si osserva un terzo (anch'esso piccolissimo) affioramento di Diabase, abbastanza compatta nello assieme, a frattura concoide, ma talmente alterata da esser rigabile coll'unghia come se fosse pietra ollare; ri si trorano spesso 
inglobati cristalli di Crisotilo e la roccia passa talora anche a vera Serpentina; questa lente diabasica viene coperta verso Ovest da una specie d'arenaria serpentinosa passante superiormente ad un'arenaria quarzoso-calcalea, a fini elementi, di color grigio rosso, alquanto fogliettata, molto dura, che si può paragonare assai bene al vero Macigno eocenico.

Noto infine che nella parte superiore del Liguriano nelle colline di Lauriano-Brozolo, specialmente tra Val Mezzana e Vul Monteu, osservai blocchi di un granito roseo, breccioso, che, quantunque non in posto, dubito fosse interstratificato nelle argille scagliose.

Secondo l'Issel vi sarebbero pure formazioni asiolitiche lignrianc presso Rivara Canavese.

Riassumendo le osservazioni esposte in questo capitolo possiamo dunque dire come nella regione in esame, oltre alle formazioni ofiolitiche che (quantunque alle falde delle Alpi Marittime e dell'Appennino settentrionale trovinsi in contatto diretto coi terreni terziarî) sono da considerarsi assolutamente come preterziarie, sonvene eziandio di quelle ascrivibili veramente al terziario e più precisamente alla parte medio inferiore del Liguriano, senza che però si possa accertare se tutte appartengano ad un dipresso, ad uno stesso orizzonte, oppure ad orizzonti diversi del Liguriano.

Le formazioni ofiolitiche terziarie del bacino piemontese sono rappresentate da veri banchi o da lenti regolari di Serpentina nettamente interstratificata agli argilloschisti taicosi del Liguriano, come presso Voltaggio, oppure da lenti per lo più irregolari di Serpentina o di Diabase (spesso profondamente alterate o Gabbro), emergenti per erosione fra le argille scagliose liguriane, come nelle colline di Volpedo e di Torino-Valenza.

In complesso possiamo osservare che la semielisse risultante dalla riunione ideale delle quattro regioni ofiolitiche del bacino terziario del Piemonte, accompagna abbastanza bene l'andamento statigrafico del Liguriano di questo bacino. 


\section{CAPITOLO IV.}

\section{Gassiniano (Bartoniano?)}

Studi anteriori.

Siccome i terreni che rappresentano questo orizzonte geologico sono pochissimo estesi in Piemonte, anzi finora se ne conosceva un solo affioramento, quello di Gassino presso Torino, così pochi sono gli autori che se ne ebbero ad occupare; è tuttavia noterole come tra questi pochi divergentissime fossero le opinioni, giacchè mentre il Collegno, che primo studiò accuratamente questa formazione; ed il Portis, che ne ebbe ultimamente a trattare, la considerano come eocenica, in generale invece dagli altri geologi, come Mayer, Sismonda; Fuchs; eec., venne creduta appartenere al Miocene.

\section{Considerazioni pretiminari.}

Allorchè alcuni anni or sono intrapresi lo studio delle colline torinesi, esaminando la zona calcarifera di Gassino, per la sua facies e per la sua ricchissima e tipica fauna, non dubitai di porla nel piano Bartoniano, piano che da tutti i geologi si ritenne finora inferiore alle argille scagliose; al Flysch, ecc., cioè al piano Liguriano.

Ma proseguendo gli studii geologici dalle colline torinesi verso Est ebbi gradatamente a constatare i seguenti fatti, che esainineremo particolarmente in seguito: 1. In molti punti gli strati colla fauna di Gassino, cioè colla tipica fauna bartoniona, si vedono star sopra alle argille scagliose, al Flysch ed agli altri depositi tipici del Ligmiano, senza che vi si possa assolutamente supporre un rovesciamento stratigrafico. 2. Mai ebbi ad osservare i depositi del Liguriano sopra quelli del Bartoniano. 
3. In diversi punti ho potuto verificare banchi di ciottoli di Calcare alberese, di Flysch e di Macigno liguriani frammezzo alle marne zeppe di fossili della tipica fauna bartoniana. $4 .^{\circ}$ Per regioni estesissime osservai il Bartoniano superiore passare in modo graduatissimo, paleontologicamente e litologicamente, al Tongriano inferiore, mentre il Bartoniano inferiore forma pure talora una transizione insensibilissima al Liguriano superiore. 5. Nei conglomerati tongriani che giacciono sopra alla formazione bartoniana non incontrai mai un ciottolo di calcare bartoniano (orizzonte che doveva essere ancora sottomare durante l'epoca tongriana) mentre vi abbondano i ciottoli di Calcare alberese, di Macigno, ecc., cioè del Liguriano allora già emerso in parte. $6 .^{\circ}$ La fauna della formazione bartoniana, se in massima parte ha carattere eocenico, presenta però eziandio molti punti di somiglianza con quella oligocenica.

Da questi principali fatti che potei constatare de visu, io deduco che in Piemonte, come d'altronde, io credo, anclie altrove in generale, ciò che si è convenuto chiamar Bartoniano sta sopra a ciò che appellasi Liguriano e non sotto ad esso come si ritenne finora.

Siccome però sono per ora ancora poco sicuri i parallellismi tra i depositi di regioni molto lontane, e non sono certo cle la formazione in questione (a Nummuliti, Orbitoidi, ecc.), sia perfettamente sincrona col Bartonthon d'Inghilterra o col Wemmeliano del Belgio e siccome forse altri non vorrà mantenere, per depositi superiori al cosidetto Liguriano, il nome di Bartoniano che si era sinora soliti porre sotto detto Liguriano, così provvisoriamente mi trovo obbligato a dare ai depositi sovraccennati di Gassino, ecc. un nome speciale, Gassiniano.

Ma per non ingenerare, con nomi nuovi, una certa confusione nel lettore, continuerò ad usare l'appellativo di Bartoniano, finchè sia posto in chiaro se questi diversi orizzonti, il Bartoniano, il Wemmetiano ed il Gassiniano siano sincroni, come inclinerei a credere, oppure se non lo sono.

In conclusione il Gassiniano, paragonabile molto bene a parte 
dei famosi depositi italiani di Priabona, di Buttrio, di Brendola ecc., sta alla sommità dell'Eocene, tra il Tongriano ed il Liguriano.

\section{Generalita.}

Due principali sono le facies con cui si presenta l'orizzonte bartoniano in Piemonte e le ebbi ambidue a constatare in quasi tutte le località dove questo terreno viene a giorno, cioè una facies di marne grigiastre facilmente frammentabili e smottabili e, più raramente, una facies di calcari più o meno arenacei, biancastri, resistenti.

Generalmente gli strati marnosi si alternano ripetutamente coi banchi calcarei e, quantunque nel complesso si possano distinguere assai bene gli uni dagili altri, all' esame minuto però presentano quasi sempre tra di loro un passaggio graduale, os-

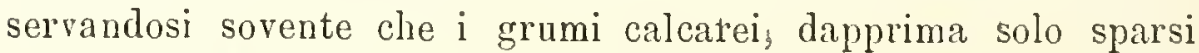
fra le marne, divengono sempre piâ frequenti in una data direzione, finchè passano a costituire veri banchi di calcare, con poca marna interposta a straterelli o ad accentramenti irregolari.

Spesso sia la marna che i calcari sono commisti a materiali sabbioso-marnosi. Talora poi, specialmente verso la parte superiore del Burtoniano, appaiono dei veri banchi arenarei passanti anche a ghiaie, spesso fortemente cementate dagl'inclusi calcari organici; questi strati sabbiosi sono dei veri depositi di litto= rale, ciò che è dimostrato non solo dai fossili clie contengono ma anche da un gran numero d'impronte organiche (specialmente di fucoidij ed inorganiche svariatissime che osservansi sulla loro superficie, impronte che sappiamo caratterizzare appunto i bassi fondi marini. Talvolta si osservano anclie fra le marne sottili banchi ciottolosi, per lo più zeppi in Nummulitidee.

Talora i bancli marnoso-arenacei sono legrermente nerastri; in basso diventano per lo più rossastri o bleuastri; comunemente fra le marne grigie o gligio-bluastre osservansi in ogni senso vene o straterelli di calcare spatizzato a struttura fibrosa: 


\section{Caratteri paleontologici.}

Lasciando alla parte III di questo lavoro l'enumerazione delle forme fossili raccolte nei terreni bartoniani ma che però sgraziatamente sono ancora in gran parte da determinarsi, indicherò qui solo i fossili più caratteristici che vi si incontrano e che servirono tanto efficacemente a determinare la vera e tanto contrastata posizione stratigrafica di questi depositi.

Senza tener conto delle numerose Carpoliti, degli abbondanti Lithothamnium e Zoophycos e degli altri resti vegetali riscontrati nel Bartoniano di Gassino, sono importanti a notarsi fra i Foraminiferi l'Orbitoides stellata, l'O. radians, l'O. papyracea, l'O. priabonensis, l'O.'stella, ecc., la Nummulites complanata, la N. Tchihatcheffi, la N. Boucheri, la N. Guettardi, la N. variolaria, la $N$. Roualti, la $N$. biarritzensis, la $N$. lueasana, la N. Saecoi, ecc.; fra gli Antozoi le Dasyphyllia, ecc.; fra i Crinoidei il Conocrinus Suessi; fra gli Echinodermi i numerosi Echinanthus ed Eehinolampas; fra i Vermi la Serpula spirulea; fra i Brachiopodi le Rhynchonella; fra i Molluschi l'Ostraea gigantea; fra i Vertebrati numerosi denti di Carcharodon, Oxy= rhina, Lamna, ecc.

Lo stato di conservazione dei fossili è molto vario a seconda della località e della natura litologica dei banchi in cui essi sono compresi; i fossili meglio conservati sono quelli clie trovansi sciolti fra le marne frammentarie, quando però essi non vi sono ridotti quasi solo più allo stato di semplice impronta, come per lo più si verifica pei resti vegetali; talvolta $i$ fossili sono alquanto schiacciati come talora si riscontra in alcuni Molluschi.

Assai ben conservati sono generalmente i fossili racchiusi nei banchi calcarei, ma, oltre ad essere in tal caso difficili ad isolare, occorrono spesso lunghi e faticosi lavori di ricerca per rintracciarli; ciò dicasi specialmente per i denti di pesce e gli Echinodermi, giacchè invece le Nummuliti, le Orbitoidi ed i Lithothamium sono i fossili che direttamente o indirettamente 
costituiscono la massima parte del materiale calcareo e possonsi quasi ovunque osservare in sezioni svariatissime.

In certi letti arenacei o marnosi si possono eziandio rintracciare i Lithothamninm facilmente liberabili dal materiale arvolgente ed uniti a resti di Molluschi e di Crostacei di littorale.

Noto infine che la lista dei fossili bartoniani che ho indicato nella parte III di questo lavoro è certamente molto incompleta, non solo a causa del trovarsi continuamente dei nuovi fossili, ciò che si rerifica per tutti i terreni, ma specialmente perchè anche i fossili che si posseggono furono imperfettamente studiati, di modo che, soltanto per dare un'idea complessiva di tale fauna, ho dovuto indicarne alcuni con determinazione solo approssimativa ed altri colla soli base delle citazioni fatte dagli autori che mi precedettero, in attesa e colla speranza di un lavoro paleontologico speciale.

\section{Distribuzione geografica.}

Il Bartoniano nel bacino terziario del Piemonte appare in diversi punti delle colline tortonesi e di quelle di Torino-Casale, ma occupa quasi sempre delle aree piuttosto allungate ma assai limitate in larghezza. Nei colli tortonesi vediamo comparire lembi bartoniani a Merlazzina, S. Giorgio, Giarella, ecc.

Nei colli Torino-Casale il più orientale affioramento di questo interessante terreno trovasi presso la borgata Raviara, a NordOrest di Ottiglio, e lo descriverò quindi d'or innanzi col nome di quest'ultimo paese.

Il secondo spuntone di Bartoniano osservasi in Valle Stura e sporge a destra e sinistra del torrente tra la borgata Cortenova ed il paese di Montalero il cui nome ci servirà quindi per indicare questo lembo di terreno eocenico.

Un'ampia zona bartoniano esiste tra Oddalengo grande e Brozolo, costituendo glan parte delle colline delle borgate S. Antonio nuoro e vecchio; si sviluppa poi estesissimamente attorno alle ampie aree Iiguriane di Verrua Savoia, Brozolo, Brusasco, Monteu, Piazzo e Lauriano. 
Una stretta zona vedesi pure sovrapporsi al Liguriano di Marmorito-Cocconato. Un piccolo spuntone di questo terreno osservasi ancora allo sbocco di Val S. Genesio nelle colline a Sud di Chivasso.

Finalmente il più occidentale ed anche il più fossilifero affioramento di Bartoniano che trovasi poco lungi da Torino nella valle di Bardassano e nella valle Maggiore di Gassino è già da lungo tempo conosciuto sotto il nome di quest'ultimo paese.

\section{Tettonica.}

I banchi bartoniani di Merlazzina pendono di $30^{\circ}$ a $40^{\circ}$ verso Ovest circa; quelli di S. Giorgio-Casasco inclinano invece a Nord, mentre le marne contemporanee di Giarella pendono di circa $50^{\circ}$ verso il Sud ad un dipresso. Il Bartoniano di Ottiglio, quantunque, per essere in gran parte costituito di marne a stratificazione poco evidente sia difficile a studiarsi sotto il rispetto della tettonica, tuttavia dall'aridamento e dalla direzione dei suoi banchi calcarei esso pare essere costituito di strati quasi verticali con direzione abbastanza regolare da Nord-Ovest e Sud-Est circa, ciò che d'altronde concorda assai bene con quello che osservasi nei circostanti terreni oligocenici.

Ancor più difficile è il determinare la stratigrafia del Bartoniano di Montalero, la quale si può tuttavia approssimativamente dedurre dall'allineamento degli affioramenti calcarei, oltre che dalla tettonica dei bancli oligocenici che appoggiansi più o meno direttamente su questo terreno eocenico; orbene da tali osservazioni risulta essere i banchi bartoniani piuttosto fortemente sollevati e diretti ad un dipresso da Nord a Sud.

Gli strati bartoniani dell'affioramento di S. Antonio sono in parte fortemente drizzati e diretti ad un dipresso da Est ad Ovest, come nelle colline a Nord di S. Antonio nuovo, ed in parte invece poco inclinati come nell'alta valle della Marca ed in Val d'Aime presso C. Nuova.

Nella grande zona bartoniana di Verrua, Brozolo, Lavriano, 
come in quella piccola di Marmorito, i banchi sono per lo più fortemente sollevati, anche portati alla verticale in qualche caso, ma conservano in generale un andamento assai regolare e concordante con quello degli orizzonti fra cui sono inclusi, specialmente col Tongriano.

I banchi del Bartoniuno di Val S. Genesio sono per lo più drizzati quasi alla verticale e diretti in complesso da Est ad Ovest, quantunque con forti varianti.

Relativamente più facile è l'esame stratigrafico del Bartoniano di Gassino, giacchè, facendo astrazione dalle perturbazioni locali, che possonsi osservare assai bene negli scavi profondi fatti per l'estrazione del Calcare, in complesso si vede che gli strati sono assai regolarmente, quantunque per lo più fortissimamente, sollevati od anche rerticali, ma che alle due estremità opposte del loro elissoide di affioramento l'inclinazione degli strati è meno potente, specialmente dal lato occidentale.

Quanto alla direzione dei banchi essa è in generale quella stessa che presenta l'allungatissima e stretta loro area di affioramento, cioè da Nord-Est a Sud-Ovest circa, solo che alle due estremiti tale direzione pare modificarsi alquanto e gli strati tendono a costituire una curva che accompagna precisamente l'ellissoide di sollevamento; infine quanto alla inclinazione si può dire che in complesso, tirando una linea mediana attraverso l'asse maggiore dell'area bartoniana di Gassino, i banchi a Sud di questa linea pendono verso Sud-Est, mentre quelli del lato opposto pendono a Nord-Orest, però con molte alterazioni locali.

Riassumendo quindi possiamo dire che mentre per osservazioni troppo localizzate parve generalmente ai geologi conturbatissima la tettonica del Bartoniano di Gassino, osservata in complesso in questa regione, come in tutto il resto del Pienonte, essa è invece di una regolarità guasi perfetta.

Le località presso Gassino dore più chiaramente si può osservare l'andamento stratigrafico dei banchi bartoniani sono: l'alveo del torrente Maggiore di Bardassano, i dintorni delle care di Gassino, ma specialmente tutta la porzione più orien- 
tale dell'affioramento in esame, dalla valle Maggiore di Gassino a C. Laurente, poichè quivi i duri banchi arenaceo-calcari messi bene allo scoperto dalle erosioni ci mostrano stupendamente la loro regolare direzione ed inclinazione.

Potenza.

Essendo pochi e poco estesi gli affioramenti bartoniani del Piemonte, è difficile indicare la potenza massima di questo orizzonte. Per quanto però si può osservare nelle colline di S. Antonio-Lauriano e presso Gassino, dove è completa l'emersione del Bartoniano, io credo che si possa considerare il suo massimo spessore come di circa 250 metri.

\section{Altimetria.}

Affiorando i lembi bartoniani solo nelle colline tortonesi e nelle colline Torino-Casale e non lungo le falde alpine, essi non possono raggiungere elevazioni molto notevoli, tanto più poi a causa della loro piccola area di emersione e per essere soggiacenti a quasi tutti gli altri terreni terziarî.

Le marne bartonicue di Merlazzina sono portate sino a 600 metri circa d'elevazione; assai più basse sono le altre zone di questo orizzonte; lo spuntone bartoniano di Ottiglio si solleva solo a 285 metri presso C. Spinosa alta, quello di Montalero raggiunge appena, presso questo paese, $250 \mathrm{~m}$.; la zona bartoniana delle colline S. Antonio-Lauriano elevasi raramente sopra ai 400 metri, come a borgata Valeisa; quella poi di Gassino arriva sino a 425 metri presso C. Caviglione, sulla destra della valle Maggiore di Gassino, a 415 metri presso C. Battaina sulla sinistra dell'indicato colle, ed a circa 400 metri a Sud della Cappella della Trinità. 


\section{Rapporto coi terreni sotto e soprastanti.}

Come si è già fatto osservare, mentre finora si credette che il Bartoniano stesse sotto al Liguriano, i rapporti chiarissimi che veggonsi in Piemonte mi indussero invece a portarlo som a al detto piano. In alcuni punti dei colli tortonesi, specialmente presso la borgata Merlazzina, si vede abbastanza bene il passaggio tra il Bartoniano ed i terreni fra cui è incluso, presentandosi la seguente serie:

$\begin{array}{cl}\text { Tongriano } & \text { Arenarie e conglomerati in banchi potentis- } \\ \text { simi con interstrati marnosi; } & \\ \text { Sestiano } & \left\{\begin{array}{c}\text { Banchi arenaceo-marnosi con strato calcareo } \\ \text { a Lithothammium, Nimmultes vasca, } N . \\ \text { Boncheri, ecc. }\end{array}\right. \\ \text { Bartoniano } & \left\{\begin{array}{c}\text { Argille marnose brune, riolacescenti, con } \\ \text { straterelli calcarei } \\ \text { Narne grigio-verdastre, smottabili } \\ \text { Alternanza di banchi marnosi ed arenaceo- } \\ \text { sabbiosi, grigio-verdicci }\end{array}\right. \\ & - \text { Argille scagliose nerastre con calcare albe- } \\ \text { rese e Macigno. }\end{array}$

Ma mentre qui pare che vi sia ancora un po' di hyatus tra. il Bartoniano ed il Liguriano, nelle colline torinesi si può in molti punti osservare fra essi un passaggio graduatissimo per mezzo di marne argillose grigio-bleuastre, violacescenti, oppure verdastre o di color rossiccio, includenti gia spesso lenti o straterelli di calcare alberese o di arenaria, per modo che sorente riesce difficile il decidere se tali banchi, talora con puddinghe nummulitifere, sono da attribuirsi all'uno piuttosto che all'altro orizzonte geologico. Questi fenomeni si possono esaminare bene nelle colline di Cortiglione-Brozolo, ma specialmente poi nei ralloni di S. Fede, di Monteu da Po e di Lauriano, dore si osserva 
spesso stupendamente la transizione insensibile da un orizzonte all'altro.

Quanto ai rapporti della formazione bartoniana coi terreni sovrastanti essi sono assai diversi secondo le varie località in cui tale terreno viene a giorno.

Nelle colline torinesi, là dove appare per breve tratto, il Bartoniano è abbastanza concordante statigraficamente coi sovrastanti terreni sestiani o tongriani, passando gradatanente ai primi ed invece essendo diviso dai secondi per un piccolo hyatus.

Mentre nelle colline casalesi gli afforamenti bartoniani, pur concordando abbastanza coi depositi oligocenici superiori, ne sono separati generalmente per mezzo di una lacuna più o meno notevole, invece nelle colline da Oddalengo grande a Lauriano e nella parte occidentale dell' affioramento di Gassino vi è generalmente un passaggio graduatissimo, sia paleontologico che litologico, al Tongriano, per mezzo di banchi intermedi marnosoarenacei ed anche talora ghiaioso-conglomeratici che si possono inglobare nel piano Sestiano.

\section{Località fossilifere.}

Mentre le zone bartoniane del tortonese offrono solo pochi resti fossili ben conservati, tutti gli affioramenti bartoniani dei colli Torino-Casale presentano numerosi fossili; credo però opportuno di indicare precisamente dove essi sono più abbondanti affine di facilitare le future ricerche a questo scopo.

Nel Bartoniano di Ottiglio si raccolgono numerose Nummuliti, Orbitoidi, Zoantari, steli di Eucrinoidei, resti di Cidaris, Ostriche $(O$. gigantea), Pecten, Litotamnii, ecc. liberamente sciolti nelle marne frammentarie grigie sotto la borgata Raviara, verso il fondo della valletta; invece tali fossili con numerosissimi $L i$ thothamnium incontransi per lo più cementati nei calcari arenaceo-maruosi delle vicinanze di C. Spinosa alta, particolarmente nel piccolo rilievo che esiste a Nord di questa Cascina; è però specialmente in quest' ultima località che si può fare una rac- 
colta paleontologica molto abbondante poichè, per la disaggregazione della marna calcarea, i fossili si trovano sparsi quasi orunque sul terreno. Più rari invece sono i resti fossili fra le marne della valletta di Cascina del Gallo. Ritroviamo poi ancora la continuazione di questa stretta zona bartoniana (lunga oltre 2 chilom.) sino in val Colobrio poco lungi dalla C. Quartera, dore è specialmente rappresentata da marne grigie friabili, con pochi straterelli calcarei fossiliferi; il tutto è sollevato quasi alla verticale e solo in alcuni punti vedesi leggermente inclinato a Sud-Orest.

Nella lente bartoniana di Montalero sotto i casali Cortenora trovansi sparsi fra le marne grigie lenti calcaree irregolari costituite in gran parte di Lithothamnium e di Nummulitidee, clie talora rinvengonsi pure isolate; invece sul fianco sinistro di Tal Stura all'estremità piủ occidentale dell'affioramento fin quasi sotto il paese di Montalero si osserva una marna grigiastra zeppa di grumuli calcarei molto irregolari e di numerosissimi fossili, specialmente nummulitoidei, che facilmente si liberano dalla marna arrolgente.

Nell'ampia zona bartoniana di S. Antonio, oltre ai soliti straterelli calcarei riccamente fossiliferi, si possono fare abbondanti raccolte di fossili liberi specialmente nell' alto delle colline a Nord di S. Antonio nuovo e qua e lia al fondo del rallone della Marca sotto Vallarolo, nonchè negli scoscendimenti di C. Nilora ed ovunque si incontrano banchi fossiliferi poveri in calcare e da lungo tempo esposti agli agenti atmosferici.

Più ad Ovest, è specialmente nell'alta Val Caserralle tra borgata Valeisa ed il Bric Pollone che potei far raccolta di una gran quantità di Nummuliti, Orbitoidi, ecc., perfettamente liberi e ben conservati; si trovano pure altre localita fossilifere tra Brozolo e Lauriano, spesso con grossi Zoopluycos, come presso C. Molina in Val Trincavenna. Zeppo di fossili è l'affioramento bartoniuno di Val S. Genesio.

L'affioramento bartoniano di Gassino, sia perchè molto più esteso degli altri due, sia perché da lango tempo conosciuto o 
studiato, presentò finora un molto maggior numero di fossili tanto animali quanto vegetali.

I resti vegetali si raccolsero specialmente nelle marne alternate coi calcari tra Villa Aprile e Cresta Battaina; $i$ denti di Pesce si trovarono pure in massima parte in questa stessa località, ma specialmente nei banchi calcarei; gli Zoantari rinvengonsi sia sciolti che inglobati nei calcari, specialmente all'estremità orientale dell'affioramento.

I resti di Molluschi, non molto abbondanti, stanno per lo più nelle marne quasi ovunque, ma sono di rado ben conservati; le Terebratule rinvengonsi abbondantissime in certi banchi marnosi alternati coi calcari di Villa Aprile c, assieme a resti di Pesce ed a impronte di Zoophycos, sono pure comuni dentro a marne grigiastre presso Villa Donaudi, come anche presso Tetti Ballo a Sud-Est di Bussolino.

Le Nummuliti e le Orbitoidi, abbondantissime assieme ai Lithothamnium nei banchi calcarei, ma in questo caso difficilmente estraibili, si possono avere invece in buone condizioni di conservazione specialmente dai banchi marnosi e marnoso-arenacei delle vicinanze di C. Defilippi; è specialmente in questa località clıe si rinvennero resti di Nummulites complanata di grandi dimensioni assieme alla Serpula spirulea; ancora nelle cave esistenti dietro questa cascina usservansi dei banchi marnosi grigi la cui superficie è completamente ricoperta di impronte assai belle di Zoophycos.

Descrizione geologica regionale.

Nelle colline tortonesi la zona bartoniana, che appare presso Merlazzina e si prolunga verso Nord, è essenzialmente costituita di marne grigio-verdastre alternate con banchi arenacei, per modo che nell'assieme essa presenta una facies che la ravvicina alquanto al Tongriano; i suoi banchi inclinano di $30^{\circ}$ a $40^{\circ}$ verso l'Ovest e poi, più a Nord, verso il Nord-Ovest. Rimangono ancora alcuni dubbi sulla zona marnoso-arenacea di Brignano- 
Pallanzona che attribuii già al Tongriano, ma che inrece è certamente eocenica, cioè o liguriana o bartoniana; ma questa incertezza è prodotta dal fatto che la facies liguriana si estende più o meno in alto verso il Tongriano a seconda delle varie regioni. Le marne grigio-verdiccie di S. Giorgio-Casasco sono forse anche attribuibili al Bartoniano come quelle di Merlazzina, sopportando pure una potente zona di marne violacescenti. Ancora in Val Curone notiamo l'affioramento di marne grigio-verdastre, farinose presso borgata Giarella; esse hanno quivi poca potenza e pendono fortemente a Sud.

Telle colline Torino-Casale il piccolo ed irregolare spuntone bartoniano di Ottiglio, della larghezza di circa mezzo clilometro al più per due chilometri circa di massimo sviluppo, si presenta essenzialmente coștituito di marne dure, frammentarie, grigiastre, a frattura piuttosto concoide (che veggonsi specialmente verso il fondo della valletta sotto la borgata Raviara) e di lenti calcaree irregolari racchiuse nelle sopradette marne; lenti le quali cominciano ad apparire sul lato destro della valletta di Rariara, ma che divengono poi assai potenti sul suo lato sinistro tanto da formare degli spuntoni sporgenti fra le circostanti marne, costituendo poscia il rilievo a Nord di C. Spinosa alta.

Verso la valle di C. Spinosa bassa, specialmente nelle vallette a Sud di C. Boscogrande, veggonsi delle marne grigie frammentarie che debbonsi ancora attribuire al Bartoniano; d'altronde questo affioramento bartoniano per quanto stretto si vede prolungarsi sino alla Val Colobrio presso C. Quartero colle solite marne farinose ed i soliti sottili banchi calcarei zeppi di fossili.

Anche l'affioramento bartoniano di Montalero, come quello di Ottiglio, consta di marne frammentarie grigie e di calcari giallobiancastri i quali sono ben evidenti specialmente alle due estreinità dell'affioramento, inentre invece presso la Cascinetta e nelle vicinanze della Casa Comunale veggonsi assai sviluppate le marne che come di solito danno origine a scoscendimenti ricordando alquanto quelli delle argille scagliose liguritue. Nel 
mezzo della valle non si puo vedere affatto il Bartoniano perchè completamente coperto dalle alluvioni della Stura.

Le lenti calcaree clie appaiono presso Cortenova hanno precisamente l'aspetto di quelle che reggonsi nel Bartoniano di Gassino, cioè sono assai compatte, mentre quelle delle vicinanze di Montalero hanno una facies concrezionata affatto speciale; inoltre sono alquanto arenacee e spesso ridotte solo più a grumi sparsi nelle marne e sempre zeppi di Orbitoidi, Litotamni ed altri fossili.

In complesso lo spuntone bartoniano di Montalero ha uno sviluppo longitudinale di oltre un chilometro per un diametro trasversale massimo di circa 250 metri.

Alle falde settentrionali delle colline di Rocca delle DonneBrusaschetto, sulla destra del Po, veggonsi comparire, tra il $\mathrm{Li}_{\text {- }}$ guviano ed i terreni oligocenici, potenti banchi marnosi grigiastri o grigio-verdicci, affatto simili a quelli bartoniani delle colline vicine; quantunque finora non abbia ancor potuto quivi ,raccogliere dei fossili tipici, tuttavia per la posizione e per la facies credo dover attribuire le marne frammentarie sovraccennate al Bartoniano che costituirebbe qui un affioramento di circa un chilometro di sviluppo, e rappresenterebbe il termine, ad Est, dell'importante zona bartoniana che passeremo ora ad esaminare.

Nelle colline a Nord-Est di Oddalengo grande, a cominciare da Val Falsina (alta V. S. Liberata), appare la formazione bartoniana, continuazione del vicino affioramento di Montalero; come di solito essa è costituita essenzialınente di banchi marnosi grigio-giallastri, spesso alternati con strati arenaceo-calcarei molto fossiliferi, ed inglobanti pure, nella parte superiore, qualche lente ghiaiosa; anzi sono appunto questi straterelli ghiaioso-ciottolosi, atccompagnati sovente da banchi sabbiosi, che rappresentandoci il Sestiano formano il passaggio al Tongriano, con cui quindi la formazione bartoniana è generalmente assai concordante.

Nel rilievo collinoso quotato m. 363 (a N. O. di Oddalengo) i bancli bartoniani sono per lo più fortemente sollevati, con direzione ad un dipresso Est-Ovest; invece più verso occidentc 
essi assumono gradatamente un'inclinazione piuttusto dolce (cioè di $30^{\circ}$ a $10^{\circ}$ ed anche meno) generalmente verso il Nord, appoggiandosi sulla zona liguriana (in gran parte però mascherata) di Cortiglione-Vagiardi; a contatto del Liguriano di Vagiardi, che continuasi sotto l'oligocene sino ad apparire in Val Bosco, la zona bartoniana, ridotta ad una sottilissima striscia sotto il paese di S. Antonio nuovo, presenta i suoi banchi arenaceocalcarei fortissimamente sollevati. In queste regioni possonsi raccogliere abbondanti fossili bartoniani specialmente nei banchi marnoso-calcarei del Bric 363 e dell'alta Valle della Marca, ed in generale quasi ovunque là dove il materiale cementante degli strati calcarei si va disaggregando; inoltre in queste regioni si possono osservare i graduatissimi passaggi tra $B a r-$ toniano e Tongriano, sia nell'alta Val d'Arne, sulla destra, sia in più punti di Val della Narca; meno graduale è inrece la transizione al Liguriano.

Verso Ovest la formazione bartoniana si sdoppia allargandosi; la zona settentrionale, prevalentemente marnosa, grigiastra o bleuastra verso la base, talora ricchissima in Orbitoidi, Nummuliti, ecc. (come nell'alta Val Caservalle; sotto Bric Pollone), si volge gradatamente ad arco regolare verso le colline di Verrua tra il Liguriano ed il Tongriano, a cui passa gradatamente, finchè coi suoi banchi piuttosto fortemente inclinati, va a scomparire sotto le alluvioni del Po (se pure non sono in parte bartoniane le marne eoceniche affiorarti sulla sinistra del Po), per ricomparire solo molto più ad Est presso Brusasclıetto; invece la zona neridionale, assai più irregolare, essenzialnuente marnosa si sviluppa nelle colline di Brozolo; talora si presenta quasi in tasche, entro le pieghe del Liguriano, come in Tal Vardesa.

Ad Orest di Val Trincavenna la formazione bartoniana; specialmente regolare e bene sviluppata lungo il margine settentrionale dell'affioramento liguriano, è come di solito in gran parte costituita di marne grigio-verdastre, scagliose, franose, ulternate con straterelli arenacei; l'andamento stratigratico è 
complessivamente da Ovest ad Est, con pendenza di $60^{\circ}$ ad $80^{\circ}$ verso il Nord. E notevole che da borgate Praje a Marcorengo si sviluppano pure in questo orizzonte potenti banchi arenacei fortemente inclinati a Nord-Nord-Ovest. Per lo più i banchi basali del Bartoniano sono rossastri, talora con arenarie nummulitifere, e fanno spesso passaggio insensibile al Liguriano, come si osserva specialmente da borgata Majalis a Lauriano; vi si trovano pure qua e là fossili diversi, anclie Zooplıycos.

Da Lauriano la zona bartoniana, seguendo l'andamento del sottostante Liguriano, si ripiega verso Sud, finchè dopo qualche interruzione scompare definitivamente sotto l'Aquitaniano presso borgata Pareglio. Lungo questo percorso non riesce sempre facile il distinguere l'orizzonte bartoniano da quello Sestiano a cui fa graduale passaggio per alternanze di banchi arenacei e marnosi inglobanti pure fossili di transizione, come ad esempio si verifica nei letti sabbioso-arenacei, e talora anche calcarei pseudo-alberesi, presso C. Gruppetto, dove si raccolgono numerose Nummuliti ed Orbitoidi.

La continuazione di questa zona bartoniana riscontrasi ad Ovest nel vallone di S. Genesio; quivi essa, pur sviluppandosi per oltre un chilometro, è limitata al fondo della Valle e presenta quasi ovunque abbondantissimi fossili, specialmente Lithothamnium, Pentacrinus, Pecten, Conocrinus, Orbitoides (O. stella O. stellata, ecc.), Nummulites (N. Roualti, N. Boucheri, N. striata, N. Fictheli var., N. Guettardi, N. Tchihatcheffi, ecc.), Operculina, Robulina, Heterostegina, ecc. E notevole che nell'alta Val S. Genesio i banchi bartoniani più fossiliferi, in complesso drizzati quasi alla verticale e diretti da Est-Nord-Est ad Ovest-Sud-Ovest, presentano sovente irregolari lenti gliaiose e ciottolose, in parte ad elementi liguriani; vi si osservano pure locali disordini statigrafici, sorgenti sulfuree, ecc. I banchi bartoniani di S. Genesio sono in rapporto sia con banclii sestiani, sia con banchi tongriani ed in parte anzi sono direttamente coperti dall'Aquitaniano.

I'indicata zona bartoniana, diretta verso Ovest, dopo esser 
rimasta sepolta per qualche chilometro dai terreni oligocenici e miocenici, ricompare a C. Laurente, costituendo poi il famoso affioramento di Gassino che esamineremo fra poco.

Per l'affiorare dei terreni liguriani tra Cocconato e Marmorito vengono anche a giorno alcune aree di Bartoniano, che ver'so Sud è limitato ad una piccola striscia diretta da Est ad Ovest ad un dipresso, mentre dal lato settentrionale si sviluppa abbastanza ampiamente, sempre colla solita facies marnosa, farinosa; esso si può osservare bene specialmente nel profondo vallone di borgata Canuto, dove fra i banchi marnosi, inclinati di circa $60^{\circ}$ verso Nord-Orest, compaiono ripetuti strati calcareoarenacei zeppi di Lithothamnium, Nummulites, Orbitoides, ecc.

In Val Roasio il Bartoniano costituisce in gran parte $i$ valloni di C. Roasio ed offre fossili, specialmente in certi strati arenaceo-calcari, allo sbocco di Val Foreste, sotto C. Goreia. Certi banchi arenaceo-ghiaiosi tra il Liguriano ed il Bartoniano si presentano molto ricchi in Nummuliti, Assiline, Orbitoidi, ecc., così presso C. Curone, poco a Sud del molino di Braja, ecc.

Fra tutti gli affioramenti bartoniani del Piemonte l'unico finora conosciuto fu quello di Gassino. Esso raggiunge appena uno sviluppo trasversale nussimo di circa 500 metri; presenta però, secondo il suo asse maggiore, una lunghezza di quasi 6 chilometri. Nella sua estremità orientale, sotto la C. del Roc e la C. Laurente da un lato e da C. Laurente circa sin presso la C. Caviglione dall'altro, nellá parte più esterna dell'affioramento, veggonsi durissimi banchi arenaceo-ghiaiosi, fortemente sollevati ed alternati con strati marnosi frammentari; banchi che specialmente verso Nord presentano numerosi fossili ed inoltre offrono spesso alla loro superficie quelle svariatissime impronte d'origine organica ed inorganica che ci indicano un deposito formatosi a poca distanza dal littorale. E specialmente poco sotto a questi banchi arenacei che compaiono gli strati calcari.

Verso C. Defilippi predominano i banchi marnosi, portati talora quasi alla verticale, alternati con banchi calcarei (spesso zeppi di Orbitoidi, Litotamnii ed altri fossili) ora molto sottili 
ora abbastanza potenti, qua e là utilizzati, e dei quali alcuni si spingono ad Est sin presso la C. Laurente; è specialmente in certi straterelli marnoso-sabbiosi vicino ai banchi calcarei che rinvengonsi numerosi fossili facili ad estrarsi completi.

Sulla sinistra del rio Maggiore di Gassino rivediamo i banchi calcareo-arenacei alternati colle marne presso la C. Canta, e la C. Mela, ma specialmente divengono potenti a Sud di Villa Aprile, nella regione detta appunto Roc di Gassino, dove essi sono escavati su larga scala da tempo antichissimo.

Più ad Ovest prendono ull assoluto predominio $\mathrm{i}$ banchi marnosi grigiastri, sempre fortemente sollevati, che si possono studiare minutamente in particolar modo nell' alveo del torrente Maggiore di Bardassano nelle vicinanze di V. Donaudi: quivi si può osservare che colle marne grigie si alternano pure marne verde-rossiccie e straterelli sabbioso-marnosi nerastri; cosi pure marne argillose rossastre, che passano a quelle del Liguriano, veggonsi presso C. Canta e presso C. Defilippi.

\section{Riassunto.}

Concludendo su ciò che si è esposto intorno all'orizzonte Gassiniano (Bartoniano?) delle regioni in esame, possiamo dunque dire che in Piemonte questo piano appare in diversi punti nelle colline tortonesi, ma si sviluppa specialmente nelle colline Torino-Valenza. Mentre finora furono molto discordi i pareri dei geologi sull'età dell' unico affioramento finora conosciuto, quello di Gassino, risulta nettamente ora che questo terreno appartiene certamente all' Eocene superiore, probabilmente al piano Bartoniano, e sta sopra al Flysch liguriano mentre finora si credette che il Bartoniano soggiacesse a tale orizzonte.

L'esaminata formazione consta di banchi marnosi, arenacei e calcarei per lo più fortemente sollevati e abbastanza concordanti nella direzione con quelli dei terreni soprastanti, da cui però sono talora separati per mezzo di una lacuna cronologica più o meno grande. 
L'orizzonte ora studiato ha in Piemonte una potenza di almeno 200 metri, si solleva a poco più di 600 metri ed è quasi ovunque molto ricco in fossili, specialmente Orbitoidi, Nummuliti, Litotamnii, ecc. In parecchi punti si possono osservare passaggi graduatissimi tra la studiata formazione bartoniana ed il Liguriano in basso ed il Sestiano in alto. 
Sestiano.

Studî anteriori.

Siccome in generale nel Piemonte esiste un liatus alquanto profondo fra i terreni eocenici ed il Tongriano, e siccome mai sinora eransi fatti minuti rilevamenti geologici nella regione piemontese, cosi i pochi e stretti lembi di Sestiano ${ }^{1}$ che appaiono in tale regione rimasero finora completamente ignorati. Io stesso dapprima vedendoli strettamente collegati al Tongriano e quasi sempre nettamente distinti dall' Eocene, a causa di un salto nella serie stratigrafica, credetti doverli riunire colla formazione tongriana.

In seguito però, dopo che ebbi a delimitare la formazione bartoniana, tra il Liguriano ed il Tongriano, potei constatare che i depositi sestiani si collegano assai bene paleontologicamente e talora anche litologicamente col Bartoniano, presentando tuttavia nel complesso una fucies abbastanza speciale, assai simile a quella tongriana.

${ }^{1}$ Nome proposto nel 1856 dal De Rouville per i depositi gessiferi di Aix (Aquct Sextice) a Palcotherium, ecc. 
Quindi, tenuto anche conto dell'importanza grandissima che questi depositi presentano sovente altrove, credo opportuno di trattarne in un breve capitolo speciale.

\section{Generaliti.}

La facies predominante nella formazione scstiana è quella di un deposito di mare poco profondo, o di littorale, più o meno in rapporto con correnti provenienti da terra.

Cioè essa consta prevalentemente di depositi sabbioso-arenacei, spesso inglobanti lenti di lignite compattissima; talora poi si incontrano straterelli calcarei zeppi di Lithothamnium e di Molluschi littoranei.

Talvolta però $\mathrm{i}$ depositi sestiani sono rappresentati da una serie di banchi marnosi grigiastri od alquanto variegati; debbo anzi notare come in alcuni punti delle colline tortonesi il Sestiano è in parte rappresentato da argille marnose bruno-violacescenti con interstrati calcarei pseudo-albcresi, cioè la una facies complessiva che ricorda assai quella del Flysch liguriano. Questo fatto ci convince sempre più che il Flysch è una formazione speciale la quale, quantunque specialmente sviluppata nell' Eocene medio-superiore, non lia alcuna importanza stratigrafica.

\section{Caratteri palcontologici.}

Se finora i depositi sestiani del Piemonte non presentarono ancora quelle ricchezze in Filliti ed in Vertebrati che osservansi in alcune parti d'Europa, tuttavia anche dal lato paleontologico essi hanno una notevole importanza in causa dei numerosi resti di Nummulitidi che vi potei raccogliere in questi ultimi tempi.

Le Orbitoidi abbondano in modo speciale, ed hanno quasi tutte una facics spiccatamente eocenica; notasi persino una varietà delia Orbitoidcs stella; non sono rare le Hesterostegina; fra le Nummuliti abbonda specialmente la Nummultes Fichteli 
con alcune varietà, oltre a $N$. Boucheri var., $N$. vasca, N. cf. variabilis, $\lambda$. cf. variolaria, ecc.

In alcuni banchi speciali trovansi pure numerosi Lithotham. nium e Molluschi di littorale:

In complesso la fauna del Sestiano si può definire una vera fauna eo-oligocenica.

\section{Distribuzione geografica.}

Dalle colline monregalesi, lungo tutto l'Appenino settentrionale sino alle colline tortonesi, manca completamente la formazione sestiana, appogriandosi direttamente il Tongriano o sui terreni preterziari o sul Liguriano, con discordanza più o meno accentuata.

Nelle colline tortonesi appaiono qua e là lembi sestiani, alla base del Tongriano, in generale là dove $\mathrm{i}$ terreni sono meno compressi.

Nelle colline Valenza-Casale mancano di nuovo completamente i depositi sestiani verificandosi quivi un hyatus più o meno forte tra il Flysch e le argille scagliose del Liguriano ed i banchi arenacei del Tongriano.

Ma a cominciare dalle colline di Brozolo e di Verrua verso Ovest vediamo apparire qua e là lembi ed anche lunghe zone di Sestiano che affiora eziandio per qualche tratto attorno agli affioramenti eocenici isolati di Gassino e di Cocconato.

\section{Tettonica.}

I banchi sestiani seguono alquanto regolarmente l'andanento stratigrafico dei terreni tongriani e concordano pure generalmente assai bene coi depositi bartoniani; senza discendere ad un esame particolare possiamo dire che $\mathrm{i}$ banchi sestiani sono in generale molto fortemente sollevati, talora di $60^{\circ}$ ed $80^{\circ}$, come nelle colline torinesi; invece là dove queste formazioni si allargano più estesamente presentano solo più inclinazioni di $35^{\circ}$ a 
$50^{\circ}$, come per lo più verificasi nelle colline di Verrua Savoia ed in alcune parti delle colline tortonesi.

\section{Potenza.}

La poca estensione che presentano $\mathrm{i}$ depositi sestiani in Piemonte non permette ancora di giudicare quale sia la potenza di quest'orizzonte; tuttavia per quanto si può osservare in alcuni punti, credo di non esagerare indicando come essi possano oltrepassare lo spessore di una cinquantina di metri.

\section{Altimetria.}

Non comparendo il Sestiano lungo le falde alpine, esso non può raggiungere in Piemonte quelle notevoli elevazioni che quivi presentano terreni molto più recenti di esso; infatti mentre nelle colline Torino-Valenza i depositi sestiani sono portati a 400 metri di altezza, nella parte più meridionale delle colline tortonesi essi oltrepassano solo di poco i 600 metri al M. Rivarossa.

\section{Rapporto coi terreni sotto e soprastanti.}

In causa della diversa costituzione del Sestiano nei colli torinesi e nei colli tortonesi, sono pure assai diversi i rapporti che esso presenta nelle due regioni colle formazioni inferiori e superiori.

Nelle colline tortonesi, dove la serie è più completa, si può vedere che il Sestiano si collega insensibilmente tanto al Bartoniano come al Tongriano, come per esempio al M. Rivarossa. Occolre però osservare che, siccome solıo poche le regioni dove appaia questa formazione, è necessario a questo proposito di continuare lo studio verso Est affine di poter determinare più nettamente quali sono i suoi limiti inferiori e superiori.

Nelle colline Torino-Casale la formazione sestiana si vede soventissimo (specialmente tra Lauriano, Verrua e Brozolo) passare gradatamente al Burtoniano per mezzo di una ripetuta alternanza 
di bancli marnosi ed arenacei; ma l'orizzonte in esame si collega poi cosi strettamente per lo assieme dei suoi caratteri col Tongriano inferiore cle, se non fosse dei suoi fossili di tipo piuttosto eocenico, avrei creduto doverlo includere senz'altro nel piano tongriano.

\section{Localitio fossilifere.}

Nelle colline tortonesi sono finora poche le località in cui ebbi a riscontrare fossili un po' abbondanti nel Sestiano; ricorderò solo come più interessante la Valle Museglia, circa duecento metri a Sud di borgata Giara, dore si incontrano marne arenacee giallastre zeppe di Molluschi, di Nummuliti (N. vasca, N. Fichteli, N. Boucheri var.) ecc. Anche al M. Rivarossa, alla base dei conglomerati tongriani incontrasi un bellissimo banco calcareo, biancastro, appartenente al Sestiano e che è costituito di un vero impasto di Lithothamnium, di Nolluschi di littorale, di Nummuliti (N. Boucheri var., N. vasca, ecc.).

Nelle colline Torino-Casale le arenarie che rappresentano in gran parte la formazione sestiana sono spesso assai ricche in fossili, specialmente Nummulitidee, cosicchè si y,uò dire che cercando con un po' di pazienza tali fossili vi si trovano quasi ovunque. Ad ogni modo indicherò i punti che mi si presentarono finora più riccamente fossiliferi: essi sono i banchi marnosoarenacei di C. Chinoni (sinistra di alta Valle Caservalle) dove raccolsi Nummulites Fichteli, N. variabitis, N. Boucheri, diverse Orbitoidi di tipo eocenico, ecc.; alcuni banchi arenacei situati sulla sponda destra del Po, a valle del porto di Rocca delle Donne, sopra alle marne bartoniane, e che contengono pure alcune Orbitoidi di tipo eocenico; le arenarie inferiori di C. Scaglione (alta valle Ardovana) dove incontrai bellissime Orbitoidi di tipo bartoniano; le arenarie compatte di Bric Sac (presso Brusasco) dove le Orbitoidi bartoniane sono unite a Nummulites Fichteli var. Aubia ed a $N$. Boucheri var.; le sabbie e le arenarie giallastre che sostengono la parrocchia di Moriondo (presso Lauriano), dove notai pure Orbitoidi di tipo bartoniano. 
In alcuni banchi arenacei che appoggiansi al Liguriano, presso C. Gruppetto (Valle Abramo) raccolsi Nummulites Boucheri, T. sp., Orbitoides di tipo bartoniano, ecc.; quantunque nell' assieme ciò ricordi la fauna sestiuna, credo tuttavia dover porre questi banchi nel Bartoniano, attribuendo la facies sestianu alla natura sabbioso-arenacea del deposito, giacchè la costituzione litologica di un dato orizzonte influisce moltissimo sulla sua natura paleontologica.

Nelle colline di Cocconato-Marmorito potei raccogliere numerose Orbitoidi a facies eocenica nelle arenarie, poco a Sud della Cappella di S. Rocco sull'alto della collina del Bricco. Ma specialmente interessanti sono alcuni banchi sestiani marnosoarenacei che compaiono in Val Fabiasco nell'alreo del torrente di fronte al Molino del Pocco; quiri infatti ebbi più rolte occasione di raccogliere numerossime Orbitoidi di tipo bartoniano, persino una forma affine all' $O$. stella, nonchè Nummalites Fichteli var. problematica, N.cf. variolaria, Nummulites sp., Heterostegina, ecs.

Forse anche nelle colline casalesi compaiono terreni sesticun, giacchè, ad esempio, i banchi arenacei che presso C. Spinosa s'appoggiano direttamente sul Bartoniano di Ottiglio presentano una fauna di Orbitoidi e di Nummuliti assai simile a quella sopramenzionata di Bric Sac (Brusasco).

Nelle colline torinesi notiamo come al fondo della ralle di S. Genesio, in stretto rapporto colle marne bartoniane a cui fanno bellissimo passaggio, appaiono banchi sabbiosi ed arenacei sestiani molto ricchi in rarie specie di Nummulites (specialmente la $N$. Fichteli) e di Orbitories a tipo eocenico.

Le arenarie inferiori che s'appoggiano sul famoso affioramento Bartoniano di Gassino, e che sono riferibili in parte al Sestiano, presentano non di rado resti di Nummulites e di Orbitoides di tipo eocenico.

Un' interessante zona fossilifera che serve di passaggio tra il Sestiano ed il Bartoniano osservasi poco a Nord-Ovest di C. Laurente sul tipico Bartoniano di Gassino; essa è costituita di 
arenarie e conglomerati a piccoli elementi con numerosi resti di Nummulites Tchihatcheff, $N$. variolaria, Orbitoides sp. ecc.

Come ho detto sopra, con ricerche accurate è certo che si troveranno fossili quasi ovunque nel Sestiano del Piemonte. Indico ancora come questo orizzonte, se non presentò finora resti vegetali ben determinabili, racchiude però spesso lenti di lignite compatta.

\section{Descrizione gcologica regionale.}

Procedendo da Orest ad Est lungo la catena alpino-apenninica è solo nelle colline di Tortona che troviamo apparire l'orizzonte Sestiano.

Vedremo nel capitolo seguente come nei dintorni di Roccaforte ligure $\mathrm{i}$ banchi inferiori del Tongriano, essenzialmente conglomeratico, racchiudono strati marnosi lignitiferi a fossili d'acqua dolce e terreste; seguitando verso Nord questa potentissima zona tongriana in Val Borbera si vede che tra essa e le argille scagliose brune del Liguriano appaiono marne grigie, farinose, probabilmente già attribuibili al Bartoniano e marne più o meno argillose grigio-brune clie sembrano piuttosto doversi inscrivere nel Sestiano.

Questa speciale formazione si va sempre più sviluppando, verso il Nord e si può comodamente esaminare salendo da Cascina della Croce al M. Rivarossa, come ebbi già a fare notare in un lavoro speciale; solo debbo osservare come credetti dapprima trattarsi unicamente di Tongriano inferiore, mentre pare piuttosto che questi terreni speciali debbansi gia in parte attribuire all'Eocene superiore.

Nella località indicata presso la borgata Merlazzina la formazione sestianc ha uno spessore di una trentina di metri circa comprendendovi il potente complesso di argille brunastre pscudoTiguriane che quivi si sviluppano assai e che in alto comprendono uno strato calcareo ricchissimo specialmente in Nummuliti ed in Litholhamnizm; poco sopra a tale strato biancastro appaiono, 
coll banchi intermedi di passaggio, i potentissimi banchi conglomeratici del Tongriano inferiore.

La formazione sestiana continua a svilupparsi verso Vigonero, Fontanelle, Solarola, Giara, ecc., presentandosi in gran parte arenacea e racchiudendo talor'a fossili, cosi, come già indicammo, presso borgata Giara.

Riserbandomi di fare ulteriori studi su questo interessante orizzonte geologico ad Est del bacino in esame, passiamo senz'altro alle colline Valenza-Torino. Quivi per un tratto lunghissimo mancano completamente i terreni sestiani; è bensi rero che nelle colline casalesi, specialmente tra C. Spinosia alta e C. Quaranta (Val Colobrio) appaiono sopra e direttamente a Sud dalla stretta zona liguriana, alcuni banchi marnosi, arenacei ed anche conglomeratici che racchiudono una fauna a Nummuliti ed Orbitoidi la quale ricorda alquanto quella sesticna; ma per la piccolezza dell'affioramento non riesce facile il distinguere se si ha qui a fare col vero orizzonte sestiano, come parrebbe, oppure solo coi banchi inferiori del Tongriano, distinzione che d'altronde non è sempre facile a farsi anche là dove questi terreni si sviluppano un po' ampiamente; lo stesso deve ripetersi per alcuni banchi delloligocene inferiore più ad Orest.

Nelle colline di S. Antonio (Oddalengo grande) si vede cliẹ la formazione bartoniana quiri molto sviluppata presenta talora nei suoi banchi superiori alcuni strati sabbiosi ed anche alquanto ghiaiosi i quali formano il passaggio tra quest'orizzonte ed il Sestiano.

Sulla sinistra dell'alta ralle della Marca, a monte del Molino del Boschetto, possiamo osservare assai bene tale passaggio che si compie sorente per mezzo di marne bleuastre, già racchiudibili nel Barloniano superiore, che sostengono una serie di banchi arenacei ed anche arenaceo-calcarei spesso inglobanti Tummuliti, specialmente la N. Fichteli.

Questi bancli arenacei attribuibili al Sestiano si estendono noterolmente verso Ovest formando ovunque la base della formazione tongriana, il cui andamento iri seguono regolarmente, foggiandosi così ad arco nelle colline di Marcorengo-Yerrua, ecc. 
In queste regioni, riguardo all' orizzonte che ci interessa, si nota generalmente la seguente serie, molto variabile però da luogo a luogo:

Banchi arenacei e conglomeratici.

Banchi marnoso-sabbiosi di cui uno o due in- $\{$ Tongriano globano ciottoli irregolarmente disseminati.

Banchi, sovente straterellati, marnosi, sabbiosi ed arenacei alternati; spesso con Nummuliti ed Sestiano Orbitoidi.

Marne grigiastre, più o meno franose, talora racchiudenti una ricca fauna di Nummuliti, Orbitoidi e Litotamnii, a schietta facies eo-
cenica.

Come ho già fatto osservare altrove per i caratteri litologici, il Sestiano si collega strettissimamente col Tongriano, ed è quindi specialmente sulla presenza di alcune speciali forme di Nummuliti (N. Boucheri, N. variabilis) e di Orbitoidi di tipo eocenico clie dobbiamo basarci per fare l'indicata distinzione. E per esempio appunto per aver trovato alcune Orbitoidi fra certe arenarie sulla sponda destra del Po, sotto Rocca delle Donne, che suppongo affiori quivi qualche banco Sestiano tra le arenarie ed i conglomerati del Tongriano e le marne grigie friabili del Bartoniano.

Nelle colline tra. Brusasco e Lauriano possiamo riferire al Sestiano, una serie di bancli straterellati arenacei giallastri, ripetutamente alternati con strati marnosi grigio-giallicci, il tutto per lo più fortemente sollevato, cioè di $60^{\circ}, 70^{\circ}$ ed oltre, con inclinazione verso il Nord all' incirca. I banchi arenacei presentano spesso alla loro superficie quelle svariatissime impronte organiche (specialmente grosse Fucoidi) ed inorganiche che dànno alla formazione una facies, direi, eocenica.

Per ripetute alternanze questa formazione sestianc passa inferiormente alle marne friabili del Bartoniano e superiormente 
a marne, alquanto simili a quelle bartoniane, che sopportano direttamente le tipiche arenarie tongriane.

I banchi sestiani qui, come altrove, si distinguono specialmente per la loro ricchezza (almeno rispetto a certi strati) in Orbitoidi e Nummuliti, fra cui notiamo particolarmente la $N$. Fichteli var. dubia e la N. Boucheri var. incrassata.

L'orizzonte in esame si sviluppa nettamente sulla sinistra di Val Trincavenna in modo da costituire la cresta elevata di. Bric Sac $(365 \mathrm{~m}$.) e si continua poscia verso Orest, però restringendosi alquanto.

Tra Val S. Fede e Lauriano, nelle colline di C. Vignassa, di C. il Vallone, di C. Gruppetto, ecc. appaiono bensì banchi arenacei con fossili a facies alquanto simile a quella sestiana, ma per la loro posizione credo debbansi ancora riferire al Bartoniano, attribuendo la detta facies paleontologica alla natura arenacea del deposito.

Invece nella collina di Moriondo, specialmente sotto la parrocchia di questo paesello, compaiono potenti banchi sabbiosoarenacei, grigio-giallastri, inclinati di circa $44^{\circ}$ a Sud-Ovest, nei quali raccolsi Orbitoidi di tipo eocenico, per cui credo debbansi già attribuire al Sestiano; cosi pure sono probabilmente in parte sestiani gli strati arenacei, inclinati di $70^{\circ}$ circa verso il NordOvest, che appaiono sulla sinistra ed in basso di Valle Abramo a Nord-Ovest di C. Gruppetto.

In strettissimo rapporto colla sottile zona di affioramento di Bartoniano in fondo a Val S. Genesio veggonsi apparire frequentemente alcuni banchi, specialmente arenacei o con qualche lente ciottolosa, che debbonsi certamente attribuire al Sestiano. Tali banchi, per lo più fortemente sollevati e diretti ad un dipresso da Nord-Est a Sud-Ovest, inglobano talora piccole lenti di lignite compattissima, come ad esempio presso V. Alberti.

Percorrendo l'alveo del rio S. Genesio si può vedere in parecchi punti come questi strati sestiani si colleghino perfettamente con quelli bartoniani; vi si nota anzi il fatto che frammezzo alle marne a facics litologica ed a fauna schiettil- 
mente bartoniana, appaiono qua e là banchi arenaceo-sabbiosi che invece inglobano specialmente numerosi resti di Nummulites Fichteli, per modo che sembrano piuttosto attribuibili al Sestiano.

Questo fatto interessante ci prova anzitutto come non esista una distinzione netta fra Bartoniano e Sestiano, ma che fra questi due orizzonti geologici vi sia un graduale passaggio con ripetute alternauze litologiche e paleontologiche; ci prova inoltre come potentemente influisca la facies litologica sui caratteri paleontologici, giacchè vediamo in diversi punti della Val S. Genesio che nei banchi marnosi si sviluppa la tipica fauna bartoniana (essendo il Bartoniano un orizzonte essenzialmente di tran. quillo deposito marino), mentre in quelli arenacei, anche inferiori ai primi, compare già nettanente la fauna oligocenica (per essere il Sestiano ed il Tongriano depositi d'indule essenzialmente littoranea o di mare basso).

Attoruo all'affioramento liguriano di Cocconato compaiono pure sottili formazioni sestiane nettamente caratterizzate in alcuni banchi dai fossili eo-oligocenici. Ancle in queste regioni senza l'aiuto della paleontologia sarebbe ben difficile distinguere l'orizronte in esame dal Tongriano, poichè è anch' esso costituito essenzialmente di sabbie e di arenarie, però alternate abbastanza frequentemente con marne grigio-bleuastre.

A Nord della zoua liguriana l'orizzonte sestiano è rappresentato da una sottile striscia arenacea che segue l'andamento dellia sottostante formazione bartoniana e che serve assai bene di passaggio al sovrastante Tongriano; sono specialmente le numerose Orbitoidi di tipo eocenico, che raccolsi sull'alto della collina del Bricco, quelle che mi avvertirono apparire qui la formazione sestiana, però ben poco sviluppata.

Sono probabilmente da riferirsi pure a questo orizzonte i banchi arenacei, inglobanti diverse lenti lignitiche però molto sottili, clie appaiono nell'alveo del rio Freddo presso il Molino di rio Freddo.

A Sud dell'affioramento liguriano di Cocconato, sopra ad una sottile striscia bartoniana, compare pure una piccola striscia mar- 
noso-arenacea di Sestiano. Ne è specialmente interessante la parte orientale che appare ben a nudo nell'alveo del torrente Fabiasco, presso il Molino del Rocco; quivi infatti frammezzo alle marne ed alle sabbie compaiono irregolari lenti sulfuree e ripetuti straterelli e lenti lignitiche, come in Val rio Freddo; quiri inoltre verso la base del Sestiano, cioè nei banchi di passaggio al Bartoniano, appaiono irregolarmente fra le marne alcune arenarie grossolane ricchissime in Nummuliti e specialmente in Orbitoidi a tipo affatto eocenico; è anzi quivi l'unico punto in cui raccolsi esemplari di Orbitoides of. stella in banchi sestiani.

Nella parte orientale dell'affioramento Bartoniano di Gassino vediamo che sul lato settentrionale delle tipiche marne calcarifere compaiono, tra C. Laurente e Villa Lara, alcuni banchi arenacei, con impronte di grosse fucoidi alla superficie, cioè con facies simile a quella che indicammo nel Sestiano di Bric Sac, ecc. nelle colline di Brusasco; con queste arenarie compaiono pure banchi ghiaioso-sabbiosi, i quali spesso racchiudono resti di Nummulitidee.

Tali fossili sono specialmente Orbitoidi di tipo eocenico e Nummuliti riferibili alle $N$. Tchihatcheffi e $N$. striata; ne possiamo concludere che abbiamo a fare qui con bancli a facies litologica piuttosto sestiana, ed invece a fauna piuttosto bartoniana, in realtà ci troviano qui sul limite delle due formazioni.

Attorno alla parte occidentale della zona bartoniana di Gassino l'orizzonte Sestiano si può sviluppare meglio; esso è costituito specialmente da arenarie, inglobanti qua e là Nummuliti ed Orbitoidi, come di solito di tipo eocenico, e da banchi conglomeratici abbastanza potenti. Anche in queste regioni riesce difficilissimo il distinguere il Sestiano dal Tongriano presentando essi una facies affatto sinile. 


\section{Riassunto.}

L'orizzonte Sestiano, che non era stato finora mai segnalato in Piemonte, si può definire come un deposito essenzialmente littoraneo o di mare poco profondo; esso consta quindi essenzialmente di sabbie, arenarie e talora anche straterelli ciottolosi, inglobando sovente delle lenti di lignite compatta.

I suoi fossili in Piemonte sono particolarmente e comunemente rappresentati da Nummuliti e da Orbitoidi di tipo specialmente eocenico, però in parte già di facies tongriana.

Il Sestiano appare solo in pochi punti del bacino terziario del Piemonte là dove si verifica un passaggio un po'graduale tra il Liguriano ed il Bartoniano, cioè in qualche regione meridionale del tortonese e nella parte occidentale dei colli TorinoCasale.

L'andaniento stratigrafico del Sestiano s'accorda perfettamente con quello degli orizzonti geologici fra cui è compreso; spesso i suoi banchi sono fortemente sollevati, talora persino di $60^{\circ}$, $70^{\circ}$ ed anche più; più sovente invece essi pendono soltanto di $40^{\circ}$ o $50^{\circ}$.

Lo spessore della formazione sestiana è assai piccolo, ciò che ci denota come essa, almeno in Piemonte, abbia un'importanza assai minore del Bartoniano e specialmente del Tongriano; pare che in complesso si possa valutare la potenza del Sestiano piemontese ad una cinquantina di metri o poco più.

L'orizzonte in esame mancando spesso le falde alpine non è in Piemonte sollevato a grandi altezce, al più verso i 600 metri, come al M. Rivarossa nel tortonese.

La formazione sestiana, dov'è più ampiamente sviluppata, offre un passaggio insensibile, graduatissimo, sia al Bartoniano che al Tongriano, formando così un bellissimo orizzonte di congiunzione tra l'Eocene e l'Oligocene. 


\section{CAPITOLO VII.}

Tongriaso.

\section{Studi anteriori.}

I primi geologi, specialmente il Sismonda, che ebbero ad occuparsi dei terreni terziari del P'iemonte, dividendoli secondo la classificazione del Ijyell in Eocene, Hiocene, Pliocene, riconobbero potersi scindere il Miocene piemontese in inferiore, medio e superiore, senza però segnare tali divisioni nelle loro carte geologiche.

L'olizzonte geologico che è descritto in questo capitolo appartiene appunto a questo Miocene inferiore degli antichi geologi e di quasi tutti i paleontologici che si occuparono del Pienonte.

Il Pareto, nella sua bella, quantunque non abbastanza minuta, classificazione dei terres terziari dell'Appennino settentrionale, propose nel 1865 il nome di Bormidiano per questi terreni niocenici inferiori e tale nome loro sarebbe certamente rimasto, se in seguito il Mayer arendo avuto occasione di studiare tali terreni in Liguria non avesse scoperto e fatto noto che essi appartengono in gran parte ad un orizzonte già conosciuto e distinto altrove, sin dal 1852, dal D'Orbigny, col nome di Tongriano, appellativo quindi che si deve senz'altro conservare per diritto di priorità; notiamo inoltre che i terreni racchiusi dal Pareto nel Bormidiano appartengono non solo al Tongriano, ma talora anche allo Stampiano ed all'Aquitaniano per ciò cle risulta dalle sue descrizioni, e quindi non esiste neppure perfetta equivalenza fra $\mathrm{i}$ due orizzonti, come furono intesi dai loro rispettivi autori.

L'Issel, il Mazzuoli e Zaccagna nella loro carta geologica della Liguria cercarono già di distinguere il Miocene inferiore dal 
medio, comprendendo però in una tinta sola il Tongriano e lo Stampiano, estendendo inoltre questo Miocene inferiore sin presso a Villanuova Mondovi, mentre credo invece che esso scompaia ad Est di S. Miclrele Mondovi.

Nelle carte geologiche in grande scala che andai pubblicando dal 1856 al giorno d'oggi distinsi sempre nettamente il terreno tongriano, coll'appellativo di Tongriano inferiore, dagli orizzonti inferiori e superiori.

\section{Gencralità:}

Considerato nell'assieme, il Tongriano del Piemonte si può dire costituito essenzialmente da un complesso di banchi conglomeratici ad elementi di natura e di dimensioni svariatissime, ciò in rapporto sia colla natura litologica dei più vicini rilievi montuosi, sia colla maggior o minor vicinanza a tali rilievi, sia infine coll'oroidrografia esistente all' epoca in cui essi furono deposti; è inoltre pure molto vario il grado di cementazione di tali conglomerati, anche ciò in stretto rapporto colla natura litologica delle regioni montuose nelle cui vicinanze furono costituiti, ad esempio presentando essi vario grado di cementazione lungo le falde delle Alpi marittime a seconda della prevalenza delle roccie calcaree o quarzitiche; infatti $i$ conglomerati tongriani sono generalmente poco concentrati alle falde settentrionali dell'Appennino ligure tra la Bormida di Spigno e Voltaggio, per essere prevalenti le roccie serpentinose nella costituzione di questa regione montuosa, ed invece si presentano spesso cementatissimi a cominciare dalle vicinanze di Voltaggio sino alla valle Scrivia, in causa della vicinanza di formazioni calcaree triassiche e liguriane; presentano poi tali conglomerati vario grado di cementazione, $\mathrm{ma}$ in generale assai notevole, in gran parte delle colline tortonesi e torinesi in causa principalmente dei banchi più o meno disturbati di calcare alberese su cui spesso si adagiano, sia direttamente che indirettamente, e da cui fu tratto il materiale cementante. 
Quanto alla costituzione litologica dei conglomerati tongriani essa è per lo più tanto strettamente collegata con quella delle prossime catene montuose, anzi spesso dei più vicini rilieri a cui essi si appoggiano, che basta sorente l'esame litologico dei ciottoli tongriani per poter conoscere la natura della roccia in posto che trovasi nelle vicinanze.

Infatti si puó dire che i conglomerati tongriani dai dintorni di Cera alla valle della Bormida di Spigno sono specialmente costituiti di ciottoli quarzitici ed anagenitici; quelli che si estendono dalla valle della Bormida a Voltaggio presentano essenzialmente elementi serpentinosi; mentre che i ciottoli del Tongriano di Val Scrivia e del Tortonese sono quasi esclusiramente costituiti da arenarie e da calcari liguriani; ed infine i conglomerati tongriani dei colli torinesi presentansi costituiti sia da elementi tolti a regioni eoceniche, ora in gran parte abrase o sepolte, sia specialmente da elementi rocciosi delle vicine Alpi occidentali, o di formazioni primarie ora distrutte o sepolte.

Noto infine come in certe località speciali, che arremo a descrivere più aranti, i banchi tongriani poggianti sulle roccie preterziarie sono costituiti di un impasto di materiale esclusivamente tolto a tali roccie e ricomposto poco dopo esser stato tolto dalle roccie in posto, per modo che riesce talora difficile il distinguere il Tongriano, cosi costituito, dalle roccie preterziarie, generalmente serpentinose o calcaree, su cui si appoggia.

I ciottoli del Tongriano si presentano spesso improntati ed anche frantumati e coi frammenti spostati ma rimasti assieme, carattere che sembra essere in Piemonte abbastanza peculiare pel Tongriano.

Quanto alla grossezza degli elementi che costituiscono i conglomerati tongriani si può dire in generale che essi sono specialmente voluminosi nei bancli che più direttamente si appoggiano alle falde delle Alpi marittime e dell'Appennino ligure, ed anzi l'enorme grossezza dei ciottoli di certi banchi in alcune località nonchè la potenza talora straordinaria dei conglomerati tongriani di alcune regioni, ci servirà assai bene per ricostrurre 
in parte, bensì grossolanamente ma con base scientifica, l'oreidrografia dell'epoca tongriana:

Oltre agli indicati banchi conglomeratici, che costituiscono la parte più importante del Tongriano del Piemonte, avremo pure più volte a constatare banchi arenacei, sabbiosi e marnosi, talora assai potenti e situati ai vari livelli, anche ai più bassi, della serie stratigrafica del Tongriano ed avremo anzi talora ad apprezzarne molto la ricchezza in fossili.

Dal complesso dei caratteri sovrapposti risulta già chiaramente la facies di mare poco profondo e di littorale dei depositi in esame; vedremo anzi in seguito come $\mathrm{i}$ dati paleontologici ci indichino pure talora un regime salmastro ed anche lacustre e terrestre.

Notiamo come nelle formazioni tongriane del bacino piemontese si incontrino non di rado lenti più o meno ampie e potenti di lignite compatta, utilizzabile, la quale anzi in diversi punti venne già operata con profitto.

\section{Caratteri palcontologici.}

Rimandando l'enumerazione dei fossili del Tongriano del bacino piemontese alla parte paleontologica del presente lavoro, basta accefinare ora in generale come i caratteri più spiccati di questo terreno nella regione in esame siano specialmente, dal lato paleofitologico, una flora di tipo tropicale (Sabal, Phonicites, Cinammomum, ecc.) i cui resti, consistenti essenzialmente in impronte di foglie, nonchè, più raramente, di fiori, di frutti, di tronchi, ecc. trovansi talora abbondantissimi in alcuni banchi speciali. Talvolta anzi, col loro accumulo i resti di piante tongriane costituiscono persino potenti lenti lignitiche.

Dal lato paleozoologico notiamo anzitutto che in complesso la fauna, come la flora, tongriana, presenta un assieme di forme in parte eoceniche ed in parte mioceniche, per modo da servire assai bene come termine di collegamento della serie biologica tra $\mathrm{i}$ due periodi geologici. Sono ad esempio ancora molto ab- 
hondanti, talora anzi quasi uniche rappresentanti della fauna tongriana, le Nummulitidee, specialmente Nommulites Fichteli, $N$. intermedia, ecc, direrse specie di Orbitoidi di cui alcune grandissime, come Orbitoides dilutata, ecc. In certe regioni poi sono straordinariamente abbondanti gli Zoantari costituenti talora delle specie di Atoll attorno ai rilievi rocciosi.

Specialmente comuni fra i Molluschi sono rarie specie di Crassatella, di Cerithinm, la Natica crassatina, ecc. Inoltre uno dei caratteri paleontologici più spiccati del Tongriano è l'alternanza, che talora si osserva, di fossili marini con fossili d'acqua salmastra, sono infatti numerosissimi i Potamides raggruppantisi specialmente attorno al P. promargaritaceus; non sono neppur rari i fossili lacustri (Limneus, Planorbis, ecc.) e terrestri fra cui specialmente importante l'Anthracotherinm magnum Cur., alcuni resti di Rhinoceros, di Cheloni, di Cocodrillini, ecc.

\section{Distribusione geografica.}

Nel bacino terziario del Piemonte l'orizzonte geologico del Tongriuno costituisce una banda in complesso assai regolare alle falde settentrionali delle Alpi marittime e dell'Appennino dalle colline monregalesi sino al Tortonese, con uno sriluppo in larghezza molto rariabile (da una semplice sottile striscia ad oltre cinque chilometri), ciò in rapporto sia colla potenza dei depositi tongriani, sia colla loro disposizione stratigrafica, osservandosi infatti talora aree molto ampie occupate da questi terreni; ciò in causa della pochissima inclinazione che presentano gli strati cle li costituiscono.

Dalla ralle della Bormida di Spigno sin oltre a quella della Stura non sono rare le comparse, per breve tratto, del Tongriano franmezzo ai depositi dello Stampiano, ciò che è doruto sia all'erosione acquea, sia all'irregolariti della sepolta regione rocciosa, sulla quale si può dire che si modella la formazione tongriana, tant' è che spesso frammezzo a queste aree di Tongriano, isolate fra i terreni stampinni, compaiono anche, e già 
li cbbi ad esaminare, spuntoni di roccie antiche, creste o cime lella sepolta regione montuosa; perciò eziandio quando quest'ultimo fatto non si verifica, anche solo dalla comparsa degli spuntoni di Tongriano possiamo supporre un locale sollevamento dei terreni anticli sottostanti.

Vedremo inoltre come in diverse regioni lembi più o meno estesi del terreno in esame trovinsi sparsi qua e là sui terreni più antichi all' infuori della banda regolare sovraccennata. Ciò è dovuto in alcuni casi a piccoli bacini secondari, in relazione però originariamente con quello principale, ma nel maggior numero dei casi solo a fenomeni d'erosione acquea clie isolarono quello che era prima unito, ciò naturalmente verso il margine della formazione in esaine.

E poi molto importante il notare come in alcuni punti a Sud del bacino terziario del Piemonte trovinsi sul clinale della catena apino-appenninica, specialmente al colle di Altare, lembi di Tongriano che servono cosi di collegamento tra i depositi che di questo terreno studieremo nel bacino pienontese e quelli che osservansi a lembi sparsi in Liguria, e quindi ci provano come durante l'epoca tongriana il mare padano comunicasse in alcuni punti con quello Adriatico per mezzo di stretti inegualissimamente frastagliati, in causa delle varie sporgenze delle roccie antiche, e ciò specialmente là dove la catena appenninica collegasi a quella alpina. Tutto questo infine ci prova come siasi notevolissimamente trasformata l'oro-idrografia ligure-piemontese dall'epoca tongriana al giorno d'oggi.

Nella catena collinosa Torino-Valenza come nelle colline tortonesi le formazioni tongriane sono abbastanza sviluppate lungo l'asse del sistema collinoso; però i conglomerati non vi hanno più quel predominio quasi assoluto che osservasi lungo l'Appennino settentrionale, ma invece vi formano delle zone o delle lenti frammezzo alle sabbie, alle arenarie ed alle marne; anzi spesso nel Tongriano inferiore veggonsi sviluppatissime le marne grigiastre, fariliose, che ricordano talora alquanto le argille galestrine del Liguriano. 
Devesi anche osservare come l'abbondanza di calcare alberese, che fa parte dei conglomerati sia tongriani sia aquitaniani dei colli Torino-Valenza e clse pare derivare dallo sfacelo del Liguriano costituente ora l'imbasamento di questo sistema collinoso, sembra provare che durante $\mathrm{i}$ periodi tongriano, stampiano, ed aquitaniano, i terreni liguriani erano ancora in massima parte allo scoperto nel medio Piemonte e quindi soggetti ad una potente denudazione.

\section{Tettorica.}

La stratigrafia del Tongriano è generalmente assai semplice e regolare, specialmente lungo le falde settentrionali alpino-appenniniche, comportandosi esso quivi semplicemente come un deposito formatosi al piede di una catena montuosa e sollevato poscia con essa senza disturbi stratigrafici profondi; quindi in tutta questa importante regione subalpina e subappenninica veggonsi gli strati del Tongriamo inferiore pendere, con inclinazione non molto forte, verso l'interno del bacino terziario, cioè verso il Nord-Nord-Ovest tra i colli monregalesi e la Val Bormida, verso il Nord-Orest circa lungo la Val Bormida di Spigno, nuovamente verso il Nord o Nord-Nord-Ovest tra la Tal Bormida di Spigno e quella della Scrivia, ripiegando poscia a Nord inclinare verso Orest ed Orest-Nord-Ovest, ed infine, dopo la conca di S. Sebastiano Curone, pendere verso il Sud allo incirca; tutto ciò naturalmente con delle varianti per lo più locali e spesso causate solo da qualche irregolarità dei terreni su cui si formarono $i$ depositi in questione, oppure dal costituir essi dei piccoli bacini secondari, come ad esempio quello di Bagnasco; quivi infatti si presentano gli strati tongriani disposti a conca, inclinando essi generalmente rerso Sud circa tra Battifollo e Garbenna ed invece verso il Nord in complesso tra Bric del Bava e Massimino.

In alcuni casi poi $\mathrm{i}$ depositi in esame si presentano quasi orizzontali o alquanto ondulati e con una leggera inclinazione 
generale (ma con molte eccezioni locali) verso il centro del bacino piemontese; è specialmente tipica a questo riguardo l'ampia regione che si stende sulla destra di Vai Bormida di Spigno da Dego e Spigno circa sin verso Giusvalla e Miojola ad un dipresso, con delle appendici a Sassello e dintorni.

Soventi si osserva come i banchi arenacei che si estendono orizzontalmente sopra una regione rocciosa, là dove si appoggiano su qualche ripido rialzo della roccia antica, si mostrano assottigliati ma fortemente sollevati e spesso quivi si arricchiscono pure di lenti ghiaioso-ciottolose; anzi in alcune regioni, come per esempio al M. del Ratto, tra l'arenaria tongriana e la serpentina antica, veggonsi enormi frammenti brecciosi o ciottolosi che ci rappresentano il prodotto dell'azione fisico-meccanica delle onde tongriane contro le roccie che costituivano lé scogliere o le sponde frastagliate del mare di quell'epoca; infatti assieme ai grossi massi sovraccennati veggonsi spesso lenti di ciottolini discoidali, levigatissimi, luccicanti, che ricordano molto bene quelli delle attuali spiaggie marine; fenomeni consimili osservansi pure attorno agli spuntoni serpentinosi di Bric Roccone, di Bric Marzapiede, ecc.

In queste particolari regioni però occorrerebbero carte in scala molto grande per far risaltare $i$ fatti svariatissimi e curiosissimi che vi si osservano, cosi ad esempio l'apparente sovrapposizione del Tongriano allo Stampiano ed anche all'Aquitaniano, come presso la Madonna di Brucette.

Dalla valle del Curone verso Ovest $i$ banchi tongriani si presentano spesso fortemente rialzati e drizzati anche sino alla verticale, talvolta anche presso il contatto collo Stampiano e coll'Aquitaniano, ciò clıe dimostra essersi talora quivi verificato un sollevamento abbastanza energico.

Nella parte settentrionale dei colli tortonesi il Tongriano presenta inclinazioni svariate, che esamineremo in seguito, e talora molto forti.

Nelle colline Torino-Valenza i banchi tongriani, come d'altronde anche quelli dei terreni sovraincombenti, subirono delle 
potenti pressioni laterali che li obbligarono a sollevarsi tanto che spesso si presentano ora quasi verticali. Nel maggior numero dei casi però, per quanto dislocata dalla posizione originaria, la formazione tongriana nell'andamento stratigrafico generale accompagna abbastanza bene $\mathrm{i}$ terreni sia sotto che soprastanti.

In complesso poi nella direzione generale gli strati tongriani si presentano allineati alquanto parallelamente all' asse principale di corrugamento e quindi anche al clinale dell'intiero sistema collinoso.

Nell' assieme quindi vediamo che dal lato tettonico il Tongriano, inclinando regolarmente lungo le falde alpino-appenniniche verso il centro del bacino terziario piemontese, forma una o due rughe assai marcate sulle colline di Tortona e di TorinoValenza, fatto che già si potè constatare nell'andamento stratigrafico complessivo del Liguriano, e che vedremo poì ancor più chiaramente riprodursi per tutti i sovrastanti terreni oligocenici.

\section{Potenza.}

La potenza del Tongriano vedesi variare molto di luogo in luogo in corrispondenza talora della maggiore o minore quantitì di materiale trasportato dalle correnti terrestri nei bassi fondi marini di quell' epoca, ma spesso in causa della configurazione e dell'andamento delle roccie antiche su cui questi terreni si appoggiano; cosi si può generalmente constatare un grande sviluppo di potenza del Tongriano là dove $i$ terreni sottostanti sono foggiati a conca, come è il caso a Sud di Ceva, oppure là dove fanno un ampio seno come per esempio nelle vicinanze di Carcare, tra Val Lemno e Val Scrivia (dove il terreno in esame oltrepassa già 1000 metri in spessore) e specialmente poi tra la Val Scrivia e la Val Borbera; anzi su quest' ultima regione avremo a soffermarci alquanto giacchè è quivi, a mio parere, che il Tongriano del bacino piemontese raggiunge li massima potenza. Infatti oltre ad occupare un'area molto vasta (quan- 
tunque non superiore a quella che di questo terreno osservasi in diversi punti lungo le falde alpino-appenniniche), gli strat: tongriani si presentano quivi spesso fortemente sollevati, mentre nei casi precedentemente indicati essi presentano generalmente un'inclinazione di solo $10^{\circ}$ a $12^{\circ}$.

Orbene, percorrendo la grande area di Tongriano che esiste fra Grondona, Roccaforte, Merlazzina e Monastero di Molo e che si presenta solcata in ogni senso da enormi burroni con pareti spesso verticali e della profondita talora di 300 a 400 metri, od anche, per maggior comoditå, osservando solo la tettonica che di questo terreno si può facilmente studiare lungo la grande strada che, chiusa in stupenda forra, esiste al fondo di Val Borbera tra Colonne e Torre dei Persi, si vede anzitutto che in queste regioni il Tongriano occupa un'area di oltre quattro chilonetri in larghezza ed inoltre che $i$ suoi banchi, pendenti tutti regolarissimamente verso l'Ovest all' incirca, presentano dapprima, cioè nella parte occidentale, una inclinazione di circa $25^{\circ}$, poco dopo di $30^{\circ}$ ad un dipresso (dalla confluenza del Rio Berotte a quella del Ritale della Fonda), in seguito, di pressochè $35^{\circ}$ e, dopo le Baracche, di quasi $45^{\circ}$, sollevandosi poscia persino di $50^{\circ}$ a $60^{\circ}$ tra la confluenza del Ritale di Avi ed il termine orientale della formazione tongriana, divenendo quivi sempre più frequenti gli interstrati giallastri o grigio-bleuastri.

Appoggiandoci a questi dati positivi si può calcolare essere la potenza del Tongriano di queste regioni, superiore a 2000 , 2300 metri; inoltre osservando che la sezione dalla quale abbiamo, per inaggior comodità, esaminato la tettonica del Tongriano, non è la più lunga che si possa condurre attraverso l'area in questione, io non credo di esagerare affermando che in alcuni punti il Tongriano del bacino terziario del Piemonte raggiunge l'enorme spessore di circa 2500 metri.

Questa cifra ci deve servire di criterio per giudicare sia dell'importanza e della lunghezza, nel tempo, di questo orizzonte geologico, sia della potente abrasione che sulle regioni emerse 
si dovette verificare durante questo periodo tongriano, poichè si è già fatto notare come il terreno in questione sia essenzialmente costituito di elementi ciottolnsi, di dimensioni srariatissime, tolti alle regioni montuose alle cui falde si appoggia.

Nei dintorni di S. Sebastiano Curone il Tongriano, quantunque foggiato a conca, noll presenta uno straordinario spessore, ciò che dipende dall' esser stato deposto già ad una certa distanza dalla più elevata regione montuosa dell'Appennino e senza il concorso di potenti correnti acquee prorenienti da terra come era il caso nelle regioni precedentemente indicate; ed iufatti il Tongriano della conca di S. Sebastiano è essenzialmente costituito di letti marnosi ed arenacei, e solo qua e lì, localmente, di banchi o lenti conglomeratiche.

Quanto alla potenza degli affioramenti tongriani dei colli Torino-Valenza benchè non superiore a quella che presentano tali terreni sul lato meridionale del bacino in esame, è tuttavia talora assai considerevole e tale da farci supporre che se fosse possibile osservare presso le Alpi aree più largamente scoperte di questo orizzonte geologico, esso si mostrerebbe forse più potente che non alle falde alpillo-appenniniche.

Infatti, per citare un solo esempio, nell' elissoide incompiuto che il Tongriano di Gassino fa attorno al Bartoniano, vediamo che, mentre le zone tongriane parallele all' asse maggiore dell'elisse (con una larghezza varia dai 150 ai 700 metri), avendo gli strati loro fortissimamente sollevati, mostrano una potenza di 400, 500 metri, inrece nella curva occidentale dell'elissoide, venendo più ampiamente a giorno la formazione in esame (quantunque con pendenza minore che nei casi sovraccennati), se ne può calcolare la potenza a circa 1200 metri e fors'anche a 1500 metri.

Anche di questa notevole potenza constatata nel Tongriano dei colli torinesi, quantunque, come già accennai sopra, probabilmente ancor minore del vero, dobbiamo tener gran conto per valutare l'enorme abrasione prodottasi durante questo periodo nelle regioni alpino-appenniniche allora emerse, giacchè la for- 
mazione in esame è sui colli torinesi, come sul lato meridionale del bacino in istudio, costituita essenzialmente da conglomerati ad elementi talora assai voluminosi, provenienti spesso da regioni montuose abbastanza lontane, eccetto che quelli di calcare e di arenaria liguriana che sono dovuti allo smantellamento di regioni eoceniclie allora emerse, probabilmente poco lontane dagli attuali depositi tongriani, ed ora invece in gran parte abrase o sepolte sotto ai terreni oligocenici.

\section{Altimetria.}

E sempre molto importante, a mio parere, l'osservale le altitudini che, rispetto all' attuale livello marino, raggiungono i vari depositi terziari, giacchè questo ci serve di sicuro caposaldo per valutare, almeno approssimativamente, il grado di emersione che subirono le regioni di cui questi terreni fanno parte, ed un bellissimo esempio di ciỏ l'abbiamo appunto esaminando l'altimetria del Tongriano nelle varie regioni del bacino terziario del Piemonte.

Infatti è precisamente presso le falde settentrionali delle Alpi Marittime, le quali per presentare-depositi eocenici sollevati a circa 3000 metri e per molti altri fatti geologici che osserveremo in seguito sono da ritenersi come la regione che ebbe a subire i più potenti sollevamenti dall'epoca eocenica al giorno d'oggi, è alle falde di questa regione montuosa, dico, che i depositi del Tongriano sono portati più in alto, oltrepassando infatti i 1000 inetri sopra Bagnasco, cioè al Bric del Bava (1004) e per circa mezzo chilometro sulla cresta che dal Bric del Bava si dirige verso Bric del Veja; è però da notarsi come in questo caso si tratti di depositi fluvio-lacustri i quali credo siansi formati a qualche elevazione sul livello marino dell' epoca tongriana.

Naturalmente nelle vicinanze di Bric del Bava sono comuni le località dove vedesi il Tongriano sollevato a 800,900 metri come si può osservare sulle unite carte geologiche. 
Più ad Est vediamo che a Sud di Montezemolo e Roccavignale il Tongriano si spinge sin oltre gli 800 (Bric Valgarda S30) ed i 900 metri (Bric Spargora), abbassandosi però rapidamente verso la valle della Bormida di Spigno dove esso lia invece una media elevazione di 400, 500 metri; osservasi però ancora verso i 700 metri qualche lembo di Tongriano sulla regione rocciosa ad Est di Ta! Bormida, così per esempio presso i casali Cravetta soprana; quivi trovansi abbondantissimi i fossili numnulitici, prova sicura di un deposito non più continentale (come era talora il caso negli esempi precitati di grandi altitudini) ma assolutamente marino; ciò aggiunge maggior importanza al fatto della notevole elevazione di questa formazione sull'attuale livello del mare.

Nella banda tongriana che fascia la regione montuosa dalla Tal Bormida alla Valle Stura vediamo i terreni in, esame sollevarsi generalmente a solo 450,500 metri e solo raramente toccare i 600 metri; ma da Val Stura verso Est osserviamo che a Sud di Mornese i depositi del Tongriano vanno rapidamente innalzandosi oltrepassando talora gli S00 metri (M. Langone S04) ed anzi toccando persino i 900 metri lungo la cresta di Castiglione ad Fst di M. Tobbio.

La notevole elevazione dei depositi tongriani si verifica ancora per lungo tratto rerso Est, mostrando cosi quanto potentemente siasi pure sollevato l'Appemnino settentrionale dopo l'epoca tongriana; così abbiamo spesso il Tongriano portato ad oltre 800 metri, come al M. Alpe (\$41), al M. Porale (S35), al M. Refin (\$00), al M. La Croce (\$20), al M. Poggio (\$50), al M. Cravasana (\$06), alla Cresta della Riva che tocca gli 850 metri; anzi in alcuni punti i banchi conglomeratici del Tonyriano raggiungono ed anche oltrepassano i 900 metri come al M. Ravezza (910) sopra Roccaforte ed al M. Rivarossa (910) ad Orest di Merlazzina, dopo di che però essi rapidamente si vauno abbassando, tanto che nella conca di S. Sebastiano Curone essi raramente oltrepassano i 600 metri.

Lungo il clinale dell'Appennino settentrionale veggonsi plac- 
che tongriune clie ci indicano chiaramente come durante l'epoca tongriana il golfo padano comunicasse quivi col mar tirreno; alcune di queste placche raggiungono notevoli elevazioni, talora di quasi 1000 metri, come vedesi ad esempio al M. Reale (902 metri), al M. Castellazzo (956 m.), al M. Reopasso (959 m.), al M. Cravi (992 m.), ecc.

Quanto agli afforamenti tongriani dei colli Torino-Talenza essi non raggiungono altitudini notevoli, rimanendo generalmente soggiacenti, anclie ipsometricamente, ai più giovani terreni miocenici sotto i quali spuntano; tuttavia a causa della resistenza dei conglomerati che in massima parte li costituiscono, vediamo che nella parte occidentale dell'elissoide di Gassino, i banchi del Tongriano si spingono sin oltre i 500 metri, come al M. S. Croce (506), al Bric Carleré (536) ed al M. Chenon (536). Giova notare qui come nell' Appennino centrale il Tongriano pare sia talora sollevato ad oltre 1500 metri, come indica lo Scarabelli nella sua Monogratia geologica della Provincia di Forli (1881).

Rapporto coi terreni sotto e soprastanti.

Quanto ai rapporti che il Tongriano ha coi terreni sottostanti essi sono generalmente, in quasi tutto il bacino terziario. del Piemonte, di semplice sovrapposizione trasgressiva, senza regolare passaggio; infatti dalle regioni dove questo terreno comincia ad apparire, lungo le falde alpino-appenniniche settentrionali, sin presso Voltaggio esso si appoggia direttamente sulle roccie preterziarie; in questo caso osservansi talora gli effetti dell'erosione prodotta sia dalle correnti acquee che agirono durante l'epoca tongriana sulle roccie antiche, sia dai Molluschi litodomi delle spiaggie marine di tale epoca cle traforarono i calcari triassici, come vedesi ad esempio presso Millesimo, presso Cairo Montenotte, ecc.

Dalle vicinanze di Voltaggio sino alle colline tortonesi appare bensi sotto al Tongriano il Liguriano, rappresentato dap- 
prima da argilloschisti talcosi, poscia da banchi calcari e quindi da argille scagliose, ma esiste tuttaria generalmente tra questi due terreni una trasgressione, una lacuna più o meno forte; però dal lato Sud della conca tongriana di S. Sebastiano Curone tale lacuna è in parte riculmata da banchi di passaggio che ebli già ad esaminare minutamente in un lavoro speciale e che accennai eziandio nei capitoli precedenti; devesi ancora osservare che il modo di sovrapposizione del Tongriano al Liguriano indica che prima della deposizione del Tongriano si dovette generalmente verificare sul Liguriano una importante azione sia erosiva sia di sollevamento con incurvamenti, per cui il Tongriuno si depose già spesso entro ad avvallamenti del Liguriano, avrallamenti talora indipendenti affatto dalle attuali vallate e rallicelle, talora invece concordanti con queste; anzi si veggono talvolta i terreni tongriani discendere molto in basso verso il fondo delle vallette, mentre che per semplice erosione essi dorrebbern solo costituire placche sull'alto delle colline.

Questi fatti sono poi ancor più evidenti più ad Orest, dove cioè sono roccie preterziarie quelle che sopportano direttamente il Tongriano.

Anzi in certi casi si osserva il fenomeno curioso che il Tongriuno inferiore pare soggiacente alla roccia antica perchè questa, come più resistente, forna talvolta rialzi che strapiombano sopra placche tongriane le quali sono applicate ai suoi fianchi. Questo si osserva ad esempio ad Ovest di Voltaggio, in Val Morsone, pochi passi ad Est di C. Acquafredda.

Noto infine come in alcuni punti il Tongriano, generalmente a facics arenacea, essendo spinto molto in alto dal sollevarsi di qualche cresta rocciosa antica, pare sovrapporsi a quei depositi stampiani che gli si appoggiano contro un po' in basso; lo stesso talvolta si verifica per la roccia antica rispetto sia al Tongriano sia allo Stampiano.

Le regioni dove meglio si possono osservare questi fenomeni stratigrafici sono specialmente quelle esistenti tra Tal Erro e Val Bormida di Spigno, i dintorni di II. Acuto, della Borgata 
Giuliani, del paesello di Montaldo sotto il Bric Calma, ecc. Tutto ciò prova che tra le deposizioni dei due sopracitati orizzonti geologici si dovettero verificare talora dei movimenti abbastanza importanti quantunque abbastanza vari da luogo a luogo.

Nelle colline tortonesi e nelle colline Torino-Valenza il Tongriano presenta per lo più inferiormente una certa trasgressione sia col Bartoniano sia col Liguriano, su cui direttamente si appoggia; in certi casi invece abbiamo gia avnto ad osservare come tale passaggio sia abbastanza graduale, sia litologicamente, che stratigraficamente, per l'interposizione del Sestiano.

Nella parte superiore dell'orizzonte in esame, cioè nel passaggio allo Stampiano, noi possiamo quasi ovunque notare quella graduale transizione clie d'ora in avanti avremo pressochè sempre e quasi ovunque a far risaltare fra i diversi successivi piani terziarii del bacino piemontese.

Questo passaggio nel caso regolare si compie generalmente per inezzo della comparsa e della sempre maggior frequenza di lenti e banchi arenacei e maruosi frammezzo ai supremi banchi conglomerati del Tongriano, finchè gradataınente questi vengono quasi completamente sostituiti da quelli, ed in tal modo si passa senza alcuna netta linea di separazione alla parte basale dello Stampiano, essenzialmente marnoso. Questo passaggio però presenta infinite varianti tra luogo e luogo sia riguardo alla natura litologica, sia riguardo alla potenza di questi banchi di passaggio; talora la separazione dei due orizzonti è abbastanza facile, talora invece la loro linea di delimitazione è molto vaga, e quindi alquanto arbitriaria e non costante per tutto il bacino.

Tali difficoltà di delimitazione si incontrano non soltanto là dove $i$ terreni sono solo visibili in pochi punti e con piccoli spaccati, ma eziandio, se non di più direi, dove essi sono messi ampiamente a nudo per tutta la loro estensione da numerosi ed enormi spaccati naturali, come, per citare un esempio fra mille che si potrebbero indicare, nel rio dei Bistolfi a Nord-Est del paese di Pouzone nell'Appennino acquense, dove tra lo Stam- 
piano ed il Tongriano si interpongono ripetute alternanze di banchi marnosi e di banchi arenacei attribuibili sia ad un piano che all'altro.

Inoltre le difficoltà di distinguere il Tongriano dallo Stampiano diventano poi grandissime e talora anche insuperabili quando si tratta di lembi isolati i quali, quantunque marnosi e con facies dello Stampiano, possono invece appartenere a qualche letto marnoso primitivamente interstratificato fra i banchi arenacei e conglomeratici del Tongriano, oppure quando si verifica, però più raramente, il caso contrario.

Le stesse difficoltà si incontrano pure nel caso, clie vedremo non raro (ad esempio dalla Val Bormida a quella di Stura) in cui lo Stampiuno diventa arenaceo-conglomeratico in gran parte, assumendo così la facies del Tongriano da cui allora si può suvente distinguere solo approssimativamente per mezzo della stritigrafia, della maggior abbondanza di banchi marnosi, oppure per mezzo di qualche banco marnoso intermedio abbastanza costante.

Il modo di transizione tra il Tongriano e Io Stampiano, modo accennato poco fa come la regola generale, si verifica per lunglissimo tratto dalle vicinanze di Mombasiglio, dove appunto ${ }^{\circ} \mathrm{co-}$ mincia ad apparire lo Stampiano, sino alle vicinanze di Millesimo; spesso lungo questa linea di sviluppo il passaggio è solo costituito da banchi arenacei grigiastri duri, ancola includibili in massima parte nel Tongriano. Invece per lungo tratto a Sud di Millesimo e di Plodio i prolungamenti più meridionali dello Stampiano, divenendo anch'essi in gran parte arenaceo-conglomeratici, sono difficilmente distinguibili dai sottostanti banchi del Tongriano, e presentano solo qualche letto marnoso intermedio.

Cosi pure più avanti in Val Bormida, specialmente sulla sua destra, ma particolarmente poi nella vastissima area di espansione che i terreni tongriani presentano verso Est, sin oltre Giusvalla, Mioglia, ecc. la distinzione tra il Tongriano e lo Stampiano diviene ancor più difficile perchè, a causa delle ondulazioni stratigrafiche che presentano questi terreni, deposti 
sopra una regione montuosa a rilievo molto accidentato, talora viene a mancare il criterio statigrafico, clie aiuta spesso per tale distinzione il criterio litologico; d'altronde quest'ultimo criterio per aree abbastanza vaste è talora profondamente alterato dalla comparsa di potenti banchi arenaceo-conglomeratici alla base ed anche nella parte media e superiore dello Stampiono tanto da renderlo talora irriconoscibile, se esaminato solo dal punto di vista della facies e quindi ancle della paleontologia.

'Tali incertezze nella delimitazione del Tongrimo e dello Stampiano incontransi su vasta scala nelle ampie placche oligoceniche tra Val Erro e Val Orba a Cimaferle, Toleto, ecc., dove sono sviluppatissimi certi depositi sabbioso-ghiaiosi, qua e là fossiliferi, che forse sono in gran parte banchi di passaggio tra un piano geologico e l'altı.o.

Dalla valle della Bormida di Spigno seguendo il percorso del Tongriano verso Est troviamo clie il suo modo di passaggio allo Stcmpiano rientra ad un dipresso nella regola generale, quantunque nei dintorni di Cassinelle lo Stampiano, presentandosi spesso arenaceo-conglomeratico, assuma talora un aspetto facilmente confondibile con quello dell'orizzonte inferiore, da cui spesso riesce solo a distinguersi per mezzo della stratigrafia; ma ad Est di Molare la distinzione tra Tongriano conglomeratico e Stampiano marnoso diventa sempre più netta per modo che la separazione dei due orizzonti, se alquanto dubbia nei banchi di passaggio, è invece generalmente assai chiara e facile nel complesso, tanto più che probabilmente esiste talora un piccolo licutus tra i due orizzonti.

Ma a cominciare dalla valle della Scrivia sino a Grondona e Torre dei Persi nuovamente la parte inferiore dello Stampiano presenta così numerosi banchi o lenti arenacee e conglomeratiche che riesce assai difficile, e spesso quindi alquanto arbitraria, la sua separazione dal Tongriano; questa difficoltì poi continua a verificarsi anche più a settentrione nelle colline tortonesi dove viceversa essa è prodotta dal divenir rari i banclì ciottolosi anche nello stesso Tongriano, il quale perde così uno 
lei caratteri più spiccati che presentava generalmente nella parte meridionale del bacino in esame.

Per presentare un esempio di questo passaggio nei colli tortonesi possiamo ad esempio indicare la seguente serie di strati che incontra a Sud di Garbagna chi dalle colline di Míntebore si reca al M. Ronzone per la cresta di C. Della Costa:

\section{(1I. Ronzone $704 \mathrm{~m}$. )}

Banchi arenaceo-calcarei duri, resistenti, alter- $\{$ Langhiono Potente complesso di banchi sabbiosi ed arenacei, grigiastri e grigio-giallognoli.

Banchi sabbioso-arenacei con concrezioni molti $\{$ Aquitaniano formi e lenti ciottolose.

Banchi sabbioso-arenacei grigio-verdastri alter-) nati con straterelli arenacei a Paleodictyon. $\{$ Stampiano Banchi sabbiosi giallastri.

Straterelli conglomeratici.
Marne grigio-azzurrastre a struttura uniforme Tongriano ed a stratificazione poco evidente, farinose.

Potenti e cementatissimi conglomerati.

\section{(Colline di Montebore.)}

Il Tongriano delle colline Torino-Valenza non presenta rappolti molto interessanti coi terreni clie gli sovrastano, coi quali però è in generale abbastanza concordante; solo in poche e liunitatissime regioni, dove compaiono zone di Stampiano, si può osservare come sia piuttosto regolare il passaggio da un orizzonte all'altro.

\section{Localiti fossilifere.}

Per quanto a chi si occupa specialmente di rilevare la carta geologica di una regione possano spesso sfuggire certi punti 
speciali che presentano maggior ricchezza di fossili, però in uno studio generale il geologo abitua abbastanza facilmente l'occhio a riconoscere dalla facies $\mathrm{i}$ banchi che sono comunemente più fossiliferi, e può quindi allora dare su questo proposito utili raggungli generali che, a chi si reca in una data località per far raccolte paleontologiche, possono riuscire assai utili onde raggiungere il suo scopo.

Orbene io credo che sia questo precisamente il caso mio, giacchè per quanto abbia sempre ed ovunque cercato di raccogliere il maggior numero possibile di fossili durante il rilevamento del bacino terziario del Piemonte, tuttavia non potei naturalmente eseguire dappertutto quelle lunghe ricerche per cui si scoprono talora certi punti particolari, affatto localizzati, nei quali i fossili sono più abbondanti, meglio conservati e facilmente raccoglibili; d'altronde queste scoperte sono dovute generalmente o al semplice caso, oppure alle ricerche di chi ha occasione di perlustrare minutamente in ogni senso una regione limitata.

Dall'esame complessivo di tutto il Tongriano del bacino piemontese ebbi a ricavare che generalmente scarseggiano i fossili fra $\mathrm{i}$ banchi conglomeratici e che invece essi sono più comuni negli strati arenacei ed arenaceo-marnosi a tutti i livelli del piano ill esame; inoltre che la loro abbondanza è specialmente notevole nei banchi arenacei che stanno nella parte superiore di questo orizzonte geologico, là dove esso passa allo Stampiano, fatto d'altronde che si verifica pure nel Tongriano di molte altre parti d'Europa. Al contrario però è specialmente verso la base del Tongriano che ebbi a constatare i banchi lignitici, racchiudenti la massima parte dei fossili terrestri e lacustri.

Nelle vicinanze di Ceva giova notare la ricchezza in fossili che presentano le arenarie tongriane nei dintorni delle borgate Bertini e Villero, ma specialmente sono importanti a questo riguardo le arenarie sotto Molere e presso lo sbocco del rio Salesso e col torrente Clavetta. Resti di Anthracotherium si raccolsero pure nelle ligniti tongriane presso S. Michele Mondovi. 
F. Silceo,

Innportantissima poi è la conca tongriana di Bagnasco-PerloNuceto, perchè nelle sue lenti lignitiche si rinvennero numerosissimi resti di Molluschi lacustri nonchè ossa di Tryonix, di Rilinoceros, di Anthracotherium. ecc.; inoltre fra gli schisti straterellati marnoso-sabbiosi quivi assai sviluppati, specialmente ad Fist ed Orest di Bagnasco tra Isola e C. Gorresio e tra il Borgo e la regione delle liocchette, si incontrano abbastanza comunemente resti di foglie e di pesci.

Verso Millesimo trovansi non rari fossili nelle marne dure e nelle arenarie passanti allo Stampiano, cosi presso il paesello di Strada, presso Nillesimo, e più avanti nella conca tongriana di Carcare; è quivi notevole ad osservare come sono talora molto fossiliferi certi sottili banclıi arenacei costituenti placclıe più 0 meno isolate nelle roccie antiche, cosl per esempio presso le Greppie a Sud-Est di Carcare, presso Cravetta soprana ad Est di Cairo, ecc.

Dobbiamo ancora qui osservare come sia specialmente verso la base dell' ampio lembo di Tongriano, che esiste nelle vicimanze del colle di Altare, frammezzo a lenti ligniticlıe alternate con marne, in un vallone a Nord del paesello di Cadibona, che si rinvennero, assieme a Molluschi continentali, numerosissimi resti di Anthracotherium e di altri Maumiferi terrestri.

Nell' ampia valle della Bormida di Spigno, specialmente alla suat destra ed in particolar modo fra Rocchetta Cairo sin poco oltre le Praie, ebbi a riscontrare un'enorme quantità di fossili frammezzo ai banchi arenacei e ghiaiosi; cosi ad esempio nelle colline ad Est di Rocchetta e di Neuye, nei dintorni di Costalupira e di C. Ciapeiroli, presso Villa del Piano, nelle vicinanze di C. Ortou, di C. Berri, di C. Dotte, di C. Fres, di Piana Crixia, di Pera, di Cheilini, di Brich Cheilini, ecc. ecc., nonchè piǹ a Nord nelle vicinamze di Merana. Fossilifero al sommo ò il bacino tongriano di Mioglia.

Notiano in questo luogo come precisamente ad Est ed a non grande distanza da questa regione così riccamente fossilifera, csistano i grandi lembi isolati o bacini tongriani di S. Giustina 
e di Sassello, tanto famosi per la loro ricchezza in fussili sia vegetali che animali; quivi particolarmente interessanti ad osservarsi sono le scogliere madreporiclie, aderenti alla roccia serpentinosa antica, che esistono in alcuni punti presso Sassello, specialmente nella valletta a Sud di Prato Valerino.

Meno abbondanti quantunque non rari sono i fossili nelle arenarie tongriane tra Spigno, Malvicino e Cartosio; assai più frequenti nelle vicinanze di Grognardo e di Ponzone in fondo ai valloni; essi si presentano poi di nuovo in quantità straordinaria fra le arenarie più o meno grossolane, giallastre, nei dintorni di Cassinelle sia a Nord, al fondo del rio Caramagna sotto C. Bassano all' incirca, sia a Sud presso C. Cappelletta al M. del Ratto (dove abbondano Nummuliti, Pettini, grosse Ostriche, ecc.), nia specialmente lungo la costa sinistra della valletta di Amione rove si rinvengono fossili non solo numerosi, ma spesso anche assai preziosi per la loro rarità; in queste regioni si raccolsero pure resti di Anthracotherium; nelle vicinanze di Ponzone si incontrano non rare lenti lignitiche con fossili lacustri o salmastri. Nelle placche tongriane di Toleto, di C. Cascinazza, di C. Pra d'Orso ecc., trovansi banchi arenacei brunastri zeppi in fossili, specialmente in Nummuliti.

Verso Est il grande sviluppo dei banchi conglomeratici rende in generale meno facile la raccolta dei fossili, eccetto che in alcuni banchi arenacei giallo-bruni che compaiono specialmente nelia parte superiore dell' orizzonte e talora sono anzi assai fossiliferi, come ad esempio sotto Lerma in Val Lemmo, mezzo chilometro circa a Sud di Carrosio, ecc.

Non è neppur raro trovare frammezzo ai potenti conglomerati alcune lenti, costituite di arenaria grossolana, molto ricche in fossili specialmente nummulitici, così ad esempio in Tal Scrivia presso Cà dei Grossi, sotto Serre inferiore, presso Pietrabissara, e più ad Est alla borgata Corti nelle vicinanze di Roccaforte, cioè veramente presso la base del Tongriano.

Quanto poi a Roccaforte è ancora a notarsi come quivi alla base affatto dell' orizzonte in esame rinvenni fra lc marnc e le 
lenti lignitiche numerosi resti di Molluschi continentali (Planorzis, Strophostoma, ecc.)

Nei banchi, generalmente marnoso-arenacei, della conca tongriana di S. Sebastiano Curone non sono rari i fossili, particolarmente nummulitici, cle per citare un esempio, abbondano in alcuni banchi marnoso-sabbiosi giallastri (passanti al Sestiano), assai simili a quelli fossiliferi di Sassello, sulla sinistra di Val Museglia, poco a Sud di borgata Giara. Anche nelle arenaric tongriane dei colli tortonesi si incontrano talora fossili, specialmente Robulina, Nummulites, ecc.

Quanto agli affioramenti tongriani dei colli torinesi sono specialmente degni di nota i banchi arenacei che, se per lo più presentano solo resti mal conservati di Molluschi, Echinodermi, ecc., sovente invece raccliudono Orbitoidi e Nummuliti clie sono molto utili al geologo rilevatore; accenniamone alcuni esempi. Sulla sinistra di Val Rotaldo, presso la C. del Conte (Olivola) si sviluppano banchi ghiaioso-arenacei ricchissimi in Nummulites Fichteli; fra le arenarie del Tongriano di C. Spinosa alta e bassa e di Castellino (destra di Val Colobrio) certi letti arenacei grossolani racchiudono numerose Orbitoidi e Nummuliti; pure numerose Nummulites Fichteli si raccolgono nei banchi sabbiosi clie si incontrano salendo da C. Pignone (Val Colobrio) a borgata Stura; questa stessa specie di Nummulite abbonda anche nelle arenarie tongriane di Salabue, nonchè tra Ponzano e C. dei Boschi e più ad Orest presso borgata Pezzere.

Diversi banchi arenaceo-conglomeratici ricchi in Orbitoidi ed in Nummuliti (fra cui la $N$. intermedia) appaiono sulla sponda destra del Po, mezzo chilometro circa a valle del Porto di Rocca delle Donne. Nei banchi arenacei del Tongriano delle colline tra Oddalengo, Brozolo e Verrua, si incontrano talora resti di piante, di Molluschi, ecc., però in generale poco determinabili in causa del cattivo stato di conserrazione; solo i resti di Nummuliti, fra cui predomina sempre la $N$. Fichteli talora unita alla $N$. miorontorta var. exilis, presentano qualche maggior importanza; se ne raccolgono presso le C. Scarfenga, C. 
Negri, C. Chinoni; nelle formazioni tongriane ad Ovest di Brusasco si incontrano pure impronte di Taphrhclminthopsis, di Palcodictyon cf. regulare (a Nord-Ovest di Bric Sac).

Località riccamente fossilifera è il fondo di Val Rio Freddo, ad Est di Albugnano, dalle falde occidentali della collina di borgata Canuto sino alla sorgente solforosa, dove sviluppansi arenarie ed anche ghiaie alquanto cementate; oltre a questi strati ricchi particolarmente in Nummulites intermedia, N. Ficleteli, Crassatella, Pecten, Echinodermi, Antozoi, ecc., sonvi pure quivi banclii sabbiosi giallastri con numerosissime piccole Nummuliti riferibili specialmente alla $N$. Fichteli, nonchè eziandio lenti marnose grigio-giallastre commiste a depositi conglomeratici e racchiudenti pure fossili di varia natura, fra cui abbastanza comuni gli Antozoi.

Fra i banchi tongriani che attorniano il Bartoniano di Gassino ebbi a riscontrare filliti poco determinabili e fossili infranti; fra le arenarie presso la Trinità di Gassino ed altrove riscontransi resti di Nummulites Fichteli; rinvengonsi poi resti di Molluschi in alcuni letti marnosi interstratificati ai potenti banchi conglomeratici.

Quanto allo stato di conservazione dei fossili del Tongriano del bacino terziario del Piemonte, si può dire che in generale esso è abbastanza soddisfacente, quantunque l'arenaria più o meno grossolana che sovente li racchiude e li riempie sia spesso cosi duramente cementata che riesce difficile la liberazione completa del fossile; quindi per il paleontologo sono specialmente preziosi quei pochi orizzonti fossiliferi che si presentano costituiti di arenaria facilmente disaggregabile, ed in caso contrario è miglior partito raccogliere solo i fossili i quali trovansi liberi o quasi liberi alla superficie del terreno che non fare scavi, per lo più infruttuosi, eccetto che trattisi di lenti eccezionalmente fossilifere oppure di quei preziosi straterelli fillitiferi che meritano certamente un'accurata esplorazione fin dove si possono seguire. 


\section{Descrizione geologica regianule.}

Come di solito incominciamo l'esame geologico regionale dal Iato Sud-Orest del bacino in studio; vediamo comparire il Tongriano coi tipici suoi potenti conglomerati di color rosso-vinoso tra Mondovi e Ceva in Val Mongia alle falde occidentali di Montegrosso e nella parte inferiore delle valli del Gatto e del Confine; i conglomerati presentano talora ciottoli enormi sparsi qua e là frammezzo agli elementi di mediocre grossezza; oltre ai banchi conglomeratici si vedono pure assai sviluppati dei letti arenacei e marnosi di color grigio-giallastro o azzurrastro in cui appaiono non di rado sottili lenti lignitiche.

Tutto ciò si può osservare bene sia sulla destra che sulla sinistra sponda di Val Mongia, ma specialmente nella zona più allargata nei dintorni di C. Masantina; quivi l'inclinazione degli strati è abbastanza regolare ma di pochi gradi verso il Nord od il Nord-Ovest circa.

Nelle colline di borgata Alberghetti il Tongriano è rappresentato sia da conglomerati di color rosso-vinoso, fortemente cementati, oppure da breccie e da arenarie cementate o sciolte; per decomposizione più o meno superficiale risulta clie spesso queste-regioni tongriane si presentano di color rossastro e sono coperte qua e lia da ciottoloni o da frammenti brecciosi con facies di ciottoli erratici.

Nelle regioni collinose tra Alberghetti e Val Corsaglia sopra alla formazione tongriana si estendono placche più o neno ampie di Elveziano; però tale distinzione è talora assai difficile a farsi. In generale si può dire che il Tongriano presenta sabbie bleuastre, banchi conglomeratici, banchi marnoso-sabbiosi di color rosso-vino o di color verde-giallastro, mentre invece l'Elreziano consta essenzialmente di arenarie più o meno cementate, spesso fogliettate, sovente con fossili, specialmente fllitici, ed è di colore giallognolo in generale; ma talora l'Elveziano di queste regioni presenta pure, rerso la sua base, bancli ciottolosi, come 
si può vedere ad esempio molto bene in Val Mongia a NordOvest di Montegrosso; quivi infatti osservasi la seguente serie di strati, inclinati a Nord-Est circa:

$$
\begin{aligned}
& \mid \begin{array}{r}
80^{\circ} \text { Marne sabbiose grigio-bleuastre con strate- } \\
\text { relli arenacei. }
\end{array} \\
& \text { 6. Strati sabbioso-arenacei con lenti ghiaioso- }
\end{aligned}
$$

Là dove è più profonda l'alterazione dei vari depositi ed è molto estesa la vegetazione, riesce quasi impossibile fare una netta delimitazione fra i due orizzonti geologici, quantunque anche nei caratteri esterni si possa notare che per lo più il Tongriano costituisce colline rossiccie a pendici più dirupate clre non l'Elveziano, il quale poi soventi forma una specie di gradino, più o meno spiccato, sulla formazione oligocenica; talvolta esistono pure piccole sorgenti acquee in questa zona di passaggio. Nei banchi congloneratici superiori del Tongriano si incontrano talora ciottoli di calcare triassico traforati dalle Litodome.

Tanto in valle delle Meje, sotto C. Apriero, quanto in diversi punti di Val Mongia presso bergata Piaggie, i banchi marnosi del Tonyriano inglobano baucli di lignite nera, lucente, compatta, simile a quella ben nota di Bagnasco. 
Sulla destra di Val Casotto, verso l'alto, incontransi qua e là lembi di conglomerato a pasta rossiccia, che paiono ancora riferibili al Tongriano, così sotto il Pilone Sacliero.

Più ad Orest, a borgata Sottana, sopra S. Elena, ecc. souri placche conglomeratiche che riesce difficile il decidere se sieno da riferirsi al Tongriano oppure all' Elveziano.

Verso Mombasiglio la formazione tongriana si sdoppia in causa dell' emersione delle roccie antiche (Talcoschisti con Serpentine), e siccome tale divisione si continua per lunghissimo tratto verso Est ed ha eziandio l'importanza di separare, grossolanamente però, i depositi marini da quelli d'acqua dolce, così credo opportuno di esaminare una zona dopo l'altra.

Dalla valle Mongia, dopo la comparsa dei Talcoschisti serpentiniferi di Porrazza, la massima parte (quasi esclusivamente conglomeratica) del Tongriano si sviluppa rerso il Sud-Est a guisa di ampia banda della larghezza dapprima di circa un clilometro, ma poi, gradatamente espandendosi, di oltre due chilometri, dirigendosi verso Est per modo da raggiungere la valle del Tanaro tra i Gerbioli ed il Martinetto di Bagnasco ed oltrepassarla per lungo tratto sino a perdersi in lembi staccati presso le borgate di Perlo e di Costa.

In questo lungo sviluppo del Tongriano frammezzo alle roccie antiche (Talcoschisti, Anageniti, Appenniniti, Calcari, ecc), i suoi banchi, generalmente con inclinazione poco forte, ed anzi talora quasi orizzontali, pendono complessivamente verso il Nord circa sino alla valle del Tanaro, ma quivi paiono disporsi i fondo di battello giacchè presentano bensì nella parte meridionale della conca un'inclinazione abbastanza regolare ver'so NordNord-Ovest, ma invece nella parte settentrionale verso Rocca Lupara, Isola, ecc. hanno una pendenza piuttosto marcata rerso il Sud ad un dipresso, il cle ci indica trattarsi qui di una specie di piccolo bacino tongriano, entroalpino, cle comunicava bensì probabilmente in modo più o meno diretto col grande bacino piemontese, ma nel quale formaronsi depositi specialmente continentali, come infatti ce lo provano i resti fossili di piante e 
di animali generalmente continentali, lacustri o terrestri, che quivi si rinvengono.

I banchi della zona longriana ora esaminata, spesso con una inclinazione abbastanza piccola, generalmente non superiore a $15^{\circ}$ o $20^{\circ}$, constano essenzialmente di elementi ciottolosi e breeciosi per lo più fortemente cementati in conglomerati o breccie resistentissimi, ciò che devesi attribuire alla presenza di formazioni calcaree triassiche poco lontane; talvolta però i materiali che costituiscono questi depositi tongriani si presentano disciolti e commisti a sabbia grigio-giallastra così che non è sempre filcile il distinguerli da quelli dei terreni quaternari che osservansi qua e là in lembi lungo la valle ad una certa elevazione sul foudo della valle stessa.

Queste difficoltà incontransi ad esempio presso Madonna della Neve, presso Liorato, sopra i Gerbidi, ecc., dove trovansi depositi ciottolosi ad elementi talora voluminosi, spesso sciolti, senza apparente stratificazione ed accompagnati da sabbie e da terra sabbiosa poco cementata e con facies recenti.

I conglomerati brecciosi di queste regioni sono formati alle spese delle roccie affioranti nelle vicinanze; cosi essi sono prevalentemente calcarei e quindi fortemente cementati dal Bric del Bava verso Battifollo; invece rerso Mombasiglio, ampiamente affiorando quivi i Talcoschisti, il Tongriano è costituito essenzialmente di frammenti talcoschistosi, quasi mai cementati, spesso talmente alterati da confondersi col Talcoschisto in posto pure superficialmente frantumato e decomposto. Se poi si esamina attentamente la composizione litologica del Tongriano salendo da Mombasiglio a Torre Scagnello si vede assai bene il graduale passaggio dal conglomerato-breccia ad elementi talcosi a quello ad elementi calcarei.

Alternati coi banchi conglomeratici troviamo poi in alcuni punti (per esempio sulla destra della valle Tanaro di fronte a Bagnasco ed alla sinistra del Borgo di Bagnasco sino alla Regione le Rocchette) assai sviluppati certi straterelli marnososabbiosi di color giallo-grigiastro e piuttosto duri, tanto da ve- 
nir escavati per ottenerne lastre; essi sono molto preziosi pel paleontologo in causa delle impronte di foglie e di pesci clse sovente racchiudono.

Quanto alle lenti lignitiche (inglobate tra i banchi marnososabbiosi, grigio-azzur'rastri ed i banchi conglomeratici) che si scoprirono in diversi punti del bacino di Bagnasco dando luogo ad escavazioni industriali e fornendo resti di Manniferi e di Molluschi continentali, sono specialmente a notarsi quelle che affiorano sulla destra della valle Tanaro di fronte ai Gerbioli, nella valletta d'Isola, presso i Massimimo (dove le marne bleuastre lignitifere appoggiansi sulla roccia talcoschistosa e rengono coperte da banchi coinglomeratici), di fronte al Borgo di Bagnasco, e sulla sinistra di Valtanaro nelle vicinanze di Bagnasco, specialmente nella valletta delle Rocchette. Inoltre nell'allungato lembo isolato di Tongriano di Perlo sonvi pure lenti ligniticlie, nelle immediate vicinanze di borgata Villaro, inglobate a marne bleuastre basanti sulla roccia in posto; quivi reggonsi pure placche residue di sabbie, ciottoli e puddinghe aderenti alla roccia in posto, costituenti talora falda acquea, nonchè sabbie rossastre commiste a ciottoli e ciottoloni per modo da simulare un deposito quaternario e talora da confondersi colla roccia in posto, come ad esempio sul lato Nord-Est del Bric Castello. Notiamo infine come presso Perlo siansi anclse riscontrati resti di Rhinoceros incisivus.

Al Bric della Biscia il Tongriano è rappresentato da frammenti irregolari di Calcare e di Talcoschisto profondamente alterati e talora difficilmente discernibili dalla roccia calcarea e talcosclistosa in posto, pure noterolmente decomposta.

In complesso pare che nel bacino di Bagnasco i depositi tongriani, disposti a conca allungata, siano rappresentati verso la base specialmente da potenti e cementatissimi conglomerati-breccie, qua e là però alquanto disciolti e talvolta inglobanti marue grigio-bleuastre lignitifere; verso la parte media e superiore invece predominano marne sabbiose straterellate grigio-giallastre fillitifere e frammenti ciottoloso-brecciosi commisti a sabbia ros- 
sastra; esistono però ripetute e talora irregolari alternanze in queste varie formazioni.

La continuazione della zona tongriana ora descritta trovasi verso Est, dnpo un interruzione abbastanza notevole, cioè ai Bric Spagnora, Valcada, ecc.; ma quivi le placelse tongriane, direi, entroalpine, vengono a collegarsi abbastanza bene con quelle clıe contornano le falde alpine, e quiudi non ne tratterò piì a parte.

Ritornando al punto di divisione, presso Mombasiglio, della zona tongriana entroalpiua da quella subalpina ed esaminando ora quest'ultima, verliamo come essa, rappresentata essenzialmente da banclij conglomeratici, vada rapidamente restringendosi, mentre i suoi strati si rialzano notevolmente costituendo le alture di Mombasiglio; poscia nella valle di Rifreddo questa zona scompare per circa un clilometro sotto alle marne dello Stampiano, ricomparendo quindi in Val Roveriana, dove però non si presenta più esclusivamente conglomeratica ma eziandio ghiaiosa ed arenacea, quindi abbastanza ricca in fossili.

Con questa facies, essenzialmente arenacea, vedesi continuare il Tongriano verso Maragna e la valle del Tanaro, ridotto però ad una sottile striscia marnoso-arenacea grigiastra, fossilifera, che spesso " difficilmente separabile dal sovrastante Stampiano essenzialmente marnoso ma passante pure, rerso la base, a fine arenarie.

Oltre a questa piccola striscia tongriana dobbiamo poi menzionare clie a Sud, ed in correlazione più o meno diretta colla fascia subalpina, esistono numerose placche tongriane generalmente isolate sopra le roccie antiche (Talcoschisti, Quarziti, Appenniniti); tali placclie sottilissime, conglomeratiche, arenacee o sabbiose, fortemente alterate, sono spesso ridotte a resti appeni riconoscibili o talora rappresentate solo più da alcuni ciottoli residui, sparsi qua e là sulla roccia preterziaria.

Generalmente queste placche trovansi isolate sui punti più elevati e leggermente pianeggianti della regione montuosa indicando così di avere originariamente costituito un velo quasi 
continuo che collegava in gran parte la formazione tongriana subalpina con quella entroalpina, tant' è che questi lembi si elevano gradatamente verso Sud, coll' elevarsi della regione montuosa, sino ad oltrepassare gli 800 metri, portandosi cioè all'altezza media dei depositi tongriani di Scagnello-Battifollo; verso Nord invece, poco a poco abbassandosi, essi vengono a collegarsi indirettamente ed anıhe direttamente, come presso i Villero, ed ai Massarelli, colla zona tongriana subalpina. Credo tuttavia che da questo velo terziario, collegante le due indicate zone sorgessero, anche originariamente, alcune isole o spuntoni di terreno preterziario, come ad esempio il Bric Bastia, costituito essenzialmente di Appenninite.

Dalla Val Tanaro continuando l'esame del Tongriano verso Est vediamo per lungo tratto fenomeni eguali a quelli ultimamente descritti. La zona subalpina piuttosto stretta, in generale assai arenacea, ma talora anche ad elementi ciottolosi enormi, si dirige verso Molere, nelle cui vicinanze essa si presenta assai ricca in Nummuliti, Orbitoidi, Ostriche, ecc.; poscia detti zona si va rapidamente ampliando, collegandosi indirettamente colla larghissima ma sottile placca tongriana sabbioso-conglomeratica (ad elementi ciottolosi talvolta colossali) di NalpotremoS. Rocco, la quale a sua volta proluıgandosi e sollevandosi molto verso Sud, si collega pure indirettamente, in causa dell'arrenuta erosione, coi depositi tongriani entroalpini di Perletta.

Nella grande placca tongriana di Malpotremo, come pure nelle formazioni contemporanee e di disposizione consimile, osserviamo ad un dipresso la seguente sezione: 
4. Sabbic rossastre, talora inglobanti ciottoli e ciottoloni sparsi irregolarmente (facies di Diluvium); talvolta banchi narnosi di color grigiastro o bleuastro.

3. Arenarie, conglomerati, puddinglıe, breccie for- Tongriuno temente cementate ma di poca potenza ( 2 a 3 metri generalmente).

2. Banco di enormi ciottoloni, talora ancora angolosi, commisti a sabbia.

1. Roccia preterziaria.

Ad Est di Molere il Tongriano alquanto sviluppato, a limiti molto irregolari, con placchette residue isolate lungo le falde occidentali di Cima dell'Alonga, e viceversa con emersioni interne, direi, di roccie antiche, si presenta generalmente a dolce inclinazione ed è costituito essenzialmente di sabbie ed arenarie (talora rossastre per alterazione) nonchè di lenti ciottolose ed anche alquanto brecciose ad elementi tolti alle più vicine regioni inontuose.

Tra Castelnuovo e la Val Bormida di Millesimo si riscontra nuovamente nell'area tongriana una specie di divisione (quantunque assai meno spiccata clie non nel caso di prima e dovuta quasi unicamente all'erosione), tra una zona subalpina arenaceosabbiosa, qua e là conglomeratica, non di rado fossilifera, spesso ridotta ad una sottile striscia, ed un'amplissima zona entro-alpina inerualissimamente frastagliata, talora molto potente; quest'ultima è costituita essenzialınente di arenarie e di sabbie (per lo più rossastre per profonda alterazione) che inglobano lenti n banchi di ciottoli e ciottoloni; questi sono talora cementati, ed allora sporgenti o costituenti creste e monoliti torreggianti, ma sovente invece sono disciolti e quindi facilmente distaccantisi dalla massa avvolgente.

Talvolta anche in località vicinissime osservansi qua arenarie smentate, dure, bruniccie, là invece sabbie rossastre, quasi disuiolte, inglobanti ciottoli e ciottoloni caoticamente disposti; 
spesso poi veggonsi le prime formare delle placchette allungate sopra alle seconde.

Sezioni stupende del Tongriano di queste regioni si possono osservare specialmente nei dintorni della Madonna del Deserto, dove questo terreno è potentissimo, messo profondamente e largamente a nudo da grandi spaccati naturali, e ricco, come di solito, in sorgenti, fra cui una rilevantissima che sbocca presso la Chiesa e che fu probabiluente il movente della costruzione di quel Santuario.

Quantunque in questa potente zona tongriana di Madonna del Deserto non abbia finora riscontrato fossili, tuttavia dal suo assieme credo che essa siasi originata in modo molto analogo a quello della conca tongriana di Bagnasco, cioè specialmente per depositi fluviali o fluvio-marini e quindi non sarebbe improbabile che vi si rinvenissero lenti ligniticlie.

Il vedere poi come questa formazione terziaria colla sua tipica facies ciottolosa, di color rosso vinoso, discende in alcuni punti sino al fondo di Val Bormida, come presso Acquafredda dove essa si appoggia direttamente sopra i Calceschisti e le Appenniniti, ci induce a credere come fin dall' epoca tongriana la regione montuosa, costituita dalle roccie antiche, presentasse già una configurazione molto irregolare e profonde vallate in cui deponevansi, a poca distanza dal litorale di quell' epoca, i terreni terziarii.

Nei dintorni di Millesimo il Tongriano, probabilmente a causit del grande sviluppo dei calcari triassici a Sud, presentasi in parte composto di arenaria calcarea cementatissima, fossilifera, compatta in modo straordinario, tanto da simulare talora una roccia càlcarea preterziaria; ciò vedesi specialmente sia poco a Nord di Valzemola, sia nella valletta ad Est di Millesimo, sia eziandio in Val Cosseria, poco ad Ovest di C. Malpenso; nei due primi casi questi banchi speciali sono escavati per materiale da costruzione.

Un fenomeno consimile si osserva poco a Sud di Castelnuoro di Ceva, presso C. Baccalotto, dove il Tongriano appoggiantesi 
sul calcare triassico simula quasi una roccia calcarea, che però si vede talora altcrnata con arenarie oppure formata da un assieme di frammenti brecciosi e di ciottoli calcarci che ci indicano un impasto dei materiali triassici fatto a poca distanza dal loro punto d'origine.

Siccome in queste regioni talora lo Stampiano diventa in parte arenaceo-conglomeratico, è spesso difficile distinguerlo dal Tongriano; gencralnente però esiste tra i due orizzonti un banco o complesso di banchi marnosi grigio-verdastri chc sono assai utili per fare tale distinzionc.

Talora i calcari triassici, là dove vengono direttamcnte coperti dai terreni tongriani, presentano dei fori di Litodomi, fori fatti ccrtamente in epoca tongriana giacclıè tali roccie formarono le scogliere ed i litorali del mare d'allora; ciò vedesi ad esempio presso il Molino a Sud di Millesimo, presso C. Malpenso in rio Cosseria ecc.: in questi casi però generalmente si osserva clie questo calcare traforato è già in partc ridotto in frammenti cementati con arenaria e quindi già appartenenti parzialmente al Tongriano.

Ad Est di Millcsimo il Tongriano, a causa del generale svilıppo dello Stampiano verso Sud, rimane per breve tratto masclierato, ma ricompare tosto coi suoi tipici e potenti conglonerati, spesso a ciottoli fortemente improntati, nell'ampia valle della Bormida di $S_{i}$ igno dove esso si sviluppa amplissimamentc, non tanto per avere una potenza straordinaria quanto specialmente perchè, essendo esso poco inclinato e l'erosione acquea avendo potuto facilmente esportare la formazione marnosa dello Stampiano, rimase a nudo per grande estensione il sottostante oriz\%onte arenaceo-conglomeratico del Tongriano assai resistente alle azioni erosive.

Esistono anche in questa regione lembi tongriani isolati, come ad esempio quelli essenzialmente ciottolosi, e ad elcmenti per lo più di Appenninite, che osservansi presso la Valle Fossocroso sopra i Talcoschisti, le Appenniniti e le Quarziti di quella località; sia detti lcunbi come i prolungamenti più mcridionali del 
Tongriano (Bric Dorin, Moncavaglione, ecc.) sono specialmente rappresentati da ciottoli sparsi irregolarmente e commisti ad una specie di terra 'sabbiosa giallo-rossastra per alterazione chimica, ciò che fa rassomigliar tali terreni a depositi diluviali di epoca quaternaria; talora anzi è così profonda la decomposizione di tutti i materiali che riesce difficile persino la distinzione dell' impasto tongriano dallo sfacelo alterato della roccia talcoschistosa.

Per esaminare minutamente la costituzione del Tongriano a facies conglomeratica è specialmente utile il percorrere la Valle di I'lodio dove i banchi ciottolosi potenti, spesso col tipico color rosso vinoso si mostrano in ampi spaccati naturali da ambi i lati della valle; d'altronde bellissimi conglomerati tongriani si pussono pure osservare sulla destra della valle specialmente là dove questo orizzonte geologico s'appoggia sulla roccia antica, cosi al Bric Dorin, tra il M. Grosso e Carcare, presso C. Moncavaglione, C. di Maciola, ecc.

Sulla sinistra poi della Valle Bormida si osservano pure potenti conglomerati particolarmente attorno agli spuntoni di roccia antica come in Val Auta tra Montenudo e Cosseria, ed in Tal Cosseria presso al Casello 22 della ferrovia; questi fatti ci rivelano la poca potenza dell'orizzonte in esame, giacchè esso presenta tosto a giorno i suoi banchi inferiori appena che si verificano leggieri rialzi nella sottostante regione rocciosa.

Importanti poi sia per il paleontologo che per l'industriale sono i banchi arenacei, talora fortissimamente cementati, che in gran parte rappresentano il Tongriano nel bacino di Carcare. Iufatti queste arenarie, in più punti fossilifere, dànno eziandio un materiale da costruzione non difficilmente lavorabile ed abbastanza resistente.

Nella stessa maniera che gia ebbimo a constatare nella formazione tongriana depositi subalpini e depositi entroalpini, cosi anche nella regione ora in esame, nonchè più avanti verso Est, ed anzi (a causa della poca elevazione generale della regione appenninica) in molta maggior estensione che non pei casi gia 
osscrvati, si può grossolanamente distinguere nell'area tongriana una zona irregolare subappenninica che avrolge le falde settcntrionali dell'Appennino settentrionale, ed una irregolarissima zona entro-appenninica di cui troviamo aree staccate, più $o$ meno espanse, presso Cadibona, Altare, Giusvalla, Mioglia, S. Giustina, Sassello, Pian Castagna, Tiglieto, ecc. e più ad Est ancora sulle alture attorno a Busalla, Ronco Scrivia, ecc.

Questa formazione tongriana entro-appenninica, più o meno direttamente comunicante in origine con quelle subappennine, sia tirrena, sia specialmente adriatica (o padana), quantunque in generale di carattere meno continentale di quello entro-alpina di Bagnasco tuttavia, oltre che di depositi marini, consta spesso di importantissimi depositi marino-salmastri con abbondanti Potamides, innumerevoli filliti, ecc. nonchè di veri depositi contincutali con ligniti, Mammiferi terrestri, Molluschi lacustri, ecc. come ad esempio presso Cadibona.

Siccome di questi depositi tongriani entro-alpini (straordinariamente ricchi in fossili) di Cadibona, S. Ginstina, e Sassello vcnnero già fatti studi accurati, specialmente dall' Issel, così mi limito in questo lavoro ad accennarli scuza esaminarli particolarmente.

Come di solito la distinzione sopraindicata del Tongriano in due zone, quantunque abbastanza ragionevole in complesso, viene talora a mancare nell' esame geologico particolare, giacchè le due formazioni si veggono congiungersi in molti punti per mezzo sia di irregolari prolungamenti sia di lembi isolati. Cosi abbiamo ad Est della conca tongriana di Carcare il prolungamento digitiforme di C. Le Greppie, l'ampia placca dei Manazzi (he va ad unirsi col bacino di Cadibona, gli sparsi lembi di Cravetto soprana (con numcrosi fossili, specialmente nummulitici, sparsi fra le arenarie), di C. Ravagni e di Meuja dci Rossi (ad alenarie commiste a sabbia rossastra per profonda decomposirione), di Pra Ellera, di Croce di Blin, ecc.; lembi tutti sottilissimi estendentesi specialmente nella parte più elevata ed alquanto pianeggiante (in parte per causa appunto della loro pre- 
senza) della regione rocciosa, costituita quivi essenzialmente di Talcoschisti e di Serpentine.

Anche in questi casi si puó supporre come originariamente questi sparsi lembi facessero parte di un ampio, se non potente, velo che ricopriva quasi completamente le roccie antiche le quali ne emergevano solo qua e là come isolotti più o meno vasti.

Dove la zona tongriana assume non solo un'ampiezza, ma anche una potenza molto considerevole è nella regione montuosa di Giusvalla tra Valle Erro e Val Valla; in questa ampia zona il Tongriano è rappresentato essenzialmente da depositi conglomeratici di color verdastro o rosso rinoso, potentissimi e ad elementi spesso voluminosissimi, come ad esempio possiamo vedere assai bene sulla sinistra dell'Erro e del Labiasco, nel vallone dell'Amore, nei monti Orsaro e dell'Avra, nelle regioni collinose di Pian Pietro, e quasi ovunque in Val Valla. Però specialmente nell'orizzonte superiore della regione tongriana in esame compaiono ed acquistano anzi un notevole sviluppo $\mathrm{i}$ banclii arenacei più o meno cementati, qua e là assai fossiliferi, costituenti pendii di forma speciale; è specialmente nei dintorni di Giusvalla clıe queste arenarie si possono osservare su più larga scala, quantunque esse appaiano ancle ampianente sriluppate a diverse elevazioni quasi ovunque, specialmente nelle parti superiori, della regione in istudio.

La potenza, sia delle arenarie, sia dei conglomerati varia immensamente da luogo a luogo, anche in regioni molto vicine.

In alcuni punti verso la base del Tongriano esistono marne bleuastre, che ricordano quelle lignitifere di Cadibona, Roccaforte, ecc. e potrebbero quindi anche inglobare lenti lignitiche e fossili continentali; si è al Bric del Ciò che veggonsi abbastanza sviluppate tali marne. Frammezzo, ma specialmente sopral ai banchi arenacei sovraccennati, veggonsi banchi sabbioso-marnosi ed anche solo marnosi, grigio-verdastri che talora sono certamente ancora includibili nel Tongriano superiore, talora invece paiono già doversi includere nello Stampiano, quasi sempre però lasciando dei dubbi riguardo all'orizzonte a cui debbonsi rife- 
rìr. Cosi banchi marnosi racchiudibili nel Tongriano sono quelli che osservansi attorno a Giusvalla presso C. Tua, al M. Nero, presso borgata della Colla, presso C. della Codolla, ecc.; sono invece di dubbio riferimento molti banchi marnosi passanti ad arenarie che osservansi tra Mioglia ed i] M. Bono, presso le borgate Pori, Botta, Berri, Preisa, Chelini, ecc.

Riguardo alla tettonica della regione accennata si può dire che in complesso $\mathrm{i}$ banchi tongriani inclinano di $10^{\circ}$ a $15^{\circ}$ verso l'Ovest od il Nord-Ovest; notiamo però numerosissime eccezioni a questa regola generale, così ad esempio i banclii arenacei delle colline di C. Labuja ad Ovest di Giusvalla pendono specialmente a Nord-Est; ma ciò clie è più notevole a questo proposito è il fatto che ad Orest di Mioglia i banchi tongriani che sopportano la zona stampiana sono fortemente sollevati e pendono verso l'Est-Nord-Est; questo ci indica clie la notevole elevazione della cresta M. Orsaro-Bric dell'Avra non è dovuta solo ad una grande potenza dell'orizzonte tongriano, ma eziandio a forti sollevamenti lovuti probabilmente ad una cresta di Serpentina o di Talcoschisto che collega le regioni rocciose di Pontinvrea cogli spuntoni rocciosi di rio della Sorba, ecc. Inoltre l'indicata forte inclinazione ad Est dei banchi conglomeratici di Bric dell'Avra, assieme all'inclinazione opposta che presentano gli stessi banchi al M. Bono, ci spiega molto bene l'allungato seno di Mioglia.

Accenno qui incidentalmente come chi volesse prendersi una idea complessiva dello stupendo bacino oligocenico dell'alta Val Bornida putrebbe ragriungere facilmente questo scopo con una salita per esempio a Piazza Grande sulla collina del Dego, giaccliè da questa altura in una giornata chiara si può abbracciare l'intiera zona oligocenica che si estende ampiamente ad Ovest ed a Nord.

Nella regione montuosa a Sud della collina del Dego si osservano ancora ampie ed irregolari aree tongriane costituite essenzialmente di conglomerati e conglomerati-breccie alternati e commisti con marna sabbiosa rossastra o con strati arenaceoghiaiosi. 
Queste formazioni tongriane si collegano indirettamente ad Ovest colla grande area fossilifera di Carcare e a Sud colla fitmosa area lignitifera di Cadibona. Quivi sopra alle roccie cristalline preterziarie si osserva una bellissima serie di banchi conglomeratici, arenacei ed argillosi, piu volte alternati, che inglobano diversi letti lignitiferi, fra cui uno più potente, ricchissimo in resti di Aathracotherium e di altri fossili continentali e lacustri.

Esaminando ora la zona subapennina del Tongriano la vediamo restringersi alquanto verso Cairo Montenotte (a causa di una specie di cresta rocciosa costituita di Serpentina, Talcoschisto e Calcari triassici che dal M. Gos si protende notevolmente verso Ovest sino alle falde del Bric del Froment), ridursi poi ad una semplice striscia sulla sinistra della Bormida sino a Rocchetta Cairo, dove nuovamente si allarga verso Est, congiungendosi poi più o meno direttaniente colla vasta area entro-appenninica, ora esaminata, di Giusvalla.

Ho già fatto risaltare altrove la straordinaria riccliezza in fossili clie presenta il Tongriano di Val Bormida da Pocchetta Cairo sin oltre Piana Crixia; rispetto alla stratigrafia di questa. area tongriana basta accemnare come la sua poca inclinazione verso Ovest o Nord-Ovest spieghi il grande sviluppo che essa presenta ad Est e quindi il frequente apparire di aree o spuntoni di roccie antiche, cosi di Talcoschisti presso Rocchetta Carro, di Talcoschisti ed Appenniniti in Val dei Bourreu a monte di C. Bertè, di Talcoschisti (attorniati da conglomerati tongriani a grossi elementi) presso lo sbocco del rio di Carpez nella Bormida, pure di Talcoschisti attorno a Dego ed a Nord di Bric Ridotte, di Serpentine ed Appenniniti al fondo di Val Bormida ad un dipresso tra $\mathrm{i}$ caselli 11 e 12 della ferrovia.

Predominano in questa vasta zona le arenarie sia disciolte, sia fortemente cementate, tanto da venir escavate come materiale da costruzione, come presso Rocchetta e specialmente presso Dego, la dove la regolare stratificazione rende facile l'estrazione di lastre un po'ampie; la noterole cementazione di queste are- 
narie di Val Bormida credo sia in gran parte attribuibile ai terreni triassici cle appaiono poco a Sud e fornirono il materiale calcareo cementante.

Tra il Tongriano e lo Stampiano vedonsi sovente ben netti bellissimi banchi di passaggio, rappresentati da strati marnososabbiosi alternati con banchi arenacei di color brunastro, come ad esempio ad Orest di Piana Crixia nella valletta di C. Valeggie; llaturalmente esistono quivi come di solito grandi difficoltà per una netta delimitazione fra i due orizzonti geologici.

Nelle placche tongriane sparse sulle roccie antiche, specialmente sulla destra della Bormida, osservansi sovente predominare gliaiette giallastre, talora un po' lucenti, e sabbie rossastre per alterazione chimica.

Non sono rare in queste località le lenti conglomeratiche, generalmente poco potenti, tra la roccia antica e l'arenaria tongriana; esse però divengono poi potentissime, ad elementi spesso enormi ed anche brecciosi, poco a Nord di Villa del Piano, ma specialmente nei dintorni di Piana Crixia tra Casazza e I,oueisi e, più a Nord ancora, sotto borgata Morere nonchè nei dintorni di Pian del Gallo.

Talora i ciottoli tongriani sono sparsi irregolarmente in una specie di pasta terrosa rossastra che ricorda alquanto il loess quaternario, talvolta invece, gli elementi rocciosi del Tongriano sono solo rappresentati da frammenti angolosi, tolti alle più vicine roccie antiche, e cementati assieme irregolarissimamente per mezzo di sabbie ed arenarie giallastre.

Lungo la linea di contatto fra la roccia antica ed il Tongriano non è raro osservare, sia nella regione in esame che altrove come vedremo, un banco conglomeratico ad elementi molto voluminosi e quasi sempre della stessa natura della roccia sottostante. Cosi ad esempio in una trincea ferroviaria presso il passaggio a livello della stazione di Cairo osservasi in modo nettissimo clie sopra ai Talcosclisti fortemente inclinati verso Sud-Ovest appoggiasi un banco (inclinato verso il Nord circa) di ciottoli di varie dimensioni caticamente commisti ad una 
specie di pasta talcoschistosa risultante dallo sfacelo quasi locale della roccia sottostante; su ciò si appoggiano poi strati conglomeratici con sabbie rossastre ed infine arenarie per lo più fortemente cementate.

Il Tongriano di Val Bormida poco a poco abbassandosi verso il fondo della valle viene a scomparire completamente sotto ai depositi dello Stampiano poco a Nord di borgata Loueisi; ma in causa dei notevoli sollevamenti che la sepolta regione serpentinosa presenta verso Nord (tanto da emergere in più punti come è già stato indicato trattando dei terreni preterziarii) ne deriva che le anche assise del Tongriano, le quali seguono generalmente l'irregolare andamento della roccia antica, rengono ad emergere dapprima solo come piccola zona frastagliata e con banchi sollevati talora di $40^{\circ}$, al fondo dei rii di borgata Morere, ma poscia amplissimamente tra Pian delle Meuje e Spigno Monferrato, sia colla facies conglomeratica (come specialmente attorno a Pian del Gallo), sia specialmente colla facies arenacea con semplici lenti ciottolose, anche però a grossi elementi, specialmente nella parte inferiore; spesso questi depositi si frammettono nelle sinuosità della roccia antica a cui direttamente si appoggiano.

Poco a Nord di Spigno, prima di giungere alla borgata Vico, il Tongriano si immerge definitivamente sotto allo Stampiano e non riappare neppure attorno all'emersione serpentinosa che già accennammo esistere quasi sotto il M. Castello sulla destra della Bormida.

Per seguire ora lo sviluppo del Tongriano verso Est dobbiamo portarci nella vasta regione cle si stende tra la val Bormida e la Valle dell'Erro, esaminando specialmente il fondo dei rii dove questo terreno viene spesso ad affiorare sotto le marne dello Stampiano.

In Val Valla il terreno in esame si presenta essenzialmente conglomeratico, ad elementi spesso enormi, talora col tipico co. lor rosso-vinoso, talvolta con potenza straordinaria specialmente sotto Montaldo e nelle vicinanze di Squameto, nel rio della 
Sorba, ecc.; sono però quivi anche bene sviluppati i banchi arenacei che talora anzi quasi da soli rappresentano l'orizzonte inferiore del Tongriano, come ad esempio al fondo del rio Rabbioso attorno alla lunga striscia di roccia antica messa a nudo dalla erosione del torrentello.

Affioramenti isolati di Tongriano, in fondo ai rii, notansi quasi sotto i casali Costa Bella, e presso la borgata Turpino, con prevalenza, in ambi $i$ casi, di banchi arenacei; nella parte alta di Val Barbiano, a Sud di borgata Scajoli, affiorano pure potenti conglomerati tongriani sotto alle solite arenarie, che poi strettamente si collegano collo Stampiano, da cui sono quindi difficilmente distinguibili.

È poi essenzialmente arenacea, quantunque con lenti ciottolose, l'irregolarissima zona di Tongriano che, ricoperta in nodo assai vario dalle marne dell'orizzonte superiore, o attornia piccoli spuntonil serpentinosi, come a Nord di borgata Giuliani ed a Nord dai casali Bergiavelli, oppure ravvolge le falde della vasta area prevalentemente serpentinosa che costituisce la regione veramente appenninica, come si può osservare sulle carte geologiche, oppure si presenta in placche isolate sulla roccia antica come specialmente si osserva dal M. Acuto sin oltre il paese di Malvicino. Noto però che al fondo di Val Roboaro ed a Sud del paesello di Miojola il Tongriano si presenta costituito verso la base dai soliti potenti conglomerati sormontati dai banchi arenacei.

E specialmente in causa della grande cementazione e della fortissima aderenza che certi banchi arenacei presentano colla roccia antica, che si può spiegare la presenza di alcune placche tongriane ancora rispettate dalla potente erosione che intaccò profondissimamente le sottostanti roccie serpentinose, ciò dicasi specialmente per i diversi, e spesso curiosamente situati, residui tongriuni che osservansi al Bric della Vite e da questo al $M$. Acuto.

A Nord di Malvicino, allungandosi sin quasi a Cartosio l'affioramento della roccia antica, si prolunga pure notcrolmente 
la zona tongriana che anzi diviene quivi abbastanza potente, forse anche perchè nella sua composizione prendono una gran parte i banchi conglomeratici clı vediamo infatti assai bene sviluppati nel rio del Senatore, attorno a Cartosio, nell'affioramento che compare al fondo del rio di C. Colombano a Nord di Bric Uccellino.

Nel rio di Saquanna attorno allo spuntone serpentinoso, il Tongriano consta specialmente di arenarie, ma lo troviamo poi conglomeratico sia presso la horgata Saquanna sia attorno ad un piccolissimo spuntone serpentinoso che osservasi tra ii torrente Frro e la borgata Saquanua.

Sono alquanto curiose le placche di Tongriano che osservansi presso il Molino di Vassallo e la C. Castagnole sulla destra dell'Erro, e che trovansi applicate alla roccia serpentinosa in morlo clie talora questa strapiomba quasi sopra esse, simulando una sovrapposizione stratigrafica.

Più verso Sud l'orizzonte in istudio si va riducendo ad una sottilissima zona arenacea, che infine si perde anch'essa, venendo coperta dalle marne dello Stampiano, ma ricompare poi in lembi più o meno ampi nelle parti pianeggianti ed elevate di Toleto e dintorni, come vedremo fra breve.

Passiamo ora all'esame del Tongriano in Val Visone, accennando però ancora che appunto come termine di passaggio, questo terreno colla facies arenacea compare eziandio al fondo di Tal Cariogna ad Est di Bricco del Brin, ma solo per breve tratto.

Un ristrettissimo ma molto importante afforamento arenaceo-conglomeratico di Tongriano appare a Nord-Est di Caratore in Val Ravanasco; esso è in sottili banchi sollevati quasi alla verticale e diretti ad un di presso da Nord a Sud e circonda quasi completamente il piccolissimo spuntone serpentinoso di C. Ferri; delimitando il Tongriano di questa importante quantunque stretta localita, si ottiene sulla carta una specie di $y$ coll'apertura a Sud.

In Val Visone il piano geologico in esame, mai molto potente, è spesso rappresentato solo da una striscia clie divide lo Stam- 
piano dalla roccia antica; ma essa si allarga alquanto verso Nord, come nella Valle ad Est di M. Capriole e nella valle di Castellamare, cioè là dove il Tongriano, non essendo più ridotto a semplice unglia, come verificasi dove esso s' appoggia sulla roccia antica, viene ampiamente liberato dai depositi più recenti che altrove generalmente lo ricoprono.

Il paese di Grognardo è fondato in massima parte sulle arenarie e sui conglomerati del Tongriano sotto cui sporge qua e Jà la roccia antica rappresentata da Serpentine e da Talcoschisti, che sviluppansi poi ampiamente e liberamente verso Sud; presso Grognardo esistono spuntoni serpentinosi nel letto del T. Visone presso Grognardo ed anche cento metri a Sud del paese, nonchè in Val Poggio anche molto a monte di questa borgata.

Sulla sinistra di Val Visone, nonchè nella valle ad Est di II. Capriole ed in Val Castellamare predominano in questo orizzonte le arenarie, ridotte talora a piccolissimi lembi placeati sulle roccie antiche, come nei dintorni di Caldasio presso le C. Fosse e le C. Del Gatto, pur comparendo eziandio qua e là, specialmente verso la base, le lenti conglomeratiche; così presso i casali Galli in fondo di Valle delle Rocche (dove compaiono spesso ciottoli di enorme rolume), tra Pian Forca e La Valle, presso Ciglione, attorno a Grognardo, in Val Poggio sotto C. Verazza, ecc.

In queste regioni incontransi pure talora lenti lignitiche nei terreni tongriani superiori, cosi ad esempio, presso Ponzone, specialmente nel vallone ad Est di questo paese; quivi infatti sopra alle arenarie ricchissime in Nummuliti, Molluschi, ecc., osservansi lenti di lignite che inglobano pure talora resti fossili (Melanopsis, ecc.).

Viceversa sulla destra della Val di Visone il Tongriano, pure ridotto generalmente a semplice striscia, è essenzialmente conglomeratico, come si osserva da Grognardo a C. Canaletto e nella parte alta di Val Caramagna, presentandosi però come sottile benda arenacea presso Morbello e come placca pure arenacea ad Ovest della Madonnina di Bandita. 
Prima di passare all' esame dei depositi tongriani di Talle Orba, devo ancora menzionare alcuni importantissimi affioramenti isolati che di questo terreno osservansi al fondo di diversi valloni ad Est di Grognardo; così quello stretto, allungato, arenaceo ad Est di M. Menno; quello amplissimo, arenaceo nella porzione superiore e conglomeratico verso la base, che occupa gran parte della valle della Pinna; quello ancor più importante, sviluppato per oltre due chilometri a Sud di S. Biagio in Tal Catramagna, che si presenta arenaceo ed abbastanza fossilifero nella parte superiore e meridionale ed invece con potentissimi conglomerati nella porzione inferiore e settentrionale in corrispondenza dell'emersione di roccie antiche più a Nord; allcora in Val Caramagna, poco a Nord del paesello di Prasco, dobbiamo menzionare l'affioramento, in due punti, di arenarie dell'orizzonte in questione, poggianti sulla zona serpentinosa antica.

Tutti questi affioramenti di Tongriano, isolati in mezzo alle marne dello Stampiano, sono causati da una specie di rialzo che la regione rocciosa forma verso Nord, tanto da sporgere per lungo tratto e costituire il Bric Marzapiede, presentandosi anche assai rilevata tra Grognardo ed Ovada, per modo che quivi i terreni tongriani sono ridotti ad un velo poco potente e facilmente intaccabile dalle erosioni acquee, mettendo così a nudo i banchi basali.

Talora nelle vicinanze di Molare tra le arenarie del Tongriano e le marne grigio-verdastre dello Stampiano compaiono banchi sabbiosi grigio-brunastri.

Se si percorrono le regioni montuose di Cimaferle, di Pian Castagna, ecc., tra la valle dell'Frro e la valle dell'Orba, si incontrano molto spesso zone tongriane anche molto estese, quantunque piuttosto sot tili, che possiamo indicare brevemente, notando però anzitutto che in queste regioni riesce sovente assai difficile il distinguere nettamente il Tongriano dallo Stampiano, sia perchè i loro caratteri tanto litologici quanto paleontologi quivi spesso si confondono, sia perchè in molti casi sono precisamente i banclii di passaggio tra un orizzonte e l'altro quelli che costi- 
tuiscono placche nella regione che passeremo brevencrite in esame.

Dalla cresta collinosa di Ponzone avanzandoci verso Cimaferle, dopo aver attraversato lo Stampiano di C. Morera si incontra la serie tongriana arenacea, assai fossilifera, clıe si continua a Nord verso Grognardo mentre che verso Ovest scompare in breve. Vediamo poi un' ampia placca tongriana sllungata, costituita dalle tipiche arenarie cementate, sotto la borgata Verzella, dove i suoi strati inclinati leggermente a Nord-Est sopportano un velo di marne stampiane.

Ma nelle ampie placche oligoceniche che formano le alture pianeggianti di Cimaferle, di Toleto, di C. Pra d'Orso, di Gorreta, ecc. vediamo svilupparsi notevolmente certi banchi speciali sabbiosi, giallastri o verdastri a piccoli ciottolini lucenti, sciolti o cementati, che ci indicano veramente un deposito littoraneo; orbene tali depositi pare si trovino nel passaggio tra Tongriano e Stampiano, sono quindi incertae sedis; tuttavia considerando la loro facies essenzialmente di mare basso e la ricchezza in fossili (specialmente Nummuliti e Pccten) che talora essi presentano, come presso Toleto, presso C. Cascinazza, poco a Nord di C. Pra l'Orso, presso M. del Gatto, ecc., pare che debbansi inglobare ancora in massima parte nel Tongriano.

Generalınente questi banchi sono appena inclinati o meglio ondulati, poichè pendono molto variamente, talora a Nord ma spesso anclie a Sud, come in generale presso Cimaferle e nell'ampia placca di Toleto, oppure ad Ovest come presso Gorreta. Talvolta però i banchi tongriani si presentano localmente molto sollevati, così a Sud di C. Mollie, dove essi pendono di $60^{\circ}$ verso Nord; così pure tra le borgate Bandita e Gorreta dove i banchi tongriani applicantisi contro le Serpentine di C. Marchese, pendono fortemente ad Est.

Gli elementi dei depositi tongriani in questione sono bell spesso brecciosi indicandoci d'aver subito solo una piccola azione ri trasporto prima d'essere depositati là dove oggi si trovano; ciò è poi ancor più evidente per certi depositi ciottolosi a gros- 
sissimi elementi (anche di oltre 4 metri di diametro), sorente ancora a spigoli ben conservati, che incontransi spesso tra il Tongriano e la roccia preterziaria, così presso Fontanaccio, a Sud di Cimaferle, alla base delle grandi placche di Toleto, di Gorreta, ecc.; vediamo cioè in questi casi il residuo del disaggregamento in posto, o quasi, degli isolotti di roccie preterziarie; disaggregamento causato dalle onde del mare tongriano.

Come ebbi più sopra ad indicare, riesce assai difficile in queste regioni il distinguere $i$ depositi tongriani dalle zone stampiane che qua e là vi si incontrano.

Dall'esame delle sorraindicate placche tongriane risulta chiaramente che in epoca tongriana queste regioni appenniniche rap. presentavano un gruppo di scogliere, sporgenti irregolarmente fra le acque marine. I depositi formatisi in quell'epoca si sono solo parzialmente conservati sino al giorno d'oggi, giacchè in gran parte furono abrasi dalle acque.

Infatti, portandoci più a Sud, incontriamo ancora qua e là sulle creste montuose alcune placche conglomeratico-brecciose, spesso sciolte, che ci rappresentano i residui di un deposito tongriano originariamente molto più sviluppato. Ne sono esempio, l'ampia placca di Pian Castagna (che a Nord mostra banchi sabbiosi verdastri), quella di Maretti, quella di Sirti; le placchette di Bric Montaldo, di borgata Ricci, ecc.; e più in basso verso Ovest le placche prevalentemente brecciose e sabbiose giallastre di C. Parasi e di Fondoferle verso il fondo di Val Erro, le quali servono così a collegare indirettamente la zona tongriana subappennina di Ponzone-Grognardo-Cassinelle con quella di Mioglia-Giusvalla e con quella famosa entroappennina di Sassello che prolungasi infatti in sottile striscia sino in Tal Erro, presso la confluenza del T. Gallaretto, a meno di un chilometro di distanza dalla zona tongriana di Fondoferle.

E a notarsi a questo proposito come tra i vari banchi tongriani sovramenzionati esistano forti differenze non solo litologiche, ciò che facilmente si comprende, ma anche altimetriche; 
griacchè mentre le placche di Cimaferle, Pian Castagna, Moretti, ecc., trovansi a circa 700 metri di elevazione, quelle invece di Fondoferle e dell'estremitì settentrionale della zona tongriana di Sassello si sollevano in media solo a $400 \mathrm{~m}$. el anzi presso S. Lorenzo, tra C. Cantonata e C. Crosa, le arenarie tongriane scendono sino al fondo di Val Erro a solo più 300 metri circa d'elevazione sul livello marino.

Questo ci prova chiaramente come nell'epoca tongriana fosse già ben plasıata l'orografia della regione preterziaria in esane, e come profondissime già vi fossero le incisioni, quantunque molto diverse da quelle attuali.

Nella valle dell'Orba il Tongriano, mentre verso Nord si presenta colla facies quasi esclusivamente arenacea con poche lenti ciottolose, verso Sud invece, specialmente presso la roccia pretermiaria, diviene in massima parte conglomeratico, come al fondo del rio Amione a Sud di Cassinelle, dall'Orba a C. Varenzana, da C. Arquaia a Pian Quini e Bric della Cacalupa, ecc.; i ciottoli sono talora molto voluminosi ed anche a spigoli abbastanza conservati per modo da dimostrare di trovarsi ora poco lontani dal loro punto di origine, cioè di distacco dalla roccia in posto; si possono ad esempio esaminare molto minutanente questi enormi blocchi, costituenti conglomerati o breccie, nella valletta di Requaglia, attorno ad un piccolo ed elissoidale spuntone serpeutinoso: cosi pure placche di breccia serpentinosa tongriana applicate alla Serpentina in posto veggonsi molto bene sulla destra dell'Orba, quasi di fronte alla Cappelletta di S. Difendente.

Ho già fatto osservare altrove la ricchezza in fossili delle arenarie di Cassinelle e di Bric del Ratio, mi rimane quindi solo ad accennare alla lunga e stretta placca di Tongriano che con posizione stratigrafica assai singolare si appoggia sul prolungamento orientale dello spuntone serpentinoso di Bric Marzapiede.

Nell'ampia valle della Stura di Ovada i terreni tongriani ora in esame furono in massima parte esportati dall' erosione acquea 
lungo l'asse. longitudinale della valle, rimanendo però abbastanza ben conservati sulle alture a destra ed a sinistra della valle stessa, a guisa di enormi placche che si avanzano molto a Sud verso Rossiglione.

Verso Nord, cioè presso i paesi di Costa, di Belforte, ecc., il Tongriano, per la sovraccennata erosione acquea, è ridotto a sottili e strette placche riparate da rialzi della roccia antica, come a Sud di Costa, oppure ad una stretta fascia che divide lo Stampiano dai Talcoschisti e dalle Serpentine della formazione preterziaria.

Già in Val Orba si era fatto notare la prevalenza che vi hanno i conglonerati nella costituzione del Tongriano, ma nella valle della Stura d'Ovada e da questa valle per gran parte del suo sviluppo verso oriente, tale prevalenza diventa assoluta, per modo che si può dire, senza esagerazione, che il Tongriano è quasi esclusivamente costituito da conglomerati, talora anche da conglomerati-breccia, in banchi potentissimi, ad elementi talora enormi; questo fatto è in gran parte dovuto, a mio parere, al notevole ed abbastanza rapido rialzarsi della regione montuosa appenninica poco a Sud della fascia tongriana in esame, per cui i materiali che vennero a costituirla non ebbero a subire lungo trasporto prima di depositarsi, e quindi la loro costituzione litologica è affatto simile a quella delle vicine roccie antiche.

Sono regioni veramente classiche per lo studio dei potenti conglomerati tongriani le vicinanze di Lerma, di Mornese, di Voltaggio, di M. Zuccaro, di Pietra Bissara, di Roccaforte, di Rocclietta Ligure, ecc.; ma senza descrivere dettagliatamente i depositi ciottolosi tongriani di tutte queste regioni, cio che ci obbligherebbe a continue ripetizioni, a causa della loro notevole rassomiglianza nelle varie località, ne indicherò solo i fenomeni più caratteristici.

Ad Est della Stura d'Ovada sino alle colline tortonesi il Tongriano assume uno sviluppo straordinario di quattro o cinque chilometri circa in larghezza; presso Lerma, Voltaggio, Pietra- 
bissara, ecc. osservansi in questa larga striscia terziaria profondissime incisioni dovute alla potentissima erosione esercitata specialmente in epoca quaternaria dalle acque dei torrenti Pioti e Gorzente, del Lemno, della Scrivia, ecc.; tali profonde incisioni naturali ci rivelano l'enorme potenza della formazione tongriana di queste regioni.

L'osservazione di questi fatti ci indica l'importanza straordinaria delle correnti acquee dipendenti dall'Appennino nel periodo tongriano.

Nella regione in esame spesso il Tongriano si inizia con un banco conglomeratico durissimo, a cui succedono sabbie grigioverdastre, poscia banchi sabbioso-ciottolosi pure leggermente verdastri ed infine potenti conglomerati a tinte talora assai caratteristiche, giacchè nei grandi spaccati naturali, che profondamente intaccano i banchi conglomeratici dell'orizzonte in istudio, si osserva spesso, oltre al solito colore rosso-vinoso, una tinta verde-violacea affatto tipica, che credo dovuta ad alterazioni chimiche specialmente del materiale serpentinoso, che in queste regioni è il principale e talora l'unico elemento costituente del Tongriano; anzi devo notare a questo proposito che i materiali ciottolosi di questo orizzonte, nella regione ora in esame sino ad Est della valle Lemno, oltre ad essere quasi esclusivamente serpentinosi, sono pure, in generale, poco fortemente cementati e quindi non utilizzabili come materiale da costruzione, ciò che si verifica invece verso la Val Scrivia, come vedremo.

Nelle vicinanze di Lerma, Mornese, ecc. la parte superiore del terreno in esame è costituita da un complesso di banchí duri, arenacei, grigio-verdastri o bruno-giallastri, con qualche lente ciottolosa, talora con arnioni, spesso ricchi in fossili che generalmente però sono littoranei ed infranti. E d'altronde questa la facies littorale arenacea che vedemmo tanto sviluppata verso Ovest ma che invece va poco a poco scomparendo verso Est, mostrandosi però ancora abbastanza individualizzata nei dintorni di borgata Bosio. 
In certe locaiità, come specialmente sulla sinistra del T. Piota, nelle ricinanze di C. Nuova e più a Sud, il Tongriano si presenta spesso con stratificazione poco eridente ed è in parte costituito da una poltiglia giallastra inglobante irregolarmente elementi ciottolosi e brecciosi spesso anche assai voluminosi; questa facies che talora però si connette colla tipica facies a conglomerati resistenti, dipende sia dalla scarsiti di materiale calcareo cementante, sia dall'abbondanza di talcoschisti alterati, sia specialmente dalla noterole decomposizione che la formazione in esame subì, talora più profondamente in certe località che non in altre vicine, per cause speciali e varie da luogo a luogo.

Nella porzione più meridionale e basale della zona tongriana tra Mornese e Voltaggio, a contatto o quasi colla roccia antica, si osserrano qua e là, come alla Cresta Cravara, al colle di C. Ermitti, ma specialmente sotto C. Biscaelli, dei banchi, generalmente di uno o più metri in spessore, costituiti da una breccia calcarea grigio-biancastra coll'apparenza di roccia in posto, ma che invece è prodotta dal disfacimento e dalla ricomposizione, in epoca tongriana, di qualche placca di calcare triassico esistente originariamente in queste vicinanze sopra alla roccia serpentinosa antica; tant' è che assieme coi frammenti calcarei ebbi pure ad osservare rarissimi elementi serpentinosi e talcoschistosi; questi caratteristici banchi appaiono verso il fondo della val Garzente, sotto la Cresta Pantaleo ed al Bric Roccon sopra C. Ronco.

La località più opportuna per esaminare questa formazione tongriana pseudo-triassica è il fondo di Val Roverno presso C. Nuova, dove appunto esistono cave e fornaci da calce; qui infatti si osserva clie sopra alle roccie serpentinuse e talcoschistose preterziarie sonvi banchi calcarei breccioso-ciottolosi inclinati approssimatamente a Nord-Orest, due o tre rolte alteruati coi soliti hanchi ciottolosi del Tongriano e talora anzi divisi dalla roccia preterziaria per mezzo dei tipici banchi breccioso-ciottolosi, di color rosso-vino del Tongriano inferiore; l'andamento e la disposizione dei suddetti banclí calcarei si può osservare molto 
meglio dalla Cresta di Biscaelli piuttosto che non al fondo di Val Roverno.

Questi banchi calcarei di C. Nuova, che sono probabilmente la continuazione di quelli di C. Biscaelli, si veggono prolungarsi notevolmente, presso Est, cioè per oltre un chilometro, sin presso la C. Costamagna, donde ripiegansi a Sud, per modo da formare una semielisse attorno allo spuntone serpentinoso dell'alta val Roverno.

Pure molto interessante, per la sua facies speciale, è la parte più meridionale della frastagliata area tongriana tra la valle Gorzente e la Val Lemno, giacchè quivi gli elementi rocciosi, in gran parte di natura brecciosa, di notevole volume, della stessa natura litologica della prossima roccia serpentinosa ed abbastanza ben cementati fra di loro, sono talora difficili a distinguersi sia dalla stessa roccia antica, talora pure brecciosa e profondamente decomposta, sia dalle locali frane o dagli accumuli brecciosi, che veggonsi specialmente nella parte più elevata della regione in esame e che sono dovuti alla semplice alterazione chimico-fisica-meccanica verificatasi quivi, specialmente in epoca quaternaria.

Se consideriamo poi l'irregolarità grandissima della linea di contatto fra il Tongriano e le roccie preterziarie, anche facendo astrazione dalle posteriori azioni erosive, che d'altronde spesso non bastano a spiegarla, ci risulta sempre più chiaro il fatto, già altrove enunciato, che cioè la regione montuosa doveva già presentare un rilievo molto irregolare quando su di essa vennero a depositarsi i terreni terziarii.

Ad Est di Voltaggio lungo la linea di contatto fra Tongriano e Liguriano (oltre ai soliti conglomerati resistenti rosso-nerastri), si osservano qua e là, come presso C. Beno, presso C. Seietti, ecc., banchi speciali costituiti essenzialmente di materiale serpentinoso, ciottoloso-breccioso, di un bel color verde, cementato da una pasta pure serpentinosa verdastra, per modo che se questa breccia è resistente, simula assai bene una roccia ofiolitica in posto, e se invece è in sfiacelo ricorda pure certe ser- 
pentine scagliose di color verde-erba, mentre in verita credo piuttosto che si tratti solo d'un rimpasto, fatto in epoca tongriana ed a poca distanza dal punto di origine, di serpentine liguriane; fenomeni consimili osservansi pure in Val Scrivia, presso la borgata Creverina.

Ma specialmente interessante a questo proposito è il grande spuntone roccioso di Carrosio che dal Sismonda renne indicato come serpentina in posto, mentre credo trattisi piuttosto di una formazione tongriana costituitasi per il rimpasto di una roccia selpentinosa, che doveva esistere a poca distanza dal punto in questione. Infatti questo spuntone si presenta costituito di un conglomerato-breccia ad elementi specialmente serpentinosi, spesso grossissimi, rilegati da una pasta calcareoserpentinosa; cercando attentamente riscontrai pure, in questa roccia, alcuni frammenti di talcoschisti e di calcare, probabilmente triassici; i ciottoli sono per lo più rivestiti da una specie di patina lucente; la pendenza complessiva di questa formazione è verso il Nord-Nord-Est all'incirca. Questa facies di Serpentina in posto che assume il Tongriano riesce meno strana quando si pensi ai fatti consimili già sovraccennati e si esaminano le formazioni contemporanee nelle vicinanze di Carrosio, a destra e sinistra di Val Lemno, dove si rede che nei banchi conglomeratici del Tongriano predominano gli elementi serpentinosi, solo che essi si presentano più o meno cementati secondo le regioni in cui si osservano.

Oltre alla zona tongriana principale esistono pure all'esterno di essa delle placche isolate, fra cui bellissima quella di borgata Fiaccone, pure in massima parte conglomeratica; tale placca, verso Orest, presenta i suoi elementi, spesso colossali ed angolosi, così disciolti e sparsi sul Liguriano, da ricordare molto bene un lembo morenico e da essere difficilmente delimitabile sulla carta.

Pure diverse placche tongriane, di cui alcune estesissime, troransi sulla destra di Val Scrivia sopra Ronco, Creverina, Isola del Cantone, ecc., e servono a dinotarci la grande estensione 
che dovettero originariamente presentare i depositi tongriani sulla regione montuosa a destra della Scrivia anche molto a Sud della regolare fascia subappennina.

Ho già fatto precedentemente risaltare la natura essenzialmente conglomeratica del Tongriano ora in esame, debbo però notare come non di rado coi banchi ciottolosi si alternino strati ed anclie potenti banchi arenacei e marnosi (di essi possiamo vedere bellissimi esempi in Val Jagarnino, ad Est di M. Zuccaro, sotto a Costapelata, ecc.), e che senza l'osservazione stratigrafica parrebbero doversi considerare come appartenenti allo Stampiano.

In Val Scrivia è poi, più che altrove, notevole la censentazione potentissima che presentano i conglomerati dell'orizzonte in esame; tale cementazione è così forte che ne risultano quei banchi enormi, talora ridotti a monoliti, che stanno specialmente sull'alto delle colline e che vengono escavati su vasta scala come materiale da costruzione.

Talvolta queste grandi monoliti torreggianti si ruppero in monoliti secondarie che in certi casi si staccarono, discesero in basso, costituendo così sul Liguriano grandi placche che talora non si possono neppure segnare sulle carte geologiche, trattandosi di terreni non più in posto. Spesso poi lungo le linee di contatto tra il Liguriano ed il Tongriano conglomeratico, questo si presenta franoso, e coi suoi frammenti staccati e dispersi ricopre per grandi estensioni il sottostante terreno per modo da rendere incerta la sua delinitazione.

L'indicata straordinaria cementazione è dovuta essenzialmente ai banchi calcarei, che in Val Scrivia costituiscono parte assai notevole del Liguriano, e che formirono quindi ai banchi tongriani gran copia sia di elementi ciottolosi, sia di materiale cementante.

Nell'alveo della Scrivia si può stupendamente osservare il passaggio tra il Tongriano e lo Stumpiano; infatti, rimontando questa valle, oltrepassato Rigoroso, si vede dapprima comparire fra le uniformi marne grigio-verdastre dello Stampiano, un banco 
di circa 80 centim. di potenza, costituito da ghiaie e ciottoli con numerosi resti fossili, per lo più infranti; poco a Sud redesi comparire un altro banco ghiaioso, quindi un ter'zo ancor più potente, ed infine enormi, poteritissimi banchi di conglomerato cementatissimo, resistente, formante verso l'alto grandi monoliti, a pareti strapiombanti lisciate, arrotondate dall' acqua che poco a poco vi si è scavato il suo alveo; tale conglomerato ha un color generale grigio-verdastro o grigio-bleuastro oscuro oppure anche rossastro per alterazione chinica.

Da Carrosio a Rigoroso, seguendo in generale la linea di passaggio tra il Tongriano e lo Stampiano, veggonsi assai sviluppati i banchi di marne brunastre alternati con grandi bancli conglomeratici, talora con inclinazione irregolare ed anche affatto contraria, localmente, a quella generale, che è ver'so il Nord circa.

Gli elementi di questi conglomerati sono non di rado di uno ed anche due metri di diametro, ma nel rio che da C. S. Martino discende nel rio Croso, ne misurai diversi, specialmente di Talcoschisto e Serpentinoschisto, che raggiungono persino 5 metri di massimo diametro e 3 o 4 metri lungo gli altri assi; d'altronde più a Sud presso C. Beno in Val Carbonasca ebbi ad osservare un enorme masso serpentinoso, facente parte del Tongriano, della dimensione di metri $S \times 5 \times 6$ e che è quindi forse il più voluminoso dei massi finora osservati in questo orizzonte geologico in Italia. Generalmente questi ciottoloni trovansi allineati in lenti speciali frammezzo a conglomerati ad elementi più piccoli od anche fra säbbie arenacee.

Continuando l'esame della fascia subappenninica del Tongriano verso Est, e lasciando in disparte le larghe placche entroappenniniche, notiano anzitutto che questo orizzonte geologico, pur continuando ad essere essenzialmente conglomeratico, nella parte sua superiore presenta una tale alternanza con banchi arenacei e marnosi, che riesce sempre più difficile il separarlo dallo Stampiano, tanto più che in quest' ultimo orizzonte si osservano quivi pure non rare lenti ed anche banchi ciottolosi. 
F poi notevole lo straordinario sviluppo verso Nord clie presenta il Tongriano in Val Scrivia, spingendosi esso sin quasi alla Varinelia; tale sviluppo è reso manifesto anche all'osservatore superficiale dai rilievi di color rossastro di Valle Buona e di Pessino, ad elementi prevalentemente ciottolosi e come di solito profondamente alterati. Il fatto che i terreni liguriani sono quivi molto sviluppati verso Nord, cioè sino alle falde meridionali del M. Magon, e cle gli strati del Tongriano dal Colle Valle Buona alla Varinella sono potentemente rialzati di $70^{\circ}$, $80^{\circ}$ e persino verticali o rovesciati in alcuni punti (tanto che per poter segnare tutte queste varianti occorrerebbe una carta topografica della scala alnıeno di 1 a 5000), ci arverte che questo grande sviluppo locale del Tongriano verso il Nord è dovuto principalmente a qualche potente curva o piega od altro fenomeno stratigrafico del Liguriano di questa regione; d'altronde più rolte si è già fatto notare come i depositi tongriani si modellano generalmente assai bene sui terreni antichi su cui si appoggiano. In questa regione inoltre esiste una grande difficoltà nella delimitazione tra $\mathrm{i}$ due orizzonti del Tongriano, verificandosi nella zona di passaggio la presenza di numerosi strati conglomeratici più o meno potenti che si alternano con quelli marnosi grigi o grigio-gialli.

Il disordine stratigrafico o meglio il potente rizzarsi degli strati tongriani, che dicemmo esistere verso Varinella, si continua ancora per lungo tratto verso Est, tanto che alle falde del M. Magon (e specialmente ciò è visibile nei banchi di passaggio tra Tongriano e Stampiano) gli strati sono non solo drizati alla verticale, ma talora paiono parzialmente rovesciati; cosi pure inclinazioni in vario senso e generalmente molto forti osservansi a Costa Piazza, a M. Poggio, a Pian dei Poggi, ma tali fenomeni sono dovuti specialmente alle irregolarità orografiche della regione su cui si deposero i terreni tongriani, nonchè ai potenti movimenti sismici che si verificarono dopo tale deposizione.

Nelle colline da Grondona al Pian dei Piaggi, oltre ai potentissimi conglomerati, osservansi spesso strati di marna dura e di arenaria che ricordano molto quelli del Liguriano. 
Verso Roccaforte i conglomerati tongriani potenti, tenacissimi, spinti oltre i 900 metri di altitudine, presentano verso il loro limite meridionale diverse placche irregolari, isclate sul Liguriano e probabilmente in parte anche dislocate dalla originaria posizione. Noteroli sono la piccola placca di borgata La Rira, l'enorme placca clie da borgata La Barca si estende sin presso i Molini di S. Martino, nonchè l'elevata placca che forma il Bricco Castellazzo $(956 \mathrm{~m}$.) e di cui troviamo numerosi grossi frammenti sino al fondo di Val Spinti. Talora si vede il Tongriano applicarsi quasi verticalmente alle roccie liguriane. Le potentissime formazioni tongriane, inclinate all' incirca verso Orest, che si elevano talora sin quasi a 1000 metri, come al M. Reale (902 m.), al M. Reopasso (959 m.), al M. Cravi (992 m.) ecc. costituiscono spesso ellormi monoliti e burroni spaventosamente profondi. $\dot{\mathrm{E}}$ in queste regioni che, specialmente verso la base del Tongriano, oltre a banchi arenacei, sonvene alcuni marnosi nerastri inglobanti lenti lignitiche con Molluschi continentali; lenti di lignite, ma generalmente ancor meno importanti, riscontransi eziandio frammezzo ai banchi conglomeratici di queste regioni ed anche in altri punti a Nord di Roccaforte.

Si noti che, malgrado la presenza di Molluschi continentali nelle marne lignitifere di Roccaforte, la vastissima zona tongriana che si estende a Nord di Roccaforte e che ci forni gii la massina potenza (oltre $2500 \mathrm{~m}$.) del Tongriano in Piemcnte, non deresi già considerare come una formazione continentale (come in gran parte è il caso per il bacino di Bagnasco), ma bensì come un deposito marino più o meno littorale e vicino ad una foce, tant'è che vi troviamo fossili marini (Nummalites, Lithothommiam, ecc.) anche fra le arenarie cle stanno alla base di questa potente formazione, cosi presso i Corti (Roccaforte), presso Merlazzina, ecc.

Talora i conglomerati tongriani in esame passano localmente a breccie, i cui elementi sono specialmente arenacei e calcarei, provenienti cioè dello sfucelo delle formazioni liguiane. 
Dopo Roccaforte la fascia di Tongriano volgendosi direttamente a Nord con ampiezza e potenza straordinaria, continua a presentarsi colla facies specialmente conglomeratica, solo con alcuni interstrati arenacei durissimi, talora fogliettati ed utili quindi per conoscere la precisa tettonica della potente formazione in esame.

Rispetto agli elementi litologici di questi conglomerati è a notarsi come, mentre tra la Val Bormida sino a Voltaggio predominano in modo assoluto le roccie anticle (specialmente serpentinose), in seguito invece prendono rapidamente il sopravvento le roccie liguriane (specialmente calcaree), tanto che a Nord di Roccaforte trovansi quasi solo più ciottoli, specialmente calcarei, tolti alla formazione liguriana, quantunque enormi ciottoloni serpentinosi trovinsi ancora nella parte superiore del Tongriano ad Ovest di M. Rivarossa; fatti che in generale trovano facilinente la loro spiegazione nell' esame geognostico della regione appeuninica alle cui falde appoggiansi i terreni tongriuni.

A Nord di Val Borbora il Tongriano diventa poco a poco meno potente, i banchi conglomeratici vanno diminuendo in numero e spessore, conservandosi quasi solo più verso la metà circa della fascia tongriana tra M. Rivarossa e M. della Croce dove presentano talvolta ancora ciottoli enormi; ma più a Nord i conglomerati compaiono solo più in banchi o lenti isolate ad elementi più o meno cementati. Invece nella parte inferiore della formazione in esame, a cominciare dalle vicinanze di Villa Ortara, tra la potente pila di conglomerati ed il sottostante Liguriano, appaiono e tosto ampiamente si sviluppano banchi nnarnoso-arenacei grigio-verdastri e nerastri, con un' inclinazione complessiva di circa $35^{\circ}$, e di cui già trattai abbastanza ampiamente sia in un lavoro speciale, sia nei precedenti capitoli.

Queste marne argillose nerastre senza apparente stratificazione e che ricordano molto bene le argille scagliose del Liguviano, veggonsi sempre più ampiamente sviluppate a Nord di M. Rivarossa, nella parte alta di Val Fonda tra C. della Croce e Parogna inferiore, compaiono per lungo tratto in Tal Borbera, co- 
stituiscono il fondo della ralletta a Sud-Orest della Torre di Montebore e continuano poi sin oltre Aja del Gallo frammezzo a potenti banchi conglomeratici ad elementi specialmente calcarei e rarissimamente serpentinosi.

Intercalati a questi banchi conglomeratici, inclinati di circa $30^{\circ}$ o $35^{\circ}$, compaiono pure talora strati marnosi nerastri inglobanti lenti lignitiche simili a quelle di Roccaforte, cosi per esempio nelle vicinanze della parrocchia di Groppello, ma in quantità sempre poco considererole.

Anche nella parte superiore della formazione in esame vanno sempre più scarseggiando i grandi banchi conglomeratici, sostituiti invece da banchi arenacei e marnosi che rendono difficile tra il Tongriano e lo Stampiano una distinzione un po'netta, la quale invece si può ottenere solo con un esame complessiro, essendo prevalentemente arenacei i banchi del Tongriano ed invece per lo più marnosi o marnoso-arenacei quelli dello Stumpiano; spesso inoltre compaiono straterelli ciottolosi nel passaggio fra questi due orizzonti.

I banchi arenaceo-marnosi del Tongriano sono talvolta curiosamente incurvati, come ad esempio si puo vedere in Val S. Gaudenzio in alcuni lirghi spaccati di fronte a C. Scabiazza, oppure si presentano anche fortemente sollerati di 50\%, $60^{\circ}$ e più, come presso Campolungo, al M. Maiassa, dore appaiono diverse lenti ciottolose, ecc.

Nella grande conca tongriana di S. Sebastiano Curone predominano assolutamente le inarne argillose grigio-rerdastre e le arenarie quasi dello stesso colore oppure giallastre e con accentramenti discoidali che ricordano i terreni aquitaniani di Garbagna comparendo solo sporadicamente lenti ciottolose, spesso fortemente cementate; cosi quella di Derrice e di S. Rocco, quella, ad elementi prevalentemente serpentinosi, tra Cresta Grattoje e M. Majassa; quella assai potente, ad elementi specialmente calcarei e raramente serpentinosi e ad inclinazione anche di $50^{\circ}, 60^{\circ}$, di Cresta Trebbia (dove questi banchi conglomerattici sottostanti a marne ed arenarie reggonsi appoggiare alquanto 
discordantemente, forse per erosione, sopra banchi sabbiosi ed arenacei giallo-verdastri); quella, pure a strati potentemente sollevati tra Cresta Sterna e Val Fossaglio sulla destra di Val Curone, ecc. ecc.

Oltre alle marne grigio-verdastre, si presentano poi sviluppatissime certe marue di tinta chiara a stratificazione talora poco evidente che costituiscono generalmente regioni a grandi burroni e poco atte alla stabile coltivazione, come per esempio presso Codevico e M. Casso in Val Biarassa, sulla destra del Gurone ecc.; appaiono anche marne di tinta leggermente violacea, farinose e facilmente smottabili, come ad esentpio tra le borgate Giara e Solaro, in Val Ronchetti a Nord di borgata Fontanelle; ma qui trattasi già di terreni appartenenti ad orizzonti più antichi.

Nell' andamento stratigrafico in complesso abbastanza regolare della conca tongriana di S. Sebastiano, osservansi tuttavia diverse locali irregolariti, specialmente dovute a ripiegature in grande ed in piccola scala; così quasi di fronte a Rostegazzo gii strati arenaceo-marnosi, inclinati di circa $60^{\circ}, 70^{\circ}$ verso Nord-Ovest, presso il Rio di Pra d'Arzola, presentano un nettissimo incurvamento a C colla concavita rivolta a Sud. Così pure ripetuti ripiegamenti osservansi negli strati marnoso-arenacei, inclinati in complesso di circa $50^{\circ}$ verso Nord-Ovest, presso la borgata Giara, ed ancor più nettamente nei banchi arenacei, pure fortemente inclinati (di circa $60^{\circ}$ verso il Sud), presso i casali La Costa a Nord di S. Sebastiano.

Forti ripiegature e strati rizzati alla verticale osservansi presso borgata Ruscon e servono in parte a spiegarci le irregolarità che vedonsi nell'andamento stratigrafico dei banchi tongriani di questa regione, dove tutte le formazioni terziarie, che vi si trovano, presentano una rapida curva verso l'Ovest, costituendo un angolo acuto, ciò che naturalmente non potè compiersi senza manifesti disturbi nella tettonica delle diverse formazioni.

Questi fatti assieme colle sovraccennate ripiegature ci rendono avvertiti che le formazioni tongriane della Conca di S. Seba- 
stiano dorettero subire, dopo la loro deposizione, potentissime azioni meccaniche dovute ad un grandioso corrugamento del sottostante Liguriano, corrugamento spiegabile a sua rolta coll'azione di potentissime pressioni laterali, e dentrn al quale rimase impigliata l'esaminata formazione tongriana, che fu cosi obbligata a ridursi in conca allungata, fortemente rizzando ed anche contorcendo i suoi strati.

La grande area tongriana di S. Sebastiano Curone ha, a mio parere, una grande importanza, poichè è qui cle arviene la divisione geologica fra il bacino terziario piemontese e quel del pavese, e del tortonese settentrionale, e ciò si verifica con un notevole cangiamento di facies nelle varie formazioni mioceniche. Lasciando per ora in disparte il terziario del pavese possiamo indicare nella conca di S. Sebastiano i seguenti fatti prin. cipali.

Nella parte meridionale, tra Dernice, Giara e Fabbrica $\mathrm{Cu}$ rone, colle arenarie, colle sabbie e colle marne si alternano diversi banchi conglomeratici, fra cui potentissimi quelli che formano la Riva Banella e la Cresta Trebbia; l'inclinazione di questi banclii varia tra $30^{\circ}$ e $60^{\circ}$ ed è a un dipresso verso Nord. Alla base della formazione, sotto ai conglomerati che sono assai ricchi in elementi serpentinosi, compaiono sabbie ed arenarie caratteristiclıe per il loro colore grigio-biancastro; questa tipica zona inglobante concrezioni ed anche banchi straterellati grigi, si può osservare specialmente bene tra borgata Solarolo e borgata Magroforte.

Su questa potente pila arenaceo-conglomeratica si appoggia. un'altra pure potente serie di strati e straterelli marnosi ed arenacei ripetutamente alternati e che nel complesso presentano una facies analoga a quella del Tongriano delle colline di Brusasco (Bric Sac) presso Torino; tale formazione, specialmente sviluppata sulla destra di Val Museglia, presenta talora anclie banchi sabbioso-arenacei giallastri che ricordano alquanto quelli dell' Aquitaniano di Garbagna; spesso i suoi strati sono fortemente sollevati ed anclie piegliettati e localmente rovesciati, ma 
nel complesso la loro inclinazione è di una quarantina di gradi verso Nord-Est all'incirca; talora colle arenarie si alternano pure letti ghiaiosi o ciottolosi con prevalenza di elementi serpentinosi; resti fossili si incontrano in queste regioni tongriane in diversi punti, ma specialmente interessanti a questo riguardo sono alcnni banchi grigio-giallastri, marnoso arenacei, che trovansi sulla sinistra di Val Museglia duecento metri a monte di borgata Giara, giacchè quivi abbondano le Nummuliti, le Orbitoidi, i Molluschi, ecc.

Qua e là incontransi pure lenti lignitiche come ad esempio presso C. Riasso in Val Curone. Invece nella parte settentrionale del bacino tongriano di S. Sebastiano Curone le formazioui in esame cle inclinano in generale verso Sud o Sud-Est, cangiano notevolmente d'aspetto; divengono in gran parte sabbiosoarenacee, grigio-giallastre in modo da ricordare alquanto la fucies dell'Aquitaniano di Garbagna, specialmente lungo la Costa Sternai e nelle colline di M. Naiassa dove parrebbe quasi di vedere placche aquitaniane sul Tongriano.

Raramente si incontrano lenti conglomeratiche, di cui però possiamo notare alcuni esempi tra borgata Marsigliano e borgata Ronco in Val Curone, sulla destra di Val Scabione a Sud di Frascata dove sono talora drizzati alla verticale.

Questi banchi sovente puddingoidi, sono spesso di color verdebruno per la loro ricchezza in elementi serpentinosi che si associano agli elementi calcarei ed arenacei, tutti derivanti dallo sfacelo del Liguriano; talora questi conglomerati passano localInente a breccie. Il passaggio tra le due sovraccennate facies del Tongriano si può osservare specialmente nelle colline attorno a S. Sebastiano Curone; regione questa interessantissima poichè ci serve quasi di chiave per comprendere come il classico Tongriano dell'Appennino ligure si trasmuti nel Tongriano dell'Appennino pavese.

Nelle colline a Nord-Ovest di S. Sebastiano la stratigrafia si presenta alquanto conturbata a causa della rapida curva clie vi debbono fare le formazioni terziarie; predominano quivi le 
arenarie alternate con marne ed inglobanti talora banchi o lenti ciottolose, talvolta a grossi elementi; l'inclinazione degli strati che è talora soltanto di pochi gradi, diviene in alcuni casi fortissima come nelle colline a destra della ralletta di Madonnina.

Dopo questa rapida curva stratigrafica presso borgata Rusconi, sotto il M. Cucco il Tongriano è ridotto ad una sottile striscia che da Val Curone si prolunga sino a Tal Grue, appoggiandosi direttamente sulle marne grigio-violacee dello Stampiano; i banchi di questa sottile zona tongriana sono drizzati quasi alla verticale, diretti ad un dipresso da Est ad Orest e costituiti essenzialmente di arenarie e di conglomerati spesso assai cementati ad elementi piuttosto piccoli e spesso di color giallo-rossiccio.

Notiamo come tra il M. Peola e le colline di Brignano, di Magrassa, ecc., si sviluppi una formazione marnosa ed arenacea che presenta in parte caratteri del Tongriano ed in parte del Liguriano alla cui zona superiore pare piuttosto doversi riferire.

Nंei banchi di passaggio tra il Tongriano e lo Stampiano si trovano talvolta le curiose impronte retiformi dei Paleodyction, come per esempio nelle vicinanze dei casali Val Scura, a NordOvest di S. Sebastiano Curone.

Nella parte settentrionale delle colline tortonesi, tra la Staffora e la Scrivia, si sviluppa ampiamente una potente zona tongriana, di costituzione assai varia secondo $i$ vari punti in cui si osserva, dell' ampiezza media di circa due chilonetri, talora con banchí arenacei a Robulina, Nummulites, ecc. Quest'importante regione tongriana è facilmente distinguibile per la sua facies speciale di colline alte e spesso ripide, clie contrasta notevolmente colla facies delle colline liguriane che sono piuttosto basse ed a pendii assai dolci.

Esaminando più minutamente questa zona tongrianc rediamo che nella sua parte meridionale dalle colline di Ramella ad Est di borgata S. Giorgio in Val Curone, sino alle colline di Sega- 
gliate, sono potentemente sviluppate le marne grigie o grigiohleuastre, od anclıe leggermente verdastre, alquanto farinose, nel complesso inclinanti verso il Nord circa; la placea di Montebello è probabilmente un lembo staccato di questa zona marnosa che deve forse riferirsi al Barloniano.

Su tali marne grigiastre si appoggiano marne grigio-violacee che dalle colline di Monperone in Val Curone sviluppansi sino alla valle di Montegioco all'incirca; tali marne, alternate più o meno frequentemente con banchi arenacei, pendono pure in complesso verso il Nord di $30^{\circ}, 40^{\circ}$. Però nella valle Marzegna si vede assai bene come questa formazione cangia poco a poco di direzione per modo da pendere dapprima a Nord-Est, poi ad Est, quindi a Sud-Est, finchè, con un' inclinazione generale a Sud, va ad appoggiarsi sui potenti banchi conglomeratici di Giarella-Monmarzino.

Ne risulta da ciò che questa zona tongriana tra la Val Curone e la Val Grue è in verità da considerarsi quasi come un seno stretto ed allungato coll'apertura rivolta ad Est.

Molto noterole è lo sviluppo che nella zona in esame assumono i conglomerati che in numerosi e potenti banchi si estendono da Val Staffora sino a valle Scrivia, e dal paese di Groppo in Val Staffora sino alla Giarella in Val Curone: questi banchi conglomeratici sono regolari, continui, ripetutamente alternati con banchi arenacei, fortemente sollevati ed inclinati verso il Sud-Sud-Est circa; essi formano cosi la cresta notevolmente rilevata di Castelpozzolo.

I ciottoli dei conglomerati tongriani in questione sono di varia grossezza e di varia natura; vi predominano in modo assoluto i calcari alberesi, le arenarie (macigno) e le Serpentine del Liguriano; il color giallastro che presentano in complesso questi conglomerati, e che è in contrasto colla tinta più o meno brunoverdastra che vedesi nei conglomerati tongriani dell'Appennino ligure, credo dipenda in gran parte dal fatto che nel primo caso gli elementi ciottolosi per il lungo trasporto subirono una decomposizione assai più profonda che non nelle zone contem- 
poranee le quali, nel secondo caso, appoggiansi direttamente alle roccie donde derivano tutti gli elementi che costituiscono i conglomerati tongriani.

Nelle colline di Giarella il Tongriano, che ingloba talora lenti lignitiche, come in Val S. Vittore sotto Cà Nistaron, presenta in complesso la seguente serie stratigrafica:

10. Marne argillose violacee

9. Banchi sabbiosi

8. Strati e banchi arenacei

7. Marne argillose violacee

6. Marne e sabbie grigie

5. Marne argillose violacee

4. Potenti banchi arenacei

3. Potenti banchi conglomeratici

2. Alternanza di strati arenacei e conglomeratici di cui alcuni molto sottili.

1. Marne sabbiose grigie o grigio-verdastre facilmente frammentarie.

Tongriano

Bartoniano

Come è indicato in questa sezione, sotto agli stupendi banchi arenaceo-conglomeratici spunta qua e là una zona di marne grigio-verdastre, abbastanza concordanti coi sovrastanti conglomerati, e caratteristiche per il loro aspetto, direi farinoso; esse si possono ad esempio osservare molto bene presso la borgata Giarella su ambi i lati di Val Curone.

Ma ad Ovest di borgata Giarella la formazione conglomeratica non si presenta più come una zona regolare, ma si mostru solo più in lenti più o meno ampie, più o meno allungate, più o meno potenti, frammezzo alle sabbie ed alle marne. Credo inutile di esaminare tutte queste lenti ciottolose di cui alcune sono molto sottili e pochissimo sviluppate; accenniamo solo fra le più potenti quella di Montemarzino, quella dell'alta valle Bosco dei Galli, quella di M. Rosso, quella di M. Cenelli-M. 
Brada-Chiesa, quella assai potente di Montegioco-Rocca di Grue, di cui è forse una continuazione la zona conglomeratica di M. dei Piaggi-M. Bosso.

Altre lenti ciottolose abbastanza notevoli vediamo comparire nella placca tongriana di M. Lena, nelle colline di Bersano, nella bassa val Repregosio, nelle placche tongriane di M. Mirano, di Sarezzano, ecc. A dire il vero questa irregolarità nella distribuzione delle lenti conglomeratiche dipende non solo dall'essere esse realmente sparse molto irregolarmente fra i banchi sabbiosi e marnosi del Tongriano, ma anche dal fatto che la stratigrafia di questo orizzonte si presenta in queste regioni alquanto disordinata.

Nelle colline poco ad Ovest di Montegioco possiamo osservare la seguente serie stratigrafica abbastanza regolare:

\author{
Tongriano $\left\{\begin{array}{l}\text { Marne bruno-violacee } \\ \text { Banchi sabbiosi grigiastri } \\ \text { Conglomerati fra strati marnoso-sabbiosi. }\end{array}\right.$ \\ Liguriano Argille scagliose brune con calcare alberese.
}

Si potrebbe forse dubitare che $\mathrm{i}$ banchi superiori di questa serie siano già da riferirsi allo Stampiano, ma mi mancano finora dati un po' attendibili per adottare tale ipotesi.

Talora fra le arenarie tongriane incontransi lenti lignitiche cle costituiscono appunto uno dei caratteri secondari di questa fornazione oligocenica.

Nel rio di Mongioco, dai banchi sabbioso-conglomeratici del Tongriano escono sorgenti sulfuree, che costituiscono pure un carattere secondario, abbastanza frequente dei banchi tongriani.

Questo vallone di Mongioco è interessantissimo per l'esame minuto del Tongriano conglomeratico quivi assai potente; gli elementi ciottolosi sono disposti in banchi oppure sparsi nell'arenaria, costituendo nell'assieme una formazione distinta grigio- 
rossastra (che ricorda alquanto le moilasses rouges, cls' io credo tongriane, della Svizzera); i ciottoli per lo più sono di circa 20 centim. di diametro in media, sonvene però eziandio di 40 a 50 centim.; per lo più constano di arenarie e calcari liguriani. talora con elementi serpentinosi probabilissimamente pure lignriani; non di rado questi ciottoli sono frantumati e coi frammenti spostati ma riuniti. Quivi i banchi arenacei presentano spesso dei ripetuti salti in piccola scala.

In complesso si può dire che nella parte settentrionale della zona tongriana ora esaminata $\mathrm{i}$ banchi pendono generalmente di una quarantina di gradi verso il Sud-Ovest, cosi tra Montemarzino e le colline di Bersano. Invece nelle colline di Montegioco e NI. Caminario i banchi sia marnosi che conglomeratici pendono di $25^{\circ}$ a $50^{\circ}$ verso il Nord-Nord-Est per modo che ne risulta una conca stretta ed allungata; a questo andamento stratigrafico generale sonvi numerosissime eccezioni per alterazioni più o meno estese.

Nella placca tongriana di M. Lena i banchi pendono generalmente verso il Nord-Est; in quella di Rocca di Grue l'inclinazione è piuttosto verso Ovest; qualche cosa di simile vediamo pure nel Tongriano di Sarezzano, di M. dei Piaggi, di M. Gambera, ecc., come pure delle colline presso il paese di Tortona, dove i banchi arenacei pendono specialmente verso il NordOvest all'incirca.

Osservansi però anche qua e là inclinazioni molto diverse da quelle ora indicate, coisi alle falde Nord-Orest di M. Gambera dove gli strati pendono specialmente verso il Sud od il Sud-SudOrest.

$\mathrm{Si}$ è detto sopra come le lentí conglomeratiche sono inglobate più o meno sporadicamente fra formazioni marnose ed arenacee, della cui potenza molto notevole possiamo formarci un' idea percorrendo i profondi valloni che intersecano le colline di Bersano-Montegioco; è quindi naturale che sianvi pure placche tongriunc che non presentano quasi lenti ciottolose; ne ̀̀ esempio quella di M. Grande, a Nord di Sarezzano, che è in 
massima parte marnoso-sabbiosa grigiastra; lo stesso dicasi della formazione tongriana che sostiene la placca clvariana di 'Tortona, poichè anche là vediamo apparire solo potenti banchi sabhioso-arenacei con lenti ghiaiose; pure solo sabbiosa è la vicina placchetta di M. S. Cristoforo. Talvolta queste formazioni marnose ricordano alquanto quelle dello Stampiano a cui però non mi pare si debbano riferire.

Credo inutile diffondermi nella descrizione di ciascuna di queste placche tongriane, visibili quasi sempre anche di lontano per costituire collinette piuttosto rialzate sulla formazione ligurianc; lì dove sonvi conglomerati molto cementati ne risultano spuntoni a facics caratteristica, come per esempio a Rocca di Grue dove per la stessa causa la vallata si restringe di tratto notevolmente per quasi un Chilometro.

Le placche arenacee dànno quasi sempre origine a sorgenti acquee; presentano solo raramente dei fossili e per to più mal conservati.

Passando ora all'esame delle colline Torino-Valenza, vi vediamo apparire per tratti estesissimi i depositi tongriani che s'appoggiano per lo più sugli affioramenti liguriani già esamillati nel precedente capitolo; anzi si può dire che gli spuntoni di questo terreno eocenico raranente sono scompagnati da placche o striscie più o meno ampie di Tongriano.

In generale si può dire che la facics di questi affioramenti tongriani corrisponde assai bene a quella che presentano tali formazioni nelle colline tortonesi e pavesi; vedremo però come in alcune regioni delle sovraccennate colline compaiano eziandio zone tongriane a facies molto simile a quella del Tongriano dell'Apennino ligure.

In rapporto coll'allungata zona liguriana di Valenza-Alessandria affiorano pure placche e striscie tongrianc poco potenti che si spingono talora sino all'alveo del Tanaro, facendo deviare notevolmente il corso di questo fume. In questa località, cioè a $\mathrm{Pa}-$ vone d'Alessandria, il terreno tongriano è rappresentato da banchi arenacei inclinati di una ventina di gradi verso Sud o Sud-Est, 
ed inglobanti grosse lenti gliaiose e conglomeratiche ben cementate; le arenarie sono piustosto grigiastre; i ciottoli per lo più costituiti di materiale liguriano e talora a spigoli ancora abbastanza conservati, spesso schiacciati, smuzzati, e coi frammenti ancora saldati, $\mathrm{i}$ banchi arenacei presentano spesso piccole rotture e spostamenti locali.

Nelle colline di Pietramarazzi la folta regetazione impedisce d'esaminare la formazione tongriana che però spicca nuovamente a Bric Mariano dove compaiono grosse lenti conglomeraticlie; queste, con inclinazione di una trentina di gradi verso il SudOrest ad un dipresso, si sviluppano anche noterolmente in $\mathrm{Val}$ Carretta ed in Val C. Pissarotto costituendo in ambi $\mathrm{i}$ casi pendii erti e dirupati; oltre agli elementi ciottolosi, spesso di volume notevolissimo e come di solito spesso frantumanti e deformati, usservansi in questi depositi elementi brecciosi di varia grossezza.

Questa zona tongriana seguendo l'affioramento liguriano si sviluppa notevolmente verso Nord, cioè sin oltre il Bric Olio, per lo più essendo solo rappresentata da banchi sabbioso-arenacei, a cui però s'intercalano talora, come appunto al Bric Olio, alcune lenti ciottolose.

Una bellissima placca tongriana isolata sul Liguriano è quella che forma le collinette di C. Miglia e C. Deamici; essa cousta come di solito di sabbie ed arenarie che inclinano parzialmente ¿Sud-Est e che inglobano lenti ciottoluse e brecciose ad elementi talora di quasi un metro di diametro e spesso schiacciati, frantumati e coi frammenti riuniti assieme.

Più a Nord tra le marne clveziane di C. Sabbioni ed il Liguriano li C. Villa appaiono ancora banchi sabbioso-arenacei, simili alquanto a quelli tongriani, ma che inrece paiono doversi attribuire all' Elveziano inferiore.

All'estremità del prolungamento liguriano di Bric Cantonieri si sviluppa una zona tongriana rappresentata da marne e sabbie che presso Madonua S. Zeno si mostrano sollerate di quasi $80^{\circ}$ con inclinazione a Sud circa ed inglobano, tra C. Baiardi e Madonna S. Zeno, una grossa lente conglomeratica. 
In queste regioni, come d'altronde in quasi tutto il resto delle colline Torino-Valenza e come anche nelle colline tortonesi, paresi, ecc., i ciottoli del Tongriano per le potentissime pressioni subíte si presentano spesso schiacciati, rotti e coi frammenti spostati quantunque per lo più ancora saldati assieme. Tale carattere serve sovente molto bene per distinguere gli affioramenti ciottolosi del Tongriano da quelli del Messiniano.

Gli elementi di questi conglomerati tongriani sono specialmente tratti dalle formazioni liguriane, constano cioè essenzialinente di calcare alberese e di arenarie (Macigno).

Ad Ovest di Valenza, approfondandosi tutti i terreni nella sella di S. Salvatore, per lungo tratto non appare più alcuna zona oligocenica; ma nell'alta valle della Guascona, frammezzo ai terreni mcssiniani si ergono due rilievi bene spiccati, cioè il Bric della Guascona ed il Bric Prelio, i quali sono costituiti di banchi sabbiosi grigiastri sollevati molto fortemente e diretti ad un dispresso da Sud-Ovest a Nord-Est.

Quantunque finora io non abbia ancor potuto riscontrare alcun fossile in questi depositi, dubito tuttavia cle si tratti qui di terreno oligocenico, probabilmente tongriano.

D'altronde poco più ad Ovest, nelle colline di Lu il Tongriano si sviiuppa amplissimamente sotto forma di marne e sabbie grigiastre inglobanti qua e là lenti più o nıeno grosse di ciottoli talora voluminosissimi. In complesso i banclii tongriani pendono di $40^{\circ}$ a $75^{\circ}$ verso il Sud ed il Sud-Sud-Est, come si può vedere specialmente presso quest'ultimo paese. Si possono eziandio osservare localmente inclinazioni diverse da. quelle sovraccennate, ciò verso Est, in causa probabilmente del vicino affioramento liguriano di Val Grana-C. Nuova.

Talora fra i terreni tongriani appaiono anche banchi marnosi bleuastri che ricordano molto quelli del Tortoniano, così per esempio nell' alto delle colline tra Bric S. Bernardo e Bric Madonna.

Tra la placea messiniana del paese di Lu e la zona messinianc del Cinitero di Lu osservansi barchi marnoso-arenacei, 
spesso straterellati, fortemente sollevati ed inclinati ad OrestNord-Orest, che paiono ancora riferibili al Tongriano.

Le principali lenti ciottolose racchiuse fra le arenarie della grande zona tongriana di Lu, sotto la quale affiora in diversi punti il Liguriano, trovansi alle falde settentrionali di Bric Morlantino, alle falde meridionali del Bric S. Maria, sulla parte bassa delle colline ad Est di Cuccaro, al fondo di Val Grana, sotto al cimitero di Cuccaro (dore i banchi arenacei diretti da Nord-Ovest a Sud-Est sono fortemente sollevati), al M. Torte, al Bric Rosa che è un rero ammasso di ciottoli, come anclie tra C. Betlemme ed il Molino di Camagna, ecc. Gli elementi di questi conglomerati sono calcari alberesi ed arenarie liguriane, nonchè in quantità notevolissima Granito, specialmente rosso, Serpentina, Eufotide, Diorite, ecc.

Tra Val Grande e Val Rotaldo la zona tongriana si mostra ampiamente sviluppata quantunque non molto potente giacchè lascia qua e là apparire la sottostante zona liguriana.

Anche in questa grande area tongriana sono specialmente $i$ banchi sabbiosi ed arenacei che predominano, ma ri si osservano purc notevoli zone marnose grigio-bleuastre, come ad esempio tra C. S. Martino e Fornace di Val Rotaldo.

Rispetto alle marne bleuastre è a notarsi che, oltre a trorarsi nel Tungriano, esse si mostrano pure sviluppatissime nell'Aquitaniano; orbene siccome in queste regioni i vari orizzonti oligocenici non sono bene sviluppati, si presentano a stratificazione irregolare, raramente fossiliferi e parzialmente mascherati dai terreni miocenici, ne segue che riesce spesso difficile il distinguere l'Aquitaniano dal Tongriano, come appunto si rerifica nelie regioni ora in esame.

La tettonica di questa grande area tongriana è molto raria da luogo a luogo, in causa dei vari afforamenti liguriani clie appaiono qua e là; però si può dire in generale che $\mathrm{i}$ banchi sono per lo più fortemente sollevati e diretti ad un dispresso da Nord-Orest a Sud-Est. Nelle colline di Camagna il suddetto andamento stratigrafico è ben visibile ovunque, i bancli si pre- 
sentano allineati da Nord-Ovest a Sud-Est e pendono di $50^{\circ}$ ad $80^{\circ}$ generalmente verso Nord-Est, comc presso Camagna, ina talora anche in senso opposto come presso le C. Corona; non di rado poi essi si presentano verticali conc vedesi sulla destra di Val della Brella presso C. Orto; tali varic inclinazioni ci dinotano rovesciamenti stratigrafici di cui troviamo la ragione negli afforamenti liguriani paralleli quivi esistenti.

I banchi sabbiosi tongriani, che si appoggiano alla zona liguviana di Val Grana-C. Nuova, sono generalmente inclinati di $40^{\circ}$ a $50^{\circ}$ verso il Nord-Est circa, pendenza che si osserva ancora nelle colline di S. Lorenzo, ma che diviene assai più forte nei dintorni di C. Montalbano dove gli strati sabbioso-marnosi si presentano talora quasi verticali.

Nelle colline di borgata Davino gli strati tongriani pendono per lo più verso il Nord all'incirca; ma verso Vignale invece le marne sabbiose straterellate, con conglomerati qua e là mostrano di nuovo assai nettamente il regolarc allineamento da Nord-Orcst a Sud-Est con pendenza assai forte, cioc̉ spesso di $70^{\circ}, 80^{\circ}$, verso il Sud-Ovest.

Quanto alle lenti conglomeraticle che appaiono sporadicamente nella regione tongriana in esame le principali sono: quella di Val Grana, Val Casamola, attorno alla zona liguriana del Molino di Camagna, dove incontransi comuncmente fra le ghiaie enormi ciottoloni per lo più serpentinosi o granitici; quclla notevolissima di C. Patrucco presso Camagna, dove assieme ai ciottoli di roccie alpine incontriamo molto abbondanti i ciottoli di calcare alberesc, spesso schiacciati, frantumati e coi frammenti spostati; quivi inoltre si osservano pure certi speciali banchi arenacei, a grana fina e di color bleuastro clic vedremo poi molto sviluppati nell'area tongriana di Villadeati.

Altre lenti conglomeratiche veggonsi tra C. Mondala e C. Cor*dera, alle falde settentrionali delle colline di borgata Davino, nei dintorni di C. del Tolè, ecc, cioè gencralmente nella parte inferiore della formazione tongriana.

Ad Orest di Val Rotaldo la zona tongriana continua a svi- 
lupparsi per lungo tratto verso Ottiglio, finchè riene ricoperta discordantemente dai depositi miocenici; nella parte settentrionale delle colline di Olivola e Frassinello è spesso difficile il delimitare con precisione il Tongriano dall' Aquitaniano, quantunque in complesso uno sia specialmente arenaceo e l'altro prevalentemente marnoso.

Nella parte alta delle colline di Frassinello predominano le marne sabbiose, inclinate generalmente verso il Nord o FordEst circa; invece verso le falde meridionali appaiono fra le sabbie e le arenarie grosse lenti ciottolose, ad elementi talora molto voluminosi, e sollevate talvolta quasi alla verticale, quantunque per lo più pendano di $70^{\circ}, 80^{\circ}$ verso il Sud-Orest.

Fenomeni consimili osservansi pure nelle colline di Olivola, solo che quivi anche nella parte alta compaiono banchi sabbiosi ed arenaceo-calcarei con grosse lenti ciottolose, con inclinazione generale a Nord circa; alle falde meridionali di queste colline e separate dalla zona ora indicata per mezzo di una zona di marne grigio-bleuastre, appare nuovamente una potente formazione sabbioso-arenacea inclinata di circa $80^{\circ}$ verso il Sud ad un dispresso ed inglobante grosse lenti ciottolose ben sovente ad elementi voluminosissimi.

Fra queste arenarie s'incontrano qua e là, specialmente presso C. del Conte, resti fossili fra cui specialmente interessanti le Nummuliti.

Questa zona arenacea conglomeratica attraversando la valle costituisce le balze dirupate delle colline di Monsinetto a destra di Val Rotaldo; ma però più ad Orest ritornando sulla sinistra di detta valle costituisce in gran parte le colline di C. del Mulino. E quivi notevole che mentre nella parte bassa di detta collina i banchi arenaceo-conglomeratici del Tongriano pendono di $40^{\circ}$ a $60^{\circ}$ circa verso il Sud-Orest in generale, invece più in alto sotto $i$ Casali Pluchin questi banchi facendo volta inclinano a Nord-Est. Questo fatto, assieme agli altri sopramenzionati, ci prova come l'affioramento Tongriano di Frassinello-Olivola-Ottiglio può essere considerato come uno stretto 
anticlinale, diretto da Sud-Est a Nord-Ovest, coperto a Nord dell'Aquitaniuno, a Sud invece direttamente dal Tortoniano, e mascherato ad Ovest dell' Elveziano. Tale anticlinale abbastanza semplice in questo caso si altera più o meno profondamente verso Est, come vedemmo, a causa delle diverse pieghe che verificansi nella sottostante zona tongriana.

Passiamo ora all'esame dell' inportantissima elissoide tongriana che dalle colline di Ottiglio si sviluppa per una quindicina di chilometri sino alle colline di Montalero in Val Stura. Anche in questa grande zona vediamo che nella costituzione del Tongriano predominano le sabbie e le arenarie inglobanti lenti, più o meno estese e potenti, di conglomerati.

In complesso l'andamento stratigrafico di questa zona è abbastanza regolare, cioè diretto da Nord Ovest a Sud Est; l'inclinazione, per lo più fortissima, è verso Nord-Nord-Est nella gamba settentrionale e verso Sud-Sud-Ovest nella gamba meridionale dell' elisse tongriana in esame; naturalmente la stratigrafia accompagna più o meno regolarmente la chiusura di detto elisse alle sue due estrenità, quella orientale e specialmente quella occidentale. Nei banchi arenacei di questa grande elissi schiacciata troviamo sovente resti fossili rappresentati specialmente da Nummuliti, che ci servono di sicura base per collocare questi terreni nel Tongriano.

Anche in quest'area liguriana mancando generalmente lo Stampiano, riesce spesso difficile il distinguere nettamente il Tongriano dall'A quitaniano, difficoltà cle già incontrammo più ad Est.

All'estremità orientale dell' elissi in esame predominano nel Tongriano i banchi sabbioso-arenacei fra $\mathrm{i}$ quali appaiono lenti - banchi ciottolosi; questi per la loro relativa durezza costituiscono la parte alta delle colline, cioè la cresta di C. BossolaC. Montion-borgata Raviara. I banchi arenacei di questa spiccata cresta collinosa pendono un po'variamente, in complesso verso il Nord-Est, ma sovente anche direttamente verso l'Est e l'Est-Sud-Est, come ad esempio nelle colline di C. De Regibus e poco ad oriente di Raviara, od anclıe, più raramente $\mathrm{e}$ solo localmente, verso l'Ovest. 
Verso la Val Colobrio, i banchi arenacei della gamba settentrionale dell'anticlinale tongriana in esame conservando una direzione assai costante da Nord-Ovest a Sud-Est, ora pendono fortemente a Nord-Nord-Est come presso C. Pallau, ora inrece sono addirittura rovesciati per modo da pendere di $70^{\circ}, 80^{\circ}$ verso Sud-Sud-Orest, come nelle colline di C. S. Gallo. Come di solito in rapporto con queste formazioni sabbiose sonvi sorgenti d'acqua, però poco abbondanti in generale.

Riguardo alla gamba meridionale dell'anticlinale in esame essa è notevolmente sviluppata; i banchi sabbioso-arenacei, talora ghiaiosi, che costituiscono la stretta collina di C. Ronco pendono in generale molto fortemente verso il Sud od il Sud-Sud-Est circa, sono qua e là fossiliferi, specialmente verso la ralletta di C. Frati, ed inglobano anche talora lenti ciottolose, come sopra S. Giustina.

Tra Ottiglio e Val Colobrio i banchi tongriani si presentano generalmente col solito andamento stratigrafico regolare, non varia però molto il grado di pendenza che è quasi sempre fortissima, solo che talora gli strati sono persino roresciati, come osservasi in diversi punti tra C. Spinosa alta e Val Colobrio, nonchè nelle colline ad Orest di S. Gottardo.

In certi banchi sabbioso-ghiaiosi non sono rari i fossili, talora alquanto frantumati, ma talora ancora abbastanza conservati, come attorno a C. Spinosa bassa, presso il Cimitero di Castellino, ecc.; raccolsi numerose Nummuliti nelle arenarie dell'alta Val C. Spinosa bassa, presso la fontana esistente quasi sotto al Cimitero di Castellino ed anche presso questo stesso Cimitero.

Quanto alle lenti ciottolose esse sono sempre molto sporadiche; così ne vediamo apparire fra le sabbie di C. Preus, fra le sabbie e le arenarie ad Orest di S. Gottardo, fra i banchi sabbioso-ghiaiosi tra le due cascine Spinosa, nelle vicinanze del Cimitero di Castellino, nonchè direttamente sopra alla striscia bartoniana; gli elementi ciottolosi sono talora di quasi un metro di diametro.

Oltre alle sabbie ed alle arenarie compaiono pure quivi ben 
distinte alcune zone marnose di color grigio che vedremo svilupparsi ampiamente più ad Ovest, e di cui una si può seguire nettamente dalle vicinanze di C. Spinosa alta alla C. Della Costa sin giù in Val Colobrio.

Ad Ovest di Val Colobrio si nota in generale il fenomeno assai curioso che la gamba meridionale dell'anticlinale tongriana ¿̀ quasi completamente masclierata dalle formazioni più recenti, mentre invece si mostra quasi completamente sviluppata la gamba settentrionale, la cui serie più completa pare che sia ad un dipresso la seguente:

Marne ed arenarie calcaree spesso ricclissime in fossili.

Elveziano

Marne dure fissili con banchi arenacei, talora assai fossilifere.

Banchi marnoso-arenacei.

Marne biancastre con interstrati arenacei.

Marne e sabbie straterellate.

Sabbie ed arenarie con lenti ghiaiose.

Marne biancastre con straterelli arenacei.

Sabbie ed arenarie con Nummulites Fiehteli, ecc. Marne grigio-bleuastre con straterelli arenacei.

Arenarie e potenti conglomerati.

$\{$ Langhiano

$\{$ Aquitaniano

Stampiano

Argille scagliose con Calcare alberese, Macigno,

e lenti ofiolitiche.

Tongriano

Liguriano

Le sabbie e le arenarie giallastre che si presentano già abbastanza sviluppate nelle colline di Castellino e sulla destra dell'alta Val C. Spinosa, si estendono notevolmente ad Ovest formando in gran parte le colline di C. Stefanon e borgata Sotto Ripa, in generale con inclinazione piuttosto forte verso il NordEst.

Queste sabbie con facies affatto speciale che ricorda quella di depositi molto più giovani, ad esempio quella dell' Elveziano di alcune regioni, vengono qua e là escavate come materiale da costruzione. 
I banchi arenacei, inglobati coi banchi marnosi (più o meno fortemente inclinati a Nord-Est), che si tagliano salendo da C. Pignone a borgata Stara, presentano pure non pochi resti di Nummuliti, a metà strada circa della salita.

Isa zona inferiore dell'elisse Tongriana in esame è costituita da potenti banchi arenaceo-conglomeratici che dalle vicinanze di C. Quartera in Val Colobrio si estendono per molti chilometri verso Ovest formando la cresta rialzata di borgata StaraPonzano-C. Ansaldi-C. Le Tane-La Vignola-C. Deferrari (Val Stura)-borgata Perosio, ecc. Lungo quest'importante zona di sviluppo la formazione si mantiene ad un dipresso costante nei suoi caratteri litologici; i suoi elementi ciottolosi in parte di roccie preterziarie ed in parte di roccie liguriane raggiungono talora dimensioni molto grandi e spesso si presentano rotti e schiacciati nel modo tipico già altrove accennato; $\mathrm{i}$ banclii in questione sono talvolta sollevati quasi alla verticale, per lo più però pendono di $70^{\circ}, 80^{\circ}$ verso il Nord-Nord-Est.

I banchi arenaceo-ciottolosi ora esaminati poggiano quasi sempre direttamente sulla formazione liguriana, talvolta però sotto ad essi compaiono lembi di una zona marnosa che rediamo più sviluppata altrove.

Sull' esaminata zona di Tongriano si appoggia una zona di marne grigio-bleuastre, alternate con straterelli sabbioso-arenacei con inclinazione abbastanza costante di $60^{\circ}, 70^{\circ}$ verso il NordNord-Est.

Tale zona, che per la sua poca durezza relativa forma quasi sempre fondi di valle o selle, si vede già ben individualizzata sulla sinistra di Tal C. Sapelli (Val Colobrin), si allarga notevolmente nelle colline di Ponzano, passa per C. Palta, restringendosi quindi noterolmente per modo che alla C. Le Tane e in Val la Vallata è ridotta a pochi metri di spessore. A tutta prima io supposi che questa zona, specialmente marnosa, potesse rappresentare lo Stampiano, ma l'arer trovato numerose Nummulites Fichtcti nei banchi arenacei ad essa superiori mi indusse a ritenerla come ancora tongriana. 
Sulla zona marnosa ora esaminata si adagia regolarmente una zona eminentemente sabbioso-arenacea, per lo più a grossi banchi, inclinati anch'essi abbastanza regolarmente di circa $60^{\circ}$ verso il Nord-Nord-Est. Tale zona che si sviluppa ampiamente tra Val Colobrio (presso C. Sapelli) sino in Val Stura, per i suoi banchi sabbioso-arenacei talora concrezionati e per l'assicme dei suoi caratteri litologici ricorda molto i banchi basali dell'Aquitaniano della parte meridionale del bacino piemontese; credo tuttaria doverla ancora inglobare nel Tongriano perchè vi raccolsi in diversi punti numerosi fossili di tipo schiettamente tongriano.

Infatti, per citare qualche esempio in proposito, lungo la cresta collinosa tra C. Volta e Salabue e presso questa borgata, dove gli strati arenacei si presentano talora persino rovesciati, oltre a numerose impronte di Taphrhelninthopsis e simili, raccolsi diverse Nummulites Fichteli ed altre forme paragonabili specialmente a quelle che riscontransi nel tipico Tongriano di Rio Freddo (Marmorito) che esamineremo fra breve. Anche a Nord di Ponzano, tra C. Nuova e C. Giordano, le sabbie contengono resti di Nummulitcs Fichteli, Cristellaria, ecc. Lo stesso dicasi per le sabbie e le arenarie di borgata Pezzare verso Val Stura.

La parte orientale dell' elissi tongriana in esame presenta un andamento stratigrafico alquanto irregolare; infatti i banchi arenaceo-conglomeratici del Tongriano invece di contornare regolarmente l'affioramento eocenico di Montalero, a partire dalla C. Perosio circa si sviluppano per oltre un chilometro e mezzo verso Nord, cioè sino a borgata Rosingo. Lungo questo percorso la zona arenaceo-ciottolosa, ad elementi spesso voluminosissimi e spesso schiacciati nel modo tipico, presenta i suoi banchi per lo più fortemente inclinati verso l'Ovest ed il Nord-Orest e viene discordantemente ricoperta dai terreni miocenici. I ciottoli del Tongriano di questa regione sono specialmente di Serpentina, Granito, Sienite, Quarzite, Porfido, Enfotide, Diorite, ecc.

Tra borgata Perosio e Montalero questi banchi sono general- 
mente sollevati alla verticale o rovesciati e con una direzione abbastanza costante da Nord-Est a Sud-Orest; qua e lia inglobano resti fossili però in generale alquanto frantumati.

Nella parte alta del paese di Montalero appaiono quei banchi arenacei che già esaminammo poco fa nelle colline di Ponzano-Crea e che dicemmo aver facies aquitaniana; essi pure inclinano di circa $70^{\circ}$ verso il Nord-Ovest.

Possiamo accennare in questo punto al fatto che sulla grande zona liguriuna di Casale si appoggiano tra Treville e S. Germano, potenti formazioni oligoceniche le quali per l'assieme dei loro caratteri litologici e per non aver presentato alcun fossile tongriano credo dover attribuire unicamente all' Aquitaniano.

Tra la pianura padana e Val Stura il piccolo affioramento elissoidale di Fabiano è attorniato da una grande elissoide tongriana di cui si potrebbe dire che esso occupa uro dei fuochi, quello orientale. Come di solito, questa formazione tongriana è rappresentata essenzialmente da banclii sabbiosi ed arenacei, alternati a zone marnose ed inglobanti lenti ciottolose come al fondo del vallone a Nord di Rocclietta, tra C. Biglia e Bric della Cava, presso Fabiano, all'estremità occidentale dell'affioramento liguriano, nelle colline di C. Savi, di Mombello e di Luvara.

Questi banchi arenaceo-conglomeratici, per la loro natura e per essere per lo più fortemente sollevati, costituiscono speciali collinette emergenti, direi, nettamente, fra le regioni collinose circostanti.

Mentre all'estremità orientale dell'elissoide in esame i banchi marnoso-arellacei pendono complessivamente di circa $45^{\circ}$ verso l'Est ad un dipresso, come si può ad esempio osservare lungo la strada clıe attornia il Bric della Cava, all' estremità occidentale invece gli strati arenaceo-ciottolosi pendono fortemente verso Ovest come si può vedere bene lungo la strada che da Val Pozzengo sale a borgata Luvara; nella restante parte dell' elisse i banchi tongriani sono in generale allineati abbastanza regolarmente da Est ad Orest, con pendenza piuttosto forte, cioè di 
$60^{\circ}, 70^{\circ}$ o verso il Sud, come nelle colline di Mombello, di Sabarana, ecc., oppure verso il Nord, come nelle colline di C. Biglia; talora però questi banchi sono rovesciati, come pare sia talvolta il caso per le colline esistenti direttamente a Sud dell'affioramento liguriano di Fabiano.

Nelle falde settentrionali delle colline che fronteggiano la pianura di Palazzolo vercellese, sopra alla zona liguriana già studiata di Brusaschetto, compaiono per oltre due chilometri di sviluppo alcuni banchi che per la loro facics e per i fossili che inglobano sono certamente da attribuirsi al Tongriano. Infatti poco a valle del porto di Rocca delle Donne, sotto ai banclii essenzialmente marnosi dell' Aquitaniano appaiono lungo il Po certi banchi sabbioso-marnosi che inglobano strati arenacei e potenti banclii conglomeratici.

Questa formazione inclinata di circa $60^{\circ}$ verso il Sud ad un dipresso mi presentò a diversi livelli, fra le arenarie, numerosi foraminiferi fra cui interessanti la Nummulites intermedia e patrecchie Orbitoidi.

La formazione ciottolosa diviene potentissima più ad Est costituendo in gran parte il lato settentrionale delle colline di Rocca delle Donne.

Allo sbocco dell'ampia valle esistente tra Rocca delle Doune e Brusaschetto prendono un grande sviluppo le marne grigiastre o grigio-verdiccie, scagliose, friabili, clie debbono già riferirsi al Bartoniano.

Dal Porto di Rocca delle Donne lungo la sponda del Po, da monte a valle, si incontra la seguente serie stratigrafica: 
Narne grigie a frattura concoide, friabili.

Marne e banchi sabbiosi.

Narne.

Aquitaniano

Stampiano

Banchi sabbioso-ghiaiosi con Nummulites.

Lenti ciottolose.

Marne.

Banchi conglomeratici.

Marne.

Strati arenacei e marnosi.

Marne grigio-verdiccie, scagliose, friabili.

Arenarie a Nummulites ed Orbitoides; argille

scagliose, calcari alberesi, ecc.

Ja zona tongriana coperta discordantemente dall'Aquitaniano pare scomparire verso Est nelle colline di Brusaschetto, dore vediamo ancora alcune lenti ciottolose le quali poggiano quasi direttamente sulla formazione liguriana che si sviluppa ampiamente tra Verrua, Marcorengo e Oddalengo grande, formando un ampio semicerchio colla convessità rivolta ad Est: essa è costituita essenzialmente di bancli sabbiosi ed arenacei straterellati giallastri che racchiudono banchi conglomeratici assai cementati; questo assieme di banchi per lo più assai fortemente sollevati, cioè di $40^{\circ}$ ad $50^{\circ}$, costituisce colline ripide ed elerate intersecate da profondi e scoscesi burroni. (Bric della Pietra, Bric Pollone, ecc.)

Le arenarie straterellate che compaiono verso la base di questa formazione littoranea e che in parte sono già riferibili al Sestiano, per la loro facies e per le impronte di cui spesso sono superficialmente coperte, ricordano molto certi orizzonti dell'Eocene superiore.

L'andamento stratigrafico del Tongriano è assai regolare giacchè vediamo i suoi strati pendere verso Sud-Est di circa $50^{\circ}$ nelle colline di Camorano e di $55^{\circ}$ ad $80^{\circ}$ al bric Castagneto, poscia di circa $50^{\circ}$ verso Est al bric delia Pietra, pendere poscia di circa $40^{\circ}$ verso Nord-Est al Bric Pollone, finchè tra Bal- 
zola e C. Pariasco cssi assumono in generale un'inclinazione assai forte (sovente di $60^{\circ}, 70^{\circ}$ ) verso il Nord all'incirca. Anclie i banchi ciottolosi di questa zona presentano un andamento assai regolare; li vediamo già ben costituiti presso borgata Monte al Bric Castagneto, più sviluppati poi al Bric di C. Nicoletti, al Bric della Pietra, ed al Bric Pollone.

Di qui il banco conglomeratico, fortemente sollevato, spesso ad elementi voluminosissimi, dirigendosi verso Lst, discende in Val Caservalle, quindi sale a $\mathrm{S}$. Anna, continuando poscia più assottigliato verso il Molino del Boschetto.

Lungo questo percorso le arenarie tongriane non mancano di presentare sovente dei fossili, sgraziatamente in generale detcriorati, tuttavia potei raccogliere qua e là Nummuliti abbastanza ben conservate, cosi sopra C. Chinoni (borgata Balzola) e ncll'alta Val della Narca sulla sinistra tra C. Negri e C. Scarfenga, dove i banchi arenacei fortemente inclinati a Nord racchiudono Nummulites Fichtcli, $N$. miocontorta var., ecc. Quest'ultima località è assai interessante poichè vi si può osservare assai bene il passaggio tra il Tongriano, il Sestiano ed il Bartoniano.

Dando un occhiata complessiva alla bcllissima conca di Oddalengo-Brozolo-Verrua-Moncestino, la vediano costituita cssenzialmente dalle seguenti formazioni: 
Marne e sabbie fossilifere. Elveziano

Marne dure, fissili, spesso fossilifere. Langhiano

Marne grigio-bleuastre con interstrati arenacei. Mirne friabili, grigie.

Potenti banchi arenacei, spesso a mamelons, gri- Stampiano giastri, talora fussiliferi.

Marne grigie, friabili, talora con interstrati cal- ; carei.

Aquitaniano

Arenarie, sabbie, grigio-giallastre, conglomerati. Tongriano

Strati marnoso-arenacei con Nummulites, Or.ti-) toides, ecc.

Marne grigio-bleuastre o violacescenti, friabili, a Nummulites, Orbitoides, Lithothamnium, ecc. Argille scagliose brune, o violacee, o rossiccie, con calcare alberese, arenarie, lenti congloineratiche.

Liguriano

La formazione tongriana a destra di Val della Marca presenta un andamento piuttosto regolare a causa dell'affioramento di zone eoceniche. Infatti i suoi banchi sabbioso-arenacei, con lenti ciottolose, che nella collina di C. Pariasco pendono di $70^{\circ}$ circa verso il Nord-Orest, rapidamente incurvandosi assumono nelle colline di C. Vignassa un' inclinazione, egualmente forte, verso il Nord-Est ad un dipresso.

Tra il Cimitero di Oddalengo grande e borgata Vallarolo le formazioni tongricune trovandosi tra due diversi affioramenti eocenici, cioè a Nord quello di C. Boschetto ed a Sud quello di Val Bosco, presentano i loro banchi diretti ad un dipresso da Nord-Orest a Sud-Est o da Est ad Orest e sollevati quasi alla verticale od anche localmente rovesciati.

Fra i banchi marnoso-sabbiosi di questa regione tongriana, oltre a diversi straterelli ciottolosi, compaiono pure lenti di lignite compattissima, come osserrasi ad esempio nelle vallettine di C. Saliceto, quasi di fronte a detta Cascina, ma ad un livello alquanto più basso; c̀ questa d'altronde una di quelle acciden- 
talità che si verificano ben sovente nel Tongriuno inferiore, di cui anzi costituiscono uno dei caratteri secondari.

Nelle colline di Vallarolo, di S. Antonio nuovo, di S. Antonio recechio e di C. Nuova, tra l'alta val d'Arne e l'alta val della Marca, il Tongriano inferiore non si presenta più generalmente in banchi rizzati alla verticale, ma generalmente invece in banchi poco inclinati ed in varie direzioni, specialmente però verso il Nord, di una trentina di gradi. Quivi la formazione tongriana, che è costituita da marne frammentarie, sabbie, arenarie, talvolta nummulitifere, conglomerati (i cui elementi presentano talora l'inizio dei fori di litodome) forma sovente delie placche sopra alle marne frammentarie grigiastre del Burtoniano che in queste regioni si osserva talora una transizione abbastanza regolare tra l'Eocene ed il Tongriano.

Alla base del Tongriano compaiono spesso banchi ghiaioso-congloneratici a ciottoli specialmente serpentinosi, nerastri, alternati con strati marnosi bruno-blenastri; potrebbero forse appartenere al Sestiano, ma finora non vi si rinvennero fossili caratteristici.

A Sud dell'affioramento liguviano di borgata Vagiardi i banchi marnosi e sabbiosi del Tongriano sono fortemente sollevati inclinando a Sud o Sud-Est; più ad Orest compaiono ancora lenti ciottolose come sotto C. Nuova, nelle colline del Cimitero di Cortiglione, ecc.

Tra borgata Valeisa e borgata Cortiglione sull'affioramento iiguriano si appoggiano dal lato meridionale potenti banchi sabbiosi grigiastri che inclinano fortemente verso il Sud o Sud-Est ed inglobano grosse lenti conglomeratiche, come di solito con numerosi elementi voluminosissimi, con frequenti ciottoli schiacciati e frantumati, per lo più di macigno, di calcare alberese e di Serpentina.

Nei tagli naturali ed artificiali vediamo che i banchi tongriani sono spesso spostati, infranti, con superficie lucenti quasi verniciate che sono vere superficie di scorrimento; anche i ciottoli sono spesso coperti da una specic di vernice lucente; sovente 
appaiono pure irregolarissime rene o lenti sporadiche. Sono questi d'altronde i fenomeni generali che in Piemonte caratterizzano abbastanza bene il Tongriano. In queste colline spesso la serie dei terreni si presenta nel seguente modo:

Arenarie, sabbie e lenti conglomeratiche.

Potente banco conglomeratico.

Sabbie, marne ed arenarie con Molluschi e Num-
muliti.

Arenarie straterellate con Nummuliti.

Sestiano

Marne grigie e bleuastre.

Bartoniano

Marne argillose violacescenti con calcare alberese ed arenarie.

Più ad Orest la formazione tongriana, interrotta da ramificazioni della zona liguriana, colle sue marne, colle sue sabbie e colle sue arenarie forma l'alto della collinetta di borgata Piaj e le colline di C. Lombardo e di borgata Vignali collegandosi cosi con quella estesissima di Brozolo-Lauriano; questi banchi sabbiosi giallastri sono fortemente sollevati, talora leggermente rovesciati; per lo più inclinati a Sud-Est o a Sud-Orest, anche dalle inclinazioni affatto diverse perchè le colline di borgata $\mathrm{Vi}$ gnali presentano dei disturbi stratigrafici abbastanza forti.

Prima di passare all'esame della formazione tongriana verso Ovest, dobbiamo accennare agli importanti affioramenti laterali che di essa appaiono più a Sud, cioè tra Nurisengo e Penango, e tra Cocconato ed Albugnano.

Fra i più interessanti affioramenti laterali di Tongriano è molto notevole quello che possiamo appellare di Villadeati dal paese principale clue vi sta sopra.

Già trattando del Liguriano si è notato come in Tal Stura ad Est di Murisengo appaia una zona liguriana poco vasta ma ben caratterizzata litologicamente e paleontologicamente. Orar in qnesta regione, come in generale, la venuta a giorno d'aree liguriane porta seco, per conseguenza, l'affioramento di formazioni tongrianc; nel caso presente il Tongriano, che non com- 
pare a Nord della zona liguriana di Murisengo, si sviluppa invece estesissimamente verso Nord-Est formando una stupenda elissi, incompiuta a Nord ed in parte mascherata a Sud dai terreni miocenici che la circondano adagyiandovisi sopra alquanto discordantemente.

Come di solito nella costituzione di questa zona tongriance preclominano in modo assoluto le sabbie e le arenarie, vi si trovano pure sviluppatissimi i conglomerati, na acquistano un' insolita importanza certi speciali banchi arenacei, durissimi, grigio-giallastri o bleuastri, a grana finissima, che vengono utilizzati in più punti come pietrisco; arenarie simili erano già comparse in altre aree tongriane più ad Est, ad esempio presso Camagna, mai però esse avevano presentato quello sviluppo che osservasi invece presso Villadeati.

L'area tongriana elissoidale in questione, vera ruga parallela all' asse maggiore dell' anticlinale dei colli Torino-Valenza, si estende dal paesello di Penango sino alla valle Stura, con uno sviluppo di oltre 8 chilometri in lunghezza, presentando invece una larghezza media di poco più ải un chilometro.

Quest'area è rappresentata specialmente da arenarie e da sabbie grigio-giallustre con lenti ciottolose ad elementi talora voluminosissimi; anche nell' andamento stratigrafico la disposizione ad elissoide allungata è abbastanza regolarmente conservata.

Verso Penango in Val Bizara sono specialmente sviluppati i banchi sabbiosi, messi sovente allo scoperto da scoscendimenti alternati talora con strati arenacei e commisti eziandio a ciottoli e ciottoloni che cominciano atd apparire nelle colline di C. Maranzana; questa facies sabbioso-ciottolosa si sviluppa sempre più nettamente verso Ovest e si può stupendamente osservare nella profonda valle di C. Moretta e di C. Marco dove veggonsi ciottoloni veramente enormi.

Ancora più ad Orest ai banchi sovraccennati si aggiungono potenti strati arenacei durissimi, inglobanti lenti conglomeratiche pure molto resistenti, per modo da costituire nell' assieme 
le erte colline di S. Spirito, di Bric Nambria, di Bric S. Lorenzo e di Villadeati.

Le lenti o banchi ciottolosi, abbondantissimi fra le sabbie in quasi tutte le regioni collinose. Tilladeati-Tal Bizara, e con elementi spesso roluminosissimi specialmente tra le colline di Alfiano Natta e quelle di Bric S. Lorenzo, si presentano talora cosi fortemente cementate da costituire dei durissimi conglomerati, di cui è bellissimo esempio quello, quasi rerticale, che furma l'alto rilievo su cui posa il Castello di Villadeati; pure potenti conglomerati osserransi nell'alta Tal Zappi sotto il Cimitero di Villadeati; d'altronde basta percorrere i profondi burroni di questa regione collinosa, sia verso Nord che rerso Sud, per conrincersi dello sriluppo straordinario che quiri presentano le facies ciottolose.

Le dure arenarie che si accentuano già assai bene nella collina di Maranzana, si sviluppano poi in modo straordinario nelle colline di S. Spirito, di Bric Nambria, di Bric S. Lorenzo (466 metri), di Bric Tribecco e di Villadeati, costituendo così la parte piu elerata e più dirupata della regione in esame.

L' andamento stratigrafico dell' importante afforamento tongriano in esame è complessivamente abbastanza regolare malgrado l'esistenza di varie lacune e di vari disturbi tettonici e luantunque apparentemente esso si presenti molto alterato per rovesciamenti e specialmente pel fatto che i terreni miocenici più giovani (Langhiano, Elveziuno, Tortoniano ed anche Messiniano) vengono quasi orunque a ricoprire direttamente parte delle formazioni tongriane con discordanze più o meno forti, mascherando quindi considerevoli porzioni di strati di ambidue le gambe della strettissima anticlinale tongriana.

Nella ralle Bizara, i banchi, preralentemente sabbiosi, del Tongriano direttamente coperti dai terreni messiniani, e, rerso Sarnico, da quelli tortoniani, inclinano in generale leggermente verso il Sud-Est circa, accennando così alla curra (risibile solo in parte) dell'elisse.

Verso Orest gli strati assumono poco a poco un' inclinazione 
verso il Sud, poi verso il Sud-Ovest, quantunque con alterazioni locali, mu con una pendenza di $25^{\circ} 030^{\circ}$; in seguito i banchi tongriani, sempre conservando una direzione abbastanza costante Nord-Ovest a Sud-Est, si rialzano ognor più fortemente, essendo già inclinati di circa $45^{\circ}$ presso Alfiano Natta, drizzandosi spesso quasi alla verticale nelle colline più ad Orest sino a Villadeati, ed anzi presentandosi talora persino rovesciati; noto però che anche in queste regioni collinose osservansi spesso banchi ad inclinazione non tanto forte, anche nella parte alta delle colline, cosi al Bric S. Lorenzo la cui sommità è costituita di banchi ciottolosi ed arenacei inclinati a Sud-Ovest circa.

Verso il margine settentrionale della zona tongriance in esame, ad Ovest di Val Bizara, l'inclinazione dei banchi sabbiosi con lenti ciottolose è assai regolare e non molto forte verso NordEst, come si può vedere assai bene per esempio presso C. Lunga, ma diventa sempre più forte e persino di $70^{\circ}$ e $80^{\circ}$ nell'alta valle Zappi; quivi veggonsi, ad un dipresso sotto al Cimitero di Villadeati, potenti banclui ciottoloso-sabbiosi inclinati più o meno fortemente in modo la rappresentare quasi una cupola di sollevamento o meglio i punto focale di un' elisse. Ad ogni modo io credo che i conglomerati ora accennati debbansi parallelizzare a quelli clie nella già studiata area tongriana di Montalero-Ottiglio costituivano la parte inferiore del Tongriano, basando colà direttamente sui terreni eocenici. E anzi probabilissimo che sotto alle formazioni tongriane esaminate esista una ruga ligntriana diretta da Nord-Ovest a Sud-Est circa; è anche ad essa clie devesi probabilmente l'affioramento ripetuto di zone messiniane entro l'area pliocenica verso Sud-Est.

I ciottoli delle zone tongriane Villadeati-Penango sono costituiti in gran parte di elementi liguriani, sia arenarie che calcari alberesi; di questi ciottoli molti presentano il carattere tipico della deformazione con frattura e spostamento notevole dei vari frammenti. Talora $\mathrm{i}$ ciottoloni, specialmente quelli serpentinosi, raggiungono anche due metri di diametro e quando per l'erosione rimangono isolati sul dorso delle colline, simulano molto bene gli crranti dei terreni glaciali. 
Per osservare i rovesciamenti dei banchi tongriani sono specialmente interessanti i dintorni di Lussello e di Cardona, dore predominano le sabbie più o meno sciolte, inglobanti qua e là lenti ciottolose irregolari; in queste regioni anzi non solo l' $A$ quitaniano ed il Langliano, ma persino le zone clvcziane e tortoniane non rengono più a giorno.

In molti punti dell' esaminata area tongrianc appaiono fra le arenarie sorgenti sulfuree assai copiose, carattere secondario che incontrasi appunto molto sovente nelle zone tongrianc.

Attorno alla zona liguriana di Cocconato-Marmorito vediamo afforare per lungo tratto $\mathrm{i}$ banchi tongriani, assai interessanti specialmente per straordinaria ricchezza in fossili che si incontrano in alcune località.

Di questa interessantissima regione, essendomi giả occupato particolarmente in un lavoro speciale, mi limito ad accennare i fenomeni principali.

La formazione tongriana cle si sviluppa specialmente a Nord della zona liguriana consta essenzialmente di banchi sabbiosi ed arenacei grigio-giallastri, i quali racchindono qua e là lenti più o meno estese e potenti di ciottoli a superficie liscia, quasi verniciata, come si può osservare ad esempio sull'alto delle colline del Bricco poco a Nord di questa borgata. Però verso il basso di Val Rio Freddo i depositi ciottolosi assumono una grandissima potenza; i loro elementi, per lo più fortemente cementati, presentano talora dimensioni notevolissime; i loro banchi resistenti sono rizzati quasi alla verticale inclinando talora di $70^{\circ}, 80^{\circ}$ verso l'Ovest circa.

Gli elementi ciottolosi come di solito risultano in parte dallo sfacelo dei calcari e delle arenarie liguriane ed in parte maggiore da roccie cristalline, alpine.

Coi conglomerati si alternano spesso banchi sabbiosi ed arenacei grigi e giallastri ed anche banchi marnosi bleuastri molto ricchi in Molluschi, Antozoi, ecc. sovente però alquanto rotti per esser spesso mescolati caoticamente con irregolarissime lenti ciottolose ad elementi sparsi. Questo speciale fenomeno osser- 
vasi specialmente bene in fondo a Val Rio Freddo presso lo sbocco della stradicciuola che scende da borgata Canuto.

Alcuni banchi durissimi arenaceo-puddingoidi, che osservansi in fondo a Val Rio Freddo, poco sotto lo Stampiano, sono molto interessanti perchè per la loro facies e per la loro ricchissima fauna a Nummuliti ( $N$. intermedia, N. Fichteli, ecc.), Antozoi, Echinodermi, Crassatelle, ecc., ricordano perfettamente il T'ongriano tipico dell' Appennino settentrionale. Questo ci fa supporre che probabilmente la formazione tongriana che si è potuto ampiamente studiare nell'Appennino settentrionale e che si è visto scomparire nelle colline monregalesi sotto ai terreni miocenici, continua lungo le falde alpine anche ad una certa distanza dalle Alpi, conservando la facies tipica subalpina, direi, ben diversa da quella del tortonese $\mathrm{e}$, in generale, delle colline 'Torino-Valenza.

Pure interessanti nella stessa località esaminata, in fondo a Val Rio Freddo, sono certi banchi sabbiosi giallastri ricchissimi in piccole Nummuliti appartenenti specialmente alla $N$. Fichteli. Ancora notevoli per ricchezza in fossili sia Nummuliti, sia Molluschi, ecc., sono certi banchi arenacei quasi verticali clie osservansi direttamente sopra ai potenti banchi conglomeratici della fontana solforosa di Rio Freddo.

In complesso possiamo dire che salendo il vallone di Rio Freddo dal Molino dello stesso nome verso Nord, incontriamo: 
9. Marne argillose grigio-bleuastre, spesso franose.

8. Banchi marnosi, friabili.

Aqnitaniano

7. Banchi arenaceo-gliaiosi, ricchissimi in Nummulites intermedia, N. Fichteli, Antozoi, Echinodermi, Bivalvi, Gasteropodi, ecc.

6. Grossi banchi sabbioso-arenacei giallastri con Nummulites Ficleteli, ecc.

5 . Complesso di banchi sabbioso-arenacei, marnosi, grigiastri, fortemente sollerati.

4. Potenti conglomerati con interstrati arenacei e marnosi fossiliferi.

3. Strati sabbioso-arenacei con letti lignitici.

Stampiano

2. Marne grigie con straterelli calcarei a Litho. thamminm, Nummulites, Orbitoides, Hetero-
stegina. Bartoniano

1. Argille scagliose brune con Macigno, Calcari f Lignviano alberesi e lenti ofolitiche.

Nella parte inferiore della formazione tongriana appaiono banchi sabbiosi ed arenacei che servono bene di passaggio al $B a r$ toniano; di essi e della loro caratteristica fauna nummulitica abbiamo già trattato studiando il Sestiano.

Quanto alla striscia tongriana, essenzialmente arenacea che appare a Sud della zona lignriana di Cocconato: essa non presenta alcun fatto interessante; i suoi banchi pendono di $60^{\circ}$, $70^{\circ}$ circa verso il Sud ad un dipresso.

Ritornando ora alla parte settentrionale delle colline torinesi, vediamo che la formazione tongriana appare ai due lati della grande zona lignviana Brozolo-Lauriano.

Infatti nell'alta valle Trincavenna in continuazione della zona arenacea tongriana di borgata Castello vediamo srilupparsi da La Fabbrica verso Ovest una potente serie di banchi marnososabbiosi straterellati, alternati con banchi arenacei ed inglobanti qua e lì straterelli ghiaioso-ciottolosi. Tali banchi, incli- 
nati di $50^{\circ}, 60^{\circ}, 70^{\circ}$ ver'so Sud-Ovest e di cui gli inforiori sono forse riferibili al Sestiano, si appoggiano direttamente sulle marne del Bartoniano.

Ma ad Ovest di C. Fantasia i banchi tongriani assumono una inclinazione molto minore, spesso di solo $10^{\circ}$ o $20^{\circ}$ verso Ovest o verso Sud, quindi questa formazione si allarga estesamente sul Burtoniano sino a C. Olaschei; vi compaiono frequentemente le tipiche lenti conglomeratiche ad elementi spesso schiacciati, frantumati e coi frammenti ancora riuniti come già avemmo ad osservare tanto sovente altrove, sempre nel Tongriano; talora questi ciottoli sono costituiti di cementatissima puddinga di cui dobbiano cercare l'origine nelle lenti conglomeratiche del $\mathrm{Li}$ guriano superiore.

Gli elementi ciottolosi della formazione in esame assumono talora un volume molto considerevole, ma in generale hanno soltanto 10 a 12 centimetri di diametro. Verso borgata Gerbole, in causa del grande svilupparsi della zona liguriana i banchi tongriani, spesso conglomeratici, si presentano di nuovo fortemente riaizati, ma pendenti a Sud-Est e vanno a scomparire verso Ovest sotto ai potenti depositi aquitaniani.

Molto più sviluppata e regolare è la zona tongrianc che si estende a Nord della formazione bartoniana; essa si inizia già sulla destra di Val Trincavenna nel rilievo di C. Borghetto, con banchi arenacei e marnosi alternati, fortissimamente sollevati e diretti da Sud-Ovest a Nord-Est circa; questi banchi, sempre con un' inclinazione di $60^{\circ}, 70^{\circ}$ a Nord-Ovest e poi a Nord si sviluppano regolarmente sino a Lauriano.

Verso la base di questa formazione compare una serie di banchi marnosi che servono assai bene a distinguere il Tongriano dal Sestiano, orizzonti cle qui, come altrove, in generale, sono molto simili litologicamente.

I banchi arenacei straterellati della zona tongriana in esame non presentano generalmente resti fossili ben conservati; spesso però vi compaiono impronte organiche ed inorganiche; notiamo anzi fra queste impronte i Paleodyction con forme molto simili a quelle del $P$. regulare del Tongriano del Tortonese. 
F. SACCO,

E specialmente nelle colline tra Marcorengo e Monteu da Po, attraverso al Bric Sac, che le formazioni in esame, quantunque fortemente sollevate, si presentano pin sviluppate: quivi infatti se ne può osservare la serie quasi completa che indico sonmariamente in questo modo:

Sabbie, marne ed arenarie grigio-giallastre.

Elveziano

Marne dure, fissili, bleuastre.

Langhiano

Marne grigie ed arenarie.

Marne bleuastre, friabili.

Marne e sabbie in grossi banchi.

Marne grigio-bleuastre, scaglioso-friabili.

Potente serie di arenarie straterellate.

Marne grigio-bleu, scaglioso-friabili.

Aquitaniano

Siampiano

Tongriano

Arenarie straterellate con Orbitoides, Nummulites, ecc.

Sestiano

Marne grigiastre, friabili, con interstrati ed anche bancli arenacei.

Bartoniano

Argille scagliose rossastre e grigio-brune, con banchi calcarei ed arenacei e lenti sabbiosociottolose.

Al Torrione Greppo, presso Monteu da Po, gli strati tongriani si presentano talora inclinati di $80^{\circ}$ e più gradi rerso il Nord, talrolta anzi essi sono leggermente rovesciati, oppure ripieghettati e contorti come per esempio si può redere presso la borgata di Mezzana; nelle colline di C. La Bracca i banchi arenacei e sabbiosi che compaiono abbastanza sviluppati, assumono, nella parte Nord-Orest una direzione complessiva da Sud a Nord con pendenza ad Est, il che ci spiega come il Tongriano scompaia per un certo tratto verso Lauriaro. Lo si vede però ricomparire presso Moriondo dove è rappresentato in parte da arenarie ed in parte da marne; anzi una parte di queste ultime, quelle più ad Orest e che rengono ricoperte direttamente e concordemente dal Tongriano, potrebbero forse riferirsi gia allo Stampiano. 
In tutto questo sviluppo del Tongriano non appaiono notevoli lenti conglomeratiche, ma solo marne, sabbie ed arenarie passanti localmente a ghiaiette.

Sottili striscie di Tongriano sembrano anche apparire qua e li in diversi punti di Valle Abramo tra il Bartoniano e l'Aquitaniano.

Percorrendo il fondo della piccola, ma importantissima vallata di S. Genesio (collina di Chivasso) si ha spesso occasione di osservare che sopra ai terreni bartoniani e sestiani, già accennati nei capitoli precedenti, appaiono sporadicamente, sotto all'Aquitaniano, alcuni banchi sabbiosi ed arenacei, per lo più fortemente, ma alquanto variamente sollevati i quali, per la loro facies e per i fossili che contengono, paiono doversi riferire al Tongriano. Sgraziatamente tali affioramenti sono cosi ristretti ed i fossili per lo più in tale cattivo stato di conservazione che riesce difficile il delimitare nettamente la formazione tongriana di questa piccola regione.

I fossili meglio determinabili sono specialmente i Foraminiferi; cosi ad esempio nei pochi banchi arenacei, quasi verticali e diretti da Est ad Ovest, che delimitano nettamente a Nord nel letto del t. S. Genesio la formazione bartoniana presso C. Baraccone, raccolsi diversi esemplari di Quinqueloculina, Cristellaria, Operculina complanata, Heterostegina, ecc.: tali banchi marnoso-arenacei che sono delimitati inferiormente da un bel banco conglomeratico a grossissimi elementi, paiono doversi riportare al Tongriano.

Più a valle si trovano anche Nummulites, per lo più lo N. Fichteli, ma riesce sovente difficile distinguere i banchi tongriani da quelli sestiani, non essendo d'altronde gli uni che la continuazione regolare degli altri.

Finalmente l'ultimo affioramento di terreno tongriano in Piemonte è quello assai sviluppato che a forma di elisse interrotta accerchia la famosa zona bartoniana di Gassino. Si è già detto sopra che una piccola parte dei banchi basali della potente formazione arenaceo-conglomeratica di Gassino è riferibile al 
Sestiano per quanto si può dedurre da alcune Numnulitidec chic vi si sono incontrate.

Il carattere predominante di questa formazione tongriana è la potenza e lo sviluppo dei suoi banchi conglomeratici; questi coustano di elementi svariatissimi sia di natura (calcari albaresi, arenarie del Liguriano e roccie cristalline dalla ricina catena alpina) sia di grossezza raggiungendo ed oltrepassando talora un metro di diametro, in alcune lenti speciali. Fra i ciottoli raccolsi anche calcari nummulitiferi grigiastri che derivano dallo sfacelo di qualcuno di quei banchi parisiani che sulle Alpi Marittime incontransi tra il Flysch liguriano ed il Cretaceo.

I hanchi conglomeratici in esame, spesso foggiati a lastroni durissimi, sono talora fortissimamente sollevati, per modo da farc un angolo di $60^{\circ}, 70^{\circ}, 80^{\circ}$ coll' orizzonte, eccetto che nella parte occidentale dove si presentano spesso inclinati di solo $30^{\circ}, 40^{\circ}$.

I ciottoli e le arenarie sono quasi sempre tra loro cementatissimi, ciò che ci spiega l'asprezza ed il carattere alpino, direi, dclla regione (a grandi cascate, a dirupi selvaggi, ecc.) costituita di questi terreni, ciò che colpisce tanto più a causa della relativa norbidezza e ricchezza in vegetazione delle circostanti colline sabbioso-marnose.

Nella partc occidentale dell'orizzonte conglomeratico in esame, sviluppandosi più ampiamente i diversi terreni si può nettamente osservarc cone di tratto in tratto fra $\mathrm{i}$ banchi arenaceo-conglomeratici compaiono potenti bancli sabbiosi-marnosi, grigiobleuastri con inclusc irregolari lenti ciottolose, sottili lenti lignitiche e fossili diversi; questi banchi marnosi si possono distinguere in tre principali, restando così diviso l'orizzontc conglomeratico in questionc in sette sotto-orizzonti secondarii; cioè uno infcriore interno conglomeratico appoggiantesi direttamentc sul Bartoniano, un secondo marnoso che vedesi specialmente a Nord del Bricco di Tetto Rosa e clic discende in Val Crirella quasi di fronte a Villa Cocchis; un terzo conglomeratico, costituente il rilievo di Tctto Rosa e quello a Nord della Madonna; un quarto 
marnoso formante la valletta ed il colle di Tetto Rosa, il colle della Madonna, discendendo a C. Grognard e perdendosi in seguito verso Est; un quinto di nuovo conglomeratico, molto potente, che costituisce lo spiccato rilievo di 'Tetti Francesi, origina la bella cascata in fondo alla valletta di Tetti Gettina, formando una specie di alta gradinata sul suo lato destro, costituendo il piccolo rilievo a Sud della Madonna ed unendosi verso Est cogli altri suborizzonti conglomeratici; un sesto nuovamente marnoso clie dà origine alla valletta ed al colle di Tetti Francesi, come pure al colle ed alle vallette di Tetti Gettina e di C. Chiara mostrandosi ancora ben visibile al fondo di Val Maggiore e poscia perdendosi come di solito verso Est per lo schiacciamento di tutti i banchi; infine un settimo potentissimo suborizzonte conglomeratico che costituisce gli alti rilievi di Bric Glıenon, Bric Carlevè, Bric la Croce, ecc.; sopra tutto ciò infine si sviluppa il potente orizzonte marnoso aquitaniano.

In complesso gl'indicati suborizzonti formano ad Ovest 0 meglio a Sud-Ovest altrettanti semicerchi i cui strati si obliterano tosto e.quasi completamente verso Nord, venendo coperti dai terreni marnosi dell'orizzonte superiore ed invece si rimpiccioliscono poco a poco verso Est prevalendo naturalmente gli strati più potenti del suborizzonte conglomeratico superiore.

Ho creduto dover esaminare alquanto minutamente quest' orizzonte tongriano percliè esso, quantunque non si mostri ancora qui certamente in tutto il suo sviluppo, ci denota cliaramente come anche nei piani o sottopiani a facies più decisamente littoranea o di basso fondo, come è il caso per quello ora esaminato, esista poi quasi sempre tuttavia una regolare alternanza di suborizzonti marnosi con quelli arenaceo-conglomeratici, ed inoltre ci indica che presso la catena alpina il Tongriano acquista una potenza rilevantissima.

I fossili sono abbastanza comuni nelle marne e nelle arenarie, ma per lo più infranti o mal conservati; comunissime sono sulle lastre arenacee le impronte giallo-rossastre di foglie, di rami e di tronchi d'albero; fra $i$ resti animali sono specialmente a ri- 
cordarsi le conchiglie di Gasteropodi e di Lamellibranchiati racchiuse nei banchi marnosi.

Nelle arenarie si riscontrano pure alcuni resti di Foraminiferi fra cui specialmente notevoli alcuni esemplari di Nummuliti. Non rari fossili osservansi pure nelle arenarie del Tongriano superiore tra Cordova ed il Casone.

Ia placca tongriana esistente a Sud di Tilla Donaudi presenta un' inclinazione, non molto forte però, verso Sud-Est.

La profonda decomposizione dei conglomerati di quest'orizzonte cssenzialmente conglomeratico è causa del color rossastro che presentano generalmente le colline che ne sono costituite.

Considerando il diretto appoggiarsi degli esaminati conglomerati aquitaniani sulle marne bartoniane raccliudenti banchi calcari, parebbe " priori clie fra gli elementi di questi conglomerati si dovessero riscontrare molti ciottoli di calcare barto. niano; ciò invece non si verifica affatto ed è anzi notevole l'osservare come, mentre coi ciottoli di origine alpina sono abbondantissimamente mescolati ciottoli e ciottoloni di calcare alberese, provenienti senza dubbio da terreni liguriani che non affiorano affatto in queste regioni, finora invece non vi raccolsi alcun ciottolo di calcare bartoniano perchè questo terreno doveva ancora essere fondo di mare durante l'epoca tongriana.

La potenza di questa formazione conglomeratica tongriana è di circa 1000 metri.

Alle falde delle Alpi centrali esiste certamente una potente fascia di terreni tongriani come si è visto lungo le falde dell'Appennino settentrionale e come, a Nord delle Alpi, si osserva in Svizzera; ma in Piemonte tale fascia tongriana subalpina è completamente mascherata dai depositi terziarii superiori e dal Quaternario: essa compare e si sviluppa poi abbastanza estesamente nella Lombardia e specialmente nel Veneto. 


\section{Riassunto.}

Da ciò che ebli ad esporre attorno al Tongriano del bacino terziario del Picmonte risulta adunque come in questo bacino tale orizzonte geologico, conosciuto finora abbastanza bene dai paleontologi col nome di Mioccne inferiore, ma invece assai poco noto dal lato geologico, costituisce al picde settentrionale della catena alpino-appenninica una fascia più o meno larga, visibile dalle vicinanze di $\mathrm{S}$. Michele Mondovì sino alle colline tortoncsi; spesso inoltre s'interna alquanto nelle regioni alpinc ed appenninc formando o dei bacini secondarii, oppure delle placclıe più o meno ampie e più o meno potenti a seconda specialmente della configurazione della regione rocciosa su cui esse posano. Le placclie entroappenninicle ci indicano chiarancnte che nell'epoca tongriana il mare adriatico o padano collegavasi col mare tirreno tra la Liguria cd il Piemonte.

La formazionc tongriana si sviluppa pure estesamente nclle colline tortoncsi e di Torino-Valenza, ma in zone generalmente piuttosto ristrettc.

Il Iongriano è specialmente lappresentato da conglomerati ad elementi talora improntati, schiacciati e frantumati, di natura e grossezza varie, in generalc, a seconda della natura e dell'orografia delle più vicine regioni montuose.

In generale possiamo dire che lungo la catcna alpino-appenninica predominano assolutamente $\mathrm{i}$ conglomerati alle falde delle regioni montuose che sollevansi potentemente a poca distanza così tra Ceva e Carcare, tra Molare e Rocchetta Ligure, e nelle colline di Torino; abbondano invece le arenarie là dove la regione montuosa che si trova vicina c̀ poco clevata e spcsso quindi irregolarmonte coperta da depositi tongriani, come ad esempio dalla Valle della Bormida di Spigno a quella di Ovada; lranno infinc grande sviluppo le marnc e lc sabbic nelle regioni distanti dalle vere regioni montuose, come nella conca di S. Sc- 
bastiano Curone, nelle colline tortonesi ed in generale in quelle di Torino-Valenza.

La tettonica del Tongriano è abbastanza regolare presentandosi i suoi strati generalmente inclinati rerso il centro del bacino, con qualche eccezione però là dore questo terreno è internato nella regione alpina od appenninica verificandosi allora una disposizione lievemente ondulata o a fondo di battello.

Nelle colline tortonesi e torinesi generalmente la formazione tongriana si dispone ad anticlinale più o meno regolare, diretta lungo l'asse orografico di queste colline.

La potenza del Tongriano, pure variabilissima di luogo in luogo, pare che si possa valutare persino a circa 2500 metri verso Rocclietta ligure. Quanto alla elevazione cui venne spinto questo terreno si è notato come non sia rara l'altitudine di 800 , 900 metri sul livello marino, ma come le massime altezze siano di poco oltre 1000 nıetri presso Bagnasco, e di quasi 1000 metri nell'appennino genovese.

$\mathrm{Si}$ è inoltre osservato come l'orizzonte geologico in esame presenti, eccetto clie in poche località nelle colline tortonesi e di 'Torino-Casale, una discordanza più o meno grande coi terreni sottostanti, mentre invece quasi sempre mostrasi superiormente un graduale passaggio allo Stampiano.

Si è fatto notare come rispetto alla paleontologia il Tongriano, presenta forme in parte dell' Eocene ed in parte del Niocene, ma che esso viene caratterizzato dal predominio di certe speciali forme di Nummulites e dall'abbondanza di Antozoi, nonchè da alcuni pochi Mammiferi e da diversi Molluschi salmastri o continentali, nonchè da numerosi resti di piante tropicali: dati paleontologici che però non si possono raccogliere ovunque, ma specialmente in alcune localitì particolari che venlero in gran parte indicate.

La descrizione geologica regionale del terreno in esame ci fece conoscere quanto siano diversi nelle varie località $i$ fenomeni clie esso presenta, pur conservando esso nel suo assieme runa certa omogeneitì ed una facics essenzialmente di mare poco profondo e di littorale in quasi tutto il bacino piemontese. 


\section{C $\triangle$ P I T O LO V I I I.}

S'LAUPIANO.

Studi anteriori.

Siccome i terreni che costituiscono l'orizzonte geologico che sto per esaminare non presentano che rari fossili e compaiono solo in una parte del bacino piemontese, così generaimente poco se ne occuparono finora $\mathrm{i}$ geologi $\mathrm{i}$ quali, o li inglobarono nel Miocene inferiore come fecero Sismonda, Michelotti, Gastaldi, ecc., o li inclusero nel Bormidiano come fece il Pareto, oppure li riunirono al Tongriano facendone un solo orizzonte come vediamo nella recente carta geologica delle Riviere Liguri e delle Alpi Marittime di Issel, Mazzuoli e Zaccagna.

i. merito del Mayer di avere pel primo fatto conoscere coi suoi scritti come questi terreni si possano distaccare da quelli esaminati nel precedente capitolo, distinguendoli egli col nome di Tongriano superiore.

\section{Generalitic.}

In complesso l'orizzonte in questione è rappresentato da una pila pì̀ o meno potente di strati marnosi, spesso friabili per modo che slittano facilmente originando enormi burroni a fianchi scoscesi, e continuamente variabili di forma per la facile erosione, in modo da ricordare talora le regioni in cui sono sviluppate le argille scagliose del Liguriano: queste marne sono per lo più di un color grigio leggermente verdastro ed al stratificazione spesso poco evidente.

In certi regioni però alle marne si sostituiscono, a certi livelli, banchi arenacei ed anche ghiaioso-conglomeratici, talora 
cosi potenti che quasi tutto l'orizzonte ne rimane costituito, nel quale caso riesce molto difficile il distinguerlo dal Tongriano che redemmo essere essenzialmente rappresentato appunto da depositi arenace-conglomeratici.

Malgrado tutte queste eccezioni locali che dipendono dalle particolari condizioni in cui si depositarono questi terreni, in complesso si puó dire che lo Stampiano corrisponde ad una facies di mare abbastanza profondo e tranquillo.

\section{Caratteri paleontologici.}

Mentre il Tongriano, specialmente colle sue arenarie, è cosi ricco in fossili, da essere veramente tipico a questo riguardo, invece le marne dello Stampiano sono generalmente sterili in fossili e quindi questo orizzonte ̀̀ nel bacino piemontese assai poco importante dal lato paleontologico; è bensi vero clie ritrovansi fossili qua e lì fra le marne 0 , più frequentemente, fra quei banchi arenacei che talvolta si presentano interstratificati a quelli marnosi, ma si tratta sovente o di resti mal conservati o cosi scarsi clie non permettono di poter stabilire pel piano geologico in esame un rera fauna completa, la quale d'altronde è complessivamente definibile come una miscela di forme prevalentemente tongriane e, in minor quantiti, di forme degli orizzonti geologici superiori; quindi non arrò neppure a trattarne nella parte paleontologica del presente lavoro.

Solo è da notare come sia specialmente sugli straterelli arenacei dello Stampano che riscontransi abbondantemente in certe località quelle curiose e regolarissime impronte, di origine ancora incerta, che appellansi Paleodictyon (P. regulare Sacc., ecc.).

Assieme ai Paleodictyon si rinvengono pure non raramente quelle svariate impronte che ricerettero il nome di Helminthopsis, Taphrhtminthopis, Hetminthoida, Nomertilites, ecc., ma che in massima parte sono ancora indeterninate o di dubbiosissima origine, serrendo solo aì geologo, almeno a mio parere, come 
prova che i terreni i quali le contengono si depositarono presso un littorale od in un bassofondo marino; anche gli Zooplyycos non sono rari fra i banchi marnosi dello Stampiano.

\section{Distribuzione geografica.}

I terreni in esame appaiono dapprima come una sottile striscia, nelle vicinanze di Ceva, quindi si vanno rapidamente sviluppando, tanto che nelle valli delle due Bormide, ma specialmente sulla sinistra di quella di Spigno, occupano un'area estesissima, caratteristica per il suo colore e per la sua orografia molto irregolare ed a profondissimi burroni.

Non di rado però si osserva clıe i depositi dello Stampiano sovrapponendosi con dolce inclinazione a quelli del Tongriano, si avanzano molto assieme a questi ultimi rerso l'interno della regione alpino-appenninica, costituendo spesso delle placclre irregolari e di varia ampiezza al disopra delle placche del Tongriano, oppure anche sviluppandosi tanto verso monte da venirsi a sovrapporre direttamente sulla roccia in posto, mascherando cosi completamente l'orizzonte inferiore, tongriano.

Ad Est di Val Bormida lo Stampiano si va di nuovo poco a poco restrigendo, fino a ridursi ad una semplice striscia cle si continua abbastanza regolare sino alla valle di Lemno. In seguito questo orizzonte si va allargando per l'ultima volta, occupa un'area assai vasta in Val Scrivia e in Val Borbera, ripiegando poscia verso Nord per modo da accompagnare regolarmente l'andamento stratigrafico generale del bacino piemontese.

Ia nelle colline tortonesi la fascia della Stampiano gradatamente si va di nuovo restringendo verso Nord, finchè nella curva che tutti i terreni terziarii fanno presso Brignano Curone, essa si riduce ad una strettissima striscia diretta da Est ad Orest circa e clre si perde verso la valle del torrente Grue.

Nelle colline Torino-Casale è solo in pochi punti che appaiono striscie di Stampiano, cioè là tove la stratigrafia è più regolare o quindi viene ad affiorare l'intiera serie terziaria. 


\section{Tellonica.}

La stratigrafia dello Stumpiuno è generalmente molto semplice e se talora vi si osservano spostamenti e ripiegamenti, trattasi solo di fenomeni locali e che non alterano l'andamento generale della formazione.

Gli strati inclinano verso l'interno del bacino piemontese con una pendenza generalmente piuttosto dolce, cioè di $15^{\circ}$ a $20^{\circ}$; soventi invece, particolarmente in Val Bormida di Spigno e regioni vicine, il grado di inclinazione è ancora minore; anzi talvolta i depositi sono quasi orizzontali od anche pendono leggermente in senso cuntrario a ciò che si verifica generalmente; come di solito i fenomeni stratigrafici ultimamente menzionati si osservano specialmente dove i terreni tongriani si aranzano verso l'interno della regione appenninica, ricoprendo per aree più o meno ampie e più o meno pianeggianti, le formazioni preterziarie come tra la Val Bormida e la Valle Orba particolarmente.

Però nelle colline tortonesi presso Brignano, là dove tutti i terreni fanno una rapida curva, anche i banchi dello Stampiano presentano dei disturbi stratigrafici e dei salti però non molto estesi; talvolta sono quasi orizzontali, talvolta invece inclinati di quasi $50^{\circ}$; dal punto dove arviene questo rapido incurvamento sin dove l'orizzonte in esame si perde, i pochi e sottili strati che ancora lo costituiscono, sono sollevati fortissimamente e portati talora persino alla verticale.

Nelle colline Torino-Valenza le sottili zone di Stampiano si accordann assai bene stratigraficamente cogli orizzonti tra cui ¿̀ comipreso; i loro banchi sono per lo più sollevati di $40^{\circ}, 50^{\circ}$ ed anche più. 
Potenza.

Trattandosi di un deposito a facies prevalentemente di basso fondo è naturale che lo Stampiano non sia molto potente, certamente molto meno che l'orizzonte inferiore.

Infatti i terreni che lo rappresentano costituiscono generalmente una semplice fascia poco larga che si va poi notevolmente assottigliando per tratti abbastanza estesi lungo le falde alpinoappenniniche.

Tuttavia in alcune regioni dove i terreni tongriani costituiscono una specie di ampia insenatura, corrispondente naturalmente ad una specie di largo golfo nel mare di tale epoca, come ad esempio in Val Bormida di Spigno, là naturalmente si osserva che anche i depositi dello Siampiano raggiungono una potenza abbastanza notevole, quantunque a causa della poca pendenza degli strati, tale potenza sia minore di ciò clue parrebbe all' osservatore superficiale.

Infatti nella valle della Bormida di Spigno tra Mombaldone, Spigno e Montechiaro, dove i banchi dello Stampiano si presentano sviluppatissimi sia in lunghezza che in altezza, io credo che essi non oltrepassino di molto la potenza di 400 metri, giacchè mentre verso il fondo della valle possiamo osservare affioramenti preterziari sin quasi sotto $\mathrm{M}$. Castello, viceversa nella parte alta delle colline ad esempio allo stesso M. Castello, compaiono già placche aquitaniane, ed inoltre l'inclinazione generale degli strati non solo è molto dolce ma non è neppure sempre costante verso una certa direzione.

Così pure nell'ampia curva che formano i terreni tra la Val Bormida di Spigno e la Val Bormida di Millesimo, presentandosi a nudo per area vastissima i terreni stampiani sembrerebbe che se ne dovrebbe valutare la potenza ad oltre $1000 \mathrm{me-}$ tri, tanto piǹ che i frequenti e potenti banchi arenacei che quivi si alternano colle tipiche marne ci indicano depositi for- 
matisi talora in bassi fondi marini poco lungi dal littorale. Tuttitria considerando la debole inclinazione generale degli strati tongriani della regione is esame, io credo clie quivi si possa ratutare la potenza dello Stampiano come non molto maggiore di 500 metri.

Ia se si esamina lo Stampiano della grande conca di Grondona nel tortonese, tra Val Scrivia e Val Borluora, lì appunto dove si è grià notata la massima potenza, di circa 2500 metri, del Tongriano, si trovir cle ancle lo Stampiano quivi ì sviluppatissimo, presenta una peudenza abbastanza regolare di circa $15^{\circ}$ o $20^{\circ}$ in media e raggiunge la potenzal di roo od 500 metri se pure non l'oltrepassa; notiamo però subito come in queste regioni lo Stampiano ha in complesso una facics di mare poco profondo ciò che ne spiega la straordinaria potenza.

\section{Altimetria.}

Trattandosi di un orizzonte essenzialmente marnoso è naturale che i banchi dello Stampiano non raggiungano elevazioni tanto noteroli come quelle dell'orizzonte inferiore e neppure come quelli arenacei del sovrastante Aquitaniano.

Infatti vediamo che generalmente i terreni in esame si elerallo raramente sopra i 500 metri; tuttaria gia a Sud di Ponzone li troviano sollevarsi oltre i 600 metri e finalmente a Sud di Millesimo lo Stampiano, però a facics in gran parte arenacea, si spinge sino ai 770 metri (Bric della Marca).

\section{Rapporto coi terreni solto e sovrastanti.}

Si è già notito nel precedente capitolo come generalmente tra il Tongriano e lo Stampiano ci sia un passaggio abbastanza graduale per' mezzo di un'alternanza di marne, di arenarie ed anche di lenti ghraiose negli strati intermedi; si è pure detto come in complesso si debba chiudere la serie inferiore con quei banchi arenacei cosi ricchi in fossili che reggonsi specialmente sviluppati da, Val Stura rerso Orest. 
La distinzione tra il Tongriano e lo Stampiano, sempre piuttosto eridente se si considerano questi terreni nel loro complesso, ¿̀ invece piuttosto difficile ed alquanto arbitraria quando si tratta di eseguirla negli accennati banchi di passaggio, cio che d'altronde è affatto naturale; tali difficolia poi s'accrescono di molto quando i banchi dello Stampiano divengono arenacei od anche arenaceo-conglomeratici come vedremo verificarsi in diverse regioni, nel qual caso però generalmente esistono ancora fra i due orizzonti geologici a caratteri litologici quasi eguali, alcuni pochi banchi marnosi che servono molto bene di separazione e che vengono a mancare solo in alcuni prolungamenti del Tongriano verso Sud entro la regione alpina.

Anche coi terreni del sovrastante Aquitaniano lo Stampiano presenta generalmente un passaggio graduatissimo pel fatto clie nella parte superiore di quest' ultimo orizzonte, per lo più marnoso, cominciano ad apparire straterelli arenacei che divengono poco a poco più frequenti, e più potenti, talora cangiandosi in veri banchi, finchè si arriva ad una formazione eminentemente sabbioso-arenacea che rappresenta l'Aquitaniano, anclie in questo caso naturalmente con delle incertezze più o meno grandi nella delimitazione dei due orizzonti.

Anzi a questo proposito debbo notare come il Nayer nel suo studio sui terreni terziari della Liguria centrale, ponga nel Tongriano, di cui amzi costituisce uno speciale orizzonte, ciò̀ Tongriano superiore o Boomin, un complesso di banchi arenaceo-calcarei che generalmente si trovano tra lo Stampiano e l'Aquitaniano; io sono piuttosto inclinato a porli alla base di quest' ultimo orizzonte geologico, sia perchè i fossili che vi si rinvengono sollo piuttosto di facies aquitaniana che tongriana (naturalmente con forme spesso comuni ai due orizzonti); sia perchè la loro fucics arenacea, che ci rappresenta una facies litoranea o di mare poco profondo, si accorda molto più con quella dell' Aquitaniano (pure prevalentemente arenaceo) che non con quella del sottostante Stampiano (essenzialmente marnoso); sia perchè il loro andamento stratigrafico, quantun- 
que per lo più concordante con ambidue gli orizzonti geologici in discorso, talora invece sembra discordare alquanto da quello dello Stampiano; sia perclè ho sovente osservato, per esempio lungo la cresta del M. Vignassa, che banchi simili affatto, litologicamente e paleontologicamente, a quelli ora in questione si ritrovano ancora ripetuti a diversi orizzonti nella parte inferiore del vero Aquitaniano; sia infine perchè durante il rileramento geologico lio potuto constatare clie se questo complesso di banchi calcareo-arenacei si presenta per lungli tratti abbastanza individualizzato per modo che sarebbe indifferentemente riferibile all' uno o all' altro dei piani geologici fra cui è compreso, invece per regioni estesissime perde affatto questa individualità, e viene a fondersi assolutamente, senza che se ne possa fare una distinzione ragionevole, cogli altri bancli sabbioso-arenacei dell'A quitaniano inferiore; invece si conserva per lo più abbastanza ben distinguibile dal sottostante Stampiano.

\section{Località fossilifere.}

Da ciò che si è esposto nel precedente paragrafo si può già dedurre che se nell'orizzonte geologico in esame si riscontrano scarsamente qua e lì resti fossili, vere località riccamente fossilifere, come quelle del Tongriano, non esistono, se pure non sono sfuggite alle mie ricerche.

Tuttavia nei banchi di passaggio tra il Tongriano ed il Sestiano, e che in parte possonsi ancora includere nello Stampiano, si osservano non di rado lenti abbastanza ricche in fossili quasi identici a quelli dell' orizzonte inferiore, così ad esempio presso Ceva, nelle vicinanze della borgata Marogna, presso Dego e Piana Crixia, lungo la cresta collinosa dai Maiani a Bric Cheilin, nelle vicinanze di Cassinelle, ecc.; alcuni fossili, specialmente Ostriche, riscontransi in alcuni strati sabbioso-ciottolosi in Val Cariogna, sotto Cavatore, e più precisanente presso il Molino di Cariogna. Pure molto ricchi in fossili, specialmente Nummulites e Lithothamnium sono i calcari biancastri, però forse giai 
longriani, che spuntano alla base dell'orizzonte in esame attorno a' Bric Narzapiede tra Molare e Grognardo.

Non rari sono nelle marne dello Stampiano le impronte di Zoophycos, abbondanti per esempio a Sud-Ovest di Cassinelle presso la borgata Galanti tra Cassinelle e Prasco presso C. Francia, tra Val Lemno e Val Scrivia presso le C. S. Martino, presso il paesello di Sottovalle, ecc.

Invece quanto ai Paleodyction ed alle svariate impronte organiche ed inorganiche che, assieme con frammenti di Cidaris e di Molluschi littorali, li accompagnano, debbo accennare come tali fossili siano specialmente comuni nello Stampiano delle colline tortonesi e più precisamente nelle vicinanze di Grondona, della borgata Persi in Val Borbera, del paesello di Molo di Borbera e dalla borgata Cioccale dove essi si possono raccogliere facilmente se si esaminano i frammenti di lastre arenacee di cui è spesso ricoperto il terreno e che derivano dal secolare lavorio di sfacelo degli straterelli arenace che in tali regioni frequentemente si alternano cogli strati marnoso-sabbiosi.

Nei piccoli afforamenti stampiani delle colline Torino-Casale scarseggiano pure $\mathrm{i}$ fossili; solo si rinvengono non di rado impronte organiche or inorganiche, anche Paleodictyon, come nello Stampiano superore di Bric Malpensato (Verrua Savoia).

\section{Descrizione geologica regionale.}

Lo Stampiano rappresentato da marne grigio-verdiccie appare nelle vicinanze di Mombasiglio nella piccola ralle delle Salette, liberandosi dal velo dei terreni miocenici che lo mascherano completamente verso l'Ovest. Peró, come generalmente si verifica nei lembi terminali di un orizzonte, queste marne stampiane sono piuttosto difficilmente separabili da quelle aquitaniane sovrastanti che si presentano solo alquanto più arenacee.

In causa dell'affioramento di roccia preterziaria che esiste presso Mombasiglio, gli strati dell'orizzonte in esame sono talora assai fortemente sollevati, ma poco ad Est assumono una 
pendenza piuttosto dolce e regolare, talora avanzandosi tanto verso Sud da mascherare completamente il Tongriano oppure da formarvi delle placcle isolate, come presso C. Ranieri: noto però che soventi volte, sia in queste regioni che altrove, certi lembi marnosi tongriani lasciano in dubbio a quale dei due orizzonti siano da riferirsi.

Nelle vicinanze delle borgate Bertini, Marogna, Costa, ecc. i banchi inferiori dell'orizzonte in studio, là dove passano insensibilmente alle arenarie del Tongriano ridotte ad una striscia piuttosto sottile, presentano qua e là resti fossili, ma generalmente in uno stato di conservazione non molto buono.

Nelle vicinanze di Ceva lo Stampiano, in gran parte mascherato dalle alluvioni quaternarie, è però messo bene a nudo dalla profonda incisione del Tanaro, osservandosi quivi nettamente il passaggio graduatissimo sia tra le arenarie del Tongriano e le marne frammentarie ad aspetto farinoso ed a stratificazione poco visibile dello Stampiano, sia tra queste ultine e quelle un po' sabbioso-arenacee, ed a stratificazione più evidente, del sovrastante Aquitaniano.

Verso Priero lo Stampiano si va allargando, costituendo gia di per sè solo le colline bianco-grigiastre, e con quell'aspetto farinoso che arremo a constatare tanto frequentemente piu ad Est. Compaiono però locali banchi arenacei frammezzo alle caratteristiche marne grigiastre: così per esempio presso il Molino di Priero sotto S. Bernardino, tra la borgata Costa e C. La Valle, ecc.

Però ad Oriente di borgata Campetto, a causa dell' enorme sviluppo dell'Aquitaniano rerso Sud, le marne dello Stampiano vengono quasi completamente maschernte, per modo che.da Castelnuovo di Ceva a Roccavignale costituiscono solo più una specie di striscia molto frastagliata, riconoscibile anche di lontano dal suo color grigiastro e per i burroni profondi che la incidono e che quasi di tratto vengono a cessare superiormente sotto un complesso di banchi arenaceo-calcarei i quali segnano l'inizio dell'Aquitaniano; questi fenomeni sono stupendamente 
osservabili sotto la Cima Monti, specialmente alla grande curva che fa la strada nazionale che congiunge il Genovesato all'alto Piemonte.

Sonvi inoltre diverse placche stampiane isolate, di cui alcune specialmente marnose, come quelle di C. Manzano, altre marnoso-arenacee, come quella molto larga ed importante di C. I. Tatti, ed altre invece piccolissime e solo dubbiosamente attribuibili a questo orizzonte geologico come quelle di C. Barchei, quella a Nord-Est dei Tetti Spinzei, ecc.

Siccome in queste regioni è molto debole la pendenza degli strati sia tongriani che aquitaniani, e siccome quivi i terreni terziari formano una grande curva, così nella profonda ed ampia valle della Bormida di Millesimo, lo Stampiano è messo a nudo per una lunghezza di quasi 9 chilometri, per modo che se ne può quivi studiare molto bene la costituzione.

Il fatto più importante che risulta dall' esame di questa vasta regione occupata dallo Stampiano è che quivi, come d'altronde anche più ad Est in Val Bormida di Spigno, questo orizzonte presenta a diversi livelli potenti banchi arenaceo-conglomeratici che alterano la tipica facies dell'orizzonte in esame. Così, per' citare solo gli esempi più notevoli, a Nord di Millesimo vediamo che in alto le tipiche marne dello Stampiano sopportano una pila di strati arenacei, che verso Nord divengono sempre più potenti, e vanno alternandosi con banchi ghiaiosi e ciottolosi talora ad enormi elementi che reggonsi specialmente sulle creste di Cima della Fonga, di Bricco delle Coste, di Bricco della Marca e di Monte della Gazza; queste ultime alture sono quasi completamente costituite d'arenarie e di conglomerati, poichè $\mathrm{i}$ banchi marnosi poco a poco si andarono assottigliando per modo da costituire solo più una specie di anello attorno al Nonte della Gazza, e da scomparire poi quasi completamente al Bric della Marca, comparendo però ancora per breve tratto tra Biestro e Costabella ma quivi tuttavia con incluse lenti ciottolose.

Mentre nelle regioni ora indicate la fucies littoranea dello Stampiano ci rende talora difficile di distinguere questo oriz- 
zonte da quello inferiore, tanto che restano ancora dei dubbi su tale distinzione riguardo ad alcune località a Sud di Millesimo e di Roccavignale, al contrario a Nord di Nillesimo i potenti banchi arenacei che appaiono particolarmente sulla cima delle alture, costituendo delle specie di larghi altipiani a dolce pendio verso Nord-Orest, ricordano molto bene i banchi dell' $A$ quituniano, tanto che rimane quivi talora il dubbio che essi debbansi veramente riferire piuttosto a quest'ultimo orizzonte geologico.

Risalendo da Millesimo alla regione Pian Giaschi, si incontra a mezza costa circa un bel banco conglomeratico breccioso che si estende notevolnente sia verso Nord, tanto da osservarsi ancora bene sviluppato presso il Molino di Cengio ed anche più avanti, sia verso Est per modo da affiorare ancora presso il Cimitero di Cosseria.

Banchi arenacei si vedono alternarsi a diversi livelli nella metà inferiore dell'orizzonte in esame tra Cairo Montenotte, Cosseria e Montenudo. Ma il più importante, più esteso e più potente complesso di banchi arenacei pseudo-aquitaniani, che credo debbansi ancora racchiudere nello Stampiano, è quello che, cominciando ad individualizzarsi nettaniente sopra a Cairo Montenotte, costituisce le parti più elevate di Bric del Formento e di Bric del Monte, del Bric della Guardia col Casteilo di Cosseria, di Bric del Cavallo, e gli altipiani ondulati di R. Pian Giaschi, Costa e Cengio, Rocchetta Cengio, Montaldo ed Arpagiasse.

La riguardo a questo potente complesso di banchi arenacei alternati solo con pochi strati marnosi, e che rerso Sud divengono sempre più potenti acquistando persino dei banchi ciottolosi (giacchè l'orizzonte arenaceo-conglomeratico di Monte della Gazza, Bric della Fonga, Bric delle Coste, Bric della Marca, ecc. poco prima studiati non è a mio parere che la continuazione meridionale del grande orizzonte arenaceo ora in discorso) sorge naturalmente il dubbio che esso sia a riferirsi piuttosto all'Aquitaniano rhe non allo Stampiano in considerazione sia della 
poca inclinazione degli strati, sia della natura sua litologica, o che quindi nelle carte geologiche, il sovraccennato ampissimo altipiano più o meno ondulato ora così variamente interrotto e così profondamente solcato, debba piuttosto segnarsi colla tinta dell' Aquituniano che nou con quella dello Stampiano. Ed in verità tale ipotesi potreble anche essere sostenuta con alcune ragioni.

Tuttavia dobbiamo osservare: $1 .^{\circ}$ come in questa regione banchi arenacei assai potenti compaiono già persino frammezzo agli strati maruoso-sabbiosi della base dello Stampiano e che essi ripetonsi a diversi livelli in questo piano geologico; $2{ }^{\circ}$ che nella parte superiore dell' orizzonte in esame compaiono quasi sempro alternanze di banchi arenacei e marnosi che servono di passaggio graduale al piano superiore per modo da rendere talora incerto a quale dei duc orizzonti geologici debbansi riferire; $3 .^{\circ}$ che nella graude curva, anticamente seno marino, di Cairo-Millesimo è naturale che durante il periodo stampiano, specialmente verso il suo termine, si depositassero più o meno potenti banclì arenacei in alternanza coi banchi marnosi (giacchı̀ si nota generalmente che nei golfi i depositi lanno una facies di bassofondo anche quando $\mathrm{i}$ contemporanei depositi vicini presentano invece facies di mare profondo), e che quindi verso la fine del periodo in esame, quando il regime di bassofondo si andava gradatamente sostituendo a quello di alti fondi, $i$ banchi arenacei fosscro in queste regioni tanto potenti da presentare nel loro complesso una facies simile affatto a quella del sovrastante Aquitaniano; $4 .^{\circ}$ dobbiamo poi osservare che se noi cerchiamo di sciogliere tale questione nella parte alta delle regioni collinose in cui l'Aquitaniano vero si sovrappone allo Stampiano, per esempio nelle vicinanze di Rocchetta Cengio, Cima dei Berti, ecc., ciò ci riesce difficile sia a causa della apparente prevalenza che sulle creste, per l'abrasione, presentano sempre i banchi arenacei sugli strati marnosi, per modo da trarre in inganno sulla vera natura complessiva degli orizzonti, sia in causa della sviluppata vegetazione e della mancanza di una serie con- 
tinuata di profondi spaccati. Se invece si percorre attentamente la parte inferiore della profonda valle della Bormida di Millesimo, lungo i cui fiancli esistono continui profondissimi tagli naturali, si osserva che il potente complesso di banchi arenacei (i quali costituiscono gli altipiani di Rocchetta Cengio, Montaldio, Cengio, Costa e le già soprannominate alture collinose più ad Est ed a Sud) viene a terminare sul fondo della valle ad un dipresso tra C. Arpagnasse e la borgata Bergalli, essendo ancora ricoperto da banchi marnoso-sabbiosi; questi sembrano veramente riferibili allo Stampiano, rimangono ancor visibili nelle vallate per circa tre chilometri e mezzo e presentano una potenza di oltre 100 metri, sopportando finalmente i potentissimi bancli arenacei di Castelvecchio, Mu, Chidini, Gabutti, S. Gervasio, ecc., i quali, a mio parere, costituirebbero la vera base dell'Aquitaniano; $50^{\circ}$ se infine notiamo che tra le due formazioni ultimamente menzionate esiste talora in queste regioni una certa discordanza stratigrafica, come ad esempio nel vallone di Madonna della Neve dove veggonsi i banchi marnosi, che credo ancora stampiani, inclinati all' incirca verso il Sud-Orest, mentre quelli arenacei aquitaniani pendono dolcissimamente verso Nord-Ovest, parmi risultare naturale la restrizione dell'Aquituniano come la segnai. sulla carta geologica. In fondo però la questione è d'indole abbastanza secondaria.

In questa vasta regione arenaceo-marnosa stampiana conpresa tra le due valli della Bormida di Millesimo e della Bormida di Spigno si possono ovunque osservare dei grandiosi fenomeni di erosione, a cui anzi riferisco la scomparsa di potenti depositi marnosi che dovevano, a mio parere, ricoprire originariamente gli altipiani di Rocchetta Cengio, Montaldo, ecc.; si notano pure qua e là degli scoscendimenti per lo più in piccola scala, come ad esempio quello nettissimo che si vede sulla destra di Val Bormida di Millesimo, presso la grande strada, mezzo chilometro a Nord di C. Ponzano; ma generalmente trattasi so?o di locali scoscendimenti poco importanti, causati dalla scomparsa, per erosione, della marna clse separa dirersi banchi arenacei. 
Inoltre l'andamento stratigrafico dello Stampiano di questa regione, quantunque molto regolare nell'assieme, presenta talora delle locali alterazioni, che anch' esse ci avvertono essersi deposti quivi tali terreni in condizioni di minor tranquilliti che non altrove in generale.

Continuando l'esame dello Stampiano verso Nord, in Val Bormida di Spigno, dobbiamo notare che sulla sua destra, qua e li sopra i depositi del Tongriano od anche sopra la stessa roccia preterziaria, osservansi placche marnose che lianno tutta l'apparenza di quelle dell'orizzonte ora in esame, a cui quindi ho creduto riferirle, pur restandomi qualche dubbio che esse possano invece appartenere a qualche banco marnoso interposto alle arenarie dell'orizzonte inferiore; viceversa vedremo poco più avanti come diversi depositi, quantunque arenaceo-conglomeratici con facies di Tongriano, debbonsi invece includere nell'orizzonte stampiano, soventi dovendoci per ciò comprendere basare molto sulla stratigrafia.

Fra le placche marnose isolate del piano in esame notiamo specialmente quella di C. Catin e le due di C. Pra Ellera, poggianti in parte sulle arenarie del Tongriano ed in parte sulla Serpentina preterziaria; nonchè l'ampia zona di Stampiano delle Neyie di Rocchetta Cairo, zona che probabilmente si collega sotto l'Alluvium coi contemporanei depositi tanto sviluppati sulla sinistra della Bormida; piccola ma caratteristica è la placca sabbioso-marnosa di Costalupara.

Più a Nord, a cominciare da poco sopra il Castello di Dego, presso i Majani, lungo la cresta collinosa dei Berri sin oltre il Bric Cheilini vediamo alternarsi banchi marnosi con banchi arenacei e talora anche ghiaioso-conglomeratici brecciosi come al Bric Cheilini, banchi che probabilmente debbonsi in parte riferire allo Stampiano, giacchè tale facies littoranea, generalmente solo caratteristica del Tongriano, vedremo d'or in avanti, per una regione assai vasta, apparire bene sviluppata anche nei depositi dell'orizzonte superiore, specialmente nella parte più meridionale delia zona in esame, cioè verso la regione montuosa. 
In queste arenarie dello Stampiano si incontrano sovente dei resti fossili quasi identici però a quelli del Tongriano, ed anzi ebli già ad accennare tale fatto parlando di quest'ultimo piano geologico.

Sulla sinistra di Val Bormida lo Stampiano a strati dolcemente inclinati verso Orest circa si presenta con una grande potenza e costituito essenzialmente di marne grigio-verdastre farinose, spesso a stratificazione appena visibile, formanti enormi burroni per modo da presentare talora un passaggio molto simile a quello che si osserva nelle regioni costituite dalle argille scagliose eoceniche.

Però verso la base osservansi sempre graduali passaggi al Tongrians, specialmente per mezzo di una alternanza di marne con banchi sabbioso-arenacei brunastri cle, come di solito, rendono difficile la distinzione dei due orizzonti. Tipica a questo riguardo è, per esempio, la valletta di C. Valeggia a Sud-Orest di Piana Crixia.

Percorrendo gli enormi valloni del Carretto, di Vignarolo, di Carpez, di Bormiola, ecc., e specialmente rimontando le loro vallette tributarie a struttura dedalica ed a continui ed enormi scoscendimenti, possiamo prenderci una chiara idea di quanto sia potente e rapida l'azione erosiva, particolarmente delle acque, sopra questi terreni terziarii.

Nella parte superiore dell'orizzonte in esame constatiamo anche qui l'apparire di potenti banchi arenacei, con svariate impronte organiche ed inorganiche a facies aquitaniana, che si riconoscono anche da lungi per costituire rilievi più spiccati, come il Bric Vaderno, il Bric di Reisa, il Castello del Carretto, ecc. e per formare delle specie di gradini sporgenti ed inclinanti verso Ovest o Nord-Ovest, lungo i fianchi delle vallate; ciò osservasi in modo assai netto specialmente nella valle dei Gelosi tra C. di Bria e C. Orecchie, ma d'altronde si può constatare anche assai bene sia nelle valli vicine, sia lungo le creste che le separano, sin oltre l'ampia valle di Cagna, per modo che se si rolesse segnare sulla carta l'andamento di que- 
sti banchi arenacei ne risulterebbero delle linee a zig-zag, fra loro quasi parallele e abbastanza regolari.

Seguendo il criterio indicato nelle pagine precedenti, quantunque alcuni di questi banchi, specialmente quelli quasi isolati sull'alto delle colline, abbiano una facics affatto aquitanianu, credetti tuttavia di doverli ancor'a racchiudere nello Stampiumo, osservandosi ancora dei potenti banchi marnosi tra essi ed il potente complesso di arenarie che inizia il vero Aquitaniano. Pcr fare la distinzione dei due piani gcologici è spesso miglior metodo esaminare una serie di grandi spaccati naturali che non osservare la serie stratigrafica minutamente; infatti nel primo caso quando si la a fare con vero Stampiano le marne abbondantemente comniste alle arenarie presentano all'occhio nell'assicme la facies stampiana, mentre nel secondo caso esaminando in dettaglio i banchi di questo orizzonte, la gran quantiti di strati arenacei che sporgono dai bauchi marnosi ci dì l'aspctto del piano Aquitaniano; per la stessa ragione per distinguere i due orizzonti è meglio assai il percorrere il fondo delle valli, dove abbondano $i$ grandi spaccati naturali clie non le creste delle colline, dove per erosione $\mathrm{i}$ banchi arenacei sono molto più appariscenti di quelli marnosi.

Noto ancora come lo Stampiano colla facies dell'Aquitaniano, quantunque sia costituito in parte di sabbie e di duri banchi arenacci, spesso si distingue dal vero Aquitaniano, per averc le sue sabbie più sciolte e per essere il sno colore piuttosto grigio-brunastro che non giallastro; ma a dire il vero questi sono caratteri cosi variabili che non è il caso d'insistervi.

E poi notevole a questo riguardo come i banchi arenacei pscudo-aquitaniani dello Stampiuno vanno gradatamente scomparendo verso settentrione (probabimente per causa della margrior distanza dalla regione veramente montuosa e quindi di una maggior tranquillita di deposizione), ed infatti a Nord di Val Cagna essi sono già molti ridotti, pur mostrandosi ancora nettamente al Mombergone; na nei più settentrionali valloni di Merina, Sereto, Fornaci, Rocchctta, Ovrano, Aprile, ecc., pre- 
dominano assolutamente le marne grigio-rerdastre, friabili, quasi farinose allorchè viste di lontano, ad enormi burroni laterali continuamente cangiantisi di forma, per modo da rendere soventi difficile la viabilità ed obbligare talora gli abitanti di queste regioni a cangiare di casolare e talora persino di paese, come per esempio avvenne per la Rocchetta, paese fabbricato al fondo della vallata omonima, e che per l'erosione acquea fu scalzato dalle fondamenta, per cui venne abbandonato e costrutto invece poco a Sud ma più in alto.

Quantunque in questa regione tipica per lo Stampiano abbiano un assoluto sopravvento le marne, come sopra ho detto, tuttavia si incontrano a diversi orizzonti strati arenacei, di rado però potenti, per modo clie riesce quivi abbastanza facile il distinguere questo orizzonte dall'Aquitaniano che si inizia con un potente e caratteristico complesso di banchi arenacei, o arenaceo-ghiaiosi, e talora anche arenaceo-calcarei, come sopra Mombaldone. Talrolta però tale distinzione riesce men facile e molto incerta a causa del fatto che anche l'Aquitaniano inferiore si presenta per un certo tratto sabbioso marnoso e quindi alquanto simile allo Stampiano, ciò che per esempio, si può vedere molto bene al fondo di Val Bormida tra Montechiaro e Denice, dore la delimitazione dei due orizzonti rimane un po'incerta ed arbitraria.

Quanto alla Stampiano che occupa un'area cosi sviluppata sulla destra della Bormida possiamo dire in complesso che mentre esso ha una facies essenzialmente littorale, da Piana Crixia sin presso Spigno, acquista invece generalmente una facies di mare abbastanza profondo e tranquillo a Nord di Spigno Monferrato, ciò che facilmente è spiegabile considerando la rispettiva posizione delle due regioni in riguardo alla catena centrale dell'Appennino.

Già erasi notato poco aranti la presenza di numerose lenti ghiaioso-ciottolose nello Stampiano, specialmente attorno al Bric Cheilini; or bene questo fenomeno si continua su ampia scala verso Nord nelle regioni collinose delle borgate Valle di Ry, 
Loueisi; esso si accentua poi cosi fattamente al Bric Calma e nelle colline di Madonna della Neve, presso Spigno (dove i conglomerati e le arenarie si sostituiscono quasi completamente alle narne), ecc., che si rimane in dubbio se quivi tali depositi debbansi piuttosto riferire al Tongriano che 1.on allo Stampiano. Eguali dubbi si incontrano sovente tra la valle Bormida e la Valle Erro sull'alto delle colline, cosi presso C. Berri, borgata Gerini, borgata Pori, C. Valpina ecc.; quivi infatti compaiono banchi marnosi alquanto arenacei e molto fossiliferi, che paiono doversi riferire allo Stampiano inferiore od almeno ai banchi di passaggio al Tongriano. Osservazioni simili si possono fare più ad Est nelle colline tra il M. Bono ed il bellissimo golfo stampiano di Mioglia.

Quanto all'andamento stratigrafico dello Stampiano di queste regioni esso è talora abbastanza irregolare, specialmente nelle immediate vicinanze degli spuntoni di roccia preterziaria, ma non di rado anche là dove s'appoggia al Tongriano; così ad esempio, tra borgata Loueisi e C. Boirona, dove i banchi marnosoarenacei che costituiscono il passaggio fra $i$ due piani geologici sono assai fortemente (talora di oltre $40^{\circ}$ ), ma localmente inclinati verso Ovest-Nord-Ovest.

Nella parte alta del paese di Spigno veggonsi marne grigiastre che rappresentano probabilmente una piccola placca di Stanpiano.

Nella vasta area occupata dal terreno in esame tra Val Valla e la Valle Erro, si incontrano sovente (specialmente nella parte più elevata dei rilievi più collinosi, come di solito a causa dei fellomeni di abrasione), banchi arenacei più o meno continui, llai però molti potenti, e che ricordano quelli del piano inferiore; talrolta anzi alle arenarie si uniscono persino lenti ciottolose, ad elementi anche molto voluminosi, come ad esempio, tra la borgata Grossi e la borgata Bissi a Nord di Pareto.

La stratigrafia della regione ultimamente esaminata presenta talora dei fatti anormali; così l'inclinazione degli strati ora è verso Sul come presso la borgata Giuliani, Brovi, ecc., ora 
verso Nord-Est come presso i casali Sbarnera, le C. Sardi, le borgate Martini, Bissi, ecc.; l'inclinazione ora è di pochi gradi, ora invece di oltre $40^{\circ}$ come a Sud di Pareto, ecc. Fatti questi che derivano specialmente dalle irregolarita del fondo roccioso su cui tali terreni si depositarono.

Nell'ampia regione collinosa compresa tra la Tal Bormida e la Val Erro, tipica pes lo sviluppo e la potenza dello Stampiano, possiamo notare come questo terreno, sempre per la solita causa gia sopra enunciata, si presenta verso Ovest essenzialmente marnoso, con uno spessore di oltre duecento metri, intersecato da profondi e spesso impraticabili burroni, cioè coll'aspetto che già osservammo per questo terreno sulla sinistra della Bormida; ciò nella regione ora in esame si può stupendamente osservare in tutta la sua bellezza specialmente nell'ampia ralle del torrente Torbo e meglio ancora nelle sue vallette laterali, quantunque anche in queste regioni compaiano talora fra le marne numerosi strati arenacei che simulano alquanto l'Aquitaniano, come per esempio, al M. Rosso, presso la borgata Barossi, ecc. Invece verso Est gli strati arenacei divengono piuttosto frequenti per modo che $\mathrm{i}$ loro frammenti spesso ricoprono gran parte del terreno, e compaiono anche qua e là lenti ghiaiosociottolose, come ad esempio, nella parte superiore delle colline situate ad Est delle borgate Costabella e Scajoli.

Anche in questa regione la stratigrafia non è sempre affatto regolare, quantunque la pendenza, dorunque assai dolce, sia per lo più verso il Nord-Ovest circa, ma le irregolarità che si incontrano si debbono quasi tutte riferire ad irregolarità stratigrafiche del sottostante orizzonte Tongriano e indirettamente, come si è già arvertito, alla ineguaglianza della sepolta regione rocciosa. A questo proposito notiamo come in fondo di Val Bormida, sotto il M. Rosso, gli strati dell'orizzonte in esame pendono regolarmente verso Nord-Nord-Ovest e che solo nella immediata vicinanza del piccolo spuntone, già altrove accennato, di Serpentina preterziaria essi si presentino di tratto, ma per poco, inclinati verso Sud-Est, senza che appaia traccia di Tongriano, ciò che in tali casi è fitto piuttosto raro. 
Non è facile la netta distinzione dello Stampiano della rogione in esame dalle placcle aquitaniane di M. Castello e di Campobrioso, ciò che dipende dalla solita alternanza di banchi sabbiosi e marnosi in questo passaggio. Lo stesso dicasi generalmente pel passaggio tra il I'ongriano, a lo Stampiano, poichè la loro delimitazione talora è necessariamente alquanto arbitraria non esistendo un carattere fisso su cui basarsi per furla precisa; per convincersi di ciò basta, per esempio, percorrere e risalire in diversi sensi il vallone a Sud-Ovest di Malvicino.

Quasi sull'apice del Bric della Vite, presso Malvicino, osservansi assieme ad arenarie e conglomerati certamente del Tongriano, resti di banchi marnosi che per l'aspetto ricordano alquanto quelli dell'orizzonte in esame, al quale però non credo opportuno riunirli, poichè è più probabile che siano invece i resti di qualche strato interposto alle arenarie del Tongriano.

A Est di valle Erro lo Stampiano si presenta generalmente colla tipica sua facies prevalentemente marnosa, alterata solo qua e là o da lenti ciottolose come presso la borgata Picve, lungo la valletta di Saquanna, ecc., oppure, e questo più frequentemente, da straterelli o da veri banchi arenacei; questi fatti si verificano sia nella parte superiore dello Stampiano come di solito nei passaggi all'Aquituniano, (per esempio, in Val Cariogna dove la distinzione tra Stampiano ed Aquitaniano riesce un po' dubbia al fondo della valle) sia nella parte inferiore dove veggonsi spesso, come ad esempio, nella valletta del Bistolfi a Nord-Est di Ponzone, potenti arenarie a facies tongriana, alternate con bancli marnosi con facies stampiana, in modo che riesce allora, affatto arbitraria la delimitazione di questi due piani geologici; ciò d'altronde, come già ebbi più volte ad accennare, ̀̀ perfettamente naturale, trattandosi di depositi che quivi si succedettero senza notevole trasgressione.

In questa valletta raccolgonsi numerosissimi fossili (fra cui moltissime Nummuliti) nei terreni di passaggio tra il Tongriano e lo Stampiuno, nelle vicinanze di Ciglione, e pure in questi ban- 
chi marnoso-arenacei straterellati di transizione si trovano non rari resti di piante; d'altronde, a dire il vero, tutte queste regioni dell'Appennino sono un vero ed inesauribile iniseo paleontologico, e chi ha occasione di percorrerlc attentamente, vi riscontra quasi orunque dei fossili.

Nella valle Visone si notano qua e là alcune placche di marna sabbiosa, attribuibili allo Stampiano, sia direttamente sulla roccia preterziaria come tra C. Carmine e C. Gameire, sia sulle arenarie del Tongriano come sopra Caldaso ed allc C. Gherpiane; talvolta inrece tali depositi marnosi costituiscono dei prolungamenti più o incno strctti sulle creste di certe colline come da Ciglione a Grognardo.

$\dot{E}$ notevole la comparsa in Val Ravanasco di due afforamenti di marne stampiane sotto all'Aquitaniano, fatto che trova la sua causa naturale nello spuntone serpentinoso che gia altrove accennammo esistere presso C. Ferri, e che alterò localmente la stratigrafia dei terreni oligocenici.

In Val Visone lo Stampiano è gcneralmente assai facilmente distinguibile dall'Aquitaniano, sia per la sua facies abbastanza uniformemente marnoso-sabbiosa, sia specialmente perchè quivi la base dell'Aquitaniano è rappresentatí da un potente complcsso di banchi arenaceo-calcarei, talora anzi quasi solo calcarei, chc costituiscono generalmente una specie di gradino a causa della loro durezza.

Sulla destra di Val Visone l'orizzonte in esame conserva abbastanza bene la sua facies marnosa, pur mostrando talora qualchc formazione sabbioso-arenacea, come ad Est della borgata Foreste, senza parlare poi dei soliti strati di passaggio al Tongriano che in queste regioni spunta frequentemente al fondo delle vallettc. L'andamento stratigrafico, appunto in causa di tali spuntoni, non è molto regolare, talora verificandosi pcrsino delle inclinazioni di $50^{\circ}$ verso Sud come nclla parte alta della valle di Castellamare, quantunquc in generale la pendenza sia verso Nord circa.

Si notano poi delle placche marnose isolate, attribuibili pro- 
babilmente all'orizzonte ora in studio, poggiate o direttamente sul 'lalcoschisto, come a Sud di C. Ronghetto o invece, in massima, parte, sulle arenarie dell'orizzonte inferiore, nelle vicinanze di C. Del Gatto, ad ogni modo sempre nelle parti alte della regione montuosa; ciò ci indica il molto maggior sviluppo che dovettero originariamente presentare questi depositi prima che le erosioni acquee li avessero ridotti a piccoli lembi; alcuni di tali lembi trovansi in specie d'insenature nella roccia e la loro conservazione è probabilmente dovuta alla loro particolare disposizione rispetto alle irregolarità della roccia antica che servi loro di riparo.

Noto ancora come a Sud della cresta rocciosa di TestacaldaTraga e addossate ad essa, veggonsi ben sviluppate marne, talora però alternate con arenaria a lenti ciottolose, che lanno alquanto l'apparenza di quelle stampiane.

Ma più ad Est, cioè verso la collina di Cassinelle, noi vediamo che a cominciare, circa, dalle vicinanze delle borgate Costa presso Morbello la facies dello Stampiano si va gradatamente alterando, almeno in parte, per la comparsa e lo sviluppo di veri banchi arenacei al'ernati talora con lenti ghiaiose e ciottolose, banchi che, sporadici e piuttosto sottili, si erano però già potuti osservare fra le marne dell'orizzonte in esame anche più ad Ovest.

Già presso la borgata Bricco queste arenarie sono assai notevoli ma dore esse raggiungono la massima potenza e dove presentano più grosse lenti ciottolose è sulla cresta collinosa di Cassinelle, C. Bricco, C. Crenna e C. Foj, dalla quale regione elevata i banchi arenaceo-ciottolosi per la regolare inclinazione verso Nord-Ovest discendono nella valle di Caramagna di cui costituiscono quasi tutto il lato destro e gran parte del fianco sinistro ad un dipresso tra C. Marta e C. Sveltro.

Questi peculiari banchi arenacei ricordano talora abbastanza bene quelli del Tongriano da cui però sonı generalmente separati per mezzo di una potente serie di banchi marnosi, come può vedersi specialmente bene sulla sinistra della valle $\Lambda$ mione; 
talora invece $\mathrm{i}$ bancli in questione parrebbero doversi attribuire all' Aquitaniano a causa anche del trovarsi sull' alto delle colline, ma tale supposizione viene dimostrata falsa dal vedere sulla sinistra di Val Caramagna tali banchi andarsi ad immergere sotto alle solite marne stampiarie. Si possono pure vedere fatti stratigrafici importanti a questo riguardo, poco a Nord della Parrocchia di Cassinelle dove i sovraccennati banchi arenacei sono coperti dalle tipiche e solite marne dello Stampiano; questo rapporto stratigrafico si può d'altronde verificare assai bene da Cassinelle sin oltre la C. Sveltro, finchè $i$ banchi arenacei in esame vanno ad appoggiarsi direttamente sulla roccia antica it Sud-Ovest delle C. Serpei.

Devesi però notare che in alcuni casi rimane qualche dubbio sulla determinazione di qualche lembo isolato di arenarie che talora credetti dover attribuire ancora allo Stampiano, come quelle delle colline di $\mathrm{C}$. del Rosso ed in altri casi mi parrero invece già riferibili all'Aquitaniano, come presso Molare e presso Prasco.

La grande zona arenacea dello Stampiano dei dintorni di Cassinelle presenta uno spessore molto variabile secondo le località, racchiude sovente banchi delle tipiche marne grigiastre, nonchè lenti od anche letti di conglomerati o di breccie ad elementi talora enormi, come in alcuni punti tra Cassinelle, C. Foj ed il rio di Caramagna. Spesso questi veri banchi si presentano ricchi in fossili, Alghe, Echinodermi, Molluschi, e talora anche denti di Anthracotherium.

In complesso la serie dei banchi tongriani dei dintorni di Cassinelle si può indicare nel seguente modo: 
Marne grigiastre che presso gli spuntoni di roc-

Stampiano-- $\begin{aligned} & \text { cia antica presentano spesso banchi arenacei. } \\ & \text { Banchi arenacei più o meno potenti e nume- } \\ & \text { rosi con lenti ciottoloso-brecciose. } \\ & \text { Marne grigio-verdastre chiare. } \\ & \text { Marne grigio-bruniccie. }\end{aligned}$ Marne grigio-bruniccie.

Tongriano $-\left\{\begin{array}{l}\text { Banchi arenacei e marne sabbiose grigio-brune } \\ \text { spesso nummulitifere. } \\ \text { Banchi arenacei e sabbie giallastre con lenti } \\ \text { ghiaiose, spesso ricchissime in fossili. } \\ \text { Banchi conglomeratici molto resistenti, di co- } \\ \text { lor brunastro. }\end{array}\right.$

E notevole che in alcune località, come al Bric Roccone ed alla Madonna di Brucette, lo Stampiano pare soggiacere affatto al Tongriano, il che ci dimostra essersi verificati quivi dei movimenti abbastanza energici tra questi due periodi geologici, ed inoltre che furono molto importanti le abrasioni avvenute sui terreni tongriani, ma specialmente su quelli stampiani.

Infine riguardo alla costituzione dello Stampiano della regione ora in esame devo accennare come nelle vicinanze di Prasco, alle falde del Bric Marzapiede, ebbi a verificare in diversi punti (ad esempio il val Pobiano, mezzo chilometro ad Est del mo-. lino di Prasco, nel paese di Prasco, qua e là alle falde meridionali del Bric Marzapiede e sin presso il suo apice) sempre direttamente sulla roccia serpentinosa antica, una formazione marnoso-calcarea, biancastra, di un metro o mezzo metro di spessore, ricchissima in fossili, specialmente Nummuliti e Lithothamnium; credo doverla attribuire alla parte inferiore dell'orizzonte in esame; è questa una formazione affatto speciale che è molto interessante e che in avvenire offrirà certamente largo campo di studio al paleontologo.

Nel passaggio tra il Tongriano e lo Stampiano di queste regioni notansi talora delle trasgressioni più o meno importanti. Così per esempio in Val Caramagna presso la C. Falabrini lo 
Stampiano si appoggia discordantemente sulle arenarie e sui potenti conglomerati del Tongriano; lo stesso dicasi per alcuni degli afforamenti del Tongriano tra Prasco, Visone e II. Lajone, come anche per regioni più ad Orest, per esempio nella Valle del Senatore presso Grognardo.

Ancora in riguardo alla tettonica dell' orizzonte in esame, notiamo che là dove $\mathrm{i}$ suoi banchi si appoggiano direttamente sulla roccia antica, notansi per lo più delle irregolaritì; in generale verificasi il fenomeno che trorandosi i banchi oligocenici a Sud dello spuntone roccioso su cui si vanno a posare vedonsi inclinare verso esso finchè gli si appoggiano contro direttamente; più di rado invece, e quasi solo presso la linea di contatto colla roccia antica, presentano l'inclinazione contraria; invece se i banchi dello Stampiano trovansi a Nord dell'affioramento roccioso su cui si appoggiano, gli strati pendono regolarmente da esso, ma la loro inclinazione va direntando sempre più forte, da $15^{\circ}$ sin oltre $70^{\circ}$, finchè quasi sempre prima di arrivare alla roccia antica vedonsi comparire le arenarie e talora anche $\mathrm{i}$ conglomerati del Tongriano, ridotto però a pochi banchi fortemente inclinati ed anche drizzati alla rerticale. Questi fatti si possono per esempio verificare assai bene alle falde settentrionali e meridionali del M. Lajone.

Nelle regioni montuose a Sud di Ponzone e di Cassinelle si è già notato sopra esistere placche tongriane più o meno ampie; orbene su queste placche osservansi pure talora lembi marnosi o sabbiosi grigio-verdicci i quali sembrano dorersi riferire allo Stampiano, cosi presso Cimaferle, presso Toleto, presso Bandita, ecc. Si nota però in queste regioni che vi sono specialmente sviluppati i terreni di passaggio tra Tongriano e Stampiano, cioè certe sabbie marnose, con straterelli ghiaiosi ad elementi lisci, luccicanti, quasi verniciati, sciolti o cementati, con un colore verdastro, gialliccio nell' assieme; trattandosi in questi casi di placclie poco estese e non collegate regolarmente colle tipiche regioni più a Nord, rimane spesso incerto se certe formazioni sono da attribuirsi allo Stampiano piuttosto che non al 
Tungriano. E certo ad ogni modo che nelle regioni in questione lo Stampiano è rappresentato dai suoi orizzonti inferiori, i quali spesso presentano strati arenacei frammezzo alle marne, come si può ad esempio vedere molto bene tra Cassinelle e Cimaferle presso la C. Moresa dove avviene il passaggio dallo Stampiano al Tongriano.

Ad Est di Molare lo Stampiano si va rapidamente restringendo pur conservando nettamente la sua tipica facies marnosa colle solite alternanze di banchi arenacei di passaggio nella parte inferiore e superiore, ma senza offrirci dei fenomeni degni di particolar menzione.

Però in Val Piola, già nelle vicinanze dei casali Massatagliata, ma specialmente poi tra l'alveo del torrente ed il paese di Lerma, nella parte superiore dello Stampiano compaiono potenti banchi arenaceo-conglomeratici i quali ricordano quelli già esaminati presso Cassinelle e costituiscono il passaggio all'Aquitaniano senza clie si possa fare una netta delimitazione dei due orizzonti geologici.

Più ad Est la zona dello Stampiano, molto ristretta, talora ridotta appena a cento metri di larghezza come tra Mornese e Val Lardana, costituendo spesso una regione pianeggiante a causa della sua facile abrasione, presenta sempre le solite marne sabbiose grigio-verdastre con rare altemanze di strati arenacei, coi soliti burroni a fianchi franosi, ecc. il tutto però ridotto a minime proporzioni a causa della ristrettezza della zona che però mai si interrompe in alcun punto. Il colore delle marne dell'orizzonte in esame è generalmente verde-grigiastro piuttosto cliaro, una là dove esse passano ai conglomerati del Tongriano si presentano sovente con un bel color verde bottiglia; inrece $\mathrm{i}$ pochi strati arenacei che si alternawo colle marne presentano per lo più una tinta giallastra.

A cominciare dal paese di Carrosio in valle Lemno, dove lo Stampiano ha appena la larghezza di duecento metri, verso l'Est questo orizzonte si va poco a poco sviluppando colle sue tipiche marne sabbiose con apparenza farinosa clie dànno luogo ai 
profondi ed intricati burroni di C. Colombara, di Sottoralle e di Rigoroso.

Nella parte inferiore le marne grigio-bleuastre direngono più dure, talora con impronte di Zoophycos, e per le solite alternanze passano gradatamente alle arenarie ed ai conglomerati del Tongriano; nella parte superiore poi, mentre generalmente la distinzione dall'Aquitaniano è abbastanza facile, almeno complessivamente, per l'apparsa dei potenti banchi arenacei clie segnano l'inizio di quest'ultimo orizzonte, invece dal M. Tignassa sin oltre Rigoroso, la metà superiore del piano in istudio è costituita da una ripetuta alternanza di letti marnosi con letti arenaceo-calcarei duri, che divengono sempre più numerosi rerso l'alto e rendono quindi molto difficile la delimitazione del piano geologico, provandoci sempre più il graduatissimo passaggio tra lo Stampiano e l'Aquitaniano.

In Val Scrivia lo Stampiano raggiunge già una larghezza di oltre un chilometro, ma in causa del prolungamento verso Nord che già notammo verificarsi quivi nei terreni del Liguriano e del Tongriano, anche l'orizzonte ora in esame è costretto a rolgersi bruscamente verso Nord, mentre nello stesso tempo i suoi strati inferiori si presentano fortemente sollerati e spesso ripetutamente incurvati (come ad esempio si pù vedere molto bene nell'alveo della Scrivia tra Arquata e Tocemola), indicandoci di aver subito delle potentissime compressioni e spinte prima di raggiungere l'assetto che ora presentano.

Questi disturbi tettonici li rediamo continuare ancora per un certo tratto verso Est negli strati inferiori dello Stampicmo; mostrandosi essi sollevati talora di $70^{\circ}, 80^{\circ}$ e persino localmente rovesciati, come per esempio a Sud di Varinella, di C. Traraghè e dei Casali Torrotte, mentre in seguito essi ripigliano generalmente un andamento stratigrafico pì̀ regolare, con un'inclinazione variabile in media da $15^{\circ}$ a $20^{\circ}$.

Ad Est di Valle Scrivia lo Stampiano si va enormemente allargando, come già si può vedere nell'ampia valle Spinti, dore questo terreno oltrepassa talora la larghezza di tre chilometri: 
ma nello stesso tempo la sua facics si va notevolmente tramutando poichè ai banchi marnosi (abbastanza omogenei ed interrotti solo da qualche straterello arenaceo-giallastro), i quali prima ne erano quasi gli unici rappresentanti, si alternano frequentissimamente straterelli arenacei (ricchissimi in svariate impronte organiche ed inorganiche caratteristiche dei depositi di mare poco profondo) e persino lenti o strati ciottolosi, come ad esempio si vede assai bene tra Variana e Grondona; inoltre l'assieme dell'orizzonte invece di essere prevalentemente marnoso come verso Ovest diventa essenzialmente sabbioso.

Le lenti conglomeratiche compaiono già, quantunque sottili e poco frequenti, nella parte superiore del piano geologico in istudio, dove sono pure frequentissimi gli straterelli arenacei, ma divengono poi sempre più comuni e potenti nella parte inferiore tanto che riesce non solo difficile ma sovente arbitraria la precisa delimitazione del Tongriano dallo Stampiano; quindi a questo riguardo bisogna limitarsi ad un esame complessivo dei terreni, dal che risulta sempre vera e giusta la distinzione di due piani geologici.

In Val Borbera lo Stampiano continua a presentare uno sviluppo straordinario in larghezza di oltre 3 chilometri ed i fenomeni che abbiamo già ultimamente menzionati, colle solite difficoltà di precisa delimitazione sia nella sua parte superiore che in quella inferiore, il che si può nettamente constatare percorrendo l'incassato alveo del torrente Borbera.

La potenza, veramente straordinaria (per l'orizzonte in esame) di oltre 800 metri che raggiunge lo Stampiano tra la Val Spinti e la Val Borbera e che è la massima che di esso potei constatare in tutto il bacino piemontese, si spiega facilmente considerando che in queste regioni, invece della solita facies di mare abbastanza profondo esso assume quella di bassofondo marino od anche talora di litorale.

Però continuando l'esame dello Stampiano verso Nord, vediamo che esso, pur conservando una facies di deposito di mare poco profondo e presentando le solite alternanze nella sua parte 
superiore ed inferiore che ne rendono difficile la netta delimitazione, si va rapidamente ristringendo, mentre nello stesso tempo i banchi che lo costituiscono assumono in generale un' inclinazione più forte, talora dï $40^{\circ}$ o $50^{\circ}$, come presso Talforno, ma più comunemente di circa $30^{\circ}$.

Nelle vicinanze dei casali Fornetti, ma specialmente di Monastero di Molo, anche sulla destra di val Cravaglia $i$ frequentissimi strati arenacei con inclinazione di $15^{\circ}$ a $20^{\circ}$, di color grigio bruniccio, ed alternati con marne e ghiaiette verdastre, presentano numerose impronte di Helminthopsis, Taphrhelminthopsis, Helminthoida, Paleodictyon, ecc. che si rintracciano specialmente nei frammenti arenacei che in certi punti ricoprono reramente il suolo in causa della demolizione abbastanza rapida delle marne interposte agli straterelli arenacei, $i$ quali quindi trovandosi senza appoggio si screpolano e vanno in frantumi.

Oltre agli indicati strati arenacei che in parte rappresentano in queste regioni lo Stampiano, compaiono pure qua e là lenti ciottolose però poco importanti come in qualche punto a Nord di Molo di Borbera, sopra la borgata Valforno, ecc., per cui le difficoltà di delimitazione di questo orizzonte direngono sempre maggiori sia perchè il Tongriano a Nord di Groppello diviene anch'esso in gran parte marnoso-arenaceo con qualche lente conglomeratica e quindi alquanto simile allo Stampiano, sia perchè questo orizzonte presenta banchi sabbiosi ed arenacei anche noterolmente potenti e nell' aspetto affatto simili a quelli del sorrastante Aquitaniano al quale serrono di graduatissimo passaggio.

Nei dintorni dei Casali Cioccale dore gli straterelli arenacei abbondantissimi sono assai ricchi in Paleodictyon ed altre impronte, la stratigrafia presenta dei fatti anormali, in concoldanza con ciò che gì notammo quivi arrenire pel Tongriano: cioè notansi delle inclinazioni svariatissime di grado e di direzione: talrolta gli strati sono quasi orizzontali, talora inrece inclinati di oltre $45^{\circ}, 50^{\circ}$, come presso i casali Valscura; talrolta con dei ripiegamenti o dei piccoli salti locali. 
Nella valletta della Madonnina, assai interessante pei diversi fenomeni geologici cle presenta, si può osservare, sul lato destro, che certi banchi arenacei grigio-giallastri (alternati con banchi marnosi) sono ripetutissimamente e regolarissimamente ripiegati per modo da costituire quasi un ondeggiamento; ciò ci prova le potenti pressioni subite da questi depositi.

Dopo la rapida curva che fanno tutti i terreni al M. Cucco, lo Stampiano è ridotto a pochi strati marnoso-arenacei, fortemente sollevati, talvolta portati quasi alla rerticale e che ranno rapidanente assottigliandosi verso Ovest finchè si perde ogni traccia di questo orizzonte prima di giungere in Val Grue.

Nella restante parte delle colline tortonesi lo Stampiano non appare più in alcun punto. Così pure nelle colline Valenza-Casale esiste sempre un hiatus più o meno profondo tra $\mathrm{i}$ terreni tongriani e quelli sovrastanti, per cui non osservasi quivi alcun afforamento stampiano.

Però nelle colline casalesi tra la val Colobrio e la Val Stura, sviluppandosi abbastanza regolarmente la serie stratigrafica clse costituisce la gamba settentrionale della grande elissoide oligocenica Ottiglio-Montalero, veggonsi pure comparire per un certo tratto, tra il Tongriano e l'Aquitaniano inferiore, strati marnosi e sabbiosi ripetutamente alternati fortemente sollevati ed inclinati di $60^{\circ}$ circa verso il Nord-Nord-Est, i quali sono probabilmente riferibili allo Stampiano; finora però non mi presentarono resti fossili un po' caratteristici.

Lungo la sponda destra del Po, quasi di fronte a Palazzolo Vercellese, poco a valle del Porto di Rocca delle Donne, osservansi fi'a le marne sabbiose, grigie, franose, dell'Aquitaniano ed $\mathrm{i}$ banchi arenaceo-conglomeratici del Tongriano alcuni strati marnosi e sabbiosi inclinati di circa $50^{\circ}$ a Sud, che sono forse riferibili allo Stampiano.

Ma nelle colline 'Torino-Casale la più bella e potente zona stampiana è quella che si sviluppa nella stupenda conca terziaria di Oddalengo-Verrua; quivi infatti si può vedere che nelle colline a Nord di Oddalengo Grande, al Piano dell' Oppio, fra 
le marne grigio-bleuastre dell'Aquitaniano e le sabbie e le arenarie del Tongriano appaiono delle speciali marne grigie, friabili, inglobanti tratto tratto degli straterelli arenacei.

Questo orizzonte, che rappresenta lo Stampiano, mentre è dapprima appena accennato, si sviluppa tosto ampiamente verso l'Est ; i suoi strati sono inclinati di una cinquantina di gradi in media verso il Nord, poi verso il Nord-Est. Questa zona stampiana, limitata superiormente da potenti banchi arenacei che rappresentano l'Aquitaniano basale, si sviluppa notevolissimamente in Val Ardovana. Quivi i banchi marnosi, farinosi, grigiastri, interrotti talora da uno straterello calcareo bianco, come al Bric Vignassa, inclinati da $30^{\circ}$ a $60^{\circ}$ verso l' Est, costituiscono una zona di un chilometro cirea d'ampiezza e della potenza di 500 - 600 metri: fatto molto notevole per l'orizzonte Stampiano.

La zona stampiana in esame è caratterizzata anche orograficarnente da burroni profondi e di forma continuamente variabile per la peca consistenza dei banchi marnosi, fritbili, quasi farinosi, per modo che quelle regioni collinose presentano, nel complesso, una facies ải desolazione affatto caratteristica, come quella che si osserva nelle regioni stampiane dell'Appennino settentrionale.

Continuando l'esame di questa zona stampiana si vede clie essa si volge rapidamente a Nord-Est, si ristringe rapidamente, i suoi banchi si rialzano fortemente inclinando di $60^{\circ}$ e $70^{\circ}$ verso il Sud-Est. Ridotta per tal modo ad una sottile striscia, caratterizzata anche orograficamente dall' abbassarsi delle colline, questa piccola zona stampiana viene a scomparire sotto ai terreni quaternarii della valle padana presso la Cà di Carluccio; la sua continuazione ad Est si è notata comparire presso il porto Rocca delle Donne. Abbiamo così una semielisse abbastanza regolare.

Attorno alle zone eoceniche ed oligoceniche di Brozolo compaiono ancora, a Nord ed a Sud, strette striscie stampiane, rappresentate come di solito, da banchi marnosi alternati con straterelli arenacei per modo da formare un passaggio graduale dal Tongriano all' Aquitaniano. 
La zona stampiana meridionale appare nell'alta Val Trincavenna e si prolunga sino in Val dei Nervi; i suoi strati inclinano di $40^{\circ}$ ad $80^{\circ}$ verso il Sud.Ovest; orograficamente essa, per la sua poca resistenza, dà origine ad una specie di gradino lungo il pendio settentrionale della catena collinosa Castello di Brozolo-Borgata Novaresi.

Verso lo sbocco della valle Trincavenna presso C. Pozzetto vediamo apparire i banchi marnosi della zona stampiana settentrionale inglobata fra le arenarie straterellate del Tongriano e le sabbie e le arenarie a mamelons dell'Aquitaniano inferiore; fra questi diversi orizzonti geologici vi è generalmente una concordanza stratigrafica abbastanza regolare, quantunque vi esistano diversi hyatus in causa del fatto che non tutti gli strati di questi vari orizzonti vengono ad affiorare.

I banchi marnosi grigio-bleuastri sono in generale sollevati molto fortemente inclinando di $60^{\circ}, 70^{\circ}$ verso il Nord all' incirca; per la loro natura poco resistente e friabile, arviene clie essi dànno spesso origine a profondi burroni franosi.

Verso Monteu da Po la zona stampiana restringendosi rapidamente viene a scomparire sotto alla formazione aquitaniana. Si debbono forse attribuire ancora a questo orizzonte geologico alcuni banchi marnosi che appaiono ad Ovest di Moriondo sotto alle arenarie dell' Aquitaniano inferiore, con cui si accordano assai bene stratigraficamente.

A Nord dell'affioramento eo-oligocenico di Marmorito-Cocconato, siccome le varie formazioni geologiche assumono un andamento assai regolare ed un'inclinazione non molto forte, possono apparire e svilupparsi per un certo tratto le tipiche arenarie friabili, grigiastre dello Stampiano, inclinate di $35^{\circ}$ a $40^{\circ}$ verso il Nord od il Nord-Orest; esse passano gradatamente alle arenarie tongriane di C. Bonico e sono coperte dalle marne aquitaniane a frattura concoide da cui sono per lo più difficili a distinguersi nettamente.

Infine nella parte occidentale della elissoide tongriana di Gassino, nei dintorni di borgata Rivodora, vediamo comparire tra 
i potenti conglomerati tongriani e le arenarie aquitaniane, una serie assai potente, ma assai limitata in lunghezza, di banchi marnosi grigiastri, friabili aventi completamente l'aspetto dello Stampiano dell'Appennino settentrionale. L'arervi incontrati, sulla superficie degli interstrati arenacei, numerose impronte di facies stampiana fa sì che io credo dover attribuire a questo orizzonte geologico tale formazione marnosa assai caratteristica.

Questi banchi stampiani inclinano piuttosto fortemente verso l'Orest od il Nord-Ovest.

Tra lo Stampiano ed il Tongriano di queste regioni pare che vi sia generalmente un po' di lacuna; invece tra lo Stampiano superiore e l'Aquitaniano inferiore esiste per lo più un passaggio assai graduale, come si può vedere specialmente allo sbocco del vallone scendente da Superga; quivi infatti riesce sorente difficile il delimitare $\mathrm{i}$ due orizzonti geologici, tanto più clie l'Aquitaniano basale si presenta pure spesso con straterelli arenacei che, per la facies e per le impronte che mostrano, ricordano molto certi orizzonti tongriani e stampiani.

\section{Riassunto.}

Lo Stampiano, bene sriluppato nella metà meridionale del bacino terziario del Piemonte, dove $\mathrm{i}$ depositi si formarono più regolarmente, e mancante invece quasi completanente nella sua metà settentrionale, è essenzialmente costituito da banchi di marne grigie o grigio-rerdastre, friabili, con una facies generale di mare abbastanza profondo, alterata solo localmente da depositi arenacei o gliaiosi indicanti un seno marino o le vicinanze di un littorale. I suoi strati hanno generalmente un'inclinazione piuttosto dolce e regolare rerso l'interno del bacino piemontese: in pochi casi la stratigrafia è alterata e mai per lunglii tratti; solo nelle colline Torino-Casale ed in piccola parte del tortonese i banchi stampiani si presentano fortemente sollevati. 
In complesso la formazione stampiana è poco potente, solo in alcune regioni offre lo spessore di duecento o trecento metri, talora persino raggiungendo la potenza di circa 800 metri; in quest'ultimo caso però essa assume una facies di basso fondo marino.

In causa della natura dei banchi che lo costituiscono l'orizzonte esaminato non s'innalza a notevole altezza sul livello marino; però alle falde delle Alpi Marittime, là dove esso si presenta con facies littoranea, raggiunge persino i 770 metri di elevazione.

Generalmente lo Stampiano è concordante cogli orizzónti geologici superiori ed inferiori a cui fa graduale passaggio, inferiormente per mezzo di alternanze di strati arenacei e conglomeratici con strati marnosi, superiormente invece con un alternanza di banchi marnosi, sabbiosi ed arenacei, per modo che in ambedue $i$ casi è sempre difficile la sua netta delimitazione.

Lo Stampiano è piuttosto scarso di fossili appunto per la sua matura di deposito di alto fondo, ma ne presenta però talora li dove compaiono banchi sabbiosi ed arenacei; anche in quest' ultimo caso trovansi in varie località abbondantissime quelle impronte di origine organica ed inorganica che caratterizzano i tranquilli depositi littoranei; in complesso però i suoi caratteri paleontologici sono molto simili a quelli del Tongriano, solo con una facies alquanto più recente che li ravvicina già alquanto a quelli dell' Aquitaniano. 



\section{CAPITOLO IX.}

Aquitaniano.

Studi anteriori.

Quantunque i terreni che corrispondono al piano Aquitaniano siano nel bacino terziario del Piemonte molto sviluppati, tuttavia si può dire che, eccetto che a Sud-Est di detto bacino, dove ebbe a far studi il Mayer, essi non vennero finora nè riconosciuti nè distinti.

Infatti il Sismonda nella sua carta geologica del Piemonte inglobò in una sola tinta tutti i terreni miocenici, nè, per ciò che risulta dai suoi scritti, si preoccupò della posizione dei terreni ora in esame, tanto più che essi non presentavano alcun fatto interessante per il paleontologo: lo stesso dicasi del Gastaldi, il quale d'altronde era piuttosto contrario alle numerose suddivisioni del Terziario.

Il Pareto che ebbe ad occuparsi più direttamente e più continuatamente dei terreni terziari e che cercò già di suddividerli ill vari piani, non riuscì però a distinguere nettamente l'assieme dei depositi che ora chiamiamo aquitaniani e che, come risulta dai suoi scritti, egli collocò in parte nel suo piano Bor- 
midiano, che è essenzialmente rappresentato dai terreni tongriani e stampiani, ed in parte nel suo piano Langhiano che invece è da ritenersi come molto meno comprensivo di ciò che risulterebbe dagli scritti del Pareto.

Quanto alle colline Torino-Casale dove l'Aquitaniano è molto sviluppato, come vedremo, finora esso era stato solo indicato dal Mayer nelle colline di Superga.

Il Mayer nei suoi scritti sulla geologia della Liguria settentrionale indicò chiaramente la presenza e lo sviluppo dell'Aquitaniano in quella parte del bacino in esame; ma nella delimitazione di questo orizzonte egli ne escluse un potente complesso di arenarie di cui costituì un sottopiano speciale del Tongriano superiore (stampiano), mentre che per i dati stratigrafici e paleontologici credo invece esso si debba inglobare ancora nell'Aquitaniano di cui costituirebbe la base.

Nella carta geologica d'Italia pubblicata nel 1881 non abbiamo a notare nulla a questo riguardo, non essendo essa pel terziario che una ricopia della carta del Sismonda.

Nella carta geologica delle Riviere liguri d'Issel, Mazzuoli e Zaccagna, i terreni aquitaniani che ri compaiono vennero riuniti a quelli del Langhiano, dell'Elveziano e del Tortoniano col titolo di Miocene medio; inoltre la loro distinzione dal Miocene inferiore (Tongriano e Stampiano), malgrado sia fatta su carta in piccola scala e con poche indicazioni topograficlse di ritrovamento, è per lo più evidentemente diversa da quella clse credo doversi fare.

Lo studio che farò nelle pagine seguenti dell'Aquitaniano del bacino piemontese metterà in chiaro quanto sia importante $e$ sviluppato questo piano geologico finora cosi trascurato anche fuori del Piemonte, mentre invece esso merita grande considerazione trattandosi di un orizzonte clie, se non è ricco in fossili, costituisce però una porzione rilevantissima dei depositi terziari. 


\section{Generaliti.}

Nel bacino picmontese l'Aquitaniano rappresenta un deposito essenzialmente di marc poco profondo c talora anche di vero littorale, essendo per lo più costituito da banchi sabbiosi passanti talvolta a bancli ghiaiosi cd inglobanti cziandio, nella parte settcntrionale del bacino in esame, potenti strati ciottolosi ad elementi sovente voluminosissimi.

Tuttavia in alcunc regioni, specialmente nelle colline TorinoCasale, compaiono a far parte dell'Aquitaniano potenti complessi di banchi marnosi di color grigiastro, ad aspetto farinoso, a stratificazione spesso poco apparente. Na, fatta eccezione degli indicati orizzonti marnosi, sono essenzialmente sabbioso-arenacei e talora anche conglomeratici i dcpositi aquitaniani che esistono alle falde della catena alpina.

Invece verso l'Appennino $\mathrm{i}$ depositi aquitaniani a causa dell'essersi formati ad una certa distanza dalla regione montuosa da cui trovavansi già separati per mezzo dei depositi tongriani e sestian;, ma specialmente a causa della poca elevazione di tale regione unontuosa, presentano raranente dei banchi ciottolosi; invece per lo più questo orizzonte è costituito da strati arenacei, ad elementi sovente assai grossolani, alternanti con strati marnoso-sabbiosi.

Il colore dei depositi aquitaniani è naturalmente molto vario specialmente a seconda della loro natura; in generalc però predomina la tinta grigio-giallognola, talora passante anche ad un colore giallo-bruno, leggermente rossiccio.

Fra gli elementi ciottolosi dell'Aquitaniano dclle colline torinesi sono a notarsi come comunissimi i ciottoli di calcare alberese, che invece scarseggiano assolutamente nelle vicine formazioni conglomeratiche dell' Elveziano. 


\section{Caratteri palcontologici.}

Si potrebbe supporre a mriori, trattandosi di un terreno a fucics di bassofondo marino o di littorale, chrs l'Aquitaniano presenti una gran ricchezza paleontologica; disgraziatamente invece in realti le cose sono assai diverse; non già clie scarseggino i fossili in questo orizzonte, chè anzi se ne trovano abbastanza comunemente a diversi livelli e quasi ovunque, specialmente nei banchi arenacei; ma, ad eccezione di particolari banchi arenaceo-calcarei che arremo a notare, tali fossili sono quasi sempre talmente infranti, erosi e ridotti a pezzi indeterminabili e così difficili a liberare dal terreno che li racchiude che pel paleontologo essi sono di ben poca utilità, e quindi non fornirono finora forme importanti al catalogo dei fossili miocenici (iel bacino piemontese; è perciò che nella parte paleontologica di questo lavoro io non arrò generalmente a menzionare fossili aquitaniani nè regetali, nè animali.

Non è quindi possibile, almeno colle attuali conoscenze, di indicare fossili caratteristici dell'Aquitaniano nella regione in esame: solo posso dire in generale a questo riguardo come $i$ fossili aquitaniani sono specialmente di facies littoranea e piuttosto sinili a quelli famosi dell' Elveziano dei colli torinesi che non a quelli del Tongriano, pure offrendo numerosissini punti di collegamento con questi ultimi.

Sono abbastanza comuni sulle lastre arenacee aquitaniane le. impronte di Helminthopsis, Taphrhetminthopsis, Helminthoida, Paleodictyon, ecc.; queste ultime con reti generalmente più ampie e piu irregolari che non nei Paleodictyon stampiani, ed invece più somiglianti a quelle dei Paleodictyon dei terreni postarpitanicui. 


\section{Distribuzione geografica.}

L'Aquitaniano ̀̀ molto sviluppato nel bacino terziario del Piemonte giacchè cominciando ad apparire presso Ceva si va tosto allargando straordinariamente per modo da costituire una noterolissima porzione delle Langhe; in seguito verso Est, quantunque si rada alquanto restringendo, costituisce sempre tuttavia una zona generalmente assai vasta che fascia ad una certa distanza le falde appenuiniche.

Come le altre formazioni terziarie sottostanti e soprastanti l'Aquitaniano presenta un' ampia curva in Val Scrivia; è ancora assai sviluppato nelle vicinanze di Garbagna ma poco piǹ a Nord compie una rapida svolta verso Est; poi in breve si restringe e scompare completamente presso Avolasca.

Nelle colline Torino-Casale l'Aquitaniano è abbastanza sviluppato specialmente verso Ovest, poichè verso Est è mascherato in gran parte dai terreni niocenici.

\section{Tettonica.}

Assai diverso è l'andamento stratigrafico dell' Aquitaniano a seconda che l'osserviamo dal lato Sud o dal lato Nord del bacino piemontese. Infatti lungo le falde settentrionali dell'Appennino i banchi aquitaniani presentano un'inclinazione assai regolare verso l'interno del bacino, inclinazione piuttosto dolce, cioè di $10^{\circ}$ o $12^{\circ}$ circa, tanto che talvolta essi avanzano molto a Sud sopra le formazioni tongriane e sestiane a cui in tali casi si appoggiano talora con una leggera discordanza stratigrafica.

Nella parte orientale del bacino piemontese i terreni aquitaniani sono alquanto più fortemente inclinati, cioè di circa $20^{\circ}$, anzi, dopo la rapida curva che essi fanno a Nord di Garbagna, essi si presentano fortemente sollevati, almeno nclla parte basale. 
Nelle Colline Torino-Valenza l'Aquitaniuno costituisce in complesso un'anticlinale principale più o meno regolare, più o meno completa, le cui gambe a loro volta costituiscono talora sinclinali ed anticlinali secondarie specialmente a Nord, provandoci ad evidenza le potenti compressioni laterali che questi terreni dovettero subire specialmente dal Nord, a causa della ricina catena alpina centrale.

Inoltre gli strati aquitaniani di questa regione collinosa si presentano per lo più fortemente sollevati, indicandoci sempre più chiaramente quanto grande sia stata la potenza delle pressioni laterali che diedero origine all'allungato corrugamento che costituì le colline Torino-Talenza.

Naturalmente in queste regioni collinose non sono rari i salti, gli spostamenti, ecc. negli strati aquitaniani; ma trattasi quasi sempre di fatti locali e quindi di poca importanza, giacchè essi quasi mai riescono ad alterare profondamente il regolare andamento stratigrafico.

\section{Potenza.}

Quando si percorrono certe regioni del bacino piemontese dove l'orizzonte aquitaniano presenta il più grande sviluppo in superficie, come ad esempio la parte Sud-Est delle Janghe, sorge naturale il pensiero cle sia straordinaria la potenza di questo piano geologico; però se si considera che là dove esso è più ampiamente sviluppato, tra la Val Bormida di Spigno, la Tal Bormida di Millesimo e la Talle del Belbo, dore cioè la zona aquitaniana raggiunge persino 15 cnilometri di largliezza: i suoi strati presentano un'inclinazione media di solo $10^{\circ}$ allo incirca, ne consegue che la reale potenza di questa formazione, quantunque molto grande, in rapporto appunto alla sua facies di bassofondo e di littorale, è però calcolabile a solo 2500 a 2600 metri circa, parendomi non probabile, quantunque non impossibile, che quiri la seric aquitaniana raggiunga i 3000 metri di spessore supposti dal Mayer. 
Nelle colline 'Torino-Valenza l'Aquitaniano talvolta presenta una notevole potenza, come ad esempio nei dintorni del Santuario di Crea, e presso Oddalengo. Dove però esso raggiunge la massima potenza è nella parte occidentale di queste colline, cioè tra Rivodora e Torino; infatti se si considera lo straordinario sviluppo che gli orizzonti marnosi, arenacei e conglomeratici dell'Aquitaniano medio ed inferiore presentano da Val Rivodora a Val S. Martino (pur tenendo conto della inclinazione degli strati molto meno forte lungo il grand'asse dell'elisse che non verso la periferia) credo che non sia esagerato il valutare la potenza deli'Aquitaniano di queste regioni collinose a circa 2000 metri, cifra che per quanto straordinaria è però inferiore a quella che mi risultò dagli studi sull' Aquitaniano della parte meridionale del bacino piemontese.

\section{Altimetria.}

Pur trovandosi i depositi aquitaniani già abbastanza lontani dalle regioni alpino-appenniniche, raggiungono talora delle elevazioni abbastanza notevoli, ciò che è in rapporto sia alla loro grande potenza sia alla loro natura arenacea che li rende più resistenti alle azioni erosive che non i terreni dei piani geologici fra cui è incluso.

Senza discendere ora a minuti particolari riguardo alle varie elevazioni presentate dall' Aquituniano nel bacino piemontese, notiano solo che mentre nella parte settentrionale i suoi bancli sono al massimo portati a circa 650 metri, come nelle colline di Superga $(654 \mathrm{~m}$.), nella parte meridionale invece ben sovente essi sono sollevati oltre i 700 od 800 metri, specialmente tra la Val Bormida di Spigno e la Val Bormida di Millesimo, così alla Cresta del Boscaccio (801 m.) presso Torre Uzzone, al Bric Puschera ( $845 \mathrm{~m}$.) tra Mombaldone e Cortemiglia ed al Bric dei Faggi $(867 \mathrm{~m}$.$) ad Est di Monesiglio.$ 


\section{Tapporto coi terreni sotto e somastanti.}

Siccome i terreni aquitaniani nel bacino piemontese in esame si collegano generalmente senza trasgressione coi terreni dei piani sotto e soprastanti, cosi generalmente nei banchi di passaggio tra l'uno e l'altro di questi orizzonti sia nella parte superiore che in quella inferiore, si verifica una tale gradazione per mezzo di un'alternanza di banchi sabbiosi, marnosi ed arenacei che, come di solito e come è naturale, liesce assai difficile e talora alquanto arbitraria la delimitazione dell'orizzonte in esame.

Quanto al passaggio tra l'Aquitaniano e lo Stampiano ebbi già a trattarne nel precedente capitolo e ne arrò a parlare più volte nel corso della descrizione geologica generale; mi basti ora l'accennare come esso talora si compie per la sorrapposizione di banclii arenacei più o meno calcarei (da Majer attribuiti ancora al Tongriano ma che io considero come facienti parte dell'Aquitaniano per le ragioni sovra esposte) che s'appoggiano sulle marne dello Stampiano, talora inrece, e più comunemente, per mezzo di un'alternanza più volte ripetuta di strati o banchi marnosi a facies stampiana con strati o banchi arenacei a facies aquitaniana, talvolta infine solo per mezzo di depositi marnosi di tinta varia, nel qual caso è sempre più difticile la delimitazione dei due orizzonti.

Non è raro il caso in cui i banchi aquitaniani che si spingono maggiormente verso la regione alpino-appenuinica si sovrappongano con una certa discordanza sui terreni sestiani e tongriani.

Nelle colline Torino-Casale l'Aquitaniano appoggiasi abbastanza regolarmente, sul Tongriano, dal quale però è per lo più separato con un hiatus assai forte.

Superiormente l'Aquitaniano passa al Langhiano per mezzo di un'alternanza di strati sabbioso-arenacei giallastri con strati sabbioso-marnosi grigiastri. A dire il vero nelle Langhe questa 
alternanza si continua anche per tutto l'orizzonte Langhiano, per modo che senza un accurato esame si passa insensibilmente dall'Aquitaniano all'Elveziano senza che appaia la facies marnosa generalmente caratteristica del Langhiano che quivi invece assume una facics di basso fondo marnoso; ma da Castino verso Est, sviluppandosi sempre più la facies marnosa del Langhiano, nella parte superiore dell' Aquitaniano lungo tutta la linea di sovrapposizione di un orizzonte all' altro, si può osservare assai bene tale gradualissimo passaggio che ne rende sovente incerta la delimitazione.

Lo stesso dicasi per tutto lo sviluppo dell'Aquitaniano lungo le falde subappenniniche sino alla valle Scrivia, giacchè ad oriente di questa valle ripetendosi nel Langhiano ad un dipresso il fenomeno già indicato per la regione delle Isanghe, cioè il fatto che esso assume una facies littoranea, con ripetuti banchi arenacei, assai difficile riesce talora la distinzione tra Langhiano ed Aquitaniano; però quest'ultimo terreno presentandosi più avanti (verso Nord-Est e Nord) costituito essenzialmente di sabbie non molto cementate, ne deriva che il passaggio fra $\mathrm{i}$ due orizzonti in esame è grossolanamente indicato da una specie di gradino che formano i banchi marnoso-arenacei del Langhiano su quelli sabbiosi dell'Aquitaniano. Non di rado però si osserva in queste regioni un po'di discordanza stratigrafica fra questi due piani geologici.

Verso la ruga liguriana Brignano-Spinetta ambidue gli orizzonti in discorso diventano marnoso-sabbiosi ed a stratificazione poco evidente e quindi ancor più difficile ne riesce la delimitazione che si deve fondare specialmente sulla stratigrafia nonchè sopra una qualche maggior ricchezza in sabbia ed un color grigio più brunastro nell'Aquitaniano che non nel Langhiano.

Nella parte orientale delle colline Torino-Valenza si osserva che, non affiorando il Langhiano, i terreni aquitaniani vengono ricoperti con discordanza più o meno notevole, dai terreni miocenici. Ma nella parte occidentale delle colline Torino-Valenza, comparendo poco a poco i banchi marnosi duri langliani, si 
osserva nuovamente, per le solite alternanze, un graduale passaggio fra $\mathrm{i}$ due orizzonti geologici tanto che, come sempre in tali casi, ne riesce spesso alquanto arbitraria la delimitazione; solo più in regioni speciali, come ad esempio tra Albugnano e Cocconato, l'assottigliamento straordinario e talora anclie la completa scomparsa del Langhiano, produce delle leggere trasgressioni tra gli strati aquitaniani e quelli dei terreni sorrastanti.

\section{Localitì fossilifere.}

Già da quanto renne detto nel precedente paragrafo risulta come poche sieno le località dove si possono raccogliere un pò copiosamente resti fossili determinabili, però nel complesso dei banchi arenacei ed arenaceo-calcarei, che lurgo le falde appenniniche settentrionali costituiscono la base dell' Aquitaniano, ebbi non raramente a riscontrare fossili littoranei ancora abbastanza conservati ed è quindi specialmente in questo speciale orizzonte che dovrebbe fare ricerche chi intendesse studiare la fauna dell'Aquitaniano inferiore del bacino in esame.

Sono specialmente preziose pel paleontologo le località dore il soviaccennato orizzonte arenaceo direnta molto calcareo, cosi presso Arquata Scrivia, M. Vignassa, Carrosio, Visone, Ponzone, Cavatore, nelle vicinanze di Nombaldone, ecc.

Anclie ricchi in fossili sono $\mathrm{i}$ banchi calcareo-arenacei che talora compaiono fra i banchi sabbioso-arenacei dell'Aquitaniano così presso Acqui dove trovansi abbondantissimi resti di Lithothannium, Zoophycos, Pecten, Pesci, ecc.

Ed anche senza prevalenza di banchi calcarei trovansi a rari livelli dell'Aquitaniano banchi arenacei con fossili abbastarza conservati, sia negli strati arenacei che in quelli marnosi, così presso Mombasiglio, presso Cera, ed in direrse altre localiti che avrò occasione di menzionare nella descrizione regionale.

Nei banchi sabbioso-marnosi, che io attribuisco all' Aquitaniano, nelle immediate vicinanze di Ceva, rerso Est e Nord- 
Fst, durante gli scavi per la ferrovia Torino-Savona, si riscontrò un resto di Chelonio e numerose conchiglie generalmente però deformate per schiacciamento.

S'incontrano pure talora dei Zooplyycos come presso Monesiglio (Langhe), sotto borgata Bosio (Val Belbo), presso Ponzone, nella conca di Garbagna, nelle colline Torino-Casale, ecc., specialmente negli strati di passaggio allo Stampiano.

Nelle colline aquitaniane di Torino-Casale e specialmente verso Tolino si riscontrano pure, specialmente fra $\mathrm{i}$ banclii arenacei, non pochi resti fossili ma in generale assai meno ben conservati clie non quelli dei vicini terreni terziari. Noto ad esempio un banco arenaceo-conglomeratico clie appare nelle colline di Chivasso allo sbocco di Val S. Genesio, sulla destra, banco il quale ricompare poi anche più ad Est presso Colombaro, e che si presenta assai ricco in Antozoi, Cytherea, Cardita, Ostrea, Ancillaria, Clavatula of. consimilis, Ranella marginata, Eburnea ef. caronis, Cassidaria, Pleurotoma cf. decorata, Conus, ecc., cioè una miscela di forme specialmente clveziane con alcune tongriane. Interessanti specialmente sono i foraminiferi i quali si incontrano comunemente fra le sabbie aquitaniane dei colli torinesi.

Alla base dell' Aquitaniano, presso Rivodora ad esempio, si possono raccogliere fra le arenarie molti resti di foraminiferi, Orbitoides, Operenlina, ecc. a facies già alquanto stampiana.

Resti di Ostriche, Pettini, Balanidi, ecc. raccolgonsi numerosi fra le arenarie, assieme ai Forıminiferi, così ad esempio nel vallone Beccia ed a Sud del Molino del Rocco nelle colline di Cocconato.

\section{Descriaione geologica regionale.}

Nella parte Sud-Ovest del bacino terziario del Piemonte l'Aquitaniano si inizia solo tra Lesegno e Mombasiglio, liberandosi poco a poco dal mantello dei più giovani terreni terziari, ed aumentando sempre di larghezza verso Est.

Esso è quivi costituito da banchi marnosi assai simili a quelli 
dello Stampiuno, solo con albastanza frequenti interstrati arenacei o talora persino con lenti conglomeratiche come presso il Castellu Zemma, la C. Gatere, la C. Lubatta, ricordando assai in queste regioni l'Aquitaniano di Superga.

Frammezin alie arenarie non sono rari i resti fossili, di cui alcuni ben conservati, specialmente tra la ralle delle Palette, il Caste!lo Zemma e la Cascina Fecchina; l'inclinazione degli strati è piattosto dolce e regolare rerso Nord-Nord-Est; il passaggio graduatissimo al Langhiano si fa per mezzo di un'alternanza di banchi arenacei e marnosi piuttosto duri; i banchi aquitaniani inferiori distinguonsi solo in complesso da quelli stampiani superiori per essere alquanto piu ricchi in strati sabbioso-arenacei grigio giallastri e quindi per una stratificazione pin appariscente; talvolta esiste anche una leggera trasgressione stratigrafica, ma in generale questi due terreni sono assai bene concordanti.

Lo stesso deve all'incirca ripetersi pei dintorni di Ceva, dove l'Aquitaniano, prevalentemente marnoso grigio-giallastro (alquanto simile a quello delle colline Torino-Casale), friabile, con interstrati arenacei, si presenta in grandiosi spaccati naturali ed è abbastanza ricco in fossili assai ben conservati, solo generalmente molto schiacciati; questo ci prova le potenti pressioni che dovettero subire questi terreni specialmente per le forze di sollevamento. D'altronde non sono soltanto $\mathrm{i}$ fossili che ci indicano tali pressioni ma anche la natura stessa degli strati marnosi che a certi livelli, sia per maggior ricchezza in materiale calcareo, sia per le sorraccennate compressioni, sono ora ridotti a lastre durissime, scagliose, molto simili a quelle che redremo sovente rappresentare il Langliano, e racchiudenti spesso fossili pure notevolmente scliacciati; ciò per esempio si verifica nell' 1 quitaniano inferiore in Val Salessola poco a Nord del Casello 37 della ferrovia, e nell'Aquitaniano superiore in Val Fornello sotto la borgata Canaloni. Anzi in quest'ultimo caso queste lastre marnose alternate con bancli arenacei e marnosi, sia per la loro facies che per i fossili (Nucula, ecc.) che raccliudono, fanno 
graduatissimo passaggio al Langhiano, quivi assai ridotto, e ne rendono difficile la netta delimitazione.

Fenomeni simili a quelli ora accennati veggonsi ancora nelle vicinanze di Sale delle Langlıe dove non è raro incontrare fossili, come ad esempio poco sotto la borgata Villarello; in seguito verso Est l'A quitaniano si allarga tosto immensamente, scompaiono quasi completamente gli orizzonti a lastre marnose dure ed invece si sviluppano specialmente $\mathrm{i}$ banchi arenacei $\mathrm{e}$ sabbiosi giallastri e le marne piuttosto tenere grigiastre, con rare e strette lenti ghiaioso-ciottolose.

Già nelle vicinanze di Mombasiglio, dove dapprima appare l'Aquitaniano, si era notata una certa frequenza di strati arenacei verso la base di questo orizzonte; tale fatto, molto utile per la distinzione di questo orizzonte dallo Stampiano, si va sempre più accentuando ver'so Est, tanto da costituirne un vero orizzonte arenaceo che per la sua durezza forma generalmente una specie di gradino sulle marne stampiane e si spinge molto avanti verso Sud sino a ricoprire talora quasi completamente lo Stampiuno come al Bric d'Arcise, sollevandosi quivi sino ad 820 metri.

Questo importante orizzonte arenaceo-sabbioso (con rare lenti ciottolose) dell'Aquitaniano basale, così prezioso pel geologo, si può dire essere abbastanza costante per tutta la parte meridionale del bacino terziario in esame, solo con varia potenza e varia facies, ciò che avremo occasione di constatare in seguito. E da questo orizzonte arenaceo, giacente talora con leggera trasgressione sulle marne stampiane, che risulta quella specie di grandioso terrazzo giallastro, resistente, sovrapposto ai terreni grigiastri farinosi, franosi, che appare tanto nettamente, anche molto di lontano, a chi dalla Val Bormida di Millesimo si dirige verso Montezemolo.

Tale complesso di banchi arenacei aquitaniani non continua però sempre ad essere così spiccatamente distinto dallo Stampiano, giacchè seguitandolo sulla sinistra della Val Bormida di Millesimo, dove esso discende lentamente verso il Nord sino a 
raggiungere il fondo della valle presso il paesello di Gabutti, notiano che, probabilmente per una più regolare successione stratigrafica tra i due piani geologici, anche lo Stampiano nella parte sua superiore presenta numerosi banchi arenacei, talora molto potenti, alternantisi con quelli marnosi, per modo che la distinzione fra $\mathrm{i}$ due indicati orizzonti diviene sempre piu difficile; per convincersene basta salire da un punto qualunque della Val Bormida al vastissimo altipiano ondulato di Montezemolo.

L'Aquitaniano medio è costituito di sabbie e di arenarie giallastre con rare lenti gliaiose alternate con potenti banchi marnosi grigiastri che talora ricordano assai quelli dello Stampiano; l'orografia del sovraccennato altipiano di Nontezemolo dipende molto dalla natura appunto dei banchi aquitaniani che, con dolcissima inclinazione verso il Nord Nord-Ovest circa, vi vengono largamente ad affiorare.

Nell'Aquitaniano superiore continuano ad osservarsi le solite alternanze di strati sabbiosi arenacei e marnosi più o meno resistenti che costituiscono il passaggio al ridottissimo orizzonte Langhiano.

Continuando l'esame dell'orizzonte arenaceo dell'Aquitaniano basale sulla destra di Val Bormida di Millesimo e seguitandolo poscia lungo tutta la sponda sinistra della Tal Bormida di Spigno, lo vediamo per lo più assai potente e quasi sempre colla stessa facies littoranea, ad inclinazione per lo più assai dolce, cioè di circa $10^{\circ}$, talvolta però di oltre $15^{\circ}$ come presso il paesello di S. Giulia, talora invece quasi orizzontale come presso il paese di Salicetto, dove pare sovrapporsi alquanto discordantemente sullo Stampiano.

Si è già notato nel precedente capitolo come, specialmente tra l'una e l'altra valle delle due Bormide e per un lungo tratto di quest'ultima, lo Stampiano, quiri a facies di bassofondo marino, presenti potentissimi banchi arenacei giallastri che costituiscono una serie di grandi altipiani, leggermente inclinati a Nord-Ovest, interrotti dalle erosioni acquee, ma che 
si spingono verso Sud sin presso le roccie preterziarie, assuinendo anzi quivi una natura piuttosto conglomeratica.

Orbene tali banchi hanno assolutamente l'aspetto di queili aquitaniani da cui ho creduto distinguerli per ragioni che non starò a ripetere poichè già esposte nel precedente capitolo; altri però potrebbe inglobarli ancora nell'Aquitaniano inferiore seguendo un criterio di delimitazione tra i due piani geologici diverso da quello che credetti opportuno di adottare; debbo ad ogni modo osservare che in queste regioni rimane sempre un po'incerta la distirizione tra questi due orizzonti geologici, distinzione che è d'altronde più facile a farsi con un esame complessivo di una serie di grandi spaccati lungo una data direzione, che non con un minuto esame e cercando di segnare tutti i banchi arenacei che affiorano sulle colline; almeno questa è l'opinione che mi è rimasta dopo d'aver seguito ambidue gli accennati metodi di osservazione, per conoscere quale fosse il migliore per la regione in esame.

Il vero orizzonte basale dell'Aquitaniano è potentissimo, costituito talora da enormi banchi sabbioso-arenacei, giallastri, in parte abbastanza facilmente erodibili per modo da risultarne bizzarre concrezioni isolate, come poco ad Est di Saliceto; talora invece compaiono potenti e durissini banchi arenacei come sulla cresta delle C. Serene, là dove a mio parere vengono a terminare rerso Sud a guisa di penisola i terreni aquitaniani; tuttavia seguendo questa cresta collinosá sino a Rocchetta Cengio ed al Bric del Monte veggonsi ancora esistere potenti bauchi arenacei clıe però paiono piuttosto già doversi attribuire allo Stampiano a facies littoranea.

Lungo la valle della Bormida di Spigno sin oltre Val Cagna continuano sempre ad apparire sullo Stampiano potenti bancli arenacei che rendono difficile la delimitazione di quello più importante che costituisce la base dell'Aquitaniano; in quest'ultimo orizzonte, nelle vicinanze del paese di S. Giulia (sperialnente al Bric Palmerei) e del Bric Costacorta, sono frequen le lenti ghiaioso-conglomeratiche, che sono invece rarissime e sottili nei 
F. SACCO,

banchi pseudo-aquitaniani dello Stampiano, come ad esempio si osserva ad Est di C. Cava; ciò ad ogni modo ci indica che in queste località alla fine di un periodo ed all'inizio di quello seguente, esisteva, oppure era poco lontana, la foce di una corrente terrestre però non molto importante.

Talora questi ciottoli di varie dimensioni si trovano, non solo fra le arenarie, ma persino caoticamente sparsi in una marna grigiastra, così ad esempio presso i casali di Noceto (S. Giulia).

Fra queste arenarie non è raro talora il riscontrare resti fossili, specialmente Pecten, ma per lo più infranti e dificilmente determinabili con esattezza anche perchè non sempre si possono liberare dalla ganga arenacea in cui sono compresi.

Sopra alle potenti arenarie dell' Aquitaniano basale reggonsi solo più, come ad esempio presso il paesello di Cagna, alcune marne sabbiose grigio-bleuastre, su cui sviluppasi un potente orizzonte costituito da un'alternanza di strati marnosi dello spessore di circa 30 cent., con straterelli arenacei dello spessore di 5 cent. ad un dipresso.

L'Aquitaniano inferiore presentasi talora un po'discordante dallo Stampiano, specialmente per la tendenza, direi, che lianno i bancli del primo orizzonte di svilupparsi molto verso Est con piccola inclinazione al disopra dei terreni stampiani alquanto più fortemente inclinati; ciò osservasi ad esempio specialmente ad Orest di Mombaldone.

A Nord di Val Cagna, assumendo lo Stampiano una facies prevalentemente marnosa, il complesso di banchi arenacei aquitaniani ora in esame (pur lasciando ancora qualche piccola incertezza di (delimitazione), rimane più nettamente individualizzato; più rare compaiono le lenti ciottolose, che reggonsi tuttavia ancora qua e là come presso C. Bosi, C. Tarareto, Roccletta, C. Pian del Buri, ecc.; quivi si rinrengono frequentissimi gli accentramenti arenaceo-calcarei; nell'assieme questa formazione arenacea talora oltrepassa persino i 30 o 40 metri di potenza.

Alle falde del Bric Arbarella, ad Orest di Mombaldone, le 
arenarie dell'orizzonte in esame diventano fortemente calcaree e talora anzi compaiono vere lenti calcaree costituite essenzialmente da Lithothamnium, con Ostrea, Pecten, ecc., fatto che già preludia a fcnomeni simili, ma in più grande scala, clıe arremo ad osservare più avanti.

Verso Denice i terreni basali dell'A quitaniano sempre più abbassandosi vengono a raggiungere il fondo della valle Bormida, mostrandosi perỏ quivi poco arenacei per modo clie riesce alquanto arbitraria la delimitazione fra lo Stampiano e l'Aquitaniano, quivi ambidue piuttosto marnosi; quest' ultimo è per lo più maggiormente ricco in interstrati arenacei.

Però generalmente le marne stampiane sono friabili, grigiastre e con stratificazione spesso poco apparente, mentre le marne aquitaniane hanno un colore grigio-bleuastro, sono più dure e romponsi in scaglie oppure concoidemente, hanno inoltre una stratificazione assal evidente anche per l'accennata alternanza di strati arenacei; talora tra questi dne orizzonti havi un banco di marne giallastre dure, ben stratificate; talvolta esiste un banco arenaceo-sabbioso; talora infine mancano anche questi strati che agevolano la delimitazione.

Al disopra dei descritti banchi basali dell'Aquitaniano si nota un'alternanza abbastanza r'egolare di strati marnosi grigiastri o grigio-bleuastri con strati arenacei giallo-brunastri di 10 a 30 centim. di potenza circa; talora predonina la marna, talora invece l'arenaria, ma sen $\_$presentare in questa serie fenomeni particolari degni di menzione.

$\dot{E}$ invece molto importante ad osservarsi come tra l'una e l'altra valle delle due Bormide questi banchi, ad inclinazione abbastanza dolce e regolare, cioè di circa $10^{\circ}$ verso il NordOvest, si sviluppino in modo straordinario per modo che la zona aquitaniana raggiunge qui per lunghissimo tratto un' ampiezza di circa 15 chilom. e quindi una potenza di oltre $2500 \quad 2600$ metri.

Non credo opportuno di fare una descrizione geologica di questa amplissima e bella regione collinosa in cui trovansi sparsi 
numerosi paesi (fra i quali più importanti sono Monesiglio, Roccaverano e Cortemiglia), e che coi suoi profondi burroni, colle sue creste sollevate sovente sin presso od oltre gli $\$ 00$ metri, coi ripidi pendii delle sue colline, presenta sovente un paesaggio quasi alpino. Siccome però la natura e l'andamento degli strati è ad un dipresso ovunque eguale, la sua descrizione geologica riescirebbe una continua ripetizione degli stessi fatti.

Credo invece più utile il considerare un po' più mirutamente la parte superiore dell' Aquitaniano di queste regioni, poichè avremo occasione d'osservarvi fatti abbastanza interessanti.

A Nord di Camerana gli ultimi 300 metri circa dell'Aquitaniano superiore non presentano più tanto regolare l'alternanza di strati arenacei con strati marnoso-sabbiosi, ma sorente invece vi si interpongono potenti banchi arenacei, come ad esempio quello su cui è fondato il paese di Monesiglio, che già preludiano a banchi simili che costituiscono la parte inferiore dell'Elveziano e dai quali anzi senza l'esame stratigrafico non sarebbero spesso discernibili, tanto più che il Langhiano è molto ridotto ed ha una faciés pure quasi completamente littoranea.

Percorrendo la Val Bormida e risalendo tutti i principali suoi contrafforti di sinistra si può osservare chiaramente nell' $A$ quitaniano superiore e nel Langhiano un'alternanza di marne con banchi arenacei che divengono verso l'alto sempre più frequenti e potenti con tutto l'aspetto di quelli del sorrastante Elveziano.

Lungo tutta questa zona superiore dell'Aquitaniano trovansi non di rado Zoophycos nelle marne sabbiose e Paleodictyon sulle lastre arenacee, in particolar modo sotto ai banchi langhiani.

L'andamento stratigrafico è sempre piuttosto regolare rerso il Nord-Ovest con un' inclinazione di circa $10^{\circ}$ o $12^{\circ}$; sovente lì dore si possono seguire direttamente coll' occhio certi banchi per lungo tratto (come per esempio lungo il fondo di Tal Bormida tra Gozzegno e Colombi) si rede che essi talora vanno restringendosi, specialmente verso Sud, finchè scompaiono 
affatto; questo ci spiega come, senza salti od altri disturbi stratigrafici, possa variare abbastanza rapidamente da un lnogo all'altro la potenza dell'Aquitaniano; talvolta si possono notare delle curve negli strati, come di fronte a Levice, dei piccoli spostamenti, ecc. ma, per quanto lio visto, essi non sono mai tali da alterare il regolare andamento stratigrafico generale.

A Nord di M. Carpino spingendosi l'Aquitaniano ancor più verso Nord-Ovest esso va ad occupare gran parte della valle del Belbo. Tra. Feissoglio c Castino potenti banchi arenacei vengono a costituire la cresta elevata clie divide la valle del Bclbo da quella della Bormida presentando nel complesso un aspetto tale da ricordare molto quelli dell' Elveziano basale. Quindi sorge l'idea che tale cresta collinosa sia costituita da una specie di placca di strati elveriani corrispondenti a quelli che mostrano la loro testata sulla sinistra di Val Belbo e dai quali ne sarebbero stati staccati per semplice crosione acquea; questo dubbio è eziandio avvalorato sia dalla poca inclinazione che presentano gli strati, sia dall'osservare su ambi i fianchi di qucsta collina divisoria, nella sua parte alta, una specie di gradino prodotto dalla maggior resistenza all'erosione che presentarono i banchi arenacei della cresta collinosa rispetto agli strati marnosi ed arenacei della parte più bassa.

Considerando però chc presso il paese di íeissoglio si verificano alcune discordanze stratigraficlie per modo clie $\mathrm{i}$ potenti banchi arenacei dell'Elveziano inferiore, inclinati all'incirca verso l'Ovest e che costituiscono il M. Carpino ( $832 \mathrm{~m}$.), sono disposti in maniera che paiono quasi andarsi a posare sopra ai banchi pure arenacei e potenti, inclinati piuttosto verso il Nord-Nord-Ovest (quantunque con delle locali irregolarita stratigrafiche) che costituiscono il Bricco della Chicsa $(774 \mathrm{~m}$.). Considerando pure che, affinchè potessero le continuazioni degli strati elveziani che appaiono sulla sinistra della Val Belbo, andare a costituire la parte superiore dclla cresta opposta, dovrebbero gli strati avere un' inclinazione di soli $5^{\circ}$ circa, mentre in generale prescntano una pendenza più forte (quantunque a dire il vero talora in- 
vece persino minore, come per esempio presso Castino al Bric Cassiero); ed infine osservando che sulla sinistra di Val Belbo, sotto ai banchi marnoso-arenacei del Langhiano i banchi dell'Aquitaniano superiore sono in parte arenacei e di facies talora clveziana, ne deriva il dubbio che debbasi ritenere come aquitaniana tutta la parte superiore della collina Feissoglio-Castino.

Però la facies elveziana della parte superiore di tale regione collinosa, certi resti fossili, le piccole inclinazioni che quivi talora presentano gli strati, certe discordanze stratigrafiche osserrate presso Feissoglio e presso Castino, l'apparsa di certe zone marnose probabilmente langhiane ed infine il già accennato gradino che vedesi lungo la cresta collinosa in questione, nella sua parte superiore, mi fa propendere piuttosto a ritenere la parte alta di detta collina come appartenente all'Elveziano inferiore.

Nella valle del Belbo l'Aquitaniano presenta qua e là resti fossili, quantunque poco determinabili, come ad esempio presso Rocchetta Belbo; non sono inoltre rari gli Zoophycos, di cui ebbi a rintracciare diverse impronte specialmente nelle dure marne arenacee sotto la borgata Bosia.

Ad Est di Castino, pur conservandosi ancora per lungo tratto la riccliezza in arenaria del Langhiano, tuttavia ne è più facile la distinzione dall' Aquitaniano poichè questo piano geologico, fatta eccezione dei bancli superiori di passaggio, assume una facies abbastanza caratteristica per la regolare alternanza di banchi arenacei e marnosi di spessore piuttosto costante.

L'Aquitaniano ha in complesso un color giallastro o localmente giallo-rossastro, non di rado dà luogo a sorgenti d'acqua; i suoi potenti banchi arenacei formano colline piuttosto erte, con stupendi piani inclinati verso Nord o Nord-Ovest. Vi sollo piuttosto abbondanti le impronte di irregolari Palcodictyon specialmente tra il paese di Vesime ed il Bric dei Galli. Alcuni di questi Paleodictyon presentano delle reti le cui aree sorpassano talora i 304 e persino 5 centim. di larghezza, come ad esempio ebbi ad osservare nelle vicinanze di Cantabona presso Castino. 
La stratigrafia è sempre molto regolare e l'inclinazione dei banchi, dapprima verso Nord-Ovest circa, si è graduatissimamente modificata sino ad essere invece diretta verso il Nord ad un dipresso.

Ad Est della Bormida di Spigno l'Aquitaniuno, quantunque ridotto ad una larghezza meta circa di quella che occupava nella regione ora descritta, presenta pur tuttavia un'ampiezza ed una potenza molto considerevole, con una facies complessiva abbastanza uniforme ed un andamento stratigrafico assai regolare; è sempre molto interessante il suo orizzonte inferiore sia dal lato geologico che da quello paleontologico e quindi lo esamineremo un po' più accuratamente.

Se verso il fondo di Val Bormida di Spigno l'Aquitaniano inferiore è in parte rappresentato da banchi marnosi come già si è notato, tosto però esso diventa prevalentemente arenaceo verso Est per modo da costituire lo spiccato rialzo su cui siede il paese di Montechiaro d'Acqui; d'altronde però è da notarsi come questa differenza litologica in regioni cosi vicine è in parte solo apparente, essendo essa dovita sia a fenomeni di erosione sia al fatto che i depositi aquitaniani che spingonsi più a Sud sull'alto delle colline presentano generalmente un po'di trasgressione rispetto al soggiacente Stampiano e quindi spesso mancano di banchi marnoso-arenacei intermedi.

In riguardo appunto allo sviluppo verso Sud che presenta talora l'Aquitaniano sull'alto della regione collinosa in esame, è importante il notare la presenza di due lunghe e caratteristiche placche arenacee aquitaniane isolate sopra allo Stampiano e forranti due notevoli rialzi cioè il M. Castello $(528 \mathrm{~m}$.$) ed il$ M. Campobrioso $(522 \mathrm{~m}$.). Ciò ci rende avvertiti che originariamente una specie di velo aquitaniano a dolcissima inclinazione doveva svilupparsi tra Ponzone e Spigno ad un dipresso, sopra al terreno stampiano cle invece ora si trova quivi messo a nudo quasi completamente in seguito alla profonda erosione acquea.

Al M. Castello gli strati marnoso-arenacei si veggono, specialmente verso Sud, assai ben separati dagli strati tongriani 
per mezzo di potenti bancli arenacei giallastri, inglobanti numerose e voluminose concrezioni arenaceo-calcaree.

In Tal Cariogna, specialmente verso C. Piccina, è abbastanza difficile la distinzione netta dell' Aqnitaniano, per lo più arenaceo e con impronte di Paleodictyon, dallo Stampiano quivi pure in gran parte costituito da banchi arenacei nella porzione sua superiore ma riccamente marnoso più in basso.

È abbastanza notevole quella specie di penisola allungata che formano gli strati arenacei dell'Aquituniano al Bric del Brin. $\mathrm{E}$ poi importante riguardo alla stratigrafia l'osservare che poco più ad oriente, a Sud del M. Capriolo, dove parrebbe terminare l'orizzonte aquitaniano, lungo la cresta collinosa che si dirige verso Ponzone ed ancora oltre questo paese, ai terreni stampiani, rappresentati essenzialmente da strati marnosi alternati con ripetuti straterelli arenacei, si sorrappongono alquanto discordantemente (e senza l'inter'inezzo del tipico orizzonte arenaceo calcareo) placche di banchi marnoso-arenacei grigio-bleuastri a frattura concoide e spesso scagliosi che paiono doversi ancora attribuire all'Aquitaniano.

Dipoi nella parte alta della collina su cui siede il paese di Ponzone e nelle sue vicinanze verso Sud ed Est (Cappella della Naddalena) questi banchi marnoso-arenacei, che attribuisco all'Aquitaniano inferiore, presentano sorente bellissime impronte di Zoophycos, denti di Squali, ecc.; talora mostrano eziandio delle lenti ciottolose come presso C. Rosso, presso il Bric Cardinelle, quasi sotto Ponzone, ecc.; spesso poi si arricchiscono talmente in calcare, per l'abbondanza specialmente di Lithothamim e d'altri fossili, da poter essere utilizzati come pietra da calce, come si verifica appunto sotto Ponzone, ma specialmente al Bric Cardinelle dore ciò si può osserrare stupendanente; quivi i Lithoihamnimm di varia grossezza si presentano sorente sparsi od agglomerati frammezzo alle marne calcaree bleuastre interstratificate a sabbie, arenarie ed anche lenticelle ghiaiose. In queste localiti l'Aquitaniano si spinge sino ai E60 metri (Bric Cardinelle) sorrapponendosi con 
qualche trasgressione stratigrafica allo Stampiano, su cui costituisce un'amplissima placca notevolmente inclinata verso l'Ovest-Nord-Ovest per modo da discendere molto verso la valle dell'Erro; forma così quella specie di altipiano irregolare di C. Rossa e di Pian del Lago, dove si notano sovente dei disturbi stratigrafici per cui i banchi arenacei (spesso inglobanti irregolari accentramenti arenaceo-calcari giallastri) sono talora inclinati di oltre $50^{\circ}$.

Questa ricchezza in calcare dell'Aquitaniano basale si riscontra poi ancora più spiccata verso Nord, così alle falde del M. Capriolo dove questi banchi arenaceo-calcarei costituiscono delle pareti a picco; essi veggonsi ancora per lungo tratto verso settentrione poichè, a causa dello spuntone serpentinoso di C. Ferri, l'inclinazione degli strati è molto dolce; anzi vi si osservano delle piccole ondulazioni, le quali ad esempio ci spiegano quella specie di anello elissoidale clie poco a Nord di C. Scati i calcari in questione presentano nell'alta valle Ravanasco, lasciando apparire al disotto le marne dello Stampiano; così pure si può notare clie mentre generalmente i banchi aquitaniani pendono verso il Nord circa, nelle vicinanze di C. Basana pendono invece leggermente a Sud, in causa del sovraccennato spuntone serpentinoso che altera localmente l'andamento stratigrafico dei sovraincombenti terreni terziari.

In Val Visone i banchi basali dell'Aquitaniano conservano ancora una notevole ricchezza in calcare, costitnendo così sul sottostante orizzonte stampiano marnoso-arenaceo una specie di gradino ben visibile anclıe da lontano su ambi i lati dell'ampia vallata; in molte località, specialmente dove si presenta all'nopo maggior comodita (come in diversi punti a Sud di Visone sin presso questo paese) tale calcare più o meno arenaceo viene attivamente utilizzato sia come pietra da costruzione cle come pietra da calce.

Ovunque quest' orizzonte è ricchissimo in fossili, Lithothamnium, Molluschi, denti di Squalo, ecc.; e quindi esso è assai prezioso pel paleontologo, quantunque non sempre lo stato di 
conservazione dei fossili sia molto soddisfacente, in particolar modo per la difficoltà di liberare il fossile dall' arenaria finissima che lo arvolge; generalmente si osserva che il banco più ricco in calcare sta sopra a banchi arenacei, potenti 3 o 4 metri circa.

Il grande prolungarsi di questo orizzonte calcareo-arenaceo verso Nord, sino a Visone, deriva dalla conformazione della sottostante regione rocciosa, la quale in queste località presenta una specie di rialzo notevolmente sviluppato verso Nord, donde gli spuntoni serpentinosi di C. Ferri, di Grognardo e di Bric Marzapiede.

Verso Est i banchi arenacei dell'Aquitaniano inferiore, pur conservandosi abbastanza potenti, tanto da formare sullo Stampiano ripidi rialzi (su uno dei quali per esempio è fondato il paese di Cremolino), tuttavia non si presentano più tanto calcarei come verso Ovest e quindi divengono meno interessant: sia pel paleontologo che per l'industriale, tanto più che nello stesso tempo tali banchi vanno pure gradatamente perdendo quel carattere d'individualità, direi, che prima li distingueva, e presentano una facies poco diversa da quella dei sovrastanti banchi aquitaniani.

Talvolta fra le marne dello Stampiano osservansi banchi arenacei che ricordano molto quelli aquitaniani lasciando talora anzi dei dubbi sulla loro vera età, come già ebbi ad accennare nel capitolo precedente; di questi banchi alcuni io credo dover inglobare nello Stampiano superiore, come ad esempio quelli inclinati di circa $30^{\circ}$ a Nord-Nord-Orest che veggonsi un cento metri circa a Sud di Cremolino, quelli che appaiono sulle colline di Priarone, ecc, e specialmente quelli delle vicinanze di Cassinelle; ma in altri casi li posizione di questi banchi arenacei, la loro facics a straterelli un po'ripieghettati e le numerose impronte di Paleadictyon a forma irregolare, mi inducono a collocarli ancora, però alquanto dubitativamente, nell'Aquitaniano inferiore, così per certi punti tra Molare ed il Bric Roccone, tra Madonna di Brucette e C. Montemartino ed alle falde meridionali del Bric Marzapiede. 
E. noterole come a causa dello spuntone serpentinoso di Bric Marzapiede e Bric Roccone su cui si veggono ancora qua e là applicate le dure arenarie dello Stampiano, queste talora pajono sovrastare alle sovraccennate placche aquitaniane, come si può vedere a Nord di Molare e specialmente a Sud di Madonna di Brucette.

Parrebbe quindi che durante l'epoca aquitaniana il Bric Marzapiede costituisse una specie d'isolotto poco lontano dalla spiaggia e che quindi tutt' all' intorno vi si potessero formare depositi aquitaniani di cui per l'erosione acquea rimasero solo più pochi residıi nelle parti più alte delle colline; naturalmente l'andamento stratigrafico di queste placche non è ovunque regolarissimo, ma in generale si può dire che l'inclinazione, sempre piuttosto dolce, è verso il Nord circa, però con delle varianti locali.

Passando or'a all'esame dell' intera zona aquitaniana compresa tra Val Bormida di Spigno e Tal Stura di Ovada, possiamo dire anzitutto come la sua costituzione sia molto uniforme e come essa sia rappresentata da una regolare alternanza di banchi marnosi ed arenacei di potenza abbastanza costante; questo per esempio si può con tutta comodità e nettamente constatare lungo la Val Bormida di Spigno tra Bistagno e Montechiaro, dove la valle, in causa della molto maggior durezza dei banchi aquitaniani in confronto di quelli stampiani e tongriani, è foggiata ad una specie di forra che mostra, specialmente nella sinistra, una stupenda serie di amplissimi spaccati naturali.

L'andamento stratigrafico è assai regolare; i banchi pendono di circa $15^{\circ}$, talora però anche di $20^{\circ}$ a $25^{\circ}$, verso il Nord in media; notansi solo alcuni locali disturbi stratigrafici, fra cui per esempio uno bellissimo si può osservare negli spaccati di destra di Val Erro, poco a Nord di Melazzo, dove si vede nella serie dei banchi una successione di rotture accompagnate da nettissimi scoscendimenti e quindi anche da locali trasgressioni stratigrafiche.

Si incontrano spesso in queste regioni degli strati arenacei 
alla cui superficie veggonsi svariatissime impronte, fra cui specialmente quelle di Paleodictyon, cosi ad esempio in Tal Erro sopra C. Pennacchi, in Tal Caramagna presso. S. Gile, ecc.

Quanto all' Aquitaniano superiore è sempre molto difficile il distinguerlo bene dal Langhiano inferiore per la solita alternanza di strati arenacei e marnosi clie gradatamente direngono sempre più frequenti e potenti verso l'alto, talrolta però con dei ritorni alla facies preralentemente arenacea, finchè si giunge al tipico Langhiano essenzialmente marnoso, grigio-bleuastro. Talora per fare tale distinzione bisogna ricorrere persino all' esame orografico; così per esempio nell'ampia valle della Bormida di Acqui, in cui sotto all'Alluvim si rerifica la sovrapposizione del Langhiano all'Aquitaniano, credetti dorer far passare il limite di questi due terreni a Nord dei rialzi di C. S. Caterina e di C. Della Notte che solleransi dalla pianura per essere costituiti di banchi specialmente arenacei inclinati di circa $20^{\circ}$ verso il Nord-Nord-Orest.

Presso Acqui, sulla destra della Val Bormida, specialmente presso lo stabilimento di Bagni, osserrasi un complesso di banchi prevalentemente calcarei, grigio-biancastri, inclinati assai regolarmente verso il Nord all'incirca come di solito, ricoperti di banchi marnosi a facies langhiana e poscia da potenti banchi arenacei, ricchi in fossili di varie sorta (specialmente Lithothamnium, Pecten, denti di Squalidi, ecc.) e con numerose e bellissime impronte di larghi Zoophycos.

Quantunque io dubiti clie in queste regioni esistano salti stratigrafici, tuttavia li ritengo abbastanza localizzati e credo quindi che questi banchi calcarei d'Acqui siano assai più recenti di quelli di Ponzone e Visone, cioè appartengano gia alla parte medio-superiore dell'Aquitaniuno; è però notevole che il calcare delle terme d'Acqui per la sua durezza assume talora quasi l'aspetto di una protrusione fra le circostanti marne, come si può per esempio osservare in alcuni punti sulla destra del rio Raranasco.

Terso Morzasco, Trisobbio, Rotteri, Bacciorini, ecc., si può 
sempre constatare il gradnalissimo passaggio, e quindi la delimitazione difficile, ed anzi spesso alquanto arbitraria, tra Aquitaniano e Langhiano; questo fatto poi si accentua specialmente tra Trisobbio e Morzasco, osservandosi quivi che numerosi bancli marnosi duri con apparenza langhiana (ad esempio presso S. Sebastiano) e con impronte di Zoophycos e resti di fossili, sono alternati con potenti banchi arenacei con impronte di $P a$ leodictyon (ad esempio presso C. Cioi) e con fucies cosifattamente aquitaniana cle io credetti opportuno di porli tutti in quest' ultimo piano geologico, quantunque in fondo la questione sia di poca importanza.

Presso Orada il limite tra Langhiano ed Aquitaniano generalmente si può segnare abbastanza bene perchè il primo orizzonte termina inferiormente con banchi di dure marne frammentarie, mentre il secondo si inizia con grossi bancli sabbioso-arenacei giallastri inglobanti spessoo degli accentramenti appiattiti discoidali; ciò almeno in complesso.

Ad Est della Stura di Ovada l'Aquitaniano continua a restringersi gradatamente, sino a ridursi a poco pin di mezzo cliiloinatro di larghezza nelle vicinanze di borgata Spcssa. L' orizzonte renaceo infcriore perde sempre più della sua importanza quantunque questo primo apparire di banchi arenacei, giallastri, di 1 o 2 metri circa di potenza, sulle marne stampiane grigiastre sia molto prezioso al geologo per la relimitazione dei due piani geologici, tanto più che per la loro durezza i primi costituiscono generalmente una specie di gradino sulle seconde; si notano talora, in questi bancli basali, sottili lenti ghiaiose, ed a questo rispetto dobbiamo accennare qui di nuovo i potenti strati conglomeratici ad elementi talora abbastanza voluminosi che presso Lerma trovansi nel passaggio fra lo Stampiano e l'Aquitaniano inferiore.

Mentre le marne dello Stampiano sono grigio-verdastre e romponsi generalmente in minuti frammenti, invece quelle che compaiono nell'A quitaniano sono piuttosto grigio-bleuastre, più dure e compatte e romponsi in generale concoidemente. 
La costituzione litologica della fascia aquitaniana è rappresentata specialmente da banchi arenacei grigio-giallastri, inclinati abbastanza regolarmente di circa $15^{\circ}$ o $20^{\circ}$ verso il NordNord-Ovest, talora abbastanza ricchi in fossili (molti Echinodermi), però piuttosto schiacciati e poco ben conservati, nonchè in impronte di Zoophycos (come presso le borgate Bonefazio, al Bric Cerata, ecc.) e non di rado con impronte di Paleodictyon di forma irregolare, come per esempio alle falde meridionali del Bric Cerata.

Continuano, com'è naturale, le solite incertezze di delimitazione fra Langhiano inferiore ed Aquitaniano superiore, tanto più che in quest'ultimo orizzonte sono abbastanza frequenti gli strati marnosi grigio-giallastri duri, spesso fogliettati e fossiliferi, che vedremo poi essere molto comuni e quasi caratteristici del Langhiano.

Tra la Val Lemno e la Val Scrivia i terreni aquitaniani si vanno di nuovo allargando, acquistando nello stesso tempo una notevole potenza.

L'orizzonte arenaceo basale che già ad Est di borgata Bosio aveva cominciato ad ispessirsi, mentre nello stesso tempo comparivano pure banchi simili, al disopra di esso, fra gli strati narnosi, continua ad acquistare importanza per modo che di fronte a Carrosio sulla destra di Val Lemno esso si presenta potentissimo ed assai ben individualizzato costituendo un' altissima parete quasi verticale sopra le marne stampiane; questo fiatto si continua sin oltre la Val Scrivia per modo che si comprende come il Mayer, clie elbe ad eseguire studi in queste. regioni tipiche del terziario, abbia creduto potersi fare di questi banchi arenacei un orizzonte geologico affatto speciale che egli appella Tongriano superiore, mentre io sono piuttosto di parere che si tratti solo di depositi che iniziano la facies di bassofondo marino che caratterizza generalmente l'A quitaniano.

Questi banchi arenaceo-calcarei, che d'altronde noul sono punto caratteristici solo della base dell' Aquitaniano, ma ricompaiono anche più in alto, come presso Cascina Grin, C. Soreto, alla 
Cresta Montada, ecc., sono ricchissimi in resti fossili a facies littoranea (Pecten, Ostrea, Lucina, Venus, Nucula, Dentalium, Gidaris, Flabellum, Lumulites, Isis, Lithothamnium, ecc.) nonchè in impronte di Zoopllycos ed altri resti fillitici poco determinabili.

A causa della loro durezza questi banchi arenacei, alternati però con diversi straterelli marnosi, si innalzano sin quasi ai 600 metri, come al M. Vallassa $(594 \mathrm{~m}$.), e vengono qua e li utilizzati come pietra da costruzione e per usi simili. Ciò si può vedere assai bene sulla sinistra di Val Scrivia tra Arquata e Rigoroso, dore questi banchi, per l'erosione anticanente esercitata dalla Scrivia, costituiscono ora una specie di parete a picco.

Sopra gli accennati banchi arenacei si veggono generalmente adagiarsi strati marnosi grigiastri, molto simili a quelli dello Stampiano e spesso alternati, come sopra già dissi, con potenti e resistentissimi banchi arenacei; tale fatto si osserva specialmente presso C. Gain ed alla (Yresta Montada; anche questi banchi e queste marne sabbiose sono sovente assai ricche in fossili littoranei, come Lithothamnium, Pecten, Ostrea, Lucina (grossi esemplari), Dentalium, ecc. per lo più abbastanza facilmente liberabili dalla ganga arenacea in cui sono inglobati.

L'ampia regione aquitaniana compresa tra Val Lemno e Val Scrivia è pure essenzialmente costituita di arenarie ma generalmente in strati abbastanza sottili, spesso alquanto ripieghettati, a materiale meno grossolano, sovente alternati con strati marnoso-sabbiosi grigio-bleuastri che divenendo sempre più frequenti nella parte superiore del piano in esame ne rendono difficilissima la delimitazione dal piano sovrastante; quindi spesso per segnare nelle carte tale distinzione bisogna ricorrere a qualche più potente banco arenaceo giallastro resistente che arbitrariamente si pone come banco supremo dell'Aquitaniano; ancle con questo metodo però si verifica sovente che il banco che si segue come limite viene a mancare oppure è coperto dalla vegetazione e quindi riesce sempre più diffcile la delimitazione dei 
due piani, ciò che è afiatto logico per terreni cle si susseguono regolarmente e senza hiatus.

I banchi arenacei di questa ampia regione aquifaniana, inclinati di circa $20^{\circ}, 25^{\circ}$ od anche $30^{\circ}$ verso il Nord-Nord-Orest, per la loro durezza resistendo assai bene agli agenti esterni dànno luogo non già a colline biancastre rotondeggianti come nel vicino Langhiano, ma bensi a colline grigio-giallastre di furma grossolanamente piranidale, cioè alquanto appuntite rerso l'alto e con pendii, a superficie abbastanza regolarmente pianeggiante, inclinati di circa $55^{\circ}$ o $30^{\circ}$, specialmente rerso il Nord ed invece più ripidi verso il Sud.

Le arenarie aquitaniane i cui frammenti costituiscono talora delle vere cassere, simili a quelle che frequentemente s'incontrano nelle regioni montuose, presentano spesso degli srariatissimi disegni labirintiformi provenienti probabilmente dal morimento dell'acqua sulla fine sabbia dei bassifondi marini dell'epoca aquituiuma, fatto che si può ora facilmente osservare non solo presso le spiaggie marine ma anche presso le rire dei laghi e dei fiumi là dove il pendio della riva è piuttosto dolce e l'acqua vi ha un movimento lento e regolare di oscillazione; ciò d'altronde si verifica anche ad una certa distanza dalla spiaggia nei bassifondi sia d'acqua marina che d'acqua dolce, là dove quest' acqua presenta una specie di lenta oscillazione ritmica per cui le onde di morimento dànno alle particelle sabbiose del fondo quella speciale disposizione a rughe parallele che, coperte in seguito da altri depositi ed indurite col tempo, ci vengono conservate ancle in depositi antichissimi.

Per fatti simili a quelli ora accemnati e per locali accentramenti che aviengono nella massa degli strati, spesso queste arenarie fogliettate si presentano curiosamente incurrate a scodella, ciò che si può indicare come uno dei fenomeni secondari clie nel bacino piemontese caratterizza specialmente i terreni aquitaniani.

Ancora fra le marne arenacee dell'Aquitaniano trovansi sovente svariate impronte giallo-rossastre che sono probabilmente residui di frammenti di regetali limonitizzati. 
Le marne che, come già accennai, si alternano pure frequentemente coi banchi arenacei, quantunque molto simili a quelle langliane, in complesso però se ne distinguono per rompersi piuttosto in piccoli frammenti che non concoidemente (in causa (lell'essere più sabbiose) e per essere di colore più spiccatamente giallo-verdastro, però con numerose eccezioni. Verso la base dell'A quitaniano queste marne divengono generalmente più potenti, di un colore quasi azzurro-verdastro, acquistano maggior durezza finchè vengono a basare sui banchi arenacei che separano questo piano geologico dallo Stampiano.

In Val Scrivia l'Aquitaniano, come si è già osservato pei terreni tongriani e stampiani, a causa dello sviluppo del Liguriano verso settentrione, è obbligato a fare una brusca deviazione a Nord, restringendosi quindi di molto, tanto da presentare solo più una larghezza di quasi mezzo chilometro nell' alveo della Scrivia; quivi i suoi strati sono inclinati verso l'Ovest circa, come vedesi presso Arquata Scrivia, in Val Campora, presso C. Radmei, ecc.

Come di solito è sempre difficile ed alquanto arbitraria la distinzione tra Aquitaniano e Langhiano a causa delle ripetute alternanze di banchi marnosi grigiastri ed arenacei giallognoli.

Nell'alveo della Scrivia, osservando gli spaccati, abbastanza netti sulle due sponde, si nota che l'Aquitaniano superiormente comincia a distinguersi dal Langhiano per mezzo della comparsa di hanchi arenacei che divengono sempre più potenti e numerosi, ma che più a Sud si appoggiano a marne dure, assai regolarmente straterellate, a facies langhiana, alternate con straterelli arenacei, finchè compaiono i soliti potenti banchi arenaceo-calcari che costituiscono la base dell'Aquitaniano.

Ad Est di Val Scrivia l'Aquitaniano invece di essere costituito di arenarie fortemente cementate diventa poco a poco più sabbioso, forse perchè sono meno abbondanti i banchi calcarei delle vicine colline liguriane dal cui sfacelo in gran parte esso è formato. Tuttavia alla base del piano geologico in istudio continuano a presentarsi banchi arenaceo-sabbicsi, più o meno fos- 
siliferi, assai meno ricchi in calcare che non quelli della sponda sinistra, e quindi meno resistenti, per cui spesso per erosione ne rimangono isolate delle concrezioni di forma svariatissima. Questo fatto vedremo divenir comune più a Nord nel Tortonese, anche nella parte superiore dell' Aquitaniano, dore nel passaggio al Langhiano si osserva un complesso di banchi arenacei alternati con marne grigio-verdastre a facics langhiana, sovrapponentisi ai banchi sabbiosi, con pochi frammenti di fossili, che costituiscono gran parte dell'Aquitaniano.

I sovraccennati banchi arenaceo-sabbioso, di color grigio-giallastro, od anche leggermente rossiccio, si distinguono abbastanza bene dai sottostanti strati arenaceo-marnosi grigiastri dello Stampiano, talora anche solo col semplice esame orografico, a causa del rialzo assai spiccato a cui dànno luogo, ma inrece si collegano molto bene coi banchi arenacei che, per quanto io creda importanti, pure paionmi includibili senz'altro nell'Aquitaniano inferiore.

Una delle località in cui meglio si possono osservare questi fenomeni è la cresta Jaume dove vedesi lo Stampiano colle sue caratteristiclie marne rerdastre omogenee (a cui si sorrappongono marne arenacee dure, grigio-bleuastre), renir ricoperto da grossi banchi sabbiosi grigiastri inglobanti voluminosi accentramenti arenaceo-calcari.

La tettonica dell'Aquitaniano nella regione ora in esame mostra talora delle irregolarità, causate specialmente dalla fortissima inclinazione che presentano talora gli strati; ciò specialmente da Val Scrivia alla Masseria Valletta, dore tali strati sono spesso sollevati di $50^{\circ}, 60^{\circ}$ ed anche $70^{\circ}$ sull'orizzonte, pur conservando essi la solita inclinazione verso il Nord circa, ma spesso presentandosi ripetutamente incurrati, ed anche alterati da piccoli salti.

In Val Borbera le sabbie grigio-giallastre e grigio-rerdastre si presentano bene sviluppate; lungo l'incassato alreo del T. Borbora se ne può segnare stupendamente la serie stratigrafica e nello stesso tempo osservarvi la perfetta graduazione nel pas- 
saggio ai piani geologici sopra e sottostanti e quindi, coi soliti dubbi nella loro delimitazione.

Nelle vicinanze del paesello di Vairano si può osservare la seguente complessiva successione stratigrafica:

Langhiano Marne grigio-azzurrognole.

Banchi arenacei alternati con marne bleuastre.

Marne grigio-verdastre alternate con sabbie e

Aquitaniano strati arenacei.

Banchi sabbiosi spesso concrezionati.

Pochi ma potenti banchi arenaceo-calcari.

Stampiano $\left\{\begin{array}{c}\text { Marne grigio-bleuastre. } \\ \text { Potenti marne grigio-verdastre con interstrati } \\ \text { arenacei. }\end{array}\right.$

Sulla destra di Val Borbora i terreni aquitaniani costituendo un'ampia curva si dirigono a Nord; seguendone lo sviluppo dobbiamo sempre più convincerci della non ragionevole individualizzazione dei banchi arenacei che ne costituiscono la base; e ciò non già perchè tali banchi arenacei vengano a mancare, ma invece perchè (come d'altronde fu già menzionato per altre regioni più ad Ovest) essi divengono frequentissimi a quasi tutti i livelli dell'Aquitaniano finchè esso passa al Langhiano, ed inoltre perchè anche nella parte superiore dello Stampiano banchi affatto simili si incontrano pure, ma molto più di rado, specialmente nella conca di Garbagna; da tali fatti derivano talora dei dubbi per certi punti speciali, così ad esempio se la collina tra S. Gaudenzio e C. Castellini debba attribuirsi tutta allo Stampiano oppure, come pare più probabile, se sopporti ad Ovest una placca di terreni aquitaniani che sarebbero rappresentati dai potenti banchi arenacei giallastri, con inclinazione di circa $30^{\circ}$ verso Orest-Nord-Ovest, che quiri si osservano.

La parte media dell'Aquitaniano è, come già dissi, essenzialmente costituita di banchi sabbiosi ed arenacei grigio-verdastri o grigio-giallastri alternati con strati marnosi di color grigio- 
verdastro a stratigrafia assai regolare; nella parte superiore continuano le ripetute alternanze che costituiscono il passagoio tra questo piano geologico ed il Langhiano, quantunque quest'ultimo orizzonte, il quale contro il solito si mostra in queste regioni prevalentemente arenaceo-calcareo, per la sua durezza e resistenza agli agenti esterni si presenti molto sriluppato verso Est, sorrapponendosi talora con eridente discordanza all'Aquitaniano; in questo caso se ne distingue abbastanza bene, non solo per la stratificazione trasgressira ma eziandio per la differenza litologica abbastanza evidente, almeno in complesso, tra i banchi arenaceo-marnoso-calcarei grigio-bleuastri del Langhiano e i banchi sabbioso-arenacei grigio-giallastri del piano in esame.

Queste trasgressioni stratigrafiche che derivano da m'inclinazione dei banchi langhiani più forte di quella dei sottostanti banchi aquitaniani si possono osservare nettamente in modo speciale sulla sponda destra di Tal di Boj negli spaccati ampi e numerosi che esistono sul fianco meridionale della collina di Sorli, ed anche abbastanza bene al fondo di Tal rio Brutto, dove l'Aquitaniano appare per un tratto abbastanza esteso.

Al fondo della ralletta Angiussi, quasi sotto il Castello di Sorli, negli spaccati profondissimi che quiri esistono, notansi alcuni locali disordini stratigrafici ed appaiono banchi sabbiosi che hanno una facics alquanto simile a quella dei banchi aquitaniani, senza che però sia possibile giudicare se reramente essi debbansi attribuire a questo orizzonte geologico o se pure rappresentino solo i banchi basali del Langhiano.

Riguardo alla base dell'Aquitaniano dobbiamo notare che nell'ampia conca di Garbagna i banchi arenacei e sabbiosi molto potenti, spesso con dei fossili abbastanza ben conservati, specialmente ad Est di M. Ronzone, non di rado con delle impronte di Paleodictyon, come di fronte a Castellini, mostrano sovente lenti gliiaiose e ciottolose, però mai molto potenti nè ad elementi roluminosi; ri si rerificano spesso dei curiosissimi fenomeni di erosione. 
L'inclinazione degli strati è di circa $25^{\circ}$ verso il Nord-Ovest, ma essa si va rapidamente modificando presso la C. Del Gallo, dove per la rapida curva dell'intiera formazione i suoi banchi pendono nettamente a Sud di $30^{\circ}$ o $40^{\circ}$ circa, talrolta anzi esscndo portati quasi alla verticale, come sotto $\Lambda$ volasca; questo fatto d'altronde concorda perfettamente con quello che quivi vedemmo verificarsi nei terreni tongriani e stampiani e sempre per la stessa causa del corruganento liguriano. In queste regioni si osserva spesso una certa trasgressione stratigrafica tra i banchi aquitaniani e quelli stampiani, per essere questi gencralmente molto più fortemente inclinati di quelli. D'altronde in queste regioni, a diversi livelli del piano Aquitaniano si verificano discordanze stratigrafiche, salti, trasgressioni, ecc., ma sempre in piccola scala.

E notevole come nell'angolo di curvatura dei terreni aquitamiani questi si spingano molto avanti verso Nord-Est, costituendo quella specie di penisola che è il M. Cucco.

Nella parte media e medio-superiore dell'Aquitaniano di queste regioni i potenti banchi duri arenacei vanno divenendo sempre più rari verso il Nord ed invece vi predomina assolutamente la facies sabbiosa; ne risultano quei profondi burroni a pareti quasi verticali e continuamente variabili di forma che veggonsi specialmente sulla sinistra di Val Grue; raramente si incontrano lenti gliaiose, come per esempio verso il fondo di Val Grue, sotto C. Posola.

L'Aquitaniano dclla parte meridionale della Conca di Garbagna si presenta ad un dipresso così costituito:

1. Banchi sabbioso-arenacei, talora con qualche fossile, specialmente Dentalium; questi banchi sabbiosi assai potenti presentano molti spostamenti ed irregolarita stratigrafiche locali;

$2 .^{\circ}$ sotto di essi compaiono marne grigiastre piuttosto sabbiose, ben stratificate ed alternate con strati marnoso-calcarei di colore quasi giallo-roseo;

$3 .^{\circ}$ succedono poscia verso il basso potenti strati marnosi grigio-verdastri che ricordano quelli dello Stampiano, i quali 
dànno pure origine ad enormi burroni con pareti scoscese, a colline irregolarissimamente frastagliate, ecc.;

$4 .^{\circ}$ infine a tutto ciò soggiaciono potenti banchi sabbiosi ed arenacei a concrezioni irregolari.

Verso Nord l'Aquitaniano superiore diventa poco a poco sabbioso e poi sabbioso-marnoso; lo stesso fatto ad un dipresso verificandosi pure pel sovrastante Langhiano ne consegue che questi due piani geologici assumono una facies talmente simile da essere difficilmente delimitabili, e talora tale delimitazione si ottiene piuttosto col criterio stratigrafico cle non con quello paleontologico o litologico; in complesso però il Langhiano ha una stratificazione meno evidente ed è più argilloso che l'Aquitaniano.

Ad Ovest di Val Grue l'orizzonte in esame si va rapidamente restringendo, perde tutti i caratteri che prima lo distinguerano, diventa specialmente marnoso solo piu con qualche strato sabbioso portato quasi alla verticale, ed infine si perde completamente poco ad Ovest del Colle di Avolasca.

I passaggi tra Aquitaniano e Stampiano si possono specialmente veder bene sia osservando i potenti spaccati naturali della spouda destra di Val Grue, quasi di fronte a C. Baiarda, sia salendo da Val Grue alla borgata Oliva per la stradicciuola di C. Prago; in questo caso si vedono nettamente i banchi sabbiosi basali deli' Aquitaniano che sono sollevati quasi alla rerticale e poscia poco a poco verso l'alto assumono una-pendenza più regolare.

Nella restante parte delle colline tortonesi comprese in questo studio, come nella parte orientale delle colline Torino-Valenza, non si osserva più alcun afforamento di terreni aquitaniani in causa delle forti trasgressioni stratigrafiche che vi si osservalio.

Nelle colline Torino-Casale l'Aquitaniano è assai sviluppato, ma in causa delle potenti pressioni a cui fu soggetto e dei susseguenti dislocamenti che dovette subire, spesso gli viene a mancare quella regolarità stratigrafica che si ebbe a notare lungo i] bordo meridionale del bacino terziario piemontese. 
Già descrivendo il Tongriano delle colline casalesi si ebbe a notare che riesce per lo più moito difficile il delimitare nettamente tale terreno dalla sovraincombente formazione aquitaniana tanto piu là dove questa comincia ad apparire, come nelle colline di Camagna e di Frassinello.

In complesso si usserva che $\mathrm{i}$ depositi aquitaniani sono specialmente marnosi, mentre quelli tongriani sono in gran parte sabbioso-arenacei; tuttavia esistono numerose eccezioni a questa regola generale, per cui spesso rimangono ancora delle incertezze nella interpretazione di certe zone oligoceníche.

Per esempio paiono doversi ancora attribuire al Tongriano le formazioni sabbiose, fortemente sollevate che sopportano i banchi elveziani di Vignale; invece sono già probabilmente da porsi nell'Aquitaniano i depositi marnoso-sabbiosi che si applicano, a Nord, sulla zona liguriana di Camagna (C. della Madonna).

Le marne grigio-bleuastre tanto sviluppate nella parte settentrionale delle colline di Frassinello e di Olivola credo doversi già porre nell'Aquitaniano, costituendo così una zona che viene interrotta ad Ovest dalle formazioni elveziane di Ottiglio, ma che ricompare poco a Nord per svilupparsi quindi estesissimamente verso Ovest.

L'irregolare area aquitaniana che trovasi ad un dipresso tra i paesi di Rosignano, Sala, Treville, Ozzano e S. Giorgio, è essenzialmente costituita da marne grigie o grigio-bleuastre spesso alternate con straterelli sabbiosi, per lo più inclinati di $40^{\circ}, 50^{\circ}, 60^{\circ}$ verso il Sud-Sud-Orest in media, quantunque talora anche, ma più raramente, in senso opposto, come ad esempio presso Ozzano, sovente riesce difficile il distinguere nettamente questi terreni da quelli superiori elveziani e bisogna perciò spesso basarsi specialmente sul carattere della maggior ricchezza in calcare e quindi della maggior durezza dei banclii elveziani che formano sovente una specie di gradino sull' Aquitaniano; d'altronde non di rado i banchi dell' Elveziano sono riccamente fossiliferi, mentre quelli aquitaniani non presentano 
generalmente noteroli resti fossili. Però in alcune localitì rimangono ancora dei dubbi riguardo alla precisa linea di delimitazione tra Aquitaniano ed Elveziano, per quanto fra questi due terreni esista un notevolissimo hiatus. La presenza di numerosi banchi sabbiosi, specialmente tra C. Incanorello e C. Faretto, ed il fatto che sotto questi depositi sviluppasi direttamente il Liguriano, farebbero dubitare che quivi debba esistere una zona tongriana, però non potei raccogliere nessuna prora positiva in proposito, mentre invece l'assieme dell'affioramento ha facies aquitaniaina.

Passando ora all' esame della grande elissoide oligocenica Ottiglio-Nontalero, dobbiamo anzitutto notare che la gamba neridionale dell'anticlinale, riguardo all'Aquitaniano essenzialmente marnosa, è molto ristretta, almeno sino a Piancerreto, ed anzi sorenti è completamente mascherata dai terreni elveziani; i suoi banchi pendono di $40^{\circ}, 50^{\circ}$ a Sud-Orest circa.

Invece la gamba settentrionale si presenta molto più ampiamente sviluppata e regolare, quantunque qui, come in generale, scarseggino $i$ fossili, o siano diffcili a raccogliersi completi. In questa zona aquitaniana, larga talora oltre un chilometro, predominano come di solito le marne grigiastre talora però alternate con banchi sabbiosi; non di rado queste marne hanno un color grigio-bleuastro abbastanza caratteristico (per esempio presso S. Grato, presso C. Vategna superiore, ecc.), che gii notammo negli affioramenti precedenti.

Tra l'Aqnitaniano e l'attorniante Elveziano quantunque esista una grande lacuna, per la mancanza dell' intiero Liguriano, non si verificano però trasgressioni stratigrafiche noteroli, anzi in alcuni punti, come per esempio a Sud di Borgati Castellino ed a Nord di C. Cocconata, alla base dell'Elveziano compaiono banchi marnosi, duri, fogliettati, blenastri che già preludiano al Langhiano, che infatti vediamo comparire poco più ad Orest. L'inclinazione dei banchi aquitaniani è generalmente abbastanza forte, ciò̀ di circa $40^{\circ}$, $50^{\circ}$ rerso il Nord-Orest; nel passaggio tra Aquitaniano e Tongriano appaiono sovente sorgenti acquee dorute ai banchi arenacei di quest'ultimo orjzzonte. 
Una sezione condotta attraverso alle colline in esame comprenderebbe la seguente serie stratigrafica:

Elveziano - $\left\{\begin{array}{l}\text { Narne più o meno sabbiose, grigiastre. } \\ \text { Marne calcareo-arenacee, grigrastre, fossilifere. }\end{array}\right.$

Langhiano - Marne dure, fogliettate, grigio-bleuastre, fossilifere.

Aquitaniano - Marne, talora un po'sabbiose, grigio-biancastre, a stratificazione spesso poco evidente.

Tongriano -- Banchi sabbioso-arenacei, grigio-giallastri, con lenti o banchi ciottolosi e con interbanchi marnosi grigi.

Bartoniano - Marne e calcari concrezionati a Orbitoides, Nummulites, ecc.

Liguriano - Argille scagliose con banchi calcarei ed arenacei.

Ad Orest di Val Colobrio la zona aquitaniana continua a svilupparsi ampiamente, acquista uno spessore di oltre 500 metrí è costituita da un potente complesso di marne grigiastre u grigio-biancastre, talora a stratificazione poco evidente e spesso con aspetto farinoso viste da lontano, per modo da ricordare alquanto le marne bartoniane: dove si può osservare l'andamento stratigrafico di questa formazione si veggono i banchi marnosi, fortissimamente inclinati, cioè dí $50^{\circ}$ a $70^{\circ}$, colla solita direzione Orest-Nord-Ovest Est-Sud-Est, pendere regolarmente verso Nord-Nord-Est. Questi depositi costituiscono generalmente colline rotondeggianti, biancastre, a facies abbastanza caratteristica; inferiormente, per mezzo di un'alternanza di strati marnosi e sabbiosi, drizzati quasi alla verticale, forse stampiani, si passa ai banchi sabbioso-ciottolosi del Tongriano.

Superiormente le marne aquitaniane passano a banchi sabbioso-arenacei, spesso assai fossiliferi che costituiscono l'elevata cresta del Santuario di Crea; malgrado la facies littoranea di questo speciale orizzonte, io credo che esso si debba inglobare piuttosto nel Langhiano che nell'A quitaniano, tanto più che alla 
sua base compaiono già diversi banchi di marne dure a facies schiettamente langhiana.

Nelle colline di Val Cerrina la zona aquitaniana, colla sua solita facies specialmente marnosa, si sviluppa ampiamente, formando una specie di conca aperta a Nord-Est.

Ad Orest dell'affioramento eocenico di Montalero, le marne aquitaniane si allargano in una zona rastissima, sino alla borgata Pozzo, costituendo una specie di semielisse aperta a Nord ed i cui banchi sono spesso sollevati molto fortemente, talora persino di $70^{\circ}, 80^{\circ}$, sia a Nord-Orest (come sulla sinistra di Val Stura), sia a Sud-Est (come sulla destra di detta valle). Queste marne aquitaniane, talora alternate con strati sabbiosoarenacei, per ripetute alternanze passano gradamente al Langhiano nella parte superiore; invece pare esista un hiatus in generale tra esse ed il sottostante Tongriano, in alcuni casi anzi l'Aquitaniano va a posarsi direttamente sul Liguriano, come presso C. Cerruti. E notevole che queste marne aquitaniane assumono spesso, forse per la forte compressione subita, una facies molto simile a quella delle marne stampiane e bartoniane, come ad esempio si può redere bene specialmente salendo a borgata Casaleggio, come pure nella parte bassa delle colline ad Est di Molino S. Quirico, ecc.

Anche attorno alla elisse tongriana incompiuta di Mombello-Fabiano compaiono le formazioni aquitaniane; in questo caso pure si nota che la gamba meridionale della elisse aquitaniana è ridotta a pochi banchi marnosi tra le marne abbastanza resistenti dell'Elveziano e le sabbie tongriane. Ma nella gamba settentrionale dell' elisse in esame, mentre compaiono ben netti i banchi langhiani, si sviluppa pure estesamente la zona aquitaniana, rappresentata in gran parte da marne grigie, talora bleuastre, talora alternate con strati sabbiosi che indicano nettamente la forte inclinazione a Nord clie hanno questi depositi.

Verso Ovest l'elisse aquitaniana si chiude abbastanza regolarmente costituendo le colline Cornale-Bric Runcali; anzi in 
quest'ultima località si osservano, sulla sponda destra del Po, diversi banchi marnosi, duri, fissili, inclinati ad Est, i quali ci avvertono che quivi sta per apparire l'orizzonte Langhiano.

Le marne aquitaniane sono utilizzate talora direttamente od indirettamente per fabbrica di laterizi, come ad esempio presso il Po sotto Cornale. Esse si sviluppano poi estesissimamente a Nord nelle colline di Camino e di Brusaschetto, andandosi ad appoggiare direttamente sul Liguriano o sul Tongriano, con un' inclinazione assai forte verso Sud; ne risulta quindi una vera conca aquitaniana.

Nelle colline di Rocca delle Donne i banchi marnoso-sabbiosi dell'Aquitaniano, inclinati fortemente a Sud, inglobano pure lenti ciottolose che ricordano quelle tongriane, fatto però che redremo ripetersi ed accentuarsi più ad Orest nell'Aquitaniano inferiore.

Per la loro poca resistenza e poca compattezza le marne grigie dell'Aquitaniano furono potentemente erose dalle acque del Po e formano ora per lungo tratto lungo la sua sponda destra una serie di caratteristici burroni profondi continuamente in via di mutamento per scoscendimenti e frane in scala più o meno vasta.

L'area aquitaniana Camino-Rocca delle Donne, ora esaminata, non ci rappresenta più una ruga completa come quella di Mombello, ma bensi una semplice gamba di anticlinale $i$ cui strati pendono regolarmente di circa $40^{\circ}$ verso il Sud sopportando in alto i terreni langhiani a cui fanno gradualissino passaggio per mezzo di ripetute alternanze di strati marnosi e sabbiosoarenacei.

Gli ultimi banchi aquitaniani con inclinazione di $40^{\circ}$ a $50^{\circ}$ verso Sud-Sud-Ovest vengono a scomparire sotto gli strati marnosi duri del Langhiano, alla base delle colline di Gabiano.

Nella parte settentrionale della elisse tongriana di Villadeati, appare una semielisse aquitaniana che posa direttamente sul Liguriano; come di solito essa è costituita essenzialmente di banchi marnosi alternati con strati sabbiosi, sollevati piuttosto for- 
temente; nel passaggio al Langhiano appaiono qui, come al Santuario di Crea, banchi arenacei già forse riferibili al Langteiano inferiore; in questa zona notansi qua e là piccoli disturbi stratigrafici specialmente sopra le borgate Ferrera.

$\mathrm{Si}$ è accennato sopra come la zona aquitaniana di CaminoRocca delle Donne scompaia verso Ovest sotto ai terreni quaternari della pianura padana; però vedesi ricomparire sotto borgata Cogria allo sbocco di Val Ardorana. Quivi osserviamo clie l'A quitaniano superiore, coi suoi banchi inclinati di circa $20^{\circ}$ a Sud-Est, per ripetute alternanze di strati inarnosi più o meno duri con strati sabbiosi, passa regolarissimamente al Langhiano. L'Aquitaniano medio è essenzialmente marnoso; invece l'Aquituniano inferiore consta per la massima parte di sabbie ed arenarie più o meno cementate, passanti talora a gliaie e talrolta inglobanti pure lenti ciottolose più o meno estese.

Fra queste arenarie si trovano sovente dei fossili (Balamus, Vermetus, Pecten, Ostrea, ecc.) per lo più però logori, infranti e poco determinabili specificamente; essi serrono tuttavia ad indicarci un deposito schiettamente littoraneo.

Le lenti ciottolose, dapprina piccole e sporadiche, divengono molto potenti nelle colline di borgata Sulpiano, dove i ciottoli assumono sorente dimensioni molto considereroli; queste lenti ricompaiono, ben sviluppate, al Bric del Cerro, di cui costituiscono ad un dipresso la cresta; ma in seguito verso Sud non ne troviamo quasi più alcuna traccia.

Invece l'Aquituniano inferiore è sempre caratterizzato in que-. ste regioni da ripetuti banchi arenacei talora fogliettati o straterellati e con impronte organiche ed inorganiche srariate ( $T$ uphrelminthopsis, Paleodictyon, Helminthopsis, Nemertitithes, ecc.); talora invece tali banchi sono concrezionati in modo da formare dei grossi mamelons che ricordano molto bene quelli dell'Aquitaniano inferiore dell'Appennino settentrionale.

Questi banclii arenacei, che presso Sulpiano inclinano di $30^{\circ}$ a $40^{\circ}$ verso Est e nelle colline di Nezzalfango inclinano di $30^{\circ}$ a $50^{\circ}$ verso Nord-Est, ricordano molto nell' aspetto quelli che 
nella elissoide eo-oligocenica Montalero-Ottiglio sviluppansi sotto alle marne aquitaniane, ma che, per contenere numerose Nummuliti, credo doversi includere nel Tongriano.

Nella regione in esame non ebbi finora mai a rinvenire traccia li Nummuliti in questi bancli sabbioso-arenacei che paionmi costituire l'Aquitaniano basale.

In valle della Marca i depositi arenacei suddetti scompaiono quasi completamente per cui le marne grigio-bleuastre dell' $A$ quitaniano vengono a basare direttamente sulle marne grigie, friabili, dello Stampiano e, più ad Est, sugli stessi terreni tongriani.

E notevole che in alcuni punti, per esempio sul lato orientale del Bric Grande (Valle Ardovana), le marne dell'Aquitaniano si presentano friabili e quasi perfettamente con quella facies complessiva che notasi nella sottostante zona stampiana; ciò ci dimostra sempre più quanto poca importanza abbiano $\mathrm{i}$ carattere litologici nella delimitazione dei piani geologici.

A destra di Val della Marca la zona aquitaniana si volge a Sud; nelle colline di C. Monfavato i suoi banchi, essenzialmente marnosi, pendono di circa $45^{\circ}$ ad Est; poscia detta zona sempre più restringendosi si volge ad Ovest, per cui i suoi strati inclinano verso il Sud circa talora di $45^{\circ}$ o $50^{\circ}$ come presso Oddalengo, talora anche di $70^{\circ}, 80^{\circ}$ come presso S. Antonio nuovo. Per tal modo da Gabiano a S. Antonio la zona aquitaniana costituisce una specie di $S$ molto schiacciato d'alto in basso; la parte più tipica di tale zona si osserva specialmente in Valle Ardovana dove si può attraversare la seguente serie stratigrafica: 
Elveziano - Marne, sabbie ed arenarie.

Langhiano - Narne fissili, dure, con strati arenacei interposti.

Marne e sabbie straterellate.

Aquitaniano Narne grigio-bleuastre (zona potente).

Marne micacee, a mamelons o fogliettate; lenti ciottolose.

Stampiano - Narne grigiastre, friabili.

Tongriano - Banchi arenaceo-sabbiosi con lenti o banchi conglomeratici.

Sestiano - Strati marnosi ed arenacei con Nummulites.

Bartoniano - Marne friabili grigie o bleuastre con Nummulites, Orbitoides, ecc.

Liguriano - Argille scagliose (Flysch) con banchi calcarei ed arenacei.

Ad Orest di Val d'Arme la zona aquitaniana si mostra assai sviluppata nei dintorni di Cortiglione, di Cà di Masino, ecc. formando colline piuttosto basse a causa della sua natura essenzialmente marnosa. Queste marne grigiastre che talora racchiudono dei fossili, generalmente però difficili ad estrarsi intieri, si appoggiano abbastanza concordantemente, ma con forte hiatus, sulle arenarie tongriane; invece nella parte superiore i suoi banchi marnosi, alternandosi ripetutamente con banchi arenacei, inclinati complessivamente di circa $50^{\circ}$ a Sud, passano gradatissimamente al Langhiano che forma la cresta di Robella.

Ad Orest di borgata Vignali la zona aquitaniana subisce un profondo cambiamento nella sua costituzione, tanto che parrebbe quasi che le due diverse formazioni non possansi includere nello stesso piano geologico; ad ogni modo è certo che lia zona marnosa ora esaminata è in parte più antica dei depositi sabbiosi, arenacei e ciottolosi che appaiono ad Ovest di Vignali e tosto si sviluppano tanto da rappresentare quasi da soli l'orizzonte arritaniano. 
In questa zona di passaggio compaiono sorgenti sulfuree a confermarci vieppiù nell' idea che quivi esista un disturbo stratigrafico abbastanza notevole.

Nelle colline di Brusasco-Lauriano la zona aquitaniana è assai sviluppata quantunque i suoi banchi si presentino tutti fortissimamente sollevati ed inclinati di $60^{\circ}$ ad $80^{\circ}$ e più verso il Nord circa.

E attribuibile a questo orizzonte la placca sabbioso-ciottolosa che posa direttamente sul Liguriano presso C. La Iiossa ad List di Brusasco. I banchi sabbioso-arenacei quasi verticali, talora con irregolari concrezioni, costituiscono la cresta di S. Bernardo.

Tale zona basale dell'Aquitaniano, con predominanza dei banchi arenacei a mamelons e con varie impronte (Taphrhelminthopsis, ecc.), continua a svilupparsi verso Orest sopra allo Stampiano, finchè viene a scomparire presso Monteu da Po.

Sopra a questa striscia arenacea si sviluppa una potentissima serie marnosa, che per la sua natura frammentaria costituisce spesso basse colline e regioni a profondi burroni, come ad esempio verso lo sbocco di Val S. Fede e presso Monteu da Po. Essa ha un aspetto molto simile a quello della zona marnosa stampiana, da cui litologicamente sarebbe ben difficile a distinguersi. Anche questi banchi marnosi, interrotti solo da pochi strati sabbiosi si presentano fortemente inclinati a Nord, talora quasi verticali; nascosti per circa due chilometri dai terreni quaternari, tra Mezzana e Lauriano, ricompaiono per un certo tratto sulla sinistra di valle Abramo.

L'orizzonte superiore dell'Aquitaniano consta, come di solito, di un'alternanza di banchi marnosi, sabbiosi ed arenacei che fanno gradualissimo passaggio al Langhiano; anch' essi pendono di $60^{\circ}, 70^{\circ}$ verso il Nord all'incirca; tale zona nelle colline di Casotto (Moriondo) ingloba lenti e banchi gliaiosi e ciottolosi abbastanza fossiliferi, fatto che vedremo verificarsi frequentemente più avanti.

In complesso nelle colline Brusasco-Lauriano si osserva la 
seguente serie stratigrafica, molto simile d'altronde a quella gia indicata neile colline Verrua-Oddalengo:

Elveziand Marne, sabbie ed arenarie.

Langhiano Narne dure, fissili, con strati arenacei interposti.

Marne e sabbie ed arenarie alternate, talora coll lenti ciottolose.

Aquitaniano Narne grigie, frammentarie (zona potente).

Banchi arenacei, talora concrezionati, con impronte svariate.

Stampiano Marne grigie, friabili.

Tongriano Strati arenacei e sabbiosi alternati con strati marnosi.

Sestiano Strati arenacei con Nummulites. Bartoniano $\left\{\begin{array}{l}\text { Narne grigiastre, friabili, con interstrati are- } \\ \text { nacei, a Nummulites, Orbitoides, Lithotham- } \\ \text { nium, Zoophycos, ecc. }\end{array}\right.$

Liguriano $\left\{\begin{array}{l}\text { Alberese e di Nacigno e lenti conglomeratiche } \\ \text { allo }\end{array}\right.$ e breccioso-calcaree.

Passiamo ora ad esaminare l'ampio orizzonte aquitaniano che si estende dalla val Valle (Vignali presso Brozolo) alla Talle della Guglia (borgata Pareglio); questo orizzonte nella parte superiore per mezzo delle solite alternanze, fa graduale passaggio al Langhiano; esso è essenzialmente costituito di banchi sabbiosi. ed arenacei, spesso con lenti e strati ciottolosi, ad elementi talora voluminosissimi, come specialmente si osserva nelle colline di Casali Campolungo, Bric Carlinotto, ecc.

Sono notevoli i bellissimi banchi arenacei, spesso a mamelons, che costituiscono la base dell'A quitaniuno sotto al Castello di Brozolo (dove sono sollevati quasi alla verticale) e sviluppansi poi ancora per lungo tratto verso Orest.

I banchi conglomeratici non veggonsi mai nella parte superior'c dell'Aquitaniano, dore cioè esso passa al Langhiano, ed invece 
si spingono spesso molto verso il basso, sin quasi allo Stumpiano; dove però la serie stratigrafica è più completa si può osservare molto bene che l'Aquitaniano inferiore è rappresentato da banchi arenacei, concrezionati, tipici; ciò si può vedere magnificamente nella collina del Castello di Brozolo, dove tali banchi sono spesso inclinati di $70^{\circ}, 80^{\circ}$ verso il Sud, e sopportano i banchi sabbioso-conglomeratici.

Resti fossili sono abbastanza comuni a diversi livelli dell'esaminato orizzonte, ma specialmente in certi banchi arenacei inferiori; questi fossili sono in gran parte molto simili a quelli del piano clveziano, ed anche il loro modo di presentarsi e la facics litologica clie li accompagna (come ad esempio si può vedere presso borgata Novaresi) ricorda perfettamente la facies e la fossilizzazione dei resti racchiusi nei famosi terreni elveziani dei colli torinesi. La facics sabbioso-conglomeratica sopra descritta è quella che vedremo svilupparsi di nuovo assai bene nell'Aquitaniano superiore delle colline di Torino.

I banchi dell'orizzonte aquitcuiano ora esaminato costituiscono una leggera curva colla concavità rivolta a Sud, presentano un andamento assai regolare ed un'inclinazione media di $45^{\circ}$, quantunque essa talvolta sia minore, ma più spesso invece di oltre $50^{\circ}, 60^{\circ}$ ed anche $70^{\circ}$.

Passando ora all'esame della zona aquitaniana che avvolge ad Ovest l'affioramento Liguriano di Lauriano, tra la pianura padana e l'alta val rio Freddo, la vediamo costituita ad un dipresso come l'ultima zona ora descritta, cioè in massima parte di banchi sabbiosi ed arenacei, grigio-giallastri o grigio-brunastri, spesso però alternati con potenti banchi marnosi grigiastri.

Anche in quest' area aquitaniana si può distinguere: $1 .^{\circ} \mathrm{un}$ orizzonte inferiore, costituito prevalentemente di grossi banchi arenacei concrezionati e di banchi sabbioso-arenacei con resti fossili e con lenti ghiaiose e ciottolose, spesso ad enormi elementi; 2..$^{\circ}$ un orizzonte medio specialmente uarnoso grigiastro con interstraterelli arenacei; $3 .^{\circ}$ un'alternanza più volte ripetuta di strati sabbiosi, marnosi ed arenacei che passano gradatissimamente al Langhicano. 
In fondo al rallone di S. Maria, presso C. Vallo Sotto, vedonsi affiorare in anticlinale diversi banchi arenacei e conglomeratici, talora fossiliferi, i quali rappreséntano l'Aquitaniano inferiore che quivi forma volta, inclinardo $i$ suoi strati in parte a Sud-Est ed in parte a Nord-Ovest, mentre nella parte alta, presso C. Tallo Sopra, i banchi si presentano in parte quasi orizzontali; in complesso si può dire che la zona aquitaniana, malgrado le numerose curve che è obbligata a fare per seguire l'andamento dei terreni eocenici sottostanti, presenta una tettonica assai regolare che s'accorda perfettamente con quella dei sorrastanti terreni langhiani ed clveziani.

Questa zona aquitaniana che con graduale passaggio viene superiormente coperta dai banchi marnosi, duri del Langhiano, si collega perfettamente e senza salti colla gamba meridionale dell' anticlinale eo-oligocenico di Lauriano-Brozolo, congiungendosi così colle zone aquitaniane delle colline casalesi.

La grande ed incompiuta semielisse aquitaniana ora esaminata presenta poi ancora a Nord-Orest una semielisse secondaria che vedremo spingersi sino alle colline fronteggianti la pianura di Chirasso; così pure a Sud-Orest la semielisse aquitaniana presenta, rispetto ai suoi banchi superiori, un'altra soluzione di continuità nelle colline di C. Lazzarino, poichè quivi l'area ora esaminata si collega con quella più occidentale che vedremo svilupparsi poi tanto ampiamente e senza alcuna interruzione sin presso Torino.

Come sempre i resti fossili, non rari specialmente nei banchi arenacei e ciottolosi, sono per lo più difficili ad estrarsi completi; se me incontra specialmente presso la borgata Colombaro, sotto borgata Torrione, al fondo di Tal della Guglia sotto borgata Pareglio, ecc.

Se si segue la zona aquitaniana, ora esaminata, nel suo sriluppo rerso Nord-Orest si vede che essa, colla costituzione sopra accennata, costituisce le colline di Colombaro con un'inclinazione di $30^{\circ}$ a $70^{\circ}$ verso il Sud-Orest; presenta fossili fra le sabbie e le lenti ciottolose di borgata Colombaro, fra le sabbie del Mo- 
lino nuovo ecc. Poscia la zona aquitaniana scompare completamente sotto ai terreni quaternari per ricomparire a poca distanza, più ad Ovest, nelle colline di Chivasso, dove si chiude l'elisse aquitaniana di cui abbiamo finora esaminato il lato settentrionale e meridionale.

In quest' area aquitaniana di Castagneto, dal paesello che vi è in parte fondato, abbiamo un'anticlinale (costituentesi in regolare curva verso Ovest) così stretta che solo pochi orizzonti di questo piano geologico possono venire a giorno ed inoltre vi si nota pel' lungo tratto un hiatus tra l'Aquitaniano ed i terreni sovrastanti, mancando generalmente tutto o gran parte del Langhiano.

Nell'affioramento aquitaniano di Castagneto lì dove esso ̀̀ più sviluppato, come sulla destra di Val S. Genesio, si possono distinguere tre orizzonti principali, cioè: $10^{\circ}$ uno inferiore essenzialmente arenaceo, con lenti ciottolose, spesso a grossissimi elementi, e talora con numerosi fossili, come presso C. Villar, verso lo sbocco di Val S. Genesio; è la continuazione di quello di borgata Colombaro, ma scompare tosto verso Ovest; $2 .^{\circ}$ un orizzonte medio essenzialmente marnoso, con interbanchi arenacei, e che è assai sviluppato sulla destra di Val S. Genesio; $3 .^{\circ}$ un orizzonte superiore, sabbioso-arenaceo, talora inglobante lenti ciottolose, ad elementi talora voluminosissimi (fra cui predominano le Serpentine ed i Calcari alberesi); questo orizzonte è specialmente sviluppato verso Ovest nelle colline di Castagneto e di S. Genesio, perchè quivi i terreni formando curva sono meno ristretti e vengono quindi ad affiorarvi molti banchi che prima non apparivano affatto; tale orizzonte superiore passa gradatissimamente in alto al Langhiano.

I fossili non sono rari qua e là, specialmente fra le arenarie, come ad esempio presso V. Gilardini, ma come di solito non molto ben conservati, e per lo piǹ d'indole littoranea e di mare poco profondo.

La tettonica dell' Aquitaniano in esame si presenta piuttosto regolare essendo gli strati delle due gambe dell'anticlinale in- 
clinati, in senso opposto, di circa $30^{\circ}$ a $45^{\circ}$, con una direzione abbastanza costante la Nord-Jist a Sud-Ovest; la gamba meridionale presenta un molto maggior sviluppo in ampiezza che non quella settentrionale la quale viene in massima parte ricoperta trasgressivamente e direttamente dai terreni elveziani; a Sud invece essendo la serie stratigrafica meno ristretta si veggono affiorare alcuni dei banchi marnoso-arenacei duri del Langhiano tra l'Aquitaniano e l'Elveziano.

Verso Ovest gli strati aquitaniani seguono la curva regolare dell'elissoide e quindi presentano inclinazioni di solo $15^{\circ}, 10^{\circ}$; la curva dell' elisse si trova poco a Sud della Cappella S. Grato, e quindi si può dire che il grand'asse della zona elissoidale esaminata trovasi portato completamente a Nord di detta zona, almeno apparentemente.

Inferiormente i terreni aquitaniani in esame basano, sempre con fortissimo hiatus, sia sul Tongriano sia sul Bartoniano, con discordanze stratigrafiche più o meno forti.

La grande zona aquitaniana che possiamo appellare di Bersano-Aramengo-Marmorito, la quale vedemmo collegarsi regolarmente a Nord coll' elissoide aquitaniana di Lauriano per l'anticlinale secondario di C. Nazzarino e clie vedremo srilupparsi notevolmente ad Ovest nei colli torinesi, si presenta specialmente costituita di bancli marnosi potenti, numerosi, che per la facile loro disaggregazione danno origine a regioni collinose caratteristiche per enormi e scoscesi burroni, continuamente in via di inutazione, ricordando assai bene le colline stampiane della zona subappennina, specialmente di Val Bormida.

L'inclinazione di questi strati niarnosi grigio-bleuastri frammentari, non sempre però ben osservabile, è generalmente assai dolce, giacclıè se essi verso la periferia della zona pendono di $40^{\circ}$ o $50^{\circ}$, verso il centro invece, cioè nelle colline di S. Rocco, di C. Bruno, di C. Saretto, di C. Massa, ecc. presentano solo più inclinazioni di $15^{\circ}, 20^{\circ}$ in media, talvolta ancora di oltre $30^{\circ}$, talora invece di solo $5^{\circ}, 10^{\circ}$; questi banclii colle loro varie inclinazioni verso il centro della zona in esame indicano che esiste una specie di 
cupola di sollevamento nei dintorni di borgata La Tana, o meglio un'ampia anticlinale diretta ad un dipresso da Nord-Ovest a Sud-Est. Verso Sud-Est le due gambe dell'anticlinale si staccano, direi, sviluppandosi l'una in Val Fredda e l'altra nell'alta val Fabiasco.

Come di solito nella parte superiore dell'Aquitaniano ai ballchi maruosi facilmente disaggregabili si alternano strati marnosi ed arenacei duri che costituiscono graduatissimo passaggio al Langhiano.

Oltre ai banchi marnosi compaiono talora nella zona aquitaniance banchi o lenti ciottolose franmezzo a sabbie ed arenarie; talora anzi i ciottoli sono voluminosissimi, cioè di uno o due metri, talora persino di 3 metri di diametro.

Questi fatti si possono osservare bene specialmente tra borgata Braja ed il Molino del Rocco, sulla sinistra di Val Fabiasco, dove predomina l'Aquitaniano sabbioso, che con facies simile continua però ancora a svilupparsi nelle colline di Marmorito e di borgata Bignona.

Le marne aquitaniane sono grigiastre, a rottura concoide e non frammentarie, almeno in generale, come quelle dello Stampiano.

Nella parte alta del vallone di Frascorina i banchi sabbiosi, arenacei e ciottolosi presentano talora dei salti stratigrafici causati dalle forti compressioni a cui andarono soggette tali formazioni.

Resti fossili si trovano, come di solito, specialmente nei banchi sabbioso-arenacei, così in Val Frascarina negli strati inclinati di $40^{\circ}, 50^{\circ}$ ver'so Nord-Ovest (specialmente fra i banchi ghiaiosi) che appaiono potentemente sviluppati particolarmente nei valloni tra C. Goreja e Molino del Rocco (Cocconato) e là dove la zona aquitaniana colle sue lenti ghiaioso-ciottolose attraversa la val Fabiasco, quivi essendo molto comuni i resti di Ostrea. Balanus, Vermetus, Pecten, ecc.

Già osservammo come in generale la tettonica dell'area aquitaniana in esame sia abbastanza regolare e le pendenze non 
molto forti; però qua e là verso la periferia di quest'area, come per esempio tra Bric Auzano ed Aramengo gli strati, con direzione ad un dipresso da Nord-Orest a Sud-Est, pendono di $60^{\circ}, 70^{\circ}$ e più verso il Nord-Est.

Na attorno allo spuntone Tiguriano di Marmorito i terreni aquitaniani si riducono molto in spessore e nello stesso tempo, per il potente sollevamento a cui andarono soggetti, presentano inclinazioni di $70^{\circ}, 80^{\circ}$ e più, verso Nord-Est nelle colline di Cocconato, verso Sud-Est in quelle di Marmorito, verso Orest circa in quelle di Albugnano.

La zona aquitaniana che si stende dalle colline di Bersano a quelle di Gassino ci rappresenta una regolare anticlinale, diretta ad un dipresso da Est ad Ovest, costituita verso la parte periferica e superiore da strati marnosi ed arenacei passanti gradualmente al Langhiano, e nella parte inferiore e centrale da potenti banchi marnosi facilmente disaggregabili e che quindi come sempre producono profondi e imutevoli burroni.

I'inclinazione degli strati, diretta verso Nord nella gamba settentrionale, e verso Sud nella gamba meridionale dell'anticlinale, è di circa $30^{\circ}$ in media nell'Aquitaniano superiore, quantunque sia talora di $50^{\prime \prime}$ o $60^{\circ}$, come in alcuni punti tra Cinzano e Bersano, ma anche solo di $10^{\circ}$ a $20^{\circ}$ come tra Sciolze e Rivalba; nella parte centrale inferiore della zona aquitaniana in esame costituendosi la curva regolare dell' anticlinale, i banchi marnosi assumono inclinazioni sempre più deboli, diventando talora quasi orizzontali verso l'asse maggiore dell'anticlinale; ciò si può osservare specialmente bene lungo la cresta collinosa che conduce da Cinzano a Villa Boccardo, come pure poco a Nord di Bersano ed in fondo alla valle Maggiore.

Infine l'nltima ed importante zona aquitaniana che abbiamo ad esaminare è quella che, a forma di bellissima e regolare elisse, interrotta solo per un breve tratto tra Rivalba e Tetto Sachero, si prolunga dalle colline di Bric Martina sino a quelle di S. Nargherita presso Torino, coll' asse maggiore della lunghezza di 15 chilom. ad un dipresso e con un diametro trasversale di circa 2 chilometri e mezzo. 
Il grand'asse reale di quest' elisse, quello cioè che corrisponde alla cresta anticlinale data dalla stratigrafia, trovasi portato notevolmente più a Nord-Ovest del grand' asse apparente della zona elissoidale che stiamo per esaminare; ciò, oltre che dalla stratigrafia, è pure indicato dal fatto che i banchi costituenti la gamba settentrionale sono in generale molto più fortemente sollevati, molto meno sviluppati ed assai più schiacciati che non quelli della gamba meridionale dell'anticlinale in questione; lo stesso rapporto esiste pure fra i banchi stretti, schiacciati, fortemente-inclinati, che costituiscono la curva orientale dell'elissoide e quelli più espansi, più sviluppati, a pendenza più dolce che formano l'arco occidentale di questa elissoide.

I' orizzonte aquitaniano in esame è marnoso, sabbioso ed anche ciottoloso, ma ad elementi per lo più non tanto fortemente cementati da costituire un vero conglomerato, eccetto che in località particolari.

Nella metà orientale dell'elissoide in questione, cominciando ad un dipresso dal punto di emersione dei banchi conglomeratici tongriani, i banchi aquitaniani, fatta eccezione dei banchi marnoso-arenacei duri che costituiscono il passaggio al Langhiano, sono essenzialınente marnosi o marnoso-sabbiosi, grigiobiancastri; a costituzione omogenea, poco resistenti, spesso alternati con strati arenacei, talvolta inglobanti qualche resto fossile (Balantium, Ostrea, ecc.); hanno cioè una facies complessiva ricordante quella dello Stampiano di Val Bormida di Spigno; essi sono facilmente erodibili e quindi formano spesso profondi burroni.

Invece nella parte cocidentale dell' elissoide, al disopra dei descritti banchi marnosi, formanti la loro curva in Val Rivadora ad un dipresso, si sviluppano ampiamente potenti banchi arenacei, ghiaiosi e ciottolosi, alternati con potenti banchi o complesso di banchi marnosi, costituendo cosi diversi suborizzonti in parte di deposito tumultuoso ed in parte di deposito tranquillo.

Talvolta veggonsi i ciottoli sparsi irregolarmente frammezzo ai banchi sabbioso-marnosi; talvolta si osservano, come per esem- 
pio nei valloni ad Ovest di Superga, banchi conglomeratici cementatissimi; i ciottoli, fra cui, come al solito, sono comunissimi quelli di Serpentina e di Calcare alberese, raggiungono spesso moli molto considerevoli, cioè di uno, due e talora anche di oltre tre metri di diametro.

Questi terreni sabbioso-ciottolosi si assottigliano rapidamente verso Est venendosi a sovrapporre all' orizzonte marnoso sovraccennato che rappresenterebbe quasi l'Aquitaniano inferiore, e, ridotti a qualche banco, vanmo finalmente a scomparire quasi completamente nelle colline di Castiglione a Nord ed in quelli di Tetti Varetti a Sud; quindi a rappresentare l'Aquitaniano rimangono quasi solo più le marne grigiastre, friabili e scagliose.

Per citare un esempio sulla costituzione dell' area in esame, possiamo indicare che attraversando le colline da Nord a Sud, dalla Villa Sambuy sino all'anticlinale stratigrafico, rediamo ad un dipresso la seguente sezione:
'Strati marnosi e sabbiosi grigiastri o bleuastri
Elveziano $\left\{\begin{array}{l}\text { con qualche letto ghiaioso, inclinati dapprima } \\ \text { di soli } 45^{\circ} \text { o } 50^{\circ} \text { rerso Nord, poi poco a poco } \\ \text { sin di oltre } 70^{\circ}, 75^{\circ} \text {; colla fauna di Superga. }\end{array}\right.$
Langhiano S Marne dure, grigio-bleuastre, con qualche strato arenaceo e lenti ciottolose.
Banchi sabbioso-ciottolosi ad elementi talora ro-
Aquitaniano $\left\{\begin{array}{c}\text { luminosissimi. } \\ \text { Narne grigio-verdastre, frammentarie, con in- }\end{array}\right.$ terstrati arenacei.
Tongriano conglomerati, talora rossastri per decomposi- zione.
Potenti e cementatissime arenarie alternate con

Credo inutile di fare una minuta descrizione di questa vasta zona aquitaniana che si può esaminare assai bene specialmentc nelle colline di Superga, e nei valloni che le intercidono profondamente da ogni lato. Sono però in particolar modo degni 
di esser percorsi i valloni di Serralunga per i loro stupendi banchi conglomeratici ripetutamente alternati coi banchi marnosi ed arenacei, tutti inclinati verso Ovest a valle e verso Sud a monte; inoltre il vallone che dal paesello di Rivodora sale sin quasi a Superga, poichè quivi si può osservare il passaggio graduatissimo dello Stampiano all'Aquitaniano.

Infatti mentre tra l'Aquitaniano ed il Tongriano in queste regioni esiste generalmente un hiatus, esaminando la formazione stampiana di Rivodora (costituita di strati marnosi friabili e di strati arenacei straterellati) si vede, verso lo sbocco del vallone di Superga, che essa passa poco a poco a potenti banchi sabbiosi ed arenacei, spesso a facies tongriana e con impronte svariate, simili a quelle dello Stampiano; inoltre vi si incontrano pure sovente fossili, specialmente Orbitoides, Operculina complanuta var. ecc. Poco a poco verso l'alto la serie dei terreni assume gradatamente la facies più schiettamente aquitaniana; i banchi ciottolosi divengono più potenti e più frequenti; compaiono grandi zone marnose e si passa sovente a potenti zone sabbioso-conglomeratiche, spesso ad enormi elementi.

Quindi nel complesso la serie stratigrafica di questa interessante regione è la seguente:

Marne, sabbie e conglomerati della parte alta delle colline di Superga.

Marne e straterelli arenacei grigiastri (pila potente).

Aquitaniano

Conglomerati ed arenarie alternate irregolarmente.

Marne, sabbie ed arenarie straterellate ed alternate con banchi ciottolosi.

Stampiano Marne grigiastre ed arenarie straterellate.

Tongriano Conglomerati potenti, rossastri.

La zona delle marne è quella che si conserva più a lungo verso Est, spesso rappresentando da sola l'orizzonte aquitania- 
no; le zone inferiori e superiori conglomeratiche invece vanno a scomparire ad Est nelle colline di Bric Pietraforata e di Castiglione.

In val Rivodora si può osservare assai bene come anche i bauchi superiori dell' Aquitaniano, quelli cioè passanti al Langhiano, si presentano talora ciottolosi. Anche i valloni di Reaglie e di S. Martino, ma specialmente quello di Mongreno, ci mostrano una serie di ampie e profonde sezioni nella potentissima serie aquitaniana.

I fossili aquitaniani sono abbastanza frequenti, specialmente fra i banchi sabbioso-ghiaiosi, e particolarnente poco sotto ai terreni langhiani, ma per lo più non sono molto ben conservati e quasi sempre difficili ad esportarsi completi; spesso poi sono già logorati e frammentati; abbondano specialmente Ostriche, Serpule, Vermeti, denti di Squalo, ecc., cioè in generale fossili di mare basso o di littorale.

Ebbi talora anche a rintracciare qualche impronta di Zoophycos nei banchi duri che fanno il passaggio al Langhiano, così per esempio presso C. Ravera (Sciolze).

Fra i fossili più importanti dell' Aquitaniano, dobbiamo notare i Foraminiferi, sia perchè si incontrano abbastanza comunemente quasi ovunque, sia perchè trovansi per lo più ancora in buon stato di conservazione; sono specialmente ricchi in foraminiferi certi speciali banchi arenacei, ad esempio quelli della cresta di Bric Pietraforata-Bric Cerret.

L'andamento stratigrafico dell' elissoide aquitaniana esaminata ¿̀ assai regolare per quanto sia varia nelle varie sue parti la inclinazione e la direzione dei banchi che la costituiscono; l'asse dell'anticlinale stratigrafico trovasi portato notevolmente a NordOvest del grand'asse apparente della elisse in questione e si potrebbe indicare ad un dipresso con una linea tirata dalle vicinanze di Villa Paradiso, presso Torino, alla C. Laurenti, nelle colline di Bussolino torinese. Tuttaria, com'è naturale, vi sono varianti notevoli rispetto a questa linea anticlinale, sia tra luogo e luogo, sia specialmente tra l'alto delle colline ed il fondo dei 
valloni. Così per esempio in val Rivadora l'anticlinale trovasi tra Rivadora e Tetti Trivero; nelle colline di Superga vedesi poco sotto la Stazione della ferrovia funicolare, per modo che la parte superiore della collina di Superca è costituita di banchi sabbioso-ciottolosi che già appartengono alla gamba meridionale dell'anticlinale; al fondo della valle di Mongreno la parte superiore dell'anticlinale trovasi presso lo sbocco del Rio Serralunga, e così via.

L'inclinazione degli strati, diretta naturalmente in senso opposto nelle due gambe della grande anticlinale, è in generale assai più forte nei banchi della gamba settentrionale che in quelli della gamba meridionale; infatti nella prima osservansi spesso delle inclinazioni di $60^{\circ}, 70^{\circ}, 80^{\circ}$, specialmente dalle colline di S. Mauro verso Est, mentre nella seconda gli strati sono per lo più inclinati solo di circa $30^{\circ}$ in media, quantunque ad Est della valle Maggiore di Gassino assumano ancle pendenza di $60^{\circ}, 70^{\circ}$ e più, collegandosi così assai bene, anche nell' andamento stratigrafico, coi banchi della gamba settentrionale nella stretta curva di C. Isaurenti.

Nella valle Maggiore di Gassino, specialmente nella sua parte sinistra, i banchi marnosi della gamba meridionale presentano un'apparente soluzione di continuità, sviluppandosi verso Est come già osservammo altrove, a guisa di anticlinale laterale, e quindi in questa regione le inclinazioni sono in alcuni punti debolissime.

Nella parte occidentale dell' elissoide aquitaniana in esame le inclinazioni sono in generale di solo $20^{\circ}$ o $30^{\circ}$ ed ancle minori, specialmente nella curva della elisse, essendo tale curva piuttosto ampia e regolare.

Ovunque nella parte superiore dell' Aquitaniano osservasi una alternanza di strati marnosi duri con strati marnosi poco resistenti e con strati sabbiosi ed arenacei costituenti nello assieme un graduale passaggio tra questo piano geologico ed il soprastante Langhiano.

In complesso quindi si può dire che l'Aquitaniano dei colli torinesi presenta la seguente costituzione generale: 
Elveziano $\left\{\begin{array}{c}\text { Narne, sabbie e conglomerati, spesso riccamente } \\ \text { fossiliferi (fauna di Superga). }\end{array}\right.$ Langhiano Marne dure, scagliose, bleuastre.

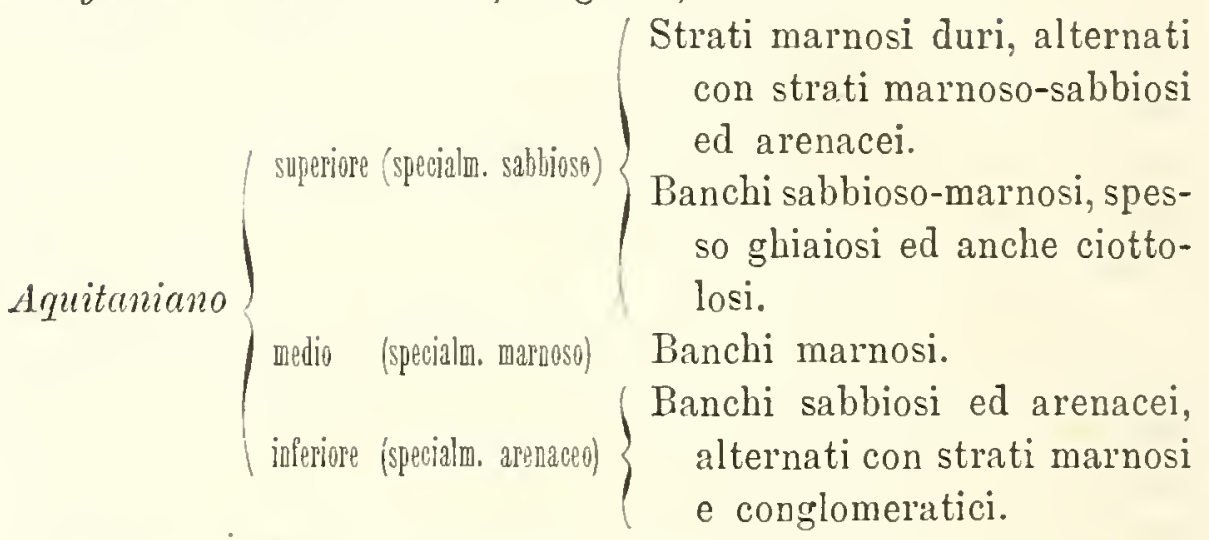

Stampiano Marne friabili con straterelli arenacei.

Banchi arenaceo-conglomeratici.

Banchi marnosi.

Tongriano Banchi arenaceo-conglomeratici.

Banchi marnosi.

Banchi arenaceo-conglomeratici.

Banchi marnosi.

Sestiano Banchi arenaceo-conglomeratici.

Bartoniano $\left\{\begin{array}{l}\text { Marne grigiastre con strati calcarei e calcareo- } \\ \text { arenacei (Orbitoides, Nummulites, Lithotham- } \\ \text { nimm, ecc.). }\end{array}\right.$

Liguriano Marne argillose rosso-verdastre.

Risulta quindi come l'Aquitaniano delle colline torinesi, quantunque per la sua facies essenzialmente di basso fondo marino debba considerarsi, a mio parere, come un unico piano geologico, tuttavia per la sua straordinaria potenza (oltre 2000 metri) e per i frequenti banchi marnosi costituenti talora rari orizzonti, possa ragionevolmente esser scisso in diversi sottopiani. 
Riussunto.

Volendo ora riassumere in breve ciò che osservammo riguardo al piano aquitaniano così importante e così sviluppato nel bacino piemontese, possiamo dire come tale terreıo, non stato finora mai distinto dagii altri terreni miocenici, eccetto che per opera del Nayer nella parte Sud-Est del bacino in esame, rappresenta in complesso, coi suoi strati sabbioso-arenacei e conglomeratici, un deposito di bassofondo marino o di littorale, quantunque racchiuda anche orizzonti secondari intermedi a facies di deposito di mare abbastanza profondo e tranquillo.

Questo terreno costituisce una larga fascia nella parte meridiomale ed orientale del bacino terziario del Piemonte, manca in gran parte dei colli tortonesi e forma diverse elissi più o meno complete nelle colline Torino-Casale.

La formazione aquitaniana è esselizialmente costituita a Sud da marne sabbiose e da arenarie, verso Nord invece da marne, sabbie, arenarie e spesso da banchi conglomeratici.

L'andamento stratigrafico del terreno esaminato ci si presentò ovunque assai regolare, malgrado locali perturbazioni, cioè i banchi aquitaniani delle Langhe, del Monferrato e del Tortonese inclinano, generalmente, di poclii gradi, verso l'interno del bacino. Nelle colline Torino-Casale invece si presentano sotto forma di anticlinali, a banchi fortemente sollevati, spesso costituendo elissoidi di sollevamento più o meno allungate, più o meno complete, spesso anche ripetute e parallele, indicando ripetuti ripiegamenti formatisi in direzione parallela all'asse principale di sollevamento di dette colline.

Si è notato come la pila dei terreni aquitaniani, in generale di spessore molto notevole, raggiunga nelle Langhe una potenza di oltre 2500 metri e nelle colline torinesi di oltre 2000 metri, sollevandosi là a quasi 900 metri e qua a poco piǹ di 650 metri sul livello marino. 
Quasi ovunque si è potuto osservare un regolarissimo passaggio tra $\mathrm{i}$ terreni aquitaniani e quelli stampiani in basso e quelli langhiani in alto per mezzo delle solite alternanze cle servono a collegare la facies di un orizzonte geologico con quella dell' orizzonte vicino. Si è però osservato come nelle colline TorinoCasale i banclii inferiori dell'Aquitaniano basino per lo più direttamente e trasgressivamente sui terreni oligocenici od eocenici, collegandosi invece senza salti ai terreni langhiani, ciò che ci indica una differenza notevole nei morimenti di suolo tra la parte meridionale e quella settentrionale del bacino terziario del Piemonte.

Nei terreni aquitaniani del bacino piemontese, specialmente nei banchi arenacei ed in quelli calcarei, trovansi abibastanza numerosi $i$ fossili, specialmente di littorale, ma quasi tutti infranti o mal conservati e quindi di difficile determinazione. In generale, tali fossili si collegano più strettamente con quelli elveziani che con quelli tongriani, pur presentando forme di ambedue questi piani geologici. 


\section{CAPITOLO X. \\ I.ANGHIANO. \\ Studi anteriori.}

Dobbiamo fare su questo terreno quasi le stesse osservazioni ehe gii faeemmo lispetto all'Aquitaniano, ehe eioè ad cceczione dell'angolo Sud-Est del baeino terziario piemontese, dove la presenza del Langhiano venne gia indieata dal Mayer nella sua nota sulla geologia della Liguria oeeidentale, in tutto il restante baeino questo terreno venno finora inglobato senz'altro nel Mioeene; eiò risulta sia dagli seritti dei vari geologi ehe trattarono di questi terreni, sia dalla earta geologiea del Sismonda. Nella reeente earta geologiea della Liguria di Issel, Mazzuoli e Zaceagna i terroni langhiani vennero, assieme a quelli aquitaniani, elveziani o tortoniani, indieati con una sola tinta, sotto il nome di Mioeene medio.

Chi però intuì meglio lo sviluppo di questo terreno nel bacino in esame fu il Pareto, al quale anzi dobbiamo la istituzione del nome di Langhiano, quantunque nel eonectto di detto geologo (per quanto si può desumere dai suoi seritti) questo nome avesse un signifieato assai più esteso di quello ehe oggi s'intenda; infatti vediamo il Pareto indicaro sovente eome langhiani depositi attribuibili invece sia all'Elveziano, sia spceialmente all'Aquitaniano; d'altronde nelle Langhe il tipico orizzonte langhiano, quale ora si intende, è ridotto a ben poea eosa.

Dal lato paleontologieo i banehi langhiani, speeialmente dei colli torinesi, fornirono gia una gran copia di matcriale (partieolarmente in Filliti e in Pteropodi) sgraziatamente stato finora eonfuso eon quello dell'Elveziano sotto il nome eompreensivo di Hioeene medio.

\section{Generalità.}

Il Langhiano prescnta nel baeino piemontese una facies, piuttosto eostante e earatteristiea, di tranquillo deposito di mare abbastanza profondo; talvolta, è vero, per l'egioni anehe notevolmente estese, questa facies viene in parte sostituita, corne vedremo, da quella di mare basso, ma in eomplesso non ne rimane alterato il caratterc prineipale sopraenunciato.

I terreni che eostituiseono il Langhiano sono speeialmente marnosi, ma di durezza molto variabile sceondo le regioni in eui si osservano; giaeehè talora essi sono poeo resistenti, quasi farinosi e faeilmente frammentari per modo da dar origine a eolline rotondeggianti, piuttosto bassc, oppure a vallate più o meno ampie; talora inveee $i$ banehi 
Tanghiani sono duri, scagliosi, sia per la compressione subita, sia per noterole ricchezza in materiale calcareo; in tal caso questi terreni sono, in generale, non molto potenti e costituiscono spesso le creste più elerate e ripide delle regioni collinose.

Il colore predominante dei depositi langhiani è il grigiastro, passante talora al grigio-bleuastro e talora al grigio-giallastro, ciò che è in rapporto colla sua natura.

In alcuni casi, che arremo occasione di esaminare, l'orizzonte presenta non solo una facies di deposito di basso fondo, ma persino lenti ciottolose, ciò che sembra in correlazione alla vicinanza di catene montuose, rcrificandosi specialmente nelle colline torinesi.

\section{Caratteri paleontologici.}

Siccome il Langhiano è generalmente un deposito tranquillo di mare alquanto profondo, $i$ fossili che ri si trorano racchiusi si distinguno o per una facies d'alto fondo o per una facies pelagica; cosi abbondano specialmente i Pteropodi [come Traginella (T'. Calandrelli), Balantium (B. pedemantanum, B. pulcherrimum) ece.], certe forme di Lamellibranchí [così Nucula, Solenomya (S. Doderleini), ecc.], alcune speciali forme di Gasteropodi, qualche Crostaceo, resti di Echinidi, spesso tutto ciò fortemente compresso, schiacciato, raramente ben determinabile.

Un fatto paleontologico importantissimo ed abbastanza caratteristico dei terreni lanyhiani di certe parti del bacino terziario piemontese è la ricchezza in resti regetali, specialmente in filliti; ciò è naturalmente in rapporto colla tranquilliti del deposito che li rachiude; infatti si comprende come in tali condizioni le foglie delle piante rirenti nei dintorni del bacino in esame, venendo trasportate dal rento o dalle correnti terrestri sino al mare, inzuppandosi quivi d'acqua poco a poco, si poterono depositare gradatamente sul suo fondo, senza quasi renire alterate.

Taturalmente lả dore, cone redremo, l'orizzonte langhiano assume una facies di basso fondo o di littorale. quiri anche i caratteri paleontologici variano assai arricinandosi molto a quelli dell Elreziano, tanto che talora (come tra Castino e Bobbio in Tal Bormida di Millesimo) ri si trorano persino Paleodictyon, impronte d'indole littoranea o di basso fondo, tanto commi sulle arenarie elveziane.

\section{Distribuzione geografica.}

Come il terreno aquitaniano, il Langhiano comincia ad apparire, nella porzione Sud-Orest del bacino terziario del Piemonte, nelle colline di Mombasiglio presso Cera, sotto forma di sottili banchi marnosi che divengono tosto potenti e caratteristici litologicamente e paleontologica- 
mente su ambi i lati dell'alveo del Tanaro. In seguito però i terreni langhiani assumono tosto una facies prevalentcmente sabbiosa o sabbioso-marnosa e la conservano attraverso a tutta la vasta regione collinosa delle Langhe, che essi tagliano obliquamente, seguendo in complesso il fianco sinistro della valle della Bormida di Millesimo; anzi l'andamento di questa valle, da Monesiglio ad Acqui circa, dipendo molto, a mio parere, dall'andamento stratigrafico dei terreni tcrziari nei quali è incisi.

Dopo aver costituito una specie di espansione in Val Belbo l'orizzonte langhiano dalle colline di Vesime si dirige verso l'Est, formando col suo affioramento una specie di nastro abbastanza regolare attorno ai terreni oligocenici già studiati. La zona langliana così poco espansa e così poco caratteristica nella regione delle Langhe, diventa invece potente, ampia, tipica, eminentemente marnosa da Cessole (ancora però nelle Langhe) attraver'so le colline del Monferrato sino alle colline tortonesi, solo restringendosi alquanto qua e la, cosi presso Trisobbio a causa di disturbi stratigrafici che quivi si verificano.

Ad Est della valle della Scrivia l'orizzonte langhiano, come d'altronde quivi mostransi tutti i ter'reni telziari, costituisce un'ampia curva per' cui poco a poco esso assume una direzione ver'so Nord, finchè, per il corrugamento liguriano Brignano-Spinetto, detto olizzonte è obbligato quasi di tratto a volgersi verso Ovest, scomparendo poi poco dopo sotto ai terreni tortoniani.

Nelle colline tortonesi che fanno parte del presente lavoro mancano affatto i terreni langhiani, ma essi ricompaiono e si sviluppano poi assai notevolmente verso Est.

Nella parte orientale delle colline Torino-Valenza il Langhiono non viene ad affiorare in alcun punto trovandosi coperto discordantemente dall'Elveziano od anche dai terreni più giovani; ma già nelle colline a Sud di Casale rediamo comparire qua e lì tra i banchi elveziani e quelli aquitaniani strati calcareo-marnosi, duri, scagliosi, attribuibili al Langhiano il quale orizzonte poco più ad Ovest si delimita e si sviluppa meglio e costituisce, in tutta la restante regione eollinosa sino a Torino, una specie di cerchio più o meno completo, generalmente piuttosto sottile, che fascia gli affioramenti aquitaniani.

I caratteristici banchi langhiani sono assai utili al geologo che studia le colline Torino-Casale servendo spesso assai bene di chiare, direi, per distinguere facilnente i depositi aquitaniani da quelli elveziani, talora litologicamente poco dissinili, e quindi anche per conosecre la tettoniea non scmpre semplice di questa interessante regione. 


\section{Tettonica.}

Nella parte meridionale del bacino terziario del Piemonte i banchi langhiani presentano un andamento stratigrafico assai regolare, con pendenza di $10^{\circ}$ a $20^{\circ}$, verso l'intermo del predetto bacino; talor'a l'inclimazione diventa bensi di $25^{\circ}$ o $30^{\circ}$, ed anche raramente di oltre $60^{\circ}$ - 70', come nelle colline presso Trisobbio, ma questi locali fenomeni stratigrafici non alterano l'andanento regolare generale della zona langhiana.

Come si è già notato pei terreni più antichi, nelle colline tortonesi là dore i banchi langhiani poggiano più o meno direttamente sui terreni liguriani dell'affioramento Brignano-Spinetto, cioè poco prima di scomparire rerso Ovest, essi sono per lo più fortemente sollevati. Nella parte orientale del Tortonese, nel Vogherese, nel Parese ece. la tettonica del Langhiano è di nuovo assai regolare nel suo complesso.

Nelle colline Torino-Casale i banchi langhiani presentano i,fenomeni stratigrafici gia accennati per quelli aquitaniani, essendo essi in generale assai fortemente sollerati, talora solo di $30,40^{\circ}$, piủ spesso di 60 ad 80 , ed anche talvolta pressochè rerticali come redremo piủ aranti.

Nell'orizzonte langhiano si osservano pure piceoli salti, scorrimenti, ece, ma sempre in minima scala e quindi mai tali da alterare il regolare andamento generale dell'orizzonte stesso.

\section{Potenza.}

Il Langhiano rappresenta nel bacino terziario piemontese un orizzonte poco potente; ciò è in diretto rapporto colla sua caratteristica natura di deposito tranquillo, marnoso, di mare abbastanza profondo; tuttavia in alcune regioni, sia perchè ri fu più rapida ed abbondante la deposizione dei terreni che costituiscono l'orizzonte in esame, sia perchè ri si rerificarono per un tempo più lungo che non altrore quelle condizioni di alto fondo nelle quali si deposero i terreni che comprendiamo col nome di langhiani (dorendoci essenzialmente basare sui caratteri litologici per delimitare questi rari orizzonti), in aleune regioni, dico, il Langhiano presenta una potenza abbastanza noterole.

È speciahmente in Val Bormida, tra Cessole ed Acqui circa, che l'orizzonte Langhiano si presenta piủ sviluppato, raggiungendo quivi la potenza di oltre 1000 metri.

Dalla Val Bormida sino alle colline tortonesi il Langhiano è abbastanza potente, sorente avendo uno spessore di poco meno di 1000 metri. 
Se nelle colline Torino-Casale i banchi langhiani sono per lo più ridotti molto in potenza, in aleune regioni invece essi si presentano abbastanza sviluppati e raggiungono anche lo spessore di cirea 500 metri, come ad escmpio nelle colline di Moncestino.

\section{Altimetria.}

Il Langhiano, come in generale i depositi di alto fondo, si eleva raramente a grandi altezze, relativamente almeno ai terreni circostanti, ciò che è in rapporto sia col suo modo di deposizione, sia colla sua natura prevalentemente marnosa.

Infatti generalmente i terreni langhiani nella parte meridionale del bacino terziario piemontese vegrgonsi sollevati a solo 400 o 500 metri; invece dove essi assumollo una facies di basso fondo e quindi una costituzione arenaceo-calearea, là reggonsi sollevati anche oltre i 700 metri, come in una notevole parte delle Langhe (ad Ovest di Camerana toccano i 750 metri) ed eziandio in alcuni punti delle colline tortonesi, come per esempio al Bric Ronzone (700 metri).

Nelle colline Torino-Valenza spesso i banchi langhami per la loro durezza costituiscono le creste delle colline stesse; laraniente però oltrepassano l'elevazione di 500 metri, come ad esempio al M. Cervet (508 metri) a Sud-Est di Superga.

\section{Rapporto coi terreni sotto e soprastanti.}

Già indicammo nel precedente capitolo come in generale esista un gradualissimo passaggio tra il Langhiano ed il sottostante Aquitaniano per mezzo di ripetute alternanze di strati sabbioso-arenacei, grigio-giallastri, con strati marnosi grigio-bleuastri; quindi non è più il caso qui di discorrerne, tanto più che su questo argomento dovremo talora ritornare durante la descrizione geologica regionale dell'olizzonte in esame; indichiamo ora solo come, specialmente nell'alto Monferrato, siano spesso assai abbondanti, verso la base del Langhiano e nel suo passaggio all'Aquitaniano, certe caratteristiche marne grigio-bleuastre, dure, fogliettate, scagliose, zeppe di fossili schiacciati.

Quanto al passaggio tra il Langhiano ed il sovrastante Elveziano dobbiamo qui ripetere eiò che già si disse e si dirà più avanti riguardo alla delimitazione tra l'uno e l'altro dei diversi orizzonti geologici del bacino in esame.

In generale infatti si osserva a questo riguardo che là ove il Langhicmo ha la sua tipica facies marnosa grigio-bleuastra, nella parte sua superiore esso comincia a presentare tratto tratto letti arenacei grigiastri o grigio-giallastri che divengono poco a poco sempre più frequenti finchè si passa in modo gradualissimo ad una formazione prevalentemente arenacea giallo-grigiastra ehe inizia l'orizzonte elveziano. 
Taturalmente qui, come scrupre, esistono incertezze piủ o meno grandi riguardo a tale divisione tra i due indicati orizzonti. Dette incertezze direngono ancor maggiori quando certi banchi arenacei spcciali che si potcrono seguire per chilometri e chilometri (tanto che sembrarano poter serrire di sicura guida per' separare il Langhiano dall'Elveziano. costituendo la base di quest'ultimo orizzonte) reggonsi in certe r'cgioni o scomparipe afiratto oppure diventar marnosi confondendosi coi banchi langhiani. di modo che per continuare la divisione dei due suddetti piani geologici i necessario ricorrere a banchi arenacci situati più in alto. Altre rolte si verifica il fatto contrario. Ma in ogni modo, per quanto ciỏ paia poco logico al geologo da tavolino, è necessario basarci su questi cangiamenti di facies, non sempre verificatisi orunque nello stesso momento geologico, per dividere due orizzonti susseguentisi regolarmente l'un l'altro, tantò più che col cangiare delle facies mutano pure naturalmente anche i caratteri paleontologici.

Di questo fatto noi avlemo spesso ad osserrare bellissimi esempi nella descrizione regionale del terreno in esame e quindi non è qui il caso di insistere su ciò ulteriormente, bastandoci per ora di stabilire come il passaggio tra Langhiano ed Elreziano sia quasi sempre graduatissimo in tutto il bacino terziario del Piemonte.

\section{Località fossilifere.}

亡े specialmente nelle regioni dove le marne langhiane sono dure e fissili che trovansi piủ facilmente resti fossili, poichè in tali condizioni potendosi (a colpi di martello dati nella direzione degli strati) aprire agevolmente, corne le pagine di un libro. le lastre marnoso-calcaree, in poco tempo scopronsi numerosissimi fossili impigliati fra gli straterelli marnosi; in generale però tali fossili sono assai fortemente schiacciati, fatto che ricsce spesso di grare inconreniente alla determinazione dei resti animali, ma che non nuoce molto a quella delle tilliti.

Là dore comincia ad apparile, a Sud-Ovest. l'orizzonte in esame, le marne bleuastre fine, lastroidi del Langhiano, mostrano. specialmente nelle vicinanze della Stazione di Cera, una straordinaria abbondanza in resti regetali ed animali; se attravcrso le Langhe questi fossili non incontransi yuasi più, a causa della cangiata facies dcl Langhiano, li ritroviamo di nuoro abbondantissimi da Vesime. Bistagno. Terzo, cce., attraverso tutto l'alto Monferrato sino alle colline tortonesi, specialmente in speciali banchi costituiti di marne scagliose clure che sono una delle più evidenti carattcristiche del Langhiano piemontese.

Nelle colline Torino-Casale le marne dure ultimamente accennate, e che quasi da sole costituiscono l'orizzonte langhiano, sono orunque ricchissime in fossili animali e regetali, ed è quindi inutile l'indicare 
particolarmente le localiti dove se ne raccolsero finora piủ abbondantemente, ciò dipendendo più specialmente da condizioni secondarie; così dalla maggiore facilità d'incavazione, dalle più lungho ricerche, ece.; basti il dire come quasi tutte le filliti descritte dal Sismonda col nome di Miocene medio, derivano precisamente dall'orizzonte langhiano di dette colline.

\section{Descrizione geologica regionale.}

Nella porzione Sud-Ovest del bacino telziario del Piemonte, poco a Nord del paese di Mombasiglio, tra Mondovi e Ceva, (e più precisamente nella piccola valle delle Salette, quasi sotto la C. Francolina), cominciano ad affiorare i terreni langhiani, dapprima rappresentati solo da sottili banchi marnosi, i quali però sono già qui alquanto scagliosi e fossiliferi, ciò che li distingue dai terreni circostanti.

Per essere piuttosto duri e resistenti questi banchi langhiani, quantumque di pochi metri di spessore, costituiscono spesso le parti più elevate delle collinette che stanno fra Mombasiglio e Ceva; la loro inelinazione è poco forte ed abbastanza regolare verso il Nord-NordOvest. La delimitazione dell'orizzonte in esame riesce, come d'altronde in generale, sempre alquanto incerta, sia per la coltivazione quivi molto sviluppata, sia per la scarsita di tagli naturali, sia specialnuente per le solite alternanze litologiche esistenti nel passaggio tra questo orizzonte ed i terreni sopra e sottostanti.

In Val Tanaro, presso Ceva, nella profonda erosione fatta dalle correnti acquee del Tanaro, i terreni langhiani si mostrano assai sviluppati, tipici, riccamente fossiliferi; costituiscono cosi unna delle regioni piu caratteristiche per studiare questo terreno e per laccoglierne i resti organici. is precisamente a metà circa tra i caselli 42 e 43 della ferrovia che, esegmendosi una bassa trincea per la costruzione della stradi ferrata (in banchi marnosi alternati con banchi sabbioso-arenacei che formano passaggio tra il Langhiano e l'Elveziano) si incontrarono interessantissimi resti di necello, descritti dal Portis col nome di Cherornis graculoides.

I banchi langliani presentano un'inclinazione media di circa $20^{\circ}$ verso il Nord-Ovest ad un dipresso; vi esistono talora piccoli salti locali, come ad esempio quello che osservasi, presso Ceva, verso la metà ch́ca dell'orizzonte in esame, nei profondi spaccati naturali della sponda sinistra dell'alveo del Tanaro.

E un fatto molto importante l'osservare come, mentre nell'alveo del Tanaro il Langhiano è potente e colla caratteristica facies di deposito d'alto fondo, come or ora aecennammo, invece di tratto sotto il forte di Ceva, e poscia attraverso tutta la vasta regione delle Langhe, quest'orizzonte speciale sembra scomparire quasi completancnte, pas- 
sandosi gradatamente dai terreni di mare poco profondo dell'Aquitaniano a quelli di natura simile dell'Elreziano.

Siccome l'andamento stratigrafico regolare ed il sorradetto graduale passaggio fra i diversi terreni esclude l'ipotesi di un vero salto, per quanto possa forse esistere un po' di trasgressione tra Aquitaniano ed Elreziano, cosi sembra doversi ammettere che in questa rasta regione delle Langhe, per un insolito sviluppo dell'area marina elceziana, i depositi littoranei inferiori di questo periodo rennero parzialmente a ricoprire quelli di mare piủ profondo formatisi ncl precedente periodo langhiano.

Irà ancor più probabile essersi quivi rerificato il fatto che, per qualche speciale fenomeno, anche dmrante lo stesso periodo langhiano i depositi si formassero quivi in bassi fondi marini littoranei, per cui cssi ei si presentano quiri con una facies littoranea alquanto simile a quclla dei due piani geologici (caratterizzati generalmente da tale facies) fra cui sono compresi, inrece che non colla tipica facies di deposito d'alto fondo; d'altronde fenomeni consimili possonsi pure osservare altrove nello stesso Piemonte e comunissimamente fuori di questa regione.

Lí si obbictterà probabilmente che se il Langhiano assume nelle Langhe una facies specialmente di deposito di basso fondo, si dorrebbe in queste regioni indicarlo assai più sviluppato di quanto io l'abbia indicato nelle carte geologiche; tale obbiezione può essere in parte giusta poichè, trovandomi in gran parte mancarc, direi, nelle colline delle Langhe i caratteri paleontologici c litologici dell'orizzonte che chiamiamo Langhiano, mi vidi naturalmente obbligato a considerarne quivi molto ristretto lo stiluppo. Ha sono pure persuaso che nelle indicate regioni collinose l'orizzonte Langhiano (stricto sensu) è realmente ridotto talora di potenza; tanto è vero ciò che presso Cera, dore i diversi orizzonti geologici in csame si possono osserrare assai bené in breve spazio, si rede chiarissimamente che tra gli strati marnosi, alternati con strati arenacei, dell'Aquitaniano ed i potenti banchi arenacei (del forte di Cera) caratteristici dell'Elceziano inferiore, troransi solo pochi strati che possonsi rerosimilmente attribuire al Langhiano; di modo che quivi l'idea di una trasgressione sorge assai naturale, tanto piu se si considera il notevole sviluppo del Langhiano nel vicino alveo del Tanaro.

Ad ogni modo è curioso il notare che, come generalmente arriene nella denominazione degli orizzonti geologici, si stabilì il nome di Langhiano per un terreno che in Piemonte si presenta quasi ormque assai stiluppato e colla sua facies caratteristica di alto fondo marimo, eccetto che precisamente nella regione delle Langhe. A dire il rero 
Pareto, che istitui nel 1865 il nome di Langhiano, vi eomprendeva pure g'ran parte dell'Aquitaniano e dell'Elveziano tanto sviluppati appunto nelle Langhe; ma siccome le denominazioni di questi due ultimi terreni sono anteriori di data al 1865, eosi il nome di Langhiano dovette solo più venire attribuito in senso più limitato a quel piano intermedio ehe si eredette poter individualizzare tra l'Aquitaniano e l'Elveziano. Si potrebbcro d'altronde fare consinili osservazioni in altri capitoli rispetto ad altri terreni; tutto questo però non rende per nulla necessario, a mio parere, di cangiare i nomi che sono gia entrati nel dominio scientifico e vi hanno preso un significato speciale; giacehe in tale easo in tutti i rami della scienza, man mano che questa progredisce, si dovrebbero fare eontinui cangiamenti di nomi senz'aleun vantaggio reale ed invece con cnorme svantaggio per la seienza stessa ehe ha già da lottare con tante e così varie c cosi grandi difficoltà reali, senza che se ne abbiano a creare delle convenzionali oltre il necessario; tanto piu poi clic in fondo tutte le divisioni e le denominazioni che fa l'uomo per sua comodita, per quanto utili, sono c saranno sempre più o meno convenzionali.

Ritornando all'csame del Langhiano delle vicinanze di Ceva, dopo aver notato tra l'alveo del Tanaro ed il forte di Ceva il rapidissimo apparente assottigliarsi dei terreni costituenti quest'orizzonte geologico, possiamo indicare come i pochi banchi marnoso-arenaeei attribuibili ancora al Langhiano, assumono un'inelinazione di eirca $15^{\circ}$ verso il Nord o Nord-Nord-Ovest.

Mentre il limite superiore del Langhiano è abbastanza nettamente traceiato dai potenti banchi arenacei giallastri dell'Elveziano basale, che solo assai piu in alto altcrnansi nuovamente con banchi marnosi grigio-bleuastri, inveec inferiormente osserviamo ripetute alternanze di banchi marnosi ed arcnacei ehe rendono incertissima e quasi sempre arbitraria la divisione netta tra Langhiano ed Aquitaniano; infatti anche in quest' ultimo orizzonte troviano a diversi livelli, persino nei piủ bassi, strati di marne grigiastre, dure, fissili, seagliose, inglobanti resti di Nucula, Balantium, eec., cioè depositi affatto confondibili con quelli tipici del Langhiano.

D'altronde pur ammettendo la ncecssità di separazione tra Aquitcniano, Langhiano ed Elveziano, che alcuni vorrebbero rimnire assieme, dcbbo peró eonvenire che la fauna e la flora di questi tre periodi geologici non subirono forse modificazioni tanto profonde come tra Aquitaniano c Tongriano, ed è quindi naturale che condizioni simili verifieatesi in regioni diverse durante questi tre periodi in momenti geologici diversi, poterono dar llogo a depositi simili ma non contemporanei, racchiudenti fossili pure simili ma non coctanci, come nel caso soviaccennato. 
Dopo oltre 6 chilom. di sviluppo verso l'Est le marne più o meno sabbiose del Langhiano si inflettono quasi di tratto verso Nord, al Brie Siesi, e continuano poseia a svilupparsi per lunghissimo tratto in tale direzione, sempre però ridotte a poea potenza e eon delimitazione ineerta ed arbitraria, specialmente rispetto al sottostante Aquitaniano.

Al Colle di Borgata Salvetti, tra Tal Belbo e Tal Bormida, il Langhiuno si mostra di nuovo per un eerto tratto colla sua earatteristica facies di marne dure, fissili, fossilifere, fatto il quale vieppiù ei eonvalida nell'idea ehe nelle regioni eollinose in esame il Langhiano esiste realmente, solo che in parte esso venne maseherato dai depositi sovrastanti ed in parte assunse la facies dei due orizzonti geologici fra i quali è compreso e da eui quindi riesce difficile distinguerlo.

Dal Colle Salvetti sino a Feissoglio, cioè per lo striluppo di oltre 4 chilom., il Langhiano, semv'e poco potente ed a limiti alquanto convenzionali, eon direzione ad un dipresso Nord-Sud, con inclinazione di cirea 10' verso Ovest, eostituisce una spceie di cordone sull'alto del fianco sinistro della profonda Tal Bormida di Millesimo; anzi ¿̇ indubitato che esiste una stretta relazione fra tale andamento stratigrafico e la oroidrografia di questa regione. Si rerifica quiri infatti un vero gradino tra la Val Belbo, il cui fondo trovasi tra i 600 ed i $500 \mathrm{~m}$. cirea sul lifello marino, e la Val Bormida il cui fondo invece trovasi tra i $350 \mathrm{~cd}$ i $300 \mathrm{~m}$. di elevazione sul livello del mare; questo fatto in parte soltanto è dovuto alla più potente azione erosira della grande eorrente acquea della Bormida lispetto a quella assai minore del Belbo, ma in gran parte deriva da fenomeni geologiei.

Talora il Langhiano, per essere in parte costituito di banchi malnosi più facilmente esportabili di quelli sopra e sottostanti, dà lnogo ad una specie di gradino lungo il pendio ehe scende dalla cresta della collina al fondo di Val Bormida; però questo earattere orog'rafico norr è molto importante, poichè non è affatto partieolare al Langhiano, osserrandosi naturalmente anehe per tutti i banehi marnosi un po' potenti della seric aquitaniana.

Come si è già notato trattandosi dell'Aquitaniano, a Feissoglio si verifica una rapida eurva accompagnata da qualche disturbo stratigrafico, per modo ehe le marne arenacee del Langhiano rengono a eostituire una parte del colle di Feissoglio, discendendo poscia in Val Belbo.

Si è pure già osservato eome la eresta collinosa tra Feissoglio e Castino sia spceialmente eostituita di potenti banehi arenaeei elıe paiono attribuibili all'Elveziano inferiore. Attorno a tale placea allungata d'Elveziano non compaiono notevoli banchi langhiani, forse perchè 
quivi la sovrapposizione del miocene all'oligocene è leggermente trasgressiva. Però osservansi vere zone langhiane sia presso Fcissoglio tra C. Rorata e C. Rubella, sia presso Castino tra Regione Cani e C. Scotto, dove affiorano molti banchi marnosi.

Sulla sponda sinistra della Val Belbo tra il Molino di Feissoglio e C. Sottana, cioè per circa 16 chilom. di sviluppo, il Langhiano si mostra sempre poco potente e con facies di basso fondo; esso presenta solo pochì banchi marnosi cd invece numerosi e potenti banchi arenaceí, per cui anche in tutto questo iungo tratto la delimitazione del Langhiano riesce molto difficile ed incerta. L'inclinazione dei suoi banchi è di circa 10' ver'so l'Ovest-Nold-Ovest.

I numerosi rii ehe profondamente incidono la sponda sinistra di Val Belbo mettono bensì nettanıente a nudo la successione stratigrafica della regione, ma con tutto ciò l'imangono sempre grandi incertezze nella scparazione dell'orizzonte in questione dall'Elreziano, ma specialmente, come di solito, dall'Aquitaniano; quest'ultimo orizzonte infatti spesso presenta banchi marnosi che parrebbero doversi includere ancora nel Langhiono; ma in verità essi reggonsi ricomparire a diversi livelli sin quasi alla base dell'Aquitaniano e quindi debbonsi più ragionevolmente racehiudcre in quest'ultimo orizzonte, sempre naturalmente ammettendosi che tali nette divisioni sono arbitraric a causa del graduale passaggio che csiste tra i vari orizzonti gcologici in esame.

Siccome gli indicati rii incidenti la sponda sinistra di Val Bclbo sono sper so difficili a risalirsi, chi volesse prendersi un'idea del modo di passaçgio esistente tra l'Aquitaniano, il Langhiano e l'Elveziano, potrà farlo comodamente lungo la grande strada (Cortemiglia-Alba) che dall'Osteria Campetto (Valle Belbo) sale a Borgomale, g'iacchè in tal caso egli potrà csaminare perfettamente tale successione stratigrafica non solo nci profondi spaccati del rio dei Bcrri, ma eziandio più da vicino nei numerosi tagli artificiali fatti per la costruzione della strada, c potrà convincersi come sia graduale il passaggio, che si inizia verso i 400 metri s. 1. m., tra Aquitaniano c Langhiano.

Infatti nella parte inferiore della valle del Belbo veggonsi i tipici terreni aquitaniani, rappresentati da banchi marnoso-sabbiosi grigiastri, regolarmente alternati con regolari banchi arcnacei, giallastri; divengono poscia più potenti i banchi sabbiosi bleuastri che acccnnano al Langhiano; vi succedono in alto grossi banchi arenacci, giallastri, a facies littoranea, che sopportano infine banchi sabbioso-marnosi bleuastri, i quali. malgraco siano ripetutamente alternati con strati e banchi arenacei, credo rappresentino il vero Langhiano.

Qucsto orizzonte geologico, dopo ripetute alternanze di banchi marnosi ch arenacei, vienc coperto, verso i $450 \mathrm{~m}$., dai potenti banchi 
arenacei giallastri, fossiliferi, dell'Elceziano; quest'ultimo orizzonte poi sopra Borgomale presenta nuoramente grandi banchi marnosi, i quali iniziano la serie delle ripetutissime alternanze di marne, sabbie ed arenarie, che costituiscono la potente pila dei terreni elreziani delle Langhe.

Dalla C. Sottana sino a Castino, sulla sponda destra di Val Belbo, il Langhiano è scmpre difficilmente delimitabile; gli si possono attribuire banchi di marne sabbiose (talora alternate anche ad arenarie) stratcrellate, grigiastre, poco fortemente cementate e quindi facilmente disaggregabili per modo da costituire spesso regioni franose, come per esempio in Regione Cani, presso S. Orsola, ecc.

Presso Castino la stratificazione dei banchi langhiani, come d'altronde anche in parte quella dei banchi elveziani, presenta alcune irregolarità; cosi nella parte settentrionale del paese reggonsi i depositi marnososabbiosi del Langhiano, nettamente straterellati, inclinare di $35^{\circ}$ a $40^{\circ}$ rerso Orcst-Sud-Orest, cioè in direzione contraria a quella solita; fenomeno però che è affatto locale.

Seguendo ora lo sviluppo del Langhiano da Castino rerso Est, vediamo che questo orizzonte geologico diricne poco a poco sempre più potente, probabilmente anche pel fatto che banchi i quali nelle Langhe crano completamente arenacei (per cui rennero inclusi nell'Elveziano e nell'Aquitaniano), direngono quiri poco a poco marnosi, a facies langhiana, in modo che paiono dorersi racchiudere nel tipico Langhiano; di questo fatto gia ebbimo occasione di trattare nella prefazione del lavoro $\mathrm{c}$ anche poche pagine più aranti in questo stesso capitolo.

E specialmente tra Castino e Cessole che possiamo vedere la facies langhiana stilupparsi rapidamente ed i banchi marnosi direnire sempre più potenti, alternandosi dapprima con numerosi banchi o complesso di strati arcnacei con impronte di Paleodictyon. Più in alto i depositi marnosi prendono il soprarrento su quelli arenacei od almeno (anche conservandosi ancora molto sabbioso-arenacei) assumono già, nello assieme, un color grigio-bleuastro che negli spaccati, anche di lontano, indica la presenza del Langhiano; infine i banchi marnosi prendono il sopravvento assoluto, osservandosi solo più qua e là, a vari livelli, più o meno sottili banchi arenacei i quali nelle ampie sezioni naturali raramente vengono ad alterare la complessiva facies marnosa, grigiastra, del Langhiano; tale terreno presenta allora una potenza molto notevole, cioè di oltre 1000 metri e, per la relativamente facile erosione dei suoi strati, diede esso origine all'ampia ralle della Bormida.

L'inclinazione dei banchi oscilla generalmente attorno a $20^{\circ}$, spesso pcrò si può osservare che alcuni pendono anche di $30^{\circ}$, in generale verso Nord o Nord-Nord-Orest. 
Se tratto tratto a diversi livelli ncll'orizzonte langhiano osservansi banchi arenacci, anche talora assai numcrosi e potenti, che ricordano in parte quelli aquitaniani ed in parte quelli elveziani, tali altcrnanze divengono poi sempre più ripetute nella parte inferiore e superiore della seric langhiana. Così per escmpio, rispetto al Langhiano basale, se eredetti di potervi includere i supremi banchi di Bric dei Galli (565 m.), la piccola vicina placea sopra C. Ferrero, i rilievi franosi di C. Biè, ed i banchi più elevati di Bric Loro e Bric Valla, ciò fu in considerazione sia della stratigratia, sia del grande sviluppo che quivi ancora osservasi dei banchi sabbioso-marnosi, talora straterellati, che danno al terreno, visto in sczione, una tinta grigiastra a facies langhiana; non posso però fare a meno di accennare come con questi banchi marnosi si alternino ripetutissimamente strati e banchi sabbioso-arenacei che costituiscono il passaggio all'Aquitaniano; anzi essi parrebbero già far parte di quest'ultimo orizzonte se i banchi sovraccennati, specialmente quelli duri, straterellati, fossiliferi (con Solenomya Doderleini, Pteropodi, ece.), non mi facessero invece inclinare a racchiuderli aneora nel Langhiano. Ad ogni modo si deve sempre ammettere l'arbitrarictà di tale delimitazione, la quale però nel complesso è dimostrata giusta anche solo da uno sguardo complessivo sulle regioni collinose in esame; infatti risulta abbastanza chiara a colpo d'occhio la distinzione tra le colline aquitaniane grigio-giallastre, a dolce e regolare piano inclinato verso Nord circa ed a ripida pendenza verso Sud, e le colline langhiane grigiastre più o meno regolarmente rotondeggianti e spesso con piramidi d'erosione e monticiattoli biancastri franosi nelle parti alte, come specialmente si può osservarc nclla curiosa regione compresa fra C. Biè e C. Vernelle.

Consimili banchi marnoso-arenacei ancora riferibili alla base del Langhiano, sempre con incerta delimitazione, possiamo ancora constatare più a Sud, a Bistagno, nelle colline di C. Galindone, dove gli strati presentano anche alcune irregolarità di andamento, cosi per esempio una pendenza di eirca $50^{\circ}$ verso Ovest nelle vicinanze della suddetta Cascina.

Alternanze simili a quelle ora accennate troviamo lungo la linea di separazione tra Langhiano ed Elveziano, di modo che per delimitare i due orizzonti uno studio molto minuto sarcbbe, a mio parere, poco opportuno in tale caso, rendendo difficilissima e sempre più incerta tale distinzione che, ad uno sguardo complessivo, risulta evidente ed affatto naturale.

Talora però i potenti banchi arenacei giallastri dell'Elveziano sovrappongonsi quasi direttamente alle marne grigiastre del Langhiano, per modo che riesce assai facile il separarc i due orizzonti geologici, 
tanto più che generalmente, appun to per l'indicata differenza litologica, l'Elveziano più resistcnte forma erte colline e costituisce una specie di gradino assai pronunciato sulle colline langhiane piu basse e spesso alquanto pianeggianti; è per tal modo che, ad esempio, ci spiegliiamo facilmente la rilevata placea elreziana su cui sorge il Castello di Sessame.

Sempre per questa facile erodibilita dei depositi langhiani, oltre che il fatto già accennato dell'ampiezza della Tal Bormida in queste regioni, riesce pur facile a comprendersi il gran numero di altipiani di erosione, coperti da allurioni posterziarie, che osserransi nelle colline di Bistagno, di Terzo, di Acqui ece.

Ad Est di Bistagno, dopo la riunione delle due Bormide, il Langhiano, sempre assai potente e con inclinazione di circa $20^{\circ}$ o $25^{\prime}$ rerso Nord, si può esaminare assai bene nelle basse colline della sinistra della Bormida, colline profondamente incise da numerosi torrentelli che ne mettono orunque a nudo l'intima costituzione, essenzialmente marnosa; vi sono però anche ripetute alternanze di arenarie grigio-giallastre che però in complesso non alterano generalmente il color grigio-bleuastro dell'orizzonte. I banchi langhiani sono in parte marnoso-sabbiosi, potenti, a rottura irregolamente frammentaria oppoure concoide, ma in parte sono pure costituiti da strati marnoso-calcarei duri, fogliettati, riccamente fossiliferi, che gia si possono osservare tra Cessole e Bistagno e che direngono poi sempre più sviluppati a diversi lirelli nelle colline di Terzo e di Acqui; essi forniranno certamente in arrenire un ricco materiale per gli studi palcontologici.

Mentre nel passaggio tra Langhiano ed Elveziano troriamo le solite alternanze litologiche e quindi le solite incertezze di delimitazione, queste direngono ancora più grandi nella transizione dal Langhiano all'Aquitaniano giacchè essa verificasi per lo più sotto le allurioni della Bormida. Quindi la delimitazione dei due orizzonti dere quiri farsi fondandosi solo sopra pochi punti di osserrazione diretta; cosi ad escmpio l'estremità meridionale dello sprone collinoso di C. Mottura (presso Bistagno) dore appaiono potenti banchi grigio-giallastri inclinati di circa 30 " verso Orest ed attribuibili probabilmente all'Aquitaniano superiore; cosi pure le colline essenzialmente arenacee di C. S. Catterima e di C. Della Notte, colline emergenti dal piano alluvionale per la loro resistenza all'erosione, ed ambedue rappresentanti con probabilità i banchi supremi dell'Aquitaniano, per quanto tali divisioni siano naturalmente scmpre molto incerte.

Tra Strevi e Morzasco la valle della Bormida, incisa completamente nei terreni langhiani, presenta un'ampiczza di oltre '2 Chilon., restringendosi poi tosto più a Nord, dore incide i banchi arenacei dell' El- 
veziano, per nuovamente allargarsi ampiamente più avanti nelle argille piacentine.

Nelle colline biancastre, talora foggiate a cupole rotondeggianti, tra Orsara e Morzasco, il Langhiano, passante gradatissimamente e con limiti indefinibili all'Elveziano, è costituito di grandi banchi marnosi grigio-bleuastri alternati con banchi o strati sabbioso-arenacei. Nella sua parte inferiore compaiono assai frequenti i banchi marnosi duri, fogliettati, scagliosi, fossiliferi; detti banchi però osservansi anche fra strati arenacei a Paleodictyon in terreni che gia attribuisco all'Aquitaniano superiore; così per escmpio nelle colline di S. Sebastiano presso Morzasco, nelle colline tra Morzasco e Trisobbio, ece. rendendo in tal modo scmpre più incerta la delimitazione, già ovunque tanto difficile, tra il Langhiano e l'Aquitaniano.

D'altronde tali banchi marnosi straterellati, pseudo-langhiani, li riscontriamo sovente, ed a diversi livelli, in quasi tutto l'Aquitaniano della parte meridionale del bacino terziario piemontese e quindi, mentre in generale essi sono specialmente caratteristici del piano geologico in istudio, invece, dopo un esame minuto anche palcontologico, dobbiamo ammettcre che tali banchi si ripetono talora cziandio in altri orizzonti geologicr, solo più raramente.

Nelle colline di Trisobbio verificansi nel Langhiano, come pure nel sovrastante Elveziano, forti disturbi stratigrafici locali per cui la zona langhiana quivi si restringe, i suoi banchi si presentano fortemente sollevati di 60', 70' con inclinazione assai svariata da luogo a luogo ma prevalentemente verso Est; come è naturale la linca di delimitazione dei duc piani subisce in queste regioni un forte disturbo nel suo andamento.

Ad Est di Trisobbio l'andamento stratigrafico del Langhiano ridiventa regolare c tale si conserva, con poche cecezioni, per tutto il restante suo percorso sino alle colline tortonesi.

Verso la base del Langhiano e nel suo passaggio all'Aquitaniano si presentano sempre abbondanti le tipiche marne dure straterellate, racchiudenti numerosi fossili; tali fossili, per lo più d'alto fondo o pelagici, sono assai schiacciati per la compressione subita dai terreni che lì racchiudono; questi poi alla stessa causa specialmente devono la loro attuale eompattezza. Se, per eitare un esempio di questi passaggi, noi procediamo da Gavi verso Sud rimontando la valle del Lemno, vediamo essere il Langhiano costituito dapprima specialmente da grossi banchi a cui succedono poco a poco inferiormente banchi più sottili; a questi si intercalano talora straterelli arenacei che negli spaceati, per la loro durczza, sporgono fuori dalla marna circostante; osservansi quivi talora banchi marnosi, duri, stratcrcllati; inferiormente ancora 
veggonsi gli strati arenacei direnir più frequenti, compaiono grossi banchi sabbioso-arenacei e si passa cosi gradatamente all'Aquitaniano, senza che si possa trovare nè rispetto alla litologia, nè rispetto alla palcontologia una netta separazione tra questi due orizzonti geologici. Tali difficoltà di delimitazione se sono giả grandi lungo i corsi dei torrenti piu importanti, che presentano una serie continua di bellissimi e profondi spaceati, rieseono poi naturalmente ancora maggiori nelle regioni collinose dove sono più rari gli spaccati e dove la struttura del terreno è spesso maseherata dalla regetazione.

Generalmente una cinquantina di metri cirea sopra ai banchi sabbiosi che iniziano l'Aquitaniano superiorc, e dai quali rimane divisa da un'alternanza di banchi marnosi ed arenacci, osservasi una caratteristica scrie (della potenza di circa 4 o 5 metri) di straterelli marnosi, regolari, grigio-giallastri, talora fogliettati e fossiliferi.

Se per le indicate alternanze riesee sempre difficile ed incerta la distinzione tra Aquitaniano e Langhiano, più facile riesce la divisione tra questo terreno ed il soviastante Elveziano a causa dei potenti e duri banchi arenaceo-calcarci grigio-giallastri che iniziano e che costituiscono la basc di questo ultimo orizzonte; però altcrnanze di strati arenacei e marnosi e conseguenti ineertezze di delimitazione, solo in minol grado, si verifieano scmpre anche in questo passaggio.

Ciò che si è detto or ora può ripetersi ad un dipresso per tutta la rasta regione compresa tra la Val Bormida e la Val Scrivia, rerifieandosi quasi ovunque gli stessi fatti; solo che talora è assai stiluppato il banco calcareo-sabbioso giallastro che si può prendere come base per dividere Langhiano da Elveziano, talora invece tale banco è meno eridente e gli strati inferiori dell'Elveziano assumono una facies pseudo-langhiand, sono cioè poco calcarei e grigiastri, per modo da riescire difficile la distinzione tra i due orizzonti greologiei.

Le colline langhiane, per la loro natura essenzialmente marnosa sono, come di solito poco elevate, piuttosto rotondeggianti, grigiastre, a dolei pendii, intersecate da valli relativamente ampie; la stratificazione dei banehi langhiani è assai regolare, la loro pendenza è di circa 25", talora però anche di 30 o 35", rerso il Nord ad un dipresso.

I fossili vi si incontrano piuttosto abbondanti ma non sempre facili ad cstrarsi interi; sono per lo più fossili d'alto fondo o pelagiei od almeno di deposito tranquillo; abbondano specialmente nelle marne fogliettate; vi si incontrano anche talora impronte di Zoophycos Gastaldii, come per esempio poeo a Sud del paesello di Massa.

Qualche disturbo stratigrafico osservai nel Langhiano inferiore spccialmente nelle colline di Masseria Pradcla, probabilmente in corrispondenza ancora allo irregolare sprone diretto verso Nord-Ovest 
che abbiamo visto verificarsi quivi in tutti $\mathrm{i}$ terreni terziali finora esaminati.

In Val Serivia, se liesce abbastanza naturale la distinzione del Langhiano dall'Elveziano, meno facile e più convenzionale è la sua delimitazione dall'Aquitaniano che è quivi assai ristretto e la cui parte superiore è distinta dal Langhiano inferiore solo per una maggior frequenza di banchi arenacei.

Ad Est di Val Serivia, seguendo il Langhiano nel suo sviluppo in Val Borbera, la cui ampiezza verso il suo termine e in parte appunto dovuta all'essere incisa in terreni langhiani, vediamo che questi si vanno alquanto rimpicciolendo ed inoltre, cio che è maggiormente degno di nota, cssi diventano poco a poco più ricchi in banchi arcnacei; questi infatti, mentre appaiono dapprima solo qua e là fra i banchi marnosi superiori, in seguito si alternano ripetutamente cogli strati marnosi a tutti i livelli del Langhiano.

Questo fatto si può osservare assai bene osaminando attentamente i profondi tagli naturali della sponda destra della Val Borbera (nel taglio stupendo che osservasi a Nord di Vignole il Langhiano è ancora abbastanza tipico); anzi senza tale osservazione diretta si potrebbe forse giungere alla conclusione che il Langhiano scompaia completanente nclle colline di Sorbi; quivi infatti esso è in gran parte costituito di duri banchi sabbioso-arenacci alternati solo con stratcrelli marnosi, benchè nelle sezioni conservi generalmente in complesso il color grigiobleuastio del Langhiano tipico.

Un fenomeno simile di trasmutazione, direi, di facies credo potrebbe anche invocarsi, come gia ebbi ad accennare, pel Langhiano dello Langhe dove esso è apparentemente ridotto a poco spessore; credo però che le condizioni non sieno completamente eguali nelle due regioni.

I banchi arenaceo-marnosi del Langhiano, con inclinazione di circa 20 " a Nord-Ovest, poco a poco sollevandosi vanno a costituire la parte alta delle colline di Albarasca, di Sorli, e di Costigliole, elevandosi sin oltre i 700 metri, come per esempio al M. Ronzone (704); tali fatti sono in stretta relazione colla speciale natura litologica del Langhiano in queste regioni.

Nelle colline di Albarasca, Sorli, ece. il Langhiano a facies prevalentemente arenacea, pseudo-elvezianc, talora persino con lenti ghiaiose, è abbastanza fiacilmente distinguibile dall'Aquitaniano per essere questo piuttosto sabbioso e quindi alquanto franabile ed inoltre perehè spesso esiste tra i due orizzonti una leggera trasgressione stratigrafica che si può ad esempio osservare assai bene sotto la borgata Sorli; tuttavia esistendo sempre ripetute alternanze di sabbie, marne ed arenarie, i limiti dei duc accennati orizzonti non sono sempre ovunque facili a 
stabilirsi nettamente, tanto più là dore non osservansi bei spaceati o dove non esiste quella specie di gradino che i duri banchi arenacei langhiani sorcnte fanno sulle meno resistenti sabbie aquitaniane.

Ho gia accennato sopra che, malgrado la prevalenza dei banchi arenacei, nelle sezioni il Langhiano conserva generalmente il solito color grigio-bleuastro a causa dei ripetuti strati marnosi grigi che si alternano colle arenarie; superiormente però il Langhiano diviene poco a poeo sempre meno marmoso finchè compaiono i potenti banchi arenaceocalcarei grigio-giallastri coi quali iniziasi, a mio parere, l'Elreziano.

Anche dall'andamento g'enerale dell'orizzonte in esame nelle colline ora studiate si può dedurre come i suoi strati, dopo formata una rapida curva al Bric Barasche, assumono una direzione complessira da Sud a Nord inelinando verso Orest di circa $20^{\circ}$ o $25^{\circ}$.

A Nord di Borgata S. Vito il Langhiano perde di nuovo poco a poco la facies arenacea e ridiventa marnoso; non costituisce più le creste delle colline; ma inveee di presentarsi in bei banchi alternati talora con straterelli più duri, come nell'alto Monferrato, assume nello assieme un aspetto frammentario, quasi farinoso, con strati talora non nettamente diseernibili; mentre che nella parte superiore esso si lascia distinguere abbastanza bene dall'Elreziano a banchi arenacei, inveee nella parte inferiore si eonfonde quasi coll'Aquitaniano; complessivamente però si prò dire che il Langhiano è alquanto più marnoso, più grigiastro e più resistente che non l'Aquitaniano, motivo pel cui esso eostituisce ancora nelle colline di Ramero, Olira, ecc. na specie di rialzo sopra all'Aquitaniano piì facilmente franabile.

Infine a Nord di Arolasea il Langhiano, eome tutti i terreni gia esaminati, presenta una rapida curva ad Ovest; nello stesso tempo i suoi banchi divengono fortemente rialzati e ramo seomparendo poeo a poeo senza che sia facile il delimitarli con precisione.

Nelle colline tortonesi settentrionali comprese in questo studio mańcano completamente i depositi langhiani, che eompaiono però più ad Est.

Nelle colline Torino-Valenza, proeedendo nel loro esame da Est ad Ovest, per lunghissimo tratto non osservasi afforamento alcuno di terreni langhiani poichè l'Elveziano appoggiasi trasgressiramente sull'Aquitaniano e tutti i terreni sono fortemente compressi e molto ridotti ill spessore, per cui gli orizzonti meno potenti, come appunto il Langhiano, non possono generalmente renire a giorno.

Nella parte orientale dell'aftioramento elissoidale oligocenieo di Ottiglio-Montalero reggonsi già qua c là apparire, nel passaggio tra Aquitaniano ed Elveziano, come presso Cereseto, presso Castellino, ecc., alcuni banchi marnosi, grigiastri, duri, che preludiano al Langhiano. 
Più ad Ovest però, nella parte settentrionale dell'affioramento suddetto, eompaiono presso Castellazzo i tipiei sottili banehi marnosi, duri, seagliosi, fossiliferi del Langhiano; essi sono fortissimamente sollevati, talora quasi verticali ed anche roveseiati, ma per lo più eon un'inelinazione di $70^{\circ}, 80^{\circ}$ ver'so il Nord-Nord-Est e con una potenza di cirea 40 o 50 metri. Questi banchi marnosi si alternano però con strati arenacei facendo eosi graduale passaggio, eon incerta delimitazione, all'Aquitaniano inferiormente ed all' Elveziano superiormente. Sono forsc ancora da riferirsi al Langhiano, come facies speciale littoranca, i banchi arenacei, riccamente fossiliferi, che formano la eresta del Santuario di Crea, giacehè sotto essi eompaiono aneora numerosi banehí marnosi eompatti del Langhiano tipieo.

Verso Casalino l'inclinazione degli strati si riduce a soli $50^{\circ}$ eirca ed essa diventa anche minore verso Ovest; però nello stesso tempo vanno gradatamente scomparendo i carattestiei terreni marnosi del Langhiano che, per una leggiera trasgressione stratigrafiea fra Aquitaniano cd Elveziano, è ridotto a pochi strati e talora anche manca completamente.

E appunto per tali trasgressioni (causate in gran parte dalle strette sinclinali ehe i terreni terziari furono costretti a formare per le potenti eompressioni laterali subite) che in Val Stura il Ianghiano è ridottissimo e spesso fortemente sollevato. Vi si possono ad esempio riferire aleuni banehi marnosi duri di Castiglione.

Come i eireostanti terreni il Langhiano forma una rapida eurva presso Rosingo, dirigendosi poseia verśo Sud; esso è allora rappresentato solo più da due o tre strati marnosi fog-liettati, seagliosi, drizzati o quasi alla verticale, potentissimamente compressi, specialmente per la strettissina sinclinale che i terreni elveziani formano in questa località; quivi naturalmente si osserva pure una spiecata trasgressione fra tali terreni e quelli aquitaniani.

Nelle eolline di Montalero gli strati langhioni si mostrano pì sviluppati ed assumono verso Cicengo uno spessore sempre maggiore, (però solo di quasi 40 metri) ed un'inelinazione generalmente assai forte, eioè di eirea $60^{\circ}$; essi si inflettono a Sud-Orest costituendo cosi l'estremità oceidentale dell'elisse stratigrafica già studiata nei capitoli precedenti.

Attraversata la Val Stura possiamo seguire ancora per qualche tempo verso Est i duri e tipici banchi langhiani, sempre passanti gradatamente agli orizzonti sotto e soprastanti e con un'inelinazione varia tra $i 40^{\circ}$ ed $\mathrm{i} 70^{\circ}$ eirca; ma poeo a poco vediamo tạli banchi rimpicciolire e finalmente scomparire presso Piancerreto, mostrandosi però ancora, ma solo per breve tratto, sotto C. Nalaterra. 
Piủ ad Est non troviamo traceia alcuna di terreni langhiani, eccetto gli accenni già sopra indicati verso Castellino; l'Elveziano allora basasi trasgressivamente ma regolarissimamente sull'Aquitaniano con un hiatus pì o meno forte secondo la località, ma in generale assai notevole.

Attorno all'affioramento oligocenico di Mombello, per la solita trasgressione tra regolare Elveziano ed Aquitaniano, rediamo nella parte meridionale mancare quasi completamente il Langhiano, osservandosi sjlo qua e là straterelli marnosi, duri, pseudo-langhiani; però tale orizronte ricomincia ad apparire presso Crosia, quantunque senza i tipici banchi fissili, ma costituito invece per lo più di strati marnosi alternati con strati arenacei, fortemente sollerati; reggonsi poscia i banchi langhiani, inclinati di circa $35^{\circ}$ o $40^{\circ}$ verso Nord, dirigersi rerso Est, incurrarsi rapidamente verso Nord al Bric del Lupo ed infine a Camino nuoramente lipiegarsi quasi di tratto relso Orest, seguendo così assai docilmente i corrugamenti che già osservammo verificarsi nei terreni aquitaniani di queste regioni.

Da Camino verso Ovest il Langhiano, che prima non avera potuto affiorare che per pochi metri, a causa della sorrapposizione trasgressiva, per' quanto regolare, dell'Elveziano sull'Aquitaniano, si sriluppa assai noterolmente per essere diventata la stratificazione assai regolare e le pendenze degli strati di solo $25^{\circ}$ o $30^{\circ}$ circa rerso il Sud; compaiono nettissimamente già sotto il Castello di Camino i suoi tipici banchi duri, marnosi, fissili, fossiliferi, che proseguono direttamente' verso Ovest, sempre noterolmente sviluppati, cioè con una potenza di circa $50 \mathrm{~m}$; essi passano gradatissimamente sia all'Aquitaniano inferiormente, sia all'Elveziano superiormente, per modo che ne rimane sempre assai incerta la delimitazione. Infine sotto le colline di Gabiano gli strati langhiani, con inclinazione di circa $40^{\circ}$ o $50^{\circ}$ a Sud, rengono ad immergersi e quindi a scomparire completamente sotto ai terreni quaternari della valle padana, ricomparendo però più ad Ovest, come redremo, nelle colline di borgata Coggia.

Attorno all'affioramento elissoidale tongriano di Villadeati rediamo ripetersi rispetto al Langhiano quasi perfettamente lo stesso fatto che aremmo ad osservare nell'affiolamento tongriano di Ottiglio-Montalero; cioè in causa della ristrettezza del corrugamento si rerifica quasi səmpre una noterole trasgressione ed un forte hyatus tra il Tongriano l'Aquitaniano e l'Elveziano, per cui il Langhiano non può generalmente venire ad affiorare; esso compare però sul lato Nord-Est dell'affioramento in esame, presso la borgata Triveja, coi caratteristici suoi banchi marnosi, fissili, fossiliferi, inclinati di circa $80^{\circ}$ verso Nord-Est.

Questi strati langhiani, con inclinazione di solo più $50^{\circ}$ o $60^{\circ}$ circa, si possono ancora seguire per lungo tratto ver'so Nord sino all'estre- 
mitå settentrionale dell'elissoide di Villadeati, finchè rapidamente assottigliandosi vengono a scomparire completamente sopra la borgata Ferrero, sovrapponendosi quivi direttamente e trasgressivamente le arenarie elveziane alle sabbie ed alle marne oligoceniche.

Si è già osservato come le tipiche marne langhiane che vengono ad immergersi sotto la pianura padana alle falde settentrionali delle colline di Gabiano, ricompaino più ad Ovest nelle colline di borgata Coggia. Or bene di qui seguendo tale orizzonte nel suo ulteriore sviluppo vediamo come esso, potente talora persino $400 \mathrm{~m}$. circa, ed inclinato di $30^{\circ}, 40^{\circ}$ e più verso l'Est ed il Nord-Est, dirigesi dapprima verso Sud, poscia verso Est, in causa delle rughe eoceniche di S. Antonio; quindi nelle colline di Ca di Garello forma una strettissima curva, dove i suoi strati vengono fortemente sollevati, talora di oltre $60^{\circ}$.

In tutta questa zona il Langhiano è in gran parte rappresentato dalle tipiche marne dure, grigiastre, fissili, racchiudenti numerosi fossili piuttosto schiacciati, colle quali però si alternano eziandio molti banchi arenacei che, come di solito, divenendo più frequenti nella parte superiore ed inferiore dell'orizzonte in esame costituiscono graduatissimo passaggio all'Elveziano ed all'Aquitaniano. 'Talora, come per esempio al Bric Favala presso Oddelengo grande, colle tipiche marne dure langhiane alternansi banchi di arenarie, più o meno calcaree, zeppe di Briozoi. Foraminiferi, ece.

Dopo la stretta curva di Ca di Garello i banchi langhiani, ancora colla tipica facies di marne dure e fissili, ma molto ridotti in potenza e sempre piuttosto fortemente sollevati ver'so Sud (talora persino di $70^{\circ}$, $80^{\circ}$, come presso S. Antonio nuovo, ma generalmente di soli $45^{\circ}$ circa) si dirigono abbastanza regolarmente ad Ovest, formano una leggera curva attorno allo spuntone liguriano di borgata Vagiardi, quivi vieppiù riducendosi in spessore per modo da prescntare solo più la potenza di una ventina di metri.

Dalle colline di Robella sino a Val Stura i pochi strati marnosoarenacei, duri, resistenti (tanto da formare le parti più elevate della collina) che costituiscono il Langhiano, coi soliti passaggi graduali agli orizzonti sotto e sovrastanti, si presentano inclinati di $60^{\circ}, 70^{\circ}$ a Sud e diventano anche quasi verticali tra Montalto e S. Biagio in causa del vicino affioramento liguriano dei Vignali.

Nell'alta valle Stura, nelle colline di casali Braja, si possono ancora osservare per un certo tratto forti raddrizzamenti di strati ed anche ripctute ripieghettature di questi, specialmente sulla destra della predetta valle alle falde delle colline Bric Serra e Bric S. Giovanni.

Più ad Ovest i duri e scagliosi banchi marnosi fossilifeli del Langhiano, scmpre ripetutamente alternati con banchi arenacei, presentano 
un'inelinazione abbastanza regolare di circa $45^{\circ}$ verso Sud-Orest, con una potenza di una trentina di metri ad un dipresso.

Nelle colline di borgata Seattara i terreni langhiani, faeendo rerso Sud-Orest una rapida curva, di cui troviamo la causa diretta in una consimile direzione che prendono i ricini afforamenti liguriani di Pareglio, si dirigono verso le eolline di Bric Bontempo e di Bric Ausano; essi ne eostituiscono appunto le parti più elerate eoi loro durissimi, e quivi assai potenti, strati marnoso-arenacei fortemente sollevati e pendenti di cirea $50^{\circ}, 60^{\circ}$ e persino $70^{\circ}$ rerso Sud o Sud-Est.

Continuando l'esame del Langhiano di queste regioni rediamo ehe al Bric Ausano esso presenta nuoramente una rapida eurva a Sud dirigendosi rel'so Sud-Est; i suoi banehi vanno poeo a poeo diminuendo di numero e di spessore presentando un'inelinazione rerso Nor'd-Est sempre assai forte, talora persino di $80^{\prime \prime}$ come presso Aramengo; talora detti banehi sono anche portati alla vertieale, come al Brie Braja, o persino leggermente rovesciati in qualche punto.

Dalla borgata Braja a Coeeonato il Langhiano, oltre all'essere molto ridotto, non offre ehe poehi straterelli marnosi fissili; si presenta in gran parte eostituito da strati marnoso-arenacei piuttosto resistenti, eoperti dalle sabbie giallastre dell'Elveziano e rieoprenti alla lor rolta un potente complesso di sabbie grigio-giallastre e di arenarie (con sparse lenti conglomeratiehe) racchiudenti fossili littoranei, per lo più infranti, dell'Aquitaniano.

Ridotti così a pochi metri di spessore e quasi rertieali, pel vicino affioramento liguriano di Marmorito, i banchi langhiani presentano sotto Coeconato un nuoro eangiamento di direzione, rolgendosi a SudOvest per modo da venire a tagliare la valle Fabiaseo presso il casotto Fornace, rieino al quale si osserrano aneora i earatteristiei straterelli marnosi, duri, scagliosi, ricchi, come sempre, di fossili animali e regetali.

Più ad Ovest, per la forte compressionc quivi subita da tutti i terreni e per la notevole, per quanto regolare, trasgressione stratigrafica esistente fra l'Aquitaniano e l'Elveziano, i banchi langhiani non possono più venire ad affiorarc; li vediamo però nuovamente eomparire, dapprima sottili ed appena discernibili, solo assai più ad Orest, sotto Albugnano.

Il Langhiano delle eolline di Albugnano e Bersano è rappresentato da poehi banchi marnoso-sabbiosi, di solo poehi metri di spessore, inclinati di cirea $40^{\circ}$ verso il Sud-Sud-Orest. Malgrado che trar essi cd i terreni sopra e sottostanti non si osservi un vero salto, tuttavia esiste una certa regolare trasgressione stratigrafica quale si può, ad esempio, esaminarc direttamente in aleuni tagli che presso Bersano mettono a nudo per un eerto tratto questi diversi terreni di passaggio e mostrano 
esistere quivi discordanze che però non alterano l'andamento regolare degli strati.

Nelle colline di Cinzano e di Sciolze i terreni langhiani, costituiti prevalentemente dalle tipiche marne dure, fissili, alternate però con banchi arenacei, presentano una media potenza ci 40 o $50 \mathrm{~m}$. ed una inclinazione variabile tra $20^{\circ}$ e $40^{\circ}$, per lo più però di solo $25^{\circ}$, ed abbastanza regolare verso il Sud eirea, formando graduale passaggio, per le solite alternanze litologiche, ai terreni aquitaniani ed elveziani.

Questa disposizione stratigrafica e la relativa resistenza dei banchi langhiani all'erosione ei spiegano quella specie di gradino regolare, diretto da Est ad Ovest, che essi formano generalmente in queste colline sul lato meridionale della Valle Maggiore di Gassino.

Nelle vicinanze di Sciolze i banehi langhiani si veggono inflettersi rapidamente e dirigersi a Nord, per modo ehe parrebbero quasi andarsi a congiungere con quelli contemporanoi della opposta parte di Val Maggiore e compiere così l'anello elissoidale dei colli torinesi. Ma invece sotto i Tetti Sachero detti strati ripigliano il primitivo andamento e volgonsi poseia verso Sud-Ovest; direzione che eonservano abbastanza costante per oltre 10 chilom., incurvandosi di nuovo a Nord solo presso Torino.

In tutta questa estesa area di sviluppo il Langhiano è costituito essenzialmonte dai suoi tipici strati marnosi fissili, ricehissimi in fossili, fra cui specialmente importanti sono le filliti che fornirono al Sismonda quasi tutto il materiale per la paleofitologia del Miocene medio del Piemonte. Come di solito vi si osservano pure ripetute alternanze di banchi arenacei e talora persino di lenti ciottolose, come ad esempio poco a Sud del Bric Palouch; questo ei dimostra che anche in localita poco lontane non furono sempre identiche nello stesso periodo geologico le condizioni di deposizione dei terreni. Talora, come ad esempio al fondo del rio dei Boschi, si vede assai bene che il tipico Langhiano superiore, a marne dure e straterellate, viene interrotto quasi di tratto da potenti banchi sabbiosi, ghiaiosi e conglomeratici riceamente fossiliferi e riferibili all'Elveziano inferiore; però poco più in alto tali banchi elveziani alternansi ancora con marne dure fissili pseudo-langhiane.

L'inclinazione degli strati è di cirea $40^{\circ}$, naturalmente con varie ma generalmente poco forti oscillazioni in riguardo; la potenza del Langhiano, essendo niinore la compressione ad assai regolare la stratificazione, diventa assai notevole, cioè di 200, 300 e più metri; ciò devesi attribuire specialmente al fatto che quivi, per l'ultima acecnnata causa, i banchi langhiani possono quasi tutti venire ad affiorar'e, tant'è che il passaggio fra essi ed i terreni elveziani ed aquitaniani diventa sempre più graduale, ed i loro limiti quindi si mostrano sempre piủ incerti. 
Nelle colline di Termofourà e di S. Margherita i fissili banchi marnosi del Langhiano, sempre ricchissimamente fossiliferi, si costituiscono poco a poco in curva regolarissima colla conressita ritolta ad Orest; in cruesto modo vengono a formare l'estremità occidentale (rispetto all'orizzonte langhiano) dell'elissoide di sollevamento da cui si è originata la collina torinese.

Passiamo ora a studiare il Langhiano dalla parte settentrionale della sovraccennata clissoide. Notisi anzitutto a questo riguardo come i banchi langhiani, i quali nella sovraindicata curva presentano un'inclinazione di circa $30^{\circ}$ verso Ovest, dopo la curva verso Est mostrano tosto una pendenza assai più fortc, cioè di cirea $45^{\circ}$ verso Nord-NordOvest; questo ei spiega il notevole rimpicciolirsi della zona langhiana da Toriuo verso Est, tanto più che in tale direzione la compressione subita da tutti i terreni e quindi la pendenza che essi presentano diventa sempre più forte. Vediamo infatti che già nelle colline di Tetti Rossi gli strati langhiani inclinano di circa $50^{\circ}$ verso Nord-Nord-Orest, e tale pendenza diventa di quasi $60^{\circ}$ nelle colline di S. Mauro e persino di $70^{\circ}, 80^{\circ}$ pil ad Est sui colli di Castiglione, di Gassino e di Bussolino torinese.

In questo percorso i terreni langhiani non solo rimpiccioliscono rispetto alla loro area apparente di sviluppo, ma realmente divengono sempre meno potenti, verificandosi (per la grande compressione ed il forte sollevamento) una continua regolare trasgressione stratigrafica in tutta la serie terziaria di queste regioni, per modo che tutti gli orizzonti sono quivi molto ridotti in spessore; naturalmente quindi il Langhiano, già sempre poco potente, è talora ridotto quivi a pochi strati, come specialmente si può osservare nelle colline di Castiglione.

Oltre ai soliti strati duri, fogliettati, vengono a formare il Langhiano numerosi banchi marnoso-arenacei, per lo più molto resistenti che talvolta anzi costituiscono quasi da soli la selie langhiana; in alcuni casi vi si osservano persino lenti ciottolose, come sotto la villa Ercolani, presso borgata S. Martimo, presso borgata S. Rocco, ece.

Ne risulta quindi come non sempre il Langhiano rappresenti unicamente un deposito di mare alquanto profondo, ma vi si debbano pur talora includere depositi di basso fondo che sono più o meno sviluppati secondo le varic località; in complesso però tali formazioni arenacee, che d'altronde gria osscrvammo altrove hel Langhiano, non alterano profondamente la facies di tranquillo deposito marino la quale caratterizza in gencrale questo orizzonte geologico.

Nelle vicinanze di Torino l'orizzonte Langhiano pel fatto, sia dell'erosione prodotta dalle correnti acquee della valle padana, sia dello sviluppo dei terreni quaternari della pianura, viene per un certo tratto 
ad essere completamente coperto dalle alluvioni quaternarie, fenomeno che vedremo ancora ripetersi più ad Est ma che non turba per nulla l'andamento stratigrafico della zona in esame.

Mentre nelle colline di Castiglione il Langhiano è quasi solo più rappresentato da banchi sabbioso-marnosi pseudo-etveziani, nella valle Maggiore di Gassino ricompaiono nettamente i tipici banchi marnosi, duri, scagliosi del Langhiano con inclinazione sempre molto forte, variante da $60^{\circ}$ ad $80^{\circ}$ eirca verso il Nord-Ovest; nelle colline di S. Dalmazzo i caratteristici strati in esame volgendosi ad Est e poi a Sud costituiscono una curva stretta ma regolarissima che rappresenta l'estremità orizzontale dell'elissoide di sollevamento dei colli torinesi.

Dopo l'accennato incurvamento della zona langhiana i suoi banchi marnosi, duri, fissili, alternati con strati arenacei o marnoso-arenacei, presentano per un certo tratto una direzione da Nord-Est a Sud-Ovest con pendenza di $60^{\circ}, 70^{\circ}$ e più verso Sud-Est; poscia, invece di continuare in tale direzione per modo da congiungersi con quelli contemporanei e poco lontani delle colline di Sciolze, vediamo tali banchi eurvarsi rapidamente ad Est e svilupparsi poi per lunghissimo tratto in questa direzione; essi costituiscono naturalmente un'area molto allargata nelle vieinanze di Rivalba dove avviene tale curva, ma in seguito riduconsi nuovamente ad una striscia poeo espansa.

Quasi ovunque si può osservare un passaggio abbastanza graduato tra i terreni del piano langhiano e quelli dei piani geologici sopra e sottostanti; quindi le loro delimitazioni riescono sempre ineerte ed alquanto arbitrarie, tanto più che spesso coi banchi tipici del Langhiano si alternano strati arenacei viceversa veggonsi pure strati marnosi, duri, pseudo-langhiani, specialmente nella parte supcriore dell'Aquitaniano (ciò ehe già più volte accennammo anche rispetto all'Aquitaniano subappennino), ma anche, quantunque più raramente, nella parte inferiore dell'Elveziano. Tuttociò ci prova scmpre più l'importanza solo relativa che hanno le minute distinzioni dei piani geologiei.

Oltre ai soliti fossili schiacciati delle marne seagliose incontransi talora impronte di Zoophycos sulla superfieie dei banchi marnosi, non fissili, del Langhiano, cosi ad esempio nella collinetta immediatamente ad Ovest di Rivalba.

Da quest'ultina regione sino al Bric La Torre $(401 \mathrm{~m}$.) i banchi langliani a facies complessivamente assai tipica, con potenza abbastanza notevole e con direzione costante da Ovest ad Est, presentano una pendenza media di $30^{\circ}$ verso Nord, inclinando di eirca $20^{\circ}, 25^{\circ}$ nelle colline di Rivalba, ma poscia di $30^{\circ}$ o $40^{\circ}$ più ad Est nelle colline di Bric la Torre. Di qui la zona langhiana, sempre assai potente, formando un'ampia curra con convessità ad Est, si dirige verso Nord 
costituendo coi suoi resistenti banchi marmosi-arenacei, inclinati di circa $45^{\circ}$ verso Ovest, la parte piủ elevata delle colline di Bric Irartino, Bric della Guglia, Bric Cirignola e Bric Carrassa, poco a poco però rolgendosi verso Nord-Ovest.

Dal Bric Carussa il Langhiano, continuando nell'accennata curva, si dirige a Nord-Orest con un inclinazione di circa 30" rer'so Sud-Orest, per modo che tra Rivalba e S. Sebastiano esso costituisce una vera conca, chiusa ad Est ed aperta ad Orest, in cui si adagiano i terreni elveziani.

Dopo aver costituito parte delle colline di C. Fraschea il I anglizano si immerge sotto le allurioni quaternaric, deposte dalle acque del Po che quivi erosero profondamente i terreni della collina. Tale terreno riappare peró poco ad Ovest nelle colline di Tetti Verde, dove é ridotto a poca potenza; anzi i suoi duri banchi marmosi ed arenacei ranno rapidamente rimpicciolendo verso Orest; nelle colline di C. Gerbido tali baxchi sono molto ridotti, in gran parte arenacei, inclinati di 50, 60 , 70 relso il Sud eirca, ed infine rengono anch'essi a scomparire completamente presso Castagneto per una trasgressione stratigrafica sempre piủ forte quantunque regolare tra l'A quitaniano e l'Elveziano.

Tuttaria sotto C. Gallinetti, nel passaggio tra Aquitaniano ed Elreziceno, rediamo ancora comparire qualeuno dei tipici banchi marnosi, duri, fissili del Langhiano nella stretta curva che quivi tutti i terreni formano in modo da dirigersi rerso Est; ma in complesso si puó dire che sul lato settentrionale dell'affioramento oligocenico di Castagneto i terreni langhiani non rengono quasi ad affiorare essendo trasgressiramente ricoperti e quindi mascherati dal potente Elveziano.

Se noi cerchiamo di seguire idealmente l'andamento della zona langliana verso l'Est, possiamo dire che essa, sotto la pianura padana, si manticne quasi parallcla all'allineamento che osservammo nel Langhiano Bric Carrassa-Tetti Verde, il quale costituisce la gamba meridionale dell'anticlinale di cui studiamo ora la gamba scttentrionale. Infatti vediamo ricomparirc il Ianghiano tipico nelle colline tra bolgata Colombaro c Lauriano, quivi anzi costituendo esso la cresta di queste colline coi suoi banchi specialmente marnosi, duri, fissili, riccamente, fossiliferi, diretti quasi da Est ad Orest ed inclinati di circa $70^{\circ}$ verso Nord, con una potenza media di 100 metri all'incirca.

A Lauriano i terreni langhiani nuovamente si immergono sotto le alluvioni quaternarie della pianura, per poscia ricomparire, quasi cogli stessi caratteri e colla stessa direzione ed inclinazione di prima, nelle colline di Monteu da Po e di Caragnolo. Quivi tuttaria il Langhiano redesi ridotto assai di potenza; anzi rerso Casamosso rengono quasi a mancare i tipici banchi marnosi, duri, probabilmente per una piủ acccntuata trasg'ressione stratigrafica tra l'Elveziano e l'A quitaniano. 
Ad Est delle eolline di Cavagnolo i banchi langhiani nuovamente seompaiono sotto i terreni quaternari di Brusaseo ed è notevole ehe la zona langhiana ehe abbiamo seguita per eosi lungo tratto nei suoi vari giri e ligiri nelle colline Torino-Casale, si perda qui completamente e per sempre, almeno agli oeehi del geologo. Ciò dipende dal fatto ehe per trovarsi gli affioramenti liguriani, ad Est di Brusaseo, specialmente nella parte settentrionale della regione collinosa TorinoCasale, i terreni terziari ehe vi si appoggiano verso Nord rimangono sepolti in gran parte sotto ai terreni quateruari della pianura padana; eiò d'altronde corrisponde pure alla maneanza del Langhiano ehe abbiamo verificata nelle colline tortonesi settentrionali.

\section{Riassunto.}

Da quanto si è esposto attolno al Langhiano del bacino terziario del Piemonte possianto dunque eonchiudere ehe questo orizzonte geologieo vi è ampiamente distribuito, quantunque in generale poeo potente, raramente oltrepassando esso in spessore i 1000 metri ed invece avendo solo una potenza media di eirca $200 \mathrm{~m}$.

Il Langhiano rappresenta in generale un tranquillo deposito di mare abbastanza profondo ed è per lo più eostituito di banchi grigiastri, marnosi, piủ di rado arenaeei, spesso induriti e seagliosi, fissili, per la potente compressione subita dopo la loro deposizione.

L'andamento stratigrafico è in complesso assai regolare; nelle colline Torino-Casale questo terreno prende parte ai ripetuti e svariati corrugamenti a cui andarono soggetti i terreni terziari di tali regioni.

Per essere il Langhiano essenzialmente marnoso esso per lo più forma colline poco elevate, relativamente almeno a quelle circostanti; tuttavia là dove esso è eostituito da banehi più resistenti, o perehè arenacei o perehè fortemente cementati, colà esso vien spinto anche oltre 700 metri nelle Langhe ed oltre 500 metri nelle eolline torinesi.

Esiste generalmente un passaggio graduatissimo tra il Langhiano ed i terreni dei due orizzonti geologici fra eui è esso compreso; ciò si rerifiea per mezzo di ripetute alternanze di banehi marnosi ed arenaeei, rarantente con trasgressioni stratigrafiche; ne risultano quindi grandi incertezze nella delimitazione di quest'orizzonte, tanto più che da regione a regione certi banchi cangiano poeo a poco di facies e naturalmente anche di earattere paleontologico.

I fossili del langhiano appartengono generalmente ad animali pelagiei o di mare alquanto profondo, sovente vi si trovallo pure numerose filliti; tali fossili abbondano specialmente nelle marne dure, sehistose, fogliettate, che sono pressocchè earatteristiche del Langhiano del bacino terziario piemontese. 


\section{CAPITOLO XI. \\ ELTEZIAX̃O.}

\section{Studi anteriori.}

Siecome il piano geologieo di cui ineominciamo l'esame è fra i piani miocenici del baeino terziario piemontese, eome d'altronde anehe in generale, uno dei più sviluppati e dei più potenti, ed è inoltre in eerte regioni straordinariamente rieco in fossili assai ben conservati, naturalmente di esso molto si sono già occupati i geologi ehe ebbero a trattare dei terreni terziari del Piemonte.

In generale però i terreni elre:iani, quali io eredo ehc debbansi intendere, furono per lo più eompresi dal Sismonda, dal Gastaldi, eec. eoi terreni langhiani, ed anehe in parte eon quelli aquitaniani, sotto il nome di Miocene medio; è sotto quest'appellativo appunto ehe vennero finora indieati i famosi fossili elveziani delle eolline torinesi, detti eziandio falsamente fossiti di Superga: dieo falsamente perehè nelle eolline di Superga havvi solo l'Aquitaniano con poehi e per lo più mal conservati fossili. Trattasi solo d'altronde in questo easo di uno di quegli errori di denominazione che derivano dalla maneanza di aceurato esame delle loealità da cui tali nomi furono tratti, ma che in fondo, purehè riconoseiuti, non reeano aleun svantaggio alla seienza.

Il Pareto nel suo bellissimo lavoro sulla divisione dei terreni terziari distingue in generale assai bene i terreni elvesiani, ehe appella però serravalliani, e ne indiea a larghi tratti l'andamento attraverso ad una parte del Piemonte; talora però vi ingloba anehe banehi langhiani, ad esempio quelli marnoso-arenaeei di Sorli, ehe hanno effettiramente una facies elvesiana; in alcuni punti poi vi ingloba pure parte dell'Aquitaniano. Sono però queste ben piccole mende rispetto al fatto importante, messo bene in chiaro pel primo dal Pareto, del grande sviluppo dell'Elveziano nel baeino terziario del Piemonte.

Il Mayer, ehe sin nelle sue prime tavole di elassificazione dei terreni terziari di Europa avera aceennato alla presenza dell'Elresiano in aleune parti del Piemonte, nella sua descrizione geologiea della Liguria distinse più nettamente questo pieno geologico indicandone lo sviluppo e l'andamento nella parte Sud-Est del baeino in esame; anzi il Mayer eredette poter suddividere l'Elvesiano in tre sottopiani che io non fui eapaee di riconoscere; debbo però eonvenire ehe in aleune regioni, ma non in generale, sonvi notevoli differcnze tra le assise inferiori medie e supcriori di questo piano, ehe però conserva generalmente una sola facies complessiva. D'altronde lo stesso Mayer nelle sue 
ultime tavole di classificazione riduce a due sole le divisioni dell'Elveziano anche nel Piemonte; ma neppure questi due sottopiani paionmi adottabili in gencrale.

Quanto alle carte geologiche accenniamo come in quella del Sismonda l'Elveziano venne indicato assieme a tutti i terreni oligocenici e mioeenici con una sola tinta corrispondente al Miocene; lo stesso osserviamo nelle carte geologiche d'Italia pubblicate dal R. Comitato gcologico nel 1881 e nel 1889.

Nella reccnte carta geologica più dettagliata pubblicata da Issel, Mazzuoli c Zaccagna l'Elvesiano, assicme all'Aquitaniano al Langhiano ed al Tortoniano venne racchiuso in una sola divisione del Miocene eol nome di Miocene medio.

Come di solito ho indicato solo qui i più importanti lavoli geologici finora fatti sull'Elveziano del Piemonte, ma risulta già chiaramentc dal sovraesposto come, per quanto su questo terreno siansi fatti maggiori studi che non su quelli prima esaminati, molto resta ancora a compierc a quel riguardo dovendosenc anzitutto segnare i limiti c lo sviluppo preciso attraverso tutto il bacino piemontese.

\section{Generalità.}

La facies complessiva del piano elveziano nel Pienınte si può nettamente definire come una facies di basso fondo marino e talvolta anche di vero littorale; questo carattere si conserva assai distinto in ogni parte del bacino per modo che l'orizzonte in csame risulta uno dei più tipici della scrie terziaria.

Oltre ai carattcri paleontologici che vedremo confermare il sopradetto, sono specialmente le sabbie, le arcnarie ed i conglomerati (talvolta ad elementi voluminosissimi), cioè i caratteri litologici, quelli che ci indicano ncll'Elveziano un deposito formatosi alquanto rapidamente ed anche talora tumultuosamente in un mare poco profondo o presso la spiaggia, per modo da non essersi sempre potuto verificare una cernita del materiale che si andava allora depositando.

Vedremo perỏ nel corso del lavoro come questo carattere generale di basso fondo sia non di rado alterato più o meno fortemente da dcpositi di mare abbastanza profondo, alternati con quelli littoranei, ciò che però non cangia la facies complessiva dell'Elvesiano.

La predominanza di arenarie, ad clementi pcr lo più alquanto dccomposti, fa si che in complesso i banchi elveziani hanno una tinta generale grigio-giallastra interrotta solo dai banchi marnosi grigiobleuastri.

Nelle colline monregalesi l'Elveziano è sabbioso-ciottoloso nella parte inferiore cd invece piuttosto marnoso-sabbioso nella partc superiore. 
Telle Langhe esso è prevalentemente costituito da un'alternanza, mille e mille volte ripetuta, di banchi marnosi, sabbiosi ed arenacei; nell'alto Ionferrato e nel Tortonese quest'orizzonte è essenzialmente costituito di grossi banchi arenaceo-calcarei, giallastri, alternati piủ o meno frequentemcnte con banchi marnoso-sabbiosi.

Nella parte orientale delle colline Torino-Talenza (come nel tortonese occidentale sino alla conca di Gabiano) l'Eliesiano è in gran parte rappresentato da banchi marmosi arenaceo-calcarei i quali da Gabiano sino alle colline di Albugnano sono invece sostituiti da banchi marnososabbiosi facenti passaggio alla caratteristica facies che presentano poi tali terreni nei colli torinesi. Nelle colline di Torino i terreni éveziani, spesso straordinariamente ricchi in fossili, sono rappresentati, oltre che da banchi marnoso-sabbiosi, da potcnti banchi ghiaioso-ciottolosi, che ricordano quelli contemporanei dei colli monregalcsi. Ciỏ ci indica cssere tali depositi comnessi per la natura litologica colle ricinanze della catena alpina, come d'altronde è naturale.

$\dot{E}$ inutile indicare come le dirisioni suddette riguardo alla fucies dell'El'eziano del bacino terziario piemontese debbonsi solo intendere in largo senso, giacchè non $\mathrm{r}^{*}$ sono nette distinzioni in proposito, ma bensi gradualissini passaggi, comnessioni, altermanze, ecc.

\section{Caralleri paleontologici.}

Per quanto sia relativamente ristretto il bacino terziario del Piemonte, tuttavia nelle rarie sue parti dobbiamo constatare noteroli differenze rispetto ai caratteli paleontologici; non giả perchè realmente esistano forti differenze nelle forme fossili, ma perchè csistono noteroli distinzioni nella distribuzione di detti fossili; questo d'altronde è in stretto rapporto colle condizioni srariate che, durante lo stesso periodo geologico, si verificarono nelle raric parti del bacino in esame.

Limitandoci ora al terreno elvesiano rediamo bensì che quasi. orunque il carattere della sua fauna ci rappresenta una facies di bassofondo marino, ma constatiamo pure che nella parte meridionale la facies palcontologica è assai più spiccatamentc littoranea che non nella polzione settentrionale; ne consegue che, se molti fossili sono comuni alle due parti del bacino, moltissimi però sono affatto peculiari ai banchi affioranti nelle colline Torino-Valenza e finora non vennero ancora trorati nell'Elveziano subappenninico. Ticeversa noi possiamo citare la mancanza, nei colli Torino-Valenza, di quelle impronte srariate, fra le quali sono specialmente carattcristici i Paleodictyon, che inrece abbondano straordinariamente nell'Elcesiano delle Langhe e dell'alto Ionferrato, essendo essi legati, secondo il mio parcre, a depositi formatisi in ma regione littoranea, sommersa di poche decine di metri 
e solo leggermente inclinata. D'altronde tale distinzione tra le due porzioni del bacino in esame si può anche fare rispetto a quasi tutti i terreni mioeenici più antichi dell'Elveziano, eiò ehe ci indica come la differenza nelle condizioni di formazione dei diversi depositi vi si conservò sempre assai spiceata durante tutto il periodo miocenico.

Trattandosi, per le colline torinesi specialmente, di ma fauna tanto rieca e famosa (fauna di Superga) sia pei Molluschi ehe per gli Antozoi, gli Echinodermi, ece., non eredo necessario fermarmici sopra per ora; ne sarà invece dato il eatalogo nella parte paleontologica del lavoro; basti qui indicare la presenza di alcune forme piu abbondanti o earatteristiche come i denti di Carcharodon megalodon, la Sprivtlimostra Bellardir, l'Atwia Aturi, il Pentacinus Gastaldii ece. ece.

\section{Distribuzione geografica.}

L'Elvesiano occupa una parte molto vasta ed importante nel bacino terziario picmontese, a causa sia della sua potenza, sia del fatto che, per essere $\mathrm{i}$ banchi che lo costituiscono assai meno fortemente inclinati di quelli degli orizzonti più antichi, esso occupa naturalmente, anche a potenza eguale, un'area molto più ampia.

Vediamo infatti che i terreni elvesiani, già assai potenti nelle colline monregalesi, le quali ne sono in gran parte costitnite, tosto anplissimamente si sriluppano nelle Langhe, vasta regione collinosa formata in parte di Aquiluniano ma in parte ancor maggiore (verso Nord-Ovest) di Elvesiano. In seguito questo orizzonte geologico, sempre eon potenza ragguarderole, dirigendosi verso Est costituisee una porzione notevolissima delle colline dell'alto MLonferrato. Sempre colla stessa direzione ad un dipresso, ma eon spessore meno noterole, l'Elreziano vicne a formare le ripide colline di Carpeneto, Castelletto di Orba, Gavi, Serravalle, ece.

Oltrepassata la Val Serivia la zona elvesiana, sempre essenzialmente arenacea, si incurva poco a poco verso Nord, prendendo così parte alla costituzione delle eolline tortonesi, finchè rapidamente impicciolendo viene a scomparire, come gli altri orizzonti miocenici, a poca distanza dall'affioramento lignciano di Brignano-Spinetta.

Però nella parte occidentalc delle colline tortonesi compaiono ancora alcuni lembi elveziani, quasi anse dclla vasta formazione elvesiana sepolta sotto la pianura alessandrino-padana; ampiamente ed assai caratteristicamente sviluppato è questo orizzonte nelle colline rogheresi, pavesi ecc.

Nella eostituzione delle colline Torino-Valenza i terreni elvesiani formano una parte importantissima, spccialmente nella porzione occidentale di detti colli, però con facies diversissima da regione a legione, come vedremo in seguito. 
Non è possibile indicare sinteticamente l'andamento dell'Elrezicuno nei colli Torino-Talenza, basta per ora aceennare come esso segua abbastanza regolarmente quello dei terreni sottostanti già sopra deseritti, ai quali si appoggia generalmente senza salti, solo talora con piủ o meno noteroli ma regolari trasgressioni; esso prende cosi parte a tutte le rarie e piu o meno regolari elissoidi di solleramento da cui ebbero origine le colline sovraccennate.

\section{Tettonica.}

L'andamento stratigrafico dei banchi elveziani è piuttosto regolare nella porzione meridionale del bacino terziario piemontese, giacehè possiamo eonstatare quasi orunque essere la loro pendenza di circa $10^{\circ}$ a $20^{\prime \prime}$ rerso l'interno del baeino. Nelle regioni (eome ad esempio nelle Langhe) in cui l'Etresinno redesi occupare un area rastissima, colà l'inelinazione degli strati è di solo $8^{\circ}, 10^{\circ}$ o $12^{\circ}$ in media; inveee piủ ad Est, dore la zona elveziana presentasi più ristretta, i suoi banchi hanno generalmente una pendenza di $15^{\circ}, 20^{\circ}$ e più.

Per quanto pieeoli salti e seorrimenti si possano osservare comunissimamente, in pochi punti però osserransi disturbi stratigrafiei in grande scala: di tali disturbi si può accemnare quale esempio abbastanza importante quello delle colline di Trisobbio, dore i banchi elvesiuni, come già quivi osserrammo pei banchi langhiani, sono fortissimamente sollevati ed anche alterati rispetto alla loro generale direzione regolare.

Nelle colline Torino-Valenza, eome in parte nei colli tortonesi, i terreni elvesiani, pur seguendo abbastanza regolarmente l'andamento dei terreni più antichi, non si presentano in generale cosi fortemente sollevati eome quelli oligoeeniei. Ad ogni modo la loro inclinazione è sorente assai notevole, per quanto raria, sia nelle diverse regioni, sia nella stessa regione tra la parte inferiore (sempre più sollerata) e lá parte superiore dell'orizzonte in esame.

Nel eor'so della deserizione regionale arremo occasione di osservare come talora per ripetuti ripiegamenti i banehi elvesiani delle colline Torino-Valenza siano disposti talora a cupola e talora a conea più o meno regolare, mai però eompletamente isolata; ambidue queste maniere di presentarsi degli strati elve ziani sono importanti perehè dànno origine o a colline od a larghe ralli orografiehe, mentre generalmente le eolline della parte meridionale del baeino piemontese sono dorute essenzialmente all'erosione aequea.

Malgrado questi ripetuti ineurvamenti degli strati elvesiani dei colli Torino-Talenza non vi si notano forti disturbi per salti o scoseendimenti, solo non di rado osserrantisi regolari trasgressioni stratigrafiehe. 


\section{Potenza.}

Come avviene per tutti gli orizzonti geologiei l'Elveziano presenta nelle varie località in cui si osserva una potenza svariatissima; in questo easo da pochi metri ad oltre 1000, 2000 metri.

Naturalmente è nelle regioni in cui l'Elveziano oceupa un'area piủ vasta che noi dovremo trovare la sua maggior potenza. Però se osserviamo solo superficialmente il grandissimo sviluppo dell'Elveartuno nelle Langhe noi saremmo indotti ad attribuirgli uno spessore veramente straordinario; ma se teniamo conto della inclinazione poco notevole ( $10^{\circ}$ a $12^{\circ}$ in media, ed anche spesso minore) dei suoi strati, pur considerando che in queste regioni collinose, per la stratigrafia regolarissima, quasi tutti i banchi depostisi nel periodo elvesiano vi vengono ad affiorare, possiamo calcolare la potenza dell'intiera pila clveziana a solo 2000 o 2500 metri circa; tale cifia è certamente ancora molto notevole ma è facilmente spiegabile considerando il modo di formazione e quindi la natura litologica dell'orizzonte in esame.

Nel Monferrato e nel 'Tortonese l'Elveziano, per quanto sempre piuttosto potente, oltrepassa raramente i 1000 metri in spessore. Invece nelle colline Torino-Valenza, o per dir meglio nella loro parte occidentale, l'Elveziano mostra nuovamente una potenza molto notevole, sovente di oltre 1000 metri; talora anzi la pila elveziana raggiunge od anche oltrepassa i 2000 metri di spessore, come nelle colline ad Ovest della conca di Casalborgone e nella estremità occidentale dei collí torinesi, cioè là dove $\mathrm{i}$ banchi elveziani vengono quasi tutti a giolno; in generale invece si verifica che per le graduali trasgressioni, causate dalle potenti compressioni e dai forti sollevamenti, solo una parte dei depositi formatisi nei varii periodi geologiei puo ora essere direttamente osservata; in gran parte invece rimane nascosta all'osservatore. Questo ulcimo fatto è specialmente accentuato pei depositi marnoso-argillosi.

\section{Altimetria.}

In rapporto colla natura prevalentemente arenacea e quindi abbastanza resistente dell'Elveziano è naturale che i suoi banchi vengano spesso a costituire colline molto elevate relativamente non solo ai terreni più giovani ma anche a quelli più antichi, specialmente rispetto al Langfiano.

Infatti pel' quanto l'Elveziano della parte meridionale del bacino in esame sia generalmente assai distante dall'asse della catena alpino-appenninica, dove in generale verificansi i piu forti sollevamenti, tuttavia in alcuni punti delle Langhe $\mathrm{i}$ suoi banchi arenacei inferiori vengono spinti sin oltre gli 800 metri, talora anzi raggiungendo quasi i 900 
metri, eome al paese di Mombarearo $(898 \mathrm{~m}$.), di dore per la grande altezza si può redere il mare e distinguerri anehe le navi; donde il nome dato al paese.

Nella restante parte del baeino in esame l'Elveziano trorasi spinto generalmente ad elerazioni assai meno noteroli per quanto esso sia quasi sempre sollevato molto più dei terreni langhiani.

Nelle eolline Torino-Talenza vediamo ehe i eorrugamenti orografiei portarono talora i banehi orografici ad altezze relativamente assai noteroli ed anzi nelle eolline torinesi è preeisamente l'Elue ziano quel terreno ehe riene a costituile la regione più elerata di tutto il sistema eollinoso Torino-Talenza, eioè il Brieeo della Maddalena (716 m.); questo fatto, oltre ehe alla notevole forza del sollevamento presso Torino, è pure in parte dovuto alla potenza ed alla natura dei terreni elvesiani di questa regione.

\section{Rapporto coi terreni sotto e soprastanti.}

Nel capitolo preeedente si è già più e piủ volte aeeennato al passaggio, sorente molto graduale, ehe si verifiea tra l'Elresiano ed il Langhiano per ripetate alternanze di banehi sabbioso-arenaeei eon banehi sabbioso-marnosi, e si è pur detto ehe, per quanto in aletme regioni le arenarie giallastre dell'Elve ziano superiore si appoggino quasi di tratto sulle marne grigio bleuastre del Langhiano eon poehi banehi di passaggio, in generale inveee nella delimitazione di questi due orizzonti geologiei si verifiea una grande ineertezza.

Anehe nella parte superiore dell'Elveziano ineontransi tali dubbi quando si ruol distinguere questo orizzonte dal soprastante Tortoniano, giaeehè generalmente questo passaggio arviene in modo assai graduale per un'alternanza di banehi sabbiosi, od anehe arenaeei, eon banehi marnosi o marnoso-argillosi.

Tale distinzione, ehe risulta quindi sempre alquanto arbitraria quando si debbono segmare sulle earte a grande seala i limiti dei due piani geologici, è inveee assai naturale quando vien eonsiclerata nel suo eomplesso, essendo essa eonvalidata sia dilla paleontologia (per quanto anel1'essa presenti graduali passaggi), sia dalla litologia (per essere l'Elve:iano eomplessiramente sabbioso ed il Tortoniano essenzialmente marnoso), sia anehe dalla orografia, giaeehè le eolline elresiane sono piuttosto elevate, a ripidi pendii e spesso soleate da profondi burroni, mentre quelle tortoniane in generale sono più basse ed a pendio assai più dolee.

\section{Località fossilifere.}

Nella zona elveziana ehe riene ad emergere nella parte meridionale del baeino piemontese non si possono generalmente designare rere 
localita fossilifere perchè $i$ fossili sono per lo più sparsi qua e là in quasi tutti gli strati ed a tutti i livelli ma viccrersa in gencrale poco conservati e spesso infranti o, sc anche intieri, difficili ad estrarsi completi.

In alcuni banchi marnoso-sabbiosi dell'Elveziano superiore sono abbondanti i denti di Carcharodon i quali si possono racogliere particolarmente rimontando i rii che, specialmente nelle Langhe, incidono profondissimamente le regioni elvesiane (Fosso Oteria nelle colline monregalesi, valloni attorno a Roddino, Serralunga, Clavesana, trincee ferroviaric presso i Tetti di Clavesana, Rio Rotaldo sotto Novello, cce., cec.). Copiosi resti di animali littoranei (Ostrea, Pecten, Balanus, ecc.) riscontransi in alcuni speciali banchi arenacei griallastri dell' $E$ veziano superiore delle Langhe, così presso S. Rocco Olmetto (Ovest di Belvedere), nelle arenaric di Madonna di Moreno (Est di Dogliani), nelle colline di S. Bernardo (Nord di Dogliani), in quelle di Monforte, di Barolo, di Diano d'Alba, cec.

Talora coi resti fossili animali incontransi anche filliti abbastanza ben conservate, specialmente in particolari bancli sabbioso-m?rnosi straterellati, così ad csempio al Bric della Guardia ed in diversi altri punti delle colline monregalesi.

Particolarmente abbondanti o, meglio, più facili a raccogliersi sono i resti fossili nei banchi arenacci sia dell'Elvesiano inferiore sia dell'Elveziano superiore, là dove essi divengono calcareo-arenacei, come in gran parte del loro sviluppo dalla Val Bormida presso Acqui sino al Tortonese; in questa zona di sviluppo si possono pure raccoglierc nell'Elveziano abbondantissimi Foraminiferi che in parte fornirono il calcare cementante; tali fossili sono però anche assai comuni negli altri depositi elveziani.

Più facili a rinvenirsi sono i resti fossili là dove esistono lenti ghiaiose conglomeratiche (così nell'Elve :iano inferiore a Nord di Monbasiglio) od anche solo ciottoli sparsi qua c là fra le marne, come spesso si asserva nelle Langhe, indicandoci ciò un deposito alquanto irregolare che produsse localmente la distruzione di animali e quindi l'accumulamento di fossili in punti speciali.

Nelle colline monregalesi (oltre alla fauna salmastra, ricea in Potamides, Melanopsis, ccc., racchiusa nelle marne lignitifere presso le sorgenti sulfuree del Santuario di Mondovì) si può racoglicre una ricchissima fauna molto simile a quella famosa dei colli torinesi, specialmente csaminando i depositi marnoso-ciottolosi; così nei rii che incidono ad Orest la collina stessa di Mondovì, qua e là lungo il Torrente Ermena, lungo l'Ellero quasi di fronte al borgo di Carassone, cce.

In alcune regioni sono abbondantissimi i resti di Zoophycos Gastaldii 
di cui è facile fare raccolta specialmente sulla destra del Tanaro alla base degli spaccati di Rocca Cigliè.

Quanto alle impronte organiche ed inorganiche di Paleodictyon, Helminthopsis, Helminthoidea, Nemeritilhes, ece, quantunque accurate ricerche me ne abbiano fornito un grandissimo numero specialmente nelle colline di Ciglie, Rocca Cigliẻ, Claresana e Belredere, tuttavia si può dire che esse sono comumissime in tutte le Langhe cd in gran parte nel Monferrato, specialmente là dore rerificansi rípetute altermanze di letti marnosi con letti arenacei.

In conchusione adunque si può dire che rere località particolarmente fossilifere non si possono indicare rispetto all'Elve ziano nella parte meridionale del bacino terziario del Piemonte; chi però rolesse raccogliervi fossili, con ricerche un po' accurate ne può trovare quasi orunque.

Molto fossiliferi sono i banchi elvesiani marnoso-calcarci delle colline tortonesi occidentali e quelli arenaceo-calcarei (spesso un rero impasto di fossili) che stiluppansi più ad Est rerso le colline rogheresi e paresi; ne sia esempio il M. Valassa.

Nelle colline Torino-Valenza sono abbondantissime le località fossilifere; nella parte orientale esse si presentano con una facies molto dirersa da quella che offrono nella parte occidentale, ciò in rapporto naturalmenté colla natura dei depositi che nelle due parti rappresentano l'Elesiano, e quindi dell'ambiente in cui vissero gili animali di quel periodo.

Infatti nella parte orientale della regione collinosa in questione predominano le marne sabbiose più o meno calcaree specialmente ricche in denti di Squali che sono sorente incontrati da quelli che escarano tali banchi per estrarne materiali da costruzione (canloni). Assieme a tali denti trovansi pure molti altri resti fossili, ma questi rirengonsi specialmente abbondanti (talora costituendo veri letti di Lithothamnium impastati con resti di Foraminiferi, di Antozoi, di Echinodermi, di Molluschi, ecc.) in alcune localita dore predominano le arcnarie più o meno cementate; si puo citare come escmpio la parte piu alta del paese di Conzano, le colline di Vignale, i dintorni di Moleto e di Ottiglio, la parte piu elevata delle colline di Villa Mandoletta (Sud di Casale), le colline di Rosignano Monferrato, di Treville, di Ozzano (specialmente sotto C. Baracone e presso C. Rira), le cime delle collinette su cui siedono il castello ed il cimitero di S. Giorgio Monferrato (dore in men di un ora si può dire che è possibile fare una raccolta ricchissima di fossili elveziani assai ben conselvati e facilmente liberabili dall'arenaria arvolgente), le colline di Torre Veglia e di Colma a Sud di Casale (dore sonvi strati di quasi un metro di spessore costituiti quasi unicamente 
di grossi Lithothamnium liberi o cementati, e strati in cui queste Alghe fossili sono fortemente cementate con abbondantissimi resti animali, specialmente Echinodermi, Antozoi, Briozoi e Molluschi). Ma di queste e di numerose altre localiti fossilifere avremo occasione di trattare più minutamente nella descrizione geologica regionale.

Nei dintorni di Villadeati i pochi banchi elveziani sono talora zeppi di fossili, fra cui abbondano specialmente i Foraminiferi.

Ad Ovest delle colline di Cocconato l'Elveziano poco a poco cangia di facies litologica e cangia quindi anche il modo di presentarsi dei suoi fossili; essi cioè non si trovano più generalmente sparsi fra le marne sabbioso-calcarce oppure ammassati in banchi calcarco-arenacei, ma invece presentansi per lo più liberi e commisti a sabbie ghiaiose od anche a veri conglomerati.

Diverse località delle colline torinesi divennero o diverranno famose per la loro ricchezza in fossili, cosi le colline di Costiglione-S. Mauro, le vicinanze di S. Raffaele (specialmente di fronte a Villa Alcssio), le colline di Mongreno, la Villa Rovasenda presso Sciolze, i dintorni di Baldissero, la regione di Telmofourà, alcuni punti di Val Ceppi, il Pian dei Boschi presso Pino torinese, diversi punti di Val Salice (Rio della Batteria), la Villa Forzano, il Monte dei Cappuccini, ccc., ecc. Ma alcune di queste località hanno attualmente solo più un'importanza relativa, sia perchè in parte sono già esaurite oppure divenute di difficile osservazione perchè coperte ora da vegetazione o da costruzioni, sia perchè la loro fama derivò essenzialmente dall'essere di facile accesso per trovarsi a poca distanza da Torino o da qualche luogo di villeggiatura di chi cbbe ad occuparsi di questi fossili. Ho creduto tuttavia doverli indicare almeno per la loro importanza storica perchè è in tali località appunto che i pionieri della paleontologia piemontese, Sismonda, Michelotti, Bellardi, Gastaldi, Rovasenda, Mayer, ecc., raccolsero quasi tutto il ricco materiale che costituisce la fauna del MIiocene medio delle colline di Torino o, impropriamente, di Superga.

Ma facendo lo studio generale dei colli torinesi potei constatarc: $\left(1^{\circ}\right)$ anzitutto che le localita fossilifere sono straordinariamentc abbondanti; $\left(2^{\circ}\right)$ che esse sono per lo più collegate colla presenza di ghiaie c di conglomerati, ed infine $\left(3^{\circ}\right)$ che i banchi più ricchi in fossili fanno generalmente parte di un orizzontc speciale che sta alla basc dell'Elveziano, per modo che, senza che io passi a numerare la seric delle numerose localita fossilifere, tenendo conto di queste due ultime leggi sarà d'or innanzi abbastanza facile, a chi vuol raccogliere fossili dell'Elve ziano dei colli torinesi il far ricerche fruttuose anche in localita finora inesplorate a questo riguardo, solo osservando la carta geologica.

Devo però subito soggiungere che, sc per la maggior parte le località 
fossilifcre dei colli torinesi possonsi raggruppare in un orizzonte speciale che sta alla base dell'Elveziano, non solo ve ne sono pure molte altre (anche ricchissime in fossili ed anzi alcune gia famose, come ad esempio quella di Baldissero) nell'Elvesiano sia medio che superiore, ma quasi ovunque l'Elvesiano è più o meno fossilifero; anzi sarebbe certamente molto utile che si facessero pure accurate ricerche nei banchi marnosi (di cui alcuni assai ricchi in Zoophycos specialmente nell'Elveriano superiore) giacchè vi si trovano spesso forme assai diverse da quelle che incontransi nei letti ghiaiosi i quali finora costituirono generalmente il solo punto di ricerca dei paleontologi; questo metodo unilaterale, direi, di ricerche paleontologiche trova la causa nel fatto che tali letti ghiaiosoconglomeratici in breve tempo di esplorazione offrono una abbondante messe di fossili, cagionando nel raccoglitore molte di quelle intime e forti soddisfazioni che ben conosce chiunque si è dato a questa sorta di r’icerche.

Notiamo poi come nelle colline di Moncucco, Aruglione, ecc., il Tortoniano superiore assume una facies littoranea pseudo-elveziana, e che solo l'csame dei fossili riesce in parte ad escludere dall'Elreziano tali terreni prevalentemente sabbioso-ghiaiosi.

\section{Descrisione geologica regionale.}

Si è già detto come in gencrale l'Elve ziano sia molto ampiamente sviluppato nel bacino in esame, per modo che arremo talora ad osservarlo in regioni dore now si potè depositare alcuno dei piani miocenici più antichi. Tale fatto dobbiamo giả notare nella parte Sud-Orest dcl bacino piemontese poichè i terreni elvesiani invcee di cominciare solo ad affiorare nelle vicinanze di Ceva, come si è indicato per lo Stampiano, il Langhiano e l'Aquitaniano, si sriluppano invece molto piì ad Ovest costituendo quasi da soli le colline monregalesi.

Sulla geologia di queste regioni collinose di Mondovì non mi arrô ad estenderc molto, arendone gia trattato minutamente in un recente lavoro speciale "I Colli Monregalesi"; da esso risulta specialmente come in detta regione l'Elve ziano inferiore sia in gran parte sabbioso, ghiaioso ed anche ciottoloso, ad elementi anzi roluminosissimi talora, facies che vedremo ancora ripetersi nelle colline torinesi, cioè là dore l'orizzonte in esame trovasi presso rcgioni alpine clevate.

Quantunque non si possano scgnare limiti ben definiti nelle colline monregalesi fia l'orizzonte elveziano inferiore, specialmente sabbiosoghiaioso, c quello superiore, specialmente marnoso, sarà però utile esaminarli partitamente anche per maggior chiarezza di esposizione.

É stulla destra dell'Ellero, allo sboceo della vallata alpina nella pianura, che vedonsi comparire le formazioni etreziane che costituiscono 
le colline di Serra S. Giuseppe; quivi gli strati marnoso-sabbiosi inclinati verso Nord-Ovest si alternano ripetutamente con grossi banchi di ghiaie, di ciottoli ed anche di breceie ad elementi spesso voluminosissimi, tanto da quasi confondersi con accumuli franosi. Talvolta questi vari elementi breccioso-ciottolosi si presentano fortemente cementati fira di loro, come osservasi specialmente bene allo sboceo di Val Maudagna presso borgata Gosi; quivi, sulla destra della valle, i banchi conglomeratico-brecciosi souo cosi potenti e tanto fortemente cementati che richiamano subito alla mente quelli simili del Tongriano.

Piủ a Nord, nelle colline di borgata Marengo e di Monastero di Vasco, la formazione clveziana, spinta talora ad oltre $700 \mathrm{~m}$. di elevazione, continua a mantenersi in gran parte ciottolosa, ed anzi in alcuni casi questi elementi ciottolosi raggiungono persino il diametro di 6,7 od anche 8 metri, così sopra borgata Marengo ed anche assai più a Nord (e quindi più lungi dalla regione alpina), come presso borgata Giusta.

In queste regioni collinose si osservano talora veri banchi costituiti solo di ciottoli, ghiaie e sabbie, specialmente presso i terreni preterziari; ma più commemente gli elementi ciottolosi, talora a spigoli ancora alquanto acuti, sono sparsi frammezzo alle marne più o meno sabbiose e quindi vengono a giorno per effetti di denudazione; ne consegue che questi ciottoli e ciottoloni veggonsi per lo più sparsi irregolarmente alla superficie del terreno, simulando quasi depositi crratici. Questo fenomeno avremo ancora occasione di esaminarlo comunissimamente nelle colline più ad Ovest, nonchè nelle colline torinesi, dove esso venne gia variamente e non sempre giustamente interpretato.

Da Monastero di Vasco verso Est i terreni preterziari costituenti le prealpi monregalesi sono variamente ricoperti dai depositi sabbiosoghiaiosi e ciottolosi dell'Elveziano inferiore per lo più leggermente inclinati verso Nord o Nord-Ovest; placche residue di queste formazioni incontransi talora isolate molto a Sud, sin quasi ad 800 metri di elevazione, come presso la cappella di S. Elena al Bric Camerano ecc. Viceversa spuntoni rocciosi preterziari compaiono anche qua e là frammezzo ai terreni elveziani molto verso Nord, cosi in diversi punti di Val Ermena e di Val Groglio.

L'assieme di queste formazioni ci indica depositi littoranci quasi tipici non solo litologicamente ma eziandio per la struttura irregolare dei banchi, per i fossili (specialmente Ostriche) inclusivi, per i fori di Litodome che incontransi su certi spuntoni di Calcare triassico (specialmente in Valle Ermena), ecc.

Tra questi banchi sabbioso-ghiaiosi e la roccia preterziaria compaiono sovente, ad Est di Ponte dei Pandolfi, diversi strati marnoso-sabbiosi, grigio-bleuastri i quali si presentano spesso localmente giallastri per 
chiazze solforose; sovente inoltre in tali banchi compaiono pure numerose ma sottili lenti di lignite; infine in alcuni punti, specialmente presso le sorgenti sulfuree, non sono rari i resti fossili appartenenti ad una fauna salmastra (Potamides, Melanopsis, ece.) affatto speciale.

Tali formazioni marnose sulfureo-lignitifere compaiono in dirersi punti sia di valle Ermena, nei valloni tributari di sinistra, sia di Val Groglio presso gli spuntoni di Calcare triassico, sia sull'alto delle colline di S. Martino, di C. Magalin, ecc.

Gli strati marnoso-arenacei, spesso giallastri, che spesso incontransi fra questi depositi elveziani inferiori sono soventissimo caratterizzati da una grande ricchezza in bellissime filliti. Talora gli strati arenacei sono cosi compatti da poter essere utilizzati come pietra da taglio, ciò che verificasi per esempio nell'alta ral Groglio a Sud di Fontana Candia, sorgente copiosissima che è pure in relazione con detti banchi.

Lungo i pendii collinosi queste formazioni littoranee assumono generalmente, per alterazione chimica, un color giallo-rossastro mentre nella parte alta delle colline (è per ciò tipico il Bric Pasquin) i numerosi ciottoloni sparsi simulano un paesaggio inorenico. E alquanto dubitativamente che attribuiseo all'Ele eziano inferiore i depositi conglomeratici di Roata sottana (Torre Mondovi).

Nelle colline a destra della Corsaglia la favies ciottolosa dell'Erresiano si mostra ancora notevolmente sviluppata, specialmente nelle colline dei Battaglio e di Bric Toselle, ripetendorisi i soli fenomeni dianzi accennati. Contemporaneamente però assumono pure un grande sviluppo i banchi arenacei grigio-giallastri, spesso molto resistenti, talora straterellati e riccamente fillitiferi, talora invece zeppi di resti di Molluschi e di Foraminiferi, spccialmente di Operculina.

Notiamo come in questc colline tra val Corsaglia e val Mongia le formazioni elveziane sovrappongonsi direttamente a quelle tongriane, talora a guisa di placche come a Borgata Bischeri, e non riesce sempie facile il distinguere le une dalle altre; generalmente però alla base dell'Elveziano esistono arenarie e conglomerati cementatissimi.

Una delle regioni in cui si può osservare meglio la sovrapposizione dell'Elveziano al Tongriano è l'alveo del T. Mongia dove notasi nettamente questa seric stratigrafica:

Narne sabbiose, grigiastre, alternate con straterelli arenacei.

Strati o banchi arenacci, grigio-giallastri, alternati con strati sabbiosi grigiastri.

Elveziano Banchi sabbioso-arenacei con lenti gliiaioso-ciottolose.

Banchi sabbioso-arenacei, alternati con banchi conglomeratici, spesso a grossi clementi.

Strati arenacei giallastri con lenti ciottolose. 
1 Grossi banchi arenaceo-conglomeratici rossastri.

Tongriano $\left\{\begin{array}{l}\text { Narne sabbiose grigio-giallastre o bleuastre, lignitifere. } \\ \text { Serie potente di banchi conglomeratico-brecciosi. }\end{array}\right.$

Nelle colline di Montegrosso vediamo ancora che i banchi inferiori dell'Elveziano inglobano abbondanti ciottoli c ciottoloni commisti a sabbic; ma poco più ad Ovest questi depositi grossolani divengono scmpre più rari riducendosi a lenti, talora fossilifere, come presso S. Giovanni in Bosco; infine tutto l'orizzonte inferiore dell'Elveziano diviene cssenzialmente marnoso-arenacco e tale si conscrva nelle Langhe, nel MTonferrato, nel Tortonese e nelle colline Valenza-Casale, solo ridivenendo ciottoloso nci colli torinesi perchè vicini alle elevatc regioni alpine.

Questo fenomeno di trasformazione di facies, di cui troviamo la causa diretta nella vicinanza delle regioni montuose e quindi delle grandi correnti acquec, si può osscrvare e seguire passo passo nelle colline monregalesi meglio che in qualunque altra regione; notiamo però che procedendo da Est ad Ovest i banchi inferiori dell'Elveziano vanno gradatamente scomparendo, per modo che i depositi arenaceo-conglomeratici di Montegrosso sono più antichi di quelli di S. Michele Mondovi, e questi ultimi più antichi di quelli affiorenti tra Mondovi Breo e Mondovì Piazza; ne risulta quindi che i banchi elveziani che sono sabbioso-marnosi a Nord di Mombasiglio, divengono gradatamente ghiaioso-ciottolosi verso Mondovi, ciò che c̀ in diretto rapporto colle correnti acquee quivi sboccanti nel mare dell'epoca elveziana.

Da tutto ciò si deve inoltre dedur'e che la distinzione fatta dell' Elveziano monregalese in inferiore e superiore, basandoci sulla costituzione geologica, è una distinzione sempliccmente locale e poco importante. D'altronde giungiamo allo stesso risultato esaminando il passaggio esistente tra le due facies in questione. Infatti nelle colline su cui siede Mondovì, come pure in diversi punti di Val d'Ellero ed in regioni vicine, osservansi sovente apparire lenti ciottolose più o meno estesc frammezzo alla formazione marnosa dell'Elveziano, ed c̀ solo gradatissimamente verso Sud che i banchi elveziani divengono sempre più ricchi in lenti sabbioso-ciottolose finchè quest'ultima facies prende il sopravvento, senza che si possa assolutamente segnare una linea di demarcazione fra le due sorta di depositi.

In Valle Ermena, a monte del ponte dei Gandolfi, tale distinzione riesce generalmente più facile, benchè vi esista sempre il passaggio graduale sovraccennato, solo più rapido; ciò si può vedere ad esempio nell'alveo stesso dal tol'rente Ermena presso il molino dei Gandolfi; fatti consimili osservansi pure sulla sinistra di Val Groglio, alle falde meridionali delle colline di S. Michele Mondovì e nell'alveo del T. Corsaglia ad Est di detto paese sino a C. Rebaudengo. In tutte queste 
regioni le lenti ed i banchi conglomeratici, talora fossiliferi, alternati con quelli marnoso-arenacei, segnano il termine superiore, direi, della. facies complessiramente littoranea dell'Elveziano monregalese.

Passando ora all'esame dell'Elreziano medio delle colline monregalesi rediamo che, se vi compaiono ancor'a irregolari lenti ciottolose, come sotto Mondovi, in Val Ellero a valle di Breo, ece., in complesso però questo orizzonte è costitnito essenzialmente da banchi marnosi grigiobleuastri, spesso alternati con strati sabbioso-arenacei, inclinati di una diecina di gradi cirea verso il Nord-Orest.

Riguardo all'inclinazione dobbiamo notare che mentre essa è talora di $15^{\circ}, 20^{\circ}$ e più (persino di $60^{\circ}$ tra Montegrosso e C. del Pollo) nell'Elveziano inferiore, va però gradatamente diminuendo nell'Elveziano medio e superiore, dore talora si mostra solo più di $6^{\circ}$ ad $8^{\circ}$. Come nella. parte infcriore dell'Elreziano, anche nella parte sua media non sono rari gli strati fogliettati ricchi in bellissime filliti, come si può verificare ad escmpio in alcuni tagli al Bric della Guardia. I Molluschi, i Polipai, i denti di Squalidi, ece. liscontransi specialmente abbondanti assieme colle lenti ghiaioso-ciottolose, come ad es. in diversi punti presso Mondori.

Quanto all'Elreziano superiore è anch'esso, come il medio, costituito di un'alternanza di strati marnosi ed arenacei grigiastri, solo che i banchi marnosi prendono gradatamente il predominio rerso l'alto finchè si passa insensibilmente al Tortoniano inferiore; questa zona di transizione quasi insensibile si può osservare speeialmente bene rimontando la valle dell'Ellero sin quasi a Mondovi dore, per l'assottigliarsi del Tortoniano, le marne elveziane sono direttamentc coperte dal Piacenziano.

In complesso la serie elreziana delle colline monregalesi si può riassumere nel seguente modo:

Tortoniano - Marne grigiastre con straterelli sabbiosi.

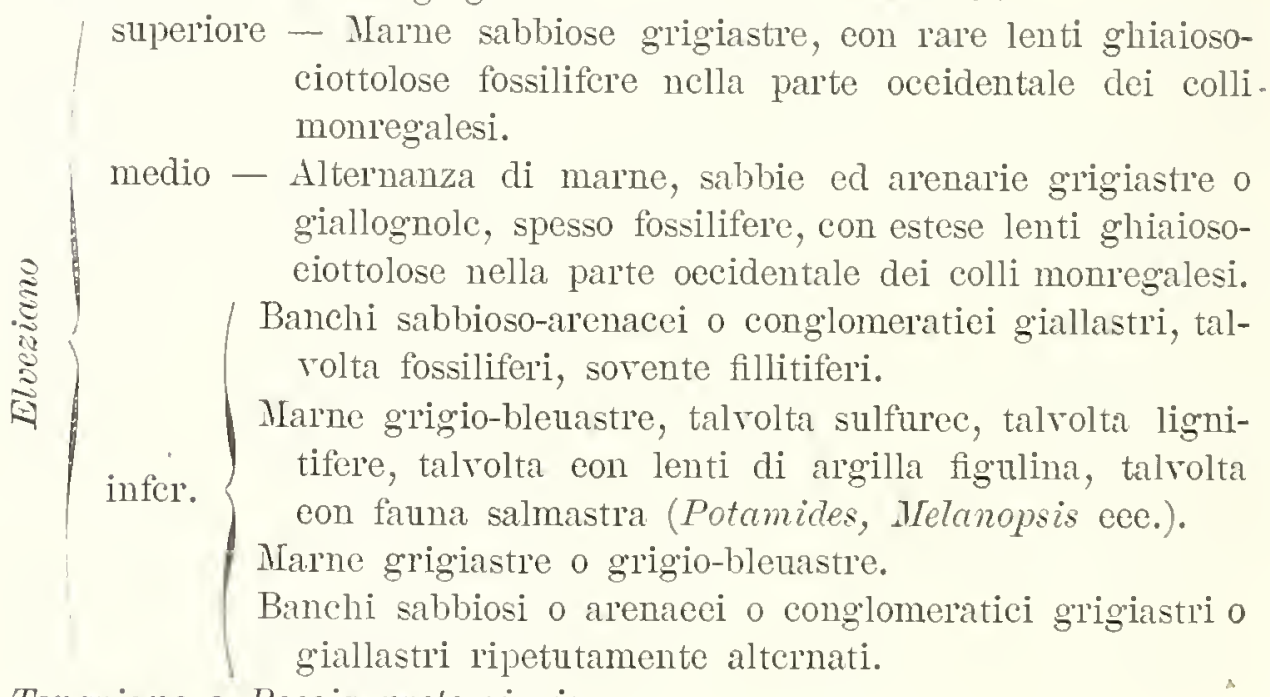

Tongriano o Roccia preteraiaria. 
Volendo ora tener dietro allo sviluppo dell'Elveziano dalle eolline monregalesi verso Nord; la vastita della zona oeeupatia da questo terreno non ei permette più di seguire quell'ordine ehe generalmente si è adottato fin'ora; tuttavia per procedere ordinati il più che sia possibile esamineremo dapprima l'Elveziano inferiore, poseia l'Etreziano superiore, attraverso l'ampia regione delle Langhe.

La base dell'Elveziano è generalmente eostituita da potenti banehi arenaeei grigio-griallastri, talvolta abbastanza fossiliferi, come ad escmpio sulla sinistra del Tanaro al bric di Montegrosso (Nord-Ovest di Mombasiglio) dove i fossili sono per lo più mescolati eon lenti ghiaiosociottolose.

Presso Ceva giả aeeennammo eome sia precisamente nelle marne, alternate eon sabbie e eon arenarie, le quali eostituiseono il passaggio tra Langhiano ed Elveziano (e forse già ineludibili in questo piano), ehe si rinvennero resti di Uecello.

Aneora nelle eolline presso Ceva sono a notarsi potentissimi banehi di arenaric e di sabbie giallastre ehe, riuniti in una pila di 40, 50 metri di potenza, appaiono a diversi livelli, eioè: alla base affatto dell'Elveziano (eostituendo le eolline del Forte di Ceva, di C. Marasano, di C. Camaloni, eee.); poi, eoll'internezzo di banehi marnosi grigiastri, poco al disopra dei banehi sovraecennati (formando le eolline di C. Maglione, di C. Beltramo, di C. Bergalli, eee.); quindi, eon nuoro intermezzo di alternanze di banehi marnoso-sabbiosi eon strati arenaeei, riappaiono nuovamente altri potenti eomplessi di banehi arenaeci ehe costituiseono le eolline di C. Ghione, di Brie Testa nera, eee.

Queste altermanze più o meno regolari si ripetono in quasi tutta l'ampia regione delle Langhe e eredo inutile di passarle minutamente in rivista perehè non avrei a far altro che eontinue ripetizioni; debbo però notare ehe banehi arenacei eosi potenti in eomplesso eome quelli che osservansi alla base dell'Etveziano sono poco eomuni nella restante scrie stratigrafiea di questo periodo; si rerifieano piuttosto continue c ripetutissime alternanze di strati marnosi, sabbiosi ed arenaeei, variamente raggruppati a seconda dei livelli stratigrafici e delle regioni in eui si osscrvano: negli spaeeati naturali generalmente predomina il eolor grigio-blenastro dato dalle marne più o meno sabbiose.

Debbo ancora aeeennare in generale eome i più potenti banchi o complessi di banehi arenacei influiseano notevolmente sulla oroidrografia delle Langhe, poiehè eon essi sono strettamente connesse le cime c le creste più alte, le grandi vallate, i veli aequei, la forma dei pendii eollinosi, ece., fenomeni tutti che è inutile passar in rivista regionalmente, ma ehe potra faeilmente eonstatare in sito ehi ha oceasione di percorrere queste belle regioni, solo osservando eon attenzione i fatti na- 
turali che gli si parano dinanzi; d'altronde tali fatti sono ovunque assai facili ad esaminarsi per i millc profondissimi spaccati naturali che incidono in ogni senso la pila degli strati elveziani della regione collinosa in questione, mettendone a nudo l'intima struttura geologica.

I fossili sono dorunque assai comuni, ma spesso difficili ad estrarsi c conservarsi intieri; anzi non di rado essi trovansi già rotti in posto, specialmente sc inglobati in banchi sabbioso-arenacei. Non sono rari gli esemplari di Paleodictyon tectiforme, specialmente negli strati arenacei di aleuni orizzonti speciali.

L'inclinazione degli strati, in generale verso Orest o Nord-Orest, è di circa $12^{\circ}$ o $15^{\circ}$ alla base dell'Elveziano, e generalmente di solo più $10^{\circ}$ o $12^{\circ}$ cd anche minore piu in alto.

Si notano talora nelle Langhe scoscendimenti, specialmente nei banchi arcnacei i quali, siccome resistono meglio agli agenti atmosferici, spesso trovansi parzialmente senza appoggio, cssendo state esportate le sottostanti marne sabbiose; quindi talora questi banchi in parte precipitano in basso o solo scoscendono alquanto, come si può ad esempio osservare nelle colline di C. Maglione presso Ccra. MIa per quanto cbbi finora ad osscrvare trattasi sempre solo di fenomeni parziali e verificatisi in piccola scala, per modo che non alterano per nulla l'andamento generale dei terreni elveziani.

Quanto alla direzione degli strati si può dire che essi accompagnano regolarmente, almeno rispetto all'Elveziano inferiore, le curve che si vcrificano nella linea di delimitazione tra Elvesiano e Langhiano: l'iguardo poi a questa linea dobbiamo ancora qui ripetere come essa sia sempre molto incerta a causa delle solite alternanze di banchi sabbiosi, marnosi ed arenacei c per la quasi mancanza delle tipiche marne indurite del Langhiano.

Nelle colline di Sale delle Langhe, Paroldo, IIombarcaro, S. Benedetto Belbo, ecc. e piủ ad Ovest verso Murazzano, osservasi ad un. dipresso la ripetizione dei soliti fenomeni sopraindicati. Accenniamo pcrò alla notevolissima elevazione, di quasi 900 metri s. I. m., che raggiungono i potenti banchi arenacei (inclinati ad Orest-Nord-Orest) su cui posa il paese di Mombarcaro; esso è il piủ alto delle Langhe tanto che nelle giornate chiare vi si gode la vista del mare, specialmente nellc prime orc del mattino.

Possiamo qui indicare i bei piani inclinati, da Ovest ad Est, che prescntano le colline di S. Bencdetto e di Niella Belbo, dalla cresta collinosa di Bric Valcadamo al fondo di Val Belbo, giacehè ciỏ è precisamente in rapporto coll'inclinazione di circa $10^{\circ}$ ehe $\mathrm{i}$ banchi arcnacei dell'Elevesiano inferiore presentano verso Ovest-Nord-Ovest; c̀ pure in stretta relazione coll'indicato andamento stratigrafico la direzione ad 
un dipresso N.E.-S.O. ehe presentano le grandi valli di Costalunga, di Rio di Pracone, di Rio di Somano, di R. Gamba, di T. Riavolo, di T. Argentella, ece.; tali vallate presentano tutte, sempre per la stessa eausa, il loro fianco destro ripidissimo, perehè taglia quasi verticalmente la pila dei banchi elvesiani, e auello sinistro invece ampio ed a doleissimo pendio per essere formato essenzialmente dalla parte superiore degli strati, specialmente di quelli arenacei, incisi solo da torrentelli secondari.

Continuando l'esame dell'Elvesiano inferiore verso Nord vediamo ehe i banchi arenaeei divengono sempre piu potenti; questo fatto verificandosi pure nei terreni sottostanti ne deriva una difficoltà ed un'incertezza sempre assai grande a delimitare i diversi orizzonti geologici; basta ad esempio osservare la potenza dei banchi arenacei ehe, con un'inelinazione di $10^{\circ}$ a $12^{\circ}$ verso l'Ovest eirca, eostituiseono la collina su cui posa il paese di Bossolasco, per eonvincerei di questo grande sviluppo delle arenarie elveziane anche ad un livello assai superiore alla base dell'orizzonte geologico in esame.

Talora trovansi pure lenti ghiaiose e eiottolose interealate ai banchi arenacei, eosì ad esempio al Bric Piandolin, poco sopra la C. Valentino, cosi pure poco a Nord di C. Manera (Serravalle delle Langhe) ed in moltissime altre localita che eredo inutile di passare singolarmente in livista.

Al M. Carpino vediamo eessare la straordinaria elevazione, di oltre $800 \mathrm{~m}$., ehe si poteva osscrvare in tutta la cresta collinosa da Mombarearo a Feissoglio; tale abbassamento è prodotto essenzialmente dal fatto che quivi i potenti. banchi arenacei della base dell'Etveziano presentano una rapida eurva ad Ovest e discendono nella Val Belbo di eui vengono a costituire gran parte del fianco occidentale, sin presso Cassano Belbo, sempre eon inelinazione di eirea $10^{\circ}$ ed anche meno, verso Ovest-Nord-Ovest.

Già trattando dell'Aquituniano e del Langhiano di queste regioni si è aeecnnato, sia alla difficile delimitazione di questi orizzonti geologiei dall'Elveziano, sia al dubbio ehe può sorgere sull'età della cresta collinosa compresa tra Feissoglio e Castino.

$\dot{\mathrm{E}}$ vero ehe su tale cresta non si trova sempre quella potentissima formazione di grossi banehi arenacei ehe invece sulla sinistra del Belbo veggonsi per lo più iniziare l'Etreziano; ma però in aleuni punti, eome ad esempio presso S. Vitale e qua e là lungo la eresta in questione, tali banehi di arenaria eompaiono ben sviluppati; d'altronde detti banchi mancano pure nell'Elveziano inferiore a Nord di Castino dove sonvi quasi solo banchi sabbiosi a stratificazione irregolare; eosi pure sabbie ed arenarie a stratificazione spesso irregolare, conturbata, con 
salti ccc., osservasi lungo la cresta Castino-Feissoglio specialmente sul lato Nord-Ovest. Su questo lato osservasi pure, in complesso, una specie di grandioso gradino con loeali disordini stratigrafici; tale gradino non ì solo riferibile a fenomeni di antica erosione esercitata dalle acque del Belbo ma credo debbasi pure in parte attribuire alla sorrapposizione dell'Elveziano sull'Aquitaminno.

A Nord di Castino i tipici banchi clee ziani presentano contorcimenti, salti, discordanze cce.; a Sud del paese reggonsi le arenarie di Bric Cassielo sovrapporsi all'Aquitaniano, per cui pare logico attribuirle all'Elvesiano inferiore, tanto più che vi raecolsi numerosi fossili eome Taphortminthopsis, Paleodictyon, Ostrea, Pecten, rertebre di Cetacei ece., ciò che in complesso è più facile trovarsi nell'Elveziano che non nell'Aquitaniano.

Non ripeto le diverse altre considerazioni che in proposito ebbi giả a fare trattando dell'Aquitaniano c rimando per ciò al detto capitolo.

Nei banchi sabbioso-arenacei dell'Elte stano basale sono assai comuni i resti fossili di fucies littoranea, così pure non rare sono le impronte di Paleodictyon tectiforme che comunissimamente poi incontransi nelle colline attorno a Cessolc, sp scialmente negli strati arenacei di passaggio tra il Langhiano c l'Elcesiam.

I banchi dell'Elvesiano inferiore che, per la profonda erosione operata dalla corrente acquea del Belbo, formano in questa valle una specie d'angolo acuto rerso Cassano Belbo, si veggono invece ritornare, direi, molto a Sud sulla sponda destra, cioè sin presso Castino, con stratigrafia però loealmente altcrata, cioè con pendenza talora di $10^{\circ}$, $15^{\circ}$ e anche più, verso il Sud o l'Est, vale a dire in senso eontrario a quello dell'andamento stratigrafico regolare.

Ad Est di Castino l'Elvesiuno inferiore discende in Tal Bormida di cui sin oltre Aqui eostituisce la parte più elevata sulla sponda sinistra. Vi si osservano sempre gradualissimi passaggi tra Langhiono cd Elve: siano. Talvolta i banchi arenacei basali di quest'ultimo orizzonte si arricehiscono talmente in calcare da poter cssere utilizzati come pietra da calce però di qualitì inferiore, cosi ad esempio presso C. Tana a Nord di Bobbio; naturalmente tali banchi sono sempre molto ricehi in fossili c quindi preziosi al palcontologo.

In eomplesso si può dire che dalle colline di Cessole-S. Stefano Belbo verso Est l'Eluesiano mostra giit una differenza assai notevole da quello delle Langhe, eioè mostra una maggior predominanza di banchi sabbiosi giallastri i quali poi divengono piu fortemente inelinati (naturalmente con grandi differenze tra la parte inferiore c quella superiore dell'Eltesiano), dapprima di circa $15^{\circ}$ e più avanti anche di oltre $20^{\circ}$; ciò costituisce una delle cause del ristringimento che quivi si osserva nella zona elvesiana. 
Siccome ad Est delle colline di Bobbio la zona elveziana vedremo mostrarsi con larghezza non più tanto grande come ad Ovest, cosi nel suo ulteriore sviluppo potremo esaminarla complessiramente; quindi ritorniamo ora nelle colline monregalesi e nelle Langhe per esaminarvi l'Elveziano superiore che prima abbiamo lasciato in disparte. Si è gia trattato nelle pagine precedenti della costituzione goologica generale dei colli monregalesi, diciamone ancora qui duc parole rispetto all'Elveziano medio e superiore.

Nelle colline su cui posa la citta di Mondovi, fra i banchi sabbiosomarnosi dell'Elteziano medio-superiore, osserviamo talora potenti strati sabbioso-arenacei che racchindono ciottoloni voluminosissimi (non di rado a spigoli poco smussati) provenienti dalla vicina catena alpina; in questi banchi speciali, che possonsi esaminare specialmente in alcuni strettissimi rii che incidono il versante Ovest delle colline in questione, sono eziandio straordinariamente numerosi i fossili, talora però infranti, i quali per la natura e il modo di presentarsi sono assai bene comparabili a quelli contemporanei delle colline torinesi.

Vediamo cioè rerifiearsi qui in piccola scala, al picte delle Alpi Marittime, ciò che assai più in grande avremo ad esaminare nelle colline di Torino parzialmente circondate a poca distanza dalla catena alpina; il che ci dimostra chiaramente esscre questo fenomeno in dirctta relazione colla vicinanza delle grandi catene montuose, ciò che d'altronde i affatto naturale.

Consimili banchi o meglio lenti ciottolose vediamo pure nella valle Ermetta a Sud di Mondovi, formando quivi conglomerati, oppure presentandosi costituiti di clementi spesso voluminosissimi (talora di oltre 6 metri di diametro) sparsi fra la marna sabbiosa grigio-blenastra ed in questo caso accompagnati da fossili abbastanza conservati. Le colline di Villa Barussia e di Canavere sono essenzialmente costituite di sabbie grigio-giallastre, talora con lenti ghiaioso-ciottolose pir o meno fossilifere.

Nei dintorni di Vicoforte predominano specialmente lc marne sabbiose, quantunque sianvi pure potentissimi banchi arenacei, da cui ad csempio originasi l'abbondante sorgente del Fo.

In complesso però si può dire che i terreni elveziani dei colli monregalesi, con inclinazione di circa $10^{\circ}$ a $15^{\circ}$ verso Nord-Ovest, presentano un'abbondanza sempre maggiore di banchi sabbioso-ciottolosi verso Sud, per modo da andarsi gradualmente a collegare con quelli essenzialmente ciottolosi dell' Etveziano inferiore gia esaminato. Invece verso Nord tali depositi divengono sempre più rari; osservansi essi tuttavia ancora assai sviluppati negli spaceati sulla sinistra dell'Ellero, quasi sotto a C. Camparo dove, commisti a marne, ghiaie e ciottoloni 
talora di oltre 2 metri di diametro, si raccolgono abbondantissimi fossili specialmente Pecten, Ostrea, Balanus, Spondylus, denti di Squalidi, Polipai aderenti ai ciottoli, ciottoli calcarei traforati dalle Litodome, ecc.

Ancola lungo l'Ellero, ma molto più a valle, quasi di fronte a C. Varino, possiamo eziandio osservare lenti di materiale ciottoloso caoticamento disperso fra i banchi marnosi o sabbiosi che quivi, come sempre in tali casi, sono riccamente fossiliferi; in questo punto, come sorente si rerifica in casi simili, le marne si presentano alquanto contorte o, meglio, a struttura irregolarmente concrezionata. Bellissimi esempi di struttura concrezionata (in modo peró diverso da quello del caso sorraccennato) e di contorcimenti di strati possiamo osservare in più punti rispetto ad alcuni grossi banchi marnosi compresi fra banchi arenacei, cosi per esempio nelle Langhe al fondo del Rio del Bandito (Rocca Cigliè), quasi sotto C. Via Piana. Tali fenomeni sono doruti in questo caso alla potente compressione esercitata sulle marne poco resistenti.

Nelle colline monregalesi l'Elieziano superiore è rappresentato essenzialmente da un'alternanza di strati marnosi, sabbiosi ed arenacei, il tutto di color grigiastro abbastanza uniforme e che di lontano ricorda assai il Tortoniano a cui d'altronde forma graduatissimo passaggio. Questa costituzione dell'Elveziano superiore si puỏ specialmente osservare chiaramente rimontando il profondo fosso Oteria dore si osserva una serie di stupendi spaccati naturali e dore si possono spesso raccogliere denti di Squalo, specialmente verso il fondo del rio. Talora si osservano anche sottili lenti ghiaioso-ciottolose interposte ai banchi clveziani. L'inclinazione degli strati è abbastanza regolare, ma poco potente, verso il Nord-Ovest.

Una simile costituzione si osserva eziandio nelle colline di Niella Tanaro, anzi quivi talora i banchi marnosi sono tanto sviluppati e potenti da ricordare assai bene il Tortoniano.

Il passaggio tra Elveziano superiore e Tortoniano si compie generalmente in modo tanto graduale che riesce difficile assai tale delimitazione, quantunque ver'so Sud-Ovest poco a poco la zona tortoniana si vada assottigliando e quindi sovrapponendo alquanto trasgressiramente all'Elveziano. In complesso si può dire che i supremi banchi etreziani, o almeno quelli che convenzionalmente pongo alla sommita dell'Elveziano, presentano numerosi strati arenacei (oltre a sottili lenti ghiaioso-ciottolose) alternati con bancli sabbioso-marnosi, per modo che negli spaceati si può seguire molto bene l'andamento stratigrafico di quest'orizzonte; invece i banchi tortoniani sono essenzialmente malnosi ed a stratificazione non scmpre nettamente riconoscibile.

Inoltre anche colla semplice osservazione superficiale si possono di- 
stinguere i due orizzonti geologici in causa della diversa orografia a cui cianno origine e del diverso modo di erosione esercitato dalle antiche correnti acquec; rediamo infatti che mentre i terreni clvezinni costituiscono le colline monregalesi, quelli tortoniani invece furono in gran parte erosi ed esportati dalle potenti correnti aequee dell'Ellero all'epoca dell'antico e molto più ampio suo corso, risultandonce le regioni pianeggianti di Piana di S. Quintino, Rifieddo, ecc.; tali regioni pianeggianti vengono a terminare, verso Sud-Est, lit dove si iniziano i tereni elveziami che furono invece assai meno erosi, per modo che quivi l'attuale alreo dell'Ellero può selvire ad un dipresso come linea generale di separazione fra Elveziano e Tortoniano.

Ritornando ora in Val Tanaro notiamo che tra le borgate di Peyron c di Pasco si sviluppa una potente (persino oltre 50 metri) ed importantissima zona conglomeratica inclinata di $15^{\circ}$ a $20^{\circ}$ ver'so Nord-Ovest e costituita di elcmenti talora voluminosissimi (spesso di oltre 1 metro di diametro), fortemente cementati assieme, ciò che ci spiega il rapido restringersi della valle in quel punto.

Questo deposito ciottoloso si può esaminare molto bene in Val Tanaro dalla regione Fornello alla C. Fosso-Drosso circa, come pure rerso il termine del rio del Froceo, verso la base del rio di Cigliè quasi sotto C. Russ; esso non si prolungra però molto ad Est e ad Ovest cangiandosi invece in potenti banchi arenacei con numerose concrezioni discoidali; talora detti banchi sono anche ghiaiosi e solo qua e la ciottolosi, sovente assai ricehi in fossili di littorale.

I ciottoli sono per lo più anagenitici o quarzitici o di Talcosehisto, ma sorenti anche di roccia diasproide, di Caleare, ece.

La rarità o quasi mancanza di ciottoli di Porfido (considerando la ricchezza in ciottoli porfirici che osservasi nelle alluvioni quaternarie ed attuali del Tanaro) parrebbe indicarci come durante il periodo mioccnico o gli affioramenti porfirici erano nelle Alpi marittime meno allo scoperto che al giorno d'oggi, oppure che l'idrografia era assai diversa da quella quaternaria.

A questo orizzonte ghiaioso-conglomeratico appartengono probabilmente ancora certi banchi arenaceo-ciottolosi, ad elententi però poco poco voluminosi, che appaiono nella valletta di C. Vignola (Est di Ciglie).

Per dare un'idea del modo di prescntarsi dell'orizzonte speciale ora in questione indichiamo ad esempio la seric che si può osservare direttamente sulla sinistra del Tanaro nel valloncello di C. Ghiara, cioè:

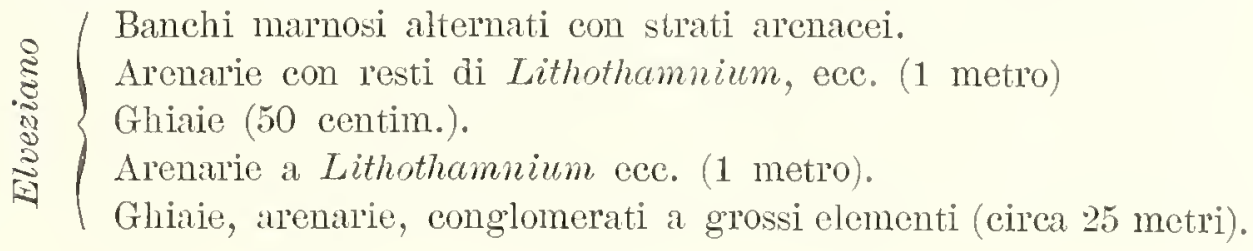


Totiamo qui ancora come sia specialmente sulla destra del Tanaro, nei profondi spaecati che osservansi ad Est e ad Orest dello sboceo del Rio del Bandito, che possonsi raceogliere abbondantissimi e stupendi esemplari, talora della larghezza di oltre 1 metro, di Zoophycos Ǵastaldii; d'altronde è specialmente alla base dei g'randi tagli che è più facile incontrare resti di queste impronte.

Poco a Nord, c quindi poco sopra (cirea 100 metri) alla sorraeeennata zona conglomeratica dobbiamo aneora notare un potente eomplesso (eirca 20 o 30 metri) di banehi arenacei, spesso ricchi in resti di Lithothammium, fortemente cementati per modo da produrre un accentuatissimo restringimento dell'alveo del Tanaro. e cla originare quella specie di sperone su cui siede il paese di Bastia. Questo speciale orizzonte, ehe sulla sinistra del Tanaro dà origine ad un'abbondante sorgente, verso Orest perde poco a poco la sua individualità; rerso Est inrece esso si può seguire per un tratto lunghissimo nelle eolline di Cigliè, Rocca-Ciglie, ecc.; passa sotto alle borgate Monteehiaro presso il Casotto Mamei, forma parte della cosidetta Regione Diroccata di Ciglie e costituisce in parte l'imbasamento di questo paese: aiscende a Nord-Orest originando la fontana Raperto, risalendo di nuoro Ferso Sud alle Cne Tignola e Perasso; di qui la serie arenacea iu esame disecnde in Tal Lavatelli, di eui eostituisce il fondo, sotto C. Ambrogio; spingesi però ancora nella ricina ralletta sin sotto C. Tia Piana per di nuoro rimontare nelle colline di Roca Cigliè alle Cne Ripette e lidiscendere nel Tallone di Brillade, ece. eon una inelinazione media di $10^{\circ}$ rer'so Nord-Orest circa.

Di questi banchi o complessi di banchi un po' potenti ne esistono moltissimi più o meno continui in tutto l'Elveziano delle Langhe a vari livelli, ma ho ereduto suffieiente d'indicarne un esempio, non presentando essi che mn'importanza affatto regionale; solo è ad osservarsi come sia specialmente in essi ehe si puo fare piu tiacilmente un'abbondante raceolta di fossili, talor'a però frantumati.

Assieme ai banchi ed agli strati arenacei e sabbiosi vediamo altermarsi strati marnoso-sabbiosi od anche solo marmosi che talora si sviluppano notevolmente in potenza e presentano allora in parte l'aspetto del Tortoniano, per modo che talrolta si dubiterebbe ehe quest'ultimo orizzonte, tauto svilmppato sulla simistra della Tal Timaro, renga in alcuni punti ad estendersi anche sulle colline delle Borgate Ciri, Chiecehio, ece. Le marne dell'Elreziano superiore, passante al Tortoniano, sono piuttosto grigio-bletastre e si rompono generalmente, eome quelle del Tortoniano, eoneoidemente; inveee quelle del restante Elveziano sono spesso grigio-rerdastre e si rompono per lo più irregolarmente; ma ciò si può dire solo in linea molto generale giaechè il 
fenomeno dipende molto dalla natura più o meno marnosi o sabbiosa dei diversi banchi.

Tali banchi marnosi, per' quanto potenti a quasi tutti i livelli dell'Elveziano, divengono naturalmente sempre più importanti nella parte superiore dell'orizzonte stesso per modo da rendere difficilissimit ed anzi arbitraria la sua delimitazione dal Tortoniano. Fia i banchi marnososabbiosi veggonsi talora ciottoli di varic dimensioni sparsi gua $c$ lit irregolarmente o, più di rado, disposti in vere lenti; così ad escmpio verso la base delle bellissime sczioni naturali di Farigliano-Neviante sulla destra del Tanaro, quasi sotto a Corsalctto.

Lo stesso si osserva nella metà inferiore di quegli enormi spaceati naturali che si appellano Rocehe perticali di Clavesana; è quivi infatti che, sopra ad un complesso di strati arenacei e marnosi alternati, stanmo banchi specialmente marnosi racchiudenti ciottoli sparsi irregolarmente e del diametro talora di quasi un metro.

Banchi arenacei ciottolosi, ad clementi spesso assai voluminosi, talora (specialmente se di Talcoschisto) anche a spigoli sporgenti, troviamo eziandio in molti altri punti, così ad esempio nel rio di Cigliè quasi sotto la Cava, nel rio della Gorea, nel rio Rivera, nel rio di Pianobosco, ecc., possiamo anzi citare in riguardo, nella parte alta clel Rio Piano Bosco quasi sotto C. Bologna, la seguente sezione:

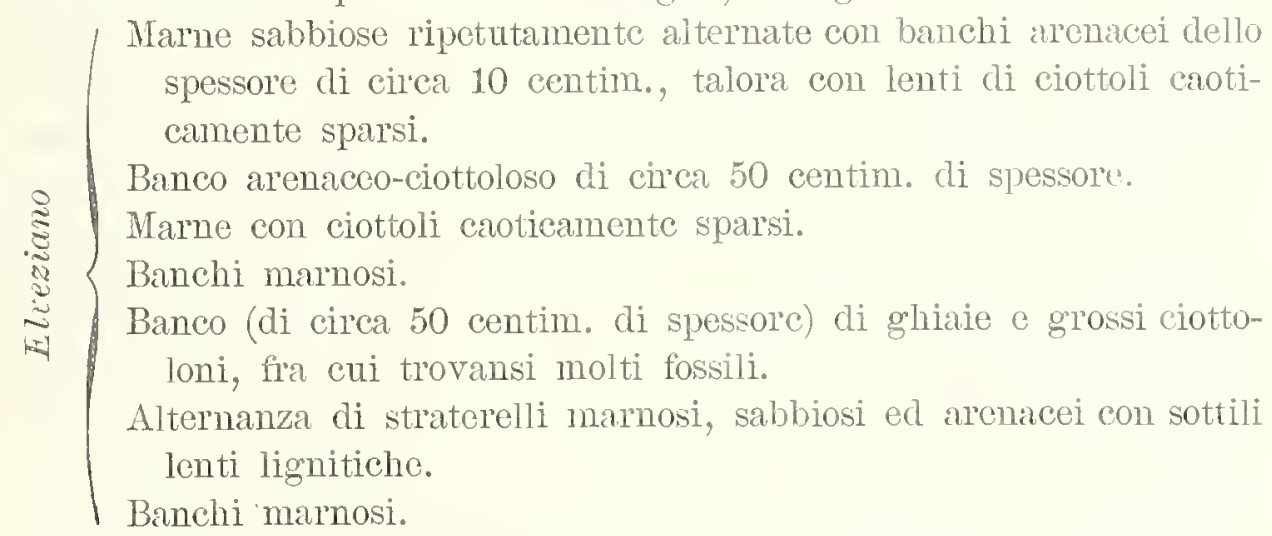

Da questo punto ridiscendendo il rio sino al Molino di Gorino troviamo ancora tali banchi conglomeratici ad elcmenti più o meno cumentati, rotondeggianti od a spigoli alquanto conservati, del diametro talora di 50, 70 e più centimetri, e racchiudenti spesso fossili, ridotti talora a semplici impronte, specialnncnte di Arca, Lucina (ef.' L. pomum), Venus, Pecten, Conus, Balanus, ece.

Verso il basso fondo di C. Bassignana, tra il Palazzo del Sot c C. il Ceretto circa, possiamo eziandio osservare direttamente bei banchi ghiaioso-ciottolosi alternati con banchi arenacei e marnosi; i ciottoli sono per lo più di Anagcnite o di Talcosehisto, in quest'ultimo caso spesso essi si presentano ancora alquanto angolosi. 
$\dot{\mathrm{E}}$ in parte da queste specie di lenti ciottolose elrezicne ed in parte dai depositi quaternari, che qua e là per breve tratto ammantano la parte più oceidentale delle Langhe, che derivano quei grossi ciottoloni, per lo più di Quarzite e di Anagenite, di oltre un metro di spessore, che reggonsi nell'alreo di alcuni torrenti, ad esempio del torrente Rea presso Dogliani; in eausa del loro volume molto considererole questi eiottoloni anche in una lunga serie di anni sono trasportati di apjena pochi metri verso valle e solo durante i periodi di piene straordinarie; origine simile hanno certi ciottoloni che reggonsi talora isolati sull'alto delle colline in luoghi dove la loro presenza parrebbe a prima rista inesplicabile.

E specialmente nei rii che profondamente incidono le labirintiformi colline di Cigliè, Clavesana, Belvedère Langhe, eee. che ho potuto raceogliere, oltre a molti Mollnsehi, come Aturia, Xenophora, ece., una quantita grandissima d'impronte organiche ed inorganiche, cone Paleodictyon, Helminthopsis, Helminthoida, Temertitithes, eee. Debbo però arrertire che tale abbondanza di impronte fossili deriva in parte dal fatto che in tali regioni ebbi a fare ricerehe più minute che altrove e per mesi interi, giacehè dette impronte sono abbastanza comuni quasi orunque nelle Langhe là dove sonvi banchi arenacei.

Crecio inutile di passare qui minutanente in rivista la serie di strati che eostituiscono I'Elreziano superiore di questa parte delle Langhe, giachè in eonelusione non arremmo che a menzionare una continua e più o meno regolare alternanza di strati e banehi marnosi ed arenacei, ciò che si può specialmente osserrare in modo stupendo rimontando i profondi ralloni che intersecano in ogni senso la regione in esame.

Debbo peró aceennare ad un banco arenaceo, riccamente fossilifero, che appare qua e lid sull alto di queste colline e ehe si presenta con una facies abbastanza caratteristica. Nelle colline di Belredere delle Langhe troviamo m'ampia placca (però dello spessore di soli 506 in.) di queste sabbic ed arcnaric ghiaiose più o meno ecmentate, siallastre, inclinate a Tord-Orest, situate sull'alto della collina tra i casali Cravili superiori e la Chiesetta di S. Roceo Olmetto; quiri si può fare ricea raceolta di Pecten, Ostrea. Balanizs, ece.

Piủ a Nord ritroviamo gli stessi banehi, inelinati a Nord-Orest, però ancora piủ potenti, pure riechissimi in fossili, sull'alto delle colline di Dogliani tra S. Belnardo e C. Abbene; li rediamo poi eontinuare sempre più sriluppati nelle colline di IIonforte, di Barolo e di Diano d'Alba, rappresentandoei i residui dei depositi littoranei della tine dell'epoea elveziana.

Queste placelne arenace non giaceiono discordantemente sui sottostanti baneli elveziani, ma ri si collegano per mezzo di alternatire, 
piủ volte ripetute, di marne, sabbie ed arenarie, eome ad csempio si puó stupendamente osservare salendo da C. Ser soprano o S. Lucia al Brieeo di C. Abbene; quindi lc plaeehe arenacee aceennate possono intcrpretarsi eome i residui di un deposito eminentemente littoraneo ehe in aleuni punti speeiali si formò eon spessore maggiore ehc non altrove.

Notiamo eome talora fra gli straterelli marnoso-arenaeei dell'Elveziano superiore trovinsi non di rado straterelli lignitici, però mai degni di eonsiderazione dal lato industriale.

Oltre ai banchi arenaeei, rieeamente fossiliferi, sovracecmnati, altri ne csistono a piủ livelli nell'Elveziano medio; senza entrare ora in dettagli a questo proposito indieo perỏ, almeno per esempio e per comodo di ehi vuole raceogliere fossili, come poeo ad Est di Dogliani in Val Rea agli strati ripetutamente alternati di arenarie, sabbie e marne, con qualehe eiottolo in esse sparso e con denti di Squalo (eosi presso il ponte di Diavolo), steeedono inferiormente presso la Madonna di Morena (o Monera) potenti banehi arenaeeo-ghiaiosi inglobanti pure eiottoli e numerosi fossili, fra eui in eerti straterelli hanno la prevalenza i resti di Serpula e non sono rari i denti di Carcharodon. Sotto questi banehi caratteristiei emergono, e veggonsi svilupparsi molto ad Est, numerosi strati arenaeei, regolarmente alternati eon strati marnosi, sopra ai quali i primi spiecano in rialzo per la loro maggior durezza.

Dalla eonfluenza del Rio Gamba sin sotto alla borgata Martina cirea compaiono nuovamente, sotto ai banehi sovraecennati, potenti strati marnosi ehe rieordano quelli del Tortoniano; sotto essi vengono a giolno altri strati arenaeei e cosi avanti non si ha più altro da constatare ehe una continua alternanza, più o meno regolare, di marne, sabbie, ed arenarie.

Ho già aecennato come sia diffieile ed arbitraria la delimitazione tra Elveziano e Tortoniano. Oltre alla maggior rieehezza in strati sabbioso-arenacei uno dei caratteri più spieeati delle assise superiori elveziane è il presentare esse sovente denti di Squalo; anzi talvolta in easi dubbi mi sono appoggiato a questo carattere per la delimitazione dei due orizzonti in esame; eosi, per citare un escmpio, riferiseo all'Elveziano le colline di Madonna delle Grazie (Sud di Dogliani) pel rinvenimento di numerosi denti di Carcharodon nelle vieinanze di C. Perotti presso S. Eleuterio, quantunque quivi siano abbastanza sviluppati i banehi marnosi a facies tortoniana.

Non eredo però ehe tale earattere paleontologico sia eselusivo dell'Elveziano, per quanto esso sia eertamente importante ed abbastanza generale in Italia e fuori; in aleuni easi quindi ho messo nel Tortoniano inferiore banchi in eui si ineontra anehe qualehe dente di Squalo, eosi le eolline di C. Candia soprana (Sud-Ovest di Dogliani) pleesso la sta- 
zione ferroriaria di Farigliano, parte della valle _iàaldo, la galleria della stazione di Bastiglia, la trincea ferroviaria di borgata Bricchetto, ecc., ecc., regioni che presentano facies essenzialmente marnosa.

D'altronde dopo arer perlustrato per dirersi mesi, in tutti i sensi, in tutti i modi e con criteri dirersi questa porzione Nord-Orest delle Langhe, dovetti sempre più convincermi dell'impossibilità di separare nettamente i due orizzonti in questione, tanto più che spesso nel rero Elreziano compaiono potenti banchi marnosi a facies toptoniana, come ad escmpio al Bric Botti, al Bric Benènti, presso S. Martino (Sud di Monforte), nelle colline di Serralunga, cce.; ricerersa poi troriamo potenti banchi arenacei a facies elveziana nel mezzo del Tortoniano come nelle colline di Norello, di Ciocchini, di Castello della Tolta ecc.

Fra i banchi sabbioso-marnosi incontransi non di rado depositi ciottolosi, così in Talle Argentella sotto C. Finas, nella perte alta di IIonforte (dore costituiscono un rero banco conglomeratico), a Nord di Monforte presso Bric Tappà, nelle ricinanze di C. Fantini, presso il paese di Sinio, sotto il Bric poco a Tord di Castiglione"Falletto, ecc. É notevole che gli elcmenti ciottolosi piuttosto che in lenti per lo più troransi sparsi qua e là nclla marna senza cernita, ed inoltre generalmente in tali punti la marna presenta una speciale struttura irregolarmente concentrica ed è quasi sempre assai ricca in fossili più o meno ben conserrati ma caoticamente disposti.

Gli elementi ciottolosi sono per lo più del diametro di 10 a 20 ccntim.; talrolta però ri sono commisti elementi rocciosi a spigoli poco arrotondati e talora anche ciottoli assai roluminosi; ma in tal caso però gencralmente questi ultimi sono di natura arcnacca, cioè prorengono solo dallo sfircelo cii orizzonti terziari più antichi. Generalmente i ciottoli sono serpentinosi, quarzosi, diasproidi o calcarci, prorengono cioè generalmente dalle Alpi Marittime meridionali.

In alcuni punti, come ad esempio poco a Nord di Monforte presso C. Fantini, ho potuto osservare grossi ciottoli di arenaria cementatissima, del dianctro di quasi 1 metro, inglobati in un banco marnoso, senz'altro accompagnamento che alcumi ciottolini sparsi irregolarmente fra la marna attorno ad essi; i ciottoli di roccia antica raramente oltrepassano quivi i 30 centim. di diametro.

A liuc il rero non è facilc lo spiegare tale disposizione dei ciottoli ricorrendo solo ad una impetuosa colrente acquea sboccante quiri nci mari di quell'epoca, ma parrebbe piuttosto accettabile l'ipotesi di caduta di ciottoli trasportati da zattere di ghinceio; non credo però affatto di rover insistcre su tale ipotesi poichè per molti motivi non la reputo accettabile scnz'altro, per quanto essa si presenti a primo tratto abbastanza seducente. 
Nelle regioni collinose in esame l'inelinazione degli strati, abbastanza regolare ver'so Nord-Ovest, è sempre assai debole, cioè di $8^{\circ}, 10^{\circ}, 12^{\circ}$, od anche meno; essa si può osservare assai bene quasi ovunque a causa degli straterelli arenacei duri, talora fogliettati, ehe ripetutamente alternansi eolle marne anche nella parte superiore dell'Elceziano, ciò che d'altronde è uno dei earatteri più spieeati che servono a delinitare questo orizzonte geologieo dal Tortoniano.

Quantunque sia assai regolare la generale stratificazione dell' Elveziano tuttavia non sono rari i salti ed i contorementi loeali, le pieghettature degli straterelli, gli aecentramenti irregolari delle marne, eee.

Si è già ineidentalmente accennato ai banehi arenacei di MLonforteBarolo; eonviene però ora ehe li esaminiamo alquanto più minutamente, sviluppandosi essi straordinariamente in queste regioni tanto famose dal lato enologico.

Il paese di Monforte è preeisamente costrutto sopra una potente plaeca arenacea ehe per la sua durezza (relativamente almeno ai banehi cireostanti) forma un notevole rialzo sulle colline eireostanti (donde l'ubieazione ed il nome del paese ehe vi è fondato); oltre ai ripetuti strati duri, arenacei, giallastri, fossiliferi, veggonsi anche strati ciottolosi trasformati in eonglomerato durissimo ehe ora si può solo piì osserrarc in poehi punti nella parte alta della eittr.

Eguali banehi, spesso raeehiudenti grossi ed irregolari noduli arenacei o lenti ghiaiose, vediamo costituire le vicine colline di Brie Tappa, Brie Giubellini, eec., e, eome di solito, alla loro base essi danno origine, verso Ovest, a sorgenti aequee ehe alimentano gran parte dei pozzi di Monforte.

Verso Nord troviamo aneora potentemente sviluppati i grandi banehi arenacei specialmente visibili nei profondi rii ehe ineidono le colline di Perno. Ha dove essi ragginngono uno sviluppo ancor più grande od almeno dove essi sono più ampiantente esaminabili è a Nord-Ovest di Monforte. Infatti a Nord-Ovest del eolle di Madonna Settevie, formato da una locale discontinuazione dei banehi arenacei, questi, eon una potenza di oltre 50 metri, veggonsi eostituire le colline di S. Pietro, di C. S. Giovanni, di C. Bosehetti, ece. andando a formare l'imbasamento del paese di Barolo e perdendosi in seguito verso la base delle eolline di S. Lorenzo.

Anehe in queste regioni si verifieano spesso sorgenti aequee alla base dei depositi in questione e partieolarmente nota ̀̀ quella eopiosissima di Valle Piana di Barolo, sotto il paese di Barolo; pure in rapporto eon eontemporanei strati arenacei, però assai meno potenti, sta la nota sorgente di Fontanafiedda.

Nelle colline di Serralunga predominano i banehi marnosi, mentre 
più ad Est nelle colline di Sinio, Albaretto, Montelupo, ecc., abbiamo bensi una continua alternanza di banchi marnosi con banchi sabbiosi ed arenacei, ma lo sviluppo maggiore è di questi ultimi; vi si incontrano spesso resti fossili nonchè Paleodictyon ed altre impronte di varia natura, lenti ghiaiose, ece.; in alcuni luoghi, come ad esempio presso borgata Ricca (Est di Diano d'Alba) sono abbastanza comuni i denti di Squalo, che d'altronde non sono rari in quasi tutto l'Elveziano.

L'inclinazione degli stiati è abbastanza regolare, di cirea $10^{\circ}$ verso Nord-Aord-Orest, eiò che influisce molto stilla oroidrografia di queste regioni collinose; così ad esempio si spiega la grande differenza che esiste tra la sponda destra (ripida) e quella sinistra (a doleissimo pendio) delle vallette di Fossa dei Quiri, Rio Ceppa, Rio Fossato, Rio S. Croce, Rio Grinzane, ecc.

Nella parte alta delle colline di Diano d'Alba ritroviamo potentissimi e earatteristici i banchi arenacei dell'Elveziano superiore inclinati a Nord-Nord-Orest, inglobanti una grandissima quantita di accentramenti arenacei, ed abbastanza fossiliferi. Ma dove reggonsi più ampiamente sviluppatí questi banchi arenacei è nelle colline albesi fronteggianti il Tanaro tra Val Talloria e Val Cherasca; quivi infatti essi affiorano quasi ovmeque, eomprendendo non di rado lenti eiottolose con Ostrea, Terebratula, ecc. (come poco ad Est di C. Prandi lungo la strada AlbaDiano) e sovente danno origine verso Nor'd (giacchè tale è la direzione prevalente degli strati) ad abbondanti sorgenti acquee, come ad esempio quelle di Villa Monsordo, ci C. Alfieri, di Villa Cantalupo, di C. S. Cassano, di C. Rio, ece.

Nelle colline ad Est di Alba non incontriamo più i sorraindicati caratteristici depositi arenacei littoranei, zeppi di fossili, dell'Elveziano stuperiore, quantunque banchi un po' simili, anche assai potenti, siano comunissimi in questo orizzonte geologico attraverso tutte le Langhe sino a collegarsi colle resistenti arenarie ealcaree delle colline del Monferrato.

Talvolta interstratificati ai banchi marnoso-arenacei trovansi lenti lignitiche, industrialmente insignificanti, come ad esempio in Tal Chelasea a Sud di Alba presso C. Pelnzza.

Credo necessario di sempre insistere sul fatto che, per quanto in complesso sia naturale e necessaria la distinzione tra Tortoniano ed Elveziano, all'atto pratico sul terreno tale delimitazione non può essere che alquanto arbitraria e non completamente uniforme fia le varie regioni, sempre in eausa delle giil tante volte indicate altermanze di banchi marnosi, sabbiosi ed arenacei che eostituiscono un gradualissimo passaggio tra i due sovraccennati orizzonti geologici; osserrando 
però complessivamente queste regioni collinose risulta nettamente in generale la distinzione fra quolle tortoniane, rotonciegrianti, biancastre, foggiate a cupola, interseeate da valli relativamente ampie od a dolei pendii, e quelle elveziane più elevate, più irregolari, a creste più aeute, di color grigiastro, intersecate in ogni senso da profondi burroni e da strette vallate a pareti sovente quasi verticali.

Nei banehi arenacei sono ovunque assai comuni le impronte di $P a-$ leodictyon e simili; esse possonsi raecogliere abbondantemente sia esaminando gli ammassi di lastre radunate qua o là eome materiale di costruzione, sia pereorrendo l'alveo dei maggiori tor'renti.

La stratificazione dell'Elveziano nelle Langhe in esame, per quanto molto regolare in complesso, presenta tuttavia disturbi locali, cioè piccoli salti o successione di salti, come ad esempio presso C. Avenc (Nord di Mango), presso C. I Forti (Ovest di Castiglione Tinella), presso S. Martino, piủ ad Est presso C. Scaglione, presso C. Abramo (Sud di Canelli) ece., eee.; d'altronde basta osservare attentamente una sezione naturale un po' sviluppata per riconoseervi quasi sempre piccoli spostamenti stratigrafiei locali.

Un punto dove si possono eomodamente osservare i fenomeni stratigrafici in questione è speeialmente il margine della strada Canelli-Cassinasco, poco sotto C. Pignatta, dove in una lunga sezione artificiale presso la strada osservasi una ripetizione di piceoli salti eon scorrimento degli strati, ciò ehe è dovuto a fenomeni fisiei verifieatisi durante il sollevamento dei terreni in esame. A poea distanza, cioè presso C. Seaglione, possiamo invece osservare nettamente una diseordanza stratigrafiea dovuta a fenomeni verifieatisi durante la deposizione dei banehi elveziani, il che ei indica eho anehe durante l'epoea elveziana si verificarono movimenti nei fondi marini.

Si osservano inoltre talora, negli strati elveziani di certe rogioni, pendenze assai forti (relativamente almeno alla loro solita inclinazione) eosì per esempio di circa $30^{\circ}$ verso Nord-Ovest nelle sovraceennate colline di C. I Forti, dove quindi probabilmente vi è una eerta trasgressione tra Tortoniano ed Elveziano.

Cosi pure è dovuto in gran parte a disturbi stratigrafici il notevole avanzarsi dell'Elveziano entro la zona tortoniana nelle eolline di Calosso, dove infatti possiamo in diversi punti osservare negli strati elveziani un'inelinazione di $20^{\circ}$ a $30^{\circ}$ verso Orest-Nord-Ovest, eosì presso C. Delle Ripe, come pure nelle eolline di Canelli, solo ehe quivi la pendenza presentasi in parte verso Est-Nord-Est; in ogni modo ne deriva quivi una trasgressione piủ o meno manifesta, più o meno generale tra i banehi elveziani e quelli tortoniani.

In tutte queste regioni collinose l'Elveziano è costituito da una 
predominanza assoluta di banchi sabbiosi, arenacei, grigio-giallastri, abbastanza resistenti che, secondo la loro pendenza, formano reri piani inclinati e danno alla regione un aspetto speciale ed un'oro-idrografia strettamentc collegata colla stratigrafia della regione stessa.

È con queste considerazioni che ci spieghiamo facilmente la direzione da Est ad Ovest delle grandi valli di Rio Tamiano, di Rio Lanlonzo, di Rio del Nango, del Rio di Camo, di Rio della Rocche, di Rio di Castiglione, di Rio delle Rocchea, ecc., ed il presentar esse il loro lato destro con pendio doicissimo e quello di sinistra invece con pendio lipidissimo.

Cosi pure il rapido ripiegarsi ad Est della grande rallata del Belbo è dovuto in gran parte alla stratigrafia elveziana per quanto possa eziandio avervi contribuito lo sbocco della Tinella ed altre cause secondarie.

In generale poi dobbiamo osservare come, mentic nella parte Orest e Nord-Ovest delle Langhe l'inclinazione stratigrafica è di circa solo $10^{\circ}$ od anche mino1e, verso Est invece essa direnta più forte, cioè di $12^{\circ}, 14^{\circ}$ nelle colline di S. Stefano Belbo, Canelli, cec., e poi anche di $15^{\circ}$ e più, verso Est. Questo fatto naturalmente si collega direttamente col noterole restringersi della zona elveziana da Orest ad Est, fenomeno che infatti dipende anche in parte dall'esserc i terreni elveziani piủ fortemente sollcrati.

Una discordanza stratigrafica tra Tortoniano ed Elveziano possiamo ancora constatare in Val Belbo presso le Case Vecchic a Nord di Calamandrana; quivi infatti rediamo che i potenti banchi arenacei dell'Elveziano, internati assai nella zona tortoniana, inclinati rerso Nord-Est, rengono coperti quasi di tratto dai banchi preralentemente marnosi del Tortoniano.

Pcrcorrendo le colline elveziane eminentemente sabbiose, comprese nclla tavolctta all'1 : 25000 di Calamandrana (una delle migliori carte . topografiche del Piemonte) e di Acqui, ritroriamo ancora soventi disturbi stratigrafici più o meno noteroli di cui, per breviti, indico duc soli csempi; cioè i banchi superiori dell'Elreziano sopra C. Crocetta (Nord di Castelboglione) che sono inclinati di circa $40^{\circ}$ rerso NordNord-Ovest, ed i banchi arenacei pure dell'Elreziano superiore sopra la bolgata Boidi (Sud-Est di Castcl Rochero) che pendono di quasi $70^{\circ}$ verso Nord-Est.

Anche alla base affatto dell'Elveziano non sono rari i salti e gli scoscendimenti locali, come ad esempio si può osselvare quasi sotto C. Valloria (Nord-Orest di Acqui) nei banchi di passaggio tra Elveziano e Langhiano.

Contuttociò si può dire che l'andamento gencrale dell'orizzonte elve- 
ziano dalle Langhe occidentali alla Valle Bormida presso Strevi è assai regolare, con pendenza media di circa $15^{\circ}$ a $20^{\circ}$ verso Nord.

Ciò che è certamente molto notevole è il graduale ristringersi della zona elveziana ver'so l'Est, fenomeno che si verifica gradualmente dalle Langhe alle colline di Montabone ma che si accentua poi in modo strordinario ad Est di quest'ultimo pacse, per modo che mentre prima questo orizzonte si estendeva ancora da 7 ad 8 chilometri in ampiczza, esso si riduce in seguito a solo pith due chilom. circa.

Nelle colline di Montabone, dei Bruni, ece. sono ancora assai sviluppati gli straterelli arenacci con impronte organiche ed inorganiche, specialmente di Paleodictyon, particolarmente nell'Elveziano inferiore e nel passaggio al Langhiono; sono pure comuni certi grumi arenacci per lo più irregolari od a forma quasi di biscotto, spesso appiattiti da un lato e tondeggianti dall'altro e soleati trasversalmente; li credo doruti essenzialmente a fenomeni di accentrazione.

Più ad Est vediamo apparile e svilupparsi tosto notevolmente nclla parte superiore dell'Elveziano una facies speciale che si cstende in scguito verso Est a quasi tutto il piano elveziano del Monferrato, della Liguria, del Tortonese e di parte delle colline Torino-Valenza.

Qucsta facies speciale c̀ rappresentata da banchi arenacco-calcarci molto resistenti, utilizzati spesso per matcriale da costruzione ed anche come pietra da calce dolce, spesso contenenti fossili sia macroscopici sia microscopici, a cui devesi in gran parte il calcarc cementante lc arenarie in questione.

Tali carattestici banchi cominciano ad individualizzarsi presso le C. Mezzanc e Bagnerc, tra Acqui e Ricaldone, costituiscono l'elevata cresta di Bric della Guardia, formando poi sul lato sinistro di Val Bormida un nettissimo gradino che discende poco a poco al basso piano della vallata presso C. Braida.

Se in Val Bormida i terreni clreziani rimangono per breve tratto mascherati dalle alluvioni, se ne può però tracciare assai bene l'andamento giacchè, a causa della relativamente notevole resistenza dei banchi prevalentemente arenacei elveziani rispetto a quella degli orizzonti geologiei fra eui è compreso, verificasi quivi un notevolissimo ristringersi della vallata; infatti quivi in detta valle anzitutto vediamo sotto Orsara una ampia conca orografica, corrispondente al passaggio tra Elveziano e Langhiano, ed inoltre possiamo osservare che i banchi arenacei dell'Elveziano superiore, corrispondenti a quelli prima studiati di Bric della Guardia sulla sinistra di Val Bormida, formano sulla sua destra una specie di sprone che da Orsara alta si spinge verso la C. S. Nichele nella bassa Val Bormida.

Nelle colline di Orsara e di Montaldo Bormida l'Elveziano, ridotto 
alla larghezza talora anche di un solo chilometro, a banchi inclinati regolarmente di $10^{\circ}$ a $20^{\circ}$ verso Nord-Nord-Orest, è costituito nella parte inferiore di un'alternanza più volte ripetuta di strati o banchi marnoso-sabbiosi ed arenacei, che passano gradatamente al Langhiano; superiormente esiste una prevalenza di duri banchi calcareo-arenacei giallastri, fra cui i piu potenti appaiono nella parte medio-superiore dell'orizzonte in esame, formando le colline di Orsara, di C. Sogino, di Montaldo, ecc., costituendo parte delle creste collinose.

Se, come diccmmo, il passaggio tra Elveziano e Langhiano si compie piuttosto gradualmente e quindi con delimitazione assai incerta, invece l'Elveziano superiore di queste regioni viene ricoperto con discordanza dai terreni più giovani per cui esiste quivi generalmente un hyatus abbastanza notevole causato specialmente dal grande avanzarsi dei depositi messiniani verso Sud, tanto che noi vediamo come nelle colline di Orsara, di S. Quirico e di Montaldo i banchi sabbioso-ciottolosi del Messiniano si adagino discordantemente e direttatamente sulle arenarie elveziane; in aleuni punti anzi, come ad escmpio presso Montaldo-Bormida, i terreni dei due orizzonti, quantunque geologicamente assai distanti, non sono facili a distinguersi per essere di natura alquanto simile.

Possiamo in proposito citarc la seguente sczione geologica che si può osscrvare percorrendo la cresta di S. Quirico:

Piacenziano - Argille giallo-bleuastre.

Iessiniano $\left\{\begin{array}{c}\text { Banchi sabbioso-Inarnosi, grigio-giallastri. } \\ \text { Banchi ghiaioso-ciottolosi ad elementi spesso assai } \\ \text { voluminosi. }\end{array}\right.$

Potente complesso di grossi banchi arenaceo-calcarci.

Elveziano Potente pila di strati sabbioso-arenacei. Alternanza di banchi marnosi, sabbiosi ed arenacei
grigio-bleuastri.

Langhiano - Grossi banchi marnoso-sabbiosi, grigio-bleuastri.

Nelle colline di Carpencto osserviamo ancora bensi potenti banchi arenacei (con mumerosi Foraminiferi, denti di Squalo, cec.) originanti spesso speciali veli acquei e sorgenti, ma essi vi si presentano spesso fortemente disturbati per modo da apparire saltuariamente qua e là, talora a guisa di spuntoni rocciosi framnezzo agli strati marnoso-sabbiosi circostanti.

$\dot{E}$ in tal modo che vediamo comparire banchi arenaceo-calcarci in Val Maggiore quasi sotto C. Bardeneto, di fronte a C. Amburino, presso C. Borgognona, ece.; cosi pure in parecehi punti tra Trisobbio e Roceagrimalda presso C. Boggiorosso, presso C. Specola, presso C. 
Belvedcre, nelle vicinanze delle borgate l'Assunta, ecc. costitucndo ripidi c caratteristici rialzi, visibili anche di lontano.

Questi fenomeni sono doruti essenzialmente a forti disturbi stratigrafici, rotture, scosecndimenti, ece. che ei sono rilevati cliaramente dal fatto clie in queste regioni gli strati non solo sono dirctti in vario scnso, spesso assai diversamente da quello normalc (Est-Ovest cirea), ma sovente si prescntano anclic sollevati di $50^{\circ}, 60^{\circ}, 70^{\circ}$, c talola sono anclie portati alla verticalc o persino leggermente rovesciati. Tali fatti possonsi specialmente osservare bene nclle colline tra Carpeneto, Trisobbio e l'Assunta, giacchè ver'so Roccagrimalda la stratificazione ritorna poco a poco abbastanza regolare.

Siccome nelle r'cgioni collinose di Trisobbio i banchi del Langhiano supcriore prendono parte cziandio agli accennati disturbi stratigrafici, ricsce quivi naturalmente sempre piủ difficile la distinzione tra Langhiano ed Elveziano, delimitazione gia scmpre tanto arbitraria nei casi di regolare stratificazione. Lo studio stratigrafico dell'Elveziano della regione ora in esame ci spicga anche in gran partc il noterolc sviluppo che occupa quivi tale ter'reno.

Nei dintorni di Roccagrimalda va scomparendo quasi completamente la facies marnoso-sabbiosa che più ad Est predominava nell'Elveziano inferiore ed invece tutto questo orizzonte geologico diviene quasi completamente costituito di potenti banchi arenaceo-calcarei, molto resistenti, usati spesso per matcrialc da costruzione e talrolta utilizzabili eziandio per materiale da calce.

Questa prevalenza assoluta delle arenarie calcarce dà alle colline elveziane di queste regioni un aspetto afratto speciale, piuttosto arido, quasi montuoso, a creste spiccate, a fianchi lipidi, con non rare sorgenti, con qualche cascata d'acqua, a vegetazione csscnzialmente arbustacea col arborea, a difficile viabilita c spesso con una tinta rossastra generale dipendente dalla dccomposizione di parte dei suoi clementi.

L'indicata facies che, iniziatasi, come dissi, nelle colline a Nord di Acqui si sviluppa completamente nei dintorni di Roccagrimalda, prosegue poi a mostrarsi sviluppatissima verso Est nelle colline di Castclletto d'Orba, Gavi, Serravalle Scrivia, ece, nonchè nel tortonese, come vedremo, costitucndo cosi una specic di spiccato nastro montuoso, direi, quasi specialc alle regioni collinose formate di Elveziano.

E naturalmente in stretto rapporto colla costituzione dcll'Elveziano il rapido restringersi della valle d'Orba, generalmente assai ampia, là dove cssa è incisa nei banchi di questo orizzonte geologico.

Naturalmente coi banchi arenacei si alternano spesso banchi malnosi e sabbiosi (ad Aturia Aturi, ecc.), ma in grado molto minore di quello che si osserva piủ ad Ovest; non di rado invece coi letti 
arenacei vediamo frammischiarsi lcnti ghiaioso-ciottolose ma generalmente solo affatto localizzate.

La zona elveziana è per lo più ridotta ad una larghezza di uno o due ehilometri soltanto; i suoi strati prescntano un'inclinazione assai regolare verso il Nord circa ma relativamente abbastanza forte, cióe di eirca $25^{\circ}$ e non di rado anche di $30^{\circ}$ o $40^{\circ}$.

Riguardo al passaggio tra Langhiano ed Elreziano nelle regioni ora in esame la loro distinzione non riesce in complesso difficile giacchè, senza una lunga altcrnativa di strati arenacei e marnosi, si passa abbastanza rapidamente dall'orizzonte langhiano cssenzialmente marnoso a quello elveziano esscnzialmente arenaceo, ed anzi per molti chilometri si può scguire assai bene un potente banco arenaceo che pare logico di prendere come base dell'Elveziano, sempre naturalmente in ria convenzionale. Cosi ad escmpio nelle regioni collinose di Gari possiamo osservare il segncnte passaggio tra i due piani in csame:

$$
\text { Elveziano }\left\{\begin{array}{l}
\text { Potenti banchi arenacco-calcarei. } \\
\text { Banchi sabbioso-arenacei, grigio-giallastri. } \\
\text { Potente complesso di banchi arenacco-calearei, gial- } \\
\text { lastri, alternati con stratcrelli sabbiosi di color } \\
\text { grigio. }
\end{array}\right.
$$

Neppure difficile riesce la distinzione dell'Elrezicno superiore dai terreni sorrastanti, sia anche solo dando uno sguardo all'orografia della regione (a causa della conformazione quasi montuosa c dello spiceato rilicro delle colline plresiane), sia pel fatto ohe esiste goneralmente una trasgressione piu o meno spiccata fira questo terreno e quelli più giovani; tant'è che il 'Tostomiano sorente redesi ridotto ad una semplice striscia, ed anzi per mn tratto assai esteso esso vicne completamente mascherato dai depositi messiniani. apparendo solo nelle più profonde incisioni.

Uno dei punti migliori ove si può eomodissimamente e molto bene osserrare il passaggio dall'Eleveiano, a banehi arenaceo-calcarei, direttamente al Messiniano sabbioso-conglomeratico, è lungo la strada Gavi-Novi, nella regione Montcrosso dove non appare traceia di banchi marnosi riferibili eon certezza al Tortoniano.

Ad Est di Gavi, sviluppandosi poeo a poco il Tomoniano, rerifichiamo di nuovo un graduale passaggio e quindi un'incerta dclimitazione fra Elveziano e Tortoniano per quanto in complesso risulti sempre ehiara e naturale la loro distinzione. Sorente incontransi fossili abbastanza ben conservati in questi banchi di passaggio, oosi ad esempio 
nelle colline di Monterotondo, presso il cimitero di Serravalle, ece. Anche sotto il punto di vista palcontologico possiamo constatare in tali banchi una fauna mista, cioè di fucies in parte lortoniana ed in parte elveziane; c quindi, eome d'altronde è perfettamente naturale, neppure i fossili possono servire per fare la sovracecnnata delimitazione, poichè questa in natura non esiste.

Nelle colline di Scrravalle l'Elbeziano si presenta ad un dipresso colla facies prevalentemente arcnacco-calcarea accennata in queste ultine pagine; è solo la comodita di studio, per trovarsi Serravalle lungo una delle principali arterie ferroviarie del Piemonte, ehe fece sì che questa regione venisse finora più comuncmente osservata ed accennata da diversi geologici come Nayer, Pa to (ehe ne trasse il nome di Serravalliano simonimo d'Elvesiano), Fuces ed altii.

Così pure i numerosi fossili giả accennati dai predetti geologi conte provenienti dalle colline di Scrravalle non devono interpretarsi quale prova di una maggior ricchezza in fossili di questa regione rispetto a quelle esaminatc e da csaminarsi, ma solo di più aceurate e ripetuto ricerehe in proposito.

Di questi fossili si puó raceoglierce gran numero, ad escmpio, in quei banchi marnoso-sabbiosi, grigiastri, o grigio-biancastri, a frattura scagliosa, alquanto resistenti, che fanno gia passaggio al Tortoniano, cosi nei dintorni del cimitero di Scrravalle, nelle vicinanze di Stazzano, cec.

Ad Est di Val Scrivia l'orizzonte Etveziano, scmpre con una facies prevalentcmente arcnaceo-calcarca, e quindi con un aspetto alquanto aspro e sclvaggio, si va gradatissimamente restringendo; poco a poco dalla primitiva direzione, Est-Ovest circa, si volge a Nord, seg'uendo cioè la curva che tutti gli orizzonti terziari formano in questa legione; l'inclinazione dei suoi strati è sentpre assai regolare, in media di $20^{\circ}$.

Sulla destra di Val Borbera, a Nord di Borghetto, possiamo osservare la seguente serie stratigrafica:

Eltesiano $\left\{\begin{array}{l}\text { Potenti banchi arenaceo-calcarei, grigio-giallastri. } \\ \text { Grossi banchi sabbiosi, giallastri, interealati a stra- } \\ \text { terelli arcnaceo-calearei. } \\ \text { Potenti banchi arenacco-calcarci. } \\ \text { Harne sabbiose, grigio-blenastre, alternatc con stra- } \\ \text { terelli arcnacei. } \\ \text { Complesso (2 o } 3 \text { metri di spessore) di stratcrelli } \\ \text { arenaceo-calcari ripetutamente altcrnati con sot- } \\ \text { tili straterelli marnosi. }\end{array}\right.$

Langhiano - Grossi banchi marnosi, grigio-bleuastri, alternati con straterelli arcnacei. 

Banehi marnosi ripetutamente alternati con banehi areinaeei.
Banchi sabbiosi, ricchi in pagliette mieacee, grigio- giallastri, alternati con qualche strato arenaceo raschiudente acecntramenti arenacei globosi o discoidi.
Narne grigio-rerdastre alternate con straterelli are- nacei.
Potenti banehi calcareo-arenacei giallastri.

Stampiano - Marne grigio-rcrdastre alternate con straterelli sabbiosi.

La distinzione tra Langhiano ed Elie:iano in queste regioni diventa səmpre più diffieile, poichè il primo orizzontc geologico, come già accennammo nel preeedente capitolo, direnta quivi poco a poco anch'esso molto arenaceo, a facies, direi, elveziana, tanto da sollerarsi anche sopra alle regioni elvesiane e da presentarne affatto l'aspetto; tuttavia osscrvando i grandi spaccati si può notare che nell'Elvesiano relo gli strati inarnosi si alternano meno frecuentemente e sono più piccoli che nel Langhiann il quale risulta cuindi di color più grigio-blcuastro; ma ad ogni modo è sempre assai arbitraria la delimitazione dci due piani geologiei in questionc, per quanto in generale si possa dire che l'Elveziano si inizia pel' lo più eon un potente eomplesso di grossi bancli arenacei giallastri, cementatissimi.

Nella parte superiore dell'Ele, iano, siccome nelle regioni in esame il Tortoniano è noterolmente sriluppato, troriamo tra questi due orizzonti geologici un passag'gio generalmente graduatissimo, colle solite difficoltà di delimitazione; però essendo il Tortonimo quiri parzialmente eonglomeratico, ne risulta in tali casi abbastanza facile la sua distinzione dalle arenarie elreziane, cosi nelle colline di C. Carlina, di Masscria Baiardo e di Cresta Argande. Però nelle colline di Vargo (e ciò è specialmente ben risibile nel vallone subito a Suck di Targo c lungo la strada ehe da Targo conduce a Costa Ginepro) anche l'Elceziano presenta nella sua parte superiore lenti c straterelli g-hiaioso-ciottolosi, fossiliferi, per modo ehe ricne anche qui a mancare il caratterc differenziale poc'anzi accennato.

Generalmente però il passaggio dall'Elvesiano al Tortoniano si compic per mezzo delle solite alternanze; cioè alle marne sabbiose torloni me, quasi uniformi, disposte in grandi banehi (costituenti colline a profondi valloni franosi), suceedono inferiormente banehi sabbiosomarnosi abbastanza duri con strati di grumuli marnoso-calcarei; quindi questi strati divengono sempre più potenti cangiandosi in veri banelii e si passa così all'Etresiano superiore.

Continuando l'esame della zona elveziana verso Nord la rediamo 
presentarsi coi soliti caratteri or ora indicati, però senza notevoli lenti ghiaiose e con una potenza relativamente assai piccola, cioc̀ di poco più di 100 metri in media. Per la loro resistenza i banthi arenatei etreziani costituiscono spesso le creste e le punte delle colline in esame, così la Cresta Ronchi, il Briceo S. Vito, ecc.; inoltre danno luogo a frequenti sorgenti acquee fra eui notevole quella di Avolasea.

A Nord di Avolasca i terreni elveziani, costituiti di un'alternanza di marne, sabbie ed arenarie, spesso assai fossilifere, formano il rilicro su cui sta la Parrocehia di Avolasca ed il Poggio del Moro; quindi sempre più rapidamente restringendosi detti terreni si ridncono a solo più pochi banchi arenacei che attraversano il paesello di Sarizzola dando luogo a piccole sorgenti; infine con stratificazione alquanto irregolare i banchi èveziani vanno a stomparire completamente al fondo di Rio Ossona venendo ricoperti dalle potenti marne tortonicane, neilo stesso modo come nelle prossime colline venivano pure a scomparire gli orizzonti terziari più antichi.

Lasciando per ora in disparte lo sviluppo notevole ed assai curioso che le formazioni elveziane presentano nella parte oricntale delle colline tortonesi e nelle colline pavesi, dove sollevansi ad oltre 750 metri, dobbiamo perỏ accennare ai limitati aftioramenti che di questi terreni appaiono nella parte oceidentale dei colli di Tortona.

Nella basse valle Ossana l'Etveziano appare nelle colline di Romagnano sotto forma di banchi sabbioso-arenacei giallastri inclinati un po' variamentc, cioè in massima parte verso il Sud-Ovest ed in parte di circa $50^{\circ}$ verso l'Ovest; queste arenarie sono assai ricche in fossili, specialmente Bivalvi, Brachiopodi, Echinodermi, ecc.; colle arenarie alternansi pure strati marnosi grigio-giallastri, armioni di varia forma, ecc.; vi si notano alcuni conturbamenti stratigrafici.

Verso Nord l'indicata formazione elveziana diventa più marnososabbiosa e quindi non sempre facilmente delimitabile dal sovrapposto Piacenziano; invece ricompaiono nettamente i banchi elveziani marnoso-calcarei, grigio-bleuastri, compatti, poco ad Est di Mombisaggio ; quivi detti banelri, inclinati di $25^{\circ}$ o $30^{\circ}$ verso Sud-Sud-Ovest, sono ricchissimi in fossili (fra cui molti denti di Squalidi) e vengono utilizzati per l'estrazione di materiale da costruzione, i cosidetti cantoni, di cui sono costituite quasi tutte le abitazioni di Mombisaggio. Anche in questo caso non è sempre facile il dclimitare le marne elveziane da quelle sorrastanti piacenziane, solo che queste sono più blcuastre, più argillose, meno calcaree e quindi meno resistenti.

Infine una placea elveziana importantissima è quella che, con forma complessivamente triangolare, costituisce il rilievo della rocea di Tortona; quivi le marné calcaree, grigiastre o giallastre, talora alquanto are- 
naeee hanno il predominio assoluto: vi appaiono pure banchi sabbiosi grigi, inglobanti frammenti rotolati di marne rerdastre. I banehi pendono di circa $20^{\circ}$ a $30^{\circ}$ rerso l'Orest all'incirca con qualche oscillazione da luogo a luogo; questa formazione elveziana è molto interessante paleontologicamente perchè ricea in modo straordinario di resti fossili, specialmente Folaminiferi, Antozoi, Echinodermi, Molluschi, denti di Squalidi, ecc.; vi si trovano anche banehi di ostriche.

Nelle colline Torino-Valcnza i terreni elveziani sono molto sriluppati, specialmente nella parte occidentale; riguardo al loro modo di presentarsi essi possonsi distinguere assai bene eomplessivamente in due sorta; eioè in Elceziano a facies marnoso-arenaceo-calearea nella parte oricntale, ed in Elceziano a facies prevalentemente marnoso-sabbiosociottolosa nella porzione occidentale; nella regione intermedia circa tra l'Est e l'Orest delle colline in questione si può constatare un passaggio assai graduale tra le die facies ora accennate.

L'Elveziano della porzione orientale dei colli Torino-Talenza ricorda molto nella sua eostituzione quello dei colli tortoncsi, specialmente quello delle vicinanze di Tortona; invece l'Elvesiano dei colli torinesi si può meglio paragonare a quello della parte meridionale dei colli monregalesi; vedremo infinc come nella parte media circa delle colline in questione si sviluppino noterolmente certi banchi arenaceo-calcarei ehe trovano la loro corrispondenza in banchi simili che redemmo sriluppatissimi specialmente nelle Langhe, nel Monferrato ed alle falde settentrionali dell'Appennino ligure.

Nella parte occidentale delle eolline di Valenza troviamo apparire le formazioni elresiane presso Pecetto di Valenza, dore csse si presentano sotto forma di marne grigiastre piuttosto resistenti, scagliose o a frattura concoide, spesso fossilifere, che nella parte superiore passano gradualmente alle marne tortoniane mentre che nella parte inferiore, verso Orest, appoggiansi direttamente sulle formazioni lign oume. Questi banchi marnosi compatti dell'Ele esiano inclinano piuttosto doleemente, cioè di $15^{\circ}$ a $20^{\circ}$, verso il Sud all'incirca nelle colline di Pecetto, ed inveee rerso l'Est ad un dipresso nelle colline di Bric Monteriolo; si osselvano però anche qua e là inclinazioni direrse, attribuibili a fenomeni locali. In complesso noi abbiamo a constatare nelle colline di Valenza un affioramento elvesiano sollevato dall'arricciamento di telreni liguriani, ora in gran parte sepolti sotto la pianura ad Est di Talenza.

Presso le C. Sabbioni c C. Visconti si rede assai bene in alcumi tagli artificiali come l'Elveriano inferiore, appoggiantesi direttamente sul Liguriano, è costituito di sabbic inglobanti lenti di ghiaiette serpentinose; questi depositi poi, per mezzo di mane dure con lenti di ciot- 
toli serpentinosi, passano gradatamente alle marne compatte, biancastre, tipiche dell'Etveziano.

Nelle colline di Valenza abbiamo la seguente serie stratigrafica: Astiano - Sabbie e calcari arenacei riccamentc fossiliferi. l'ucensiano - Argille bleuastre assai fossiliferc.

( Marne e sabbie argillose grigiastre o grigio-verdastre o Messiniano $\left\{\begin{array}{c}\text { giallastre od anche brune. } \\ \text { Sabbie giallastre e calcari grumulosi. }\end{array}\right.$

Conglomerati in lenti cutro banchi sabbiosi.

Sabbie giallastre, arenarie straterellate con letti ciottolosi.

Tortoniano $\left\{\begin{array}{l}\text { Sabbie straterellate grigie fossilifere. } \\ \text { Marne ed argille bleuastre con qualche banco sabbioso. } \\ \text { Marne sabbiose grigiastre straterellate. }\end{array}\right.$ Elvesiano - Marne grigie compatte.

Tongriano - Conglomerati entro sabbie giallastre e sabbie giallo-rossiccic in banchi.

Liguriano - Argille scagliose nerastre e marne argillose grigiastrc con grumuli biancastri, calcari alberesi ed arenarie frammentatc.

A Nord-Ovest della citta di Valenza sorge, direi, dalla pianura padana una regione collinosa su cui stanno i paeselli di Monte e di Pomaro; in causa dei rivestimenti quaternari che ammantano in gran parte queste colline, poche sono le località, e solo dal lato settentrionale, in r.ai si poșa osservare la loro natura geologica; trattasi anche qui di n urne grigiastre (con fossili non rari ma difficili ad estrarsi comple', alternate con banchi sabbioso-arenacei giallastri, come vedesi assai bene sotto il castello di Pomaro; i banchi marnosi, più o meno compatti, talora utilizzati presso Monte per estrazione di cantoni, inclinano di $20^{\circ}$ o $30^{\circ}$ rerso il Sud-Est circa, per modo che pare esista poco lungi, verso Nord-Ovest, una ruga ligurianr, ora completamente coperta dai depositi quaternari dalle valle padana, ma che sorge fuori più ad Ovest a costituire i colli di Casale-Pontestura.

Dall'assieme dei caratteri che presentano i terreni costituenti le colline sovraesaminatc pare che cssi debbansi pure attribuire all'Etve ziano, specialmente alla sua parte superiore.

Nelle colline di Conzano l'Elvesiano compare per breve tratto sotto forma di banchi marmoso-calcarei pili o meno arenacei, utilizzati qua e là per materiale da costruzione, come ad esempio tra Conzano e C. Vallone nuovo; nella parte alta del paese predominano le arenarie marnose grigio-giallastre molto ricche in fossili.

E assai difficile la delimitazione dell'affioramento elveziano di Conzano e per eseguirla sul terreno dobbiamo in parte fondarci sull'oro- 
grafia non essendo molto ehiara la stratigrafia; d'altronde i banehi elresiani non presentano sempre netti earatteri di distinzione da quelli dell'Aquitaniano: l'accennata diffieoltà specialmente si rerifiea nello sviluppo occidentale della zona elveziana in questione.

Ad Ovest di Conzano vediamo apparire tra l'A quitaniano ed il Tortoniano (eon trasgressione più o meno mareata eon ambidue i terreni) una lunga striseia di Elveziano nelle eolline di rignale. Come di solito qucst'orizzonte è quivi rappresentato da grossi banehi arenaeco-ealearei, riccamente fossiliferi (speeialmente in Mollusehi, Echinidi, Foraminiferi, eee.), nettamente inelinati a Sud-Orest, utilizzati su rasta scala eome materiale da costruzione, eosi presso C. Intersenga, presso Vignale, presso C. Nuova, ece.; è eurioso l'osserrare nella parte oceidentale del pacse di Vignale le profondissime e regolari eare ehe si spingono sin sotto le ease, eostituite del materiale tolto, direi, loro disotto.

E precisamente alla durezza eonsiderevole di questi banehi elreziani ehe deresi la noterole elevazione del paese di Vignale. Appartengono probabilmente aneora a questo orizzonte quei banehi arenaeeo-calearei, drizzati quasi alla verticale e diretti all'ineirea da Nord-Est a SudOrest, ehe ineontransi poeo a Nord-Est di Tigmale, presso la strada ehe conduce a Camagna; questi banchi speciali eostituiscono un pieeolo rialzo sopra alla eollina aguitaniana su eni si basano.

Ad Orest dell'ampia valle di Rotaldo l'orizzonte elrezicno si sviluppa amplissimamente ed irregolarmente per modo che ne riesce diffieile una regolare descrizione. Tuttaria i terreni in questione possono eomplessiramente considerar'si eome faeenti parte di una grande elissoide di solleramento eon diverse elissoidi secondarie e eoll'asse maggiore diretto da Est ad Orest circa. Esaminiamo quindi dapprima la zona elveziana costituente una gamba dell'anticlinale: ad esempio quella meridionale.

A Nord di Oliva nelie colline di MIoleto, al disotto dei terreni messiniani di C. Mízzana, ma eon delimitazione molto incerta (a causa della coltivazione e dell'allurione della larga vallata di Ponara), veggonsi affiorare e tosto svilupparsi potentemente i banehi ealcareo-arenacei dell'Elreziano con inelinazione alquanto raria, ma prevalentemente di eirea $30^{\circ}$, verso Est.

Questi banehi elreziani sono quivi largamente seavati eome materiale da costruzione e presentano una grande riechezza in fossili; fra questi sono particolarmente notabili veri letti di Lithothamnium, in modo speeiale da Moleto a C. Moletto inferiore; sono pure in relazione alla natura di tali banehi le numerose sorgenti aequee che esistono in queste vicinanze.

L'Elveziano di Moleto, il quale probabilmente si collega con quello 
che studieremo in seguito (di Cellamonte, Rosignano, ece.) per mezzo di banehi ehe attraversano la Val Ponara sotto C. Magrina, si stende diseordantemente, come una potente placea, sopra i terreni aquitaniani i quali veggonsi quindi affiorare verso Nord e verso Sud.

Lungo la cresta collinosa tra Olivola e C. Vische i banehi elveziani, inelinati a Nord-Est, vengono escarati in alcuni punti; una placea isolata pare inoltre esistere nella parte più elevata dello stesso paescllo d'Olivola.

É però specialmente nelle colline di Ottiglio e rel'so Est, particolarmente nell'Elveziano superiore, che l'eseavazione dei banehi marnosocalcari è sviluppata in seala vastissima per otteneme materiale da costruzione (quindi il nome di borgata Prera) sotto la solita forma di parallelepipedi (cantoni); non è il caso che ci fermiamo ad indieare tutti questi punti d'escavazione, giaechè in gran parte essi derivano solo sia dalla maggiore o minor comodità di trasporto del materiale eseavato, sia dalla maggiore o minor vicinanza dei centri abitati, ece.

I banchi arenaceo-calearei dell'Elveziano, di color grigiastro o grigiogiallastro, inveee di inclinare a Nord-Fist, come prima si verificava, a comineiare dalle colline di C. Gaetano, formando una leggera anticlinale, veggonsi pendere ver'so Sud o Sud-Est, talora di quasi $40^{\circ}$ come presso la Nadonna, ma generalmente di solo $25^{\circ}$ o $30^{\circ}$.

Nei predetti banchi sono sovente comunissimi i resti fossili, così per esempio veri letti a Lithothamnium presso la Capella della Madonna, e talora potenti strati che non risultano d'altro ehe di un impasto di Foraminiferi, Antozoi, Echinodermi, Nollusehi, cee., come per esempio ad Ottiglio ed all'estremita orientale della eresta di S. Gottardo presso il suddetto paese. La posizione stessa del paese di Ottiglio è precisamente in diretta relazione colla zona elvesiana a causa della sua costituzione, del suo modo di presentarsi e delle sorgenti aequee a cui dà origine.

Tra l'Elveziano ed il sottostante Aquiluniano esiste naturalmente un notevole hyatus ehe rappresenta almeno tutto il Langhiano, oltre ad una parte dei due sorraindicati orizzonti; tuttavia questa trasgressione stratigrafiea non è sempre ben visibile, tanto essa è regolare; spesso è la orografia che aiuta il geologo nella delimitazione dei dne orizzonti sul terreno, a causa di una specie di gradino ehe formano sovente i duri banehi arenacei dell'Elvesiano su quelli marnoso-sabbiosi, e quindi relativamente meno resistenti, dell'Aquitaniano; non di rado però tale distinzione riesee difficile, specialmente dove la coltivazione maschera per lunghi tratti la natura del terreno ed anche perchè sovente esiste un passaggio litologico abbastanza graduale fra i terreni dei due orizzonti geologiei. 
Quanto al passaggio tra Elveziano e Tortoniano esso si puỏ osservar bene ad Ottiglio verso Ovest e si mostra in generale assai graduale per le solite altermanze di banchi marnosi, sabbiosi ed arenacei, e specialmente per un graduato indurimento, direi, dei banchi marnosi, dal Tortoniano all'Elveziano: quindi anche in questo caso l'orografia riesce molto utile al geologo per delimitare i due orizzonti; formano infatti i terreni clvesiani colline assai piủ crte e piủ alte che non i terreni tortoniani; ne risultano però sempre naturalmente in tali delimitazioni notevoli incertezze inerenti al modo graduale di passagorio tra i due piani geologici in questione.

E precisamente nei banehi ele siani superiori, passanti al Tor\%. niano, che cominciansi ad osservare le prime care di cantoni, che sono perỏ piủ abbondanti ad un livello alquanto inferiore, perchẻ pir resistente ne è la marna arenaceo-calcarea; specialmente famose in queste regioni sono le cave dei dintorni di Patro e di Carpi.

Ciò che havri poi ancora di noterole rispetto alla zona elveziann ora in esame è che essa rappresenta solo una porzione dell'intiero orizzonte elresiano, in gran parte invece sepolto; tant'è che questa zona si allarga noterolmente più ad Orest, là dore cssa può meglio esplicarsi.

Ad Ovest di Val Colobrio i banchi elcesiani, che nel loro passaggio all'Aquilaniuno danno talora origine a sorgenti acquee, si presentano spesso fortemente sollerati (in particolare quelli inferiori), cioè di $50^{\circ}$, $60^{\circ}$ e piủ, ma con inclinazione abbastanza regolare verso il Sud od il Sud-Orest; nell'Elvesiano superiore di queste regioni continuano ad osservarsi non poche cave di materiale da costruzione, utili anche al paleontologo perchẻ spesso forniscono resti fossili, specialmente abbondantissimi denti di Squalo.

Ad Orest della borgata Perno i terreni elvesinni presentano notevoli fenomeni stratigrafici, cioè dispongonsi a forma di conca nellá parte superiore dell'orizzonte ed invece a stretta sinelinale nella parte inferiore, ad Ovest; rediamo infatti che nelle colline di Perno, di Cosso e di Palmaro i banchi marnoso-arenacei dell'zlesesano superiore, escavati qua e là e passanti abbastanza gradualmente al Torloniano, pendono di $20^{\circ}$ a $10^{\circ}$ verso il Sud-Est e verso l'Est, disponendosi a semiecrehio ed andandosi poseia ad appoggiare discordantemente sui terreni aquitaniani delle colline d'Alfiano Natta.

Se invece teniamo dietro allo sviluppo dei banchi basali dell'Elvesiano nelle colline di Terfangato, di Pessine, di Oddalengo piccolo, ece., sino in valle Stura, li rediamo fortemente inclinati, spesso di $50^{\circ}, 60^{\circ}$ verso il Sud eirea; ma sulla destra di Valle Croce e di Valle Zoppi, contro l'clissoide oligocenica di Alfiano-Villadeati, rediamo i banchi 
elveziani prescntarsi bensi ancora fortissimamentc sollevati, cioè di $60^{\circ}, 70^{\circ}$ c più, ma con inclinazione opposta a quella sovraecennata, eioè verso il Nord od il Nord-Ovest circa.

Ne risulta quindi evidente in queste eolline una vera sinclinale, compresa tra duc elissoidi oligoceniche, c colla gamba settentrionale molto più ampia e sviluppata che non quella meridionale.

Nella valle Stura, c per oltre un chilometro nelle colline sulla sua sinistra, si può osservare assai nettamente la continuazione dell'indicata stretta sinclicale eloritune, le cui gambe si mostrano qui di cguale sviluppo ad un dipresso; oppure quella di Sud-Ovest è la più potente, al contrario di ciò che osserviamo nelle colline più ad Est.

Sulla sinistra di Val Stura la zona clveziana sinora seguita va a collegarsi eon quella formante la gamba meridionale dell'elissoide di sollevamento Ottiglio-Montalero e quindi l'abbandoniamo momentaneamente per studiare tale gamba meridionale dall'Est all'Ovest.

Si è gia detto come in Val Ponara, a Nord di Olivola c di Frassinello, la zona elve siana di Moleto pare collegarsi per mezzo di stretto istmo colle ampic zone che dello stesso terreno osserransi nelle colline più a Nord, chindendo cosi ad Est la grande elissoide Ottiglio-MLontalero.

Già nelle colline casalesi vediamo apparire placchc o strette zone elveziane; particolarmente notabile è la piceola e sottile placea di arenaria calcarea con banchi marnosi, che osservasi al Cimitero di S. Giorgio Monferrato e che ci rappresenta un lembo residuo di una zona elve zirnn primordialmente assai più estesa; c̀ specialmente notevole questa placca, oltre a che per la sua speciale posizione, per Ia sua straordinaria ricchezza in fossili (otoliti di Cetacei, denti di Squali, Molluschi, Briozoi, Antozoi, Echinodermi, Litotammi, ece.) che si possono facimente liberare dalla arcnaria avvolgente. Pcr quanto la scarsita di tagli naturali non permetta osservazioni numerose in questa collina, ho creduto tuttavia poter scparare la placer fossilifera accennata dai banchi marnosi, che ritengo aquitumiani, formanti quasi tutta la collina di S. Giorgio. Una gran parte, quella alta, del paese di S. Giorgio è fondata sopra banchi calcarei, giallastri, straordinariamente fossiliferi c costituenti un'altra placca di Elveziano sull'Aquitaniano; si notano talora lenti ghiaiose in questi depositi elveziani littoranei.

La più vicina zona elveziana, a cui certamente si collegara la placea esaminata, è quella delle colline a Nord di Terruggia; questa zona piuttosto stretta, ricoprente trasgressivamente l'A quitaniano, è ricoperta a sua volta, trasgressivamente, dai terreni messiniani; si inizia quasi sotto Villa Mandoletta coi soliti banchi arenaceo-calcarei, utilizzati come matcriale da costruzione, riccamente fossiliferi; si continua a Sud-Ovest nelle colline di Torre Veglia (località caratteristica per la straordinaria 
abbondanza di grossi Lithothamnium liberi, utilizzati persino come pietriseo) e di Colma, dove nuovamente troviamo stupendi banchi a Lithothumium e strati calcarei formati da un rero impasto di fossili, specialmente presso la C. Lucchina a Sud di Valle Bartolomeo.

L'inclinazione di questi banchi è di circa $20^{\circ}$ verso il Sud-Est. Nelle colline di Garriano e di Castello Uviglie l'Eliesiano riene ricoperto da qualche banco marnoso attribuibile al Tortoniano.

Nelle colline di Rosignano i banchi arenaceo-calcarei, potenti, tipici, ricchissimi in fossili, veggonsi inclinare di pochi gradi verso il Sud circa; sono escavati su rasta scala come materiale da costruzione, particolarmente per il paese stesso di Rosignano. Notiamo ancora come nei banchi elreziani di Rosignano osservansi certi strati o lenti costituite prevalentemente di Calcare a grana abbastanza fina, che può ricerere una bella pulitura ed essere quindi perfino utilizzato come marmo. Tale fatto d'altronde si riscontra pure altrove in queste colline ma, ch'io sappia, è solo a Rosignano che si utilizzò questo calcare come vero materiale ornamentale.

Numerosissimi fossili riscontransi pure in certi banchi arenaceo-calcarci del Cimitero di Rosignano, delle colline di Cellamonte (dore esistono pure diverse cave di cantoni).ece.

Ad Ovest di Cellamonte i terreni elvesiani, collegantisi a Sud colla zona cliesiana di Moleto, e disposti a sinclinale tra duc anticlinali oligoceniche, non presentano altro di noterole che speciali strati o lenti costituite di grumuli arenaceo-calcarei, giallo-1'ossastri; questo deposito si rede comparire ancora più ad Orest qua c là, specialmente nelle colline ad Est e Nord di Cereseto, così tra C. Plano e C. Casciano, presso C. Magnona, ece.

In queste stesse colline di Cereseto vediamo però anche assai sviluppati i caratteristici banchi calcareo-arenacei, (costituenti appunto la parte alta del paese) fortissimamente inclinati, cioè di circa $60^{\circ}$, $70^{\circ}$ ver'so Nord-Nord-Est, ed appoggiati con leggera trasgressione sui banchi aquiluniani.

Verso Nord invece i terreni elresiani attorniano abbastanza regolarmente la scmielissoide aquitaniana di Treville e si mostrano colla tipica facies marnoso-arenacea c fossilifera nella stessa collina di Treville; quivi veggonsi pendere di circa $30^{\circ}$ rel'so Nord e sono cscarati su vasta scala come materiale da costruzione.

Questi banchi, sempre colla stessa facies, con quasi la stessa inclinazione, colla stessa ricchezza in fossili, c dornnque utilizzati per lo stesso scopo, noi possiamo seguire regolarmente nelle colline di Ozzano e di C. Bertazzi.

Più ad Est però questi banchí marnoso-arenacei cessano presso 
C. Amelio (quantunque primordialmente con molta probabilità cssi si collegassero coll'Elveziano di S. Giorgio Monferrato) appoggiandosi al Liguriuno dei colli casalesi e circoscrivendolo verso Ovest con inclinazione a Sud o Sud-Ovest circa; per tal modo la Val Rivara si può considerare in gran parte come una valle orografica causata da una sinclinale dei banchi elveziani.

Lungo la linea di contatto, che avviene con notevole trasgressione, tra l'Elveziano ed il Liguriano, spesso i banchi del primo sono zeppi di fossili (denti di pesce, Molluschi, Briozoi, Echinodermi, Foraminiferi, fra cui grosse Orbitoidi, Litotamni, ecc.); questo fatto si può specialmento osservare in aleuni speciali punti, cosi fra le arenarie sotto Baraccone e nelle marne calcaree di C. Riva.

La valle della Stura da Cerrina al Po presenta un'anpiezza molto grande e deve tale conformazione all'esscre lungo questo tratto una vera valle orografica rappresentata da un'ampia sinclinale che quivi fanno i terreni elvesiani.

Infatti nelle colline di Quarti i banchi dell'Elnesiuno, appoggiati trasgressivamente sul Liguriano, pendono verso l'Orest circa; riceversa nelle regioni collinose di Rocchetta, Solonghello, Mombello, ece., gli strati marnosi o marnoso-calcarei (quindi talora usati come materiale da costruzione) inclinano più o meno fortemente, talora di oltre $30^{\circ}$, verso il sud circa. Tale inclinazione, sempre però più debole da Nord a Sud, si continua sino al bassopiano della valle, quivi conformandosi a fondo di battello per modo che dalla parte opposta, ciò̀ sulla destra di tale valle, i banchi presentano un'inclinazione contraria affatto a quella di prima.

Nelle colline di Castellazzo, Serralunga di Crea, Casalino, ece. i banchi elvezicmi, spesso marnoso-calcarei c quindi come di solito utilizzati qua e là per cantoni (specialmente famose sono in riguardo le cave di Casalino), presentano un'inclinazione fortissima, spesso di oltre $40^{\circ}, 50^{\circ}$, verso il Nord-Nord-Ovest, il ehe ei spiega eziandio la differenza orografica esistente fra i due fianchi (assai più crto il destro che non il sinistro) della valle Stura in queste regioni.

Sulla destra della Stura l'Elveziano inferiore si può distinguere assai bene dall'Aquitaniano in causa della comparsa dei tipici banchi marnosi, duri, fogliettati del Langhiano; invece sulla sinistra questi mancano e la delimitazione fra i due indicati orizzonti, sovlapponentisi con notevole trasgressione, si deve basare specialmente sulle differenze litologiche (per essere l'A quitaniano piuttosto sabbioso-arenaceo) ed anche sull'orografia, a causa del costituire sovente i banchi inferiori dcll'Elvesiano un forte rialzo sulle creste collinose dell'Aquitaniano, e quindi un corrispondente restringersi delle singole vallette. 
Questi caratter'i orografici per quanto sccondari sono talora l'unica risorsa del geologo in campagna, specialmentc là dove la coltivazione maschera quasi completamente il terreno profondo, come è ad esempio il caso nelle colline di Rocchetta, di Bric Runcali, ece., dove rimanc quindi alquanto incerta la delimitazione degli orizzonti geologici.

Essendo i banchi elcesiani troncati di tratto verso Nord dall'erosione del Po, tra Bric Runcali ed il Molino della Smeralda (Est di Pontestura) non è possibile di giudicare dello sviluppo che essi presentano sotto lc alluvioni della pianura padana in queste ricinanze; tuttaria dall'andamento stratigrafico generale dei terreni credo poter arguire che tale sviluppo c̀ assai piccolo e che a poca distanza dalla regione collinosa i terreni elvesiani, con o senza intermezzo di una zona aquitaniana, si appoggiano già sul Liguriano, continuazione della zona analoga costituente le colline casalesi.

Rimontando l'ampia valle secondaria o Gaminella di Gabiano, si osserva che anche in questo caso tale ampiezza deriva dall'essere questa ralle d'origine orografica, cioè di sinclinale con asse diretto da Sud-Est a Nord-Orest e che passa poco a Sud di Gabiano. Questa sinclinalc è però alterata ad Est da una sinclinale secondaria che dà origine al bacino orografico di Piazzano e Castel S. Pietro.

Infatti se si esamina l'andamento della zona elvesiana ad Orest di Mombelio, si vede che cssa muta rapidamente direzione, attorniando l'elissoide oligocenica di Mombello; tale formazione ha i suoi strati fortemente inclinati ad Orest c Nord-Orest nelle colline di Pozzengo e Crosio, e direttamente a Nord, con pendenza di $35^{\circ}, 40^{\circ}$, nelle colline di M. Sion e di Bric del Lupo.

In seguito i banchi di dure marne, più o meno arenacee, dell'Elvesiano si dirigono a Nord-Nord-Est in ral Dordagna (valle in parte orografica per stretta sinclinale); nel loro passaggio ai pochi banchi langhiani cssi danno luogo ad una copiosa sorgente, c ranno a costi- . tuire le colline su cui è fondata la parte alta del paese di Camino.

Di qui i terreni elveziani rapidamente si inflettono ad Orest e con tale dirczione ed un'inclinazione media di $30^{\circ}$, ma raria tra $20^{\circ} \mathrm{c}$ $40^{\circ}$ (a seconda che si tratta dei banchi inferiori o superiori dell'orizzonte in esame), essi costituiscono le colline di Castel S. Pietro, Gabiano e Moncestino renendo utilizzati in moltissimi punti (specialmente attorno a Martinengo c Zoalengo) per estrarne materiale da costruzione.

A Nord di Moncestino i banchi inferiori dell'Eltesiano renncro esportati dall'erosione delle acque del Po, ma si può segnare abbastanza bene l'andamento della piccola parte di zona elveziuma sepolta sotto alle allurioni quaternaric tenendo conto dell'andamento stratigrafico di questo terreno c del Langhiano. 
Poco ad Ovest di Moneestino si veggono i banehi elreaiuni ripiegarsi rapidamente a Sud e poscia a Sud-Est, assumendo un'inclinazione di circa $25^{\circ}$ vel'so l'Est ed il Nord-Est.

Nella sinclinale orografica Gabiano-Honcestino-Villamiroglio la gamba meridionale è molto più sviluppata di quella settentrionale e quindi i suoi strati generalmente si presentano più dolcemente inclinati formando gradualissimo passaggio al Langhiano per mezzo di ripetute alternanze di strati sabbioso-marnosi con strati marnosi duri fogliettati; ma nelle colline di Varengo e Rosingo i banchi elvesiani rapidamente si rialzano, mostrando una pendenza di oltre $30^{\circ}, 40^{\circ}$ verso il Nord circa.

Mentre che nelle colline ad Est di Rosingo gli strati elvesiani, con regolare pendenza verso il Nord-Est circa ed appoggiantisi con leggera trasgressione sui banchi aquitamiuni (da cui sono separati per mezzo di pochi strati riferibili dubbiamente al Lenghiano), vanno a collegarsi coi giì descritti terreni contemporanei di Casalino sulla destra di Val Stura, invece a Sud di Rosingo vediamo la zona elvesiana prolungarsi in forma di stretta striscia a stratigrafia assai curiosa.

Cioè quella specic d'istmo che collega il bacino elvesiano ora studiato con quello di Oddalengo piccolo, esaminato nelle pagine precedenti, ¿ rappresentato da una sinclinale strettissima, eoll'asse diretto secondo la lunghezza del sopradetto istmo, vale a dire da Nord-Est a Suci-Ovest circa.

Nella collina di Bric Roneato c di C. Cà di Garello la gamba occidentale della sinelinale in questione è abbastanza sviluppata, con banchi fortemente inclinati ad Est eirca e passante gradatamente al Langhiano, ma la gamba orientale manca completamente o è ridotta a solo pochi strati sollevati quasi alla verticale ed appoggiantisi trasgressivamente sui terreni aquitaniani, coll'intermezzo di qualche stratercllo marnoso, duro, fogliettato, che ricorda il Langhiano.

Però nelle colline di S. Maria e di Oddalengo grande la sinclinale divcnta più regolare, a gambe quasi eguali e costituite di banchi inclinati di $50^{\circ}, 60^{\circ}, 70^{\circ}$; anche orograficamente questa struttura stratigrafica ci si rivela con due colli (quello di S. Maria e quello tra Oddalengo grande e Vallestura) corrispondenti alla conca della sinelinale, e con forti rialzi collinosi (Bric Fungaio, Brie di Madonna di Moneuceo, ece.) corrispondenti alle gambe fortemente sollevate della sinclinale stratigrafica.

Facciamo infine notare che ad Ovest del bacino elvesiano di Gabiano, come d'altronde gia cominciava a verificarsi in questo stesso bacino, i terreni elesiani cangiano poco a poco di natura; invece di 
marnoso-calcarei divengono piuttosto marnoso-sabbiosi, spesso grossolanamente arenacei.

D'altronde anche dal lato industriale questo cangiamento litologico ha un'importanza molto notevole, poichè verso Ovest rengono a mancare nell'Elvcziano quei banchi marnoso-calcarei a grana fina e lesistenti agli agenti atmosferici che abbiamo visto cosi largamente utilizzati nelle colline casalesi finora esaminate; a dire il vero nelle colline di Corteranzo, Robclla e Cocconato vediamo ancora nell'Elveziano superiore banchi marnoso-calcarci (con non pochi fossili, fra cui comuni i denti di Squalo) che potrebbero essere utilizzati come materiale da costruzionc (cantoni), ma però generalmente essi sono più porer'i in calcare che non i banchi analoghi osservati ad Est, e quindi facilmente si alterano quando esposti per lungo tempo agli agenti esterni.

Ad Ovest di Oddalcngo grande la sinclinale elee íana ora esaminata si va allargando rapidamente; i banchi costituenti la sua gamba orientale-meridionale si rolgono a Sud, costituendo le colline di Ciccngo e Frastolo, con un'inclinazione di $50^{\circ}, 60^{\circ}$ e più rerso l'Orest cd il SudOrcst, sino a collegarsi con quelli già studiati di Oddalengo piccolo; ne risulta quindi chiusa, accerchiata dall'Elresiano, l'elissoide oligocenica di Montalero-Ottiglio.

Quanto alla gamba settentrionalc della sinclinale di Oddalengo grande vediamo che i suoi strati, con una pendenza di $40^{\circ}, 50^{\circ}$ a Sud, si dirigono abbastanza regolarmente verso Ovest per modo da costituire le colline di Rio della Valle, Case Turini, Corteranzo, Robella ecc.

Dobbiamo peró notare che nelle regioni collinose di Corteranzo e Robella l'andamento stratigrafico della zona elveziana è assai regolare, per modo che mentre i banchi inferiori hanno un'inclinazione di $40^{\circ}$, $50^{\circ}$ e piủ, per gradualc transizione i banchi superiori (a tinta grigiobiancastra per modo da rassomigliare molto al Tortoniano a cui passano inscnsibilmente e da cui si distinguono quasi solo per la. maggior durezza) presentano pendenze molto più deboli, cioè di $20^{\circ}$, $30^{\circ}$ ed anche meno.

Invecc, a causa dell'aftioramento tongriano che forma l'elissoide secondaria Villadeati-Alfiano Natta, noi vediamo che i banchi elvesiani a mezzogiorno delle colline di Case Turini si rialzano rapidamente verso Sud assumendo una forte inclinazione a Nord ed attorniando il prolungamento settentrionale dell'elissoide tongriana di Villadcati.

Quindi i banchi elveziani costituiscono la parte esterna dell'anticlinale stratigrafica; la valle Stura della borgata Ferrero alle falde delle colline di Villadeati risulta scavata nella parte centrale quasi della suddetta anticlinale.

I terreni clresiani che dalle colline di Case Turini si dirigono verso 
Sud-Est, formando il Bric di S. Candido, di S. Giorgio, ece. sino a connettersi con quelli contemporanei, gia studiati, sulla destra della Stura, non presentano altro di notevole che una forte pendenza a NordEst; essi veggonsi inferiormentc formare una graduale transizione agli strati langhiani.

Invece seguendo lo sviluppo dell'Elreziano delle colline di Case 'I'urini verso Murisengo, ece. vediamo anzitutto che esso basa direttamente e piủ o meno trasgressivamente sull'Aquilaniano, ed inoltre che esso rapidamente muta di natura litologica mostrandosi essenzialmente arenaceo, invece di marnoso sabbioso come era prima.

Infatti gia nelle colline di C. Bicocca possiamo osservare come coi banchi marnoso-sabbiosi, inclinati di cirea $40^{\circ}, 45^{\circ}$ ad Ovest-Sud-Orest, si alternino ripetutamente banchi arenacei giallastri che divengono però sempre più potenti ed abbondanti verso Sud-Est; infine questi prendono un'assoluta prevalenza e vengono cosi a costituire la cresta collinosa di Murisengo, del Monte Lungo, cec. sino a Villadeati, con una pendenza di circa $50^{\circ}$.

Questa zona arenacea elvesiuna (paragonabile assai bene a quella simile e contemporanea della parte meridionale del bacino terziario piemontese, specialmente dell'alto Monferrato e del Tortonese) formò la sovraccennata cresta di colline, cagiono il forte ristringersi di Val Stura all'osteria Gattinara e diede origine a numerose sorgenti acquee, fra cui importante quella sulfurea della Pirenta nel passaggio all'A quitaniano. Tale zona inoltre è ancora notevole dal lato industriale pcl fatto che questi banchi arenacei duri, molto resistenti, sono utilizzati su vasta seala come materiale da costruzione, ben diverso però dai cantoni delle colline casalesi, per essere molto piủ arenacei ed anzi spesso grossolanamente arenacei.

Alcuni resti fossili vengono talora riscontrati entro queste arenarie, ma, ad eccezione dei denti di Squalo, essi sono generalmente poco determinabili.

Proseguendo l'esame della zona elveziana a Sud-Est di Villadeati, si vede che essa si restringe rapidamente, riducendosi a semplice striscia, che infine scompare completamente sia perchè coperta discordantemente dai terreni più recenti, sia anche perchè mascherata parzialmente dagli stessi banchi longriani che per la compressione subita oltre a disporsi in stretta anticlinale, si mostrano talora persino rovesciati.

Naturalmente da Murisengo sin dove la zona elveziana in questione scompare completamente, essa si presenta in trasgressione evidente coi terreni sotto e soprastanti.

É notevole come dalla fontana della Pirenta sino a Villadeati e 
Molinasso le arenarie eleciane si presentino in certi banchi come un rero impasto di Foraminiferi, di Pecten, di Balanus, ece., cioù a facies di deposito littoraneo; questi banchi hanno in complesso una pendenza di cirea $45^{\circ}$.

Proseguendo l'esame dell'Elteziano rerso Ovest, oltre le colline di Robella, vediamo i banchi inferiori di questo orizzonte, passanti gradatamente ai tipici strati langhicmi, costituire per lungo tratto la sponda sinistra di Val Stura con un'inclinazione media di circa $40^{\circ}, 45^{\circ}$ a Sud-Orest; predominano i banchi sabbioso-marnosi grigiastri, spesso alternati con veri banchi arenacei; non ri sono rari i fossili, ma in generale difficili ad estrarsi completi.

Tra le colline di Moransengo e quelle di Tonengo i banchi elveziani si volgono rapidamente verso Ovest e poi, disponendosi in strettissima curva, si ripiegano dapprima verso Sud, quindi verso Sud-Est, andando a costituire le colline di Cocconato.

Da tale andamento stratigrafico deriva una vera sinclinale o conca orografica, aperta solo al Sud-Est rerso la borgata Sartù e la Piere di Cocconato, là dove l'Elleziano passa gradatamente ed insensibilmente al Tortomiano.

In questa conca elveziana, abbastanza regolare, che possiamo appellare conca di Tonengo, oltre ai banchi marnoso-sabbiosi, talora alquanto calcarei e quindi resistenti, che ne costituiscono la parte principale, dobbiamo menzionare la presenza qua e là di strati marnosi, duri, foglicttati, pserdo-langhiani, fossiliferi; questi ad esempio possonsi osservare nel rilievo esistente subito a Sud di Tonengo, dove essi pendono di cirea $20^{\circ}$ verso il Sud ad un dipresso.

Pure notevoli sono alemi grossi banchi sabbioso-arenacei, giallastri, o giallo-rossastri che appaiono verso la parte inferiore dell'Elvesiano e reggonsi specialmente sviluppati nelle vicinanze di C. Nuora di Cerrabello, nella parte alta del rio di Mainia sin presso Aramengo.

Quanto all'andamento stratigrafico dei terreni eleceiani della sinclinale in esame si deve solo notare che, come naturale, i loro banchi, inclinati abbastanza regolarmente rerso l'interno della conca, presentano una pendenza più o meno forte secondo che sono più o meno ricini alla parte esterna della conca stessa. Vediamo infatti che i banchi basali, i quali passano gradatamente al Langhiano, presentano per lo più pendenze fortissime, cioè di $50^{\circ}, 60^{\circ}, 70^{\circ}$ e più, specialmente nella gamba Sud-Ovest della sinclinale in studio; mentre invece rerso il centro della conca suddetta le pendenze divengono assai dolci, cioè di solo $15^{\circ}$ o $20^{\circ}$.

Ad Orest di Cocenato la zona elvesiana, fortemente compressa e spinta a Sud dall'affioramento liguriano di Serra (già precedentemente 
studiato) elee altera l'andamento di tutte le circostanti formazioni mioceniche, si riduce molto di ampiezza (in alcuni punti a solo 200 metri circa) e coi suoi banchi inclinati di $30^{\circ}$ a $70^{\circ}$ verso sud viene a costituire la cresta di Airali, Marmorito, C. Cavallotto, Bignona, ece.

La grande differenza, sopraindicata, nel grado di inclinazione si verifica tra i banchi inferiori e quelli superiori dell'Elveziano; questo terreno nella parte basale si vede appoggiarsi direttamente sull'dquitrmicno, bensi con hyatus, ma senza notevole trasgressione stratigrafica, mentre nella parte superiore passa rapidatamente, ma senza salti, ai pochi banchi marnosi che rappresentano il Tortoniano.

A costituire l'Elveziano di queste colline, oltre alle marne sabbiose, prendono parte notevole potenti banchi arcnacci durissimi che formano appunto la parte alta della cresta di Marmorito e che ricordano molto bene i banchi, dello stesso orizzonte geologico, che abbiamo avuto ad esaminare presso Mrurisengo; in ambidue i casi questa facies arenacea dell'Ele ziano si collega con facies simili che abbiamo avuto occasione di far notare nell' Elreziano della parte meridionale del bacino terziario piemontese, specialmente nel Monferrato e nel Tortonese.

E ancora in relazione con questa zona arenacea una sorgente d'acqua sulfurea che osservasi nell'alta valle di Rio Freddo, quasi sotto C. Martima.

Ad Est delle colline di Bignona diversi fatti importanti devonsi notare nella zona elveziana; anzitutto essa si allarga rapidamente ed assume un andamento abbastanza regolare che conserva in tutto il suo sviluppo nei colli torinesi; inoltre vi appare una nuova facies speciale per la comparsa ed il subito sviluppo di banchi ghiaioso-eiottolosi, ad clementi spesso voluminosissimi; infine assieme a questa nuova facies, e probabilmente in relazione abbastanza stretta con essa, notiamo eziandio quella straordinaria ricchezza in fossili che rese famose le colline torinesi, col falso titolo di colline di Superga.

Quindi in complesso noi possiamo distinguere nelle colline TorinoValenza tre facies generali della zona elveziana, cioè l'Elveziano marnoso-arcnacco-calcareo, in alcuni pochi punti riceamente fossilifero, (nelle colline Valenza-Gabiano); l'Elvesiano prevalcntemente marnososabbioso, talora arcnaceo (dalla conca di Gabjano alle colline di Albugnano); cd infine l'Elveziano prevalentemente sabbioso-ciottoloso spesso ricchissimamente fossilifcro (nclle colline torinesi).

Nelle colline di Albugnano la facies ciottolosa dell'Elveziano si esplica quasi di tratto ed in modo veramente straordinario, specialmente nella sua parte medio-inferiore. Questi banchi ciottolosi, ad elementi talora voluminosissimi, si possono osservare assai bene nelle colline di Cascine Pianfiorito, di S. Lucia, di C. Luea, nella parte settentrionale 
dclla collina di Albugnano, ecc.: essi sono quasi sempre alternati con banchi ghiaiosi, molassici, in cui sono generalmente sparsi numerosi ciottoli. E precisamente in queste molasse grigio-rerdastre (per essere ad clementi prevalentemente serpentinosi) che troransi resti fossili in grandissima abbondanza, così ad esempio nei dintorni di S. Lucia, nclle ricinanze stesse di Albugnano, discendendo verso S. Emiliano, andando verso Bersano, ecc., cce.

Il volume molto notevole (anche 203 metri di diametro) di qualcuno dei ciotoli immersi nelle molasse elreriane fa sì che essi difficilmente possono essere trascinati a ralle dalle correnti acquee; quindi per la lenta e continua degradazione dei terreni superficiali tali ciottoloni poco a poco rengono a giorno e rimangono isolati sulle cime e sui fianchi delle colline, simulando assai bene massi erratici, tanto più che sorente cssi hanno spigoli poco smussati; questo ci spiega l'errore in cui cra dapprima caduto il Gastaldi credendoli massi erratici trasportati dai ghiacciai quaternari. Gli stessi fenomeni già osserrammo nclle colline monregalesi.

La zona elve:iana, che coll'intermezzo della zona arritaniana si appoggia all'affioramento liguriano di borgata Scrra, presenta i suoi strati assai fortementc inclinati rerso $1^{\circ}$ Orest ed il Sud-Orest, ed ancora nelle colline di S. Gottardo rediamo i banchi marnosi molassici dell'Elre

Invece prosegunendo l'esame della zona elveriana rerso Orest, rediamo come essa si rada gradatamente allargando, assumendo anche una potenza di 1600, 1700 metri; la sua tettonica si presenta regolarissima, giacchè mentre da Albugnano a Cinzano, nella parte inferiorc dell'orizzonte in esanc, i banchi presentano una pendenza di $30^{\circ}, 40^{\circ}$ rerso Sud, ad Est di Cinzano invece ed in tutta la parte media e superiore dell'Elvesiuno l'inclinazione degli strati è in media di solo $20^{\circ}$, talora con oscillazioni tra i $15^{\circ}$ ed i $25^{\circ}$.

Mentre ad Est di Albugnano l'Elieziano si appogrgia direttamente sull' Aquitaniarro con un grande hyatus, comprendente almeno tutto il L.nnghiano, inrece ad Orest di Albugnano tale lacuna si ra gradatamente r'iempiendo per l'apparsa dei banchi marnosi tipici del Lan. glizuno, ai quali quelli elreziani fanno graduale passaggio; per tal modo spesso ne riesce molto incerta la delimitazione, tanto più che sorcnti appaiono, a ripetuti livelli, strati marnosi duri pseudo-langliani frammezzo ai carattcristici banchi sabbioso-ghiaiosi dell'Elvesiano inferiore.

Quanto alla costituzione dell'ampia zona cleesiana in esame, tra Albugnano e Baldissero, si può dire in complesso che essa è eminentemente sabbiosa quantunque coi banchi sabbioso-arenacei o sabbioso- 
marnosi grigiastri o grigio-giallastri si alternino pure comunemente, e formino anzi talora piccoli orizzonti speciali, diversi complessi di banchi marnoso-grigiastri o grigio-bleuastri.

Inoltre a diversi livelli nella scrie elcesiana compaiono strati o banchi ciottolosi ad elementi o cementati in conglomerato, oppure, ed è questo il caso piủ frequente, solo commisti con ghiaie e molasse, od anche sparsi irregolarmente fra sabbie più o meno grossolane; per tal modo si osservano comunemente sparsi in modo irregolarissimo alla superficie di queste colline (specialmente nell'Elveziano medio) enormi ciottoloni a facies di massi erratici.

Chi volesse in breve tempo e comodamente osservare l'inticra serie dell'Elveziano delle colline in esame, ha solo da percorrere la strada che da Moncucco conduce, in eresta di collina, a Cinzano e taglia perpendicolarmente gli strati. Vedrebbe in tal easo come coi banchi sabbiosi si alternino spesso banelii marnosi (i quali anzi al Bric del Galletto prendono per un certo tratto un'assoluta prevalenza) ed anche strati o banchi di ciottoli.

Possiamo indicare ad un dipresso nelle colline in esame questa caratteristica serie stratigrafica:

Astiano - Marne sabbiose e sabbie giallastre fossilifere (Briano).

Piacenziano - Marne argillose blenastre riccamente fossilifere (Sud di Fornaci di Briano).

Messiniano - Marne grigiastre con lenti calcaree e gessifere (Fornace S. Martino).

Marne più o meno sabbiose, fossilifere (Tetti Borelli).

Banchi marnoso-sabbiosi. assai fossiliferi, con strati o lenti

Tortoniano ciottolose (Noncueco).

Strati specialmente sabbiosi.

Strati gliaioso-ciottolosi (Bric S. Paolo).

Alternanza di banchi sabbioso-molassici con banchi marnosi grigio-bleuastri (C. Fontana).

Complesso di banchi sabbiosi (Bric S. Giuseppe).

Complesso di banchi marnosi (Bric del Galletto).

Banchi sabbioso-molassici assai fossiliferi.

Potenti banchi arenaceo-conglomeratici, talora a ciottoli voluminosissimi (C. Prelle - C. Bruno).

Elvesiano $\{$ Strati sabbioso-arenacei.

Alternanza di banchi maruosi grigio-bleuastri con strati sabbiosi.

Straterelli ghiaioso-ciottolosi (Villa Serra).

Banchi sabbiosi e maruosi alternati (Cinzano).

Strati sabbiosi alternati con strati marnosi, duri, fissili, pseudo-langhiano. 
Elve iano $\left\{\begin{array}{l}\text { Straterelli ghiaioso-ciottolosi. } \\ \text { Alternanza di strati sabbioso-marnosi con straterelli pseudo- } \\ \text { langhiani. }\end{array}\right.$

Langhiano - Complesso di strati marnosi, duri, fogliettati, scagliosi. grigio-bleuastri, fossiliferi.

Aquitaniano - Potente complesso di banchi sabbioso-marnosi grigiastri (C. Rosotti).

In complesso abbiamo nell'Elreziano di queste regioni tre livelli a banchi ciottolosi, di cui però il primo è il più importante.

Debbo però subito accennare che l'indicata serie litologica dell'Elreziano non si dere ritenere per nulla come generale, rerificandosi inrece moltc e profonde variazioni locali nella zona elrezicuna.

Rignardo agli orizzonti più riccamente fossiliferi si può dire in generale come essi siano collegati ai banchi ghiaioso-molassici ed anche a quelli ciottolosi, indicandoci così come di tratto in tratto durante l'epoca elvesianu si rcrificassero deposizioni tumnltuose che distruggerano in gran parte la fauma marina accumulandone i resti coi depositi grossolani che si formavano in tali momenti. Però le località più riccamente fossilifcre troransi nell'Elreziano inferiore, cosi tra il Briceo di C. Montalto e quello di C. Bavengo (Bersano), melle colline di Sciolzc (specialmente famosi sono quiri i banchi molassici ciottolosi del giardino di Tilla Rovasenda), nei dintorni di Bardassano, ecc., ecc. dalle quali località rennc estratto gran parte del materiale costituente la stupenda collezione palcontologica del Car. L. Rovasenda.

Nella zona elreziana ora in esame, specialmente nelle colline di Sciolze, si potrebbe scindere complessivamente la serie eleeziana in tre orizzonti speciali, cioè: $1^{0}$ un orizzonte inferiore marnoso-sabbioso con letti c lenti ciottolose, ricchissime in fossili; $2^{\circ} \mathrm{mm}$ orizzonte medio specialmente sabbioso, grigio-giallastro, fra cui sonvi banchi speciali con Foraminiferi e resti di Pentacrinus Gastaldir, e banchi zeppi di ralve di Pecten; $3^{\circ}$ un orizzonte superiore costituito da un'alternanza di banchi sabbiosi e marnosi, talos a con lenti ghiaiose, non di rado fossilifere, orizzonte cioc̀ che fa passaggrio al T'ortoniano.

Quanto all'Elceziano superiore ed alla sua delimitazione dal Tortoniano dobbiamo osscrvare come tra questi due piani geologici si possa constatare in diversi punti un bellissimo passaggio sotto il punto di rista paleontologico.

Infatti se percorriamo certe colline che sono costituite da banchi sabbioso-marnosi cd anche gliaioso-ciottolosi che dal lato litologico parrebbero rappresentare l'Elveziano superiore, vi possiamo in molti punti osservare strati assai ricchi in fossili (fra cui numerosi Foraniniferi) a spiccatissima facies tortoniana; ciò rerifichiamo ad esempio presso 
Moneueeo, nelle eolline di Villa Majolo, di Avuglione, di Marentino, di Tetti Gaiotto, di Montaldo, eec. Quindi tali depo;iti, per quanto presentino la facies litologiea dell'Elvezirno, debbonsi piuttosto porre nel Tortoniano in considerazione della fauna ehe eontengono.

D'altronde nel bacino terziario del Piemonte fenomeni simili gia ineontrammo nelle eolline di Stazzano dove si verificarono condizioni speeiali di sedimentazione tumultuosa durante l'epoca tortoniana.

Non è d'altra parte a stupire che in alcune regioni nel periodo di transizione tra l'epoea elvesinna e quella tortoniana il periodo di deposizione tumultuosa o di littorale siasi prolungato per un certo tempo per modo ehe quivi la facies, direi, elveziana si presenta aneora nel Tortoniano inferiore, eome è precisamente il easo per le eolline di Vargo-Stazzano nel Tortonese e nelle regioni JoncuceoMarentino.

Ad Ovest di Pavarolo la zona elveziana si va alquanto restringendo a eausa della compressione e della spinta a Sud prodotta dall'emersione del Bartoniuno di Gassino; in eonseguenza di questo fatto vediamo naturalmente i banehi elveziani assumere una pendenza piu forte. Però se nell'Etveziano inferiore gli strati inelinano di eirea $30^{\circ}$ o $40^{\circ}$ ver'so Sud-Est, nell'Elveziano superiore inveee tale inclinazione diviene sempre più debole, eioè di solo $20^{\circ}$ in media.

Come in generale, nei eolli torinesi vediamo ehe la serie elveziana è costituita da un'alternanza irregolare di marne, sabbie, molasse e eonglomerati, eolla prevalenza loeale ora dell'mna ed ora dell'altra formazione litologiea. Gli strati eiottoloso-eonglomeratiei, ehe maneano nei banehi superiori dell'Elvesiano, sono invece estanti fra i banehi basali dello stesso orizzonte e eompaiono poi a diversi livelli nella serie stratigrafica di quest'orizzonte.

Verso la parte mediana o medio-inferiore della serie clvesiana osservasi un potente complesso di banehi essenzialmente marnosi grigiobleuastri a facies alquanto simile a quella del Tortoniano; essi dànno origine a eolline che rieordano molto bene quelle lortoniane. Sono ad esempio eolline di questo tipo quelle di S. Grato (Baldissero), di C. Chiapusso, di Tetti Civera, di Brie Barletto, cee.

Sempre assai graduali sono i passaggi dei terreni elce siani in esame sia al Langhiano inferiormente sia al Tortomiano superiormente, tanto che la loro delimitazione, partieolarmente in questo seeondo easo, diventa assai ineerta.

Volendosi esaminare l'intiera serie mioeeniea delle regioni in esame, eiò riesee assai facile portandoei, per esempio, dai Tetti Ceppi a Superga, nel qual corso si tagliano i seguenti orizzonti geologici: 
Tortoniano - Banchi marnosi, grigio-bleuastri.

Elveziano $\left\{\begin{array}{l}\text { Sabbie marnose, grigiastre, a Zoophycos. } \\ \text { Banchi sabbioso-ghiaiosi. } \\ \text { Potente complesso di marne e sabbie marnose. } \\ \text { Banchi arenaceo-conglomeratici, riccamente fossiliferi, } \\ \text { alternati con strati marnosi. }\end{array}\right.$

Langhiano - Marne dure, scagliose, fossilifere, con interstrati sabbiosi ed anche ghiaiosi.

Potenti aremarie e conglomerati con ciottoli di calcarc alberese.

Aquitaniano Mralne e sabbie.

Potenti conglomerati.

Marne sabbiose grigio-rerdastre inglobanti irregolarmente ciottoli di calcare alberese.

Riguardo ai fossili dobbiamo notare anzitutto un fatto generale ed importante specialmente per chi fa raccolte paleontologiche; che cioè essi abbondano specialmente nei banchi molassico-ghiaiosi che costituiscono la base dell'Elvesiano; li troriamo quindi numerosissimi al Bric del Pilonetto, a Nord del Bric Piola, in Val Ceppi a Sud di Tetti Civera, al M. Cervet, al Bric Caros, in fondo al Rio dei Piani, al Bric delle Ghiaie, ece, ecc.

È ancora sempre in questa zona basale dell'Elve ziano che sono racchiuse le famose localita fossilifere del Termofoura, di Tal Salice (Rio della Batteria), del Monte dei Cappuccini, ecc., le quali fornirono la maggior parte dei fossili che figurano nelle raccolte paleontologiche di tanti musei col nome di lossili di Superga.

Ma, oltre a questa zona particolarmente fossilifera, troransi eziandio fossili a diversi livelli della serie elvesiana, specialmente là dove sonvi banchi sabbioso-molassici o ghiaioso-ciottolosi; ciò ci indica come tali depositi tumultuosi furono la causa precipua di una parziale distruzione rapida della fauma marina dell'epoca clvesiana e quindi dell'accumulamento di numerosi fossili in certi banchi speciali. Come esempio di tali orizzonti fossiliferi dell'Eltesiano mediano citiamo quello che passa sotto Baldissero tolinese e che remne già largamente sfruttato da geologi italiani e stranieri: in queste ricinanze ed in continuazione dell'accennato orizzonte, veggonsi banchi molassici ricchissimi in resti di Aluria Aluri, cosi tra C. Bassa ed il Cimitero di Baldissero.

Nell'Elvesiano superiore i fossili divengono meno frequenti e meno facili ad estrarsi completi dalle marne arrolgenti ; notiamo però in questo punto la frequenza di resti di Zoophycos, specialmente comumi in Tal Ceppi quasi sotto i Tetti Ceppi.

Incontransi poi talora nella parte medio-superiore dell'Etresiano 
particolari banchi arenaceo-calcarei molto duri, talora ricehissimi in Lithrthammium, Lucina pomum, ece, così a Pino tolinese presso la strada che sale alla Parrochia, così pure nelle vicinanze della Villa Verdina, sopra la C. Pietra del Gallo, cee. Ė ad un dipresso nella continuazione di quest'orizzonte verso Ovest che verliamo eomparire potentissimi banchi conglomeratici ad elementi talora enormi.

Ad Ovest di Pino torinese la zona elveziana si allarga notevolissimamente essendo i suoi strati meno compressi e quindi disponendosi essi a largo semicerchio con pendenza alquanto più dolce di quella che verificasi ad Est di Pino. D'altronde siceome la parte occidentale dei colli torinesi costituisce l'estremità di una grande elissoide di sollevamento, quivi (come sempre si verifica in tali easi) i terreni si sviluppano estesamente, venendo a giorno una gran quantità di strati che nelle parti laterali dell'elisse rimangono per lo più nascosti.

Infine serve ancora a spiegarci la vastità della zona elveziana ad Ovest di Pino l'esame della sua costituzione litologica, giacchè vediamo che vengono a costituirla potentissimi banchi ciottolosi ad elementi voluminosissimi i quali talora formano veri conglomerati, come ad esempio in Val Canape sotto C. Bric Mantel; generalmente invece i ciottoli sono sparsi più o meno abbondantemente fira sabbic ed arenarie, per modo che, colla abrasione di queste, essi rimangono isolati sulle cime e sui fianchi collinosi ; tali ciottoloni pscudo-erratici, là dove si trorano in qualche athbondanza, dànno alla collina l'aspetto di vera morena, come già constatammo nelle colline monregalesi. Questa facies speciale delle colline elveziane riscontrasi specialmente al Bric delle Fontanine, al Bric della Croce, al Bric S. Vito, al Bric della Maddalcna, al M. Calvo, al Bric Villa Roasio, ecc., cioè lungo la cresta collinosa; essa è pure caratterizzata per i pendii generalmente più ripidi che non altrove, per la vegetazione semiselvaggia ece.

Credo inutile di passare in esame i diversi numerosissimi strati e banchi ciottolosi che appaiono nelle colline torinesi ora in esame, tanto più che la loro potenza ed il loro numero varia molto a seconda dei diversi punti; basti accennare in generale come i banchi ciottolosomolassici dell' Elvesiano inferiore siano specialmente notevoli per la ricchezza dei loro fossili, mentre i potentissimi e piu volte ripetuti banchi eiottolosi dell'Elveziano medio si fanno notare particolarmente per l'enol'me volume (talora oltre 30 metri cubi) di alcuni dei eiottoli che essi racehiudono.

Questi diversi banchi ciottolosi, ripetutamente alternati con banchi o complessi di banchi marnosi, sabbiosi e ghiaiosi, si dispongono tutti sull'estremita oceidentale della collina torinese in forma di semielisse il cui grand'asse è diretto da Nord-Ovest a Sud-Ovest circa, cioè ad 
un dipresso dalle colline di S. Margherita a quelle di S. Vito; ne risulta quindi chiaro il fatto che una parte estesissima della zona elreziana costituente la curra occidentale dell'elisse in esame, rimasc sepolta sotto i tcrreni quaternari della pianura padana; ciò dipende solo in parte dalle erosioni fatte dalle acque dell'epoca quaternaria, ma in gran parte sopratutto da un vero riempimento (avvenuto per opera specialmente dei terreni pliocenici e quatcrnari) della conca ondulata esistente primordialmente fra le colline torinesi e la vicina catena delle Alpi occidentali.

D'altronde questa parziale scomparsa della zona settentrionale dell'elisse clvesiana dei colli torinesi avremo d'ora in aranti sempre a constatarla da Ovest ad Est, finchè tale zona eleesiana ad Est di Brusasco scompare completamente sotto i terreni eostituenti la pianura padana.

Ho già più volte accennato come $\mathrm{i}$ ciottoli dei terreni miocenici in esame non trovinsi generalmente riuniti assicme in forma di reri conglomerati, ma siano per lo più sparsi irregolarmente fra ghiaie e molasse od anche frammezzo a banchi marnosi, come specialmente si osscrva nell'Elceitano, superiore dolle colline di Monealieri-Rerigliasco. Questo fatto, clic già abbiamo pure verificato per depositi simili e contemporanei delle colline monregalesi, unitamentc al fatto della grossezza enorme di alcuni ciottoli, della loro forma generale, dell'essere essi ancora talrolta alquanto angolosi, del prescntarsi sorente accumulati in punti speciali, cce., cec., farebbero supporre per il loro trasporto l'agente glaciale, sotto forma di zattere galleggianti.

D'altro canto pero si possono fare a tale teoria diverse obbiezioni di non poco valore, per cui pare più logico ammettere solo l'azione di potenti correnti acquee. Tali considerazioni si sono gia srolte trattando dell'Elveziano dei colli monregalesi.

Riguardo ai l'esti fossili dell'Elcezinno dei colli torinesi, se essi abbondano specialmente nei banchi basali, come già si è acconnato, non mancano però nella sua parte media c superiore, particolarmente fra le molasse, come di solito. Non è raro trovare Ostriche, Scrpnle, ece, aderenti ai grossi massi sparsi nel terreno elvesiano: ciò ci indica che dopo la loro deposizione tali ciottoloni rimasero a lungo scoperti sul fondo marino prima di esser sepolti sotto a banchi sabbiosomarnosi. Dobbiamo poi notare rispetto alla natura degli clementi ciottolosi, come essi siano esscnzialmente di origine alpina, in massima parte serpentinosi ed eufotidici e che, al contrario di ciò che osservammo nei conglomerati aquilaniani, manchino quasi completamente i ciottoli di calcare alberese del Ligujiano, quantunque alcuni pochi elcmenti ciottolosi di questa natura si possano ancora osservare qua e là, specialmente nell'Etve ziano inferiore delle colline di Sciolze. Questa mareata differenza litologica fra i conglomerati dei duc accennati pe- 
riodi geologici è certamente molto notevole; essa ci indica come durante l'epoca elvesiana fosscro gia quasi completamente coperti quei terreni liguriani che inveee durante l'epoca aquilamianu, trovandosi a nudo per tratti vastissimi, venuero potentemente erosi pel' modo che i loro elementi costituiscono ora parte importantissima dei conglomerati di tale epoea.

Molto varia è la direzione e l'inclinazione degli strati clrezioni a scconda delle regioni; possiamo solo dire, in generale, riguardo alla pendenza, come essa sia specialmente forte (cioè di $45^{\circ}, 50^{\circ}$ ) nell'Elveziano inferiore, la dove esso forma una rapida curva, cosi nelle colline fronteggianti direttamente Torino; in reee l'inclinazione $\partial$ di solo $25^{\circ}$ o $35^{\circ}$ nell'Eleesiano medio, come nelle colline tra Cavoretto, Revigliasco, l'Eremo ed il Pino; infine essa si riduce a solo $20^{\circ}$ in media nell'Elecsiano superiore.

La conformazione orografica della collina torinese è in rapporto assai stretto colla stratigrafia c colla eostituzione dei terreni elvesiani che la eostituiscono; questa correlazione d̀ d'altronde un fatto generale e quindi è inutile aggiungere ulteriori spicgazioni ed osservazioni, le quali potra invece facilmente fare chiunque percolra le colline in esame, conoscendone la stratigrafia e la natura geologiea.

Notiamo infine come la zona elvesiana dei colli torinesi raggiunga al Bric della Maddalena la massima elevazione (716 metri) che si osservi nelle colline Torino-Valenza; fatto ehe è in relazione specialmente colla grande vicinanza della catena alpina e colla grande potenza delia serie elveziana in queste regioni.

Di fronte a Torino l'inticra zona elveziana scompare sotto ai terreni quaternari della pianura padana, ma ne rediamo ricomparire la parte inferiore poco più ad Est, cioè presso Borgata Sassi, e costituire così la parte esterna delle eolline di S. Mauro, Castiglione, Gassino, cec.

Lungo questa zona di sviluppo possiamo anzitutto osservare il passaggio gradualissimo che si verifica tra l'Elveziano ed il Lunghiano, inoltre notare l'abbondanza grande di fossili che riscontrasi fra i banchi basali molassico-ciottolosi dell'Eleziano (ciò che va d'aecordo colla regola generale ammessa dianzi in proposito), ed infine osservare come i banchi di questo orizzonte si presentino fortemente sollevati, raggiungendo un'inclinazione di circa $45^{\circ}, 50^{\circ}$, verso Nord-Ovest, nelle colline di Sassi e di S. Mauro, ma persino di $70^{\circ}, 80^{\circ}$ nelle colline di Castiglione e di Gassino, naturalmente con ma gradazione tra i banchi inferiori e quelli superiori della zona elveziana visibile. Tale fortissima pendenza è in stretta relazione col vieino affioramento eocenieo.

Come di solito la natura litologica di questa zoua ellesiana è prevalentemente sabbiosa ed arenacea; abbiamo però giả indicato esservi 
sorente banchi molassico-ciottolosi verso la base; inoltre se ne osservano a livelli superiori, come ad esempio nella ralle ILaggiore della Ressa, 150 metri circa a Sud della borgata Ressa. Esistono inoltre strati marnosi — sovente alternati con banchi sabbiosi — ed anche potenti banchi marnosi pseudo-tor/oniani nella parte esterna delle colline in esame, cosi nei dintorni di C. Barberis, di Villa Alban, di Villa Scarsa, di Tetti Mochino, ecc.; però tali banchi fanno ancora parte dell'Elresiano medio e corrispondono ad un orizzonte simile che allo stesso lirello abbiamo gia notato nel versante meridionale della regione collinosa ora in csame. Vi fu cioè evidentemente, verso la metà circa dell'epoca elvesiana, un periodo abbastanza lungo di deposizione lenta, tranquilla, di fine fanghiglia.

Per dar un'idea gencrale dclla costituzione delle colline in esame possiamo citare ad esempio la sezione geologica che s'incontra salendo dalle colline di S. Mauro a Superga, cioè:

/ Banchi sabbiosi, grigio-giallastri.

Banchi marnoso-sabbiosi, grigiastri.

Elveziano Banchi sabbiosi altcrnati con strati marnosi, fossiliferi.

Banchi sabbioso-arenacei con strati e lenti ghiaioso-conglomeratiche assai fossilifere.

Langhiano - Marne pii o meno arenacee, grigiastre, dure, scagliose. Strati ghiaioso-conglomeratici fra marne sabbiose.

Aquitaniano

\section{Banchi conglomeratici ed arenacei.}

liarme biancastre o grigiastre, più o meno alternate con strati arenacci.

A Nord-Est delle colline di Gassino rediamo la zona elcesiann incurvarsi gradatamente attor'no all'elissoide aquitaniano-langhiana la cui estremità oricntale si trova precisamente nelle colline presso C. Laurenti. Naturalmente, come si verifica in tali circostanze, la zona elvesiana si allarga quivi di molto e si cstenderebbe certamente assai di piủ se non esistcsse l'emersione eo-oligocenica di Castagneto-S. Genesio, la quale altera profondamente la tettonica della zona elvesiana in csame; anzi per esaminarla regolarmente dobbiamo descriverla secondo il suo andamento stratigrafico.

Nelle colline di Bussolino torinese i terreni elvesiani si comportano in modo assai simile a quello osservato poco fa ad Orest, cioè hanno un'inclinazione di $30^{\circ}, 40^{\circ}$ nella parte collinosa fionteggiante la pianura padana, ma si sollevano rapidamente a Sud per modo da raggiungere tosto un'inclinazione di $60^{\circ}, 70^{\circ}, 80^{\circ}$, rerso Nord-Orest; tale grado d'inclinazione essi conscrvano per lungo tratto, costituendo la parte esterna dell'estremità orientale dell'elissoide di C. Laụrenti, quantunque 
naturalmente varii la direzione della loro pendenza che è a Nord cirea presso S. Dalmazzo, poi a Nord-Est, quindi ad Est, come nelle colline di Villa Dellala.

Per quanto possa supporsi, dopo un primo csame complessivo, che la descritta zona elveziana vada a collegarsi con quella gial csaminata di Sciolze, Baldissero, ece., costituendo così un'intiera elissoide, invece, come si è gia quivi osservato pei terueni langhiani ed aquituniani, tale elissoide rimane interrotta.

Infatti nelle colline di Rivalba si osserva che i banchi marnosi e sabbiosi dell'Eleezixno, talora ricchi in Zoophyycos, a facies talvolta langhiana per modo da rimancre sovente incerta la delimitazione dei due orizzonti che quivi passano gradatamente l'uno all'altro, tali banchi, dico, si presentano nella parte occidentale inclinati per poco ad Est, ma poscia rapidamente si volgono ad Oriente ed assumono una netta inclinazione a Nord.

Quindi discendendo dal Bric del Cervo al fondo della Valle Maggiore di Gassino incontriamo la seguente serie stratigrafiea:

Elveziano $\left\{\begin{array}{l}\text { Banchi ghiaioso-sabbiosi con lenti e strati di ciottoli } \\ \text { c ciottoloni, talora voluminosissini. } \\ \text { Banchi arenacco-\$abbiosi, a stratificazione alquanto } \\ \text { irregolare, talora con lenti arenaceo-ghiaiose ed } \\ \text { arnioni arenacci. } \\ \text { Banchi sabbioso-marnosi, fossiliferi. } \\ \text { Complesso di banchi specialmente marnosi, gri- } \\ \text { giastri, talora pseudo-langhiani, talora però } \\ \text { alquanto sabbiosi. } \\ \text { Banchi sabbioso-marnosi, spesso fossiliferi. }\end{array}\right.$

Langhiano - Complesso di banchi marnosi, duri, grigiastri, scagliosi, talora alquanto arcnacei, talora alternati con strati sabbiosi fossiliferi.

Aquitaniano $\left\{\begin{array}{l}\text { Banchi sabbioso-marnosi o marne frammentaric, } \\ \text { talora a stratificazione alquanto incerta, talvolta } \\ \text { però con strati marnosi, duri, pseudo-langhiani. }\end{array}\right.$

La pendenza degli strati elreziani che è di solo $30^{\circ}$ in media, con oscillazioni da $20^{\circ}$ a $45^{\circ}$, si conscrva quasi invariata per un lunghissimo tratto, quindi nell'alta val Leona incurvandosi gradatamente verso Nord, con un'inclinazione di cirea $45^{\circ}$ nella parte basale, cssi vengono a costituire la conea di Borganino e S. Pietro.

La cagione di tale andamento stratigrafico la troviamo direttamente nei vicini affioramenti cocenici di Lauriano i quali, cmergendo, hanno sollevato la seric miocenica sovrastante.

Continuando ancora l'incurramento della zona elvesiana vediamo i 
suoi banchi, con un'inclinazione però di solo più $30^{\circ}$ circa rerso il Sud-Ovest, attraversare la val Leona c eostituire le colline di S. Sebastiano; in seguito però cssi, incontrando l'affioramento eo-oligocenico di Castagneto, rimangono compressi e quindi fortemente sollerati.

Quivi infatti gli strati elveziani si presentano inclinati di $40^{\circ}, 50^{\circ}$, $60^{\circ}$ e più; nello stesso tempo cambia la loro direzione, assumendo essi dapprima un'inclinazione a Sud-Est; quindi nell'attorniare l'indicata elissoide di Castagneto, presentano una pendenza a Sud, poscia a Sud-Orest, poi ad Orest, ed infine a Nord-Orest; con quest'ultima inclinazione (che è talora di solo $20^{\circ}$ o $30^{\circ}$ nella parte basale, ma generalmente di $60^{\circ}, 70^{\circ}$ ) si veggono i terreni elvesiani immergersi sotto ai terreni quaternari della pianura padana quasi di fronte a Chivasso.

Dall'esame dell'andamento stratigrafico della partc inferiore della zona elveziana S. Raffacle-Casalborgone, risulta nettamente come essa costituisea una vera conea, abbastanza ampia ad Est per modo da dar origine alla larga valle Leona; detta valle nelle vicinanze di Casalborgone si può quindi veramentc considerarc eome una vallata orografiea di sinclinale (quantunque molto modificata dalle profonde erosioni) ristretta ad Orest, perchè compressa tra due elissoidi di sollevamento, di Castagneto a Nord c di C. Laurenti a Sud.

Ne risulta quindi naturalmente che mentre nell'ampia eonca di Casalborgone i banehi elesiani presentano talora inelinazioni doleissime cd anzi essi sono talvolta per lunghi tratti quasi orizzontali, eome nei dintorni di Casalborgone, inveee più ad Orest questi banchi sono scmpre fortemente inelinati e solo pcr breve tratto presentano una pendenza più dolec, cioè là dove si verifica il mutamento d'inelinazione.

Se per escmpio si vuole osservare facilmente e nettamente il fatto or ora aceennato, basta seguire la strada che eonduee per eresta da Castagneto alla Cappella di S. Dalmazzo; in questo caso si tagliano per lungo tempo i banchi elveziani inclinati di eirea $50^{\circ}$ verso Sud, ma, attraversata la eresta di Brie del Vaj, si vede che al colle di S. Antonio (colle in parte di sinclinale) la loro pendenza diventa dolcissima, quindi poco dopo gli strati, incurvandosi a conca, assumono un'inclinazione opposta a quella di prima, cioè rerso Sud; tale inelinazione è dapprima assai dolce, ma tosto diventa fortissima eioè di $60^{\circ}, 70^{\circ} \mathrm{c}$ più, finchè si passa ai terreni langhiani.

Nelle colline di S. Raffaele l'esaminata sinclinale va gradatamente scomparendo ed i tcrreni elvesiani assumono una regolare inclinazione di $25^{\circ}$ a $45^{\circ}$ ver'so Nord-Orest, riannodandosi cosi gradatamente con quelli di Bussolino e di Chivasso.

In complesso quindi si può dirc che l'andamento stratigrafico della 
zona elveziana in questione, per quanto vario, si presenta abbastanza regolare, se si cecettuano aleuni pieeoli disturbi loeali ehe si osservano ad esempio sopra le Piane di S. Raffaele, pressa la C. Gora (Nord di Casalborgone) eee., ma che non alterano per nulla l'andamento regolare generale degli strati.

Si è gia detto sopra eome la Val Leona si possa eonsiderare in gran parte eome una valle di sinclinale, per quanto molto modifieata dalle erosioni aequee; quasi la stessa eosa si può dire della valletta Losa, la quale, quantunque profondissimanente ineisa dalle aeque, fu in origine una valietta orografiea di sinelinale; tant'è ehe l'angolo assai accentuato elie essa fa verso S. Antonio è in stretta relazione eon un angolo simile ehe forma l'asse della sinclinale stratigrafica.

Aneora in stretta relazione eoll'andamento stratigrafieo sono la posizione e la direzione delle ereste eollinose più elerate di questa regione, cioè le eolline di S. Giovanni $(572 \mathrm{~m}$.), il Brie del Cerro (501 m.) ed il Brie Martina (536 m.), appartenenti all'elissoide di C. Laurenti, e la eresta del Brie del Vaj $(583 \mathrm{~m}$.) ehe fa parte gria dell'elissoide di Castagneto. É pure eoll'esame stratigratieo ehe ei spieghriamo qui, eome altrove, molti fenomeni oroidrografiei, inesplieabili altrimenti, eosi ad esempio la notevole differenza esistente fira i due lati della valle del Pertengo, a pendio doleissimo a destra, ripido, ruinoso a sinistra.

Riguardo alla zona elveziana in esame dobbiamo aneora far diverse considerazioni in rispetto alla sua eostituzione litologiea. L'Elveziano inferiore presenta, eome di solito, una ripetuta alternanza di banehi marnosi e sabbiosi ehe eostituiscono gradualissimo passaggio al LanGhumo; ne derivano quindi le solite ineertezze di delimitazione fra i due orizzonti; però attoruo all'elissoide eo-oligoeeniea di Castagncto, sieeome tutti gli orizzonti geologici lidueonsi molto, anehe i banehi elveziani inferiori seompaiono in gran parte e generalmente quivi l'Elveziano si appoggia eor trasgressione regolare sui terreni aquitaniani.

In questo orizzonte inferiore dell'Elveziano trovansi bensi resti fossili, ma non più cosi frequenti e ben conservati eome nelle eolline torinesi.

Al disopra di questo orizzonte sabbioso-marnoso compaiono banchi sabbioso-ciottolosi ehe ver'so il eentro del baeino di S. Raffaele-Casalborgone non solo assumono una potenza straordinaria, ma raeehiudono elementi spesso voluminosissimi i quali (per la graduale abrasione delle eireostanti sabbie) rimangono sparsi e isolati sulle ereste e sui fianchi collinosi, per modo ele ne risulta per tali eolline quell'aspetto morenico, direi, ehe abbiamo già potuto ampiamente esaminare nelle eolline torinesi e monregalesi.

Sono preeisamente le eolline più clevate della regione ora in esame, 
cioè il Bric Torniola, la cresta di S. Giovanni, il Bric del Cerro, il Bric Martina e l'inticra Cresta dcl Vaj, che offrono sviluppatissimo il fatto accennato, ciò che d'altronde ne spiega appunto in massima parte la grande elevazione, relativamente alıneno alle prossime colline sabbioso-marnose. Anche in queste regioni, come nelle colline torinesi, questi ciottolini e ciottoloni, talora di grossezza enorme, non di rado a spigoli ancora abbastanza conservati e di oligine alpina, non formano reri banchi conglomeratici, ma trovansi invece per lo più ammassati irregolarmentc, bensi in orizzonti particolari, ma specialmente in alcuni punti, oppure anche sovente sono sparsi qua e lì irregolarmente fra le arenarie più o meno grossolane.

Questo tipico orizzonte ciottoloso, che rappresenta l'Eleeziano medioinferiore, forma nel suo complesso, ncl centro circa della conca elveziana in esame, una specie di irregolare triangolo colla base ad Est; csso racchiude ancora potenti banchi sabbioso-arenacei che rappresentano i depositi più recenti (Elvesiano medio) della zona in esame.

Dobbiamo ancora notare rispetto alla costituzione litologica della zona in esame come ri appaiano eziandio potenti banchi di una speciale arenaria giallo-rossastra, banchi che possonsi osservare ad esempio salendo da C. Garrone al Bric del Cerro, presso il Pilone Caporale (Sud di S. Sebastiano), nella partc alta di Rio di Valle presso il colle di S. Antonio (Bric Martina) ecc.; queste arenarie presentano talora una stratificazione irregolare, indicando depositi formatisi in un basso fondo marino talvolta alquanto agitato.

I fossili non sono lari specialmente fra le molasse che si alternano o che ricoprono gli accennati banchi ciottolosi, cosi ad esempio in inolti punti attorno a S. Raffaele, località importante per ricerca di fossili.

Nella parte inferiore dell'Elveziano tra Castagneto e borgata Ossoli esiste una scarsa sorgente minerale fra marne grigio-bleuastre inglobanti ghiaie e ciottoli che sonvi sparsi in modo irregolare.

Nella zona di terreno elvesiano che si rede sviluppata tra S. Raffaele e Chivasso, ad eccezione del piccolo spuntone di C. Cimena, dove vediamo marne grigio-bleuastre pseudo-tortuniane, prendono un grande sviluppo le arenarie alternate con banchi ciottolosi o molassico-ciottolosi, spesso fossiliferi, che vengono talora ad appoggiarsi direttamente sull'Aquitaniano, mancando il Langhiano e l'orizzonte inferiore dell'Elvesiano: si notano pure quivi ciottoloni voluminosissimi. L'inclinazione è generalmente abbastanza forte, talora anche di $70^{\circ}$ e più, ma con noteroli dircrsità da luogo a luogo.

Se di fronte a Chivasso la zona elvesiana viene a scomparire completamentc sotto ai terreni quaternari della pianura, studiando attentamente la costituzione geologica delle più settentrionali propaggini 
delle colline più ad Est, ritroviamo per breve tratto la continuazione della parte inferiore di questo orizzonte geologico. Esso infatti costituisce i banchi prevalentemente sabbioso-arenacei della collina di C. Cerrea presso Lavriano, dove essi si presentano fortemente sollevati, con inclinazione cioè di $60^{\circ}, 70^{\circ}$ circa verso il Nord.

Un'ultima apparsa dei banchi sabbiosi dell'Elucziano osservasi ncle colline di Cavagnolo dove essi sono pure fortemente inclinati a Nord e passano gradualmente al Langhiano nella parte inferiore.

Verso Brusasco l'orizzonte elveziano, assieme a quello langhiano ed aquitaniano, scompare completamente sotto i terreni quaternari della pianura padana e quindi qui termina l'esame di questo importante piano geologico clıe abbiamo visto presentare tanti e cosi svariati andamenti nelle colline Torino-Valenza.

\section{Riassunto.}

Cerchiamo ora di riassumere in poche righe le osservazioni principali fatte attorno all'Elveziano del bacino terziario del Piemonte, dove esso rappresenta una parte importantissina sia per potenza che per estensione c per ricchezza in fossili.

L'Elveziano del Piemonte venne finora generalmente indicato come Miocene medio assieme con diversi terreni più antichi; solo il Pareto ed il Mayer ne mostrarono l'individualità come vero piano geologico, scnza però segnarlo come tale su carte geologiche.

Il caratterc generale dell'orizzonte elveziano è di rappresentare essenzialmente un deposito di mare poco profondo, per quanto vi si incontrino pure a diversi livelli, ed in modo vario secondo le regioni, depositi piủ o meno potenti di mare abbastanza profondo.

Vediamo infatti che nella parte meridionale del bacino piemontese verso Ovest (Langhe) i terreni elveziani sono essenzialmente costituiti da un'alternanza piủ volte ripetuta di banchi sabbiosi cd arenacei, con strati marnoso-sabbiosi; compaiono talora ciottoli sparsi qua e lả ed ancle veri banchi ed ammassi ciottolosi, ad elementi spesso voluminosissimi, come nella parte meridionale dei colli monregalesi presso le falde alpine; ciò ci indica il nesso assai stretto, e d'altronde naturale, esistente fia lc vicinanze della catena alpina e la natura litologica dei depositi elveziani che si stendono alle sue falde.

Nella zona elveziana del Monferrato assumono gradatamente uno sviluppo molto notevole i banchi arenaceo-calcarei che vengono a costituire la massima parte dell'orizzonte in esame, e che con tale facies si continuano ancora nel tortonese.

Un fenomeno simile troviamo pure nell'Elveziano delle colline TorinoValenza, giacchè nella loro parte orientale tale orizzonte geologico è 
specialmente rappresentato da banchi marnoso-arenacei, calcarei, i quali nella parte occidentale, o colli torinesi, si cangiano a poco a poco in banchi sabbioso-marnosi spesso alternati con strati e lenti ghiaioso-ciottolose. ad elementi talora roluminosissimi. anche qui, come nei colli monregalesi, in stretta relazione colla vicinanza della catena alpina.

L'Elvezicno costituisce m'ampia zona, talor'a anzi rastissima, come nelle Langhe sul lato meridionale del bacino piemontese, mentre inrece nelle colline Torino-Talenza essa si presenta irregolarmente distribuito, per lo più attorno ad elissoidi di solleramento.

In eonseguenza di eiò rediamo che mentre gli strati elreziani sul lato meridionalc del baeino in esame sono, in generale, regolarmente inclinati rerso il centro del bacino stesso, inrece nelle colline TorinoValenza essi presentano svariate inclinazioni, spesso costituendo ripetute pieghe, ma in generale senza grari disturbi stratigrafiei.

La potenza dell'Elveziano, per quanto molto raria da luogo a luogo, è però generalmente assai grande, in relazione appunto colla natura dei depositi che lo costituiscono; in eomplesso si puo dire che questa potenza ra aumentando, nel bacino in esame, da Est relso Orest, eioè verso le Alpi, com'è naturile, essendo specialmente di origine alpina gli elementi che formano i depositi di questo piano geologico.

Infatti è nelle Langhe e nelle colline torinesi che si può rerificare come la pila dei terreni elveziani superi in spessore i 2000 metri, raggiungendo anzi probabilmente i 2500 metri di potenza.

Cosi pure è specialmente nella parte oceidentale del bacino terziario del Piemonte ehe si osserrano i terreni elveziani spinti alle clerazioni più noteroli, cosi di oltre 700 metri (Bric Maddalena $716 \mathrm{~m}$.) nelle colline torinesi, e di quasi 900 metri (Mombarcaro $898 \mathrm{~m}$.) nelle Langhe. Questi fenomeni sono in relazione colla ricinanza della catena alpina, sia perchè, per le suddette regioni dall'accennata vicinanza deriva una maggior potenza dei depositi,sia perchè le regioni più prossime alla catena alpina furono naturalmente più fortemente sollevate che non quelle situate a maggior distanza; inoltre l'indicata forte elerazione dell'Elreziano nelle Langhe ci conferma sempre più nell'ipotesi. giil altre rolte accennata, che cioè nell'epoca terziaria la regione che rannoda le Alpi marittime agli Appennini sia stata assai più potentemente sollerata che non la restante parte della catena alpina.

Non è d'uopo d'insistere sul fatto, indicato tante rolte nel corso del laroro, che cioè generalmente i terreni elreziani passano gradatissimamente ai terreni langhiani inferiormente ed ai terreni tortoniani snperiormente; solo ehe, se questo fatto si può dire costante nella parte meridionale del bacino in esame, dore la"stratigrafia è scmplieissima e regolare, esso presenta però qualche eccezione nelle colline tortonesi e 
di Torino-Valenza, giaeehè quivi non di rado vi è trasgressione, generalmente regolare però e senza salti, tra l'Eleeziano ed i terreni sopra e sottostanti, eome si è notato nella deserizione regionale.

Infine riguardo ai fossili dell'Elve ziano del bacino terziario piemontese è ben nota la loro abbondanza in forme ed in individui, tanto da eostituire una fauna tipica, la cosidetta fauna di Superga.

Questi fossili però, per quanto l'Etvesiano sia quasi sempre fossilifero, non trovansi abbondanti e ben eonservati in ogni punto della zona elvesiana, ma invece sono specialmente aceumulati in regioni e banehi speeiali, particolarmente eioè negli strati molassico-ciottolosi delle colline torinesi (dette falsamente colline di Superga); eiò indiea che tali aeeumuli di fossili debbonsi specialmente a suecessivi depositi tumultuosi che di tratto in tratto lianno eagionato la morte di molti animali marini e quindi l'reeumulamento dei loro resti in banchi spceiali.

Esistono però eziandio abbondantissimi fossili quasi ovunque nei telreni elvesiani, specialmente nei banchi calcareo-marnosi o caleareoarenacci, eome si è notato particolarmente in pareechi punti delle colline casalesi e tortonesi, nonchè nel Monferrato e nelle Langhe. 


\title{
CAPITOLO XII.
}

\author{
TORTONIANO.
}

\section{Studi anteriori.}

Il piano gcologieo di eui stiamo per trattare cra finora noto ai geologi e paleontologi piemontesi sotto il nome di Hiocene superiore, ma ne era quasi completamente sconosciuto lo sviluppo nel bacino telziario del Piemonte, giacchè riguardo ad esso si accennarano quasi solo le località fossilifere di S. Agata-fossili e di Stazzano nel Tortonese.

Il Sismonda nella sua carta geologica del Piemonte unì i terreni tortoniani eogli altri terreni mioceniei in una tinta sola.

Il Pareto aecettò bensi il nome di tortoniano per i terreni in esame, ma non credette poterlo distinguere dal Pliocene di cui ne fece il piano inferiore (opinione ora assolutamente abbandonata); d'altronde si limita anch'egli, riguardo al Picmonte, ad accennare il Tortoniano delle suddette località fossilifere.

Il MIayer pel primo seppe diagnosticare ed indiridualizzar bene il Tortoniano piemontese, esaminandolo accuratamente nell'angolo SudEst del baeino terziario in esame, dore ebbe a studiarlo durante le frequenti escursioni da lui fatte per ricerca di fossili.

Nella recente carta geologica delle Riviere liguri e delle Alpi IIarittime pubblicata da Issel, Mazzuoli e Zaccagna il Tortoniano è detto nel testo esplieativo esser stato inglobato nel Wiocene medio assiemo all'Elveziano, al Langhiano ed all'Aquitaniano; ma nella parte NordOrest delle Langhe, che non sono probabilmente mai state percorse dai predetti geologi, la zona tortoniana è in gran parte indicata come Pliocene e Messiniano.

Dopo il 1884 in diversi lavori speciali sul terziario del Piemonte, ebbi a trattare ed anche ad estendermi sullo studio del Tortoniano.

\section{Generalità.}

L'orizzonte tortoniano è generalmente caratterizzato nel bacino terziario pienontese da una facies essenzialmente marnosa la quale ei indica trattarsi di un deposito formatosi in modo piuttosto tranquillo e ad una certa profondità sotto il livello marino.

Queste marne somo di un color grigio-blenastro, spesso a rottura irregolarmente coneoide e non molto resistenti, per eui danno luogo a colline biancheggianti, piuttosto basse e rotondeggianti, molto favorevoli alla viticoltura. 
Però talvolta si incontrano anche nella formazione tortoniana depositi sabbioso-arenacei e persino localmente ciottolosi (come tra Stazzano e S. Agata e in qualche parte dei colli torinesi) ciò che però non altera la facies complessiva sovraccennata. Più frequente è invece il caso che nella parte superiore del piano in esame compaiano marno dure, fogliettate, inglobanti fossili di mari bassi o quasi chiusi; ¿̀ questa una facies complessivamente maremmana che si può considerare come un sottopiano, sarmatiano, dell'orizzonte Tortoniano.

\section{Caratteri paleontologici.}

Senza entrare per ora in un esame paleontologico ci basti ricordare in generale come la fauna dell'orizzonte in questione serva di mirabile collegamento fra quella miocenica e quella pliocenica, avendo ancora numerosi rappresentanti della prima e gia molte forme della seconda. Tuttavia nel suo assieme la fauna tortoniana ha una facies affatto caratteristica, tanto più che possiede forme proprie come risulterà dalla rivista paleontologica che trovasi alla fine del presente lavoro.

Devesi però notare, rispetto ai caratteri paleontologici del Tortoniano, che la fauna così ricca e famosa di questo piano in certe parti del Piemonte, non devesi per nulla considerare come una caratteristica generale di tale terreno, giacchè in realtà si verifica generalmente un fatto ben diverso.

Infatti in quasi tutto il Piemonte le marne tortoniane offrono ben rari fossili, solo qua e là qualche piccola Ostrica, qualche raro Turbinolide, qualche Teredine impigliata in frammenti di legname lignitizzato, qualche Sindosmya o qualche altro Mollusco più o meno ben conservato e sovente difficile ad estrarsi intiero; nella parte inferiore trovasi talora qualche dente di Carcharodon, ma trattasi sempre ad ogni modo di fossili assai scarsi e non molto interessanti perchè incompleti.

$\dot{\mathrm{E}}$ invece soltanto in alcuni punti delle colline tortonesi e più di rado delle colline torinesi, specialmente là dove colle marne si alternano e si frammischiano sabbie e ghiaje più o meno grossolane, che compare quell'abbondanza di fossili, ben conservati e facilmente liberabili dal terreno inglobante, i quali resero famoso in Piemonte questo piano, tanto che si trasse il suo nome appunto dalle colline di Tortona. D'altronde per quanto sia ritenuta caratteristica del Tortoniano questa fauna delle colline tortonesi, essa è in verità una fauna alquanto locale e legata a condizioni che non furono affatto generali pel mare, anche solo piemontese, del periodo tortoniano, di modo che la fauna più o meno scarsa che generalmente si raccoglie fra le marne tortoniane del Piemonte, ha una facies alquanto diversa da quella delle famose regioni fossilifere dei colli tortonesi. 


\section{Distribuzione geografica.}

L'olizzonte tortoniano forma una zona abbastanza continua nella parte meridionale del bacino in esame; peró sia verso Orest sia in diversi punti nelle colline del Monferrato esso si riduce ad una sottile striscia od anche scompare del tutto per essere fortemente compresso od alquanto trasgressivamente coperto dai terreni terziari piủ giovani.

Nell'angolo Nord-Est del bacino piemontese il piano in esame, dopo essersi ampiamente sviliuppato nelle famose regioni fossilifere di Stazzano e S. Agata, si va lapidamente restringendo e scompare completamente verso Nord, nelle vere colline tortonesi, per modo che anche in questo caso il nome di Ton/oniano non ha una derivazione esatta.

Nelle colline Torino-Talenza il terreno tortoniano, che appare per un certo tratto nella loro punta orientale, manca quasi completamente nella loro parte scttentrionale, essendo coperto dai terreni quaternari della valle padana, ma si può seguire con poche interruzioni lungo le loro falde meridionali, da Val Grana sin presso IIonealieri circa.

\section{Tettonica.}

L'andamento stratigrafico del Tortomiano è piuttosto semplice e regolare; infatti in tutta la porzione meridionale del bacino questo terreno presenta una pendenza piuttosto dolce, di cirea $6^{\circ}$ a $10^{\circ}$, talora anche minore, verso il centro del bacino stesso; ma nell'angolo Sud-Est della regione in esame l'inclinazione diventa alquanto più forte, rara-

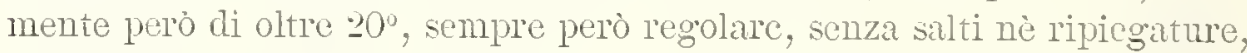
cceetto che in piccola scala.

Lungo le falde meridionali delle colline Torino-Talenza i terreni tortoniani pendono abbastanza regolarmente rerso il centro del bacino terziario con un'inclinazione di cirea $12^{\circ}, 15^{\circ}$ in media; però in dirersi punti la loro pendenza direnta assai più forte, cioè di oltre $30^{\circ}$ o $40^{\circ}$ in causa di vicinc elissoidi di sollevamento.

Dobbiamo notare in generale come esista sempre una grande diversità nel grado d'inclinazione tra gli strati superiori e quelli inferiori del Tortoniano; ciò d'altronde è anche in relazione col fatto, tante volte ripetuto, del graduale passaggio che per lo piu si verifica tra l'Elveziano ed il Tortoniano, in rispetto alla litologia, alla palcontologia ed alla stratigrafia.

Devo poi richiamare l'attenzione sull'interessante fatto stratigrafico che nelle colline Torino-Valenza il Tortoniano è completamente escluso da quci frequenti c talora multipli ripiegamenti a cui invece prendono parte i terreni terziari più antichi. Ciò pare indicarei come potentissimi fenomeni sismici si siano verificati rerso la fine dell'epoca elreziana; 
questo d'altronde va d'aceordo colle idee dei geologi d'oltr'alpe, specialmente svizzeri; solo ehe in generale essi non ammettono più per la regione alpina quel potentissimo movimento sismico che eredo invece siasi ancora verificato verso la fine del Pliocene, griacchè i depositi marini plioceniei sono spinti talora, in Piemonte, sin oltre i 500 metri.

\section{Potenza.}

Il Tortoniano, come tutti gli orizzonti a facies complessiva di mare alquanto profondo, non presenta mai una grande potenza; soventissimo è rappresentato da solo pochi metri di narne.

Però in alcule regioni del tortonese e speciahnente nella parte settentrionale delle Langhe la serie tomonian! assume uno spessore di oltre 200 metri; anzi nella parte Nord e Nord-Ovest dell'ultima l'egione accennata l'ampiezza noterolissima che presenta l'area tor'toniana, pur tenendo conto della pendenza piuttosto dolee degli strati, ci fa valutare ad oltre 500 metri la potenza del Tortoniano che quivi può completamente esplicarsi per il regolarissimo andamento stratigrafico generale dei terreni terziari.

\section{Altimetria.}

Come tutti gli orizzonti prevalentemente mamosi, il Tortonicno in nessuna regione del Piemonte è portato a grandi altezze, anche perchè la sua deposizione fu posteriore ai grandi movimenti sismici che si verificarono appunto verso la fine del periodo elvesiuno.

Vediamo infatti che generalmente la zona tortoniana, dove fu più sollevata, si trova ad un'altezza inferiore ai 400 metri, per lo più anzi sotto ai 300 metri; è soltanto nelle colline tortonesi che in alcuni punti le marne sabbiose del Tortoniumo superiore sono spinte eccezionalmente sin quasi ai 500 metri, come presso S. Allosio.

Nelle colline Torino-Valenza i terreni tomtonimi si sollevano generalmente solo poco sopra i 200 metri, eccetto che nella parte più occidentale dove li vediamo spingersi talora sin oltre i 400 metri.

E. notevole il fatto che il Tortoniano in nessun punto del bacino terziario piemontese ragginnge quell'elevazione di 500 e più metri, cui invece giungono talora i depositi pliocenici; questo fenomeno, strano a primo aspetto, deriva solo dal fatto che in nessun punto i terreni tortoniani s'appoggiano, visibilmente almeno, alle falde montuose, le quali somo le parti del bacino terziario che furono soggette ai più forti sollevamenti; tale condizione invece si verifica talora pei terreni pliocenici alle falde delle Alpi Narittime. 
Rapporto coi terreni sotto e soprastanti.

Il piano tortoniano non formando che un anello nella lunga catcna o serie regolare di deposizione dei terreni terziari del Piemonte si attacca gradualmente coi piani sopra e sottostanti.

Gia nel precedente capitolo si ebbe occasione frcquentissimamente di accennare, sia in linea generale che nella descrizione regionale, come il graduale passaggio dai terreni eleeziani preralentemente sabbiosi, a quelli tortoniani prevalentemente mamosi, si compia per mezzo di una ripetuta alternanza di banchi sabbiosi, marnosi ed arenacei; ciò rende difficile ed anzi, a dir meglio, spesso arbitraria una netta delimitazione dei due orizzonti, per quanto complessiramente essi siano ben distinti. Talora poi depositi racchiudenti fossili di facies preraJentemente toroniana presentano inrece una fauna litologica piuttosto elve iana, come rerificasi in una parte dei colli torinesi.

Riguardo alla parte superiore del Tortoniano vi possiamo pure spesso osservare un graduale passaggio al ILessiniano inferiore, sia per una maggior abbondanza in strati marnoso-sabbiosi, talvolta anche a facies e fauna sarmatiana, sia per la comparsa di qualche sporadica lente arenaceo-calcarea che preludia allc più grandi lenti messiniane. In generale pcrò la distinzione fra Tortoniano e Messiniano riesce fra le più facili nella serie terziaria del Piemonte, sia per la natura litologica generalmente assai dirersa fra due piani geologici, (donde risulta una diversa resistenza all'erosione c quindi una specie di gradino tra il terreno tortoniano e quello messiniano), sia per una certa trasgressione che pare esista sorente tra l'uno e l'altro orizzonte, fenomeno probabilmente in rapporto colla natura marcmmana o littoranea dei depositi messiniani.

Ad ogni modo arremo occasione di osselrare sorente nel colso dello studio del Tortoniano come anche la sua distinzione dal Meśsiniano sia spcsso incerta per i graduali passaggi che li collegano.

\section{Località fossitifere.}

Da ciò che si è sopra detto risulta già chiaramente che, per quanto esteso sia il piano tortoniano attrarerso a quasi tutto il bacino terziario del Piemonte, tuttavia le localita dore si possa far ricea messc di fossili ben conscrvati sono assai poche e limitate quasi solo alla regione Nord-Est di detto bacino.

Anche in quei banchi arcnacei (fra cui il più importantc è quello di Norello-La Morra nelle Langlie) i quali talora interrompono la formazione marnosa del Tortoniano, troviamo pochi e generalmente poco interessanti fossili di littorale, spesso anche mal conservati. 
Piủ importanti sono eerti orizzonti speciali che compaiono talora nel Tortoniano superiore e ehe sono costituiti di marne straterellate, le quali rieordano assai quelle tanto comuni nel Messiniano e elıe spesso racehiudono una gran quantità di fossili sehiacciati, specialmente Pesei, Crostacei, Filliti, ece.

Io credo che tale facies, la quale rappresenta generalmente il prodotto di un deposito formatosi in un mare poco profondo od in una maremma come indicano alcuni fossili, si possa appellare facies sarmatiana. In Piemonte citiamo come esempio di queste località fossilifere a facies scrmatiana le colline della Morra (Langhe) poco ad Ovest della Cappella di S. Pietro e presso C. Fontanazza, le eolline di Nizza Monferrato presso C. Masearino e Villabassa, ecc.

Fra le regioni fossilifere piủ notevoli menzioniamo le colline a NordEst di Stazzano, la Val di Vargo, la famosa valle di Rio Bocca d'Asino (alta Val Armarengo), i dintorni di Monterosso, di Vargo, di Sardigliano, di Cuquello, le colline a profonde e franose incisioni di Giusulanella, di Bavantore, di S. Agata-fossili, di S. Allosio, ece.

$\dot{\mathrm{E}}$ in queste regioni ehe Bellardi, Miehelotti, Sismonda, Nayer, Doderlein, ece., vennero a laccogliere quei tesori paleontologici ehe ora ornano i Musei italiani ed esteri e che arricchirono di tante e cosi importanti forme la paleontologia terziaria.

All'estremità orientale delle colline Torino-Valenza, tra Monte-Castello e Pietramarazzi, esiste un affioramento di marne tortoniane assai rieeo in fossili, solo che la vegetazione viticola, quivi estesissima, rende la raccolta dei fossili quasi solo limitata alle rive del Tanaro; in queste regioni le marne, alquanto sabbiose, fogliettate del Tortoniano eomprendono spesso filliti, pesci, crostaeei, ece., a facies sarmatiana.

Lungo le falde meridionali delle colline Torino-Casale il Tortoniano si presenta generalmente poco riceo in fossili, quantunque anche in questo caso quasi ovunque il diligente riecreatore ne possa raccogliere in più o meno buon stato di eonservazione. Però nella parte oecidentale delle colline sovraecennate tra Moncucco, Barbasio, Avuglione, Marentino : Montaldo, ece., le marne sabbiose del Tortoniano si presentano ricche in fossili, simili a quelli delle eolline tortonesi; già famose al riguardo sono le immediate vieinanze di Tetti Borelli. Queste località meritano ricerche piủ prolungate di quelle fatte finora e ne risulterà eertamente la eonoscenza di una fauna molto rieea ed importante.

\section{Descrizione geologica regionale.}

Nella parte Sud-Ovest del baeino terziario piemontese, alle falde oeeidentali delle colline monregalesi, il Tortoniano è ricoperto trasgressivamente dalle alluvioni del Terrazziano e quindi non osservasi in 
alcun punto adagiarsi direttamente sulle roceie preterziarie delle Alpi Marittime; ma probabilmente, anche se si togliesse il relo allurionale, non si vedrebbe la zona tortoniana spingersi sin contro la regione montuosa giacchè essa si restringe rapidamente rerso Sud per modo che tra Mondovi e la falda alpina le marne argillose del Piacenziano ricoprono direttamente l'Elvezicono.

Infatti mentre a Nord delle colline monregalesi la zona tortoniana ha una larghezza di circa quattro chilom., presso IIondorì inrece alla distanza di un chilometro e mezzo dall'Elveziano di Val Ellero compaiono le tipiche argille piacenziane nelle incisioni di rio Fenestrera.

Inoltie nella galleria (1) che si scarò recentemente presso la stazione di Mondovi, per la ferrovia Cuneo-ILondori, poco dopo arel tagliate le marne compatte dell'Eleraiano superiore (contenenti pochi fossili ed inglobanti talora ciottoli e ciottoloni sparsi irregolarmente) si incontrarono le marne argillose, riccamente fossilifere del Piacenziano, per modo che riesce evidente che il Tortoniano manca quiri completamente o quasi.

Infine nelle stesse colline monregalesi vecliamo le argille piacenziane sorrapporsi direttamente ed alquanto trasgressivamente sulle marne sabbiose dell'Elveziano; solo verso Nord, nelle colline di Torre Rossa, osservansi tra questi due orizzonti geologici banchi marnosi che potrebbero forse gia attribuirsi al Tortoniano, per quanto tale attribuzione rimanga molto incerta e quindi ben poco importante.

Dove cominciamo a redere le tipiche marne tortoniane è sulla sponda sinistra di Val Ellero a valle di Carassone sino allo sboce dell'Ellero nel Tanaro. In tutto questo percorso quasi orunque osserviamo quel passaggio graduale tra i due terreni che rende incertissima la loro delimitazione; questa riesce invece facilissima in complesso osservando l'orografia della regione poichè le marne tortoniane furono facilmente abrase c ridotte a regioni pianeggianti, coperte dal Terrazziano, mentre le marne sabbiose e le arenarie dell'Elceziano superiore poterono gieneralmente resistere meglio all'erosione delle acque dell'Ellero e costituiscono quindi ora una regione collinosa, cioè la parte settentrionale delle colline monregalesi.

A Nor'd di Val d'Ellero si può esaminare assai bene l'intiera seric tortoniana nella valletta di Branzola, dore le marne tortoniane, per

(1) Questa galleria, fatta senza preventivo esame geologico del telreno si trovia quilsi tutta in un terreno argilloso, inzuppato dacqua, instabile e sottostante immediatamente ad un vero e potente velo acqueo, per modo che essa richiese un tempo ed una spesa immensamente superiore a ciò che erasi prima supposto e, quél che é peggio, tale galleria sarà in avrenire ben sovente in riparazione. 
lo piin povere in fossili, si veggono coperte, presso borgata S. Giovanni, dalle marne messiniane. Anehe nella profondissima Val Pesio si può esaminare su vasta seala la formazione tortomiana che però, verso Orest, pare ricoperta dalle marne piacenziane direttamente o solo con pochi banchi messiniani intermedi: quasi lo stesso fatto osservasi nell'incassato rio di Carrù.

In tutte queste rogioni il Tortoniano è costituito essenzialmente di marne grigio-bleuastre, poco fossilifere, a frattura grossolanamente concoide, a stratificazione regolare, con una pendenza di $6^{\circ}$ a $10^{\circ}$ eirea verso l'Ovest-Nord-Orest, talora altemate con straterelli sabbioso-arenačei che divengono sempre più fiecuenti verso la base dell'orizzonte in esame, finchè si passa affatto insensibilmente all'Elveziano, come si può osservare Iungo la Val Tanaro da Bastia a Farigliano.

Anche in questo caso, come si è notato pei colli monregalesi, la distinzione fra Tortoniano ed Elveziano riesce faeile in complesso; poichè il primo orizzonte costituisce ora regioni pianegrgianti (Carrù-Piozzo), per la forte erosione esereitatavi dalle acque del Tanaro, ed il secondo invece forma regioni collinose (Langhe); attualmente ì diviso l'un terreno dall'altro per mezzo della profonda ineisione del Tanaro. Più a Nord però, dove vediamo che le formazioni tortoniane si portano sulla destra del Tanaro, là constatiamo come esse diano pure origine a regioni pianeggianti, fia eui specialmente importante il Pian Cerreto.

Si è però già notato nell'esame dell'Elveziano come anche nella parte occidentale delle Langhe osservinsi, nella porzione alta delle colline dei Ciri, di Clavesana, ece., banchi marnosi che parrebbero ancora riferibili al Tortoniano, ma che probabilmente inveec fanno gid parto dell'Elveziano superiore.

A Nord di Carrù la zona tortoniana si allarga tanto da raggiungere un'ampiezza di cirea 6 ehilometri, ed una potenza di cirea 500 metri, se non maggiore; essa conscrva però sempre la stessa facies prevalentemente marnosa con irregolari noduli piritiferi o ferriferi, con poehi fossili (specialmente rare ostriche o legnami lignitizzatl traforati dalle Teredini) che però divengono meno searsi verso la base dell'orizzonte, comparendovi già, ad esempio, qualche dente di Squalo; in questo modo il graduale passaggio litologieo, gia tante volte accennato, tra Tortoniano ed Elveziano è pure accompagnato e confermato da una insensibile transizione paleontologica. Quindi rimane molto incerta la delimitazione di questi due orizzonti nelle colline di F'arigliano, Dogliani, Monchiero, ece., per quanto a fine di segnarla si cerchi di tener conto della litologia, della stratigrafia, della orografia e dei dati paleontologici, che non sempre però s'accordano fra di loro a causa di varianti locali di diver'so gencre. 
Se risaliamo le profonde e bizzarramente erose vallette di Rivaletto e Mondalaria vediamo le marne tortoniane renir coperte dalle marne messiniane a Dreissena, Melanopsis, Neritina, ecc., oppure interrotte da lenti gessifere che iniziano la formazione messiniana.

Tra la formazione tortoniana marnosa, poco permeabile, e le alluvioni terrazziane degli altipiani di Morozzo, Lequio, ece., esiste generalmente un velo acqueo abbastanza costante ed importante.

Proseguendo l'esame della zona tortoniana rerso Nord vi si rede comparire una facies speciale, cioè un orizzonte arenaceo-sabbioso, grigio-giallastro, abbastanza ricco in fossili di littorale (Foraminiferi, Molluschi, Crostacei, ecc.), il quale viene ad interrompere nella parte media inferiore la serie dei banchi marnosi.

Naturalmente, in rapporto colla speciale costituzione arenacea di tali banchi d'origine littoranea, questi si presentano piuttosto resistenti e costituiscono quindi specie d'altipiani inclinati secondo la pendenza degli strati.

Vediamo questo fatto iniziarsi nettamente sull'alto della collina di S. Nicola, a Nord di Monchiero, e verificarsi per tutta la cresta collinosa che si estende da Novello al Castello della Volta, per modo da dare alla regione collinosa un aspetto affatto differente da quello solito delle colline tortoniane.

Per raccogliere i fossili di questa zona arenacea e per esaminarla da vicino sono interessanti a percorrersi i ralloni di C. Marmiglione, di C. Rostagno, dei Corini, dei Ciocchini, di Bergera, ecc., legioni caratterizzate anche oroidrograficamente da ripide gradinate, profondi spaccati, numerose sorgenti, ecc., cioè da tutti quei fenomeni esterni che accompagnano quasi sempre gli orizzonti arenacei.

A Nor'd del Castello della Volta gli accennati banchi sabbiosoarenacei divengono meno importanti, assottigliansi rerso Cerequio e C. Fontanazza, perdendo in seguito la loro individualità.

Nelle vicinanze della Cappella di S. Pietro, poco sopra ai banchi di Castello della Volta, veggonsi marne sabbiose grigiastre, straterellate, che inglobano una gran quantità di fossili schiacciati, Pesci, Crostacei, filliti, ece.; quasi lo stesso fatto vediamo ripetersi presso La Mol'ra, poco sopra la C. Fontanazza, dove le marne straterellate fossilifere sono però più dure, lastroidi. Questa facies speciale del Tortoniano medio superiore credo debba considerarsi come corrispondente alla facies sarmatiana che furi del Piemonte è spesso molto sviluppata, talora anzi occupa gran parte del Tortoniano, e sovente è rappresentata da depositi calcarei, da Tripoli, ecc.

Mentre che nelle colline di Barolo, di Grinzane, ecc., continua sempre a verificarsi il graduale passaggio fra Tortoniano ed Elveziano, per 
mezzo delle solite alternanze litologiche, invece riesce abbastanza facilc c naturale la distinzione delle marne grigiastre, franose, relativamente molli, del Tortoniano superiore, dai banchi arenacco-sabbiosi o marnosogessiferi del Messiniano inferiore che per la sua durezza costituisce generalmente una specie di gradino sul sovraccennato terreno. Anzi è probabile che esista una trasgressione stratigrafica più o meno notevole fra questi due orizzonti geologici. Questa ipotesi parrebbe anche convalidata dal rapido restringersi della zona tortoniana tra la Morra e Barolo a causa della grande estensione che quivi presenta la placea messiniana verso Nord, sovrapponendosi essa, probabilmente con una certa trasgressione, regolarissima però, sulla formazione tortoniana che ne rimane in parte mascherata.

A Nord di Castiglione Falletto la zona tortoniana si allarga nuovamente, tanto da raggiungere un'ampiezza di oltre 4 chilom., e costituisce colline biancheggianti, basse e rotondeggianti, a causa della sua natura essenzialmente marnosa, interrotta solo da straterclli arcnacei o sabbiosi con pochi fossili mal conservati.

La natura litologica della zona tortonicna ebbe grande importanza sull'oroidrografia delle regioni collinose delle vicinanze di Alba; quiri infatti vediamo come la vallata del Tanaro, che divide le Langhe dall'Astigiana, sia appunto scavata per un tratto lunghissimo nella zona tortoniana; questa regione, quando il Tanaro (verso la metì dell'epoca quaternaria) si volse a Nord-Est, doveva gia presentarsi come una regione di basse colline, che poterono quindi essere abbastanza facilmente erose ed appianate da detta fiumana la quale trovava invece una forte resistenza all'erosione sia a destra, nelle arenarie clveziane, sia a sinistra nelle formazioni gessifere ed arenacee del Messiniano.

Sono in rapporto a queste potenti e profonde erosioni, eseguite dal Tanaro in epoca abbastanza recente, i grandi spaccati naturali (sempre in ria di mutazione per sfacclo, frane, ecc.) che si osservano su ambi i lati della valle, così sotto Scaparone, sotto C. La Torre, sotto Guarene, sotto C. Ghersi, presso Barbaresco, ecc. sempre nelle marne piủ o meno sabbiose del Tortoniano. Tali profondi spaccati naturali esistenti su ambi i fianchi della valle, anche lungi dall'attuale corso del Tanaro, ci indicano sia che il corso del fiume è molto variabile, portandosi ora da un lato ed ora dall'altro, sia che in tempi geologicamente poco lontani quasi tutto l'ampio fondo di Val Tanaro era occupato da un'ampia fiumana.

亡 inutile fermarci sulla descrizione di quella vastissima zona tortoniana che si stende da Alba a Costigliole d'Asti, con una ampiezza talora di 7 od 8 chilom., giacchè vi osserviamo i soliti caratteri litologici, paleontologici, orografici, ece. che si sono giả notati più avanti; 
così pure vi si verifica il graduatissimo passaggio tra questo orizzonte e l'Elveziano superiore, colle solite incertezze di delimitazione.

L'inclinazione degli strati è assai regolare verso il Nord-Nord-Orest, di solo $6^{\circ}$ od $8^{\circ}$ ed anche minore nella parte superiore della serie.

Sempre relativamente facile è la divisione del Tortoniano dal NLessiniano, spesso anche solo coll'esame orografico, per quella specie di gradino piủ o meno marcato che il sccondo orizzonte forma sul primo. Pcrò sembra che anche in questo passaggio, per quanto si tratti di terreni di natura assai distinta, non vi sia trasgressione stratigrafica, giacchè spesso il Tortoniano si chiude colle prime lenti gessifere che compaiono frammezzo ai suoi banchi marnosi superiori, o con un'alternanza di banchi marnosi con banchi sabbiosi.

Nelle colline di Costigliole d'Asti, a causa del rapido rivolgimento ad Est che presenta l'orizzonte messiniano, la zona tortoniana si ristringe di molto pur comparendo ancora a tratti, sotto alla placea messiniana, nelle incisioni che la intaceano piủ profondamente, cosi nclle parti alte di Val Merza, di Val Bragna, di Tal Repulento, di Val Pontiselli, ece.

In vcrità però queste aree tortoniane sono spesso di difficile delimitazione a causa della regetazione e delle poche erosioni naturali.

Nci banchi di passaggio tra Elveziano e Tortoniano ossertansi talora disturbi stratigrafici locali, cosi ad esempio presso C. Taceaneo (borgata S. Martino), dove reggonsi gli strati inclinare persino di $30^{\circ}$ o $40^{\circ}$ verso Nord-Est, in causa di salti c scoscendimenti, perỏ parziali c quindi poco importanti.

La zona tortoniana, dopo abbandonata la Val Tanaro, si dirige ad Est, e conservando la sua facies prevalentemente marnosa, assieme ai caratteri generali che l'accompagnano, si ra gradatamente restringendo, mentre però nello stesso tempo i suoi banchi assumono un'inclinazione a Nord alquanto piủ scntita di prima, cioè di circa $15^{\circ}$.

Mentre i rapporti tra il Tortoniano ed il Messiniano pare si conscrvino abbastanza simili a quelli finora osservati ad Orest, sembra invece che si rada accentuando una certa trasgressione tra il Tortoniano e l'Etreziano come si puỏ giả ricavare da aleune discordanze stratigrafiche nei banchi di passaggio tra i duc olizzonti, cosi nelle colline di Calosso, di Canclli, alle Case Vechic presso gli Asinari, ecc.

Nelle colline tra Val S. Gioranni (Talle del Tufo) e Tal Nizza il Tortoniano, con incerta separazione dal Messiniano (specialmeute tra Bric Giorgio e Val Nizza), presenta nella sua parte medio-supcriore una facies che a primo tratto lo fa confondere col Messiniano.

Vediamo infatti che nella parte alta della collina Bric Cappellana compaiono banchi sabbiosi i quali anche ai caratteri esterui ricordano 
le eolline messiniane. Coi depositi sabbiosi appaiono eziandio marne sabbiose più o meno dure, straterellate, riechissime in fossili, specialmente in Pesei, Crostacei, filliti, ece., come si può ad esempio osservare assai bene presso la C. Villa bassa e la C. Masearino.

Abbiamo eioè nuovamente a eonstatare in questa regione il fatto, già osservato presto il Castello della Volta (Barolo), ehe una parte del Tortoniano presenta una facies sarmatiana.

Ad Est di Val Nizza vediamo che il Tortoniano, conservando la sua solita facies marnosa, si va gradatamente restringendo, mentre si aceentua la sua trasgressione coi terreni sopra e sottostanti, benchè in verità questa trasgressione sia eosi regolare che riesce scmpre abbastanza graduale il suo passaggio, specialmente all'Elveziano.

Nelle colline di Alice Beleolle, pel grande sviluppo verso Sud ehe presenta la placea messiniana, la zona tortoniana visibile si riduec a pochi strati ed a poehi metri d'ampiezza, allargandosi alquanto tra le borgate Masino e Torrazza per la speciale posizione stratigrafica, cioè perehè essa costituisce una placea sul versante settentrionale delle colline di Bric della Guardia.

In val Bormida il Tortoniano si restringe di nuovo rapidamente; nelle colline ad Est di questa valle riappare solo più a striseie sottili, interrotte per lunghi tratti, sempre a causa specialmente del fatto ehe i banehi del Messiniano inferiore, essendo depositi di maremma o di littorale, ed inoltre più resistenti all'erosione, si sriluppano molto a Sud sopra ai depositi tortoniani, marnosi, di mare abbastanza profondo.

Nel rio della Baretta, a Nord di Montaldo Bormida, il Tortoniano è messo a nudo per oltre un ehilometro dalla profonda ineisione di detto torrente; quivi si osserva come nella sua parte superiore sianvi ciottoli sparsi fra le marne, quindi straterelli ciottolosi, poseia veri banehi ghiaioso-ciottolosi, i quali alternandosi colle marne tortoniane fanno passaggio al Messiniano inferiore, ehe in queste regioni è molto ricco in depositi ciottolosi.

In Val Stanavazzo il Tortoniano, ridotto a sottile striseia, è quasi ovunque coperto della vegetazione e solo osservasi in aleuni burroni presso C. Campogrande; le sue tipiche marne possonsi esaminare bene nell'ineassata valle di Rio Maggiore, trovandosi esse invece nell'ampia valle d'Orba quasi eompletamente eoperte dai depositi allurionali.

Ad Est di Val d'Orba la striseia tortoniana, nettamente esaminabile solo in piceoli tratti, come nelle vallette di Arbarolo e di Arbidosa, si va sempre più assottigliando, è appena discernibile a Nord del Cimitero di Castelletto d'Orba, ed infine nelle colline di S. Cristoforo viene maseherata dai potenti banchi arenaeeo-eonglomeratiei del Messiniano.

Sieeome le interruzioni della striseia tortoniana dipendono essen- 
zialmente dal grande avanzarsi dei terreni messiniani verso Sud nella parte elevata della regione collinosa, così è naturale che la profonda ineisione (di oltre 100 metri) del torrente Lemme abbia messo a nudo per breve tratto, al fondo di questa valle, le marne tortoniane.

Ma a eomineiare dalle colline di Gavi i varii orizzonti geologiei non sono più tanto sehiaceiati eome verifieasi nelle regioni ultimamente esaminate (in causa del noterole spingersi a Nord dei terreni preterziari dell'Appennino settentrionale), e quindi essi si possono sviluppare assai ampiamente, tanto più che si verifiea quivi una grande eurva che eostituisee il seno di Val Serivia.

É pereiò ehe noi vediamo anche la zona tortoniana riapparire alle falde meridionali del M. Mesma, ed allargarsi poeo a poeo verso Est tanto da ragginugere la larghezza di quasi un ehilometro. La sua costituzione è essenzialmente marnosa.

Riesce abbastanza faeile la distinzione del Tortoniano dal Messiniano per la differenza litologiea, ehe è naturalmente aecompagnata quasi sempre da caratteri orografiei; invece vi si osserva un graduale passaggio litologieo e paleontologico all'Elreziano superiore per modo ehe la delimitazione riesee molto incerta ed arbitraria.

Ad Est di Val Serivia, dove un forte gradino separa il Messiniano dal Tortoniano, questo terreno si sviluppa notevolissimamente ed assume earatteri litologiei e paleontologici speciali, assai importanti.

Vediamo infatti ehe nella parte media e medio-inferiore della seric tortoniance eompaiono, assieme ai banehi marnosi, non solo quei banehi sabbiosi o sabbioso-arenacei che formano il solito passaggio alla seric elveziana, ma cziandio banehi arenaeeo-eiottolosi, ad elementi talora abbastanza considerevoli, generalmente eostituiti di quelle roeeie eoeeniche (caleari, caleari arenacei, assai di rado serpentine) che formano gran parte della vieina eatena appenniniea.

Sovente i depositi eiottolosi eostituiseono non veri banehi ma sempliei lenti più o meno sviluppate; eosi percorrendo la parte bassa del rio di Vargo, speeialmente nelle vieinanze della confluenza del rio C. Verno, si vede assai bene eome le tipiehe marne argillose azzurrastre del Tortoniano, ehe ad Ovest presentano solo in alto aleune alternanze di banchi arenaeci, rerso Est inveee passino rapidamente a banchi arenaceo-conglomeratiei mentre le marne scompaiono quasi eompletamente, rimanendo solo più aleuni strati marnosi grigio-azzurrastri tra i potenti banehi arenaeei ehe costituiscono l'imbasamento di Vargo.

Nel Tortoniano inferiore si possono esaminare questi banchi o lenti eiottolose nelle eolline di Villa Castelletto, di C. Iola, di C. dell'Asse, di Poggio Forehe, lungo gran parte della valle di Rio Vargo, presso C. Basalini, eee., eome pure fra i banehi basali del Tortoniano nelle 
colline di Masseria Bosehetto, di C. Carlini, di Masseria Baiardo, di C. Campolungo, di Masseria Boseo e di Vargo. Questi banchi sabbiosoghiaioso-conglomeratici del Tortoniano inferiore, quando si trovano a costituire la parte alta delle colline, assumono generalmente un color rossastro per decomposizione, tatto d'altronde che osservasi in quasi tutti i conglomerati esposti per lungo tempo ag:i agenti esterni.

Nel Tortoniano medio esiste una lente di grossi ciottoloni sotto Masseria Zegna, e sottili lenti di ciottolini presso Cuquello.

Nelle colline di Masseria Traghetto, di C. Ronco, di Cuquello, ece., sono assai sviluppate certe marne sabbiose giallastre, straterellate, abbastanza caratteristiche che ricordano alquanto quelle a fauna sarmatiana che gia notammo presso la Morra, presso Nizza Monferrato, ece.

A Nord di Cuquello non incontransi più notevoli lenti ciottolose fia le marne del Tortoniano e si può quindi considerare la sovraccennata facies ciottolosa di questo orizzonte geologico come affatto locale, in relazione colla foce di una corrente terrestre che già in quell'epoca preludiava all'attuale Scrivia; d'altronde i fenomeni litologici sono anche conservati dai dati paleontologici che ci mostrano non rari i fossili di acqua salmastra come Melania, Melanopsis, Potamides, cce. commisti coi tipici fossili marini del Tortoniano.

Sta certamente in relazione con questa facies di foce o di mare poco profondo, in cui venivano talora fluitati materiali grossolani, quella straordinaria ricchezza in fossili che rese famose queste colline, conosciute generalmente col nome di colline di Stazzano; esse sono solcate da profondi burroni, dove più facile è la raccolta dei fossili ehe trovansi generalmente ammucchiati in lenti frammezzo a ghiaie e ciottoli; questo fatto che già constatammo altrove, specialmente trattando dei fossili elveziani dei colli torinesi, ci indica come probabilmente la subitanea fluitazione di materiali grossolani fu causa della molte degli animali che vivevano in quel mare c del conseguente accumulo delle loro parti fossilizzabili.

Fra le valli di questa regione piủ note ai paleontologi è specialmente da menzionarsi quella di Armarengo (Bocea d'Asino) tra Monterosso e Poggio Forche; infatti nelle sue molteplici ramificazioni quasi ovunque, sia in posto che negli scoscendimenti e fra le alluvioni del torrente, s'incontrano abbondanti resti di quella famosa fauna di Tortona che serve di mirabile collegamento tra quella elveziana e quella piacenziana.

Meno abbondanti, quantunque non scarsi, sono pure i fossili sia nel Tortoniano inferiore di Val di Vargo, sia nel Tortoniano medio e superiore di Monterosso, di Sardigliano e di Cuquello.

Il trovarsi le lenti ciottolose specialmente nella parte inferiore e media del Tortoniano di Stazzano, e l'incontrarsi fra tali ciottoli solo șcạ- 
sissimi elementi serpentinosi, sono fatti che contraddicono assolutamente alle idce del Mayer, il quale stabili pel Tortoniano superiore l'orizzonte Stazzaniano, basandolo sul fenomeno affatto locale sorraccennato che esso crede derivi da un cono sottomarino di Serpentina.

Nei dintorni di Vargo, specialmente dirigcndoci rerso Costa Ginepro, si osserva come i banchi arenacco-marnosi (con lenti ciottolose) del Tortoniano inferiore passino a banchi arenaceo-sabbiosi, inglobanti pure lenti ciottolose, dell'Elveziano superiore, il che ci indica come già rer'so la fine di quest'ultimo periodo cominciassero a presentar'si nelle regioni ora in esame quelle speciali correnti aequee che quivi in seguito diedero ai depositi tortoniani la particolare facies sorraccennata.

Preseguendo l'esame della zona tortoniana verso Nord, vediamo come essa, con una potenza scmpre considerevole, sia costituita di marne sabbiose grigio-bleuastre, generalmente poco coerenti; ne deriva che le colline che ne sono costituite si presentano ben spesso solcate da profondi burroxi, franosi, continuamente mutevoli di forma e che formano regioni preziose per raccoglierc fossili. Basti accennare a questo proposito, i profondi ed intricati burroni di Rio dei Piaggi, di. Rio Vastantina, ece., nelle vicinanze di S. Agata, paese che appuntu per tale straordinaria abbondanza, in fos,ili tortoniani fu distinto da altri paesi dello stesso nome coll'appellativo di S. Agata Fossiti.

Se si esamina il Tortoniano inferiore si vede che i fossili direngono meno frequenti e che colle marne si alternano strati c banchi sabbiosi ed anche arenacei; questi col divenir sempre più frequenti passano gradatamente alla serie predominantemente arenacea che rappresenta l'Elveziano supcriore.

Nel Tortoniano superiore le marne si distinguono per una g'rande ricchezza in fossili, fra cui numerose sono le forme d'acqua salmastra, Melania, Melanopsis, Peringia, Potamides, ece, che ci indicano anche in questo caso un passaggio abbastanza graduale tra il Tortoniano edil Messiniano; ed infatti se taloria non riesce difficile la loro delimitazione, anche solo coll'esame orografico (per costituire le marne gessifere o calcaree od arenacee del Messiniano una specie di leggero gradino sulle marne pỉ̉ o meno farinose del Tortoniano), spesso però possiamo constatare che fra i superiori banchi marnosi di quest'ultimo orizzonte compaiono qua e la lenti calcaree che preludiano a quelle messiniane, rimanendo così incerta la divisione dei due piani geologici, come ad escmpio si puó osservare discendendo da S. Agata al Molino di Castellania.

L'inclinazione dei banchi tortoniani è di circa $15^{\circ}$ a $20^{\circ}$ nella parte inferiore della serie e diventa sempre piủ debole nella parte supcriore, tanto che talora, per fenomeni di crosione, vediamo comparire per 
breve tratto le marne tortoniane entro la zona messiniana, eome ad esempio nel torrente Rile poeo a Nord della sorgente sulfurea.

A Nord delle famose eolline di S. Agata fossili la zona tortoniana continua a mostrarsi ampia, potente e tipiea; nei profondissimi, larghi e franosi burroni delle eolline di S. Allosio eontinuano a trovarsi abbondanti i fossili; quivi però non vemnero finora quasi mai raeeolti per esser queste regioni poeo eomode a pereorrersi.

Nei dintorni di Costa Vescovato il Tortoniano, ehe eome tutti gli altri orizzonti di questa regione si volge ad Ovest per l'emersione della ruga liguriana di Brignano-Spinola, si va pure gradatamente restringendo, mentre nello stesso tempo si aeeentua sempre piul la trasgressione stratigrafica esistente fra esso ed i terreni fra eui è eompreso; infatti per l'assottigliarsi e lo seomparire dei vari piani pretortoniani, vediamo i banehi inferiori della zona tortoniana appoggiarsi direttamente sul Langhiano e, più ad Ovest, sullo stesso Liguriano.

Anehe nel Tortonimo superiore osserviamo eome esso venga rieoperto sempre più trasgressivamente dai banehi basali del Messiniano, finehè le marne tortoniane, sempre abbastanza rieche in fossili, vieppiu assottigliandosi, scompaiono completamente nelle eolline di Paderna, sotto ai terreni più reeenti.

Nella restante parte dei eolli tortonesi in esame non osservasi piu aleuna eomparsa di zona tortoniana, la quale però riappare tosto poeo più ad Est, nel vogherese.

Passando all'esame delle eolline Torino-Valenza vediamo eome già nella loro parte più orientale eompaiano e sviluppinsi ampiamente le formazioni tortoniane in eausa di una ruga assai forte ehe quivi si verifiea. In questa regione il Tortoniuno è, eome di solito, rappresentato essenzialmenie da marne grigio-bleuastre talora eompatte, a frattura quasi eoneoide, talora inveee (speeialmente nella parte basale dell'orizzonte) straterellate, fogliettate. In ambedue i easi questo deposito è in generale abbastanza rieeo in fossili; nelle marne eompatte ehe possonsi stupendamente esaminare lungo la sponda sinistra del Tanaro, da Pietramarazzi a Nonteeastello, raeeolgonsi numerosi fossili tipiei, simili a quelli di Stazzano e di S. Agata; inveee nelle marne fogliettate si trovano piuttosto eommi le impronte di filliti, di Pesei cee., eioè la fauna della facies sarmatiana.

Gli affioramenti tortoniani di queste regioni sono essenzialmente tre, eioè due ad Est ed uno ad Orest del eorrugamento liguriano. Ampia ma molto irregolare è la zona fortoniana Pietramarazzi-S. Zeno, la quale presenta i suoi strati inelinati di eirea $20^{\circ}$ verso l'Est ad un dipresso; sotto Pietramarazzi però l'inelinazione delle marne fogliettate è di quasi $30^{\circ}$ verso l'Est-Nord-Est. Questa zona si appoggia ad Ovest 
sui terreni tongriani od anche direttamente su quelli liguriani, e sopporta invece ad Est ed a Nord i banchi marnosi, sabbiosi ed anche ghiaiosi del Messiniano; però tali passaggi spesso si possono solo intravvedere a causa del gran sriluppo dell'agricoltura in queste regioni. A Nord di Montecastello le marne tortoniane vengono licoperte direttamente dalle marne argillose del Piaceñiano i eui fossili numerosi e tipici raccolgonsi lungo la sponda sinistra del Tanaro.

La seconda zona tortoniana non è altro che la continuazione settentrionale di quella di prima, da cui è solo interrotta per una specie di curiosissimo golfo o braceio che il Messiniano forma da Est ad Ovest sin contro il Liguriano; questa zona tortoniana è abbastanza regolare; essa si sviluppa da Est ad Orest all'incirca ed i suoi strati pendono di una ventina di gradi verso il Sud in media, solo che nella parte occidentale prevale la pendenza a Sud-Est, perchè quiri il Tortoniano appoggiasi direttanente ad Orest sul Liguriano: la pendenza degli strati diventa gencralmente meno forte nel passaggio all'Elceziano tanto che in alcuni punti, come verso il Bric Castellar, i banchi si presentano appena inclinati.

Questi depositi tortoniani vengono regolarmente ricoperti a Sud dal Messiniano, mentre che a Nord essi sovrappongonsi, pure regolarissimamcnte, alle compatte marne elveaiane. Il passaggio fra il Tortoniano e l'Etveziano è quasi sempre insensibile per le solite alternanze di marne più o meno compatte. Anche assai graduale è il passagrgio del Tortoniano al Messiniano. Infatti in questa zona la parte superiore del Tortoniano (come si può magnificamente osserrare ad esempio salendo dalla valle delle Redini al Bric Osnara lungo la strada di C. Varnera) si presenta costituita in gran parte di marne, più o meno sabbiose, foglicttate, racchiudenti filliti, resti di Pesce, ecc., cioè la fauna samatiana che già avemmo più volte occasione di osservare altrove; orbene queste marne straterellate presentano pure spesso la facies messiniana ed anzi passano gradatissimamente a quest'ultimo orizzonte gcologico per mezzo di marne argillose brumastre; ma anche in questo caso $i$ suddetti passaggi sono resi molto incerti per il velo di terreno vegetale che in gran parte maschera le formazioni terziarie.

La zona tortomiana più oceidentale si sriluppa spccialmente da Sud a Nord per circa 5 chilom.; la sua costituzione è simile a quella accennata per le altre duc zone, cioè essa consta di marne grigio-bleuastre talora argillose e marne sabbiose, fogliettate, fossilifere; queste ultime osservansi specialmente presso Villa Vittoria, dove è caratteristica la facies samatiana; l'inclinazione degli strati è di $20^{\circ}$ a $25^{\circ}$ verso Ovest, almeno nella parte meridionale della zona, giacchè nella parte orientale la tettonica si modifica alquanto; infatti, invece d'una semplice 
gamba di anticlinale diretta Nord-Sud, si inizia nella parte settentrionale un'anticlinale, ad arco dolcissimo, dirctta ad un dipresso da Est ad Ovest, c che costituisce appunto l'inizio della ruga terzirria TorinoValenza.

Questi depositi lor foniani appoggiansi direttanente ed alquanto trasgressivamente sul Tomgriano a Sud-Est e sul Liguriano a Nord-Est; essi sono poi ricoperti abbastanza regolarmente verso Ovest dai terroni messiminni, da cui anzi non c̀ sempre facile scpararli appunto per la gradualita di tale passaggio; è pure difificile molto il delimitare lo sviluppo del Tortoniano ad Ovest di Bric Voina.

In tutte queste regioni, come di solito, i caratteri orografici trovansi in stretta relazione colla natura geologica.

L'anticlinale che costituisce i colli in esame prescnta un arco cosi debole che vi aftiorano solo i tcr'reni messiniani; però presso S. Salvatore questo arco si accentua maggiormente per modo che vi appaiono anche le marne grigio-bleuastre del Tortoniano. Nelle colline di S. Salvatore le marne tortonirme pendono di $20^{\circ}$ o $25^{\circ}$ a Sud-Est circa; verso C. Galletto tale pendenzi è solo più di pochi gradi, con legricrc ondulazioni; di qui a borgata Valdolenza il Tortoniano forma anticlinale poichè i suoi strati divengono quasi orizzontali, poscia, formata la volta stratigrafica, pendono leggermente a Nord eirca.

Anche in queste regioni il passaggio dal T'ortoniano al Messiniano si compie graduatissimamente c quindi ne è alquanto arbitraria la delimitazione.

Più ad Ovest appaiono i terreni olifocenici, ma siccome contro essi vanno ad appoggiarsi direttamente i depositi messiniani, cosi la formazione tortoniana rimane mascherata per lungo tratto, apparendo solo a striscie più ad Ovest come vedremo. In queste regioni più ancora che altrove la coltivazione maschera in massima parte la natura geologica del tcrleno che lc costituisce.

Sul lato Nord dell'asse principale di sollevamento delle colline Tolino-Casale esistono in due sole regioni, nelle colline casalesi, gli indizi di affioramento dei terreni tor loniani cioè nelle vicinanze di Conzano e di Rosignano. Infatti sulle marne arenace dell'Elve ziuno di Conzano c tra esse c lc marne calcarifcre messiniane, veggonsi comparire, ad Est del suddetto pacse, banchi mamosi grigio-bleuastri ehe, pel quanto non mi abbiano mostrato fossili caratteristici, pure considero come rapprescntanti la zona tomoniana; questa limane coperta a Nord dai depositi piacenziani mentre scompare rapidamente a Sud per la compressione prodotta dall'affioramento dei terreni liguriani.

Qualche cosi di consimile possiamo osservare nelle colline a Sud di Rosignano, tra Terruggia e Cellamonte ad un dipresso; quivi infatti 
rediamo per un certo tratto che, tra le marne piì o meno calcarifere del Wessiniano e le marne sabbioso-arenacee dell'Elie:iano, compaiono, specialmente presso il Castello di UTiglie, banchi marnosi grigiobleuastri che sono probabilmente attribuibili al Tortoniano, per quanto non ri abbia ancora potuto raccogliere fossili caratteristici. Lungo tutta la restante falda settentrionale delle colline Torino-Talenza non abbiamo piu a constatare in alcun punto l'affioramento della zona 10 r $^{2}$ toniana, che trotasi completamente coperta dai terreni quaternari della pianura padana.

Se inrece passiamo all'esame del rersante meridionale dei colli Torino-Talenza, troviamo che ben diverso e ben più importante è lo sriluppo dei terreni tortoniani.

Li rediamo infatti apparire in forma di stretta zona marnoso-sabbiosa, grigiastra, nelle colline di Cuccaro Monferrato e svilupparsi per lungo tratto rerso Orest come piccola fascia, con stratificazione abbastanza regolare rer'so Sud, ma con pendenza piuttosto forte.

Ma poco dopo attraversata la valle di Grana, non esistendo più nelle ricinanze affioramenti ligmioni che alterino l'andamento stratigrafico dei terreni miocenici, rediamo che la zona fortoniana (indicata anche orograficamente da larghe ralli e da basse eolline rotondéggianti) tosto si aliarga noterolissimamento, mentre nello stesso tempo i suoi banchi, specialmente marnosi, tipici, assumono una pendenza assai più dolce di prima.

Nelle colline ad Orest di Tignale rerificandosi forti discordanze stratigrafiche nei terreni oligoeenici ed eleciani ne dobbiamo pure eonstatare, direi, il contraccolpo nella zona tortoniona la quale si ra restringendo, mentre i stoi strati assumono talora inclinazioni abbastanza noteroli. sempre però regolari, rerso il Sud cirea.

Contuttociu i terreni tortoniani conselvano sempre uno stiluppo abbastanza noterole, anzi a Nord di Monealro raggiungono anche un ampiezza di oltre un chilometro; ma in seguito rapidanente essi si l'estringono ineurrandosi a C, e rengono a scomparire completamente contro l'aftioramento tongriano di Alfiano Natta.

$\dot{E}$ anzi a notar'si a questo riguardo eone la disposizione stratigrafica dei banchi del Tortoniano ci dimostri chiaramente come durante tale periodo si cra gia nettamente aceentuata l"elissoide di solleramento che diede origine alle colline tongriane di Alfiano-Villadeati, per modo che esistera un piccolo seno tra tale elissoide e quella principale di Ottiglio-ILontalero.

Questo seno si ̀̀ riempito solo poco a poco durante il periodo miocenico postelceziano e durante il periodo pliocenico; ne risulta chiaro il tatto che in questa regione, come d'altronde abbastanza general- 
mente, dopo un potente movimento sismico verifieatosi sullat tine del periodo elvesiano, non abbiamo più a constatare notevoli fenomeni di questo genere sino alla fine del periodo astiano, poichè vediamo i terreni astiani costituire ancora la parte centrale del piceolo seno in questione.

E interessante la costituzione geologica di questo scno di Moncalvo, poichè noi vi possiamo constatare, riprodotto in miniaturia, direi, ciù ehe in grande osservasi nell'intiero bacino terziario del Piemonte.

Quanto ai rapporti della formazione tortoniana ora esaminata coi terreni sopra e sottostanti, essi sono assai vari nelle varie regioni; in generale si può dire che le trasgressioni stratigrafiche divengono piuttosto forti là dove la zona fortoniuna si restringe di molto, ma in generale invece si osserva un passaggio abbastanza graduale, specialmente tra Tortoniano ed Eleesiano, poichè i banchi prevaluntmente marnosi del primo divengono poeo a poco più compatti, più resistenti, più arenaceo-calcarei, finchè passano insensibilmente ai banchi previllentemente calcareo-arenacei del secondo, senza che sia possibile delimitarli nettamente; ciò velificasi specialmente nelle colline tra Ottiglio e borgata Cosso; anche in questo caso l'orografia aiuta alquanto il geologo nel tracciare questi limiti tra piano e piano, poichè vediamo che la formazione tortonirma costituisce in complesso colline assai più basse di quelle elveziane.

Sparso fra le marne tortoniane pare si trovi cziandio talora Cloruro di Sodio poichè vediamo che in questa zona esistono sorgenti salate, fra cui più notevole quella di C. Milano tra Vignale ed Olivola; d'altronde tale fatto non è nuovo pel Piemonte, verificandosi anche in alcuni punti del Monferrato, pure entro la zona tortoniana.

Se nella parte orientale dell'elissoide tongriana di Alfiano scompare completamente la zona tortoniana sotto al Messiniano (che si spinge con trasgressione evidentissima sin contro le colline tongriane), invece al Molino Bizara vediamo comparire tra il Messiniano ed il Tongriano (con fortissima trasgressione stratigrafica rispetto a quest'ultimo) le marne tortoniane le quali, come sottile striscia, si dirigono ver'so NordOrest, cingendo alla base le colline tongriane, finchè, sempre piủ compresse e fortemente sollevate, vengono di nuovo a scomparire completamente nelle colline di Cardona.

Però poco a Nord-Ovest, nelle vicinanze di Murisengo, scomparendo quivi l'elissoide tongriana e quindi l'andamento stratigrafico dei terreni divenendo più regolare, vediamo che non solo riappare la zona marnosa tortoniana, ma essa tosto si va sviluppando, costituisce, coll'ampiezza di oltre $1 / 2$ chilom., un certo tratto del fondo di Val Stura (ciỏ che ne spiega l'ampiezza in questo punto), quindi le colline di Tuffo 
(nome derivato appunto dalli natura eminentemente mamosa di tali colline), tinchè si restringe nuovamente verso Cocconato in causa dell'affioramento liguriano che colà esiste.

In tutto questo tratto noi vediamo come di solito un insensibile passaggio tra i terreni elvesiani marnoso arenacei e quelli tor\%oniani più marnosi, meno compatti, meno calcarei, più biancheggianti, ece. Invece per quanto sia pure piuttosto graduale il passaggio tra Tortoniano e Itessiniano, tuttaria la loro delimitazione riesce meno arbitraria a causa della loro natura litologica abbastanza dirersa.

In causa dell'afíoramento ligurano di Marmorito tutti i terreni ad esso circostanti rimangono fortemente ridotti di larghezza, compressi ed inclinati; cosi anche la zona fortonimna ad Orest del rio di Fabiasco è ridotta ad una sottilissima striscia, appena constatabile, che nella parte superiore delle colline costituisce piccoli colli, per la sua natura eminentemente marnosa.

Gia nelle vicinanze di Tetti Borelli i depositi fortoniani divengono alquanto sabbiosi, ed inglobano numerosi fossili tipici, abbastanza ben conserrati e molto simili a quelli delle famose localita del Tortonese; oltre però alle note sabbie marnose di Tetti Borelli si possono trovare nel terreno fortoniano di queste regioni molte altre localita fossilifere, solo che la coltivazione è di grave intoppo a queste ricerche, tant' è che i punti che furono alcuni anni or sono molto fruttiferi per le raccolte paleontologiche ora sono coperti dalla regetazione pratense.

Na specialmente noterole è il fatto che il Tormoniano medio ed inferiore si presenta quivi in massima parte costituito di banchi sabbiosi con lenti od interstrati ghiaiosi e ciottolosi, talora anche a grossi elementi; questi banchi inclinano di circa $20^{\circ}$ a $25^{\circ}$ ver'so Sud in media, sono talora riccamente fossiliferi: anzi è appunto la natura dei fossili che fa si che detti depositi si debbano riportare al Tortoniano piuttosto che non all'Elreziano come indicherebbe la natura del terreno. Le colline di Moneuceo somo tipiche a questo riguardo; vi è facile la raccolta dei fossili; questi però non presentano la tipica fucies tor toniana, che sarebbe una facies di tranquillo deposito marino, ma bensi una fucies di fauna littoranea; sotto questo rispetto le regioni in esame sono assai interessanti permettendoci di completare le conoscenze malacologiche delle varie zone batimetriche del mare tortoniano.

Nelle colline di Bric S. Paolo colle sabbie si alternano marne argillose bleuastre racchindenti la tipica fauna forfoniana; più a Nord si passa insensibilmente ai depositi dell'Elceziano superiore che si inizia per lo più qui, come piủ ad Orest, con sabbie e marne arenacee grigie, compatte.

Verso Ovest la zona tortoniana ripresentasi prevalentemente mar- 
nosa, quantunque osservinsi ancora diversi banchi sabbiosi, fossiliferi, specialmente presso borgata Rivalta. Il grande sviluppo dei depositi marnosi ei spiega la forma rotondeggiante e la poea elevazione delle colline di C. Briceo, C. Grisella, C. Canarasso ece.

Ma rerso Avuglione e Marentino la zona tortoniana offre ancora un notevole sviluppo di depositi sabbiosi, arenacei con lenti più o meno estese di ghiaie e di conglomerati; questo fatto si può osscrvare in numerosi tagli sia naturali che artificiali nelle colline su eni siedono i due paeselli sovracitati; qua e là vennero eziandio attivate cave per l'estrazione dei eiottoli agglomerati sporadieamente in diversi punti.

Nelle colline di Villa Majolo però si sviluppano le marne argillose grigio-bleuastre, colla facies tipica del Tortoniano, e racchindenti pure numerosi fossili molto simili a quelli della fimosa fauna tomtoniana di S. Agata e di Stazzano. Quivi, come sempre, e graduatissimo erl incerto il passaggio tra il Tor toniano inferiore e l'Elveziano superiore; tale passaggio si compie per mezzo di sabbic ghiaiose fossilifere appoggiantisi a marne sabbiose, compatte, grigiastre.

Verso Montaldo la facies sabbioso-arenacea del T'ortoniano si limita alla parte inferiore di questo piano, eostituendo le colline su eui siede il paese di Montaldo; numerosi fossili possonsi quivi raccogliere verso la base del Torfoniano poco a Sud dei Tetti Gaiotto.

In conclusione dobbiamo constatare nel Tortoniano delle colline esaminate qualche cosa di simile a quanto goì indicammo pel' le famose colline tortonesi, cioè uno stiluppo locale di fucies littoranca frammezzo ai soliti tranquilli depositi marini.

L'inclinazione degli strati tortoniani della zona ultimamente esaminata varia dai $15^{\circ}$ ai $20^{\circ}$ eirea.

Ad Ovest di Marentino le marme tortoniane si allargano noterolmente e molto rapidamente, eiò che sempre più ci conferma nell'ipotesi che i banchi sabbioso-ciottolosi di Marentino-Moneuceo siano cla considerarsi come una facies locale littoranea (pseudn-elveziana) del Tortoniano, eome si ̀̀ gia osservato nelle colline di Vargo nel tortonese.

Da Marentino a Pecetto la zona lortomiana, essenzialmente marnosa, però con interbanchi sabbiosi, si presenta assai sviluppata, cioè di oltre un chilom. d'ampiezza in media; $\mathrm{i}$ fossili non vi sono abbondanti; la marna è piuttosto dura, a rottura per lo più concoide; i banehi inelinano regolarmente di cirea $15^{\circ}$ verso il Sud-Est.

Esiste sempre un passaggio graduatissimo, quasi insensibile, dal Tor toniano inferiore all'Elve:iano superiore e quindi affatto arbitraria ne risnlta la loro netta delimitazione.

Quanto alla divisione del Tortomiano dal Messiniano, venendo a maneare in quest'ultimo orizzonte le leuti gessose e calcarce, essa di- 
venta diffieilissima, sia perehè non sempre le marne dei due piani presentano grandi differenze fra loro, sia specialmente perehẻ il loess e la vegetazione mascherano quasi completamente le formazioni terziarie, ed anehe là dove queste sono visibili, esse per lo piu si presentano così profondamente alterate ehe riesee ben di rado di poterne rieonoscere i primitivi earatteri e quindi il piano di eui fanno parte. E quindi solo eon pochi dati ehe, per quanto abbia eereato, potei tracciare l'andamento generale della linea di divisione tra il Tortoniano ed il Messiniano: altri dati potranno alquanto modificarla.

In ultimo ad Ovest di Peeetto la zona toitoniana si ra gradatamente restringendo, finchè, eoll'ampiezza di eirea ${ }_{2}^{1}$ ehilometro essa ra a seomparire eompletamente sotto ai terreni quaternari della pianura padana.

\section{Rialssunto.}

Rieapitolando eiò ehe si è esposto rispetto ai terreni tortoniani del Piemonte, dobbiamo anzitutto dire eome essi, indicati generalmente eol nome di Miocene superine, erano finora quasi solo eonoseinti nell'angolo Sud-Est del bacino terziario in esame.

L'orizzonte tortoniano lappresenta essenzialmente una formazione piuttosto tranquilla di un mare abbastanza profondo lentamente sollevantesi, ed è quindi eastituito prineipalmente da marne grigio-bleuastre; è solo localmente, ed in pochi easi, che i banehi marnosi si alternano e si fiammischiano eon arenarie, ghiaie ed anche conglomerati, oppure che compaiono nella parte medio-superiore del Tortomiano marne e sabbie straterellate le quali pei fossili ehe racehiudono paiono rappresentare la fucies samatiana.

Il Tortoniano eostituisee, nella parte settentrionale del baeino piemontese, una specie di zona più o meno ampia, raramente interrotta; invece esso è generalmente assai più ridotto nella parte meridionale. delle colline Torino-Talenza ed affiora appena in due punti nella parte settentrionale delle suddette eolline.

L'andamento stratigrafieo della formazione tortoniana è piuttosto regolare; pochi sono ed affatto loeali i disturbi stratigrafiei; la pendenza, raramente di oltre $15^{\circ}$ o $20^{\circ}$, è diretta rerso il eentro del baeino; si puỏ dedurre dall'assieme del modo di presentarsi dei terreni tortoniani, come essi siansi deposti dopo arvenuto il potentissimo morimento sismico ehe delineò l'oroidrografia della catena alpino-appenniniea e eagionò in gran parte il eorrugamento delle colline torinesi.

Quantunque il Tortomiano sia generalmente di poea potenza, per lo più dello spessore di eirea 100 o 200 metri, talora però esso assume una potenza di 400 e forse anehe di 500 inetri. 
Per essere essenzialmente marnosa e per non presentarsi in alcun punto appoggiata alle falde alpine od appenniniche, la formazione tortoniana del Piemonte non si presenta spinta a grand'altezza, in pochissimi punti a quasi 500 metri.

In generale si osserva nel Tomoniano, eome in quasi tutti gli altri orizzonti terziari del Piemonte, un graduale pessaggio ai piani genlogiei sopra e sottostanti; in aleuni punti però esiste una trasgrressiono più o meno evidente che separa questo orizzonte da quelli soprastanti, ma speeialmente da quelli ehe gli stanno sotto; questo fatto in gran parte è preeisamente in rapporto eol fatto aecennato del forte movimento sismico verifieatosi prima dell'inizio del periodo tortoniuno.

La fauna tortomiana del Piemonte è essenzialmente marina, generalmente non molto rieea, in alcune regioni però straordinariamente eopiosa eome nelle eolline tortonesi ed in alcuni punti delle eolline torinesi. Questa fauna serve di mirabile anello di eollegamento tra la fauna elvesiona e quella piacensiana, avendo earatteri dell'una e dell'altra, oltre a presentare molti earatteri proprî.

Talvolta eoi fossili marini, oppure in banehi speeiali, speeialmente nel Tortoniano superiore, trovansi pure fossili d'aequa salmastra ehe preludiano alla fauna essenzialmente maremmana del Messinictno. 


\section{CAPITOLO XIII.}

MESSINIANO.

\section{Studi anteriori.}

A causa prineipalmente delle formazioni gessifere inglobate nell'orizzonte messiniano, rediamo che diversi autori ebbero gia piủ rolte ad oceuparsi della sua costituzione geologica; del Sismonda ma specialmente del Pareto troviamo infatti direrse pubblicazioni in cui si accenna ai depositi gessosi ed ai terreni flurio-marini che si comprendono ora col nome di terreni messiniani. Tali lavori però riguardano specialmente le colline tortonesi; solo rediamo nella carta geologiea del Sismonda come esso indichi colla lettera or i principali affioramenti gessosi messiniani che egli raceliude nel Miocene superiore, opinione divisa pure dal Gastaldi, mentre invece il Pareto costituisce dei depositi messiniani, assieme con quelli tortoniani, la base del Pliocene.

$\dot{E}$ il Mayer il primo geologo che, studiando la regione Nord-Est del bacino terziario piemontese, seppe indiridualizzare la formazione eminentemente maremmana del Iressiniano, sciogliendo così la questione, in altro moclo insolubile, se questi depositi appartengano piuttosto al Miocene che al Pliocene.

Nella recente carta geologica delle Riviere liguri e delle Alpi Marittime di Issel, Mazzuoli e Zaccagua, i terreni messiniani, considerati come Miocene superiore, appaiono appena per breve tratto, ma ne è affatto elronea la delimitazione.

Due anni ol sono descrissi l'andamento e la costituzione della zona messiniana attraverso a tutta la parte meridionale del bacino terziario piemontese, da Mondovi a Tortona; credo anzi opportuno di rimandare eziandio a quel lavoro, a cui somo minite otto sezioni geologiche, chi ruole oceuparsi del Messiniano del Piemonte. Di questo stesso terreno ebbi ancora a trattare più o meno diffusamente in diversi larori di descrizioni geologiche locali.

\section{Generalità.}

Il Messiniano costituisce nella serie terziaria piemontese uno degli orizzonti meglio individualizzati sia dal lato palcontologico che dal lato litologico; complessivamente si può definire una formazione maremmana.

Vediamo infatti essere esso costituito da depositi marnosi raceliudenti spesso una fauna d'aequa salmastra e lenti più o meno vaste e 
potenti di Gessi e di Calcari, e ciò in quasi tutto lo sviluppo della zona messiniana.

Si osservano inoltre sottilissime lenti di Zolfo inglobate nel Gesso, là dove questo minerale si presenta in ammassi più potenti, cosi nelle colline della Morra, di Alice, di Carezzano, ece.

Inoltre nella costituzione dell'orizzonte in questione appaiono pure numerosi banchi, talora potentissimi, di sabbie, di arenaric e di conglomerati che ci indicano depositi di foce.

Sono pure caratteristiche certe marne sabbiose straterellatc, grigiastre o giallastie, che compaiono spesso nclla serie messiniana e che spesso sono assai riccamente fossilifere.

Il colore della formazione messiniana non è generalmente caratteristico; dobbiamo tuttavia a questo proposito menzionare anzitutto come talora le marne di questo orizzonte abbiano una leggera tinta grigioverdastra che raramente si incontra altrove, e specialmente come spesso vi si osservino strati marnosi nerastri, carboniosi, che costituiscono quasi una specialità del Messiniano e che, per essere facilmente reperibili, sono sempre molto utili al geologo per riconoscere questo terreno.

Notiamo infine come per la sua natura litologica, specialmente là ove è arcnaceo, o calcareo, o gessifero, il Messiniano si differenzia spesso anche nei caratteri esterni dagli orizzonti fra cui è compreso, in particolar modo dal sottostante Tortoniano sul quale forma sovente una specie di gradino più o meno fortc.

Generalmente si può dire che in Pienonte il Messiniano è alla base specialmente sabbioso-ghiaioso e nella parte superiore cssenzialmente marnoso; le lenti calcareo-gessifere si trovano specialmente vcrso la base del Messiniono nella parte Sud del bacino, ed invece specialmente nella sua porzione media nella parte Nord del bacino stesso.

\section{Caratteri paleontologici.}

Assieme ai caratteri litologici del Messiniano anche quelli palcontologici servono assai bene a distinguere l'orizzonte in questione da quelli superiori ed inferiori; infatti nelle varie formazioni terziaric del Picmonte osservansi bensì talora fossili terrestri, d'acqua dolce o d'acqua salmastra commisti qua e là e sempre raramente coi fossili marini, ed inoltre avremo anche a constatare un piano fluvio-lacustre che chiude la serie terziaria, ma è solo nel Messiniano che troviamo una vera fauna salmastra ricca, sviluppata, caratteristica. Sono specialmente svariate forme di Dreissena, Adachna, Cyrena, Neritodonta, Melania, Melanopsis ed Hydrobia quelle che abbondano fra le marne e le sabbic messiniane; inoltre vedremo che in certi punti non sono rari i resti di larve di Libellula, di Pesei d'acqua salmastra/Lebias, 
Cobitis, Gobius), nonchè abbondantissime filliti che serrono a darci una chiara idea della splendida flora che si sviluppò in Piemonte durante il periodo messiniano.

Però, oltre alla suddetta fauna salmastra, dobbiamo pure accennare come, per regioni estesissime, cosi nelle colline Torino-Valenza, il Messiniano presenti depositi racchiudcnti fossili marini, però generalmente littoranei; talora questi banchi a fauna marina costituiscono l'intiera formazione messiniana, talora inrece si alternano coi banchi a fauna salmastra o stanno loro al disotto.

Notiamo infine che, per quanto ebbi ad osservare in diversi punti dove $i$ fossili sono meglio conservati, la fauna marina del Messiniano ha maggior somiglianza con quella piacensiana che non con quella che si considera come tipica del Tortoniano.

\section{Distribuzione geografica.}

Man mano che dalle folmazioni terziarie più antiche passiarno a quelle più recenti, rediamo che le zone dei diversi piani si vanno arvicinando al centro del bacino in esane. Cosi rispetto al terreno messiniano rediamo come esso formi, dentro alla celchia miocenica, una zona abbastanza regolare, quasi continua, ai due lati dell'ampia conca pliocenica dell'Astigiana. L'ampiezza della zona messiniana raria molto nelle rarie regioni, in rapporto sia colla potenza delle formazione, sia coll'andamento stratigrafico della zona stessa e dei terreni sopra e sottostanti.

Uno sviluppo più ampio del terreno messiniano troriamo nella parte orientale e meridionale delle colline Torino-Talenza; sul lato settentrionale di tali colline, verso Casale, possiamo in piì punti constatarc l'affioramento ed anche un certo sviluppo del Messimiano, che però ad Orest di Casalc viene a mancare completamente.

Notiamo infine come a cansa dello sviluppo sotterranco, rerso SudEst, della elissoide di solleramento che abbiamo constatata nelle colline tongriane di Villadeati-Alfiano, per lungo tratto nell'alto Monferrato appaiano irregolari zone messiniane frammezzo ai terreni pliocenici.

\section{Tettonica.}

Avvicinandoci ai terreni terziari piủ giovani la stratigrafia direnta scmpre più semplice e l'inclinazione dei depositi sempre più debole. Riguardo ai terreni messiniani possiamo dire come la loro pendenza sia generalmente di $4^{\circ}$ a $6^{\circ}$ od anche minore ed abbastanza regolarmente diretta rerso il centro del bacino.

Talvolta il regolare andamento stratigrafico è localmente alterato da scoscendimenti, salti, ecc., specialmente nelle regioni gessifere, a causa 
della facile dissoluzione del Gesso. Si notano pure talvolta pieghettature ed ondulazioni negli straterelli marnosi del Messiniano; ma trattasi solo di fenomeni locali e di poca importanza in generale.

Potenza.

Per quanto si abbia a che fare con una formazione più o meno littoranea e quindi talvolta costituita di elementi grossolani c rapidamente deposti, la pila dei banchi messiniani non raggiunge mai una potenza molto grande. Sovente il suo spessore è assai minore di 50 metri; talvolta però supera anche i 200 metri.

Ad ogni modo questa potenza del Messiniano, poco considevole in complesso, specialmente considerando la natura generale di questo piano geologico, prova come il periodo messiniano, per quanto importante, fu assai più corto di quello Elveziano, di quello Aquitaniano e degli altri terreni terziari a facies di mare basso che lo precedettero.

\section{Altimetria.}

La zona messiniana si presenta generalmente ad un'altezza di 200 - 300 metri sul livello marino, tuttavia in aleuni punti i suoi banchi inferiori sono spinti sin oltre i 500 metri, come a S. Allosio nel tortonese ed anche oltre i 550 metri come al Bric del Dente presso la Morra nelle Langhe.

Tale elevazione, maggiore di quella che osservasi nella zona tortoniana, è dovuta essenzialmente alla maggior durezza che hanno generalmente i banchi arenacei e ciottolosi del Messiniano inferiore.

\section{Rapporto coi terreni sotto e soprastanti.}

A causa della facies piuttosto speciale del Messiniano e conseguentemente della sua costituzione alquanto particolare, la sua delimitazione dai terreni fra cui è inglobato riesce generalmente più facile e naturale che non per gli orizzonti finora studiati, tanto più che parmi si debba ammetterc che l'inizio e specialmente il termine del periodo messiniano furono seguati da forti movimenti sismici, per modo che talora esiste una certa trasgressione stratigrafica fra la formazione messiniana e quelle sopra e sottostanti, come avremo occasione di constatare nel cor'so della descrizione geologica regionalc.

Sovente però si può osservare un passaggio graduale tra il Tortoniano ed il Messiniano, specialmente per la comparsa di depositi a facies di bassofondo marino fra i banchi marnosi superiori del primo orizzonte; tale passaggio diventa poi affatto insensibile e difficilissimo a segnarsi là dove il Messimiano non presenta la sua solita facies littoranea, ma consta solo di banchi marnosi. 
Lo stesso deve ripetersi ad un dipresso pel Messiniano superiore, giacchè generalmente non riesce difficile il distinguere le marue piacensiane grigio-bleuastre, a numerosi fossili marini, da quelle messiniane grigio-verdastre o bruniccie spesso con fanna salmastra; ma in molti casi vengono a mancare tali caratteri cosi spiccatamente distintivi ed allora la suddetta delimitazione riesce molto incerta.

\section{Località fossilifere.}

I punti dove si possono raccogliere pin abbondantemente i resti della. fauna salmastra del Messiniano piemontese troransi quasi tutti nella parte superiore, specialmente marnosa, di questo piano geologico; per cui si puó dire che il rero orizzonte a Congerie (Dreissene) del Picmonte è generalmente ridotto a pochi metri di spessore e sta nella parte suprema del piano Messiniano, nel passaggio al Piacenziano.

$\dot{\mathrm{E}}$ secondo questa specie di legge della posizione stratigrafica dei fossili messiniani (legge da tenersi presente da chi vuol far ricerca di tali fossili) che sono distribuiti i punti fossiliferi di Rio Riraletto (presso Bene-Vagienna), di Priosa (presso Narzole), di rio IIalboschetto (nelle colline della Morra), di rio Gavel (presso Castagnito d'Alba), di Valle Arbidosa, dei Cazzulli e di Cappella S. Stefano (presso Castelletto d’Orba), di Gavazzana (colline tortonesi), ece., ece. Talora tuttavia questa fauna salmastra trovasi anche nel Messiniano medio o medio-inferiore, come per esempio a S. Marzano Olireto presso C. Tanelle.

Quanto ai resti di Pesci, di Crostacei, di larve di Libellnla, di piante, cce., sono specialmente ricchi in tali fossili certe caratteristiche marne sabbiose straterellate che ben sorenti vengono a costituire parte della formazione messiniana, cosi lungo le falde occidentali delle colline della IForra, specialmente presso il Tanaro, di fronte a regione Cravessania, presso il borgo di S. Vittoria d'Alba, nelle vicinanze di Gnarene di Alba, di Magliano d'Alba, ece.

I fossili marini (Arca, Nassa, Chaenopus, Turritella, ece.) troransi solo in poche localita, specialmente fra le marne del Messiniano medio ed inferiore, cosi nelle suddette colline della Morra lungo il Tanaro, quasi sotto C. Manzoni, nelle vicinanze della Morra e di Verduno, nelle colline di S. Agata c di Castellania nel tortonese.

Nelle colline Torino-Valenza il Messiniano è raramente fossilifero ed in ogni modo tali fossili sono quasi sempre marini, per lo pin littoranei, come Lucina, Pecten, Lithothamnium, ecc. e raramente ben conservati. Ne possiamo raceogliere in pochi punti, cosi nelle colline di Penango, sul lato Orest del Bric Mongrande, nelle colline di S. Giorgio (Cocconato) presso C. Termine e presso la borgata Costanieto; nelle colline di Lu, come al Bric Stagnino; nelle colline di Valenza, come al Bric Paradiso, ece., cce. 


\section{Descrizione geologica regionale.}

Riguardo alla parte meridionale del baeino terziario in esame sara utile prender visione di quanto ho scritto in due note speciali: "Il piano Messiniano in Piemonte " (Mondovì-Guarene e Guarene-Tortona).

Nella parte Sud-Ovest del bacino terziario in esame il Piacenziano sovrapponendosi trasgressivamente sul Tortoniano, ed anzi persino direttamente sull'Elveziano, maschera completamente la zona messiniana ehe eompare solo ben visibile nel torrente Branzola tra Mondovi e Magliano Alpi. Quivi infatti vediamo ehe, presso il ponte di S. Giovanni, alle marne argillose, bleuastre, rieehe in fossili marini del Piacenziano soggiaciono depositi marnoso-eiottolosi che eredo messiniani, i quali fanno poi passaggio inferiormente ai terreni tortoniani.

Tale formazione assai sottile presenta ad un dipresso questa serie: Piacenziano - Marne argillose azzurrastre, riecamente fossilifere. Marne straterellate, talora ripieghettate, giallastre. Strati ghiaioso-eiottolosi.
Messiniano Marne grigio-verdastre o giallieeie inglobanti lenti ghia- iose, talora a strati alquanto eontorti.
Baneo marnoso, nerastro.

Tortoniano - Potenti banchi marnosi, grigio-bleuastri con fossili marini non rari.

A Nord della sovraceennata loealiti pare ehe il Piacenziano si sovrapponga di nuovo trasgressivamente sui terreni sottostanti, ma a causa dei depositi alluviali e della vegetazione non potei più eonstatare nettamente, sin presso Bene-Vagienna, la presenza del Messiniano, quantunque nella valle del Pesio sotto Gratteria abbia osservato marne ehe pare gli si possano riferire.

Nell'ineassato rio di Rilavetto, tra Piozzo e Bene, le marne messiniane si mostrano di nuovo nettamente coi loro earatteri sia paleontologiei ehe stratigrafiei. Vediamo infatti quasi sotto C. Gay che, sotto alle tipiehe argille azzurre del Piacenziano, straordinariamente rieco in fossili eome di solito, compaiono, con leggera trasgressione stratigrafiea, marne grigiastre o grigio-verdastre, talvolta fogliettate, inglobanti irregolari strati ghiaioso-eiottolosi e racehiudenti resti di Dreissena, Adachna, Neritodonta, Meluniu, Melansopsis, eee.

Verso la base della formazione messinian", anche qui di ben piccola potenza, le marne si presentano in banchi regolari che riposano infine sui grossi banchi marnosi eompatti del Tortoniano superiore.

Nella profonda valletta del torrente Branzola possiamo esaminare minutamente, poeo ad Est del Molino di Bene, la serie messiniana ehe qui per la prima volta ei presenta verso la base una notevole lente 
gessifera utilizzata industrialmente sulla destra della valle, dove infatti ¿ piu potente. Talc serie si presenta ad un dipresso cosi costituita:

Piacenziano - Marne grigio-bleuastre, ricchissime in fossili marini.

Messiniano $\left\{\begin{array}{l}\text { Marne grigio-rerdastre con fossili d'acqua salmastra. } \\ \text { Strato marnoso nerastro, con fossili marini. } \\ \text { ILarne grigio-giallastre. } \\ \text { Lenti gessifere in marne salbbiose, grigiastre, strate- } \\ \text { rellate. }\end{array}\right.$

Tortoniano - Marne compatte, grigiastre.

La lente gessifera pare scompaia sulla sinistra di Val Jilondalavia, ma la possiamo nuovamentc constatare poco a Nord, nell'incisione di Val Geminella, dove essa è potente, accompagnata dalle solite marne stratcrellate e viene escarata su vasta scala per uso industriale.

Perỏ nelle ricinanze di Narzole la formazione gessosa si assottiglia, si riduce a sottili lenti sporadiche; a Nord di Priosa si presenta di nuovo piu potente sriluppandosi anzi estesamente, in modo speciale poi sulla destra del Tanaro, nelle colline di Heane, di Alferi, di Tel-duno, ecc., nelle quali localitá essa riene più o meno attivamente cscarata. Questa formazione gessosa $\dot{t}$ per lo piir inglobata in marne grigiobleuastre, piu o meno sabbiose, spesso straterellate; non di rado racchiude fossili marini, o d'acqua salmastra od anche filliti, cosi presso il Tanaro quasi sotto C. Manzoni, in diversi punti presso la Morra, presso Terduno, ecc.

Nei profondi tagli delle vicinanze di Priosa si puó vedere assai nettamente la seguente serie stratigrafica:

Piacenziano - Narne azzurre con numerosi fossili marini.

Hessiniano $\left\{\begin{array}{l}\text { Potente complesso di marne grigiastre con fossili d'acqua } \\ \text { salmastra (Jelanopsis, Melania, Teritodonta, Ada- } \\ \text { chna, Dreissena, ece.), qualche fillite c qualche fos- } \\ \text { sile marino. } \\ \text { Banco gessifero. }\end{array}\right.$

Tortoniano - Marne compatte, grigiastre, con fossili marini.

Ma nelle colline della Morra la formazione gessifcra pare inrcee sorrapporsi a quella arenaceo-ciottolosa, o, meglio, pare che l'una sostituisca in massima parte l'altra, innestandosi fra di loro, tant'è che una netta delimitazione tra di esse è talora impossibile.

Fra le lenti gessose non sono rare le traccie di Zolfo sia sparso tra i cristalli di Gesso, sia disposto in piccole c sottili lenti, cosi ad esempio lungo il Tanaro presso la Galleria Trifoglietto, presso Meane, ece.

Si è gia accennato come negli affioramenti messiniani antecedentemente csaminati compaiono spesso lenti ghiaioso-ciottolose; questa formazione littoranea diventa più spiceata presso Priosa e, sotto formal 
specialmente di arenarie giallastre, si mostra poi ampiamente sviluppata sulla destra del Tamaro nella parte alta delle colline di Quaranta e di S. Bartolomeo, costituendo quella specie di dirupato gradino che dal Tanaro per i Bernocehi si estende sino alla borgata S. Antonio.

Nella Valle di Rio Torbido, specialmente nelle vicinanze di S. Antonio, si può osselvare stupendamente questa formazione littoranea, in parte costituita di arenarie ed in parte di veri banchi ciottolosi anche a grossi elementi (10, 20 centim. e piú, talvolta persino di oltre 50 centim.), banchi che vengono a posare direttamente sulle marne tortoniane.

Nelle colline della Morra la formazione arenaceo-eiottolosa diventa potentissina, forma ad Est ed a Sud un alto e ripidissimo gradino sul Tortomiano, su cui essa riposa con ma certa trasgressione, però assai regolare; si puó osservare lo stesso terreno, pure assai esteso, nel rio dei Berri, sulla sinistra del rio dei Brandini, ece.; quivi esso si alterna però con marne grigio-blenastre più o meno straterellate, talora anche con strati marnosi nerastri.

Tra le arenarie e le marne trovansi anche talora lenti calcaree; non vi sono rari i resti fossili, specialmente le filliti.

E a questa resistentissima formazione arenacco-conglomeratica che si deve specialmente il fatto ehe il Messiniano inferiore raggiunge nello colline della Morra la massima elevazione (553 m. al Bric del Dente) che si conosea di questo terreno nel Piemonte.

Talvolta fra le arenarie trovansi piccole lenti o geodi gessose che ci avvertono come la formazione gessifera e quella arenacea siano in parte contemporanee.

A Nord della Morra la zona arenacea si assottiglia rapidamente e scompare quasi completamente sotto alla formazione gessifera che vi si sviluppa invece estesissimamente; si osservano peró ancora per lunghi tratti, cioè sino al Tanaro a Nord di Verduno, alcuni banchi sabbioso-arenacei, spesso ricchi in fossili marini, per lo piu infianti, banchi i quali dividono la formazione gessosa dalle marne tortoniane.

Il Messiniano marnoso superiore è potente e riechissimamente fossilifero presso Narzole, Priosa cec., presentando però verso la base numerosi strati sabbiosi ed arenacei che fanno insensibile passaggio alla zona arenacea antecedentemente esaminata.

Nelle colline della Morra la formazione marnosa è generalmente non molto potente; la si puỏ esaminare specialmente nel profondo rio di Malboschetto, dove anzi si possono raceoglicre non pochi resti dei caratteristici fossili d'acqua salmastra. Ma piủ a Nord la zona marnosa si assottiglia rapidamente, per modo che vi spunta attraverso, come presso C. Travaglio, qualche area gessosa; ne troviamo ancora traccic presso il Tanaro, sotto il Bric del Diavolo, dove vedesi inoltre apparire, 
tra le caratteristiche marne rerdastre del Messinicuno superiore, uno strato marnoso nerastro, simile a quello già riscontrato più a Sud.

Infine però anche questa sottile striscia marnosa caratteristica scompare quasi completamente e là dore la zona messiniana attrarersa la ralle del Tanaro detta zona è ridotta quasi unicamente alla formazione gessifera. la quale infatti rediamo ricomparire sulla sinistra del Tanaro come unica rappresentante della serie messmiana.

Le marne gessifere di S. Vittoria somo importanti oltre che dal lato industriale anche rispetto alla paleontologia. come quelle che fornirono resti di Chelonio. di Pesci, di Piante, ecc.: tali resti, rinvenuti durante la costruzione della linea ferroriaria Bra-Alba. troransi spesso inglobati completamente fia i cristalli di Gresso, fatto importante a notarsi per la spiegazione dell'origine dei depositi gessosi.

Quiri la formazione gessifera. molto potente, pare innestarsi senza. salti coi sorrastanti depositi marnosi del Piacenziano, come si può chiaramente osserrare, ad esempio, discendendo dal Borgo di S. Tittoria al C. อ̀ della ferrovia.

La potente formazione gessifera continua per lungo tratto a rappresentare l'intiera zona messiniana formando le ripide balze di Borgo S. Tittoria, di C. Roncaglia, di C. Ciappella, di Bric Paradiso, ecc.: però fra le marne gessifere appaiono pure lenti di calcare alquanto concrezionato che si possono ossel'rare specialmente nelle colline di C. Roncaglia. colline che appunto perciò presentano in alcuni punti un color giallo-rossastro.

Ad Est di Bric Paradiso l'orizzonte gessifero costituisce solo più la parte inferiore del Wessiniano, offre ancora qua e là qualche lente calcarifera come presso C. Lora: esso si presenta per lo piủ sotto forma di marne sabbiose. gessifere, giallastre; straterellate. racchiudenti spesso numerosissime filliti, come ad esempio sotto il Bric Monte presso Guarene.

Verso la base del Messiniano le lenti gessose appaiono irregolarmente fra le marne grigiastre per modo che risulta difficile ma netta distinzione di questo terreno dal Tortomiano, per quanto in complesso tale delimitazione sia facilitata da quella specie di gradino che per lo piủ il Messiniano inferiore forma sul Tortoniano.

La zona gessifera. assottigliata presso Guarene. ridirenta potente presso il borgo di S. Giuseppe (Castagnito) dore essa è escarata attirissimamente su rasta scala: ma in seguito la fomazione gessifera. sempre con inclinazione di pochi gradi rerso Nord-Orest. ridirenta meno importante e, gradatamente assottigliandosi. riene a scomparire completamente poco olne un chilometro ad Est di Magliano d"Alba.

Al disopra dell'orizzonte gessifero si sriluppa una zona più o meno 
ampia di marne, sabbic ed arenaric. Vediamo comparire tali marne al Bric del Paradiso, dove anzi esse si presentano anche alquanto calcarec ed accompagnate da una grossa lente di durissimo conglomerato, como osservasi poco sopra C. Gerbola.

Le sabbic e le arenarie del Messiniano medio si sviluppano notevolissimamente nelle colline dei Sionesi, di Guarcne e di Bric S. Lucero, dando luogo a ripide balze ed a sorgenti acquce (ad esempio quella del Borbora) e formando spesso un gradino sulla zoula gessifera.

In questo orizzonte medio del Messiniano si notano talora, verso la base, potenti banchi ghiaioso-ciottolosi, come osservasi presso Guarene, ma sono specialmente importanti certe marne sabbiose straterellate perchè straordinariamente ricche in resti fossili, come ad escmpio nella parte alta del Bric Monte presso Guacrne.

Le formazioni arenacce possonsi osservare ancora assai sviluppate nelle colline di S. Lucero, di Bric del Bosco, di C. Gorra, cec.; invece le marne foglicttate osservansi tipiche ed assai potenti particolarmente attorno a Magliano d'Alba.

Nella parte superiore affatto del Messiniano predominano le marno grigiastre, o grigio-verdastre, talora con sottili strati nerastri (spesso utili al geologo per delimitare il Messiniano dal Piacenziano), talora poi racchiudenti i resti della tipica fauna salmastra a Melanopsis, Neritodonta, Dreissena, ecc.; una di queste località fossiliferc trovasi nella valle Gavel (presso Castagnito) tra C. Madenasso e C. Riazzolo.

In complesso nelle colline di Guarene d'Alba la zona messiniana, tipicamente regolare, ci presenta ad un dipresso questa seric:

Piacenziano - Marne argillose azzurle, licchissime in fossili marini.

( Marne grigio-verdastre con stratcrelli nerastri e fossili d'acqua salmastra (zona a Dreissene).

Marne fogliettate e strati sabbioso-marnosi, talvolta con

Messiniano filliti, sabbie, arenarie e conglomerati in alternanza con strati marnosi talora fillitiferi.

IIarne sabbiose grigio-giallastre, fogliettate, gessifere c spesso fillitifere.

Marne grigiastre con lenti gessose.

Tortoniano - Marne grigio-bleuastre, compatte.

Tra Castellinaldo e Priocca, in fondo alla Valle Priocca, fiammezzo alle marnc piacenziane, veggonsi in due locaiita, cioe a Nord-Ovest di Bric S. Michele e ad Orest di Bric Genestreto, aleune marne grigioverdastre ed alcuni sprazzi di marne nerastre ehe, per quanto non abbiano finora fornito fossili caratteristici, credo tuttavia riferibili al Messiniano; d'altronde non è per nulla straordinario che i banchi di questo orizzonte, inclinati di pochi gradi verso Nord-Ovest, possano 
talora, per fenomeni di erosione, venir messi allo scoperto in mezzo alla zona piacenziana, tant'è che rediamo presso Prioeea la zona messiniana prolungarsi molto a Tord per esportazione dclle argille piacenziane. La delimitazione di questi piccoli affioramenti l'icsce però difficilissima senza scari speciali, tanto più che l'allurione recente li ricopre in gran parte.

A Nord Est di Magliano Alpi la zona messiniana si presenta aneora pær un certo tratto molto arenacea, come si rede specialmonte sulli sinistra di Valle Bertinetto, ma in seguito essa direnta esscnzialmente marnosa o marnoso-sabbiosa, grigio-verdastra, spesso con noduli irregolari bianco-giallastri; talora le marne messiniane sono induritc, alternate eon straterclli sabbiosi o finissimamente fogliettatc. Gencraimente verso la base del Messiniano di queste eolline di S. Pietro, di Gorone, ece. trovansi lenti ghiaioso-eiottolose, come possonsi osserrare, ad esempio, su ambi i fianchi di Tal Sorso, rerso il suo sboeco in Tal Tanaro, presso C. Cotella, rerso lo sboceo di Val Cherpore, di Tal Parella, ecc.

Ad Est di Govone presso il Tanaro ricompare, nella parte basale del Messiniano, la formazione gessifera. inglobante talora lenti ciottolose (impigliate fra gli stessi cristalli di Gesso), e che direnta tosto potente e quindi largamente utilizzata, costituendo per lungo tratto la sponda sinistra del Tanaro, quindi mostrandosi sriluppata sulla sponda destra tra Remonsino ed il Molino Veechio. In quest'ultima regione, dove pure esistono numerose care di Gesso, reggonsi stupende monoliti gessose e la stratigrafia si presenta talora localmente alterata, per il solito fenomeno di dissoluzione.

La formazione gessifera, maseherata per brere tratto dai banehi sabbioso-arenacei di C. Mattci, si può ancora seguire per lungo tratto nelle colline di S. Anna e dell'Amnunziata, essendo dorunque utilizzata con maggiore o minore attività; in segraito però essa scompare gradatamente, impregnando solo più qua e la le marne e le arenarie. oppure mostrandosi in lenti più o meno importanti inglobate nel Messiniano inferiore, come redremo in seguito.

La parte più importante della serie messiniana è quiri rappresentata da marne, sabbie ed arcnarie passanti talora a conglomerati, la cui distribuzione è irregolarissima ed impossibile a delimitarsi con preeisione.

Le colline di Costigliole d'Asti sono opportunissime per lo studio del Messiniano, sia per la rarieta delie formazioni che vi si ossertano, sia per lo sviluppo grande che esse ei presentano a causa della lievissima inclinazione stratigrafica; quest'ultimo fatto ci spiega non solo l'apparire di zone lorloniane abbastanza importanti entro la stessa area messiniana in seguito ad erosioni (come in Valle Nerza, in Talle Bragua, 
in Val Repulenta, in Val Pontiselli) ma anehe il fatto ehe in queste regioni la zona messiniann assume un'ampiezza di quasi 5 chilom., per quanto abbia appena una potenza di circa 100 metri, sovente anzi molto minore di 100 metri.

Senza entrare in minuti dettagli riguardo alla eostituzione di questa ampia zona messinima, si puó aecemare in eomplesso eome quivi le lenti eonglomeratiehe, intreeeiate più o meno eolle sabbie e colle arenarie, presentino un grande sviluppo specialmente nelle colline di S. MIichele e di Brie la Ghiaia ad Est di Costigliole; esse si mostrano pure qua e là presso Remonsino, nelle colline del borgo Annunziata, dei Bori, di Brie Sino, nelle rieimanze di Costigliole direttamente sopra alle marue fortoniane, sotto C. Marasso (S. Giovanni), sotto C. Capra in Val Bragna, presso i tetti Francia, nei dintorni di Canetto e Zuechetto, a Nord di Agliano presso i Fornetti e presso S. Roeeo e C. Giorgio.

Le sabbie e le arenarie hamno un'assoluta prevalenza nella eostituzione del Messiniano, e si riconoscono anehe ai earatteri esterni per costituire ripide balze e per dar origine a sorgenti acquee.

Infine dobbiamo aneora menzionare essere ampiamente sviluppate le marne, per lo piu grigiastre, talvolta bleuastre, talrolta nerastre come presso borgata Pasquana e Casa Nova alta, e talora persino giallo-rossieee, spesso straterellate nel modo tipico, come, ad esempio, nelle immediate vicinanze di Costigliole, nella parte alta del Brie di Lu, ece.

Non sono neppur rare fira le marne sabbiose piecole lenti di caleare, però granuloso e molto impuro, generalmente eollegate piủ o meno direttamente eolle lenti gessifore, easi al Brie di Lu, presso C. Bianeo, tra Brie Moasca e S. Marzano, ece.

Le lenti gessifere s'ineontrano sporadieamente verso la base del his'ssiniano e talvolta sono eosi poeo estese ehe dopo qualehe tempo d'eseavazione restano esaurite eompletamente, mentre vieeversa talora, ma di rado, casualmente se ne mettono al,tre nuove allo seoperto.

Troviano una sottile lente di Gesso sotto la borgata Bori, un'altra potente e quindi eseavata su ampia scala al Brie del Gesso presso Loreto, una terza assai più pieeola al Brie S. Miehele; alemi banehi gessiferi eompaiono verso la parte media delle balze meridionali di Brie Lu, ed anzi ee ne spiegano il ripido pendio a Sud; una lunga lente gessosa compare a mezza costa di Bric delle Roeche e Brie del Mugnaio sempre dal lato meridionale.

L'affioramento di una lente gessifera presso borgata Banchetti, dove essa viene attivamente eseavata, è in rapporto eolla vieina comparsa del Torloniaño dentro alla zona messiniana; lo stesso dere dirsi per la pieeola lente gessosa ehe appare ad Agliano, presso la Cappella di San Sebastiano e quindi gia nel Messiniano medio. 
Credo opportuno far risaltare questo fatto ehe, mentre in generale nella par'te meridionale del baeino terziario del Piemonte la formazione gessifera sta direttamente alla base del Messiniano, in aleune regioni invece, eome, ad esempio, in quelle ora in esame, le lenti gessose appaiono framinezzo alle formazioni marnose e sabbiose anche nella parte medio-inferiore della pila messiniana.

Notiamo la sorgente solforosa (Aequa mareia) che esee dalle marne messiniane in Val Repulento, quasi sotto Agliano.

Ad Est di Agliano la zona messiniana si restringe noterolissimamente a causa del notcrole avanzamento a Sud ehe presentano i depositi pliocenici che costituiscono quivi una speeie di seno, il seno di Castelnuoro Calcea.

La formazione gessifera continua a prescntarsi in lenti più o meno allungate; di queste la più importante è quclla che, con una lunghezza di cirea 2 ehilom. e ${ }^{1 / 2}$, si stende dal Brie ILomburo al Bric di MIorsca frammezzo alle marne sabbiose del Messiniano inferiore; sono inveee molto meno sviluppate le lenti gessifere di S. Marzano Olireto, di M. Olireto e di C. Tanelle nell'alta valle del Tufo; per una rapida eurra del Messiniano troviamo lenti di Gesso al Brie Ghersi ed al Bric S. Margherita, dove esse stanno fira le marne sabbiose del Messiniano medio-inferiore.

La parte principale della zona messinima tra Agliano e Nizza Monferrato consta di banchi sabbiosi ed arenacei grigio-giallastri, con inclinazione abbastanza regolare verso Nord-Nord-Est, i quali originano diverse sorgenti aequee, perỏ spesso temporanee, il ehe è in rapporto eolla piccola zona di raccoglimento.

Alternati eoi banchi arenacei stanno strati e banehi marnosi talora grigio-giallastri fogliettati, ed allora non di rado fillitifeli, come al M. Oliveto, talora invece eompatti grigio-bleuastri cd inglobanti anche i caratteristiei fossili d'acqua salmastra (Melanopsis, Hydrobia, Neritodontu, ecc.) eome, ad esempio, presso le C. Tanelle ad Est di San Marzano; è noterole eome in questo caso tale fauna salmastra si trovi nel Messiniano medio-inferiore, montre generalmente essa si incontra solo nel Messiniano superiore.

Le marne grigio-bleuastre del Messiniano superiore rieordano talor'a molto bene quelle del Piacensiano, cosi al Brie MIombaruzzo, al Bric della Muda, eec.; è anzi sovente assai difficile delimitarri i due orizzonti. In aleuni casi però si puo constatare che le marne messiniane, pur inglobanti fossili marini, fra cui molti Foraminiferi, presentano talora effloreseenze gessose negli inter'strati. Nella regione ultimamente accennata riesee pure difficile il distinguere i terreni messiniani da quelli tortonicuni, tanto piủ in causa della coltirazione estesissima. 
Verso Nizza MIonferrato, se i banchi sabbiosi si mostrano abbastanza numerosi nelle colline di C. Bonasso e di C. Valentino, predominano però essenzialmente le marne, spesso gialliccie e bleuastre, tipicamente fogliettate, come vedesi nelle colline di C. Gagni e di C. Squarza, dove trovansi pure alcune sottili lenti calcareo-marnose.

Ad Est di Val Belbo la zona messiniana, sempre con un'ampiezza di oltre due ehilometri, continua a mostrarsi colle sue varie facies sopramenzionate.

La formazione gessifera si presenta in sottili lenti verso la base del Messiniano come al Bric di C. Nicolao, sul lato Est ed Ovest del bric di C. Pola, lungo la cresta di C. Garetta e C. Cutica, sotto C. Castelgaro e presso C. Oddone; sporadiche lenti gessose incontriamo pure nel Messiniano medio (fra le arenarie e le marne), cosi sulla sinistra di Val Cervino sopra C. Fonda e nell'alta valle Gherlobbia sotto C. Andusia settentrionale.

Ma ad Est di Val Cervino la formazione gessifera acquista una potenza ed uno sviluppo straordinario, tanto che in alcuni punti, come al Bric di C. Boidini, essa presenta uno spessore di circa 100 metri e raggiunge talvolta un'ampiezza di oltre dne chilom.; sono quindi famose le colline di Alice Belcolle per il grande numero di cave di Gesso.

Non è neppur raro di riscontrare quivi qualche sottile lente di Zolfo frammezzo alle marne gessifere, fatto che constatiamo gcncralmente là dove più sono potenti i depositi di Gesso.

Nelle colline di Bric Boschi e di C. Oddone la zona gessifera è in parte mascherata da placche arenaceo-conglomeratiche, tanto che essa spunta solo verso il fondo delle vallate; essa si estende invece più liberamente attorno ad Alice e nelle colline ad Est, dove si dispone ad ampia placea sulla destra di Val Caranzano finchè, rapidamente restringendosi, vienc a scomparire completamente presso C. Canova tra le marne tortoniane e le marne sabbiose del Messiniano, di cui costituisce veramente la base.

Le lenti di Calcare più o meno impuro, più o meno cariato, non sono rare in questa regione messiniana, sia nella stessa formazione gessifera, come presso C. Galletta (Nord di Castelrochero), C. Rossa, C. Tana, C.'Vantignosa, C. Rocchiè, C. Guasasco, ecc.; sia fra le marne sabbiose, in stretta relazione colle lenti gessose, così presso C. Albertetti (Sud di Nizza), C. Botto, C. Oddone, C. Gaglione, ecc. Un grandissimo sviluppo assumono le formazioni ciottolose tra la Val Belbo e la Val Bormida, ma per quanto si possa dire ehe in complesso esse costituiscono la parte medio-inferiore del Messiniano, tuttavia la loro irregolare distribuzione pare talora contraddire alquanto tale legge gcncrale, poichè detti banchi ciottolosi appaiono talora anche nella parte 
media della serie messiniana, mentre inrece talvolta nella parte inferiorc stanno marne e sabbie.

Una grossa lente ciottolosa troviamo nel Messiniano medio fira l'alta valle Gherlobbia e le colline di Fontanile; i ciottoli sono talvolta persino di 1 metro di diametro e si presentano spesso costituiti di arenaria derivante dai terreni miocenici piủ antichi; in parte perỏ constano di roccie provenienti dall'Appennino Settentrionale e dalle Alpi IIarittime orientali, cosi Quarzite, Appenminite, Calcare triassren, ecc. . Lna piccola lente conglomeratica si nota nel Messiniano inferiore da Tal Cerrino a C. Oddone. Tale lente si cangia poi rerso Est in un rero orizzonte arenaceo ciottoloso che costituisce sulla zona gessosa larghe placche, come vedesi al Bric Boschi ed al Bric di C. Oddone; essa forma poi un'ampia ed irregolare zona, a cominciare dal Casello superiore, nelle colline di C. Ravera, di C. Bussi, di Ricaldone, ecc.; assottigliasi in seguito sino a scomparire sotto S. Andrea in forma di piccole lenti o strati alternati con sabbie e marne.

In tutto il suo svilupppo l'indicata zona arenaceo-ciottolosa che basa direttamente sull'orizzonte gessifero, come è il caso nella serie tipica, dà luogo a colline dirupate, boschive, a gradinate (fra cui è specialmente notevole quella che da C. T'iotta si mostra ben evidente sino alla borgata S. Andrea) ed a sorgenti acquee spesso assai copiose; ció si osserva ad esempio presso il paesc di Ricaldone, la cui posizione credo derivi precisamente da tale ricchezza in sorgenti. Sono spesso utilizzati gli elementi sabbiosi e ciobtolosi come materiale da costruzione e come pietrisco. Scientificamente è importante l'esame di queste lenti ciottolose poichẻ esse ci indicano in parte la distribuzione e la potenza dei corsi d'acqua del periodo messiniano.

La restante parte, specialmente quella superiore, del Messiniano è costituita di banchi sabbiosi e marnosi grigiastri o giallastri, che spesso originano sorgenti e colline dirupate, come per esempio a Nord di Castelletto Molina; talora questo orizzonte forma placche anche direttamente sulla zona gessifera, come al paese di Alice Belcolle.

La stratigrafia è generalmente abbastanza regolare, tuttavia osserriamo talora salti e discordanze locali, come ad esempio nell'alta Tal Glierlobbia presso C. Alorti.

Nel passaggio tra Messiniano e Piacenziano esiste generalmente ma leggera ma regolare trasgressione stratigrafica, che permette una delimitazione abbastanza facile fra i due orizzonti, ma che talora si accentua piir chiaramentc e si riconosec anche all'irregolare sorrapposizione di un terreno sull'altro, così per csempio nclle colline a Sud di borgata Bazzana (Nizza).

Ad Est di Val Bormida troviamo la zona messimiana noterolmente 
ristretta, (ciò che s'accorda col fenomeno identico che osscrrasi nei terreni terziari premessinioni di queste regioni) ma ancora colla sua solita costituzione, cioè con prevalenza di arenarie e di conglomerati nella parte inferiore e di marne nella parte superiore.

I banchi ciottolosi, che erano scomparsi ad Est di S. Andrea, ricompaiono nettamente nelle colline di C. Valle di sotto e si veggono prolungarsi verso oriente nelle colline di C. Cantalupo, di C. Albergo, dei Ricciotti, dei Bartameloni, di S. Michele, ece.; essi sono talvolta costituiti di elementi voluminosissimi (sovente di quasi 1 metro di diametro); la loro natura è varia e vi prendono parte calcari alberesi. Più ad oriente $\mathrm{i}$ depositi ciottolosi si riducono a lenti ghiaioso-ciottolose che riveggonsi assai bene in. Val Maggiore, e sono poi completamente mascherate dalle alluvioni dell'Orba.

Lungo tutto questo sviluppo la zona ghiaiosa origina, come di solito, numerose sorgenti ed è escavata qua e là per pietrisco, per materiale da costruzione, ece.; è specialmente notevole il fatto della forte trasgressione stratigrafica con eui detta zona appoggiasi ai terreni più antichi, tanto che spesso, limanendone completamente coperte le marne tortoniane, i bancli sabbioso-ciottolosi messiniani appoggiansi direttamente sulle arenaric elvesinne; perciò talora, come ad esempio presso Montaldo, ne rimane alquanto dubbia la delimitazione.

安 poi importante l'osservare, ancora nella valle della Baretta presso i Bartameloni, una lente gessifera tra le marne tortonicue e le arenarie ghiaiose del Lessiniano, mentre per altri 20 chilometri verso Est non incontreremo più tale speciale formazione.

Il Messiniano superiore, specialmente marnoso, o marnoso-sabbioso, talora con piccole lenti ghiaiose, come presso C. Toniotta (Montaldo), è per' lo più ridotto ad una sottile zona, divisibile però solo alquanto arbitrariamente dall'orizzonte inferiore. Questa zona è distinguibile dalle sovrastanti marne piaceniame per non presentare quella ricchezza in fossili marini che quclle invece hanno.

Ad Est di Montaldo le marne sabbiose del Messiniano superiore si allargano talvolta abbastanza notevolmentc e spesso si prescntano grigio-biancastre e fogliettate nel modo tipico, come si può ad esempio osservare presso il torrente Orba, poeo ad Est di C. Schicrano.

Ad Est della valle d'Orba la zona messiniana si presenta per un ccrto tratto specialmente marnoso-sabbiosa (eccetto qualehe lente ghiaiosa come presso C. Gallaretta), grigio-giallastra con strati brunastri, e molto ricea in fossili, come ad esempio ad Est di Castelletto d'Orba nella valletta Arbidosa, sotto i Cazzulli e presso Cappella S. Stefano. Trattasi sempre della solita tipica fauma salmastra a Dreissena, Adachna, Cyrena, Neritodonta, Melania, Melanopsis ed Hydrobia. 
Questi fossili trovansi in diversi strati lungo la serie messiniana; così risalcndo il torrente Arbidosa vediamo la seguente serie:

Piacenziano - Marne azzurrastre licche in fossili marini.

( Narne grigiastre.

Strati sabbiosi giallastri con Dreissena, Irydrobia, ecc., Messiniano per lo più alquanto rimanegratati.

Narme azzurrastre con abbondantissime Cyrena, Hydrobia e Melanopsis.

Marne e sabbie nerastre con fossili d'acqua salmastra.

Tortoniano - Marne grigiastre con fossili marini.

In seguito l'orizzonte marnoso si restringe alquanto e costituisce solo più una parte, quella superiore, dell'intiera zona messiniana, essendo direttamente coperto dalle marne sabbiose piacenziane ricchissime in fossili marini di mar profondo ed anche di littorale, come ad escmpio sotto C. Poggio (Nord-Ovest di Gavi), dove sonvi numerosi Foraminiferi, indicandoci una specie di zona di passaggio (che dapprima eredetti dover riferire al Messiniano superiore) tra i due orizzonti geologici accemnati.

La facies ciottolosa, che si presenta solo sporadicamente nelle vicinanze di Castelletto, diventa, rerso Est, la fucies preralente, essendo rapprescntata da banchi numcrosi e potenti nelle colline di S. Cristoforo, di C. Giustiniana, di M. Mesma, di Zerbe, ecc., sino alla ralle della Serivia, dore per la loro durezza tali banchi costituiscono il nettissimo gradino della Nanifattura di Cotone ed il noterole ristringimento della valle sotto il Pian della Botte.

Le località dore questi conglomerati (spesso ad elementi quarzitici e serpentinosi e talora di oltre 1 metro di diametro) si possono esaminare meglio c più direttamentc sono le balze di S. Stefano, di C. Camarela, di Rio Lagoraro, la valletta di Gavalusso e quella di Parè sotto borgata Zerbe; non vi sono l'arce le sorgenti acquce, ma in generale regione si presenta arida, sclraggia, ruinosa, a ripidi pendii, a profondi burroni, cce.

Assicme alle lenti ciottolose trovansi eziandio, a costituire il Messiniano inferiore e medio, potentissime sabbie, arenarie e marne più o meno sabbiose, che per cssere poco consistenti, formano talora colline solcate da profondi burroni, come si può redere ad esempio nell'alta valle Lagoraro, nell'alta val MIcsma, nell'alta valle Gavalusso, ece.

Un fenomeno che si presenta assai spiccato nelle colline messiniane ora in esame è il color rossastro che csse assumono e che è specialmente noterole al M. Mesma; tale colore derira da una decomposizione piuttosto profonda degli elementi, in gran parte serpentinosi, che costituiscono le marne sabbiosc ora csaminate e che da tempo lunghissimo si trorano esposti agli agenti esterni. 
Talvolta questo color giallo-rossastro delle eolline sabbioso-ciottolose del Messiniano rende difficile la delimitazione delle plaeehe alluviali pure sabbioso-eiottolose e giallastre del Quaternario, eome ad esempio tra la Val Lemno e il N. Mesma.

In alcune loealità le arenarie messiniane divengono molto resistenti e rieordano assai bene quelle elveziane, tanto più che esse presentano puro fossili marini, speeialmente frammenti di Ostriehe; eiò possiamo ad esempio osservare nell'alta valle Parè, speeialmente sul suo lato destro, quasi di fronte a borgata Zerbe; anzi è a notare che tali arenarie si presentano variamente inelinate, talvolta di $20^{\circ}$ e più, anehe in senso contrario alla pendenza generale della zona, pendenza che è di poclif gradi verso il Nord-Nord-Ovest. Credo però si tratti solo di irregolarità stratigrafiehe loeali e quindi non di importanza generale.

Quanto ai rapporti della zona messiniana eoi terreni eireostanti dobbiamo notare eome eontinui evidente quella trasgressione stratigrafica ehe già si è osservata ad Ovest, speeialmente rispet to all'Elveziano, il quale talvolta è eoperto direttamente dai banehi messiniani, eome a S. Cristoforo, e tra la Val Lemno ed il M. Mesma.

Più graduale è inveee il passaggio tra il Messiniano ed i terreni plioeenici, per quanto sia forse anehe qui ammissibile una leggera, per quanto regolare, trasgresssione.

Passando ora all'esame delle eolline tortonesi notiamo subito come compaia e tosto si sviluppi ampiamente la formazione gessifera il eui ultimo punto di eomparsa si trova oltre 20 chilometri ad Ovest di Val Serivia.

É tra Masseria Zegna e C. Piano della Botte presso la Serivia ehc vediamo eomparire, fra le arenarie basali del Messiniano, una lente g'essosa che però seompare presto verso Monterosso; ritroviamo un'altra lente pure pieeola, ma più potente della prima, presso Sardigliano poco a Sud di C. Valerana; vediamo eomparire un'altra sottile lente gessosa nella valletta del torrente Rile presso la sorgente d'aequa solfolosa ed anzi probabilissimamente in relazione eon questa.

Molto più potente ed allargata ei apparc la zona gessifera di rio dell'Isole, e di Giusulana, e la potentissima lente gessosa su cui sta il paese di S. Agata fossili. Ma la massima potenza di questa speeiale formazione osservasi, per oltre un clilometro, al fondo dell'incassata valle di Castellania, eome pure nella parte bassa della valletta di Pelleto, sulla eresta delle Streghe da Cappella S. Biagio al Bric delle Streghe e nell'alta valle Gravalone sino al paese di Cornigliasea, ehe vi è fondato sopra direttamente, seomparendo poi eompletamente la zona gessosa poeo a Nord di questo paesello.

In tutto questo sviluppo della zona gessifera troviamo frequentissime 
care di gesso; possiamo osservarvi bellissimi fenomeni di erosione, di dissoluzione, di locali spostamenti stratigrafici, curiose monoliti, ece.

Tra i banchi gessosi, per lo più a grossi cristalli, si trorano talora anche sottili ed affatto sporadiche lenti di Zolfo. come ad esempio tra Costa Vescovado e S. Biagio, lungo la cosidetta Rija dello Zolfo. alla base del Nessinamo; notiamo come questi piccolissimi depositi di Zolfo appaiano qui, come nelle altre località piemontesi, là dore la formazione gessosa è più potentemente sviluppata.

I banchi gessosi sono inglobati in marne alquanto sabbiose grigiastre o giallo-rossastre od anche grigio-bleuastre; in quest'ultimo caso comprendono spesso numcrosi fossili marini che paiono collegarsi meglio a quelli piacenziani che non a quelli tortoniani, per quanto trorinsi nel Messiniano inferiore. Tali marne azzurrastre fossilifere incontransi pure a Nord-Orest di S. Biagio, nella valletta Rivera, sulla sinistra di Val Castellania, in regione Cenerana, ecc.; d'altronde tali marne non trotansi solo fra i Gessi ma anche in orizzonti superiori ad essi.

In stretta relazione coi depositi gessiferi sono le lenti calcarifere (talora utilizzate dall'uomo come Calce dolce) che si intrecciano coi primi e che sorente li sostituiscono completamente; già presso C. Valerana (Tal Rile) appaiono questi Calcari impuri, cariati, quasi carniole, che si mostrano alquanto più potenti a C. Costa Míezzana ed a C. Pagano presso Giusulana. ma si sviluppano poi noterolissimamente a Nord di S. Agata fossili. Infatti se i Calcari sotto questo paese, discendendo al MIolino di Castellania, compaiono solo in piccoli accentramenti nelle marne tra Tortoniano e Messiniano, invece nelle colline di Castellania e di Mossabclla essi formano reri banchi (fra marne più o meno sabbiose) che si sorrappongono alla formazione gessosa intrecciandosi con essa, finchè a Nord di Cornigliasca detti Calcari la sostituiscono completamente formando la base del Messiniano.

Questi banchi marnoso-calcarei costituiscono la parte alta delle col-" line di Carezzano superiore e di Paderna, finchè rengono a scomparile presso Spinetto, sotto ai terreni piacenziani che ii ricoprono con eridentissima trasgressione stratigrafica.

Era queste lenti calcarifere e gessifere esistono pure raste aree di marne o marne sabbiose, grigiastre o grigio-bleuastre, che costituiscono anche una parte importante del Messiniano inferiore.

Il Messiniano medio del tortonese consta di un'alternanza irregolare di banchi marnosi o marnoso-sabbiosi e di potenti banchi arenaceo-conglomeratici che per la loro durezza formano alte e dirupate colline e foggiansi talora a grandiose gradinate ed ampi piani inclinati corrispondenti ai rari banchi conglomeratici; in questa zona sono naturalmente assai commi le sorgenti acquee piu o meno 
eopiose, profondi burroni, ripidi pendii, rii tortuosi, numerose monoliti, cee.

Un lembo staecato di questa formazione arenaeeo-conglomeratica vedesi nelle eolline di S. Allosio, dove essa si spinge sin oltre i 500 metri (509 m.), pur rimanendo inferiore per elevazione a quella ehe osscrvammo nelle eolline della Morra.

A eausa della profonda deeomposizione spesso questi terreni sabbiosociottolosi assumono un color rossastro, donde il color rossieeio delle colline messiniane come già osservammo più ad Ovest.

Fra i banehi arenaceo-eonglomeratici, speeialmente ver'so la metà della seric, trovansi spesso veri orizzonti marnosi che rieordano molto bene i terreni piacenziani e talora racehiudono pure fossili marini pure di facies piacenziana; talvolta inveee incontriamo nella parte superiore dell'orizzonte le earatteristiehe marne ncrastre, come presso la C. del Tornitore (Est di Cassano Spinola), e non di rado anehe la tipica fauna salmastra come ad esempio presso Carezzano inferiore, poeo ad Est di questo paese.

L'indieato orizzonte, essenzialmente conglomeratieo, dopo aver assunto nelle colline tortonesi meridionali una grande potenza, talora di cirea 100 metri, ed un'ampiezza talora di oltre 2 ehilom., si restringe rapidamente nelle colline di Paderna, seomparendo poi eompletamente poeo a Nord di questo paescllo, sotto ai terreni piacenziani.

I banchi supremi della scrie messiniana eonstano essenzialmente di marne grigiastre o grigio-giallognole, più raramente nerastre, talora alquanto sabbiose, che formano eosì un orizzonte poeo potente, ma però importante perchè raeehiude assai spesso la earatteristica fauna salmastra a Dreissena, Adachna, Cyrena, Neritodonta, Iydrobia, Melania, Melanopsis, come ad esempio nell'alta val Conzega (Cassano Spinola), poeo ad Est di Gavazzana lungo la strada S. Agata-Cassano, cee.

Quest'orizzonte marmoso forma un passaggio abbastanza graduale alle marne (eon numerosi fossili marini) del Piacenziano, dalle quali però esso viene eompletamente maseherato poco a Nord di Padcrna.

È questo l'ultimo punto della parte meridionale del baeino piemontese che ei presenti la tipiea fauna salmastra del Messiniano; è notevole che le varie loealità indicate eome fossilifere nclla zona messiniana, pur presentando nell'assieme una facies uniea, di maremma, tuttavia offrono gencralmente eiaseuna qualche eosa di speciale.

Per citare un esempio del eome si presenti costituita in complesso la serie messiniana, accennerò quella che si osserva nelle colline di Torre Sterpi e di Carezzano: 
Marne e sabbie più o meno compatte, grigio-giallastre, pseudo-astiane, con pochi fossili di littorale.

Alternanza di marne e sabbie azzurrastre con marne e sabbie giallastre, generalmente fossilifere.

Potente complesso di marma argillosa azzurrastra con fossili di mare profondo.

MLarne e sabbie argillose con granuli biancastri e con fauna salmastra.

Strati marnosi e sabbiosi alternati con potenti banchi

Messiniano arenaceo-conglomeratici.

Banchi marnoso-sabbiosi con calcare impuro, concrezionato.

Marne sabbiose gialliccie o grigiastre con lenti gessose.

Tortoniano - Harne grigio-blenastre ricche in fossili marini.

La stratigrafia dell'intiero piano Messiniano delle colline tor'tonesi meridionali è assai regolare in complesso, pel quanto si notino trasgressioni stratigrafiche sia rispetto ai terreni sottostanti che riguardo a quelli soprastanti; tant' è che noi troviamo, rerso le colline di Spinetto, che le marne a grumi calcarei del Messiniano inferiore si redono per oltre un chilometro appoggiarsi senz'altro sul Liguriano ed essere ricoperte direttamente dal Piacenziano.

Nella parte Nord-Est delle colline tortonesi ricompaiono le formazioni messiniane colle solite zone ciottolose, gessifere ecc.; spesso però vi si incontrano banchi di raria natura inglobanti fossili marini di facies specialmente piacenziana. La zona messiniana potente, spesso assai ricea in fossili animali e regetali, si continua regolare e per lo più ampia, ver'so l'Est nella parte settentrionale delle colline rogheresi, paresi ecc.

Passancio ora all'esame delle colline Valenza-Torino vediamo che nella loro parte orientale è molto notevole lo sviluppo della formazione messiniana sia in grandi zone allungate sia in ampie placche irregolari.

Nella estremità orientale di dette colline infatti già appare un bellissimo lembo messiniano che costituisce le alture di Montecastello; trattasi essenzialmente di banchi marnosi e sabbiosi, grigio-giallognoli, talora fogliettati, talora alquanto arenacei, raramente con lenti ghiaiose; questi depositi pendono in complesso verso l'Est ma con grandi rarianti sia di direzione sia di grado, oscillando a questo riguardo tra i $30^{\circ}$ ed i $50^{\circ}$ circa; anzi in alcuni casi, come nella parte bassa e settentrionale del paese, la pendenza a Nord-Est diviene ancora più forte. In questa località si osserva rerso Orest un passaggio abbastanza graduale tra il Messiniano inferiore ed il Tortoniano. La placea ora esaminata di Montecastello ci denota come grande debba essere lo sviluppo della formazione messiniana tra le colline d'Alessandria e quelle di Tortona. 
Ad Orest del paese di Rivarone si estende una lunga ed irregolare zona messiniana che si spinge snlla formazione tortomiana sin contro gli affioramenti ligurî̀n. Tale curiosa disposizione stratigrafica è doruta ad una specie di sinclinale irregolare che i depositi tortoniani formano in causa del trovarsi essi tra il sollevamento di Pecetto a Nord c quello di S. Zeno a Sud; quiudi probabilmente goia in origine la maremma messiniana dovette inoltrarsi quivi a g'uisa di stretto e lungo seno frammezzo ai rilievi eo-miocenici allora appena accennati.

Da questa speciale disposizione stratigrafica della regione in esame comprendiamo sia le irregolarita della formazione messiniana, sia le direrse pendenze che prescntano i suoi strati; questi sono in complesso leggermente inclinati, di rado di oltre $10^{\circ}$ o $15^{\circ}$, e per lo più rerso il Sud all'incirca, con rarianti a Sud-Est c Sud-Orest; solo rel'so il bric Cantonieri essi assumono una forte pendenza rerso il Nord-Est.

Qui, come a Montecastello, nella costituzione del Messiniano predominano le marne più o meno sabbiose, ma a queste si agoimgono numerosi e potenti banchi sabbiosi ed arenacei, talora granulosi, grigiogiallastri ed inoltre, specialmente nella parte occidentale, grosse lenti ghiaioso-ciottolose inglobate irregolarmente fra le sabbie.

In complesso nelle colline di Talenza la formazione messiniana presenta la seguente serie stratigrafica:

Piacenziano - Marne bleuastre.

Messiniano $\left\{\begin{array}{l}\text { Marne e sabbie argillose grigiastre o brune, oppure } \\ \text { grigio-giallo-rerdiccie. } \\ \text { Sabbie giallastre e calcari grumulosi. } \\ \text { Conglomerati in lenti entro le sabbie. } \\ \text { Sabbie griallastre, arenarie straterellate con letti ciottolosi. }\end{array}\right.$

Tortoniano $\left\{\begin{array}{l}\text { Sabbie marnose straterellate grigie. } \\ \text { Marne ed argille bleutastre. } \\ \text { Marne sabbiose grigiastre fogliettate. }\end{array}\right.$

Nella parte meridionale delle colline di Talenza-Alessandria la formazione messiniana, che comincia ad apparire presso Talle S. Bartolomeo tra il Tortoniano ed il Pincenziano, si sriluppa tosto estesissimamente rel'so l'Orest tanto che costituisce da sola pel' lunghissimo tratto le colline tra la pianura padana e quella alessandrima.

La costituzione della serie messiniana varia alquanto d'alto in basso. Cioè nella parte inferiore osserransi pel lo più numerosi banchi sabbiosi, giallastri, talora arenacei, più o meno grumuloso-calcarei (C. Ferrero), spesso con strati o lenti ghiaioso-ciottolose perfino conglomeratiche (Sud di Bric Paradiso); è per questa natura litologica piuttosto resistente del Messiniano inferiore che ci spieghiamo come esso costituisca generalmente rilievi collinosi abbastanza spiccati (Bric An- 
tonino, Bric di C. Ferrero, Bric Rampina, Bric del Pero, Bric Paradiso, ecc.. ecc.) sopra ai bassi colli tortoniani; spesso le sabbie marnose si presentano lipetutamente straterellate. carattere che osservasi specialmente nel passaggio tra il Mcsiniano ed il Tortoniano.

La parte superiore del Messiniano è specialmente rappresentata da marnc ora sabbiose ed ora argillose, spesso alternate con reri banchi di sabbie grigio-giallastre; gli strati argillosi sono spesso alquanto ondulati e rariegati, cioè grigio-rerdastri, giallo-rossicci, brunastri, ecc., carattere che redcmmo già altrore prescntarsi frequente nella formazione messmiana. Talora le arenarie messinime sono alquanto fossilifere, come per esempio al Bric Paradiso. Però il grande sriluppo della coltivazione, specialmente riticola, in queste regioni fa si che è spesso difficile l'esaminarne la costituzione gcologica.

Quanto alla tettonica essa è abbastanza regolare nel complesso, quantunque non di rado osselrinsi altcrazioni locali abbastanza spiccate; nclla parte meridionale delle colline in esame da Valle S. Bartolomeo al Bric Paradiso gli strati pendono di $15^{\circ}$ a $20^{\circ}$ alla base, e di $10^{\circ}$ a $15^{\circ}$ in alto, rerso il Sud-Sud-Orest: inrece mella parte settentrionale delle stessc colline la pendenza è all'incirca rerso il Nord. Tra il Bric del Paradiso e la Talle Bertolini si compie la parte occidentale dell'elissoide messmiana, pel cui i banchi quiri pendono generalmente rerso l'Orest di $20^{\circ} \mathrm{C}$ piủ. Più ad occidente la stratigrafia delle colline mediane della zona messmiana diriene irregolare in causa del rappresentare esse l'asse un po' rariabile dcll'anticlinale; coṣi troriamo gli strati quasi orizzontali al Bric della Francia, pendenti in rarie direzion: (con preralenza ad Est) melle colline di Frascondino, formanti cupola al Bric Iongrande ecc.; in queste regioni sono sriluppatissimi i banchi di sabbie e di arenarie gialle straterellate alternati cogli strati marnosi.

Vcrso S. Salvatore la stratigrafia diriene più regolare per l'emersione dclla zona toitoniana: quiri i depositi messiniani sono rappresentati da sabbie e da marne grigiastre straterellate, alteruate con strati arenacei giallastri, durissimi, fogliettati, il tutto con una pendenza di $20^{\circ}, 30^{\circ}$ e più, ma abbastanza regolare rerso il Sud-Est; la durezza di certi banchi arenacei del nessiniano ci spiega qui, come nei colli di Talenza, l'elerazione di certe colline, cosi della Torre di S. Salratore, di Bric Lorenzo, di Bric Carlotta, cec., ece.

Ad Orest di S. Salvatore, nclla parte settentrionale del sistema collimoso sviluppasi ampiamente la zona messiniana a banchi per lo più leggerissinamente inclinati a Nord ed alquanto ondulati; nella parte inferiore di questo orizzonte osserrasi talora, come tra Bric S. Pietro e Taldolenga, un graduale passaggio al Tortoniano per mezzo di strati marmosi ed argillosi"grigi o brunicei, spesso con grumuli biancastri di 
caleare impuro; nella parte media e superiore predominano le marne grigiastre, talora straterellate, alternate con strati sabbiosi e eon lenti calcaree, eome ad esenipio presso la C. La Vallara dore trorasi pure una sorgente solfurea al fonclo della valle.

Più ad Orest compaiono pure lenti ghiaioso-ciottolose, come ad esempio in Val Guaseona, dore esse danno origine a sorgenti acquee. Ma piu importante è lo sviluppo delle lenti ealearee, più o meno grumolose, frammezzo alle marne ed alle arenarie variamente inclinate, spesso quasi orizzontali; ne sono eostituite parti notevoli del Briceo Stagnina (dove trovansi pure fossili littoranei, come Pecten, Lithothemnizm, eee. spesso con lenti eiottolose), del Bricco del Pogrio, del Brieeo Cimitero di Lu, e, per quanto si puỏ redere, anche della parte alta del paese stesso di Lu. Queste arenarie calcaree, spesso grumulose e eariate, reggonsi eomparire in placche nelle colline della fiazione di Mirabello (C. Annibalini), al Montalberto e nella collinetta ad Est del Molino ntoro di Val Grana. Sulla sinistra di Val Grana rieompaiono aneora per breve tratto le marne messiniane con grumuli calcarei specialmente nella parte inferiore, ma tosto questa zona seompare sotto ai terreni piacensiani della conea plioceniea di Occimiano; è interessante questo grande sviluppo delle lenti calcarce messininne poiehè vedremo queste comparire anche nella parte meridionale delle colline in esame.

Nelle eolline ad Est di Conzano il terreno messiniano appare ancora per breve tratto sotto forma di marne più o meno sabbiose coll grumuli calcarei, eome si pùo osserrare presso C. clel Monte e presso C. Borghina; ma esso riene tosto ricoperto dai terreni piacenziani della grande conca pliocenica di Occimiano.

Queste marne più o meno calcarifere ehe, pur mancanclo di dati paleontologiei, eredo dorer attribuire al ressiniano, appaiono ancori sulla destra di Val Rotaldo nelle vicinanze di C. S. MLaria e sviluppansi poi ampiamente nelle eolline di S. Bermardo, C. Bertrisio, C. del Conte, ecc. Quivi anzi nella costituzione dell' orizzonte in esame osservansi pure arenarie ealcarifere, marne arenace più o meno resistenti, grigio-blenastre o gialliecie, straterellate in modo da ricordare simili orizzonti ehe si sono osservati nella zona messiniana della parte meridionale del bacino piemontese. Tale eostituzione litologica ei spiega la presenza di veli acquei e di sorgenti nelle colline in esame.

Più verso Sud, nelle colline di C. Ble, di C. Mezzana, ece., la zoma messiniana si restringe rapidamente e si riduce ad una sempliee striscia, interrotta tra borgata Coppi e Cellamonte, che si riconosce speeialmente per le sue marne sabbiose grigio-rerdastre o gialliccie od anche nerastre e per i stoi caleari impuri, grumulosi, che osservansi aneora nelle colline di S. Martino, come ad esempio presso C. Cavalla. 
Verso Terruggia la striscia messiniana si allarga alquanto, le sue marne assumono talora la caratteristica tinta grigio-rerdiccia e brunastra (come si puỏ osservare presso C. Rinera); reggonsi ancora qua e lả lenti di calcare grumuloso impuro (come presso C. Passerella); sono assai sviluppati i banchi sabbiosi; infinc a caratterizzare assolutamente questa zona messiniana, che ha un' ampiezza di oltre un Chilometro, compare presso S. Germano una potentissima lente gessosa, escarata su ampia scala per uso industriale.

L'andamento stratigrafico della zona messiniana ora esaminata è abbastanza regolare, cioè con pendenza di circa $15^{\circ}$ o $20^{\circ}$ rer'so l'interno del piccolo seno pliocenico di Occimiano; peró nella lente gessifera di S. Germano possiamo verificare inclinazioni alquanto diverse da quella tipica, ciò che forse si deve solo attribuire a quei disturbi stratigrafici locali che abbiamo gia notato cssere tanto commi altrove nelle formazioni gessose.

Passando ora all'esame del lato meridionale dclle colline casalesi, ad Ovest di S. Salvatore, vediamo come la zona messiniana è noterolmente sviluppata; i suoi strati pendono di $10^{\circ}$ a $20^{\circ}$ rerso il Sud ad un dipresso, talora però sono quasi orizzontali oppure ripetutamente, ma leg’germente, ondulati. Nella costituzione di detta zona, oltre alle marne ed alle argille, hanno una grande importanza speciali banchi sabbiosi ed arenacei grigi o, più spesso, giallastri, spesso straterellati; inoltre lc lenti di calcare cariato, biancastro (talora passante gradatamente ad arenarie), che compaiono già al Bric Lorenzo, si sviluppano poi estesissimamente al Bric di borgata Olimpia e qua e là anche nelle colline piủ ad Ovest, costituendo rilicvi speciali biancheggianti leggermente rossicci per alterazioni chimiche.

Queste lenti calcaree, commiste a banchi arenacei, troransi per lo piu alla base della serie messiniana; così le rediamo costituire in parte $\mathrm{i}$ rilievi ad Est ed Orest di borgata Trisolio (dore colle arenarie appaiono pure lenti ghiaioso-ciottolosc), di Bric Morlantina, ecc.; anzi è spesso l'apparsa di qualche grumulo calcareo che ci arrerte della presenza della formazione messiniana talora maschcrata dalla coltivazione. La dorc il calcare è piil sviluppato esso si presenta giallo biancastro, leggiero, cariato, spesso con grossi vani quadrangolari od irregolari, talora con alcuni ciottolini sparsivi irrcgolarmente. I banchi o lenti ciottolose del Messiniano, a pendenza poco forte, sono costituite di elementi molto arrotondati e generalmente poco roluminosi, per lo più quarzitici, talora serpentinosi, raramente di calcare alberese, di color biancogiallastro nell'assieme ed inglobati in sabbia giallognola. Nelle ricinanze della borgata Trisolio si vede assai bene clie il banco di calcare cariato è coperto direttamente da arcnarie compatte, fine, spesso fo- 
glicttate ed altcrnate con banchi sabbiosi e conglomeratici assai potenti; per lo più il banco conglomeratico principale sta alla base della seric, subito sopra alla zona calcarifera.

Presso Cuccaro la zona messiniana diventa sottilissima ed è rappresentata solo più da pochi strati sabbioso-marnosi inglobanti straterelli calcariferi; il tutto è inclinato di circa $30^{\circ}$ o $35^{\circ}$ verso Sud-Sud-Est, in causa della vicinanza di uno spuntone di Liguriano.

Questi strati calcariferi si possano esaminar bene specialmente alle falde meridionali della collina del Castello di Cuccaro, dove cssi vennero anche escavati per ottenerc calce dolce, come si fece pure in più punti nelle zone calcarifere sopra menzionate.

La striscia messiniana, che scompare quasi dcl tutto presso il cimitero di Cuccaro, si allarga poscia alquanto verso Ovest foggiandosi a placca chc, colle sue marne inglobanti granuli calcarei, costituisce le colline di C. Mellana e di C. Pozzo Marrone.

Ma a cominciare dalle colline di Altavilla e procedendo verso Ovest noi vediamo che la zona messiniana si sviluppa amplissimamente e costituisce da sola vastc regioni collinose; questo fcnomeno è causato dal fatto che il corrugamento che abbiamo constatato nclle colline Villadeati-Alfiano Natta non cessa già a Penango, dove vediamo chiudersi l'elissoide tongriana, ma si prolunga invece sottcrraneamente, direi, verso Sud-Est, manifestandosi specialmente col sollevamento della formazione messiniana i cui strati quindi per un'arca vastissima sono quasi orizzontali o foggiati ad amplissima curva anticlinale da Pcnango a Grana; essi formano invece una leggerissima sinclinale tra Moncalvo ed Altavilla, naturalmente con irregolarità varie, pel' esempio con una piccola sinclinale tra Penango e borgata Bolla per modo che quivi vediamo adagiarsi ampiamente e non interrotti i depositi pliocenici.

Siccomc però questa formazione messiniana, non esscndo stata molto sollevata, potè vcnir ricoperta in massima parte dai terreni piacensiani ed astiani, ne conscgue come sia gencralmente solo al fondo delle vallate che, per erosionc, compaiono qua e là quelle arec messiniane, più o meno vaste, che passeremo ad esaminare brevemente.

Nell'alta valle di Grana, come pure in quelle laterali di Alberetto, di Pozzolo, di Casorzo, cce., la formazione messiniana è messa largamente allo scopcrto per oltre 7 chilometri; essa è rappresentata da marne più o meno sabbiose che inglobano strati o lenti di calcare cariato, come nclla bassa valle Albaretto, nella bassa valle Pozzolo, nei colli di C. Scassola, nell'alta valle di Casorzo, al Bric Moreto, al Bric S. Vito, cec., località tutte dove tali calcari impuri, giallastri, cariati, vengono talvolta escavati per ottcnere calce dolce.

Più importantc a notarsi in quest'ampia area messiniana è la pre- 
scnza di numerose piccole lenti gessose; cosi sotto Casotto Botta (Altavilla), sul fianco orientale della collina di C. Baratta, presso C. Gorgo, alle falde settentrionali del Bric Pievano e delle colline di Montemagno e di Grana, presso il fondo di Val Grana, sia a sinistra sotto il Bric di C. Capretto, sia sul fianco opposto. Quasi tutte queste lenti gessifere rengono ora cscarate e presto saranno completamente esaurite.

Non sono rare in questa zona le sorgenti acquee, spccialmente al fondo della valle.

Nella parte alta di Val Gaminella tra C. del Cavaliere e la ralle di Donco vediamo comparire, sotto alle marne argillose del Piacenziano, diversi banchi marnosi colle solite lenti di calcare cariato. come si può vedere specialmente prosso C. Pozzopregno e sotto il Bric Castervelli; trattasi di un piccolo affioramento messiniuno.

Un'area messiniana, pure completamente racchinsa tra il Pliocene, ma assai più sviluppata dell'ultima accennata, comparc, sempre per' erosione, mell'alta valle della Rotta tra Sassia, S. Desiderio e Calliano.

Quivi infatti rediamo come lc marne messiniane inglobino numerosi letti di calcarc impuro e cariato come osserrasi sotto S. Desiderio nell'alta valle del Rio, sotto C. Montarsone, alle falde settentrionali del Bric del Bosco, presso il Cimitero di S. Desiderio, sotto C. Famulenta, ece.; inoltice osservansi pure due noteroli lenti gessose, escarate abbastanza attivamente, una alle falde occidentali del Bric del Bosco e l'altra lungo la costa meridionale del Bric Montar'sone, presso le cascine dello stesso nome.

Un'ultima area mssininna, isolata fra i terreni pliocenici, appare al fondo della valle della Pictra (Calliano); in questa ralletta le lenti gessifcre sono numerosissime e quasi tutte escavate st rasta scala per modo che non ne è lontano l'esaurimento. Ne notiamo sotto Calliano, presso C. Della Pietra, sopra C. Valsabona, presso C. Durando e sotto C. Vercelli; probabilmente esse fanno parte di un orizzonte solo.

Al termine di Valle della Pietra osservasi che dalle marne arenaceogessifere sgorgano copiose solgenti, di cui una solforosa.

Ritornando all'esame della regolare zona messiniana che scgue le falde della catcna collinosa principale, notiamo come tra il paese di Altavilla ed il Cimitcro esista ma piccolissima lente gessifera; essa è la prima che si incontri sul lato meridionale delle colline Torino-Talenza procedendo da Est ad Orest.

I banchi nessiniani sono generalmente marnosi o marnoso-sabbiosi, alquanto piu resistenti dei terreni tortoniami, sui quali spesso essi costituiscono una specie di gradino; sorente detti terreni messiniani si distinguono, come di solito, per inglobare lenti o banchi calcarci, come ad esempio presso S. Bernardino, presso Berguntino, nelle colline 
di C. Roneo e di Montessino superiore, nell'alta valle Rotaldo, sia sulla sua sponda destra presso C. Borgarello, C. Varvere, sotto la Conceria e nel Brieeo (314) a N. O. di Grazzano, sia sulla sua sinistra nelle colline di C. del Moneo, di C. Avalle, nella eollinetta ad Ovest di C. Belvedere e di fronte a Grazzano nella parte bassa della vaile.

In questo sviluppo della zona messinicuna, talora di oltre 1 Chilom. in ampiezza, ineontrasi una sola lente gessosa, verso la metà della serie, sulla destra di Val Rotaldo di fronte a C. del Monco.

Notiamo il fatto interessante ehe la zona messimiana ora esaminata, nelle eolline di Casorzo dista appena due ehilometri da quella che, sul versante settentrionale della eresta collinosa principale, attornia il seno pliocenico di Oeeimiano, per eui risulta chiaro ehe durante il periodo messiniano csisteva quivi appena uno stretto istmo di terreno oligoeenieo, se pure non esisteva aneora un piccolo braceio di mare ehe faceva eomunicare il golfo di Oecimiano eon quello di Casorzo.

Da Grazzano verso Orest la zona messiniana eonsta essenzialmente di marne sabbiose, grigiastre o giallo rerdieeie, talora bianeastre od anehe rossiecie, alquanto arenaeee, stratelellate, come ad esempio presso C. Veeehia (Ovest di Monealvo); piu avanti rieompaiono le lenti di ealeare eariato, dapprima solo sporadiehe eome nelle eolline di Godio, di C. Speranza (Guazzolo) eec., quindi piủ potenti eome presso C. MIontieello e C. Campasso, finehè esse assumono un notevolissimo sviluppo nelle eolline di Penango al Brie Mongrande, dove esse vengono eseavate su vasta seala.

Le colline messiniane di queste regioni spesso si distinguono anehe ai earatteri esterni per la loro elevazione e per la tel'ra argillosa, rossastra, ehe in parte le rieopre; il calcare talor'a è farinoso, talora duro e cariato, talora anche eompatto; spesso le marne ehe inglobano le formazioni ealearee sono alquanto sabbiose, fogliettate, grigio-bianeastre.

Sorenti le zone ealearifere si riconoseono da lungi per il eolor rossastro del terreno, eolore ehe deriva peró solo da alterazioni ehimiehe verifieatesi alla superfieie del terreno.

Nelle eolline di Penango è poi importante il notare ehe fira le marne ealcaree esistono talora in gran numero resti di Mollusehi (speeialmente di Lucina) viventi nei bassi fondi marini; tali fossili si possono raeeogliere abbondantemente nelle eave di C. Baldovino, dove il ealeare spesso assái duro, bianco-bleuastro, talvola pseudo-alberese, in aleune lenti speeiali pare un rero ealeare lumaehella per esserc zeppo di valve di Lamellibranehiati.

Nella eonea di Monealvo, e probabilmente in relazione con tale eonformazione partieolare, (sia perchè in una conea tranquilla potè meglio formarsi il deposito gessoso, sia perchè esso ci si presenta ora quasi 
completamente denudato) troriamo enormemente sviluppata la formazione gessifera (cscarata in molti punti) che assume talora un'ampiezza di quasi 1 chilom., come tra Guazzolo e la linea ferroriaria, e si prolunga ininterrotta da C. Chioso sino borgata Gessi, formando ad un dipresso l'orizzonte medio del Messmiano di queste regioni.

Generalmente la formazione gessosa è accompagnata da marne argilloso-sabbiose, grigio-biancastre, rerdastre od anche rossiccie per alterazione chimica, spesso con giranuli marnoso-calcarci irregolarissimi.

Quanto al rapporto della zona messiniana ora esaminata, tra Cuccaro e Penango, cogli orizzonti fra cui cssa è inglobata, si puỏ dire che ri esiste gencralmente una trasgressione stratigrafica più o meno forte, ma piuttosto regolare; il passaggio tra ressiniano (a marne e sabbie grigiastre o grigio-biancastre) e Tortoniano (specialmente marnoso) è sorente abbastanza graduale, tanto che talora la loro distinzione si dere basare sull'apparizione delle lenti calcarifere o su caratteri orografici; forte però è la discordanza che presentano i banchi messiniani di Guazzolo-Penango coi sottostanti terreni oligocenici.

E pure alquanto trasgressiramente che i depositi pliocenici si appogrgiano sui terreni messiniani; tant' è che talora i banchi astiani sono da essi separati solo per mezzo di pochi stratcrelli di Piacenziano, cd anzi questi talrolta vi mancano anche completamente.

Proseguendo l'csame della zona messiniana ad Orest di Penango, rediamo come essa, talora coll'ampiezza di quasi due chilom. e coll'intermezzo di soli pochi banchi elresiani e tortoniani, da cui discorda alquanto stratigraficamente, fascia a Sud l'elissoide tongriana di Alfiano Natta; restringesi alquanto rerso Tilladeati, per nuoramente ampliarsi noterolissimamente relso Orest.

In tutta questa zona di sriluppo il Messimiano è essenzialmente rappresentato da marne grigiastre, talrolta alquanto arenacee, spesso inglobanti banchi o lenti di calcari giallastri, cariati, come rediamo nelle colline di C. Saluta, di C.S. Lorenzo e C. Lusengo, di Casarello, di Cardona, di S. Roceo, alle falde Sua-Orest di Bric S. Giolgio, ece.

In questa zona non mancano neppurc le lenti gessifcre, quantunque tutte piccole, spesso peró importanti perchè ei segmalano la presenza del Messiniano anche là dore non esistono tagli naturali per rivelarcelo, cosi in Tal d'Inralle (Sud-Orest di Penango), dore troviamo aleuni grumuli gessosi sulla sponda sinistra poco a monte del Molino Talsesio.

Sottili e corte lenti gessose possiamo pure rerificare poco ad Orest di Penango quasi di fronte a C. Tiorba, ad Est ed Orest dello sprone collinoso di C. Castelmerlino, a Sud di Alfiano tra C. Gambagrossa e C. Borghi, nelle immediate ricinanze di C. Gesso (alta ralle Razzano) e presso C. Panissa (Cardona). 
Dopo il restringimento che la zona messiniana presenta presso Villadeati, a causa specialmente di una specie di conca che quivi formano i depositi piacenziani, i terreni ora in esame dirigonsi regolarmente verso Orest con un'ampiezza media di oltre un chilom. e earatterizzati molto bene dalle tipiche formazioni calcarifere e gessifere.

Le lenti gessifere, che formano quasi orunque oggetto di escarazione più o meno attiva, costituiscono lenti irregolari, di varia forma, e di ampiezza e potenza pure svariatissime. Tediamo infatti che tra C. Vallone presso Villadeati e C. Allovia nell'alta Val del Pozzo compare una lunga e stretta striscia gessosa; un'altra lente assai piủ ampia, lunga oltre un chilom., osservasi tra l'alta valle del Pozzo, la Torre S. Pietro ed il Bric Stiora; una larga area gessifera si incontra nuovamente nelle colline di C. Cavagna e C. La Corte; una lumga e stretta zona gessosa si vede poco piu ad Orest svilupparsi dalle vicinanze del Molino Madonna sin oltre S. Antonio presso C. Valletto; piccoli accentramenti gessosi si osservano nella valletta dei Bauchicri, sia sotto C. Vajo, sia alla sua congiunzione colla Valletta del T. Versa.

Potentissima è la formazione gessifera tra lc borgate Gesso e Banengo, tanto che la parte superiore di questa regione collinosa si presenta spesso in forma di grosse monoliti luccicanti di clistalli di Gesso, monoliti prodotte sia da erosione naturalc sia da escavazione artificiale, quivi attivissima; questa zona gessosa si estende per poco in Val Bauchieri ma discende verso Ovest sino al fondo di Val Bravie nelle vicinanze di C. Viassa.

Piccolissime lenti gessifere troviamo poi ancora poco sotto borgata Gesso alla base del Messiniano, quasi di fronte a C. Sabbione (fra marne sabbiose griorio-giallastre), alla borgata Vastapaglia, presso C. Tane, ed in due punti sulla sponda sinistra di Val Fabiasco quasi di fronte a C. Vairola.

Per lungo tratto mancano, ad Ovest di Piovà, gli affioramenti gessosi; ne vediamo comparire un piccolo spuntone nella parte bassa della profonda ralletta tra Schierano e Pino d'Asti quasi sotto S. Martino; altre sottili lenti incontransi presso C. Bonetta (Sud di Albugnano) e presso C. Rubattini; infine una noterolissima lente gessosa sviluppasi da C. Bombardone a Fornace S. Martino presso Moncuceo, costituendo gran parte delle colline dei Canova presso Bardella ed essendo quasi ovunque attivamente escavata, sia perchè assai potente, sia perchè essa rappresenta la lente gessifera più oceidentale delle colline Torino-Valenza; infatti piu ad Orest compaiono solo più lenti ealcarifere, finchè si perdono anche queste completamente.

Quanto alla posizione delle lenti gessifere nella serie dei terreni messiniani pare che esse si debbano specialmente includere nella 
parte media del Messiniano, quantunque reggansi non di rado anche verso la parte basale di quest'orizzonte e talrolta eziandio immediatamente sotto ai terreni piacenziani, come si osserra sopra le Fornaci di Briano (Moncucco); in questo caso però credo si abbia che fare con una trasgressione stratigrafica alquanto più accentuata, per quanto regolare, di quella che esiste generalmente tra Piacenziano e Messiniano, come d'altronde talora si verifica anche tra questo orizzonte ed il sottostante Tortoniano.

Lc esaminate lenti gessifere sono inglobate in marne piủ o meno sabbiose, talora arenacee, spesso calcarifere, che costituiscono la massima parte della zona messiniana,

Le lenti o strati calcariferi (talora utilizzati per estrazione di calce dolce) sono specialmente sviluppati a Sud di Murisengo, nelle ricinanze di C. Crocetta e nelle colline di II. Lungo e di C. Zucchi; li ritroriamo in piủ punti al Bric Stiara assieme a marne sabbiose e ad arenarie, talora con fossili marini come presso Costanieto; tali strati si mostrano assai sriluppati nelle colline di S. Carlo e di borgata Costanieto, formando colline a ripidissimi pendii.

Lenti calcarifere costituiscono il rialzo che osservasi immediatamente a Sud del paesello di Tufo; riscontransi pure sotto C. Termine, assicme ad arenarie ricche in fossili marini, specialmente Pecten, Cardium, Ostrea, Cidaris, frammenti di Bambusa, ece. In dette colline si può osservare in complesso la seguente serie stratigrafica: Astiano - Sabbie marnose giallastre con fossili di littorale.

Piacenziano $\left\{\begin{array}{c}\text { Narne bleuastre assai potenti con fossili di mare abba- } \\ \text { stanza profondo. } \\ \text { Talora banchi sabioso-arenacei giallastri con fossili di } \\ \text { littorale c talvolta con lenti ghiaiose. } \\ \text { Narne azzurrastre ricchissime in fossili marini. } \\ \text { Banchi sabbiosi. }\end{array}\right.$

Messiniano Lenti gessifere alternate o sostituite da lenti calcarifere. / Banchi di calcare impuro, grumuloso, cariato.

Tortoniano - Narne grigio-bleuastre.

Nelle colline di S. Giolgio e di Montiglio molti banchi sabbiosi si alternano con marne nella costituzione della zona messimiana clie laggiunge talora un'ampiezza di oltre due chilometri e mezzo.

A Sud di Cocconato continuano a mostrarsi sviluppatissimi i banchi marnoso-arenacci, calcariferi, specialmente nella parte inferiore del Messiniumo, come redesi assai bene nelle colline di C. Rosangana, di C. Agnese, di C. Pracosto, di C. Tajo, ece.

Nelle colline di Bancngo e di Case Sabbioni, dore sonri pure lenti calcaree, appaiono eziandio fia le marne sabbiose del Messinano al- 
eune lenti ghiaiose, ad elementi però non molto voluminosi; notiamo ancora qui l'apparsa di una sorgente d'acqua fortemente g'essata che osservasi al fondo di Val Bravic, sotto le Case Vo.

Ad Ovest di Val Fabiaseo le lenti calcarifere divengono piu numerose e più potenti, quindi sono cscavate in parecchic località; le possiamo osscrvare nelle colline di C. Vairola, di Bric Capella, presso lc casc Fornace (dove si trovano anche alcuni resti fossili), nelle colline di C. Pozzo, di S. Martino, di S. Francesco (Pino d'Asti) e di C. Bonetta; quivi veggonsi pure lembi delle tipiche marne nerastre che notammo cosi abbondanti nella parte meridionalc del bacino picmontese.

Altre lcnti di marne calcarifere esistono più ad Orest nelle colline di S. Michele, di Bardella, di C. Ciandro (Monenceo), di S. Lorenzo c Barbasio, nonchè in Val del Lago d'Arignano, sia dal lato della C. Calcinera (cosi denominata appunto da cave di Calcare grumuloso, concrezionato, spesso a frattura poliedrica) sia presso Marentino.

Infine le ultime lenti di questi grumuli calcari un po' sriluppati osservansi sull'alto delle colline di Tetto Andio e presso C. Fruttero; infatti in seguito verso Ovest la zona messiniana è solo più rappresentata da marne piủ o meno sabbiose, grigiastre, talora con gr'umuli biancastri, marnoso-calcarei, talvolta alquanto straterellate, talora invece senza aleun carattere csscnziale che serva a distinguerle dai banchi tortoniani, tant'c̀ che questo fatto (assieme al grande sviluppo del loess e della coltivazione ed alla profonda decomposizione di tutti i terreni) fa si che nella porzione occidentale delle colline torinesi riesca incertissima la delimitazione della zona messiniana, la quale d'altronde ci rappresenta un deposito marino e quindi non offre più quei carattcri così differenziali che si sono riscontrati generalmente nel Messiniano delle altre regioni piemontesi.

\section{Riassunto.}

Se si dà uno sguardo generale alla formazione messiniana del bacino terziario piemontese, si vede come essa vi si mostri ampiamente sviIuppata c presenti interessantissimi fenomeni, mentre finora non ne era stato fatto alcun studio minuto c generale.

Il fatto più importante a notarsi è la natura stessa della formazione messiniana che rappresenta essenzialmente un deposito di basso fondo marino od anche di maremma, carattere quest'ultimo che è però più accentuato nella parte meridionale del bacino in esame che non nella sua partc settentrionalc.

L'indicata natura dei terreni messiniani è provata non solo dai dati 
paleontologici, ma eziandio da quelli litologici; infatti fra i depositi littoranei di marne, sabbic e conglomerati, talora ad clcmenti roluminosissimi, incontrasi spesso formazioni calcaree e gessifcre le quali noi sappiamo depositarsi quasi esclusiramente nei bassi fondi marini, specialmente presso il littorale dei mari chiusi o quasi chiusi.

La grossezza che presentano talora gli elementi ciottolosi del Wessiniano presso la catena alpino-appenninica dimostra quanto in quell'epoca siano state potenti le correnti acquee e conseguentemente anche come siano state allora assai grandiose le precipitazioni atmosferiche.

La seric messiniana presenta, ncl complesso, all'incirca la seguente successione stratigrafica:

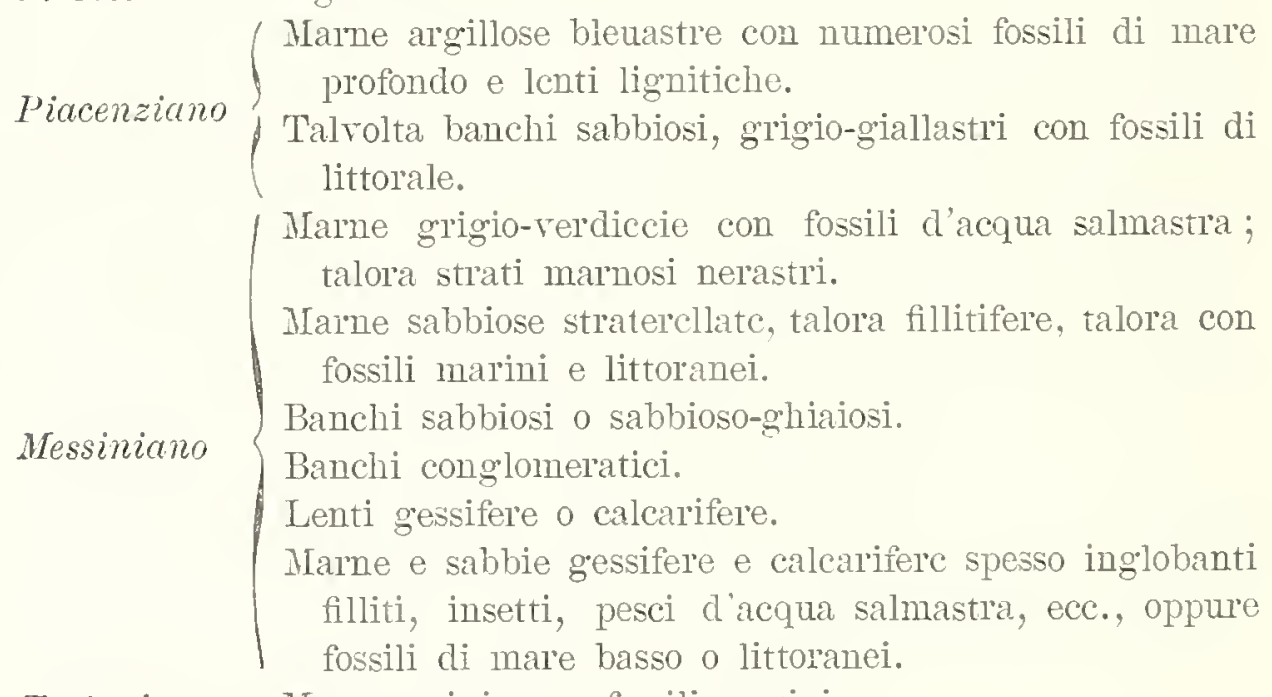
Tortoniano - Marne grigie con fossili marini.

L'orizzonte messiniano si presenta come una zona piủ o meno ampia che costituisce nel bacino piemontese una specic di irregolare elissoide, interrotta però ad Est ed Orest, e che inoltre abbraccia anche la parte oricntale delle collinc Casale-Valenza; la comparsa, sopra esaminata, di piccole zone messiriune entro l'area pliocenica è doruta solo a speciali cupolc di sollevamento che però non alterano il regolare andamento generale del terreno messiniano, i cui strati generalmente inclinano di solo pochi gradi verso il centro del bacino.

Non è molto grande la potenza dclla serie messiniana che generalmente misura solo 40 o 50 metri di potenza, quantunque in alcume località, dove compaiono i banchi ciottolosi, lo spessore dell'inticro orizzonte possa anche raggiungere, se pure non oltrepassare, i $200 \mathrm{~m}$.

La massima elcvazione a cui giunge il Messiniano inferiore è di circa $550 \mathrm{~m}$., mentre invece generalmente l'altezza sul livello marino delle colline messiniane oscilla fra i $200 \mathrm{~cd}$ i $300 \mathrm{~m}$.

Il terreno messiniano, meglio di tutti gli altri orizzonti terziari, si 
può distinguere dai terreni fra cui è compreso non solo per la natura sua alquanto speciale, ma perchè talora si osserva una qualche trasgressione stratigrafiea, generalmente però molto regolare, tra esso ed i terreni sotto e soprastanti; tuttavia per estensioni vastissime si puó notare un passaggio abbastanza graduale fra i banchi del Messiniano ed i banchi sia del Tortoniano sia del Piacenziano, tant'è che non sempre ne riesce facile la delimitazione.

I fossili del Messiniano piemontese sono in parte d'acqua salmastra (Dreissena, Cyrena, ddachna, Veritodonta, Melania, Melanopsis, IIydrobia, ecc.), e questi sono i più importanti perchè earatteristici, ma in parte anche marini, nel qual caso presentano una molto maggiore affinità con quelli del Piacenziano che non con quelli del Tortoniano.

I fossili marini trovansi specialmente nel Hessiniano inferiore e medio, quelli salmastri invece nel Messiniano superiore; alle falde delle colline Torino-Valenza, dove è specialmente sviluppato il Messiniano medio ed inferiore, troviamo solo fossili marmi, spesso però di littorale. 


\section{CAPITOLO XIV. PIACENZIANO.}

\section{Studi anteriori.}

I terreni pliocenici che passeremo in esame attrassero sempre l'attenzione dei geologi sia italiani che stranieri, i quali ebbero a visitare il Piemonte; però anche in questo caso, come si è osserrato rigurardo ai terreni terziari più antichi, è specialmente alla raccolta dei fossili straordinariamente abbondanti e molto ben consertati in detti terreni che si rirolsero le cure di detti scienziati. Quindi se la fauna conosciuta del Piacenziano piemontese non è certamente inferiore a quella che presentano le altre famose regioni fossilifere del subappennino italiano, poco invece è ancora stato detto riguardo al modo di presentarsi e di svilupparsi di questa importante formazione geologica.

Generalmente i depositi piacenziani sono indicati col nome di Pliocene inferiore; nella Carta geologica del Piemonte del Sismonda, arendo questo autore fatto passare la divisione tra Miocene c Pliocene ad un dipresso tra i terreni messiniami e quelli piacenziani, il Piacenziano seguc in complesso abbastanza bene il limite esterno dell'area pliocenica; ma il Sismonda riuni il Piacenziano in una tinta sola coll'Astiano.

Il Pareto adottò già il nome di Piacentino pel Pliocene inferiore, ma non seppe distinguerlo bene dal Wessiniano e neppure dal Tortoniano. Come di solito è specialmente al Mrayer che tocca il merito di arer bene distinto e caratterizzato il Piacenziano piemontese nel suo studio geologico della Liguria, studio che comprende l'angolo Sud-Est del bacino terziario del Piemonte.

Telle recenti carte geologiche sia della Francia, di Carez e Tasseur, sia delle riviere liguri e delle Alpi marittime di Issel, Mazzuoli e Zaccagna, sia delle Alpi Occidentali di Zaccagna, sono separate le aree plioceniche piemontesi in base specialmente alla carta del Sismonda.

A cominciare dal $188 \pm$ ebbi più rolte ad occuparmi dei terreni piacenziani del Piemonte, presentando anche diverse carte geologiche di varie località in cui questi terreni aftiorano ampiamente.

\section{Generalità.}

In complesso la formazione piacenziana ha una facies abbastauza caratteristica di mare alquanto profondo, ciò che ci è prorato sia dai dati paleontologici sia da quelli litologici. Infatti, anche astrazione 
fatta ora dai fossili, per lo piì il Piacenziano del Picmonte, come in generale quello delle regioni subappennine, ¿s rappresentato da marne argillose grigio-azzmrastre che ci dinotano un tranquillo deposito marino formatosi ad una profonditi abbastanza notevole.

Tuttavia se tale ì il modo generale di presentarsi del Piacenziano, vedremo nella deserizione geologica regionale come non di rado eompaiano pure nella sua serie stratigrafiea potenti strati sabbioso-marnosi griallastri ed anehe veri banehi arenaeeo-calearei, talora ghiaiosi, giallognoli, i eui fossili sono speeialmente rappresentati da Molluschi di mare poeo profondo od anehe di littorale. Qucste formazioni littoranee si alternano generalmente eoi depositi di mare urofondo, ma talora rappresentano quasi da sole l'orizzonte piacenziano.

Per la natura litologiea che generalmente presenta il terreno piacenziano, esso eastituisee per lo più eolline basse, rotondeggianti, bianeastre o, per erosione, ampie regioni pianegrianti: generalmente tali regioni sono piuttosto minide a eansa dell'argillosita del terreno.

La eostituzione ehimiea delle tipiehe marne argillose azzurre del Piacenziano, per quanto un po' dirersa da luogo a luogo, ̀̀ ad un di presso la seguente:

\begin{tabular}{|c|c|c|c|c|c|c|c|c|}
\hline $\mathrm{Si} \mathrm{O}^{2}$ & - & & & & & $\cdot$ & • & 0.5145 \\
\hline $\mathrm{CaO}$ & . & $\cdot$ & . & • & • & - & - & 0.1172 \\
\hline $\mathrm{M}^{2} \mathrm{O}^{3}$ & - & • & • & • & • & . & . & 0.1190 \\
\hline $\mathrm{K}^{2} \mathrm{O}$ & . & . & . & . & . & $\cdot$ & . & 0.0154 \\
\hline $\mathrm{Na}^{2} \mathrm{O}$ & - & • & • & $\cdot$ & . & $\cdot$ & . & 0.0294 \\
\hline $\operatorname{Mg} \mathrm{O}$ & . & . & & . & & ${ }^{\circ}$ & . & 0.0131 \\
\hline $\mathrm{Fe}^{2} \mathrm{O}^{3}$ & . & . & & . & . & $\cdot$ & . & 0.0686 \\
\hline $\mathrm{CO}^{2} \cdot$ & . & • & . & • & & . & . & 0.0950 \\
\hline $\mathrm{Cu}$. & . & • & & & & $\cdot$ & traceie & e sensibilissime \\
\hline Perdita & - & . & & & & . & . & 0.0278 \\
\hline
\end{tabular}

Superfieialmente spesso le marne azzurre per alterazione chimica divengono giallastre, per modo che talora simulano le marne astiane.

\section{Caratteri paleontologici.}

Come già ho sopra indieato, i fossili del Piacenziano appartengono per lo piủ ad animali di mare abbastanza profoudo, e si trovano generalmente sparsi e ben eonservati entro le marne azzurre, indicandoci eome esse siansi depositate assai tranquillamente.

$\dot{\mathrm{E}}$ però notevole il fatto ehe là dove nella stessa formazione piacenziana eangia la facies litologiea, cioè si ineontrano banehi sabbiosi giallastri fra le marne azzurre, quivi si osserra pure un mutamento di facies paleontologiea, giaeehè eompare una fauna quasi identiea a 
quclla che vedremo caratterizzare $i$ depositi astiani. $\dot{E}$ per ciò che alcuni non vorrebbero distinguere i terreni piacenziani da quelli $a$ stiani, mentre in verità talc distinzione c̀ giustissima e cor'risponde complessiramente a due fasi distinte e successive del mare pliocenico; solo che, come di solito, tali divisioni dei diversi piani geologici sono relative e non assolute; ed è naturale che i depositi della stessa natura che riscontransi in piani geologici diversi, ma direttamente e gradualmente successiri, prescntino faune affini in corrispondenza diretta coll'ambiente. In generale però la fauna di marc profondo ebbe spccialmente modo di srolgersi nel periodo piacenziano, mentre quella di mare basso trovò un favorerolissimo ambiente di sviluppo particolarmente nel periodo susseguente, l'astiano. Il catalogo paleontologico r'cnderà evidente tale differenza.

Notisi poi che, siccome una gran parte dclle raccolte paleontologiche del Pliocene derivano dai banchi di passaggio tra Astiano e Piacenziano, essendo cssi sempre ricchissimi in fossili (che hanno naturalmente caratteri intermedi, cioc̀ dell'una e dell'altra fauna), ne risultò in molti l'opinione che la fauna piacenziana non sia da staccarsi da quella astiana.

Sono abbastanza comuni nel Piacenziano i resti regetali, specialmente fiammenti d'albero, lignitizzati.

Possiamo qui accennare il fatto che, se si paragona la fauna del Piacenziano del Piemonte con quelle dello stesso terreno del littorale ligure, si trora che quest'ultima ha un carattere di clima alquanto più caldo e per strettissimi punti si avricina a quella tortoniana; questo fatto ci avrerte scmpre piu di quanto influiscano il clima e l'ambiente sulle faune c sulle florc degli orizzonti geologici, poichè in orizzonti contemporanei esse possono csscre molto diverse a seconda delle varie località.

\section{Distribuzione geografica.}

Per quanto la formazione piacenziana costituisca uno dei pì̀ recenti depositi terziari del bacino piemontese, tuttaria, pel grande sviluppo dei terreni astiani, essa appare generalmente solo come una zona attorniante il centro del bacino stesso. Siccome però i suoi strati hanno soltanto una piccolissima pendenza verso l'interno di detto bacino, la zona piacenziana, invece di presentarsi come una striscia più o meno larga, come è generalmente il caso pei terreni più antichi, si presentż inrece spesso ampiamente allo scoperto, in modo particolare sul fondo delle vallate, a causa della profonda erosione postpliocenica: ne derivano quindi quelle espansioni linguiformi che per lo più la zona piacenziana mostra in direzione dell'interno del bacino terziario, che è d'altronde anche un bacino idrografico. 
La distribuzione geografica della zona miacenziana, specialmente nelle colline tortonesi e nelle colline Torino-Valenza (le quali nella parte orientale ne sono quasi del tutto circondate in modo piủ o meno visibile) è assai regolare. È poi notevole la comparsa di una placea piocenziana presso la Verrua sul lato settentrionale delle colline TorinoCasale, poichè tale affioranento ci indica un grande sviluppo del terreno piacenziano, sotto i depositi più recenti, tra le colline Torino-Valenza c la catena alpina, sviluppo che ci è poi provato dalla comparsa di lembi piacenziani alla base stessa delle Alpi; probabilmente la zona piacenziana che, sotto alle alluvioni quatcrnaric della valle padana, fascia le colline Torino-Casale dal lato Nord, s'appoggia discordantemente sui terreni terziari mioeenici ed eocenici di dette colline.

Lungo le falde alpine la zona piacensiana, generalmente ricoperta dai terreni alluvionali e glaciali del Sahariano, è però visibile in piủ punti ad Est della valle dell'Orco sino in Lombardia, ed anzi talora, come in Val Sesia, s'interna notevolmente dentro la regione alpina.

\section{Tettonica.}

Anche regolarissima è quasi sempre la stratigrafia dei terreni piacensiami giacchè essi sono per lo piủ quasi orizzontali od inclinati solo di $3^{\circ}$ o $4^{\circ}$; gli strati pendono leggermente verso l'interno del bacino in esame; tale pendenza divicne alquanto piủ accentuata verso il margine esterno della zona piacensiana, cioè là dove quest'orizzonte s'appoggia sui terreni piủ antichi terziari o preterziari. Vedremo inoltre come in alcuni punti i banchi piacentiani siano anche sollevati di oltre $20^{\circ}$, ma generalmente solo per brevi tratti.

Sono assai frequenti i disturbi stratigrafici locali per scoscendimenti in piccola scala e specialmente per contorsioni delle marne argillose (a causa della subita compressione) o per irregolare deposizione originale degli strati.

\section{Potenza.}

Come di solito, trattandosi di un tranquillo deposito di mare piuttosto profondo la formazione piacensiana non offre una grande potenza, sovente anzi il suo spessore è ridotto a pochi metri lungo la zona di affioramento; generalmente però la potenza della serie piacenziana è di 40 o 50 metri; in alcuni casi essa raggiunge od oltrepassa anche i 100 metri, come ad esempio nelle colline di Marenzana e Cassine (Val Bormida), dove forse arriva a circa 150 metri di spessore, e nelle colline di Gavazzana-Villarvenia, dove il Piacenziano è in parte anche costituito di depositi di mare poco profondo; è probabile che verso il centro del bacino, ad esempio sotto la pianura alessandrina o meglio ancora sotto la pianura padana, la potenza del Piacenziano sia talora anche 
molto maggiore di 100 metri, ma ciò pcl Piemonte non renne ancora provato con profondi pozzi, come si fece altrore.

\section{Altimetria.}

Per quanto i terreni piacenziani non siano molto potenti e presentino poca resistenza all'erosione, tuttaria, siccome in alcuni punti essi vennero deposti contro le attuali falde alpine, pei movimenti sismici essi poterono renir spinti anche maggiormente in alto di quello che osservasi nei terreni messiniani del Piemonte.

É specialmente al piede delle Alpi Marittime che notasi la massima elerazione del Piacenziano le eui tipiche marne argillose, riccamente fossilifere, sono spinte nelle colline monregalesi, tra IIondorì e Ticoforte, all'altezza di circa 570 metri, come redesi alla Cappella Tia Crucis presso C. Regis.

Generalmente però la zona d'affioramento dei terreni piacenziani trorasi tra i 200 ed i 300 metri sul lirello marino e certamente nella curra che essi fanno nel bacino piemontese essi si abbassano talora ad un livello anche inolto inferiore a quello attuale del mare.

Alle falde settentrionali delle Alpi centrali osservasi che la formazione piacensiana si solleva ad oltre 250, 300 metri, ed anzi lả dore essa si addentra molto nella regione alpina, come in Val Sesia presso Crevacuore, Guardabosone, Talduggia, ece., quivi essa raggiunge ed oltrepassa anche d'alquanto i 100 metri d'elerazione.

\section{Rapporto cai terreni soito e somrastanti.}

Si è gia osservato nel precedente capitolo come tra il Piacensiano ed il Messiniano non sia generalmente difficile la distinzione, a causa dclla diversa natura litologica e paleontologica che essi presentano, nonchè di una piccola e regolare trasgressione stratigrafica che talrolta si osserva tra i due orizzonti geologici: notammo peró che con tutto ciò talvolta la delimitazione del Piacenziano dal Nessiniano riesce alquanto difficile ed arbitraria, esistendo un graduale passaggio fia i terreni che li costituiscono.

Studiando il passaggio del Pincenziano all't stiano si vede quasi orunque che esso si presenta talmente graduale e con tali altermanze litologiche e paleontologiche che la delimitazione dci due orizzonti riesce quasi scmpre affatto incerta ed arbitraria; non è meno rero perỏ che queste due formazioni osservate ncllo assieme sono generalmente così spiccatamente diverse che è del tutto naturale il tenerle distinte.

L'indicato passaggio si compie specialmente per m'alternanza di strati marnoso-sabbiosi, g'rigio-giallastri o giallo-rossastri, con strati marnoso-argillosi azzurrastri, nella parte superiore del Piacenziano; rediamo 
poseia eomparire piủ in alto veri banchi sabbiosi giallastri con fossili di mare poeo profondo, di littorale, e passiamo così all'Astiano ehe però nella parte inferiore ed anehe medio-inferiore presenta aneora ripetute alternanze di strati marnosi o marnoso-argillosi grigio-bleuastri eon fossili di mare abbastanza profondo, donde deriva l'impossibilità di una netta delimitazione tra i due terreni in questione, poiehè essi si susseghono gradatissimamente.

Generalmente però, tolte le indُieate oscillazioni, la distinzione dei due piani risulta in eomplesso abbastanza facile a causa delle differenze sia di eolore, sia di fossili, sia di natura litologiea, ehe presentano gli orizzonti in questione; tale delimitazione è però aneor piil faeile quando tra essi csiste una leggera trasgressione stratigrafiea come vedremo verificarsi in alcune regioni.

\section{Località fossilifere.}

Rispetto ai terreni mioeeniei, per quanto essi siano quasi sempre più o meno fossiliferi, si sono potute indicare aleune località ove per eause speeiali i resti organici si trovano pii abbondanti. Invece rispetto ai terreni piacenziani si può dire in generale ehe essi sono quasi ovunque straordinariamente riechi in fossili ed è anzi questo un loro earattere spieeatamente distintivo.

È quindi inutile segnare la lista delle loealità ove più numerosi si riseontrarono $\mathrm{i}$ fossili, giaeehè tale riechezza dipende in gran parte solo dalle rieerehe piủ o meno lunghe, più o meno aceurate, dall'esame di certi banchi o di certi altri, piuttosto che non da una reale maggior abbondanza locale in fossili, quantunque anche questo fatto talora si verifiehi per cause speeiali.

Il Piacenziano è in Piemonte, eome in generale in Italia, un vero maseo inesauribile di fossili plioeenici, quindi non indieheremo qui le loealità ehe presentano maggiori riechezze paleontologiehe e ne faremo inveee solo aeeenno nel eorso della deserizione regionale.

Le famose loealità fossilifere di Villavernia, Volpedo, Castelnuovo d'Asti, Viale presso Montafia, Vezza d'Alba, M. Capriolo presso Bra, Masserano, eee., debbono specialmente la loro rinomanza all'esser state, per cause speeiali, percorse più attentamente e più a lungo da ehi si oceupa di rieerehe paleontologielie.

In generale $\mathrm{i}$ fossili sono meglio eonservati nelle marne azzurre molto argillose ed abbondano poi speeialmente verso la parte superiore del Piacenziano là dove le marne divengono alquanto sabbiose, passando gradatamente all'Astiano.

Tuttavia devesi notare ehe per la rieerea di certi Foraminiferi e di certi Braehiopodi, generalmente piuttosto rari, è importante il margine 
esterno di quella zona pliocenica che forma una specie di seno tra Casalc e Vignale, specialmente nci dintorni di Castel Lignano. Ma, ripcto, il Piacenziano del Piemonte è quasi orunque ricchissimamente fossilifero e quindi è inutile indicare località speciali a tale riguardo.

\section{Descrizione geologica regionale.}

Trattandosi di un terreno che, per quanto esteso ed importante, ha una facies generale litologica c paleontologica abbastanza costante e conosciuta, non è il caso di dilungarsi nella sua descrizione regionale.

Il Piacenziano è fra i terreni terziari marini del Piemonte quello che si può osservare piủ a Sud-Orest presso le Alpi Marittime; lo riscontriamo infatti, colle tipiche sue marne azzurre fossilifere, in Tal Pesio ancora a monte di Pianfei (dove tocea i 500 metri circa di elevazione) ed in Val Brobbio sin presso il paese di Margarita.

Da questo punto discendendo la Val Pesio rediamo che, se per un breve tratto, tra Morozzo e Crava, le alluvioni villafranchiane (con una trasgressione stratigrafica piuttosto manifesta, per quanto abbastanza regolare) mascherano completamente i tcreni piacenziani, questi in scguito si mostrano potentemente sviluppati ed ovunque straordinariamente ricchi in fossili; è interessante un piccolo banco sabbioso-ghiaioso che trovasi fra le marne a livello del Pesio quasi sotto Roccadebaldi, giacchè quivi, assieme a molti resti vegetali lignitizzati, troransi pure Hetix, Cassidula, ece., ciò che ci indica lo sboceo di una corrente proveniente da terra ed un regime littoraneo.

Il terreno piacenziano, sempre cogli stessi caratteri litologici e paleontologici, si può seguire lungo tutti i confluenti del Pesio, specialmente lungo il torrente Pogliola sino alla borgata Vigliani dore arriva ai 500 metri di elevazione, venendo coperto dalle marne sabbiose dell'Astiano; simile altezza raggiunge pure il Piacenziano nella ralletta di C. Grissia, poco sotto detta Cascina, dore si puỏ esaminare molto bene il passaggio tra Piacenziano ed Astiano.

In alcuni banchi marnoso-sabbiosi della Tal Pesio, specialmente presso il ponte, si possono raccogliere nunerosi resti di Pteropodi (Cleodora pyramidata, Cuvieria intermedia, cce.); nella stessa localita, solo più in alto, cioè verso Breolungi e Coppa d’Oro, si osserva che il Piacenziano supcriore è in gran parte costituito di sabbie grigiastre ed anche grigio-giallastre, spesso però alternate e ricoperte dai tipici banchi marnosi azzurrognoli.

Sotto Magliano Alpi le marne argillose pincenziane, spesso con Metula mitraeformis, si appoggiano alle marne compatte del Tortoniano o direttamente o coll'intermezzo (specialmente sul lato destro della vallata) di marne grigio-giallastre attribuibili forse al Messiniano. 
Si è già osservato nel precedente capitolo come in Val Branzola esista presso S. Giovanni una netta sovrapposizione del Piacensimo sul Messimimo: risalendo tale valletta si continuano a vedere (con qualche interuzione per cansa delle alluvioni quaternarie) le marne piacenziane sin oltre C. Canarero c, in Val Fenestrera, sin oltre C. Puntura; in Valle Ellero i banchi piacensiani si spingono molto a Sud sul lato sinistro, sovrapponendosi direttamente, ed alquanto trasgressivamente, sulle marne elveziane; cssi però sono quasi completamente mascherati dalle alluvioni terrazziane.

亡̀ molto importantc lo sviluppo del Piacenziano nelle colline monregalesi dove la sua presenza non fu finora mai neppure supposta, mentre invece esso si presenta con tutti i soliti tipici caratteri litologici e paleontologici.

Infatti sulla collina su cui sta Mondovi-Piazza possiamo in diversi punti (specialmente discendendo rerso Carassonc) constatare la presenza delle marne azzurre sotto all'Astiano, ed inoltre nelle profonde incisioni prodottc dai rivoletti nella parte occidentale di detta collina si può osselvare come sui banchi elveziani, a ciottoli voluminosi, sovrappongansi discordantemente marne argillose che, inclinando leggermente a NordOvest, costituiscono un velo acquco assai notevole cd assai regolare, caratterc solito delle argille piacenziane quasi impermeabili.

Le colline piacenziane del Monregalese sono generalmente rotondeggianti e giallastre; talvolta il Piacenziano è tipicamente azzurro o solo giallastro alla superficic per alterazione chimica, talora invece csso è alquanto sabbioso, grigio-giallognolo, come per esempio al Bricchetto.

Quanto ai carattcri paleon tologici essi sono osscrvabili nettissimamente in molti punti ad Est di Mondovi-Piazza, specialmente al Bricchetto, al Pílone Viriglio, attorno alla C. Torrazza, nclle vicinanze di C. Torre rossa c spccialmente presso la Cappelletta Via Crucis sotto Villa Regis, dove le marne piacensiane, inclinate di soli pochi gradi verso il Nord circa, si presentano sollevatc ad oltre 560 metri, l'altitudine massima raggiunta dal Piacenziano in Picmonte. In tutte le sorraccennate località dei colli monregalesi si possono raccogliere in quantità grandissima c ben conscrvati i fossili tipici del Piacenziano (Filliti, Foraminiferi, Echinodermi, Lamcllibranchiati, Pteropodi, Gasteropodi, ecc.), alcuni anzi rari altrove, come ad escmpio ccrti Crostacei.

D'altronde la presenza dei terreni piacenziani sull'alto delle colline monregalesi non ha nulla di straordinario, rappresentando essi la naturale continuazione di quelli csistenti sulla sinistra dell'Ellero.

L'imbasamen to dell'ampio altipiano di R. Banale è costituito specialmente di argille piacenziane che possiamo però osscrvare solo in alcuni pochi punti, così per esempio in un piccolo burrone a Nord di S. Giu- 
seppe (Magliano), più nettamente nel Rio Richelma e nel rio Lama Grande (dove redesi presso C. Mondini la diretta sorrapposizione del Piacensiano al Tortoniano), ma specialmente nel rio Rilaretto che gia nominammo altrove per lo sviluppo di una zona messiniana che sopporta le marne argillose e sabbiose del Piacenziano quivi, come orunque, straordinariamente ricco in fossili.

In Val Mondalavia i terreni piacenziani, sorrapponentisi ad Est sulle marne gessifere del Messiniano, sviluppansi ad Orest sin presso i pacsclli di Burey e d'Isola essendo poscia ricoperti da una sottile formazione astiana. A Nord di Bene-Tagicnna la zona piacensiana rimane per lungo tratto ricoperta dalle alluvioni antiche del Temazsiano e ricompare solo più nelle profonde incisioni di Tal Stura e dei suoi tributari, noncliè di Tal Tanaro.

In Val Tanaro incominciano ad incontrarsi alcuni banchi piacensiani, coprenti la potente pila dei terreni messiniani, sotto il paesello di Priosa; ma li vediamo poco dopo sviluppatissimi ed anzi per un certo tratto costituenti quasi tutto il fondo della rallata, che quivi naturalmente si presenta notevolmente ampia (Isorella-Bric Diarolo).

Sulla destra del Tanaro esistono alcunc espansioni, direi, del Piacenziano sul Messiniano, ma trattasi solo di placche irregolari, sottili, di difficile delimitazione e che riconosconsi specialmente per il color biancastro delle marne $\mathrm{c}$ per i resti di Ostrea cochlear; 'a sorrapposizione del Piacenziano sul Messiniano si compie quindi generalmente con una trasgressione stratigrafica più o meno spiccata, ma abbastanza regolare. Col tempo, per l'erosione, la coltivazione, cce., alcuni lembi sottili di Piacenziano scompariranno completamente, fatto d'altronde assai comune per gli ultimi banchi che si appoggiano sul Messiniano.

Sulla sponda sinistra del Tanaro, tra Trifoglietto e Cherasco, le marne piacensiane sono spesso alternate con banchi sabbiosi od anche leggermente arenacei grigiastri.

Risalendo l'incassata ralle della Stura di Cuneo si osservano, per oltịe 15 chilom. le marnc piacenziane orunque riechissime in resti fossili ben conservati; lo stesso dicasi delle profonde rallette tributarie di destra, cioè quelle del rio Crosio (dove reggonsi ripiegature di strati e dove talora le marne si presentano alquanto impregnate di petrolio), del rio Giarana, del rio Angetta (dore spesso osservansi banchi sabbiosi od anche sabbioso-ghiaiosi grigio-giallastri, con fossili di littorale, alternati eolle tipiche marne piacenziane), del rio Glidone (lungo il quale si possono vedere bellissimi esempi di ripiegamenti degli strati per compressionc), del rio di Cherasco, ece., sino al rio Veglia, dove si può stupendamente osscrvare, come d'altronde anche lungo le cosidette rocehe di Salmour, il gradualissimo passaggio tra Piacenziano ed Astiano, per cui incertissima ne riesce la delimitazione. 
Notiamo in gencrale come dalle falde delle Alpi Marittime a Cherasco i terreni piacenziani si sono sempre abbassati gradatamente, cioc̀ da oltre 500 a solo più 200 metri od anche meno, come allo sbocco della Stura di Cuneo nel Tanaro; però se la formazione piacenziana si va gradatamente abbassando verso il centro del bacino terziario, cioè verso Nord-Est, essa conserva però generalmente verso Nord-Ovest un'elevazione abbastanza costante come si può ad escmpio osservarc sotto Bra dove le marne in esame spingonsi ancora a $270 \mathrm{~m}$. d'altezza.

L'amplissima pianura di Pollenzo è dovuta appunto alla zona piacensiana facilmente erodibile, risultando tale bassopiano dall'escavazione operata dalle acque di Stura c Tanaro quando si rimirono sotto le colline braidesi; rimane a prova di cio il piccolo rialzo di M. Capriolo, costituito in gran parte di marne argillose plioceniche ricchissime in fossili, fra cui alcuni (Sepie ad esempio) piuttosto unici che rari.

Sulla destra del Tanaro, nelle colline di Verduno, esistono ancora alcuni scarsi residui di tcrreni piacenziuni, cogli stessi caratteri che gia osservammo in simili placche piu a Sud.

Quanto alle colline braidesi, senza entrare qui in minuti dettagli, basti accennare come vi si possa ovunque osservare, al fondo delle valli, il gradualissimo passaggio tra l'Astiuno ed il Piacensiuno che si presenta coi soliti suoi carattcri e che forma quasi sempre superiormente un velo acqueo abbastanza costante.

Ad Est di S. Vittoria le marne piacensiane poggiano sulle marne gessifere dol Messimiano senza apparente trasgressione, quantunque esista quivi una piccola lacuna nella serie stratigrafica.

Nelle Valli di Ridone, di S. Biagio, di Montaldo, ece., oltre ai soliti fenomeni (vallate relativamente larghe, sorgenti acquee, passaggio graduale tra la formazionc marnosa inferiore e quella sabbiosa superiore) del Piacenziano superiore si osserva un noterole sollevarsi di questo orizzonte da Est ad Ovest, trovandosi esso per esempio a solo 220 metri presso Corneliano ed a circa 260 metri sotto Baldissero; ne risulta quindi che, siccome i banchi piacenziani si sollevano a Sud-Est appoggiandosi ai terreni messimiani, la zona piacenziana, considerata nel suo assieme, nella regione in esame si presenta foggiata a leggera conca allungata da Sud-Ovest a Nord-Est; ciò dipende sia dalla forma del fondo marino all'epoca della deposizione delle marne piacenziane, sia da movimenti sismici postcriori a tale deposizione.

Si osservano inoltre talvolta ondulazioni nei banchi marnosi, locali stratificazioni trasgressive, ecc. Spesso nel passaggio tra Piacensiuno ed Astiano abbondano resti di Chacnopus pespelicani ed incontransi assai sovente lenti lignitiche; talora anche veggonsi strati sabbiosi grigiastri che inglobano frammenti rotolati di marna azzurra; non di 
rado trovansi eziandio accentramenti od anche veri banchi ealcareoarenaeei di forma svariatissima, spesso inglobanti resti di Pecten, Ostrea. eee.; tali formazioni si possono attribuire tanto al Piacenziano eome all'Asticno, quantunque generalmente sembrino già eostituire la base di quest'ultimo orizzonte. É a notarsi a questo riguardo ehe, sieeome una gran parte dei fossili plioceniei deriva appunto da questi banehi di passaggio, è spesso impossibile dire se essi siano piacensiuni od astiani: lieseono quindi utilissime le raccolte fatte intelligentemente in eerti banehi speeiali aserivibili eon eertezza all'uno o all'altro orizzonte, quantunque in verita sulla differenza delle due faune influisea piuttosto l'ambiente in eui esse vissero ehe non l'età.

Continuando l'esame della zona piacenziana si nota come a Nord di Val Ridone essa non si appoggi più direttamente sulla formazione gessifera, ma ne sia divisa da potenti banehi sabbioso-marnosi ehe rappresentano il Vesciniano superiore; ne risulta però sempre abbastanza netta la delimitazione speeialmente per mezzo dell'esame dei fossili; d'altronde è probabile ehe esista anehe in queste regioni tra i due orizzonti geologiei una piecola ma regolare trasgressione stratigrafica.

A Castagnito i banehi marnoso-sabbiosi del Piacenziano sono sollerati ad oltre 350 metri; altezza ehe, per quanto inferiore a quella eonstatata più a Sud, è perù aneora assai noterole poichè è superiore a quelle che si osservano più ad Est in tutto il Piemonte.

L'amplissima valle di Borbore è in gran parte esearata nella zona piacenziana; questa ad Orost sollerasi sino ai 260 metri sotto S. Stefano Roero e sotto Monteu Roero, mentre gradatamente abbassandosi verso Est si trora solo più a 150 metri al suo sbocco in ral Triversa.

In questa rasta ed importante ralle di Borbore, eome nelle sue numerosissime rallette laterali, osservansi sempre $\mathbf{i}$ soliti earatteri ed $\mathbf{i}$ soliti fenomeni della formazione piacenziana, in gran parte eoperta da alluvioni sabbiose e eiottolose e da loess più o meno potente; il suo andamento stratigrafieo è assai regolare, essendo i banehi quasi orizzontali o solo leggerissimamente inelinati rerso Nord.

É inutile insistere sul fatto eridente di per sè ehe l'oroidrografia delle regioni in esame $\dot{e}$ in strettissima relazione colla loro eostituzione geologiea; basta pereiò dare un'veehiata alla earta geologiea.

Si è già notato altrore la eomparsa d'affioramenti messiniani entro la zona piacensiana tra Castagnito e Priocea; d'altronde è spesso assai difficile distinguere nettamente una formazione dall'altra, come si può ad esempio eonstatare nelle eolline stesse di Prioeca.

La profondissima escarazione fatta dalle aeque del Tanaro ei spiega eome la zona piucenziance sia stata messa a nudo per un'estensione assai notevole sino al centro del bacino terziario, eioè sino alla stessa 
eitta d'Asti, per modo che in alcuni punti la zona meridionale d'affioramento del Piacensiano dista appena tre o quattro chilometri dalla zona settentrionale che fa parte dolla collina Torino-Valenza; è d'altronde questo un fatto naturalissimo per uno degli ultimi e quindi dei più superficiali depositi terziari del bacino piemontese.

La collina su cui è basata la città d'Asti, per csaminare una regione interessante rispetto all'nomo, ci presenta un bellissimo escmpio del graduale passaggio, d'altronde osservabile quasi ovunque, tra Pi $\alpha$ censiano ed Astiano. Infatti la parte bassa della eittr, tra i 120 cd i 125 metri circa, è fondata sulle tipiche marne azzurre, sommamente fossilifere dol Piacenziano; la parte media, che rappresenta la porzione maggiore, tra i 125 ed i 140 metri circa d'elevazione, basa sopra strati marnoso-sabbiosi grigiastri ancora abbastanza fossiliferi, che costituiscono il passaggio all'Astiano; infine la parte piì alta della citta, dove sono le Carceri, il Castello, ecc., sta sopra le sabbie giallastre dell'Asticno tipico con non rari fossili di mare basso o di littorale. Abbiamo così l'imbasamento della citta d'Asti diviso geologicamente in 3 zone che si riconoscono anche dall'orografia, corrispondendo a tre terrazze che si formarono pel la diversa resistenza che ciascuna zona presentava all'crosione esercitata dalle correnti acquec man mano che queste andavano restringendosi ed approfondandosi.

is pure specialmente alla natura della formazione piacensiana che si deve l'enorme ampiezza della pianura del Tanaro tra Asti e Castello Annone, tant' è che presso questo paese, scomparendo il Piacensiano sotto all'Astiano, rerso i 110 metri, di tratto quiri si restringe la valle del Tanaro, la quale da 3 chilom. di ampiezza si riduce a solo poco più di $1 / 2$ chilometro. Anche in questa regione è interessante l'osservare il gradualissino passaggio tra Piacen iano ed Astiano, giacchè fra le marne sabbiose giallastre di quest'ultimo orizzonte veggonsi ancora sovente comparire, ad Est di Annone, strati marnoso-argillosi azzurrastri affatto simili a quelli del Pircenziano, così sotto C. Rapetti, sotto C. Gabetti, ece.

Risalendo le vallette che dalla Val Tanaro si dirigono a Sud ver'so la valle del Tiglione, le vediamo quasi tutte intaccare più o meno profondamente le marne sabbiose del Piacensiano, fossilifero al sommo, e presentante gradualissimi passaggi all'Astiano.

Ritornando ora alla parte meridionale della zona piacensiana vediamo come i suoi rapporti di sovrapposizione al Hessiniano presentino talora alcune irregolarita; questo fatto specialmente si osserva sulla destra di Val Bragna (Costigliole) tra S. Carlo e S. Gioranni dove le marne piacensiane formano quasi placche sulle colline messiniane quivi sviluppatissime verso il Nord, spingendosi sin presso Isola d'Asti; 
parrebbe quindi che le formazioni piacenziane siansi quivi deposte in una specie di conca entro la formazione messiniana. E certo ad ogni modo che nelle colline di Moncacone, Repergo, ece. riesce spesso difficile di distinguere il Messiniano dal Piacenziano.

Più ad Est constatiamo fenomoni consimili attorno alle colline messimiane di Agliano, che fanno una specie di penisola attorniata dai terreni piacen iani, i quali vi si appoggiano con una certa discordanza. La zona piacensianr forma poscia l'ampio seno di Castelnuovo Calcea spingendosi sin presso la zona tortoniana.

In val Tiglione il Piacenziano viene a scomparire completamente sotto l'Astiano nelle vicinanze di Bclveglio, per quanto sia sempre alquanto difficile stabilire tali confini, specialmente a causa dell'allurione che ricopre i terreni terziari sul fondo dclla valle.

Quantunque il Piacenziano delle regioni ora in esame non abbia generalmente una potenza maggiore di 30 o 40 metri, tuttaria per la potente erosione del Belbo, la zona piacenziana si allarga in tale ralle per quasi 5 chilom. tra Nizza, Incisa e Castelnuoro Belbo.

Nelle colline ad Est di Nizza, specialmente presso Bazzana, osservasi benc la trasgressione stratigrafica tra Messiniano e Piacensiano.

Seguitando l'csame della formazione piacensiana verso Est rediamo come essa diventa gradatamente più potente, costituendo da sola colline rotondegrgianti, biancastre, coll'ampiezza di uno o due chilom. e presentando uno spessore di 100 c jiù metri, come osselvasi ad esempio nelle colline di Maranzana, Cassine, ece.

Come generalmente si rerifica nel bacino terziario del Piemonte anche nelle regioni in esame la distinzione tra Piacenziano ed Astiano ¿ generalmente assai facile in complesso, per quella specie di gradinata che formano le marne sabbiose di quest'ultimo orizzonte sulle marne argillose dcl primo, nonchè per notevoli differenze litologiche c palcontologiche.

Ad Est della Val Bolmida, che tra Rivalta e Castelnuoro Bormida è appunto molto ampia perchè incisa nelle marne argillose del Piacenziano, ritroviamo ancora questo orizzonte ben stiluppato, con una ampiezza di oltre due chilom., in parte nascosto a Nord dai depositi alluvionali del Sahariano che incominciano a mostrarsi assai potenti e molto sviluppati verso Sud anche entro le regioni mioceniche.

E per questo fatto che il Piacensimno ad Est di Val Bormida, quantunque formi una zona ampia oltre 2 chilom., è in massima parte invisibile c si osserva solo nelle incisioni fatte dai corsi d'acqua.

Continua generalmente ad esistere una regolare e più o meno forte trasgressione stratigrafica tra il Messimiano, ridotto per lo più ad una piccola striscia, ed il Piacensiano tipico, riccamente fossilifero; 
quest'ultimo invece passa gradatamente all'Astirno. come di solito per mezzo di banchi marnoso-sabbiosi grigiastri elie abbondano straordinariamente in fossili animali e vegetali (specialmente Pteropodi), come si può vederc in Val Salso, in Val Orseceo, ece.

Sempre gli stessi fenomeni si osservano nella zona pracen irma ad Est della Valle d'Orba; notiamo tuttavia che il passaggio tra i terreni di questa zona ed i terreni messimumi si compie assai più gradualmente che non ad Ovest; tant'è che in alcuni punti, ad esempio sotto C. Poggio (Nord di Gavi), osserviamo tra i due orizzonti alemi banchi marnoso-sabbiosi grigio-giallastri con fossili di mare poco profondo (anche numerosi Foraminiferi) che, per quanto siano ancora da riferirsi al Piacenziano inferiore, tuttavia gilà ci indicano un passaggio alla formazione maremmana del Messinicuo superiore.

Al contrario nelle regioni in esame osserviamo che le marnc azzure del Piacensiano supcriore, rieche come sempre in MLlluschi, Foraminiferi, cce., sono ricoperte direttamentc dalle marne, dalle sabbic e dai conglomerati del Tillafranchiano, come si può osservare nettissimamente in modo particolare presso Tassarolo. Ciò è dovuto in parte all'erosione opcrata dalle correnti acquee villafieunchiune che possono aver esportato il sottile deposito di Pliocene superiore marino, in parte al fatto di una deposizione alquanto trasgressiva degli strati villafranchiani sul Piacensiano, per modo che i sottili depositi astiani non possono venire ad affiorare, ma sono completamente mascherati dai terreni plioccnici alluviali. Pcrò in massima parte l'indicato fenomeno ì dovuto ad una reale diretta successione dei depositi allutionali sui depositi marini. Infatti discendendo il rio MLesma si osserva che, 30 metri circa a valle del ponte di Tassarolo, le tipiche marne azzurre fossilifere del Piacenaiano superiore presentano numerose lenti lignitiche; poscia pochi metri piủ a valle compaiono fra dette marme rere lenti ghiaiose e conglomeratiche; infine alle marne piacensiume sovrappongonsi sabbie grigiastre con banchi ghiaiosi ed un potente strato marnoso grigio-verdastro, cioè il tipico Tillufirnchiano che diventa poscia sempre più ghiaioso verso Nord.

In val Scrivia la zona piacenziana, nella curva che quivi fanno tutti i terreni tcrziari, assume talvolta un'ampiezza di oltre quattro chilom., ma in gran parte essa è mascherata dalle alluvioni terrazsiane e recenti.

Nelle colline tortonesi tra Cassano Spinola e Villalvernia il Pitceñiano si puỏ esaminare molto bene c quivi presenta il fenomeno assai notevole di esserc in parte costituito di marne e sabbie giallastre, alternate o sostituite alle marne azzurre, con fossili di mare basso o di littorale, cioè con tutta l'apparenza dell'Astiano. Questo fatto si 
osserva in modo speciale sotto C. Castellaro (Cassano Spinola), nelle colline a cui si appoggia il paese di Cassano, nelle colline di Garazzana, di Cresta Sguardia (dove osservansi pure lenti ghiaiose), di Cresta Magrina, ece. sin oltre le colline di Madonna della Guardia (Torre degli Sterpi); generalmente sono queste colline riconoscibili anche di lontano per un colol giallo-rossastro. Parrebbe a primo tratte che si tratti qui soltanto di uno sviluppo notevole dell'Astiano rerso Est per modo da coronare le eolline piacen viane; però se si considera: $1^{0}$ che l'Astiano vero in queste regioni o manca assolutamente, come redemmo per lungo tratto ad Orest di ral Scrivia, oppure è ridotto a pochi metri di spessole, come osservasi presso Villalvernia; $2^{\circ}$ che in alcuni punti, come presso Cassano Spinola, presso Gavazzana, ecc. questi banchi a facies astiana trovansi poco sopra il Messiniano superiore; $3^{\circ}$ che nella conea di Val Scrivia si è già osservato, nei terreni torloniani c messiniani, una spiecatissima facies di deposito di foce, in causa di notevoli correnti acquee quiri sboccanti nel mare durante tali epoche geologiche; da tutto eiò pare possa dedursi che i depositi pseudoastiani delle colline tortonesi si debbono ancora inglobare nel Piacensiano, tanto più che fenomeni consimili si osserrano, quantunque meno spiceati, anche altrove nella parte meridionale del bacino piemontese, ed inoltre in parechi punti nella zona piacensiana alle falde delle colline Torino-Valenza.

Le colline tortonesi, specialmente dei dintorni di Villalvernia, sono famose paleontologieamente per i numerosi resti fossili pliocenici che ri si rinvenncro; però, fatta eccezione di alcuni banchi sabbiosi zeppi di Foraminiferi e di Molluschi di piccola mole. di cui taluni rarissimi, altrore, le marne argillose di Villalremia presentano la solita riechezza paleontologica che osservasi quasi ovunque nel Piacenziano del Piemonte, e debbono specialmente la loro fama a rieerche più accurate per parte dei palcontologici che si recarano alle celebri localita fossilifere del Tortoniano di S. Agata fossili.

Il passaggio tra il Piacenziano ed il Messiniano si compie abbastanza gradualmente benchè vi esista forse talora una piccola trasgressione stratigrafica; tale trasgressione inveec si aeecntua fortemente verso Nord, giacchè vediamo i banchi del Piacensiano inferiore presso Paderna poggiare direttamente sul Messiniano inferiore e poscia, rerso Spinetta, sullo stesso Liguriano.

Il passaggio tra il Piacentiano e l'Astiano si può osservare solo presso Villalremia c pare che non si compia alquanto rapidamente.

Nella parte orientale dei colli tortonesi ricompare la zona piacensianc colla solita facies prevalcnte di marne azzurre, in parte però mascherate da loess, spccialmente verso Orest. 
Passando ora alle colline Torino-Valenza vediamo. come nella loro parte orientale appaiano gia ben sviluppati i depositi piacensiani i quali costituiscono una parte delle basse colline tra Montecastello o Rivarone, appoggiandosi quivi direttamente e discordantemente sul Tortoniann; i loro banchi sono leggerissimamente inclinati ad Fst circa e ricchissimi in fossili che possonsi raceogliere facilmente lungo la sponda sinistra del Tanaro. Verso Rivarone la striscia piacenziana va allargandosi ; assieme alle tipiche marne azzurre compaiono diversi banchi sabbiosi giallastri che talora sono zeppi in fossili di mare basso, così lungo la riva sinistra del Tanaro da C. Mula al porto di Rivarone; anzi presso questo porto l'alternanza delle sabbie gialle colle marne bleuastre ei indica gia il passaggio all'Astiano. Da Rivarone verso Ovest le falde settentrionali delle colline sono costituite da Piacenziano, però mascherato quasi completamente dal lorss; verso Nord invece la formazione piacensiana è ricoperta dal Villafranchiano.

Più ad occidente la zona piacenziana, liberandosi dal velo villafranchiano, ricompare presso Valenza, ma è quivi appena visibile nelle più profonde incisioni esscndo essa generalmente mascherata da un potentissimo deposito di loess quaternario.

Siccome si pù constatare la presenza dclle tipiche marne azzurre piacenziane verso lo sbocco del rio Fogliabella nel torrente Grana, c siccome nella valle Corpus Domini spuntano sotto C. Dell'Anda, marno azzurrastre che paiono del Piacenziano, così sembra ragionevole l'ammettere che una zona di questo terreno si estenda sotto il deposito quaternario tra le colline mioceniche di Pomaro c quelle di S. Salvatore.

Tale ipotesi, che si potrebbe dilucidare con opportuni scandagli, ¿ poi confermata dal fatto che poco ad Ovest, nelle colline di Mirabcllo, la dove veggonsi tagli che raggiungono i terreni sottostanti al loess quatcrnario (come ad csempio poco sotto Castello Grana), si possono osservare assai bene le marne sabbiose grigio-giallastre piacenziane, con fossili, fra cui specialmente abbondanti i resti di Ostrea cochlear.

Gli stessi fatti si possono pure constatare in diversi punti delle colline di Occimiano, là dove il velo di loess è meno potente o in qualche modo inciso ed esportato, cosi presso il Castelio Cavalla, nelle vicinanze di C. S. Maria (dove i banchi marnosi del Piacenziano sono talora ancho utilizzati come materiale da costruzione sotto forma di cantoni), di C. Fondighera, di C. Boccalatte, ece.

Quantunque i depositi sovraccennati constino spccialmente di banchi sabbioso-marnosi grigio-giallastri, tuttavia per essere alternati a banchi marnosi bleu e per i fossili che presentano pare che si debbano riferirc piuttosto al Piacenziano che non all'Astiano; d'altronde alle stesse conclusioni sono giunto esaminando le formazioni alquante simili ehe rappresentano il Piacenziano nella conca pliocenica di Val Scrivia. 
Se nelle basse colline appena ondulate di Mirabello, Occimiano, Sterani, ece. la zona piacenziana è quasi mai risibile (per essere mascherata dal loess quaternario deposto dalle aeque sia della pianıra padana, sia e specialmente da quelle discendenti dalle stesse colline di Moncalro, Vignale, e S. Salvatore), invece lia dore i banchi basali del Piacenziano si appoggiano sui terreni mioceniei, quiri essi si possono sorente esaminare abbastanza bene. Cosi nelle colline di Conzano rediamo gli strati piacenziani inclinati di $2^{\circ}$ o $3^{\circ}$ rerso il Nord circa e costituiti di una alternanza di marne grigie con banchi di marne e sabbie di color giallastro, e riecamente fossiliferi. $\dot{\mathrm{E}}$ ben eridente la loro sorrapposizione trasgressiva e discordane sui terreni mioceniei di varie etả.

Gli stessi fatti si osserrano nelle collinette di bolgata Bonina e specialmente presso il Castello di Ligmano, dove le marne sabbiose, passanti talora a rele arenarie giallastre, sono spesso ricchissime in resti fossili fra cui molti Foraminiferi, Brachiopodi, ece., rarissimi inrece altrore, trattandosi qui di una fauma speciale, in relazione coll'ambiente speciale in cui si deposero i banchi piacenziani in esame.

E anzi a notarsi come l'aspetto delle arenarie fossilifere di Castel Lignano, di C. Vecchia, ecc. le furebbe quasi riferire all'Elreziano se il complesso dei fossili, fra cui ad esempio abbonda il Plearonectes cristatus, non ne indicasse inrece l'eta piacenziana.

Però in diversi punti si possono anche quiri osservare le tipiche marne azzure piacenziane, cosi alle falde orientali delle colline di C. Il Sin, presso la borgata Coppi, la borgata S. Martino, ece.

Generalmente però le formazioni piacenziane sono costituite o da sabbic giallastre o da marne pure di color giallognolo, ma quasi sempre sono caratterizzate dai resti fossili che racchindono.

La sorrapposizione del Piacenziano ai banehi messiniani arriene sempre con una certa trasgressione stratigrafica, regolare, ma abbastanza evidente. Nello colline di Terruggia si osservano assai nettamente lé marne giallastre piacenziane inclinate legegermente rerso Sud-Sud-Est.

In complesso dunque si può dire elıe tra le colline casalesi e quelle di S. Salvatore esiste ma specie di golfo piacenziano, rerso il eai centro inelinano in complesso, quantunque di solo dne o tre s'radi, i banchi marnosi e sabbiosi che rappresentano la formazione piacenziana.

Lungo le falde settentrionali delle colline Torino-Casale, quantunque manchi assolutamente ogni affioramento tortoniano e messiniano, tuttavia osservasi in un punto, nelle colline di Verrua di fronte a Crescentino, una piccola placea piacenziana, appoggiata direttamente e discorlantemente sul Liguriano. Questa plaeca è costituita di banchi arenaceo-ealcarci giallastri, alternati con banehi marnoso-sabbiosi di egual colore, inclinati di cirea $25^{\circ}$ verso il Nord ed inglobanti in al- 
cuni punti numerosi fossili, i quali, malgrado la natura affatto spccialc del deposito in esame, lo fanno ritencre come piarenziono. D'altronde una costituzione alquanto simile a quella ora indicata si ̀े pure gia osservata nel Piacenziano delle colline tortonesi, nella conca piacenzianc di Oceimiano e si avia pure a notare in alcuni punti della zona piacenziana che fascia a Sud le colline Torino-Valenza.

Ad ogni modo è sempre assai interessante la piccola placea piacenziana del Castcllo di Verrua-Savoia, poichè essa ci indiea come sin presso le falde settentrionali delle colline Torino-Casale si spingano i terreni piacenziani della pianura padana (quasi sempre mascherati dalle alluvioni quaternarie di detta valle), probabilmente sovrapponendosi essi affatto discordantemente sui terreni terziari più antichi che costituiscono le indicate colline.

Passaudo ora all'esame della zona piacenziana che si stende lungo le falde meridionali delle colline Torino-Valcnza, possiamo notare come nella parte orientale di dette colline per lungo tratto tale terreno sia ridotto ad una striscia sottilissima od anche non compaia affatto.

Infatti all'estrema punta orientale delle colline di Alessandria-Valenza, sotto il pacsello di Parone, reggonsi sulla sponda sinistra del Tanaro alcuni straterelli marnosi blcuastri, riferibili al Piacenziono, che soggriacciono alle arenaric calcari dell'Astiano e s'appoggiano discordantemente sui banchi sabbioso-conglomeratici del Tongriano.

Ad Ovest di Pavone non è piủ possibile osservare aleun affioramento di Piacenziano il quale compare poi presso Valle S. Bartolomeo come una striscia sottilissima, grigiastra, marnosa, visibile qua e li sotto al loess, all'humas e alla vegetazione tanto sriluppata in queste regioni collinose da costituirc un serio ostacolo agli studi greologici.

Questa striscia piacenziana a delimitazione sempre alquanto incerta sia pei motivi sopraddetti, sia per un passaggio abbastanza graduale alla zona astiana, si va in complesso gradatissimamente allargando verso Orest; essa offie qua e là resti fossili abbastanza abbondanti, come presso Castelletto Scazzoso, presso Salcido, ecc.

Ad Orest dell'affioramento liguriano di Cuccaro, siccome i terreni terziari non si presentano più tanto compressi come nclla parte oricntale delle colline in esame, anche la formazione piacenziana può maggiormente svilupparsi sia in potenza, sia specialmente in ampiezza; anzi a causa del fatto già accennato nel precedente capitolo, cioè dell'esistenza di un'elissoide secondaria di sollevamento (Villadeati-Alfiano) prolungantesi ancora rerso Sud-Est, anche la zona piacenziand ne subisce le conseguenze stratigrafiche, dividendosi, dirci, in due zone: una a Sud di Val Grana ed una ampia, foggiata a seno, a Nord della valle stessa; la prima forma una specic di striscia tra Messiniano ed 
Astiano, la seconda è spesso disposta a placche sul ILessiniano e coperta o no a sua volta da minori placche d'Astiano.

La potenza della formazione piacenziana è di circa una rentina di metri in complesso; i suoi caratteri litologici e paleontologici sono ad un dipresso quelli tipici già indicati.

Riesce sempre difficilc distinguere le marnc piacenziane da quelle messiniane nonchè dalle marne grigio-giallastre della base dell'Astiano, a causa dei passaggi graduali csistenti fra i due terreni; quindi al fondo delle ralli dore sonri pochi spaccati o dore il loess maschera le formazioni costituenti il fondo della valle stessa, cosi in Tal Ginepro, Val Pralungo, Val Rovere, Val S. Gioramni, Tallescura. ecc.. rimane sempre alquanto incerto se affiori il Piacensiano vero o solo le marne grigie dell'Astiano inferiore; spesso bisogna fondarsi unicamente su caratteri oroidrografici per risolvere il dubbio.

Totiamo come interessanti le isolate placche piacensiane di Altavilla e di S. Bernardino, l'assottigliarsi (tabra anzi la scomparsa per breve tratto) della striscia piacensiann tra Casorzo e Honcalvo e l'ampio seno pincensiano di Calliano-Casorzo-Moncalto.

Ad Est di Calliano la zona piceensianc è straordinariamente allargata, raggiungendo talora un'ampiezza di 5 o 6 chilom., ciò che dipende non tanto dalla potenza della formazione in esame (giacchè il suo spessore è al più di 60, 70 metri) quanto invere dall'essere essa quasi orizzontale per modo che ricompare per erosione al fondo delle vallate (Fosso del Marehese, Fosso della Galleria, Tal Trombetta, Tal S. Michele, Vallc Nocciola, ece.) entro l'area astiana e si puỏ ancora osscrvare rerso il centro del bacino, oltre 10 chilom. a Sud della linea di sorrapposizione del Piacenziano sul Messiniano. Ne risulta quindi che la zona piacen iana del versante settentrionale del bacino terziario del Piemonte trovasi in alcuni punti separata di soli 7 od 8 chilom. da quella del versante meridionale del bacino stesso.

Nell'ampia area piacenziana Tonco-Nontiglio osservansi spesso sull'alto delle colline placche di marne giallastre che preludiano all' Astiano e di cui anzi rimane talora incerta l'attribuzione piuttosto all'uno che all'altro orizzonte.

Un fatto interessante che gia osservammo in diverse regioni piacensiane del Piemonte c che si ripete nclla regione in esame, è la comparsa di banchi sabbioso-arenacci, duri, giallastri, ricchissimi in fossili di littorale, a facies astiana, frammezzo alle marne argillose grigioblenastre del Piacenziano. Possiamo osservare ciò ad esempio nelle colline a Nord di Scandaluzza sotto la borgata Anselmi, presso borgata Alberengo; se le sabbie arenace su cui posa Nontiglio sono piuttosto ascrivibili all'Astiano rero, rediamo invece banchi pseudo- 
astiani, ealeareo-arenacei, talora inglobanti pure lenti eiottolose zeppe di fossili (Pecten, Ostrea. Lrecina, eee.), frammezzo ai depositi piacenziani sotto borgata Roeea, a C. Zagnano, a C. Chiap, eee.

Depositi simili osservansi aneora presso borgata Carboneri, tra C. Pozzo e Primeglio, nell'ineassato vallone tra Sehierano e Pino d'Asti presso C. delle Roeehe, sotto C. Monsparone (Ovest di Pino d'Asti) eee.

Si tratta cioè in eomplesso di un baneo interrotto, a racies littoranea, formatosi localmente verso la metà del periodo piacenziano.

I rapporti del Piacensiano eol Messiniano e eoll'tstiano non presentano fatti diversi da quelli prima aeeennati; cioè leggera trasgressione nel primo caso, passaggio gradualissimo nel seeondo; i fossili piacensiani sono sempre abbondantissimi quasi ovunque.

Ad Ovest di Montiglio la zona piacenziana si restringe noterolmente, eome d'altronde quivi restringonsi tutte le formazioni terziarie prepiacenziane a eausa dell'affioramento liguriuno di Coeconato; tant'è ehe talora esiste solo più una sottile striseia di Pracensiano tra Astiano e Messiniano. Ma, in causa della leggerissima inelinazione della formazione piacentiana, possiamo aneora osservare questo orizzonte geologico per molti ehilometri verso Sud al fondo delle valli d'erosione, speeialmente in Val Brarie sino a Cortazzone e in Val Vernetto sin oltre Montafia.

Per quanto comunissini siano ovunque i fossili piacenziani, sono tuttavia speeialmente notevoli a questo riguardo i valloni di Primeglio, di Pino d'Asti, di Castelnuovo d'Asti, le vicinanze di Viale presso Montafia, eee.

Verso Ovest la zona piacenizima. pur eonservando la stessa conformazione di prima, è solo più osservabile direttamente in poehi punti a eausa del mantello di loess ehe in gran parte la masehera; quindi ad oeeidente di Andezeno, divenenclo sempre pit̀ potente il vero loess (lavaero delle vieine eolline mioeeniche), riesee sempre più diffieile il delimitare il Piacensiano dal Messiniano, tanto più ehe quest'ultimo perde in parte i suoi earatteri distintivi (Gessi e Caleari); eosì puro non sempre è faeile la distinzione del Piacenziano dall'Astiano, speeialmente pel gradnale passaggio esistente fra i due orizzonti.

Ad ogni modo i earatteri paleontologiei e litologiei rimangono sempre inalterati, eome si può osservare speeialmente nelle ineisioni al fondo delle valli, dal lago d'Arignano (sulla eui sponda orientale si possono raecogliere abbondantissimi fossili) sino alla valletta di S. Bartolomeo dove riesee pure eopiosa la raceolta paleontologica nel Piaceñiano.

La potenza della zona di Piacenziano ehe viene ad affiorare varia assai seeondo i luoghi; generalmente non è maggiore di 30 o 40 metri, spesso invece è minore. 
Ad Orest di Chieri la zona piacenziana si restringe sempre di più. ridueendosi ad una semplice striseia che allo sboceo di Tal S. Bartolomeo scompare definitiramente sotto i terreni quaternari della ralle padana, sotto i quali però dere fasciare la parte occidentale dell'elissoide di solleramento che costituisce i colli torinesi.

Per compiere lo studio del Piacensiano del Piemonte accennammo diversi lembi che di questo terreno appaiono al piede delle Alpi.

Nella parte meridionale del bacino terziario piemontese si è notato eome i depositi piacensiani s'appoggino direttamente in più punti sulle falde settentrionali delle Alpi Marittime presso Mondori e Villanuova Mondovi, sollevandosi ad oltre 500, 550 metri.

Ad Orest di Tal Pesio, lungo le falde delle Alpi Harittime e delle Alpi Cozie, per la potenza del bilurium e per le loro profonde incisioni non redesi in aleuna parte affiorare il terreno piacen siano: ma ad Est della Talle dell'Oreo sino in Lombardia ne possiamo segmalare qua e là diversi punti d'affioramento ehe, per quanto generalmente poco estesi, riescono assai interessanti; infatti essi ci indieano come la presenza di questo terreno al piede delle Alpi sia non già un fenomeno cecezionale, come si credette per molto tempo. ma bensi il fatto generale: e se per estesi tuatti non si può troral traccia di lembi piacenziani subalpini ciò è doruto, quasi unicamente, all'essere essi mascherati dai terreni quaternari che quixi, o sono molto potenti oppure furono poeo profondamente incisi dalle correnti acquee.

Già ad Est del grandioso cono di deiezione della Stura di Lanzo, presso Levone, nella profonda escarazione del rio di Ca Vielton (o rio Torto), vediamo comparire al fondo della valle per oltre un elilom., ad un altezza di $3 \pm 0,350$ metri circa, aleuni banchi sabbiosi (spesso anzi ghiaiosi e con irregolari lenti ciottolose, e talora lignitiferi) che per il loro colore azzurrastro e per trorar'si sogrgiacenti a circa 80 metri di Astiano e di Fossaniano credo debbansi gia attribuire al Piacenziano superiore od almeno agli strati di passaggio tra Piacenziano ed Astiano. È questa certamente una facies speciale del Piacenziano. ma è una facies subalpina che osserterento ancora più ad Est e che d'altronde si spiega mol to facilmente per quelle correnti acquee che, scendendo dalle ragioni alpine, sboccarano nel tranquillo mare piacenziano.

Sulla sinistra di Tal d'Orco, nelle ricinanze di Castellamonte, appaiono al basso delle eolline di Preparetto, in pochi punti nell'ineisione del torrente Malesina, alcuni banchi sabbioso-arenacei, talora ghiaiosi o decisamente conglomeratici, di color grigiastro, che eredo appartengano all'Astiano inferiore passante al Piacenziano e che formano quindi una graduale transizione ai banchi sorraccennati di Lerone.

Strati affatto simili a quelli sopraindicati di Castellamonte ossertansi 
ancora in Val Chiusella presso il ponte dei Preti. Strati marnosi bleuastri a fucies pincenziann si possono anche vedere nei burroui di Piana o di Sento (Borra grande); però essendo essi intercalati a potenti banchi sabbiosi giallastri, debbonsi ancora attribuire all'Astiuno.

Presso il paesello di S. Martino Canarese, verso lo sboceo orientale della Boriana, profondissima ineisione formatasi nei terreni quaternari e pliocenici dell'anfiteatro morenico d'Irrea, rediamo comparire per breve tratto, sotto ai banchi giallastri di sabbie, di marne e di ciottoli dell'tstimo e del Fossaniano, alcuni strati di marna marina grigioverdastra che probabilmente costituisee gia la parte superione del Piacensiano; d'altronde qui, come in generale dore non si possono esaminare diversi spaceati, rimane alquanto incerto se questi banehi marnosi di passaggio tra Astiano e Piacenziano debbansi attribuire piuttosto all'uno che all'altro orizzonte.

Qualche cosa di consimile si può ancora osservare nell'ambito stesso dell'anfiteatro morenieo d'Ivrea, più ad Est, cioè nelle vicinanze di Borgomasino. Quivi infatti, risalendo le piceola valletta del rio Oriale, incontriano presso il Ponte di Garla, verso i 225 metri di elevazione, banehi marnosi bleuastri, con fossili marini, che credo debbansi attribuire al Piacensiamo superiore. Gli accennati banchi mannosi si possono aneora seguire per un certo tratto lungo il torrentello di Oriale sin quasi a 240 metri d'elerazione, venendo essi ricoperti o da poehi straterclli di sabbia giallastra dell'Astiano o direttamente dai depositi moreniei inglobanti fossili pliocenici infianti ed erosi, fenomeno che è tanto comune nell'anfiteatro morenico d'Irrca.

Per quanto poca cosa sia ciò che di Piacenziano si può osservare entro l'ambito di detto anfiteatro glaciale, ne possiamo però già trarro come eonseguenza: anzitutto che gran parte della regione pianeg'gianto interna ha per substratum il Piacensiano mascherato da depositi di "Yerrasiano e di Alluvium, cd inoltre che una parte notevole di terreno piacen itano dovette esscre crosa e rimaneggiata dall'avanzantesi ghiacciaio che costruì l'anfiteatro; da ciò si comprende la gran quantita di frammenti di conehiglie di Molluschi püeenziani che trovansi mescolati coi depositi prettamente glaciali, il che diede origine a ben note e deploreroli polemiche scientifiche.

Proseguendo verso Est ineontriamo nel biellese diversi affioramenti pircenziani. Verso lo sboceo del Chiebbia nella pianura, presso la fabbrica Ratto, si osservano banchi grigio-bleuastri (ben stratifieati, leggermente inclinati a Sud e racchiudenti numerosi frammenti lignitici) che paiono doversi attribuire al Piucensiano, quantunque la mancanza di fossili, l'essere $\mathrm{i}$ banchi in massima parte sabbiosi ed anzi spesso ghiaiosi ed anche ciottolosi, renda alquanto dubbia tale 
determinazione; questo deposito rappresenta probabilmente una facies speeiale, subalpina, del Piacenziano e si eollega molto bene eoi banehi simili ehe già osservammo presso Lerone.

Veri depositi piacenziani, sabbiosi, grigio-bleuastri, straordinariamente rieehi in fossili si ineontrano, rerso i 260,270 metri d'elerazione, alle falde delle eolline di Cerreto, sia a Nord in Val Quargnasca, sia a Sud tra Fondovilla e Villa Mazzueehetti; banchi simili, ad elerazione simile, sempre ricehissimi in fossili, si osservano presso Quaregna nel vallonetto a Ford di borgata Parlamento; eosi pure lungo lo Strona, presso Cossato. Tutti questi locali affioramenti ei indicano eome le marne del Piacen iano superiore eostituiseano il substratum dell'ampia ralle del Cervo tra Cerreto, Cossato e la Barraggia o altipiano di Candelo, solo rimanendo esse maseherate dalle allurioni del Terrasiiano e reeenti. Tant'è che in alcuni punti sulla destra dcl Cerro alla base delle balze settentrionali di detta Barraggia, eome pure qua e là rerso la parte inferiore dei valloni che l'ineidono profondamente, osserransi talora, anche assai a Sud (eosi presso C. Colombo), eerti banehi marnosi azzurrastri formanti passaggio tra Piacenziano ed Astiano.

Ad Est di Cossato, nel profondo rallone del rio Osterla, possiamo nuovamente osservare per oltre un ehilom., tra i 230 ed i 240 metri d'elerazione, le marne sabbiose azzurre, riceamente fossilifere, del Pia. cenziano. E noterole eome i fossili di questa regione nel loro eomplesso ricordino meglio quelli tipiei dell'Astiano ehe non quelli tipiei del Piacensiano, ciò che spiegasi colle differenze elimatologiehe e d'ambiente ehe si verifiearono in regioni diverse nello stesso periodo geologieo; deresi inoltre notare in proposito che i banehi fossiliferi di Masserano, del rio Osterla, eee. rappresentano in parte il Piaceñiano superiore passante all'Astiano.

Già da molto tempo sono famosi i banehi pi ucensiani di Masserano, donde geologi italiani e stranieri trassero rieche raecolte paleontologiche. Questi banehi, straordinariamente fossiliferi, appaiono eol tipieo eolore azzurrognolo al fondo di Val Osterla, verso i 237 metri d'elevazione, alle falde del M. della Guardia, e si possono seguire lungo il letto del torrente per oltre due chilometri eioè sin presso C. Barone, sotto Masserano, dore raggiungono gia l'elerazione di oltre 260 metri.

Tanto in questo easo, eome negli altri preeedentemcnte aceennati, le marne argillose del Piacenziano si reggono appoggiare direttamente sulla roeeia antiea e fanno inveee graduale passaggio alle marne sabbiose giallastre dell'Astiano inferiore; lo spessore del Piacensiano in queste ultime suc propaggini alle falde delle Alpi è sempre di solo poehi metri.

Ad Oriente di Masscrano per lungo tratto non è più messo allo seo- 
perto aleun lembo di Piacensirno che rimane completamente mascherato dall'Astiano e dai terreni quaternari.

Ma risalendo la Val Sesia incontriamo diversi resti del terreno in esame, lembi che hanno una spcciale importanza a causa della loro posizione, entroalpina, direi, giacchè essi ci danno l'assoluta celtezza che il mare pliocenico potè talvolta in speciali regioni costituire dei piccoli fyords entro la regione alpina od almeno subalpina.

Infatti risalendo la Val Sesia lungo la sua sponda destra si incominciano a trovare traceie di marne miacensiane presso la borgata Piane e presso Serravalle Sesia; caratteristico è un piccolo lembo di marne sabbiose azzurre, ben stratificate, inclinate leggermente ad Est, compatte, fossilifere (inglobanti frammenti cd anche enormi blocehi di Porfido) le quali presso il Ponte di C. Bianca sulla Sessera si veggono poggiare direttamentte sulla roceia porfirica e penetrare nelle sue irregolari anfrattuosita.

Ma ancor più interessante è il fatto che, addentrandoci di parecchi chilometri in Val Sessera, ritroviamo nuovamente, dapprima presso la borgata Vardella e poscia nelle vicinanze di Crevacuore, lembi piacenziani colla solita facies di marne azzurre, oltremodo ricche in resti fossili e sollevate sin oltre i 400 metri.

È specialmente nel Croso di Volpiano che si può fare un'abbondante raccolta di fossili. In queste regioni il Piacenziano è assai più esteso di quello che veramente appaia, costituendo, sotto le alluvioni, il bassopiano di S. Koceo, Pianezza e Crevacuore, apparendo ancora nettamente al Cimitero di Crevacuore coi suoi banchi sabbioso-marnosi grigiastri formanti giả passaggio all'Astiano.

Infine un lembo di Piacenziano esiste ancora in Val Strona presso Guardabosone, dove esso è specialmente osservabile in aleuni rivoletti sopra C. Caraglione.

In tutte queste regioni il Piacenziano poggia direttamente sulle roccie antiche, fra le cui irregolari insenature si è depositato, e passa gradualmente ai banchi giallastri, sabbiosi o ciottolosi, dell'Astiano e del Fossaniano.

La conservazione di questi lembi piacensiani, come pure degli altri che osservansi entro la regione alpina, è dovuta essenzialmente all'essere essi stati protetti dalla loro speciale ubicazione contro le erosioni delle grandi correnti acquee, specialmente per trovarsi in tranquilli seni roceiosi.

E certo quindi che originariamente era molto più estesa che non oggi in queste regioni entroalpine la formazione piacensiana, di cui d'altronde probabilmente alcuni piccoli lembi, mascherati dalle alluvioni c dal terreno vegetale, rimangono ancora ignorati. 
Se ora ritolnando in Valsesia ne risaliamo la sponda sinistra, ritroriamo, a monte di Romagnano, numerosi lembi viacensiani anche assai estesi ed importanti, quantunque una parte noterole di questi terreni rimanga nascosta sotto ai terreni allurionali. Senza entrare in minuti particolari a questo riguardo basti accennare come marne piacenziane reggansi appoggiarsi ai rilieri porfirici nelle collinette di Borgata Barraggiotta, di C. Gibellina, delle borgate Torchio, Marietta, Negri, ece, ed essere assai sviluppate presso Grignasco. Se ne osserva un piccolo lembo presso il ponte di S. Quirico: infine a MLntrigone presso Borgosesia reggonsene aucora resti notevoli i quali ci indicano come il mare pircensiano si spingesse molto addentro in Val Sesia e che quindi detta valle dovesse orograficamente essere sin d'allora eostituita in modo assai simile a quello che presenta attualmente.

Anche nella valle Stroua, ralle laterale di Talsesia. esistono dirersi residui piacensiani cosi di fronte alla Cartiera Baragorione, presso C. Porcellino e Pracesolo, e dalla borgata Crabbia inferiore sino al Molino Bagatto, quiri spingendosi essi sin oltre i 400 metri di elerazione, cone si è osservato in Val Sessera presso Crevacuore.

Ad Oriente di Tal Sesia si continuano ad osservare qua e là affioramenti piacensiani sotto ai depositi alluviali e glaciali del Suhariano; così presso Boca, Maggiora, Yergano, Gargallo, Auzate. Bugnate, Gozzano, ecc., per modo che risulta chiaro lo stiluppo quiri ininterrotto della formazione piacensiana sotto ai terreni quaternari.

Nelle immediate vicinanze di C. della Torre, presso la Torre del Buccione, ebbi ancora a rintracciare, sotto ai depositi morenici, un lembo di Puceraiano, riceamente fossilifero come di solito. che trorasi addentrato di oltre un chilom. nell'ambito del lago d'Orta, fatto interessante riguardo all'origine dei grandi laghi subalpini.

Ad Est del lago d'Orta e dell'Agogna compaiono ancora qua e là lembi piacenziani sempre ricchissimi in fossili, così tra Gozzano er Arona ed anche molto addentro nell'ambito del lago Magoriore come a Taino presso Angera, dove il Piacenziano poggiasi strettamente sul Tomgriano.

Accenno infine come in diversi punti lungo le falde delle Alpi lombarde, così alla Folla d'Induno, lungo l'Olona, a Faido ed in altri punti presso il lago di Varese, a Pontegana, nci dintorni di Balerna e di Chiasso, ad Almenno e Nese presso Bergamo, ece., esistano pure affioramenti piacensiani di cui non ho pin ad oceuparmi perchè furi del mio campo di studio, ma che sono importanti a notar'si perchè mettono fuori dubbio il prolungarsi in Lombardia della formazione piacensiana subalpina, solo che, come di solito, essa vi è quasi completamente coperta e mascherata dai depositi quaternari allurionali e glaciali. 


\section{Riassunto.}

L'orizzonte piacensiano, cosi noto ai praleontologi eol nome di Sul, appennino o di Pliocene inferiore, ma di cui finora non esisteva ancora aleuna deserizione geologiea generale riguardo al Pismonte, si presenta per Jo più eolla facies delle tipiehe marne argillose azzurrastre; c̀ un deposito tranquillo di mare abbastanza profondo; solo in regioni speçali esso è rappresentato da depositi di mare basso o di littorale (sabbie e marne giallastre e talora strati ghiaiosi) elie sostituiscono in parte più o meno grande le tipiche marne azzurre; talora, pur eonservando il tipieo color azzurrastro, i banehi piacemsiant si presentano sabbioso ciottolosi, un $100^{\prime}$ deltoidi e senz'altri fossili ehe frammenti lignitiei, eome in aleune regioni al piede delle Alpi centrali.

La zona piacenziana forma una speeie d'elisse, irregolare, frastagliata ed interrotta, attorno all'amplissima area astiana eostituente il centro del baeino terziario piemontese; eompare pure in lembi più o meno estesi alle falde settentrionali delle eolline Torino-Valenza, e si estende, rieoperto dai terreni più reeenti, sotto alla pianura padana; tant'è ehe esso eompare in pareeehi punti lungo le falde alpine meridionali ad Est della Valle dell'Oreo sino in Lombardia.

Regolarissimo è l'andamento stratigrafico generale della formazione piacensiana i eui banehi inelinano leggerissimamente verso il eentro del baeino terziario, e presso le falde delle alpi eentrali pendono pure di poehi gradi verso Sud all'incirea, eon modifieazioni locali (pieghettature, seoseendimenti, eee.) di poea importanza.

Lo spessore della formazione nüacenzưur è piuttosto pieeolo, eioè di eirea 40 o 50 metri in media, raramente di oltre 100 metri, eiò ehe è in relazione eolla natura stessa del deposito.

E inveee assai notevole l'elevazione che presso le falde alpine raggiungono i terreni piacensiani, giacehè mentre essi nelle regioni eollinose del Piemonte trovansi solo a 200 o 300 metri di altezza, ju'csso le Alpi eentrali veggonsi talora sollevati ad oltre 350, 400 metri, anzi alle falde meridionali delle Alpi Marittince essi sono talora portati a 500 e quasi a 600 metri, eome nelle eolline monregalesi. Ciò pare provarei come nel potente movimento sismieo che chiuse l'epoea plioeeniea le Alpi marittime meridionali si sollevarono più potentemente ehe non le Alpi eentrali, e ehe la eatena alpina si sollevò assai più intensamente delle regioni interne del baeino terziario.

Se non di rado si nota una trasgressione più o meno leggera tra il Messiniano ed il Piacenziano, il ehe è in rapporto eolla loro natura tanto divcrsa, invece troviamo quasi sempre un passaggio litologieo e 
palcontologico gradualissimo tra il Piacenziano e l'Astiano, di modo che la loro delimitazione non si può quasi mai fare nettamente, per quanto in complesso trattisi di due orizzonti ben distinti.

I fossili marini, orunque straordinariamente abbondauti dal che deriva l'importanza e la celcbritu di questo terreno in Italia) sono assai ben conservati e costituiscono una ricchissima fauna di mare abbastanza profondo; pero là dore la tipica focies di marne azzurre del Piacenziano è sostituita da depositi di facies littoranea o di mare basso, quiri compaiono pure fossili littoranci simili a quclli dell'Astimo, indicandoci quanto l'ambiente influisca sulla fauna' dei dirersi orizzonti geologici, alterando anche completamente quei caratteri palcontologici che si ritengono in gencralc ne siano i reri distintiri.

L'abbondanza dei fossili mucersiani è specialmente noterole negli strati superiori di quest'orizzonte geologico, cioè nei banchi di passaggio all'Astiuno. 


\title{
C A P I TOLO X V.
}

\author{
ASTIANO.
}

\section{Studi anteriori.}

A eagione del grande sviluppo che l'orizzonte astiano presenta in Piemonte, e più aneora a eausa della sua straordinaria r'icchezza in fossili, da molto tempo esso vi è conoseiuto eol nome generieo di sabbie gialle dell'Astigiana o, più seientificamente, di Pliocene superiope. Però studi generali su questo terreno non vemnero ancora fatti sinora.

Il Sismonda nella carta geologiea del Piemonte riuni l'Astians al Piacenziano sotto il nome di Plincene marino; lo stesso vediamo riprodotto, togliendolo dalla earta del Sismonda, nelle recenti carte droll'Italia (1881), della Francia di Carez e Vasseur (1886) e relle Alpi Oecidentali di Zaeeagna (1888).

Il Pareto sin dal 1865, aeectando il nome di Astiano per questo caratteristieo orizzonte geologieo, ne diede assai bene i caratteri generali senza peró diseendere al suo esame speciale. Il Mayer nel suo studio sulla Liguria oeeidentale ebbe pure a trattare dei terreni astiani ehe appaiono nell'angolo Sud-Est del baeino terziario del Piemonte.

In questi ultimi anni in aleuni studi di speciali regioni del terziario piemontese ebbi sovente ad oeeuparmi dell'Astiano e dei suoi fossili, dandone anehe regionali earte geologiche.

\section{Generalità.}

La formazione astiana è specialmente caratteristiea litologieamente e paleontologieamente per arere una facies di deposito di mare basso passante a deposito littoraneo. Sono speeiamente marne e sabbie grligiogiallognole o, più eomunemente, solo giallastre quelle ehe costituiseono questo orizzonte in modo piuttosto uniforme. Vi s'ineontrano pure talvolta lenti o straterelli ghiaiosi. Talora per regioni abbastanza estese, come ad esempio nelle eolline tra Bra e Canale, si osserva ehe l'Astiano inferiore è eostituito da sabbie grigiastre mentre l'Astiano superiore ò formato di sabbie gialle; sieeome però tale distinzione non è affatto generale in tutto il baeino in esame così basterà aeeennarla.

Questc marne e queste sabbie fine o grossolane si presentano per lo più seiolte per modo ehe le regioni ehe ne sono costituite eangiano faeilmente di forma coll'andar del tempo a eausa dell'erosione rapida e eontinua. Questo ei spiega la eostituzione spesso labirintiforme di quella vasta regione astigiana ehe, trovandosi ad un livello inferiore 
a quello dell'alta valle padana, è costituita da una serie di colline di erosione, per cui vi possiamo studiare perfettamente bene ed in tutti i suoi particolari l'ultimo deposito del mare padano.

Non di rado, specialmente nella parte inferiore della serie astiana, si incontrano anche banchi di arenarie grigiastre o giallastre dure, che debbono in gran parte la loro compattezza al calcare delle conchiglie (Pecten, Ostrea, Terebratula, ecc.) le quali vi si trovano abbondantemente disseminate.

In causa della natura eminentemente sabbiosa dell'Astiano, le colline che ne sono costituite sono generalmente piuttosto aride e riconoscibili anche di lontano pel color giallastro, pei ripidi pendii e per una speciale regetazione.

\section{Caratteri paleontologici.}

Senza discendere ora ad indicazioni speciali di fossili, che troransi nel catalogo paleontologico, possiamo solo dire in generale che la fauna dell'Asticno è una fauna di mare basso o di littorale; da ciò la predominanza dei generi recten, Ostrea, Balanus, ece. Talora anzi si osservano, specialmente nell'Astigiana, veri banchi di circa ${ }^{1 ' 2}$ metro di potenza, estesissimi, costituiti quasi unicamente di un ammasso di Ostriche con Pettini.

Non sono pure rari i resti di grossi Cetacei ed anche di Proboscidati sulle cui ossa stanno talvolta aderenti Ostriche; quest'ultimo fatto, assai interessante, ci prora come durante il periodo astiano, contemporaneamente alla deposizione delle sabbie gialle marine, si formarano pure quei grandi delta villafranchiani sui quali virevano abbondanti i Proboscidati, i cui resti renivano talrolta fluitati in mare e quiri sepolti tra i depositi ed i fossili marini.

I fossili dell'Astiano non sono per lo più isolati e sparsi qua e là, come spesso si ossel'va per quelli del Piacen ziano, ma sono invece quasi sempre radunati in banchi ed anche in lenti speciali; in certi casi anzi i fossili reggonsi ammassati in gran quantità in dati punti, ed allora per lo più essi si presentano frantumati e corrosi pel trasporto e pel ballottamento subito prima di essere deposti.

Quanto ai resti regetali è importante il notare che nell'dstiano, come nel Messiniano, troransi assai sorente ed a diversi livelli banchi sabbioso-marnosi in cui abbondano le filliti che appartengono ad una flora in gran parte scomparsa dal Piemonte e di clima assai più caldo di quello che quiri esiste attualmente, ciò che ra perfettamente d'accordo col carattere della fauna marina. 


\section{Distribuaione geogrufica.}

Per essere l'ultimo deposito marino del bacino terziario del Piemonte, il terreno Astimno ne occupa la parte centrale; quantunque sia questa la formazione geologica che possiede uno sviluppo reale minore che non i terreni prima studiati, essa oceupa tuttavia un'area estesissima trovandosi in gran parte allo scoperto, specialmente nel bacino dell'Astigiana.

Nella parte Sud-Ovest della regione in esame l'Astiano appare gia presso lo sboceo del Pesio nella valle padana, e dopo avel toccato le colline monregalesi si dirige a Norel, in gran parte mascherato dai terreni quaternari. Liberato da questo mantello l'Astiuno si sviluppa ampiamente nelle colline braidesi ed astesi; di nuovo esso viene parzialmente nascosto dai depositi quaternari nell'alto Monferrato.

Verso Est la formazione astiance si assottiglia rapirlamente, venendo sostituita dai depositi fluviali del T'illafianchinno, finchè essa viene a scomparire quasi completamente nel tortonese, dove osservasi solo più in pochi punti e con piccolo spessore.

Non appare affatto l'Astiuno lungo le falde settentrionali delle colline Torino-Valenza; invece alle loro falde meridionali, iniziandosi ad Est come striscia sottile, esso si ra rapidamente estendendo verso Ovest, sino a costituire la parte settentrionale della vasta regione astese. Più ad Ovest però l'Asticuno, essendo ricoperto dai terreni quaternari, nuovamente si riduce ad una striscia che fascia le colline torinesi e che scompare completamente verso Mroncalieri.

Lungo le falde meridionali delle Alpi centrali la formazione astiana appare assai sviluppata ad Est della Valle di Lanzo sino al Lago di Orta, provandoci cosi come quivi il mare astiano si spingesse sin contro le falde alpine, talora anzi internandosi alquanto entro la stessa regione alpina, come verificossi in Val Sesia.

\section{Tettonica.}

Molto sempliec è la stratigrafia dell'Astiano essendo i stoi banchi per lo più quasi orizzontali; solo nella periferia della zona astiana inclinano gli strati di pochi gradi verso l'interno del bacino; lo stesso osservasi nei lembi subalpini.

Pcrò, se raramente osservansi alterazioni, ed in ogni caso sempre locali, che modifichino il regolare andamento stratigrafico della formazione astiana, sovente invece si può notare, con un esame dettagliato dei suoi banchi, come in essi siano spesso verificabili inregolarità che ci indicano una formazione deltoide ed un deposito costituitosi presso spiaggia od in bassi fondi marini, e quindi sotto il dominio dei movimenti di onda, di marea, di tempesta, ece. 
Questi fenomeni stratigrafici si osscrvano specialmente nella parte superiore dell'Astiano, cioè nei suoi banchi di passaggio al Fossaniano.

Potenza.

Per essere un deposito di mare poco profondo e per la sua natura litologica l'Astiano è in generalè più potente del Piacenziano; tuttavia lo spessore dei suoi banchi raramente raggiunge i 150 o $160 \mathrm{~m}$., come osservasi ad esempio presso Corneliano d'Alba: in media inrece essa è inferiore ai $100 \mathrm{~m}$; si può quindi dire che in complesso vi fu una diminuzione abbastanza graduale nella potenza dei dirersi terreni terziari del Piemonte, dai più antichi ai piủ recenti, ciò che in gran parte è in rapporto col gradualc riempirsi del bacino piemontese.

\section{Altimetia.}

Siccome i depositi astiumi, come quelli piacensiani, si spingono talora sin contro le falde alpine, cosi cssi si possono quivi osservare sollevati ad altezze molto considerevoli. Presso le Alpi marittime troviamo infatti i tipici banchi sabbiosi giallastri dell'Astiano portati ad oltre 500 metri tra la Val Pesio e la Tal d'Ellero, e possiamo constatare che a Mondovi Piazza questo terreno si solleva a circa 560 metri. che è l'clevazione massima raggiunta dall'Astiano in Piemonte.

Alle falde meridionali delle Alpi Centrali la formazione astiana, peró in gran parte con facies fossaniana, si spinge in alcuni punti sin oltre i 500 metri, come osserrasi ad esempio nelle colline di Castellamonte ed in Tal Sesia nelle vicimanze di Creracuore.

\section{Rupports coi terremi sotto e sorrastanti.}

Nel capitolo precedente si è già notato come sia quasi sempre affatto insensibile il passaggio tra Piacensiano ed Astiano per causa di una alternanza più volte ripetuta di marne e sabbie grigio-azzurrastre con marne e sabbie gialle.

Rispetto all'Astiuno superiore notasi pure generalmente un passaggio graduatissimo, ed a limiti mai segnabili con certezza, tra le sabbie gialle astiane e le sabbie ghiaiose ed i banchi ciottolosi del Fosramiano.

D'altronde è questo un fatto del tutto naturale trattandosi di un deposito di mare basso che si trasforma verso l'alto gradatamente in un deposito littoraneo e di maremma, finchè si eangia in una formazione di delta fluriale.

Talvolta però, ma di racto, si osserva che la formazione villafranchima si sorrappone quasi direttanente a quella astiuna, nel qual caso esiste per lo piu o una leggera trasgressione stratigrafica oppure un po' di erosione fatta dalle correnti acquee del rillafranchiano sui depositi del Fossaniano o dell'Astiano superiore. 


\section{Località fossilifere.}

Come gia si disse del Piacenziano anehe per l'Astiano si può ripetere come esso sia quasi ovunque riccamente fossilifero, ed è quindi inutile segnare una lunga lista di localita dove si raccolsero piủ abbondantemente fossili, poiehè ciò dipende specialmente dal metodo e dalla continuita delle ricerehe.

Notasi però come i fossili siano generalmente piủ abbondanti nei banchi basali dell'Astiano, in quei banchi eioè ehe fanno il passaggio al Piacenziano; si ritrovano pure sovente banehi molto ricehi in fossili, pero meno ben conservati che nel primo caso, nella parte superiore dell'Astiano quando ineomineiano ad apparire le lenti ghiaiose.

In generale là dove fra le sabbie astiane, a diversi livelli, veggonsi straterelli di sabbie grossolane o di ghiaie, là quasi sempre si ineontrano abbondanti fossili, giacchè quivi si verificò una deposizione alquanto tumultuosa ehe cagionò la morte degli animali ehe viverano su quel fondo di mare e maturalmente ne accumulò quivi i resti.

$\dot{\mathrm{E}}$ pure utile per la ricerca dei fossili l'esaminare aeeuratamente i grandi banehi d'Ostriche ehe incontransi molto sovente nell'Astigiana, inesauribile tesoro per la paleontologia plioceniea.

Le famose regioni fossilifere di Val d'Andona, dintorni di Asti, ecc., debbono la loro eelebrità, come gia si disse pel Piacenziano, a ricerehe speciali fatte in quelle regioni, mentre in quasi tutta l'Astigiana, nelle colline braidesi, ecc., i banchi zeppi in conchiglie si incontrano in quasi tutte le vallette incise un po' profondamente nella formazione astiana.

Lo stato di eonservazione dei fossili è generalmente meno soddisfacente di quello ehe osservasi nel Piacenziano, a eausa della natura del deposito che li ingloba e delle condizioni in cui esso si è formato.

Quanto ai banehi fillitiferi si ineontrano anch'essi o nei banehi inferiori dell'Astiano, come presso Bra (donde si estrasse la bella eollezione paleofitologiea del Prof. Craveri) o dagli strati superiori di questa formazione eome presso Madonna di Galizia (Bene-Vagienna), in Val Piana tra le borgate Tucci e Corsana (Ferrere d'Asti) ece., ecc. Quanturque siano specialmente eerti banchi marnoso-sabbiosi, giallastri, fogliettati, quelli che racchiudono le filliti dell'Astiano, tuttavia il loro incontro è per lo più fortuito, perehè tali fossili non appaiono generalmente nelle sezioni naturali ed occorre quasi sempre osservare la superfieie degli strati per rintracciarle. Spesso fillitifere sono le sabbie gialle dell'Astiano subalpino.

Una ricchissima ed alquanto speeiale fauna di Astiano riscontrasi nelle marne calcaree giallastre tra Val S. Bartolomeo e Parone d'Alessandria, all'estremità orientale delle eolline Torino-Valenza. 


\section{Descrisione geologica regionale.}

La vastità dell'area occupata dall'Astiano nel hacino picmontese richiederebbe una descrizione molto lunga per trattare particolarmente d'ogni regione; siccome peró la formazione in esame è in complesso abbastanza uniforme, cosi sarà possibile, come pel Piacenziano, di descriverla brevemente a grandi tratti.

Siccome l'area astiana nell'ampia regione collinosa dell'Astigiana ocempa quasi tutto il centro del bacino, così non è piủ possibile la distinzione tra le formazioni meridionali e settentrionali del bacino stesso; per comodità di descrizione tuttaria seguiró come linea di divisione tra i due lati della conca astigiana la Talle del Tanaro sino ad Asti e il suo prolungamento ad Orest sino a V'illafranca d'Asti.

Al piede settentrionale delle Alpi marittime si incontra la formazione astiana tra il 'Pesio e l'Ellero, dore essa costituisce il substratum di parte dell'altipiano di Pianfei e dell'altipiano di Roraceo, passando inferiormente alle marme bleu del Piacenziano ed appoggiandosi direttamente a Sud sulle roccie preterziarie, talcoschisti, serpentine e calcari, quiri lagogiung'endo l'elerazione di quasi 550 metri.

Deresi peró notare come in queste regioni, poco sopra ai banchi grigio-giallastri dell'Astiano tipico, compaiano banchi sabbioso-marnosi ed anche argillosi a tinte rariegate e senza fossili, per modo da indicarci depositi di marcmma ascrivibili già al Fosscniano. Questo d'altronde va d'accordo col fatto che poco a Nord e ad Orest l'Astiano è completamente sostituito dal Tillafranchiano come redremo in seguito.

La formazione sabbiosa, e quindi facilmente permeabile, dell'tstiano origina, alla sua base, un relo acqueo che scorre sulle marne aroillose del Piacenziano, ciò che ci spiega la raria profondita, talora reramente straordinaria (60, 70 metri), dei pozzi fatti negli altipiani di Roracco.

La profonda erosione eseguita dalle acque dell' Ellero esportò una parte noterole di Astiano che si stendera da Branzola alle colline monregalesi; peró un residuo di quest'antica estensione lo troriamo ancora in queste colline dove esso costituisce precisamente quel cocuzzolo su cui siede Mondorí Piazza, quiri sollerandosi a pressochẻ 560 metri, massima elerazione raggiunta dall'stiano in Pienonte.

Questo piccolo lembo astiano di Mondorí Piazza é appena visibile in pochi punti, spccialmente sotto il Castello, dove appare colla tipica facies di sabbie giallastre fossilifere (Pecten, Spatangus, filliti, ecc.), leggermente inclinate a Tord-Nord-Orest; quivi, come di solito, la placea di Astiano assorbe l'acqua di piogoia che l'attraversa per fermarsi sui banchi marnoso-argillosi del Piacenziano su cui essa scorre costituendo cosi un velo acqueo assai costante; questa falda acquea 
naturalmente ha il suo efflusso più abbondante verso Nord-Ovest, nel terzo superiore cirea d'altezza della collina tra Piazza e Breo.

A Nord della regione ora esaminata la formazione astiana, per l'elevarsi delle Langhe ad Est e per l'avanzarsi del Villafranchiano ad Orest, ed infine per le potenti c raste erosioni fitte dalle correnti acquee, trovasi ridotto ad un lembo poco estcso che è in parte coperto dal Sahariano dell'altipiano Banale ed è solo visibile in piccoli burroni tra C. Quaglia ed il paesello d'Isola.

Sulla sinistra di Val Mondalavia si può osservare l'Astiano lungo quasi tutta la terrazza tra lio Dafin e Podio; vi si possono anzi raccogliere, tra Madonna di Galizia e C. il Palazzo, nunerose filliti, Echinodermi, Molluschi, ecc. Lo stesso si nota lungo la terrazza orientale dell'altipiano di Piamboseo tra Podio c Castello Galateri, solo ehe in questo caso, come sempre si verifica lungo i fianchi delle terrazze a dislivello non molto folte, la formazione astiana è solo visibile in pochi punti, essendo generalmente mascherata dai terreni di scoscendimento, dall'humus, eec.

Sulla destra di Val Stura la formazione astiana è messa completamente a nudo sino alla sua base dalle profondi incisioni dei torrenti ehe scendono dall'altipiano di Piambosco; quivi trovansi numerosissimi fossili, specialmente nel passaggio tra Astiano e Piacenziano, e si incontra anche ver'so la parte superiore della serie un baneo a filliti, eehinodermi, ece. che forse corrisponde a quello indicato poco sopra.

Certi banchi marnoso-calcarei dell'Astiano inferiore si prescntano traforati dai Molluschi litodomi.

È notevole in Val Stura il fenomeno del graduale assottigliarsi della formazione asticna da valle a monte e da destra a sinistra, per modo che, mentre sotto Salmour essa ha una potenza di 80 o 90 metri, presso il Molino Nuovo di Val Veglia presenta solo più lo spessore di 2 o 3 metri; contemporaneamente si verifica un aumento di potenza dei dcpositi villafrachiani ehe sostituiseono cosi poco a poco quelli astiani innestandosi gradualmente fia di loro per mezzo della formazione fossaniana.

Questo fatto che, meglio che in alcun altro punto, si può osscrvare molto chiaramente in Val di Stura presso Fossano, ei dimostra come il Villafranchiano sia da considerarsi piuttosto come una facies fluviale del periodo astiano che non come un periodo a parte, e come tali depositi siano in gran parte contemporanei a quelli astiani.

E particolarmente utile per questo studio il risalire attentamente la valletta incisa dal torrente Veglia.

Sulla sponda sinistra di Val Stura l'Astiano, generalmente piuttosto sottile, si presenta talora assai ricco in fossili (come ad esempio presso 
F. SAcco

Briceo dei Fauli nel vallone di Masseria Nosaretto) specialmente in certi banchi giallo-grigiastri dell' Astiano medio inferiore.

A Nord di Cervere, come a Nord dell'Eremo di Cherasco, le sabbie dell'Astiano superiore furono esportate dalle correnti acquee di TanaroStura allorquando esse confluivano col Po rerso Carignano, quindi di questo orizzonte osserviamo solo più per lungo tratto i banchi inferiori, di cui un lembo redesi ancora nella parte superiore del II. Capriolo, lasciato quasi come testimone dalle correnti acquee di Stura-Tanaro.

Nelle colline braidesi la formazione astiana, ancora completamente conservata in tutta la sua potenza, che è talora di oltre 100 metri, e profondamente incisa in ogni sen 0 da piccoli torrentelli, ri si mostra completamente a nudo e studiabile quindi in tutti i stoi dettagli, a cui però non è ora opportuno discentere in questa descrizione, poichẻ essi troransi gia esaminati in laroli speciali.

Verso la parte inferiore dell' Astiano trovansi spesso (alternati coi tipici banchi marnos--sabbiosi gialli) strati marnoso-sabbiosi grigio-bleuastri riechissimi in fossili, come si può ad esempio osservare presso Bra salendo aria cappelletta di S. Michele, presso Pocapaglia, e negli stupendi valloni d'erosicne di Rio della Crošl, di Rio della Ghia, ece.; d'altronde come di solito, quasi or unque zono riccamente fossiliferi questi banchi di passaggio fra $i$ due orizzonti geologici, talora anzi ri si trorano pure resti regetali, sia tronchi lignitizzati, sia filliti. Tra queste località fillitifere deresi appunto menzionare come piu fruttuosa la trincea ferroviaria presso Bra al C. 62, dore le marne fogliettate dell'Astiano inferiore fornirono, assieme a Crostacei, Molluschi, ecc.. una ricchissima raccolta di foglie di piante, conservate ora nel Aruseo Craveri di Bra.

Nell'Astiano medio e superiore, costituito di sabbie e marne gialle, raramente grigiastre, non si incontrano più generalmente banchi con fossili tanto abbondanti e ben conservati; negli strati superiori della serie, dove cominciano a divenire piủ frequenti gli straterelli ghiaiosi" che passano al Fossumiano, là si ritrorano lenti riccamente fossilifere, ma per lo più questi resti sono alquanto corrosi od infranti.

Telle colline di Corneliano d'Alba possiamo osservare che l'Astiano raggiunge in alcuni punti, per esempio al Bric Montaldo, una potenza di oltre 160 metri, spessore il quale è uno dei più noteroli che presenti questa formazione in Piemonte.

Molto utile per la raccolta di fossili e per lo studio anatomico, direi, della formazione asti ina e dei suoi graduatissimi passaggi al Piacensimno in basso ed al Fossaniann in alto, nonehẻ pel l'esame di bellissimi fenomeni d'erosione, è il percorrere i profondi valloni che limitano ad Est l'altipiano di Sommariva rerno. Baldissero d'Alba, Montaldo Roero, Monteu Roero, S. Stefano Rocro, Monta, ecc., paesi che si trorano ad un dipresso sulla linea di displurio tra Val Tanaro e Val Po. 
In queste eolline si può osservarc eome generalmentc l'Astiano sia abbastanza uniformemente grigio nolla sua parte inferiore e giallastro inveee nella parte sua superiore, per modo che parrebbe doversi poter quivi distinguere l'1stiano in due sottorizzonti seeondari; ma trattandosi d'un fatto non generale nel baeino in esame, eredo inopportuno di diseendere a tale suddivisione.

Verso la base dell'Astiano si osservano talora in queste colline, come anche altrove nell'Astigiana, banchi arenaeei grigiastri che inglobano aecentramenti arenaeeo-ealearei, irregolarmente ovoidi, duri, i quali spesso nell'interno mostrano una speeie di camera eentrale irregolarc vuota, o ripiena di marna sabbiosa.

Qui eome altrove, esiste quasi orunque un relo aequeo abbastanza eostante alla base dell'Astiano; in eomplesso questa formazione, eome quella piacensiana, si abbassa verso Nord-Est e si solleva ver'so Ovest, almeno sino alla linea di displuvio Po-Tanaro, ad occidente della quale l'Astiano pende piuttosto regolarmente a Nord-Orest.

Nell'ampia Val Borbore e nei suoi numerosissimi affluenti osserviamo generalmentc gli stessi fenomeni dianzi aceennati; vediamo sempre le solite ineertezze nella delimitazione dell'Astiano per i gradatissimi passaggi ehe esso presenta ai terreni dei piani geologici tira cui è eompreso; eonstatiamo il velo aequeo basale, i banehi inferiori rieeamente fossiliferi, speeialmente se grigiastri od alquanto marnosi, ehe ei indieano la vieinanza del Piacenziano anehe nelle valli puramente astiane, eosi ad esempio in Val Maggiole presso Madoma di Vatiera, presso il Molino della Roeea (dove anzi probabilmente esiste un affioramento di Piacenzicno superiore sotto all'alluvione della vallata), in rio glande di Barrano sotto Valperosa, presso Serralunga, ece., loealita dove l'Astiano è ridotto a solo più 50 metri eirea di potenza.

Ne risulta quindi assai ehiaro il fatto ehe l'Astiano si assottiglia gradatamente rerso Ovest, venendo invece sostituito poeo o poeo dal Fillafranchiano, per eui è presumibile ehe sotto l'alta ralle padana l'Astiano generalmente non esista affatto, oppure sia ridotto a poehi strati, forse di Fossaniano.

Spceialmente ver'so Ferrere e Villafianca d'Asti veggonsi eomparire grossi banehi d'Ostrea e di Pecten nella parte superiore dell'Astiano. così nella parte bassa di Val Gherba e di Val Grande, alla base delle colline di Cantarana, di Serralunga, eec.

Sulla destra di Val Borbore, sui piani terrazzati di C. Piana, di S. Grato, di Gherbino, cee., il velo di loess rende aneor piủ ineerta del solito la delimitazione tra Piacensiano ed stiano. Riguardo a questa linea di separazione, in generale assai regolare, notansi tuttavia talora leggere ondulazioni, come pe esempio a Vaglicrano d'Asti, dove essa si 
solleva alquanto più che non nel suo andamento normale. In generale l'Astiano si va graduatamente abbassando rerso il centro del bacino per modo che, mentre la sua base si trova a cirea 200 metri d'elerazione presso Canale, ed a 250 metri presso Gorone, osservasi solo piti a 130, 140 metri d'elerazione presso Asti.

Esaminando le colline astesi ad Est di Val Tanaro vediamo l'Astiano costituirne la parte principale con una potenza raramente superiore ai 100 metri, e generalmente collo spessore di solo pochi metri rer'so Sud, costituendo spesso soltanto sottili placche di varia forma e di incerta delimitazione sopra le colline piacenziane che talora (specialmente nella parte loro superiore) per alterazione chimica, assumono un aspetto giallastro per modo da essere difficilmente distinguibili da quelle astiane; d'altronde trattasi solo generalmente di quei banchi di passaggio, quindi incertae sedis, la cui collocazione piuttosto in uno che nell'altro orizzonte non ha in fondo grande importanza.

Nelle colline di Rocea d'Arazzo, Montaldo Scarampi, Belveglio, Mombercelli, Vinchio, Cortiglione e Rocchetta Tanaro, importanti per le ricchezze palcontologiche del Piacensinno, troransi comunissimi nell'Astiano grossi banchi sabbiosi zeppi di fossili tra cui predominano però quasi sempre le Ostriche; tali banchi stanno specialmente verso la base dell'Astiano, come osservasi presso il Tanaro di fronte a Castello Annone, al fondo di Val Tiglione, presso borgata Piana, presso Belveglio, ece, ed in mille altri luoghi nella parte bassa delle vallette che incidono profondamente queste regioni collinose; troviamo eziandio tali banchi a quasi tutti i livelli della serie astiana, solo che predominano sempre più ver'so l'alto le Ostriche, finchè esse divengono quasi i soli rappresentati paleontologici della formazione in esame.

I limiti tra Astiano, Fossaniano e Tillafranchiano, gia sempre difficili a segnare per i graduali passaggi che si verificano tra i vari orizzonti, divengono ancora più inecrti (a cansa del velo allurionale ê della mancanza di incisioni profonde) in Val Tanaro ed in Val Tiglione, là dore la formazione astiana scompare definitiramente sotto ai terreni più recenti.

Ad Est di Val Belbo l'area dell'Astiano tipico, sostituito in gran parte dal Fossaniano e mascherato dal Tillafianchiano, diminuisce notevolissimamente di ampiezza ed anzi si riduce solo più ad una striseia marnoso-sabbiosa giallastra, della potenza media di circa 50 metri ed includente i soliti fossili, generalmente però non con quell'abbondanzi che si era notata esistere nelle colline astiane piu ad Orest.

La striscia astiana, pur conservando i suoi caratteri litologici e paleontologici tipici, si assottiglia sempre più verso oriente; tra la valle Bormida e la valle Orba essa è appena piu osservabile in pochi punti 
sotto al mantello villafianchiano e sahariano specialmente nelle vallate di rio Salso, di rio del Grano, di rio Orseceo, dove di solito veggonsi riceamente fossiliferi i banehi marnoso-sabbiosi, grigio-giallastri che formano il passaggio tra Astiano c Piacenziano.

Infine poco ad Est di Val d'Orba i banchi sabbiosi dell'Astiano, sempre più assottigliandosi, scompaiono eompletamente in val Lemme, conservandosi solo più per breve tratto la sottile formazione fossaniuna come indizio del Pliocene superiore marino.

Per lungo tratto in Val Serivia il I'illafianchiuno si vede sovrapporsi direttamente al Piacenziano non venendo a giorno l'Astiano; eredo tuttavia che csso esista pure, tan'̀ che csso ricompare per breve tratto presso Villalvernia dove è specialmente visibile poco ad Ovest di C. Macassia; ̀̀ quivi rappresentato da pochi banchi sabbiosi, giallastri, molto ricchi in Ostrea, Pecten, ecc., che sono tosto ricoperti ad Ovest da depositi conglomeratiei probabilmente villafianchiani.

Ho già indicato precedentemente le ragioni per cui pare si debbano inglobare nel Piacensiano le sabbie gialle a facies astiana delle colline di Cassano Spinola, Gavazzana e Torre degli Sterpi.

Nella restante parte dei colli tortonesi mancano completamente le formazioni astiane che veggonsi solo comparire piu ad Est lungo le falde meridionali delle colline vogheresi, pavesi cce.

All'estremita orientale delle colline Torino-Valenza sonvi appena traccie d'Astiano presso Rivarone; invece presso Pavone d'Alessandria vediamo conparire speciali banchi marnoso-arenaceo-calcarci, giallastri, zeppi di fossili (Pecten, Ostrea, Serpula, Echinodermi, Foraminiferi, Lithothamnium, ecc.), inclinati fortemente, cioè di circa $20^{\circ}$, verso Sud-Orest ed appoggiati direttamente, o solo coll'intermezzo di qualche straterello marnoso azzurrastro di Piacenziano, sui terreni miocenici.

Questi banchi, molto importanti per ricerche paleontologiche, utilizzati eziandio come pietra da ealce e da costruzione, appunto per la gran quantita di calcari organici ehe contengono, pare ehe per l'assieme dei loro caratteri si debbano riferire all'Astiano inferiore; tuttavia considcrando come in parecehi punti del bacino terziario piemontese il Piacenziano assuma eziandio una facies astiana e presenti una costituzione simile a quella sorraccennata, rimane qualche dubbio in proposito, tanto più che quivi tutti i terreni sono compressi, molto ridotti in spessore ed in gran parte mascherati dalla vegetazione.

I banchi astiani in questione si veggono immergersi sotto le aeque del Tanaro a Sud di Pavone, ed è anzi alla loro notevole resistenza che deresi la conservazione di qucsta punta orientale delle colline Torino-Valenza.

Verso Ovest la formazione marnoso-ealcarea dell' Astiano diventa tosto 
più cstesa e potente e la rediamo escarata su ampia scala in diverse loealità dove si possono raccogliere abbondantissimi fossili.

In Val S. Bartolomeo sovrappongonsi cd alternansi cogli strati marnoso-calcarei anche i caratteristici banchi marnoso-sabbiosi; questi piu ad Ovest divengono i principali rappresentanti dell'Astiano, giacchè i primi si riducono a poche lenti che appaiono ancora qua c là verso C. Bordis alla base della serie astiana, finchè scompaiono completamente.

A causa sia dell'essere il Piacenziano ridotto ad una. striscia piuttosto sottile, sia del metamorfismo superficiale di tutti i terTeni, sia del grande sviluppo della coltivazione, è sempre molto difficile il delimitare l'Astiano dal Piacenziano, spesso dorendosi solo fondare questa divisione su caratteri esterni, fra cui più spiccati sono il colore e l'orografia per il piecolo rilievo che sovente formano i banchi astiane inferiori sui banchi piacenziani superiori.

Ad Ovest di Castelletto Scazzoso, alle falde meridionali delle colline, sopra ai banchi superiori dell'Astiano si appoggiano strati marnoso-argillosi con lenti sabbioso-ghiaiose che sembrano già doversi includere nel Tillafranchiano, quantunque sia molto difficile tale distinzione non solo per i graduali passaggi (banchi di marne argillose, straterelli ghiaiosi, cec.) esistenti tra questi due terreni, ma anche per un relo piu o meno potente di Quaternario che spesso si stende sulle ultime pendici di queste colline mascherando i terreni sottostanti.

Nelle colline di Fubine, oltre ai fossili sparsi fra le marne sabbiose, cominciano ad incontrarsi banchi d'Ostriche, specialmente nella parte superiore della formazione astiana, cosi ad esempio presso C. Maraviglietta, presso C. S. Cristoforo, alla Cresta della Serra, ece.

Ad oecidente di Fubine l'area astiana si estende noterolissimamente assumendo un'inclinazione dolcissima a Sud circa. pur osservandosi talora pendenze locali assai diverse da quella generale sorraindicata; lc colline astiane, costituite essenzialmente di sabbie giallastre, assumono quell'aspetto tipico che presentano in generale nell'Astigiana.

A causa del forte corrugamento laterale, gia più volte accennato, Villadeati-Alfiano, che si prolunga noterolmente verso Est, tanto da far sentire la sua influenza sollerante sin presso Fubine, anche la zona astiana si allarga estesamente rimanendo in parte isolata (per erosione posteriore alla sua deposizione) a Nord di Val Grana, formando placehe più o meno estese, e spesso di difficile delimitazione, sopra alle placche piacenziane od anche direttamente sul Messiniano.

Ne possiamo infatti osservare una piccola placea formante il eocuzzolo di Altavilla, e placche più ampie e svariatissime nella parte alta delle colline di Casorzo, Grazzano e Moncalvo.

Tra Casorzo cd Ottiglio, presso C. Belvedere e C. Avalle, osservansi 
alcuni banchi sabbioso-calcarei, giallastri, riccamente fossiliferi, leggermente inelinati a Sud-Sud-Est e che paiono attribuibili all' tstiano, il quale quivi baserebbe direttamente sulle marne e sui ealeari grumosi del Messimano; non sarebbe peró improbabile che si trattasse di un banco pseudo-astiano del Piacensiano, giacchè vi si incontrano resti di Ostraea cochlear.

D'altronde tali strati calcareo-marnosi o calcareo-arenacei, talora giallo-rossastri, rappresentanti l'Astiano, gia li potemmo osservare in diversi altri punti del bacino piemontese e li vediamo poi molto sviIuppati poco ad Ovest nelle colline di C. Tirello, di C. Imerti e di Moncalvo, eioè verso il margine del mare astiano: condizione questa che dovette influire molto sulla speciale conformazione di tali banchi.

La resistenza all'erosione che presentano i predetti banchi arenacei, leggermente inclinati a Sud-Sud-Est circa, ei spiega come cssi mascherino quasi completamente a Nord la zona piacensiana che appare solo pì in sottilissima striscia oppure non è visibile affatto.

In queste colline, come in generale, riesce sempre molto incerta la delimitazione tra Piacenziano ed Astiano dove questo ̀̀ marnoso-sabbioso, a causa del metamorfismo superficiale, della coltivazione e specialmente dei soliti banchi di passaggio tra i due orizzonti geologici.

Nel golfo pliocenico di Moncalvo i banchi giallastri arenaceo-calcarei dell'Asticno acquistano una grande potenza, costituiscono l'alto delle elevate colline su cui siede il paese di Moncalvo, sono ricchissimi in fossili littoranei (Ostraca, Pecten, Balanus, ecc.) per lo più infranti, e costituiscono come di solito un velo acqueo alla loro basc.

Esaminando ora l'area astiana a Sud di Val Grana, la vediamo ampia, potente (giacchè mostra talora uno spessore di circa 100 metri) e poco frastagliata, eccetto nelle colline di Montemagno, Grana c Calliano alle cui basi spuntano affioramenti messiniani.

I banchi di quest'ampia area astiana presentano la tipica costituzione marnoso-sabbiosa giallastra; colle solite alternanze di strati grigiastri verso la base. Nella parte superiore invece, come si può specialmente esaminare verso Sud nelle colline di Refrancore-Castello, Annone-Quarto, la formazione astiana diventa più povera in fossili, presenta quasi solo più resti di Ostriche, e per mezzo di straterelli ghiaiosi giallo-rossastri od argillosi giallo-verdastri, ascrivibili al Fossaniano, passa ai depositi villafranchiani generalmente assai sottili. Come di solito esistono sempre incertezze in tali delimitazioni, specialmente nella valle del Tanaro dove i depositi terrazsiani mascherano per grandi tratti i terreni terziari.

Nella parte settentrionale della grande area astiana in esame vediamo come ancora per ampie estensioni questa formazione costituisca 
placche, ora isolate per erosione, di incertissima delimitazione e riccamente fossilifere sull'alto delle colline di Tonco, Frinco, Scandeluzza, Rinco, Colcaragno, Montiglio, ece.

Più a Sud le placche astiane sono tuttora collegate fra di loro, come nelle colline di Corsione, Montechiaro, Cortanze, Cunico, Piea, ece.

Colle sabbie gialle sovente, non solo verso la base dell'Astiano, ma anche in alto, alternansi marne grigiastre, spesso assai ricche in fossili e che originano piccoli veli acquei di poca importanza.

Ancor più a Sud rediamo la formazione astiana, estesissima, costituire da sola una regione collinosa molto rasta; in ral Versa, per la profonda erosione esereitata dalle acque, la zona astiana si restringe a solo cinque chilom. di sriluppo.

Le tipiche sabbie gialle hanno un predominio assoluto nella costituzione dell'Astiano di queste regioni; ri si incontrano spesso banchi d'Ostriche naturalmente coll'accompagnamento di una ricchissima fauna littoranea; le inclinazioni stratigrafiche sono sempre legrerissime e generalmente rérso Sud-Est.

Tra Callianetto ed Asti all'incirca le colline presentano rerso la parte alta numerosi banchi ghiaiosi, la sabbia diventa giallo-rossastra, generalmente con rari fossili, passandosi così gradatamente al Fossaniano che a sua rolta collegasi insensibilmente col Tillafranchiano. Queste colline sabbioso-ghiaiose, giallo-rossiccie sono tutt'ora in gran parte boschive, in rapporto appunto alla speciale natura del terreno.

Percorrendo le colline plioceniche tra Asti e Villafianca, dore l'Astiano scompare sotto al Tillafranchiano, possiamo sempre osservare presso Val Borbore il graduatissimo passaggio tra Astiano e Piacenziano: fatto questo che già esaminammo nel precedente capitolo, particolarmente rispetto alla città d'Asti. Nella parte alta delle colline esiste un passaggio assai graduale alle placehe villafranchiane per mezzo degli strati ghiaioso-ciottolosi del Fossaniano. È pure noterole come verso Orest l'Astiano si assottigli mentre si ispessisce inrece il Tillafranchiano: ciò che già osserrammo altrove e che ci prova essere questi due depositi in parte contemporanei.

Fra i supremi strati sabbiosi astiani riscontriamo sorentissimo bei banchi d'Ostriehe (talora gigantesche) di Pettini, ece., così nelle colline di borgata Cravera, presso il paese di Taldondona, in Tal Monale, specialmente nelle colline di Baldichieri e di C. Mandoletta, ece, ece.

Questi banchi fossiliferi superiori, in complesso formano un gran banco unico clie attrarersa tutta l'astigiana ed è messo a nudo in mille punti dalle erosioni acquee; esso riesce spesso utile al geologo perchè facilmente rintracciabile e gli segna quasi il termine della serie astiana; è poi preziosissimo pel paleontologo che vi trova un tesoro inesauribile 
per lo sue ricerche a vi può fure in breve tempo una raccolta abbondantissima con poca fatica.

Rieordiamo a questo proposito come le famose ricchezze paleontologiche di Valdondona si debbano in gran parte al sovraccemato banco dell'Astiamo superiore, nonchè a strati fossiliferi, che, come di solito, incontransi a più livelli nella seric astiana; del resto tale straordinaria ricchezza paleontologica è pressochè comune a tutte le colline astiane dell'Astigiana.

Nelle colline di Mombarone, Cinaglio, Camerano Casasco, Montafia, Vallunga, ece., la formazione astiana raggiunge ora una potenza di cirea 100 metri; in generale però il suo spessore ì minore. Verso la sua base ossertransi sovente, tra i tipici banchi marnoso-sabbiosi gialli, banchi marnosi grigio-bleuastri che rendono molto incerta ed arbitraria la distinzione tra Astiano e Piacenziano; ne siano esempio, fra mille che si potrebbero citare, le marne bleu riccamente fossilifere che appaiono in Val Camerano, poco a valle di C. S. Bartolomeo, e che inglobai ancora nell'Astiano, per quanto abbiano facies piacenziana.

A causa del rapido svilupparsi del Villafranchiano verso Ovest l'Astiano ne resta completamente mascherato; d'altronde dal suo assottigliarsi in tale direzione possiamo arguire che sotto la valle del Po, tra l'Astigiana e lc Alpi Warittime, l'Astiano venga completamente sostituito dal Tillafranchiano.

Nelle colline di Cortandone, di Valrovino, di Miglino, di Capriglio, ece., possiamo ancora osservare notevoli banchi d'Ostriche a cui sorrappongonsi i pochi sabbioso-ghiaiosi del Fossaniano che costituiscono graduale passaggio ai depositi villafranchiani.

Nella parte settentrionale dell'arca astiana, cioè nelle colline di Piori, Cerreto, Passerano, Primeglio, Pino d'Asti, Mondonio, Castelnuovo, Moriondo, cec. reggonsi ancora a diversi livelli nella scrie delle sabbie gialle astiane, banchi straordinariamente richi in fossili. Questi banchi in cui, come di solito, le Ostriche hanno generalmente la prevalenza, sono leggerissimamente inclinati a Sud, anzi spesso appaiono quasi orizzontali, si presentano talvolta fortemente cementati, specialmente verso il limite settentrionale dell'arca astiana, indicandoci la spiaggia marina di quell'epoca, e formano così in alcuni punti sul Piacensiann placehe rilevate su cui appunto furono spesso fondati paeselli eome Passcrano, Primeglio, Schierano, Pino d'Asti, ecc.

Ad Ovest di Moriondo la formazione astiana è ridotta ad una fascia irregolare (della larghezza di solo più due o tre chilom. c di potenza minore di 50 metri) che, appoggiandosi con insensibile passaggio al Piucensiano, einge a Nord la collina torinese mentre a Sud c̀ ricoperta dai depositi villafranchiani; da questi è quasi impossibile delimitarla 
nettamente, non solo a causa dei soliti banchi di passaggio, ma speeialmente a eausa dei depositi quaternari (fra cui tiene il massimo posto il loess) i quali maseherano quasi eompletamente le falde collinose in questione, per modo ehe quiri la distinzione tra Piacenziano ed Astiano rimane più incerta del solito.

Contuttoeiò possiamo aneora in dirersi punti far raecolta di fossili frammezzo alle tipiche sabbie gialle, eosì nelle colline di Arignano, di Andezeno, di Chicri e di Trofarello (la cui parte alta basa preeisamente sopra un baneo d'Ostriehe eoperto da loess).

E notevole un banco sabbioso-arenaeeo ad Ostrea, Pecten, Terebratula ecc. nella parte medio-superiore dell'Astiano, eosi ad esempio presso Tetti Souspir. Talrolta s'ineontrano pure in queste eolline resti di piante, specialmente verso la base della formazione astirna.

Dove però l'alterazione ehimica penetrò profondamente attraverso i banchi sabbiosi di quest'orizzonte, i fossili sono spesso scomparsi quasi eompletamente, rimanendone solo più le impronte.

L'inelinazione degli strati è sempre doleissima e piuttosto regolare verso il Sud-Sud-Est. Come di solito esiste per lo più un velo aequeo alla base dell'Astiano, e l'orografia vedesi in gran parte dipendere dalla eostituzione geologiea della regione, profondamente modifieata però dalle erosioni aequee.

Nelle eolline di Troffarello la formazione astiana è ridotta a poehissimo spessore; osservasi aneora nella valletta di Villa Sampỏ e scompare eompletamente poeo dopo sotto ai terreni sahariani della pianura padana, probabilmente seomparendo poi effettivamente del tutto, poeo ad Orest, e venendo sostituita dai depositi villafranchiani che si sviluppano sino alle falde alpine, maseherati però dal Sahariano.

Se ora passiamo alle falde alpine notiamo eome la formazione astiana vi manchi talora completamente. Infatti se dalle ricinanze di Mondovi, dove osservammo lembi astiani alle falde settentrionali delle Alpi Marittime, ei portiamo rerso Orest, rediamo apparire il Villafranchiano.

Da Val Gesso sino alla Dora Riparia i depositi sahariani maseherano i terreni plioeeniei; ma sotto il eono di deiezione della Stura di Lanzo i nuovamente il Villafranchiano ehe appare eome eostituente il Pliocene superiore subalpino, per modo ehe, eonsiderando eziandio lo sviluppo dei depositi villafranchiani nella parte oceidentale delle eolline astesi, braidesi e fossanesi, è naturale l'ammettere ehe sotto l'alta ralle padana manea rerso Ovest quasi eompletamente l'Astiano.

Ma ad Est della valle della Stura di Lanzo, e più preeisamente ad Est dello sprone roecioso di Madonna dell'Annunziata, nelle colline attorno a Lerone e Crosaroglio, comineiamo a reder eomparire i banehi marnosi, sabbiosi e ghiaiosi giallastri dell'Astiano addossati alle roccie 
antiche alle falde alpine; coi banchi giallastri si alternano talora verso il basso strati sabbioso-marnosi grigiastri, ma più frequentemente invece banchi ghiaioso-ciottolosi giallo-rossastri ehe iniziano il Fossaniano; i fossili marini sono piuttosto rari, littoranei e quasi solo più allo stato di impronta; non rare invece sono le filliti.

Verso la base dell'Astiano veggonsi talora apparire, come in Val di Ca Vietton, le sabbie azzurrastre (anch'esse spesso commiste a lenti ghiaiose) costituenti la zona di graduale passaggio al l'iacenziano superiore.

Ad un dipresso colla medesima costituzione e colla stessa facies si paỏ osservare l'Astiano nella parte basale delle colline plioceniche che s'addossano alle falde alpine tra Rivara Valperga e che per mezzo di profondissime incisioni naturali si possono anatomizzare, direi, in tutti i loro minuti particolari.

La grande corrente acquea della val d'Oreo ha spazzato via completamente al suo sboceo, durante il periodo sahariano, i depositi pliocenici; li ritroviamo però poco ad Est dello sboceco di detta valle, eioè nei profondi burroni delle colline di Talantini, di Cresto e specialmentc presso Castellamonte. e nelle colline a Nord di questo paese.

Quivi la formazione astiana, come quella subalpina or ora esaminata, da Levone a Cuorgnè si presenta con una facies assai diversa da quella che osservasi generalmente in Piemonte, ma affatto paragonabile a quella dell'Astiano subalpino tra Val Pesio e Val Ellero; cioè questo Astiano consta di sabbie giallastre, talora giallo-rossiecie, alternate, verso la base, con banchi marnoso-sabbiosi grigiastri ed inglobanti, a diversi livelli della serie, lenti o grossi banchi ghiaioso-eiottolosi; scarseggiano i fossili, specialmente nella parte media e superiore dell'orizzonte.

In eonelusione l'Astiano subalpino è una formazione littorale, depostasi in un'acqua alquanto salmastra (quindi generalmente inadatta allo sviluppo della fauna marina). Tali depositi furono spesso conturbati da correnti acquce provenienti da terra che originarono i preaccennati banchi ciottolosi, rendendo cosi sempre piu difficile lo sviluppo della vita marina.

A dire il vero mentre la parte basale del Pliocene subalpino sup. per essere generalmente costituito di marne e sabbic gialle alternate con strati marnosi grigiastri, può ascriversi al vero Astiano, la parte media c specialmente poi quclla superiore si deve gia riferire al Fossaniano, rappresentando essa litologicamente e paleontologicamente reri depositi di littorale o di delta submarino; anzi in alcuni punti delle colline plioceniche di Castellamonte, come anche di Rivara-Cuorgnè si osscrva che il Fossaniano sup. presenta letti argillosi grigio-verdastri e depositi ciottolosi che già preludiano al Villafranchiano. 
Lungo il torrente Malesina presso C. Nigra regoronsi banchi grigiastri, sabbioso-ghiaiosi od anche conglomeratici, i quali rappresentano l'Astiano inferiore, però già a facies littoraneo-deltoide. per modo che si possono quasi racchiudere nel Fossaniano. Cosi pure nella. parte inferiore delle colline Cornaglia-Vivario le marne e le sabbie giallastre dell'Astiano tipico, con qualche fillite e qualche impronta di Molluschi littoranei, non hanno che poca potenza, giacchè appaiono tosto rerso l'alto i banchi ciottolosi che iniziano il Fossaniano.

I banchi arenaceo-conglomeratici del Ponte dei Preti, qnantunque appartenenti alla base del Pliocene superiore, debbonsi per la loro fucies riferire al Fossaniano. Invece nei profondi burroni di Pian Torinetto e di Sento (Borra grande) si può osservare una scrie abbastanza potente di strati marnosi e sabbiosi giallastri, o, piu di lado. grigiastri. cioè l'Astiano quasi tipico, passante gradatamente al Fossaniano rerso l'alto; esso è talora abbastanza ricco in fossili, specialmente nella sabbia grigiastra della parte inferiore dore troransi Pecten. TTassa, Ostraea, ece.

Nella profonda incisione della Boriana, ed in torrentelli vicini, osservasi l'Atiano ad un dipresso colla medesima costituzione or ora indicata; però compaiono alla sua hase aleuni banchi pracmsinni ed inoltre verso l'alto esso, pur passando gradatamente al Fos.sunimo. si presenta direttamente coperto di tratto, per erosione, dai depositi morenici, inglobanti pure naturalmente fossili pliocenici, fatto ad un dipresso generale per le formazioni glaciali della cerchia s. GioranuiCaluso-Borgomasino; infatti io considero come $10 \%$ eno moiemicn. costituito in parte di materiale pliocenico rimaneggiato, quei depositi inglobanti frantumi di fossili plioceniei commisti a ciottoli glaciali, che osscrvansi presso Perosa, Mercenasco, Candia. Caluso, Tische, Mazzè, Borgomasino, ece. e che furono considerati come reri depositi terziari da Sismonda, Bruno, Baretti, Stoppani, Carez e Vasseur, Zaccagna, ecc.

Sulla parte orientale del grandioso anfiteatro morenico d'Trea non si possono osservare depositi astiani, ma lembi più o meno estesi di questi terreni debbono probabilmente esistere tuttora sotto alla gigantesca morena laterale sinistra detta la Serra; tant" sino nella ralletta Oriale, sopra alle marne azzurre del Piacensiano, si veggono aleuni straterelli sabbiosi giallastri che pare formino la base dell'alta ralle Oriale e sono ascrivibili probabilnente all'Astiano inferiore di cui rappresenterebbero gli scarsi residui.

Al di fuori dell'anfiteatro morenico d'Irrea, verso Est, nella parte orientale delle colline su cui poggia il borgo di Mongrando si possono osservare sabbie giallastre grossolane commiste a potenti banchi ghiaiosi e ciottolosi; per la loro facies esse ricordano molto i depositi dell'Astiano littorale o Foszaniamn a cui parrebbero quindi ascrivibili: però siccome 
non vi si potè ancora rintracciare alcun fossile, rimangono ancora al.. cuni dubbi su ciò, non essendo impossibile che i depositi sahariani inferiori assumano talvolta la facies indicata.

Lungo le falde montuose tra Mongrando e Biella manca assolutamente ogni traccia di Astiono, e se anche questo terreno fosse quivi originariamente esistito, com' e probabile, esso venne in gran parte esportato dalle correnti acquee quaternarie ed in parte si trova probabilmente nascosto sotto ai depositi alluvionali.

Poco ad Esst di Biella, verso lo sboceo di Val Chiebbia esistono presso la fibbrica Ratto banchi sabbioso-ghiaiosi e spesso anche eiottolosi, grigiastri verso il basso e giallastri verso l'alto a stratificazione regolare nella palte infuriore ed invece irregolare, spesso deltoide, nella parte superiore. Questi depositi, che si appoggiano direttamente a Nord sulle roceie antiche e che sono coperti dai potenti banchi ciottolosi del Sahariano, quantunque nom abbiano ancor fornito fossili si debbono probabilmente considerare come i rappresentanti del Piacenziano superiore e dell'dstiuno a fucies fossaniuna, per quel carattere, direi, di foce che gia osserrammo in depositi subalpini sinili e contemporanei, come presso il Ponte dei Preti e presso Castellamonte, solo che là essi si presentano generalmente più cementati a causa della maggiore abbondanza del materiale caleareo.

Continuando il nostro esame verso Est vediamo che nelle colline tra Ronco e Vigliano le sabbie gialle dell'Astirno si sviluppano notevolissimamente, tanto clie presso borgata Avandino esse hanno gia una potenza di quasi 100 metri; però la parte superiore di questa formazione per i suoi caratteri devesi gia ascrivere al Fossaniano, essendo essa molto ricea in banchi ghiaiosi e ciottolosi.

Nelle colline di Valdengo, Cerreto, Quaregna, Lessona, ecc., vediamo sempre lo stesso fatto ad un dipresso, cioè potenti sabbie giallastre che in basso o terminano colle sabbie azzurre del Piacensiuno, come vedesi sotto Cerreto, presso Cossato, ece., oppure s'appoggiano direttamente sulle roccie antiche cristalline come ì il caso più generale; in alto invece terminano coi depositi fossaniani e sahariani, sollevandosi sin oltre i 350 metri.

Prima di passare all'esame del cosidetto bacino pliocenico di Masserano accenniano al fatto interessante che anche lungi dalle falde montuose si osservano per lungo tratto, sulla destra del Cervo, i terreni astiani potentissimi che veggonsi costituire, sotto ai depositi sahariani, l'imbasamento dell'altipiano o barraggia Candelo-Villanuova.

Quivi l'Astiuno è rappresentato dalle solite alternanze di sabbie e marne grigic o gialle, in cui si incontrano non di rado strati fossiliferi; generalmente però delle conchiglie marine rimane solo più l'im- 
pronta interna od esterna, essendo seomparso il ealeare; sono pure eomuni aleuni straterelli riccamente fillitiferi. A eausa delle profonde ineisioni fatte dal Cervo ne] suo pereorso antico ed attuale, il terreno astiano si può esaminare più o meno nettamente lungo tutte le falde dell'altipiano in esame, sino a Villanuova; anzi talrolta rerso la base di questo terreno redonsi eomparire, nei burroni più profondi di Castellengo e Cascina Colombo, speciali banehi di marna bleuastra che già ei indicano la base dell'Astiano.

In queste regioni si puo poi seguire molto bene l'insensibile passaggio tra tstiano e Fossaniano, le cui facies si intreeciano in modo tale da renderne arbitraria la netta separazione: predomina però la frecies fossaniana.

Passando ora sulla destra di Taí Cerro, ad Est del C. Strona, rediamo le sabbie gialle dell'Astiano essere pel lungo tratto mascherate dai terreni quaternari e comparire quasi solo nei tagli fatti dai rii; ma ad Est dell'alta barraggia Margherita, per non essersi piủ potuta espandere la grande corrente aequea del Cerro, i terreni pliocenici rimasero in gran parte liberi dal relo quaternario e possiamo quindi osservarvi molto ben sviluppato l'Astiumo alla base delle eolline ehe si estendono a Sud di Masserano con un aspetto talmente simile a quello delle colline astiane ele par proprio di trorarci in un lembo d'Astigiana trasportato presso le falde alpine.

I banehi sabbiosi giallastri dell'Astiano racehiudono spesso bellissime filliti ed anche numerosi resti di Mollusehi, specialmente bivalvi (Pectunculus, Panopaea, Pecten, Lucina, eee.) generalmente però ridotti alla sola impronta interma; come di solito si può osservare in queste eolline il graduatissimo passaggio fra l'Astiano e gli orizzonti sotto e soprastanti.

Ad Oriente di Masserano, nelle colline di Brusnengo, Roasio, Lozzolo, ecc, i banchi astiani ranno poco a poco scomparendo perchè della formazione pliocenica emergono dalla piantura solo più le assise stperiori costituite essenzialmente di Fossamiano.

Sopra ai lembi jiacensinni che ncl precedente capitolo si è notato trovarsi entro la Val Sesia, esistono pure quasi sempre. lia dore le colrenti aequee non li hanno esportati, depositi sabbiosi: o sabbioso-marnosi giallastri ehe rappresentano precisamente l'Astiano. Tediamo eio nella parte alta delle eolline plioeeniehe di Grignaseo, in aleuni dei lembi plioeenici di Valduggia e speeialmente sopra ai sorraesaminati depositi piacenziani di Creraenore; in ogni easo si osserva sempre un passaggio assai graduale tra i due orizzonti geologici. Notiamo però ehe i tipiei banehi astiani sono generalmente poeo numerosi poichè eompaiono tosto verso l'alto gli strati eiottolosi del Fossamiano, ed anzi 
sovente quest'ultimo orizzonte si collega direttanente al Piacensiano senza intermezzo di bánchi aserivibili al vero Astirmo.

Ad Est della Valsesia le formazioni astiane visibili presso le falde alpine sono ridotte a lembi assai scarsi, sia perchè esse vi sono poco potenti, sia perchè furono in gran parte erosi dalle correnti acqueo oppure perehè eoperte dai depositi del Quaternario. Ne rediamo gli scarsi residui, spesso appoggiati alle roceie porfiriche, presso Boca, Marello, Maggiola, Fornaci di Maggiora, qua e là sui fianchi di Val Sizzone, presso Motto Fiorio, e ad Orest di Gargallo sotto la borgata Pianezza, regione interessantissima la quale ci segna il limite settentrionale astiano nella insenatura orografica del lago d'Orta.

Ad oriente dell'Agogna la formazione astiana scompare affatto, non giả perchè erosa o mascherata, ma bensi perchè sostituita dalle formazioni deltoidi e lacustre-fluviali del rillafianchiano.

\section{Riassunto.}

La formazione astiana del Piemonte, la quale forni gia alla scienza paleontologica un materiale ricchissimo, non venne finora in generale studiata accuratamente dal lato geologico. Essa rappresenta un deposito di mare poco profondo, ed anzi talora di littorale, ed è quindi costituita essenzialmente da sabbie e ghiaie giallastre, talora alternate però con sabbie grigiastre, il tutto generalmente piuttosto sciolto.

Il terreno astiano, essendo uno dei più recenti e quindi dei piủ superficiali della serie terziaria, si mostra largamente sviluppato nel eentro specialmente del bacino terziario piemontese; appare tuttavia anche per lunglie zone alle falde delle Alpi marittime e centrali e talrolta anche entro le regioni alpine. La sua stratigrafia è assai regolare, essendo i banchi astiani generalmente quasi orizzontali oppure leggermente inclinati verso il centro del bacino piemontese; notansi perỏ talvolta piccole irregolariti stratigrafiche locali che debbonsi pinttosto a fenomeni verifieatisi durante la deposizione di questo terreno che non a fenomeni avvenuti in seguito per movimenti sisniei od altro.

Malgrado il grande sviluppo dell' Asticno, ciỏ ehe farebbe supporre " miomi dovesse esso presentare una notevole potenza, il suo spessore, lit dove si presenta massimo, è di cirea 150, 180 metri; in media però esso è inferiore ai 100 metri.

Avuto riguardo all'essere l'Astiano uno degli ultimi depositi dell'êra terziaria ì interessante l'osserrare come esso presso le falde alpine si spinga sin oltre i 500, 550 metri di elevazione, prova certa di un potentissimo movimento sismico di sollevamento che chiuse il periodo pliocenico. 
Graduatissimo si compie quasi orunque il passaggio tra i depositi astiani e quelli macensiani in basso e quelli fossaniani o villafianchimi in alto, per mezzo delle solite alternanze di strati che presentano i caratteri dell'uno e dell'altro orizzonte.

La flora assai ricca che è racchiusa in alcuni strati speciali dell'Astiano indica un clima relativamente caldo. assai più mite di quello quaternario; quanto alla fauna essa è vera fauna di mare poco profondo o di littorale, ed i suoi resti più o meno ben conscrrati sono pure per lo più aceunulati in speciali lenti o strati sabbioso-ghiaiosi, verso la base e la meti della serie stratigrafica.

La distribuzione dei tereni astiuni nelle regioni subalpine ci dimosta che durante il periodo restirno il mare padano si spingera solo per alcuni tratti sin contro le falde delle Alpi, sorente inrece se ne trovava allontanato o per fenomeni orogenici localmente più accentuati oppure per più potenti depositi fluviali che, come naturale, fecero rapidamente aranzare in mare i delta di quel periodo. 


\title{
CAPITOLO XVI.
}

\author{
FOSSANIANO
}

\section{Studi anteriori.}

Siecome questo orizzonte dell'Astiano venne solo da me individualizzato einque anni or sono eon un'apjosita llota, non esistono naturalmente in proposito studi speciali per opera di altri geologi; notiano tuttavia eome i resti fossili di grossi Mammiferi terrestri che spesso s'incontrano nell'Astigiana e che formarono materia di vari lavori paleontologiei, derivano in parte appunto da questi terreni fossrmiani che passereno ora ad esaminare.

\section{Generalità.}

La formazione fossaniana si può definire una formazione di littorale o di maremma a seconda delle varie località in eni si osserva; essa è costituita essenzialmente, nel primo caso, di sabbie più o meno grossolane alternate e commiste con lenti e banehi di ghiaie e di conglomerati, il tutto di color giallastro o rossastro; nel seeondo caso da sabbie e narne argillose giallastre od a tinte svariate, specialmente rossiecie, verdastre od azzurrognole; nel primo caso la stratifieazione ci indica un deposito più o meno tumultuoso formatosi presso spiagrgia ed a poea distanza da essa, spesso in relazione con un vicino sboceo di corrente terrestre, mentre nel secondo easo abbiamo che fare con una formazione piuttosto tranquilla depostasi in bracei di mare ehinsi o comunieante solo per poco coi grandi bacini marini, cio ehe ci spiega la scarsitì e spesso anzi la mancanza di fossili in questi terreni. Sovente però le due facies sovracennate si confondono l'una coll'altra per lo sboceo di grosse correnti terrestri entro a bacini maremmani, come verifieasi specialmente presso le falde alpine, dove spesso il Fossaniano assume la forma di un gran delta.

\section{Caratteri paleontologici.}

In generale si può dire che i caratteri paleontologici del Fossaniano rispetto all'Astiano sono earatteri negativi, giacehè in cansa della sua natura maremmana o littorale gli animali marini non poterono vivere assolutanente oppure i loro resti rennero rotti, erosi, distrutti. Tuttavia in aleuni casi, speeialmente alla base del Fossaniano, ineontransi aneora lenti ghiaiose fossilifere; spesso però ì gusei calearei sono cosi fattamente logori da essere difficili a determinarsi specificancente; 
è poi fenomeno curiosissimo, specialmente nei depositi fossaniani subalpini, che i fossili trovansi ora ridotti alla semplice impronta interua od csterna essendo scomparso il materiale calcareo.

In ogni modo trattasi sempre di una fauna speciale, littoranea e salmastra, rappresentata essenzialmente da Ostrea, Cardium, Pecten, Mactra, Cerithium, Terebra, Nassa. Trochus, Balanus. ecc. Fra tutti questi fossili è specialmente comme l'Ostrea edulis Lin. la quale forma talora piccoli banchi o meglio lenti di agglomerazione a dirersi livelli della seric stratigrafica del Fossaniano.

Tale Ostrica osserviamo anche al giorno d'oggi svilupparsi assai nelle maremme e nelle lagune attuali.

E poi importante a notarsi il fatto che una parte considerevole dei resti di grossi mammiferi terrestri, comc Mastodonti, Elefanti, Rinocelonti, Ippopotami, cce., che si rinvengono nel Pliocenc dell'Astigiana, oltre che nel Tillafranchiano riscontransi frcquentemente appunto fra i banchi sahbiosi e ghiaiosi giallo-rossastri del Fossaniano; quivi anzi si osserva che ai resti di questi animali terrestri aderiscono talora valve di Ostriche a provarei sempre più la contemporanea deposizione di terreni marini e terrestri durante la seconda metà del Pliocenc.

Notiamo infine che ancora ncl Fossaniano riscontransi spesso inammenti regetali limonitizzati, o silizzati od anche solo lignitizzati; inoltre in alcuni banchi marnoso-sabbiosi, specialmente se fogliettati, si trorano non di rado filliti abbastanza ben conservate $c$ che collegansi perfittamente con quelle dell'Astiono, appartenendo anch'esse ad una flora di clima abbastanza caldo od umido.

\section{Distribuzione geografica.}

Il Fossaniano accompagna quasi sempre l'Astiano di cui costituisce per lo più la parte suprema e quindi, nel bacino terziario in esame, la parte intcrna. Devesi però subito notare che, mentre i banchi fossaniani sono abbastanza sriluppati nella parte meridionale del bacino terziario piemontese, essi inrece si riducono a ben poea cosa lungo le falde delle colline Torino-Talenza, fatto che $i$ in stretta relazione colla generate diversita di sviluppo e di potenza che arevano lc correnti acquee scendenti, nel primo caso dalla catena alpino-appenninica, e nel secondo caso solo da una, regione di colline poco clevate.

Naturalmente si presenta molto sviluppata la formazione fossaniana lungo le falde delle Alpi ed entro le stesse regioni alpine dore però essa non venne sostituita dai depositi villafranchiani, come redremo essere il caso più comunc; ̀̀ spccialmente presso le falde alpine che osserransi nel Fossaniano i banchi ciottolosi più potenti cad elementi più voluminosi, tanto che spesso queste formazioni rassomigliano piuttosto a depositi diluriali del Sahariano che non a terreni pliocenici. 
Dal premesso si può dedurre che la distribuzione geogratiea del Fossaniano è assai interessante a notarsi poichè essa ci da il modo di ricostrurte in parte l'oloidrografia del bacino picmontese durante la scconda metì dell'epoca pliocenica.

\section{Tettonica.}

Come si ì detto per l'Astiano anche la formazione fossaniana presenta un andamento stratigrafico regolare essendo i suoi banchi quasi orizzontali ed appena inclinati verso l'interno del bacino; tuttavia, in rapporto appunto del modo di deposizione di questo terreno, vi constatiamo sovente eoll'esame dettagliato che i suoi banchi presentano spesso disturbi locali, cioè stratifieazioni a delta, trasgressioni stratigrafiche, deposizioni irregolari per l'urto delle onde sulla spiaggia, eec. ecc.

\section{Potenza.}

Svariatissimo i lo spessore che prescnta il Fossaniano nci vari punti in cui si osserva, talora cssendo ridotto a minnscoli straterelli ghiaiosi di pochi centimetri, e talvolta invece assumcndo una potenza di oltre 50 metri; anzi presso le falde alpine non di rado i banchi ghiaiosociottolosi che, alternandosi colle sabbie, costituiscono il sott'orizzonte fossaniano compaiono già direttamente all'apice del Piacenziano. rappresentando l'intiero Pliocene superiore, nel qual caso il Fossaniano raggiunge anclic uno spessore di oltie 70 metri.

\section{Altimetria.}

Siccome il Fossaniano costituisce sorente, specialmente presso le falde alpine, il coronamento della seric pliocenica è naturale che i suoi strati si trovino spesso sollevati a noteroli altezze; infatti presso le Alpi centrali ed entro le stesse regioni alpine lo vediamo sollevarsi sino ai 500 c persino ai 520 metri, come nelle colline di Castellamonte ed in più punti in Val Sesia, specialmente presso Crevaeuore c presso Guardabosone. Anche nelle colline ad Ovest di Villanova Mondovi, al piede delle Alpi Narittime, i banchi superiori della serie plioeenica, che per la loro natura di deposito marcmmano si possono inglobare nella formazione fossaniana, si mostrano sollcvati in alcuni punti oltre i 500 e sin quasi ai 550 metri.

\section{Rapporto coi terreni sotto e soprastanti.}

Già studiando l'Astiano si è più volte aceennato come i suoi limiti superiori siano spesso molto ineerti a causa del gradnalissimo passaggio che formano i suoi banchi con quelli del Fossaniano per mezzo di una ripetuta alternanza di marne, sabbie, ghiaie e conglomerati, tanto che 
una separazione netta fra i due terreni è affatto impossibile, mentre invece, considerandoli in complesso, essa risulta molto naturale.

Le stesse incertezze ad un dipresso s'incontrano nel Forsaniano superiore là dove questo terono passa al I'illafianchiano quantunque in tale caso esista generalmente uno speciale banco ciottoluso, più o meno potente sccondo i luoghi, che serre, conrenzionalmente almeno, come limite fia i due terreni.

Dove pcrò, come presso le falde alpine, il Fossamiano è coperto direttamente dai depositi sahariani, questa sorrapposizione si presenta o con salto, oppure graduale. Infatti in alcuni casi i depositi diluriali si adagiano abbastanza trauquillamente sui supreni banchi fossaniani per modo che, per essere pure questi in gran parte ciottolosi e ad elementi grossolani, si osserva una specie di passaggio tra i terreni plioeenici e quelli quaternari, come ad csempio in molti punti dclle eolline biellesi; in altri casi invece, specialmente allo sboceo delle grandi valli alpine, si osserva che i depositi sahariami si sorrappongono direttamente ai banchi del Fossamiano medio, risultanrlo quindi chiaro ed cridente quivi un hiatus, derivante dal fatto che le correnti acquee del Sahariano erosero la parte superiore del Pliocene prima di deporre banchi eiottolosi. La dore sono i depositi morenici che sortappongonsi direttamente al Fossaniano lo hyatus sorraccennato esiste sempre.

\section{Localiti fossilifere.}

Non esistono veramente speciali localiti fossilifere del Fossaniano. ma si può dire ehe in quasi tutta l'Astigiana nel passaggoio tra quest'orizzonte e l'Astiano incontransi resti sparsi, oppure reri banchi, di Ostriche. E nel Fossaniano di Bra che si rinvenne il cranio del Felsinotherim Gastaldit; è pure fra le ghiaie fossmimne dell'alto di Incisa Belbo che si raceolscro numerose ossa e denti di Proboscidati assieme a Pecten ed Ostreu; lo stesso dicasi di molte altre localita dell'Astigiana ehe fornirono resti simili, terrestri e nuarini commisti.

I frammenti di albero silicizzati riscontransi particolarmente abbondanti nelle eolline fossaniane tra Bra e MIontù, dove pure osserransi spesso banchi d'Ostriche, straterelli marnoso-sabbiosi con Cardium c con altre forme maremmane; ancora in queste colline, nonchè nelle vicinanze di Ferrere, specialmente in Tal Casetta presso borgata Tucci, incontrasi straterelli narnoso-sabbiosi giallastri, zeppi di filliti assai ben conservate. Banchi fillitiferi simili, oppure filliti sparse fira le marne sabbiose osservansi nel Fossamiano subalpino, specialmente nel bicllese, ma neppure in questo caso si possono indicare punti precisi in cui si possa fare sempre una raccolta abbondante di fossili. 
Descrizione geologiea regionale.

E al piede settentrionale delle Alpi Narittime tra Val Pesio e Val Ellero ehe vediamo comparire il Fossaniano nella parte Sud-Orest del baeino piemontese; quivi questa tormazione, che in basso si collega affatto insensibilmente coll'Asticuo, è rappresentata in massima parte da depositi di maremma e di laguna, eioè da banchi sabbiosi ed argillosi a tinta prevalentemente giallastra, ma sovente anehe variegata, eioè rossiceia, grigiastra, verdognola, bleuastra, ece.; queste argille, utilizzabili talora come tera figulina per maiolica grossolana, sono affatto sprovviste di fossili, se si eceettuano aleuni poehi resti regetali generalmente indeterminabili; è soltanto verso il basso della serie, eioè nel passaggio all' Astiano, che compaiono straterelli fillitiei, impronte di Mollusehi, resti di Schisaster, eee.

Speeialmente nêlla parte alta del Fossaniano riscontransi lenti o straterelli ghiaiosi che poi vengono eoperti direttamente dal Snleariano; tale sovrapposizione 'si presenta abbastanza regolare nell'altipiano di Roraeeo o S. Grato, poiehè quivi le correnti aequee del periodo suhariamo non erosero o solo assai poco i banchi plioceniei, fatto che vedremo riprodursi in modo quasi identico anehe al piede meridionale delle Alpi centrali nel Canarese e nel Biellese.

Nella regione in esame i depositi fossanimi, la dove appoggiansi direttamente alle Serpentine, ai Taleosehisti ed ai Caleari to inssici delle Alpi, veggonsi sollevati sin oltre i 500 metri, ed anzi in aleuni punti sin quasi ai 550 metri, fatto notevole per valutare la potenza dei movimenti sismici ehe si verifiearono in queste regioni dopo il Plioeene.

E poi degno di nota eome la zona fóssaniana in questione abbia una estensione di solo poehi ehilometri quadrati trovandosi limitata a Sud dalle regioni alpine e ad Est dalle eolline monregalesi, essendo stata esportata a Nord dalle correnti aequee del Pesio durante il periodo

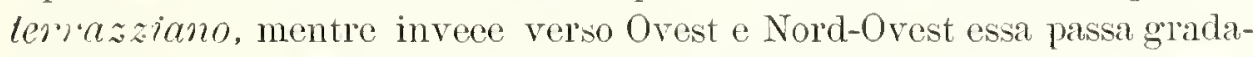
tamente al Villufi•rnchiuno; se ne può quindi arguire con sieurezza elıe nella seeonda meta del periodo plioeenieo il mare si spingeva bensì aneora sin eontro le falde delle Alpi Marittime, ma sotto forma soltanto di uno stretto golfo o braceio lagunare, ad aequa non solo assai salmastra, ma anehe molto fangosa e ricea di sali minerali ehe produssero poseia le tinte variegate delle marne argillose fossaniane.

Riguardo a quest'interessante formazione fossaniana subalpina bastano tali poehi cenni, essendo essa gia stata minutamente esaminata in un lavoro speciale; occorre però aneora osservare come in certi banchi del Tillafianchiano inferiore trovinsi talora fra le sabbie e le ghiaie grigio-giallastre, cosi ad esempio sulla sinistra del Pesio presso 
Morozzo, alcuni trammenti di Molluschi marini che indieano di esser gia stati rimaneggiati alquanto prima di venir deposti: forse si tratta qui di un delta la eui base è in parte sottomarina, od almeno di un deposito fatto da correnti aequee ehe intacearono i banchi littoranei pliocenici; in ogni modo abbiamo quivi depositi ehe paiono quasi fare passaggio tra il Tillafranchiano ed il Fossaniano.

Nelle piccole ineisioni naturali ehe esistono nella parte Nord-Orest dell'altipiano di Banale, tra Isola e Perrueea, speciaimente presso C. Noiola osservansi nel passaggio tra Astiano e Tillafranchirmo aleuni strati sabbioso-ghiaiosi attribuibili al Fosscmumo che però è qui ridotto a pochissimo spessore.

Più earatteristica e più potente si può osservare, quantunque solo per breve tratto, la formazione fossaniana nella parte meridionale di R. Pianboseo, partieolarmente nel rio Dafin, dore spesso troviano fra le sabbie straterelli ghiaioso-eiottolosi, marne argillose fogliettate, inglobanti talora piecoli banehi d'Ostriche, cioè la tipica frecies del Fossaniano ehe passa gradatamente all'Astimo rer Est ed al rillafranchiano rerso Orest.

Qualehe eosa di simile, quantunque meno nettamente a eansa degli spaeeati poeo profondi e dei grandi seoseendimenti, si osserva pure nella parte alta del Rio Ghidone.

Dore però il sott'orizzonte Fossaniano ì studiabile nei suoi più minuti particolari è in Tal Sturar di Cuneo presso Fossano, speeialmente poi nella incassata valletta di Veglia; senza entrare in un minuto esame di questo terreno, ciò che remne già fatto in un altro laroro, basti accennare come si osservi qui il passaggio graduatissimo tra $i$ poehi banchi sabbiosi e marnosi giallastri dell'Astiano ed i banehi più numerosi e potenti di sabbie, glliaie e conglomerati, a tinta complessira grigiastra e giallognola del Fossaniano, il quale a sua rolta mostra pure una transizione insensibile al sovrastante Tillafianchiano; fra le sabbie ghiaiose fossaniane, speeialmente verso lo sboeeo della ralletta, si possono raecogliere numerosi fossili di littorale, erosi, rotolati, accumulati in lenti; si notano aneor piin eommemente ed in diversi punti, particolarmente fra le sabbie grigiastre, bellissimi banehi d'Ostriehe, fra cui forse è il più importante quello che csiste presso il Molino nuoro lungo la strada ehe sale a Loreto.

La parte superiore del Fossaniano è costituita da un grosso baneo ciottoloso, a struttura talora deltoide, e che rappresenta probabilmente un delta submarino il quale riempir le conche irregolari ancora esistenti in queste regioni sostituendori eosì il regime flurio-lacustre del rillatinchiano.

Sulla sponda destra della Valle della Stura si osserva ehe l'orizzonte 
fossamiano, assottigliandosi e rapidamente sollevandosi, compare a coronare la potente seric astiana, venendo coperto direttaniente dal biluvium sahariann: la formazione fossaniunue especialmente rappresentata da straterclli e lenti ghiaiose e ciottolose di color giallo-rossiastro per lo più senza fossili, ma anche talora da banchi argillosi, straterellati, grigiastri, che raeehiudono resti sparsi o piccoli ammassi d'ostriche. Sempre però diminuendo gli strati ghiaiosi e ciottolosi rer'so Nord, il Fussaniano va a scomparire poco a valle di Salmour, quantunque, lenti eiottolose si incontrino ancora più a Nord ma sporadicamente sia fia le sabbie astimne, sia fra le marne e le sabbie del Piacrnsiumo.

Sulla sinistra della Stura la zona fossaniana, rappresentata spceialmente da banchi ghiaioso-ciottolosi di color grigio e giallistro, is spesso a fucies deltoide, come si può osservare assai bene nei burroni lungo Stura presso C. Teitasso; più a valle vedesi il Fossaniano, assai carratteristico e potente sotto la borgata Chiaramelli, assottigliarsi gradatamente tanto che verso Cervere è quasi solo più rappresentato da straterelli ghiaiosi alternati fra le sabbie gialle fossilifere; perio nelle vallette del IIolino nuovo di Cervere riappaiono i potenti e ripetuti banchi ciottolosi del tipico Fossaniano, che però poco a Nord scompare completamente, almeno all'occhio dell'osservatore, rimanendo maschcrato dai depositi terrasiani e ricomparendo solo molto più a Sectentrione nei colli braiclesi.

$\dot{E}$ nelle vieinanze del pacse di Bandito che tra il Fillapranchiano e l'Astimn tipico veggonsi strati ghiaiosi che ci indicano la presenza dell'orizzonte littoraneo del Fossaniano, dapprima poco earatteristieo, ma che si va sempre piủ individualizzando verso Nord-Est; è precisamente fra i banchi sabbioso-ghiaiosi del Fossamiamo inferiore che, presso la cappella di S. Michele, si rinvenne il cranio del Felsimotherimin Gastaldit.

Fra le regioni piemontesi che meglio si prestano per l'esame del Fossuniano sono certamente da annoverarsi le colline di Pocapaglia, Solnmariva Perno, Baldisscro d'Alba, Montaldo Roero, Monteu Roero, S. Stefano Rocro e Montà; quivi infatti; specialmerte verso Nord-Est, troviamo messa a nudo in mille punti la serie completa di questa formazione gcologiea, cioè: alla base straterelli ghiaiosi giallo-rossastri, (talora con fossili littoranei logori) che alternandosi colle sabbie formano l'inizio della serie in esame; quindi gli strati ghiaioso-eiottolosi del Fossaniann medio, alternati con sabbie e marne argillose grigiogiallastre od anche blcuastre, talora con resti di Cardium e di altri Molluschi littoranei ma specialmente d'Ostriche sparse o agglonlerate in piccoli banehi; infine gli strati sabbiosi e ghiaiosi, per lo più giallastri, quasi sempre senza fossili, della parte suprema del fossanicuo 
che per lo più passa al Trillafranchiano per mezzo di qualche banco ciottoloso. spesso a struttura deltoide.

Come si è osservato gỉ altrove, riesce difficilissina e quindi in parte arbitraria la distinzione del Fossaniano non solo dall'Astiano, ma anche dal Tillafianchiann, tanto ehe talora bisogna pereio anche basarsi alquanto sui caratteri esterni, come ad esempio sull'orografia e sull'idrografia che sono in stretta relazione colla complessiva costituzione geologica; infatti rediamo che sulla cresta delle colline il Tillafranchano si inizia ad Est con rilieri piủ eminenti che non quelli delle regioni rossamiane circostanti; cosi pure al fondo delle valli l'alreo. asciutto per g'ran parte dell'anno, si mostra ocelipato da un piccolo eor'so d'acqua a cominciare ad un dipresso dal punto dore il Trillarionchiano in strati argillosi succede, per sorrapposizione, al Fossuniano specialmente sabbioso e quindi permeabile.

La parte alta dei profondi e labirutici burroni di Pocapaglia, Baldissero, S. Stefano Roero, ece., mostra in mille modi tutte le gradazioni di passaggio tra i banchi astiani e quelli fossaniani, eioè tra il deposito di mare basso ed il deposito di littorale.

Qua e là nella formazione fossaniuna si incontrano ampie e potenti lenti ciottolose, talora utilizzate come pietrisco specialmente dore gli elementi sono più voluminosi, quarzitici e non decomposti, così per esempio presso Sommariva Perno, al Bric Gallante, nelle Rocehe dei Garbini, al Bric Cane Morto, ecc.; i eiottoli sono generalmente di 5 o 6 centim. raramente di oltre 20 centim. di diametro; in queste regioni il Fossuniano spesso raggiunge e talola oltrepassa i 400, 430 metri d"elerazione, eio che è assai noterole in paragone di quello che si osserva nelle colline astesi.

In diversi punti, ad esempio in Val Cane Morto (Baldissero), osservansi i banchi ghiaiosi disposti a struttura deltoide.

Alcuni bauchi maruoso-argillosi originano parziali reli acquei, peró di pochissima importanza, e si rivelano con piecole sorgenti di rado costanti; così le fontane della Corogna, della Mastra, della Panada, di Salomona, della Fa, di Tal Campetto, ecc, e più aranti di Fontana Val Romaldo, di Fontana Bosa, ece.

Straterelli sabbiosi assai ricchi in fossili o, meglio, maremmosi, si trorano in Tal di Rio Largo, lungo la strada che sale all'alto di Val Peschiera; Ostriche e banchi d'Ostriche esistono in molti punti ver'so la base del Fossaniano, ma anehe nella sua parte superiore come ad esempio in Tal S. Luigi presso C. Amie C. Audano, in Val Prella sotto C. Ajmoj, nell'alta Talle S. Lorenzo salendo a Madomna delle Grazie sotto Begioni, nell'alta Valle Lanzarotti, in Tal Campetto, ecc.

I sorraccenati banchi argilloso-marnosi che si alternano non di rado 
colle sabbie e colle ghiaie del Frossaniano, spccialmente nel frossaniano medio, se generalmente souo di colore giallastro, non di raclo però presentano pure tinte svariate, grigic o bleuastre (per modo da ricordare quasi il Piacenziano, come ad esempio in Val Valverna presso S. Luigi) o rossastre, o verdastre, cioc quelle tinte che abbiamo gia detto essere tanto fiequenti nel Frossaniano, a facies maremmana, delle falde alpine; spesso questi depositi argillosi ricordano molto bene quelli che costituiscono gran parte del rillafranchiano.

In alcuni punti, ad esempio presso borgata Lajone, fia i banehi fossaniani si incontrano già quei conceutranenti argilloso-nanganesiferi, detti volgarmente muirs, ele con costituzione poco differente, sono molto abbondanti nel Sakariano.

Nelle regioui ora esaminate il Fossaniono non ha potenza superiore ai 60 o 70 metri; più comunemente il suo spessore è assai minore.

A Nord dell'altipiano di Montà la zona fossaniana continuando nella sua direzione ver'so Nord-Fst, si presenta ancora per lungo tratto assai ben sviluppata e nettamente studiabile per' un'enorme quantiti d'incisioni che la mettono a nudo quasi ovunque.

Il Fossaniano occupa il fondo di Val Crosa e di Val Battista sin poco oltre il paese di Ferrere dove esso viene coperto definitivamente dal Tillafranchiano; in questa valle compaiono talora banchi fossiliferi a Cardium, Ostraea, ece. eome ad esempio presso la borgata di Triniti ; risalendo i fianehi di Val Crosa troviamo generalmente veriso il basso il Fossaniano costituito da sabbie giallastie con lenti ghiaiose che divengono sempre piu frequenti verso l'alto, finchè si passa ad un grosso banco, potente talora 7 od 8 metri, di ghiaie e di eiottoli frammisti a sabbia irregolarmente stratificata; questo baneo, ehe forma il passaggio al Villafranchiamo, ¿̀ per lo più rossastro verso il hasso e giallo-bianehiccio o grigiastro verso l'alto, talora poi presenta anehe lenti nerastre o rossastre per ossidi di Ferro e di Manganese; il tutto è coperto dalle sabbie e dalle marne argillose del rillafianchiano.

Il banco sabbioso-ghiaioso ora accennato, talora cementato e quindi sporgente, si può quasi ritenere come il residuo, direi, di quei numerosi banchi di ghiaie e di ciottoli che verso Sud costituiscono gran parte del Fossaniano.

In Val Piana la zona fosseniana, è costituita dai soliti banchi ciottolosi, ghiaiosi e sabbioso-marnosi; in questi ultimi, speeialmente se fogliettati, come pure fra le argille grigiastre, raccolgonsi talora numerosi resti fillitici come nelle vicinanze dei Tucei, sotto C. Agostino, ece.

Nel labirintiforme rilievo collinoso esistente tra il Brie Torniola ed il Molino della Rocea in Val Maggiore, il Fossaniano, interrotto solo nell'alto di Val della Pietra, forma una specie di lunga ed irregolarissima 
placea sopra ai banchi astiani, essendo alla sua volta in parte mascherato da minori e più o meno sporadiche placche villafranchiane. Consimile costituzione geologica troriamo ancora nelle colline di Bric Tarò, Torrazzo, Cantarana, ece.. sino alla valle Triversa, e solo gradatamente la formazione in esame si assottiglia, e si riduce a pochi banchi glhiaiosi che scrvono però sempre assai bene a distinguere il Villafranchiano dall'tstiano; vi scarseggiano i fossili, che però compaiono piuttosto abbondanti subito sotto, cioc̀ nei supremi banchi astiani.

Invece, in quella serie di colline comprese tra Bric S. Nicola, Montà. Cisterna d'Asti e Bric del Mondo, le lenti e gli straterelli ghiaiosi del Fossaniano a facies littoranea compaiono solo nella parte più alta, formando talora isolette fossaniane sui coeuzzoli delle colline.

La stesca costituzione si osserra ad un dipresso nelle colline di Valperosa, dove le lenti ghiaiose ramo sempre più scarseggiando e gli strati fossaniani sempre più riducendosi, in guisa che anche in questo modo risulta gradatissima transizione dal Fossaniano all'Astiano, tanto più che anche in questo orizzonte sonvi non di rado a diversi livelli ghiaiette disposte in lenti piu o meno estese.

Continuando l'csame del Fossaniano si rede come questa formazione geologica si trasporti, per dir eosi, sulla sinistra di Tal Trarersa e Val Borbore, occupando il centro del bacino terziario per modo che non riesce più possibile la distinzione seguita finora per comodità d'esposizione, tra lato Sud e lato Nord di detto bacino.

Le colline tra Baldichieri ed Asti si prescntano generalmente piuttosto basse e pianegrianti nella parte superiore, costituita dalle allurioni villafranchiane: or bene tra i depositi poco potenti del Tillafranchiano c le sabbie gialle dell'tstiano si osservano quiri sempre alcuni sottili straterelli ghiaiosi, frammisti alle sabbic, che rappresentano precisamente il Fossaniano lidotto così ad un orizzonte ben poco considelevole, ma tuttavia abbastanza costante.

Pero se si esamina il passagrio tra Astiano e rillafranchiano nelle colline più a Nord, cjoè verso MIontatia, Cortazzone, ece., si nota che anche questa sotile formazione fossaniona scompare gradatamente, od almeno non si presenta più cosi individualizzata come a Sud, quantunque tra i due regimi, marino e fluviale, della seric pliocenica superiore si continui a redere, come di solito, un graduale passaggio per mezzo di depositi littoranci e maremmosi; è anzi specialmente nella parte superiore dell'Astiano che incontransi numerosi banchi d'Ostriche; questi indicano appunto una regione salmastra che non è però abbastanza spiceata da costituire il tipico orizzonte fossaniano.

Nella parte alta delle colline di Serraralle d'Asti e di Sessant troriamo ben sovente fra le sabbic gialle lenti o straterelli ghiaiosi o ciot- 
tolosi rossastri a piccoli elementi, talora altermati con marne argillose inglobanti qualche Ostrica, eiò ehe ci rappresenta ancora le ultimi propaggini della formazione fossaniana.

Nella vasta regione collinosa cho si estende a Nord d'Asti, specialmente nelle regioni Madonna Viatosto, Giberto, Carbone, ecc., sin cirea al Bric Bubu, la facies fossaniana acquista nuoramente una celta importanza, giaechè le sabbic giallo-rossastre costituenti la parte superiore di dette località si frammischiano e si alternano ripetutamente con ghiaie piủ o meno grossolane che ci indicano essersi quivi prolungato per un tempo abbastanza noterole il regime littorale e salmastro, forse per lo sboceo di qualche corrente terrestre. Inoltre, a convalidare la stessa idea esiste il fatto della scarsità assoluta di fossili marini frammezzo a queste sabbie ghiaiose, rossastre che talora hanno uno spessore di parecehie diccine di metri. Sotto alle suddette sabbie rossastre sonvi talora banchi marnoso-calcarei o arenacei resistenti the formano una specie di cordone sporgente lungo i fianchi collinosi.

Ia poco ad Est delle colline d'Asti, sulla destra della valle Versa, la formazione fossaniana diminuisce d'estensione e di potenza riducendosi nuovamente a pochi straterelli ghiaiosi che osservansi sulla cresta delle colline rerso Nord; così nelle vicinanze di C. Giardino, di Casotto Fea (Castiglione d'Asti), di C. Bric, di Bric Stelletta, di C. Valporana, di Casotto Barone (Refiancore), ece.; invece poco più a Sud, cioc̀ nel vero centro del bacino astigiano, il sottile orizzonte fossaniano viene ricoperto dai depositi villafranchiani costitnenti la parte alta delle colline pianeggianti di Bordoni, Castello Annone, Poggio, Maddalena, ece.

In tutte lc vallette che intersecano questa curiosa regione labirintiforme, incidendola piủ o meno profondamente, si possono osservare molto bene gli straterelli marmoso-argillosi e ghiaioso-ciottolosi del Fossamiano, talora dello spessore di solo un metro, che si collegano strettamente coi terreni astiani e villafranchiani, tanto che la loro delimitazione ricsce sempre, come di solito, alquanto arbitraria.

Bellissime sezioni naturali nel Fossaniano potente reggonsi sulla destra di Val Fudro, di fronte alla borgata Crocetta, dove la zona in questione presentasi ancora abbastanza potente, quantunque la presenza di resti d'Ostriche fra le stesse lenti ghiaiose renda quivi sempre più incerta la distinzione tra Astiano e Fossaniano.

Lasciando per ora di segnire la formazione fossaniana verso NordEst, cioè verso le falde delle colline Torino-Valenza, dove d'altronde essa va quasi scomparendo, e portandoci invece sulla destra di Val Tanaro, vi troviamo ricomparire quest'orizzonte geologico sull'alto delle colline di s. Roceo, Rocchetta-Tanaro, Belveglio, ece. 
Quivi però il Fossaniano è specialmente rappresentato da marne argillose c da sabbie giallastre e grigiastre con qualche raro resto d'Ostrica. e qualche agglomerazione manganesifera (mürs) : esso ha cioè una vera facies di maremma e preludia alla formazione fluriale rillafranchiana che infatti compare ncttamente poco ad Est.

ì probabile che qualche straterello villafranchiano si sorrapponga ai depositi antichi delle colline rerso Rocehctta, poichè incontriamo quiri sull'alto aleuni letti argillosi inglobanti concrezioni giallastre.

Nelle colline tra Rocehetta-Tanaro, Masio e Val Tiglione il Fossctvicuo, col solito carattere di deposito littoraneo passante a deposito maremmano e quindi superiormente a deposito tluviale o villafranchiano, viene osservato ovunque ma con poca potenza; ne è incertissima la delimitazione specialmente per i banehi marnoso-argillosi grigiastri (originanti talor'a veli acquei) che appaiono a diversi livelli dall'Astiano al Tillafranchiano; in alcuni casi poi osseryansi vore lenti ghiaiosociottolose con frammenti rotolati di Ostrued, Pecten. ece.. ed anche con resti d'Ostraea in posto fra la marna argillosa.

Nelle colline dei Fiorotti i banchi fossaniani passano gradatamente verso Est a banchi argillosi che indicano l'inizio del Tillafranchiano.

Sulla destra di Val Tiglione la formazione fossamiana si ra gradatamente meglio individualizzando, mentre nello stesso tempo direnta pure poco a poco più potente: le lenti ciottolose divengono più numerose ed anzi si eangiano in reri straterelli costanti, che sono generalmente mascherati in massima parte da ampie placehe villafranchiane, ma che si mostrano talvolta anche assai estese, come sull'alto delle colline di Cortiglione. La piceola placea fossamiana che ricopre la collinetta d'Incisa Belbo i interessante pel avel presentato numerosi resti di Proboseidati frammisti ad Ostraea, Pecten, eec.

Ma se nelle regioni finora indicate il Fossaniano ha appena pochi metri di potenza, invece sulla destra del Belbo, a Sud di Castemnoro", esso diventa potentissimo. tipico, ampiamente sriluppato e sostituisce in parte la formazione astiura. Infatti percorrendo le colline di Bruno, Mombaruzzo, Maranzana, Cassine. cec., vediamo come tra le sabbie goialle astrance le sabbie ghiaiose alternate con letti aroillosi del ribnfianchiano esiste una potente formazione, taloria dello spessore di oltre 50 metri, costituita cssenzialmente di sabbie, ghiaie e ciottoli in letti alternati e commisti che ci lappresentano $n$ vero deposito littorale, e nello stesso tempo ci indicano come dovera probabilmente essere pure quiri ricina la foce di qualche corrente terrestre.

Questi banchi ciottolosi ad clementi talora di oltre 10 o 15 centim. di diametro, talvolta sono cementati e duri, per lo più invece si presentano incoerenti e damno quindi origine generalmente a regioni 
dirupate, soleate da profondi burroni, continuamente in via di modifieazione e che mettono a nudo la costituzione geologica della regione.

Dall'esame geologieo minuto che si può fare nelle colline in questione risulta, eome di solito, che, se è gradualissimo il passaggio tra le sabbie astiane e le ghiaie fossanimne, passaggio sorente indicato da qualehe straterello di Ostriebe, insensibile pure è la transizione tra il Fossaniano ed il rillafranchimo: questo orizzonte si può dire generalmente cominci in basso eon qualehe straterello eiottoloso alternato con banehi sabbioso-argillosi che, per essere meglio resistenti all'erosione, iniziano le regioni pianeggianti, le quali sempre piu si sviluppano e si allargano verso Nord-Est.

Fra i banchi fossaniani non sono rari i resti d'Ostriche; è invece difficile d'ineontrare altri fossili in buono stato di eonselvazione.

Le regioni eollinose ora indicate eostituiscono uno dei migliori punti del Piemonte dore si possa studiare il Fossmiano a freies littoranea, tanto più ehe le numerosissime sezioni naturali rendono ancor più nettamente esaminabile l'intiera sua serie che non nelle eolline Bra-MontàFerrere d'Asti, dove la formazione fossmarma è pure potentissima.

Ad Est di Cassine la zona fossaniana si assottiglia rapidamente; vedesi però ancora molto bene attraversare le colline a destra di Tal Bormida, comparendo talora in forma di strati arenaceo-conglomeratici nelle incisioni dei rii di Salso, della Lupa, del Grano, di Stanavazzo e d'Orseeeo, a guisa di striscia ghiaiosa dello spessore di poehi metri; colla stessa fucies e potenza si può ancora seguire la zona fossaniana ad Est di Val d'Orba; in Val Lemno essa rappresenta quasi da sola il plioeene superiore marino, e seompare infine eompletamente verso 'Tassarolo, dove la formazione fluviale villa franchiana si sorrappone direttamente a quella marina del Piacenziuno.

Quest'ultimo rapporto fra il Pliocene inferiore e superiore si è gria detto nei precedenti capitoli come si eontinui per un tratto lunghissimo sin verso Villalvernia, dove eompaiono a rappresentare il Pliocene superiore marino aleuni banelii sabbiosi con Ostriche che rappresentano bensì un deposito di mare basso e di littorale, ma ehe pare debbansi ineludere piuttosto nell'.tstiano che non nel Fossaniano.

Dalle colline tortonesi proeedendo verso Est lungo le falde tell'Appennino si ineontrano aneora qua e là zone fossaniane, ma già fuori del nostro campo di studio.

Lungo le falde meridionali delle eolline Torino-Valenza manea, in generale, la facics fossanima, per non essersi quivi formate eorrenti aequee un po' notevoli scendenti da dette eolline.

E bensì vero però che in queste regioni si osserva quasi sempre come tra l'Astiuno ed il I'illafiranchiano esistano banchi di passaggio, sab- 
biosi ed alrgillosi, i quali ci rappresentano certamente depositi salmastri di transizione tra un olizzonte e l'altro; ma essi sono cosi sottili ed hanno un'indiridualitả cosi poco spiccata che non é il caso di esaminarli particolareggiatamente.

Nelle colline ad Orest di Fubine compaiono già qua e là sprazzi ghiaiosi nei supremi banchi astiami, spesso rossastri ed a struttura di deposito littorale. Ma è poi specialmente ad occidente di Refrancore che le lenti ghiaioso-ciottolose direngono fiequenti, cstese, sviluppate, ed iniziano cosi reramente la zona fossaniana che si spinge rerso Nord, sull'alto delle colline, sino alla C. Sarró, al Bric Astore, alla C. Bric, ece. collegandosi a Sud colla formazione fossaniuna del centro del bacino astigiano gia esaminata nelle pagine precedenti.

Dirigendoci rerso le colline torinesi si puo osservare come generalmente il Fossamiano tipico manca affatto, quantunque ri si potrebbero probabilmente inglobare diversi straterelli ghiaioso-sabbiosi o marnosi elre formano il passaggio tra Astiano e Tillafianchiano e che appaiono eziandio sull'alto di alcune colline, ad esempio di C. Sto, di Bric delle Giare, di C. Manirolto, ece., a Sud di MLondonio.

Gli stessi fatti si osservano ancola rerso Orest, ma sempre meno chiaramente a cansa del relo di loess quaternario che maschera in gran parte i terreni pliocenici.

Passando ora all'esame delle falde alpine constatiamo che dalle vicinanze di Villanuova Mondovi, dove si osserra un lembo di Fossaniano. questa formazione non appare piu per un tratto lunghissimo rerso Nord, cioè solo allo sbocco di Val Malone, giaceliè debbonsi probabilmente riferire al Guaternario certi depositi argilloso-sabbiosi, grigiogiallastri che reggonsi presso le Tarernette fra Cumiana e Frossasco.

Ad Est del cono di deiczione della Stura di Lanzo incominciansi già a riscontrare nelle vicinanze di Barbania (come specialmente si puỏ osservare assai bene nel rio delle Lombarde) aleuni banchi irregolari sabhioso-ghiaiosi, prevalentemente giallastri, che paiono già dorersi includere nel Fossaniuno, quantunque formino uno spiceato passaggio ai depositi fluriali del rillafianchiano.

Ma contro le falde alpine presso Levone troviamo nettamente costituita la tipiea formazione fossaniana che, limitata ad Orest dallo sprone di Montiglio, si mostra invece cstesa e potentissima rerso Est, formando in massima parte la collina di M. Valle con uno spessore di circa 60 metri; è specialmente nei profondi burroni fronteggianti la borgata Crosaroglio che si può csaminare in tutti i suoi dettagli la tipica serie fossumiana costituita da un'alternanza, piủ rolte ripetuta, di banchi e lenti ghiaioso-ciottolose rosso-giallastre con sabbie e letti nurmosi griallognoli o, più raramente, grigiastri. 
Gli elcmenti ciottolosi sono talora abbastanza voluminosi, anche nei banehi inferiori del Fossaniano, ciỏ che ci prova come verso la metà del periodo pliocenico fossero abbastanza considerevoli le correnti acquee che scendevano dalle regioni alpine; questo d'altronde va d'accordo con ciò che osserveremo riguardo al rillafranchiano con ciò che si disse, specialmente dai geologi d'oltr'alpi, rispe to alla eosidetta prima epoca glaciale, che credo corrisponda appunto alla seconda metà del periodo pliocenico.

Ad Est di M. Valle la zona fossaniuna fu in gran parte abrasa dalle correnti acquee del Quaternario; ne vediamo peró ancora residui sotto il Diluvium sahariano costitnente l'altipiano di Piano prime foglie, Vla Sillano; alle falde infatti di detto altipiano compaiono marne sabbiose ed argillose giallastre e biancastre, utilizzate talora, come anche presso Levonc, per fabbricazione di stoviglie e simili; con tali hanchi alternansi ghiaic o lenti ciottolose giallo-rossiecie.

E questa legione di Levone una località assai interessante sia per vedervi stupendamente sviluppata la tipiea serie rossaniana, sia perchè vi si possono osscrvare nettamentc i suoi rapporti col Diluvium.

Ad Oriente di questa regione il Fossaniano, in massima parte distrutto ed in parte mascherato dai depositi alluvionali, non apparc piu che in pochi punti presso Rivara nelle incisioni dcl $T$. Viana e dei suoi tributari di sinistra; ma in questo caso i banchi fossaniani, per esserc in gran partc rappresentati da ghiaie e ciottoli, non scmpre si possono facilmente distinguere dal Dilucium, quantunque in complesso se ne differenzino per essere meno rossastri, per presentare spesso letti marnoso-argillosi giallastri, per essere costituiti di elencnti eiotolosi meno decomposti che non quelli del Sahariano, ed infinc per mostrare sovcnte letti marnoso-argillosi bleuastri abbastanza caratteristici e che possiamo eonstatare in più punti, specialmente lungo il rio sccudente da borgata Rolandi.

Anche nclle colline di C. Ricea, dei Falletti, ecc., appaiono in diversi punti, dove l'erosione è più profonda, i terreni fossamiani sotto al Diluvium ed alle alluvioni terrazziane; ma li possiamo poi nuovamente osservare in tutta la loro potenza nei profondi burroni di Pertusio, i quali mettono completamente a nudo la tipica e complcta serie dell'orizzonte in esame; questa formazione invece scompare gradatamente verso Valperga, poichè fu completamente esportata allo sboceo di Val d'Orco dalla fiumana diluviale del Sahariano, e riappare solo piủ nelle colline ad Ovest di Spinetto.

Risalcndo il rio dei Talentini ineontransi, di fronte a questi casali, alcuni banchi argilloso-sabbiosi bleuastri, spesso lignitiferi, talora con strobili di Conifere ancora ben conservati, quantunque alquanto schiae- 
ciati; tali banchi acquiferi a facies villafranchiana, utilizzati per estrazione di argilla refrattaria, si alternano con depositi sabbiosi e marnosi giallastri e grigiastri, più raramente o meno abbondantemente lignitiferi, ehe paiono dorersi ancora includere nel Fossaniano; tale questione non si puó risolvere con certezza per mancanza di fossili caratteristici, ma d'altronde non ha grande importanza trattandosi di depositi salmastro-fluriali ad origine mista.

Assieme alle marne sabbiose biancastre, pure utilizzate come terra refrattaria, si alternano spesso letti o lenti di ghiaie e ciottoli biancastri dilarati, ad elementi talora assai grossi; il tutto basa direttamente sulla roccia in posto, profondamente decomposta, che appare al fondo del rio.

Fatti simili osserriamo nei numerosi piccoli burroni di Cresto, Pagliero, Castellaccio, ecc.; banelii sabbioso-ciottolosi, giallastri, che paiono pure ascrivibili al Fossaniano, osservansi anche tra C. Galenga e Castellamonte: ma è specialmente nelle colline a Tord di Castellamonte che si puo osservare il Fossaniano in tutta la sua potenza e con uno sviluppo tale, che a ehi percorre dette colline pare talora di trovarsi nella classica Astigiana, sc non fossero i frequenti banchi ciottolosi che gli rammentano essersi formati questi depositi presso lo sboceo di grosse correnti aequee scendenti dalle regioni alpine.

Un lembo di Fnssaniano, rispettato dalla fiumana diluriale dell'Oreo. per essere protetto dal liliero roccioso di ILontebello. costituisce le collinette di Torre di Malakoff; esso rerso la sua base presenta in alcuni punti, come presso Preparetto, banchi sabbioso-ghiaioso-conglomeratici, blenastri, simili a quelli del Ponte dei Preti, che ei indicano la ricinanza del Piacenziano, il quale dere probahilmente trorarsi a poca profonditá sotto l'allurione della pianura.

Telle rallette profondamente incise di Mora, di Banasso, di Vivario. ece.. si può, in centinaia di bellissimi spaccati, osservare la serie fossaniana tipica, potente. talora fillitifera, più spesso però solo lignitifera, specialmente lit dove esistono strati bleuastri. I banchi ciottolosi, spesso di non lieve spessore, sono sempre assai frequenti frammezzo alle sabbie giallastre; sorente essi sono costituiti di elementi grossolani e simulanti talora nell'assieme il Dilurium sahariano, da cui anzi non sono sempre facilmente delimitabili nella parte superiore. Pare infatti che in quelle regioni dore non esisterano nel Sahariano forti correnti aequee che sboccassero dalle regioni alpine, piccola o (quasi uulla sia stata l'erosione dei depositi fossaniani che spingonsi quindi talora sill oltre i $450 \mathrm{~m}$. d'elevazione.

Anche nella parte bassa di Regione Tespia osscrransi banehi sabbioso-ghiaiosi. talora anelie eiottoloso-breceiosi, gialkastri o giallo-ver- 
dieei o rariegati, che paiono oncora attribuibili al Fossanirno, e sono formati essenzialmente dai materiali dei prossimi rilievi montuosi.

Rispetto ai duri banchi arenneeo-eonglomeratici del Ponte dei Preti ebbi già ad acecmnarc eome essi abbiano una facies alquanto fosstniana eome quelli di Reparetto, indicandoci di appartenere gia alla base del Plioeene superiore.

Di nuovo potente e ben visibile la serie fossaniana ricoprente i banchi astiani fossiliferi, nei burroni di Pian Torinetto, Piana e Sento, eioè là dove i torrenti hanno ineiso l'ammanto morenico che maschera l'ampia zona pliocenica, la quale deve costituire il substratum di part della morena laterale sinistra dell'anfiteatro morenico d'Ivrea.

Infatti poco più a sud, nella profondissima ineisione del T. Boriana, verso lo sboceo di detta valle, riscontriamo nuovamente sopla a pochi strati di Piacenziano e di Astiano, alcuni banchi ghiaioso-ciottolosi giallastri che rappresentano il Fossamiano e sopportano direttamente la potentissima pila dei depositi glaciali, riuscendo quivi evidente il fatto ehe tra i suddetti depositi pliocenici ed il terreno glaciale vi fu un'erosione abbastanza notevole; questa erosione eredo debbasi attribuire in nussima parte all'azione del ghiacciaio stesso della valle d'Aosta duraute il suo moximento d'avamzamento.

Quanto agli altri depositi sabbioso-ciottolosi ed ai fossili plioeenici della parte meridionale dell'anfiteatro d'Trrea, ele vennero finora attribuiti al Pliocene, per me non sono altro che depositi glaciali costituiti in parte da terreni pliocenici rimaneggiati assieme coi loro fossili; eecettuo però l'affioramento piacenzicmo di Val di Garla presso Borgontasino, dove appaiono pure pochi straterelli sabbiosi giallastri, che sono piuttosto da attribuirsi all'Astiano ehe non al Fossaniano.

All'esterno dell'anfiteatro morenieo d'Irrea, rerso Est, osservansi gia presso Mongrando, alla base della collina su cui siede il bologo di questo paesello, diversi banchi sabbioso-ghiaioso-ciottolosi, di color giallastro o giallo-rossieeio, soggiacenti al terreno diluvio-glaciale c che si possono forse attribuire al Fosscmirno, se pure non rappresentano solo una facies speeiale del Dilurium; questione ehe rimane per ora insoluta in maneanza di fossili. Qualehe eosa di simile ai banehi ora indieati osservasi pure piủ ad Orest in Val Viana alla base di alcuni spaeeati fronteggianti la C. Vignasse.

Riguardo ai depositi fossaniani del Biellese ebbi gria ad oceuparmene partieolarmente in altro laroro, per cui ora mi linnito ai eenni generali più interessanti in proposito.

Curioso ì il pieeolo affioramento di sabbie e ghiaie grossolane, ad irregolare stratifieazione deltoide, ehe osservasi allo sboceo di Val Chiebbia presso Fabbrica Ratto, appoggiandosi quivi direttamente detto terreno sui banehi pure sabbioso-ghiaiosi del Piacenziano. 
Invece bellissina, tipiea, potente, talora fossilifera, per lo piư fillitifera, è la formazione fossaniana che, divisa dal Piacenziano per mezzo di banchi più o meno numerosi d'Astiano, costituisce la massima parte delle colline di Valdengo, Cerreto, Quaregna, Lessona, Masserano, ecc.; essa è per lo jủù coperta da depositi sahariani, ora però ridotti dalle rosioni acquee a lembi talora di soli pochi metri quadrati di ampiezza. Sono interessanti i passaggi, sorente abbastanza graduati, tra il Diturium ed il Fossaniano nelle loro ultime ramificazioni, direi, a Nord, come presso Llontebello, Borio, ece.

Sono poi reramente tipici per lo studio dettagliato della serie fossanirna subalpina i profondi spaccati che la erosione delle acque del Cervo e dei suoi affuenti di destra ha prodotto sul lato settentrionale ed orientale della Barraggia di Candelo e Castellengo. la quale è bensi coperta stuperficialmente da un velo di Dilurium sahariano, (che va spessendosi da Tord a Sud, ma la cui costituzione principale è precisamente rappresentata dalla formazione fossaniana fillitifera, con rir petuti banchi ciottolosi, insomma colla tipica sua facies subalpina.

Questa formazione continua ancora ad esser visibile per lungo tratto ver'so Sud, sotto ai dejositi diluriali e quaternari, tant è che presso Iottalciata e Gifflenga cssa riche qua e là escarata per estrarre resti lignitici che ri si rinrengono in lenti poco importanti, come già notammo nelle colline di Castcllamonte: in ambidue i casi gl'indieati resti fossili e la natura dei banchi che li racehiudono ci indicano nei depositi in yuestione un rero passaggio tra Fosaniano e Tillafranchiano, cioè tra la formazione maremmana e quella flurio-lacustre.

Ad Orest di Masserano la zona fossaniana si ra rapidamente restringendo per essere in gran parte coperta dai depositi allurionali, per modo che essa appare solo piu contro le falde alpine, scomparendo poi completamente due chilom. circa ad Fst di Gattinara, cioé alla collinetta di C. ['ccineglio. E notevole che in tutta questa regione la formazione fossamiana invece di presentare numerosi, potenti e grossolani banchi ciottolosi, come generalmente si rerifica nel biellese e nell'eporediese, sia in gran parte costituita di banchi sabbioso-argillosi con solo pochi e sottili letti ghiaioso-ciottolosi; fatto ehe credo sia in stretto rapporto col volume delle correnti acquee sboccanti dalle ralli alpine e quindi coll'importanza di dette ralli. Infatti nelle regioni prealpine tra Masserano e Gattinara, non esistendo rallate molto importanti, è naturale che lungo le falde alpine nelle maremme del periodo pliocenico si formassero quivi abbastanza tranquillamente depositi marnoso-argillosi solo raramente conturbati da depositi d'indolc alquanto tumultuosa.

Le lenti ed i letti aroillosi grigiastri o giallastri od anche rossicci incominciano ad interealarsi frequentemente fra le sabbie e le ghiaiette 
delle colline di Portia, Procengo e Trabuco, dove vengono qua e lit estratte come materiale refrattario; ma tale fucies argillosa diventa ancora più spiccata nelle colline a Nord di Roasio e di Corticella dove più abbondanti sono le cave per l'uso sovrindicato; quivi peró riesec talora difficile il distiuguere nettanente i terreni fossamiani, già alquanto alterati, dai depositi quaternari e persino talora dai terreni porfirici profondamente decomposti e ridotti a vere collinette terrose, direi, rossastre.

Siamo cosi giunti alla Val Sesia la quale, come si è già accennato, offire l'interessantissimo fatto di racehiudere anche molto entro montc depositi pliocenici, parte dei quali sono racehiudibili nel Fussuniuno. come d'altronde si potera prevedere a mior\%.

Risalendo la Val Sesia dal suo lato destro ineontriamo gia nella conca di Piana un lembo di Plioecne superiore che pcró, per essere in massima parte costituito da sabbie c marne con poehe lenti ghiaiose, si può inglobare nel vero Astiano.

Se peró, percorrendo la Val Sessera, ne esaminiamo i lembi pliocenici, troviamo che il Pliocene superiore è quasi completamente rapprescntato da banchi ghiaiosi e ciottolosi giallo-rossastri alternantisi ripetutamente con sabbie e marne argillose giallastre; abbiamo cioè ben rappresentato il tipico Fossaniano passante talora direttamente al Piacenziano, il quale d'altionde, come si è già osservato, è spesso rapprescntato da banchi sabbiosi giallastri, psendo-astiani, alternati colle tipiehe marne sabbiose od argillose az\%urrognole.

La formazione fossaniana che si spinge quivi talora ad oltre $500 \mathrm{~m}$. di elevazione, è spccialmente ben visibile nelle colliue di Pianceri, e se ne può esaminare la serie completa, leggermente inelinata verso Est in complesso, ad esempio lungo la strada incassata che sale da Pianezza alla sovradetta borgata.

Presso Guardabosone è assai interessante un potente banco arenaceoconglomeratico, giallastro, di tipieo fossaniano, leggermente inclinato a Sud-Est cirea, e che costituisce l'alto della collina, essendo specialmente ben visibile nei tagli della strada presso Cappella Lupia.

Nel Pliocene superiore tra Borgosesia e Valduggia vediamo beusi ehe colle sabbie gialle si alternano talora straterelli ghiaioso-eiottolosi griallorossieci, specialmente nelle colline di Valbusaga, ma ill conplesso ¿̀ specialmente all'Astiano che debbonsi riferire questi depositi, che nell'assieme lamno una facies di deposito abbastanza tranquillo per essersi formati in una specie di conca relativamente riparata dalle correnti aequec; d'altronde pare probabile che durante l'epoca pliocenica l'oroidrografia della Valsesia fosse alquanto diversa da quella attuale.

Lc stesse osserrazioni ad un dipresso debbonsi ripetere per il Pliocene superiore delle collinette tra Grignasco e Cavallirio. 
Nella parte inferiore dei profondi burroni che ineidono il Dilurium di Cavallirio e Romagnano appaiono banchi giallo-rossastri. sabbiosociottolosi ehe, quantunque ricordino alquanto certe faries del Fossaniano, credo però debhansi già attribuire al Sahariano.

Lungo le falde montuose tra la Tal Sesia e la valle Agogna si possono osservare diversi lembi di Plioeene superiore, in parte ascrivibili al Fossaniano, cosi ad esempio i banehi ciottolosi su cui, con intelmezzo d'un deposito quaternario, basa il paese di Boca: cosi pure i banchi sabbioso-argillosi giallastri che eompaiono in un profondo burrone ad Orest di Maggiora dore sono essi escarati come aroilla plastica: poco lungi verso Est sulla destra della valletta Palazzina possiamo constatare veri strati ciottolosi interealati colle sabbie gialle.

Discendendo la val Sizzone possiamo osservare the se sin presso Marzalesco sul Piacenziano compaiono le sabbie gialle dell'Astiano, nei profondissimi spaceati di Marzaleseo e di holgata Balco. sotto al tipico e potente Di7urium compaiono banchi argilloso-sabbiosi giallastri alternati con potenti banchi ciottolosi goiallo-rossastri. einè terreni i quali. piuttosto che non al Sahoriano paiono doversi ancora attribuire al Fonsaniano, colla sua facies di deposito torrenziale ehe gia osservammo in diverse altre località alle falde delle Alpi.

Se risaliamo la valle Agogna o se ci portiamo verso la valle del Ticino, possiamo constatare che i depositi del Pliocene superiore vennero in massima parte esportati durante il Sahariano, sia dalle correnti aequee sia dagli antichi ghiaeciai nella loro lenta diseesa rerso Sud. In parte perỏ tali depositi esistono tuttora, mascherati dai terreni quaternari diluriali e glaciali; raramente invece essi sono messi a nudo dalle incisioni profonde. come è per esempio il caso pel Pliocene di Pianezza presso Gargallo, dove osservansi aleuni banchi di Fosscniano tra l'Astiano ed il Jilucium.

Ia ad Est della valle dell'Agnona le formazioni astione vengono rapidamente sostituite da quelle deltoidee o lacustro-fluviali del rillafranchiamo che nella Lombardia, sotto forma specialmente di Ceppo. rapprezenta quasi da solo il Pliocene superiore, mancandori affatto la facies marina o maremmana.

\section{Ricasunto.}

Sc, dopo aver esaminate le diverse regioni dove aplate la formazione fussaniana, vi diamo uno sguardo generale, vediamo come per il notevole suo sviluppo, per la potenza che spesso laggimge, per i fossili che talora raeehiude e per la sua facies assai caratteristiea, nonehr pei tenomeni a cui è collegata, essa ben merita di esser distinta dal- 
l'Astiano in senso stretto, quantunque con questo e eol Villafranchiano costituisca un piano solo, il piano Asticne o Pliocene superiore.

Il Fosscniono rappresenta un deposito di littorale o di marcmma, passante talora già ai depositi fluvio-laeustri, e quindi ¿̀ rappresentato, secondo le varie localita, da sabbie, ghiaic e banchi o lenti ciottolose, oppure da argille sabbiose variegate.

La formazione fossoniana rappresenta talora, in tutto od in parte, il Pliocene superiore delle falde alpine, ld dove essa non è sostituita dalla formazione fluvio-lacustre o villafrenchiona. Inoltre il Fossaniemo c̀ largamente sviluppato nell'alta valle padana verso Est, nonchè alle fialde della regione appenninica, mancando invece quasi eompletamente lungo le falde delle eolline Torino-Valenza, in causa delle poco notevoli colrenti acquee scendenti da detti colli.

L'andamento stratigrafico del Fossaniano, abbastanza regolare nel complesso, è invece soventissimo conturbato nei particolari per struttura deltoide, littoranea, cce.

Per regioni estesissime il frossaniano è lidotto a pochi metri di spessore od anche a pochi straterelli tra Astiano e Villafranchiano, come osservasi specialmente nell'Astigiano; talora però ragơiunge la potenza di 50, 60 e più metri. Siccome esso è un deposito essenzialmente subalpino presentasi spesso sollevato ad oltre 400 ed anehc oltre 500 metri come si può constatare specialmente presso le Alpi Harittime ed in diversi punti di Val Sesia (Pianceri, Plello, ece.).

La formazione fossaniana costituisce quasi sempre passaggio insensibile all'Astiano e talora persino direttamente al Piacenziano come in alcune località presso le Alpi centrali; superiormente essa passa pure quasi sempre gradatissimamente al Tillafranchiano, ma talora inveec e ricoperta in modo diretto dal Sahariano, nel qual caso per lo piu esiste fra i due terreni un hiatus ehe ci indica essersi quivi verificata un'erosione più o meno potente sul principio dell'epoca quaternaria, quantunque in altri casi riesca invece difficile distinguere un terreno dell'altro.

I carattcri paleontologici sono spesso negativi in rispetto all'Astiano così riceamente fossilifero; altre volte però, ed anche per regioni molto estese, i banchi fossaniani racchiudono resti di Molluschi littoranei o di maremma e frammenti scheletrici di Nammiferi terrestri; piu abbondanti sono i resti vegetali rappresentati o da lenti lignitiche oppure da bellissime impronte fillitiche; tan to la fauna ele la flora sono ancora di tipo astiano e la differenza dipende solo dal diverso ambiente in cui vissero gli organismi di cui conservaronsi i resti. 


\title{
CA P T OLO X VII.
}

\author{
TILLAFRANCHIANO.
}

\section{Studi anteriori.}

L'orizzonte geologico di cui passeremo ad occuparci venne già esaminato da parecchi geologi in causa dei numerosi e spesso giganteschi resti fossili che racchiude in aleune regioni; ma la maggior parte di tali geologi, con a capo il Gastaldi, che pur diede a questi terreni il titolo di allucioni plioceniche, eredette doverii riferire al Quaternario jiuttosto che non al Terziario.

Già il Sismonda Angelo compresc l'mmportanza di questa formazione. che indico giustamente col nome di Pliocenc superiore lacustre, e che anzi nella sua carta geologica del Piemonte tentò già di delimitare, in modo però molto imperfetto.

Il Mayer, che pur tanto fece per la conoscenza del Terziario Piemontese, non diede che pochi cenni riguardo a questo terreno, chc egli appellò Armusiano e che credette dorer distinguere completamente dal liano astiano. Invece il Pareto, a cui dobbiamo l'appellativo di T'illafianchiano. studio molto accuratamente questa formazione in qualche sunto del bacino terziario piemontese, nonchè in altre parti d'Italia . ne compresc l'importanza e credette opportuno di indiridualizzarlo.

Però tutte le osservazioni di detti geologi si riferiscono quasi solo alle fimose localita tossilifere dclle colline di Villafianca d'Asti e rimase finora sconosciuto affatto il grande sviluppo che ha realmente il rillatranchiano nel bacino piemontese.

In quei punti delle regioni subalpine dove la formazione geologica in esame vicne affiorare e non tu abrasa dalle erosioni acquee, essa renne finora ritenuta da Gastaldi, Baretti. ece.. come quaternaria: Eugenio Sismonda posc nel Miocene medio certi filliti che riscontransi nel Tillafranchiano sotto il cono di deiezione della Stura di Lanzo.

In questi ultimi anni ebhi io stesso più rolte ad oceuparmi, sia geologicamente sia paleontologicamente, del terreno villafinchiano che includo ancora assolutamente nel Terziario c considero come una facies flurio-lacustre del periodo astiano o Pliocene superiore, ritenendo eziandio come pliocenici molti depositi che osserransi alle falde ed entro le regioni alpine sia in Italia che fuori e che rennero tinola considerati generalmente come quaternari. 


\section{Caratteri paleontologici.}

Per essere il Villafianchiano l'ultimo termine della serie pliocenica, esso presenta naturalmente nei suoi caratteri paleontologiei mua certa affinità eon quelli dei soprastanti terreni quaternari, ció ehe ci sprega come in gencrale i geologi abbiano ineluso i depositi cillufirnthami nel quatemario piuttosto che non nel terziario; tale affinita paleontologica cresce poi ancora maggiormente quando le formazioni villufirunchiane che si esaminano trovansi presso od entro regioni alpine (specialmente poi se a Nord della catena delle Alpi), cioè in eondizioni di temperatura e d'ambiente alquanto simili a quelle che predominarono nella susseguente epoca quaternaria.

Ma se inveee si studia il Tillafienchinno a qualche chilometro di distanza dalla ecrehia alpina, si può constatare eome i suoi caratteri paleontologici siano essenzialmente plioceniei, giacehè vi si osserva una ricehissima fama di clima caldo e spesso anzi di regime costiero, indieandoei cosi la vieinanza della spiaggia marina all'epoca in cui vissero gli animali di eui troviamo i resti nella formazione in esame.

Tra i Vertebrati sono specialmente importanti i Mastodonti, gli Elefanti, i Rinoceronti, gl'Ippopotami, i Cervi, i Cavalli, cec. Tra gl'Invertebrati abbondano i Mollusehi laenstri e terrestri che, oltre ad appartenere ad una fauna di elima molto dolce e spesso di littorale, presentano pare sovente strette affinita con forme asiatiche, aficane ed amerieane, differendo talora molto dalle forme ora viventi in Piemonte; aecenniamo per esempio i Craspedopom, le Emmericia, le Triptychia, le Glandina, le Testrcella, alcune forme di Helix, di levlign. di Clausilia, di Limnaea, di Plunorbis. di Cyclostome, di Unio, di Margaritance, ece, ece.

Anche la flora villafranchinna, quantuncue tinora non molto studiata, mostra un earattere, direi, terziario piuttosto che non quaternario, tant'è ehe il Sismonda, che, senza aver fatti stndi geologici in proposito, ne ebbe in esame aleuni resti, credette doverli attribuire al Miocene medio; però anehe rispetto alla flora devesi notare che spesso presso monte molte delle for'me di regetali, che ebbero tanto sviluppo nell'epoea quaternaria, già compaiono sulla fine del Pliocene e si presentano anzi assai abbondanti fra i banchi villufienchiomi, per modo ehe ne risulta graduale il passaggio paleontologico tra i due periodi geologiei.

Quanto allo stato di eonservazione dei fossili tillarianchiani, esso è in generale poeo soddisfacente; infatti le ossa dei Vertebrati, se in aleuni casi si presentano mineralizzate e quindi di facile estrazione o conservazione, per lo più invece trovansi in tale stato di alterazione ehe oceorrono eure grandissime e mezzi di tossilizzazione, direi, arti- 
ficiale, per poterli estrarre: i soli denti sono quasi sempre ancora ben conservati e quindi si raccolgono in una certa abboudanza.

Le conchiglie dei Molluschi. essendo fragilissime e per lo piu arrolto in marna molto compatta, richiedono pure lunghe, minute e pazientissime eure per essere estratte dal terreno e pulite in modo da essere studiabili; in generale però sono quasi complete e solo in eerti banchi si presentano deformate dalla compressione. Quanto ai resti di piante esse consistono in rami od in frammenti di tronco lignitizzati. oppure in impronte di forklie le quali sono le più importanti per grli studi paleontologici, e si raccolgono specialmente fra i banchi marnosi o marnoso-sabbiosi fogliettati.

\section{Generalitio.}

Considerato nel stro complesso l'orizzonte villupranctiano si può realmente definire una formazione flurio-lacustre deposta dalle correnti acquee che nella fine dell'epoea plioeenica discenderano dalle regioni alpino-appenniniche e, sboceando in mare vi costruivano veri del ta aranzantisi rer'so l'interno del golto padano.

Te risulta quindi che questa formazione consta esscnzialmente di depositi sabhiosi, ghiaiosi e ciottolosi, per lo piu incoerenti ma talora convertiti in rere arenarie e eonglomerati durissimi (cepro). specialmente presso le fillde alpine, mentre invece rerso l'interno del bacino essa si presenta costituita in gran parte di sabbie. marne ed argille con pochi letti ghiaiosi; in ambidue i casi ineontransi a dirersi livelli della soìie villaf un hum straterelli argillosi impermeabili che damno orignine a reli acquei. i quali sono uno dei caratteri secondari esterni più spiceati dell'orizzonte in esame.

Taria molto il colore dei terreni villafranchiani a seconda della sua posizione, della sua costituzione, ece; devesi però osservare a questo riguardo come le marne argillose sorraecennate presentino spesso un color grigio-rerdastro, od anche verde, e talrolta, piủ raramente perỏ, persino azzurrognolo.

La grossezza degli elementi che costituiscono i conglomerati villufi-anchinui raria moltissimo a seconda delle regioni in cui essi si osservano. Tella parte centrale del hacino piemontese i ciottoli sono per lo piur ridotti a 30 t centimetri di diametro; tuttaria lá dore le correnti acques furono più potenti troviamo ciottoli della grrossezza di 10 a 20 centimetri persino a to chilon. di distanza dalle regioni alpine; rerso le falde delle Alpi i eiottoli direngono man mano piủ grossolani. finchè al piede delle Alpi riscontransi non di rado, anehe nella meta inferiore della sprie cillrfiranchirmu, lenti ciottolose i cui clementi raggiungono talora persino 1 metro di diametro. 


\section{Distribuzione geografica}

Essendo il Tillafranchiano una speeie di delta plioeenico è naturale ehe esso si ineontri speeialmente presso le falde alpino-appenniniche e nella parte depressa del baeino in esame, eome infatti si rerifica.

Però la massima parte della formazione rillafianchiana subalpina rimane invisibile per esser eoperta da un deposito più o meno potente di Sahariano ed anehe talora di Temassinno. eome è preeisamente il easo tra la Doria Riparia ed il Gesso.

Il Villafranchiano ineomineia a rendersi visibile verso lo sbocco montano di Val Pesio e eontinua a mostrarsi piủ o meno ampiamente in Val Stura di Cuneo; sviluppasi ampiamente nelle eolline di Bra, di Sanfrè, di Ceresole d'Alba, di Pralormo, sino al eentro orografieo del baeino astigiano, dove il terreno in esame eostituisee le fancse colline fossilifere di Ferreve, di Villafiranca, di S. Paolo, eee. In seguito la formazione villafranchianc, notevolmente assottigliata e ristretta, si prolunga rerso Est lungo l'asse della sinelinale del baeino pliocenico.

Ad oriente delle eolline d'Asti la zona villafianchiana aumentata, direi, dalle eorrenti aequee ehe seendono dall'Appennino settentrionale, di nuovo si allarga noterolmente assumendo nello stesso tempo un notevole spessore, solo ehe essa rimane in gran parte maseherata dai depositi sahariani e terrassiani.

La zona villafranchiana faseia in modo eontinuo le eolline terziarie dell'alto Monferrato e dall'Appennino ligure, solo seomparendo verso le eolline tortonesi per essere maseherata dai terreni quaternari.

Certamente la formazione villafianchiana forma is substratum della pianura alessandrina, ma riesee solo visibile alle falde delle eolline Torino-Valenza, sia per breve tratto nella loro estremità orientale, sia specialmente lungo il pendio meridionale; infine tale terreno viene a rieollegarsi colla striseia preaceennata della eonca astigiana, distaecandosene però aneora per formare una faseia lungo le falde meridionali delle eolline torinesi, finehè viene a seomparire eompletamente ver'so Ovest sotto ai depositi quaternari.

Se le formazioni villafranchiane subalpine sono in massima parte maseherate, nell'alta valle padana, dai terleni quaternari, a sinistra però della Dora Riparia esse vengono a giorno in mille punti per lungo tratto nelle incisioni naturali più profonde e talvolta entro speciali eonehe roeciose entroalpine, eome presso Lanzo.

La pianura eompresa fra le prealpi eanaresi ed i colli di Torino presentasi eostituita essenzialmente di terreno villafjamchiamo appena maseherato da depositi quaternari; ma più ad Est nell'Eporediese e nel Biellese questa formazione è in gran parte sostituita dal Fossamiano, 
ricomparendo però poco ad Est nella valle del Ticino ed ampiamente sviluppandosi nella Lombardia (ceppo) e nel Veneto.

\section{Tellonica.}

La formazione villafranchiana considerata nel suo assieme presenta un andamento stratigrafico assai regolare, una disposizione quasi orizzontale con dolce pendenza rerso l'intelno del bacino: osserrata inrece nei particolari, mostra una stratificazione irregolarissima, ben spesso deltoide, cio che ì in stretto rapporto col suo modo speciale di formazione; sovente poi riesce eridente essersi rerificate forti erosioni tra un banco e l'altio.

L'esame generale dell'orizzonte villafranchiano mostra che esso è sorente costituito di ampie lenti intrecciate, piuttosto che non di reri banchi continui, fatto che è pure in rapporto coll'origine fluviale ed anzi spesso torrenziale di questi depositi.

\section{Polens $\alpha$.}

¿̀ facile comprendere come rariabilissimo sia lo spessore che presenta la serie villafranchiana. specialmente in rapporto colla posizione della regione in cui la si osscrva; mentre per escmpio nell'Astigiana il suo spessore è di appena pochi metri. presso le falde alpine inrece non di rado è di oltre 50 metri. come ad esempio presso Lanzo.

ILa è poi noterole il fatto che in alcune regioni assai lontane dalla cerchia alpina, come ad esempio nelle colline ad Orest di Villafranca d'Asti, alla distanza di una einquantina di chilom. dalle faldi delle Alpi, la formazione in esame, fatta astrazione dai banchi superiori ascrivibili già al Sahariano, ha una potenza di quasi 100 metri; ciò ci denota una ben gr'ande potenza nelle correnti acquee che in quell'epoca oceuparano l'alta valle padaua e potevano trasportare molto lungi dagli sbocehi alpini una quantita tanto considererole di materiale in parte grossolano.

\section{Altimetria.}

Siecome i depositi villafranchiani per essere di origine abbastanza recente non subirono dopo la loro formazione aleun ripiegamento per compressione laterale e conselvarono, con solo piccola alterazione, la loro disposizione originaria, così rerso il centro della conea terziaria piemontesc essi sono poco elevati sul livello marino attuale; ma siccome essi presero necessariamente parte al grandioso movimento sismico che chiuse il periodo pliocenico e che si accentuò molto noterolmente come morimento sollerante nella catena alpina, così i terreni rillafranchiani subalpini si mostrano talora sollevati a 300,400 metri, ed anzi quelli 
della conca di Lanzo in regione Momello, lagrgiungono pelsino l'elevazione di 600 metri, che è l'altezza massima a eui giungono i ter'eni pliocenici in Piemonte.

Notiamo infine come anche in diversi punti delle eolline Bra-MIonti i banehi ciottolosi del Fillafranchiano inferiore reggansi spinti ad oltre 400 metri d'elevazione, quantunque trattisi di regioni notevolmente distanti dalla catena alpina.

\section{Rapporto coi terieni solto e sovrastanti.}

Quel regolare passaggio che osservasi attrarerso a tutta la scrie terziaria picmontese, e su cui ho tanto insistity nel corso di queste lavoro, si può ancora generalmente constatare tra il Tillafranchicno ed i depositi plioeenici marini; anzi gia nel preeedente capitolo, trattando del Fossaniano ebbi più voltc oecasione di far notare eome quest'orizzonte a facies littorale o maremmana serve appunto a rendere più graduale il passaggio tra i depositi eontinentali e quelli marini del plioeene superiore. In aleune regioni però, anche abbastanza estese, si è notato che il Villafranchiano si sovrappone direttamente a: Piacenziano o per erosione o piuttosto perehè quivi già originariamente esso sostituisce quasi del tutto la formazione marina del Pliocene superiore, giaeehè eronologieamente il Tillafranchiano e l'Astiano possono, a mio parere, essere perfettamente sincroni, quantunque generalmente nel baeino piemontese il primo serva di eoronamento al seeondo.

Quanto ai rapporti del Villafranchiano eoi terreni quaternari non possiamo dire ehe esista generalmente un passaggio graduale tra l'uno e gli altri, spesso anzi possiamo rerifieare in questo punto della scrie stratigrafica una trasgressione che per lo più però non è molto forte, ed è dovuta quasi sempre a fenomeni di erosione; questa erosione fu talora aecentuatissima, eosi ad esempio presso lo sboeco delle ralli alpine, per modo ehe quivi risulta chiaro ed evidente il distaeeo tra il Villafranchiano, di cui furono asportati i banchi superiori, ed i terreni quaternari direttamente sovrapposti. Talvolta inveee questa erosione non fu molto forte ed è quindi solo nei piủ ampi spaceati naturali che riesee chiara la distinzione tra i terreni villafranchiani e quelli sahariani; in non poche regioni però (specialmente ad una eerta distanza dalla eerchia alpina) dore durante il quaternario sboceavano le impetmose eorrenti aequee, il passaggio tra il Tillafranchiano ed il Sahariano risulta anche abbastanza graduale, osservandosi alternanze di banchi a facies or dell'uno or dell'altro orizzonte, per modo che la loro delimitazione riesce quasi tanto incerta come quelle che si fecero in generale convenzionalmente nella serie terziaria. 


\section{Località fossilifere.}

Sono giả note da lungo tempo le famose localitả di Solbrito, S. Paolo, Dusino, Villafranca, Ferrere, ecc., nell'al to astigiano, dove si rinvennero e si rinvengono continuamente resti di Vertebrati, ma non si può dare una regola per tali ricerehe, ed è quindi essenzialmente il caso che fa scoprire tali fossili; sono però generalmente i banchi sabbioso-ghiaiosi del Tillafranchiano inferiore dell'Astigiana oceidentale quelli che presentano piủ comunemente i resti in questione.

Assieme alle sabbie fossilifere ora accennate si riscontrano pure talora resti di Mollusehi, come ad esempio nelle vicinanze di Tillafranca d'Asti nella valletta di Stanavasso specialmente sotto le C. Traversole (dove si trovò pure un completo scheletro di Mastodonte), presso C. Crotino (dove si raccolse anche uno scheletro quasi intiero di Rinoceronte), e nei grandi spaccati fronteggianti la C. Nuova che mi fornirono un ricchissimo materiale malacologico; ancora aceenniamo al trovarsi alcuni resti di Molluschi presso Villafranea in Val Marrone, sotto C. Raviola.

Ma è specialmente nelle mame argillose grigio-verdastre o grigioazzurrognole che raccolgonsi qua e là abbondanti resti di Molluschi fluviali e terrestri, cosi in Tal Montiasca (Talfenera), rerso il suo sbocco, al fondo di Val Battista (Ferrere) sotto C. del Barbiere especialmente poi presso Ceresole d'Alba in Valle Oscura ed in Val Ricciardo dal Ponte della Iadonna sino al paese di Ceresole.

La valle della Stura di Cuneo, presso Fossano, è quella che mi ha fornito la massima parte dei Molluschi villafranchiani, ciỏ che però devesi in parte anche attribuire all'aver io potrto quivi proseguire tali ricerche per molte settimane durante più anni; anche qui ebbi a raecogliere zanne di Proboscidati fra le sabbie del Tillafranchiano medio; invece i resti di Molluschi trovansi per lo più solo nelle marne argillose, spesso compattissime, del Tillafranchiano medio-inferiore. Lelocalità più interessanti e produttive per tali ricerche palcontologiche sono, sulla riva sinistra della Stura il rio di S. Giaeomo presso C. Costamagna, ma speciamente la parte bassa dei grandi spaceati di Villa Pastore presso Fossano; sulla riva destra incontransi pure marne fossilifere in alcuni spaccati presso la Stura, poco a Sud di C. del Porto, ed inoltre ghiaie e conglomerati con zame di Proboscidati presso il ponte della Trinitì.

Nella bassa astigiana si raccolsero pure numerosi resti di Vertebrati fra le marne e le ghiaie villafianchiame. ma è quasi sempre ignoto il loro punto preciso di ritrovamento.

Nel IIonferrato le marne dell'orizzonte geologico in esame presentano pure talora fossili specialmente Mollusehi, per esempio al fondo di Tal Cervino (Nord-Orest di Cassine) di fronte alla C. della Chiesa. 
Ma è specialmente nelle colline a Sud di Novi ligure, alla rimione di Val Parè e di Val Gavalusso, ed in Val di Vaj sotto Tassarolo cho incontransi, fra i banchi ghiaioso-ciottolosi, alcme lenti marnose rirchissime in resti di Molluschi, di estrazione però molto difficile.

Nei depositi villafranchiani entroalpini di Lanzo pare siansi pure ritrovati, assieme alle ligniti, ossa di Vertebrati, ma non ne potei constatare la natura.

Quanto ai resti vegetali essi sono abbondantissimi ovunque sotto forma di frammenti d'albero lignitizzati o limonitizzati; non di rado si incontrano pure filliti fra le marne argillose dell'astigiana, come ad csempio nell'alto delle colline di Baldichier'i d'Asti; ma dove questi resti fillitici riscontransi piu abbondanti, spesso assieme a lenti lignitiche, è alla base del cono di deiezione della Stura di Lanzo, sia in Val Ceronda sia lungo la Stura, lungo il Talone, lungo l'Oreo, ece. li dove rengono a giorno le marne argillose fogliettate del rilla fi anchiuno medio. Pure intcressanti a questo riguardo sono i dintorni della Caccia in Tal Ceronda, il fondo della valletta Faudaglia e di rio Seceo, le sponde del Sangone nelle vicinanze di Front sin presso Brandizzo, l'alveo dell'Oreo presso Felletto, ecc., ecc.

Descrizione grologica regionale.

La formazione villufianchionct, che in quasi tutta l'alta valle padana e completamente mascherata dai dopositi quaternari, viene solo messa a giorno verso Est nelle profonde incisioni quivi fatte dalle correnti acquee sui terreni terziari e quaternari.

E solo nella valle del Pesio e del Brobbio che incomincianu ar incontrare il rillafianchiano col suo tipico carattere di formazione subalpina, costituito cioè di banchi conglomeratici per lo più abbastanza ben cementati ed alternati con banchi sabbiosi e nuarnoso-argillosi, i quali ultimi, di color grigiastro o grigio-giallastro, costituiscono per lo più regolari veli acquei ed originano così numerose sorgenti sia nelle valli d'erosione, sia anche sulla regione pianeggiante, tra Margarita e Montanera, giacchè quivi i terreni villafranchiani sono appena coperti da un relo sottile di depositi quaternari; gli strati ghiaiosi e ciottolosi presentano spesso una vera struttura deltoide inclinando localmente di $20^{\circ}, 30^{\circ}$ per lo più verso Est o Est-Sud-Est all'incirea.

E notevole il fatto che fra le sabbie e le ghiaie del Villafianchiano inferiore sotto Morozzo si incontrano eziandio resti frantumati di 'Molluschi di littorale, specialmente di Ostriche, ciò che ci prota sempre pì la colrelazione esistente tra il Tillafranchiano ed i terreni marini del Pliocene, spesso confondendosi gli uni cogli altri per mezzo di delta ghiaioso-ciottolosi, dapprima sottomarini, che per continua deposizione 
cangiaronsi in regioni continentali, in massima parte però percorse dalle correnti acquee o coperte di laghi e paludi.

Nelle vicinanze di Morozzo è interessante l'osservare. ciò che già esaminai in altro laroro, come il I'llapianchiano si appoggi direttamente sulle marne argillose azzurre del Pircenziano, essendo sostituito poco ad Est dall Astiano e dal Fossaniano.

Nell'antica ralle del Gesso, ora percorsa dal T. Mondalavia, osserransi sulla sua destra per un certo tratto i banchi caratteristici del Tillufianchimo. specialmente nei profondi riroletti presso Perrucea; sulla sinistra invece. questo telreno appare solo per breve tratto presso la Trinita, essendo in massima parte coperto dai terreni quaternari. Invece nella ralle della Stura di Cuneo il Tillafienchiono si mostra stiluppatissimo. ben esaminabile e sorente fossilifero. Siccome però di questa importante regione ehbi già a pubblicare dirersi larori, in cui il terreno in questione renne csaminato molto minutamente. cosi mi limitcrò in proposito ad accennare solo i fatti piủ importanti.

Discendendo la ralle della Stura, lungo il suo pereorso nella pianura padana. incominciamo a redere comparire il rillufiunchiono presso IIontaneia al fondo della valle, quivi però essendo srelato piuttosto dalle sorgenti acunee che non da reri spaccati naturali. Ha poco più a Nord la formazione rillufiunchioma si mostra in tutta la sua potenza e colla tipica facies. direi. subalpina. cioè con prevalenza di conglomerati ed arenarie alterinate con sabbie e marme argillose spesso straterellate, come gia si puo minutamente osserrare nelle profonde incisioni delle ricinanze di S. Albano Stura.

Fra le ghiaie cillafiemetiane della destra della Stura, salendo dal Ponte al segmale 569 . raccolsi più rolte frammenti di zanne di proboscidati; come pure ne incontrai sulla sponda sinistra rerso la metà circa dei profondi spaceati di C. Saglietti (Fossano

Le numerose ed istruttire sezioni naturali che reggonsi lungo la dirupata sponda destra della Stura da S. Albano sino alla C. del Porto, mettono stupendamente a nudo la costituzione del terreno in csame, coi suoi potenti conglomerati a ciottoli talora improntati e leggermente rigati, colle sue ghiaie ed arenaric talrolta disposte localmente a forma di reri delta torrenziali, colle sue marne grigiastre o grigio-rerdastre. racchiudenti non di rado resti ben conserrati della tipica fauna malacologica villafirmehimu.

Per la compattezza di questi terreni spesso la corrente fluriale escara in essi marmitte dei giganti, rerticali od olizzontali, dore si rerificano i cosidetti $100^{\circ}$ ghi o mulmelli talrolta di forza assai noterole.

La formazione rillafianchiman si pro pure studiare in tutti i suoi più minuti dettagli percorrendo la valletta del $T$. Teglia sino alla 
Trinita, nel qual easo si osserva anche l'interessante ed abbastanza graduale passaggio fia questo orizzonte geologico ed il sheh(u) iano, come pure l'insensibile transizione ehe esiste fra i depositi eillufiranchiani e quelli fossaniani.

Quanto alla riva sinistra della ralle di Stura, che ci mostra talora stupende sezioni naturali di 70, 80 metri d'altezza, come sotto C. Saglietti e sotto V. Pastore, essa è assai interessante dal lato paleontologico, poichè è appunto verso la base dei sorradetti grandiosi spaccati, come pure nei tagli minori di fronte alla C. Del Porto, che racolsi la massima parte della fauna malacologica del Tillufiennchiano piemontese; cssa è quindi questa certamente una regione classiea per lo studio della formazione illlafiranchima sia sotto il punto di vista litologico che paleontologico. Inoltre quivi si può pure osservare il passaggio tra la sua fucies subalpina (verso Sud) e quella tipiea dei colli astesí (rerso Tord); cd infine è pure qui possibile constatare il fatto importantissimo ehe la formazione villufienchiumu. la quale verso valle ricopre il Fussanirno e l'Astiano, verso monte inrece li sostituisee quasi completamente, per modo che risulta chiaro allora il sincronismo delle due formazioni, che altri vorrobe porre in periodi geologiei affatto distinti. IIa pel l'esame dettagliato di tutti i fatti ehe osservansi in questa intercsante legione, ad orriare inutili ripetizioni, rimando agli studi particolareggriati che ebbi gia a farce su questo riguardo in precedenti lavori.

Anche l'incassato Rio di S. Giaeomo mette bene in mostra l'intiera scrie rillafranchiana e nci suoi banchi marnosi offre anehe resti fossili, speeialmente presso C. Costamagna.

Ridiscendendo la valle della Stura troviamo che il T"illafranchiano scompare completamente dalla sponda destra e si va apparentemente sollevando sul lato sinistro, osserrandosi solo piủ in pochi spaecati nel rio della Tagliata; più a Nord vegrgonsi ancora qua e là i banchi ghiaioso-ciottolosi e marnosi del Thllafi unchimo nei rii che ineidono l'alta terrazza del Famolaseo, così presso C. Perussia (Grinzano) e nel rio Rittano; ma in seguito questa formazione scompare completamente sotto al velo quaternario, formando il substsatum di una gran parte dell'alta ralle padana.

Nelle colline braidesi ricompare la formazione villafianchiana, che si estende poi vastissimamente verso Nord e Nord-Orest per modo che anche in questa regione cssa può renir esaminata in tutti i suoi particolari per mezzo di mille spaccati più o meno profondi.

Uno studio minuto di questa vasta zona villufianchiana ci obbligherebbe a continuare ripetizioni ed inoltre non ei permettcrebbe di affierrare l'assieme della costituzione dell'orizzontc in questione, ciò che 
è il più importante, quindi credo opportuno limitarmi in proposito a considerazioni gencrali.

La serie villafranchiana si inizia generalmente con banchi ciottolosi commisti a marne e sabbic giallo-grigiastre; essi rappresentano certamente depositi trasportati da una forte corrente fluriale, che talora shoccara in lagune od in maremme. per modo che tali banchi formano un'insensibile transizione al Fossaniano: siccome questi depositi ciottolosi presentano una certa resistenza all'crosione, almeno in paragone dei terreni sotto giacenti, cosi rerso Est essi formano quasi sempre sulla cresta delle colline una specie di rialzo sulle regioni fossamime: questo osservasi al Brice della Guardia (392 m.) al Bric (420 m.) ad Est di Bric Bossola, al Bric Torozzo (4t0 m.) che costituisce il punto piu elevato della regione in esame, al Bric Hontata delle pietre (430 m.), a. Bric della Rovere ( $418 \mathrm{~m}$.$) , ecc., ece.$

A tali banchi si sorrappone una serie di strati marnoso-argillosi, sabhiosi, ghiaiosi e talvolta anche ciottolosi, piủ rolte alternati e commisti. che rappresentano una pila di oltre 50 metri di potenza in alcuni punti: è verso la metà circa o la metà superiore di tale scrie che incontransi quegli importanti banehi marnoso-argillosi grigiastri, od anche verdo-bleuastri, che racehiudono una ricea fauna malacologica con numerose Trintychiu, come osserrasi specialmente nella parte bassa di Val Ricciardo, tra il ponte della Madonna e Ceresole d'Alba, come anche nella valletta confluente della Talle Oscura.

Le marne, di color giallo-rerdastro od anche di un bel color verde oltremare, sono spesso ricche in grumuli calcarei stariatissimi; invece le marne grigie rerdastre a struttura piủ omogenea sono quelle che si presentano più ricehe in resti fossili, come pure sono spesso fossilifer'i alcuni straterelli nerastri, con frammenti di lignite, che incontransi talora frammezzo alle suddette marne bleuastre.

Questi strati argillosi originano spesso reli aequei e quindi sorgenti che qui, come quasi orunque, formano uno dei caratteri più evidenti dell'orizzon te villufiranchiano: si osserva anzi come al fondo delle valli, (pel' gran parte dell'anno) l'alveo del torrente si presenti asciutto finchè scorre sull'Astiano e sul Fossaniano. mentre che vi ricompaiono le acque quando si entra nella regione rillafranchiana.

Fra i banchi sabbios: o marnosi od anche ciottolosi non è raro di incontrare lenti piủ o neno vaste di concrezioni dure, irregolari, nerastre o rosso-giallastre. che sono costituite in gran parte da ossidi di ferro o di manganese e ricordano assai bene i mürs del Quatemario. Ne possiamo osscrrare un bellissimo esempio in fondo di Val Rieciardo un chilometro circa a monte del Ponte della Madonna, dove csse dàno pure origine a qualche sorgente d'acqua. D'altronde si incontrano pure 
tali concrezioni non raramente nelle colline di S. Grato, di Valunga, di C. Maruceo del Bosco, ece.

Si incontrano talvolta anche nelle regioni villafranchiane in esame aleuni resti di Proboscidati, nonchè tronchi di piante, specialmente di Conifere, silicizzati; siecome peró quasi sempre tali rinrenimenti si fanno nell'alrco dei torrenti, cosi rimane spesso incerto se tạli fossili provengano dal Villafranchiano o dal Fossamiano.

Oitre ai sovraccennati banchi marnosi verdastri fossilifcri, esistono pure comunissimanente a diversi livelli della scrie villafranchiana, banchi marnosi o marnoso-sabbiosi giallastri che ricordano n1olto quelli del Fossaniano, ed inoltre banchi della stessa natura ma di color biancastro o bianco gialliccio con passaggi alla tinta rossastra, come per esempio in Val Pocapaglia, poco a ralle di borgata Paolorio, ed in molte altre località in Tal Ricciardo, in Tal S. Lorenzo, ecc.

Le sabbie giallastre del Tillafranchiano si presentano talvolta fortemente cementate, ed allora ricordano assai bene certi speciali banchi astiani dell'Astigiana; $17 n$ bell'esempio di cio si osserva nelle immediate vicinanze di Pralorme, sotto la Parrocchia.

Si noti come talvolta al fondo delle valli che incidono le regioni vitlafranchiane incontransi resti di Ostriche, ma essi provengono dalle erosioni del Fossaniano, giacchè le conchighic di questi Molluschi, per la loro resistenza, spesso sono trasportate molto lungi dal loro punto d'origine senza subire alterazioni molto forti.

Quanto al Tillafranchiano superiore esso consta essenzialmente di marne sabbiose grossolane giallo-rossiccie, alternate e commiste a banchi ciottolosi, anch'essi di tinta simile, per modo da ricordare spesso assai bene i depositi sahariani, ai quali, infatti, paiono talora formare graduale passaggio; ciò per escmpio si può osscrvare in Val Pocapaglia tra Paolorio e Sommariva Boseo; lo stesso vedesi nci profondi burroni di C. Berte (Val S. Lorenzo), dove osserransi in basso banchi villafranchiani sabbioso-argillosi, giallognoli, rerdicei ed anche bleuastri, talora straterellati, i quali sono coperti da numerosi banchi ghiaiosi e ciottolosi quaternari, ed infine da un deposito di loess impuro, rossastro, grumuloso, calcareo.

Quando perỏ il Villafranchiano non è coperto dai depositi sahariani, esso termina per lo più con hanchi marnoso-argillosi di color gialliecio o grigio-verdastro, che dàno un carattere speciale alla regione ed una facies caratteristica anche alle strade (fangose d'inverno, dure, irregolari, in estate). Qunesto speciale deposito si formo for's'anche in parte durante il periodo quaternario la dove le correnti acquee scolavano lentamente lungo le regioni pianeggianti ma con dolce pendio; infatti questa speciale formazione, talora con lentì di mïrs, rediano 
che accompagna sorentissimo il Villafranchiano, di cui forma quasi la copertura ovunque questo terreno si presenta in regioni ampie e pianeggianti.

Nella porzione superficiale dei terreni villafranchiani incontransi talora concrezioni calcareo-ocracee, cosi presso il Bric Cavallasso, al Bric Cecchina nelle colline Bra-Sommariva Bosco, ed in molte altre località più a Nord, come ad esempio presso Valmaggiore (Ferrele) ecc., ccc.; ma siccome tali concrezioni reggonsi per lo piủ là dove vengono a terminare, rerso Est, i depositi sahariani, cosi non sarebbe improbabile che esse si fossero formate solo in epoca quaternaria: d'altronde però concrezioni argilloso-calearee simili riscontransi anche ai livelli piủ bassi nella serie villafranchiana, specialmente fra le marne argillose.

Dove esiste un po' di erosione tra Tillafranchiano e Sahariano, come per esempio si osserva nettamente presso i Tartapini, allora si distingue facilmente un terreno dall'altro, tanto piu che il Sahariano è in complesso di colore più rossastro, mello sabbioso, più ter'roso, ad elementi più imegolarmente commisti clie non nei banchi villafranchiani; ma dore queste erosioni sono meno appariscenti riesce meno facile tale distinzione, specialmente perehẻ il Tillafranchiano superiore è spesso ghiaioso-ciottoloso, e viceversa i banchi sahariani non presentano in queste regioni quei grossi elementi ciottolosi che li caratterizzano vel'so monte, per cui pare talora esista fra questi due orizzonti geologici un passaggio abbastanza graduale.

Mentre che nelle regioni in cui abbiamo finora esaminata la formazione villafranchiana questa ci si presentava molto ricca in banchi conglomeratici, questi invece ranno gradatamente diminuendo rerso Nord-Est nelle colline di S. Lorenzo, di Pralormo, di Cellarengo, di Valfencra, ece.; contemporaneamente anche dimimisce poco a poco la grossezza degli elementi ciottolosi. Invece si sviluppano sempre più i. banchi marnoso-sabbiosi ed argillosi grigiastri e giallognoli, talora anche rossastri, che originando colline a morbidissimi pendii, danno alle regioni villafranchiane un aspetto ondulato affatto speciale che osservasi ancor più spiccatamente nelle colline che passeremo ora in csame. Pcr osservare chiaramente la serie villafranchiana di queste regioni si può, ad esempio, discenderc da Valfenera in Val MLontiasca dove abbondano le sezioni naturali, che nel complesso mostrano la seguente serie geologica: 
Sahariano ....- Loess giallastro, grossolano, con poca ghiaictta.

Argilla giallo-bleuastra o verdiccia, con grumuli calcarci, alternata con lenti sabbiose grigiogiallastre, spesso a struttura deltoide.

Banco argilloso verde-blcuastro.

Villafranchiano . Sabbie e marne giallognole o grigiastre.

Sabbia grigio-gialliccia con letti di argilla verdeblcuastra.

Sabbie e marne argillose grigiastre.

Argilla verde-blcuastra con Tivipara, ece.

Esaminiamo ora lc classiche regioni villafranchiane dcll'alta astigiana, cioè alle colline di Ferrere, S. Paolo, Villafianca, ece., che fornirono tanti preziosi resti alla Paleontologia piemontese. Quivi la formazione villafranchiana o costituisce solo placche irregolari più o meno ampie, ghiaioso-argillose, sull'alto delle collinc al disopra del Fossaniano, come tra Monta, Ferrere e Cantarana isino in Val Triversa, oppure, divenendo più potente, come verso Ovest, costituisce quasi da sola le vaste regioni collinose di Cellarengo, di Valfenera, di Villafianca, ece., presentando solo talora verso l'alto piccoli veli di terreno quatcrnario sotto forma di loess giallastro piuttosto argilloso.

Nella costituzione del Villafranchiano di queste regioni prodominano le marne sabbiose e lc sabbie grigie o grigio-giallastre. Qua e là le sabbie si agglutinano in vere arenarie durissime, come ad esempio in Val Capitolo di fronte alla C. Capitolo. Sia le sabbie sia le ghiaie spcsso rossiccic, talora brunastre, che non di rado sono ad esse alter-. nate c commiste, presentano una disposizione deltoide assai marcata, come si può osservare nella suddetta località nei grandi spaccati di Val Stanavasso di fronte a C. Nuova, ece., ecc.

Ver'so la base del Tillafranchiano compaiono sovente straterelli ghiaiosi ed anche ciottolosi a piccoli clementi che fanno gradualissimo passaggio al Fossaniano.

Le marne argillose sono spesso grigio-bleuastre o grigio-verdastre, talora anzi di un bellissimo verde oltremare, come ad esempio si può osservare in fondo di Val Cuneo, quasi sotto C. Cuneo (Valfenera).

Nella parte superiore del Villafranchiano, là dove generalmentc questo terreno vicne coperto dal loess sahariano, si incontrano quasi sempre letti di grumnli argilloso-calcarei giallicci, commisti a marna argillosa grigio-giallastra, fatto che già osservammo nelle regioni più a Sud e che possiamo riscontrare quasi ovunque sull'alto delle colline di S. Michele, di Dusino, di Solbrito, di S. Paolo, dei Savi, ece., ed anche più ad Ovest, ad escmpio nelle colline di C. Rorei.

Quanto alle località fossilifere non è veramente il caso di farne un 
catalog.o, poichè quasi ovunque, in queste regioni. sino alle eolline di Roatto e Valreale si trovano resti di Vertebrati e di Molluschi; denti e frammenti ossei di grossi Mammiferi (per lo piủ Rinoceronti e Mastodonti) si raccolgono ben sorente dai contadini, specialmente negli scavi per le vigne; i resti jiù completi di Rinoceronte e di Mastodonte si trovarono rerso lo sbocco di Val Stanarasso e nelle trincee ferroviarie tra Dusino e borgata Antoniassi, specialmente in banchi sabbioso-ghiaiosi rossastri che spesso inglobano lenti nerastre pel ossidi di Ferro o Manganese; peró tali lenti nerastre incontransi anche a diversi livelli nella serie astiana. Le conchiglie terrestri e lacustri raccolgonsi specialmente nelle marne argillose. eome al fondo di Tal Crosa sotto Villata (dore le marne si altemano con banchi sabbiosi), al termine di Val Montiasca (Talfenera), sotto C. Trarersole, in fondo di Tal Marsone sotto C. Rariola (Villafranca) eec., ma troransi pur talora abbondantissime tra le sabbie, come ne è bellissimo esempio lo scoscendimento di Val Stanarasso di fronte a C. Nuora, dore racolsi una gran quantitì di fossili rari ed abbastanza ben conservati.

In questo grande spaccato osscrrasi in complesso la seguente serie: Mlarna sabbiosa straterellata (1 metro).

Sabbie grigie grossolane (3 metri).

Sabbie e ghiaie grigiastre e rossastre spesso a struttura deltoide (8 metri).

Marne bleuastre ed argille grumulose verdastre ( 1 metro e $\left.{ }^{1} / 2\right)$.

Sabbie grigio assai fine (2 metri).

Le regioni collinose esaminate, oltre alla caratteristica loro forma rotondeggiante ed a pendio dolcissimo, per essere costituite in gran parte di banehi marnoso-argillosi. presentamo pure, per la stessa causa. numerose sorgenti, fatto che gia ebbimo occasione di osservare in quasi tutte le altre regioni cillafranchiane. Sempre in relazione colla costituzionte eminentemente sabbioso-argillosa di queste colline sta la natura fangosa delle strade.

Procedendo rerso Est, cioè rerso il centro del bacino astig̣iano, la zona cillafranchiona, tanto potente e sviluppata ad Orest, si va inrece rapidamente assottigliando e restringendo; nello stesso tempo essa trasportasi completamente sulla sinistra di Val Triversa e di Val Borbore per modo che la sinelinale oroidrografica dell'epoca pliocenica risulta trovarsi alquanto piu a Nord che non quella del Terazziano, ciò che è forse attribuibile in parte a movimenti sismici.

Per l'indicata diminuzione del rillafranchiono ad Est della valle Cortazzone-IIonalo, esso costituisce solo piủ placehe irregolari, sabbioso-ghiaiose ed argillose, talora fillitifere, piì o mono ampie, sull'alto delle colline sopra l'Astiano a eui esso fil sempre graduale 
passaggio per mezzo di straterelli sabbiosi ton eiottolini dilavati o rossastri, ehe rappresentano il Fossanimno pure molto ridotto; sovente anzi riesce incerta la delimitazione di aleuns piceole aree (specialmente verso Nord) che per alenni caratteri paiono attribuibili al lirlafranchiano, mentre per altri ricordano pinttosto la facies fossaniena.

Tra la famosat Val d'Andona ed Asti la formazione villafrenchiena, ridotta a poehi straterelli ghiaioso-argillosi, enstituisce una speeie di velo sull'alto delle colline astirne, quivi foggiate a forma di altipiani isolati, irregolarissimamente frastagliati, a delimitazione incerta, come di solito, e ehe trovansi ad un livello press'a poeo egruale, inclinando però complessivamente verso l'interno del baeino astigiano.

Presso Asti il velo villafranchiano, eeetto aleuni sottili lembi presso Madonna di Viatosto, venne in massima parte esportato dalle grandi correnti acquee di Borbore-Tanaro che deposero quivi inveee un potente strato di loess grossolano eommisto a ghiaiette.

Ad Est di Asti la formazione in esame continua per lungo tratto a svilupparsi solo sulla sinistra di Val Tanaro, sempre colla solita facies poe'anzi menzionata, cioè di sottili placehe sabbioso-argillose ehe costituiseono altipiani labirintiformi e collegansi insensibilmente col Pliocene marino, mentro ehe superficialmente esse presentano greneralmente argille più o meno grumulose, la cui costituzione od almeno alterazione è forse dovuta in parte anche al periodo quaternario.

In complesso queste basse colline pianeggianti tra Quarto, Castello Annone e Croectta presentano la seguente serie stratigrafiea:

Villafranchiano. $\left\{\begin{array}{l}\text { Argilla passante a loess, talora eon grumuli di muirs. } \\ \text { Sabbie argillose con ghiaiette e concrezioni cal- } \\ \text { earee. }\end{array}\right.$ Fosscniano... $\begin{aligned} & \text { Sabbie grigio-giallastre. } \\ & \text { Sabbie giallastre en ghiaiette giallo-rossastre o } \\ & \text { bruniecie. }\end{aligned}$ Astiano..... Sabbie e marne argillose con resti d'Ostriche, frammenti di legno silicizzati, eec.; talora lenti ghiaiose.

A valle di Castello Amnone la formazione villafranchiana si vede svilupparsi anche sulla destra di Val Tanaro, dove ora la esaminereno per tenere l'ordine generale finora segruito nella descrizione regionale.

Trattando delle colline tra Rocea d'Arazzo, Val Tiglione e Roechetta Tanaro dissi eome esse terminino per lo più con marne argillose, che, quantunque ricordino alquanto quelle villafianchione ed anzi raechindano talora anche grumuli di muirs, tuttavia eredetti attribuire aneora al Fossaniono per avervi ineontrato qua e là resti d'Ostrica.

Ma ad Est della borgata di Cornalea compaiono, nell'alto delle eol- 
line, sopra agli strati fossaniani, veri banchi sabbioso-argillosi giallastri con lenti ghiaiose già attribuibili al rillafranchiano, il quale peró non c sempre ben delimitabile dai depositi fassaniani.

Questo orizzonte, che si inizia in forma di placche sul Fossaniano. col quale gradatamente si confonde. si ispessisce rapidamente verso Est, tanto che a Hasio costituisce già l'inticra collina, con una potenza di oltre $40 \mathrm{~m}$. e viene cosi a formare, sotto le allurioni quaternarie. il substratum dellalreo del Tanaro, congiungendosi colla zona rit7afranchiana, che si sriluppa sulla sinistra di Val Tanaro.

Le numerose sorgenti, che indicano una rera zona acquifera, sotto Masio lungo il Tanaro, sulla destra del Tiglione a ralle del Molino La Turca sin sotto Redabue ed in altre rallette piu a Sud, ci lappresentano i soliti caratteri secondari esterni del Tillafranchiano, quiri molto ricco in banchi marnoso-argillosi alternati con quelli sabbiosi ed anche alquanto ghiaiosi.

Quanto alla parte superiore del Tillafranchiano incontriamo in queste regioni le stesse difficoltà che già osservammo nclle colline dcll'alta astigiana, di Cellarengo, di Pralorino, di Ceresole d'Alba. ecc.; è, cioè, difficile il delimitare i depositi veramente villafranchiani da quelli quaternari, sia perchè i primi superticialmente per costituzione originaria - per alterazione chimica presentano una facies molto simile a quella che generalmente offrono i depositi quaternari, sia specialmente perchè in realtà questi si estendono per tratti rastissimi sopra alle pianeggianti colline rillafranchiane a guisa di relo di loess di spessore molto variabile; il loess infatti viene, per dir cosi. a terminare ad unghia verso Orest, mentre sempre più si ispessisce ad Est, finchè tra esso ed il Tillafranchiano si intelpongono anche strati ghiaiosi e ciottolosi che rappresentano relamente i depositi sahariani.

Data tale costituzione geologica, sulle carte geologiche si possono gencralmente tralasciare i piu sottili veli di loess come poco importanti. tanto piu che sorente in queste regioni di transizione tra rithafranchiano e Sahariano è sempre difficile distinguere nettamente i depositi di loess dai terreni sabbioso-argillosi superficiali del Fillafranchiano.

I fenomeni ora indicati ripetonsi in modo quasi analogo nelle colline tra Val Belbo e Val Bormida: quiri infatti la formazione villafranchiana, che costituisce solo un sottile deposito sull'alto delle colline a Tord di Incisa, ed c pure poco potente presso Bruno, Maranzana, ece. si ispessisce lapidamente verso Est. acquistando una potenza di oltre 50 o 60 metri; vi predominano come scmpre le sabbie. talora ghiaiose. c le marne argillose grigio-giallastre o grigio-rerdicele. talvolta grumulose, talrolta con resti di Molluschi, come per esempio in fondo di Val Cerrino presso C. Della Chiesa. 
Minute osservazioni sull'insensibile passaggio (per mezzo delle solite alternanze) tra Fossaniann e Villafranchiano possonsi fare nelle dirupate eolline di Bruno, Mombaruzzo, Maranzana, eee.; vi notiamo eome la facies caratteristiea del deposito fluviale eonsista speeialmente nella sua notevole riechezza in banehi argillosi, donde in parte deriva la forma pianeggiante eon eui generalmente terminano le eolline che ne sono eostituite.

Anehe in queste regioni, eome già osservammo nelle eolline tra Bra e Monta, là dove la zona villafianchiana termina su quella fossaniana, generalmente si verifiea una speeie di rialzo in eausa di una relativa maggior eompattezza dei banchi villafranchiani basali inferiori, per lo più ghiaioso-argillosi.

Quanto al passaggio tra Sahariano e Tillar ranchiano, esso è sempre ineerto ver'so Orest sull'alto delle colline per i fatti sovracecennati, tanto piu che pare ehe talora anehe i superiori banehi villafranchiani presentino lenti o grumuli di mïrs, eome vedesi, per esempio, ad Est di C. Nizza (Maranzana); inveee tale sovrapposizione riesce chiara e netta in dirersi profondi spaccati ehe ineidono le eolline verso Orest; così per esempio nelle vieinanze di Gamalero in Val Baldovero a valle di C. Lasagna, nella trineea ferroviaria della stazione di Sezzè (dove le marne argillose giallastre, granulose, del Villafranchiano sono direttamente eoperte dai banehi eiottolosi a grossi elementi del Sahariano che termina eon 4 o 5 metri di loess rossastro, sabbioso-argilloso, stratifieato) ed in diversi punti tra Spazzona e Sezzè. In queste ultime regioni il Sahariano è gia ben eostituito con banchi ghiaiosi e eiottolosi a eolore giallo-rossastro ed a facies complessira abbastanza caratteristiea; quivi probabilmente si è verificata un'erosione abbastanza notevole tra il periodo villafranchiano ed il periodo sahariano.

Il Villafranchiano superiore di queste regioni è in gran parte sabbioso-argilloso, rosso-giallastro e con una facies complessiva che l'avvieina alquanto ai depositi sahariam, eome ad esempio si può osservare in aleuni profondi spaceati naturali verso lo sboeeo di Val Cervino.

Ad Est di Val Bormida la formazione villafianchiana è in massima parte maseherata dai potenti e sviluppatissimi depositi sahariani e terrazziani trasportati dalle antiehe fimane della Bormida e dell'Orba, e solo la si può osservare qua e là nelle ineisioni più profonde speeialmente nella valletta d'Or'seeco e sotto Capriata d'Orba.

Notiamo però eome anehe dalle poche osservazioni dirette ehe si possono fare nel Villafinchiano delle regioni situate ad oriente di Val Bormida, risulta ehiaramente eome quivi il terreno in esame sia molto più rieeo in banehi ghiaiosi e eiottolosi ehe esso non lo sia nell'Astigiaua; ciò è naturalmente in rapporto colla grandezza della 
fiumana pliocenica di eui la Bormida e l'Orba attuali non sono che i meschini residui; d'altronde tale eostituzione, in gran parte ciottolosa, del Villafranchiano delle regioni in esame va pure d'aeeordo eolla potenza, eollo sriluppo e colla ricehezza in conglomerati a grossi elementi ehe vediamo pure presentare quivi il Sahariano.

Tanto in Val Riolo eome in Val Lemne la zona villafranchiana appare solo qua e la in sezioni non molto profonde, ehe peró ei indicano sempre la natura essenzialmente ghiaioso-argillosa di questo terreno.

Interessante è il pereorrere la ralle Riasco a Sud di Pasturana e specialmente le sue diramazioni nei rii Mesma, Vai, Gavalusso e Parè. Quivi infatti, anzitutto osserrasi come il Tillafranchiano inferiore s'appoggi direttamente sulle marne argillose del Piacenziano: inoltre nelle lenti marnose esistenti fra i banehi e le lenti ghiaioso-ciottolose possiamo sorente raccogliere $\mathrm{i}$ resti di una ricea fauna malacologica d'acqua dolee e terrestre a facies eomplessira di elima dolee; sono specialmente proficue per queste rieerche le rieinanze di Tassarolo (Val di Vaj) e l'alta ral Riasco presso la sua biforeazione.

Quanto al Villafranchiano superiore esso è costituito specialmente di eonglomerati ad elementi di medioere grossezza e talvolta a spigoli abbastanza eonservati; talrolta la cementazione, e quindi la durezza, di questi conglomerati è abbastanza noterole, eiò ehe, unitamente alle lenti mar'noso-argillose giallo-rerdastre o giallastre formanti veli acquei, serve a distinguere grossolanamente il Villafranchiano dal Sahariano, quantunque sia sempre diffieile tale delimitazione.

In Val Scrivia la formazione villafianchiana non appare sriluppata in aleun punto; solo vediamo per brere tratto sulla sinistra dell'alreo di questo torlente alcuni banehi eonglomeratici, duri, inglobanti lenti sabbioso-marnose ehe sono forse attribuibili al rillafianchiano, giacchè anehe sulla riva destra, ad Orest di C. Macassia, osserransi simili depositi eonglomeratiei appoggiar'si sulle sabbie grossolane dell'Astiano: la stretta che presenta quiri la valle della Scrivia tra Molino dell' Edifieio e C. Macassia è dovuta appunto all'esistenza di questi conglomerati villafrunchiani.

Passando ora all'esame delle eolline Torino-Valenza, vediamo tosto comparire la formazione villafranchiana nella loro parte piu orientale.

Infatti sotto al potente relo di loess sahariano, che eostituisce l'altipiano di Bassignana, eompaiono qua e là i banchi sabbioso-argillosi del Tillafranchiano: ma è speeialnente sulla destra del Po sotto MIugarone e tra C. Bollotti e Castel Menada che questa formazione si puo esaminare minutamente in grandi spaccati. Quivi essa si presenta colla tipica facies, inferiormente di marne argillose, gialliccie o grigio-yerdastre, grumuloso-ealearee, e smperiormente di lenti e banchi sabbiosi 
e ghiaiosi, talora anche ciottolosi, giallastri, a stratificazione alquanto irr'cgolare, ma complessivamente orizzontale; come di solito abbondano quivi i veli acquei prodotti dai letti argillosi.

Questo lembo di Tillafranchiano, il quale è l'unico che si osser'vi nclla parte settentrionale delle eolline Torino-Vílenza, ¿̀ assai interessante poichè ci indica per questa formazione una estensione molto maggiore di quella che si potrcbbe supporre a priori.

Esaminando le falde meridionali delle colline Torino-Valcnzà (quantunque i depositi di loess e la profonda alterazione non permettano quivi uno studio molto minuto) si può già vedeŕc come nelle colline di Quargnento appaiano i depositi villafianchiani piuttosto argillosi, appoggiantisi legolarissimamente sui banchi astiani, tanto che, anche per le eause sovraccennate, la delimitazione dei due terreni riesce, come di solito; alquanto incerta.

Verso Orest la formazione villafranchiana si va rapidamente allargando, quantunque superiormente essa si presenti coperta da un sottile velo di loess quaternario, almeno nelle regioni piancggianti, verso sud; coi suoi banchi marnosi, sabbiosi ed argillosi si alternano pure talora alcune lenti ghiaiose; spesso anzi troviamo uno straterello di ghiaictte giallo-rossastre tra questo deposito ed il sottostante Astiano.

A Sud di Refrancore la formazione villafranchiana della parte settentrionale del bacino in istudio si collega con quella della formazione meridionale che già esaminammo nelle pagine precedenti trattando delle colline di Castello Annone, Quarto, Asti, Sessant, Monale, Villafianca, ecc. L'orizzonte in questione si sviluppa notevolissimamente in potenza ed ampiezza da Villafranca d'Asti ver'so Ovest, ma vicue tosto mascherato dai depositi quatcrnari che costituiscono la porzione superficiale della pianura di Villanuova, Poirino, ecc.

Però il Tillafranchiano si può ancora seguire per lungo trátto ver'so Nord, costituendo o placche più o meno potenti, più o meno ampic e irregolari sull'alto delle colline astiane, come tra Cortandone e Castelnuovo, oppure formando da solo inticre colline a pendii dolcissimi, come verso S. Paolo, S. Bartolomeo e Buttigliera d'Asti, raggiungendo tálola quivi una potenza di circa 70, 80 metai e più.

Come sempre la formazione villafranchiana è quivi eostituita essenzialinente di banchi sabbiosi c marnosi, spesso argillosi, tanto da originare veli acquei importanti, talora con straterelli gliaiosi e con lenti sparse di grumuli argilloso-cálcarci giallástri.

Il passaggio tra Tillafranchiano e Sahariano rimane sovente alquanto indefinito; esso è indicato appunto da una maggior frequenza di strati argilloso-grumulosi e da lenti di mürs nerastro, che paiono iniziare la serie quaternaria. 
Ad Ovest di Buttigliera d'Asti mancando sezioni naturali profonde ed cssendo invecc potente il relo di loess quaternario, la zona villafranchiana non è più risibile direttamente, quantunque continui certamente a svilupparsi, non solo lungo le falde delle colline, ma anche sotto ai depositi quaternari dell'alta ralle padana sin contro le Alpi.

Infatti, sc da Val Pesio, dove abbiamo osservato i depositi villafranchiani subalpini, sino alla valle della Dora Riparia, lungo le falde delle Alpi marittime, non si incontrano affioramenti di questo terreno, ciò è dovuto, a mio parere, piuttosto alla potenza dei depositi quaternari ed alla poca profondità delle incisioni, che non ad una reale mancanza di una formazione villafranchiama subalpina.

Già i banchi conglomeratici più bassi che appaiono lungo la Dora Riparia (specialmente ben visibili nella forra di Alpignano), e che sono affatto paragonabili al cempo lombardo, ricordano molto i conglomerati del Tillafianchiano superiore, quantunque siano forse ancora da considerarsi come quaternari; ma poco a Nord di questa località, in Tal Ceronda, dove è profondissima l'incisione postsahariana, la formazione in csame appare nettamente colla sua tipica facies ed anzi con non rari fossili regetali che appartengono ad una flora di clima abbastanza dolce, ciò che si accorda coi dati paleontologici dedotti dall'esame della fauma dell'Astigiana, di Val Stura di Cuneo e delle vicinanze di Nori Ligure.

A dire il vero in Val Ceronda non esistono profoncle incisioni che che mettano a nudo la formazione in esame, ma essa appare solo qua e là nel lctto stesso del torrente nonchè in alcuni piccoli tagli presso la Cassa, il True di Miola, ece., dore reg'gonsi anche banchi e lenti ghiaioso-ciottolose, giallo-rossastre, che, altermandosi con sabbie e marne, sembrano quasi formare passaggio tra Tillafranchiano e Sahariano.

Però al fondo della valletta di Rio S. Roeco la formazione villa $\alpha$ franchiana si può osservare molto bene per circa un chilometro e sí nota come essa sia quivi costituita dalle tipiche marne verdastre o giallastre, talora rossiccie, spesso straterellate, alternantesi con banchi sabbiosi e con straterelli e lenti ghiaiose; quivi però probabilmente mancano i banchi supremi del Villafranchiano, stati crosi dalle correnti acquee che deposero il Diluvium sahariano.

L'unico punto del Piemonte in cui si possa esaminare il Tillafranchiano entroalpino si è nelle ricinanze di Lanzo, in regione Momello tra C. Praja c C. Margaula, dove della formazione in csame, certamente molto più sviluppata originariamente. venne ancora conscrvato un lembo, protetto contro l'azione erodente delle colrenti acquee sahariane dallo sprone roccioso di Novaire.

Questo piccolo residno villafranchiano è rappresentato da un'alter- 
nanza più volte ripetuta di banehi marnoso-argillosi, sabbiosi, ghiaiosi e eiottolosi, a stratifieazione per lo piu alquanto irregolare; gli strati argillosi, talora giallo-rossieei, sono spesso fogliettrti. I depositi marnosi sono o grigio-giallastri od anehe bleuastri ed è specialmente in questo easo ehe s'ineontrano lenti lignitiehe le quali, in diversi punti ed in diverse epoehe, diedcro già oeeasione a lavori di estrazione, certamente però poeo profieui; assieme a tali ligniti pare siansi pure trovati, molti anni or sono, resti sehelctriei ehe disgraziatamente andarono perdu i.

Le marne grigiastre ora aeeennate sono per lo più molto impure, eioè molto sabbiose ed anzi sovente inglobano ghiaiette biancastre che danno al deposito un aspetto simile a quello ehe presenta talora la morena profonda: sono peró persuaso trattarsi di un vero deposito fluriolaenstre.

I banehi più alti del lembo villafranchiano in esame sono essenzialmente ghiaioso-eiottolosi, già preludiando alla formazione sahariana; essi spingonsi sino ai 600 metri, elevazione eertamente molto notevole è la massima raggiunta in Piemonte dai terreni plioceniei.

Nella metà inferiore della serie stratigrafiea del Villafranchiono di Momello appaiono potenti banehi di eiottoli molto roluminosi, del diametro eioè di quasi 1 metro in aleuni casi, eiò che dà al deposito un aspetto molto simile a quello del Dituvium sahariano, quantunque anche fra questi banehi eiottolosi esistano letti e lenti di marne sabbiose ed argillose giallastre, quali diffieilmente ineontransi nel vero Diluvium. Questo deposito ad elementi grossolani, che vedesi verso la base del Villafranchiano di Lanzo in fondo a valle Uppia sotto Nomello, eredo eorrisponda a depositi eonsimili ehe ineontransi sotto i banehi lignitiferi villafranchiani subalpini nelle Alpi meridionali e settentrionali e ehe, appunto per la loro facies quaternaria, indussero i geologi ad inglobarli nel quaternario, tanto piu ehe talora pare ehe eolà siansi pure trovati eiottoli glaeiali, ciò ehe però non vidi affatto nel lembo in esame.

Per quanto si tratti di un deposito entroalpino tuttavia esso presenta anche i earatteri esterni tipiei del Tillafranchiano, eosì numerose sorgenti aequee prodotte dai letti argillosi; se i suoi banchi eiottolosi non sono eementati eome talora altrove, eio dipende speeialmente dalla maneanza di roeeie ealearee nelle vallate da eui derivano i suoi elementi.

Nell'alveo della Stura a Sud di Lanzo veggonsi talora affiorare le marne argillose fogliettate, grigio-verdastre, del Tillafranchiano ed anzi vi si possono anche raeeogliere resti di filliti; in generale però le ineisioni non sono tanto profonde da metter bene a nudo la formazione villafranchiana. Ma continuando l'esame verso Est ineontriamo nuovamente sezioni interessanti del Villafranchiano nella ineassata Val 
Faudaglia e nelle sue vallettc laterali di sinistra, specialmente in quella del rio del Crot dore i banchi sabbioso-argillosi acquiferi del Villufranchiano sono direttamente ricoperti, con evidente hyatus per erosione, dai potenti banchi ciottolosi del Sahariano.

Siccome i caratteri litologici, paleontologici ed anche estelni che presenta il Villafranchiano di queste regioni corrispondono a quelli tipici già sopramenzionati e siccome d'altronde di questa regione ebbi già a fare uno studio speciale, cosi mi limito ad acconnare come rerso Barbania la formazione in esame pare faccia passaggio al Fossaniano, per quanto osservasi nel rio delle Lombarde; il Tillafranchiano poi appare sia sotto al Diluvium sahariano lungo le falde della terrazza FrontVolpiano, costituendo una specie di gradino, e nelle rallette che la incidono un po' profondamente, sia qua e là sotto all'Allurium terrazziano del basso-piano del Malone sin quasi alle falde dei colli torinesi, essendo superficialmente rappresentata per lo più da marne argillose fogliettate fillitifere ed anche lignitifere come ad esempio lungo il Malone presso Front; non mancano poi lenti e banchi sabbiosi, ghiaiosi e conglomeratici alternati colle marne argillose giallo-rerdiccie.

Nel rillafranchiano superiore perỏ, come osservasi ad esempio sotto Vauda di Front in Val Faudaglia e presso Front in Val rio Secco; compaiono numerosi banchi ciottolosi che formano passaggio a quelli sahariani; se ne distinguono in generale pel colore meno rossastro e per esser costituiti di elementi più piccoli, più dilarati, spesso con lenti o interstrati sabbioso-argillosi, talora con locale stratificazione deltoide. In alcuni casi rediano che il Tillafranchiano per le sue sabbie e ghiaie giallastre ricorda alquanto la costituzione del Fossaniano, cosi in certi spaccati presso Front, presso Lombardore, ecc.

Anche in Val d'Oreo, sino a Faletto circa, nell'alveo del torrente sonvi letti marnosi fillitiferi che paiono villafranchiani.

E quindi l'orizzonte villafianchiano quello che forma il substratum dell'ampia pianura che si estende tra le Alpi centrali e le colline torinesi e che origina coi suoi banchi argillosi un relo acqueo continuo, importantissimo.

Ad Est, presso le falde alpine, si è già visto nei capitoli prècedenti come il Pliocene superiore sia rappresentato dal Fossaniano, il quale terreno talora presenta anche banchi che per la loro costituzione accennano essersi depositati in condizioni poco dissimili da quelle in cui si formarono i depositi villafranchiani.

Mancano invece affatto i tagli un po' profondi ehe ci mostrino la natura dei terreni pliocenici soggiacenti al Quaternario ad una certa distanza dalle Alpi; solo incontrianio nuoramente il Tillafranchiano; come già si è detto; alle falde delle colline di Valenza, per modo che 
io credo doversi ammettere come tale formazione avvolga completamente a Nord le colline Torino-Valenza, nello stesso modo ehe probabilmente cssa eostituisce quasi ovunque il substratum dell'alta valle padana, essendo mascherata in ambidue i casi dai depositi quaternari.

$\mathrm{Si}$ è già notato precedentemente come le formazioni marine (Astiano str. sensu) e maremmane (Fossaniano) del Pliocene supcriore subalpino vadano seomparendo rapidamente ad Est della valle dell'Agogna, venendo sostituite dal Villafranchiano. Questo terreno infatti gial sompare nella valle del Ticino ed è specialmente ben visibile lungo il fiume nei profondi spaccati esistenti presso Castelnovate. Quivi il Tillafianchiano è caratteristicamente rappresentato da marne argillose grigiogiallastrc, che originano diverse sorgenti d'acqua e racchindono stupende lenti lignitiche.

$\dot{\mathrm{E}}$ certo che il Villafranchiano estendesi molto a Sud di Varallo Pomba al fondo dell'ampio alveo del Ticino, ma le potenti alluvioni temazsiane e recenti lo mascherano in massima parte; il rapido allargarsi dell'alreo del Ticino a Sud di Varallo Pomba è probabilmente in rclazione appunto coll'affioramento della formazione villafranchiana.

\section{Riassunto.}

Rieapitolando le osseryazioni fatte sulla formazione villafianchiana del Piemonte dobbiamo anzitutto fal notare eome essa, nei pochi punti in eui era stata esaminata, venne finora da quasi tutti i geologi attribnita al Quaternario per: presentare essa caratteri, speeialmente litologici, che la fanno rassomigliare alquanto ai depositi sahariani. Infatti essa consta essenzialmente di un'alternanza più volte ripetuta di marne argillose, di sabbie, di ghiaie e di conglomerati; naturalmente gli elementi che costituiscono questa formazione sono più grossolani presso monte cle non lungi dalla catena dclle Alpi; anzi, a noll glan distanza dalle falde alpine, spesso il Villafranchiano si presenta sotto forma di veri conglomerati molto resistenti, ceppoidi, e talora nei lembi cntroalpini offre pure, nella sua metà inferiore, alcuni banchi di ciottoloni assai yoluminosi.

I banchi marnoso-argillosi sono spesso di color grigio-verdastro o giallastro, ma anche bleuastri; eastituiseono quasi sempre veli acquei costanti ed abbastanza vasti.

In complesso il Iillafranchiano è un deposito fluvio-lacustre che, specialmente sotto forma di delta, si andò avanzando gradatamente da monte a valle nella seconda metì dell'epoca pliocenica.

L'orizzonte villafranchiano è molto esteso nel Piemonte malgrado eio non appaia a tutta prima. Infatti l'esame dei suoi affioramenti ci fa supporre che, sotto ad un velo più o meno potente di depositi quaternari, esso costituisea il substratum di quasi tutta l'alta yalle pa- 
dana e della pianura alessandrina, essendo invece ridotto generalmente nell'Astigiana a placche piủ o meno vaste sull'alto delle colline astiane.

Presso le falde alpine il Tillafranchiano generalmente si trora mascherato dai terreni quatcrnari, oppure renne in gran parte abraso dalle correnti acquee dell'epoca quaternaria; in alcuni casi però lembi villafranchiani si possono ancora osservare nelle profonde incisioni fatte dalle acque del periodo terrazzians: rarissimamente sono conservati resti di Villafranchiano cntro-alpino, come presso Lanzo.

L'andamento stratigrafico del terreno in esame è regolare nel complesso, i suoi banchi inclinando leggermente da monte e valle; perỏ con irregolarita locali indicanti un deposito torrenziale o deltoide.

In alcuni punti, come nell'alta astigiana, in Val Stura di Cuneo, nel lembo presso Lanzo, ccc., la serie stratigrafica del Villafianchiano raggiunge una potenza di quasi 100 metri; generalmente però il suo spessore è assai minore, cioè di solo 30 o 40 metri, talora anzi di solo 304 metri.

L'altitudinc che raggiunge l'orizzonte in esame è naturalmente maggiorc presso le falde alpinc che non altrove; rediamo tuttavia come esso si spinga sin oltre i 400 metri nelle colline tra Bra e Montà; raggiunge però i 600 metri solo nel lembo entro-alpino di Lanzo.

La formazione villafianchiana quasi sempre si collega insensibilmente coll'Astiano per mezzo dei depositi littoranci e maremmani del Fossaniano; talora cssa però si appoggia direttamente sul Piacen siano o per erosione o perchè rappresenta da solo il pliocenc superiore. Invece quasi sempre si osserva un piccolo hyatus tra Villafianchiano e Sahariano, a causa specialmente di un po' d'crosione esercitata dalle acque sull'inizio dell'epoca quaternaria; talora però, specialmente là dove le correnti acquee sahariane non furono molto impetuose, pare esista un passaggio abbastanza graduale tra i supremi banchi villefranchiani c quelli inferiori del Sahariano.

La flora villifianchiana, di clima temperato-dolce, è rappresentata, oltre che da ligniti, da numerose filliti abbastanza ben conservate; tali resti s'incontrano specialmente nei depositi subalpini od entroalpini, come si verifica purc nci terreni contemporanei del Lombardo-Veneto c delle falde settentrionali delle Alpi.

La fauna di questo periodo geologico si riscontra invece specialmente nei depositi lontani dalle falde alpine ed è rapprescntata da grossi Mammiferi c da numerosissimi Nolluschi, gli uni e gli altri indicanti un clima dolcc e più caldo di qucllo che esiste attualmente in Piemonte.

Tanto la flora che la fauna, considerate nel loro complesso, pure essendo di tipo prevolentemente. pliocenico, formano già un graduale passaggio alla flora ed alla fauna quaternaria, specialmente nei depositi subalpini ed entroalpini. 


\section{BACINO QUATERNARIO DEL}

P I E M O N T E 
Se tipico è il bacino del Piemonte per il regolare sviluppo di tutta la serie terziaria e pei numerosi e ben conservati fossili che si riscontrano in tali terreni, non vi è meno interessante la formazione quaternaria; questa infatti vi si presenta in diversi modi e con diversi terreni, talora anche fossiliferi, per modo che eziandio sotto questo punto di vista si puo dire che il Piemonte costituisca un bacino quaternario affatto tipico come regione, non più marina, come quella terziaria, ma continentale.

Non vi è forse formazione geologica che, come il Quaternario, presenti tanto profonde differenze d'interpretazione e di suddivisione a seconda dei diversi luoghi in cui si esamina e dei diversi autori che la studiano. Infatti nella sua delimitazione dal Terziario esistono incertezze grandissime, e, a mio parere, si inglobano spesso nel Quaternario inferiore molti depositi continentali, i quali, malgrado che per cause speciali presentino facies e talora persino faune simili a quelle del Quaternario, tuttavia debbono ancora cronologicamente attribuirsi al Pliocene.

Quanto alle suddivisioni delle formazioni quaternarie, notevolissime sono pure le differenze tra i geologi; giacchè alcuni, come il Tardy, vorrebbero costituire quasi d'ogni strato un periodo o sottoperiodo geologico, mentre altri inclinerebbero a considerare tutto il Quaternario rome una semplice appendice del Terziario. 


\section{$-5 \% 1$}

Se a ciò si aggiunge che le formazioni quaternarie ora studiabili sono solo per piccola parte marine, ed invece in massima parte continentali, svariatissime di forme, di spessore, di aspetto, a stratificazione spesso irregolarissima, di origine ora fluviale, ora lacustre, ora glaciale, ora mista, ecc., si comprende come lo studio del Quaternario, malgrado sia questa la formazione più recente e che si va tuttora deponendo sotto i nostri occhi per modo che parrebbe essere di facile interpretazione, è invece forse uno dei più difficili, o, meglio, uno di quelli che furono resi più difficili e complicati dai geologi.

Quantunque i miei studi sul Quaternario siansi limitati sinora all'Alta Italia e specialmente al Piemonte, con solo poche escursioni di paragone in Svizzera, in Fraucia ed in Inghilterra, tuttavia mi risultò abbastanza chiaro il concetto che la formazione quaternaria è generalmente divisibile in due grandi periodi principali: il primo corrispondente all'epoca diluvir,-glaciale ed a cui venne dal Mayer dato il nome di Sahariano; il secondo che dalla fine dell'epoca glaciale giunge sino al giorno d'oggi e pel quale proposi alcuni anni fa il nome di Terrazziano, poichè è specialmente in questo periodo che si formò la massima parte delle tipiche terrazze, sia lungo i littorali, sia nelì'interno dei continenti.

La relativa scarsità di resti paleoetnologici nelle regioni da me studiate non mi permette sicuri paralellismi tra i periodi proposti dai paleoetnologi e quelli sovraccennati, basati su fenomeni geologici. In linea generale però si può dire che il Sahariano corrisponde in parte alla prima metà circa del periodo paleolitico.

Premessi questi pochi cenni generali passiamo all'esame del Quaternario del Piemonte; avverto però come avendo già trattato con monografie speciali le regioni più importanti a questo riguardo, basterà ora esaminare queste formazioni quaternarie sotto un punto di vista alquanto generale. 


\section{Sahariano.}

Questo periodo geologico, separato dal Terziario per grandiosi ed abbastanza generali fenomeni orogenici, si inizia, secondo il mio modo di vedere, collo straordinario sviluppo dei ghiacciai e si chiude col loro rapido ritirarsi verso le loro sedi attuali; corrisponde cioè al cosidetto periodo diluvio-glaciale e naturalmente, come tutti gli orizzonti geologici, presenta limiti spesso incerti, sia al suoprincipio, sia al suo termine.

Infatti già durante la seconda metà dell' epoca pliocenisa, cioè durante l'Astiano, cominciarono a verificarsi le copiose precipitazioni atmosferiche che iniziarono il grandioso sviluppo dei ghiacciai e delle correnti acquee e che quindi causarono la formazione di potenti depositi Huvio-lacustri (villafranchiani). D'altra parte il ritiro dei ghiacciai non si presentó sempre in egual modo dovunque, nè si verificò di tratto ma con oscillazioni di regresso e di progresso, ecc., quindi anche assai incerta riesce talora la delimitazione della fine del Sahariano.

A seconda del modo di formazione, cioè per opera delle correnti acquee o per opera dei ghiacciai si possono distinguere i terreni sahariani in Diluvium e Morene; anche in questo caso si nota esserri formazioni di passaggio tra un terreno e l'altro.

Studi anteriori. - Fu essenzialmente il Gastaldi il geologo che si occupỏ del Quaternario piemontese; fu anzi egli il primo a studiare profondamente i terreni glaciali, specialmente quelli dell'anfiteatro morenico di Rivoli, ed a dissirare le molte jdee preconcette che esistevano in proposito; ne trattarono poi più o meno ampiamente il Martins, il De Mortillet, l'Omboni, il Sismonda, il Pareto (che lo appelló Areneano) il Baretti, lo Stoppani, il Bruno Luigi ed io stesso.

Il Gastaldi aveva già riconosciuto a grandi tratti l'individualità del Dituvium sahariano che egli comprendeva talora col titolo assai giusto di antichi coni di deiezione.

Non esisteva peró finora uno studio generale e minuto nello stesso tempo e diversissime erano le opinioni sulle divisioni, delimitazioni ed interpretazioni dei depositi diluvio-glaciali del Piemonte. Così il sismonda non ammetteva il terreno morenico, lo Stoppani ritenera che 
gran parte dell'anfiteatro morenico d'Ivrea si fosse depositato in mare; il pliocene superiore fluvio-lacustre (Villafranchiano) era quasi da tutti i geologi confuso col Quaternario; le formazioni sahariane mal distinte da quelle terrazziane, ecc.

Generalitì. - Le formazioni sahariane essendo di varia origine, fluviale, glaciale, di scolo, ecc., se ne indicheranno i caratteri generali sul principio dei sottocapitoli Diluvizm e Morenico.

Caratteri paleontologici. - Poco è a dire sui fossili del Sahariano del Piemonte, poichè la natura dei suoi depositi è generalmente contraria alla conservazione dei resti orşanici. Indichiamo solo come nei banchi terroso-marnosi, specialmente del loess, si raccolgano qua e lá numerosi molluschi terrestri e d'acqua dolce (specialmente Hyalinia, Buliminus, Pupa, Limnoea, Clausilia, Vertigo, Fruticicula, Eulota, Terophila, Succinea, Pisidium, ecc.), appartenenti a specie in parte tuttora viventi presso il punto in cui trovansi fossili, in parte emigrate ed in parte anche estinte.

Si raccolsero pure scarsi resti di Cerous megaceros, di Elephas primigenius e talora accumuli di Ursus spceleus.

Distribuzione GEograficA. - Essa varia molto a seconda che trattasi di Diluvium o di terreno morenico; lasciando in disparte la regione montuosa vediamo ccme nelle pianure il Diluvium trovisi ora ridotto a lembi più o meno ampi e di forma svariata lungo le falde alpine e collinose, là dove potè in qualche modo rimanere protetto dalle erosioni posteriori, poichè nella parte media della pianura esso fu in massima parte spazzato via, almeno superficialmente, dalle correnti acquee del periodo terraziano. Peró la formazione diluviale, mascherata dalie alluvioni più recenti, deve essere generalmente molto sviluppata sotto la pianura padana, tant' è che la vediamo apparire nelle incisioni più profonde della Stura di Cuneo, della Maira, della Dora Baltea, del Ticino, ece. In alcuni pochi casi rimasero sulla pianura alcuni alipiani diluviali isolati, quasi capisaldi residui dell'antico sviluppo del Diluvium, così quelli di Banale tra il Pesio e l'antico corso del Gesso; quello di Salmour tra l'antico corso del Gesso e la Stura; quello di Fossano tra la Stura e la Mellea; quello di Montariolo fra l'antico corso della Dora Baltea ed il Po; quello di Candelo fra il Cervo e l'Elvo; quello di Novara fra il Ticino e la Sesia, ecc. 
Quanto al terreno morenico il suo sviluppo e la sua distribuzione sono in diretto rapporto colla ubicazione e coll'ampiezza del bacino di raccoglimento e della vallata da cui deriva. Vediamo quindi come le grandi vallate del Ticino, d'Aosta e di Susa ci presentino rispettivamente i grandiosi anfiteatri morenici del Lagn Naggiore, d'Ivrea e di Rivoli, ampiamente avanzantisi e sviluppantisi sulla pianura. Invece le vallate minori ci presentano solo lingue moreniche terminali più o meno vicine allo sbocco della valle montana.

Tettonica. - Poco è a dirsi a questo riguardo. Le formazioni diluviali, a stratificazione più o meno regolare, pendono in generale dolcissimamente da monte a valle. I depositi morenici presentano pure zjesso una stratificazione o pseudostratificazione irregolare, oppure speciali contorcimenti, ripiegamenti ed accentramenti nelle lenti marnoso-argillose; ma in generale essi mostrano la tipica struttura caotica.

Potenza. - Variabilissima è la potenza delle formazioni sahariane a seconda della loro natura e della loro ubicazione. Il Diluvium presso le falde alpine ha uno spessore oscillante in media tra i 10 ed i 40 metri, ma che può talora giungere sino a 70 od $\$ 0$ metri.

Verso il centro della pianura talora il Diluvium va assottigliandosi in modo da terminare quasi ad unghia, come ad esempio osserrasi nel tipico cono di deiezione di Lanzo; talvolta invece pare si conservi potente od anche si ispessisca maggiormente, ma la nıancanza di pro ondi scandagli rende incerta tale questione.

Quanto al terreno morenico, esso costituisce sovente solo un sottile velo a lembi irregolari sui terreni più antichi; peró in certe regioni, dove trovasi specialmente accumulato, esso può raggiungere una grande potenza; ció vediamo ad esempio nella morena laterale destra (TranaVillarbasse) dell'anfiteatro morenico di Rivoli, e, meglio ancora, nella famosa morena laterale sinistra (La Serra) dell'anfiteatro d'Ivrea la quale presenta uno spessore reale di oltre $3 \mathrm{CO}$ metri, ed uno spessore apparente di oltre 400 metri.

Althetria. - Riguardo ai terreni quaternari non ha grande importanza l'esame altimetrico, trattandosi di terreni d'origine continentale; d'altronde le formazioni moreniche si trovano nella regione montana, quasi a tutte le elevazioni, anche le più notevoli. Quanto al Diluoium 
anch'esso mostrasi talora a grandi altezze entro la regione alpina; presso le falde delle Alpi trovasi tra i 600 ed i 400 metri circa di elevazione e naturalmente si abbassa poco a poco verso la pianura.

RAPport col terreni sotto E soprastanti. - L'esame dei rapporti che esistono fra il Sahariano ed i terreni sottostanti è certamente molto difficile ed è perciò quello su cui sono più varie e disparate le opinioni dei geologi. Siccome di ció ebbi ad occuparmi più volte, sia nei capitoli Villafranchiano e Fossaniano, nello studio del «Bacino terziario del Piemonte ", sia in diversi altri lavori, mi limiterò ad accennare ora come, secondo il mio parere (derivato da numerosi studi e confronti) siano da riferirsi al Pliocene superiore molte formazioni fluvio-lacustri che generalmente sono considerate invece come quaternarie, cosi le formazioni villafranchiane in generale (vere alluvioni plioceniche) e più specialmente quelle entro-alpine o subalpine di Lanzo, del Malone, del Ticino, ecc.; cosi pure ${ }^{\star l}$ le formazioni fossaniane del Canavese, del Biellese, ecc.

È poi specialmente nell'alta valle padana e nella Lombardia che appaiono quelle formazioni conglomeratiche che, col nome di Ceppo, vengono generalmente considerate come quaternarie. Orbene, anche in questo caso numerosi confronti e considerazioni di vario genere m'indussero ad inglobare una parte del Ceppo nel Pliocene superiore fluvio-lacustre o villafranchiano; ho detto parte, poichè in verità il nome di Ceppo corrispondendo in generale a conglomerato, naturalmente devesi ammettere anche come assai esteso e frequente il Ceppo sahariano; anzi è molto interessante osservare come sovente esista un passaggio abbastanza regolare tra il Ceppo villafranchiano ed il Ceppo ed il Diluvium sahariano, vediamo cioè talvolta come il Ceppo villafranehiano (per lo più fortemente cementato, con interstrati grigiogiallastri, sabbioso-argillosi, più o meno acquiferi) spesso poggiante direttamente sulle argille azzurre del Piacenziano, presenti superiormente banchi ciottoloso-sabbiosi, meno cementati, in parte già riferibili al Sahariano inferiore, e passanti poi gradatamente o rapidamente agli strati terroso-sabbioso-ciottolosi giallo-rossastri (Ferpetto) del tipico Diluvium sahariano. Tale passaggio è talora tanto regolare che riesce incertissima e talvolta arbitraria la delimitazione del Pliocene dal Quaternario e quindi facile l'esagerazione in un senso o 
nell'altro. Tali graduali passaggi si verificano non solo nel casc delle formazioni ceppoidi od in altro modo continentali, ma anche talora fra le formazioni littoraneo-maremmane del Fossaniano ed i depositi saha. riani.

Sorente però si osserva che il Diluoium sahariano, il quale spesso si adagia su terreni di ogni età, si presenta pure sovrapposto alquanto discordantemente ai depositi pliocenici che furono nella parte superficiale erosi più o meno potentemente dalle correnti diluviali; in tali casi naturalmente riesce facile $l a$ distinzione dei due terreni. Questi rapporti di discordanza esistono pure fra il Pliocene ed il terreno morenico che è generalmente distinto dal primo per mezzo di erosioni abbastanza notevoli e quindi per sovrapposizione irr solare.

Noto qui come io ritenga senz'altro quali terreni prettamente morenici diversi depositi a facies e struttura glaciale che racchiudono fossili pliocenici rimaneggiati od infranti, così i depositi di Candia, Caluso, Mazzè, ecc.

Quanto ai rapporti del Sahariano coi terreni sorrastanti essi sono di facile indicazione, giacchè le formazioni sahariane o terminano regolarmente la serie dei depositi quaternari costituendo colla loro parte superiore ( $\rho$ er lo piủ rappresentata da loess) il terreno superficiale, oppure si presentano direttamente ricoperti, per erosione, dalle allurioni terrazziane, naturalmente con discordanza o meglio con hyatus, tanto più notevole quanto più forte e lunga fu l'azione erosira. Quando però la formazione diluviale non termina superficialmente con un netto ed unico piano, ma presenta uno o più piani terrazzati che per la loro posizione e natura paiono ancora essersi formati sulla fine del Sahariano, risulta assai difficile il distinguere le formazioni di questo periodo da quelle del susseguente Terrazziano.

Località fossilifere. - Si è già detto sopra come il Sahariano si presenti generalmente scarsissimo di fossili in causa della natura essenzialmente torrenziale o caotica delle formazioni che lo rappresentano. Notiamo tuttavia l'esiste za di alcune carerne ossifere, fra cui specialmente importante quella di Bossea in Val Corsaglia e quella del Bandito in Val Gesso.

Abbastanza ricco in fossili è il loess in generale lurgo i pendii meno ripidi delle colline e specialmente di quelle di Torino: rari vi 
sono i resti di Vertebrati, ma frequentissimi quelli di molluschi terrestri, più raramente d'acqua dolce.

\section{Diluvium.}

Con questo appellativo si comprendono i depositi alluvionali, fluviali e torrenziali, formatisi nell'epoca sahariana, i quali sono rappresentati essenzialmente da banchi ghiaiosi e ciottolosi alternati e variamente commisti con terreni sabbiosi e terrosi; il colore di questi depositi è per lo piu il giallognolo, ora grigiastro, ora rossastro, a seconda degli elementi che li costituiscono e del grado di alterazione chimica a cui andarono suggetti. Anzi a questo proposito è a notarsi che in molti casi, in causa della superficialità del deposito, tale alterazione fu cosi profonda che i ciottoli in parte si argillificarono o furono ridotti in materiale incoerente.

Gli elementi ciottolosi del Diluvium sono per lo più poco cementati fra di loro, tuttavia nella sua serie si incontrano talora veri banchi conglomeratici resistentissimi, i quali talvolta simulano i banchi villafranchiani ed anzi non è sempre facile il distinguere gli uni dagli altri.

E importante a notarsi come nella parte superiore, superficiale, del Diluvium esista quasi sempre un deposito piuttosto sottile, ciò̀ dello spessore di due o tre metri in media, di marna terrosa, giallastra o rossiccia, cioè di loess, il quale rappresenta il deposito fangoso formato dalle ampie e vaganti correnti acruee del Sahariano quando, sul finire di questo periodo, esse cominciavano lentamente a ritirarsi lungo una linea speciale. Si comprende quindi facilmente come in questa fase dette correnti acquee, invece di fluitare e depositare banchi e lenti di ciottoli, ghiaie, ecc., cioè il tipico Diluvium, nella parte assiale del loro corso, dove erano più potenti, esse incominciassero ad erodere il piano su cui scorrevano, incidendovi poco a poco un alveo; invece nella. parte laterale del loro ampio corso le acque, limacciose ed a movimento lento, dovettero naturalmente deporre la fanghiglia che tenevano in sospensione; è così che si originò in generale il loess nella pianura padana; altrove ebbi già ad esaminare i diversi altri metodi, meno generali, con cui si formarono vari depositi di loss quaternario del Piemonte ed è quindi inutile di accennarli qui nuovamente. 
Considerati nell'assieme i banchi di Diluvium si presentano quasi orizzontali o leggerissimamente inclinati da monte a valle; ma esaminati nei particolari mostrano una stratificazione irregolarissima, spesso deltoide, o meglio di carattere torrenziale, il che è in stretto e naturale rapporto col tumultuoso loro modo di origine.

Variabilissimo è lo spessore del Diluvium; talora esso presenta Ja massima potenza, che può anche essere di quasi 100 metri, presso Je falde delle Alpi, assottigliandosi poi sia verso il centro della pianura, sia entro le stesse regioni alpine; ciò pel motivo semplicissimo che il deposito di questo terreno è dovuto al fatto che le grandi correnti acquee sboccanti dalle valli alpine arrivando alla pianura ed allargandovisi non poterono più trascinare i materiali grossolani che avevano trasportato fin là e quindi li depositarono in gran parte subito presso le falde alpine. Peró nella parte assiale della grande conca padana il Diluvium deve anche essere assai potente, ma ad elementi più fini che non quelli dei veri coni di deiezione alpini, in causa degli abbondanti materiali sabbioso-argillosi che venivano trasportati e depositati dalla grande fumana sahariana della valle del Po.

Non è molto importante l'elevazione che raggiunge il Diluoium poichè, a mio parere, essa non deve essere molto diversa da quella originaria, essendo la sua deposizione posteriore al grande sollevamento alpino che portò i terreni pliocenici ad oltre 500 metri d'altezza. Tuttavia siccome il fenomeno del terrazzamento, oltre che ad una magra generale, succeduta al grande periodo di piena del periodo sahariano, è pure probabilmente dovuto in qualche parte a fenomeni di sollevamento, assai meno intensi ma in continuazione di quello che chiuse il terziario, così parte dei depusiti di Diluvium trovansi probabilmente ora un po' più in alto, rispetto al livello marino, che non al loro momento di origine; ma in Piemonte per mancanza di depositi marini sahariani tale fatto è difficile a constatare con sicurezza.

Nelle vallate alpine dove i ghiacciai si svilupparono tanto da sboccare nella pianura è raro trovare ancora depositi di Diluoium; invece in quelle che presentarono solo un mediocre sviluppo glaciale troviamo il Diluvium avanzarsi molto entro la regione alpina sino all'incontro delle formazioni moreniche. Questo fatto è importante come quello che ci prova che il Diluvium, se soggiace al terreno morenico là dove i 
due terreni si incontrano, in generale invece è contemporaneo alle formazioni glaciali del Sahariano, anzi in vastissime regioni ne $\dot{e}$ l'unico rappresentante.

Ciò d'altronde è naturale poichè questi due terreni non sono altro che il risultato di uno stesso fenomeno, cioè la grande precipitazione atmosferica verificatasi nel periodo sahariano e che, secondo le regioni e le circostanze, si esplicò qua in masse glaciali, là in grandiose correnti acquee, quelle depositanti torrenti morenici, queste invece $D i$ luvium.

Si comprende eziandio facilmente come durante la discesa dei ghiacciai nelle vallate alpine essi venissero preceduti da depositi alluvionali e quindi là dove alla fine essi sostarono costruendo anfiteatri o semplici cordoni morenici, là per lo più il terreno glaciale posa sopra al Diluviam che termina quivi in sottile, ciò che solo in parte è dovuto a fenomeni di erosione per mezzo dell'agente glaciale.

Nel Piemonte si potrebbero suddividere grossolanamente i depositi di Diluvium in alpini, collinosi e della pianura; di molto piủ importanti sono questi ultimi che esamineremo quindi più accuratamente senza peró entrare in troppi dettagli che farebbero perdere l'idea d'assieme del terreno in questione.

Nella Lombardia il Diluvium si presenta ad un dipresso colla stessa facies, disposizione e forma che in Piemonte; cioè sotto ai depositi glaciali, verso la loro periferia, ma specialmente dall'esterno, direi, dei terreni morenici si estendono verso valle le formazioni diluviali sahariane a guisa di conoidi schiacciate ed inclinate verso il centro della pianura padana. Naturalmente fra la formazione morenica e quella diluviale evvi una zona costituita di terreni d'origine mista, zona che rende quindi molto oscillante ed arbitraria la delimitazione dei due terreni.

In generale la formazione ciottolosa è coperta da un velo di loss; il tutto poi è per lo più fortemente arterato e decomposto, almeno alla superficie, quindi prende un aspetto speciale giallo-rossiccio; questo Diluvium cosi decomposto ricevette in Lombardia il nome di Ferretto.

In seguito alle ampie e profonde erosioni fatte dalle correnti acquee durante il periodo terrazziano, le formazioni del Diluvium vennero in gran parte abrase, incise variamente, tagliuzzate e ridotte ora a formare altipiani ondulati, più o meno terrazzati lateralmente, che ven 
gono volgarmente appellati vaude, brughiere, groane o barraggie. Il dislivello tra la parte superiore di questi altipiani ed il basso-piano dell'attuale corso dei fiumi è assai forte presso monte ed inrece ra gradatamente diminuendo verso il centro della pianura padaná, tanto che in alcuni casi $i$ due piani rengono quasi a confondersi fra di loro a venti, trenta e più chilometri dalle falde alpine.

Tra il torrente Olona ed il Ticino la formazione diluviale tipica è assai potente ma non molto sviluppata in estensione, almeno apparentemente, perchè a Sud di Somma Lombarda-Gallarate-Cassano essa renne quasi completamente abrasa nella parte superiore dalle correnti acquee dal Terrazziano; ne rimasero ancora taluni lembi residui come presso Gallarate, Samarate, ecc.

Verso Tord si vede il Diluvium insinuarsi sotto il terreno morenico, assottigliarsi gradatamente fino a scomparire affatto; come di solito vedesi, specialmente al termine meridionale della espansione glaciale, che esiste gradualissima transizione fra il Diluvium ed il morenico in generale per mezzo di loess impuro commisto a ciottolini ed inglobante talora grossi ciottoloni che ci segnalano l'azione glaciale.

Nell'alveo dell'Olona, a valle di Solbiate all'incirca, e nell' alveo del 'Iicino a valle di Golasecca, le ripide sponde mostrano sorente a nudo il Diluvium inferiore ciottoloso-sabbioso, grigio-giallastro, talora subceppoide (mentre il tipico Diluvium medio-superiore è terroso-rossastro, a faeies di Ferretto) e che anzi passa spesso inferiormente al vero Villafranchiano, sotto forma di Ceppo oppure di banchi conglo. meratici ed argilloso-lignitici come nel Ticino.

Ad Orest del Ticino vediamo il Diluoium che, mentre si innesta a monte coi terreni morenici ad un dipresso lungo una linea irregolarmente ondulata Borgomanero-Pombia, si sviluppa poi ampiamente a Sud costituendo altipiani, incisi variamente dai torrentelli orjginari del Terdobbio e dell'Agogna, e che, gradatamente abbassandosi, vanno poi a confondersi quasi colla sottostante pianura terrazsiana; però residui di questo Diluvium osservansi ancora qua e là nella pianura stessa dove costituiscono altipiani per lo più allungati, da Nord a Sud: fra essi tipico specialmente è quello di Novara-Vespolate; però rispetto a questo altipiano noto che gli strati suoi superiori debbonsi giá riferire al principio del periodo terrazisano, come lo indicano con tutta 
chiarezza le differenze altimetriche esistenti più a monte fra $\mathrm{i}$ diversi piani terrazzati.

Tra la valle Agogna e la valle Sesia il Diluvium è ancora conservato in gran parte verso monte, costituendo, couse di solito, altipiani ondulati, profondamente incisi dai torrentelli, formati da banchi sabbioso-ghiaiosi e ciottolosi, giallastri o rossicci per decomposizione, e ricoperti da un velo di loess pure giallo-rossastro talora assai potente; presso monte questo Diluvium si appoggia direltamente sulle roccie antiche le quali peró sono per lo piu talmente decomposte alla superficie che il terriccio che ne risulta si connette e si confonde col loess sahariano.

In Valsesia si puó osservare stupendamente bene il fenomeno già accennato sopra, cioè l'inoltrarsi del Diluoium nelle vallate alpine sino all'incontro dei terreni glaciali; infatti vediamo come il terreno diluviale, che costituisce allo sbocco della Valsesia gli altipiani di Romagnano, Ghemme, ecc., si trovi ancora molto addentro nella regione alpina sin oltre Borgosesia; è vero che in queste regioni entroalpine trattasi solo più di piccoli lembi di Dilucium, come ad esempio quelli di Fenera, di Valbusaga, ecc., ma ció si spiega colla potente abrasione avvenuta durante il periodo terrazzian' entro a questa valle, dove le correnti acquee dovevano essere impetuose ed erosive al sommo, tant'è che alcuni di detti residui di Diluvium entroalpini trovansi ad un livello di 100 metri superiore all'attuale fondo della valle.

A monte di Borgosesia vediamo nettamente nelle colline di Pianezza e Cortiglia che sui depositi ciottoloso-terrusi del tipico Diluvium si sovrappone il terreno morenico caratteristico, terreno che incontriamo poi più o meno sviluppato sui fianchi di tutto il resto di Valsesia.

Ad occidente della Sesia i terreni diluviali tipici vennero in gran parte crosi, almeno superficialmente, per mod che gli altipiani di Roasenda, Buronzo, ecc., non rappresentano più il tipico Diluvium ma già i più antichi depositì del Terrazsiano. Peró numerosi, irregolarissimi, più o meno vasti residui di Diluvium sahariano troviamo in tutto il biellese sin presso le falde alpine dove esso si appoggia o sui terreni pliocenici o direttamente sulle roccie antiche, o entro le stesse regioni alpine come, ad esempio, in Val Cervo, non essendovisi svilup- 
pati molto i terreni glaciali; si può spesso constatare in queste regioni come il Diluoium ciottoloso passi gradatamente presso le falde alpine a depositi diluvio-brecciosi pure in parte sahariani, cioè costituiti dl elementi rocciosi, che, per essere stati poco rotolati, conservarono gli spigoli abbastanza angolosi.

Troriamo inoltre il Dilucium nella pianura biellese dore esso costituisce altipiani ondulati o affatto isolati, come la baraggia CandeloVillanova (che è appunto rivestita superiormente da depositi ciottolosodiluviali, spesso profondamente decomposti col solito relo di loess terroso-argilloso giallo-rossiccio), oppure collegati colla stupenda morena laterale sinistra di T'alle d'Aosta, cioè colla Serra; anche in questo caso si puó chiarissimamente osservare che i terreni diluviali, costituenti gli altipiani della Bessa, presentano graduale passaggio ai depositi glaciali, a cui però soggiacciono nel loro punto d'incontro; ció è specialmente risibile nelle colline di Donato-Mongrando ed in Valle Olobbia.

Questi vari altipiani del biellese sono molto istruttivi come quelli che ci segnano con sicu:ezza l'antico corso delle correnti acquee sulla pianura durante l'epoca quaternaria, corso che fu molto diverso da quello attuale.

Entro il grandioso anfiteatro morenico di Irrea non esistono affioramenti di Diluoium, il quale d'altronde credo vi manchi reramente; però nella parte periferica di questo anfiteatro, sotto ai depositi morenici, devono esistere terreni diluriali, continuazione e termine, verso monte, del Diluvium della circostante pianura; infatti già nei profondi tagli di San Martino Canarese e altrore osservasi che alla base dei depositi morenici tipici appaiono banchi ciottolosi che indicano già un passaggio al Diluoium. Questo fatto poi è evidente nella forra di Mazzè, dove vedesi nettissimamente il tipico terreno morenico potente, con fossili pliocenici rimaneggiati ( $d$ 'onde l'opinione che si trattasse di reri depositi pliocenici), sovrapporsi, con passaggio abbastanza graduale, al Diluvium stratificato; questo poi si va assottigliando rapidamente verso l'interno dell'anfiteatro, mentre invece esso diventa sempre più potente verso Sud per modo da costituire in massima parte il terreno ciottoloso basale della pianura padana.

In causa dell'erosione e della susseguente deposizione alluvionale compiuta dalle correnti acquee scorrenti sulla pianura padana durante 
il periodo terraziano, parte del Diluoium della regione padana in esame è stata esportata o coperta dai depositi terrazziani. Però nella pianura vercellese, come nel biellese, esistono ancora alcuni altipiani diluviali, quasi capisaldi dell'antica pianura padana sahariana; ne sono esempi principali l'altipiano, allungato da Ovest ad Est, di Montarolo presso Trino, e quelli di Torrazza di Verolengo. Si tratta qui di lembi di Diluvium superiore passante al Terrazziano inferiore rispettati dalle correnti acquee terrazsiane, ed infatti la loro forma segna nettamente la direzione dei corsi d'acqua che li isolarono.

Dopo indicati i lembi diluviali sahariani del vercellese è opportuno accennare come anche presso le falde delle colline Casale-Valenza esistano residui dell'antica pianura sahariana; solo che tali residui invece di essere costituiti da banchi ciottolosi, come il Diluvium subalpino, sono rappresentati essenzialmente da depositi terrosi o loess, giallo-rossastri, con straterelli ghiaiosi sparsivi irregolarmente. Ciò dipende dal fatto che questi terreni sahariani, d'altronde poco potenti, furono deposti in gran parte dalle acque scendenti dal rilievo collinoso Casale-ialenza, ed in parte dalla fiumana padana specialmente ruei suoi periodi di piena, ma già in condizioni tali da non poter più trasportare e quindi depositare elementi ciottolosi grossolani, almeno in regola generale.

Un ampio velo di loess sahariano, ridotto ora per l'erosione delle acque a tanti lembi isolati irregolarissimi, si estende sui depositi piacenziani della conca pliocenica di Occimiano-Frassinello nella parte inferiore di Val Rotaldo; tali depositi trovansi ora a $20,30,40$ e più metri sull' attuale fondo della valle, quantunque le correnti acquee eroditrici non abbiano mai potuto essere molto voluminose nè potenti.

Depositi simili sviluppansi ampiamente e regolarmente verso Est. costituendo l'altipiano di Mirabello-Lazzarone-Valenza-Bassignana-Rivarone, altipiano che termina a Sud contro le falde collinose, a Nord è limitato sia dal rialzo collinoso di Pomaro, sia dal corso attuale del Po, mentre ad Est è troncato dall'attuale corso del Tanaro; questo altipiano di loess sahariano si eleva di 10 a 30 metri sulla circostante pianura terrazziana. Tale zona sahariana è interessante costituendo l'unico lembo di questo terreno alle falde settentrionali delle colline Torino-Valenza; la sua conservazione è dovuta alla conca che quivi 
formano dette colline per modo che non vi potè influire direttamente come agente di erosione la grande fiumana del Po. Notiamo peró come sul dorso delle colline Torino-Valenza osservinsi non di rado depositi di loess sahariano, proveniente dalle alterazioni e dal trasporto a breve distanza dei terreni terziari stessi di dette colline; dell'origine, del modo di presentarsi, ecc. del loss dei colli torinesi ebbi già ad occuparmi ampiamente altrove con una monografia speciale, per cui non è più il caso che di farne cenno.

Ancora sviluppatissimo e quasi intatto e il Diluoium nella parte Sud-Ovest esterna dell'anfiteatro d'Ivrea, costituendo esso tra l'Orco, il Po e la Dora Baltea l'ampio altipiano, dentell:io verso Sud, di Agliè-Montanaro-Caluso; tale falto si spiega facilmente, giacchè in questa rasta regione dopo la fine del periodo saharian, le poderose correnti acquee sboccanti dalla valle d'Aosta non poterono espandersi liberamente sulla pianura diluviale e quindi eroderla superficialmente, come si verificò altrove in generale, ma dovettero invece arrestarsi nel loro corso im petuoso entro l'ampio cerchio morenico che divenne quindi un bacino lacustre. Naturalmente le acque che escivano poi da questo bacino non avevano più una grande forza di espansione e di ercsione; inoltre esse sboccarono specialmente dalla parte Sud-Sud-Est della conca lacustre, per modo che la pianura sahariana dı Sud-Orest rimase in parte intatta, solo isolata ad Orest dalle acque dell'Orco ed a Sud da quelle del Po; qui, come in generale, i depositi ghiaioso-ciottolosi sono ricoperti da un velo di loess.

Ad Ovest della Valle d'Aosta presso le falde alpine esistono ancora numerosi ma poco potenti residu li Diluvium con facies, posizione, ecc., quasi identiche a quelle delle prealpi biellesi; anche qui i depositi diluviali si appoggiano o sulla rocia antica oppure sui terreni pliocenici superiori maremmani, com resso Castellamonte, presso Rivara, ecc. Allo sbocco di Val d'Oreo sonsi nettamente i terreni diluviali venir coperti dai depositi moren $-x$ che poi da soli rappresentano il Sahariano più addentro nella $\mathrm{r}$. nta alpina.

Ad occidente dell'Orco il Diluvium whariano si sviluppa amplissimamente a costituire il tipico cono di wrone della Stura di Lanzo, che per la sua unità ed importanza fu _.. ongetto d' una monografia speciale. In complesso però vi si verifica: li stessi fatti che abbiamo 
finora esaminati, solo che la formazione diluviale è meglio conservata nella sua disposizione complessiva originaria.

Infatti contro le falde alpine vediamo il Diluvium ciottoloso, ad elementi un po' grossolani, passanti anche a depositi brecciosi, spesso profondamente decomposti e frammischiati a terriccio giallastro, poggiarsi direttamente sulle roccie antiche e talora addentrarsi anche molto nella regionc alpina, come in Val Verna ed in Val Soassolo, costituendo i bellissimi e fertili pianori di Forno di Rivara, di Corio e di Neviglie; in queste due ultime regioni la formazione diluviale verso monte viene poi ricoperta e tosto sostituita dal terreno morenico, come abbiamo già osservato altrove. Questi piani di Diluvium trovansi ad un' elevazione talvolta di oltre 100 metri sulla pianura terrazziana vicina, ciò che ci dà un'idea della potentissima erosione esercitata quivi dalle correnti acquee dopo il periodo sahariuno.

Man mano che ci allontaniamo dalle regioni alpine l'altipiano diluviale si va gradatamente abbassando, finchè presso Volpiano c la Venaria esso presenta solo più un dislivello di una decina di metri rispetto alla sottostante pianura terraziana.

Il primitivo cono di deiezione della Stirra non è completo poichè venne profondamente e largamente sbrecciato ed eroso nella partc media, per circa $1_{[} 3$ del suo sviluppo originario; tale erosione velne fatta dalle acque stesse della Stura durante il periodo terrazziano; anzi siccome questo fenomeno del terrazzamento si compiè a gradi e di questi diversi gradi fu in certe regioni lasciata traccia per numerose terrazzc a vario livello, cosi quivi non è sempre facile distinguere con sicurezza i depositi che si debbono ancora attribuire al Sahariano da quelli che sono già inglobabili nel Terrazziano; ciò si verifica specialmente presso le falde alpine.

L'altipiano di sinistra della conoide in esame, conosciuta col nonse di Campo di Cirie, di S. Maurizio e di Lombardore, è subtriangolare, eroso e limitato a Sud dalle acque della Stura, ad Est da quelle dell'Oico ed a Nord da quelle del Malone; la base è costituita di terreno villafranchiano, passante verso Nord al Fossaniano; il Diluvium è potentissimo presso monte e va gradatamente assottigliandosi verso valle. Di questo fatto credo si debba tenere assai conto per non esagerare nella potenza che si deve attribuire al Diluoium sahariano nella parte media 
della valle padana. I ciottoli di questo deposito sono talora assai voluminosi, spesso decomposti, argillificati e quindi facilmente riducibili in poltiglia; alia superficie del Diluvium esiste sempre un velo di loess giallo-rossastro più o meno argilloso.

La formazione diluviale in esame si avanza entro la regione alpina sino all' incontro dei terreni glaciali, sia in Val Malone che in Valle del Tesso ed in Valle Stura; questo passaggio si compie in modo che riesce per lo più assai difficile il delimitare nettamente un terreno dall'altro, poichè tra l'uno e l'altro esiste una formazione diluvio-glaciale di origine mista.

L' altipiano di destra della conoide della Stura è pure subtriangolare come quella di sinistra, solo un po'meno alto, ma di costituzione assai simile; s'appoggia ad Ovest alle falde alpine, è limitato ad Est dalla Stura ed a Sud dalla Ceronda; quest'ultimo torrente incide profondamente ed ampiamente detto altipiano da Fiano a S. Gillio; alla base di questa formazione diluviale compaiono qua e lá, specialmente in Val Ceronda, i terreni villafranchiani.

Presso le falde alpine si può osservare il passaggio gradualissimo fra il ipico Diluvium ciottoloso ed i depositi dilurio brecciosi o diluriofranosi dei pendii montuosi, tanto che spesso rimane iucerto se certi depositi debbonsi ancora porre nel Diluvium sahariano o già in un orizzonte più recente.

Lungo la valle Casternone-Cero.uda rerificasi l'innesto del cono di deiezione della Stura con quello della Dora Riparia e di Val Casternone; ma in causa del grande sviluppo dell' apparato glaciale di Val Susa, si puó quivi osservare che il terreno morenico di questa rallata si sovrappone, innestandovisi, al Diluvium della Stura di Lanzo; perỏ le formazioni più interessanti per osservare questa transizione furono appunto abrase dalle acque della Ceronda.

Allo soucco della valle di Susa manca completamente il Diluoium per il solito motivo che esso è sostituito dalla formazione morenica quivi sviluppatissima; probabilmente sul principio del periodo sahariano Ie acque della fiumana della Dora sboccando dalla valle alpina depositarono quivi un po' di alluvione, ma tosto sopraggiunse la massa glaciale per modo che tale formazione cesso di depositarsi ed anzi fu probabilmente alquanto abrasa dalla corrente glaciale. 
Però ad Est di Avigliana sotto i terreni morenici sonvi già alcuni indizi di depositi ciottolosi stratificati passanti al Diluvium; questo terreno poi appare nettamente, ancora entro l'ambito dell' anfiteatro morenico, lungo la Dora con potenti banchi conglomeratici.

Nella profonda forra di Alpignano-Pianezza per i profondi ed ampi tagli naturali si puo vedere nettissimamente in mille punti il passaggio graduatissimo fra il Diluvium ed il terreno morenico, per modo che si è quasi sempre incerti riguardo alla linea di separazione da segnarsi fra questi due depositi. In questa forra i banchi inferiori conglomeratici hanno tutto l'aspetto del Ceppo lombardo, tanto da lasciar nascere il dubbio che quivi appaia un po' di Villafranchiano.

Nella parte esterna della cerchia morenica si vede sviluppatissimo, a Sud della Dora, il terreno diluvio-glaciale rappresentato da loess, da sabbie e da irregolari strati ciottolosi; la linea abbastanza netta di separazione tra morenico e Diluvium, linea che osservasi a Nord della Dora fra Pianezza e Druent, credo sia dovuta al fatto che verso la fine del periodo sahariano le acque che uscivano, o direttamente dal ghiacciaio riempiente ancora l'anfiteatro morenico, oppure, in seguito, dal lago occupante tale anfiteatro, trovandosi libere dagli impedimenti delle colline moreniche ad Est di Pianezza si allargarono tosto sulla pianura diluviale e, pel natural pendio, dirigendosi specialmente verso N.E? erosero leggermente le falde delle colline moreniche più esterne di Pianezza-Druent.

Ad Est del grandioso anfiteatro morenico di Val Susa, detto anche di Rivoli, troviamo ampiamente sviluppato e quasi intatto il Diluvium sino a Torino, essendo esso solo inciso, profondamente ma poco ampiamente, dalle acque della Doria Riparia tra Pianezza e Torino: ne derivano quindi due altipiani diluviali, uno più grande, subquadrangolare, compreso fra le colline moreniche, la Dora, il Po ed il Sangone, ed uno più piccolo subtriangolare, compreso tra la regione morenica, la Ceronda, la Stura, il Po e la Dora. Questo Diluvium è costituito di banchi conglomeratici ad elementi spesso molto cementati tra loro ed in generale assai meno decomposti che nel Diluvium del cono di deiezione di Lanzo. Sotto a questi conglomerati diluviali esiste un velo acqueo regolare importantissimo che alimenta i pozzi di Torino e si rivela con numerose e copiosissime sorgenti in tutte le incisioni un po 
profonde; tale zona acquea è probabile scorra direttamente sui terreni oillafranehiani che abbiamo già visto costituire altrove sovente veli acquei potenti.

Sopra ai banchi sabbiosi, ghiaiosi e ciottolosi si stende quasi sempre un velo di loss giallastro, però in generale poco potente.

La conservazione di questi amplissimi altipiani è dovuta alla difesa naturale che essi ebbero contro le correnti acquee sboccanti dalle vallate alpine, in causa sia specialmente delle barriere opposte a tali correnti dai cordoni morenici, sia del pendio piuttosto rapido (da Orest ad Est) di questa regione, motivo per cui le acque incisero profondamente il loro alreo senza espandersi e senza erodere molto lateralmente.

Rispetto alla valle del Sangone devesi notare che il Diluvium, il quale si collega verso monte, nel modo altre volte indicato, coi terreni morenici, verso valle si presenta molto sviluppato e potente, costituendo l'altipiano di Giaveno; a dire il vero qui, come in altre regioni diluviali presso monte, il Diluvium _si presenta non perfettamente pianeggiante ma alquanto terrazzato, quantunque, a mio parere, tali terrazze siansi formate ancora nel periodo sahariano.

Tratıandosi di formazioni diluviali entro monte e poco lontane dai terreni glaciali, i loro elementi ciottolosi sono talora enormemente sviluppali e, come di solito, esse passano talora anche a depositi brecciosi presso le falde alpine.

E notevole poi come per l'enorme espandimento della massa glaciale di Val Susa, la ralle del Sangone ne rimase sbarrata ed il suo Diluvium venne cosi coperto dai depositi morenici della valle di Susa; tant'è che in diversi punti, sia presso il Sangone, sia verso i laghi di Avigliana, reggonsi affiorare i banchi di Diluvium stratificato, tipico, sotto ai terreni glaciali.

Siccome nel periodo sahariano, specialmente nel suo principio, la fiumana del Sangone volgeva verso Avigliana, andandosi cosi ad unire con quella della Dora, come ci indicano certi depositi diluviali, cosi non èmolto notevole il suo Diluoium ad Est di Trana, ed anzi esso ò quasi completamente mascherato dai depositi terrazsiani e non è ben discernibile da quelli della Dora e della Chiusella fra cui rimase, direi, soffocato.

A Sud del Sangone in quasi tutta l'alta valle padana, special- 
mente occidentale, le correnti acquee dopo il periodo sahariano cont:nuarono ancora per lungo tempo ad espandersi largamente sulla pianura, riducendosi negli attuali loro alvei solo in epoca abbastanza recente; ne consegue che i terre in diluviani sahariani furono superficialmente erosi alquanto, e poi coperti da depositi alluvionali terraziani; quindi il Diluvium tipico spesso manca affatto (almeno apparentemente, poichè invece esso è assai potente sotto pochi metri di Terrazziano) oppure esso è ridotto a lembi, per lo più poco estesi, presso le falde delle Alpi, cioè là dove le correnti acquee, sboccanti impetuosamente dalle vallate atpine, incisero profondamente il Diluvium allo sbocco delle vallate, rispettandone estese zone intermedie prima di espandersi ampiamente più a valle.

Lungo le falde alpine, là dove non esistono ampie valli, trovansi depositi ciottoloso-brecciosi e terrosi, in gran parte di epoca sahariana, più o meno coperti da depositi simili, però più recenti, ma che ad ogni modo hanno ben poco l'apparenza del tipico Diluvium; ne ê esempio quella specie di cornice rilevata che fascia il rilievo serpentinoso di S. Giorgio e sulla quale è fondato Piossasco Piazza; esiste quivi una specie di velo di loss rossastro, grossolano, impuro, inquinato di materiali ciottoloso-franosi, provenienti dai pendii vicini.

Invece allo sbocco della vallata Chisola e delle vallette sue affluenti troviamo vari altipiani diluviali, per lo più fortemente inclinati rerso valle, ma che anch'essi presso le falde alpine passano ad accumuli brecciosi; così il piano inclinato di Campetto Cappella, di C. Fortunato, di Cumiana, di Paschero, di Tavernette, di Frossasco, di Roletto, ecc. In tutte queste regioni i depositi diluviali sono in parte alterati, quindi giallo-rossastri, spesso cogli elementi ciottolosi ancora parzialmente a spigoli poco smussati, ed il tutto è quasi sempre coperto dal solito loess alquanto grossolano.

Oltre a questi depositi, complessivamente assai grossolani, osservansi pure talora, specialmente tra i torrenti Arculero e Noce, banchi sabbioso-terrosi giallastri o bleuastri che ricordano certe zone fossaniane subalpine di Castellamonte e di Rivara: sinora non vi raccolsi alcun fossile.

Fenomeni consimili osservansi in Val Chisone; allo sbocco di questa vallata alpina non si vede quasi più traccia di Diluvium, perchè esso 
fu superficialmente abraso e coperto poi dal Terrazziano; invece ne troviamo diversi residıi, però diluvio-brecciosi, talora pseudo-glaciali, entro la valle alpina sui suoi due fianchi, ad altezze anche di 50, 60 e persino 70 metri (ma anche assai meno) sul fondo della vallata; ne sono esempi le alte terrazze di Gay, Fossati, Ronco, Gondini, ecc. Talora il loess diventa assai potente come a Nord di Abbadia Alpina.

In questa valle, come altrove, cessano i depositi diluriali là dove appaiono le formazioni glaciali, ciò che con gradualissimo passaggio verificasi presso Villar Perosa.

A Sud del Chisone esiste un altipiano subtriangolare ed abbastanza vasto di Diluvium su cui stanno: S. Secondo Pinerolo, le borgate Airali, Moreri, ecc; è quivi sviluppatissimo il loess giallastro o rossastro, come si può vedere in moltissimi tagli naturali ed artificiali.

Nel periodo sahariano e forse anche terrazziano le acque sboccanti da Tal Chisone dovevano gettarsi a Nord-Est in parte, espandendosi cosi a danno, direi, della corrente acquea assai piủ piccola della Chisola; ciò si può dedurre dall'esame litologico delle alluvioni, essendo la costituzione geologica della valle alpina del Chisone assai diversa da quella di Val Chisola.

In Val Pellice vediamo che su ambi i lati del torrente esistono residui diluviali abbastanza estesi e potenti che si spingono ad Est sino a ravvolgere lo spuntone di scisto cristallino su cui posa il castello di Bricherasio.

La potenza visibile di questo Diluvium è talora di oltre 50 metri, ma talvolta essa è apparentemente esagerata dalla presenza di rialzi rocciosi antichi che ne sono ravolti senza che appaiano, o solo raramente, nelle sezioni, come verificasi appunto tra S.Giovanni e Bricherasio.

$\dot{\mathrm{E}}$ noterole in queste colline sahariane, specialmente nella parte più alta, ad esempio presso le C. Gross e Saret, come fra i ciottoli ed il loss grossolano siano pure sparsi numerosi cioltoloni e frammenti angolosi di facies morenica.

Entro la valle alpina del Pellice si vede svilupparsi per lungo tratto il Diluvium, formando esso gli altipiani laterali di S. Giovanni, Rua, Luserna, Lusernetta, ecc; quivi sempre notansi diversi ordini di terrazze che collegano gradatamente il Dilucium più alto e più antico col Terrazziano, senza che sia sempre facile delimitare uno dall'altro. 
Finalmente poco a monte di Torre Pellice questo Diluvium si innesta coi depositi morenici e non si sviluppa piu verso Ovest.

A mezzogiono del Pellice, mentre come di solito osserviamo la pianura padana senza alcun residuo diluviale superficiale, perchè tutto il suo Diluvium, che deve esscre quivi abbastanza potente, è coperto dal Terrazziano, invece contro le falde alpine le alluvioni sahariane furono rispettate dalle correnti acquee della seconda metá dell'epoca quaternaria e quindi si sono conservate ancora in parte.

Tali lembi diluviali formano così una più o meno ampia fascia al piede delle Alpi Marittime settentrionali, innestandosi verso monte coi depositi breccioso-franosi (che d'altronde talora costituiscono quasi completamente questi lembi sahariani subalpini), ed invece essendo limitati ad Est da una linea più o meno ondulata che segna la massima espansione laterale delle correnti acquee del periodo terrazziano; tale espansione deve esser stata abbastanza grande, poichè, dove la regione alpina si spinge un po' più del solito verso la pianura, là le falde rocciose rimasero gereralmente spoglie di formazioni diluviali, abrase dalle sovraccennate correnti acquee terrazaiane.

Fra tali altipiani diluviali, per lo più a forte pendio verso la pianura, notiamo come più importante quello allungato di BibianaBagnolo, quello (in forma di conoide terminante ad unghia verso Est) di Bagnolo-Ripoira-S. Pietro d'Assarti allo sbocco di Valle Infernotto, quello pure foggiato a piccola conoide fortemente inclinata, di S. Antonio, quello più allungato di Madonna dell'Oca- Envie, ecc.

Non è molto lontana neppure nella storia l'epoca in cui il Ponei periodi di piena sboccando dalla valle alpina talora volgeva a Nord, allargandosi sopra il bassopiano che si estende ad Est del pianoro diluviale di Envie; si comprende quindi facilmente come durantc il periodo terrazziano abbiano potuto rimanere isolati verso valle i sud detti lembi di Diluvium per le erosioni esercitate dalle ampie fiumane scorrenti sulla pianura padana.

Tali lembi diluviali non si presentano per lo più ben tipici, ma ad elementi in gran parte brecciosi per il poco trasporto subito; talora anzi detti elementi sono in parte molto voluminosi per modo da ricordare quelli dei depositi inorenici, come vedesi ad esempio nella conca. diluviale di Barge. 
In val di Po, appunto per l'ampiezza della fiumana che l'occupara, furono in gran parte abrasi i terreni diluviali; ne rimasero solo alcuni lembi, ad elementi un po' brecciosi, specialmente sulla sponda destra della vallata, formando cosi gli altipiani irregolari di Rifreddo, di Martiniano, di Serro, ecc. Essi sono soltanto interessanti perchè ci indicano come il piano sahariano di Val di Po si trovasse originariamente elevato di 60 ad 80 metri sull'attuale fondo della ralle.

Nel lembo sahariano di Croesio gli elementi ciottolosi sono ampiamente commisti con grossi elementi brecciosi che preludiano già al terreno glaciale, il quale appare poi nettamente poco a monte, presso Paesana.

Nella pianura, allo sbocco di Val Po, i terreni diluviali venreru completamente spazzati via, almeno superficialmente, dalle acque di questo fiume, per modo che non ne rimane traccia allo scoperto e solo alle falde seltentrionali dello sprone roccioso di Saluzzo truviamo un piano inclinato formante una specie di fascia attorno a dette colline; si tratta di un deposito poco potente costituito in massima parte dello sfacelo dei micaschisti gneissici fucilmente alterabili.

A Sud di Saluzzo mancano per lungo tratto residui diluriali un po' importanti, perchè le fiumane sboccanti dalle vallate alpine pel naturale pendio a Nord tosto si volgevano in tale direzione, anche durante il periodo terraziano, rasentando le falde delle Alpi e quindi esportando, superficialmente almeno, i terreni diluviali prima deposti; restano peró qua e là alle falde alpine depositi poco potenti, brecciosi franosi, sfacelo dei pendii rocciosi vicini e di cui l'età è un po' mista, direi, essendosi gia cominciati a formare durante il Sahariano, ma avendo pure continuato a formarsi in seguito.

Cosi pure entro la ralie alpina di Varaita esistono solo scarsi e mai tipici lembi di Dituvium, il quale a Brossasco riene poi completamente sostituito dalle formazioni glaciali; tale scarsita deriva dallu strettezza della valle per cui i depositi diluviali furonofacilmentespazzati via durante il periodo terrazziano.

Passando alla Valle Maira dobbiamo ancora constatare come nella pianura che si estende al suo sbocco manchino apparentemente (perche coperti dalle alluvioni terraziane), i depositi diluviali sahariani. E bensi vero che da Busca a Dronero esiste sulla sinistra della Maira 
un alto terrazzo, passante per S. Alessio e $\mathrm{S}$. Mauro, il quale potrebbe far supporre che l'altipiano a Nord di esso sia ancora un residuo di Diluvizm, ma l'esame complessivo delle varie formazioni quaternarie e delle varie terrazze di queste regioni $\mathrm{mi}$ fa credere piuttosto che sul principio del periodo terrazsiano la fiumana della Maira si espandesse ancora sin contro le falde alpine Dronero-Busca e che solo in seguito incidesse la terrazza sopraindicata.

Ma se quivi il Diluvium è mascherato superficialmente dal Terrazziano, esso appare peró nettamente nei profondi tagli dell'alveo in cui scorre ora incassata la Maira.

Queste profonde ed ampie sezioni nel Diluvium che osservansi lungo la Maira, a cominciare già da Busca sino a S. Damiano, sono importantissime come quelle che mettono a nudc completamente la costituzione intirca del Diluvium e ci permettono di studiarlo minutamente.

La consarvazione di questa zona diluviale, formante per lunghissimo tratto il fondo della valle alpina, è dovuta in gran parte alla notevole cementazione che presentano i suoi elementi i quali formano spesso un vero conglomerato cementatissimo, paragonabile per esempio a quello che osservasi nella forra di Alpignano allo sbocco di Val Susa ed a quello della forra di Rocca Sparvera in Val Stura di Cuneo, cioè al Ceppo della Lombardia. I banchi conglomeratici sono piuttosto potenti, abbastanza regolari nel complesso quantunque di costituzione irregolarissima nei particolari.

Lo spessore della formazione diluviale deve essere piuttosto grande nella pianura, dove però non possiamo valutarlo; invece diventa gradatamente minore entro la valle alpina, cioè solo di 10 a 12 metri ed anche meno; vediamo infatti tratto tratto che sotto al Diluvium, anche in mezzo della valle, spunta la roccia antica, cosi presso Dronero, presso S. Ponzo, ecc.

Oltre a questo Diluvium tipico che, coperto dalle alluvioni del Terrazziano antico, compare solo nei tagli presso la Maira, esistono ancora lembi diluviali abbastanza conservati, anche superficialmente, allo sbocco di alcune vallate laterali: ne è esempio il piccolo altipiano di C. Pajano-Copetti che rappresenta in gran parte il cono di deiezione di Val Moschiera, inciso dal torrente Moschiere rispettato in parte dalle acque della Maira per trovarsi in una specie di conca rocciosa. 
A Monte di Cartignano vediamo che sopra ai lembi più o meno estesi di conglomerato diluviale esistono qua e là ciottoloni spesso angolosi che preludiano al terreno morenico; questo appare solo presso S. Damiano, e quivi cessa lo sviluppo del Diluvium tipico.

A Sud della Maira lungo le falde delle Alpi non troviamo notevoli residui diluviali, sempre per la stessa causa della grande espansione delle correnti acquee sboccanti dalle vallate alpine; lo stesso dicasi per la Valle Grana che offre solo piccoli e rari lembi dilusio-brecciosi non importanti.

Da Grana procedendo verso mezzogiomo, presso Bernezzo, allo sbocco di ralle del Cugino, osservansi stretti altipiani diluriali residui, che rappresentano il piccolo cono di deiezione di detta valle, ma che non presentano la tipica costituzione cicttolosa.

Qualche cosa di simile esiste pure presso le falde alpine tra $\mathbf{S}$. Rocco di Bernezzo e la Stura di Cuneo; infatti osservasi quivi una specie di ampio altipiano su cui siede Ruata Cotone, Cervasca e Tignolo, altipiano limitato ad Est da un terrazzo assai netto, Ruata Rivetta-C. Spazzaforio, e che credo possa ancora considerarsi come un residuo di Diluvium rispettato dalle correnti acquee terrazziane per la sua posizione speciale contro le falde alpine.

Interessantissimo ci si presenta il Dïuvium di Val Stura, üuantunque esso sia stato superficialmente abraso quasi ovunque. Infatti nella profonda incisione eseguita dalla Stura nella pianura pidana possiamo studiare molto bene in tutti i suoi dettagli la formazione diluviale sahariana che deve es ere assai potente presso monte, poichè le incisioni di oltre 50 metri che osservansi nel circondario di Cuneo sono lungi ancora da metterne a giorno la base, per cui credo non esagerato il supporre che la sua potenza possa essere in alcuni punti anche di quasi 100 metri.

Pe»ò rerso valle il Diluvium diminuisce gradatamente di spessore, finchè presso Montanara compaiono nella sua parte inferiore i terreni pliocenici villafranchiani che in breve sostituiscono completamente il Diluoium rella ccstituzione dell'alveo della Stura; questo terreno quindi viene per lungo tratto a mancare perche er so dalle correnti acquee terraziane, ma ricompare poi ancora più verso ralle a costituire gli altipiani di Fossano e di Trinita-Salmour. 
Da cio risulta chiaro il fatto, gia osservato altrove, che in co-u plesso il Diluvium va talora diminuendo di spessore da nonte a valle.

Addentrandoci nella valle della Stura continuiamo a vedere lungo le pareti dell'alveo le formazioni diluviali potenti, per lo più conglo. meratiche, ad elementi talora molto grossolani; di tratto in tratto compaiono alla $\frac{1}{2}$ ase le roccie antiche.

Alla superficie il Diluvitum fu alquanto eroso dalle acque terrazziane ed è coperto da Terrazziano antico; però a cominciare dalla Beguda verso valle, vediamo che sul Diluvium trovansi sparsi depositi ad elementi assai grossi ed un po' angolosi con 'facies morenica. Ma il primo vero e tipico lembo morenico che si incontra risalendo la Val Stura è quello che costituisce il rilievo di Pian di Gajola; quivi vengono pure a cessare le formazioni diluviali quantunque ancora presso Pianetto e Tetti Maigri su ambo i lati della vallata, osservinsi banchi brecciosi conglomeratici compatti, che paiono indicarci un' origine diluvio-glaciale.

Nelle vallate alpine del Gesso e della Vermenagna, per la strettezza della valle e l'impeto delle correnti acquee, pochi, stretti e non tipici sono i lembi diluviali che tuttora esistono, specialmente allo sbocco di vallette secondarie.

Nell'alveo del Gesso, lungo il suo percorso sulla pianura, osservasi il Diluvium potente, ma in gran parte però mascherato da depositi terrazziani di varie età.

Ad Est del Gesso osserviamo un notevolissimo cangiamento nel modo di presentarsi del Diluvium, o, meglio, dei suoi attuali residui; cioè mentre in generale dalla Dora Riparia al Gesso questo terreno si poteva quasi solo osservare nelle incisioni dei torrenti, perché abraso superficialmente, invece nella parte orientale dell'alta valle padana il Diluvium si è tuttora in gran parte conservato sino alla sua parte superficiale, solo presentasi variamente e più o meno profondamente inciso e ridotto a lembi di varia forma e lunghezza.

Questo fenomeno è dovuto essenzialmente al fatto che nella regione che passeremo ora ad esaminare le correnti acquee, durante il periodo terraziano, invece di allargarsi su tutta la pianura padana, cominciarono tosto a restringersi lungo certi assi speciali, quivi profondamente scavando ed incidendo il loro alveo, rispettando cosi vaste regioni 
diluviali che per tale lavorio di erosione e di terrazzamento si tramutarono poco a poco in quelli altipiani a cui accenneremo ora breremente.

Allo sbocco della valle del $\mathrm{T}$. Colla, la formazione diluviale è ancora in gran parte conservata e costituisce l'altipiano, a dire il vero ben poco sollevato sulla pianura terazziana, di Boves-S. Mauro.S. Magno-Rivoira, ecc.; il gradino piuttosto basso che limita questo $D i$ luvium verso Nord ci indica come quivi esista una ben piccola differenza di età tra questo terreno sahariano ed il vicino terraziano; anzi tale divisione parrebbe a priori alquanto arbitraria se non venisse convalidata da quanto osservasi più ad Est, dove i due terreni si distinguono sempre più spiccatamente.

Tra il rio Beal ed il Pesio vediamo infatti che l'altipiano diluviale ¿ abbastanza ben conservato tra Peveragno, Beinette e Bores, mentre ad Orest esso si eleva appena di pochi metri sulla prossima pianura terraziana; verso Est invece, ad esempio presso S. Maria Rocca, se ne distingue con un dislivello di oltre 20 metri individualizzandosi così perfettamente. In questa regione diluviale è notevole la copiosissima sorgente che origina il lago di Beinette; essa è forse doruta ad un velo acqueo scorrente sui terreni villafranchiani superiori e che è deviato dal suo corso naturale e spinto a giorno dall'incontro dei coni di deiezione stati deposti specialmente dalle fumane sboccanti dalle vallate di Stura, Gesso e Vermenagna; è infatti specialmente lunga questa linea di sovrapposizione del Diluvium al Villafranchiano che troviamo molto numerose ed abbondanti le sorgenti presso Margarita. tra questo paese e Montanera, in Val Stura sotto il Murazzo, ecc.

Nella stretta valle alpina del Pesio non incontriamo notevoli lembi diluviali, ma solo depositi diluvio-brecciosi pseudo-morenici, come allo sbocco di Val Grosso, ecc.; lembi simili, ma ad elementi assai meno grossolani, incontriamo pure più a valle presso il Piano, Peveragnina, ecc.

Continuando l'esame dei terreni diluviali ad Est del Pesio troviamo il bellissimo altipiano di Pianfei-Blangetti, il quale, però, quantunque sia assai rilevato sulla pianura terpaziana, ncn rappresenta ancora il lipico Diluvium, ma bensi un deposito formatosi nel periodo di pas saggio tra il Sahariano ed il Terraziano. Infatti presso le falde alpine 
a Sud di borgata Viglioni vediamo vari lembi diluviali situati molto più in alto che il piano di Pianfei, ma specialmente poi verso Est troviamo sviluppatissimo il tipico Diluvium che costituisce l'elevato altipiano di Roracco-S. Grato-Villanuova Mondovi; questo Diluoitum è assai potente, si solleva presso monte sin oltre i 600 metri, è costituito di depositi terroso-ciottolosi ad elementi spesso grossissimi, sovente affatto decomposti; il tutto è coperto da un velo assai notevole di loss impuro giallastro o rossiccio il quale anzi presso monte è talora l'unico rappresentante del Sahariano, come già osservammo altrove in simili casi.

Questa importante formazione diluviale è dovuta all'azione riunita delle acque del Pesio e di quelle dell'Ellero.

Ad Est dell'interessante altipiano diluviale ora esaminato vediamo estendersi ad un livello minore un vastissimo piano piu volte terrazzato, cioè quello di Branzola--S. Luigi--Merlo-Avagnina, ecc. Malgrado la sua posizione inferiore a quella del Diluvium di Roracco e malgrado i terrazzamenti che lo suddividono in diversi piani, credo che questa formazione si possa ancora inglobare nel Diluvium, il quale sarebbe in questo caso stato depositato verso la fine del periodo sahariano, formando cosi passaggio al Terrazziano, di cui vediamo le tipiche alluvioni nella vasta pianura estendentisi a Nord e Nord--Est.

Se risaliamo la valle del Tanaro a monte di Carrù, vediamo che, dal lato destro, sul dorso delle colline terraz̃iane sono ancora conservati diversi lembi di Diluvium ciottoloso-terroso, giallastro che sono spinti in certi punti sin oltre i 600 metri di elevazione come al Bric Bicocca; in queste formazioni diluviali ebbero certamente anche qualche parte le acque di Val Corsaglia.

Tra Lesegno e Ceva, sempre sulla sinistra di Val Tanaro, esiste uríampia ma sottile zona di Diluvium formante un piano fortemente inclinato verso Nord e ad un dipresso della stessa natura che quella dei lembi sovraccennati.

Entro la valle alpina del Tanaro la fiumana che lo percorse durante il periodo terraziano ne esportò quasi completamente ogni deposito di Diluvium; si trovano solo qua e là, come di solito allo sbocco di vaste rallette laterali, alcuni depositi alluvio-brecciosi, però non sempre di età ben precisabile, forse in parte sahariani. 
Ritornando ora all'esame dell'alta v'alle padana, dopo arer passato in rivista $\mathrm{i}$ deposti diluvialidelle numerose vallate alpine che vi convergono, dobbiamo accennare come sulla destra del Tanaro, alle falde occidentali delle Langhe, esistano presso Dogliani piccoli e sottilissimi lembi di terreni ciottolosi, sabbiosi e terrosi giallastri che rappresentano il Diluvium, e che fer quanto poco importanti in sé, servono però ad indicarci l'elevazione e lo sviluppo ad Est della grande fiumana del Tanaro durante il periodo sahariano.

Ma ad Ovest del Tanaro esistono regioni rastissime in cui il $D_{i}$ luvium è ampiamente e tipicamente rappresentato; tali regioni, per le continue erosioni verificatesi durante il periodoterrasiano, furono ridotte a vasti altipiani, come ebbi già ad esaminare minutamente altrove. In generale quivi osserviamo che il Dilucium ha solo una potenza di circa 10 o 15 metri: è costituito essenzialmente di ciottoli di rarie dimensioni, taluni persino di quasi un metro di diametro, commisti con terriccio grossolano e giallastro, più o meno decomposti a seconda dei luoghi e delle loro superficialità; al disopra di ciỏ si estende il solito leess giallo--rossiccio, talcra potente due o tre metri: su di esso non è raro incontrare lenti più o meno estese di speciali concrezioni ocracce, costituite in gran parte di ossido di Manganese con ossido di ferro ed elementi terrosi eterogenei. Tali curiose formazioni, probabilmente depostesi sul fondo di acque stagnanti molto mineralizzate, verso la fine del periodn sahariano, ricevettero volgarmente il nome di Mürs o Gherloun: talora esse sono ridotte a grumuli staccati sparsi nel loss; si trovano già sviluppate sui tipici allipiani diluriali di Roracco-Villanuova Mondovi e si incontrano poi comunissimalıente in quasi tutte le regioni diluviali della parte destra dell'alta valle radana. Dette formazioni ci indicano come rerso la fine del periodo suhariano, quando le correnti acquee cominciarono a raccogliersi lungo a.isi speciali, rimanessero sul piano ondulato diluriale numerose conche lacustri che poco a poco andarono essiccando, spesso naturalmente con dei ritorni, direi, in causa delle fiumane traboccanti (in epoca di piena) dagli alvei che si andavano allora appena abbozzando.

L'altipiano diluviale situato più a Sud è quello detto del Banale esso è subtriangolare; suddivisibile per l' età di formazione in due parti quella occidentale, più piccola, subtriangulare compresa tra i paesellr 
di Succhi, Magliano ed Isola, è la più antica e rappresenta il tipico Diluvium; quella orientale, assai più grande, subquadrangolare, è la più recente poichè il suo Diluvium fu deposto sulla fine del periodo sahariano, mentre già le correnti acquee avevano ccminciato ad erodere ed a terrazzare, donde il gradino che divide le due sovraccennate porzioni dell'altipiano Banale.

A Nord dell'ampia vallata escavata dalle acque del Gesso quando, invece di unirsi colla Stura sotto Cuneo, andavano a congiungersi col Tanaro presso Bene-Vagienna, esiste un amplissimo altipiano diluviale, pure subtriangolare è suddivisibile in una parte occidentale (Trinità-Burey-Salmour) più antica ed in una orientale (Burey-Podio--Eremo di Cherasco--Salmour) più recente, con un gradino divisorio disposto a piano inclinato ed ondulato.

Sulla sinistra dell'incassata valle della Stura di Cuneo si sviluppa un' estesissima zona diluviale, allungata da Sud a Nord, cioè da Fossano al Motturone; anche questo lungo e stretto altipiano si puó distinguere in un altipiano meridionale più antico, detto di Famolasco, che si estende sino alla borgata Cappellassa all'incirca, ed in uno settentrionale più basso e quindi più recente che si allunga sino al Motturone; però questo secondo piano diluviale più recente non è più attribuibile solo alle acque del Tanaro come era il caso per i due primi altipiani sovraccennati, ma bensi anche a quelle di Grana (Mellea). Questo altipiano di Fossano venne isolato ad Ovest specialmente dalle erosioni delle correnti acquee del T. Mellea; infatti anche oggi talvolta questo torrente nelle piene, tende a portarsi verso Fossano come fece in tempi non molto lontani, lasciando come residuo la regione ghiaiosa, detta Coda del drago.

Esaminando ora la valle padana più verso Nord, notiamo un fatto assai interessante, che cioè, mentre durante il periodo sahariano le grandiose fiumane che, raccolte quasi in una sola, percorrevano detta valle, si spingevano molto verso Est cioè sin quasi ai limiti occidentali dell'attuale regione astense, invece durannte il periodo terraziano esse si ritirarono molto più ad Ovest. Ne derivò naturalmente che queste correnti acquee abrasero superficialmente e ricoprirono con alluvioni i terreni diluviali della massima parte dell'alta valle padana, ma rispettarono invece quelli della parte orientale di detta valle, ter- 
razzandoli lungo una linea ondulata passante per Bra-Sommariva BoscoTroffarello. :

Questa linea è ora segnata da una terrazza la quale è dapprina accentuatissima, cìò di quasi 100 metri a Sud; invece essa va sempre più indebolendosi, direi, verso Nord, per modo che non è sempre facile il segnarla nettamente tanto più che essa viene ad essere resa assai irregolare dalle incisioni fatte dai torrentelli tributari di destra.

In questa vastissima zona diluviale Bra-Valfenera-Buttigliera d'AstiTroffarello si può ancora sovente distinguere un Diluvium antico che forma gli altipiani piu elevati, ed uno meno antico che si trora sui lati delle valli di erosione a livelli un po' più bassi che il Dilnoizm tipico; anzi là dove sonvi più ordini di terrazze riesce talora incerta la separazione del Diluvium sahariano dal Terrazziano.

Il Diluvium di questa importantissima zona non è in generale molto potente, ed anzi è solo nella parte sua occidentale che alla sua costituzione prendono parte banchi ciottolosi, coperti da loess grossosolano, mentre invece nella porzione orientale la formazione diluviale è rappresentata quasi unicamente da un terriccio giallo-rossastro, più - meno argilloso, cioè da loess, con cui si alternano spesso lenti ghiaiose assai estese, e che inoltre ingloba non raramente zone di grumuli del sovraccennato gherloun.

Lungo la frastagliatissima linea divisoria esistente tra la valle padana e l'alta regione astigiana il velo sahariano è ridotto spesso per erosione a lembi isolati irregolarissimi; si puó osservare in mille punti la costituzione del suo loss, spesso con grumuli manganesiferi, calcarei, ecc., e che talvolta parrebbe quasi formare un passaggio graduale al Villafranchiano.

Verso Cambiano i depositi diluviali sono costituiti superficialmente, invece che da lcess, da banchi sabbiosi o sabbiosi-terrosi i quali fanno passaggio al vero loess, essi rappresentano il deposito formato dalle correnti acquee là dove, dopo aver percorso l'alta valle padana, trovarono un ostacolo al loro libero corso nel rilievo dei colli torinesi, essendo perciò obbligati a rallentare il loro movimento e quindi a deporre grandi accumuli di sabbia, ció che fu anche coadiuvato dal lavacro delle colline, in gran parte sabbiose; è per il suddetto motivo che anche nella pianura di Carignano il sottosuolo è in parte costituito da potenti banchi sabbiosi. 
Notiamo ancora come il Diluvium saharano non si arresti alle falde dei colli torinesi ma vi si inoltri molto sotto forma specialmente di loess, che in massima parte però è dovuto all'abrasione delle stesse colline terziarie, come ebbi già ampiamente a dimostrare in altro lavoro. Simile modo di origine hanno pure i numerosi ma sottili ed irregolari veli di loss che s'incontrano in molte regioni sul dorso delle colline Torino-Valenza, dell'Astigiano, delle Langhe, dell'alto Monferrato, ecc., ma su cui non credo dovermi fermare, non avendo essi in generale una grande importanza ed essendo dovuti specialmente a fenomeni locali.

Passando ora all'esame della grande pianura alessandrina, vediamo come in essa si ripeta ad un diprẻsso quanto osservammo per l'alta valle padana, solo in scala minore non esistendo all' intorno una regione alpina.

Siccome durante il periodo sahariano le acque dell'alta valle padana non si gettavano ad Est nell'Astigiano, come in parte ora fanno, ma tutte proseguivano verso Nord passando fra le Alpi Cozie ed i colli torinesi, così in quel periodo l'Astigiana, regione originariamente pianeggiante, leggermente ondulata, non fu percorsa che dalle piccole correnti acquee scendenti dal lato settentrionale delle Langhe e dal lato meridionale del rilievo Casalborgone-Valenza; quindi dalla parte astense le formazioni diluviali della conca alessandrina non ricevettero un grande contributo.

Considerando come le acque dell'alta valle padana durante il periodo sahariano si spinsero verso Est sino alla pianura di Poirino e come l'immissione (avvenuta alla fine del periodo sahariano) del Tanaro nell'Astigiana è dovuta all'erosione di una semplice e sottile barriera sabbiosa tra la Morra e Bra, riesce interessante e curioso il pensare che se nel periodo sahariano una parte delle acque dell'alta valle padana, soprafatto il lieve ostacolo che le tratteneva ad Est, si fossero gettate nella regione astese, completamente mutata da quella attuale ne sarebbe rimasta la configurazione oro-idrografica di questa amplissima regione e conseguentemente anche di diverse altre del Piemonte.

A costituire il Diluvium della pianura alessandrina contribuirono specialmente le acque della Stura, dell'Orba, della Scrivia e dei loro 
rispettivi confluenti; di tale Dilucium sono tuttora conservati integralmente porzioni assai vaste, specialmente presso le falde appenniniche, mentre che verso valle la formazione diluviale è, come di solito, in gran parte erosa superficialmente e ricoperta dalle alluvioni terrazziane.

Tella parte Nord-Ovest della pianura alessandrina osservasi come la formazione diluviale, mentre con diverse terrazze si collega regolarmente col Terraziano di detta pianura, verso settentrione invece si appoggia regolarmente sul Villafranchianə, pur terminando a frastagli ed a lembi irregolari in causa delle erosioni acquee. Questo deposito diluriale, che spingesi talora, con veli di loss, molto avanti nella regione collinosa, è poco potente, in gran parte terroso-ghiaioso e dere specialmente la sua origine alle correnti acquee che sboccavano con impeto dagli Appennini liguri, ed allargavansi tosto su tutta la conca alessandrina. Esso venne poi in massima parte eroso dalle acque del Tanaro durante il periodo terrazziano; i lembi più o meno ampi rimasti tuttora sulla sinistra del Tanaro trovansi ora a 30,40 e più metri di elevazione sull'attuale corso di questo fiume.

Tra il Tanaro ed il Belbo esistono diversi lembi di Diluvium ciottoloso e terroso che verso Ovest si estende molto a guisa di velo di semplice loess argilloso, gialliccio, che copre per larghi tratti il T"illafranchiano superiore, dal quale anzi non è sempre facile distinguerlo. Questo Diluvium è probabilmente dovuto in parte alle correnti acquee che, allargate e divaganti, rappresentavano il Belbo durante il periodo sahariano.

Da Origlio a Cassine possiamo osservare numerosi altri lembi, per lo più allungati da Est ad Ovest od isolati, di Dilucium poco po. tente, rappresentato in gran parte da loess argilloso verso Est ed inrece grossolano e con lenti ghiaiose verso Ovest.

Nelle colline di Cassine questi residui diluviali trovansi già sollevati di 60 a 70 metri sul fondo dellattuale vallata, il che ci dimostra come in queste regioni sia andata rapidamente crescendo, da valle a monte, l'azione erosiva esercitatasi durante il periodo delle terrazze.

Se poi ci inoltriamo ancora di più nella valle della Bormida troviamo a diversi livelli sul dorso delle colline che stendonsi alla sua destra, ed anche molto lungi dalla vallata attuale, numerosi ma sot- 
tilissimi lembi di tipico Diluvium ciottoloso (ad elementi anche voluminosissimi), spinti sin oltre i $3 \mathcal{E} 0$ metri di elevazione, come presso Castel Rochero, cioè ad un livello superiore di oltre 200 metri a quello dell'attuale fondo di Val Tanaro. Ciò ci indica chiaramente, anzitutto come nel solo periodo terraziano le acque della Bormida incisero nei terreni terziari un alveo profondo oltre 200 metri, il che è certamente assai notevole, dimostra inoltre che durante il Sahariauo le Langhe presentavano una configurazione ben diversa da quella attuale; probabilmente esse costituivano già una regione molto ondulata, ma di certo infinitamente meno collinosa, meno incisa e meno frastagliata, che non al giorno d'oggi, poichè tali modificazioni si verificarono specialmente durante il periodo terraziano.

Quanto poi al non incontrarsi più a monte, sia qui in Val Bormida, sia nelle altre vicine vallate appenniniche, residui diluviali un po' notevoli, ciò dipende semplicemente dal fatto che a monte le acque erodevano soltanto senza poter depositare in causa dell'impeto della loro discesa.

Tra la Bormida e l'Orba si sviluppano amplissime zone diluviali, potenti a valle, assottigliantesi a monte; come di solito in generale i banchi ciottolosi, spesso a grossi elementi più o meno decomposti ma quasi sempre giallastri, sono coperti da loess; tali zone formano come di solito altipiani di forme irregolari, inclinati a Nord, finchè essi venno quasi a confondersi colla pianura terrazziana da cui sono appena distinti per un gradino di pochi metri; invece a Sud tali altipiani si innalzano notevolmente tanto che talora trovansi ad oltre 100 metri di elevazione sull'attuale fondo della Bormida e dell'Orba.

Spesso nelle regioni più a monte i lembi di Diluvium sono ridotti a qualche ciottolone sparso sul dorso delle colline, residuo di un deposito originariamente più esteso e potente.

Tra l'Orba e la Scrivia esistono ancora estesi altipiani diluviali foggiati sullo stesso stampo di quelli preaccennati, irregolari, allungati da Sud a Nord, abbassantisi gradualmente (rispetto ai bassipiani circostanti) verso Nord, mentre verso monte si sollevano persino di 100 metri sull'attuale livello della Scrivia. Queste zone di Diluvium appongiansi a Sud trasgressivamente su diversi orizzonti terziari ed a Nord invece adagiansi regolarmente sul Villafranehiano, da cui anzi 
non sono sempre facilmente distinguibili a causa della natura in gran parte ciottolosa di ambedue $\mathrm{i}$ depositi.

Sulla destra della Scrivia, cioè alle falde occidentali dei colli tortonesi ritroviamo ancora numerosi lembi diluviali, per lo più ridotti a placche poco estese, poco potenti, talora rappresentate solo da loss verso Est; questi depositi di Diluvium che presso Cassano Spinola sono notevolmente sollevati sul Lassopiano della Scrivia, si ranno gradatamente abbassando verso Nord tanto che presso Tortona rengono quasi a confondersi colle alluvioni terraziane.

Abbiamo cosi esaminato succintamente i diversi lembi diłuviali che sono tuttora conservati attorno alla vasta pianura padana e che anticamente, cioè sulla fine del Sahariano, erano tutti assieme collegati a costituire una specie di conca sola, a superficie alquanto più rilevata che non l'attuale; siccome peró l'erosione terraziana non dorette essere molto forte nella parte interna della pianura alessandrina, così è naturale il dedurre che in questa vasta regione, sotto alle allurioni terraziane si estenda una zona più o meno potente di Diluvium che ricopre regolarmente le formazioni villafranchiane.

I lembi diluviali di Valenza-Rivarone servono molto bene a collegare il Diluvium della pianura alessandrina con quella delia pianura padana.

Ritornando alla grande vallata padana, se ne esaminiamo la parte meridionale possiamo osservare come in generale allo sbocco delle valli appenniniche esistano formazioni diluviali piü o meno estese, costituenti altipiani piủ o meno elevati sulla vicina pianura terrasiana; se di ciò vi è appena accenno al termine di Val Curone, sriluppatissimo invece si mostra il Diluvium allo sbocco di Val Staffora dore esso si presenta a diversi livelli pei ripetuti terrazzamenti che servono di passaggio tra il Diluvium saharianu e le alluvioni terraziane. Fenomeni simili si ripetono lungo le falde appenniniche rerso Est, ma non è più qui il caso di passarli in esame.

Se si considera la formazione diluviale sahariana in rapporto colla idrografia sotterranea si nota tosto come esista tra esse un nesso assai stretto che dipende dalla natura e dalla posizione del Diluoium; infatti essendo questo un deposito per lo più superficiale ed in gran parte ghiaioso-ciottoloso, quindi talora permeabile, sovente le acque 
di piuggia lo attraversano facilmente; e siccome sotto al Diluvium esiste per lo più la formazione villafranchiana con banchi marnosoargillosi, cosi in generale alla sua base si costituisce una falda acquea, regolare, potente, molto importante, come già acrennammo trattando del Villafranchiano.

Ne consegue che le regioni diluviali, specialmente quelle ridotte ad altipiani, sono per lo più alquanto aride, poichè l'acqua di pioggia penetra facilmente nel suolo e viceversa scarseggiano le correnti acquee superficiali. Però là dove il loess è un po' argilloso ed i banchi ciottulosi alquanto decomposti ed argillificati, là si verifica invece che l'acqua di pioggia non può quasi penetrare nel terreno ed anzi forma allora sovente pozzanghere più o meno vaste secondo l'arografia della regione; in molti casi poi si osserva che nella pianura si forma un relo acqueo più o meno regolare tra il Diluvium compatto e 10 Alluvium più incoerente, e ciò ci spiega diversi fenomeni generali di idrografia sotterranea, cosi numerose sorgenti acquee, pozzi poco profondi, ecc. Dove il Diluoium è molto potente si vede come talora nella serie diluviale, frammezzo ai banchi ciottolosi, ghiaiosi e sabbiosi sianvi pure banchi marnosi, talora argillosi, i quali dànno origine a veli acquei per lo più però poco estesi e poco importanti.

Ad ogni modo nelle sezioni naturali ed artificiali che tagliano la serie alluviale, mentre è piuttosto raro che esistano sorgenti acquee fra gli strati di questa formazione, esse compaiono invece abbondantissime alla sua base tanto che questo fatto serve poi talora come carattere secondario per delimitare il Sahariano dal sottostante Villafranehiano.

Riguardo all'ubertosa pianura lombarda è ben noto come essa debba in gran parte la sua fertilità al sistema d'irrigazione continua fondato essenzialmente sulle sorgenti artificiali perenni o fontanili; esse derivano da una importantissima falda acquea che si estende dal Novarese sino al Friuli e che, mentre è poco profonda lungi dalle Alpi, diventa invece più profonda verso la regione alpina. Orbene, questo fenomeno tanto importante per l'agricoltura della valle padana, credo sia in stretta relazione colla natura, posizione e sviluppo della formazione diluviale.

Fenomeni simili riscontransi pure in diverse regioni del modenese e della pianura piemontese, sia a monte che a valle di Torino, ecc. 
Quanto all'orografia si deve solo notare come il Diluvium costituisca generalmente soltanto regioni pianeggianti che spesso, per le erosioni verificatesi nel periodo terpazziano, sono ora ridotte ad alipiani più o meno ampi e variamente elevati sulla circostante pianura.

Però questi altipiani presentano sempre una pendenza assai sensibile verso il centro della pianura padana, costituendo cosi, quando le erosioni non furono troppo ampie e profonde, bellissime conoidi rentagliformi.

Se alle falde degli Appennini e tra le due Dore in Piemonte questi coni di deiezione furono talmente erosi e srentrati da essere ridotti or a a lembi irregolari, costituenti gli altipiani suddetti, invece nell'alto Piemonte verso Ovest, dore le erosioni acquee furono meno profonde, troviamo ancora talvolta conservate le conoidi foggiate a ren. taglio con pendenza assai forte presso monte, come possiamo verificare assai bene dando un semplice sguardo alle Carte topografiche a linee curve, per cui credo inutile discendere ora a particolari in proposito. Noto solo come in generale la pendenza delle conoidi sahariane sia più forte che quella delle conoidi terraziane, eccetto che trattisi di piccole conoidi locali allo sbocco di rallette alpine.

Stretto ed importantissimo è il nesso esistente fra il Dilucium e l'agricoltura, costituendo esso in gran parte il terreno superficiale e quindi originando in massima parte l'humus, specialmente col suo velo di loss.

Da quanto si è già detto riguardo all'idrografia delle regioni diluviali è facile arguire come esse sovente si presentino un po'aride, e quindi non riducibili a coltivazione pratense, ma piuttosto atte alla coltivazione del frumento e del grano turco; siccome però queste regioni costituiscono spesso altipiani, cosi sui loro nargini a dolce pendio prosperano abbastanza bene le riti. Ma dore il loess es molto argilloso, quindi impermeabile, e molto ricco in sostanze minerali, quiri per fenomeni fisici e chimici risultano regioni ben poco favoreroli all'agricoltura; pur troppo famose a questo riguardo sono le brughiere lombarde e le vaude o barraggie piemontesi; aggiungasi poi ancora che ben sovente nella parte superficiale del loss sahariano si incontrano lenti estese di quelle concrezioni manganesifere e ferrifere ap- 
pellate mürs o gherloun, le quali costituiscono di per sè un vero flagello, direi, per ogni sorta di coltivazione.

Dai depositi di Dituvium si estraggono talora sabbie e ciottoli per costruzione e per pietrisco, quantunque il loro stato di alterazione renda tali materiali generalmente poco durevoli; invece molto piu importante è l'uso che si fa del loss per fabbrica di laterizi.

In cerie regioni le marne argillose del Diluvium si utilizzano come colore grossolano, cioè come terra d'ombra; in altre regioni, come nel biellese, le sabbie del Diluvium presentano talora numerose pagliette d'oro e quindi vengono rimaneggiate per ricerche aurifere.

\section{Terreno morenico.}

Nel Piemonte una parte assai notevole delle formazioni depostesi durante il periodo sahariano entro la regione delle Alpi od allo sbocco delle vallate alpine è dovuto direttamente all'agente glaciale e costituisce il cosidetto terreno morenico o terreno glaciale. Questo deposito è assai meno importante che non il Diluvium, almeno rispetto alla valle padana, scopo precipuo di questo lavoro; quindi mi limiteró su tale riguardo ad osservazioni generali sopra le formazioni moreniche terminali che sono le più interessanti come quelle che ci indicano il maggior sviluppo dei ghiacciai d'ogni vallata alpina e spesso inoltre vengono a formare parte della regione padana innestandosi col Diluvium.

Sono già ben noti ad ogni geologo la struttura, la facies speciale, ecc., delle formazioni moreniche, senza che sia qui più il caso di accennarle; vedremo come il loro sviluppo sia in stretto rapporto colla posizione e coll'importanza della vallata alpina da cui derivano. Esse in generale non presentano regolare stratificazione, ma piuttosto una disposizione irregolare, caotica; non di rado peró assumono una pseudostratificazione, che può anche accentuarsi maggiormente in certe regioni speciali dove gli elementi glaciali, prima di depositarsi, subirono una specie di cernita e quindi ricevettero una parziale disposizione a strati.

La potenza del terreno morenico è variabilissima da luogo a luogo; per lo più appare assai maggiore di quello che sia realmente, perchè questo terreno spesso ammanta come semplice velo terreni antichi e diluviali; talvolta però osservansi accumuli morenici di centinaia di 
metri di spessore, come ad esempio è il caso per la cosidetta Serra d'Ivrea, morena laterale sinistra del ghiacciaio di valle d'Aosta.

Non ha grande importanza l'altimetria del terreno morenico, eccetto che per conoscere la potenza e l'espansione che raggiunse la massa glaciale in ogni valle alpina; sovente si riconosce in tal modo che nelle grandi vallate il pelo del ghiacciaio si elevó di 400 a 500 metri sul fondo roccioso della valle stessa.

Negli elementi rocciosi del terreno morenico hanno una grande preralenza quelli più resistenti, cioè granito, quarzite e serpentina, con grandi diversità al riguardo in rapporto colla costituzione litologica della valle alpina da eui il ghiacciaio è disceso. Già trattando del Dilucium si sono accennati i rapporti che esistono tra esso ed il terreno morenico; cioè che questa formazione si sovrappone a quella diluriale, alla quale fù generalmente graduale passaggio, eccetto là ove per speciali condizioni la massa glaciale avanzantesi sul Dilutium poco prima deposto e quindi incoerente, lo erose alquanto nella parte superficiale.

Ben noti sono gli straordinari sviluppi delle formazioni glaciali nelle Alpi e nelle prealpi della Lombardia, dove esse anzi si avanzano molto nella pianura padana costituendo una serie di collinette cordoniformi, caratteristiche; quelle che si allargano allo sbocco dell'ampia valle del Ticino costituiscono il grande e complicato anfiteatro morenico detto del Lago Maggiore.

Questo sviluppatissimo anfiteatro glaciale non si presenta tanto tipico e regolare come quelli di Irrea e di Rivoli, sia perchè assai largo è lo sbocco della vallata in modo che il ghiacciaio si potè espandere molto ed irregolarmente, sia perchè in tale espansione terminale detto ghiacciaio incontrò numerosi ostacoli in spunteni o colline preesistenti di terreni secondari, eocenici, oligocenici ed anche miocenici, per modo che ne fu impedits il regolare sviluppo, e ne troviamo quindi spesso i depositi sparsi in diverse posizioni; sia infine perchè le erosioni quivi verificatesi nel periodo terrazilano furono molto potenti, vaste ed irregolari per modo che le formazioni glaciali ne rimasero assai smembrate ed irregolarmente incise.

Peró se si considera nel suo complesso l'anfiteatro morenico in questione se ne puó ricostrurre l'assieme unitario e tipico ad amplisismo arco suddiviso in tanti archi o cordoni minori. Vediamo infatti 
la bella morena laterale destra che fiancheggiando (iuterrotta qua e lá) il Mottarone si sviluppa regolare da Corgiago a Ghevio, Invorio, Gattico e Borgoticino, sino a congiungersi colle colline moreniche esterne di Besnate, Sumirago, ecc., ed interne di Golasecca, Vergiate, Casale, ecc., costituendo cosi il complesso apparato frontale dell' anfiteatro. Seguitando la curva vediamo come le colline moreniche frontali vadano poi a congiungersi colla grande ed elevata morena laterale sinistra di Gavirate-Varese, la quale si espande anche alquanto verso Arcisate.

Oltre a queste formazioni più importanti del gran cerchio morenico in esame notiamo esistere numerose ed ampie morene d'ostacolo (di cui è tipo quella di Angera), parecchi bassi cordoni morenici di ritiro (come ad esempio quelli tra Borgoticino ed il Lago Maggiore, quelli di Ranco-Ispra, ecc.), morene insinuate (com e attorno al Mottarone) roccie levigate, striate, solcate, stupendi erratici, specialmente nelle morene laterali e d'ostacolo, ecc. Pure molto interessante e tipico, per quanto piccolo, è l'anfiteatro morenico del lago d'Orta; esso è regolare, con diverse gradinate o meglio cordoni concentrici abbastanza ben conservati anche nella porzione terminale che chiude, superficialmente almeno, il lago d'Orta, colle belle morene laterali di S. MaurizioPogno a destra e di Miasino-Ameno-Gozzano a sinistra. Il tutto è posato o sulle roccie antiche o sul pliocene ed innestasi a Sud col Diluvium come osservasi bene specialmente nei dintorni di Gargallo; anche in questo anfiteatro glaciale esistono morene insinuate, ampie zone di roccie striate e levigate, ece.

In Valsesia i ghiacciai non si svilupparono tanto da raggiungere il termine della vallata, ma si fermarono presso Borgosesia, costruendo la bellissima morena di Cartiglia; questo deposito morenico si appoggia sopra il Diluvium sostituendolo in breve completamente verso monte.

Nelle prealpi biellesi non troviamo residui morenici un po' notevoli, se si eccettui il lembo pseudo-glaciale del Santuario d'Oropa.

E invece ben noto come grandioso, immenso, sia stato lo sviluppo delle masse glaciali della valle d'Aosta per cui esse non solo raggiunsero lo sbocco della vallata alpina ma si spinsero inoltre notevolissimamente sulla pianura padana costruendo cosi l'amplissimo anfiteatro morenico di Ivrea, che è forse il più grandioso degli anfiteatri glaciali 
d'Europa; di esso ebbi già ad occuparmi in un lavoro speciale per cui mi limito ora ad accennarne $\mathrm{i}$ fenomeni principali.

Considerando nel suo assieme l'anfiteatro morenico d'Ivrea vi si possono distinguere tre parti principali, cioè: la tipica, stupenda morena laterale sinistra (la Serra), che si eleva talora di oltre 400 metri sul piano interno dell'anfiteatro; la morena laterale destra Lessolo-Caluso, che però sotto certi aspetti si potrebbe anche considerare in parte come morena frontale; infine l'irregolare morena frontale Caluso-Cavaglià, che si inoltra notevolmente entro il piano interno dell'anfiteatro, sino a Tina ed Albiano, per mezzo di morene medio-frontali od incidenti. Ciascuna di queste parti è poi suddivisibile a sua volta in tanti cordoni morenici irregolarmente concentrici formanti vallette o bacini stretti ma allungatissimi; già trattando del Diluvium si è osservato che in alcuni junti, come in Valle Olobbia e nella forra di Mazze, si reda questa formazione fluviale passante gradualmente nella parte superiore al terreno morenico; uguali transizioni, quasi insensibili, esistono nella parte esterna deli'anfiteatro, per cui ne rimane assai incerta la delimitazione in molti casi.

È noto ai geologi come in diverse località dell'anfiteatro glacialedi Valle d'Aosta si rinvengano numerosi fossili pliocenici, del Piacenziano superiore, commisti a depositi di facies morenica, per cui si dedusse in generale che esistevano in queste regioni veri terreni pliocenici in posto alquanto alterati per l'intervento di fenomeni glaciali; già trattando del pliocene ebbi ad osservare che per diversi motivi credo invece che tali depositi siano semplicemente morenici, sahariani, e che i fossili pliocenici inclusivi derivino da un' erosione superficiale e da un conseguente rimaneggiamento dal Piacenziano superiore; questo fenomeno, semplice in sè, deve essere tenuto in conto perchè con esso si spiegano facilmente diversi fatti che, sia in Italia, sia altrove, per le diverse interpretazioni che ricevettero dai diversi geologi diedero origine a gravi polemiche.

Nella valle dell'Orco la massa glaciale assai potente giunse sino allo sbocco della vallata alpina, quivi deponendo le sue morene terminali, poco potenti, direttamente sulle roccie antiche oppure anche, in certi punti, sopra a lembi diluviali poco prima deposti.

Nella parte alta di Val Malone presso borgata Picat incontransi 
qua e là accumuli ciottoloso-brecciosi, talora a grossi elementi, che paiono doversi riferire in parte all'agente glaciale. Lo stesso dicasi per la valle del Tesso, a monte di Castiglione, dove peró la formazione glaciale si presenta veramente tipica, sebbene non molto sviluppata, e passante gradatamente a quella diluviale, che è profondamente decomposta appunto nelle vicinanze di borgata Castiglione.

In valle di Lanzo, quantunque $\mathrm{i}$ ghiacciai siano stati molto potenti durante il periodo sahariano, tuttavia essi non raggiunsero lo sbocco della vallata ma si arrestarono contro una stretta rocciosa, la forra di S. Ignazio, pochi chilometri a monte di Lanzo; anche in questa regione si possono vedere nel piano Castagna formazioni diluvio-glaciali che passano gradatamente al morenico verso monte ed al Diluvium verso valle.

Giungiamo cosi alla valle di Susa la quale presentỏ un tale sviluppo di ghiacciai nel periodo sahariano, che essi, sboccando dalla valle alpina, si espansero sulla pianura a formare il grandioso anfiteatro morenico di Rivoli che già fu oggetto di una monografia speciale, per cui basterà ricordarne i caratteri essenziali.

In causa dello sprone roccioso Avigliana-Monconi che divise in due la massa glaciale discendente da Val di Susa, l'apparato morenico che ne risultò presenta numerose irregolarità ed anzi potrebbesi distinguere in due anfiteatri diversi: uno piccolo, laterale destro, Avigliana-Trana, ed uno grandissimo Avigliana-Rivoli; se invece vuolsi considerare tutta questa formazione glaciale come costituente un anfiteatro unico, i cordoni morenici di S. Ambrogio-Giaveno-Trana ne costituirebbero la morena laterale destra, quelli di Trana-Reano-Rivoli il grandioso apparato frontale, e quelli di Almese-Casellette-Druent, la inorena laterale sinistra, molto allargata e quindi poco rilevata.

Già trattando del Diluvium si fece notare la netta sottoposizione che in molte località questo terreno presenta rispetto alla formazione glaciale a cui spesso forma graduale passaggio; si osservò pure come passaggi simili osservinsi nella parte esterna dell'anfiteatro, specialmente a Sud della Dora e presso Giaveno.

In causa delle erosioni fatte dalle acque del Sangone nel periodo terraziano una parte della formazione morenica ad Est di Trana venue esportata, e ció che ne rimase venne ricoperto dalle alluvioni terrazziane, come appunto verificossi presso Sangano e Bruino. 
Oltre alle formazioni moreniche esterne principali sono pure notevoli i pseudo cordoni interni sia nel grande sia nel piccolo anfiteatro; specialmente importanti quelli di Trana e di Arigliana per aver dato origine a conche lacustri e torbose.

Nella valle del Sangone incontransi lembi di formazioni glaciali solo a monte di Coazze, nei dintorni di Forno, ma esse non sono molto tipiche.

Risalendo la valle del Chisone veggonsi comparire i depositi morenici subito a monte di Villar Perosa costituendo essi le colline di Ciappelle presso Dubbione (dove si spingono sino ai 700 metri di elevazione formando anche una vera morena insinuata), di Pinasca, ecc. Stupenda è la morena di sbarramento di Perosa.

A Villar Perosa si può osservare la solita zona di terreno fluvioglaciale; inoltre in queste regioni presso Villar Perosa, presso i Saret e più a morte sotto borgata Bernardi si veggono comparire, in alcuni tagli naturali, speciali banchi marnoso-argillosi giallastri o bleuastri, i quali a primo tratto ricordano i depositi piacenziani o certi terreni oillafranchiani entroalpini (Leffe, Lanzo, ecc.); io credo peró che si tratti qui soltanto di un deposito sahariano collegato probabilmente colla formazione delle morene di fondo o con fenomeni lacustro-glaciali, perchè questi depositi sono in parte straterellati e talora leggermente inclinati a Nord.

Nella Valle Pellice la massa glaciale si spinse sin quasi a Torre Pellice; incomincia infatti ad osservarsi qualche erratico gneissico-granitico presso S. Margherita, specialmente ai Coppini; troviamo poi poco più a monte il terreno morenico ben sviluppato, quantunque in parte rimaneggiato superiormente dalle acque terpasiane e talora difficilmente distinguibile dai depositi franosi formatisi pure in periodo terraziano.

La valle alpina del Po malgrado la sua importanza non diede ricetto, durante il Sahariano, ad una massa glaciale tanto sriluppata da giungere sino alla p:anura; infatti devesi rimontare la vallata per molti chilometri senza trovare nette traccie glaciali, finchè presso Croesio incominciansi ad osservare depositi a grossi elementi angolosi che peró non sono ancora veramente glaciali; ma già prima di giungere a Paesana il piano ondulato di borgata Allemagna ed i ciottoloni 
che vi si veggono sparsi ci indicano esistere quivi un deposito morenico, forse però già alquanto rimaneggiato dalle acque terrazziane.

Subito a monte di Paesana il terreno glaciale si presenta assolutamente tipico, ondulato, potente, a ciottoli talora di oltre 2 metri di diametro, insomma colla sua facies caratteristica; solo che le potentissime erosioni terraziane ne esportarono una parte grandissima, lasciando soltanto come residuo la terrazza o altipiano ondulato di Paesarla-Ghisola, sulla sinistra della valle.

In causa della ristrettezza della Valle Varaita si è già notato non esistervi importanti residui sahariani diluviali; lo stesso deve dirsi per i depositi glaciali; probabilmente il ghiacciaio di questa valle giunse sin presso a Brossasco, poichè quivi osservansi numerosi ciottoloni ad elementi angolosi (ciò che pure notasi lungo i pendii di Cabella), quantunque veri depositi morenici non si possano indicare sin quasi a Sampeyre.

La Val Maira che ci presenta un Diluvium tanto tipico, ebbe il suo ghiacciaio che si spinse sino a S. Damiano; è quivi infatti che vediarso come alie formazicni diluviali si sovrappongano e si innestino con graduale passaggio i depositi a grossi elementi irregolari che rappresentano il terreno morenico; anche a valle di S. Damiano osservansi numerosi ciottoloni sparsi qua e là alla superficie del terreno; na essi, se originariamente glaciali, furono già probabilménte trasportati e rimaneggiati dalle acque terrazziane e quindi non servono per darci precisi ragguagli sulla formazione glaciale.

Anche la Val Grana, per quanto piccola, ebbe il suo ghiacciaio assai potente e sviluppato; infatti già presso il cimitero di Monterosso trovansi erranti del diametro di cinque metri; vedesi poi la formazione morenica, quantunque non perfettamente tipica, ma un po' diluvio-brecciosa, sotto il borgo di Levata di S. Pietro, dove le formazioni glaciali si confondono con quelle diluviali della valletta laterale di destra.

Sviluppatissimo fu il ghiacciaio che durante il periodo sahariano occupó la valle della Stura di Cuneo; esso infatti nel periodo di massimo sviluppo si spinse sino alla pianura padana terminando però quivi in lingua per modo che i suoi depositi frontali sono poco elevati; inoltre tali depositi furono in parte rimaneggiati dalle correnti acquee sul 
principio del periodo terraziano per modo che ora ne rimangono solo più traccie, non sempre ben chiare, tra la Beguda ed il Ponte dell'Olla.

Ma subito a monte di Gaiola, sopra alle formazioni del Diluoium vediamo una bellissima collinetta costituita di tipico deposito glaciale ad enormi ciottoloni; essa ci rappresenta veramente il residuo più completo, per quanto piccolo, della morena frontale del ghiacciaio di Valle Stura, corrispondendo in età al rero periodo degli anfiteatri morenici; più a monte $\mathrm{i}$ depositi morenici sono assai comuni e sviluppati su ambi i lati della valle alpina.

Tra Mojola e Demonte il terreno glaciale abbastanza ben conservato sulla sinistra della valle si presenta cementato, un po' breccioso ricordando alquanto il Diluvium; ma se ne distingue per presentare enormi ciottoloni spesso a spigoli ben conservati.

Risalendo la valle del Gesso si trovano depositi alluvio-brecciosi, pseudo morenici, allo sbocco di Val Madonna della Bruna; pare però che il ghiacciaio siasi soffermato a monte della forra rocciosa di C.ma dei Gros: ne troviamo sicure traccie presso Andomo, dove i ciottoloni diluvio-glaciali sono commisti a voluminosi frammenti rocciosi, specialmente granitici, di tipo morenico; tali depositi ritroviamo poi anche sulla destra della valle a monte di borgata Colombara, e quindi in lembi più o meno ampi in tutto il resto della vallata; talora il terreno morenico è mascherato da alluvioni o frane terraziane.

Nella Valle Vermenagna, siccome stretta e percorsa durante il periodo terraziáno da fiumane impetuose, mancano quasi completamente $\mathrm{i}$ depositi sahariani nella parte bassa della vallata alpina; ritroviamo scarsi ed incerti residui glaciali presso Vernante e Tetti Blangèr; è solo a Limone che la formazione morenica assume una facies più caratteristica. Cosi pure in Val Pesio nnn trovansi netti residui morenici che molto in alto; solo presso S. Bartolomeo esistono accumuli che potrebbero in parte avere origine glaciale; da S. Anna all'altipiano di Tetto nuovo veggonsi sparsi irregolarmente fra le sabbie argillose gialle numerosi ciottoloni con apparenza morenica, se pure essi non rappresentano il Diluvium di Val Grosso. Lo stesso dicasi per la valle dell'Ellero e della Corsaglia che soltanto molto a monte presentano scarsi residui slaciali. 
Nella valle del Tanaro, per la sua ampiezza ed importanza, potè costituirsi un vero ghiacciaio abbastanza sviluppato, il quale discese sin oltre Garessio; infatti se $\mathrm{i}$ depositi diluvio-brecciosi che veggonsi presso Mursecco e Piangrande credo siano piuttosto coni di deiezione delle vallate laterali, al cui sboceo si trovano, che non formazioni glaciali; invece sul rilievo di talcoscisto e eloritoscisto che esiste presso borgata Garberini osservansi numerosi ciottoloni, specialmente anagenitici, lisciati, del diametro talora di quosi 3 metri, sparsi irregolarmente e che hanno completamente la facies di ciottoli morenici. Credo quindi si debba ritenere che il ghiacciaio di Val Tanaro, dopo sorpassata la forra rocciosa di Garessio, si allargò sulla pianura di borgata Ponte deponendo cosi la sua morena frontale contro lo sprone roccioso dei Garbarini; ma le potenti correnti acquee del periodo terrazziano esportarono in gran parte questi depositi, rimanendone solo più pochi residui in certi seni rocciosi.

Nella restante parte orientale della catena montuosa che circonda il Piemonte a mezzogiorno non notansi depositi morerici degni di particolare menzione, specialmente perche alcuni accumuli brecciosi, che parrebbero doversi attribuire all' azione glaciale, sono probabilmente prodotti da correnti acquee o da altri fenomeni.

Passiamo ora ad alcune osservazioni d'indole applicata che si possono fare sul terreno morenico: sotto il rispetto dell'idrografia dobbiamo notare come in generale questa formazione, per essere in parte marnoso-argillosa, per quanto impastata con elementi ciottolosi grossolani, si mostri piuttosto impermeabile, tanto piu quando trattasi di morena di fondo che è più argillosa e più compatta; ne deriva quindi che le conche moreniche quasi sempre si trasformano in conche lacustri e poscia in torbiere; assai rare sono le sorgenti acquee nel terreno glaciale, ma nello stesso tempo questo terreno conserva una certa umidità; invece le sorgenti divengono quasi sempre frequenti ed abbondanti alla base dei depositi morenici, specialmenta là dove sotto al terreno glaciale appare il Diluvium.

Caratteristica è l'orografia dei terreni morenici in causa del costituire essi quasi sempre regioni piu o meno fortemente ondulate, collinose, un po' labirintiche nei particolari ma disposte secondo una legge generale abbastanza regolare, quando osservate nel complesso; 
sovente anzi è la stessa orografia, il paesaggio, ciò che serve a distinguere a primo tratto una regione morenica da una regione diluviale od alluviale.

Per la sua configurazione collinosa e per la sua natura litologica il terreno glaciale è generalmente molto atto alla coltivazione della vite e degli alberi da frutta, specialmente in certe regioni speciali; $\dot{e}$ poi notevole come entro le vallate alpine, ed in generale nelle regioni rocciose, i lembi glaciali si distinguano quasi sempre da lungi per la rigogliosa vegetazione a cui dànno ricetto, mentre nelle vicinanze fanno contrasto le aride regioni ove la roccia è quasi allo scoperto, perciò le formazioni glaciali costituiscono un elemento importantissimo per l'agricoltura e quindi per la prosperità delle vallate alpine.

Nella costruzione di strade, trincee, gallerie, ecc,, entro i terreni morenici devesi tener conto specialmente della natura spesso argillosa, quindi facilmente fangosa e per conseguenza instabile, che talora essi presentano; in modo speciale ciò è a considerarsi quando tali opere debbonsi eseguire lungo i pendii della rallata là dove le morene formano soltanto placche sulla roccia in posto; si comprende come tali depositi pcissano facilmente scorrere sulla superficie rocciosa tanto più che questa fu già quasi sempre levigata dall'agente glaciale prima della deposizione della morena.

Dei materiali costituenti i terreni glaciali si utilizzano sorente gli erranti perchè in generale sono formati da roccie cristalline poco alterate e quindi atte per costruzione ed anche per pietra ornamentale; anzi sgraziatamente tale lato utilitario che presentano gli erranti fa si che a poco a poco essi vadano scomparendo, e sarebbe quindi il caso che in un modo qualsiasi venissero protetti alcuni di questi tipici residui di un fenomeno geologico cosi grandioso qual è stato lo sviluppo glaciale del periodo sahariano. Inoltre certe sabbie e certe argille glaciali vengono pure utilizzate sia come materiale da costruzione, sia come materiale da laterizi; i ciottoli talora servono per pietrisco.

\section{Terrazziano.}

Esaminando le formazioni diluviali si è gia notato come in parecchie regioni, specialmente presso le falde alpine il fenomeno del 
terrazzamento siasi talora iniziato giả sulla fine del periodo sahariano; ma tale fenomeno grandioso, generale, caratteristico, si verificò su ampia scala soltanto durante il periodo seguente che credetti quindi opportuno appellare terraziano.

Orbene dalla natura stessa del fenomeno del terrazzamento è facile arguire: anzitutto come non sia facile il distinguere le formazioni terrazziane più antiche da quelle sahariane più recenti, quando si verificò regolarmente la successione del fenomeno di terrazzamento; ed inoltre come i depositi terrazziani si possano suddividere in molte età diverse a seconda del numero delle terrazze, ed infine come, variando moltissimo da regione a regione tale numero, non si possa partire da un criterio unico generale per suddividere queste formazioni terrazziane in sottopiani diversi.

E perciò che io credo di dover trattare in generale dei depositi terrazziani come costituenti una formazione unica, salvo ad accennarne le suddivisioni principali là dove esse si presentano un po'importanti. Generalmente queste formazıoni alluviali vennero finora trascurate dai geologi che le considerarono di poca importanza; solo vennero esaminati accuratamente alcuni depositi torbosi perchè utilizzabili, o perchè fossiliferi.

In complesso le formazioni terrazziane sono alluvioni ciottolose, ghiaiose e sabbiose, alquanto stratificate, non molto potenti dello spessore soltanto di 2 o 3 metri, talora peró assai maggiore, con spessore abbastanza costante per estensioni assai grindi, talora con interstrati marnosi; quasi sempre esse sono poi coperte da un velo di loss che ê generalmente più sottile, meno argilloso, meno compatto, più giallastro e meno alterato di quello ricoprente il Diluvium.

I depositi terrazziani sono in generale meno profondamente decomposti di quelli sahariani perchè più recenti e quindi da meno tempo esposti agli agenti esterni; però rarissimamente incontransi fra di essi quei banchi conglomeratici che talora veggonsi far parte del Diluvium sahariano di certe regioni, specialmente subalpine ed entroalpine.

Il colore di questi terreni è per lo più il giallastro-terroso; più rara è la tinta rossiccia tanto comune invece nei depositi diluviali.

Se la fauna e la flora terrazziana sono molto simili a quelle attuali, ed è quindi inutile di trattarne qui, solo è ad indicarsi come i resti 
fossili, consistenti specialmente in molluschi terrestri e lacustri, incontrinsi quasi solo nel loess e negli strati argillosi dei depositi torbiferi, come ad esempio presso Trana.

La distribuzione geografica dei terreni terrazziani è in strettissimo rapporto colla idrografia superficiale, trattandosi di formazioni deposte unicamente dalle correnti acquee nei loro vari periodi di rac. coglimento lungo una zona sempre più stretta.

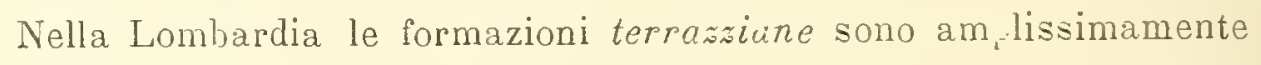
rappresentate, poichè, eccettuati i depositi glaciali e diluviali che esistono presso le falde alpine, esse occupano l'intiera pianura lombarda; presso monte questi depositi possonsi distinguere, a secondo dei livelli che occupano, in varie età; invece verso il centro della pianura esse costituiscono quasi un solo piano. Tuttavia vi si può fare talora una distinzione fondandoci sulla natura loro; infatii presso le falde alpine e per molti chilometri verso valle il Terraziano è di natura ghiaiosociottolosa, grossolana; invece verso il centro del piano lombardo tale alluvione diventa naturalmente sempre più fine, più minuta, cioè sabbioso-argillosa con straterelli ghiaiosi, ecc.; non credo tuttavia che solo su questo criterio si possa fondare una distinzione scientifica del Terraziano lombardo.

A Suci del Lago Maggiore molto ampia è la zona terazziana tra i depositi diluviali e morenici rispettati dall'erosione del Ticino; tale zona si va rapidamente allargando verso il bassopiano, collegandosi con quelle della vicina vallałà ed estendendosi poi per quasi tutta la pianura.

Fra mezzo alle formazioni glaciali del grande anfiteatro morenico del Lago Maggiore sono molto sviluppati i depositi terraziani antichi e recenti sia attorno ai laghetti, sia nelle valli esistenti tra i cordoni morenici, sia lungo il Ticino; talora essi troransi a diversi livelli indicandoci i diversi periodi di erosione od anche i diversi periodi di regresso del ghiacciaio, corrispondendo cio a varie altezze e larghezze dei laghi intermorenici; un bell'esempio di ciò osservasi tra Borgoticino ed il Lago Maggiore per la presenza di quattro piani gradinati, cioè quello degli Asseri (m. 250 circa), quello di C. dei Preti (m. 230 circa), quello di Cartiera Conelli (m. 205 circa), e quello littoraneo (m. 197 circa).

A Sud dell'anfiteatro del Lago Maggiore esistono bellissimi residui 
di Terraziano antico, collegantisi insensibilmente col Diluvium sahariano a cui altri petrebbe forse attribuirli, cosi il lungo e stretto altipiano di Gallarate-Cardano-Ferno-Lonate Pozzolo, sulla sinistra del Ticino, e sulla destra un altipiano ancor piủ importante cioè quello di Pombia-Oleggio-Bellinzago-Codemonte Abbadia di Dulzago-FornaciSuno-Cressa, ecc. Quésto amplissimo altipiano terrazziano è poi anche importante, poichè, per quanto esso sia stato sbrecciato dalle acque del T.Terdoppio, ad esso si collega l’altipiano allungato di Novara-Vespolate. Tutti questi altipiani sono costituiti di formazioni diluviali sahariane, coperte da depositi terrazziani, e quindi non possonsi indicare quali altipiani sahariani come rarrebbe a primo tratto; per convincerci di cio basta risalire la pianura verso monte ed osservare come tra l'altipiano di Pombia (a cui corrisponde perfettamente quello di Novara) ed il vicino altipiano di tipico Diluvilm sahariano di Divignano-MottoTensa siavi una differenza altimetrica di quasi 50 metri per l'erosione verificatasi all'iniziarsi del Terrazziano. Notisi come questo piano di Pombia trovisi elevato di circa 100 metri sull'attuale livello del Lago Maggiore, ciò che ci prova i grandi mutamenti idrografici compiutisi gradatamente in queste regioni.

Altipiani amplissimi appartenenti al Terrazziano medio sono quelli di Busto Arsizio, Cuggiono, ecc., a sinistra del Ticino, e di Cameri, Galliate, Trecate, ecc., sulla sua destra. Da questi altipiani vastissimi si passa poi più o meno gradatamente, per mezzo di varie gradinate, sino alle alluvioni attuali; la valle del Ticino presenta esempi bellissimi di tali gradinate successive, specialmente fra lo sbocco del Lago Maggiore e Marano-Vizzola

A Sud dell' anfiteatro morenico del lago d'Orta sono poco sviluppate le formazioni terraziane antiche; le troviamo però negli altipiani dell'Oratorio di Auressa, di C. Ghiacciaia-C. Geola e specialmente nell'ampio altipiano di Suno-Castelletto, che va a congiungersi con quello sopracitato del Ticino.

L̀ poi interessante osservare il grande sviluppo delle formazioni terraziane dei dintorni di Gozzano, indipendentemente cioè da quelle depositate dalle correnti acquee dell'Agogna, giacchè ciò ci prova come non solo durante tutto il periodo sahariano ma anche durante la prima metà del periodo terraziano le acque del lago d'Orta, elevate circa 
60 metri più che non oggi, in parte fluissero a Sud attraverso le colline moreniche di Buccione.

In Valsesia osserviamo fenomeni consimili; cioè entro la valle alpina le formazioni terraziane, di forma irregolarissima, sono abbastanza estese e costituiscono altipiani troncati, verso l'asse della ralle, da un terrazzo assai spiccato; quivi si possono distinguere vari crdini di terrazzi per cui si passa gradatamente dalle formazioni terraziiane, abbastanza antiche, all'alluvione recente, senza che sia sempre facile il distinguere l'una formazione dall'altra poiche si succedettero sovente senza salti.

Appena fuori della valle alpina veggonsi le zone terraz:iane allargarsi estesissimamente; una stupenda zona di Terraziano molto antico, cioe depostosi sull inizio affatto del periodo in esame, si estende tra la Sesia ed il Cervo, dalle falde alpine sin quasi ad Albano Vercellese, costituendo l'amplissimo altipiano di Roasenda; si potrebbe forse supporre che si tratti qui ancora di Diluvium, ma i rapporti che detta zona presenta sia coi depositi pliocenici subalpini, sia coi tipici altipiani diluriali di Romagnano ad Est e di Cossato e Villanuova ad Ovest, mi fa piuttosto inclinare a pcrre già questo terreno nel Terraziziano antico. Per la difficoltà di comparazione di questi terreni fra regioni lontane non sarebbe peró impossibile che altrove, per esempio nell'alto Piemonte, sianc state da me inglobate nel Diluvium recenti formazioni depostesi contemporaneamente a quelle qui foste nel Terrazziano antico.

Oltre a questa grande zona terraziana antica di Roasenda osservansi lungo la Sesia numerose altre zone terraziane più recenti ché, per mezzo di diverse terrazze, vanno poi infine a confondersi coll'Alluvium; nel complesso queste formazioni si possono considerare coma appartenenti alla seconda fase del periodo terraziano e costituiscono una zona amplissima che si allarga a ventaglio da monte a valle indicandoci come sia siato graduale il restringersi delle correnti acquee dal principio alla fine del periodo terraziano.

Nel Biellese possiamo constatare fenomeni molto simili a quelli scpra accennati riguardo alla divisione delle formazioni terrazziane, cioè possiamo pure distinguerle in antiche e recenti. Quelle antiche (Terraziano $I$ ) si spingono sino alle falde alpine, essendotalora separate all' attual basso piano delle valli per mezzo di un terrazzo spiccatis- 
simo, come è quello di Biella-Candelo; invece verso valle l'altipiano di questo Terrazziano antico si va sempre piu abbassando sin quasi a confondersi colle alluvioni recenti; questo ci prova sempre piu quanto siano difficili e spesso arbitrarie in certe regioni quelle distinzioni che altrove sono facili e ben nette.

Un fatto importantissimo che ci indicano le formazioni del Terracziano del biellese è che sin verso la metà di questo periodo geologico la fiumana del Cervo, sboccando dalla valle a!pina, si univa a quella dell'Elvo, gettandosi direttamente a Sud e rispettando cosi l' altipiano diluviale di Candelo-Villanuova; è solo nella seconda metà del periodo Terraziano che le acque del Cervo deviarono ad Est scavandosi profondamente il loro alveo attuale tra le colline plioceniche di Cerreto e l'altipiano di Candelo; nel periodo di transizione tra i due cosi diversi regimi idrografici sovraccennati, una parte delle acque del Cervo incise la vallata Candelo-Benna, ecc., deponendovi un'alluvione terrazziana formante passaggio tra quella antica e quella recente.

Le alluvioni terrazziane del secondo periodo sono relativamente meno sviluppate che non quelle del primo, con cui però quasi si confindono verso il centro della pianura padana; anch'esse, come di solito, passano gradatamente alle alluvioni attuali per mezzo di ripetute e sempre più basse terrazze.

Rispetto ai terreni terrazziani depositati dalle acque sboccanti dalla valle d'Aosta esse ci presentano fenomeni speciali in rapporto coll'anfiteatro morenico d'Ivrea; infatti detto grandioso anfiteatro cangiossi nel periodo terrazziano in amplissimo bacino lacustre, quindi depositi, in gran parte melmosi, allora formatisi in esso assunsero un aspetto alquanto diverso dal solito e servirono in gran parte a riem piere il fon to di questa conca lacustre; ma in certe speciali regioni presso le falde moreniche si dovettero naturalmente depositare, sulle sponde di questo gran lago, alluvioni littoranee spesso a struttura deltoide, per lo piu ghiaioso-ciottolose, ma talor anche sabbioso-argillose; è in tal modo che io credo debbansi interpretare certi depositi che trovansi sopra i i terreni morenici tra Strambino, Caluso e Mr ncrivello.

Il piccolo sviluppo apparente delle formazioni ter razziane antiche entro l'ambito dell'anfiteatro glaciale è dovuto in parte a mascheramento per opera delle alluvioni posteriori ed in parte ad erosione per opera delle correnti acquee. 
Le acque che uscivano dall' ampio lago d'Ivrea sul principio del periodo terraziano, non essendo ancora stata incisa la forra di Mazzè, sboccavano da varie parti ampiamente, in particolar modo durante i periodi di piena; perció i bassi colli di Cavaglià e di Mazzè dovettero in diversi punti servire di canale scolatore alle acque lacustri straboccanti; queste quindi si espanderano sulla sottostante pianura diluviale di Santhià-Cigliano, ricoprendola con un sottile velo di alluvione, piuttosto fine, terrasiana, ed anche erodendo alquanto superficialmente il Diluvium, come ci dimostra chiaramente la terrazza di S. Quirico-C. Chiappine. In questo modo il Terrazziano antico di Talle d'Aosta si collega con quello contemporaneo del Cervo e dell'Elvo, quantunque sia di natura e di potenza assai diversa in causa del modo di origine alquanto diverso.

Quanto alle formazioni terraziane più recenti che collegansi gradualmente colle alluvioni attuali esse si presentano sviluppatissime entro l'anfiteatro morenico d'Ivrea, dove sono rappresentate essenzialmente da depositi anche abbastanza potenti, marnoso-argillosi, cioè da fanghiglia stata deposta sul fondo del lago che andava man mano abjas sandosi e restringendosi, sino a ridursi alle attuali piccole conche di Candia e di Viverone. Viceversa fuori della cerchia morenica le formazioni terraziane del secondo periodo sono piuttosto ghiaioso-ciottolose e poco sviluppate perchè la Dora Baltea, incisa poco a pocola forra di Mazzè, intaccò pure profondamente la regione pianeggiante che si estendeva a Sud, senza divagare molto lateralmente.

Anche rispetto ai depositi terrasiani dell'Orco si può fare lá suddetta divisione in due categorie rispetto all'età di loro formazione, quantunque tale divisione risulti spesso assai incerta; infatti la bella terrazza che dalle vicilanze di Cuorgnè si estende per Rivarolo, Feletto, ecc., sin molto verso Sud, limita assai bene il Terrazziano antico della destra dell' Orco; sulla sinistra ne troviamo pure la delimitazione abbastanza chiara tra Montanaro e Caluso; ma se poi cerchiamo di segnare i confini di questa zona verso S. Benigno e verso Orest, cadiamo in delimitazioni un po' troppo arbitrarie, appunto per il passaggio, spesso insensibule, esistente fra le varie formazioni terpaziane sino alle alluvioni attuali.

Le alluvioni terraziane depostesi durante il secondo periodo sono 
piuttosto ampie, divisibili in parecchie zone subparallele, corrispondenti a diverse linee di terrazzamento, più o meno continue.

Prima però di lasciare il Terrazziano antico dell' Orco è opportuno d'aggiungere come sul suo lato sinistro esso si colleghi presso Chivasso con quello della Dora Baltea; tale terreno è limitato a Sud da una terrazza abbastanza netta costrutta dalle acque del Po, terrazza che da Chivasso passa per Castelrosso e Verolengo, prolungandosi sino a Calciavacca; dopo un' ampia interruzione, causata dalia erosione della Dora Baltea, la terrazza divisoria tra Terraziano antico a monte e Terraziiano reeente a valle, riappare presso Cerrone; quindi con andamento irregolarmente ondulato e con frequenti interruzioni, causate da corsi d'açua secondari, esso si sviluppa verso Est per S. Grisante, Ramezzena, Robella, Rive, Stroppiana, ecc., sino a raggiungere la terrazza detta della Sesia. La terrazza ora accennata è importante come quella che ci delimita nettamente l'ampiezza del Po durante la seconda metà del periodo terrazziann.

Anche rispetto alle alluvioni state deposte dalla Stura di Lanzo nel periodo terrazziano sulla pianura padana si potrebbero fare diverse distinzioni di età, prendendo per base le varie terrazze che osservansi sia a destra sia a sinistra del corso della Stura; ma siccome esse sono spesso interrotte e vanno scomparendo verso valle, cosi non credo opportuno di scendere qui all'esame loro; basterà accennare in generale alla forma triangolare che presenta nel complesso la zona terrazziana, ciỏ che ci indica un graduale e continuo restringersi delle correnti acquee durante il periodo terrazziano; verso valle le alluvioni terrazziane della Stura si uniscono insensibilmente con quelle del Po e delle correnti acquee vicine, fra cui specialmente interessante è quella della Ceronda; in queste regioni, come altrove, tra il Terraぇ̃aiano antico (che in alcuni lavori appellai pseudo-diluoium) e le alluvioni recenti vi è quasi sempre una serie di depositi intermedi segnati da divcrse terrazze, piủ o meno numerose secondo le località.

Nell' interno dell' anfiteatro morenico di Val Susa osservansi, riguardo al Terrazziano, fenomeni alquanto simili a quelli già indicati per l'anfiteatro d'Ivrea; cioè i depositi terraziani hanno una facies essenzialmente lacustre; quelli antichi sono in massima parte ricoperti dai più recenti, ed è quasi solo con tagli artificiali che si possono 
mettere a giorno lembi di Terrazziano antico spesso a struttura deltoide, come ad esempio ebbi ad csservare in una profonda frana presso il lago piccolo di Avigliana. Ma l'ampia regione pianeggiante dell'interno dell'anfiteatro di Rivoli è riferibile al Terraziano del secondo periodo, formante per ln più graduale passaggio alle alluvioni attuali.

Fuori di quest' anfiteatro, verso Est, il Terrazziano si presenta a numerosi livelli, formando una serie completa dai depositi più antichi a quelli più recenti; ma essi sono ben-poco sviluppati in ampiezza, perchè la Dora Riparia incise profondamente il suo alreo senza diragare molto, nè a destra, nè a sinistra, escavando solo in limiti assai stretti; ciò dipende dalla forte pendenza della regione su cui ébbe a correre la Dora, ma specialmente dal fatto (comune con quanto si osservò per la Dora Baltea) che per la strettezza della forra di Alpi. gnano-Pianezza la corrente acquea, obbligata a restringersi, acquistò una maggiore velocità e quindi una grande forza erosiva. L̀ solo presso le culline torinesi che il Terraziano della Dora Riparia si unisce con quello del Po.

Debbo ancora notare, riguardo ai terreni quaternari di Tal Susa come la linea di terrazze abbastanza regolari che separa il terreno morenico da quello diluviale, a Nord della Dora, credo sia spiegabile supponendo che verso la fine del periodo sahariano, se pure non già all'aurora del Terraziano, la fiumana di Val Susa, sboccaudo dal bacino lacustre presso Pianezza per un po' di tempo si allargò verso Nord: Est, cioè verso la Veneria, forse erodendo leggerissimamente il Dilucium; molto minore è stata l'espansione della fiumana sulla destra della Dora, tant' è che vennero conservate le colline sabbiose di Grugliasco. Cioè si dovette verificare qui qualche cosa di simile a quanto abbiamo visto essere arvenuto nella parte esterna dell'anfiteatro d'Irrea.

Entro la valle alpina del Sangone, ad Ovest di Trana, osservansi, i soliti graduali passaggi tra il Diluvium ed il Terraziano antico, fra questo e quello recente, sino a giungere alle alluvioni che si vanno deponendo al giorno d’oggi.

Ma a Sud delle formazioni glaciali e diluviali della Dora Riparia noi possiamo constatare che quasi iutta l'alta valle padana, sin contro le Alpi Marittime orientali, è coperta solo da alluvioni terrazsiane, 
poichè durante il periodo terrazziano quivi le correnti acquee sboccanti dalla cerchia alpina erano ancora molto espanse e si collegavano fra loro in modo che le formazioni diluviali sahariane vennero quasi completamente erose alla superficie e riccpertc da depositi terrazziani. Anzi questo fenomeno di allargamento delle correnti acquee sull'alta valle padana non si verificò solo durante il principio del periodo terrażiano, ma continuó ancora sin quasi alla fine, tant' è che grandi allagamenti ed espansioni delle acque di questa regione si verificarono ancora nel periodo storico; d'altronde di ciò è poi anche prova manifesta la poca profondità che hanno in generale gli alvei attuali dei corsi d'acqua che solcano l'alta valle padana dal lato occidentale.

Quindi mentre in complesso parrebbe dovcrsi specialmente inglobarc nel Terraziano antico le alluvioni che coprono gran parte dell'alta valle padana, con un esame minuto delle cose si trova sovente che le alluvioni quivi depostesi nella prima metà del periodo terrazziano furono in seguito erose o coperte da altre alluvioni durante la seconda metà di tale periodo; in ogni caso vi è quasi sempre passaggio graduatissimo tra le alluvioni terrasiane e quelle recenti.

Non credo sia il caso di esaminare ora singolarmente le varie regioni corrispondenti ad ogni vallata alpina, tanto piu che quasi subito fuori della regione montuosa tutte queste alluvioni di origine diversa si confondono assieme nella pianura, poichè originariamente le correnti acquee si collegavanoassieme quasi appena sboccate dalla rispettiva valle alpina; noto soltanto come l'esame della natura dei ciottoli costituenti queste alluvioni terrasiane serva talora per guidarci a conoscere i cangiamenti che avvennero nell' andamento delle correnti acquee dal periodo terrazziano al giorno d'oggi.

Fra le terrazze notiamo come più interessanti: sulla sinistra del Chisone quella di Riaglietto-Pinerolo-Riva-Baudi, ccc.; sulia sua destra quella di C. Bima-Osasco, ecc. Riguardo al Pellice possonsi notare diverse terrazze specialmentc entro la valle alpina tra Torre Pellice e Bricherasio, anzi non è sempre facile distinguervi il Terraziano antico dal Diluvium stato deposto sulla fine del Sahariano.

Nella pianura tra Cavour e Saluzzo è solo da poco tempo che le acque si raccolsero negli attuali loro alvei; sono ben note al riguardo 
le opere di prosciugamento e di risanamento eseguite dall'uomo in queste regioni.

Molto sviluppata e più volte terrazzata è la formazione terraziana nella valle del Po sin quasi a Paesana.

A Sud di Saluzzo vediamo che la pianura padana invece di presentare una pendenza regolare dalle Alpi verso il centro della pianura stessa, inclina invece assai nettamente nel suo assieme verso Nord o Nord-Nord-Est il che dipende dalla direzione che quivi ebbero le correnti acquee, non solo durante il Sahariano, ma anche durante il Terraz:iano; tant' è che per questa speciale direzione le acque erosero quivi quasi completamente le formazioni diluviali subalpine. Questo fatto possiamo verificarlo non solo per il Terraziano subalpino della Varaita, ma anche, in minor grado, in quello della Maira, che presenta la parte sinistra della sua conoide pendente a Nord-Ovest.

Ancora riguardo alla Maira è a notarsı la bellissima terrazza che trovasi sulla sua sinistra da Dronero passando per S. Mauro, Busca, S. Bernardo, ecc. Questa terrazza delimita a Nord una regione di Terraz:iano antico. Notiamo ancora rispetto alle acque della Maira come esse durante l'epoca terraziana si incidessero un alveo molto profondo per modo che qui si ripetono in parte i fenomeni già osservati per le due Dore e che vedremo ripetersi per la Stura e per altri corsi d'acqua piu a Sud.

La Stura di Cuneo presenta fenomeni veramente tipici, rispetto al terrazzamento, in quasi tulto il suo percorso; sulla pianura è sviluppatissimo il Terraziano antico, ricoprente direttamente il Dilívium sahariano; nel profondissimo alveo del filme osservasi sovente una bellissima serie di terrazze che formano un passaggio quasi insensibile dal Terraziano antico alle alluvioni recenti; tipiche affatto per questi studi sono le vicinanze di Fossano specialmente la sponda destra della Stura. Fenomeni consimili osservansi pure nella valle del Gesso specialmente nel breve suo percorso sulla pianura.

Ciò che è molto notevole, riguardo alla fiumana del Gesso, è che originariamente essa, sboccando dalla valle alpina, si doveva gettare a Nord-Est, come lo prova chiarissimamente l'inclinazione che in tal senso presenta il suo cono di deiezione; la suddetta direzione si conservó d'altronde ancora durante la prima metà del periodo terrazsiano e ne 
risultò l'ampio alveo, ora quasi asciutto, divi lente l'altipiano del Banale da quello di Piambosco.

Il Pesio presenta un grande sviluppo di Terraziano antico che ra ad unirsi e confondersi a Nord con quello del Gesso; si è già notato altrove come le alluvioni coprenti l'altipiano di Pianfei potrebbero forse riferirsi a depositi formatisi sulla fine del Sahariano; ma la questione in fondo non ha grande importanza.

Riguardo all' Ellero si incontrano gli stessi dubbi nell' esame dell'altipiano di S. Luigi-Merlo-Avagnina, ma quivi le diverse terrazze che osservansi fanno comprendere meglio il passaggio dal Diluvium sahariano alle alluvioni del Terraziano antico; queste alluvioni poi si allargano estesissimamente verso Nord in modo da costituire i grandi pianori di Breolungi, di Riofreddo, ecc., sino a contondersi con quelli antichi del Tanaro.

In Val Tanars le all uvioni terraziane antiche sono relativamente molto sviluppate in generale entro monte; lungo il percorso attraverso alle colline terziarie si trovano peró numerosi altipiani terrazziani, spesso isolati, irregolarissimi, su ambi i lati del fiume, indicandocene cosi l'antica ampiezza.

Ma a Nord di Bastia il Terraziano antico del Tanaro si allarga estesissimamente; sulla destra esso presenta numerosi residui presso San Bartolomeo, Clavesana, Farigliano, Dogliani, Bergero, ecc., sulla sinistra poi costituisce amplissimi altipiani, come quello di Carrù, di Piozzo, di Lequio, di Narzole, di Cherasco, ecc.

Questi altipiani terraz ziani, ora profondamente solcati da numeros torrentelli, sono importantissimi, sia per loro ampiezza che ci indica l'enorme larghezza che avevano quivi le fiumane durante la prima metá del perjodo terraziano, sia per la loro notevole elevazione (talora di quasi cento metri) sopra l'attuale fondo di Val Tanaro, sia infine per la loro distribuzione che ci indica nettamente i rapporti originari (tanto diversi da quelli attuali) delle grandi correnti acquee che coprirono per lungo tempo sovente questa regione del Piemonte.

Fra i fenomeni più notevoli di questa categoria possiamo menzionare l'antica riunione del Gesso direttamente col Tanaro presso Bene Vacrienna; ma specialmente l'antico corso del Tanaro da Cherasco a Bra e quindi per Caramagna, ecc., riunendosi esso poscia tosto colle 
fiumane della parte occidentale della valle padana; è a questo percorso delle acque del Tanaro durante la prima metả del periodo terrazziano che devesi la terrazza Bra-Sommariva Bosco-Torniello, ecc.

Anche gli scarsi corsi d'acqua discendenti dalle collinette di $\mathrm{Ce}-$ resole, Pralormo, Poirino, ecc., terrazzarono alquanto le loro vallette d'erosione: in questi casi, più ancora che altrove, riesce quasi sempre molto difficile il distinguere il Diluvium dal Terrazziano e questo dalle alluvioni recenti.

Quanto ai depositi formatisi dalla parte orientale dell' alta ralle padana durante la seconda metà del periodo terrazicino, essi non sono molto importanti perchè poco estesi relativamente e limitati all'attuale alveo della corrente acquea che li ha deposti, terrazzando contemporaneamente le sue sponde nel periodo di erosione.

Passando ora all'esame del Terraziano nella regione astese risulta già chiaro da quanto si è esposto sopra cone nella importantissima valle del Tanaro attraverso a tale regione non debbano esistere alluvioni del Teiraz̃aiano; probabilmente cioè prima esisteva una va'lata corrispondente all'attuale amplissima valle del Tanaro, ma le sue antiche alluvioni terrazziane vennero completamente erose, esportate dall'irrom pente fiumana del Tanaro.

E invece assai interessante osservare come alluvioni del Terrazsiano antico si trovino lungo la valle del Borbore sulla sua sinistra sino a monte di S. Damiano d'Asti, il che ci dimostra l'antichità di, questa valle d'erosione, l'antica ampiezza del corso d'acqua (il Borbore) e lo spostamento abbastanza spiccato che esso presentò rerso Est, lasciando così quasi intatte a sinistra le antiche alluvioni terraziane.

Residui simili incontransi pure presso Baldichieri, cioè al termine delle vallette di Monale e di Triversa, il che ne attesta anche la relativa antichità. Ad ogni morlo la forma, disposizione ed elevazione delle alluvioni terrazziane antiche dell' Astigiano ci dimestrano come questa regione già sin dal pericdo Sahariano dovesse essere soggetta a fenomeni generali di erosione, i quali prepararono le ampie vallate terraziane, ristrettesi e complicatesi in seguito durante il periodo terraziano.

Queste alluvioni terraziane antiche, che si elevano generalmente solo di 20 a 30 metri sull'attuale fondo delle vallate, sono per lo più 
assai sottili e costituite essenzialmente di loess giallastro con straterelli sabbiosi e ghiaiosi giallo-rossicci, ad elementi poco voluminosi, che derivano in massima parte dall'abrasione dei depositi fossaniani e oillafranchiani.

In molti casi si può osservare assai bene il passaggio dal Terrazziano antico alle alluvioni recenti per mezzo di diverse terrazze; ne è tipico esempio la stessa collina su cui siede Asti, collina la quale si presenta ripetutamente terrazzata da Nord a Sud, dal Villafranchiano di Madonna Viatosto all'alluvione recentissima della sponda del Tanaro.

In causa dell' irruzione, direi, della grande fiumana del Tanaro nel centro dell'Astigiana $\mathrm{i}$ sottili depositi di Terrazziano antico vennero quasi completamente abrasi tra Asti e Castello Annone, giacchè quivi le acque del Tanaro si dovettero per lungo tempo gettare impetuosamente verso Nord costruendo cosi l'amplissimo bassopiano che s'estende per diversi chilometri ad Est di Asti.

Ma a valle della forra di Castello Annone ritroviamo sviluppatis. sime le alluvioni terrazziane antiche che costituiscono altipiani molto vasti sulla sinistra del Tanaro; il più ampio ed antico è quello che, iniziandosi con diversi lembi (C. S. Giorgio, C. Boschetto, ecc.), forma poi l'esteso pianoro di Felizzano, Quargnento, Montalto, ecc., la cui delimitazione a Sud è data da una terrazza molto frastagliata che passa per Felizzano, Solero, C. Conzana, ecc.

La parte superficiale della grande pianura alessandrina è quasi del tutto costituita da alluvioni ciottolose, sabbiose e terrose state deposte verso la metà del periodo terrazziano, specialmente allora che la fiumana del Tanaro aveva abbandonato l'antico corso dell'alta valle padana per gettarsi attraverso la regione astese; evidentemente a questa deposizione terraziana contribuirono, colle acque del Tanaro, quelle del Belbo, della Bormida, dell’Orba e della Scrivia.

La valle del Belbo era già ben costituita fin dal principio del periodo terrazziano, giacchè troviamo sulla sinistra dell'attuale vallata, sin presso Nizza, alluvioni state deposte durante la prima metà di questo periodo

In Val Bormida le alluvioni terrazziane antiche si possono osservare ben distinte sin presso Bistagno, poichè piu a monte se ne trovano ancora traccie, ma meno estese e meno caratteristiche; esse trovansi elevate talora di oltre 30 a 40 metri sull'attuale fondo della valle. 
Allo sbocco delle vallate appenniniche che fronteggiano la pianura alessandrina si possono sempre distinguere assai bene le alluvioni del Terraziano antico da quello del Terraziano recente, essendovi nette e ben spiccate terrazze tra le une e le altre; così abbiamo i bellissimi altipiani antichi di Castelnuovo Bormida alto, di Capriata d'Orba, di Francavilla Bisio, di Novi Ligure, ecc. Ma verso valle tali terrazze vanno abbassandosi sin quasi a scomparire, per modo che allora la sovraccennata distinzione rimane piu difficile a farsi e spesso anzi è troppo arbitraria per insistervi oltre.

Le formazi ni terraz̃iane che esistono allo sbocco delle vallate appenniniche sono assai più potenti ed a più grossi elementi che non quelle dell'Astigiana, ció che è facile a comprendersi; quasi ovunque esse sono ghiaioso-ciottolose, coperte del solito velo di lœss.

Dall'esame delle varie formazioni terrasziane della regione alessandrina, largamente intesa, risulta come durante la massima parte del periodo terrazziano le correnti ac puee sboccanti dall' Astigiana e dagli Appennini liguri si allargassero su tutta la pianura d'Alessandria, restringendosi alquanto fra Tortona e Montecastello per unirsi così, a guisa di ampio velo acqueo, colla grande fiumana del Po; è solo verso la fine del Terraziaiano che queste correnti acquee si raccolsero poco a poco nel loro letto attuale, il quale infatti è ampio e poco profondamente inciso, tanto che è in esso tuttora assai variante il corso stesso delle acque.

Rispetto al lato settentrionale delle colline Torino-Talenza è belı difficile distinguere diverse età fra i depositi terrasiani, poichè lè scarse correnti acquee non ebbero generalmente la forza di produrre quegli importanti terrazzamenti che sono la guida piu sicura per la delimitazione delle formazioni alluviali del periodo in esame.

Anche esaminando lo sbocco delle vallate appenniniche ad Est di Tortona si vede che, mentre presso le colline sonvi ancora residui di Terrazziano antico, invece verso valle la pianura è coperta essenzialmente da alluvioni state deposte durante la seconda metá del periodo terraziano.

Quindi da quanto si espose sopra dobbiamo dedurre come la massima parte, quella centrale, della pianura padana sia ricoperta da un velo più o meno potente di deposito alluviale, formatosi durante il pe- 
riodo terraziano, sia durante la sua prima metà, sia arche, per regioni estesissime, durante la sua seconda metà.

Grandissima ¿' l'importanza delle formazioni terrazziane in causa del loro grande sviluppo sulla pianura, sede principale dell'uomo. Trattandosi di depositi essenzialmente ghiaioso-ciottolosi, non ancora molto decomposti, essi sono per lo più facilmente permeabili; ma generalmente l'acqua che ha filtrato attraverso ad essi, giunta alla sua base, trova depositi più compatti, sia quaternari che più antichi, e quindi forma quivi un velo acqueo abbastanza regolare e costante; tale falda acquea è poi regolarissima lá dove le alluvioni terrazziane ricoprono direttamente le marne più o meno argillose del Pıacenziano o del Villafranchiano, fatto comunissimo nella parte orientale dell' alta valle padana, come pure altrove. Questo velo acqueo viene utilizzato sia per uso domestico sia talora anche per agricoltura; esso dà origine a numerose sorgenti là dove esistono tagli naturali alquanto profondi. Notisi però come l'acqua scorrente sotto le alluvioni terraziane sia spesso meno pura che quella che scorre sotto i terreni diluviali, perchè questi in generale sono più potenti e meno permeabili, per cui la falda acquea sotterranea rimane più pura.

Le regioni coperte da depositi terraziani presentano un aspetto oro-idrografico abbastanza uniforme; formano cioè piani molto regolari, assai più regolari che non quelli costituiti da Sahariano, sia perchè anche originariamente i depositi sahariani vennero fluitati un po' irregolarmente, sia perchè in seguito essi subirono erosioni molto più prolungate che non quelli terraziani.

Come dice lo stesso loro nome i terreni terpaziani ricoprono per lo più pianori terrazzati, spesso scaglionati l'uno presso l'altro e più o meno elevati sull'attuale fondo delle vallate. Questa disposizione a terrazze, di cui ebbi già a trattare in un lavoro speciale, è opportunissima sia allo sviluppo dei centri di abitazione, sia all'agricoltura.

Rispetto all' agricoltura l'importanza delle formazioni terrazziane è massima appunto per l'ampiezza delle pianure che ne sono ricoperte e per il velo di loess superficiale che forma la base dell'humus, cioè del terreno vegetale; nelle valli alpine le alluvioni terrazziane costituiscono la più importante e talora anche l'unica parte produttiva dal lato agricolo; è certo ad ogni modo che lo scaglionamento delle 
terrazze sia nelle vallate alpine, sia nelle valli di erosione che incidono la pianura padana, è sommamente favorevole alla coltivazione specialmente del frumento e del granturco: ubertosissime poi sviluppansi le praterie sulle alluvioni terrazziane là dove non scarseggia l'acqua.

Delle alluvioni terrazziane si utilizzano sovente i ciottoli, le ghiaie e le sabbie specialmente per costruzioni, raramente per pietrisco; il loss viene sovente usato come materiale per fabbrica di laterizi.

Prima di lasciare il Terraziano dobbiamo ancora accennare come sia specialmente durante questo periodo che le conche lacustri poco profonde, originate dalla disposizione concentrica dei cordoni morenici, si tramutarono poco a poco in torbiere, le quali sono quindi più o meno direttamente collegate coi fenomeni glaciali; gli è infatti fra le irregolari regioni moreriche del Lago Maggiore e delle due Dore che troviamo comunissimi i depositi torbosi, più o meno ampi e profondi a seconda dei bacini in cui si formarono. Mi limito qui ad accennare all' importanza industriale di questi depositi, ed anche alla loro importanza scientifica nel senso che essi sovente racchiudono, assieme ad una ricca flora e ad una ricca fauna, specialmente malacologica, ben conservati, resti dell' uomo preistorico dell'epoca delle abitazioni lacustri, epoca che credo corrisponda all'incirca alla seconda metá del periodo terraziano.

Quanto al lato industriale di queste torbiere dobbiamo peró notare come ormai esse colle escavazioni di pochi anni, siano quasi completamente esauste in causa della loro poco potenza (raramente di oltre 5 o 6 metri), per cui fra breve non esisteranno più in Piemonte depositi torbosi un po' importanti.

\section{Alluvioni recenti.}

Secondo il mio modo di redere scindendo l'epoca quaternaria in due periodi, Sahariano e Terrazziano, questo seccndo giungerebbe sino al giorno d'oggi, poiche esiste sovente' una serie non interrotta di terrazze dagli altipiani diluviali al piano attuale di deposizione delle correnti acquee; nè ha per me valore di carattere distintivo il criterio storico, poichè dobbiamo assolutamente ammettere che già in un periodo veramente storico dell'umanitả si formassero terrazze ampie, importanti, ed ora abbastanza rilevate sul fondo attuale delle rispettive valli d'erosione. 
Quindi rispetto alle alluvioni che si vanno deponendo ora nell'alveo dei fiumi altro non abbiamo a dire in generale se non che esse costituiscono una continuazione regolarissima delle alluvioni terrazziane, cioè sono costituite di ciottoli, ghiaie e sabbit piu o meno terrose; di rado però queste formazioni poterono già essere coperte dal velo di loess che si depone per lo più nelle epoche di piene straboccanti, ma non troppo impetuose; è per questo motivo, oltre che per le grandi varianti a cui vanno soggette le regioni alluviali lungo i corsi dei fumi, che queste alluvioni recenti sono generalmente poco atte alla coltivazione, tanto più che tali depositi non ebbero ancora a subire a lungo le azioni atmosferiche e quindi ad alterarsi superficialmente per modo da originare un terreno atto a convertirsi in humus.

Non credo quindi che sia qui il caso di passare ad una descrizione dettagliata dei vari apparati alluvionali recenti delle correnti acquee che solcano la pianura padana, tanto più poi che le Carte topografiche ne dànuo un'idea sufficientemente esatta riguardo alla distribuzione, mentre la costituzione varia da luogo a luogo anche in regioni vicinissime.

E ben noto come da queste alluvioni attuali l'uomo tragga comunissimamente i materiali sabbiosi e ciottolosi per costruzione e per pietrisco; certe sabbie alluviali sono aurifere (come quelle dell'Orco, della Dora, del Cervo, ecc.) e quindi vengono escavate per questa proprietà, d'altronde ben poco profittevole.

Per il solito motivo della facile permeabilitì, in rapporto colla natura loro, le alluvioni recenti costituiscono per lo piüregioni aride, ma esse presentano un velo acqueo a poca profundità, almeno in generale. Ancora al giorno d'oggi si vanno qua e lá formando, in certe regioni acquitrinose, sottili ed impuri depositi torbosi, ma generalmente non meritevoli di essere utilizzati. Cosi pure presso certe sorgenti calcarifere è comune il riscontrare depositi di calcare concrezionato, spesso di forme elegantissime, talora utilizzate come pietre ornamentali.

\section{Paleoetnologia.}

I resti paleoetnologici del Piemonte vennero specialmente studiati ed illustrati dal Gastaldi, per cui basterà qui accennarli. Tali resti ap- 
partengono unicamente al periodo neolitico, che corrisponde in gran parte al Terrazziano; la mancanza di residui paleolitici in Piemonte è attribuibile in massima parte al clima quivi meno temperato che altrove, ed alle copiosissime precipitazioni atmosferiche che, sia per se stesse sia per il grandioso sviluppo glaciale e le enormi correnti acquee che ne derivarono, resero quasi inabitabile la regione piemontese durante tutto il periodo sahariano.

Per motivi consimili ci possiamo spiegare come non siansi trovati, resti paleoetnologici nelle caverne ossifere piemontesi, mentre essi abbondano cosi straordinariamente nelle numerose caverne della vicina Liguria.

I resti paleoetnologici del Piemonte consistono specialmente in ascie di pietra levigata ed in cuspidi selciose di freccia che troransi sparse qua e là alla superficie del terreno, specialmente nelle Langhe, nell'Appennino settentrionale ed in qualche vallata alpina; recentemente si rinvennero pure due bellissime cuspidi di selce nelle colline Torino-Casale, cioè tra Cinzano e Bersano e presso Ozzano.

Ma la maggior ricchezza paleoetnologica è presentata da depositi torbosi, antichi laghetti che in parte furono occupati da abitazioni lacustri, specialmente durante l'epoca del bronzo; tuttavia diversi resti, ad esempio cuspidi di freccia trorate recentemente nelle torbiere di Trana, fanno credere che alcune regioni lacustri fossero già abitate nella seconda metà del periodo neolitico, quando i ghiacciai battevano rapidamente in ritirata. Anzi si puo dire che $i$ resti trorati nelle abitazioni lacustri mostrano graduale passaggio dal periodo neo= litico a quello del bronzo, e da questo al per:odo storico.

I più notevoli o più comuni resti paleoetnologici delle torbiere sono oggetti di pesca, canotti, ruote di carro, oggetti di ornamento, stoviglie grossolane (di cui si trovarono pure frammenti sui colli torinesi presso Sciolze), punte di freccia, ecc.

Le regioni più caratteristiche al riguardo sono l'anfiteatro morenico della Dora Baltea e quello del Lago Maggiore.

La rora pianura padana, ora cosi riccamente popolata, fu l'ultima regione ad essere abitata dal'uomo, in causa delle espanse correnti acquee che, più o meno vaganti, la ricoprirono in massima parte durante sran parte del periodo terraziano. 


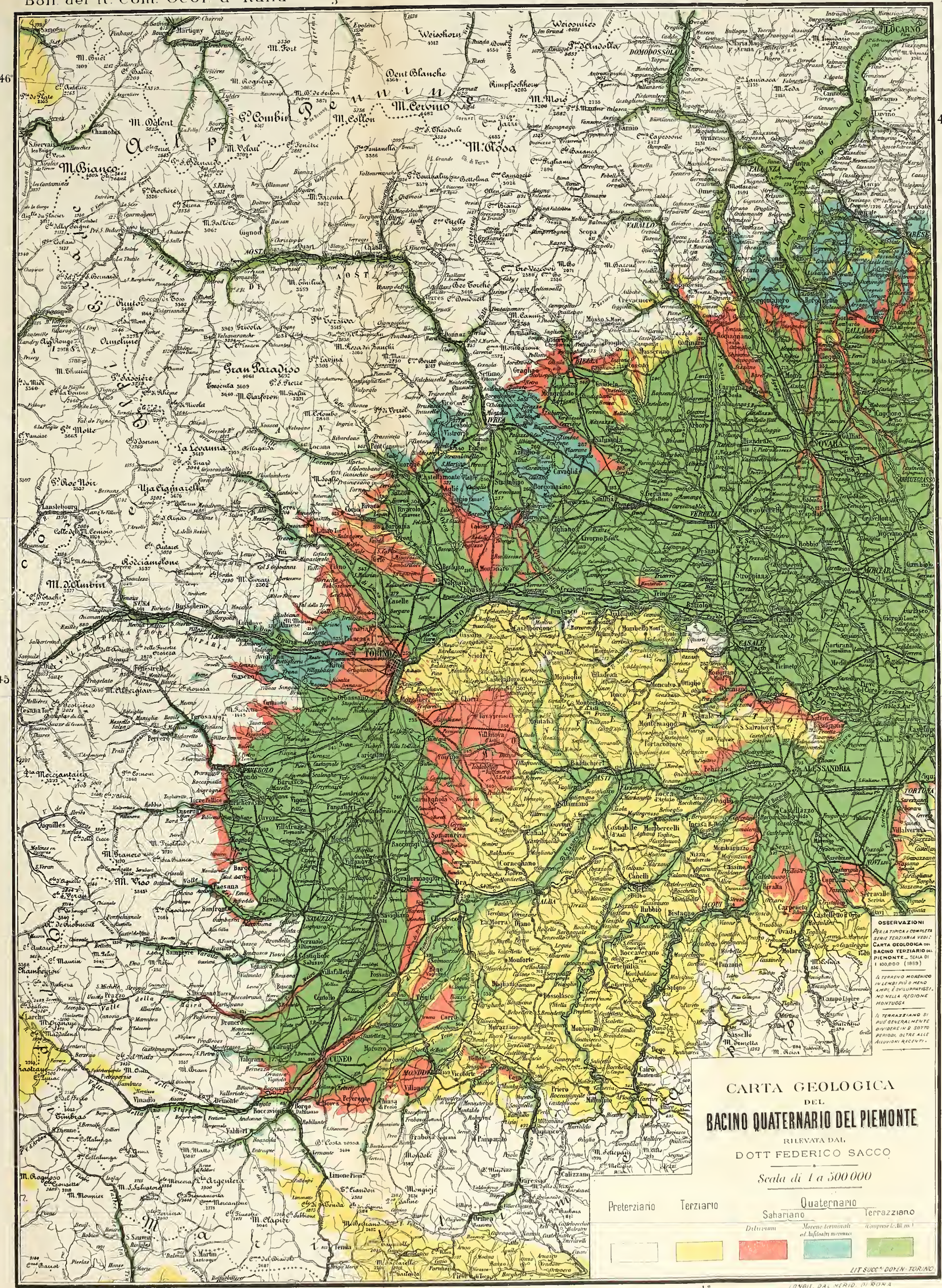




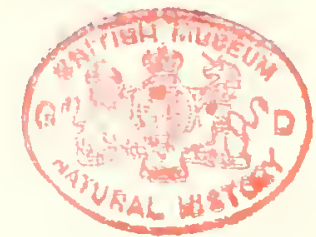




\title{
CATALOGO PALEONTOLOGICO
}

\section{DEL BACINO TERZIARIO \\ DEL P I M O N T}

\author{
N O T A
}

DEL

Prof. FEDERICO SACCO

mergorgeson

R O M A

TIPOGRAFIA DELLA R. ACCADEMIA DEI LINCEI 1889 
Estratto dal Bollettino della Società geologicu italianu

Vol. VIII, fasc. 3. 
A cominciare da Borson e da Brocchi sino a giungere al giorno d'oggi, cioè per il corso di quasi un secolo, i numerosi e svariatissimi fossili racchiusi nei terreni terziarî del Piemonte vennero esaminati e descritti in cento lavori diversi, più o meno importanti, inseriti in riviste ed accademie scientifiche di vario genere, italiane ed estere. Tutto questo immenso materiale paleontogico accumulato per tanti anni e da tanti autori, riesce ora in parte difficilmente utilizzabile, sia perchè appunto esso è troppo slegato e disordinato, sia perchè dal lato geologico esso non corrisponde più alle recenti viste scientifiche, difetto questo assai grave inquantochè può essere solo corretto da chi conosce minutamente l'intiero bacino terziario del Piemonte e può esaminarne accuratamente i fossili. È perciò che avendo ora terminato lo studio particolareggiato di detto bacino credetti opportuno di passare eziandio in rivista $\mathrm{i}$ fossili e di redigerne un catalogo, completo il più che fosse possibile, secondo gli studi fatti sinora su di essi. In questi stretti e modesti limiti di semplice catalogo ridussi questo lavoro paleontologico per diverse ragioni. Anzitutto vari scienziati, quali Portis, Issel, Tellini, Squinabol, ecc. si vanno ora occupando appunto minutamente e sapientemente dei vertebrati, dei molluschi, dei foraminiferi, delle piante ecc. del bacino in esame; inoltre io sono ben lungi dal possedere nei singoli rami della paleontologia quella competenza che ciascuno dei suddetti miei carissimi amici ha per $i$ suoi lavori prediletti, e quindi a tale riguardo mi limito anch'io a studi speciali sopra rami particolari; infine anche se aressi la competenza necessaria per fare un minuto 
studio paleontologico sul bacino terziario piemontese, e se avessi tutta la buona volontà per eseguirlo, non mi basterebbero probabilmente nè la vita, nè i mezzi materiali per compierlo degnamente.

Quindi riguardo agli studi paleontologici dobbiamo cercare tutti assieme, ciascuno secondo le proprie forze, di far aranzare, come si è fatto pel passato, la conoscenza paleontologica del bacino piemontese per mezzo di contribuzioni più o meno importanti secondo le varie circostanze; qui invece mi limito semplicemente a riassumere quanto già fu fatto in proposito, ordinandolo però secondo il nuovo indirizzo dato dagli studi geologici dettagliati, ciò che credo assai interessante, perchè oramai le antiche divisioni segnate dal Lyell nella serie terziaria e seguite finora dai paleontologi piemontesi non bastano più alle esigenze dei lavori geologici accurati che si vanno ora facendo; quindi se i dati paleontologici non vengono posti al corrente, direi, colle nuove idee geologiche, essi perdono alquanto della loro importanza, mentre invece se di tutti i fossili costituenti il ricchissimo ed oramai famoso materiale paleontologico del Piemonte si conosce il preciso orizzonte geologico da cui essi provengono, parmi ne derivi un rantaggio immenso non solo por la paleontologia, ma eziandio per la geologia terziaria in generale. E questo il motivo essenziale che mi spinse a compilare il seguente catalogo, il quale quindi non può ancora per nulla considerarsi come un catalogo definitivo nè per determinazione, nè per numero delle specie. Per convincersi di ciò basta dare un'occhiata alle parziali monografie fatte recentemente su alcuni fossili del Piemonte; esse infatti, ciascuna nel proprio campo, segnano un progresso immenso sui lavori paleontologici fondamentali che furono fatti specialmente verso la metà del corrente secolo; di modo che si può ben giustamente presumere che quando sarà compiuto lo studio paleontologico accurato di tutti i fossili terziarî del Piemonte, il loro catalogo conterrà un numero di specie, o forme che dir si voglia, molto maggiore di quello del catalogo presente. Il catalogo attuale, rappresentando un momento, direi, nella serie degli studi paleontologici sul terziario piemontese, offre naturalmente grandi diversità nelle sue varie parti, poichè alcune, trattate da poco, si trovano al corrente cogli studi recenti, altre invece rimasero indietro di molti lustri, ed abbisognerebbero di un 
forte rimáneggiamento per essere portate al pari delle prime, certi rami poi furono finora appena sfiorati, e per questi sarebbe quindi necessario uno studio quasi iniziale. Inoltre nelle varie parti di questo catalogo esistono anche forti discrepanze causate dal vario modo di intendere i limiti della specie, e q'1este differenze si osservaino non soltanto tra un autore e l'altro, ma anche nello stesso autore (il Bellardi ad esempio) tra i lavori più antichi e quelli più recenti; in generale si osserva che, come di solito, dapprima si aveva tendenza a rapportare le forme fra loro poco dissimili ad una stessa specie, soventi ancor vivente, senza tener gran conto di certi minuti caratteri differenziali; ora invece, esagerandosi in senso opposto, si creano spesso tante specie quante sono le forme appena fra loro un po' diverse.

Per parte mia credo, a questo riguardo, che, pur dovendosi tener conto di tutte le minime differenze di forme anche indicandole con nomi o numeri o lettere speciali, debbasi fare largo uso, direi, delle varietà, raggruppando queste attorno a tipi specifici più costanti, ciò che sarebbe di grande giovamento al geologo, mentre riuscirebbe altresi molto utile al paleontologo, per riconoscere più prontamente $\mathrm{i}$ fossili e per rintracciare più facilmente $\mathrm{i}$ loro rapporti e la loro filogenia. Ma nel presente catalogo non è il caso di fare innovazioni che necessiterebbero un completo rimaneggiamento ed un profondo studio paleontologico. Darò ora solo pochi cenni sui diversi rami di questo catalogo, affinchè riesca facile il riconoscere quanto ancora è da farsi per perfezionarlo e completarlo.

Riguardo alla Paleoicnologia sono appena indicate alcune delle principali impronte che si ebbero a studiare in questi ultimi anni, ma immensamente più grande sarebbe invero il loro numero, se si volesse tener conto di tutte le infinite forme di impronte che si presentano in tutti gli orizzonti, specialmante sugli strati arenacei.

La Paleofitologia si trova tuttora in gran parte allo stato in cui la lasciarono i lavori del Sismonda Engenio; solo ultimamente, riguardo ai regetali inferiori del Liguriano e del Tongriano, si ebbe un'efficace contribuzione per opera dello Squinabol, che è ad augurarsi continui in questi studi tanto importanti quanto difficili e quindi troppo trascurati. È certo che in questa parte del catalogo paleontologico è necessaria in arvenire una seriissima re- 
visione che dovrà togliere molti errori di classificazione, tanto facili d'altronde a commettersi quando si debbono solo prendere come base parti incomplete ed anche poco ben conserrate. Esistono poi ancora specialmente pel Bartoniano, pel Tongriano e per l'Astiano del bacino piemontese materiali ricchissimi ed affatto rergini di studio.

Passando alla Paleozoologia esaminiamone partitamente $\mathrm{i}$ singoli rami. Per quanto la lista dei Protozoi riesca abbastanza copiosa, è certo però che si tratta qui ancora di uno studio da farsi in massima parte; sgraziatamente i materiali di questo studio, mentre abbondano straordinariamente nelle marne e nelle sabbie di quasi tntti i piani terziari piemontesi, mancano invece (in causa delle difficoltà di estrazione) quasi completamente in tutte le collezioni paleontologiche, se si eccettua quella prirata del car. Roresenda che ne conserva un certo numero dell'orizzonte elveziano dei colli torinessi. Quindi chi rolesse dedicarsi a questi studi dorrebbe dapprima percorrere il bacino piemontese raccogliendo orunque e razionatamente, secondo le carte geologiche, numerosi campioni di marne e di sabbie a foraminiferi per procedere poscia al loro studio; dopo poco tempo che si facciano tali ricerche si riconoscono abbastanza bene questi orizzonti fossiliferi, d'altronde comunissimi, ed i risultati nuovi ed interessanti di detto studio ricompenserebbero certamente la fatica di questo laroro a cui vado incoraggiando allieri ed amici. A provare che non è la mia una semplice ipotesi, basta indicare il fatto che recentemente il Tellini cogli esemplari di Nummulitidi, raccolti da lui e da me nei terreni inferiori del Piemonte, potè pubblicare una importantissima monografia su questi fossili tanto caratteristici quanto trascurati.

Riguardo ai Celenterati molto renne già fatto, specialmente per opera di Michelotti e di Sismonda; ma se si considera il materiale immenso che di questo tipo si è accmulato nelle collezioni di fossili piemontesi, sia pubbliche che prirate; se si pensa come in raste regioni. specialmente dell'Appennino ligure esistono allo scoperto Teri banchi corallini che in poco tempo potrebbero fornire al raccoglitore una messe straordinariamente ricea di forme svariatissime, e se si considera quali grandi progressi fece negli ultimi anni lo studio di questo gruppo di animali, è certo che 
anche rignardo ad esso vi è ampio o fecondissimo campo di lavoro pel paleontologo.

Gli Echinodermi vennero studiati specialmente dal Sismonda già molti anni addietro, di modo che, sia per i numerosi esemplari raccolti, sia per le diverse modificazioni avvenute nella determinazione di queste formo, ne sarebbe necessaria una generale revisione.

Quanto ai Molluscoidi, se la classe dei Brachiopodi ricevette una illustrazione abbastanza notevole, quantunque parziale, per opera del Segnenza, invece quasi tutto ancora è a farsi riguardo ai Briozoi; è vero che si tratta di forme difficilissime a studiarsi, ma di esse nelle collezioni sono accumulati abbondanti materiali provenienti da quasi tutti i piani del terziario piemontese, quindi esse al paziente paleontologo fornirebbero mezzo di fare un lavoro in gran parte nnovo e molto interessante.

Del tipo dei Molluschi, importantissimo sopra tutti per abbondanza di forme, fra cui moltissime affatto caratteristiche, furono assai variamente studiati i varî ordini.

I Lamellibranchiati classificati in gran parte dal Sismonda, in parte pure studiati dal Michelotti, rappresentano certamente la classe di Molluschi che venne sempre più trascurata, perchè le loro forme sono molto difficili ad aversi complete ed in stato tale da esaminarsi minutamente e presentansi quindi di difficile determinazione; con tutto ciò molto ed assai bel materiale venne raccolto di bivalvi in questi ultimi venti anni e quindi sarebbe opportuno di ripigliarne lo studio e portarlo almeno al livello di quello delle univalvi; per persuadersi delle novità grandi che si troverebbero in questo studio basta osservare i progressi enormi, per quanto parziali, fatti fare dal Bellardi colla sua monografia delle Nuenlidi.

Rispetto ai Gasteropodi sonvi certi ordini, ad esempio quello degli Scafopodi, dei Prosobranchi, dei Ciclobranchi e degli Aspidobranchi, che rimasero finora trascurati come i Lamellibranchiati in generale; ma certi altri invece, dopo gli studi, ora già un po' invecchiati, del Sismonda e del Michelotti, ricerettero un impulso così potente per opera del Bellardi, che le monografie di questo valente paleontologo debbono certamente venir poste fra i più importanti lavori della moderna paleontologia; ciò dicasi per gli Eteropodi, pei Pteropodi e per parecchie fra le famiglie più 
elevate dei Gasteropodi. È a notarsi come anche in questo grandioso lavoro : I Molluschi dei terreni terziari del Piemonte e della. Liguria, il Bellardi mutò alquanto il suo modo d'interpretare la specie tra le prime due parti e le seguenti; secondo il mio modo di vedere parmi più giusto il concetto seguito nei due primi rolumi, giacchè negli ultimi sembrami che troppo frequentemente siansi elevate a specie le semplici varietà. Riguardo ai MIolluschi terrestri, d'acqua dolce o salmastri (Melania, Melanopsis, Potamides, Polmonati ecc.), ebbi ad occuparmene in modo speciale in questi ultimi anni, risultando anche qui nettamente il fatto che è così grande la ricchezza della farna terziaria del Piemonte che studi particolari eseguiti sopra una parte di essa danno luogo alla scoperta di numerose ed interessantissime forme nuove. I pochi Cefalopodi vennero bellamente illustrati dal Bellardi nella prima parte della sua sovraccennata Monografia.

Pel tipo degli Artropodi sono quasi solo da accennarsi i Crostacei; fra essi l'ordine dei Cirripedi, molto abbondante di forme in tutti i piani del terziario piemontese, avrebbe bisogno di una seria revisione che eliminerebbe senza aubbio molti errori di determinazione; i Malacostraci ricevettero una recente illustrazione per opera del Ristori.

I Vertebrati del bacino terziario piemontese, quantunque immensamente meno numerosi degli invertebrati, non sono però meno importanti per certi ordini; in parte vennero gia illustrati: i Pesci per opera dell'Eugenio Sismonda, i Cheloni ed i Cetacei pei larori specialmente del Portis; gli altri mammiferi particolarmente per gli studi del Sismonda e del Gastaldi: con tutto ciò i molti materiali accumulati da alcuni anni, specialmente i numerosi resti di pesci, necessiterebbero nuovi studi sia parziali che generali.

Dal sopradetto risulta che il catalogo che qui presento, se in certi punti rimane ancora un po' addietro nella scienza, in complesso però segna un enorme progresso sopra quello ultimo pubblicato dal Sismonda nel 1847.

Dal complesso poi dell'esame dei fossili terziarî piemontesi si può dedurre il fatto, abbastanza interessante, che le faune e le flore del Tongriano e dello Stampiano sono molto simili fra di loro, e che lo stesso deve dirsi rispettivamente di quelle dello Aquitaniano, del 
Langhiano e dell'Elveziano, come pure di quelle del Piacenziano e dell'Astiano; per modo che se ad esempio si volesse adottare la distinzione dell'oligocene, dal lato paleontologico parrebbe più logico pel Piemonte di inglobare l'Aquitaniano nel Miocene piuttosto che non nell'Oligocene, come generalmente si usa, quantunque certamente la fauna aquitaniana presenti ancora molti punti di somiglianza con quella stampiana. A questo riguardó è poi da notarsi che certe specie indicate come trovate in diversi orizzonti geologici dovranno poi col tempo in parte venir scisse in forme (anche solo varietà) diverse, e debbono la loro attuale ampia distribuzione apparente al modo un po' troppo largo usato dapprima dai paleontologi nell'intendere la specie.

Debbo poi accennare come in alcuni casi, però fortunatamente abbastanza vari, non si conosce il punto preciso di rinvenimento di un dato fossile, per cui rimane incerto l'orizzonte geologico a cui esso debba venir attribuito; cio viene indicato nel catalogo con un punto interrogativo nella colonna del piano geologico a cui più probabilmente pare appartenga tale fossile.

Nella parte paleoicnologica non si può seguire un ordine razionale, trattandosi per lo più d: impronte di origine affatto incerta; riguardo alla Paleofitologia tenni in complesso l'ordine seguito dallo Schimper nel suo Traité de Paléontologie végétale; invece per la Paleozoologia adottai essenzialmente la classificazione seguita dallo Zittel nel suo Handbuch von Paleontologie. 


\section{PALEOICNOLOGIA}

\begin{tabular}{|c|c|c|c|c|c|c|c|c|c|c|c|c|c|}
\hline 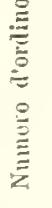 & $\mathrm{F} O \mathrm{P}$ II $\mathrm{E}$ & $\mid$ & 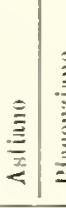 & , & 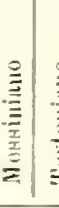 & 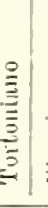 & לֶ. & 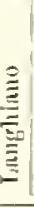 & & 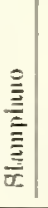 & & & 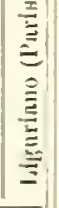 \\
\hline 1 & Paleodictyon regulare sacc........ & & & & & & & & & $?$ & & & \\
\hline 2 & maximum Sace. е гаr... & & & & & & & & & $\therefore$ & & & \\
\hline 3 & tectiforme Sacc. e rar... & & & & & & & & & + & & & \\
\hline 4 & miocenicum, Sacc....... & & & & & & & & & . & & & \\
\hline 5 & sp. . . . . . . . . . & & & & & & & & & + & & & ? \\
\hline 6 & Tulliporites bombicoides Sace. ...... & & & & & & & & & + & & & \\
\hline $\bar{\tau}$ & stellaris Sacc......... & & & & & & & & & -1 & & & \\
\hline 8 & Munsteria annulata Schafh. . . . . . . & & & & & & & & & & & & \\
\hline 9 & minima squin. ...... & & & & & & & & & & & & \\
\hline 10 & Isseli Squin. . . . . . . . & & & & & & & & & & & & \\
\hline 11 & Taphorhelminthopsis pedemontana sacc. e & & & & & & & & & 4 & & & \\
\hline 12 & recta Sacc.......... & & & & & & & & & + & & & \\
\hline 13 & expansa sacc........ & & & & & & & & & $\div$ & & & \\
\hline 14 & spec. ........... & & & & & & & & & & & & \\
\hline 15 & Helminthopsis hieroglyphica Heer. e rar. & & & & & & & & & + & & & + \\
\hline 16 & Helminthoida labyrinthica Heer. . . . . . & & & & & & & & & & & & \\
\hline 17 & crassa Schafh. e rar. .... & & & & & & & & & $\div$ & & & + \\
\hline 18 & miocenica Sacc. e rar... & & & & & & & & & & & & \\
\hline 19 & irregularis Squin. ..... & & & & & & & & & & & & \\
\hline 20 & sp. . . . . . . . . & & & & & & & & & $\div$ & & & \\
\hline 21 & Trohetrinthoida dertonensis sace..... & & & & & & & & & + & & & \\
\hline 22 & Laminarites pseudoichnites Squin. e rar. & & & & & & & & & 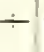 & & & \\
\hline 23 & Eoclathries fenestiatus squin........ & & & & & & & & & & & & \\
\hline 21 & Dureillides? eocericus Squin........ & & & & & & & & & & & & 4 \\
\hline 25 & Vemertilites Strozi Menegh. . . . . . & & & & & & & & & & & & + \\
\hline $20^{3}$ & miocenica sacc........ & & & & & & & & & & & & \\
\hline 27 & pedemontana sacc..... & & & & & & & & & & & & \\
\hline 28 & langarum Sace........ & & & & & & & & $\therefore$ & & & & \\
\hline 29 & sp. . . . . . . . . & & & & & & & & & & & & \\
\hline 30 & dertonensis Sacc. . . & & & & & & & & & & & & \\
\hline
\end{tabular}




\section{PALEOFITOI OGIA}

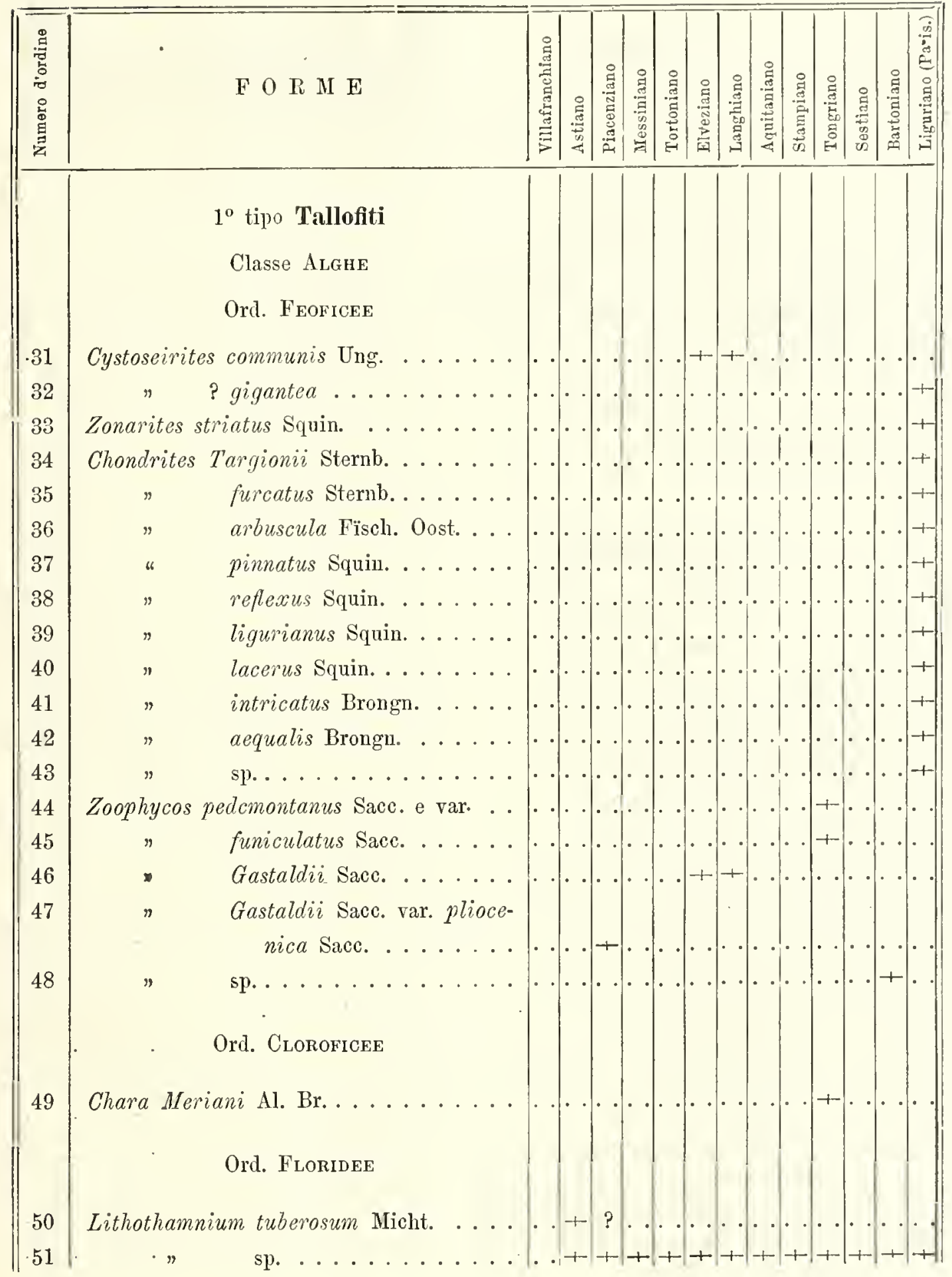




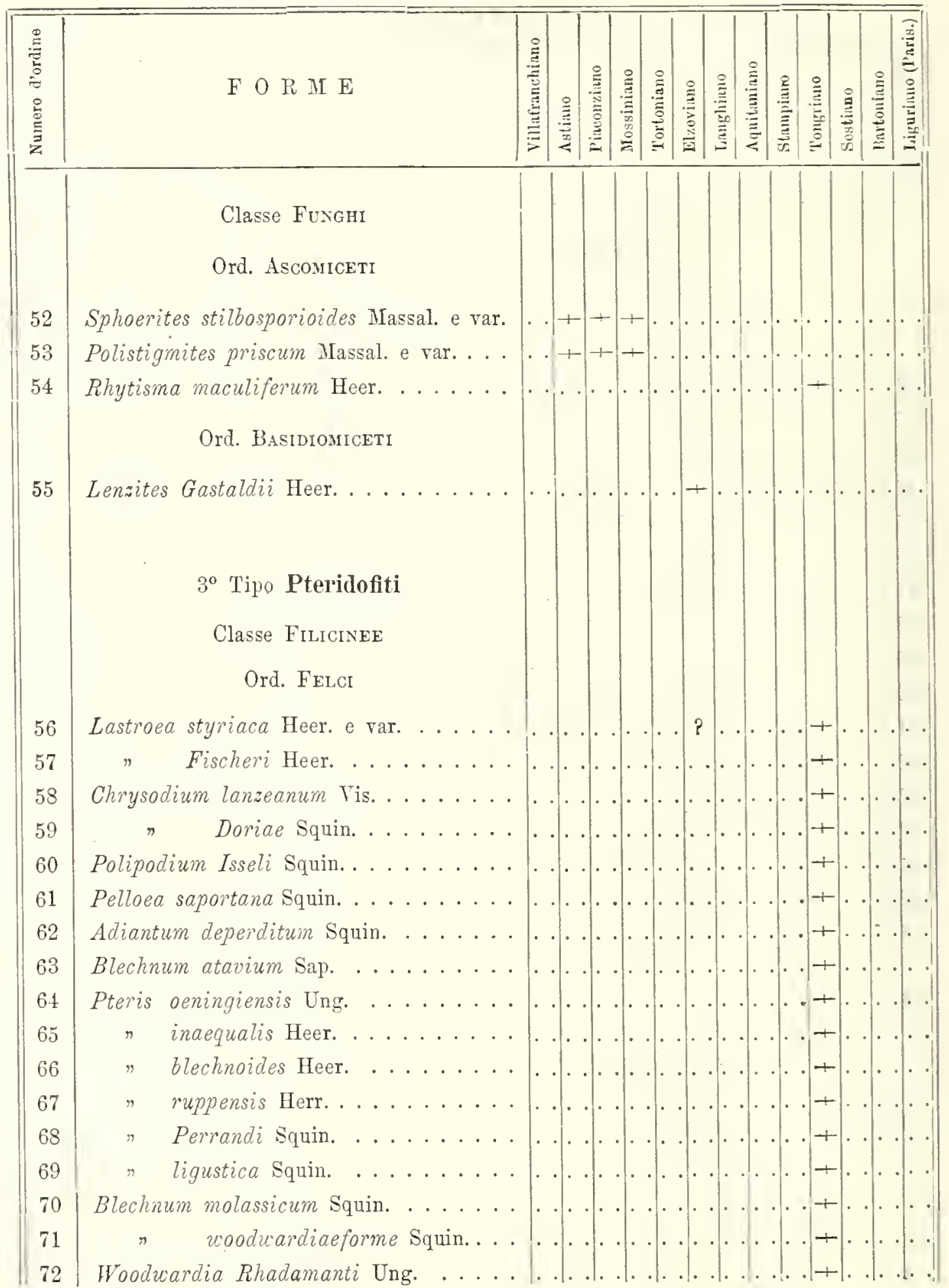




\begin{tabular}{|c|c|c|c|c|c|c|c|c|c|c|c|c|c|}
\hline 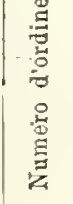 & $\mathrm{F} O \mathrm{P} M \mathrm{~N}$ & 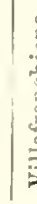 & $\mid$ & & & $=$ & & है & & & & 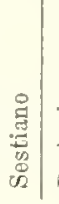 & 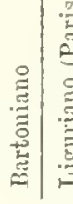 \\
\hline
\end{tabular}

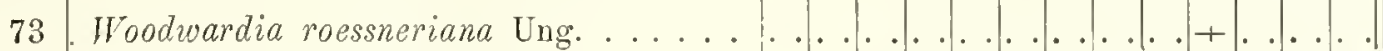

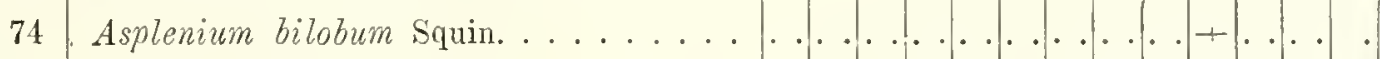

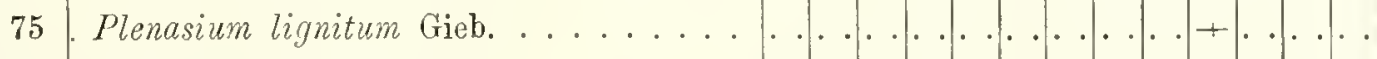
76 Hypolepis amissa Squin. . . . . . . . . . . . . . . . . . . . . . 77 Goniopteris stiriaca Heer. . . . . . . . . . . . . . . . . . . . . . . .

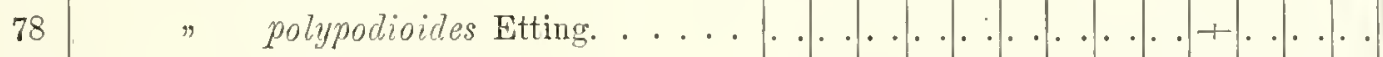
$79 \quad " \quad$ helvetica Heer. . . . . . . . . . . . . . . . . . . 80 Aspidium Meyeri? Heer. .............................

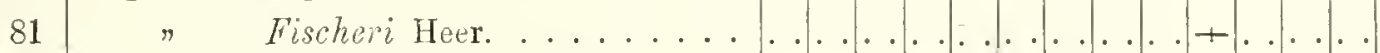

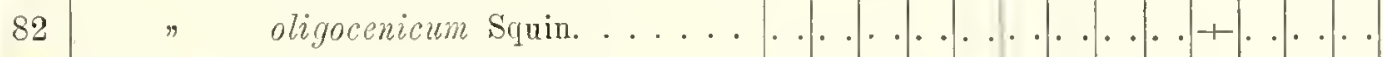
83

Trichomanes Sacci Squin.

Hymenophyllum Beccarii Squin.

Sphenopteris eocenica Etting.

Benizia calopteris? Deb. e Etting.

Spiropteris s

Classe Calamariee

Ord. Equisetinee

Equisetum Parlatorii Heer.

$"$

sp.

$3^{\circ}$ Tipo Fanerogame gimnosperme

Classe Gimnosperme

Ord. Conifere

Glyptostrobus europeus Heer. . . . . . . 


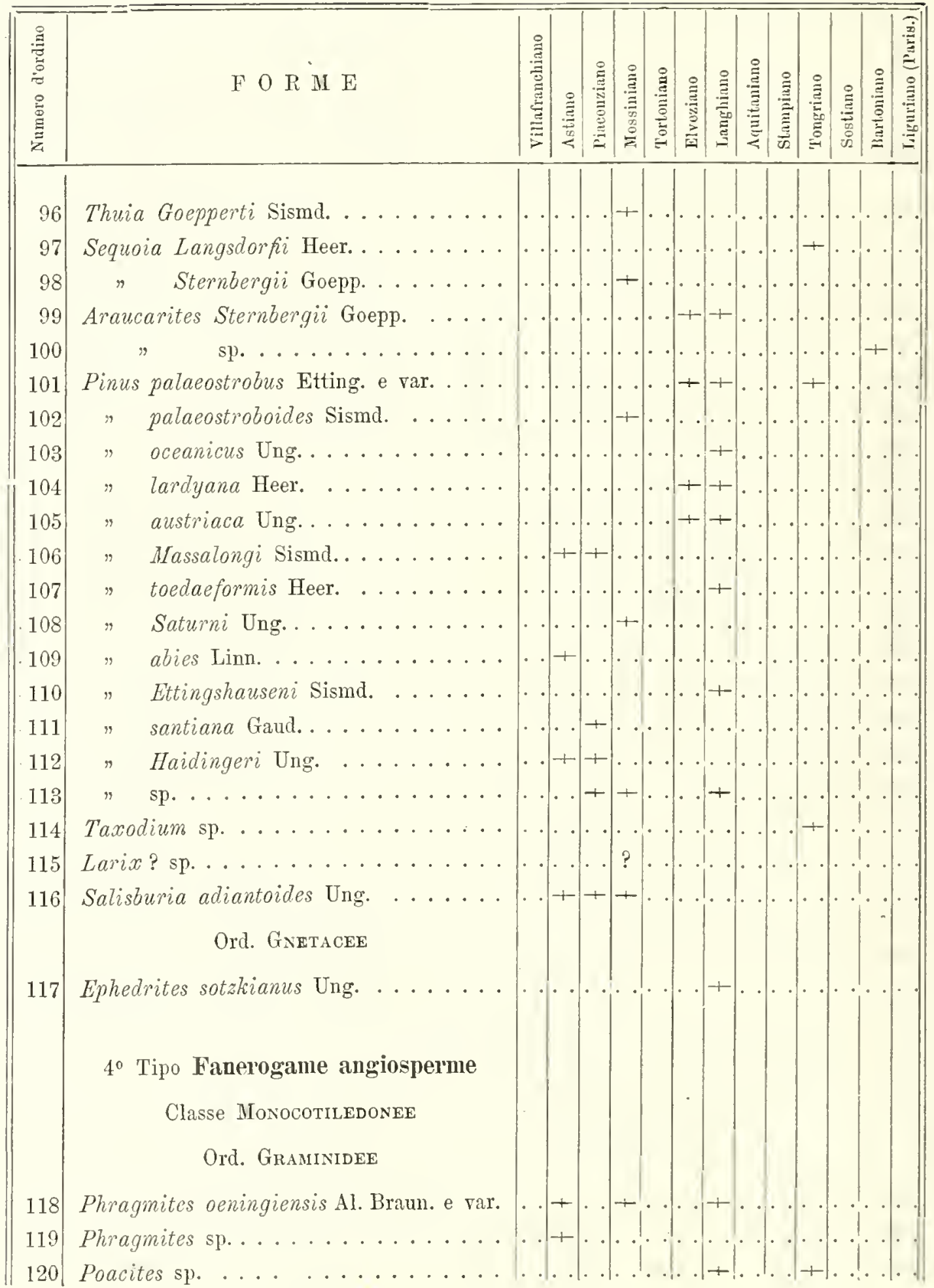




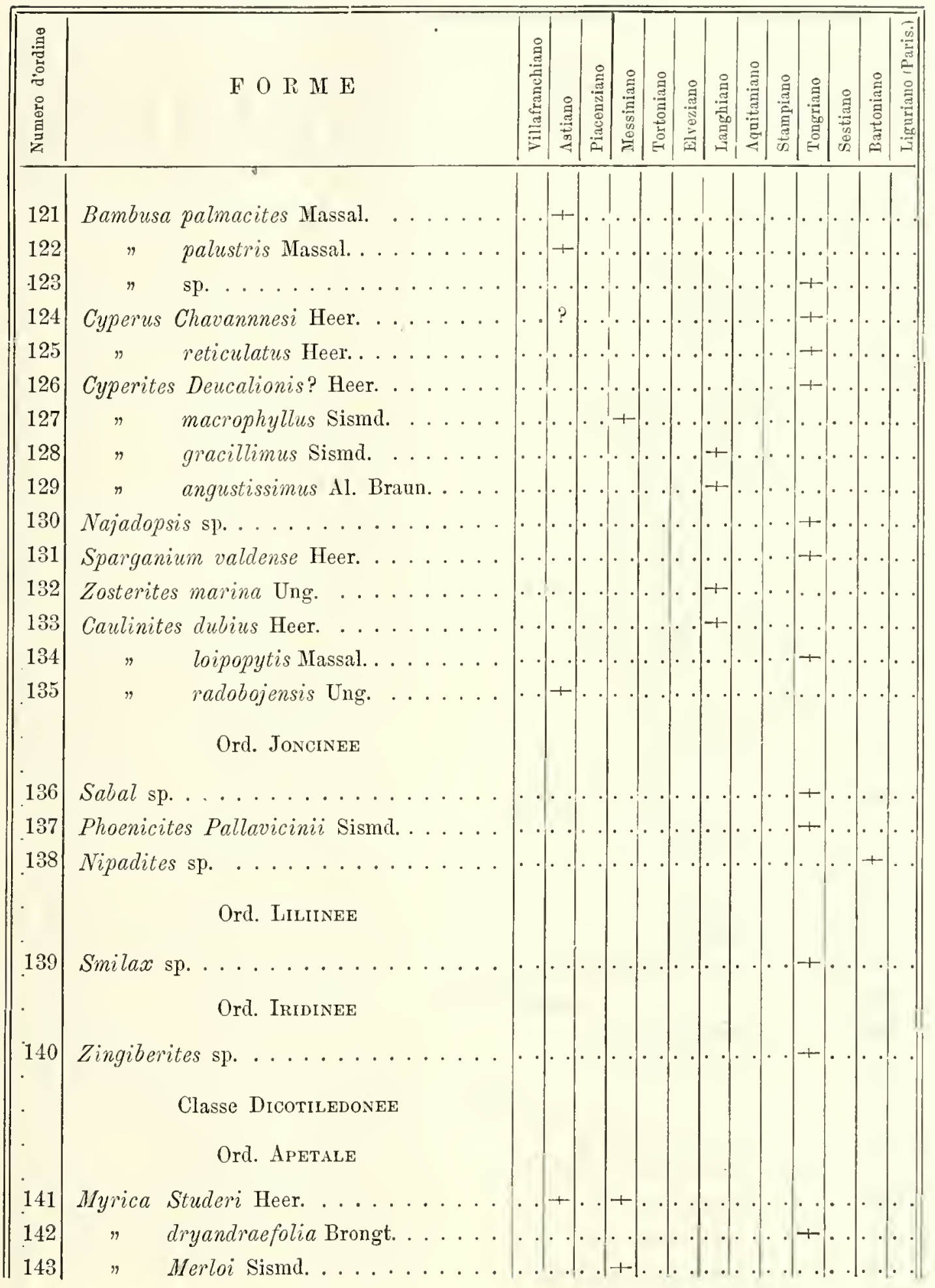




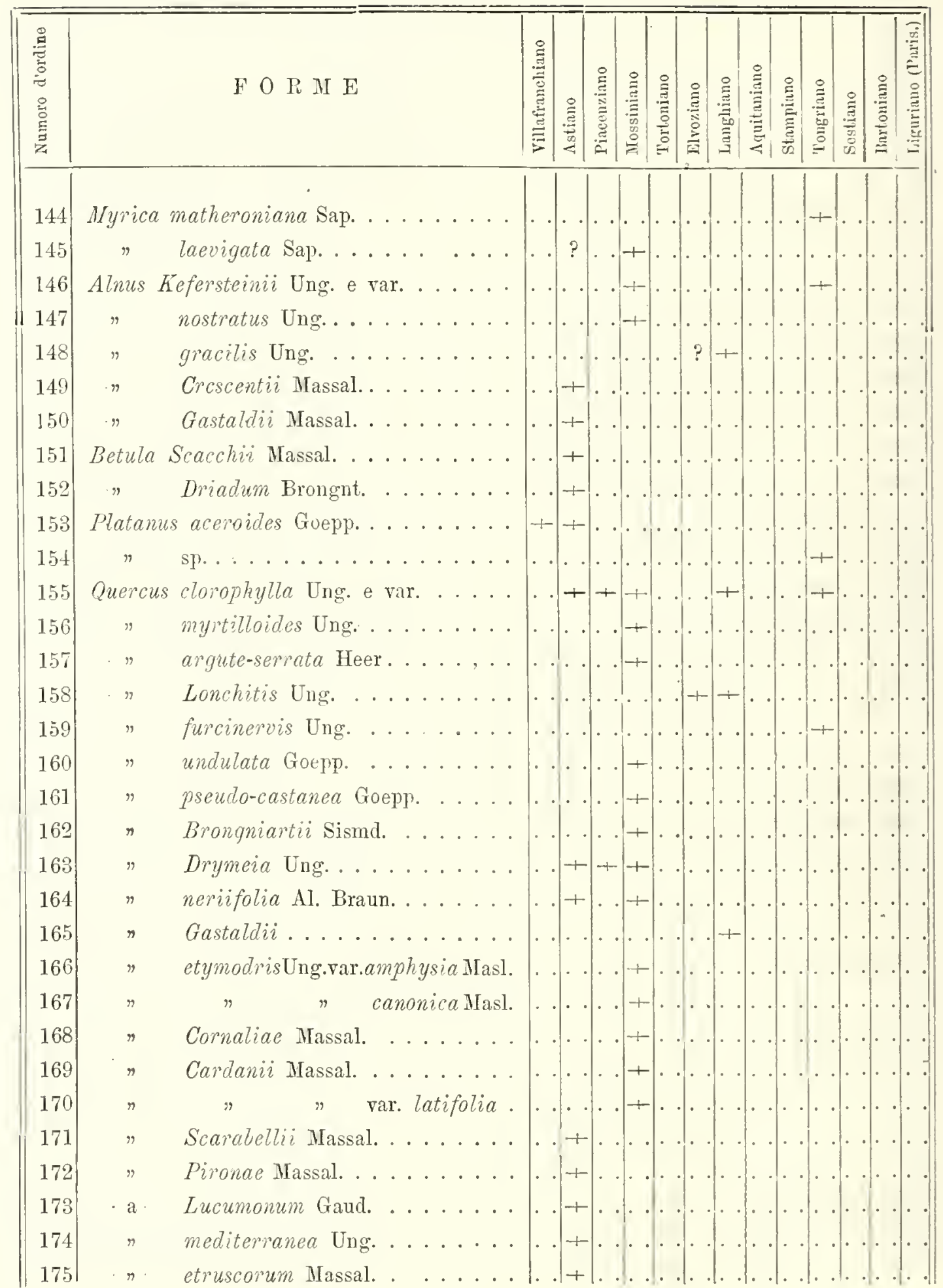




\begin{tabular}{|c|c|c|c|c|c|c|c|c|c|c|c|c|c|c|}
\hline 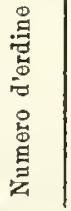 & $\mathrm{F} O \mathrm{R} M \mathrm{E}$ & 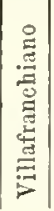 & 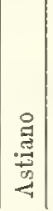 & 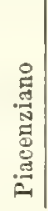 & 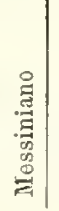 & 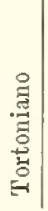 & 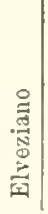 & 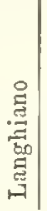 & 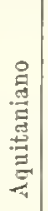 & 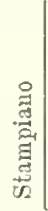 & 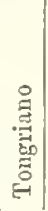 & 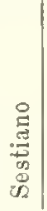 & 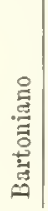 & 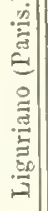 \\
\hline 176 & Quercus ilex? Linn. .......... & . & + & & • & & & & & & & & . & - \\
\hline 1.77 & $s p \ldots \ldots \ldots \ldots \ldots \ldots$ & & +1 & & & & & & & & & & • & - \\
\hline 178 & Corylus Heeri Sismd. ........ & & + & + & +- & & & & & & & & . & - \\
\hline 179 & " gigas Sismd. ........... & & & & $-1-$ & & & & & & & & . & - \\
\hline 180 & Fagus Deucalionis Ung. ........ & • & & & + & & & & & & & & & \\
\hline 181 & castaneaefolia Ung......... & & & & +1 & & & & & & & & & . \\
\hline 182 & Marsilii Massal. ....... & . & + & & . & & & & & & & & • & \\
\hline 183 & Gussonii Massal. ....... & & & & + & & & & & & & & & \\
\hline 184 & betulnefolia Massal. ...... & & + & + & & & & & & & & & & • \\
\hline 185 & Castanea Kubingi Kow. e var. ..... & & -+ & & +1 & & + & + & & & & & & \\
\hline 186 & $" \quad$ Ungeri Heer. . . . ..... & & + & & + & & & & & & & . & . & • \\
\hline 187 & atavia Etting. ......... & & -+ & & + & & & & & & & . & . & - \\
\hline 188 & $" \quad$ Tornabenii Massal. ....... & . & + & & +1 & & & & & & & 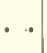 & 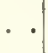 & • \\
\hline 189 & 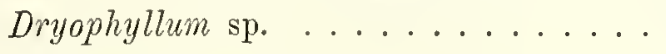 & & 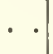 & & . & & & & & & & & & · \\
\hline 190 & Carpinus grandis Ung. e var. . . . . . . & & + & & . & & +- & + & & & & . & - & . \\
\hline 191 & $"$ ablonga Ung. ......... & - & + & & $\cdot$ & & & & & & & . & . & \\
\hline 192 & Populus balsamoides Goepp........ & & + & & -1 & & & & & & & . & & 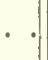 \\
\hline 193 & Gasparinii Massal. ....... & & + & & ${ }^{\circ}$ & & & & & & & & & \\
\hline 194 & Lcuce Ung. e var. . . . . . . & . & + & . & . & & & & & & + & & & \\
\hline 195 & " leucophylla Ung. ....... & & + & & $\sigma^{\circ}$ & & & & & & & & & \\
\hline 196 & $s p \ldots \ldots \ldots \ldots \ldots$ & 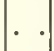 & + & & . & & & & & & & & - & \\
\hline 197 & Salix macropylla Heer. ........ & . & & & $1^{\circ}$ & & & & & & + & . & & \\
\hline 198 & angusta Al. Braun. . . . . . & $\cdot$ & & & + & & & & & & & . & - & \\
\hline 199 & "denticulata Heer. ........ & . & & & + & & & & & & & & & \\
\hline 200 & 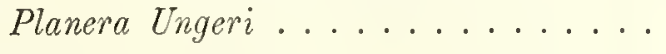 & . & + & & + & & & & & & & & • & \\
\hline 201 & $s p \ldots \ldots \ldots \ldots \ldots$ & . & . & 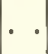 & 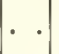 & & & & & & + & & • & . \\
\hline 202 & Ulmus Braunii Heer. . . . . . . . . & 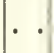 & & . & + & & & & & & & & . & - \\
\hline 203 & Bronnii Ung. ......... & 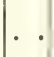 & & & + & & & & & & & & & \\
\hline 204 & Samniorum Massal. . . . . . . & 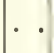 & + & & · & & & &. & & & & & \\
\hline 205 & plurinervia Ung. ....... & - & + & & • & & • & • & ${ }^{\circ}$ & • & - & & & \\
\hline 206 & Ficus lanceolata Heer e var. ...... & . & + & & + & & & + & & · & & & & \\
\hline $207 \mid$ & $" \quad$ tiliaefolia Heer. & & & & $1+1$ & & & & & & & & & \\
\hline
\end{tabular}




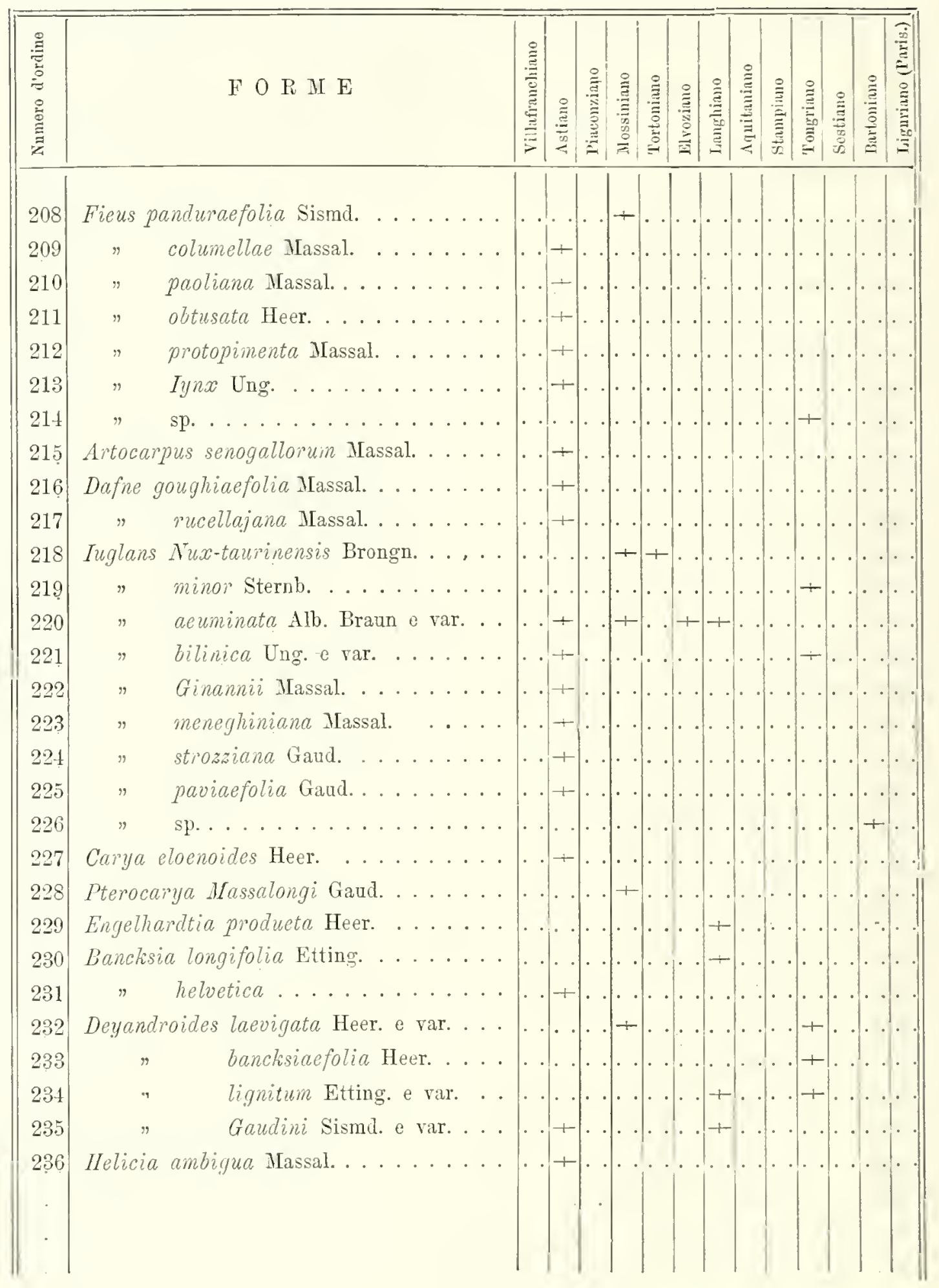




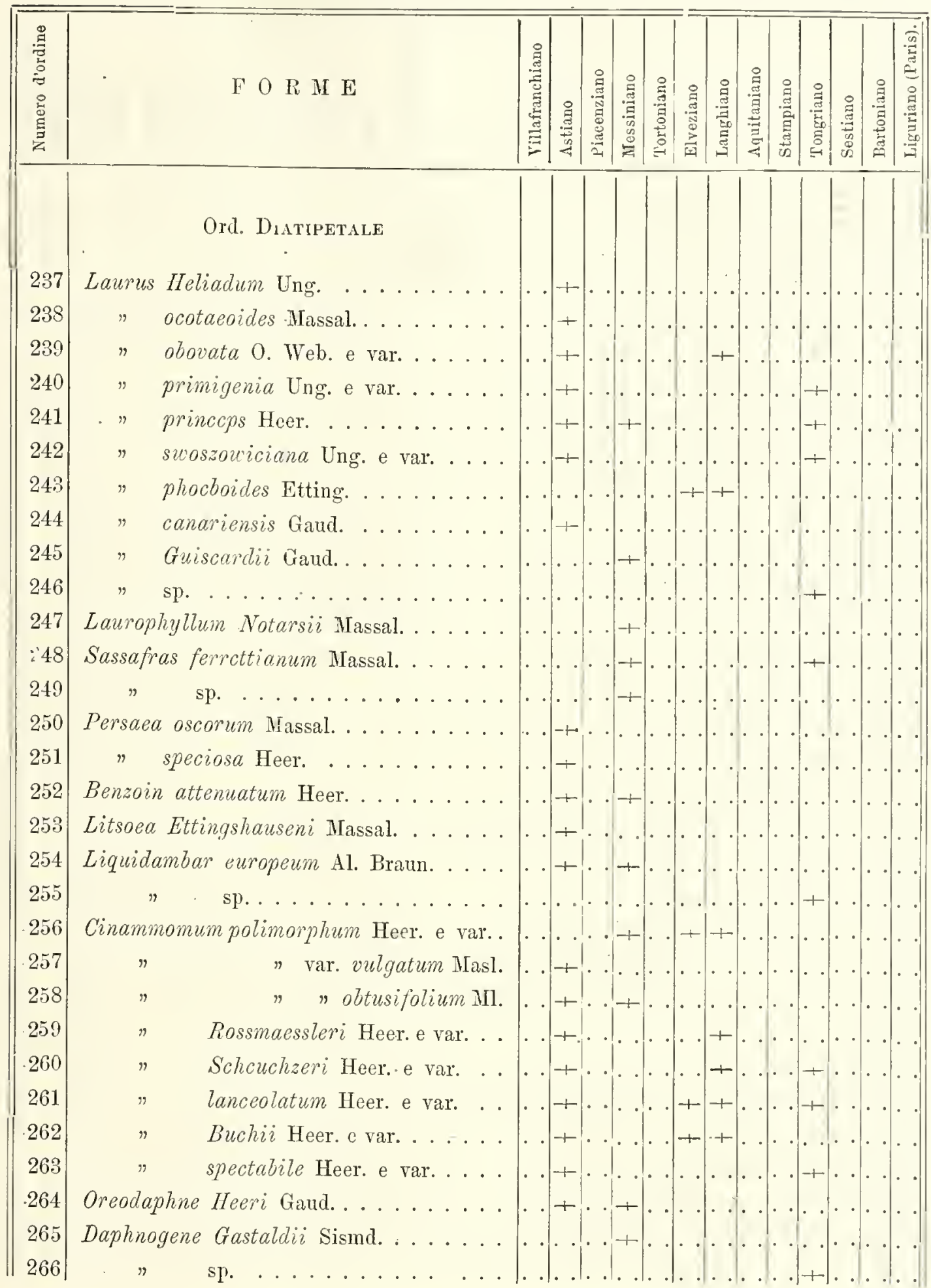




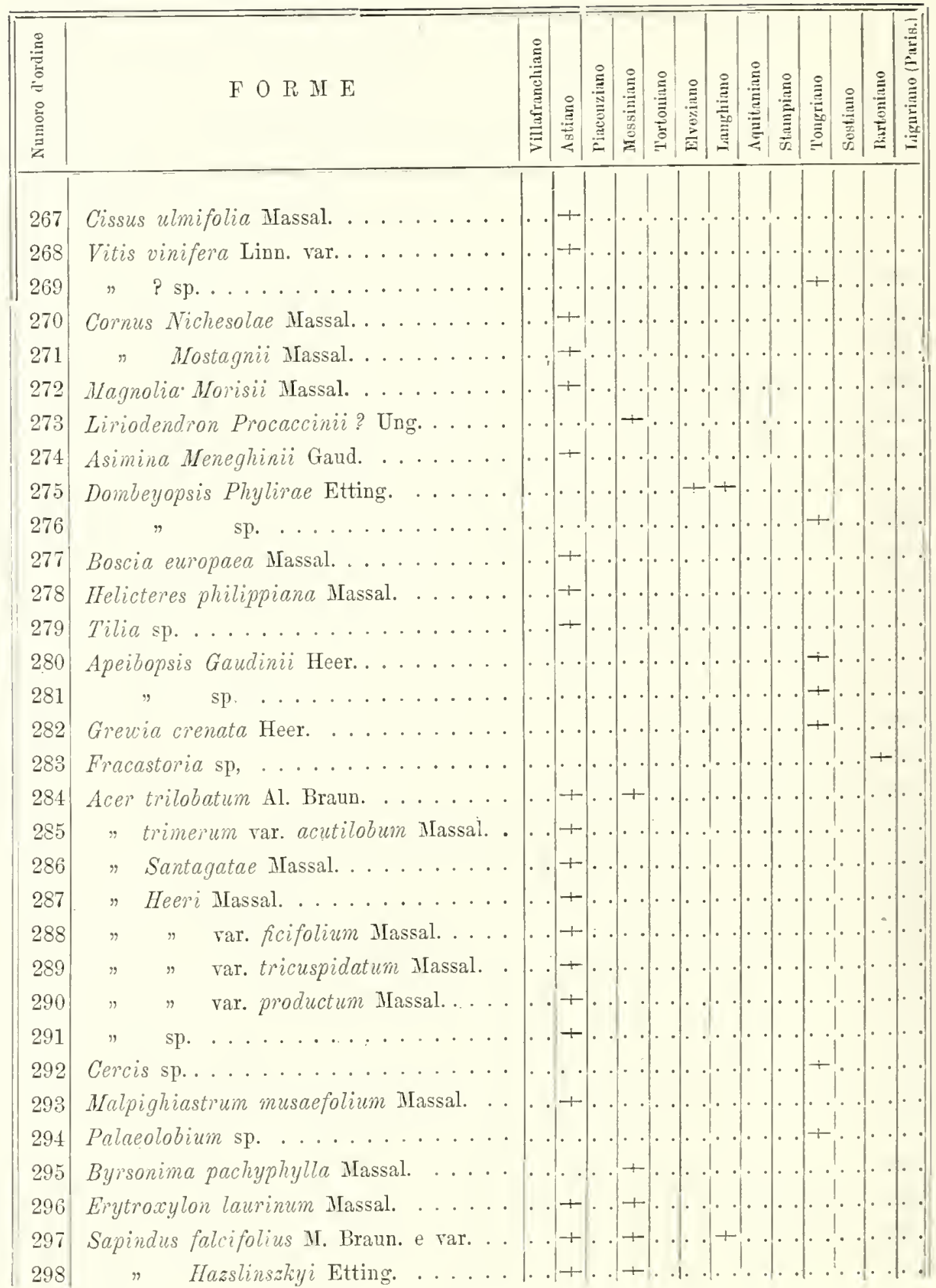




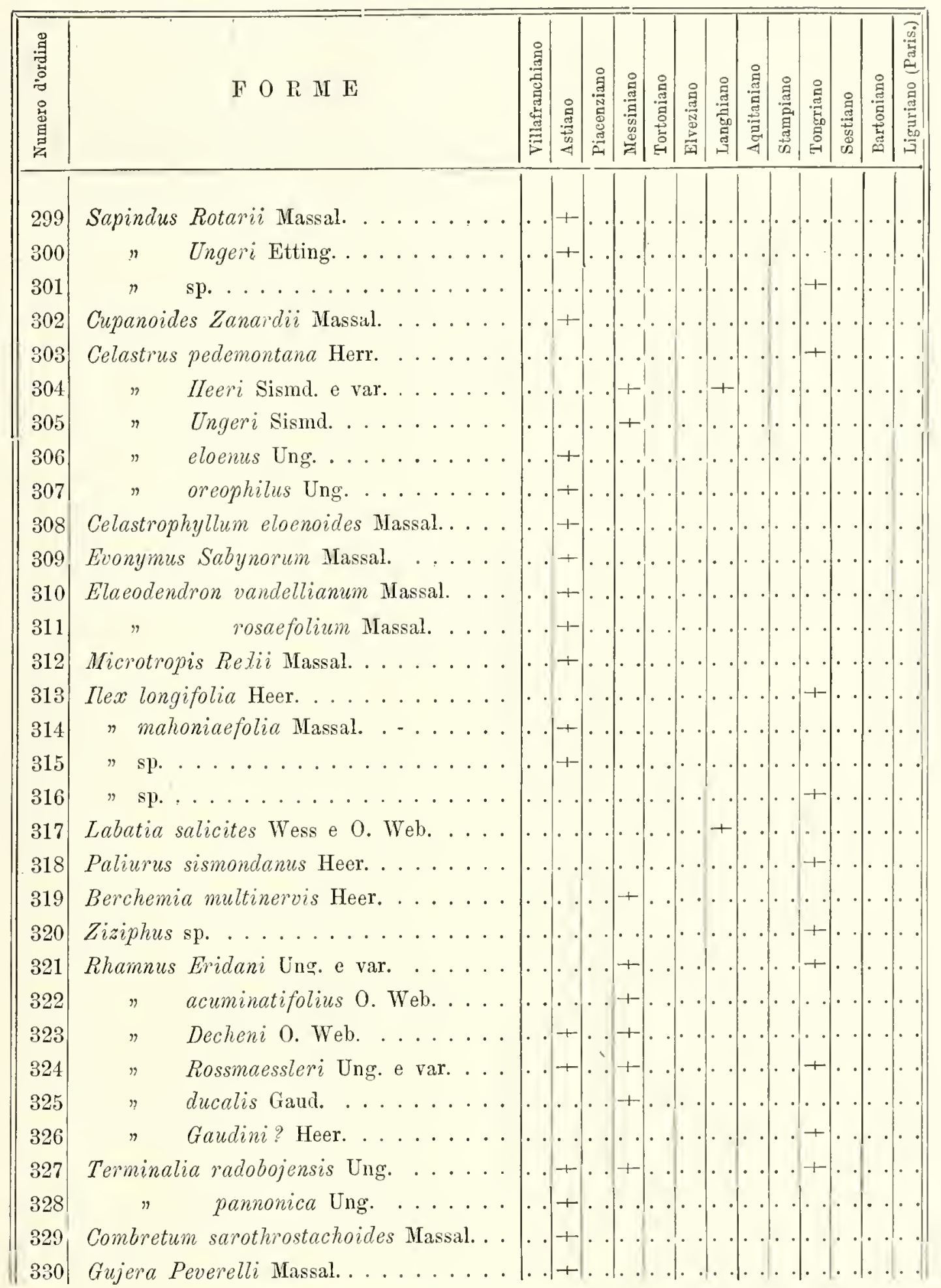




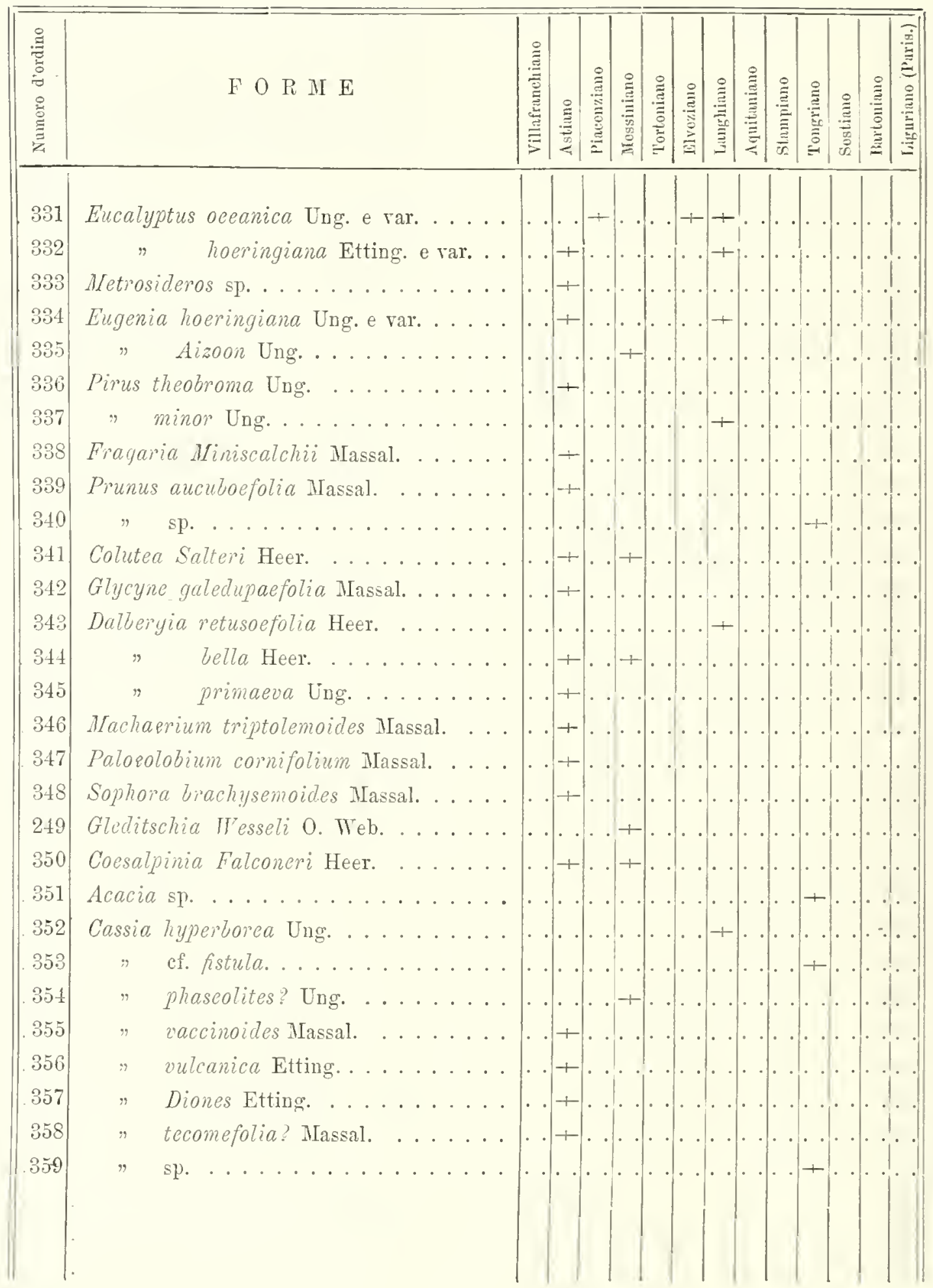




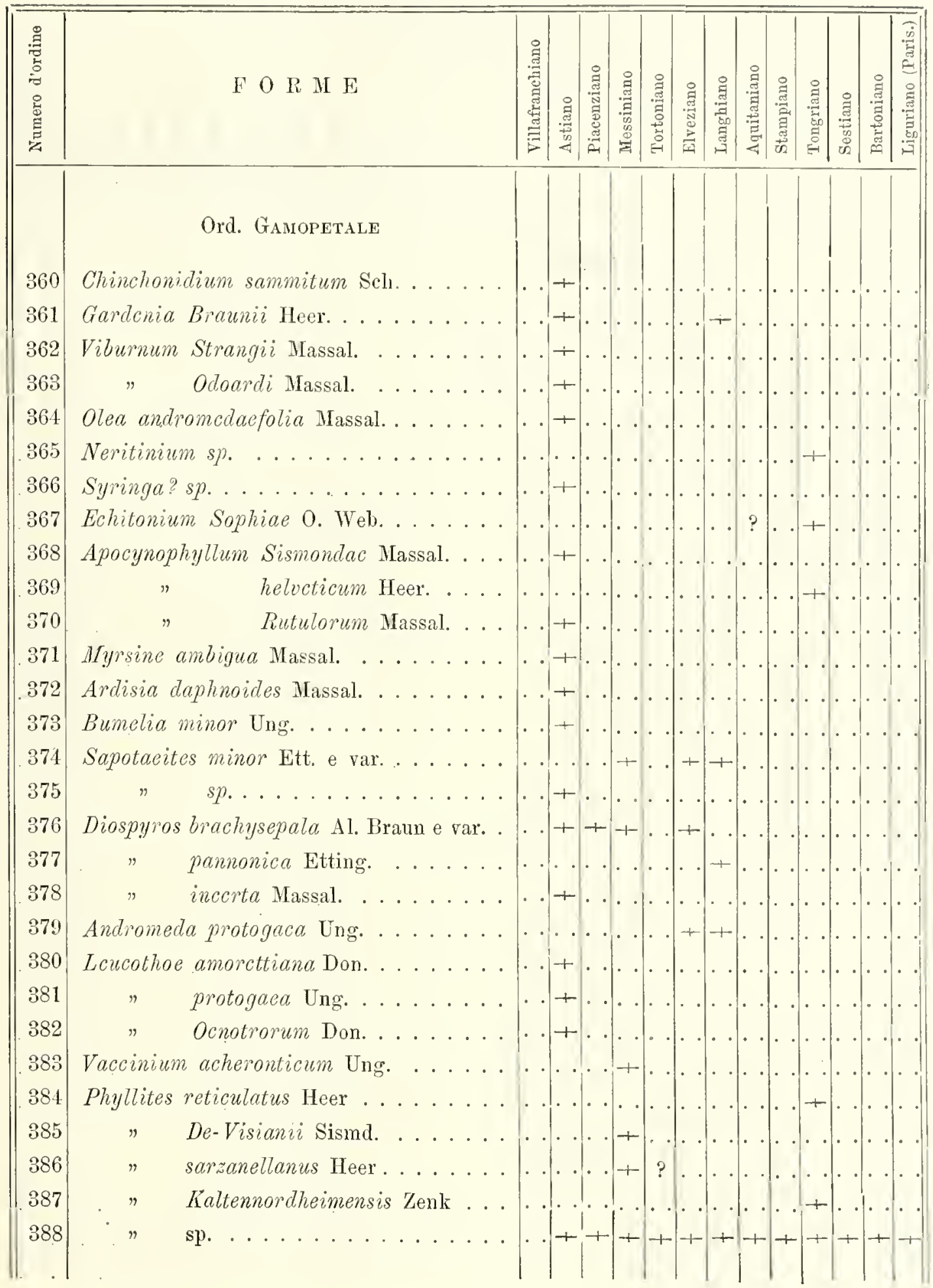


PALEOZOOLOGIA

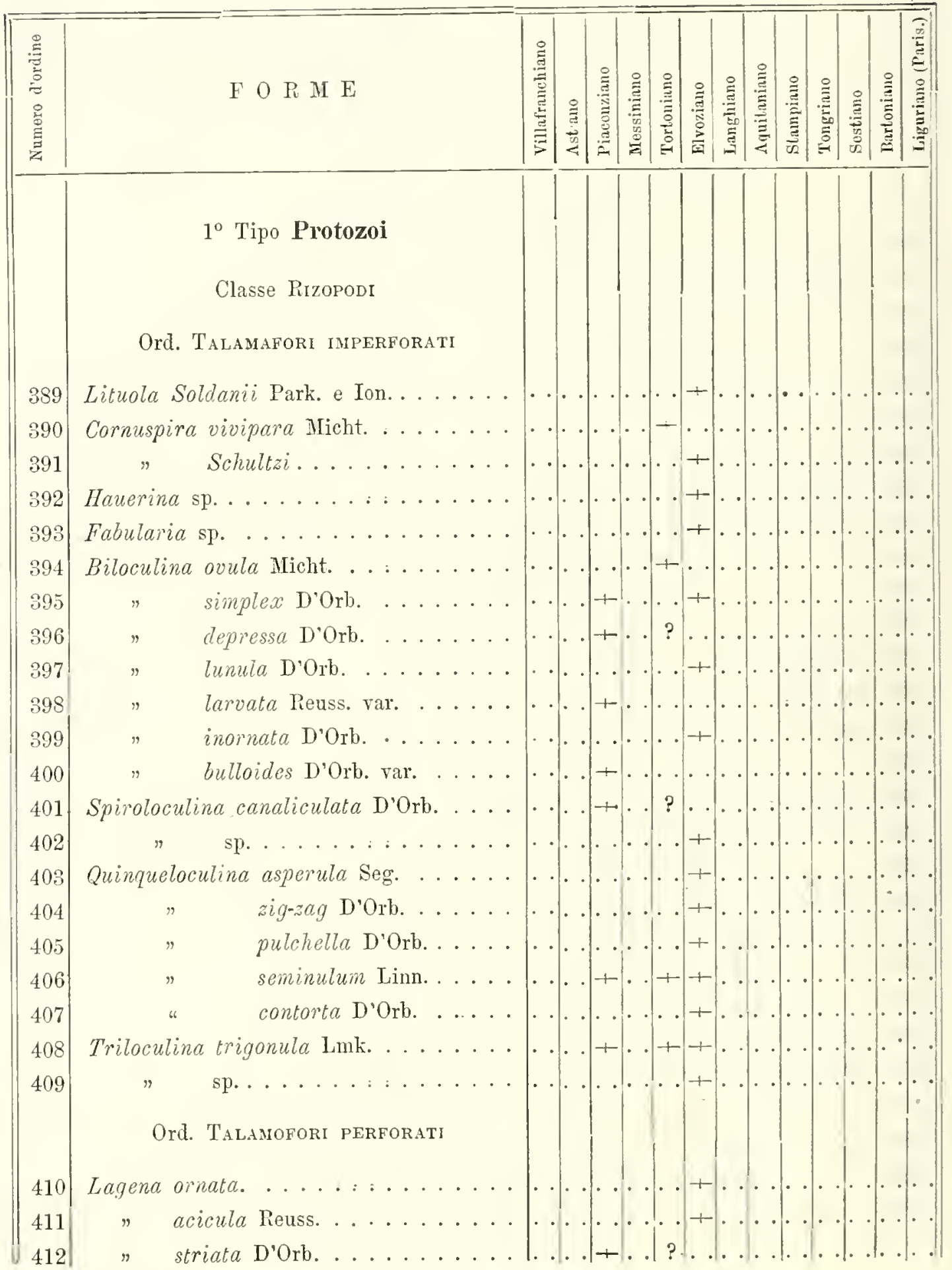




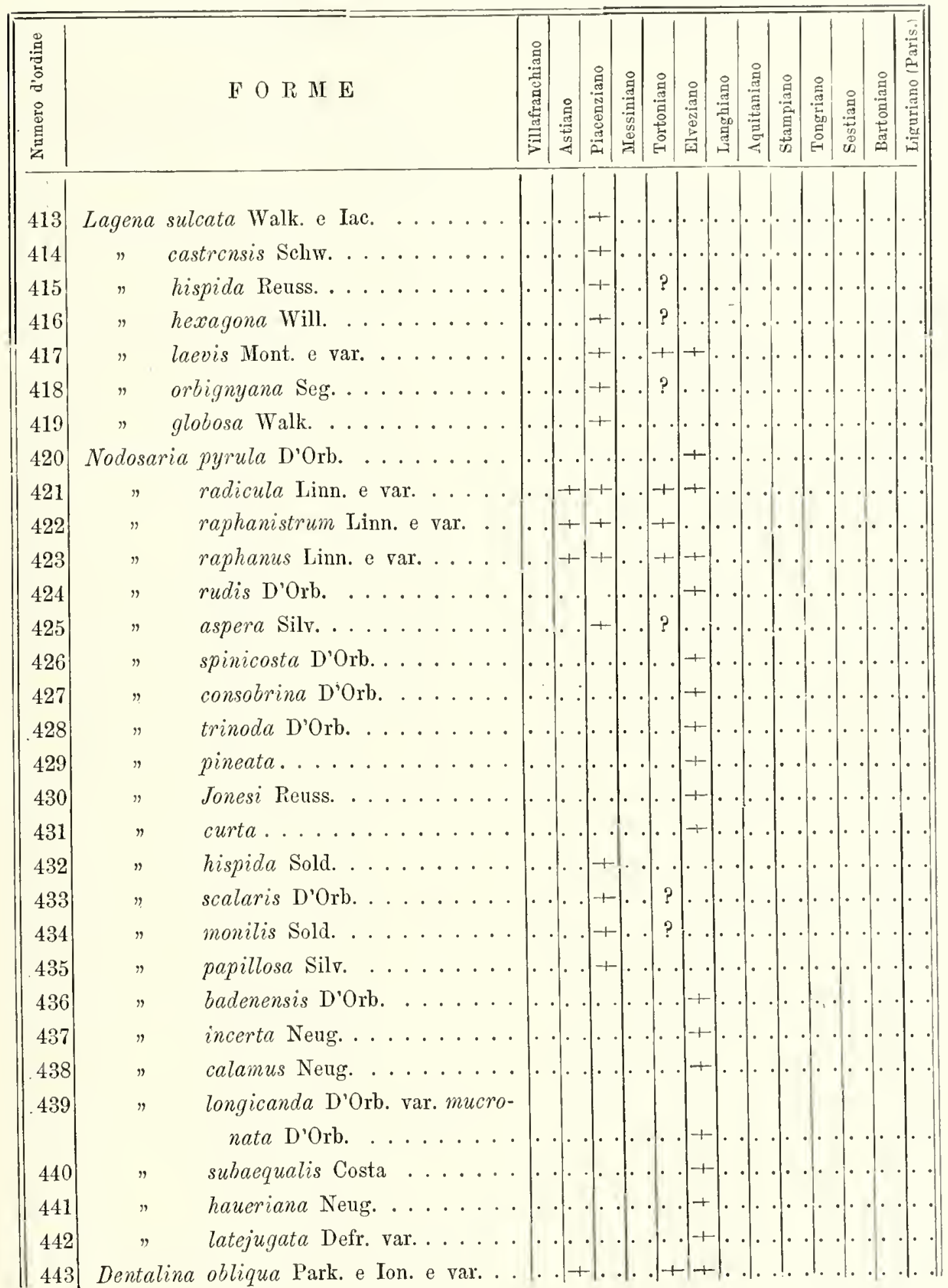




\begin{tabular}{|c|c|c|c|c|c|c|c|c|c|c|c|c|c|c|}
\hline 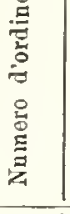 & & $\mathrm{F} O \mathrm{R} M \mathrm{II}$ & 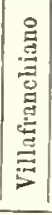 & : & 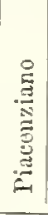 & 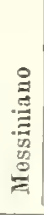 & 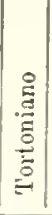 & 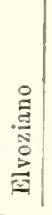 & $\mid$ & 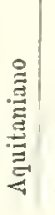 & 号 & 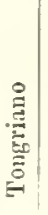 & 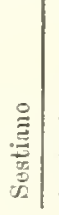 & 竎 \\
\hline 444 & Dentalina & Verneulii D'Orb. & & & & & & + & & & & & & \\
\hline 445 & $"$ & elegans D'Orb. . . . . . . . & . & & & & & + & & & & & & \\
\hline 446 & $"$ & Scharbergana Neug....... & & & & & & + & & & & & & \\
\hline 447 & $n$ & bifurcata D'orb. . . . . . . & . & & & & & + & & & & & & \\
\hline 448 & $"$ & mucronata Neug. . . . . . . . & & & & & & + & & & & & & \\
\hline 449 & $"$ & soluta Reuss. . . . . . . . . & . & & & & & + & & & & & & \\
\hline 450 & $"$ & Erevis D'Orb. .......... & . & & & & & + & & & & & & \\
\hline 451 & $"$ & tenuicallis Reuss. . . . . . . . & & & & & & + & & & & & & \\
\hline 452 & $"$ & multilineata Born. . . . . . . & . & & & & & + & & & & & & \\
\hline 453 & $"$ & boueana D'Orb......... & . & & & & & + & & & & & & \\
\hline 454 & $"$ & semicostata D'Orb. . . . . . & . & & & & & + & & & & & & \\
\hline 455 & $"$ & acuta D'Orb. .......... & . & & & & & + & & & & & & \\
\hline 456 & $"$ & inornata D'Orb. e var. . ... & & & + & & & + & & & & & & \\
\hline 457 & $"$ & consobrina D'Orb. ........ & & & & & & + & & & & & & \\
\hline 458 & $"$ & floscula D'Orb. . . . . . . . & . & & & & & + & & & & & & \\
\hline 459 & $"$ & acuticosta Reuss. . . . . . . . & . & & & & . & + & & & & & & \\
\hline 460 & $"$ & pauperata D'Orb. e var. .... & . & & + & & $?$ & + & & & & & & \\
\hline 461 & $"$ & communis D'Orb. . . . . . . . & . & & + & & $?$ & . & & & & & & \\
\hline 462 & $"$ & guttifera D'Orb. ........ & . & & + & & $?$ & & & & & & & \\
\hline 463 & $"$ & elegantissima D'Orb. . . . . & . & & + & & & & & & & & & \\
\hline 464 & Orthocerina & a Murchisoni Reuss. . . . . . & & & & & & + & & & & & & \\
\hline 465 & Vaginulina & legumen Linn. e var. ..... & & & . & & + & + & & & & & & \\
\hline 466 & $"$ & badenensis D'Orb.? ...... & & & -1 & & $?$ & $?$ & & & & & & \\
\hline 467 & Marginuline & ra Mülleri Reuss. . . . . . . . . & & & & & & $1-$ & & & & & & \\
\hline 468 & $"$ & insarcta Reuss. . . . . . . & & & & & & + & & & & & & \\
\hline 469 & $"$ & pediformis Born. . ..... & & & & & & + & & & & & & \\
\hline 470 & $"$ & glabra D'Orb. . . . . . . & & & & & & + & & & & & & \\
\hline 471 & $"$ & regularis D'Orb. . . . . . . & & & & & & + & & & & & & \\
\hline 472 & $"$ & rugosecostata D'Orb. .... & & & & & & + & & & & & & \\
\hline 473 & $"$ & triangularis D'Orb. . . . . & & & & & & + & & & & & & \\
\hline 474 & $"$ & Ionesi Reuss. . . . . . . . . . & & & & & & + & & & & & & \\
\hline 475 & $"$ & glabra D'Orb. . . . . . & & & & & $?$ & & & & & & & \\
\hline
\end{tabular}




\begin{tabular}{|c|c|c|c|c|c|c|c|c|c|c|c|c|c|c|c|}
\hline 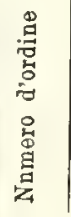 & & $\mathrm{F} O \mathrm{R} \mathrm{M} \mathrm{E}$ & 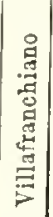 & 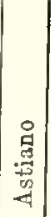 & 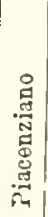 & 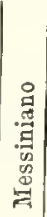 & 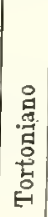 & 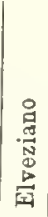 & 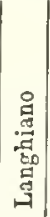 & 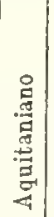 & 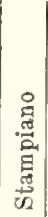 & 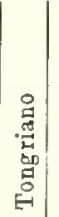 & 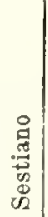 & 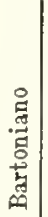 & 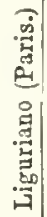 \\
\hline 476 & Marginulina & a costata Batsch........ & . & . & - & & 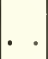 & -1 & & & & - & & & \\
\hline 477 & $"$ & hirsuta D'Orb........ & . & . & • & & $\cdot \cdot$ & + & . & & & $\cdot$ & & & \\
\hline 478 & $"$ & $\mathrm{sp} \ldots \ldots \ldots \ldots$ & . & - & + & . & + & $\cdot$ & . & - & . & - & & & \\
\hline 479 & Cristellaria & aculeata D'Orb. e var. .... & . & . & - & . & + & + & . & . & & . & & 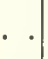 & • \\
\hline 480 & $"$ & calcar Linn. e var. ...... & . & + & + & . & + & + & . & . & . & . & & & . \\
\hline 481 & $"$ & cassis Ficht. e Moll. e var. . & . & + & + & . & + & . & . & . & & . & & . & . \\
\hline 482 & $"$ & ariminensis D'Orb. ...... & . & & + & - & . & . & . & . & . & . & . & . & \\
\hline 483 & $"$ & cymba Park et Jon. ..... & . & & • & . & & + & $\cdot$ & . & & . & & & \\
\hline 484 & $"$ & depressa Micht. ....... & 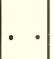 & & & . & & + & & & & & & & \\
\hline 485 & $"$ & nummulitica Gümb. . . . . . & 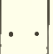 & & & . & & + & • & . & & . & & & \\
\hline 486 & $"$ & Partschi Micht. ........ & $1^{\circ}$ & & & . &. & +- & . & . & & . & & & \\
\hline 487 & $"$ & cymboides D'Orb........ & . & & & . & & + & . & . & & $\theta^{\circ}$ & & . & \\
\hline 488 & $"$ & cultrata Montf. ....... & . & & 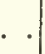 & . & $\cdot$ & + & . & . & . & . & . & 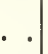 & \\
\hline 489 & $"$ & hauerina D'Orb. c var. ... & . & & + & . & $?$ & + & . & . & & $\theta^{\circ}$ & & & \\
\hline 490 & $"$ & Schloembachi Reuss. . . . . & & & & • & $\cdot 1$ & + & & 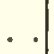 & & & & & \\
\hline 491 & $"$ & 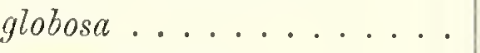 & . & & & & & + & & & & 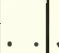 & 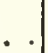 & & \\
\hline 492 & $"$ & simplex D'Orb. ....... & & & & & & + & & . & & . & & & \\
\hline 493 & $"$ & Iosephinia D'Orb. ....... & . & & & & . & + & . & 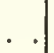 & . & . & . & & \\
\hline 494 & $"$ & grata Reuss. . . . . . . . & 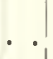 & & & & . & + & & . & & & . & & \\
\hline 495 & $"$ & compressa D'Orb. ...... & & & & & & + & . & . & . & & . & & \\
\hline 496 & $"$ & lanceolata D'Orb. . . . . . . & & & & 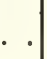 & . . & + & & . & . & & . & & \\
\hline 497 & $"$ & 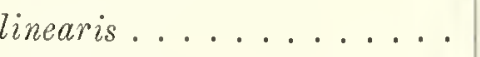 & & & & • & . & + & & . & . & & . & & \\
\hline 498 & $"$ & italica Defr.......... & & & & & . & + & & 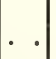 & . & 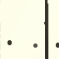 & - & & \\
\hline 499 & $"$ & variabilis Reuss. . ..... & $\theta_{0}$ & & + & . & $?$ & & & & & . & & & \\
\hline 500 & $"$ & triangularis D'Orb. . . . . . & $0^{\circ}$ & & + & & • & & & . & . & & . & & \\
\hline 501 & $"$ & latifrons Brady......... & $l^{\circ}$ & & + & • & $?$ & & & $\cdot$ & . & . & & & \\
\hline 502 & $"$ & confusa Seg........... & $\sigma^{\circ}$ & & + & & $?$ & & & 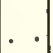 & & . & & & \\
\hline 503 & $"$ & semimpressa Reuss. . . . . . & & & & & $?$ & & & & & & & & \\
\hline 504 & $"$ & (Robulina) similis D'Orb. . . . & & & & & & + & & . & & & & & \\
\hline 505 & $"$ & $" \quad$ intermedia $\mathrm{D}^{\prime} \mathrm{Orb}$. & & & & & & + & & $\left.\right|^{\circ}$ & . & . & & & \\
\hline 506 & $"$ & limbosa Reuss. . . & & & & & & + & & & & . & & & \\
\hline 507 & $"$ & inornata D'Orb. . . & & & & & & & & & & 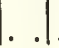 & & & \\
\hline
\end{tabular}




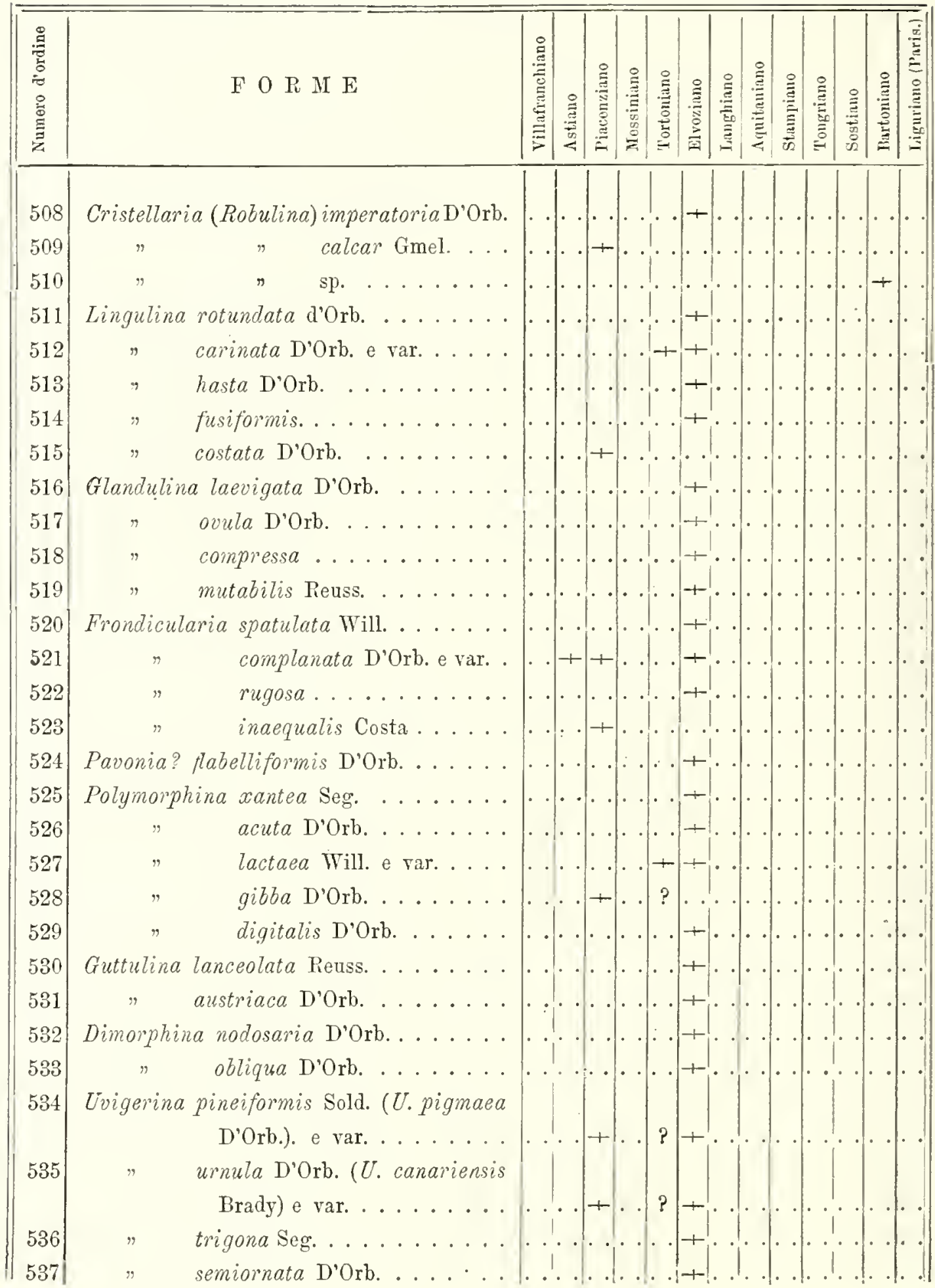




\begin{tabular}{|c|c|c|c|c|c|c|c|c|c|c|c|c|c|}
\hline 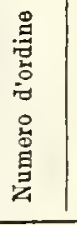 & $\mathrm{F} O \mathrm{R} \mathrm{ML}$ & 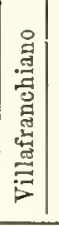 & 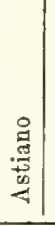 & 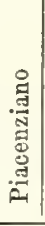 & & 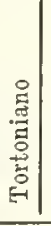 & 量 & 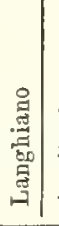 & 業 & & & 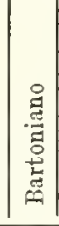 & 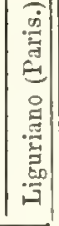 \\
\hline 538 & Uvigerina aculeata D'Orb. e var. . . . . & & & + & & $?$ & $?$ & & & & & & \\
\hline 539 & $" \quad$ asperula Czizek e var. . . . . & & & + & & $?$ & & & & & & & \\
\hline 540 & Sagrina? striata Schw........... & & & & & & & & & & & & \\
\hline 541 & Textularia amphorina Sold. e var. . . . & & -1 & + & & & + & & & & & & \\
\hline 542 & $" \quad$ carinata D'Orb. e var. . . . & & & & & + & + & & & & & & \\
\hline 543 & cylindrica Micht. ....... & & & & & & + & & & & & & \\
\hline 544 & deperdita D'Orb. ...... & & & & & & + & & & & & & \\
\hline 545 & gracilis D'Orb. . . . . . . & & & & & & + & & & & & & \\
\hline 546 & $" \quad$ gibbosa D'Orb. ....... & & & & & & + & & & & & & \\
\hline 547 & $" \quad$ subtilis D'Orb. ....... & & & - & & & + & & & & & & \\
\hline 548 & cotusa D'Orb. . . . . . . & & & . & & & + & & & & & & \\
\hline 549 & agglutinans D'Orb. e var. . & & & + & & & + & & & & & & \\
\hline 550 & complanata D'Orb. ...... & & & - & & & + & & & & & & \\
\hline 551 & gramen D'Orb. ....... & & & - & & & + & & & & & & \\
\hline 552 & obtusa D'Orb. . . . . . . . & & & & & & + & & & & & & \\
\hline 553 & pygmaea D'Orb. . . . . . . . & & & • & & & + & & & & & & \\
\hline 554 & Mariae D'Orb. . . . . . . & & & & & & + & & & & & & \\
\hline 555 & abbreviata D'Orb. var. . . . . & & & + & & & & & & & & & \\
\hline 556 & Bigenerina agglutinans D'Orb. e var. . . & & & + & & ? & + & & & & & & \\
\hline 557 & Verneuilina spinulosa Reuss. . . . . . . & & & + & & . & & & & & & & \\
\hline 558 & Bolivina aenariensis Costa var. . . . . & & & + & & $?$ & & & & & & & \\
\hline 559 & punctata D'Orb. ......... & & & + & & ? & & & & & & & \\
\hline 560 & Beyrichi Reuss. . . . . . . . & & & + & & & & & & & & & \\
\hline 561 & 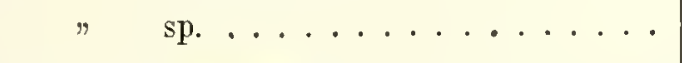 & & & & & & + & & & & & & \\
\hline 562 & Valvulina communis D'Orb. ........ & & & & & & + & & & & & & \\
\hline 563 & $" \quad$ gramen Dorb. ........ & & & & & & + & & & & & & \\
\hline 564 & $" \quad$ umbilicata Born. ....... & & & & & & + & & & & & & \\
\hline 565 & Bulimina fusiformis D'Orb. . . . . . . & & & & & & + & & & & & & \\
\hline 566 & $" \quad$ pyrula D'Orb. e var. . . . . : & & & + & & ? & 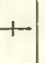 & & & & & & \\
\hline 567 & buchiana D'Orb. e var. .... & & & + & & $?$ & + & & & & & & \\
\hline 568 & ovata D'Orb. . . . . . . . . & & & & & & + & & & & & & \\
\hline 569 & pupoides D'Orb. e var. & & & + & & ? & + & & & & & & \\
\hline
\end{tabular}




\begin{tabular}{|c|c|c|c|c|c|c|c|c|c|c|c|c|c|}
\hline 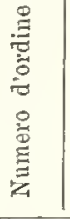 & $\mathrm{F} O \mathrm{R} M \mathrm{E}$ & $\mid$ & & 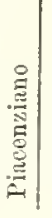 & 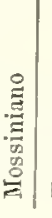 & . & 旁 & 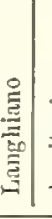 & & & 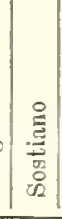 & 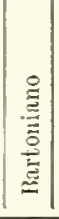 & 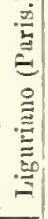 \\
\hline 570 & Bulimina aculeata D’orb. . . . . . . . & & & + & & & & & & & & & \\
\hline 571 & $" \quad$ inflata Seg. .......... & & & + & & & & & & & & & \\
\hline 572 & $" \quad$ (Robertina) arctica D'Orb. .. & & & & & & + & & & & & & \\
\hline 573 & Asterigina? planorlis sold. . . . . . . . & & & & & & & & & & & & \\
\hline 574 & Cassidulina serrata D'orb. . . . . . . . & & & & & & + & & & & & & \\
\hline 575 & laevigata D'Orb. . . . . . & & & + & & & & & & & & & \\
\hline 576 & Bradyi Norm. . . . . . . . . . & & & + & & & . & & & & & & \\
\hline 577 & Orbulina universa D'Orb. e var. ..... & & + & + & & + & + & & & & & & \\
\hline 578 & $" \quad$ porosa Terq. .......... & & & + & & & . & & & & & & \\
\hline 579 & Globigerina rugosa D'Orb. . . . . . . . . & & & & & & + & & & & & & \\
\hline 580 & gibba D'Orb. ........ & & & & & & + & & & & & & \\
\hline 581. & bulloides D'Orb. ........ & & & + & & ? & . & & & & & & \\
\hline 582 & regularis $\mathrm{D}^{\circ}$ Orb. . . . . . . & & & + & & ? & & & & & & & \\
\hline 588 & bilobata D'Orb. . . . . . . & & & . & & & + & & & & & & \\
\hline 584 & triloba Reuss. . . . . . . . . . & & & & & & + & & & & & & \\
\hline 585 & quadrilobata D'Orb. . .... & & & & & & + & & & & & & \\
\hline 586 & Pulienia communis D'Orb. . . . . . . . . & & & & & & + & & & & & & \\
\hline 587 & $"$ sphoeroides D'Orb. ....... & & & + & & & & & & & & & \\
\hline 588 & Sphoeroidina bulloides D'Orb. e var. . . & & & & & & + & & & & & & \\
\hline 589 & austriaca D'Orb. . . . . . . & & & & & & + & & & & & & \\
\hline 590 & sp. . . . . . . . . & & & & & & + & & & & & & \\
\hline 591 & 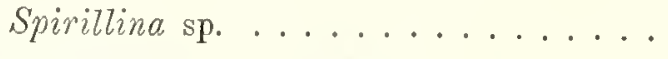 & & & & & & + & & & & & & \\
\hline 592 & Discorbina mamilla Will. . . . . . . . & & & & & & + & & & & & & \\
\hline 593 & orticularis Terq. ....... & & & + & & $?$ & & & & & & & \\
\hline 594 & globularis D'Orb. ....... & & & & & & + & & & & & & \\
\hline 595 & Planorbulina tuberculata Sold. e var. . . & & & & & + & + & & & & & & \\
\hline 596 & rotula D'Orb. . . . . . . . & & & & & & + & & & & & & \\
\hline 597 & Truncatulina lobatula Walk. e Jon. e var. & & & + & & + & $1-$ & & & & & & \\
\hline 598 & bouena D'Orb. ........ & & & & & & + & & & & & & \\
\hline 599 & ungeriana D'Orb. e var. . & & & + & & $?$ & + & & & & & & \\
\hline 600 & Haidingeri D'Orb. . . . . . & & & & & & + & & & & & & \\
\hline 601 & refulgens D'Orb. . . . . . . & & & & & & + & & & & & & \\
\hline
\end{tabular}




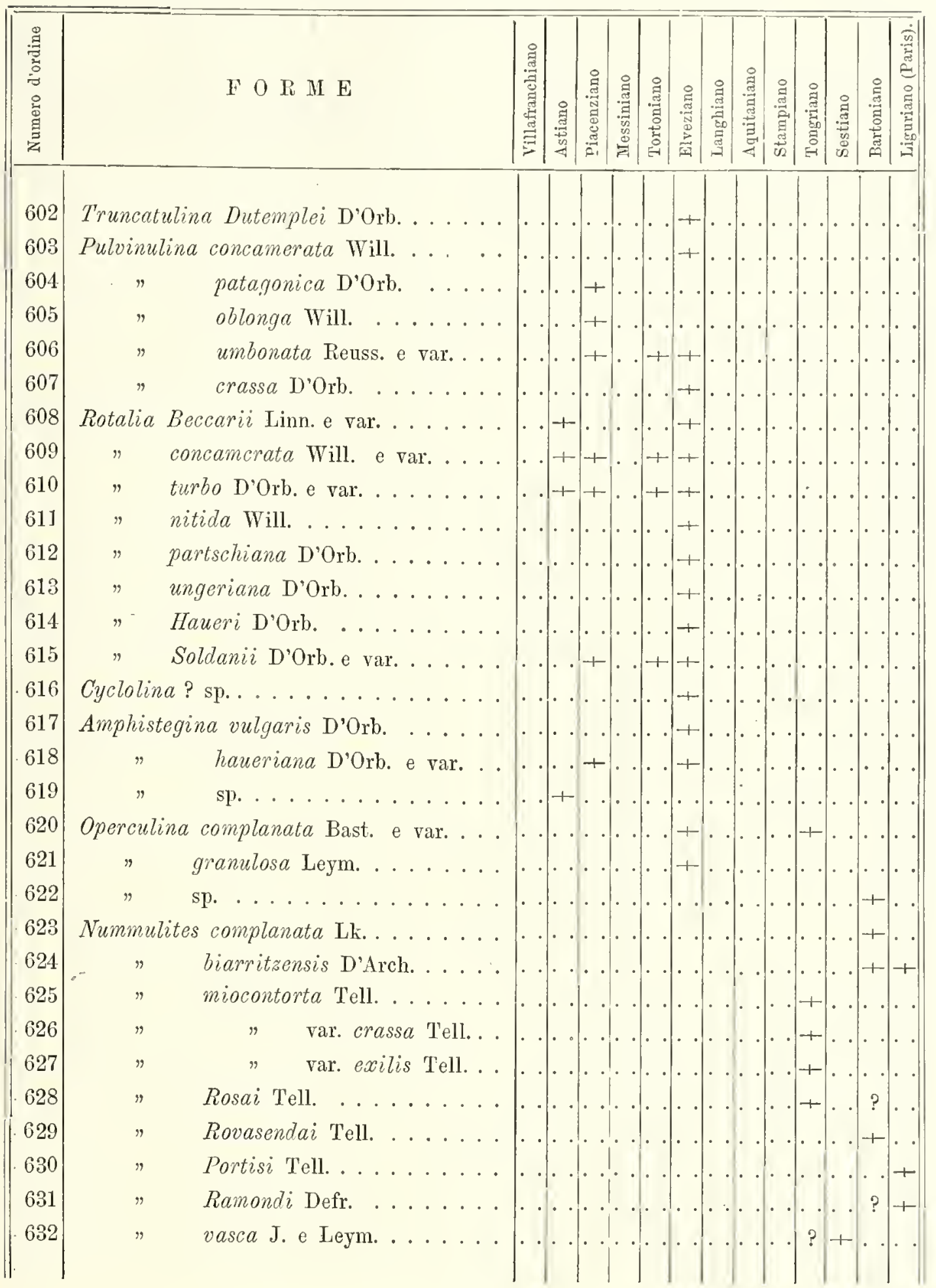




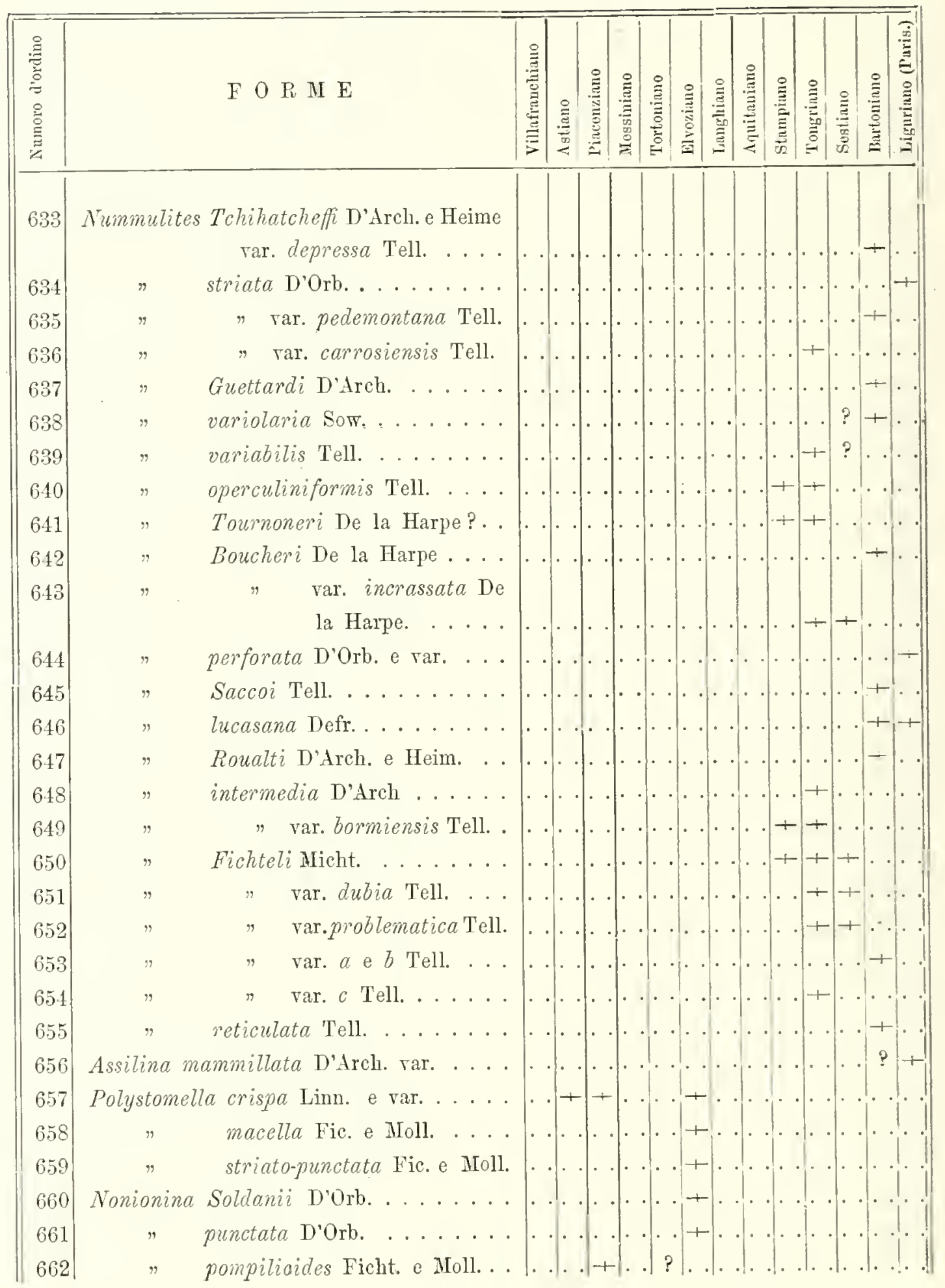




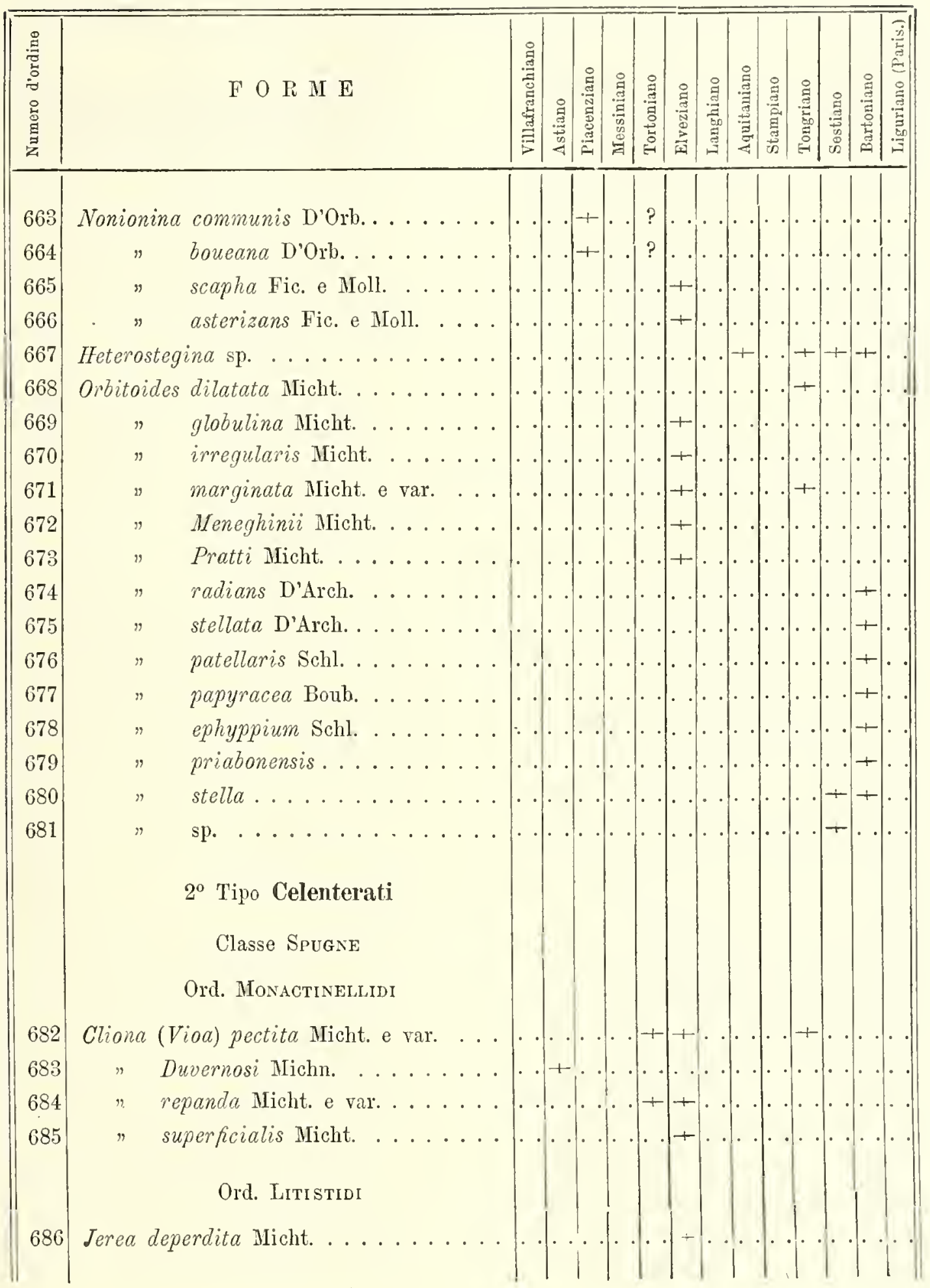




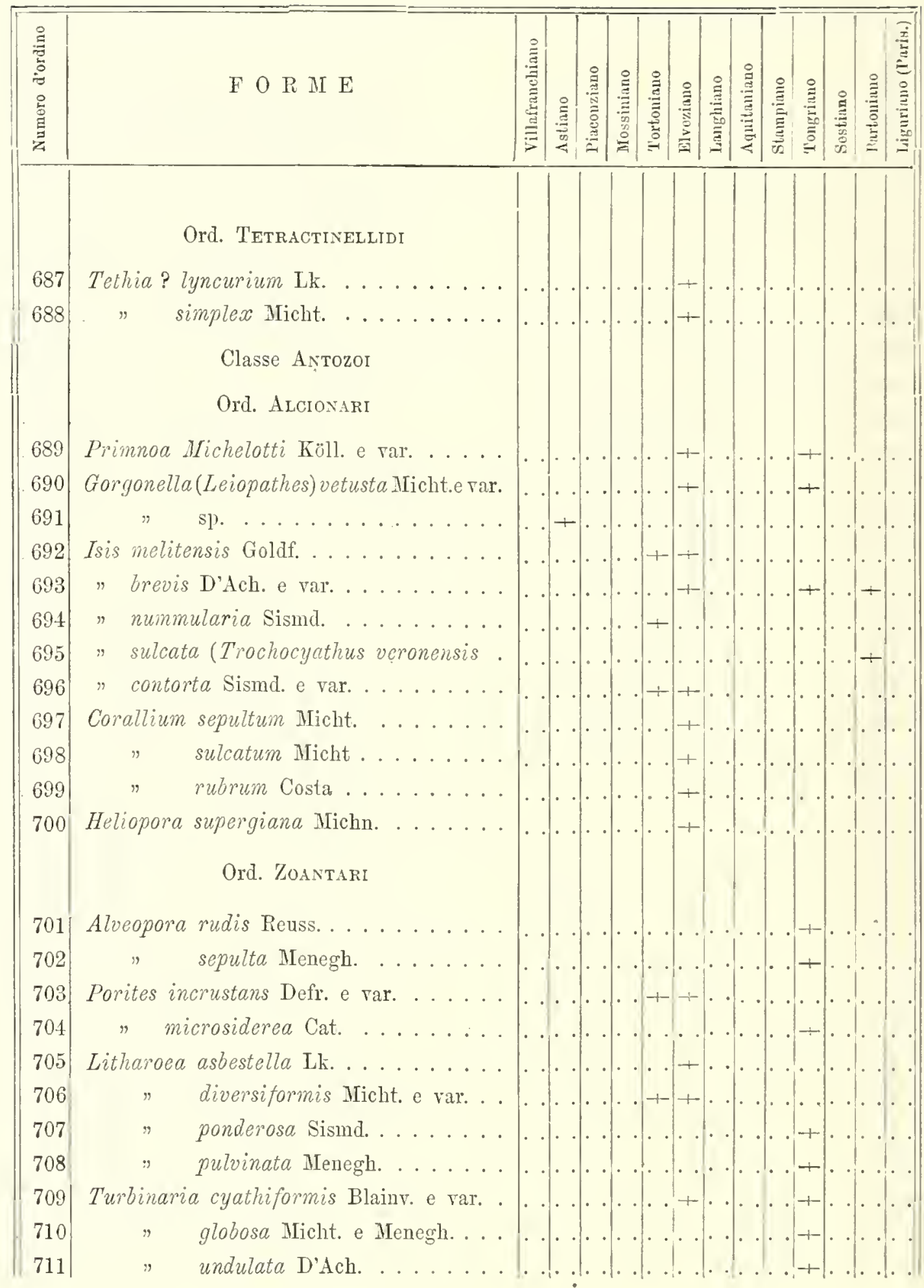




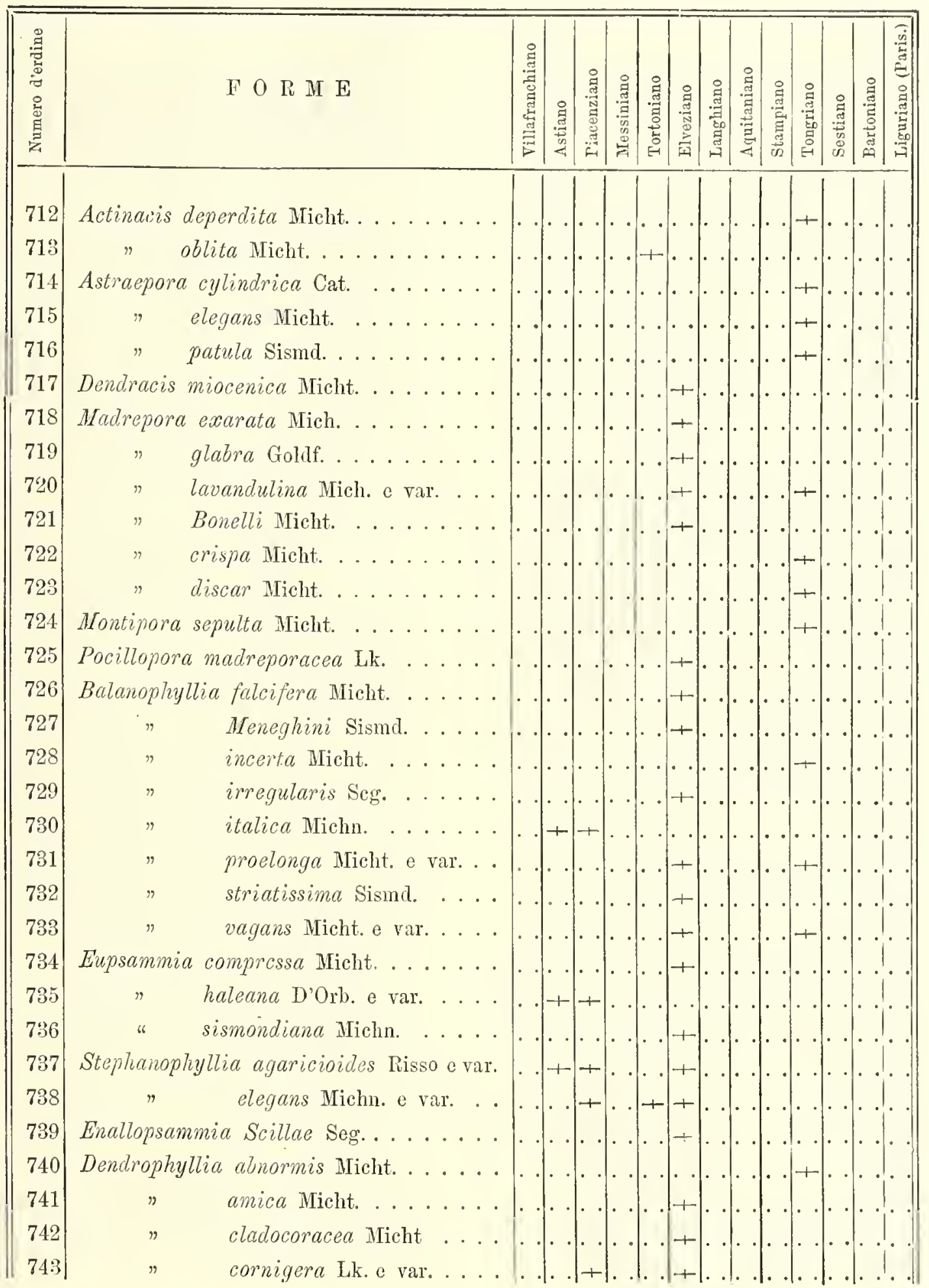




\begin{tabular}{|c|c|c|c|c|c|c|c|c|c|c|c|c|c|}
\hline 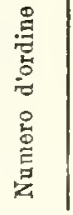 & F O R M E & 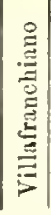 & 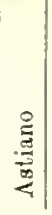 & 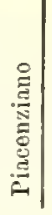 & 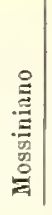 & & 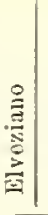 & 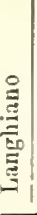 & & & & & 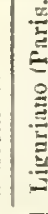 \\
\hline 744 & Dendrophyllia digitalis Blainv. . . . . . & & & & & & + & & & & & & \\
\hline 745 & $" \quad$ globulina Mricht. . . . . & & & & & & + & & & & & & \\
\hline 746 & irregularis Blainv. . . . . . & & & & & & + & & & & & & \\
\hline 747 & longeva Micht. ....... & & & & & & + & & & & & & \\
\hline 748 & Michelini Nicht. . . . . . & & & & & & + & & & & & & \\
\hline 719 & taurinensis E. H. ..... & & & & & & + & & & & & & \\
\hline 750 & trifurcata Micht. . . . . . & & & & & & + & & & & & & \\
\hline 751 & sp. . . . . . . . . . & & & + & & & & & & & & & \\
\hline 752 & Lobopsammia miocenica Micht. . . . . . . & & & & & & & & & & $t$ & & \\
\hline 753 & Cyclolithes? Borsoni Nichn. . . . . . . & & & ? & & & ? & & & & & & \\
\hline 754 & Thamnastraea volvox Micht. ....... & & & & & & & & & & & & \\
\hline 755 & Dimorphastraea bormidensis Micht. ... & & & & & & & & & & & & \\
\hline 756 & Comoseris cistaeformis Micht. . . . . . . . & & & & & & & & & & & & \\
\hline 757 & deperdita Micht. . . . . . . . & & & & & & & & & & & & \\
\hline 758 & Protoseris miocenica Micht. ........ & & & & & & & & & & & & \\
\hline 759 & Podabacia patula Micht. . . . . . . . . & & & & & & & & & & & & \\
\hline 760 & Cyathoseris appennina Michn........ & & & & & & & & & & + & & \\
\hline 761 & falcifera Cat. ........ & & & & & & & & & & 4 & & \\
\hline 762 & parvistella Micht. . . . . . & & & & & & & & & & & & \\
\hline 763 & scripta Micht. . . . . . . . & & & & & & & & & & & & \\
\hline 764 & Trochoseris cornucopia Micht. . . . . . & & & & & & & & & & & & \\
\hline 765 & miocenica Micht. . . . . . . & & & & & & & & & & & & \\
\hline 766 & venusta Micht. . . . . & & & & & & & & & - & & & \\
\hline 767 & Moltlivaultia bormidensis Milne-Edw. . & & & & & & & & & & & & \\
\hline 768 & carcarensis Micht. . . . . . & & & & & & & & & - & & & \\
\hline 769 & compressa Sismd. . . . . . & & & & & & 1 & & & & & & \\
\hline 770 & coronula Micht. & & & & & & + & & & & & & \\
\hline 771 & Iapheti Micht. e var. . . . . & & & & & & + & & & & & & \\
\hline 772 & humilis Micht. . & & & & & & & & & & & & \\
\hline 773 & patula Micht. . . . . . . . . & & & & & & + & & & & & & \\
\hline 774 & Lithophyllia Basteroti E. H. . . . . . . & & & & & & + & & & & & & \\
\hline 775 & Leptomussa abnormis Micht. . . . . . . & & & & & & & & & & & & \\
\hline
\end{tabular}




\begin{tabular}{|c|c|c|c|c|c|c|c|c|c|c|c|c|c|c|}
\hline 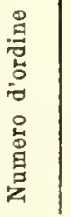 & $\mathrm{F} O \mathrm{R} \mathrm{H} \mathrm{E}$ & 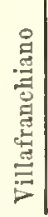 & 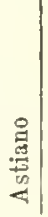 & 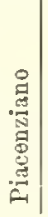 & 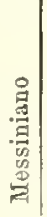 & 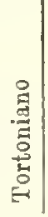 & 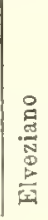 & 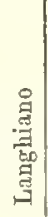 & 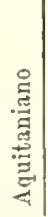 & 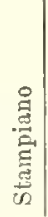 & 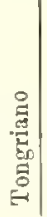 & 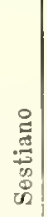 & 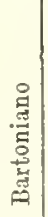 & 可 \\
\hline 776 & Circophyllia conica Micht. ....... & . & & & & & 十 & & • & & & & & \\
\hline 777 & Dasyphyllia elongata Sismd. . . .... & . & 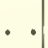 & & & & + & . & & & & & 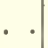 & , \\
\hline 778 & crectiuscula Micht. ..... & . & - & & & & & & . & & + & & & \\
\hline 779 & miocenica Micht. ...... & 1. & & & & & & & $\cdot$ & & + & & & \\
\hline 780 & taurincnsis E. H. . . . . . & . & . & & & & & . & . & & + & & & \\
\hline 781 & sp. . . . . . . . . . & . & . & & & & & . & . & & & & + & \\
\hline 782 & Calamophyllia pseudo-flabellum Cat.... & . & . & & & & & • & . & & + & & & \\
\hline 783 & Rhabdophyllia stipata D'Ach........ & . & & & & & & • & . & & + & & & \\
\hline 784 & Tecosmilia conferta Micht. ....... & 1. & . & & & & & & . & & + & & & \\
\hline 785 & $" \quad$ depressa Michn........ & . & . & & & & & . & . & & + & & & \\
\hline 786 & Symphyllia crebriformis Micht. ..... &. & . & & & & & & . & & + & & & \\
\hline 787 & Mycetophyllia dubia Cat. ........ & 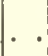 & & & & & & & . & & + & & & \\
\hline 788 & interrupta Peuss. ..... & . & . & & & & & & . & . & + & & & \\
\hline 789 & repanda Micht. ...... & . & & & & & - & & . & • & + & & & \\
\hline 790 & stellifera Michri...... & . & & & & & & . & . & . & + & & . & 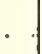 \\
\hline 791 & $" \quad s p \ldots \ldots \ldots \ldots \ldots$ & . & • & & & & & 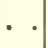 & . & & & & + & \\
\hline 792 & Elophyllia magnicostata Sismd. ..... & . & • & & & & & . & . & & + & & & \\
\hline 793 & " profunda Michn........ & . & & & & & & & & & & & & \\
\hline 794 & Tridacnophyllia cichorium Micht. .... & . & · & & & & & & . & & + & & & . \\
\hline 795 & Tridacnophyllia subangulata Micht. . . . & . & & & & & & & & & + & & . & \\
\hline 796 & Manicina antiqua Micht.......... & 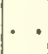 & & & & & & & 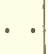 & & + & & & \\
\hline 797 & Meandrina Bellardii E. H. ..... & . & & & & & & - & . & & + & & & \\
\hline 798 & Diploria intermedia Micht. ....... & . & & & & & & & 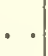 & & + & & & \\
\hline 799 & Hydnophora affnis Micht. ....... & . & & & & & & & & & + & & & \\
\hline 800 & anceps Micht. ........ & . & & & & & & & . & & + & & & \\
\hline 801 & collinaria Cat. ....... & . & & & & & & & & & + & & & \\
\hline 802 & elongata Micht........ & 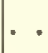 & & & & & & & & & + & & & \\
\hline 803 & meandrinoides Mich. ..... & & & & & & & & & & + & & & \\
\hline 804 & sativa Micht. . . . . . . . . & . & & & & & & & & & & & & \\
\hline 805 & Plesiophyllia mutata Micht. ...... & · & & & & & & & • & & + & & & \\
\hline 806 & profunda Micht. . & & & & & & & & • & • & + & & & \\
\hline 807 & radiata Micht. . & & & & & & & & & & & & & \\
\hline
\end{tabular}




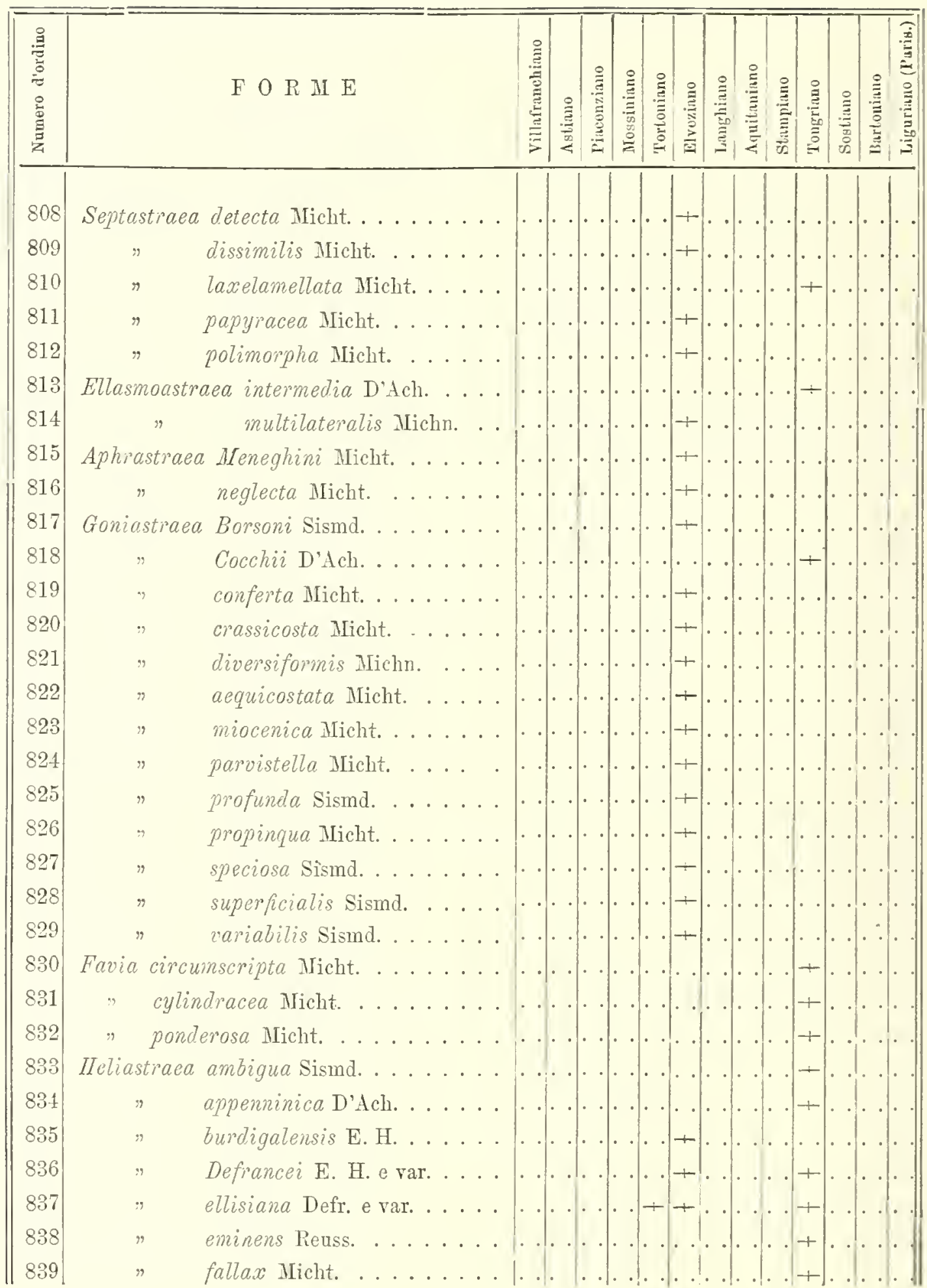




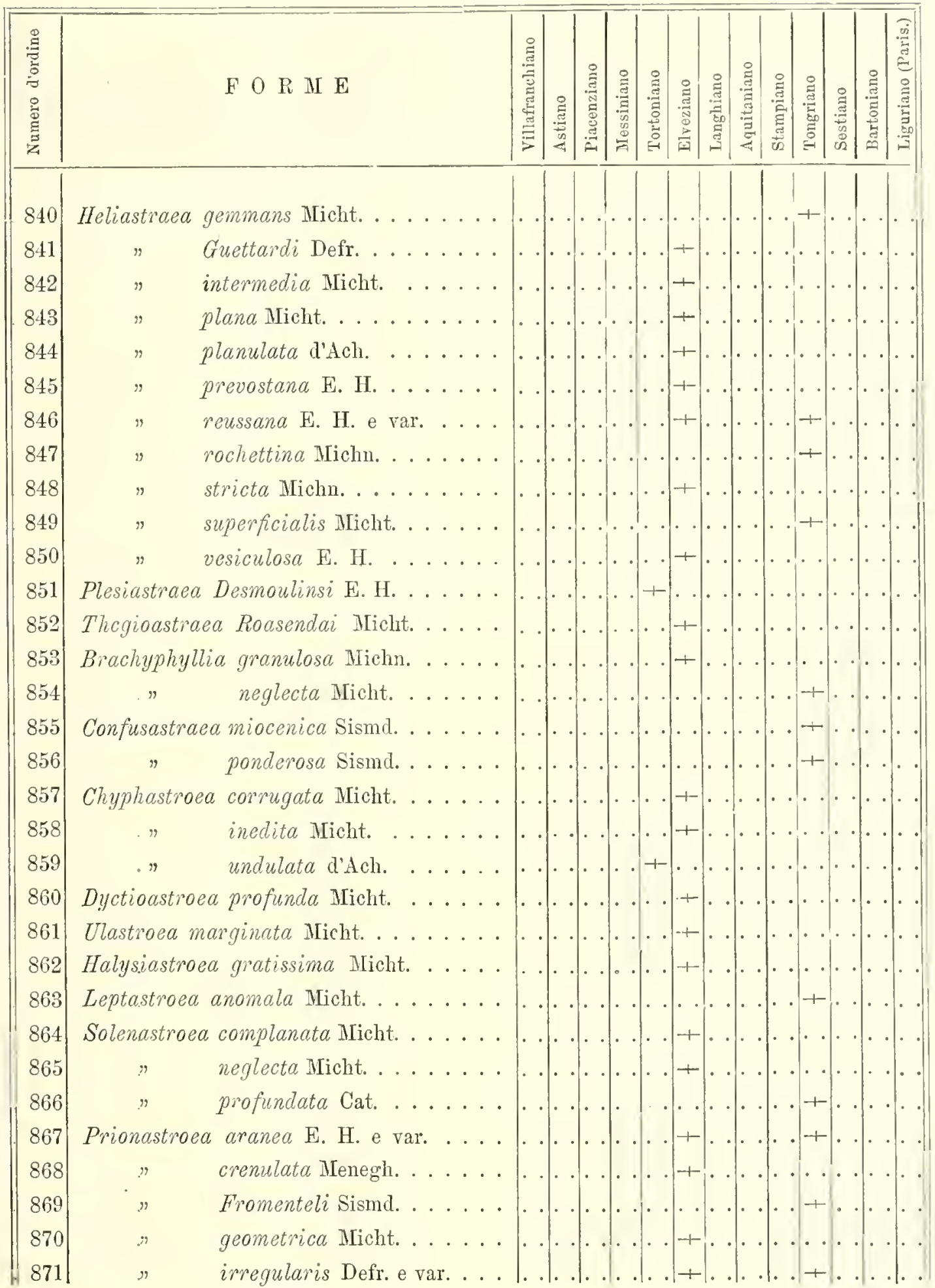




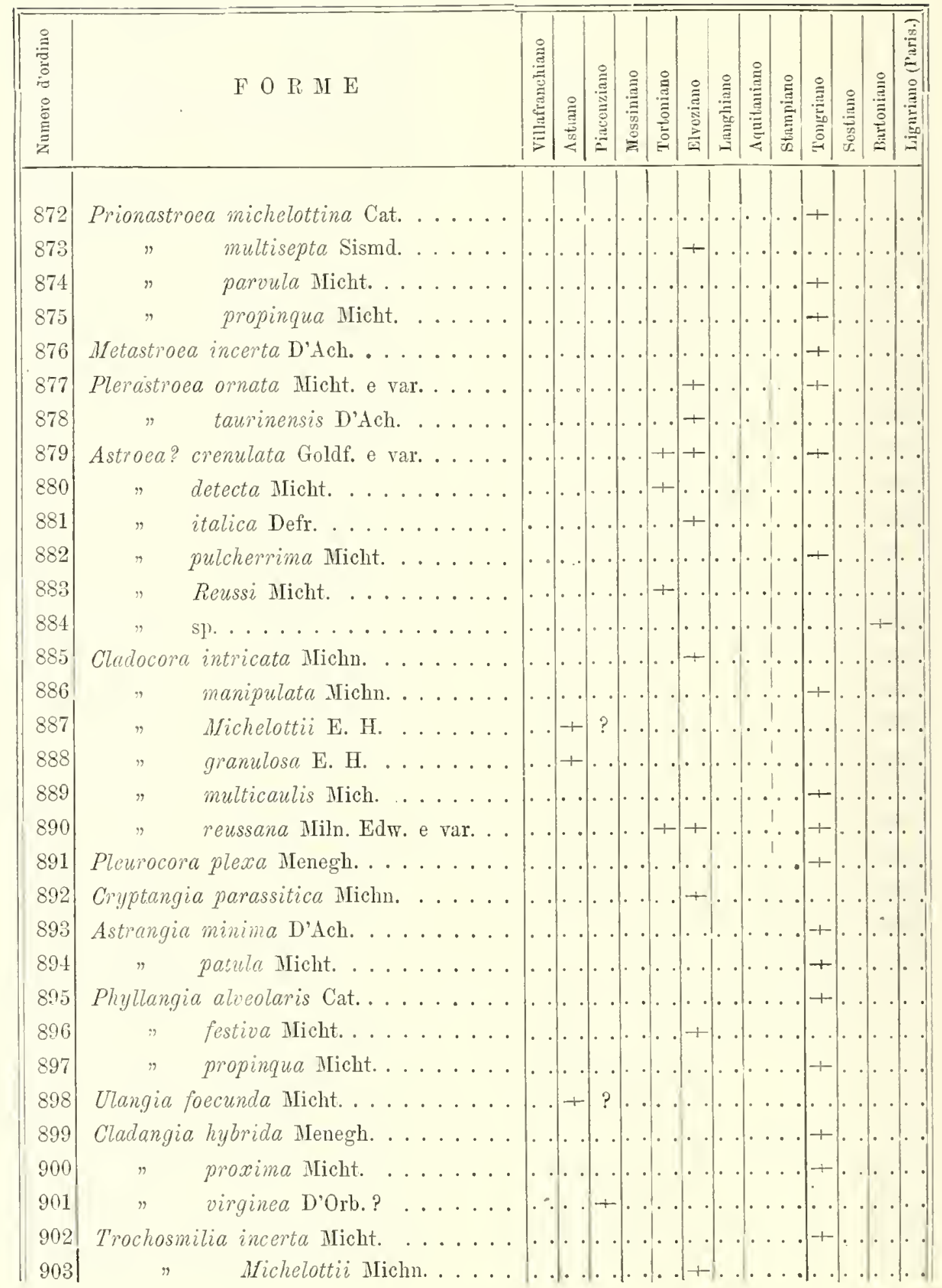




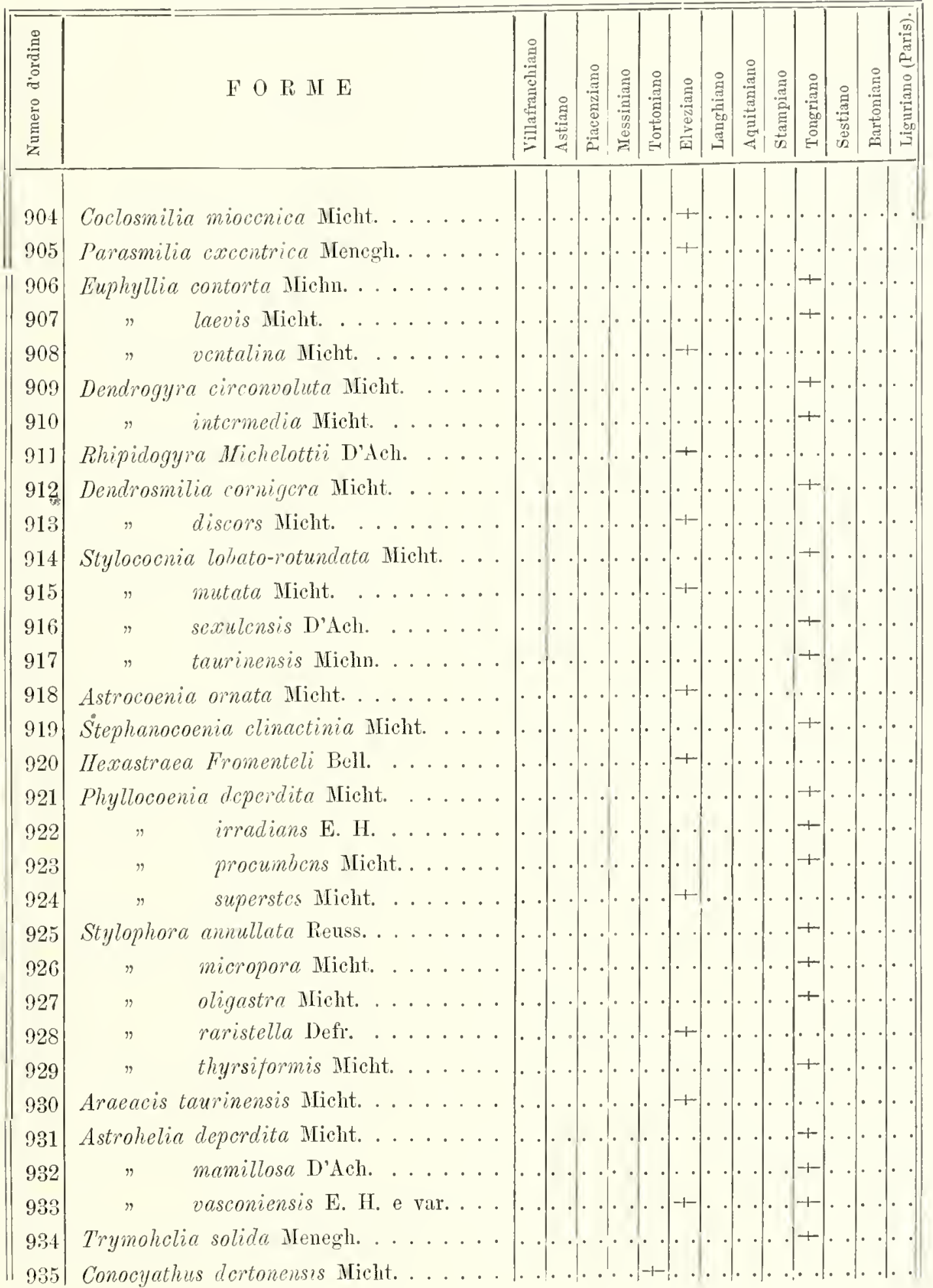




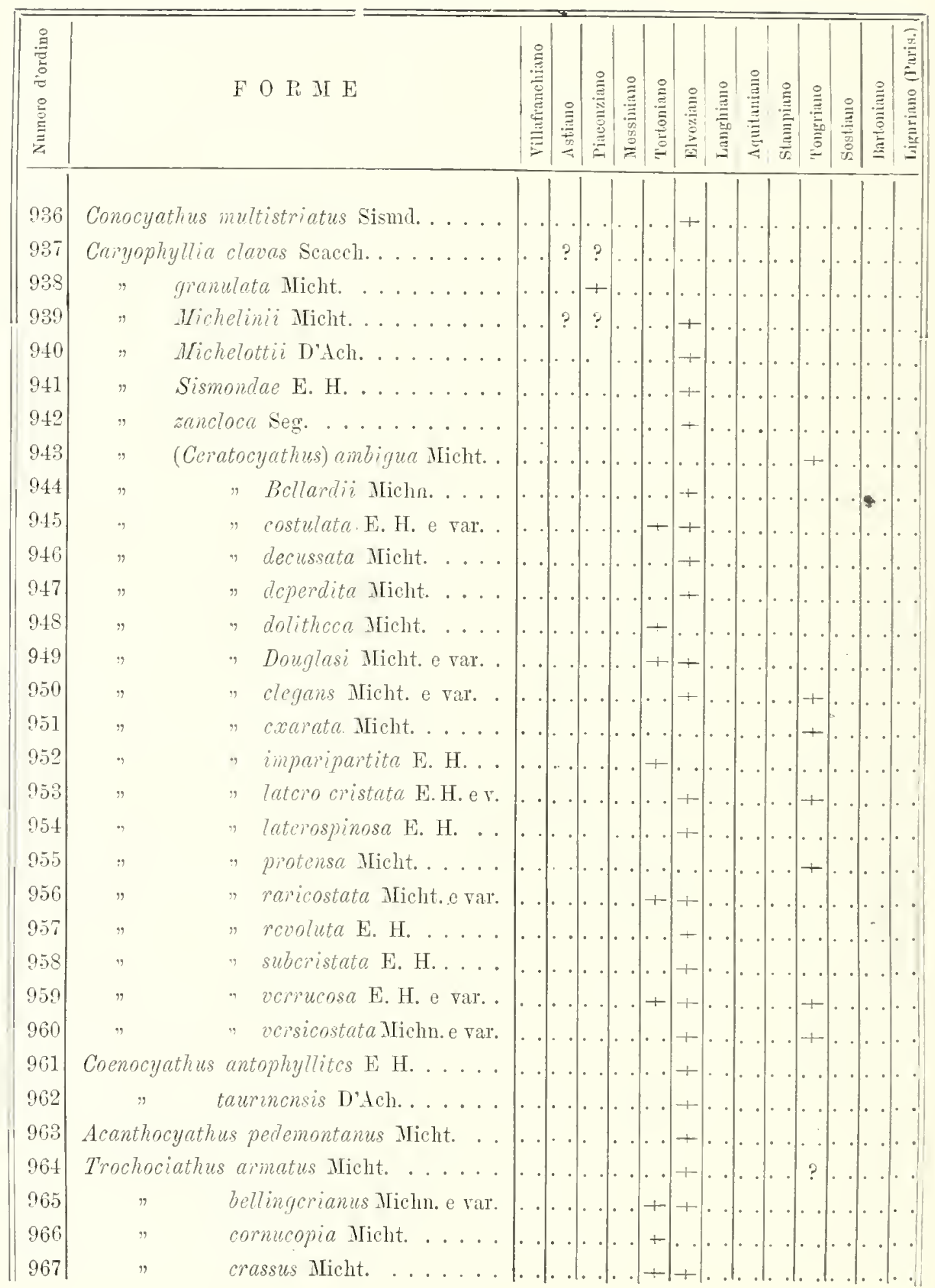




\begin{tabular}{|c|c|c|c|c|c|c|c|c|c|c|c|c|c|c|}
\hline 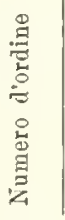 & $\mathrm{F} O \mathrm{IH} \mathrm{E}$ & 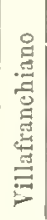 & 兽 & 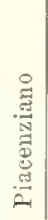 & 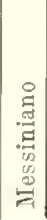 & 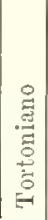 & 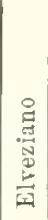 & 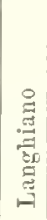 & 总 & 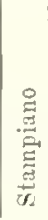 & 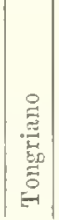 & 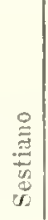 & 总 & 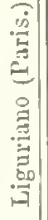 \\
\hline 968 & Trochocyathus mitratus Goldf. ...... & 1. & • & . & & + & + & & . & & & & & \\
\hline 969 & obesus Micht. ....... & . & & & & - & & & & . & & & & \\
\hline 970 & ponderosus Micht. ..... & . & & & & + & + & & . & - & & & & \\
\hline 971 & punctrtus Micht. ..... & . & & & & & $4-$ & & - & . & . & & & \\
\hline 972 & pyramidatus Micht. e var. & . & & & & + & + & & . & . & & & & \\
\hline 973 & $\operatorname{simplex}$ E. H. ...... & . & • & & & 7 & + & & . & . & & & & \\
\hline 974 & Sismondae E. H....... & . & . & & & & + & & - & . & & & & \\
\hline 975 & sublocvis E. H. ...... & . & $\cdot$ & • & & & + & & . & . & & & & \\
\hline 976 & sulcatus E. Sismd. . . . . & . & . & . & & - & + & & . & . & & - & & \\
\hline 977 & undulatus Michn. ..... & & $\cdot$ & & & + & & & . & - & . & & & \\
\hline 978 & Deltocyathus cylindricus Micht....... & & & & & & + & & . & . & . & & & \\
\hline 979 & italicus Micht. ...... & . & $10^{\circ}$ & $1^{\circ}$ & & $-1-$ & + & & . & - & . & & & \\
\hline 980 & taurinensis Micht. . . . . . & 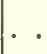 & . & 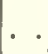 & & $\cdot$ & + & & . & . & . & . & & \\
\hline 981 & Paracyathus cristatus Wicht. ...... & 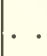 & & & & $1^{\circ}$ & + & & . & . & . & & & \\
\hline 982 & pedemontanns Michn. .... & . & + & $?$ & & . & $\cdot$ & 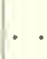 & . & $a^{\circ}$ & . & ${ }^{\circ}$ & & \\
\hline 983 & turonensis E. H....... & . . & - & & & & + & & . & . & . & $\cdot$ & & \\
\hline 984 & Smilotrochus? macroseptus Micht. .... & . & . & . & & + & . & & . & . & . & ${ }^{\circ}$ & & \\
\hline 985 & tuberosus Micht. ...... & 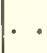 & & & & & + & & . & | & . & & & \\
\hline 986 & Ceratotrochus duodccim-costatus Goldf. . & . & $-1-$ & + & . & 10 & & & . & . & . & 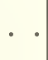 & & \\
\hline 987 & multiserialis Micht. . . . . & . & & . & & $-1-$ & + & & . & . & & & & \\
\hline 988 & multispinosus Micht. . . . & . . & $?$ & • & & + & + & 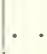 & 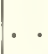 & . & . & & & \\
\hline 989 & perplexus Micht....... & & & & & & + & & . & . & d & & & \\
\hline 990 & rimosus Micht......... & & 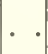 & & & + & & . & 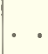 & . & . & - & & \\
\hline 991 & Conotrochus typus Seg........... & & & 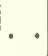 & & + & + & & . & . & 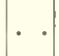 & ${ }^{\circ}$ & & \\
\hline 992 & Discotrochus Wichelotti Mihne-Edw. ... & & (" & & & & + & & ${ }^{\circ}$ & ]$^{\circ}$ & . & $0^{\circ}$ & & \\
\hline 993 & Stylotrochus Fromenteli Sismd...... & 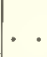 & & & & & + & & $1^{\circ}$ & . & 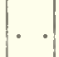 & 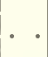 & & \\
\hline 994 & Flabellum acutum E. H. ......... & & & & & + & & & & 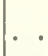 & . & & & 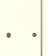 \\
\hline 995 & cuneatum Goldf. ....... & & & + & & & & & & . & & & & \\
\hline 996 & asperum E. H. ........ & & & & & -1 & + & & & - & & & & \\
\hline 997 & avicula Michl. e var. . . . . . & & & + & & + & + & & & . & -1 & & & \\
\hline 99 & depcrditum Micht....... & & & & & & & & & & & & & \\
\hline 99 & dissitum Micht......... & & & & & & & & & & & & & \\
\hline
\end{tabular}




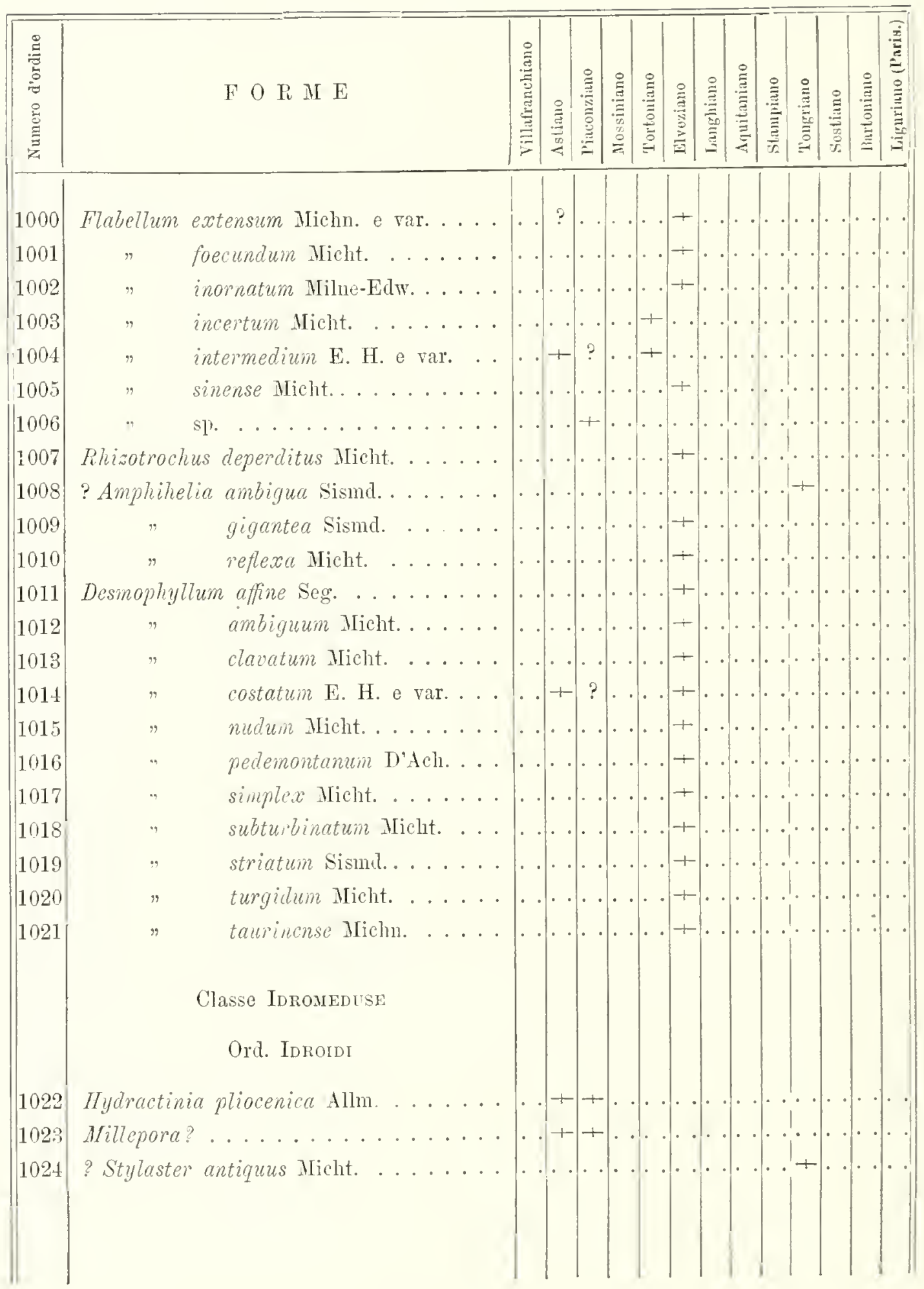


Catalogo paleontologico del bacino terziario del Piemonte

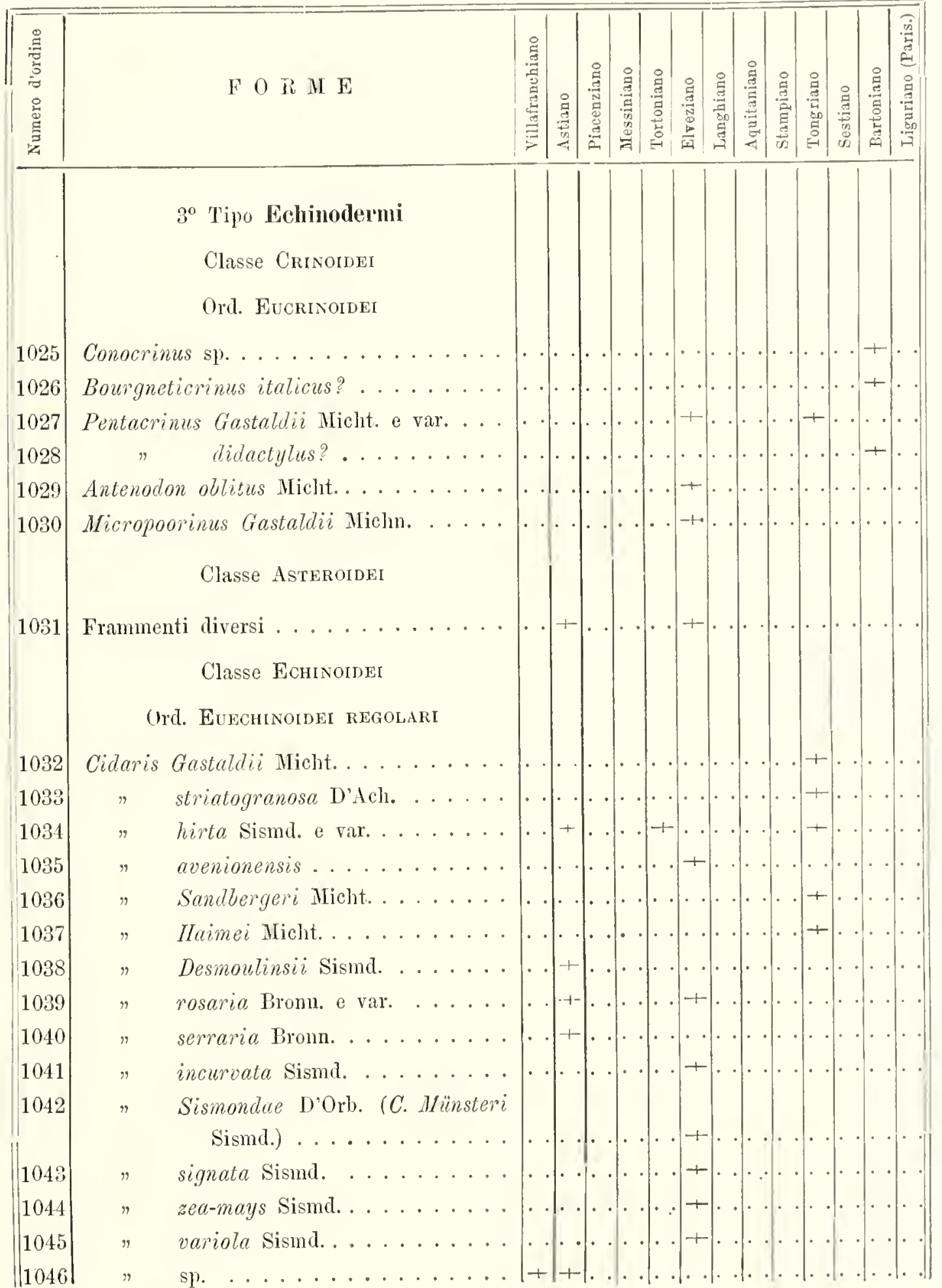




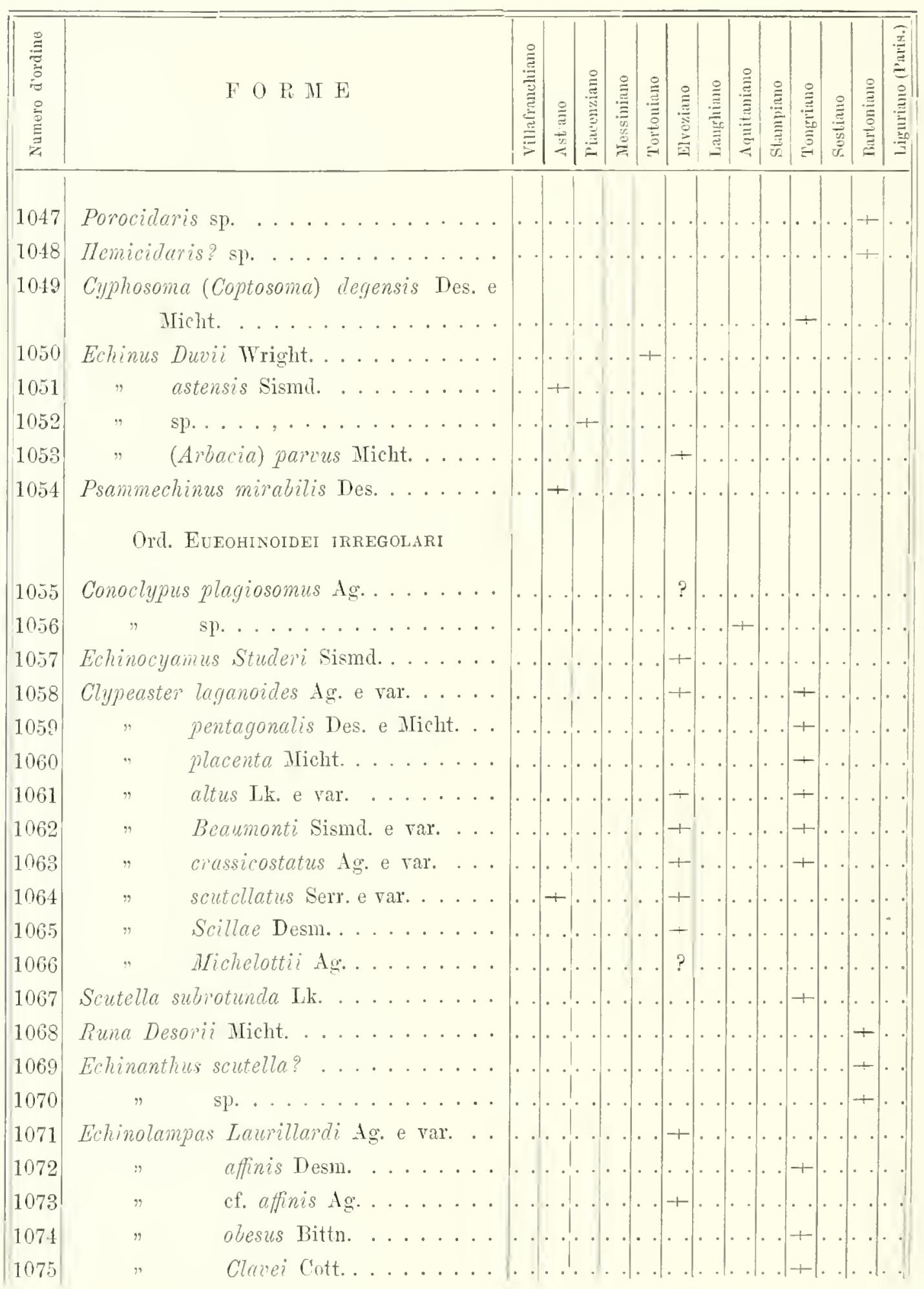




\begin{tabular}{|c|c|c|c|c|c|c|c|c|c|c|c|c|c|c|}
\hline 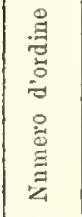 & $\mathrm{F} O \mathrm{R} \mathrm{ML} \mathrm{E}$ & 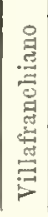 & 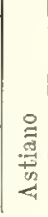 & 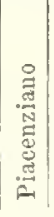 & 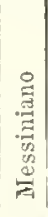 & 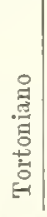 & 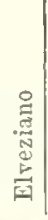 & 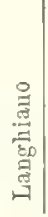 & 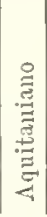 & 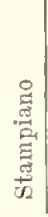 & 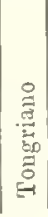 & 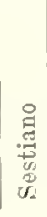 & 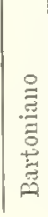 & 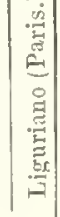 \\
\hline 1076 & Echinolampas politus Desml. ....... & . & - & & & & 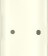 & & & • & + & & & \\
\hline 1077 & ef. Douvillci Cott. ..... & . & . & . & . & & . & & & . & + & & & \\
\hline 1078 & conicus Laub. ....... & . & . & & & . & - & & & - & + & - & & \\
\hline 1079 & Studeni Ag. ........ & . & . & $?$ & . & & . & & & . & & - & & \\
\hline 1080 & IIemiaster Gratcloupi Sismd. ....... & & . & . & & & + & & & - & & - & & \\
\hline 1081 & Scillae Wright......... & . & . & $\cdot$ & . & . & . & & - & . & + & . & & \\
\hline 1082 & hemiglobus Mazz. ........ & . & . & . & . & & . & - & • & & + & - & & \\
\hline 1083 & canaliferus sismd. e var. ... & . & + & . & . & . & + & • & & - & & - & & \\
\hline 1084 & major Def. .......... & . & + & + & & . & . & & . & . & & • & & \\
\hline 1085 & Brissopsis Borsoni Sismd. . . . . . . & . & + & + & . & - & $\cdot$ & & $\cdot$ & - & . & & & \\
\hline 1086 & Genei Sismd. ........ & . & ${ }^{\circ}$ & $?$ & 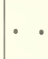 & & + & & . & . & . & & . & \\
\hline 1087 & internedius Sism九l. ...... & . & - & . & . & - & + & & • & - & . & & . & \\
\hline 1088 & ovatus Sismd. ........ & $\left.\right|^{\circ}$ & . & . & 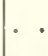 & - & + & & • & . & - & - & & \\
\hline 1089 & Pccchiolii Des........ & . & . & + & . & - & & & . & $\cdot$ & . & & & \\
\hline 1090 & Lorioli Bittn. ........ & 1 & . & & & & $1^{\circ}$ & & & . & + & & & \\
\hline 1091 & 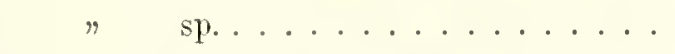 & 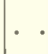 & . & . & . & . & . & & . & . & + & & & \\
\hline 1092 & (Toxobrissus) Michclottii Des. & . & $10^{\circ}$ & & & & & & & . & + & & . & \\
\hline 1093 & Linthia aurislcporis MLaz. ........ & . & . & & & & & & & . & + & & & \\
\hline 1094 & montisrotundi Maz. ....... & $\left.\right|^{\circ}$ & & 1 & & & & & & . & + & & & \\
\hline 1095 & Schizaster Bcllardii Ag. e var....... & . & 1 & . & . & . & + & & & . & + & & & \\
\hline 1096 & 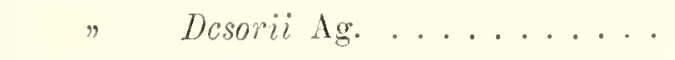 & . & . & - & & & & & & . & $-1-$ & & & \\
\hline 1097 & Scillac Ag. e var. ....... & . & . & . & 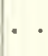 & . & + & & . & . & + & & & \\
\hline 1098 & princeps Bittn. ....... & . & $0^{\circ}$ & & & & & & & . & + & & 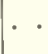 & \\
\hline 1099 & subcilindricus ......... & . & & 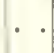 & & & & & & . & + & & . & \\
\hline 1100 & rimosus Des. ........ & & & • & & & & & & 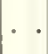 & + & & . & \\
\hline 1101 & 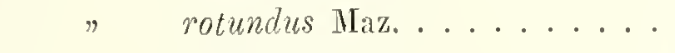 & - & & . & · & & & & - & - & + & & 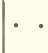 & \\
\hline 1102 & 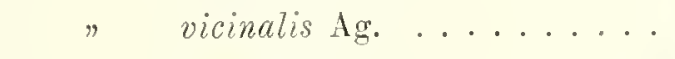 & 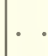 & & 1 & & & & & 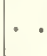 & & + & & & \\
\hline 1103 & 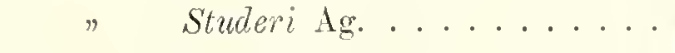 & • & & - & & & & & . & . & + & & . & \\
\hline 1104 & trigonalis $\Lambda g . . . . . .$. & & & - & & & & & . & & + & & & \\
\hline 110 & 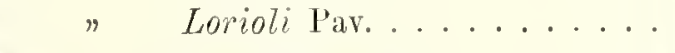 & & & - & & & & & & & + & & . & \\
\hline 1106 & Laubei Bittn. . . . . . . & & & . & & & & & , & & + & & & \\
\hline $110^{\circ}$ & subdectivus Maz. ....... & & & & & & & & & & & & & \\
\hline
\end{tabular}




\begin{tabular}{|c|c|c|c|c|c|c|c|c|c|c|c|c|}
\hline 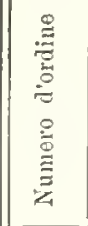 & $\mathrm{F} O \mathrm{P} M \mathrm{E}$ & 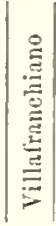 & 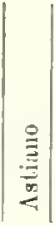 & $\mid$ & 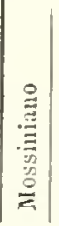 & 莺 & 量 & & 竞 & 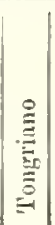 & & 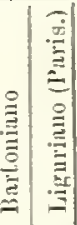 \\
\hline 1108 & Schizaster acuminatus Ag. . . . . . . & & & & & & & & & $\div$ & & \\
\hline 1109 & Pericosmus Edvardsii Des. ....... & & & & & & + & & & & & \\
\hline 1110 & aequalis Ag. . . . . . . . . & & & & & & & & & & & \\
\hline 1111 & $" \quad$ latus? Ag. ........ & & & & & & & & & + & & \\
\hline 1112 & Peroni Cott. . . . . . . . . & & & & & & & & & + & & \\
\hline 1113 & $" \quad$ calosus Manz. . . . . . . . & & & & & & + & & & & & \\
\hline 1114 & Eupatagus latcralis Ag. . . . . . . . . & & & . & & & + & & & & & \\
\hline 1115 & elongatus?.......... & & & & & & ? & & & & & \\
\hline 1116 & $" \quad$ depressus Dub........ & & & & & & & & & + & & \\
\hline 1117 & $" \quad$ De Konicki Wright. . . . . . & & & & & & & & & & & \\
\hline 1118 & Maretia Desmoulinsi Cott......... & & & & & & & & & + & & \\
\hline $\mid 1119$ & $" \quad$ gregicoguensis . . . . . . . & & & & & & & & & 1 & & \\
\hline 1120 & Spatangus chitonosus Sismd. . . . . . . & & & & & & + & & & & & \\
\hline 1121 & $" \quad$ Desmarestii MIunst. e var. . . . & & + & & & & + & & & & & \\
\hline & $4^{0}$ Tipo Vermi. & & & & & & & & & & & \\
\hline & Ord. Chetopodi. & & & & & & & & & & & \\
\hline 1122 & Serpula foraminosa Bon. .. & & + & & & & & & & & & \\
\hline 1123 & $"$ minima Lk. .......... & & - & & & & & & & & & \\
\hline 1124 & protcnsa Lk. e var. ........ & & + & + & - & + & & & & & & \\
\hline 1125 & $" \quad$ (Rotularia) spirulaea Lk. .... & & . & & & & & & & & & \\
\hline 1126 & Vermilia? triquetra Lk. e var. . . . . . & & + & + & & + & & & & & & \\
\hline 1127 & Spirorbis miocenicus Micht. . . . . . . & & & & & & t & & & & & \\
\hline 1128 & Ditrupa incurva Ren. .......... & & + & + & & & & & & & & \\
\hline & $5^{0}$ Tipo Molluscoidi. & & & & & & & & & & & \\
\hline & Classe Briozor. & & & & & & & & & & & \\
\hline & Ord. Giminolemati. & & & & & & & & & & & \\
\hline 1129 & Discoporella umbellata Defr. & & & & & & & & & & & \\
\hline 1130 & Dcfrancia miocenica Micht. & & & & & & & & & & & \\
\hline
\end{tabular}




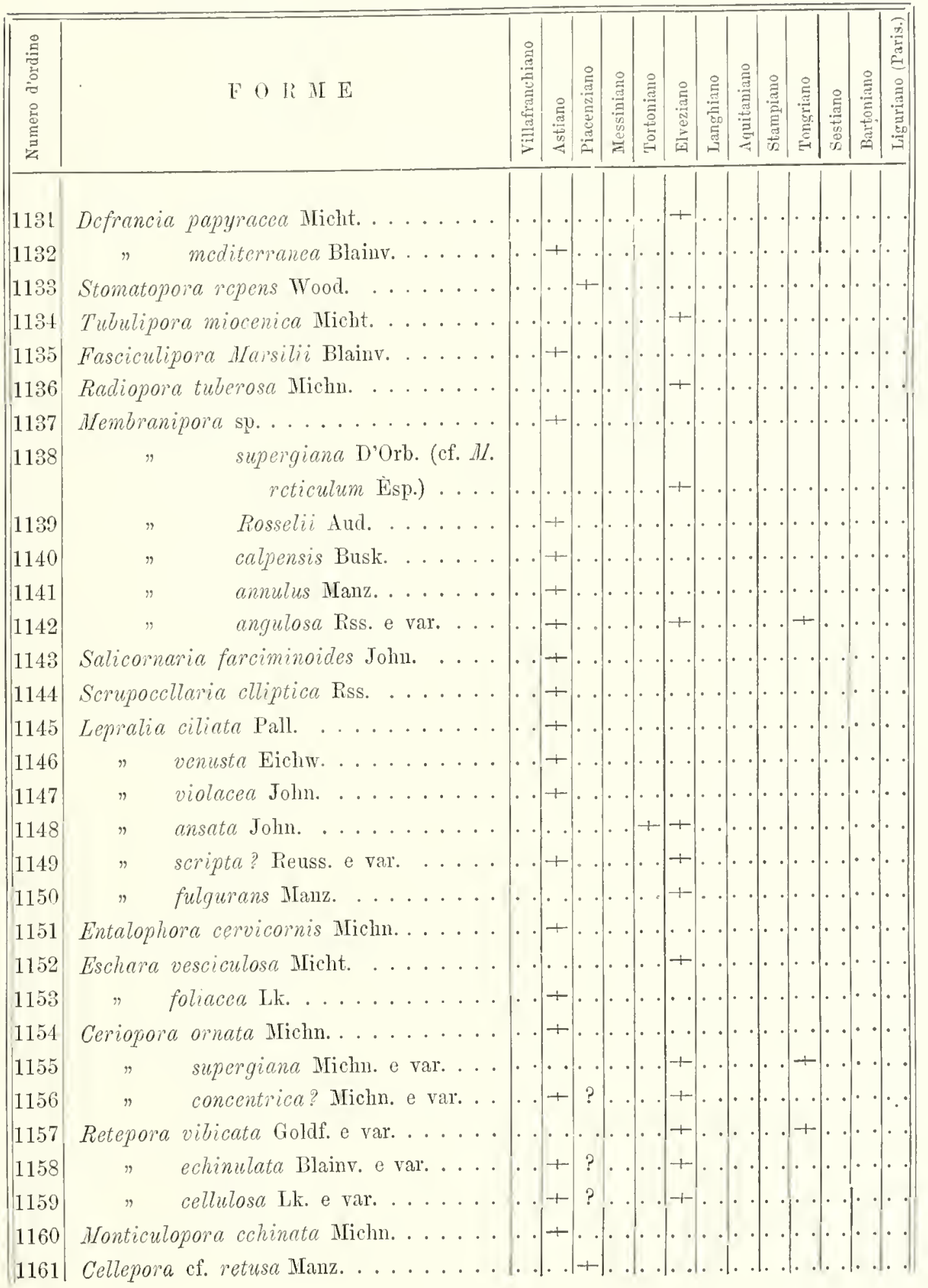




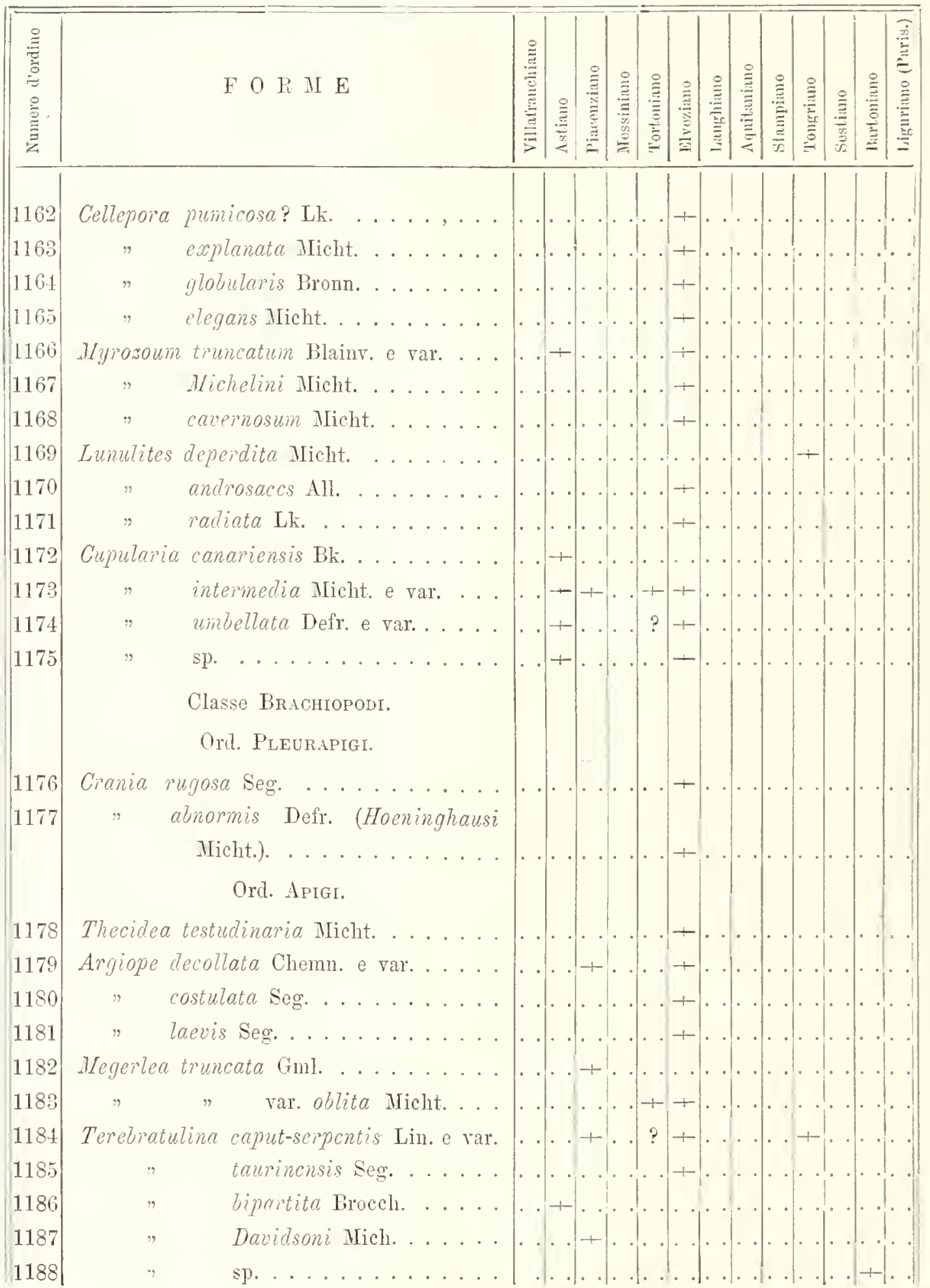




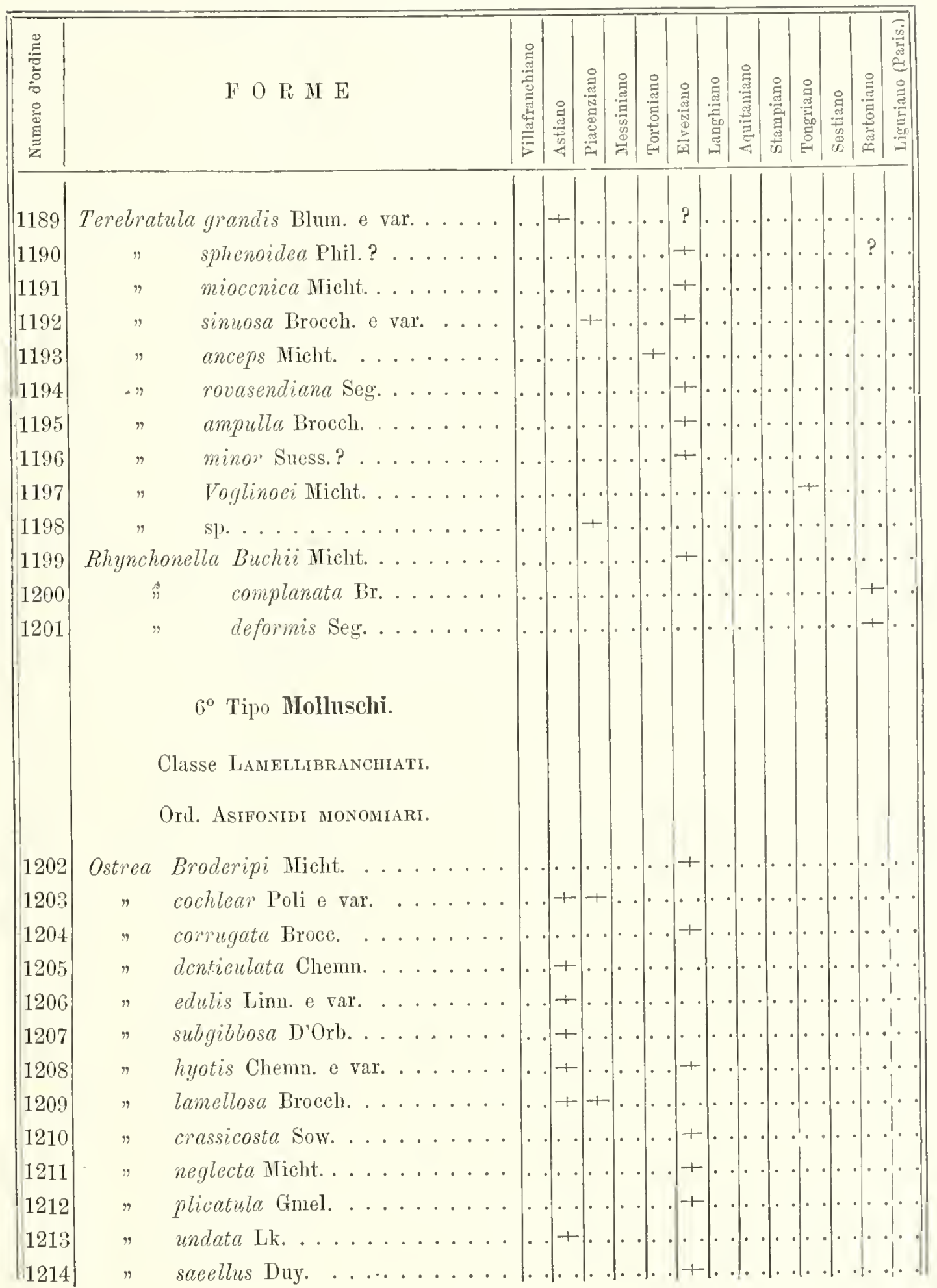




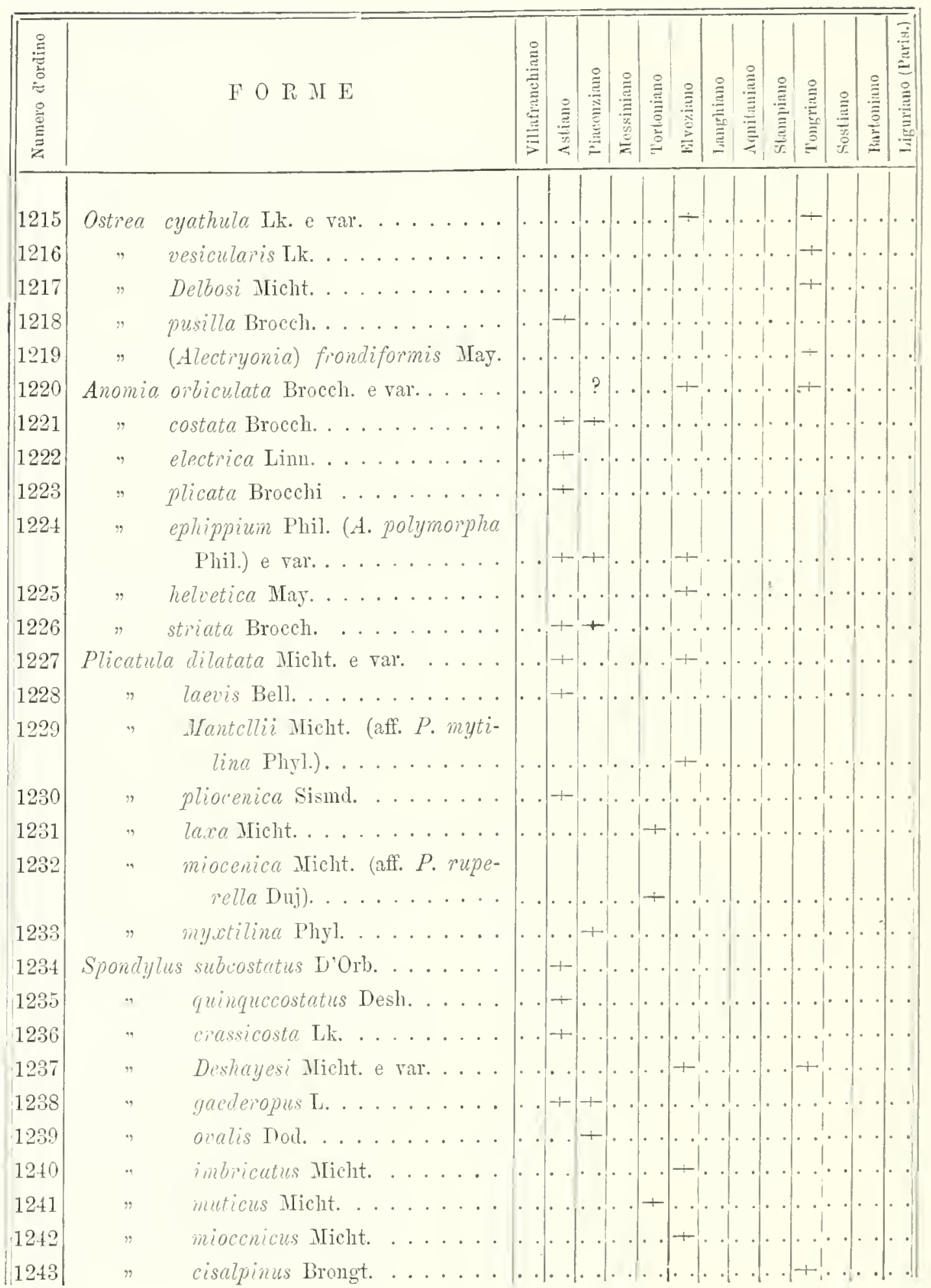




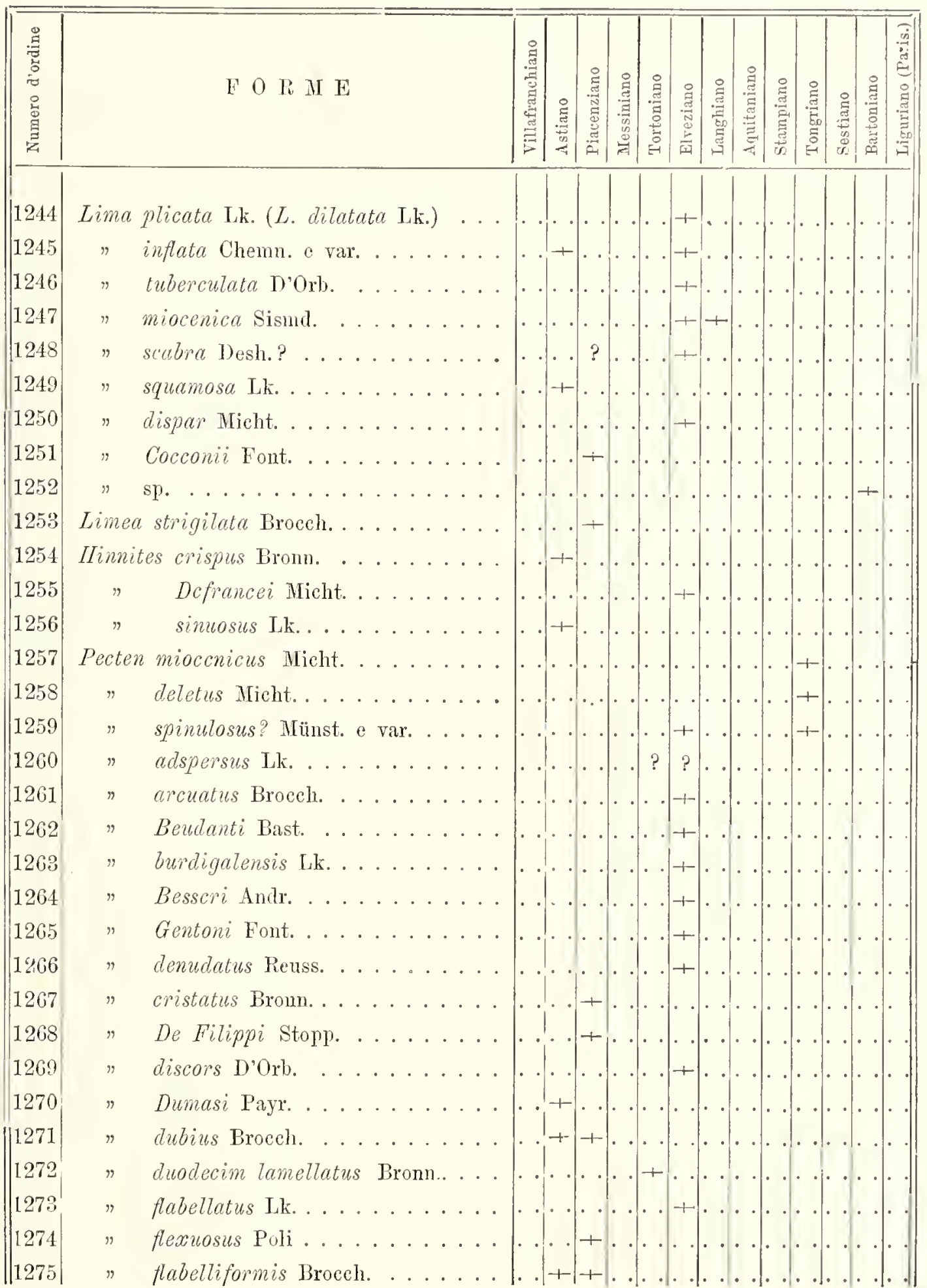




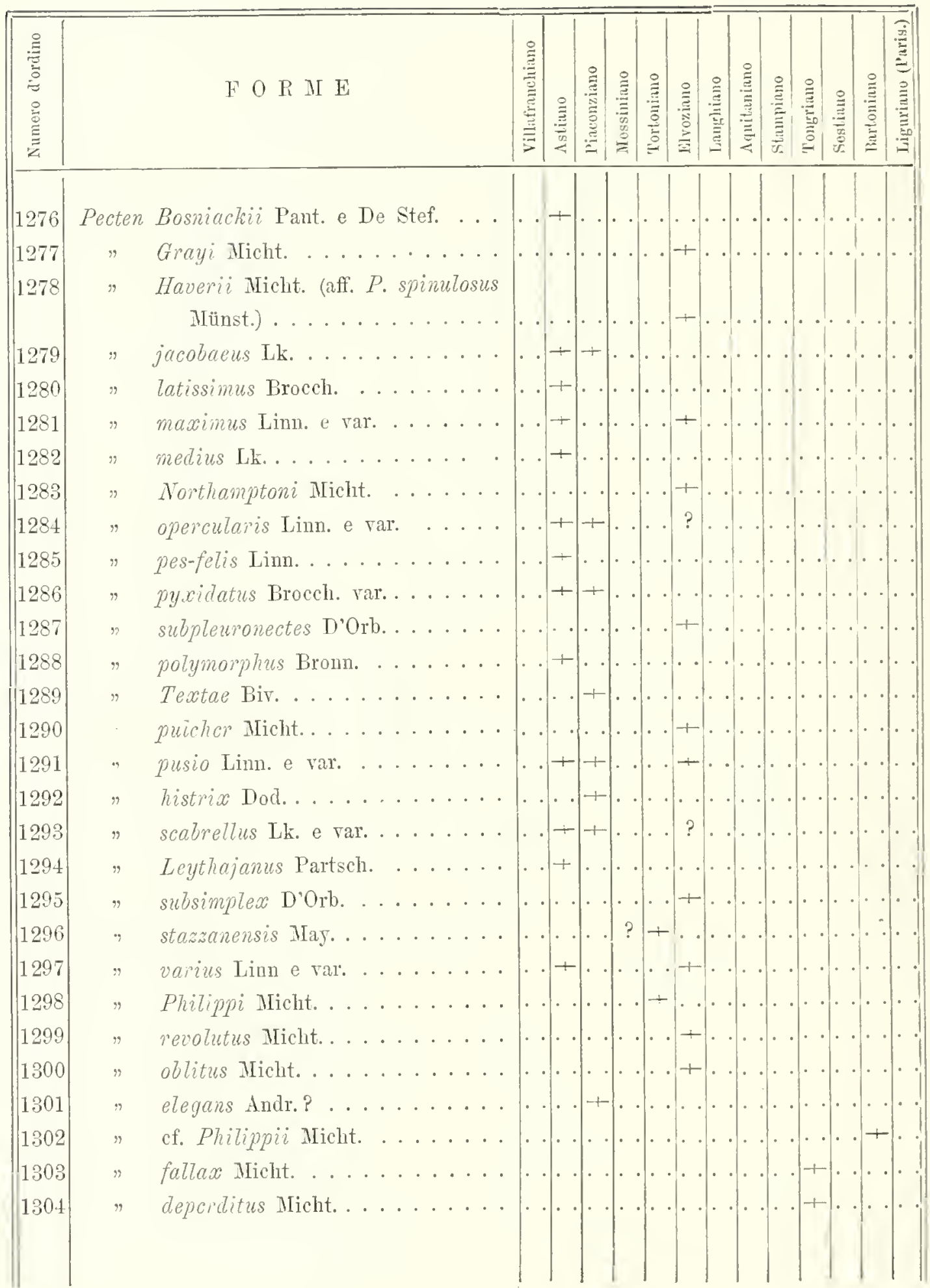




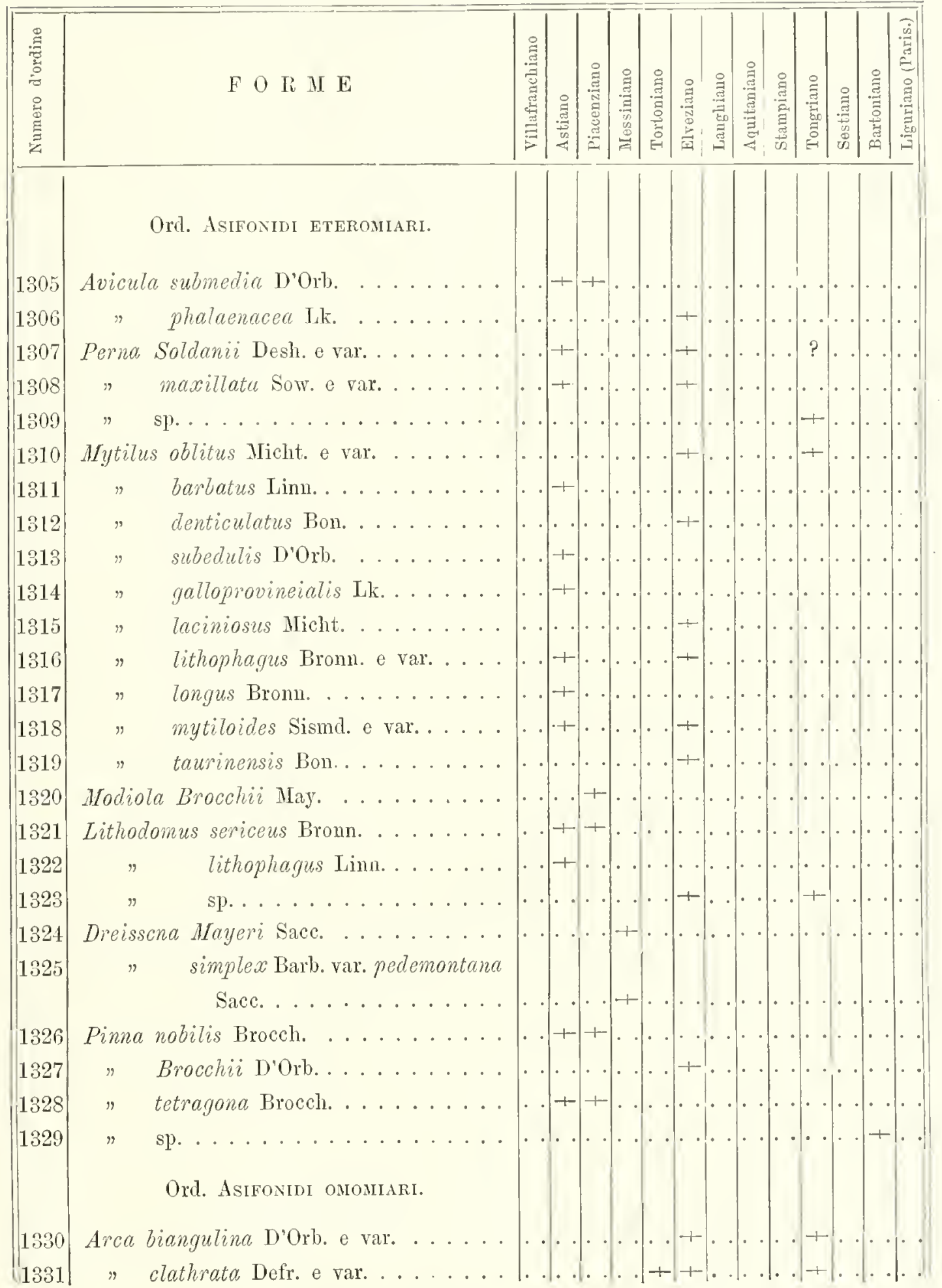




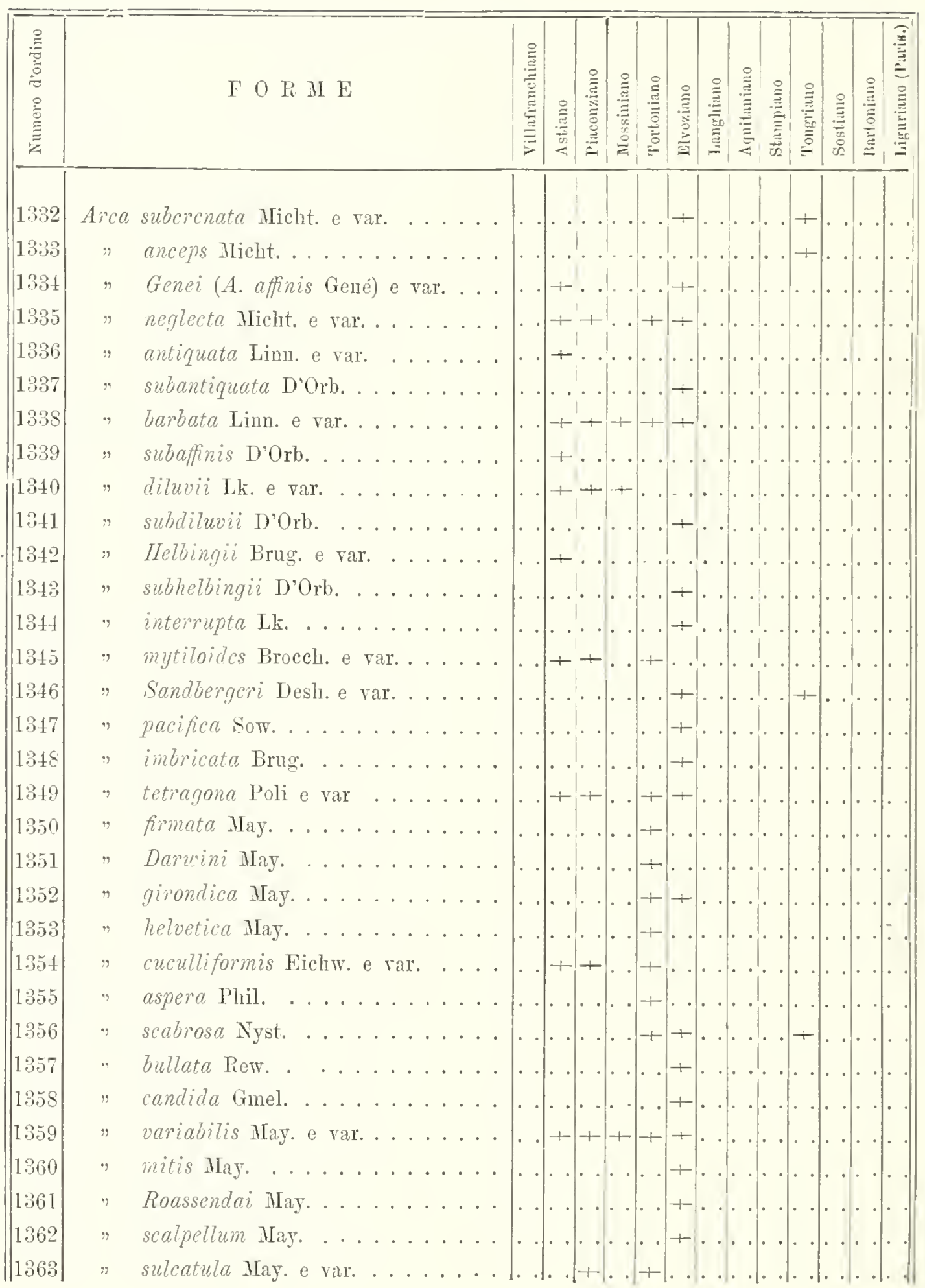




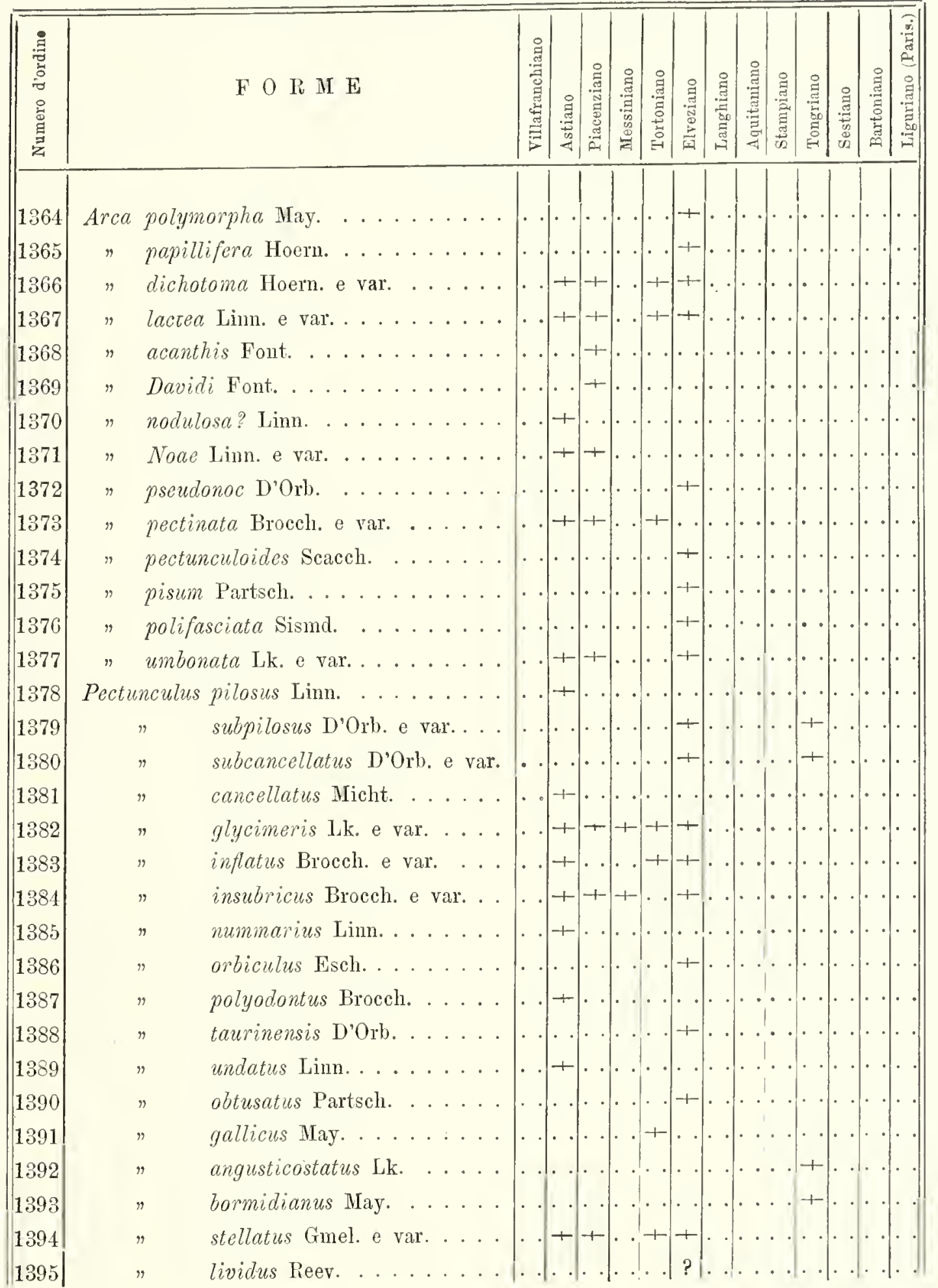




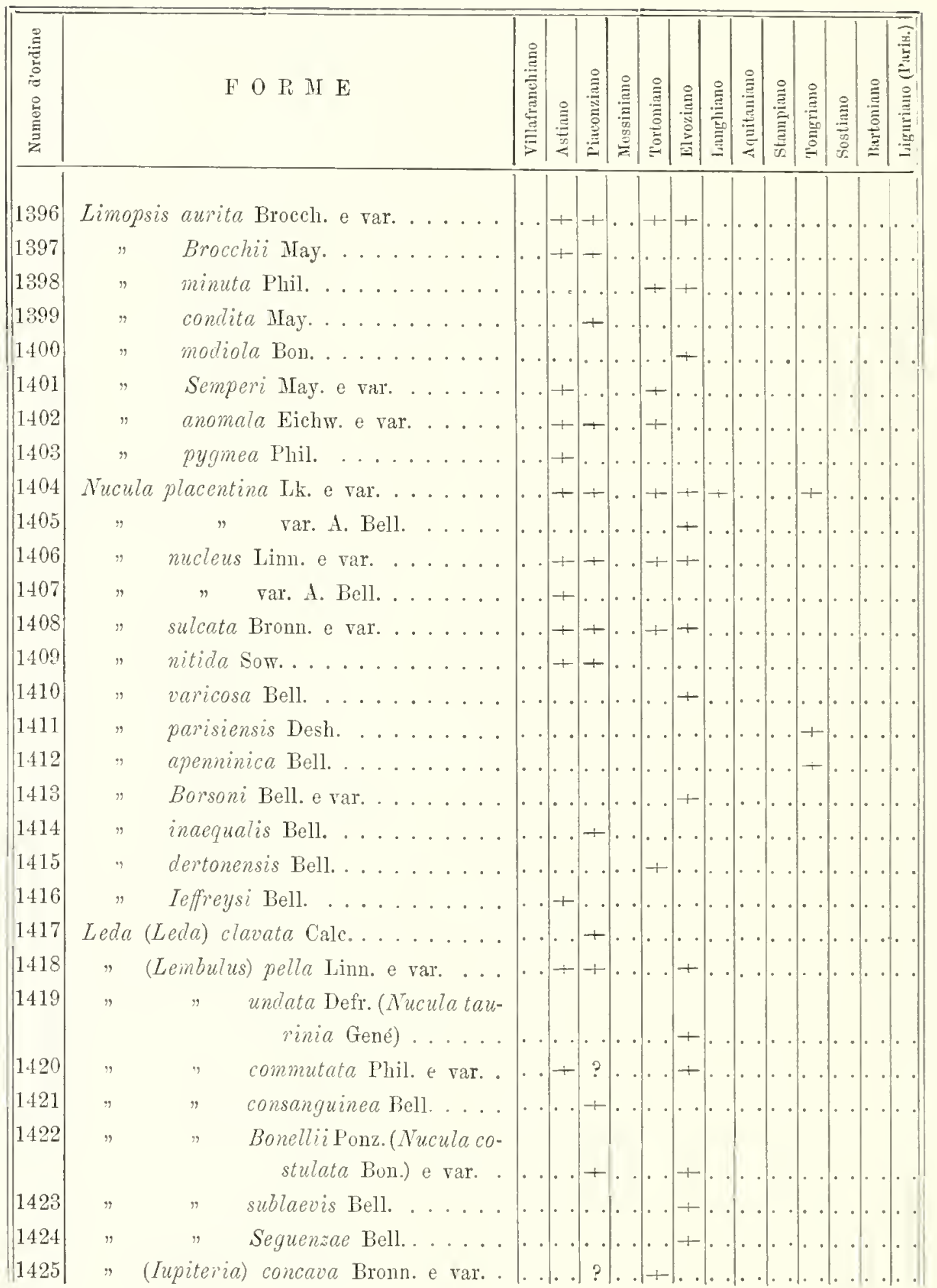




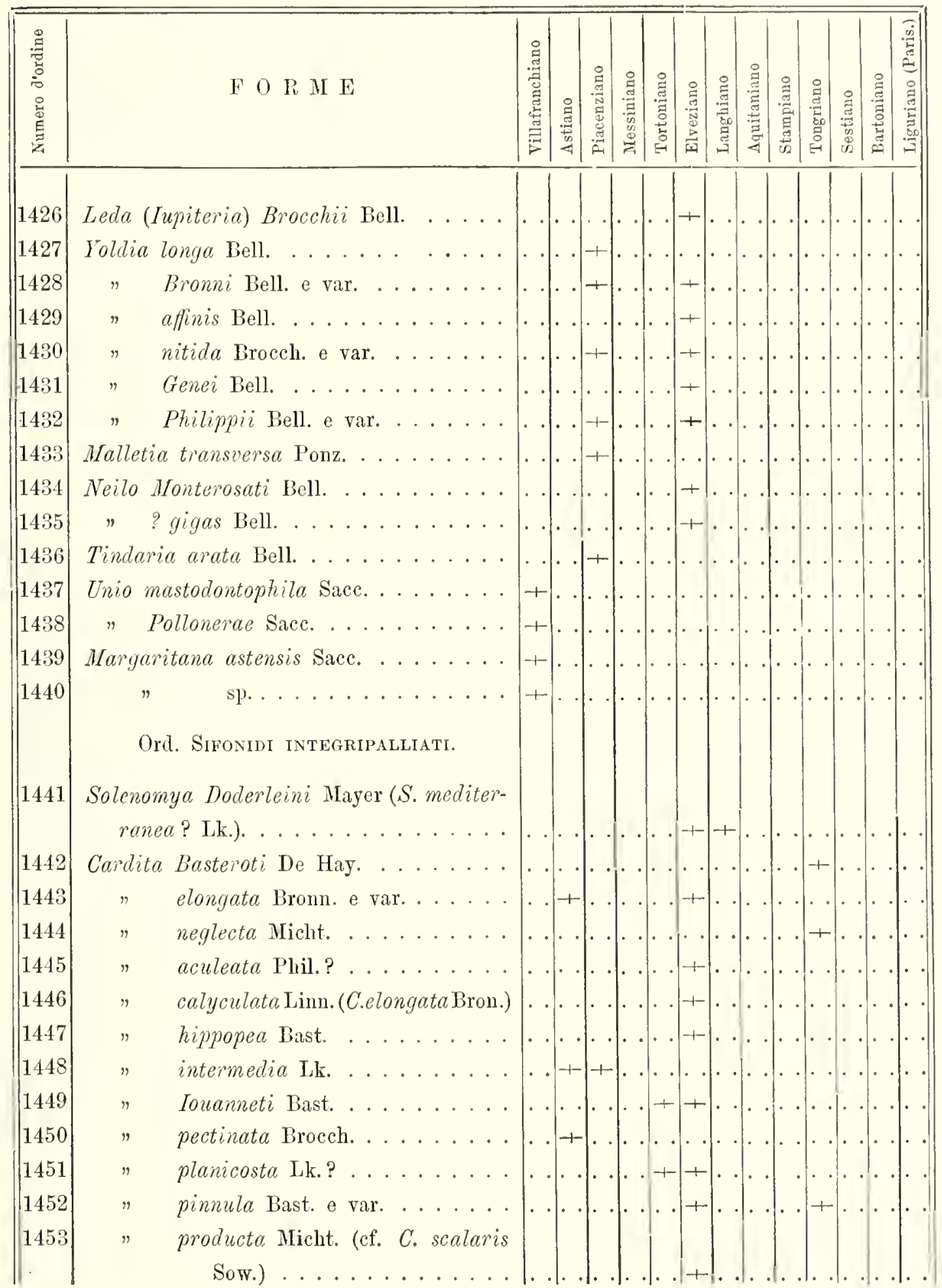




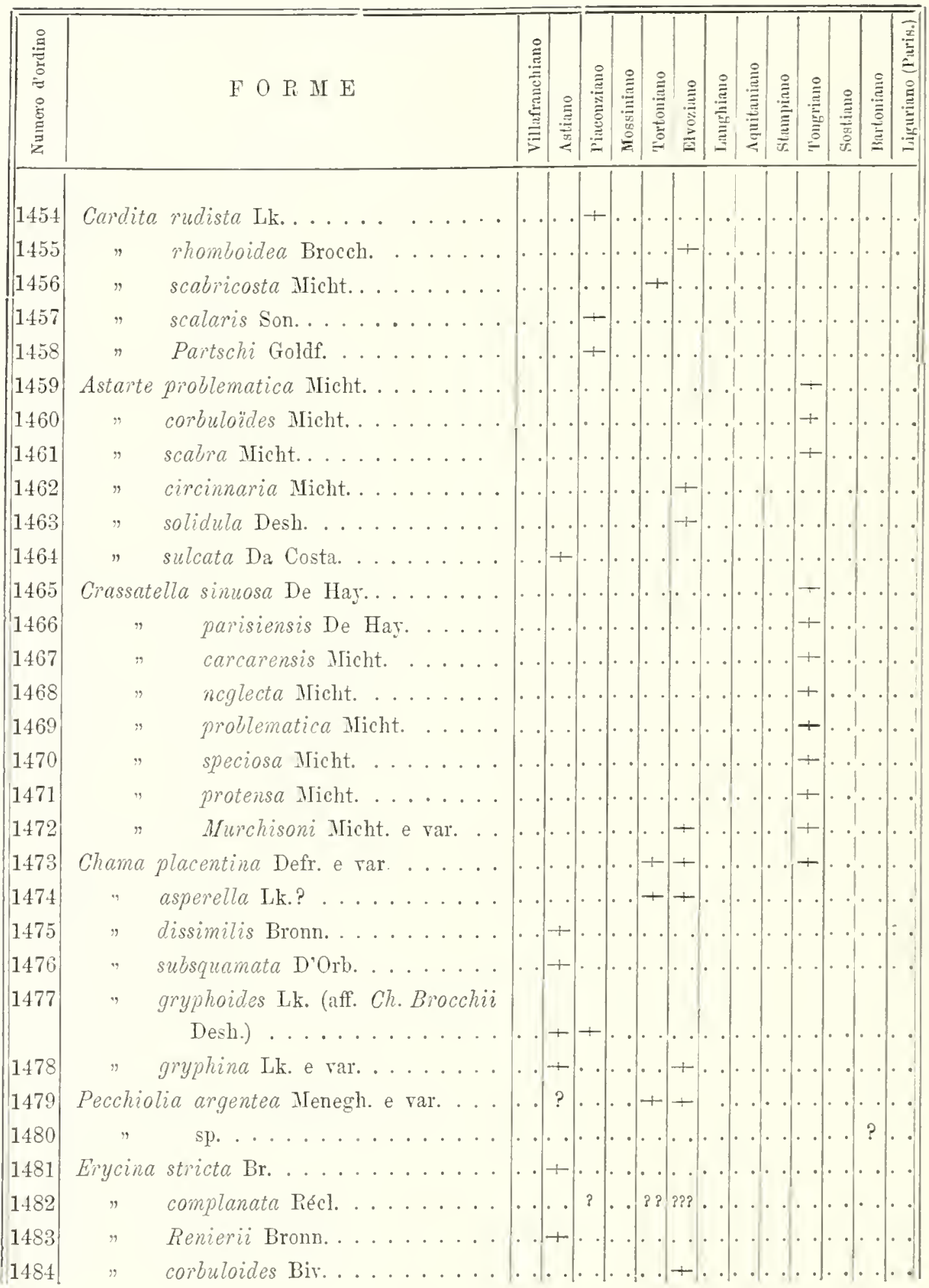




\begin{tabular}{|c|c|c|c|c|c|c|c|c|c|c|c|c|c|c|c|}
\hline 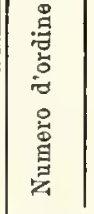 & & $\mathrm{F} O \mathrm{R} \mathrm{M} \mathrm{E}$ & 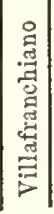 & 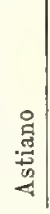 & 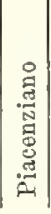 & 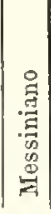 & 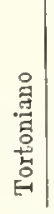 & 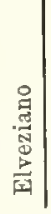 & 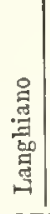 & 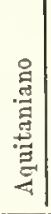 & 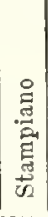 & 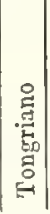 & 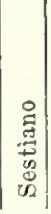 & 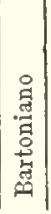 & 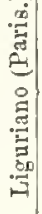 \\
\hline 1485 & Erycina & seminulum Phil. ....... & · & & + & . & & & & & & - & . & & \\
\hline 1486 & Diplodon & nta fragilis Bronn. e var...... & $\cdot$ & & $\cdot$ & · & • & + & & & • & + & & & \\
\hline 1487 & $"$ & laevigata Micht....... & . & & . & . & • & & & 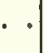 & · & + & . & $\cdot$ & \\
\hline 1488 & $"$ & apicalis Phil. ........ & $\cdot$ & + & 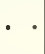 & - & & & & • & - & $\cdot \cdot$ & - & $\cdot$ & - \\
\hline 1489 & $n$ & lupinus Broceh. e var. . . . . & 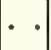 & + & . & - & & + & & - & . & . & • & . & \\
\hline 1490 & $"$ & astartea Nyst. ........ & $\cdot$ & & + & . & & $\cdot \cdot$ & • & · & . & - & . & . & \\
\hline 1491 & $"$ & rotundata Mont. e var. . . . . & . & + & 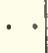 & & & + & & . & & $\cdot \cdot$ & . & - & \\
\hline 1492 & $"$ & ? obliquata Micht........ & $\cdots$ & . . & . & · & & . & & · & - & + & . & . & \\
\hline 1493 & Axinus & angulatus Sow.?........ & . & . & . & & & + & & - & . & $\cdot$ & - & & \\
\hline 1494 & Lucina & Rollei Micht........... & . & . & & - & & · & & 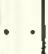 & . & + & . & . & \\
\hline 1495 & $"$ & subconcentrica D'Orb. ...... & $\cdot$ & $\cdot$ & $\cdot$ & & - & - . & - & . & 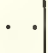 & + & " & & \\
\hline 1496 & $"$ & miocenica Micht. e var....... & . & - & $?$ & . & - & + & & - & - & + & . & - & \\
\hline 1497 & $"$ & tumida Micht. e var. . . . . . & $\cdot$ & . & · & $\cdot$ & - & + & $\cdot \cdot$ & 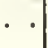 & . & + & . & . & \\
\hline 1498 & $n$ & tenuilamellata Micht. ...... & $7^{\circ}$ & . & 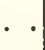 & - & - & . & & • & . & + & & . & \\
\hline 1499 & $"$ & 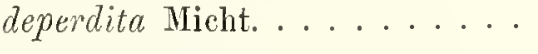 & 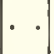 & . & - & . & - & . & · & • & . & + & . & . & - \\
\hline 1500 & $"$ & strigosa Micht. e var. . . . . & $\cdot$ & - & 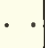 & $\cdot$ & - & + & & - & - & + & · & . & • \\
\hline 1501 & $"$ & Agassizi Micht. e var. . . . . & $\cdot$ & . & • & . & + & +1 & 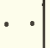 & . & . & + & $\cdot$ & . & • \\
\hline 1502 & $"$ & rigautiana De Hay. e var. ... . & . & 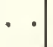 & & . & - & + & . & . & · & $1+$ & $\cdot$ & . & • \\
\hline 1503 & " & astensis Bon. e var. . . . . . . & $\cdot \cdot$ & + & + & $\cdot$ & - & $?$ & · & . & - & - & - & $\cdot$ & • \\
\hline $\mid 1504$ & $"$ & columbella Lk.? ........ & $\Gamma^{\circ}$ & 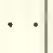 & $\cdots$ & 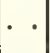 & 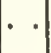 & + & $\cdot$ & $\cdot$ & • & - & - & . & \\
\hline 1505 & $"$ & 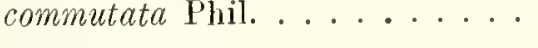 & 1 & + & + & $\cdot$ & . & . & - & . & · & - & . & $\cdot$ & . \\
\hline 1506 & $"$ & 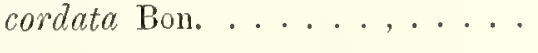 & . & + & & • & & & - & 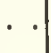 & . & . & $\cdot$ & ${ }^{\circ}$ & \\
\hline 1507 & $"$ & 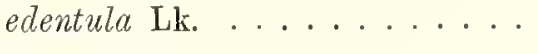 & . & + & . & . & & & - & - & - & . & · & ${ }^{\circ}$ & - \\
\hline 1508 & $"$ & 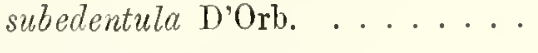 & & . & 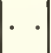 & . & & + & & 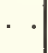 & $\cdot$ & - & & . & \\
\hline 1509 & $"$ & glabella Bon. ........... & . & + &. & . & & $\cdots$ & . & . & • & . & · & . & \\
\hline 1510 & $"$ & spinifera Montag. e var. .... & $\cdot$ & $\cdot$ & + & $\cdot$ & + & + & • & - & $\cdot$ & - & · & 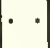 & \\
\hline 1511 & $"$ & hiatelloides Bast. ........ & . & . & . & . & +1 & + & & & 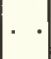 & & & & \\
\hline 1512 & $"$ & angulata D'Orb. . . . . . & & $b^{\circ}$ & & . & . & + & & & & & • & & \\
\hline 1513 & $"$ & lupinus Brocch. ........ & $l^{\circ}$ & - & & . & . & + & • & . & - & & $\dot{1}^{\circ}$ & - & \\
\hline 1514 & $"$ & 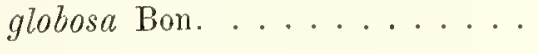 & & + & & & & & & & & & . & . & \\
\hline 1515 & $"$ & lactea Lk. . . . . . . . . & & + & & & & & & $\cdot$ & $\cdot$ & & & & \\
\hline 516 & $"$ & leonina Bast. . & & $1+1$ & & & & & & & & & & & \\
\hline
\end{tabular}




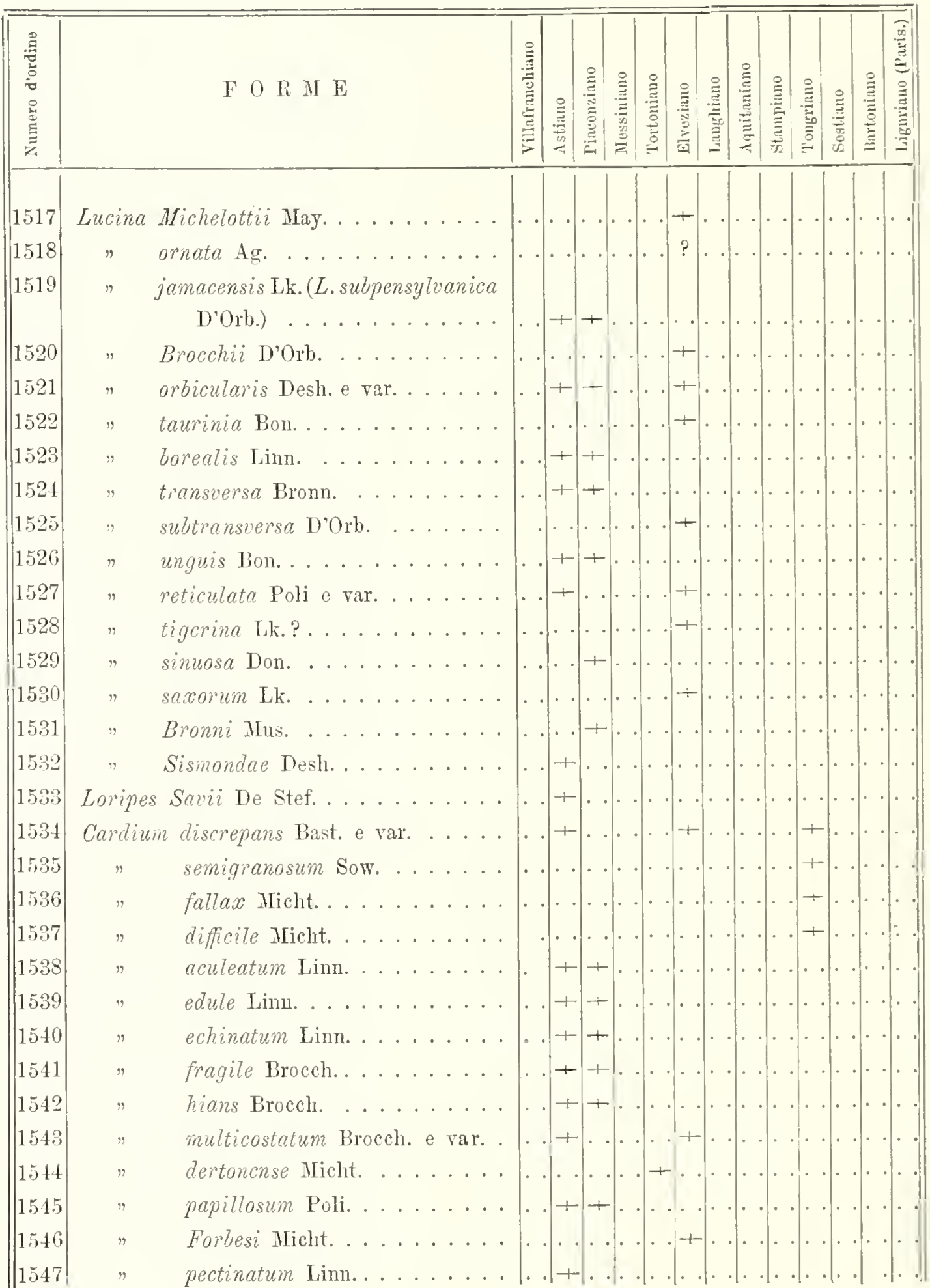




\begin{tabular}{|c|c|c|c|c|c|c|c|c|c|c|c|c|}
\hline 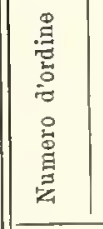 & $\mathrm{F} O \mathrm{R} \lambda \mathrm{E}$ & 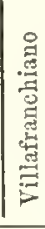 & 总 & 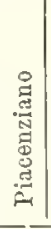 & 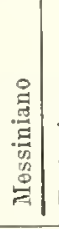 & 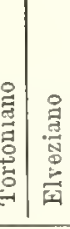 & 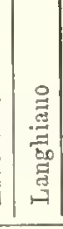 & 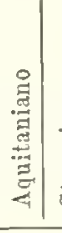 & & 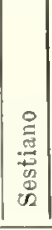 & & 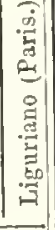 \\
\hline 1548 & Cardium rusticum Chemn. . . . . . . . & & & & & & & & & & & \\
\hline$|1549|$ & semigranulatum sow. . . . . . & & & & & + & & & & & & \\
\hline $\mid 1550$ & Sottcri Micht. . . . . . . . & & & & & & & & & & & \\
\hline 1551 & striatissimum Bon. . . . . . . & & + & & & & & & & . & & \\
\hline 1552 & striatulum Broceh. . . . . . & & & & & & & & & & & \\
\hline 1553 & sulcatum Lk. .......... & & & & & & & & & & & \\
\hline 1554 & taurinum Micht. . . . . . . . . & & & & & + & & & & & & \\
\hline 1555 & $\begin{array}{r}" \quad \text { trigonum Sismd.(C.trigoncllum } \\
\left.\mathrm{D}^{\prime} \mathrm{Orb} .\right) \ldots \ldots \ldots \ldots\end{array}$ & & & & & & & & & & & \\
\hline $\mid 1556$ & turonicum May. . . . . . . . . . & & & & & + & & & & & & \\
\hline $\mid 1557$ & subturgidum D'Orb. ....... & . & & & & + & & & & & & \\
\hline $\mid 1558$ & Adachna nova-rossica Barb. ........ & . & & & + & & & & & & & \\
\hline 1559 & castellanensis Cap........ & . & & & + & & & & & & & \\
\hline 1560 & semisulcata Reuss......... & . & & & + & & & & & & & \\
\hline $\mid 1561$ & bollenensis May. . . . . . . . . & $\cdot$ & & & + & & & & & & & \\
\hline 1562 & Spratti Fuchs. . . . . . . . & • & & & + & & & & & & & \\
\hline $\mid 1563$ & secans Fuchs............ & . & & & + & & & & & & & \\
\hline 1564 & Partschi MIay. . . . . . . . . & & & & + & & & & & $\therefore$ & & \\
\hline 1565 & carinata Desh........... & . & & & + & & & & & & & \\
\hline $\mid 1566$ & banatica Fuchs. ......... & & & & T & & & & & & & \\
\hline $\mid 1567$ & $" \quad$ macrodon? Desh. ....... & & & & $\rightarrow$ & & & & & & & \\
\hline 1568 & sp. . . . . . . . . . & & & & + & & & & & & & \\
\hline 1569 & Cyrena (Ditypodon) Suessi May. ..... & & & & + & & & & & & & \\
\hline 1570 & " Brongniarti Bast. . . . . . . . . & & & & & & & & + & & & \\
\hline 1571 & $" \quad$ var. . . . . . . & & & & & & & & + & & & \\
\hline $\mid 1572$ & $" \quad$ convexa Brongnt. . . . . . . . & & & & & & & & + & & & \\
\hline 1573 & Cyclas Zenonii Sacc............ & + & & & & & & & & & & \\
\hline 1574 & Pisidium Capcllinii Sacc. . . . . . . . . & 1 & & & & & & & & & & \\
\hline 1575 & $" \quad$ fossile sacc. .......... & & & & & & & & & & & \\
\hline 1576 & Miocardia seguenzcana Cocc. ....... & & & & & & & & & & & \\
\hline 1577 & Isocardia cor Linn. . & & & & & & & & & & & \\
\hline
\end{tabular}




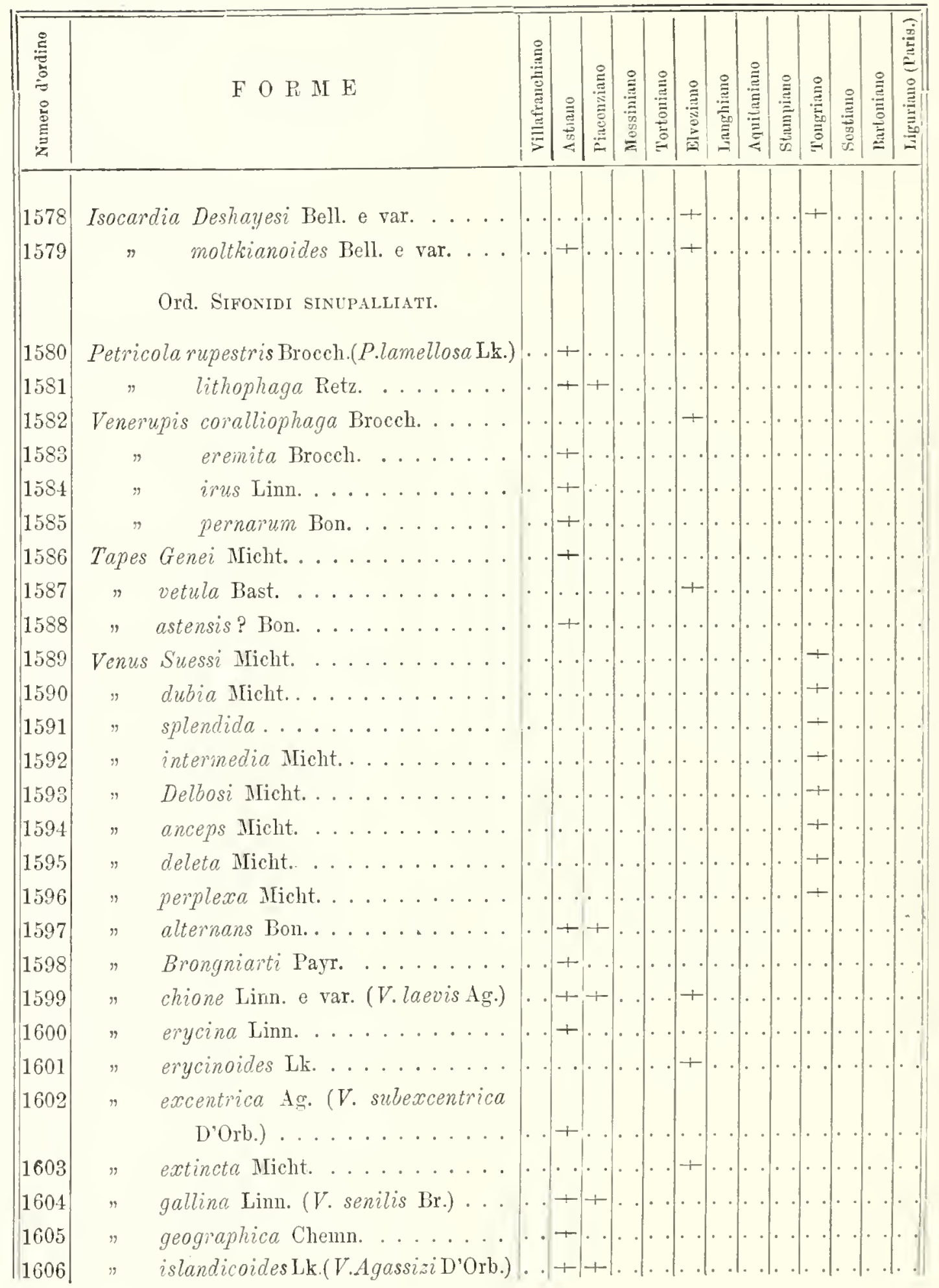




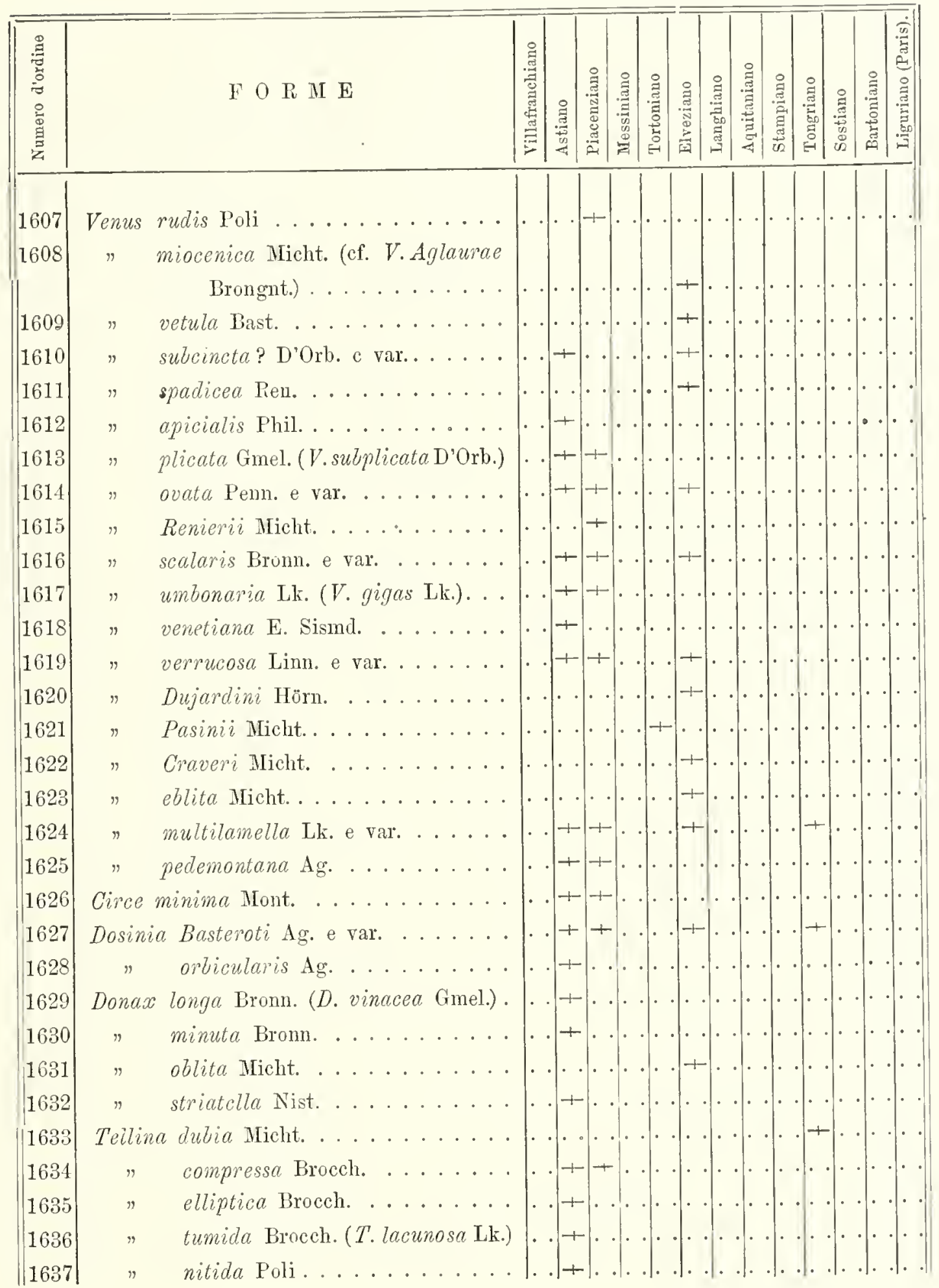




\begin{tabular}{|c|c|c|c|c|c|c|c|c|c|c|c|c|c|c|}
\hline 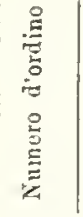 & $\mathrm{F} O \mathrm{P}_{\mathrm{U}}$ II $\mathrm{E}$ & 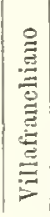 & 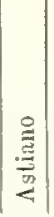 & 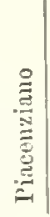 & 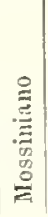 & 号 & 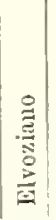 & 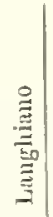 & 总 & 总 & 号 & 彦 & | & 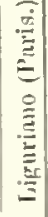 \\
\hline 338 & Tellina planata Linn, ......... & . & + & + & & & & & & & & & & \\
\hline 39 & serrata Ren. e var........ & . & + & • & & • & + & . & & . & & & & \\
\hline 10 & " striatella Brocch........ & . & + & & - & . & $\cdot$ & $\cdot$ & . & & & & & \\
\hline 11 & subcarinata Brocch. ...... & - & + & · & . & . & . & . & · & • & 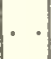 & & & \\
\hline 1642 & donacina Linn. ......... & . & + & + & [. & - & . & $\cdot$ & - & . & . & - & . & \\
\hline 1643 & ventricosa De Serr....... & . & + & + & . & . & $?$ & . & & & . & & & \\
\hline 1614 & " Bowerbanki Micht........ & & & - & . & 1. & + & . & & & & & . & \\
\hline 1645 & Areopagia crassa Penn. ......... & & + & . & . & . & $\sigma^{\circ}$ & . & & & 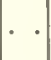 & & . & \\
\hline 1646 & gigantea Sismd. ....... & & + & . & . & . & . & . & - & . & . & . & . & \\
\hline 1647 & telata Sismd. ........ & & + & - & . & . & . & $1^{\circ}$ & . & . & . & . & 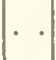 & \\
\hline 1648 & $" \quad$ corbis Bronn. ........ & 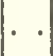 & + & 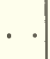 & 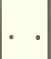 & & . & . & . & . & ${ }^{\circ}$ & & 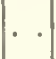 & \\
\hline 1649 & Gastrana fragilis Lin. ......... & & & + & . & . & . & & & $\cdot$ & . & & . & \\
\hline 1650 & Gari feroensis Ginel. e var.(G.muricata Ren.) & . & + & & . & & + & . & & . & . & & & \\
\hline 1651 & " uniradiata Brocch......... & & + & + & $\cdot$ & & • & • & • & $\cdot$ & & & & \\
\hline 1652 & "vespertina Lk............ & . & + & & $\left.\right|^{\circ}$ & $\sigma^{\circ}$ & . & ]$^{\circ}$ & . & . & . & & 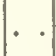 & \\
\hline 1653 & IIatula Labordei Desh. ......... & & 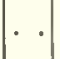 & & . & . & + & & . & . & ${ }^{\circ}$ & & & \\
\hline 1654 & "repanda Micht. ........ & & + & . & $\sigma^{\circ}$ & . & • & & . & & . & • & & \\
\hline 1655 & Syndosmya apelina Ren. (S.Renierii Bron.) & & + & & & & & & & • & & 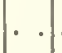 & & \\
\hline 1656 & $" \quad$ alba Wood........... & . & 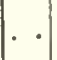 & + & & 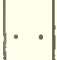 & . & & . & & . & & & \\
\hline 1657 & Solecurtus coarctatus Linu. ....... & . & + & + & & . & . & . & l. & . & . & . & . & \\
\hline 1658 & dilatatus Bon........ & & 17 & & & & & & & . & 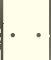 & & & \\
\hline 1659 & strigilatus Linn. e var. . . . . & . & + & $\cdot$ & & . & + & - & . & . & . & & - & \\
\hline 1660 & Ceratisolen legumen Linn......... & . & + & & . & & & & & 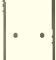 & . & & & \\
\hline 1661 & Solen cnsis Linn. ............. & 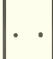 & + & & . & & & & & . & . & & & \\
\hline 10 & $"$ Olivii Micht........... & & 1 & & & & & & & . & . & & & \\
\hline 1663 & 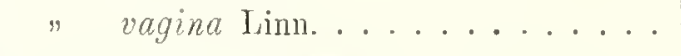 & & + & $e^{\circ}$ & 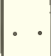 & & & & $\cdot$ & . & . & & & \\
\hline 1661 & Glycimcris Faujasi ITén.(G.glycimeris Born.) & & + & & & & • & & - & . & . & & & \\
\hline 1665 & Gastaldii Micht........ & & & $\cdot$ & & & & & . & $\cdot$ & + & & & \\
\hline 1666 & corrugata Dix......... & . & & . & & & & & . & $\cdot$ & + & & & \\
\hline 1667 & $\begin{array}{l}\text { Ileberti Bosy.(Lutraria aeutan- } \\
\text { gula Micht.) ......... }\end{array}$ & & & & & & & & & $\cdots$ & $1+$ & & & \\
\hline & Menardi Desh. e var. ... & & & & & & & & & & $1+$ & & & \\
\hline
\end{tabular}




\begin{tabular}{|c|c|c|c|c|c|c|c|c|c|c|c|c|c|c|}
\hline 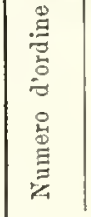 & $\mathrm{F} O \mathrm{R} M \mathrm{E}$ & 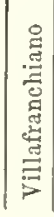 & 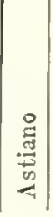 & 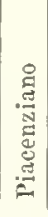 & 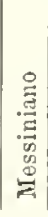 & 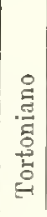 & 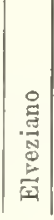 & 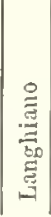 & 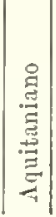 & | & 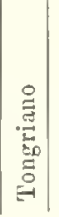 & 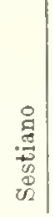 & 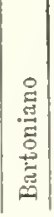 & 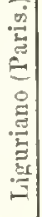 \\
\hline 1669 & Glycimeris subalpina May. e var...... & . . & ? & . & - & . & + & & & & & & & \\
\hline 1670 & Saxicava arctica Linn. e var........ & . & + & + & $\cdot$ & $?$ & $?$ & & & & & & & \\
\hline 1671 & elongâta Brocch........ & . . & & . & . & . & + & & & & & & & \\
\hline 1672 & miocenica Micht. . . . . & . & . & . & . & . & + & . & . & - & - & & & \\
\hline 1673 & turgida Micht......... & . & & . & . & + & b. & & . & & . & & & \\
\hline 1674 & minuta Linn. ......... & . & . & . & . & $\cdot$ & + & & • & & ]$^{\circ}$ & & . & \\
\hline 1675 & Pholadomyaquaesita Nicht. ....... & . & . & . & . & . & |. & & . & $\cdot$ & + & & & \\
\hline 1676 & $\begin{array}{r}" \quad \text { Delbosii Micht. (Ph. Puschii } \\
\text { Goldf.) } \ldots . . . .\end{array}$ & $1{ }^{\circ}$ & $b^{\circ}$ & & & & & & & & + & & & \\
\hline 1677 & corbuloides Micht. . . . . & . & . & • & $\cdot$ & - & $\cdot$ & & . & . & + & & . & \\
\hline$|1678|$ & arcuataLk. (Ph.Meriani May.) & $\cdot$ & $\cdot$ & & - & . & + & . & . & 10 & . & & & . \\
\hline 1679 & subarcuata D'Orb........ & . & $\cdot$ & $\cdot$ & $\cdot$ & • & . & & & & + & & & \\
\hline 1680 & trigonula Micht....... & 10 & (" & & - & & & & & $\cdot$ & + & & & \\
\hline 1681 & cuneiformis May. ....... & . & 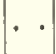 & $e^{\circ}$ & 1. & $\cdot$ & 1 & & | & . & + & & & \\
\hline 1682 & cf. Meriani......... & . & & $\cdot$ & - & . & . & & & - & $\cdot$ & & + & \\
\hline 1683 & 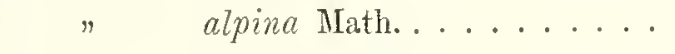 & . & . & . & - & . & + & & . & [" & · & & & \\
\hline 1684 & Thracia phaseolina Kien. ....... & ]$^{\circ}$ & & + & & - & $\cdot$ & & & & & & & \\
\hline 1685 & $"$ pubescens Leach. ........ & . & + & $10^{\circ}$ & & & . & & & & & & & \\
\hline 1686 & Eastonia rugosa Chemn. ........ & . & + & & $\Gamma^{\circ}$ & & 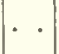 & & & & & & & \\
\hline 1687 & Mactra lisor Ant........... & . & + & & & & - & & & & & & & \\
\hline 1688 & stultorum Linn. ....... & . & + & & & & . & & & & & & & \\
\hline 1689 & triangula Ren. e var....... & . & + & + & . & - & + & & & & & & & \\
\hline 1690 & subtruncata Da Costa..... & . & + & + & . & - & 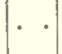 & & & & & & & \\
\hline 1691 & riberiana Cocconi ........ & . & + & $\cdot$ & . & & & & & & & & & \\
\hline 1692 & aspersa Sow. ......... & . & . & & . & . & + & & & & & & & \\
\hline 1693 & Lutraria declivis Micht. ........ & & & & & & & & & & $-1-$ & & & \\
\hline 1694 & 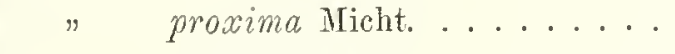 & & & & & & & & & . & + & & & \\
\hline 1695 & elliptica Ik. e var. . . . . & . & + & + & & + & -1 & & & & & & & \\
\hline 1696 & 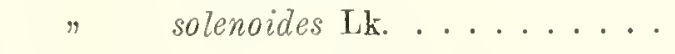 & 1 & + & & & & & & & & & & & \\
\hline 1697 & rugosa Chemntz........ & & + & & & & & & & & & & & \\
\hline 698 & 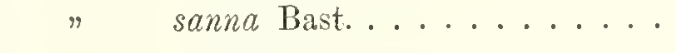 & & & & & & & & & & & & & \\
\hline 89 & hemntz e var. . . & & & $1-$ & & & + & & & 1. & & & & \\
\hline
\end{tabular}




\begin{tabular}{|c|c|c|c|c|c|c|c|c|c|c|c|c|}
\hline 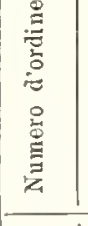 & $\mathrm{F} O \mathrm{R} \gg \mathrm{E}$ & $\mid$ & $\frac{0}{\frac{a}{2}}$ & | & 买 & 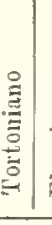 & & & 焉 & $\mid$ & & 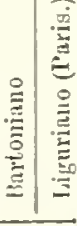 \\
\hline 1700 & Cardilia Michelottii Desh. . . . . . . & & -+ & & & & & & & & & \\
\hline 1701 & 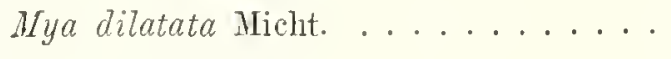 & & + & & & & & & & & & \\
\hline 1702 & $"$ testarum Bon. ............. & & + & & & & $\therefore$ & & & & & \\
\hline 1703 & Corbula carinata Duj. e var. . . . . . . & & . & & & + & + & & & + & & \\
\hline 1704 & " Deshayesi E. Sismd. . . . . . . . & & & & & & + & & & & & \\
\hline 1705 & neglecta Hicht. . ...... & & & & & & & & & + & & \\
\hline 1706 & $" \quad$ costellata Desh........... & & + & & & & & & & & & \\
\hline 1707 & $"$ gibba Oliv. e var......... & & + & 4 & & + & -1 & & & & & \\
\hline 1708 & $" \quad$ proboscidea Sismd. . . . . . . . & & + & & & & & & & & & \\
\hline 1709 & $"$ revoluta Broceh. e var. ..... & & + & & & $?$ & $?$ & & & & & \\
\hline 1710 & Neaera cuspidata Oliv............ & & + & & & & & & & & & \\
\hline 1711 & Gastrochaena abbreviata Bon........ & & +- & & & & & & & & & \\
\hline 1712 & dubia Penn......... & & + & + & & & & & & & & \\
\hline 1713 & Clavagella oblita Micht. & & & & & & & & & + & & \\
\hline 1714 & bacillaris Desh. ........ & & + & & & & & & & & & \\
\hline 1715 & Brocchii Lk. . . . . . . . & & + & + & & & & & & & & \\
\hline 1716 & Jouannetia semicaudata Desin. ...... & & & + & & & & & & & & \\
\hline 1717 & $\begin{array}{r}\text { Pholas Jouanneti Desh. (Ph. semicauda } \\
\text { Desm.)............ }\end{array}$ & & & & & & T & & & & & \\
\hline 1718 & Teredo norvegica Speng. e var....... & & + & + & & + & + & & & & & \\
\hline & Classe Gasteropod & & & & & & & & & & & \\
\hline & Ord. SCAFOPODI SOLENOCONCHI & & & & & & & & & & & \\
\hline 1719 & Dentalium aprinum Linn. ......... & & 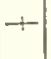 & + & & & & & & & & \\
\hline 1720 & asperum IIicht. . . . . . . . & & & & & & & & & & & \\
\hline 1721 & Bouei Desh. e var. ...... & & & + & & & + & & & & & \\
\hline 1722 & circinnatum sow. ....... & & & & & & ? & & & & & \\
\hline 1723 & gadus MIont. e var. . . . . . . & & & + & & -1 & & & & & & \\
\hline 1724 & dentale Linn. . . . . . . . . & & 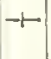 & + & & & & & & & & \\
\hline 1725 & dispar Mayer. . . . . . . . . . & & & + & & & & & & & & \\
\hline 1726 & fissura Lk. . . . . . . . . & & + & & & & & & & & & \\
\hline 1727 & fossile Linn. e var. . . & & + & + & & ? & +1 & & & & & \\
\hline
\end{tabular}




\begin{tabular}{|c|c|c|c|c|c|c|c|c|c|c|c|c|c|c|}
\hline 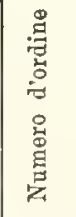 & F $O \mathrm{R} M \mathrm{E}$ & 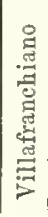 & 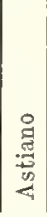 & 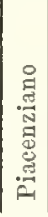 & 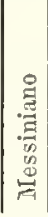 & 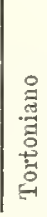 & 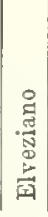 & 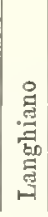 & 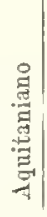 & 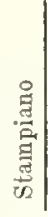 & 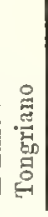 & 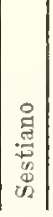 & 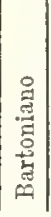 & 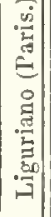 \\
\hline 1728 & Dentalium inaequale Bronn. e var..... & . & . & + & . & + & • & & & & . & & r & \\
\hline 1729 & Jani Hörn. . . . . . . . . . & . & . & . & $\Gamma^{\circ}$ & + & • & & & & & & & \\
\hline 1730 & miocenicum Micht....... & . & & & $\Gamma^{\circ}$ & -+ & • & $1^{\circ}$ & & & . & & 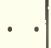 & \\
\hline 1731 & Michelotti Hörn. e var. . . . . & . & + & + & . & + & - & . & & & . & & & . \\
\hline 1732 & Noe Bon. . . . . . . . . & . & + & & $\cdot$ & . & & - & & & & & & . \\
\hline 1733 & pseudoentalis Lk. e var..... & . & & + & . & + & . & . & & & . & & & \\
\hline 1734 & Lamarki May. ........ & . & & 1 & . & + & $\cdot$ & - & & & . & & 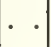 & . \\
\hline 1735 & rectum Linn. ......... & . & . & . & . & + & + & . & & . & . & . & . & . \\
\hline 1736 & subsexangulare D'Orb. (D.scx- & & & & & & & & & & & & & \\
\hline 1737 & $\begin{array}{l}\text { angulare Lk.) e var. . . . . } \\
\text { elephantinum Brocch. . . . . }\end{array}$ & . & $\begin{array}{l}? \\
+\end{array}$ & - & . & + & . & . & & . & . & . & & \\
\hline 1738 & striolatum Pisso? ...... & . & . & . & . & . & + & & & . & . & . & . & . \\
\hline 1739 & triquetrum Brocch. ...... & - & . & . & . & -1 & . & & . & . & & - & 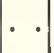 & \\
\hline 1740 & acuticosta Desh. e var. .... & . & + & . & . & & + & & & . & 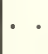 & & . & \\
\hline 1741 & $\begin{array}{r}" \quad \text { ? Sowerbyi Micht. (aff. D. incur- } \\
\text { vum Ren.) .......... }\end{array}$ & & & & & & + & & & & & & & \\
\hline & Ord. Placofori & & & & & & & & & & & & & \\
\hline 1742 & 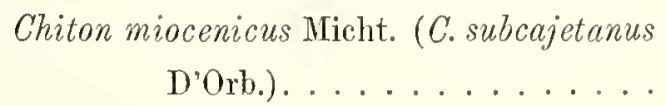 & & & & & & + & & & & & & & \\
\hline 1743 & Chiton Polii Desh.? ......... & 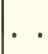 & & & & & + & & . & . & & & . & \\
\hline 1744 & $" \quad$ (Lepidopleurus) cinereus Linn. . . & . & . & + & & & & & . & . & - & & . & \\
\hline & Ord. Prosobranchi ciclobranchi & & & & & & & & & & & & & \\
\hline 1745 & Patella Borni Micht........... & $1^{\circ}$ & & & & . & + & & & & & & & \\
\hline 1746 & crenata Micht........ & . & & & . & $\mid$ & . & - & 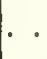 & & + & & . & . \\
\hline 1747 & diluvii Micht. .......... & - & + & & & & $\cdot$ & . & & & & & - & \\
\hline 1748 & polygona Sismd........ & & & & & - & + & 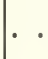 & . & & . & . & . & \\
\hline 1749 & anceps Micht. ......... & . & & & & $1^{\circ}$ & -1 & & & & & & . & \\
\hline 1750 & Helcion neglectus Micht. ......... & - & & & & - & + & $1^{\circ}$ & & & - & & . & \\
\hline 751 & Klipsteinii Micht. . & & & & & & + & & & & & & & \\
\hline
\end{tabular}




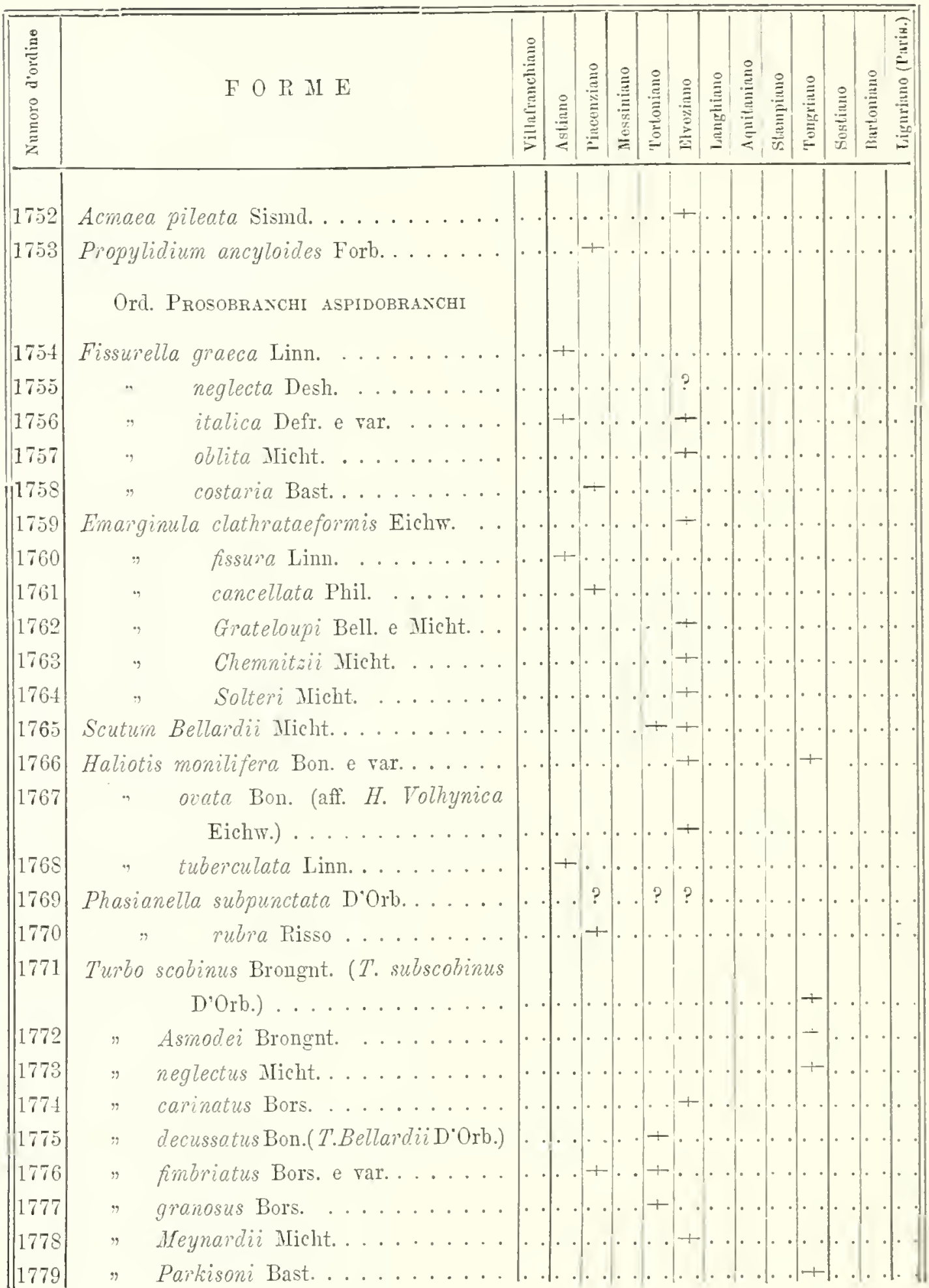


Catalogo paleontologieo del baeino tersiario del Piemonte

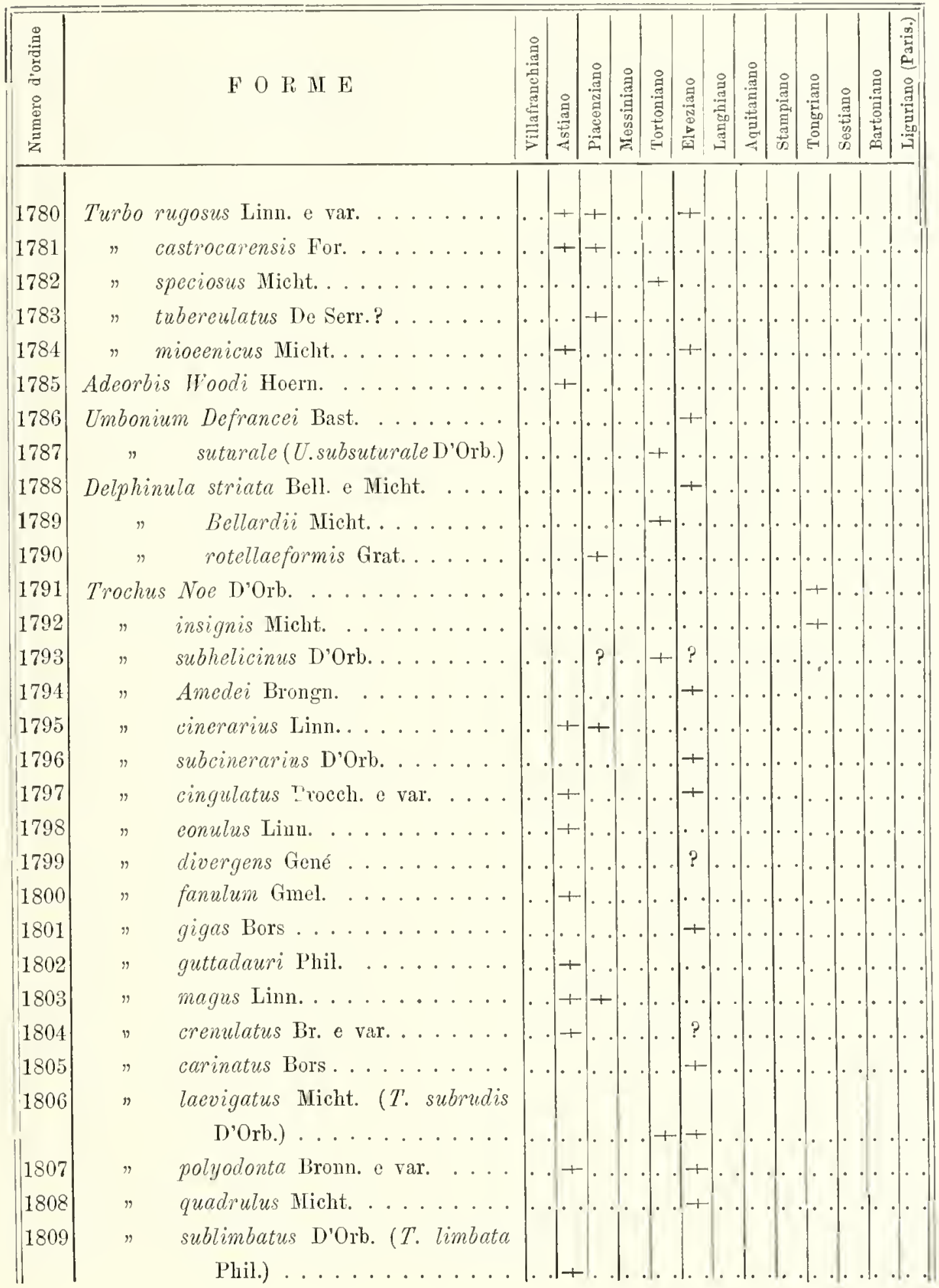




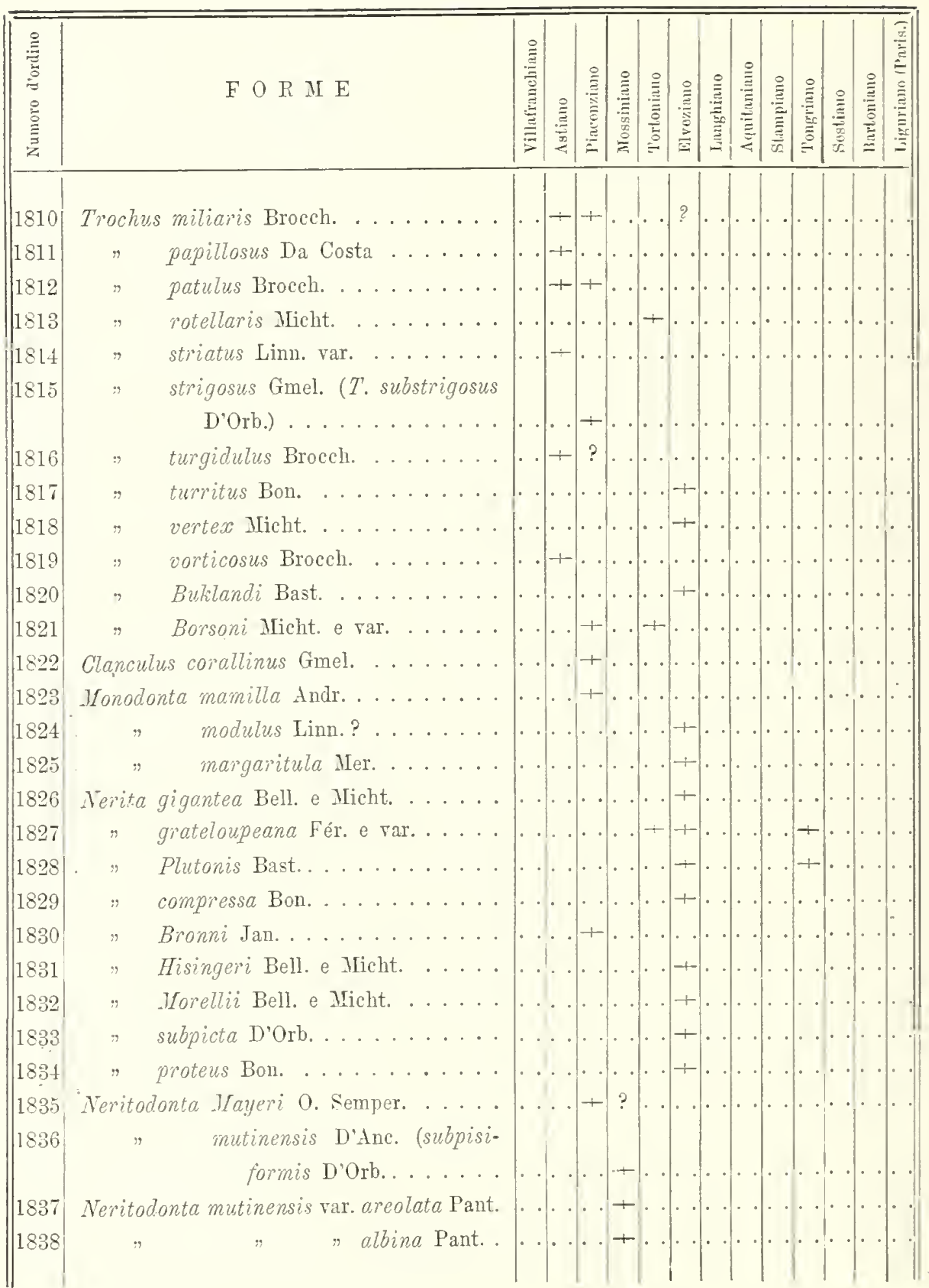




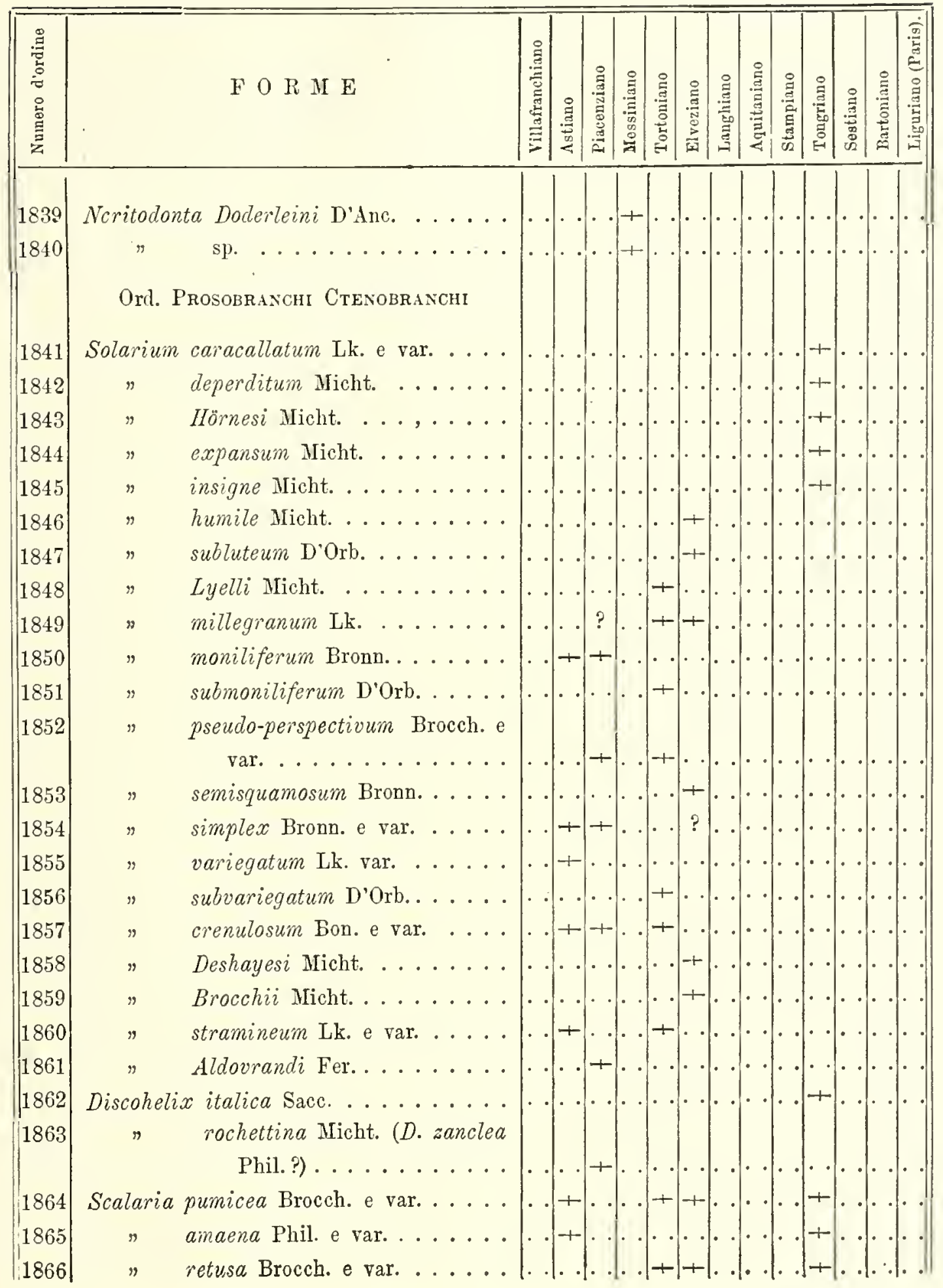




\begin{tabular}{|c|c|c|c|c|c|c|c|c|c|c|c|}
\hline 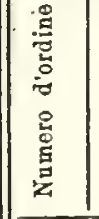 & $\mathrm{F} O \mathrm{R} M \mathrm{E}$ & $\mid$ & & & & & & 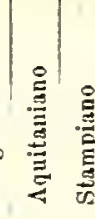 & & 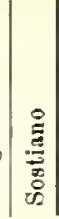 & '. \\
\hline $\mid 1867$ & $\begin{array}{r}\text { Scalaria reticulata Micht. (S. subreticu- } \\
\text { lata D'Orb.)......... }\end{array}$ & & & & & + & & & ? & & \\
\hline 1868 & pulchella Bir........... & - & . & & & ? & & & & & \\
\hline 1869 & alternicostata Bronn. . . . . . & & + & & & & & & & & \\
\hline 1870 & cancellata Defr. ......... & 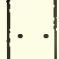 & + & & & & & & & & \\
\hline 1871 & clathra Brocch. ....... & & + & & & & & & & & \\
\hline 1872 & clathratula Adans. ....... & . & + & + & & & & & & & \\
\hline 1873 & 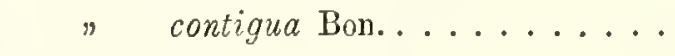 & & + & & & & & & & & \\
\hline 1874 & disjuncta Bronn. ........ & . & . & & - & & & & & & \\
\hline 1875 & impressa Bon. .......... & & + & & & & & & & & \\
\hline 1876 & lamellosa Brocch. ........ & & . & & - & & & & & & \\
\hline $\mid 1877$ & lanceolata Brocch. e var..... & 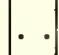 & + & & - & & & & & & \\
\hline|| $1878 \mid$ & muricata Risso ........... & & + & & & & & & & & \\
\hline 1879 & pseudo-scalaris Brocc...... & . & + & + & & & & & & & \\
\hline $\mid 1880$ & scaberrima Micht. . . . . . . & & & & & + & & & & & \\
\hline 1881 & spinosa Bon. . . . . . . . & & & & & & & & & & \\
\hline 1882 & sulculata Bon. . . . . . . . & . & + & & & & & & & & \\
\hline 1883 & tenuicosta Michd. . . . . . . & & + & & & & & & & & \\
\hline 1884 & torulosa Brocch. . . . . . . & . & - & & & & & & & & \\
\hline 1885 & trinacria Phil. ......... & & + & & & & & & & & \\
\hline $\mid 1886$ & variabilis Jan. . . . . . . . . & & + & & & & & & & & \\
\hline 1887 & 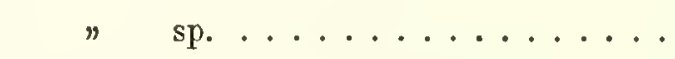 & • & & & & & & & & & + \\
\hline $\mid 1888$ & Turritella taurinensis D'Orb. e var. . . . & & & & & & & & & & \\
\hline 1889 & communis Risso......... & . & + & + & & & & & & & \\
\hline 1890 & bicarinata Eichw. e var. ... & & & ? & & & & & + & & \\
\hline 1891 & Bellardii May. . . . . . . . . & & & & & & & & & & \\
\hline 1892 & cathedralis Brongt. e var. .. & & & & & & & & + & & \\
\hline 1893 & laevissima May. . . . . . . . & & & & & & & & & & \\
\hline 1894 & desmaretina Bast. e var. ... & & & & & & & & + & & \\
\hline 1895 & Sismondai May. ..... & & & & & 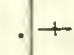 & & & & & \\
\hline 1896 & strangulata Grat. e var..... & & & & & & & & + & & \\
\hline 1897 & aspera Sismd. & & & & & & & & & & \\
\hline
\end{tabular}




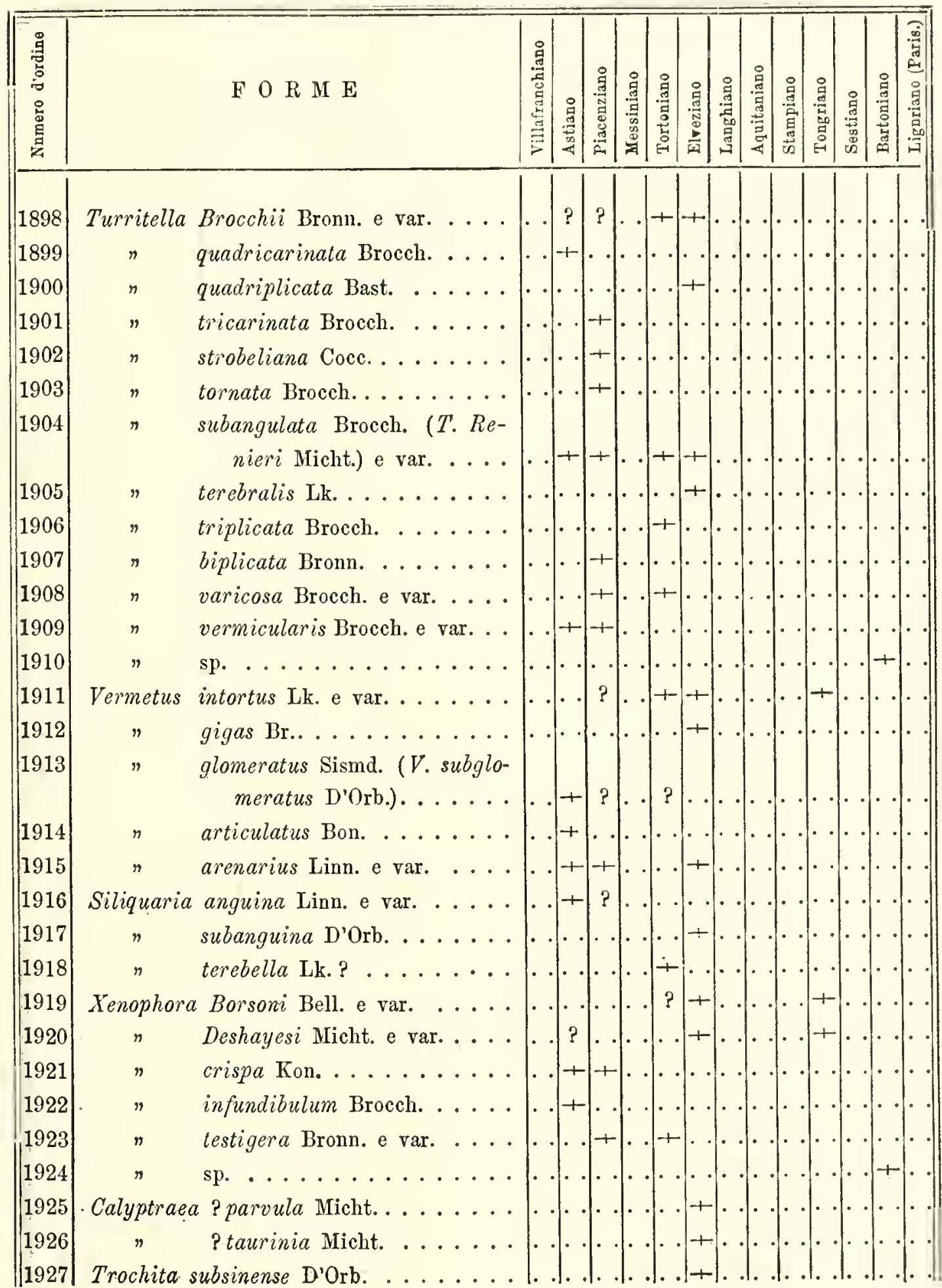




\begin{tabular}{|c|c|c|c|c|c|c|c|c|c|c|c|}
\hline 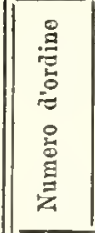 & $\mathrm{F} O \mathrm{R} \mathrm{ML}$ & | & $\mid$ & 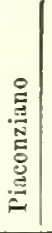 & & 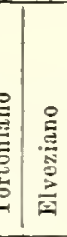 & | & & & 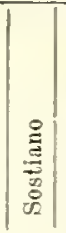 & 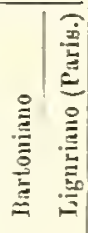 \\
\hline 1928 & Trochita gualterianum Gené....... & & & & & + & & & & & \\
\hline 1929 & $" \quad$ muricata Br. ......... & & + & & & & & & & & \\
\hline 1930 & $" \quad$ sinensis Lin. . . . . . . . . & & + & & & & & & & & \\
\hline 1931 & Crepidula cochlear Bast. . . . . . . . & & + & & & & & & & & \\
\hline 1932 & " mythiloidea Bell. e Micht. .. & & & + & & & & & & & \\
\hline 1933 & $" \quad$ spirifera Bon. ........ & & & ? & ? & $?$ & & & & & \\
\hline 1934 & $" \quad$ unguiformis Lk. ....... & & + & & & & & & & & \\
\hline 1935 & IIipponyx interrupta Micht. . . . . . . & & & & & + & & & & & \\
\hline 1936 & " sulcata Bors. e var. . ..... & & & & & + & & & + & & \\
\hline 1937 & Capulus glabratus Bon. .......... & & + & & & & & & & & \\
\hline 1938 & $" \quad$ anceps Hicht. e var. ....... & • & & & & + & & & + & & \\
\hline 1939 & $"$ faraniellus Gené ........ & & & & & + & & & & & \\
\hline 1940 & " pedemontanus Bon. ........ & & + & & & & & & & & \\
\hline 1941 & sulcosus Brocch. . . . . . . . . & & + & & & & & & . & & \\
\hline 1942 & neglectus Nicht. ........ & & & & & + & & & & & \\
\hline 1943 & -edai Micht. . . . . . . . . . & & & & & + & & & & & \\
\hline 1944 & inuosus Brocch. . . . . . . . . & & + & & & & & & & & \\
\hline 1945 & aevis Bronn. .......... & & + & + & & $?$ & & & & & \\
\hline 1946 & $\begin{array}{r}" \quad \text { hungaricus Linn. (C. dispar Bon.) } \\
\text { e var. ............. }\end{array}$ & & + & + & & + & & & & & \\
\hline 1947 & Sigaretus Michaudi Micht. e var. . . . . & & & & & + & & & + & & \\
\hline 1948 & $" \quad$ subhaliotideus D'Orb....... & & + & & & & & & & & \\
\hline 1949 & $\begin{array}{r}\text { Deshayesi Micht. (aff. S.clathra- } \\
\text { tus Recl.) .......... }\end{array}$ & & & & & + & & & & & \\
\hline 1950 & Natica Josephinia Risso e var.(N.olla Serr.) & & + & + & & + & & & + & & \\
\hline 1951 & $"$ submamilla D'orb. e var. .... & & & & & + & & & + & & \\
\hline 1952 & crassatina Lk. .......... & & & & & & & & + & & \\
\hline 1953 & spirata Desh. . . . . . . . . . & & & & & . & & & + & & \\
\hline 1954 & elongata Micht. . . . . . . . . . & & & & & & & & + & & \\
\hline 1955 & compressa Bast. ......... & & & & & + & & & & & \\
\hline 56 & fasciolata Bon. . . . . . . . & & & ? & & & & & & & \\
\hline
\end{tabular}


Catalogo paleontologico del bacino teriario del Piemonte

\begin{tabular}{|c|c|c|c|c|c|c|c|c|c|c|c|c|c|c|}
\hline 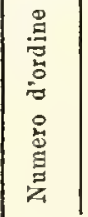 & $\mathrm{F} O \mathrm{R} \mathrm{M} \mathrm{E}$ & 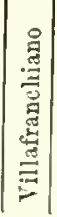 & 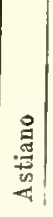 & 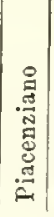 & 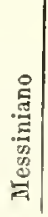 & 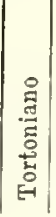 & 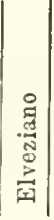 & 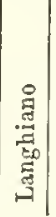 & 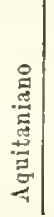 & 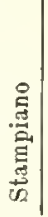 & 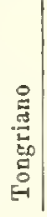 & 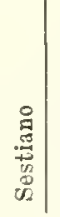 & 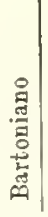 & 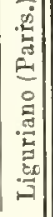 \\
\hline 88 & Natica helicina Brocch. e var. ..... & . & + & + & . & + & + & & & & - & & & \\
\hline 1959 & 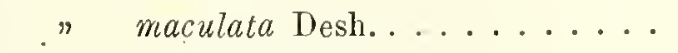 & . & & $?$ & • & & . . & & & & • & & & \\
\hline 60 & submamillaris D'Orb. . . . . . & . & [" & & r & . & + & & & • & - & & & \\
\hline 61 & millepunctata Lk. e var. ..... & . . & + & + & . & ? & . & 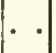 & . & . & • & & & \\
\hline 1962 & sismondiana D'Orb. ....... & $\cdot$ & & 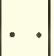 & $\cdot$ & - & + & & & & & • & & \\
\hline 63 & plicatula Bronn.......... & . & + & + & . & ( & & ( & 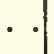 & - & . & & & \\
\hline 1964 & pseudoepiglottina sismd. . . . . & . & & & & . & +- & & 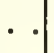 & • & • & & & \\
\hline 65 & redempta Micht. . ....... & . & & & . & + & $\cdot$ & - & & • & - & & & \\
\hline 1966 & scalaris Bell. e Micht. ..... & . & & & . & . & + & & & & & & & \\
\hline 1967 & tectula Bon. e var. . ....... & . & + & + & . & $?$ & & & & & & & & \\
\hline 19 & turbinoides Grat......... & . & + & • & - & - & . & & & & & & & \\
\hline 1969 & umbilicosa Bon. ......... & . & + & & • & - & I & & 1 & • & & & & \\
\hline 1970 & Valenciennesi Payr. ....... & . & + & . & $\cdot$ & [0 & . & & - & - & & & & \\
\hline 1971 & Valvata (Gyrarbis) cristata Müll. ... & -+ & . & . & . & . & . & & . & & & & & \\
\hline 1972 & (Cincinna) Lessonae Sacc..... & + & & $l^{\circ}$ & . & $\left.\right|^{\circ}$ & I & [" & & • & & & & \\
\hline 1973 & Vivipara Pollonerae Sacc........ & + & & & . & . & . & . &. & & & & & \\
\hline 1974 & Bitinia tentaculata Linn. var. Tellinii Sacc. & + & . & $\cdot$ & . & . & . & . & . & - & & & & \\
\hline 1975 & Emmericia pliocenica Sacc........ & + & & & & & . & & & . & & & & \\
\hline 1976 & IIydrobia Escofferae Tourn. ........ & . & & . & + & $?$ & . & I. & & [0 & & & & \\
\hline 1977 & Fontannesi Cap......... & . & & . & + & $?$ & . & & & 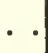 & & & & \\
\hline 1978 & stagnalis Bast. $\ldots \ldots \ldots$ & . & & . & + & . & ${ }^{\circ}$ & & & - & & & & \\
\hline 1979 & etrusca Cap. ......... & . & & . & + & & - & & & . & & & & \\
\hline 1980 & abtusa Sandb. ........ & . & & . & + & & & & & & & & & \\
\hline 1981 & acuta Drap. ......... & & & & 7 & & & & & & & & & \\
\hline 1982 & perforata Pant. ........ & . & • & . & + & & . & . & & & & & & \\
\hline 1983 & (Peringia) subcarinata Bon. . . & . & [. & $?$ & + & + & " & & & I & & . & & \\
\hline 1984 & 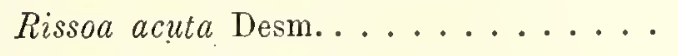 & . & • & + & $\cdot \cdot$ & . & $\cdot$ & & & . & & & & \\
\hline 1985 & 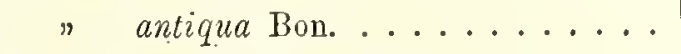 & & + & $\cdot \cdot$ & & . & & & & & & & & \\
\hline 86 & Bonellii Sismd......... & 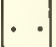 & & + & & & & & & & & & & \\
\hline 87 & 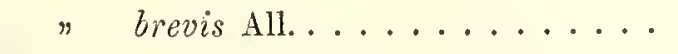 & & & + & & & & & & & & & & \\
\hline 080 & cimex Brocch. ..... & & & & & & & & & & & & & \\
\hline 8 & D Po & & & & & & & & & & & & & \\
\hline
\end{tabular}




\begin{tabular}{|c|c|c|c|c|c|c|c|c|c|c|c|c|c|}
\hline 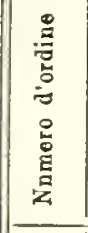 & $\mathrm{F} O \mathrm{P}$ II $\mathrm{E}$ & 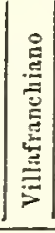 & 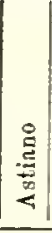 & 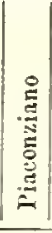 & 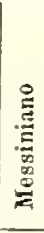 & 芳 & 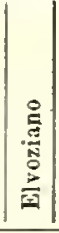 & 节 & | & & 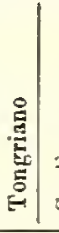 & 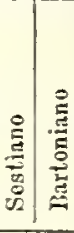 & है \\
\hline 1990 & Rissoa equestris Bon............ & & + & & & & & & & & & & \\
\hline 1991 & $"$ laevigata Bon. . . . . . . . . & & + & & & & & & & & & & \\
\hline $\mid 1992$ & " Brougkieri Payr. ........ & & + & & & & + & & & & & & \\
\hline 1993 & n striolata Pisso. .......... & & + & & & & & & & & & & \\
\hline 1994 & $"$ decussata Mont. ......... & & & + & & & & & & & & & \\
\hline 1995 & $"$ acinus Brocch. ......... & & + & + & & & & & & & & & \\
\hline 1996 & $" \quad \operatorname{minuta}$ All. . . . . . . . . & & + & & & & & & & & & & \\
\hline 1997 & $" \quad$ sulzeriana Riss........... & & & + & & & & & & & & & \\
\hline $\mid 1998$ & $"$ textilis Bon. .......... & & + & & & & & & & & & & \\
\hline 1999 & zetlandica Mront. ......... & & - & + & & & & & & & & & \\
\hline 2000 & Rissoina pusilla Brocch. e rar. . . . . & & + & + & & & + & & & & & & \\
\hline 2001 & Acme cf. lineata Drap. . . . . . . . . . & + & & & & & & & & & & & \\
\hline 2002 & Lacuna basterotina Bronn. . . . . . . . . & & + & & & & & & & & & & \\
\hline 2003 & Fossarus costatus Brocch. . . . . . . . & & + & & & & & & & & & & \\
\hline 2004 & Eulima subbrevis D'Orb. . . . . . . . . . & & + & & & & & & & & & & \\
\hline 2005 & $" \quad$ subhastata D'Orb......... & & + & & & & & & & & & & \\
\hline 2006 & $" \quad$ lactea D'Orb............. & & . & 1 & & & & & & & & & \\
\hline 2007 & $n \quad$ polita Linn............. & & + & + & & & & & & & & & \\
\hline 2008 & $n \quad$ ventricosa Forb. ......... & & • &.+ & & & & & & & & & \\
\hline 2009 & $" \quad$ Scillae scacc. ........... & & + & + & & & & & & & & & \\
\hline 2010 & " Philippii Rain.Vanden Eck.e Ponz. & & & + & & & & & & & & & \\
\hline 2011 & $"$ subulata Don............ & & + & + & & ? & & & & & & & \\
\hline 2012 & Niso terebellum Phil............. & & + & & & & & & & & & & \\
\hline 2013 & "burdigalensis D'Orb.......... & & & $?$ & & & $?$ & & & & & & \\
\hline 2014 & Pyramidella plicosa Bronn. e var. .... & & + & + & & & $?$ & & & & & & \\
\hline 2015 & Turbonilla gradata Mont. ......... & & & & & & & & & & & & \\
\hline 2016 & rufa Phil. .......... & & & + & & & & & & & & & \\
\hline 2017 & $" \quad$ costellata Grat. ........ & & & & & & & & & & & & \\
\hline 2018 & $" \quad$ suturalis Bon........... & & & & & & & & & & & & \\
\hline 2019 & $" \quad$ gracilis Brocch......... & & & & & & & & & & & & \\
\hline 2020 & " plicatula Brocch. ...... & & & & & & & & & & & & \\
\hline 1 & $" \quad$ columnaris. Bon: & & & & & & & & & & & & \\
\hline
\end{tabular}




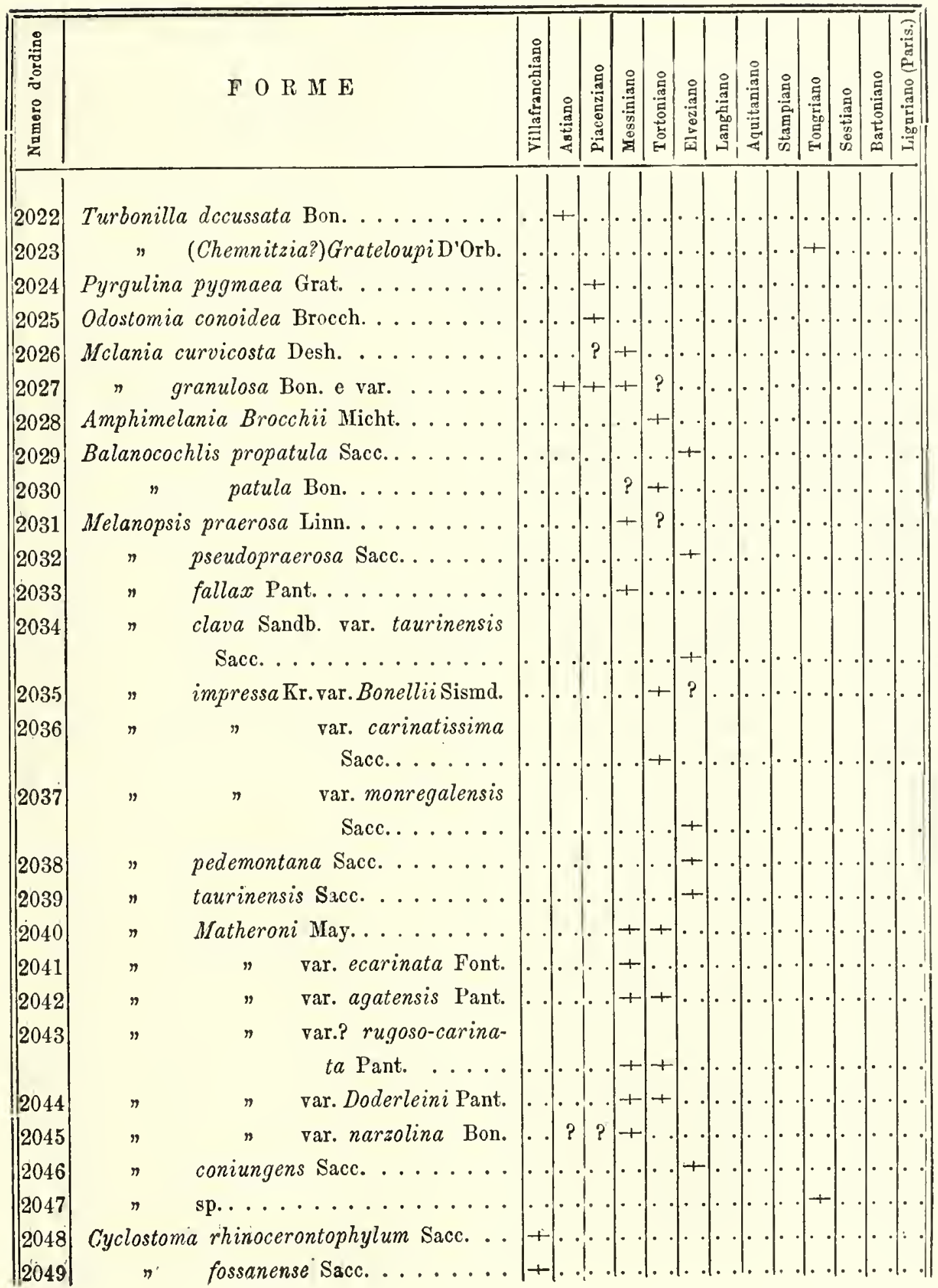




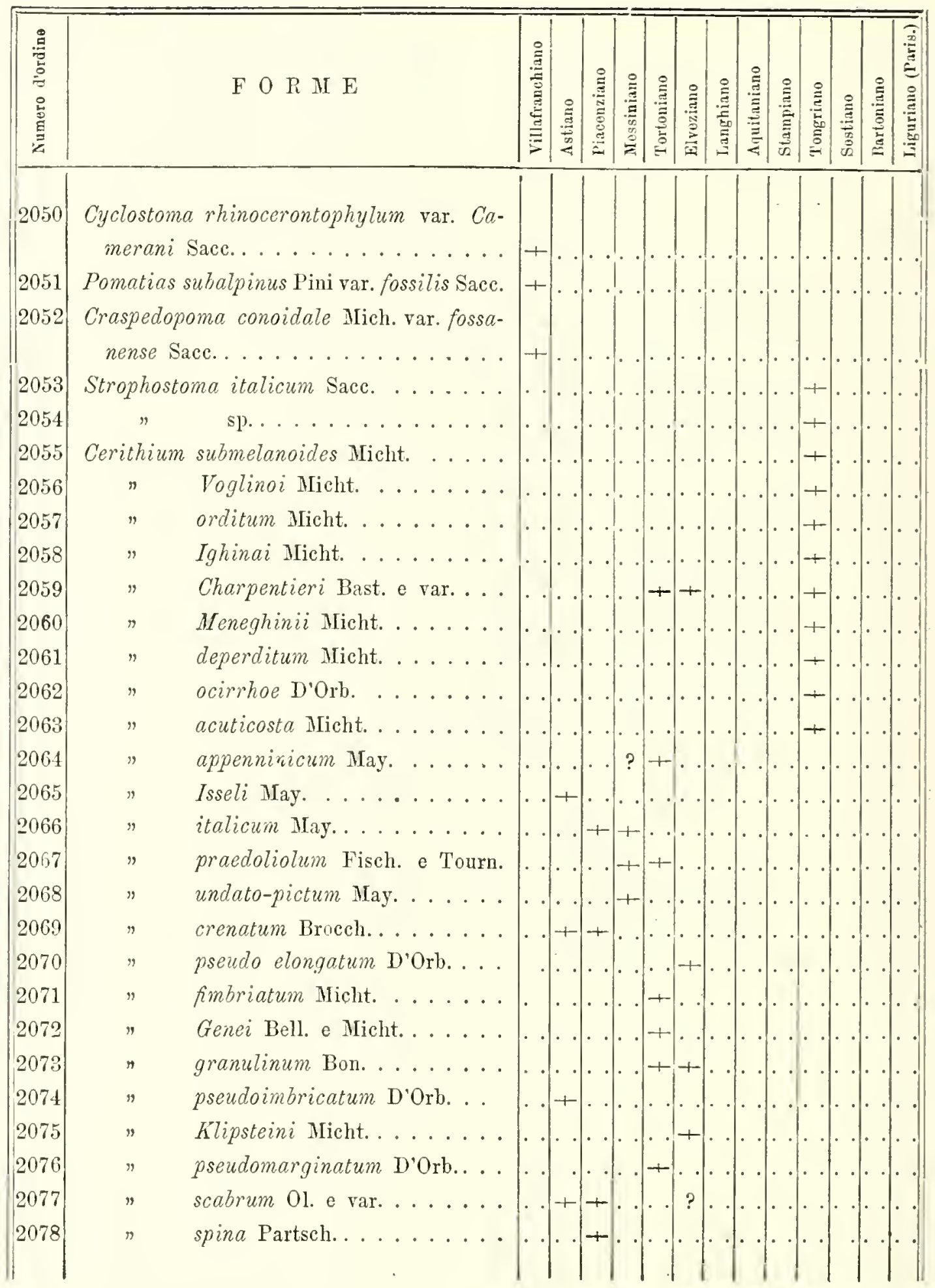




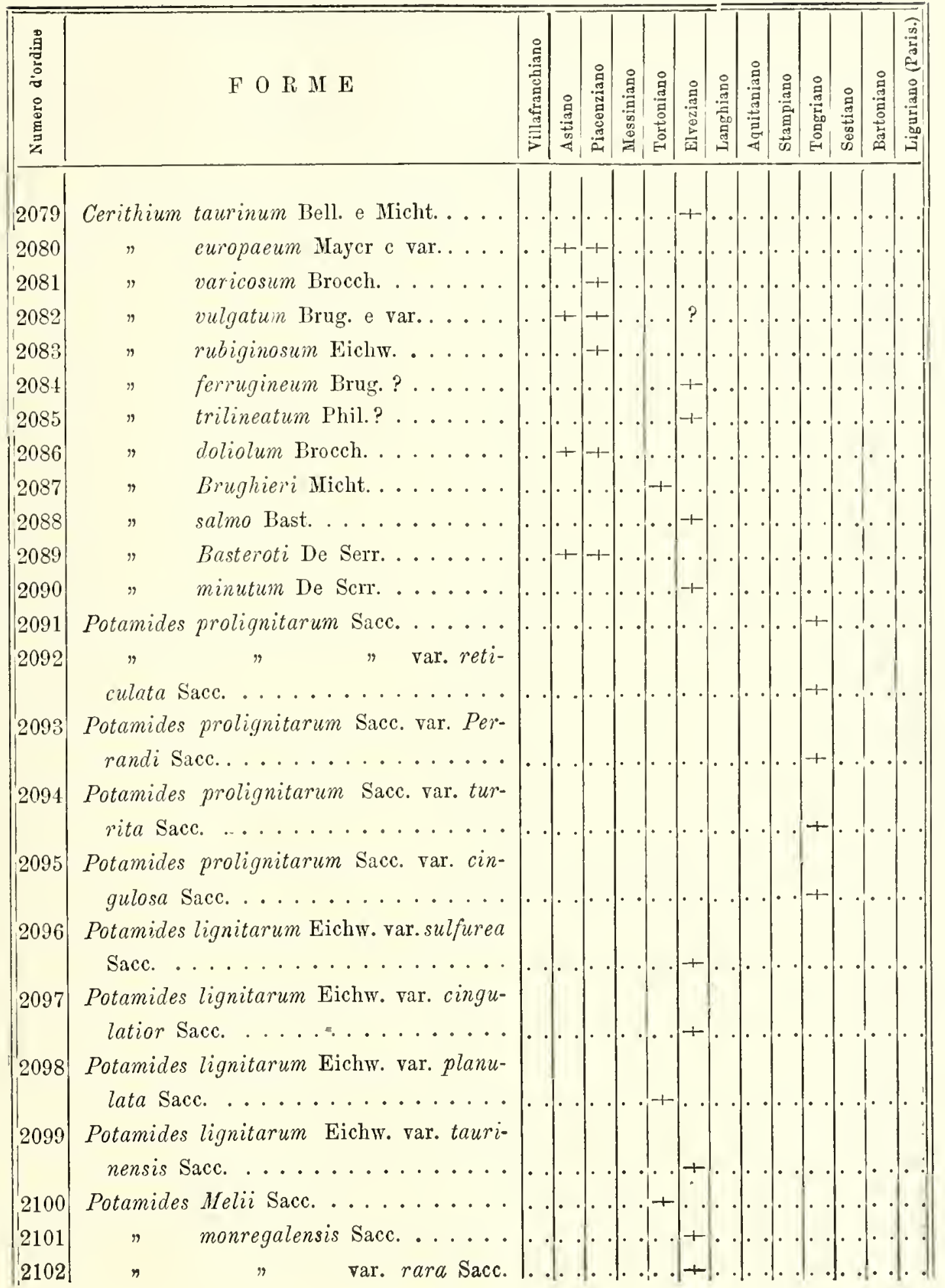




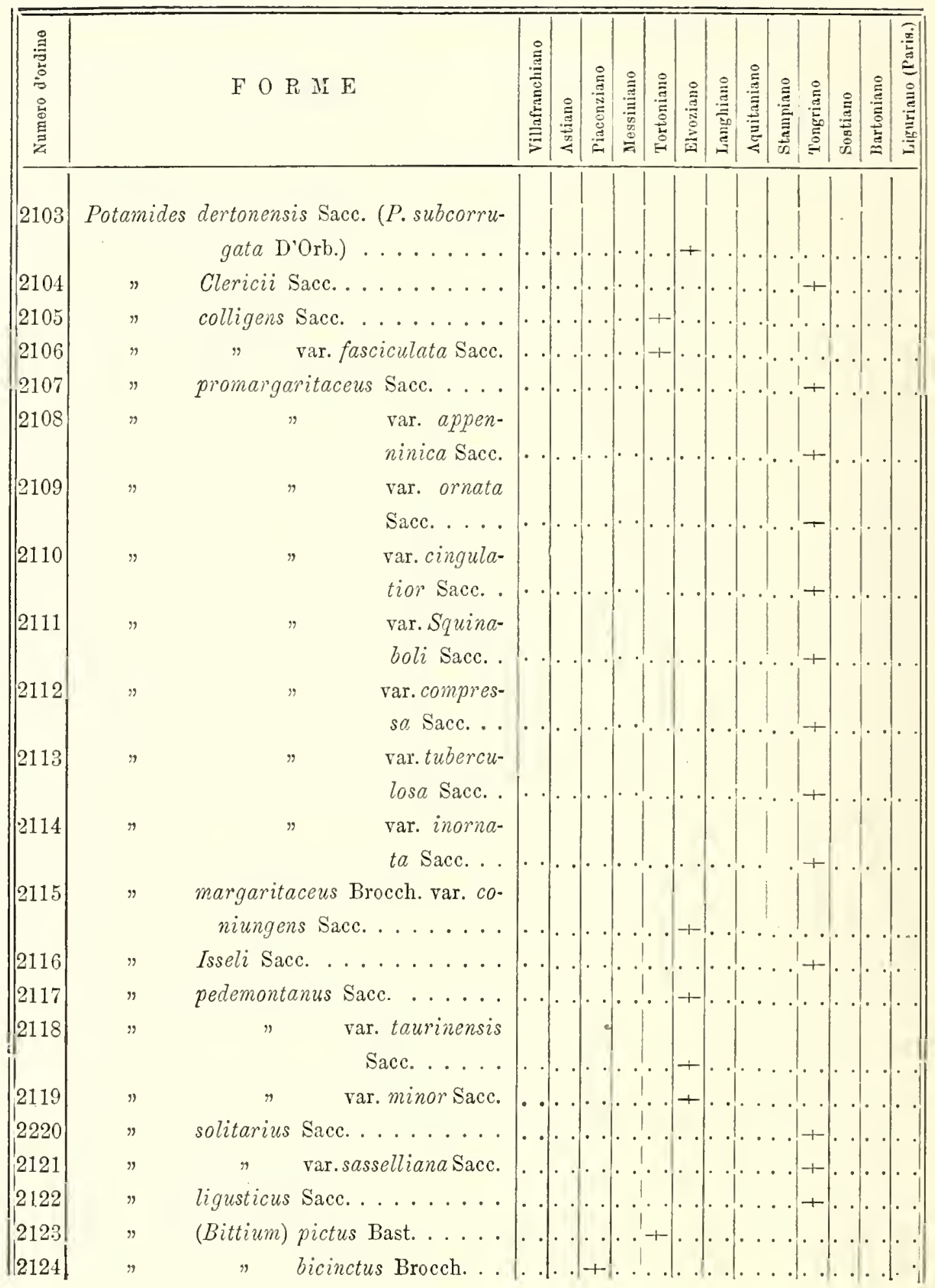




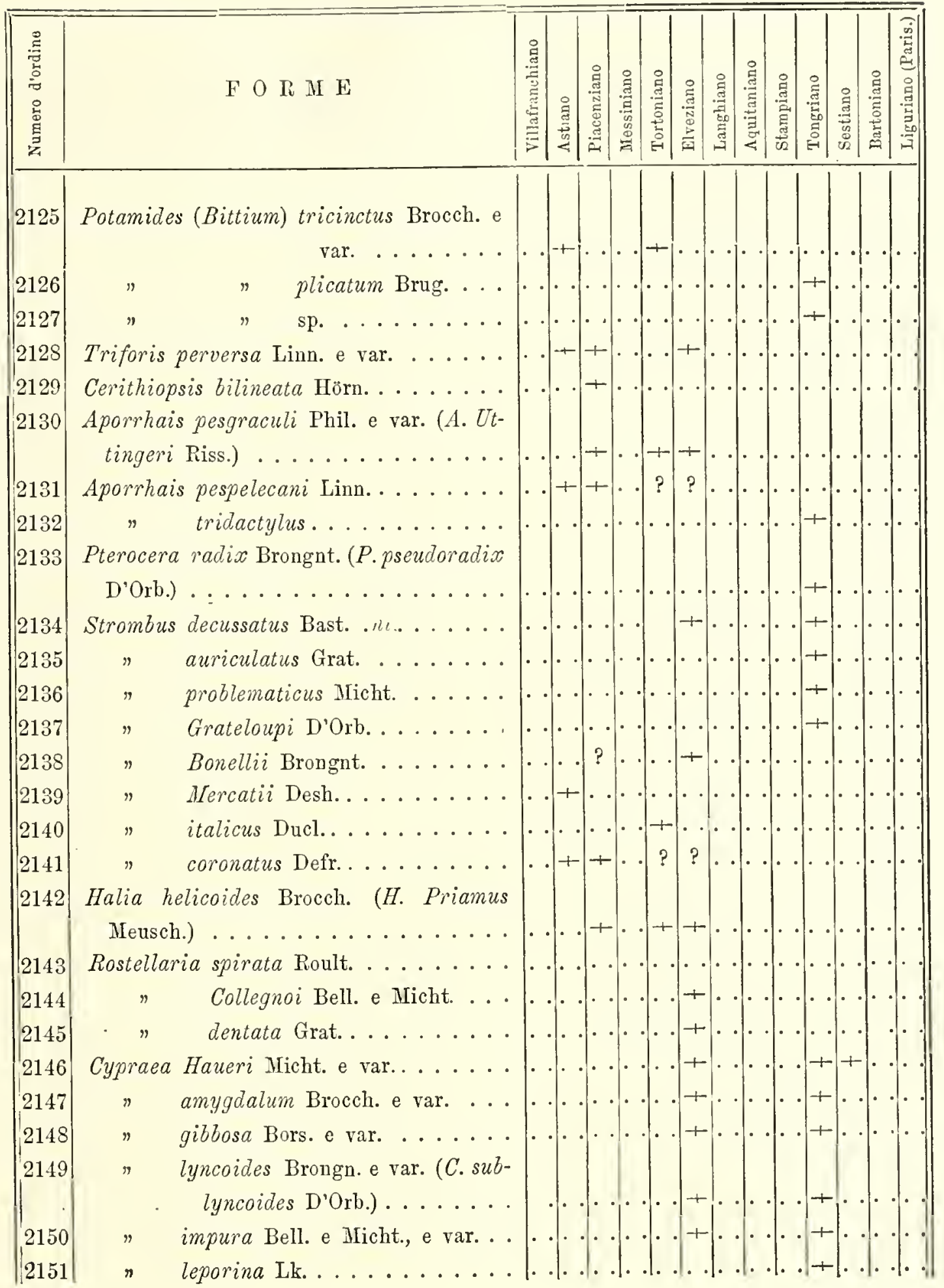




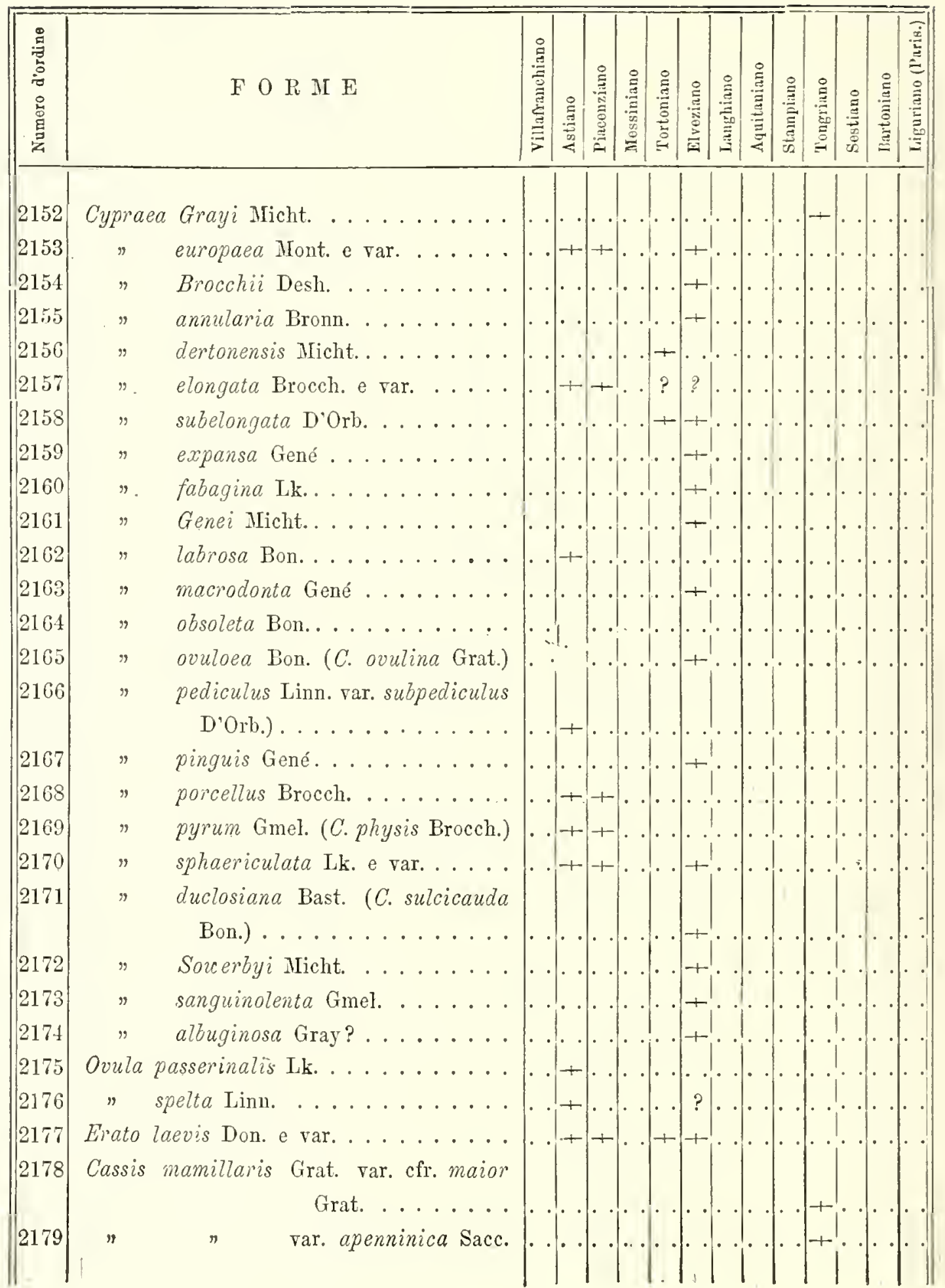




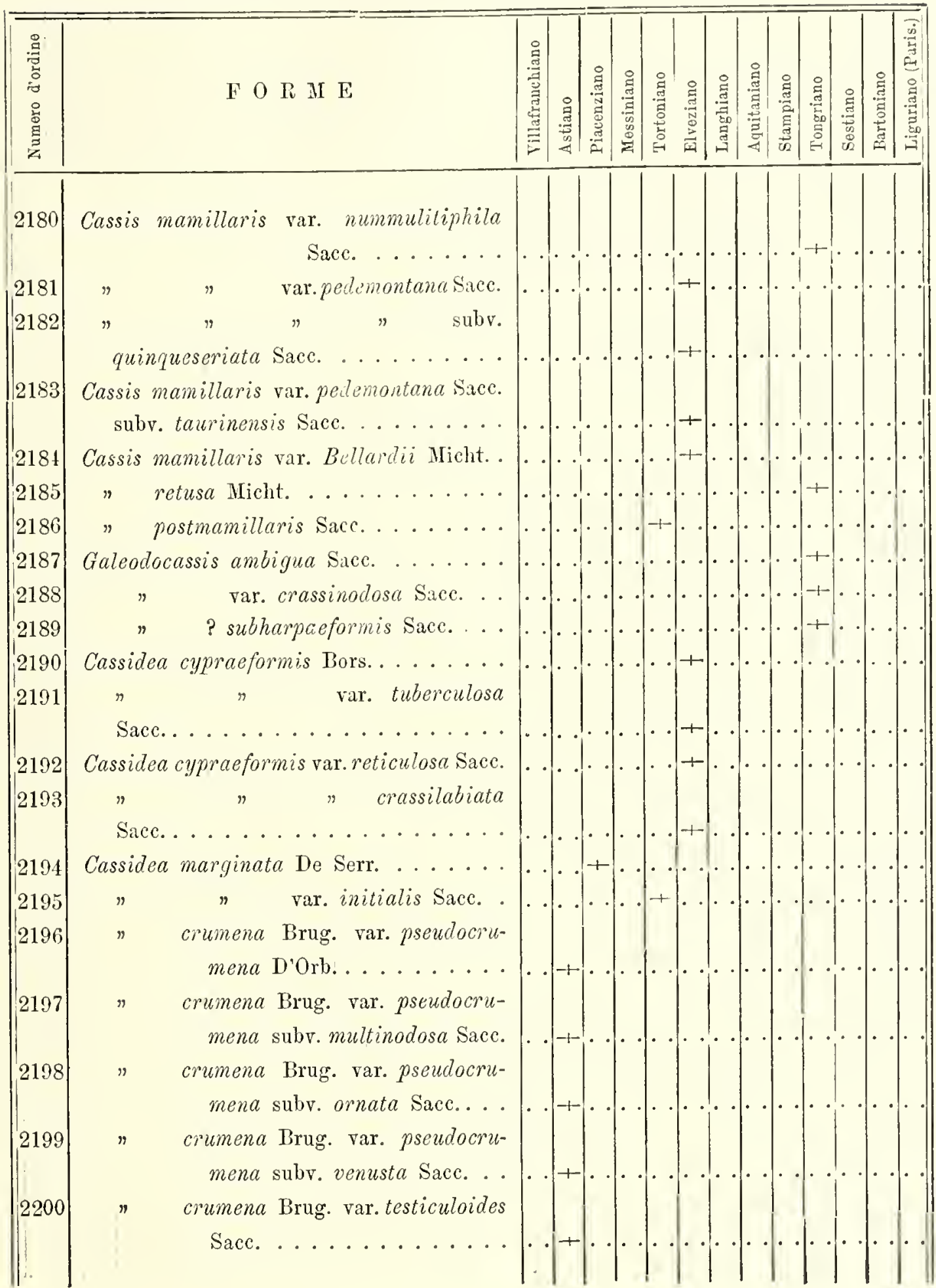




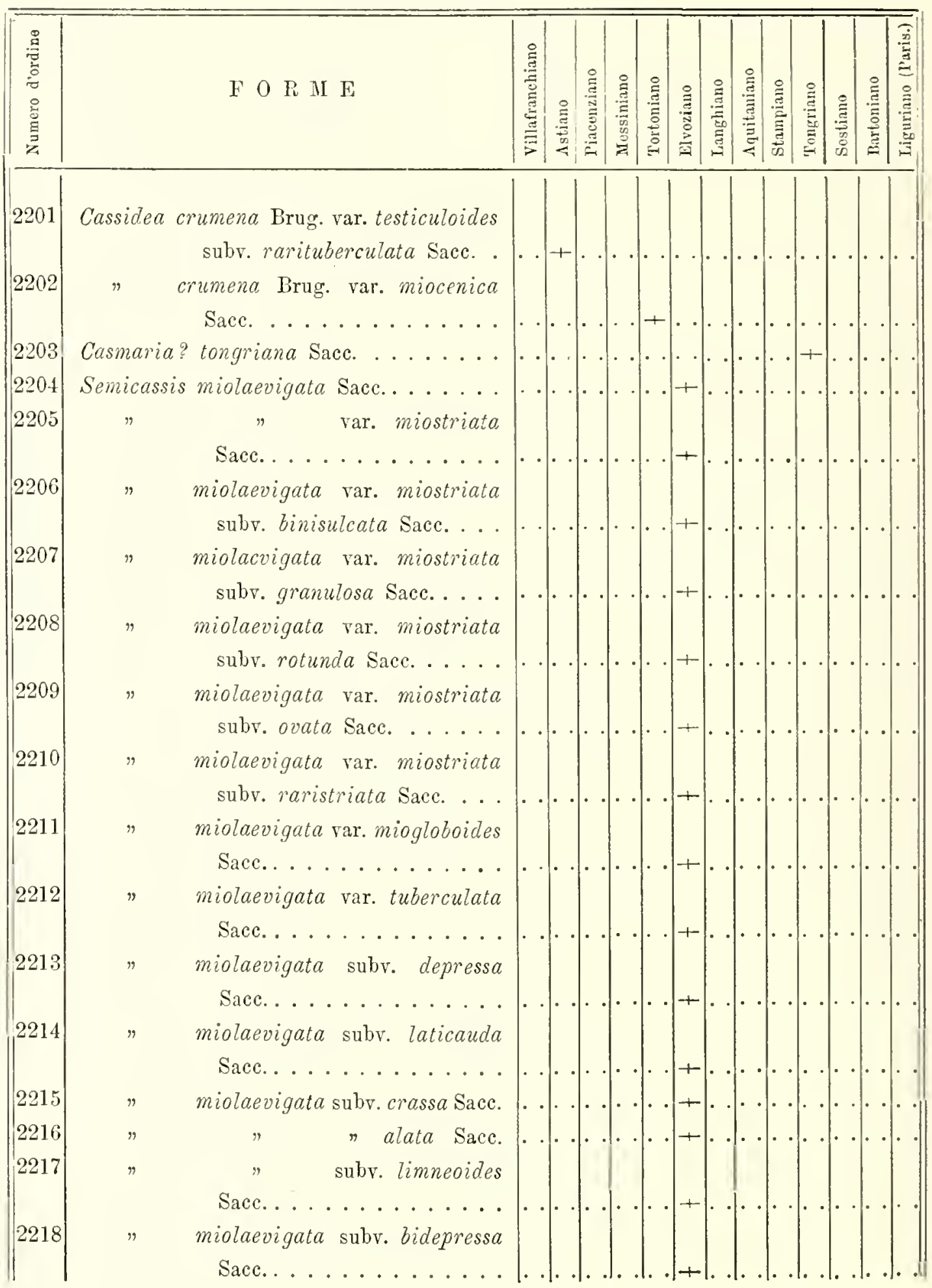




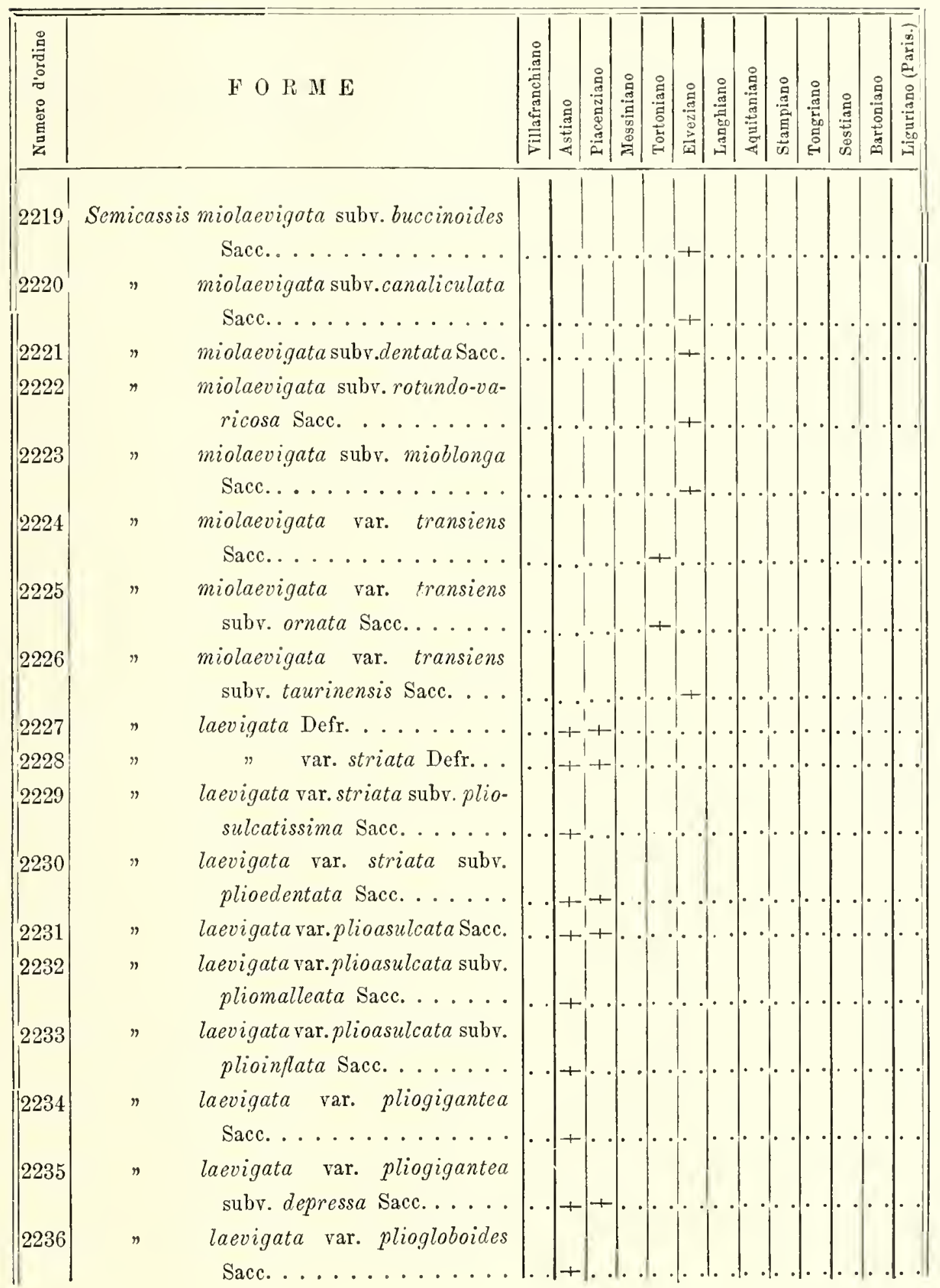




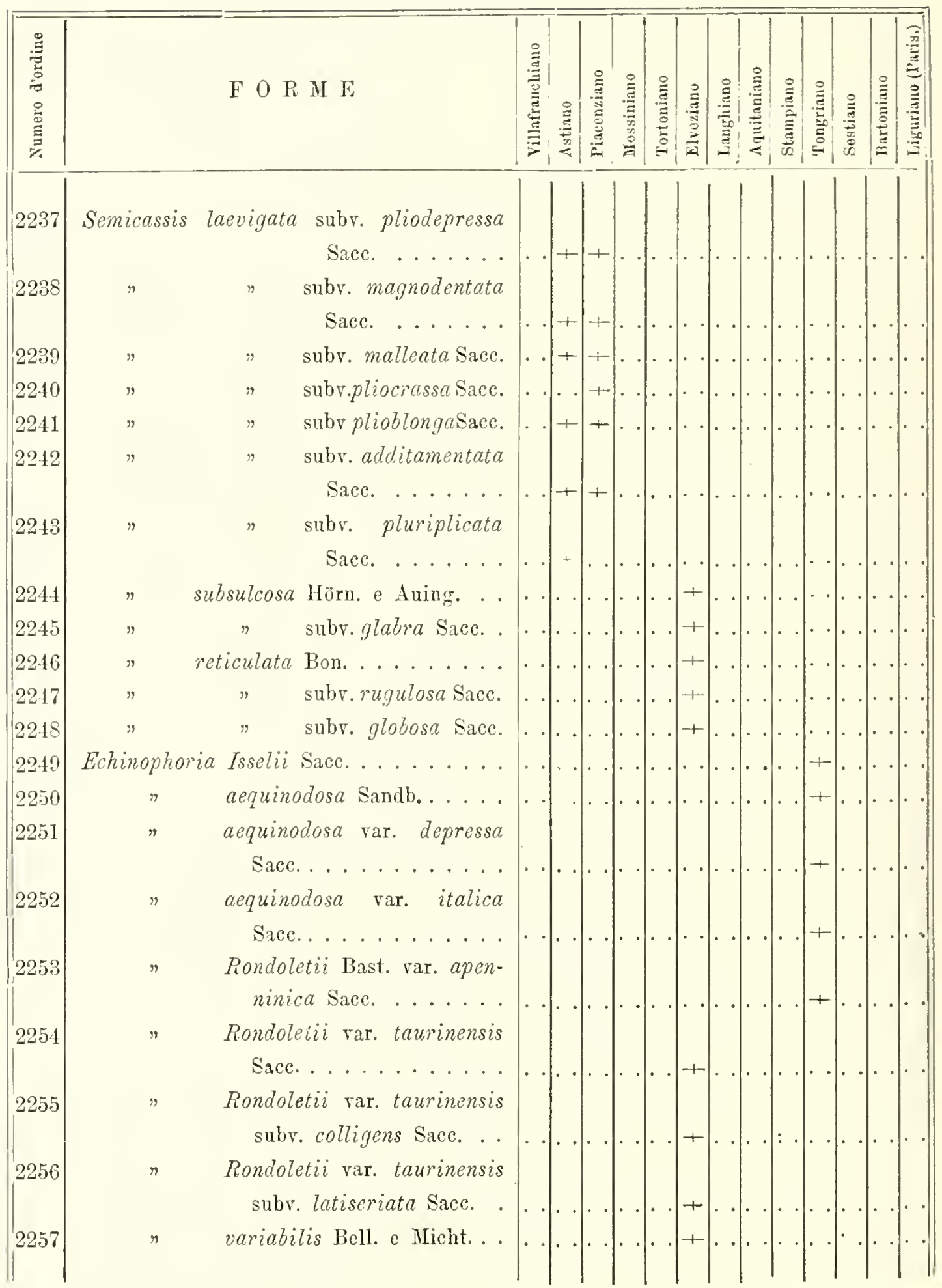




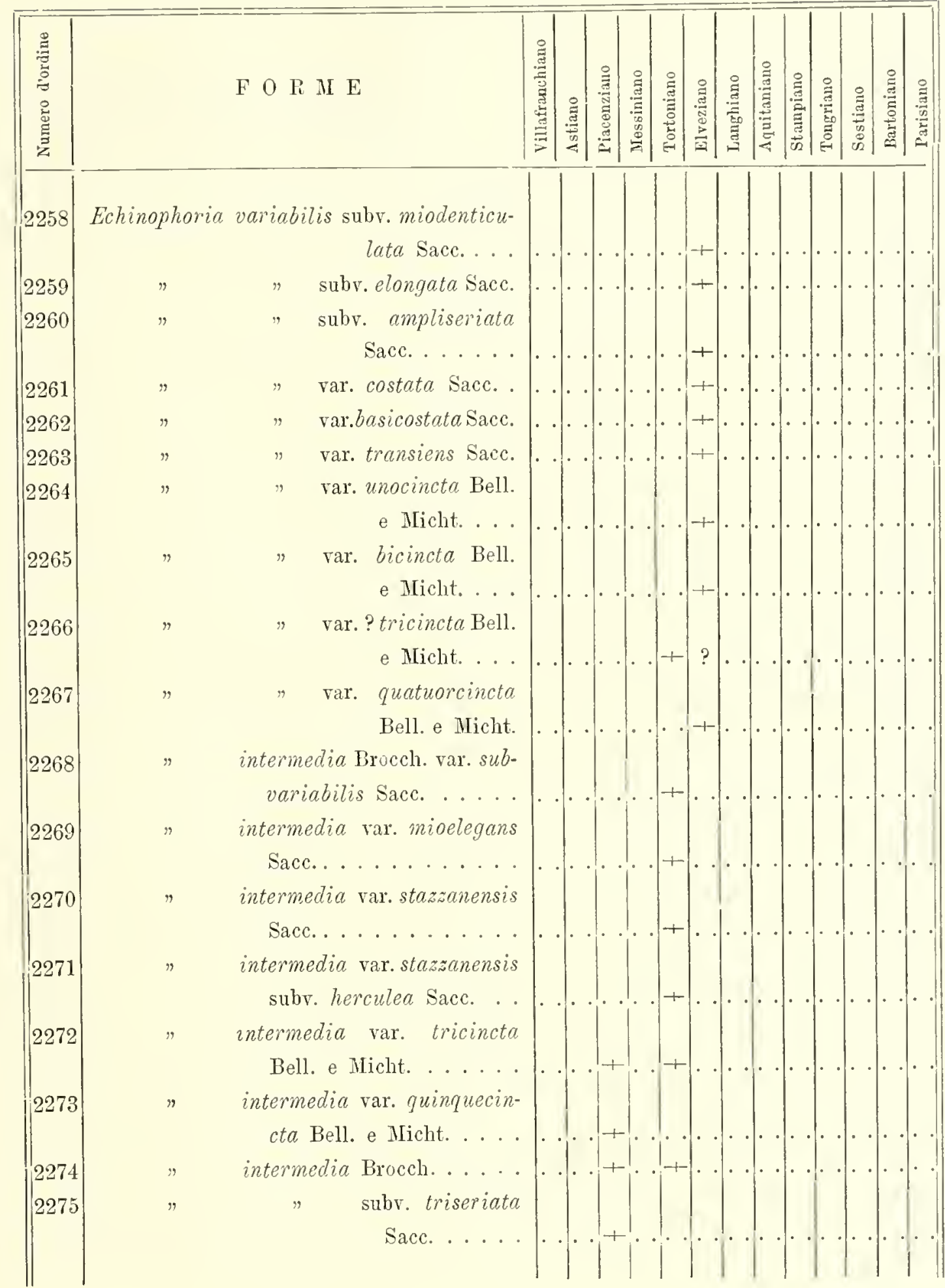




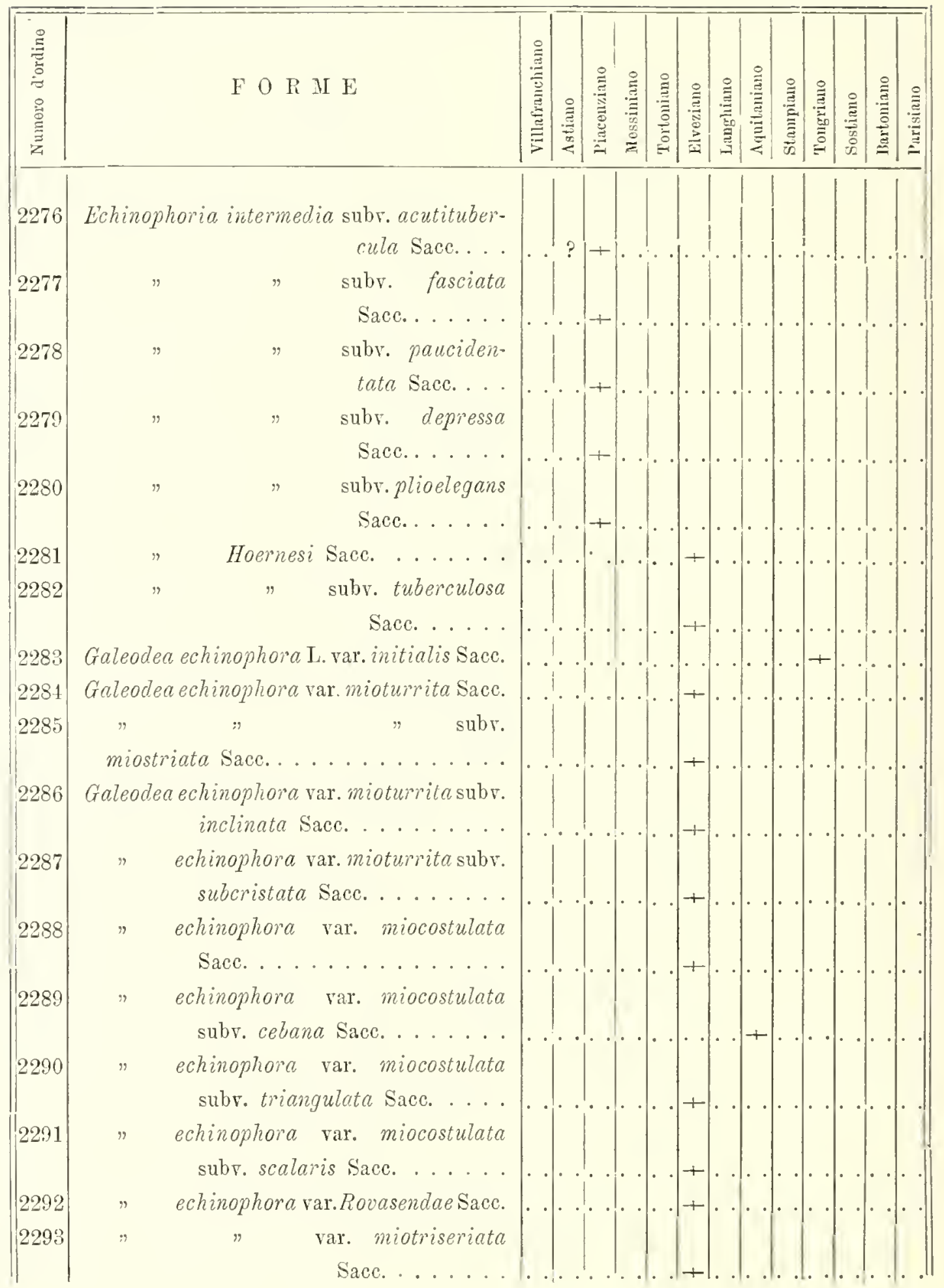


Catalogo paleontologico del bacino terziario del Piemonte

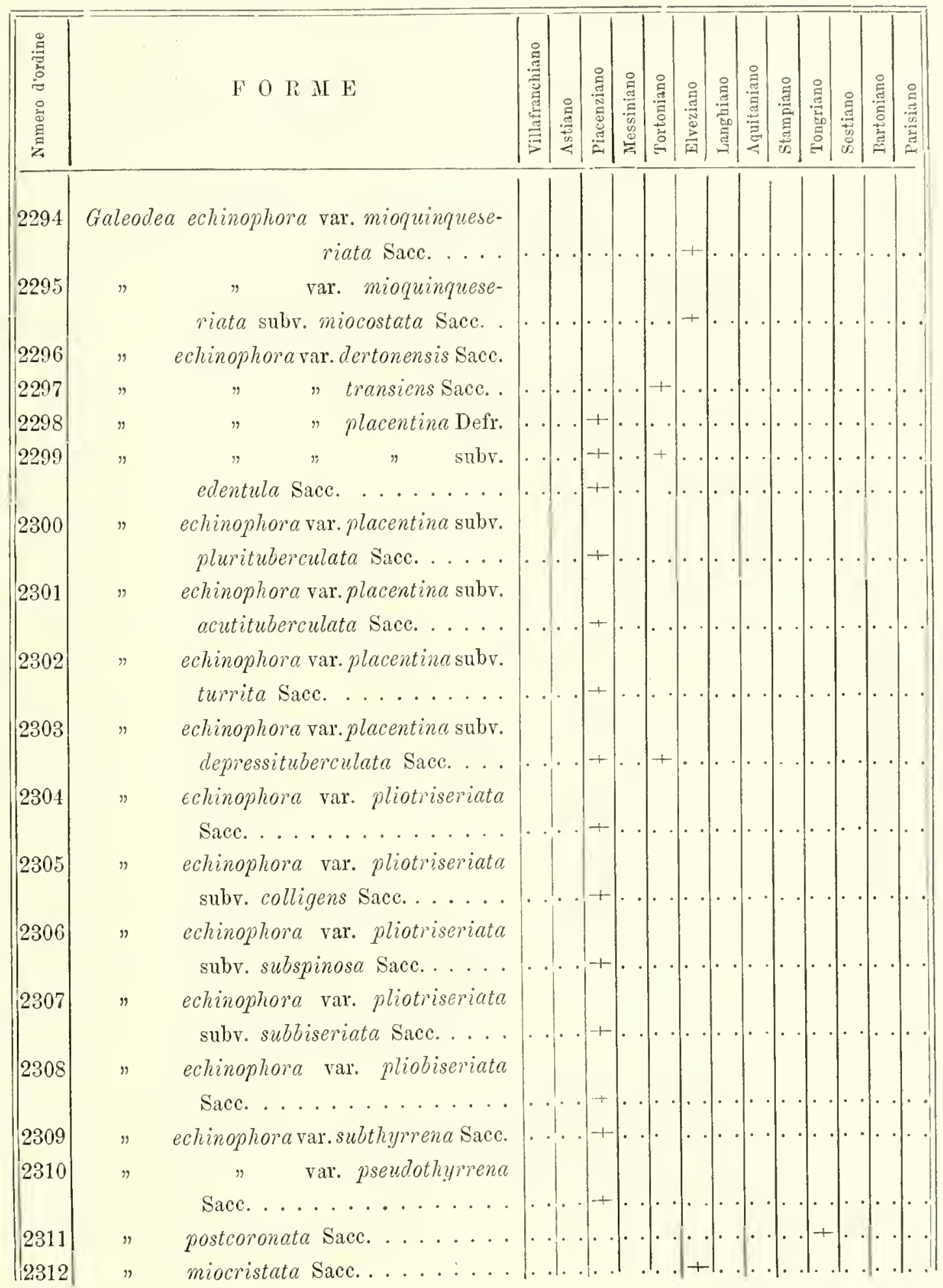




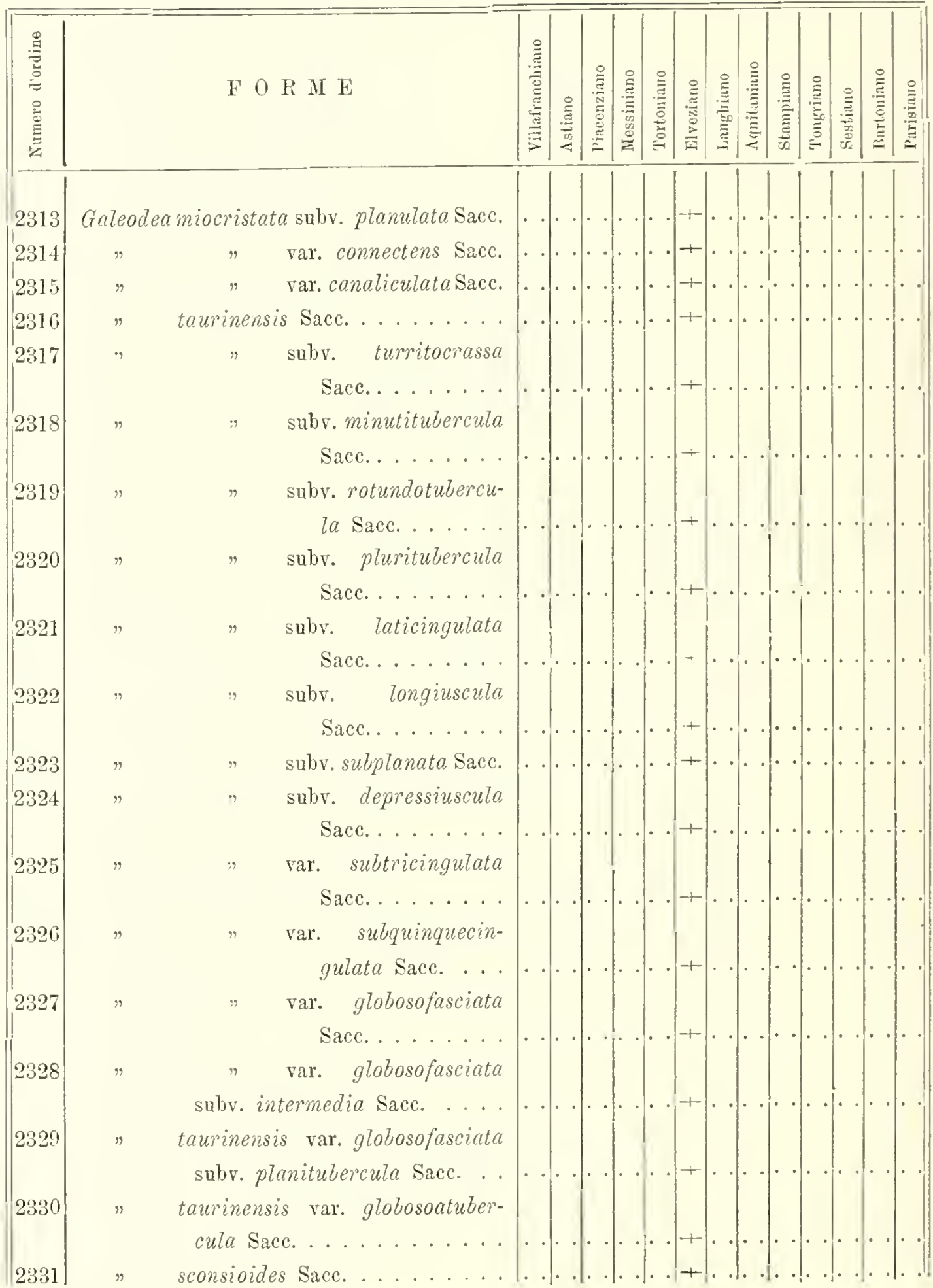




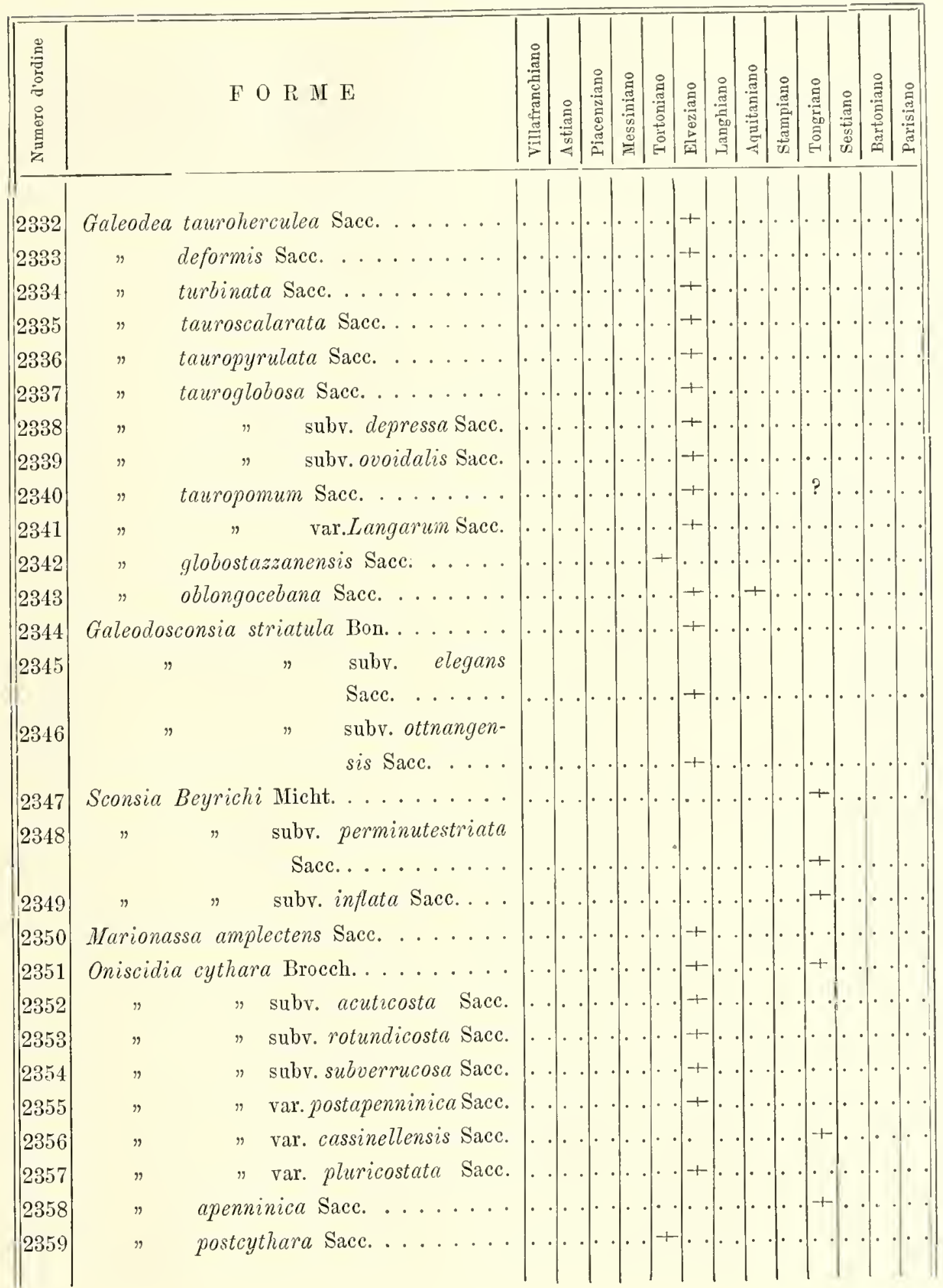




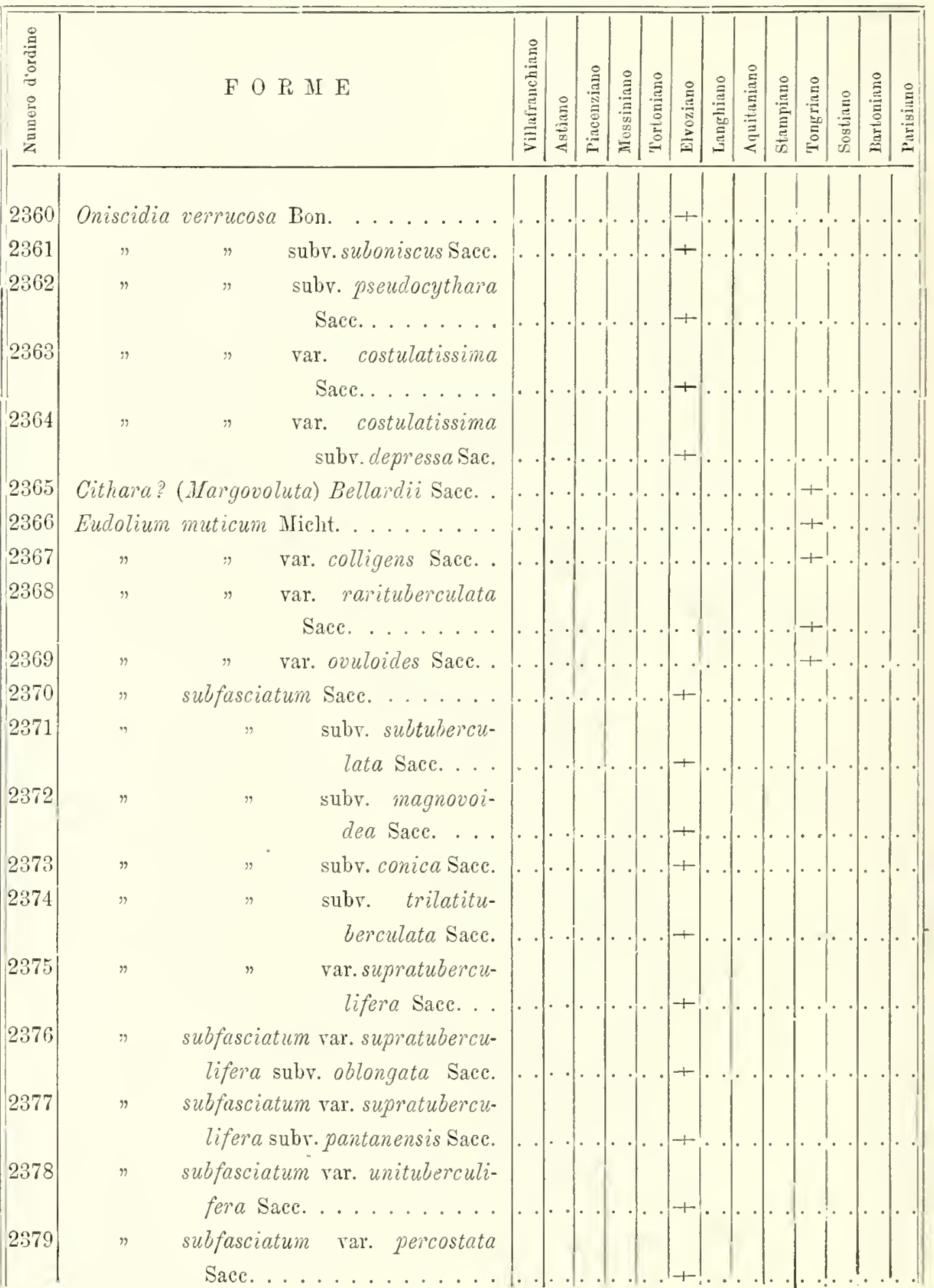




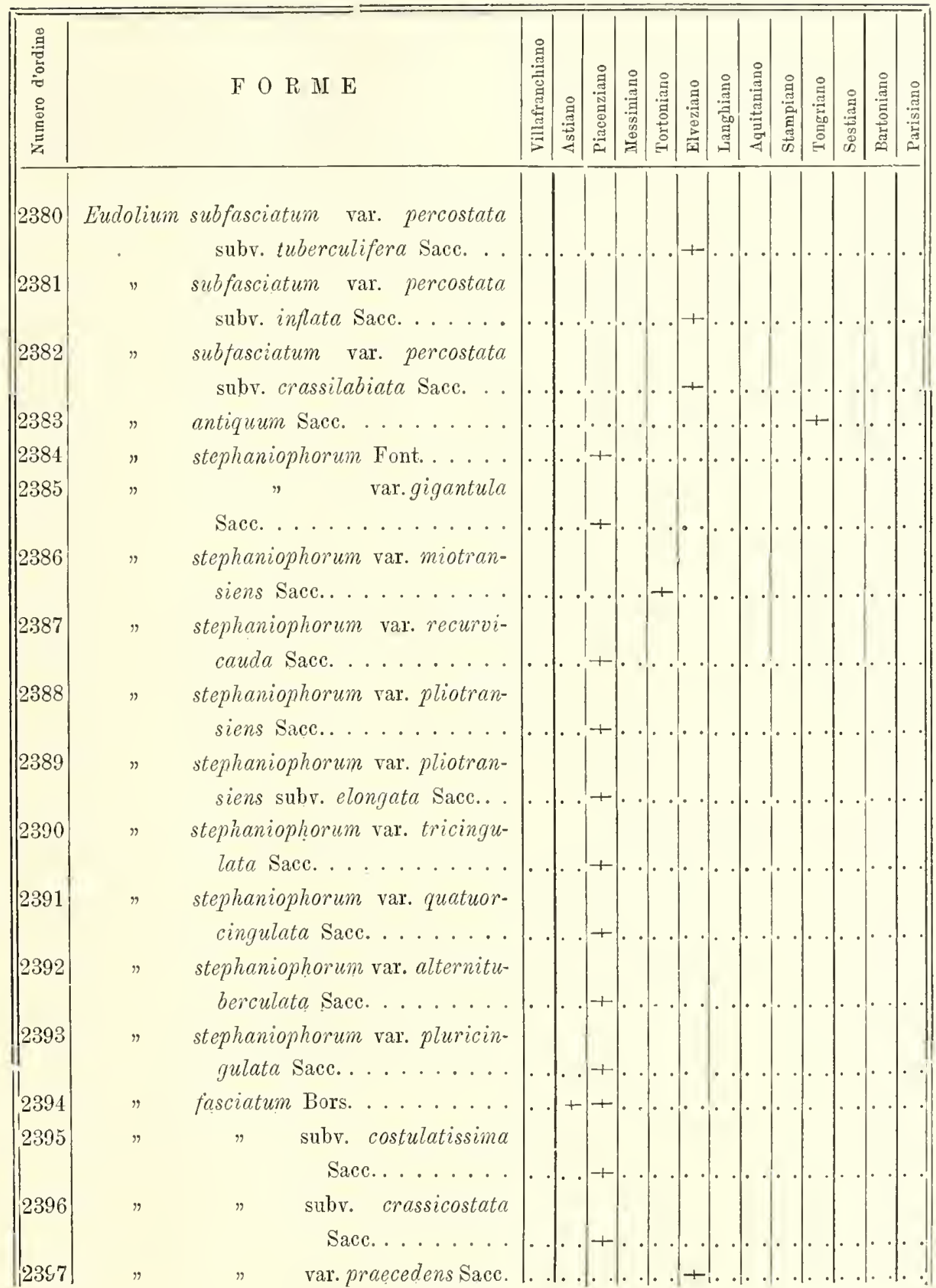




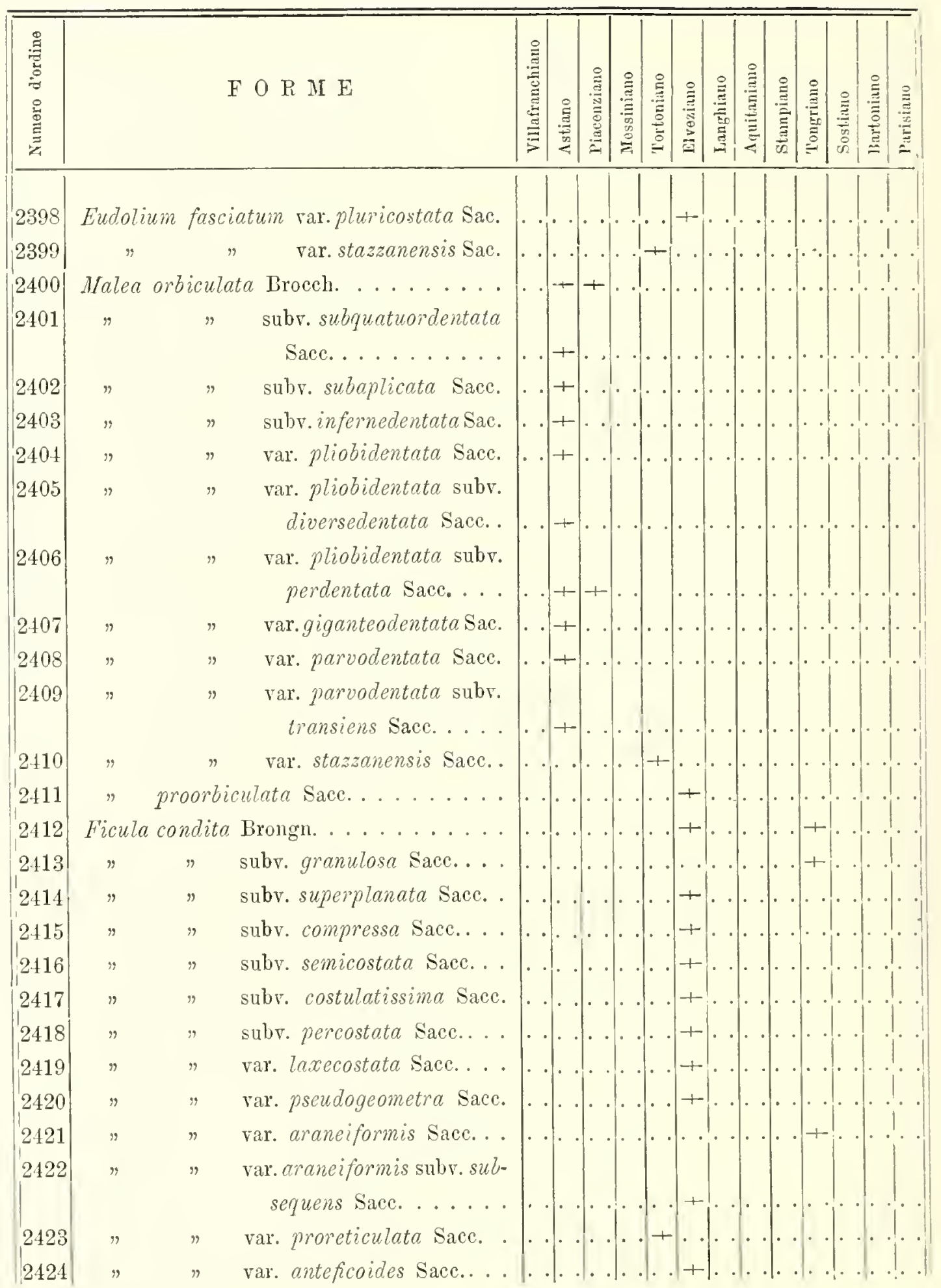


Catalogo paleontologico del bacino terziario del Piemonte

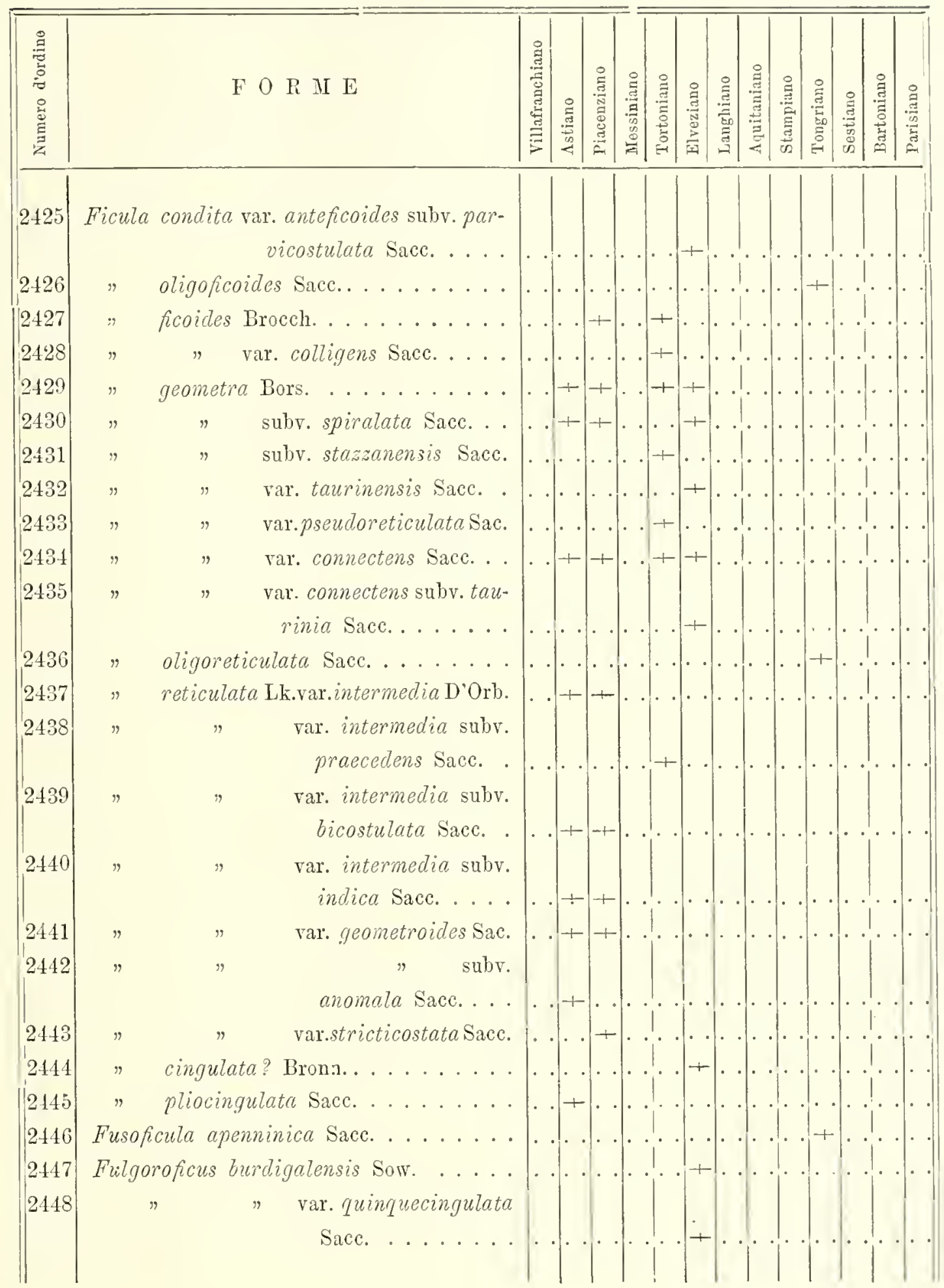




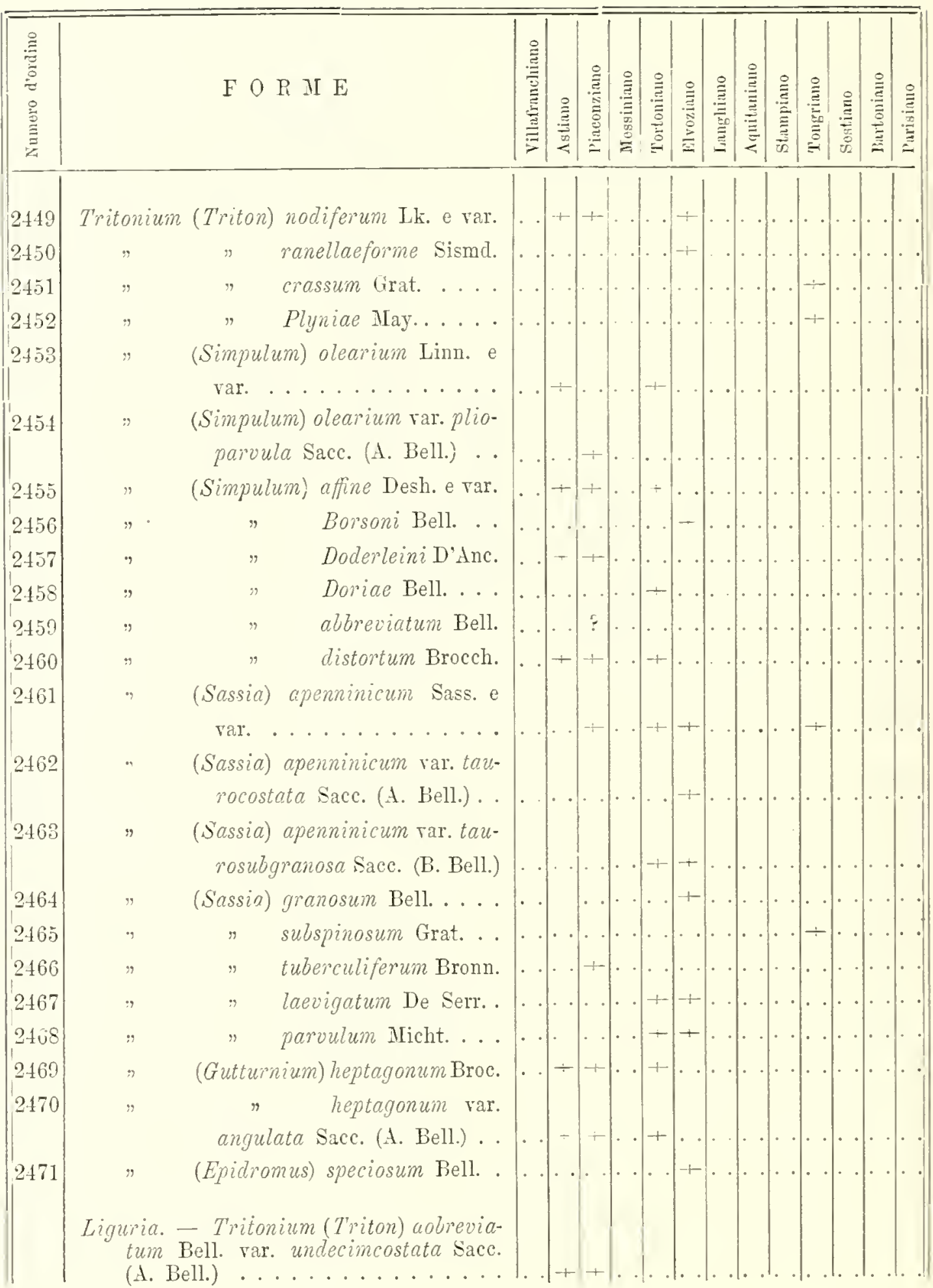




\begin{tabular}{|c|c|c|c|c|c|c|c|c|c|c|c|c|c|c|}
\hline 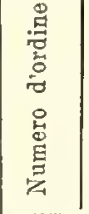 & $\mathrm{F} O \mathrm{R} \| \mathrm{E}$ & 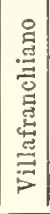 & 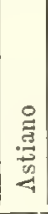 & 总 & 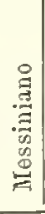 & 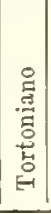 & 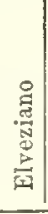 & 号 & : & 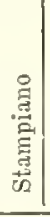 & 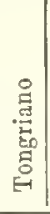 & 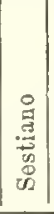 & 兽 & : \\
\hline 2472 & Tritonium (Epidromus) praetextum Bell. & & & & - & - & + & & $0^{\circ}$ & & & & & \\
\hline 2473 & obscurum Reev. . & . & - & & & - & + & . & . & & & - & & \\
\hline 2474 & $" \quad$ Deshayesi Micht. & • & & & · & · & + & & . & & & & & \\
\hline 2475 & " elongatum Micht. & - & & & . & . & + & & . & 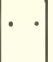 & & . & & \\
\hline 2476 & Persona tortuosa Bors. e var........ & . & + & -1 & $\cdot$ & . & + & . & . & & $\cdot$ & & & \\
\hline 2477 & $" \quad$ Grasi Bell. e var. ....... & 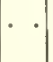 & . & + & . & . & + & . & $\cdot$ & . & & & & \\
\hline 2478 & Ranella (Bufonaria) nodosa Bors. .... &. & -1 & & . & . & & - & . & . & $\cdot$ & - & - & \\
\hline 2479 & $" \quad$ dosa Sacc. (A. Bell.) .... & $\cdot$ & + & & · & . & $\cdot$ & $\cdot$ & & & & & & \\
\hline 2480 & $\begin{array}{l}\text { (Bufonaria) nodosa var. mioquin- } \\
\text { queseriata Sace. (B. Bell.) } .\end{array}$ & 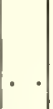 & & & & + & & . & $\cdot$ & & & & & \\
\hline 2481 & (Bufonaria) Bellardii Weink. . &. & & & - & & + & . & . & . & & - & & \\
\hline 2482 & (Lampas) tuberosa Bon. ..... & . & . & & - & - & + & . & . & . & + & - & & \\
\hline 2483 & $\begin{array}{l}\text { (Lampas) tuberosa var. latovari. } \\
\text { cata Sacc. (A. Bell.) . . . . }\end{array}$ & & & & & $\cdot$ & -1 & & & & & & & \\
\hline 2484 & $\begin{array}{l}\text { (Lampas) tuberosa var. nodosis- } \\
\quad \text { sima Sacc. (B. Bell.)...... }\end{array}$ & & & & & & + & & & & & & & \\
\hline 2485 & $\begin{array}{l}\text { (Lampas) tuberosa var. quadri- } \\
\text { costata Sacc. (C. Bell.) } \ldots .\end{array}$ & & & & & & + & & & & & & & \\
\hline 2486 & $\begin{array}{l}\text { (Lampas) tuberosa var. contiguo- } \\
\text { varicata Sace. (D. Bell.) ... }\end{array}$ & & & & & $\cdot$ & + & & ${ }^{\circ}$ & & & & & \\
\hline 2487 & $\begin{array}{l}\text { (Lampas) tuberosa var. acutinu- } \\
\text { dosa Sacc. (E. Bell.)..... }\end{array}$ & . & & & [" & & + & & & & & & & \\
\hline 2488 & $\begin{array}{l}\text { (Lampas) tuberosa var. granoso- } \\
\text { parva Sacc. (F. Bell.) . . . . }\end{array}$ & & & & 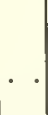 & 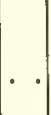 & + & 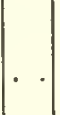 & & . & - & | & - & \\
\hline 2489 & (Lampas) consobrina May..... & & & & & + & $\cdots$ & & & - & . & . & . & \\
\hline 2490 & $" \quad$ multigranosa Bell... & & & & & 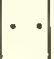 & + & & & . & & & & \\
\hline 2491 & " Michaudi Micht. . . . & & & & & + & • & & - & · & & & & \\
\hline 2492 & Lessonae Bell...... & & & & & & + & & & & . & & & \\
\hline 93 & (Apollon) gigantea Lk. c var. • & & & + & & + & + & & & & & & & \\
\hline 2494 & elongata Bell. c Micht. & & & & & & + & & & & & & & \\
\hline 2495 & a Bell. & & & & & & & & & & & & & \\
\hline
\end{tabular}




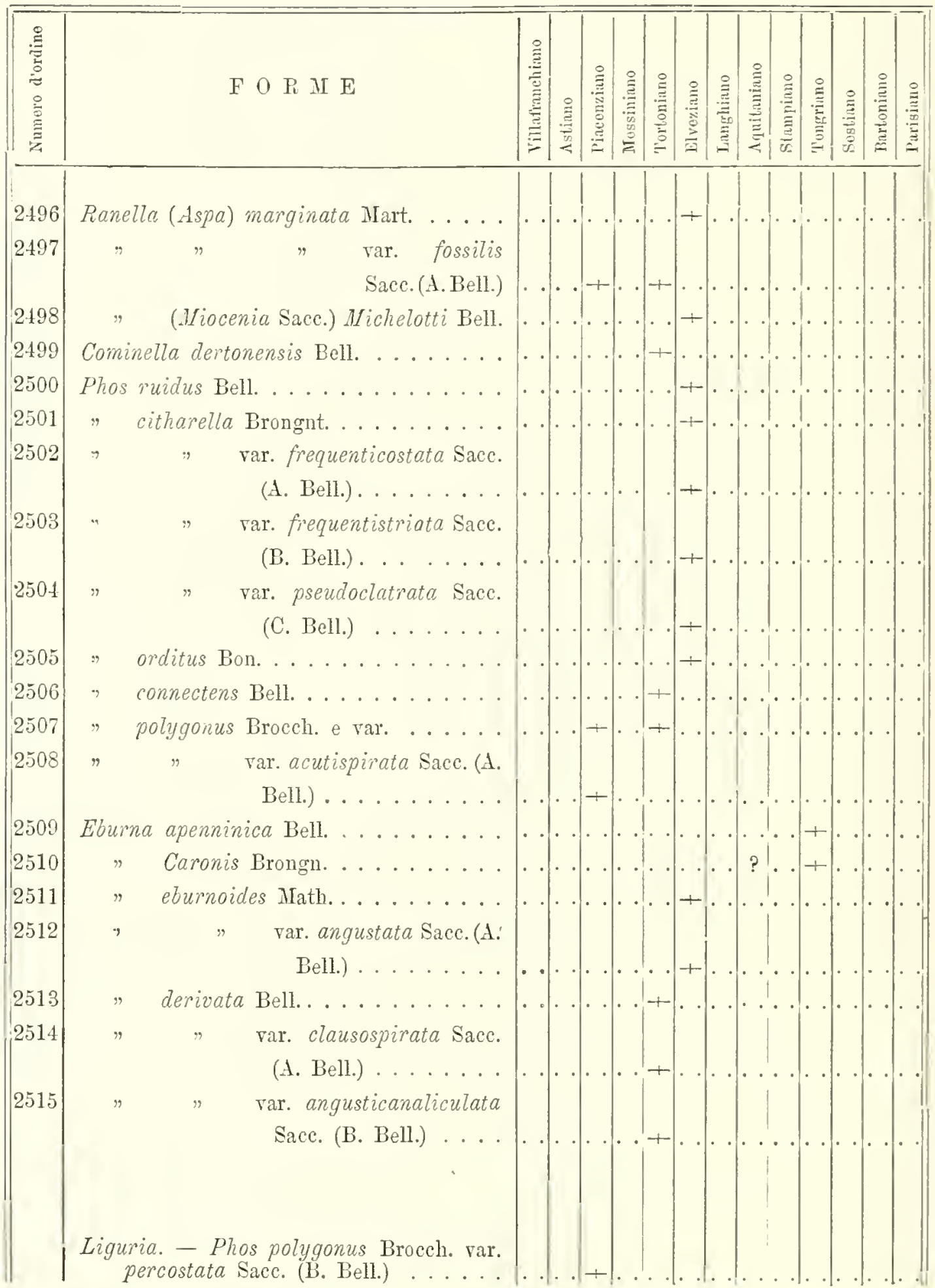




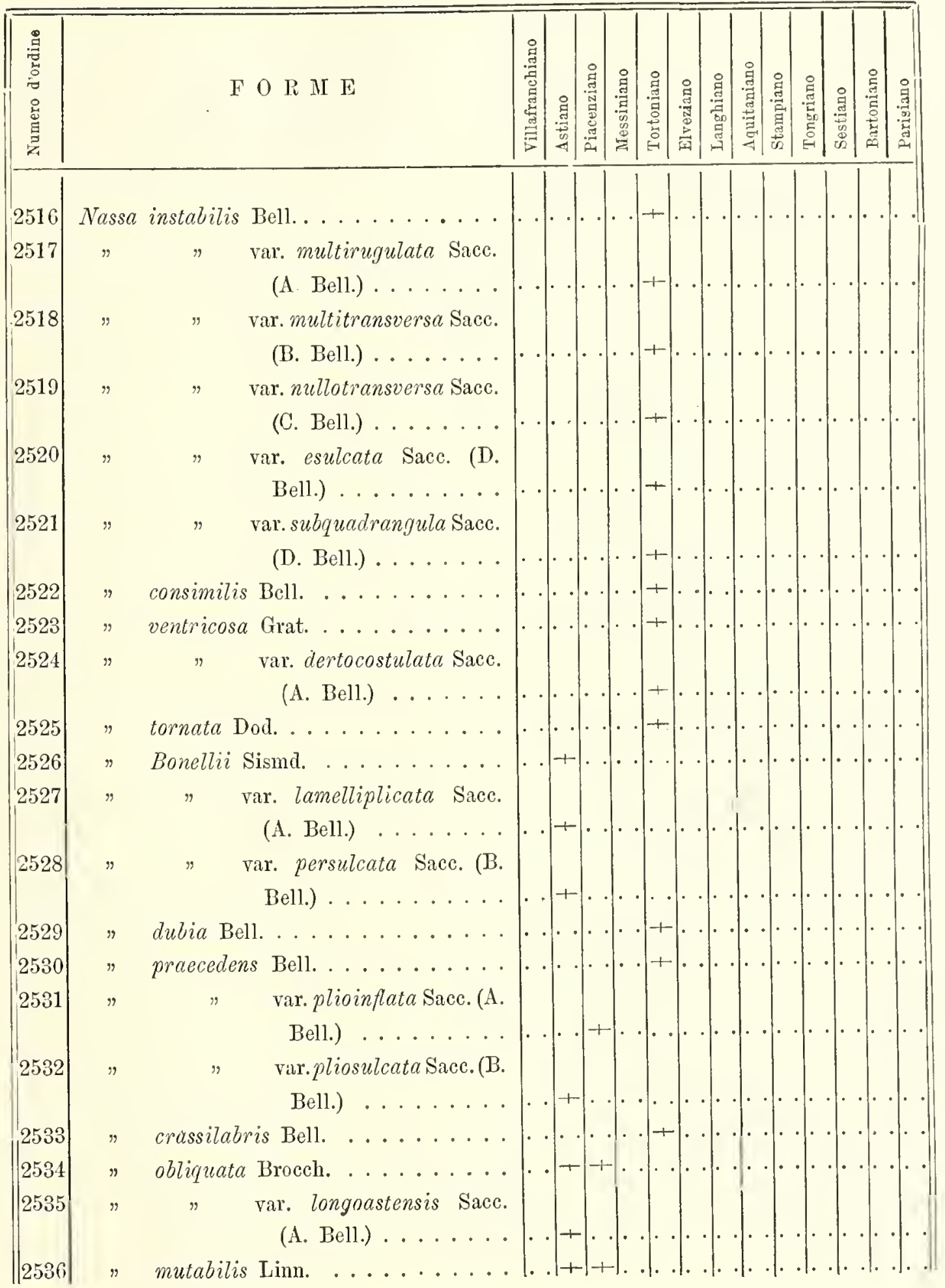




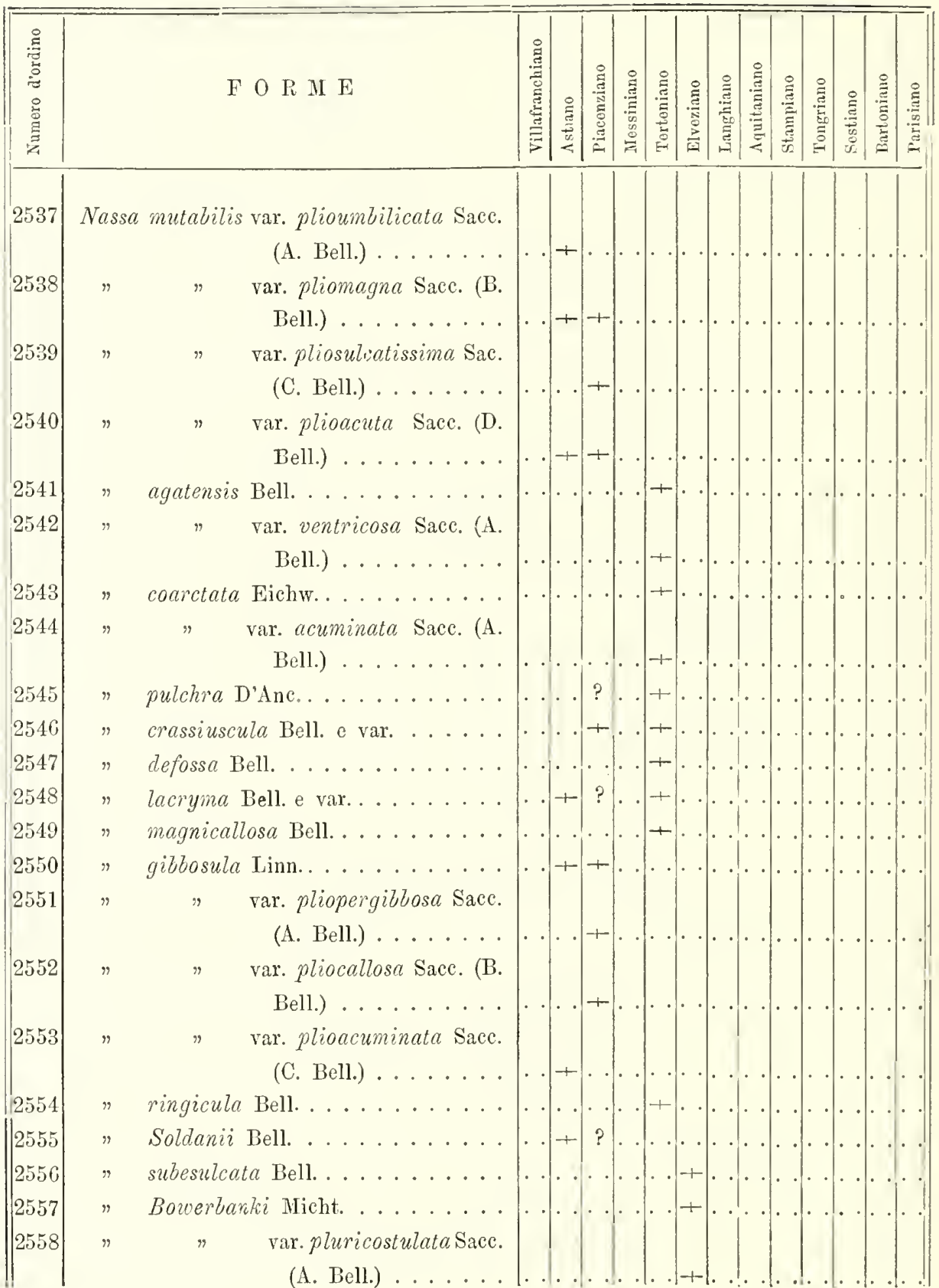




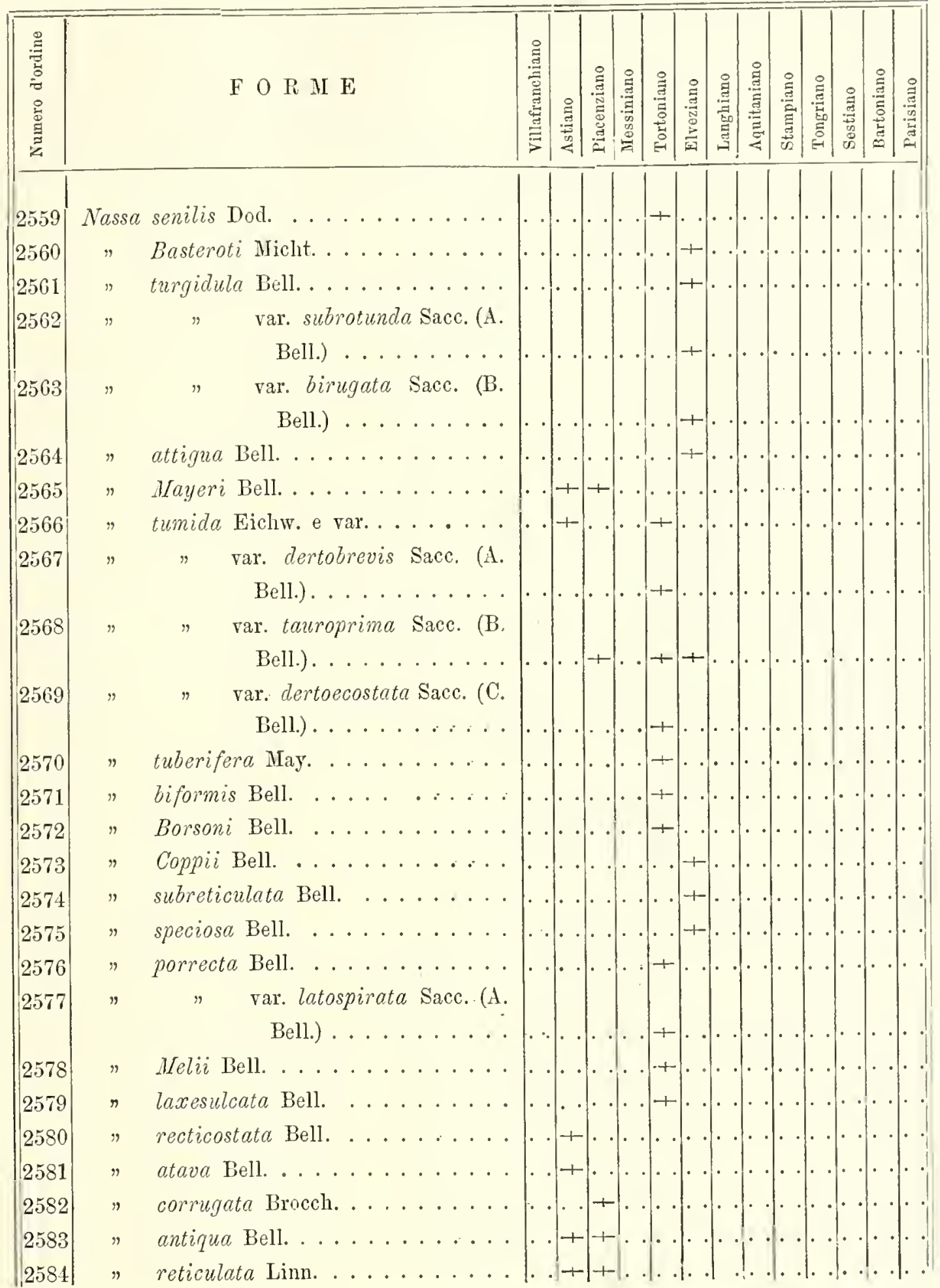




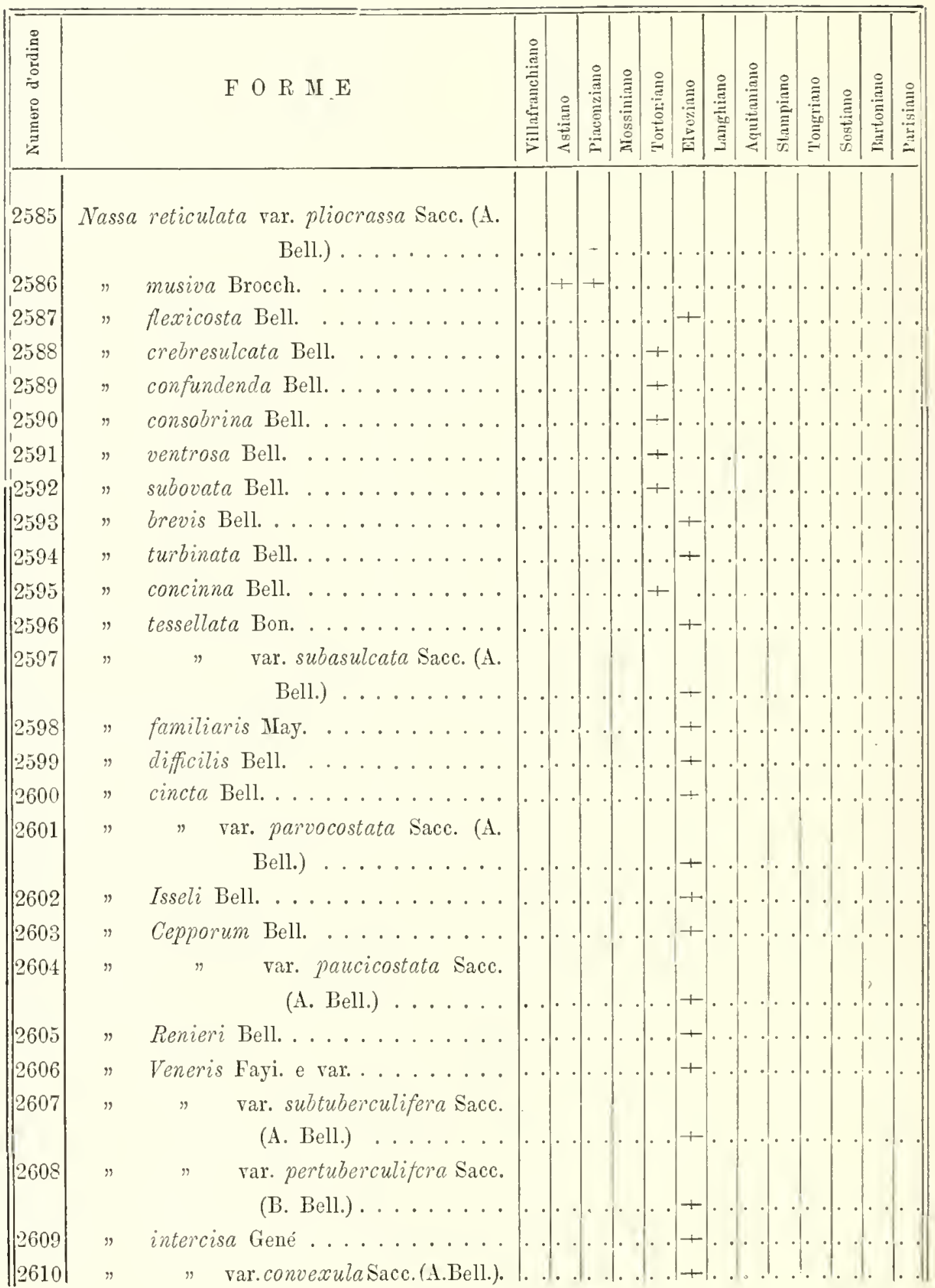




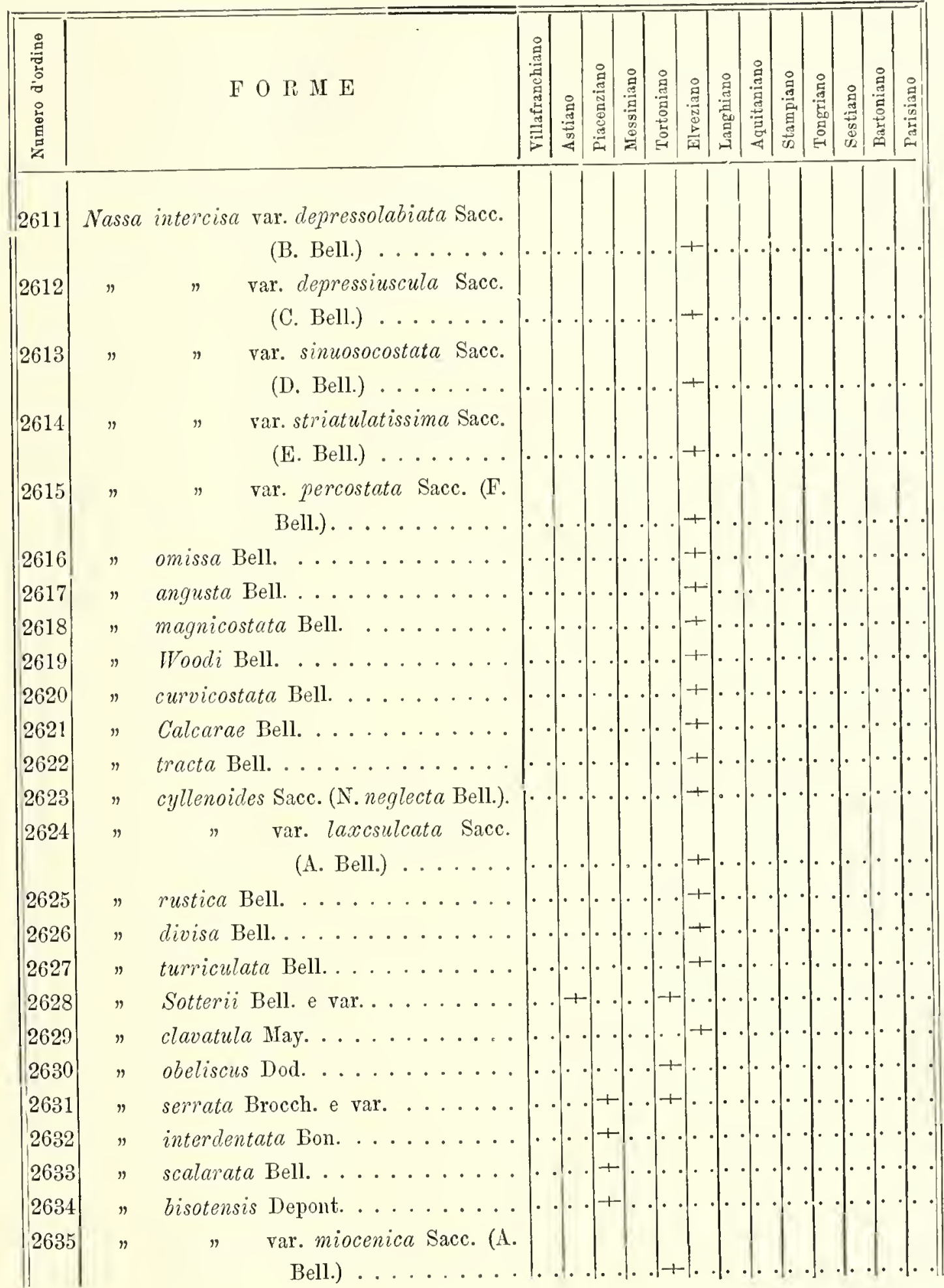




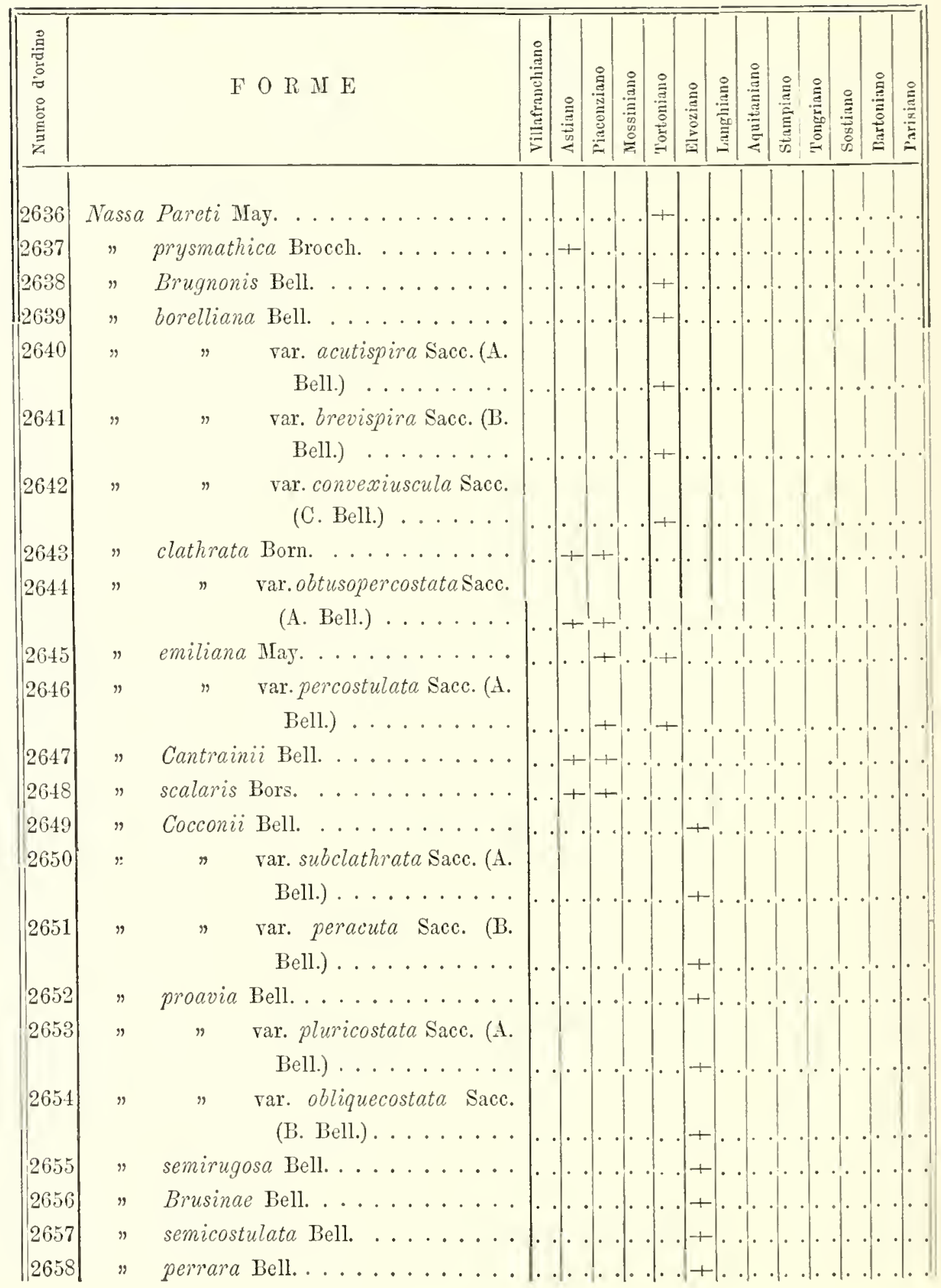




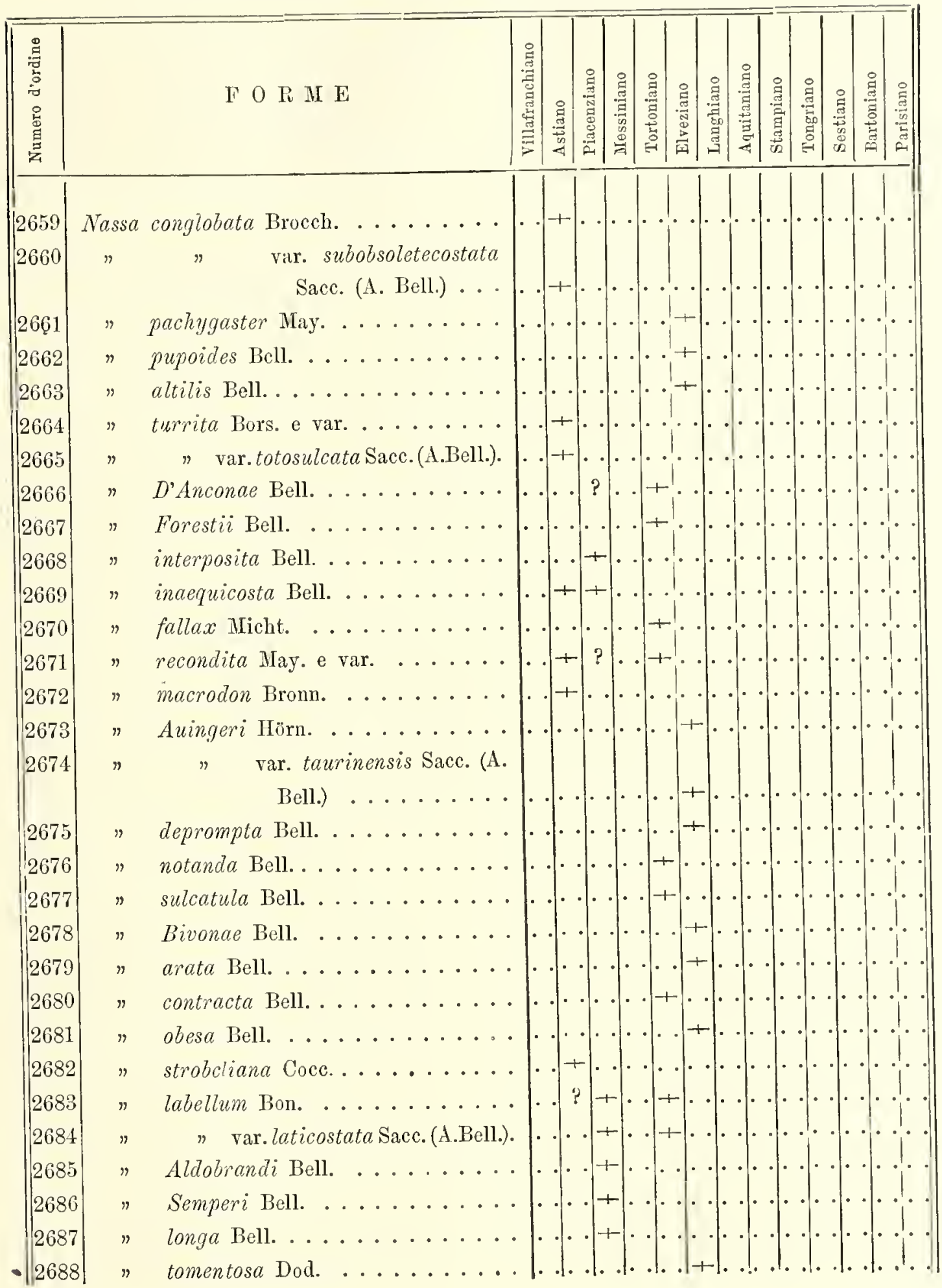




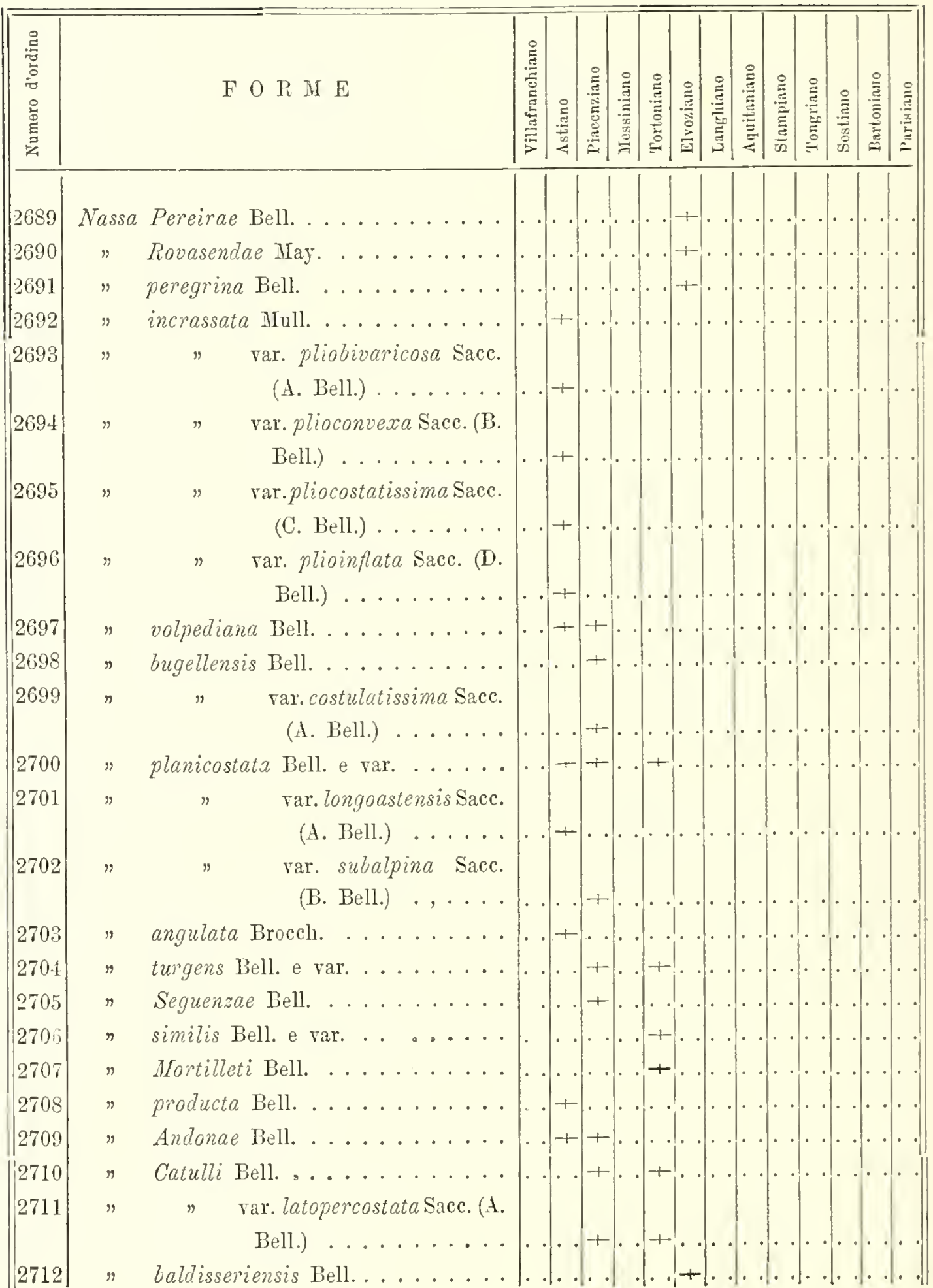




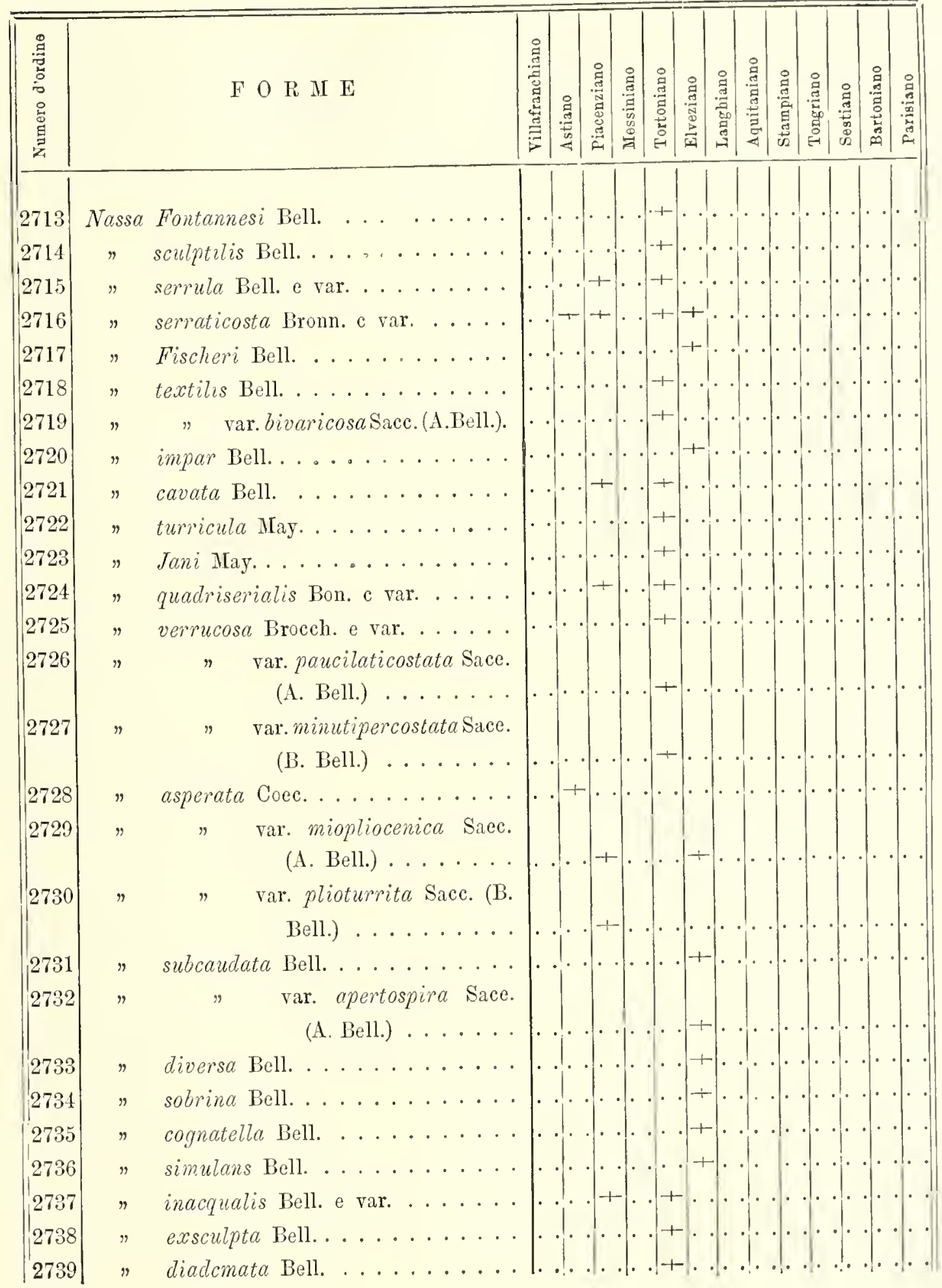




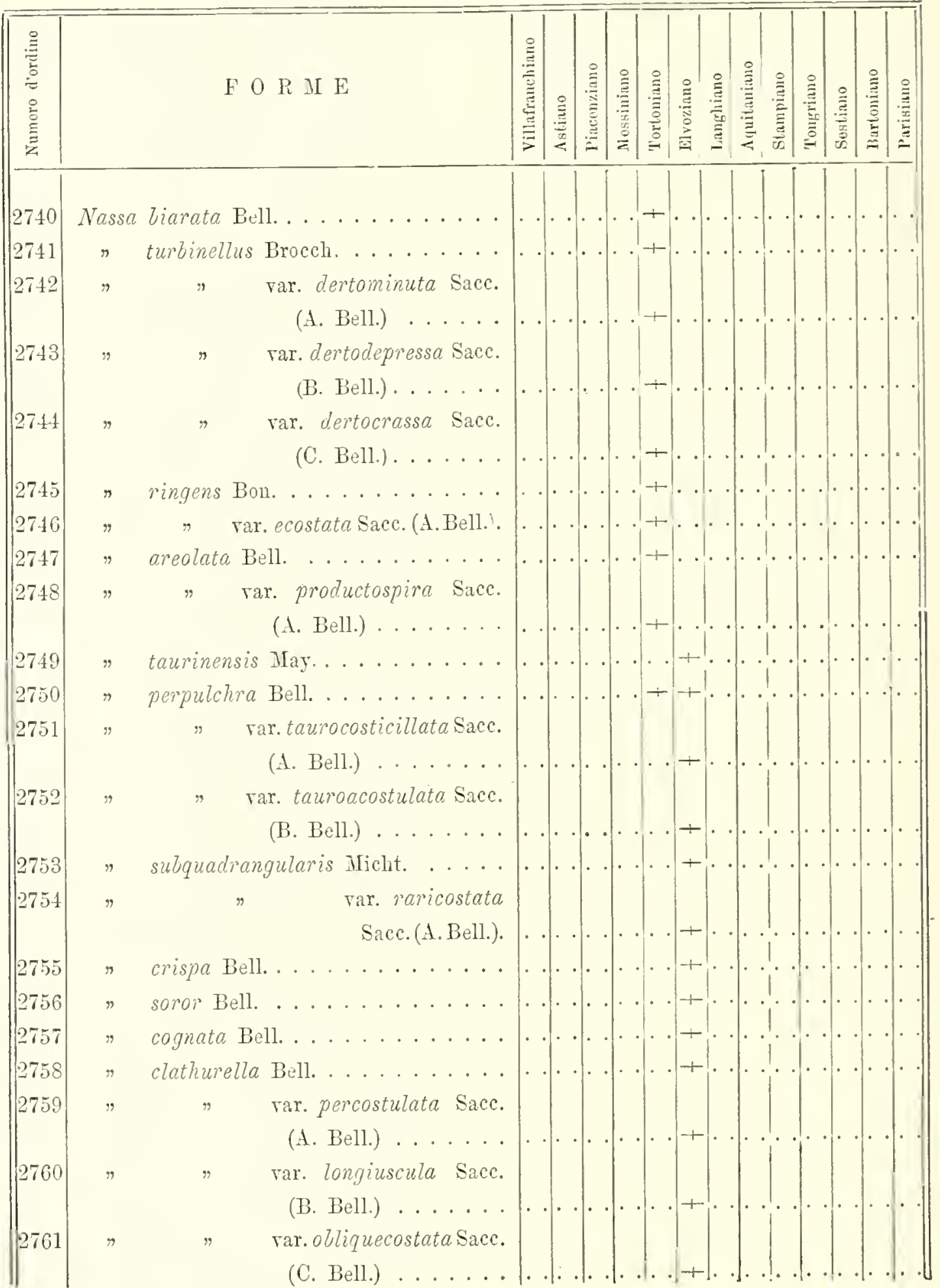


Catalogo paleontologico del baeino tersiario dcl Piemonte

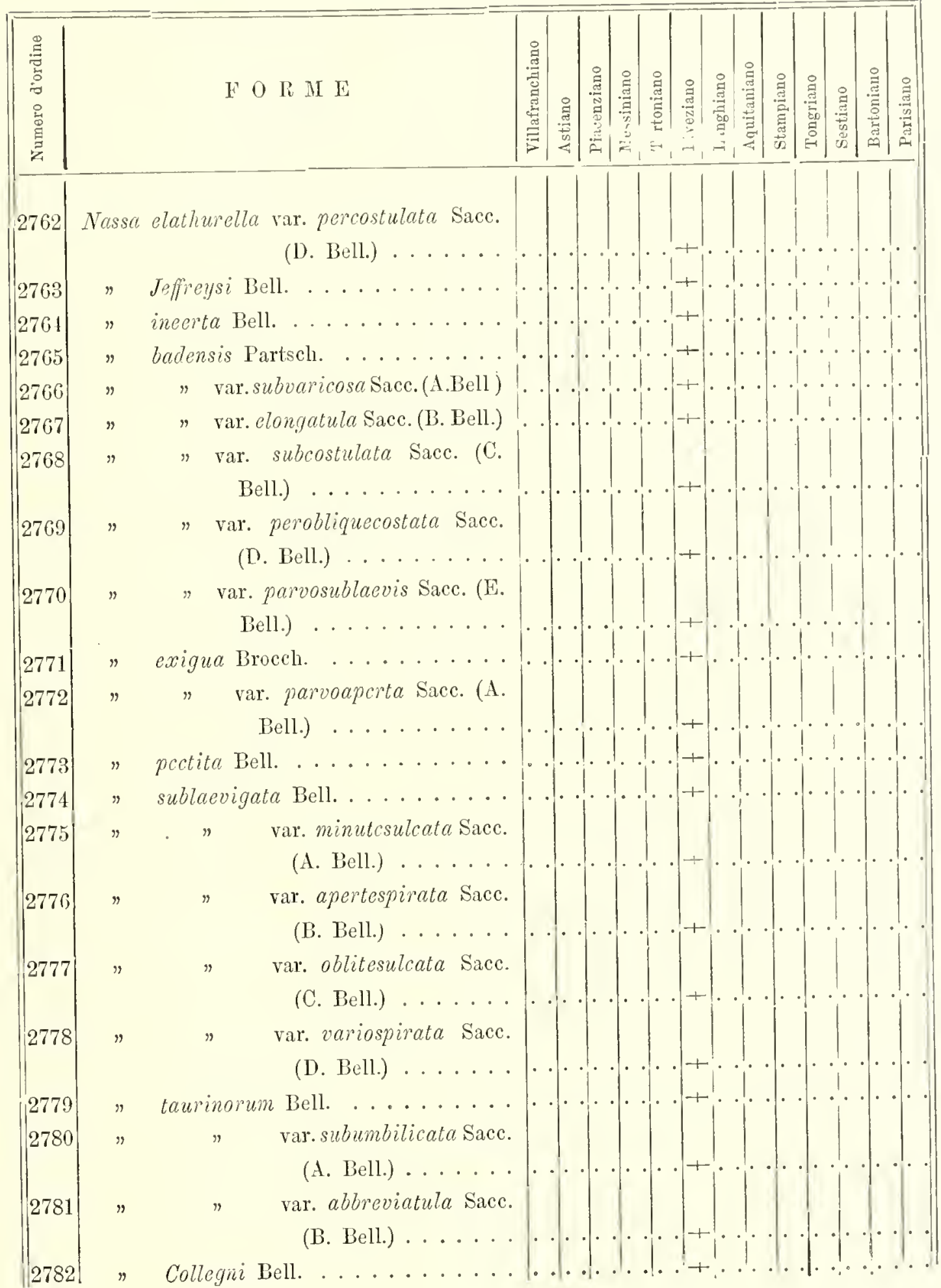




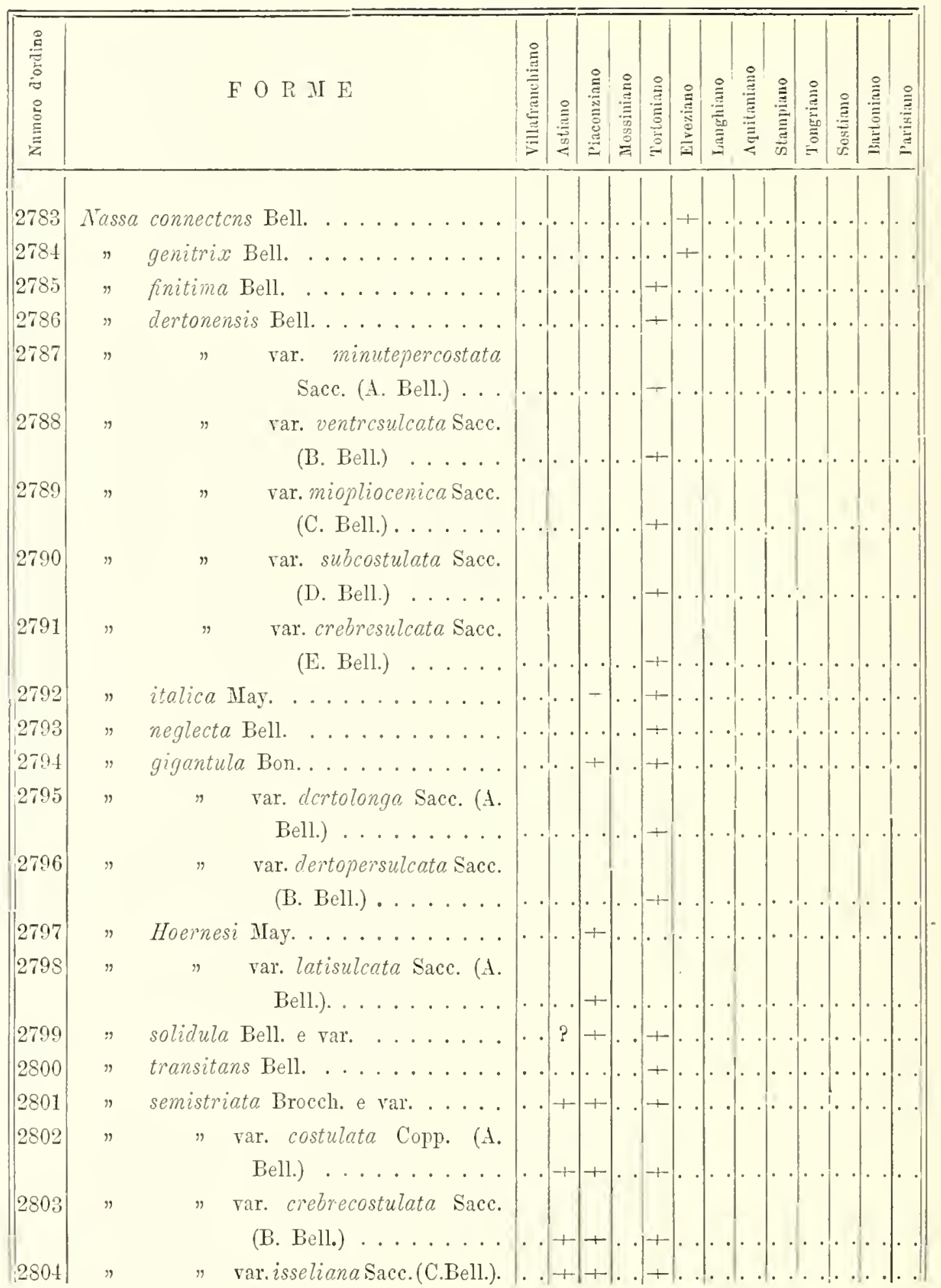


Catalogo paleontologico del bacino terziario del Piemonte

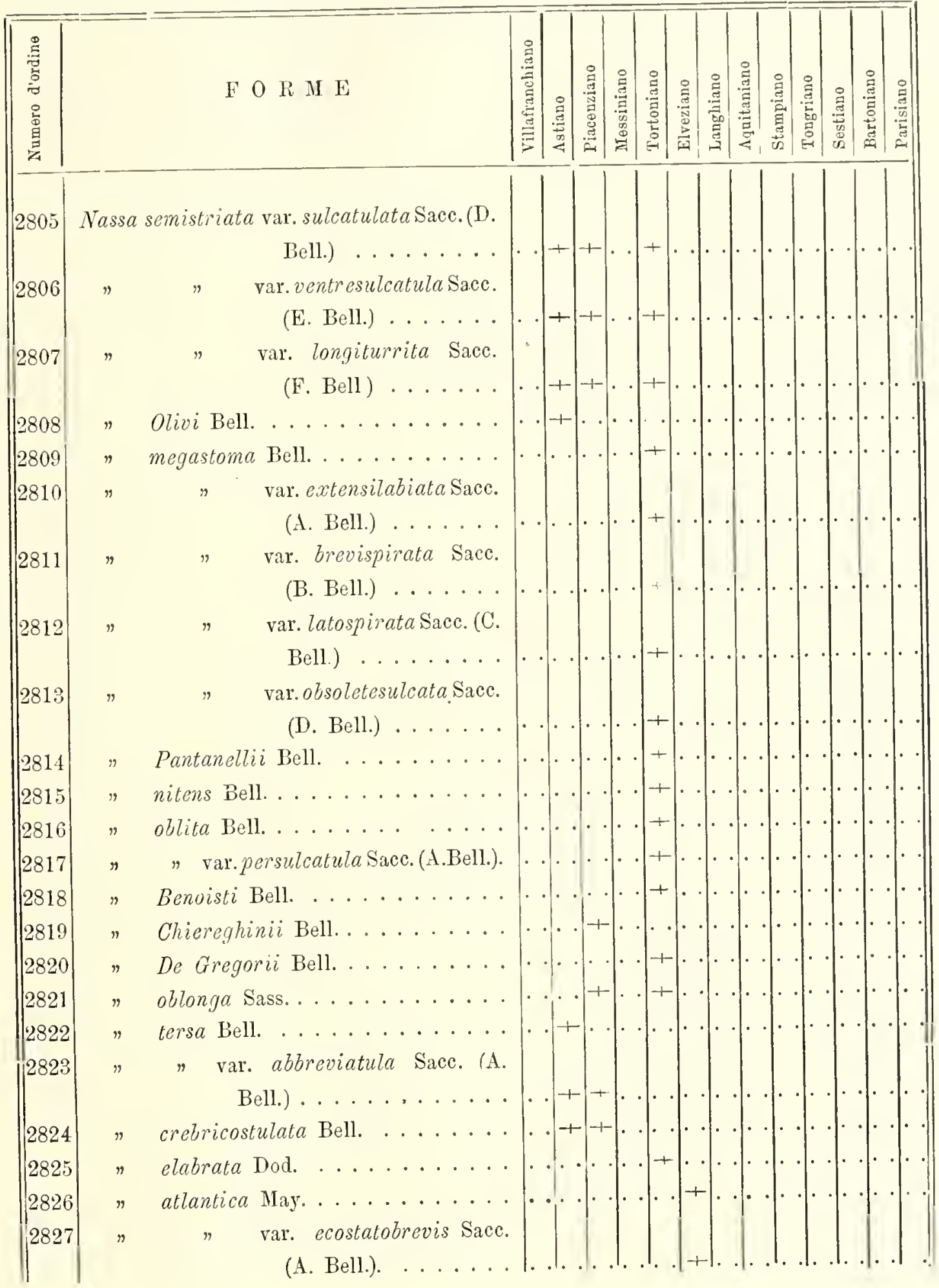




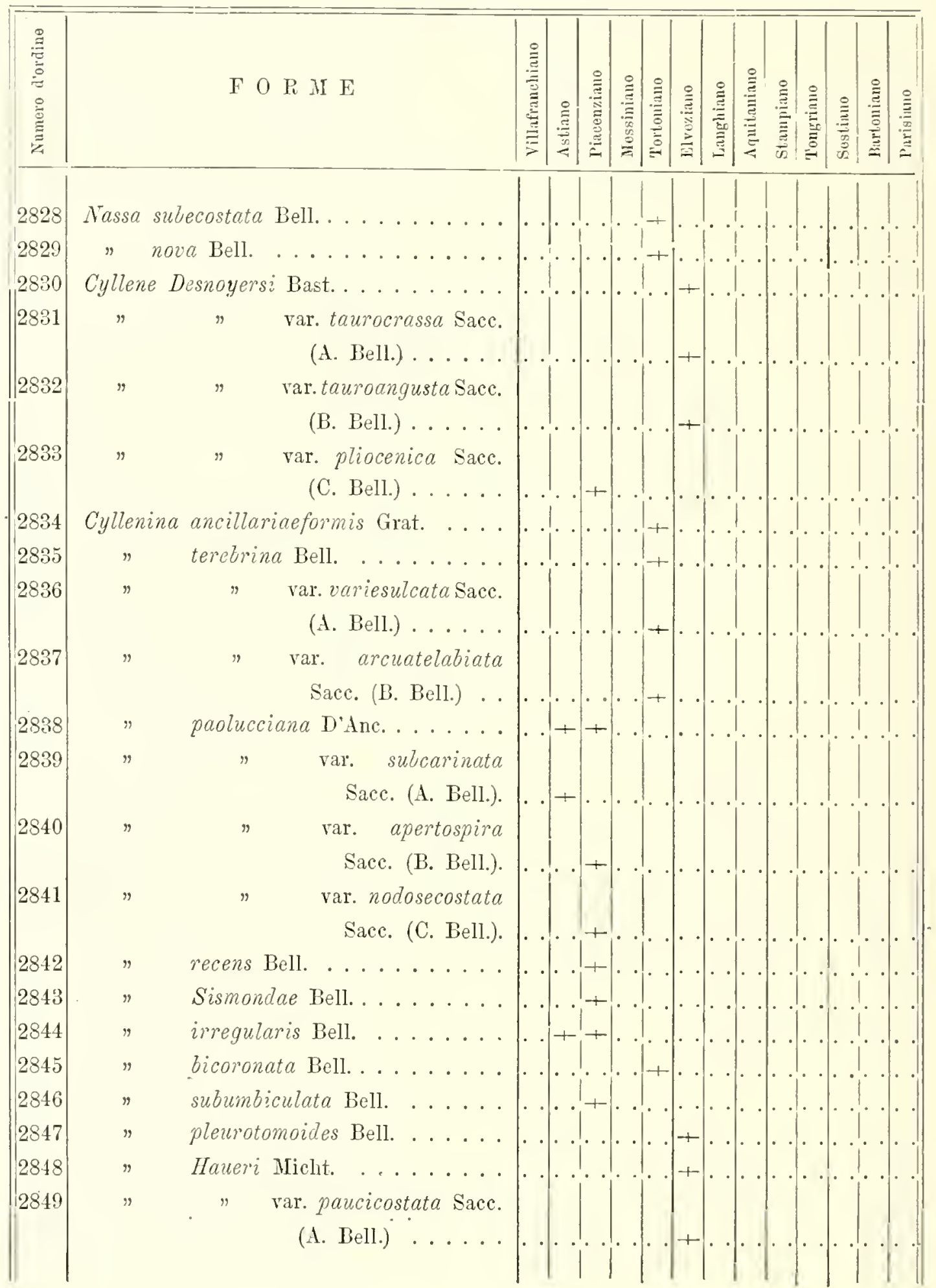




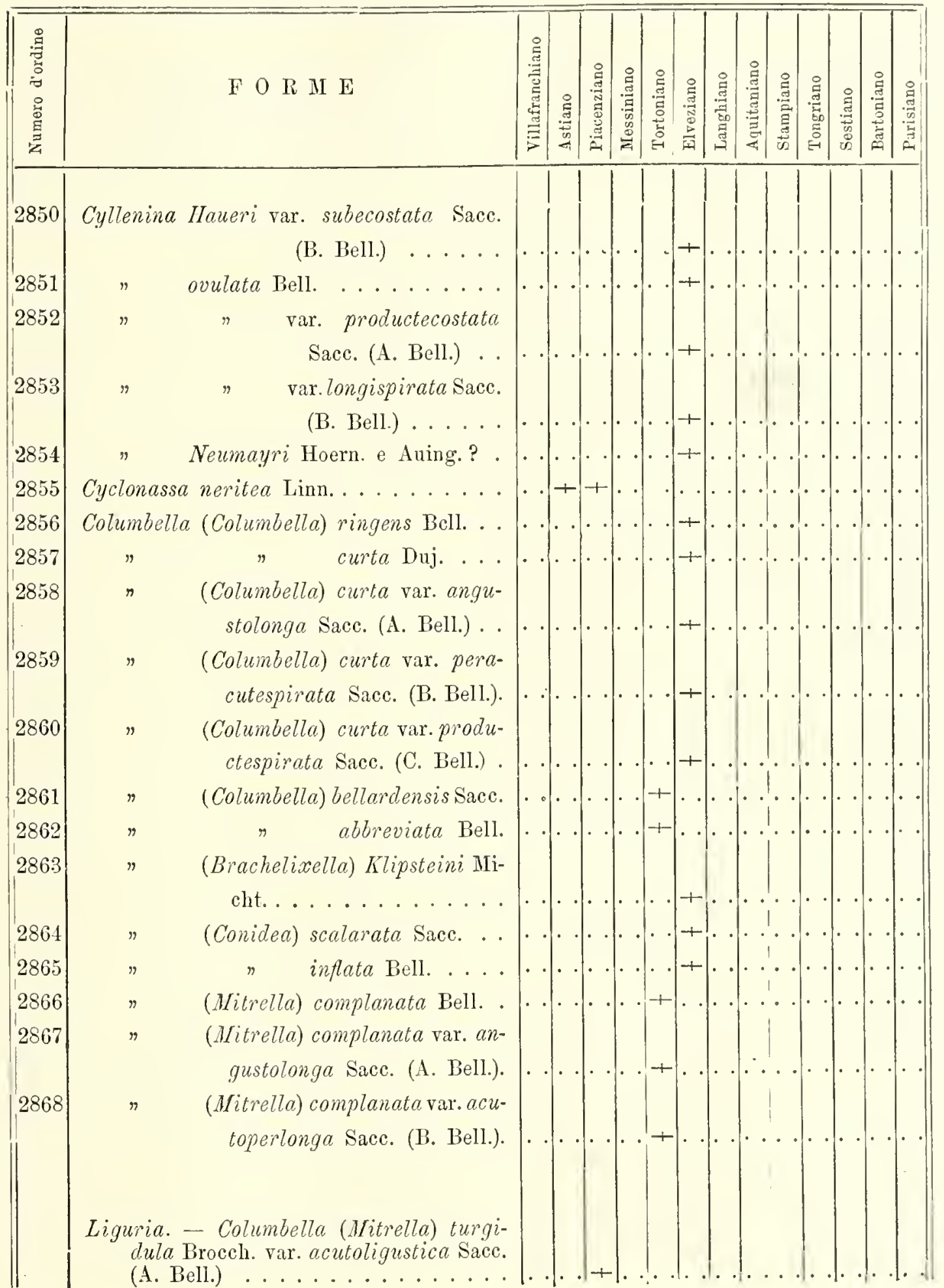




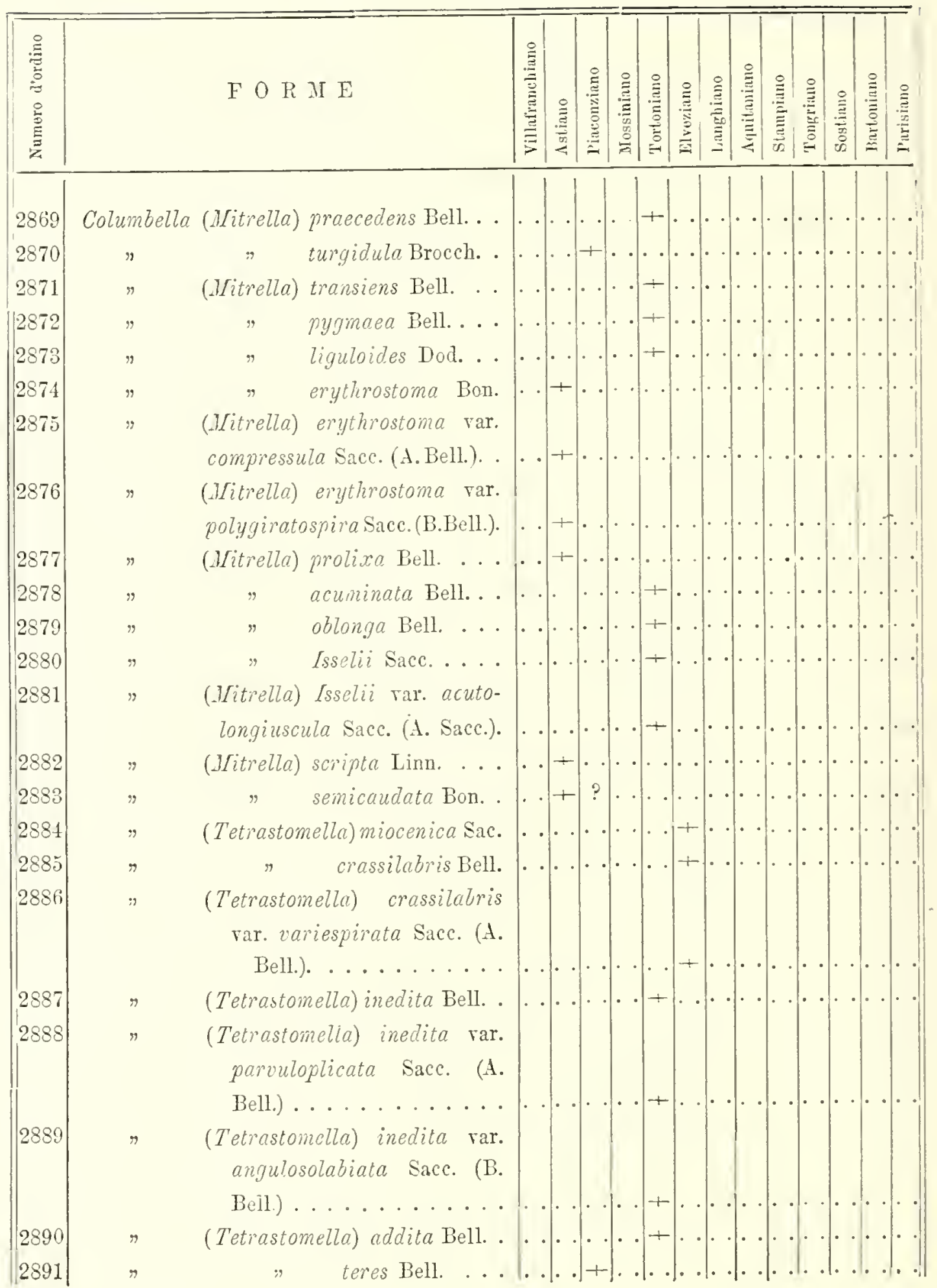




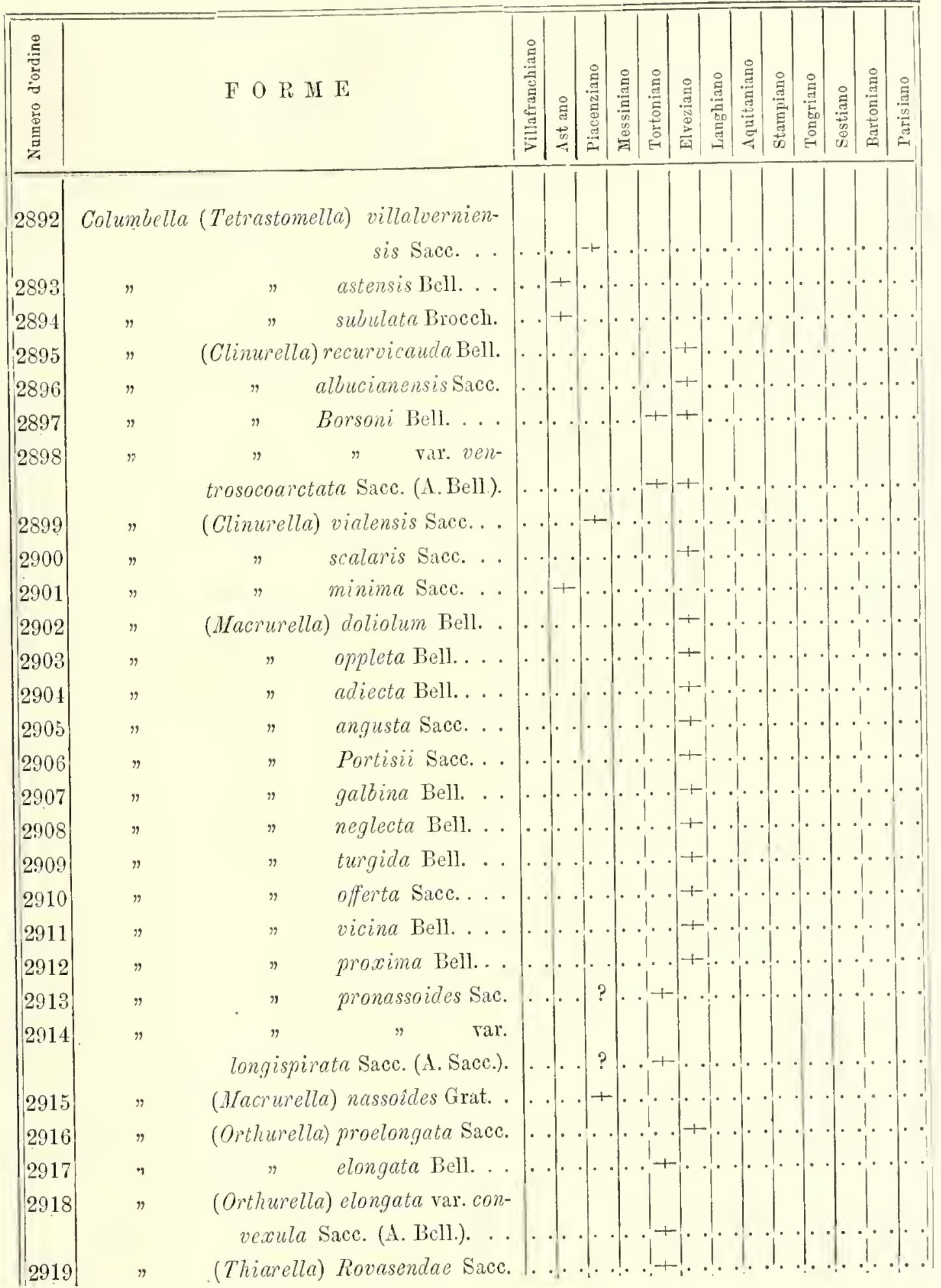




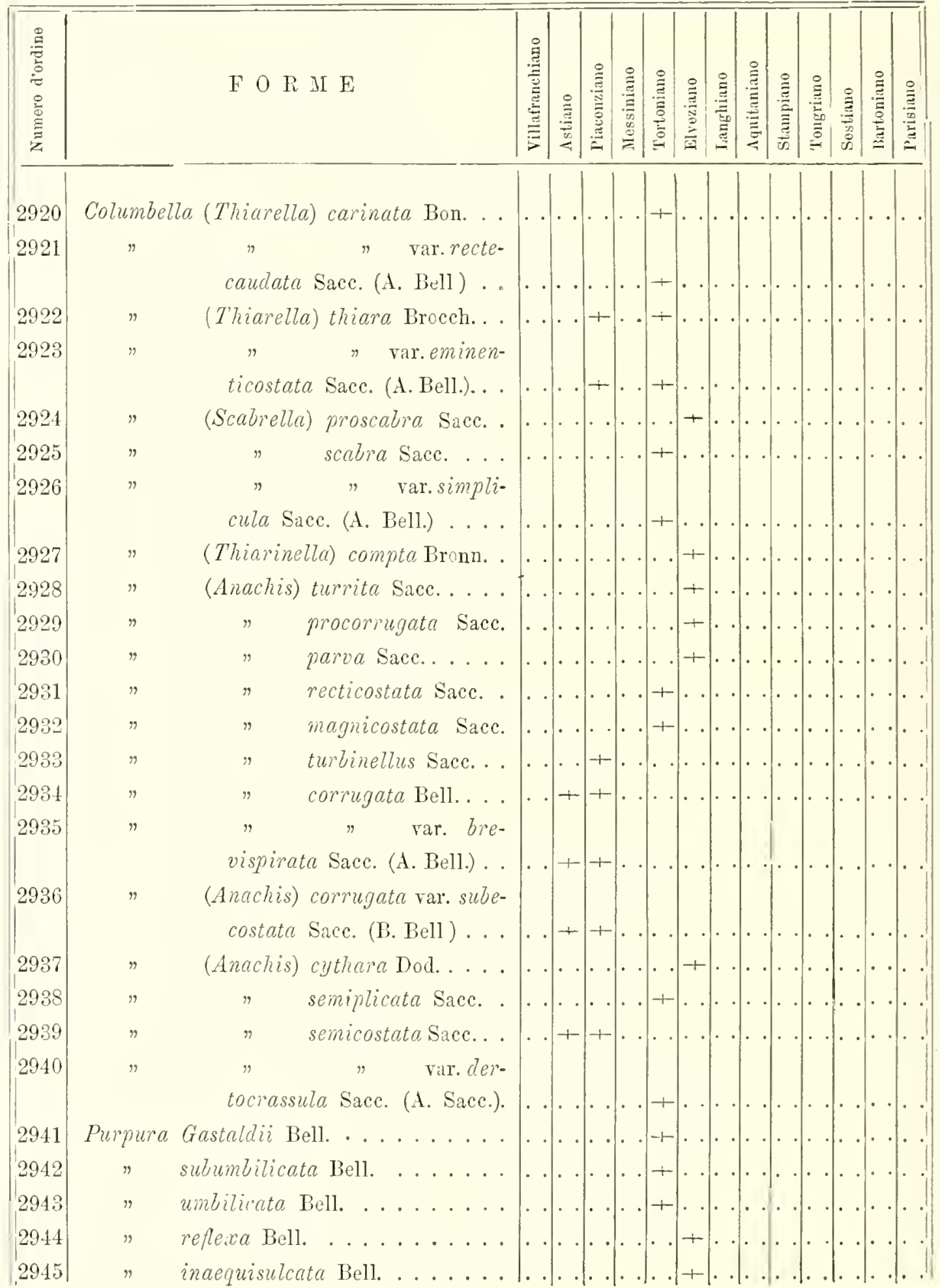




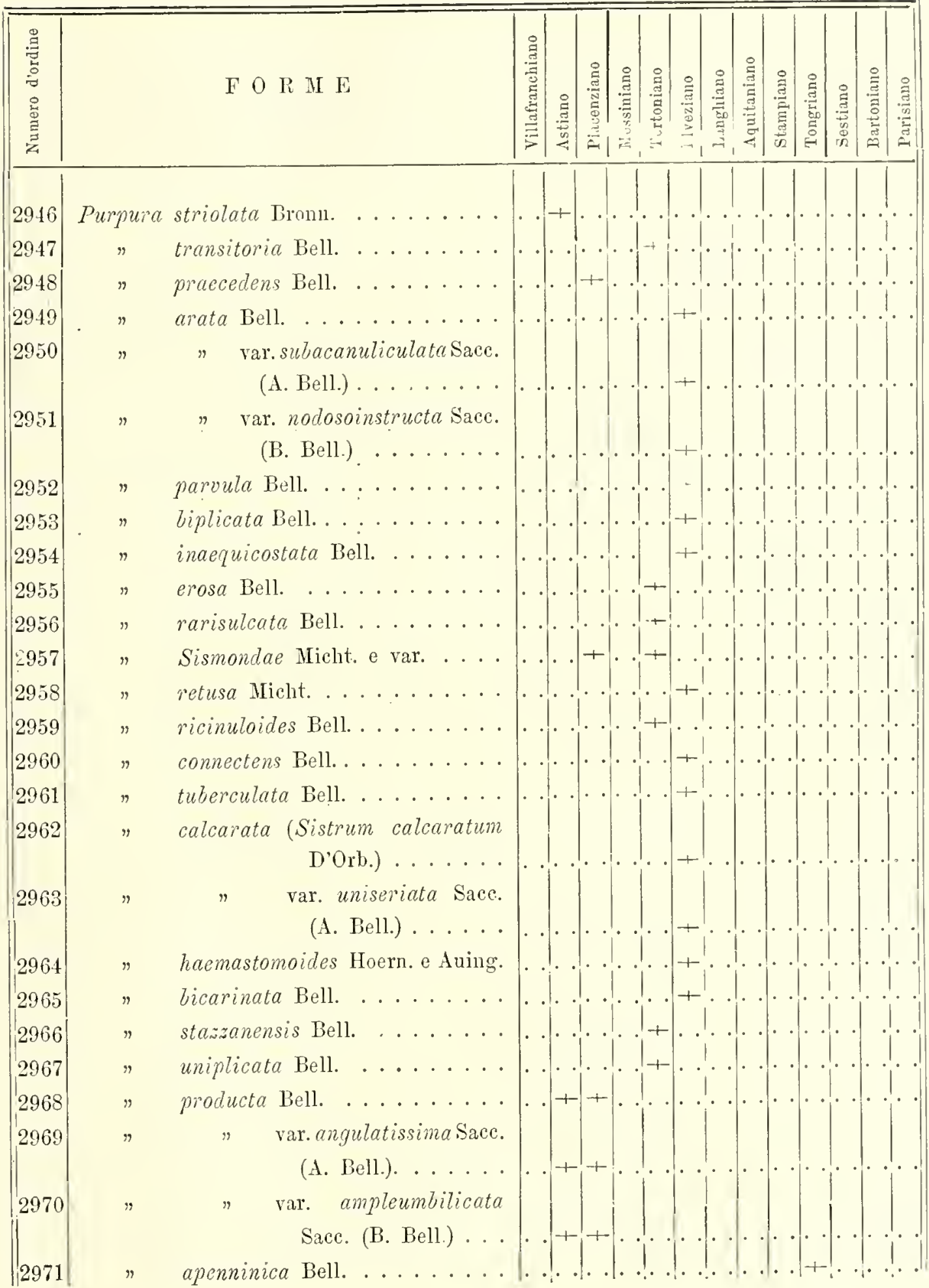




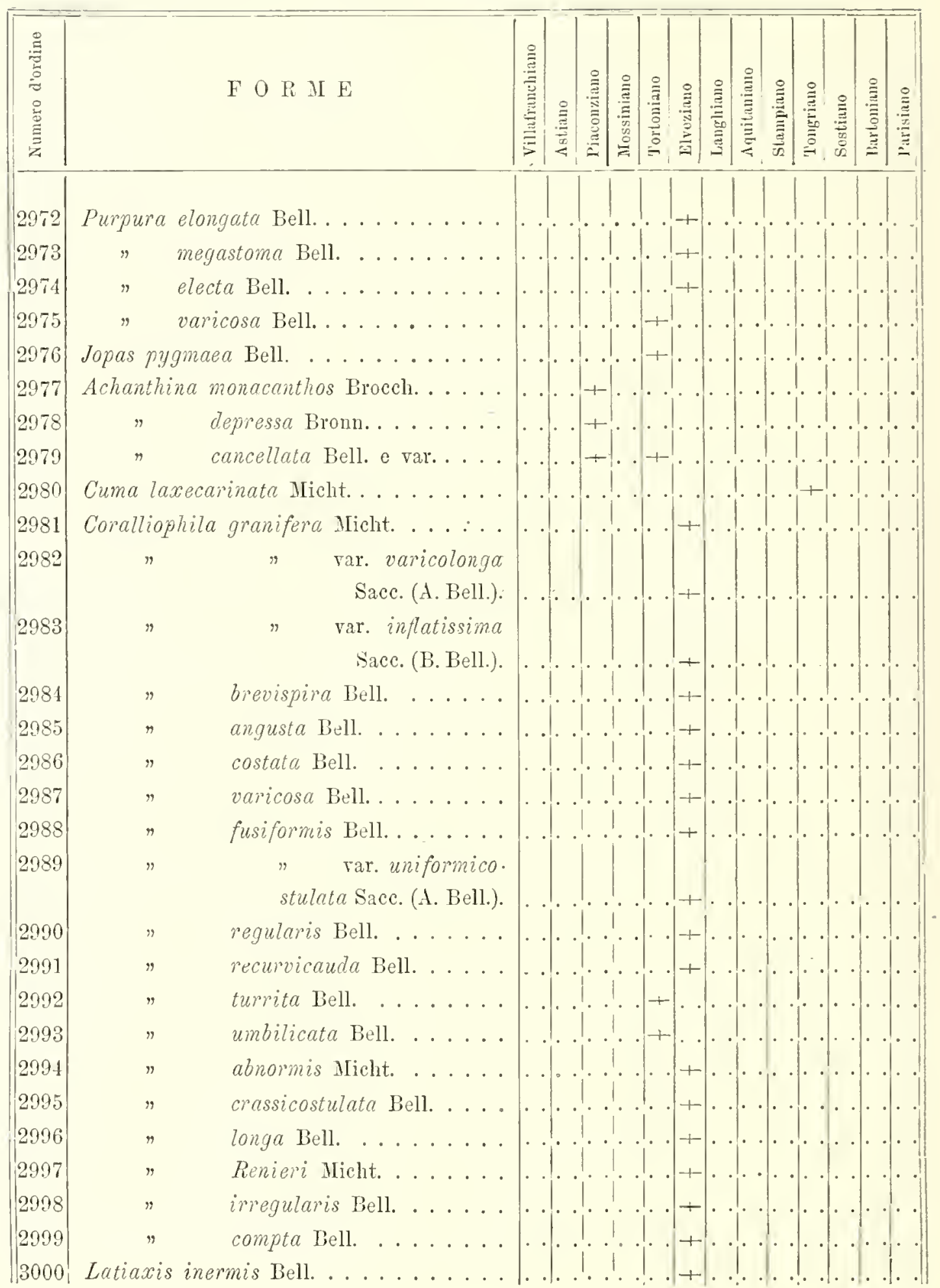


Catalogo paleontologico del bacino tersiario del Picmontc

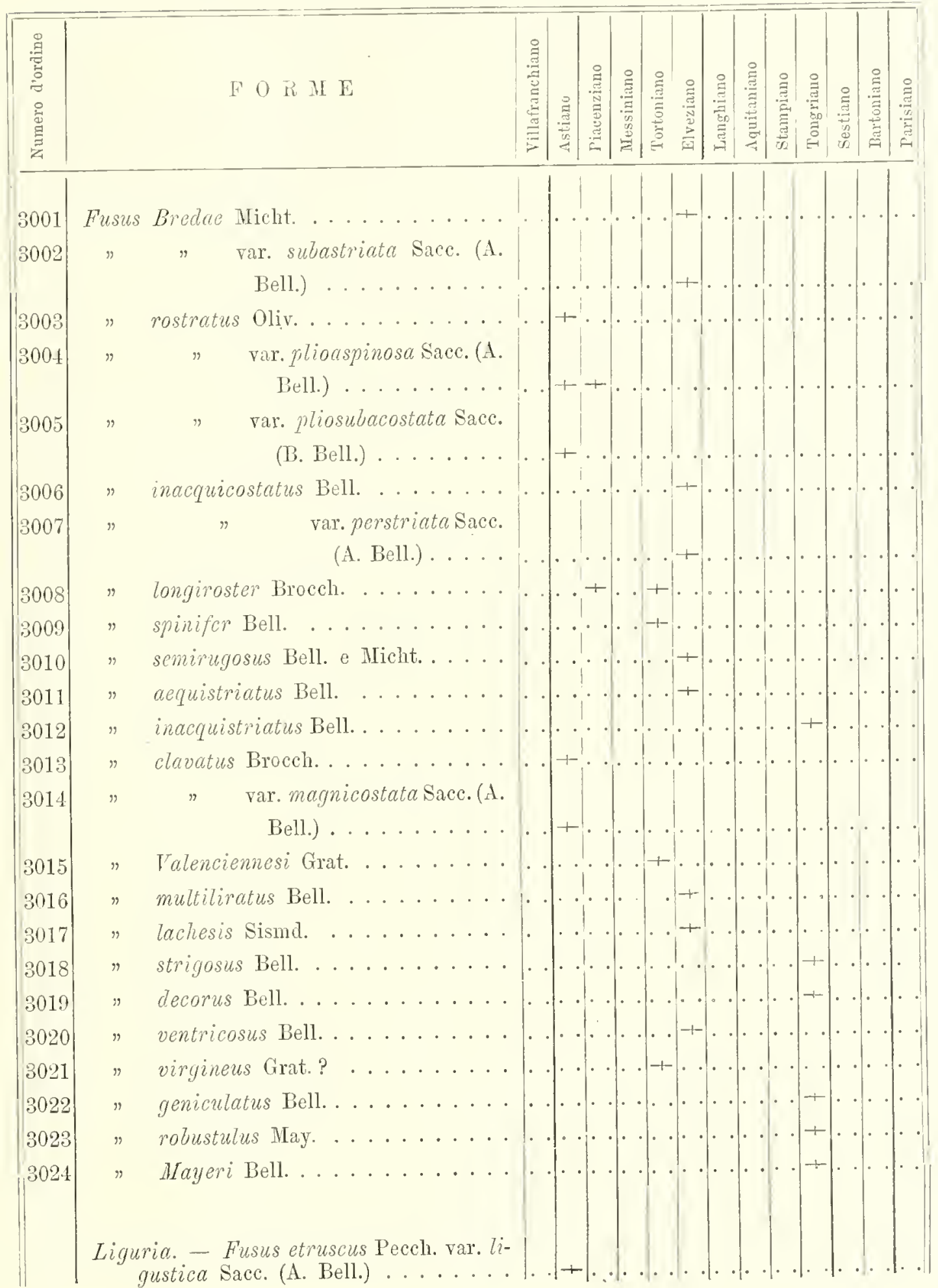




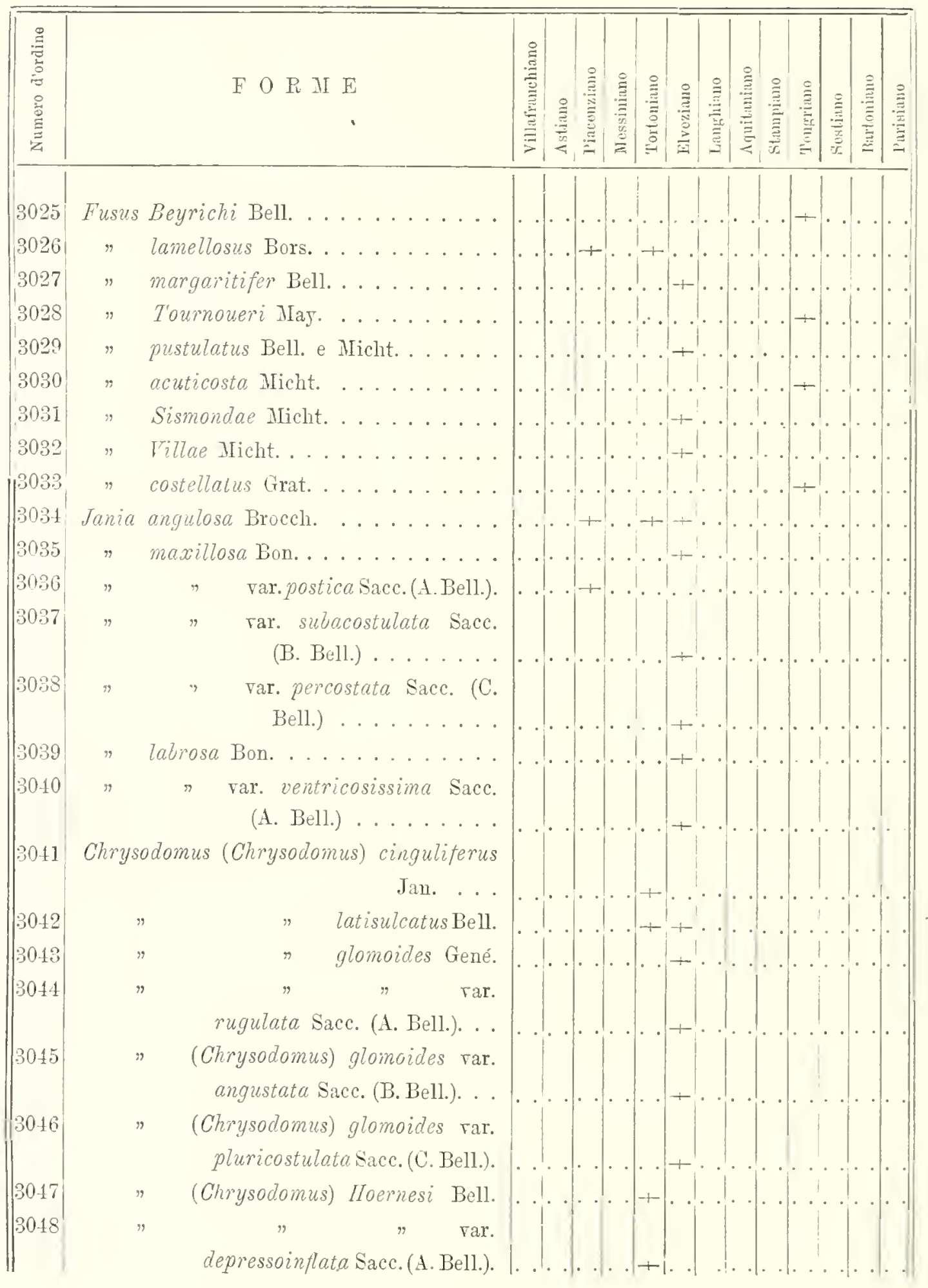




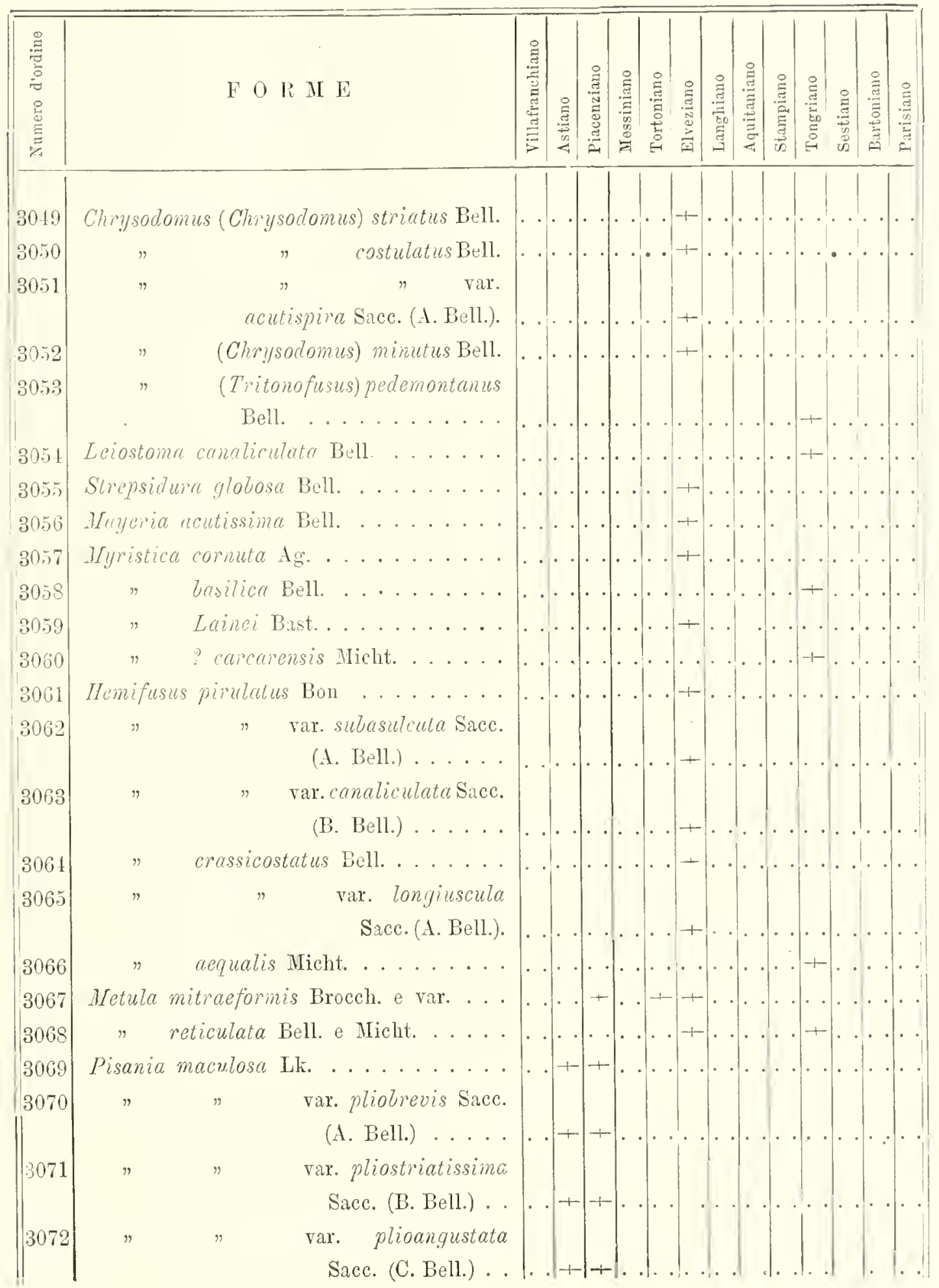




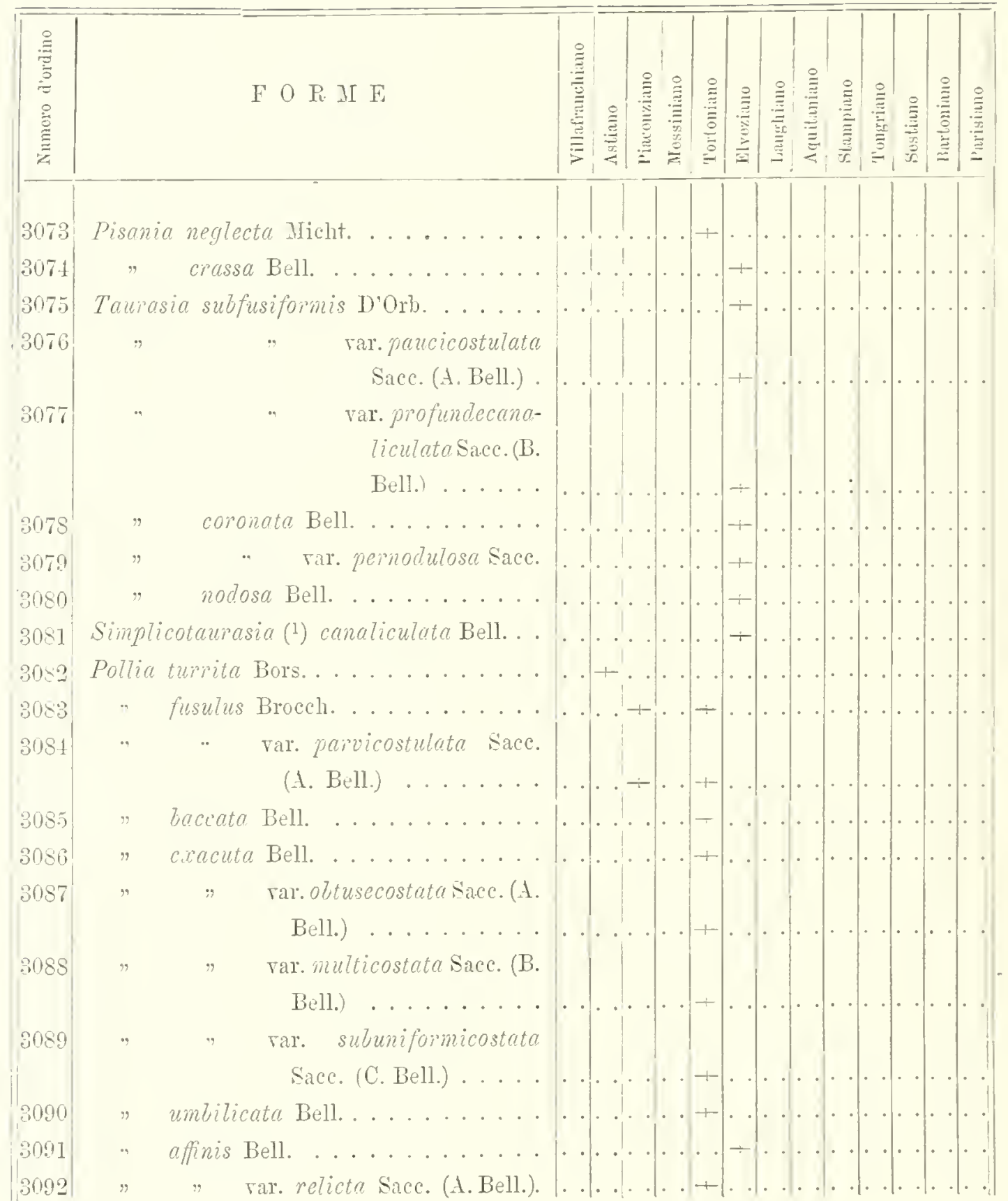

(1) Propongo per questa forma il nome di Simpticotaurasia inrece di Purpurelta proposto dal Ballardi, perche questo nome renne già usato sin dal 1872 in altru senso, cioè yer la Puipurella columellaris Lk. 


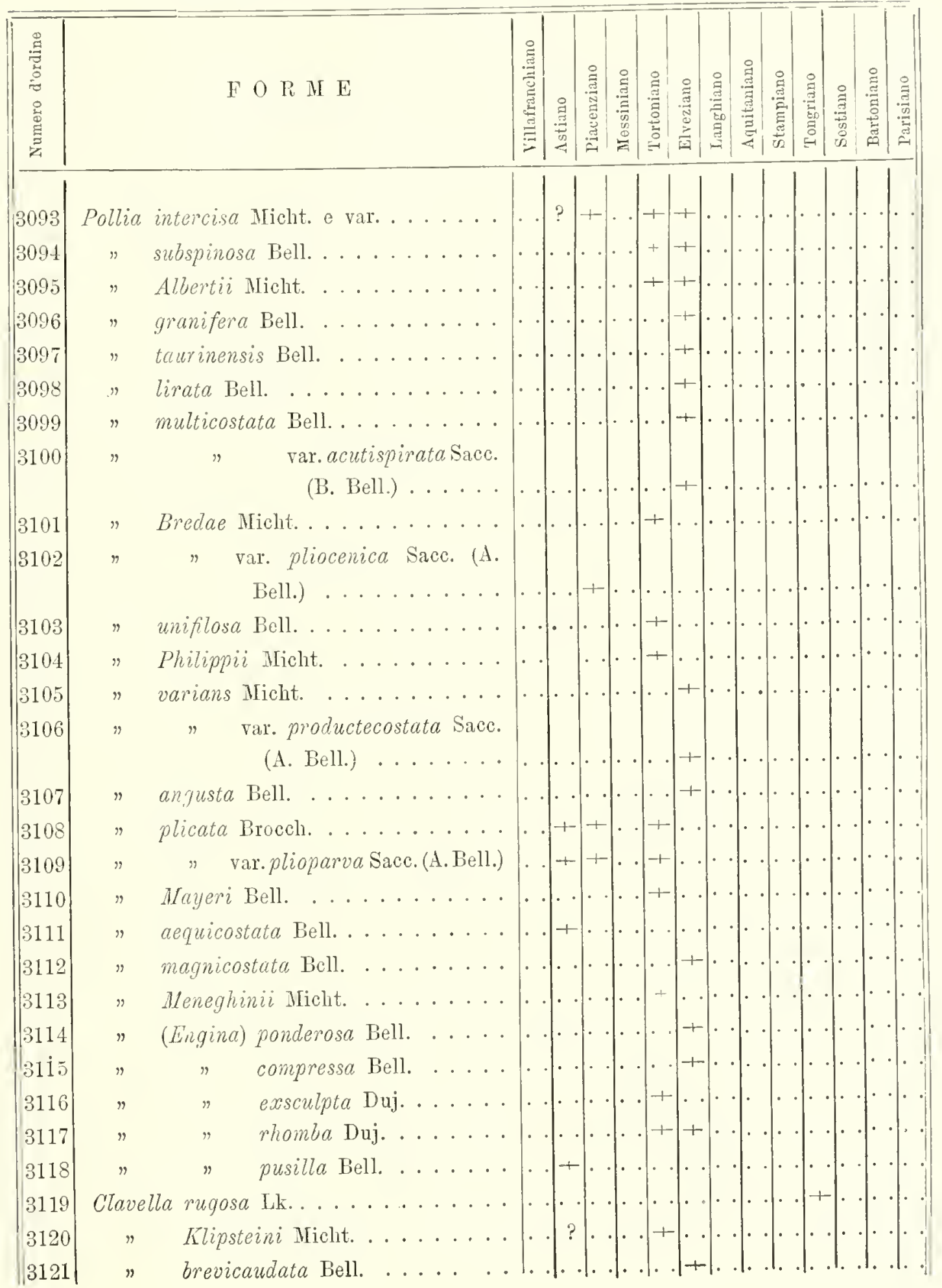




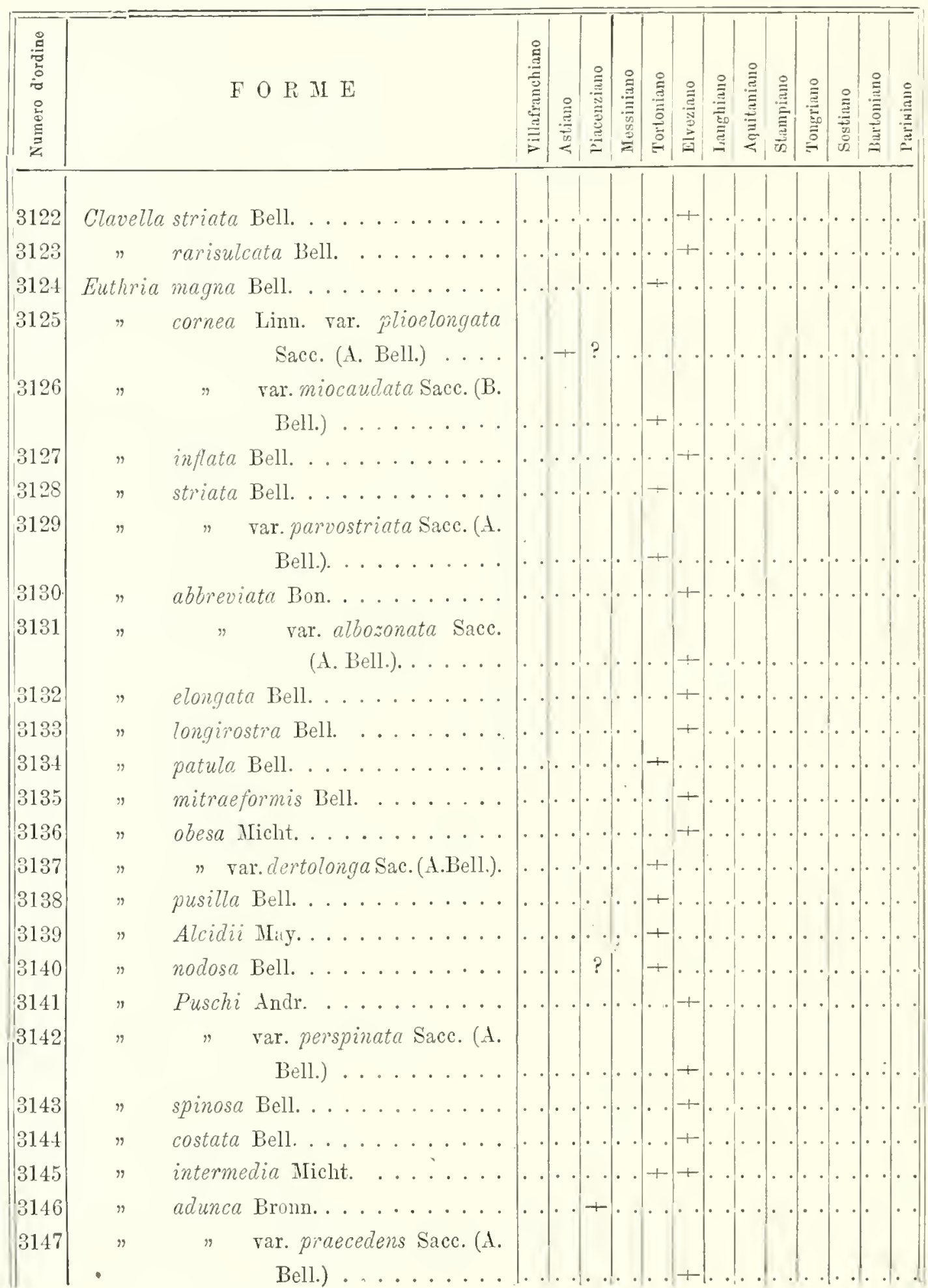




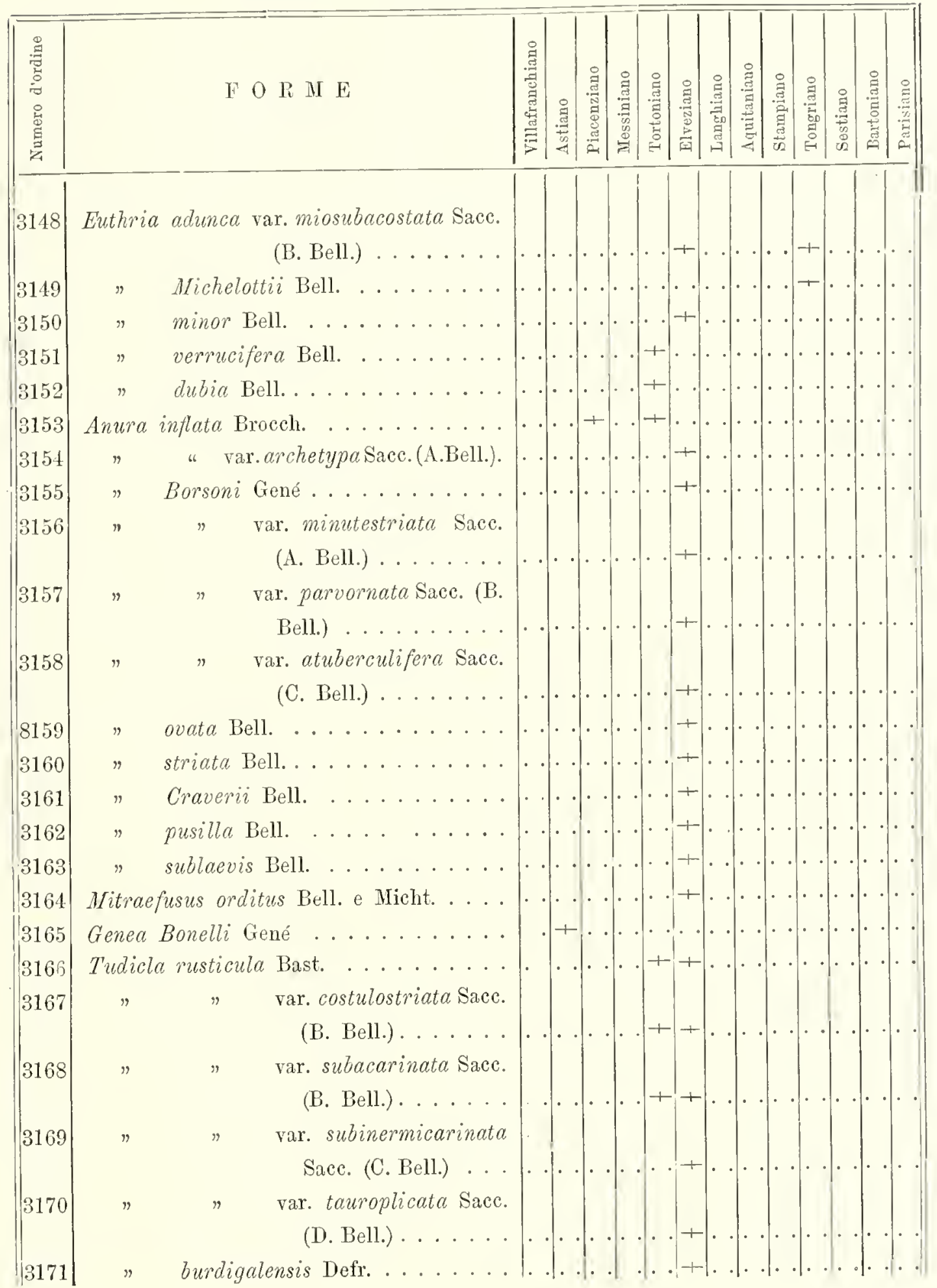




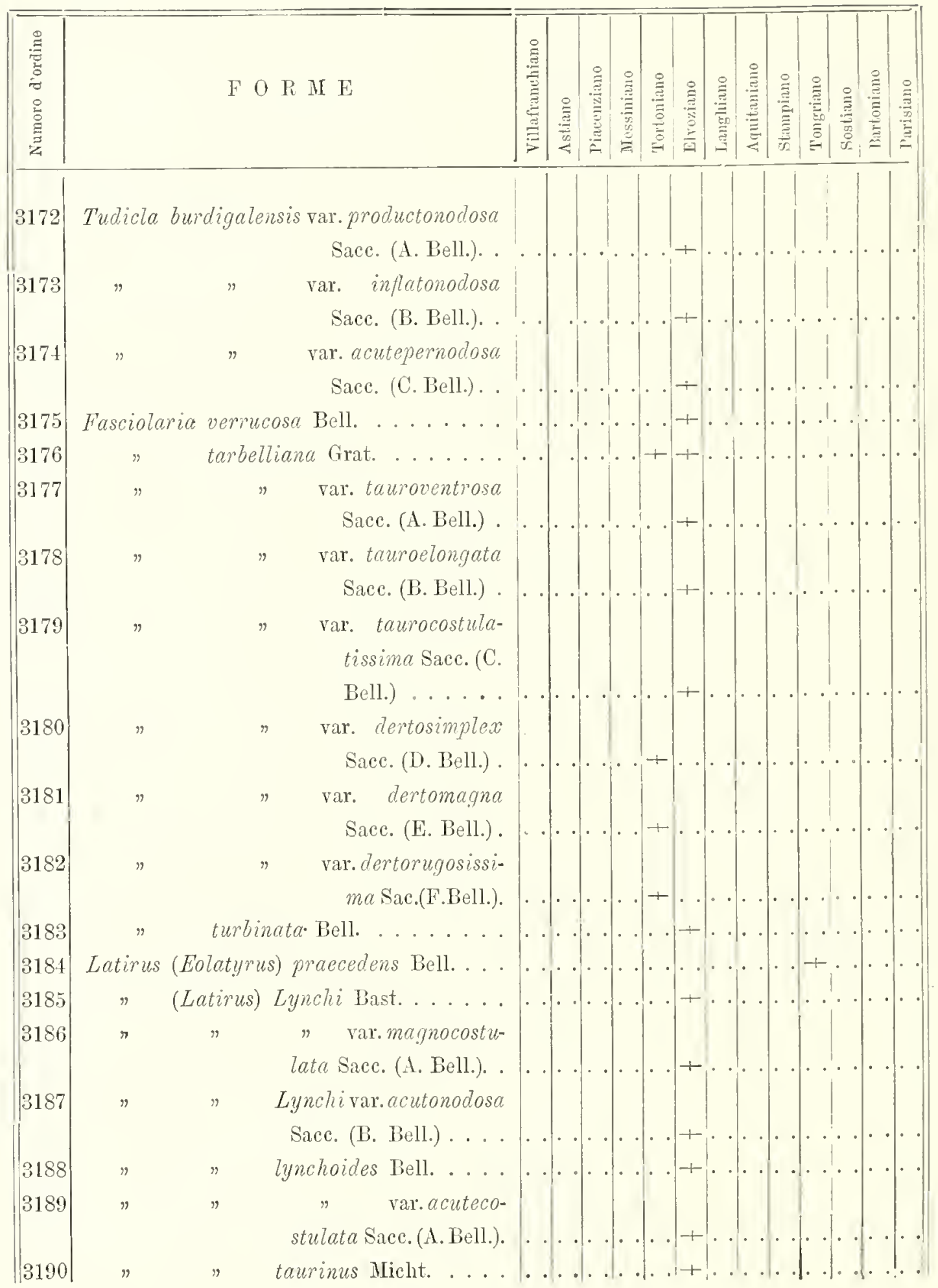




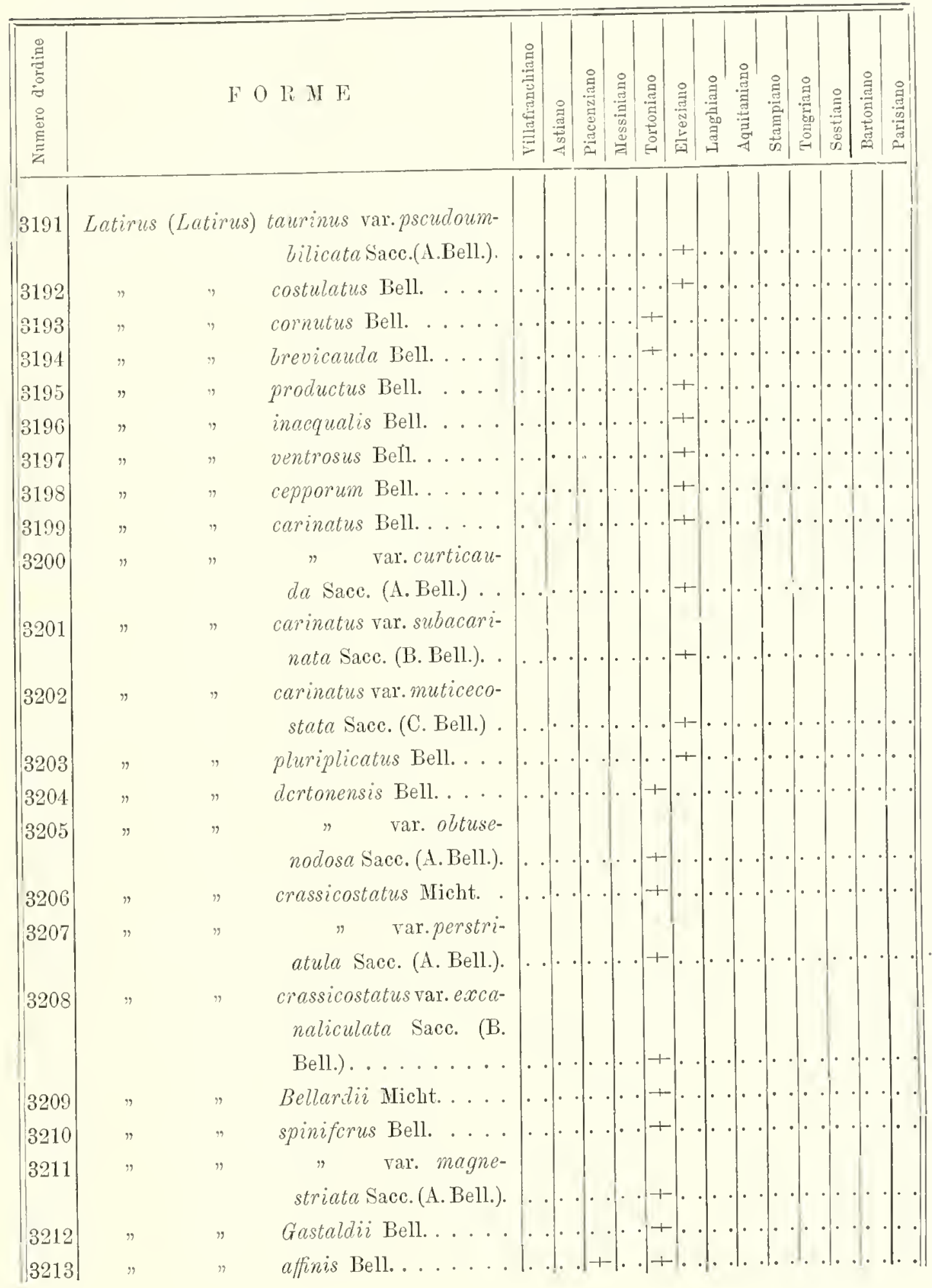




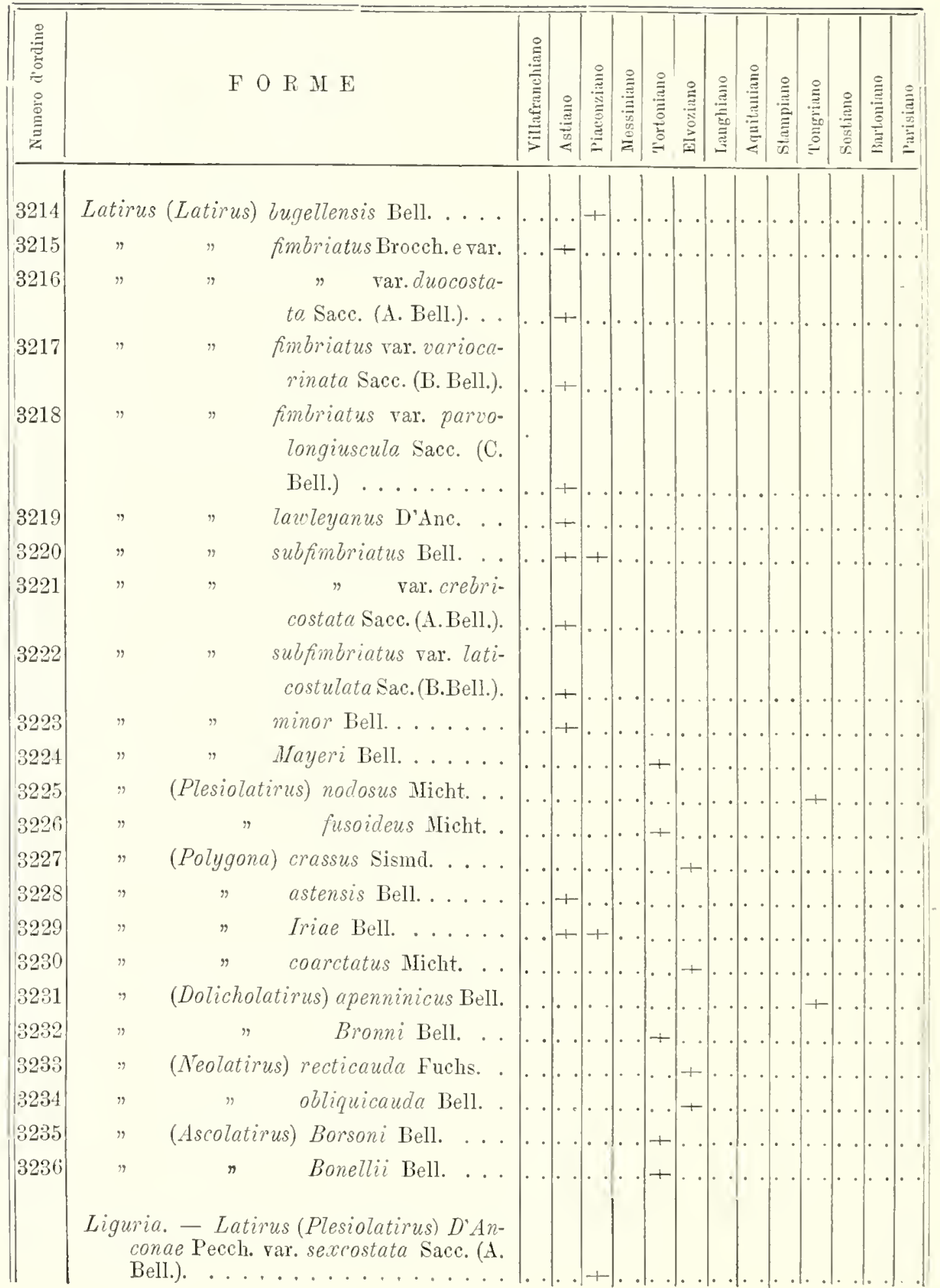




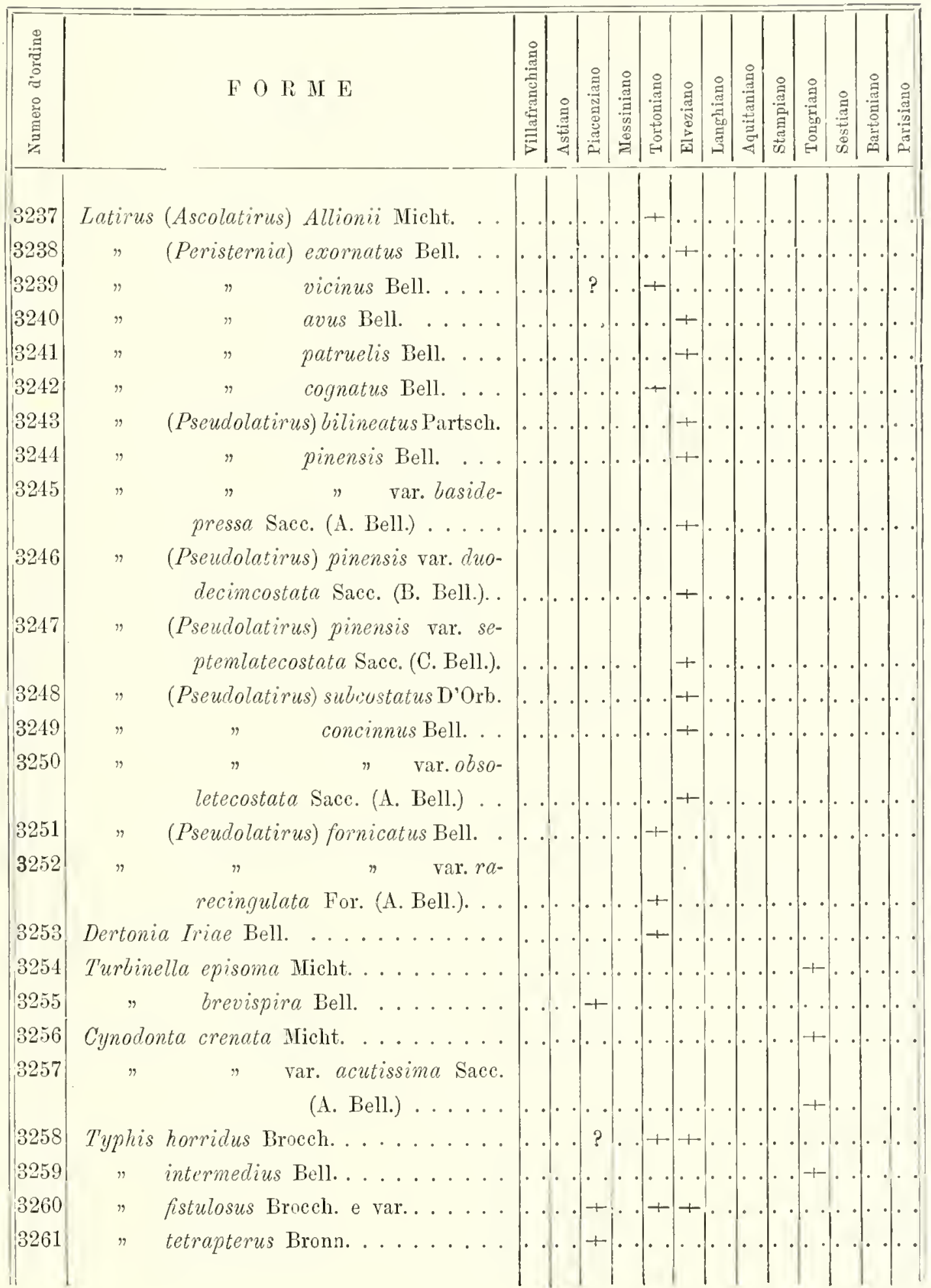




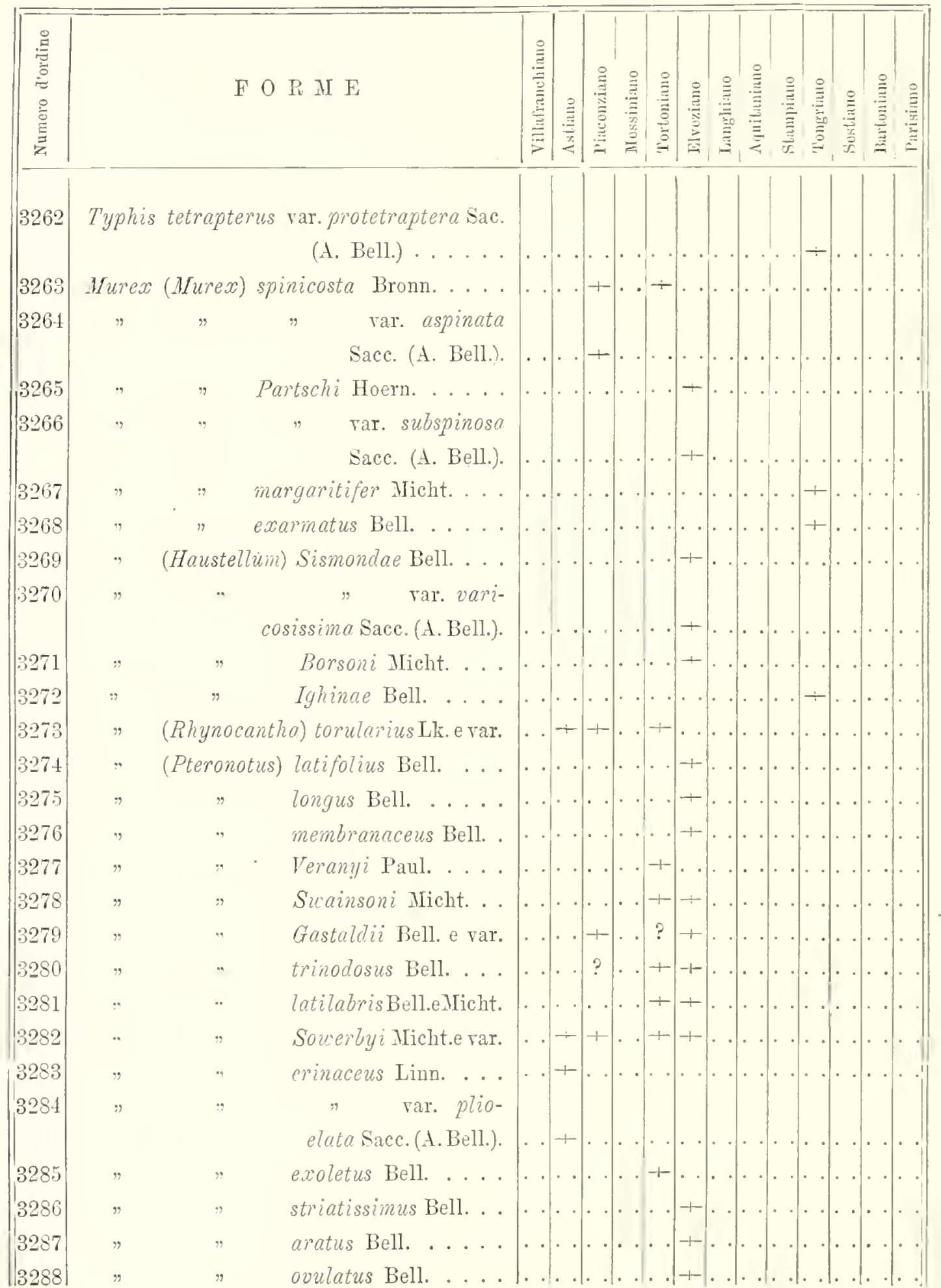


Catalogo paleontologico del bacino terziario del Piemonte

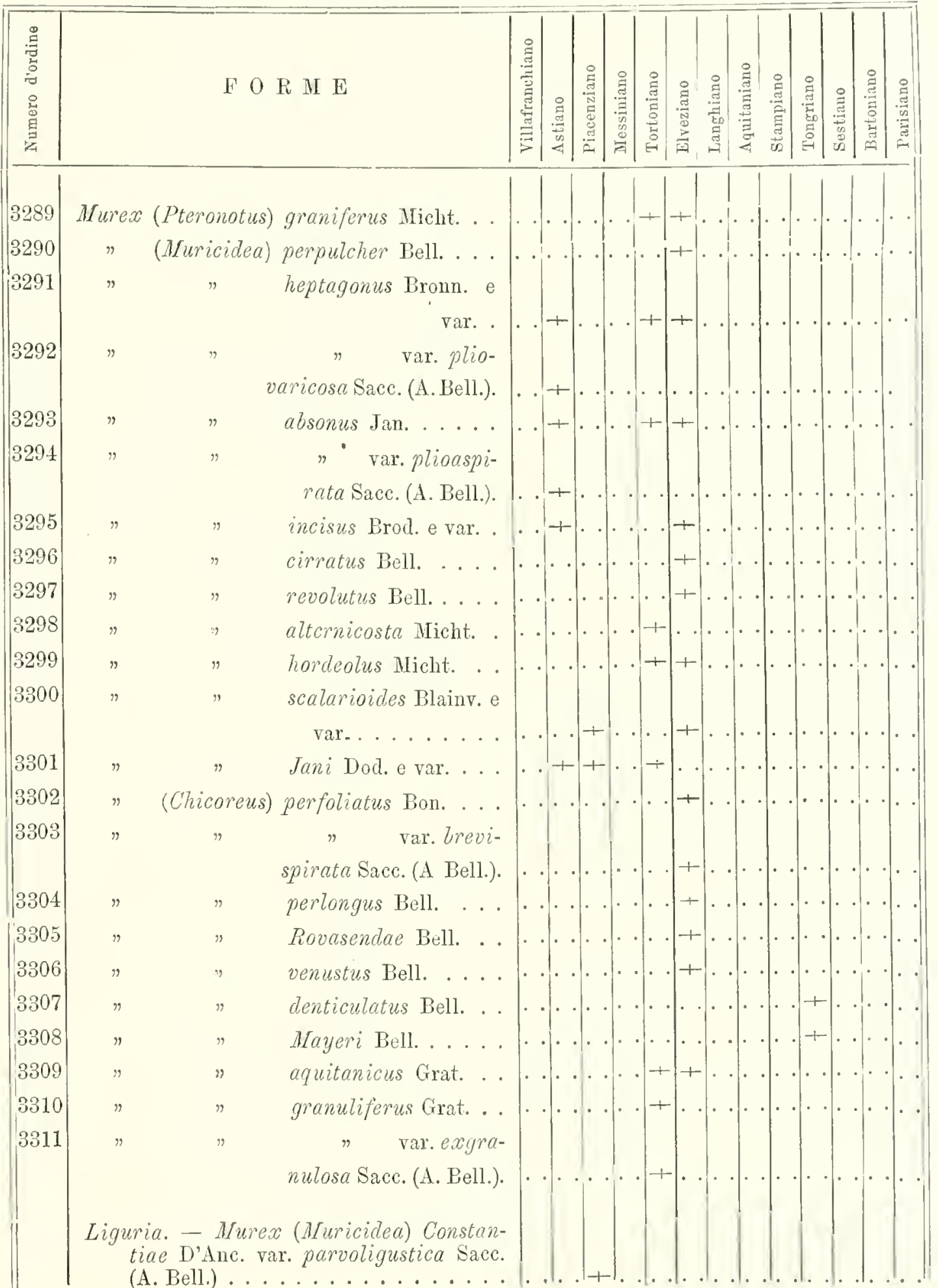




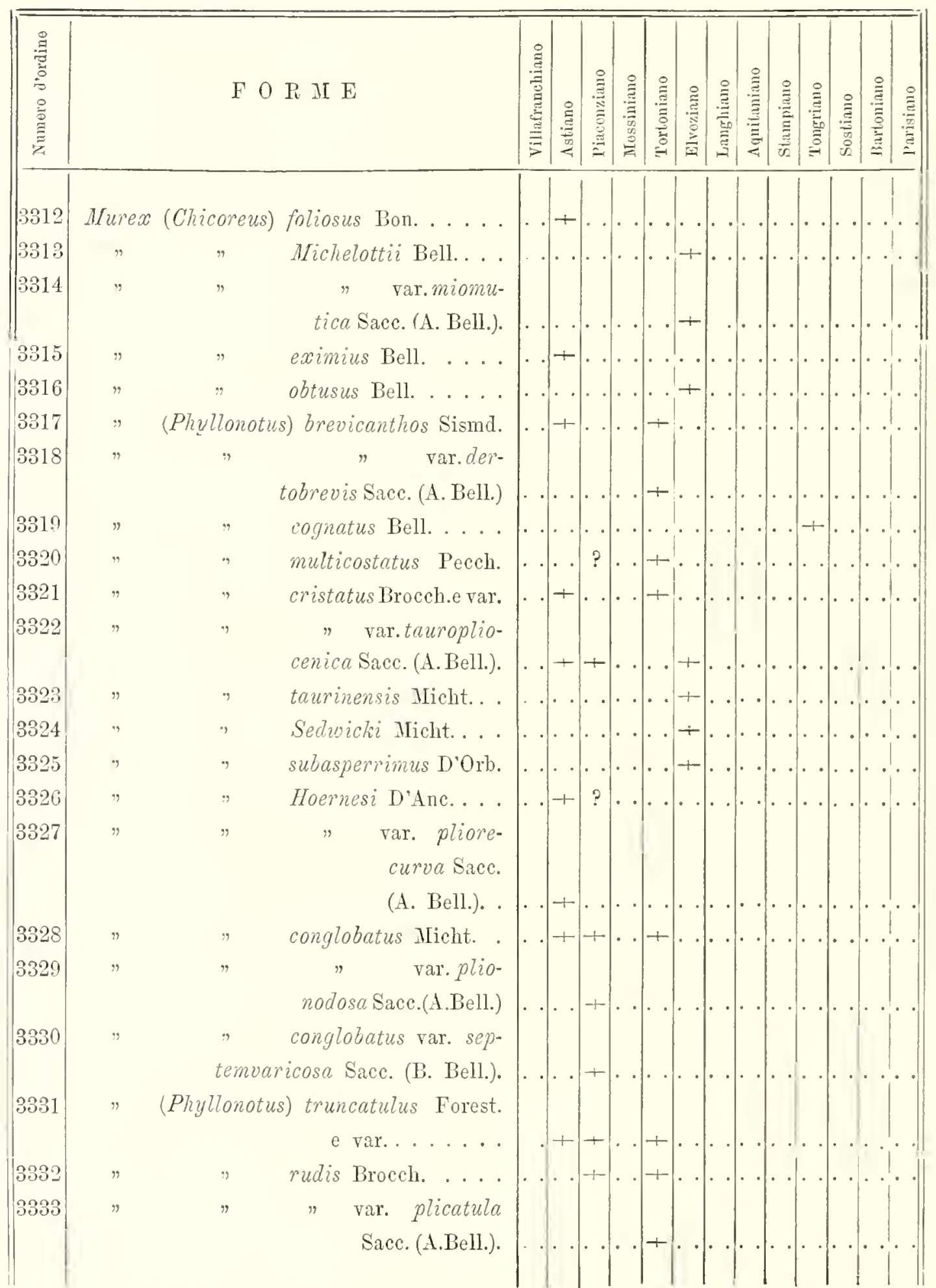




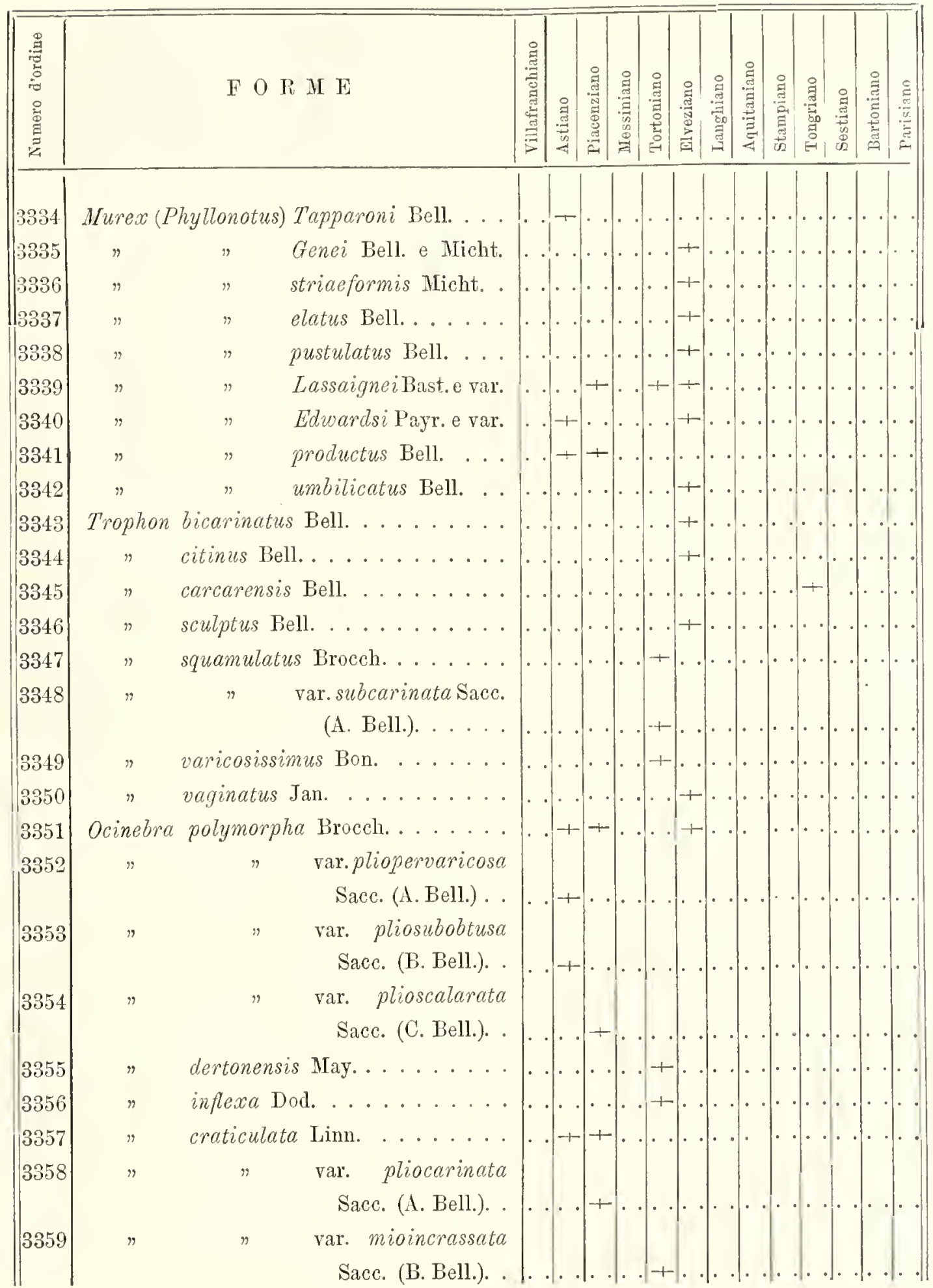




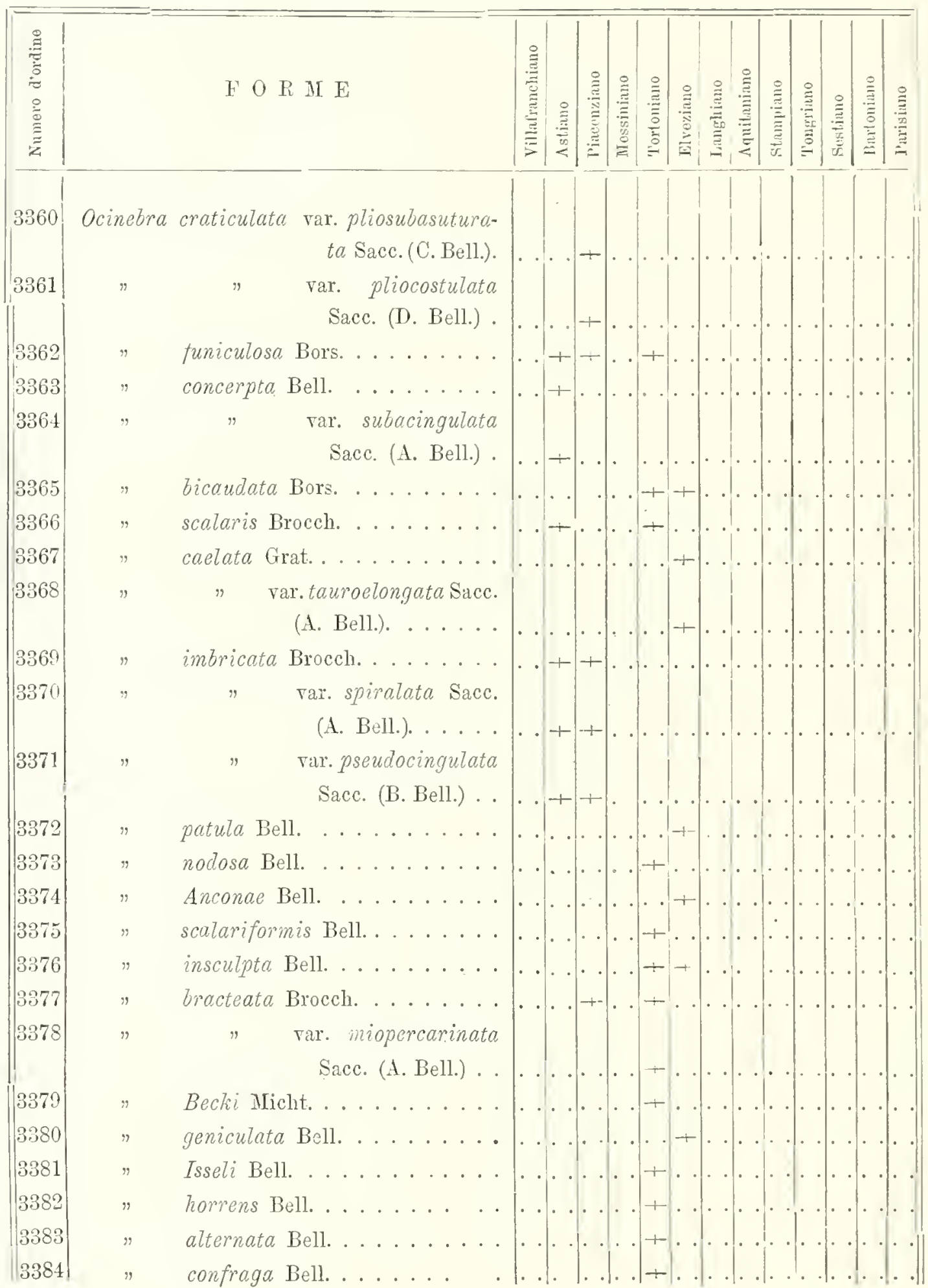


Catalogo paleontologico del bacino terziario del Piemonte

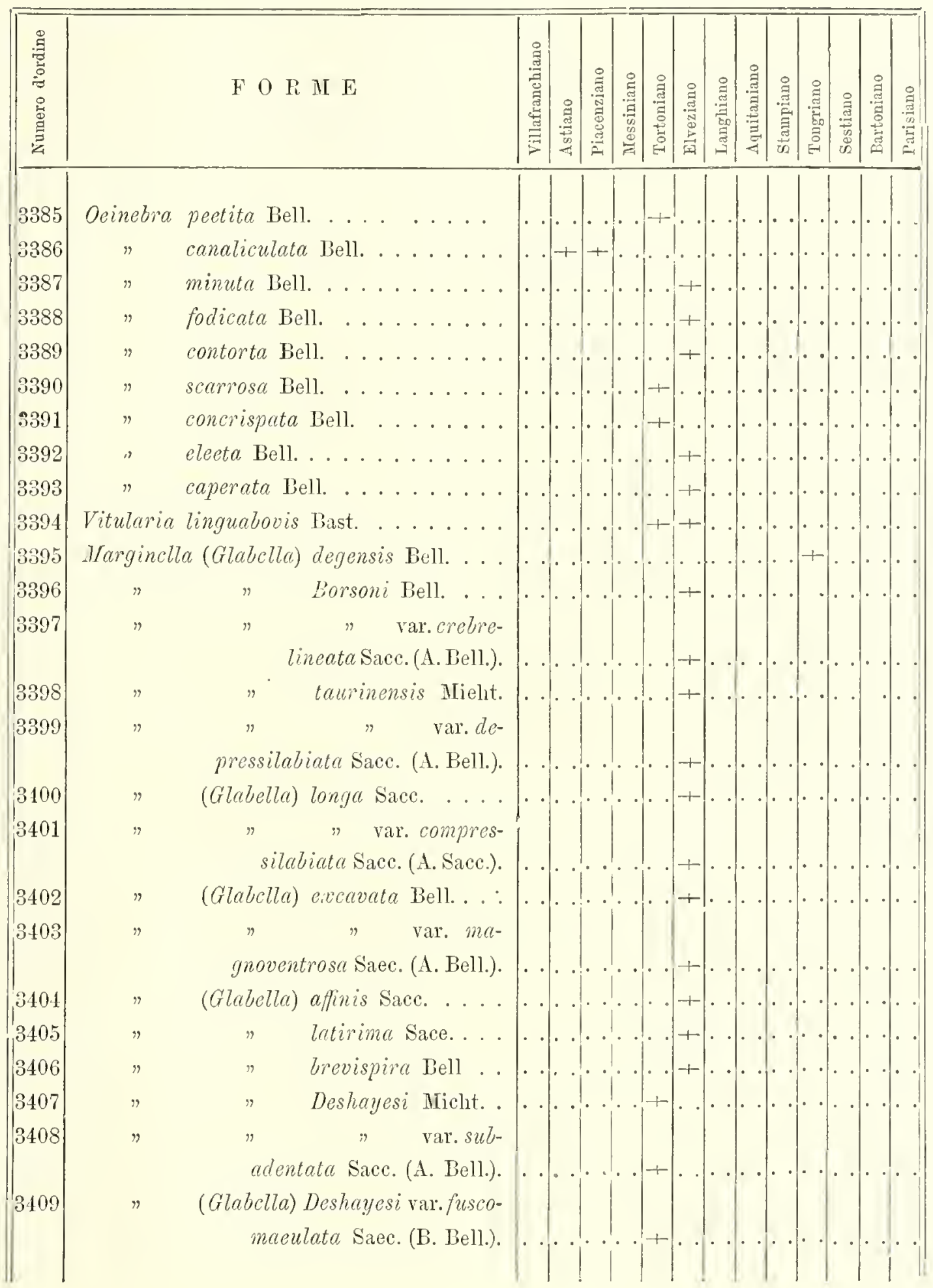




\begin{tabular}{|c|c|c|c|c|c|c|c|c|c|c|c|c|c|c|c|}
\hline 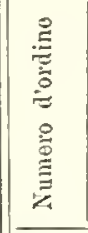 & & $\mathrm{F} O \mathrm{R} M \mathrm{E}$ & 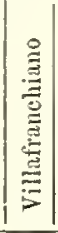 & 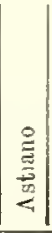 & 竎 & 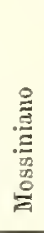 & 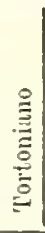 & 党 & 高 & 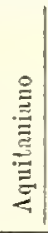 & 9 & | & 苞 & & 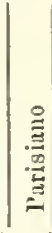 \\
\hline 3410 & $\operatorname{Mar}$ & $\begin{array}{r}\text { nella (Glabella) Deshayesi var. subre- } \\
\text { ctelabiata Sacc. (C. Bell.). }\end{array}$ & & & & & & & & & & & & & \\
\hline 3411 & & (Stazaania) emarginata Bon. . & & & & & + & & & & & & & & \\
\hline 3112 & & $\begin{array}{c}" \text { var.brun- } \\
\text { neozonata Sacc. (A. Sacc.). }\end{array}$ & & & & & & & & & & & & & \\
\hline 3113 & & $\begin{array}{r}\text { (Volvarina) elongata Bell. e } \\
\text { Micht. }\end{array}$ & & & & & & & & & & & & & \\
\hline 3114 & & $\begin{array}{ccc}" & \text { var. al- } \\
\text { bidolineata Sacc. (A. Bell.). }\end{array}$ & & & & & & & & & & & & & \\
\hline 3115 & & (Volvarina) parvula Sacc. . & & & & & & 4 & & & & & & & \\
\hline $3 \pm 16$ & & $" \quad$ oblongata Bon... & & & & & + & & & & & & & & \\
\hline 3417 & & (Persicula) subovulata D'Orb. & & & & & & & & & & & & & \\
\hline 3418 & & $" \quad$ brevis Bell. . . . & & & & & + & & & & & & & & \\
\hline 3419 & & $" \quad$ conoidea Bell. . . & & & & & + & & & & & & & & \\
\hline 3420 & & $" \quad$ Iriae Sacc. . . . & & & $t$ & & & & & & & & & & \\
\hline 3421 & & (Gibberula) clandestina Brocc. & & & 1 & & & & & & & & & & \\
\hline 3422 & & " $\quad$ miliacea Lk. ... & & & & & & & & & & & & & \\
\hline 3423 & Wits & Dufresnei Bast. . . . . . . . . & . & & & & & & & & & & & & \\
\hline $3+24$ & $"$ & apposita Bell. . . . . . . . . . . & . & & & & & + & & & & & & & \\
\hline 3425 & & $\begin{array}{r}" \quad \text { var. sulcatissima Sacc. (A. } \\
\text { Bell.) ......... }\end{array}$ & & & & & & + & & & & & & & \\
\hline 3426 & & $\begin{array}{r}" \quad \text { var. inflatobrevis Sacc. (B. } \\
\text { Bell.) } \ldots \ldots \ldots\end{array}$ & & & & & & & & & & & & & \\
\hline 3427 & $"$ & taeniolata Bell. . . . . . . . . & & & & & & & & & & & & & \\
\hline 3428 & $"$ & clavata Bell. . . . . . . . . . . . & & & & & & & & & & & & & \\
\hline 3429 & $"$ & brevispirata Bell. . . . . . . . & & & & & & + & & & & & & & \\
\hline 3430 & & $\begin{array}{r}\quad \quad \text { rar. sulcatulata Sacc. } \\
\quad \text { (A. Bell. }) \ldots \ldots\end{array}$ & & & & & & & & & & & & & \\
\hline 3431 & $"$ & laxesulcata Bell. . . . . . . . & & & & & & + & & & & & & & \\
\hline 3432 & $"$ & tumens Bell. . . . . . . . . . . . & & & & & & 1. & & & & & & & \\
\hline 3433 & $"$ & amygdalacea Bell. . . . . . . . . & & & & & & + & & & & & & & \\
\hline 131 & $"$ & doliolum Bell. . . . . . . . & & & & & & & & & & & & & \\
\hline
\end{tabular}




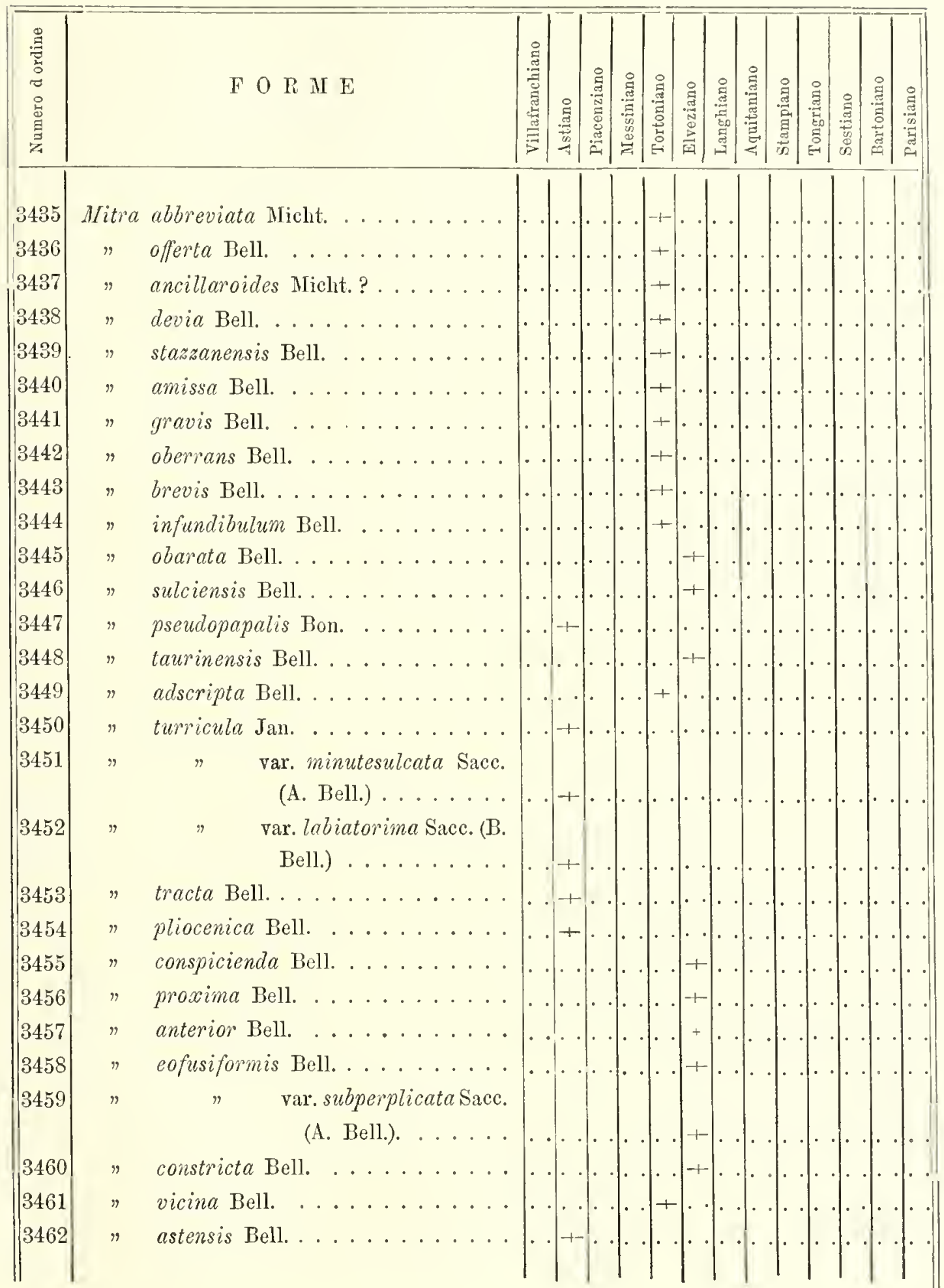




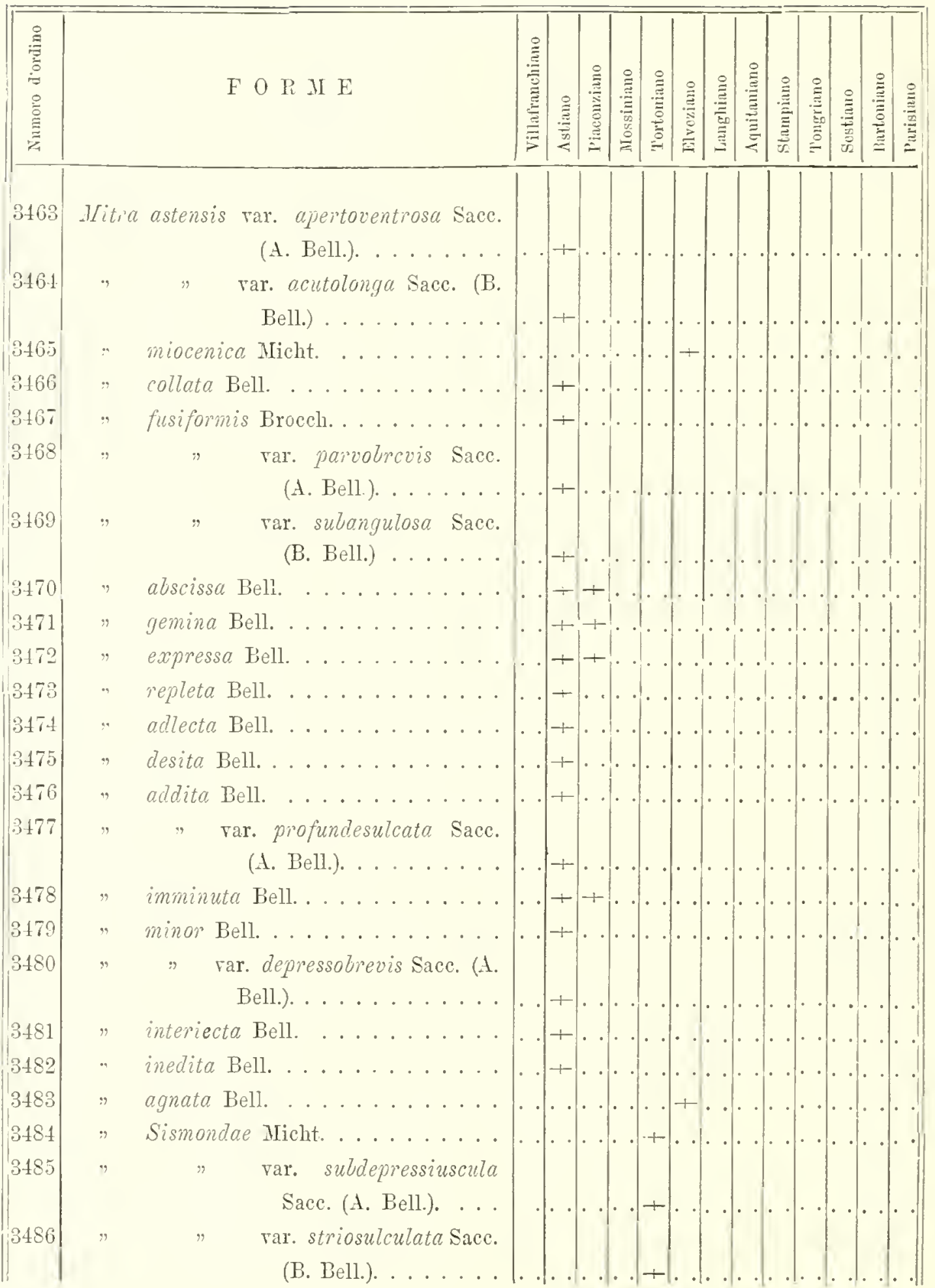




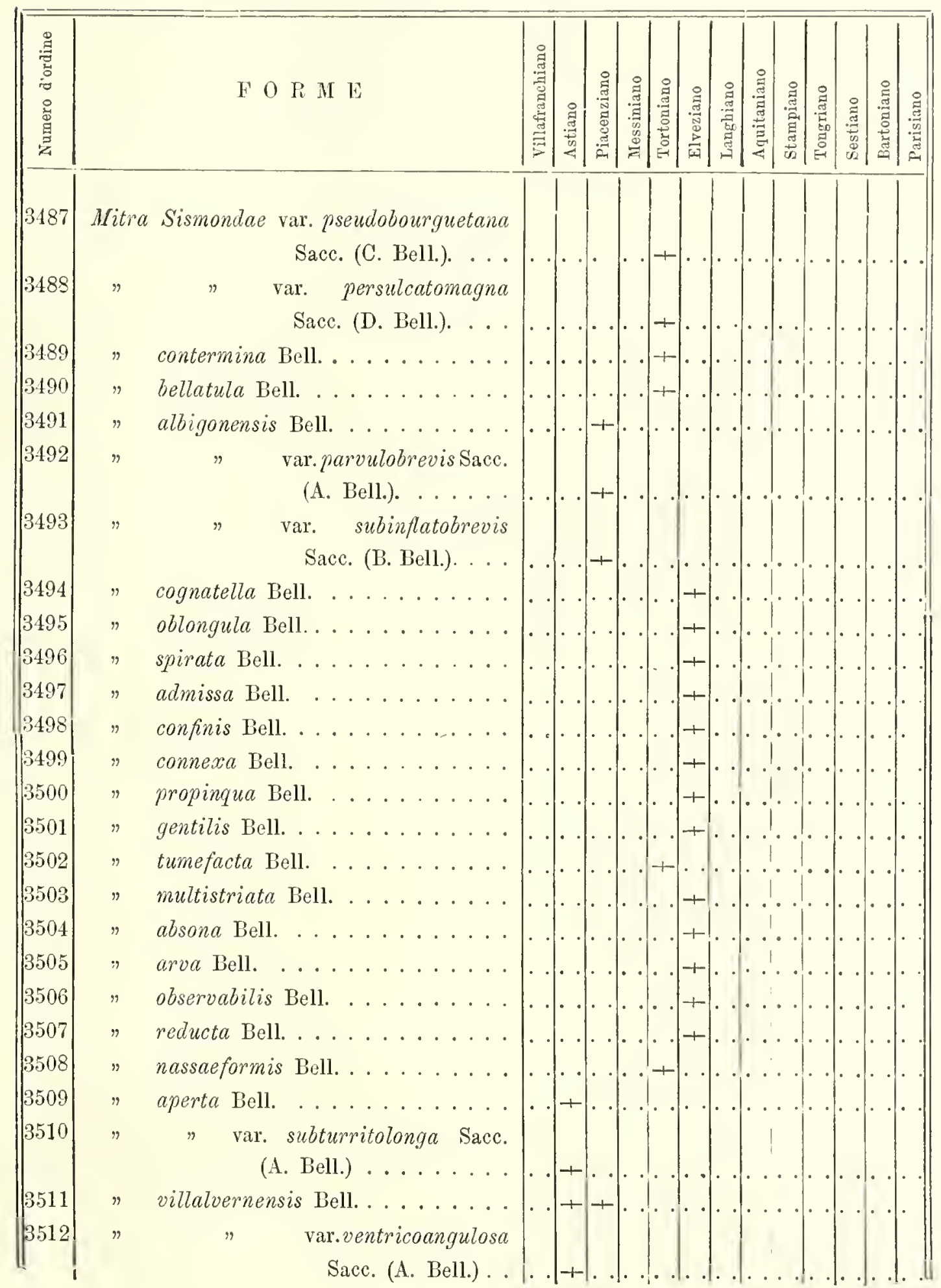




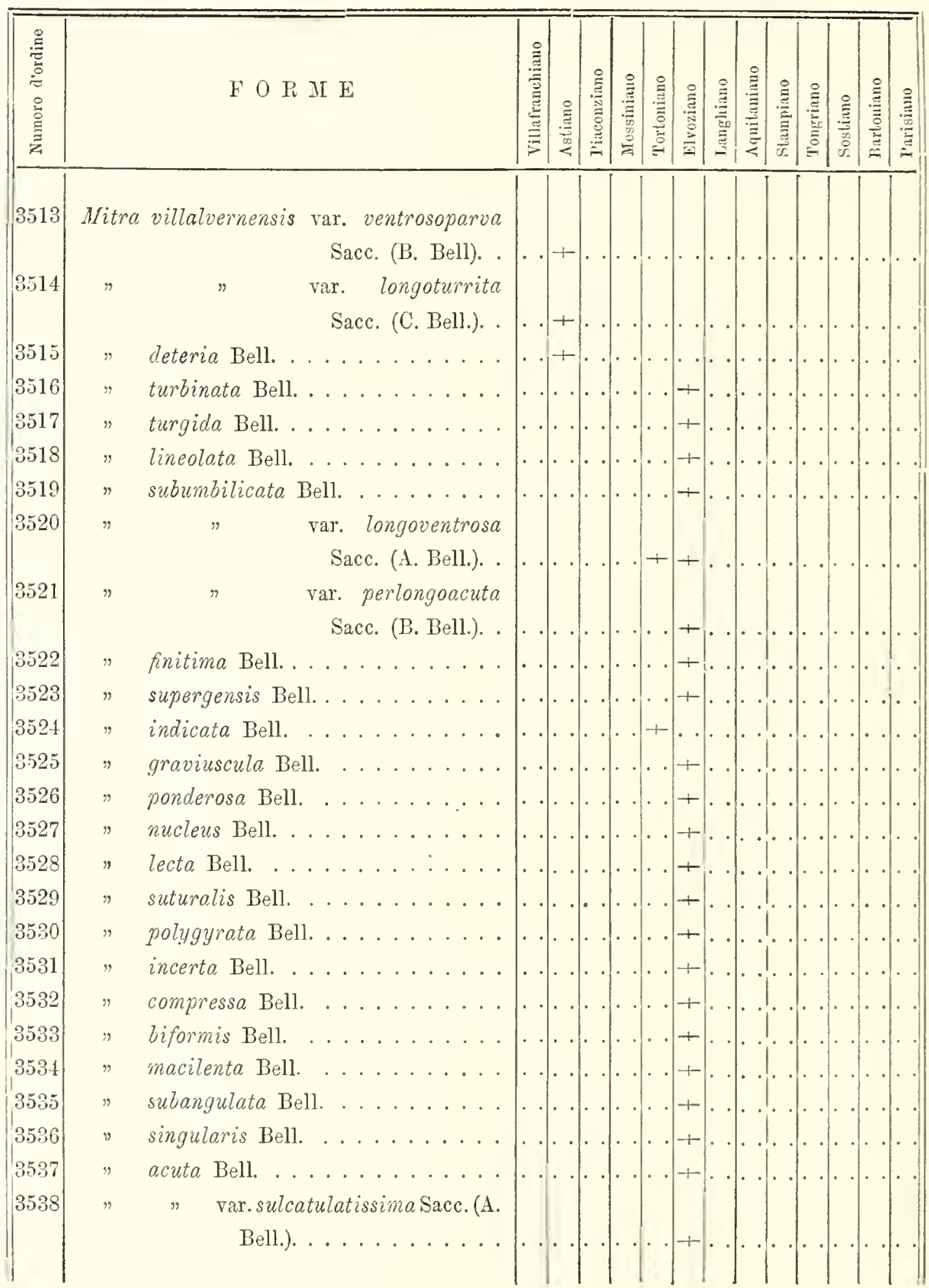




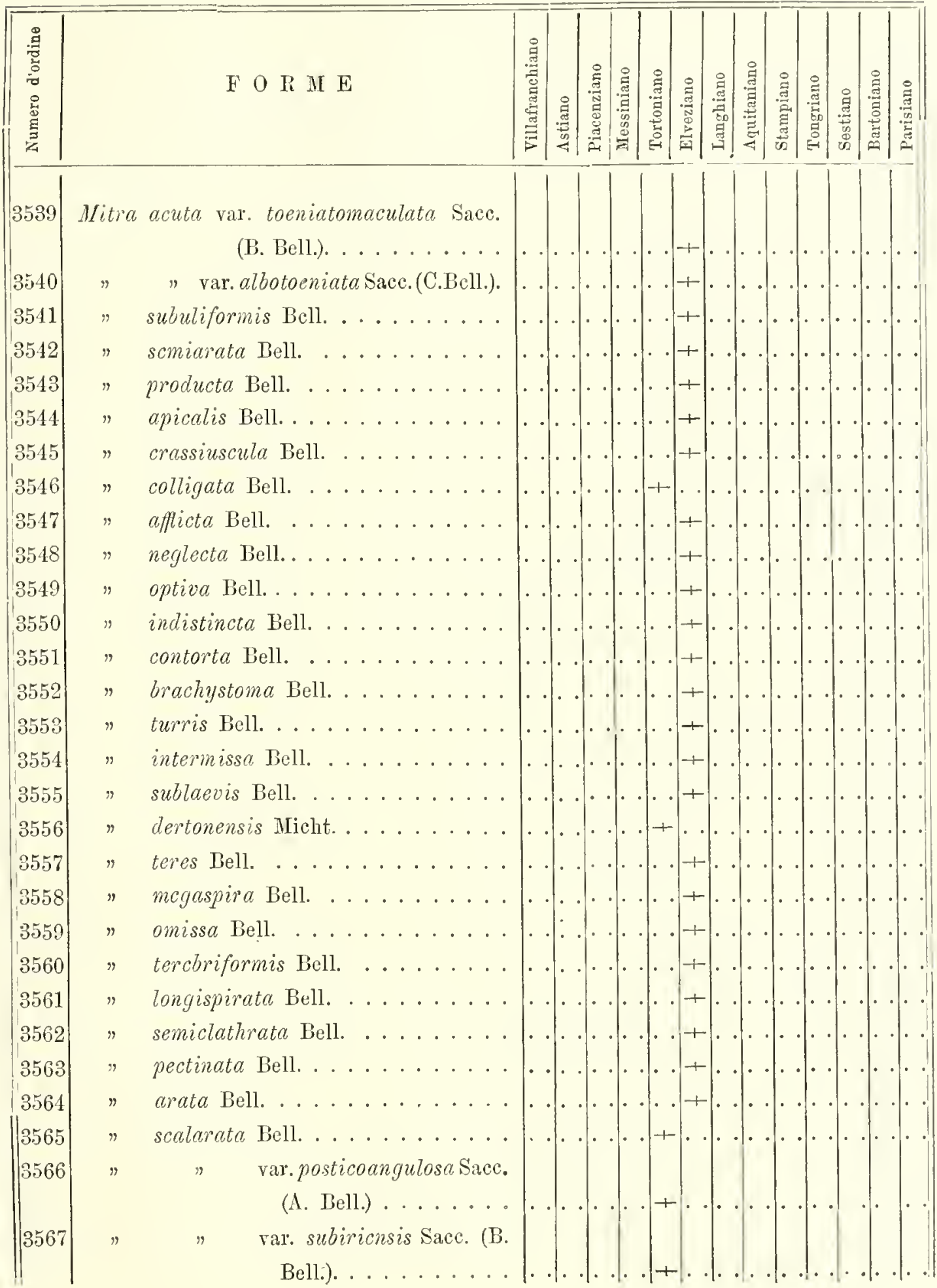




\begin{tabular}{|c|c|c|c|c|c|c|c|c|c|c|c|c|c|}
\hline 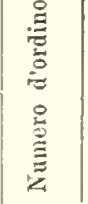 & $\mathrm{F} O \mathrm{R}$ II $\mathrm{E}$ & . & & & 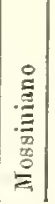 & 善 & 焉 & |. & 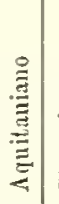 & & & 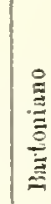 & \\
\hline 8568 & Mitra iriensis Bell. . . . . . . . . & & & & & + & & & & & & & \\
\hline 3569 & $"$ protensa Bell. . . . . . . . . . & & & & & & & & & & & & \\
\hline 3570 & $"$ goniophoro Bell. . . . . . . . & & & & & + & & & & & & & \\
\hline 3571 & $"$ subcarinata Bell. . . . . . . . . & & & & & + & & & & & & & \\
\hline 8572 & $"$ protracta Bell. .......... & & & & & + & & & & & & & \\
\hline 3573 & $"$ citima Bell. . . . . . . . . & & & & & . & + & & & & & & \\
\hline 3574 & $"$ paucisulcata Bell. .......... & & & & & & -+ & & & & & & \\
\hline 3575 & $"$ sorarcula Bell. . . . . . . . . . . & & & & & & 4 & & & & & & \\
\hline 3576 & $" \quad$ avula Bell. ............ & & & & & & + & & & & & & \\
\hline 3578 & $"$ 'albucianensis . . . . . . . . . & & & & & & + & & & & & & \\
\hline 3578 & $"$ suballigata Bell. . . . . . . . . & & & & & + & & & & & & & \\
\hline 3579 & $\begin{array}{r}" \quad \text { var. transversesulcata } \\
\quad \text { Sacc. (A. Bell.) } \ldots\end{array}$ & & & & & + & & & & & & & \\
\hline 3580 & $\begin{array}{r}" \quad \text { rar. petroinflata Sace. } \\
\quad(\text { B. Bell. }) \ldots \ldots,\end{array}$ & & & & & + & & & & & & & \\
\hline 3581 & $"$ venusta Bell. . . . . . . . . . & & & & & + & & & & & & & \\
\hline 3582 & $"$ alligata Defr. . . . . . . . . & - & + & + & & & & & & & & & \\
\hline 3583 & $\begin{array}{r}" \quad \text { var. aequopersulcato Sace. } \\
\quad(\text { A. Bell.). } \ldots \ldots . .\end{array}$ & & & + & & & & & & & & & \\
\hline 3584 & $\begin{array}{l}" \quad \text { rar.quatuorsulcatula Sacc. } \\
\quad(\text { B. Bell.). . . . . . }\end{array}$ & & + & $\div$ & & & & & & & & & \\
\hline 3585 & $" \quad$ optabilis Bell. . . . . . . . . . & & & & & & & & & & & & \\
\hline 3586 & $"$ praecedens Bell. . . . . . . . . . & & & & & & & & & & & & \\
\hline 3587 & $"$ Bonellii Bell. . . . . . . . . . & & + & + & & & & & & & & & \\
\hline 3588 & $\begin{array}{r}" \quad \text { var. angustoocuta Sacc. (A. } \\
\text { Bell.) } \ldots \ldots \ldots \ldots\end{array}$ & & + & $\div$ & & & & & & & & & \\
\hline 3589 & $" \quad$ dignota Bell. . . . . . . . . . . & & & & & & & & & & & & \\
\hline 3590 & $\begin{array}{r}" \quad \text { var. subosulcato Sace. (A. } \\
\text { Bell.) .......... }\end{array}$ & -1 & + & & & & & & & & & & \\
\hline 3591 & $\begin{array}{r}" \quad \text { var. convexoparva Sace. } \\
\quad(\text { B. Bell. }) \ldots \ldots \ldots\end{array}$ & & + & & & & & & & & & & \\
\hline & $"$ interposito Bell. . . . . . . . . & & & & & & & & & & & & \\
\hline
\end{tabular}




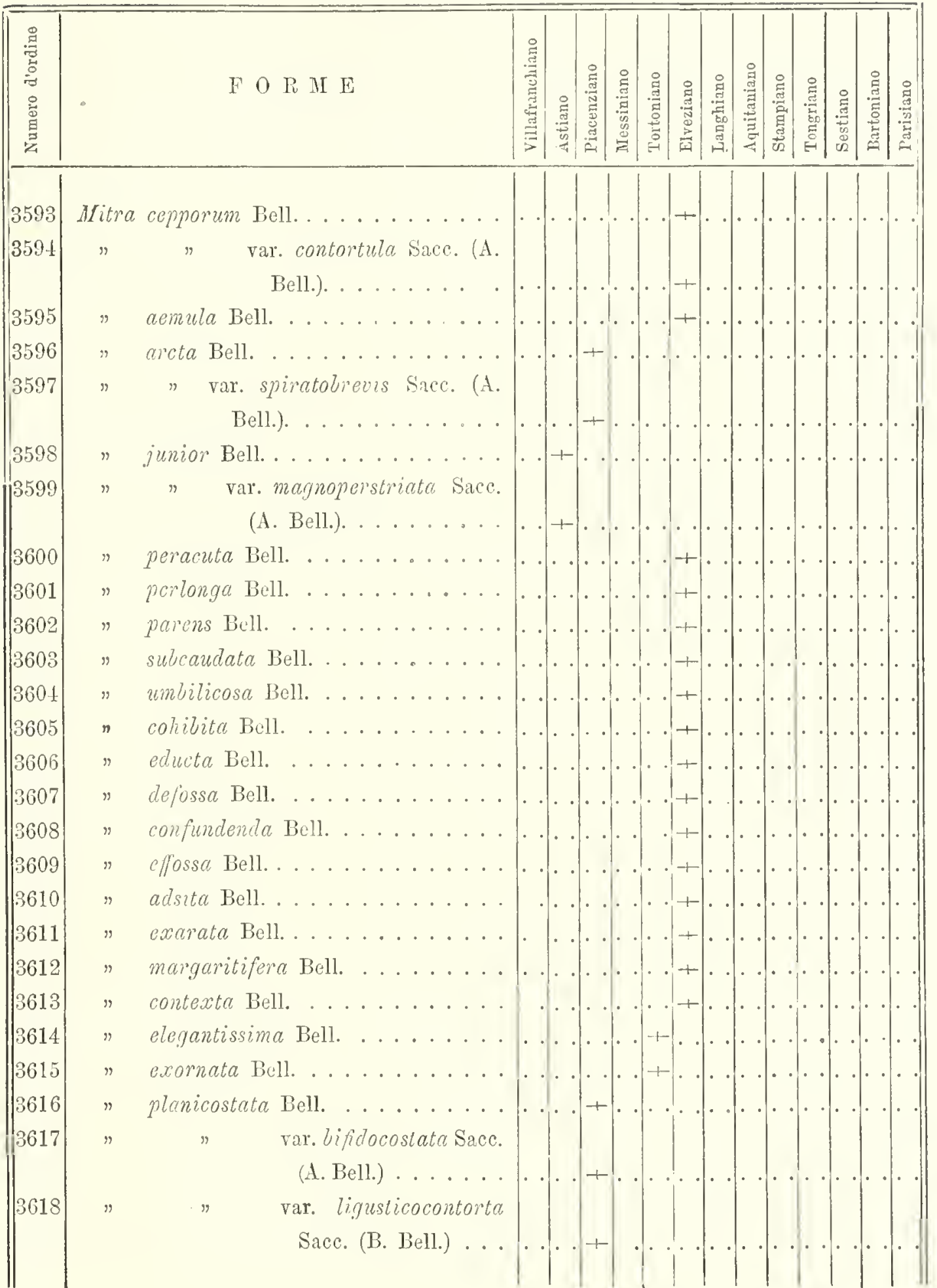




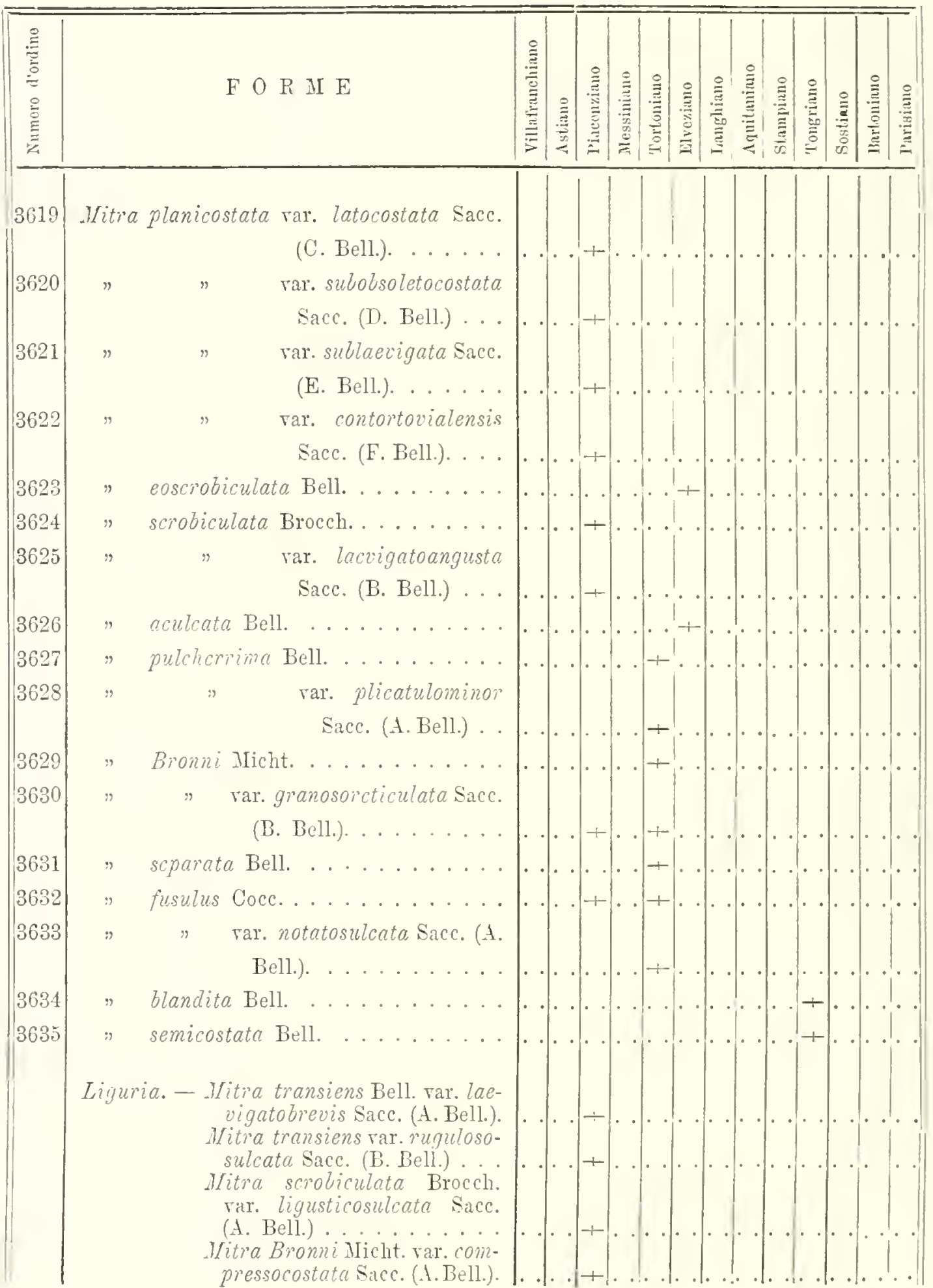


Catalogo paleontologico del bacino terziario del Piemonte

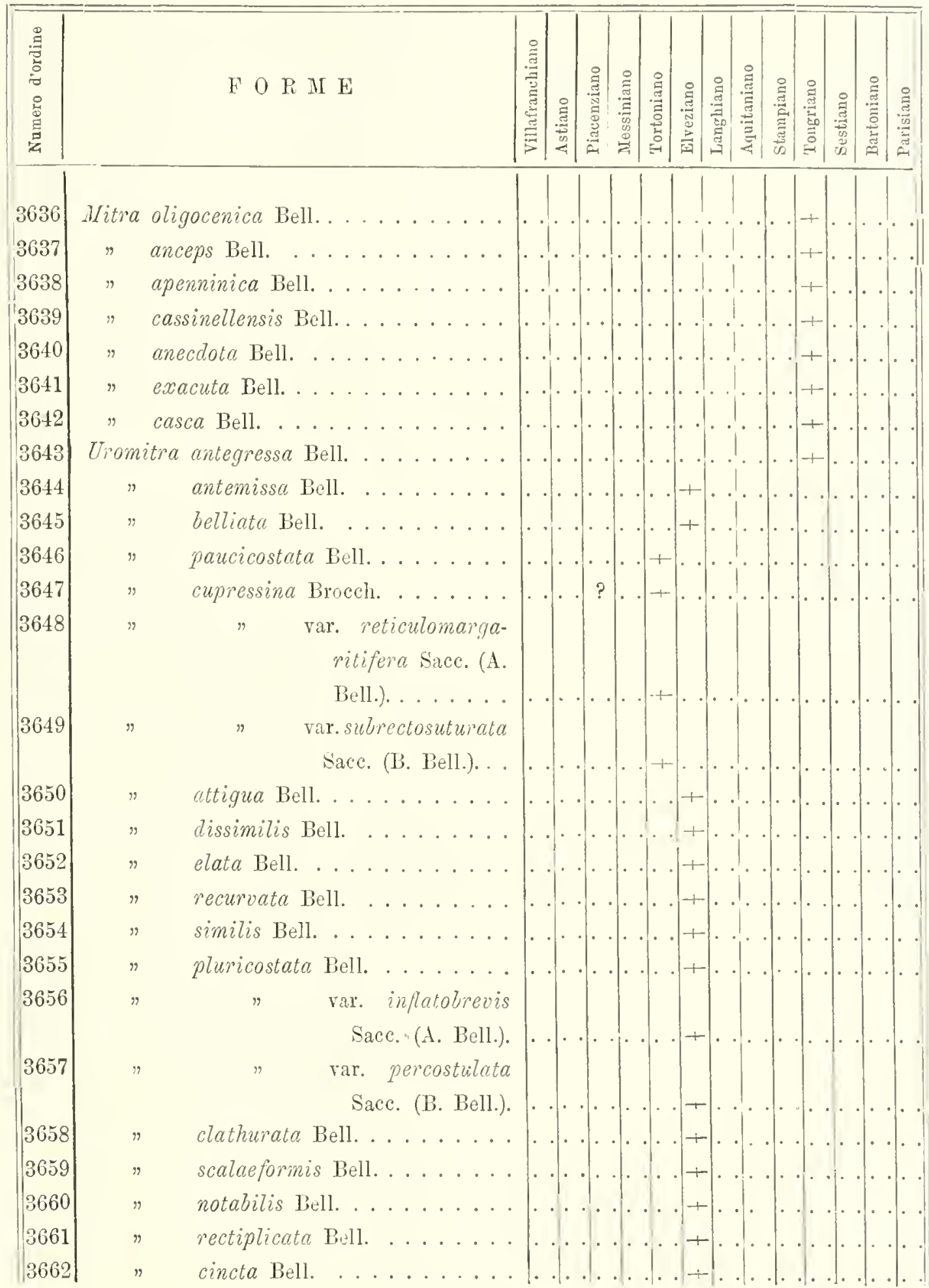




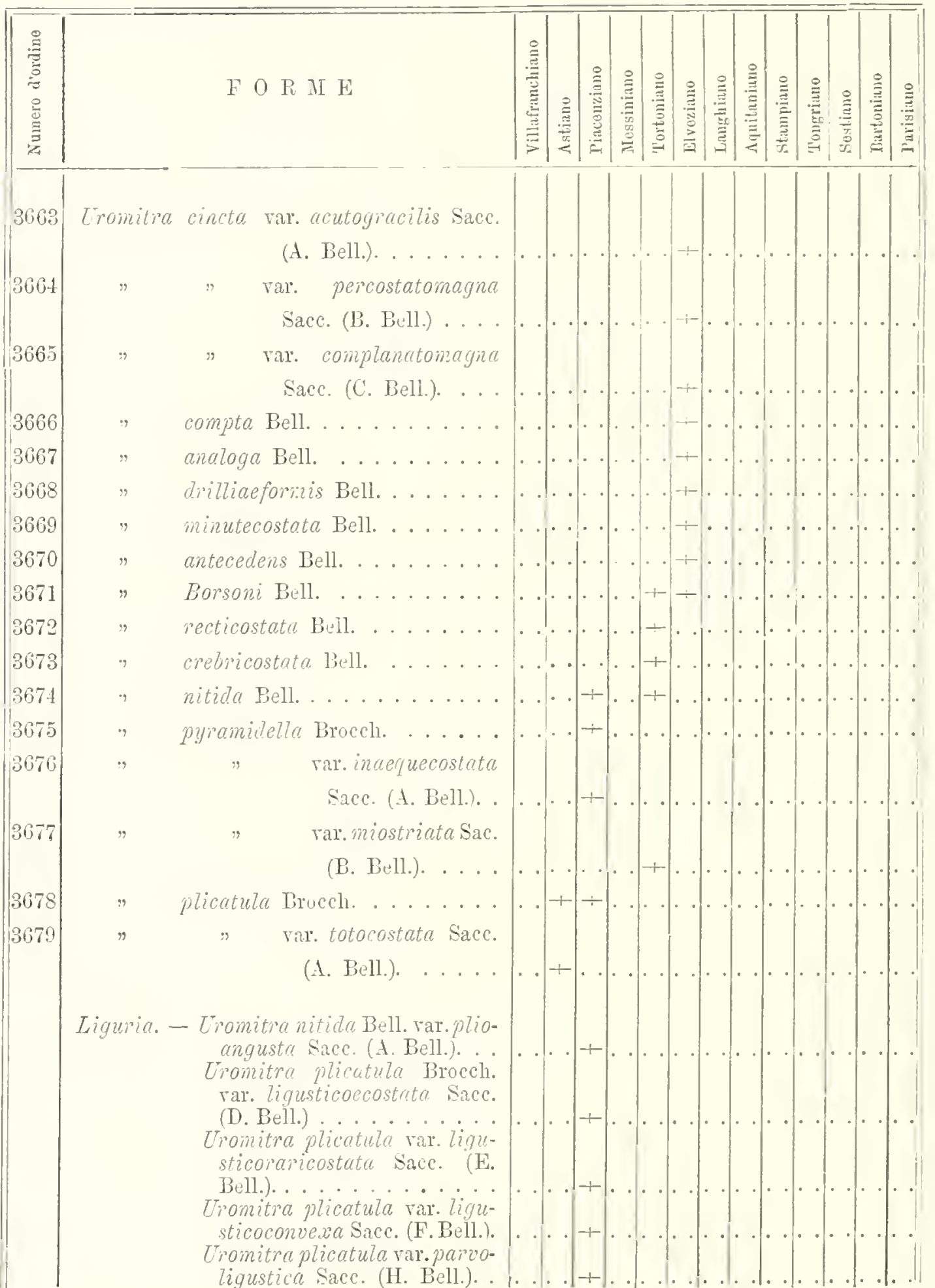




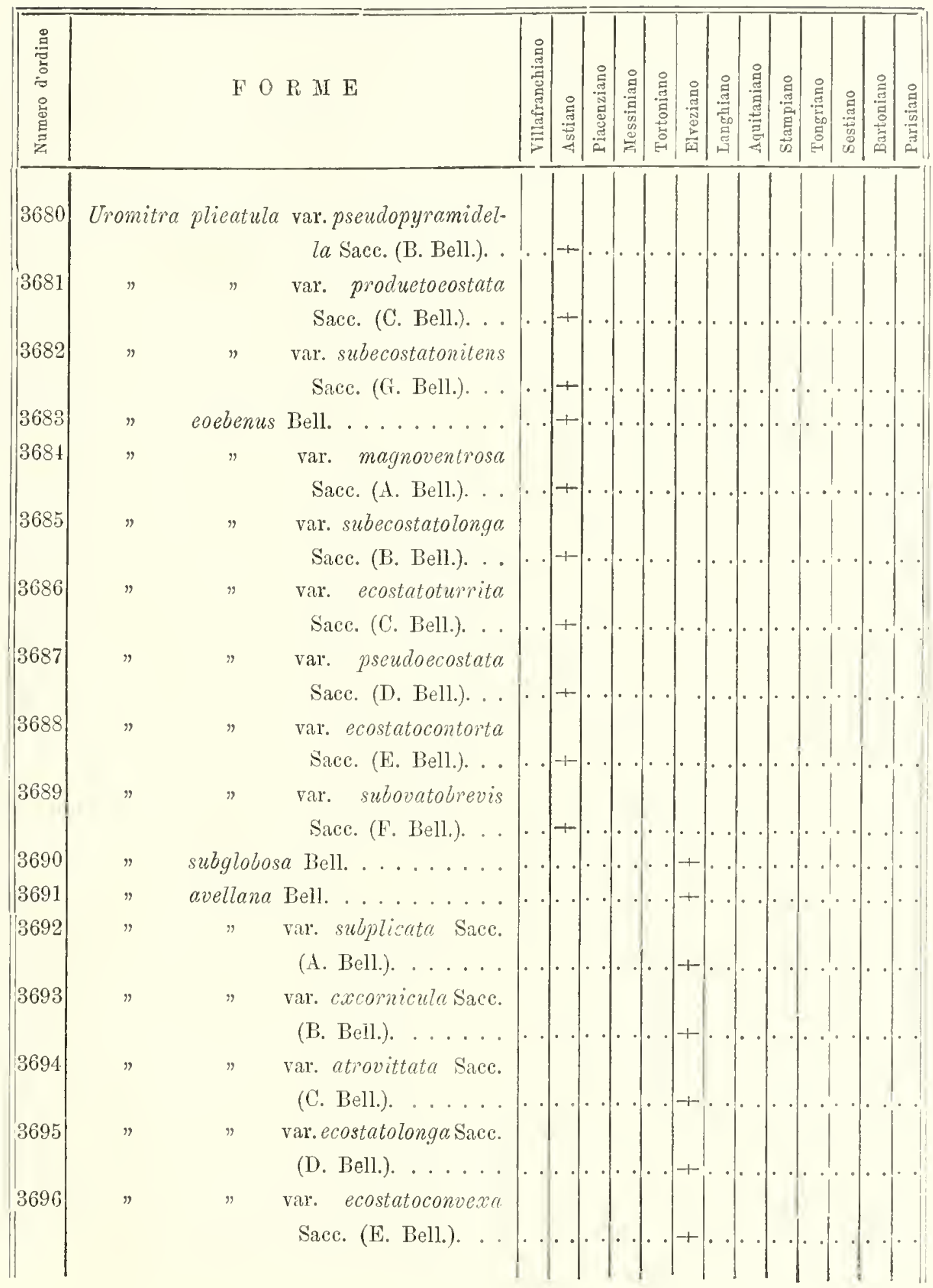




\begin{tabular}{|c|c|c|c|c|c|c|c|c|c|c|c|c|c|}
\hline 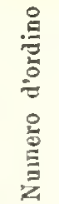 & F $O P$ P $M$ & 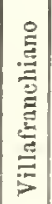 & . & 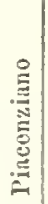 & 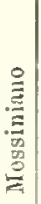 & | & 莺 & 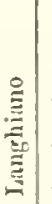 & 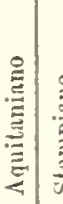 & 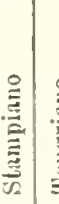 & 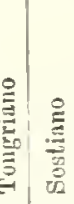 & & 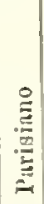 \\
\hline
\end{tabular}

3697 Uromitra avellana var. subturritovittata Sacc. (F. Bell.). ... . .........+

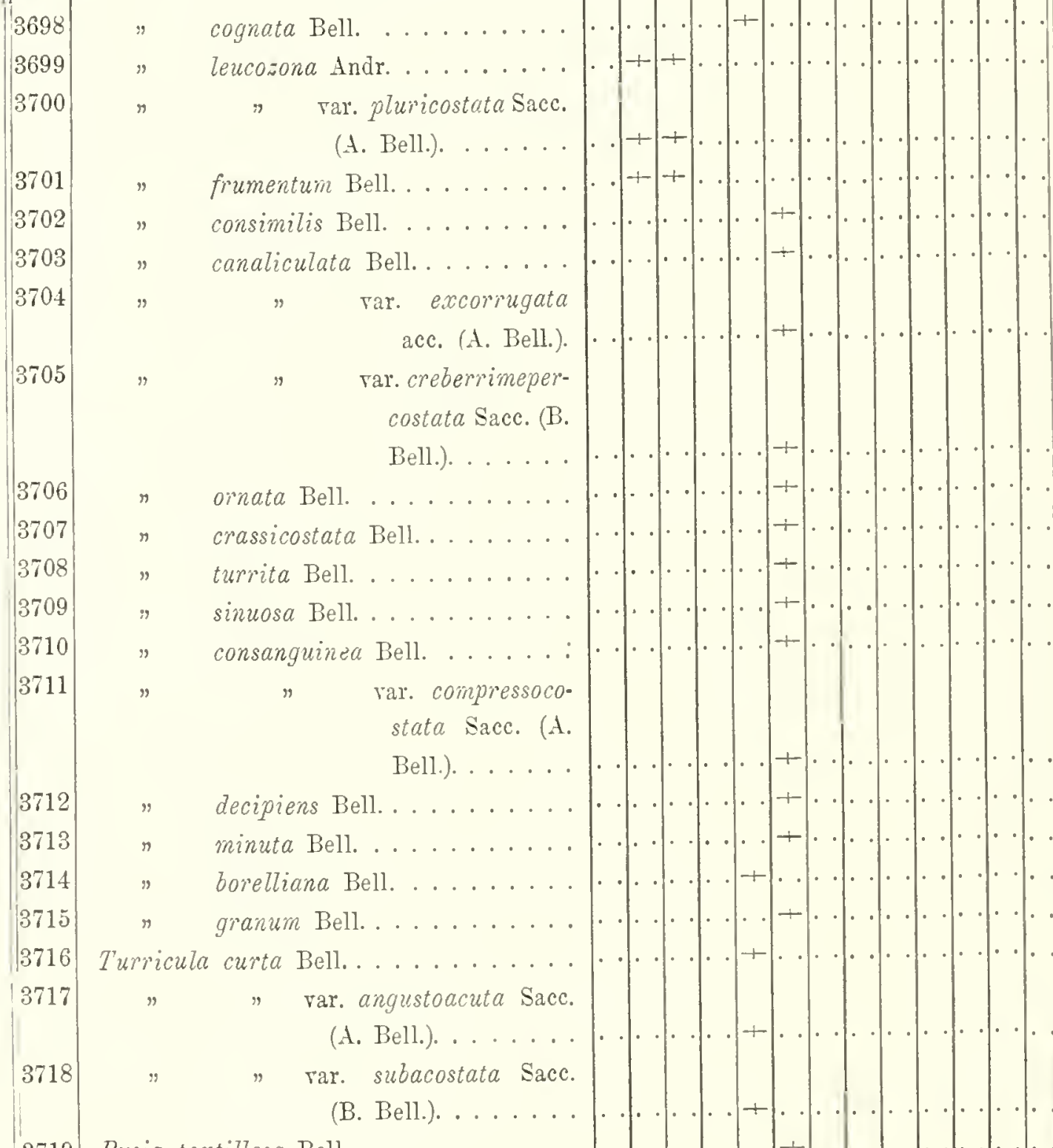




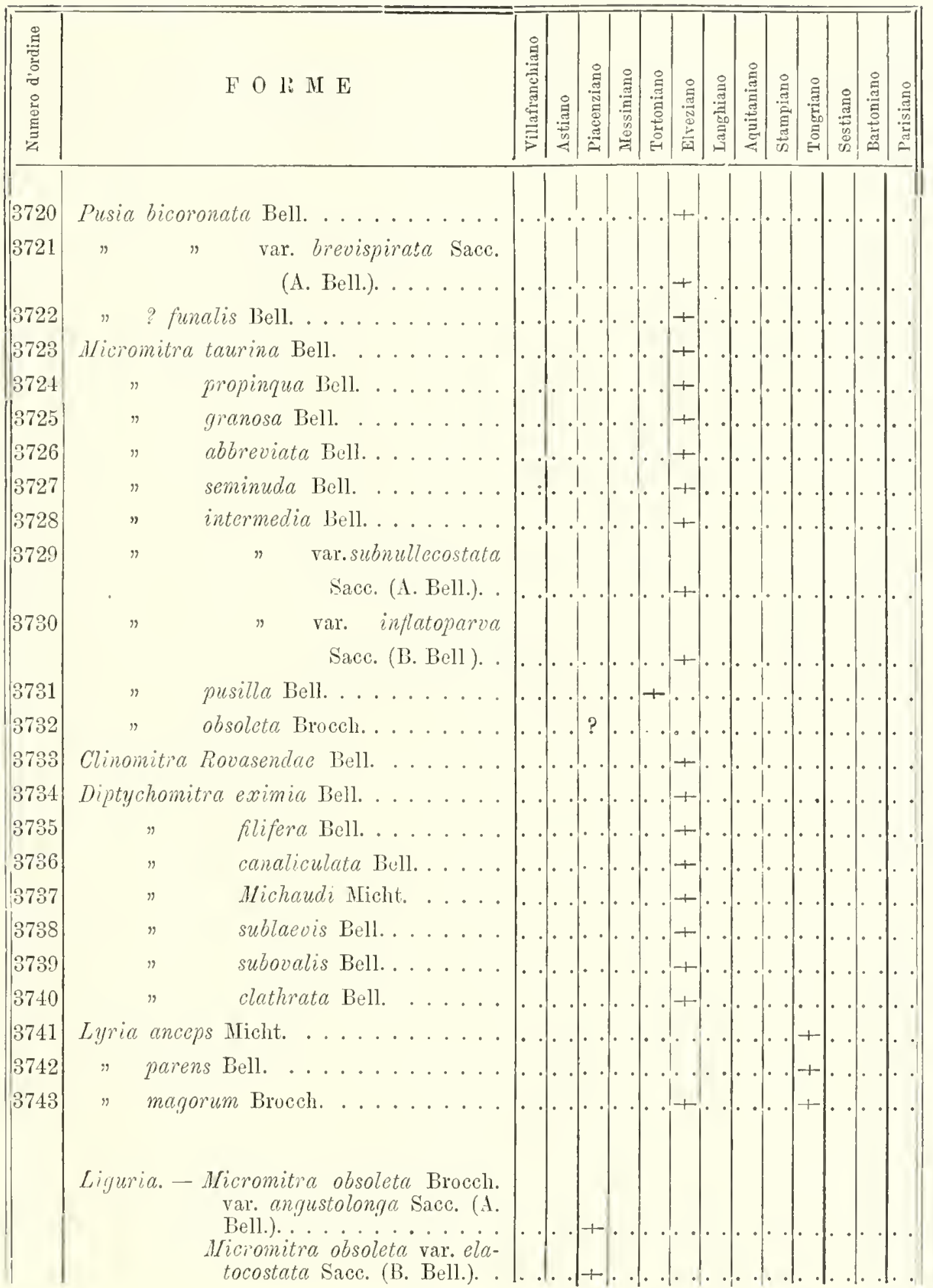




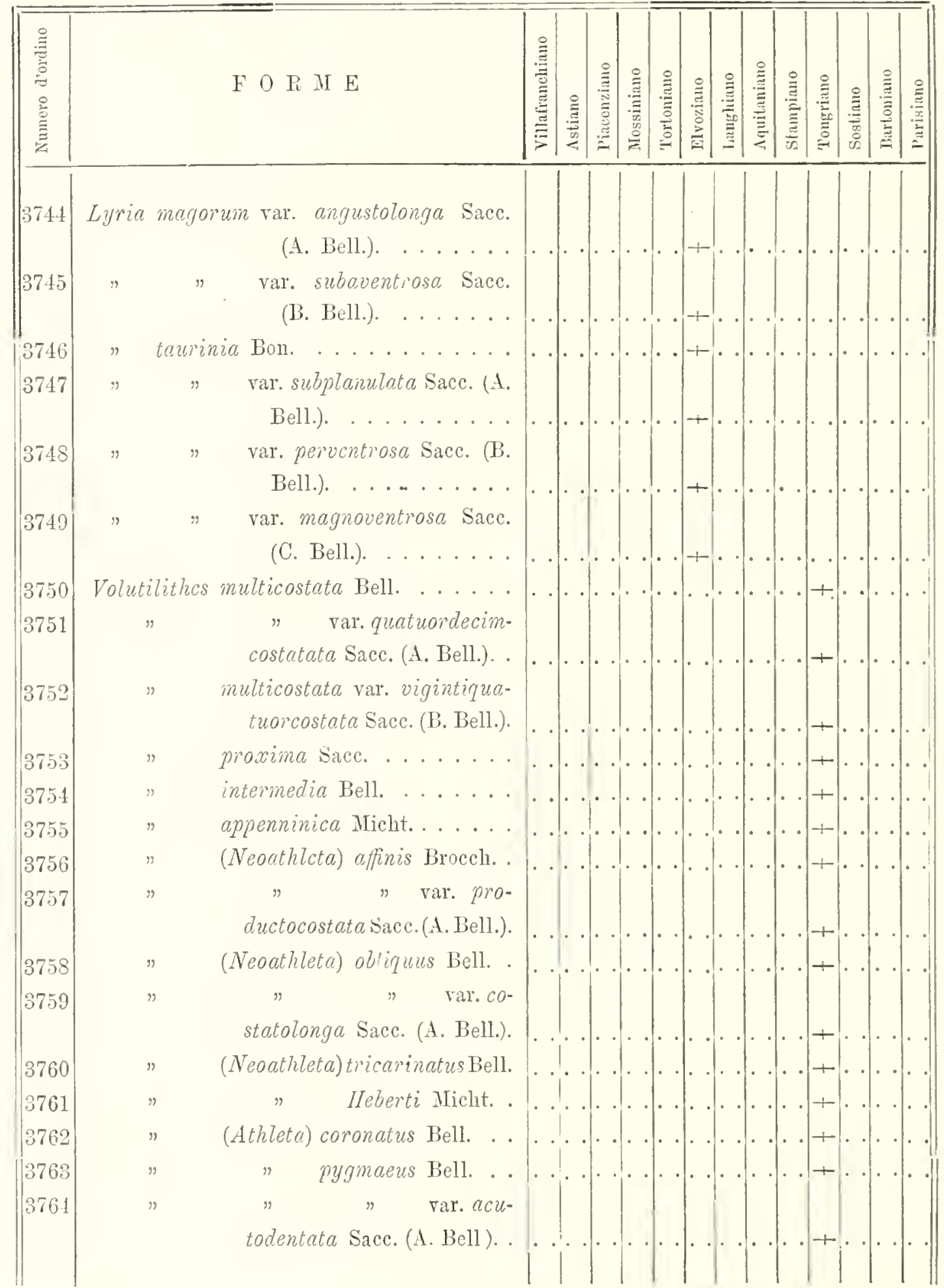




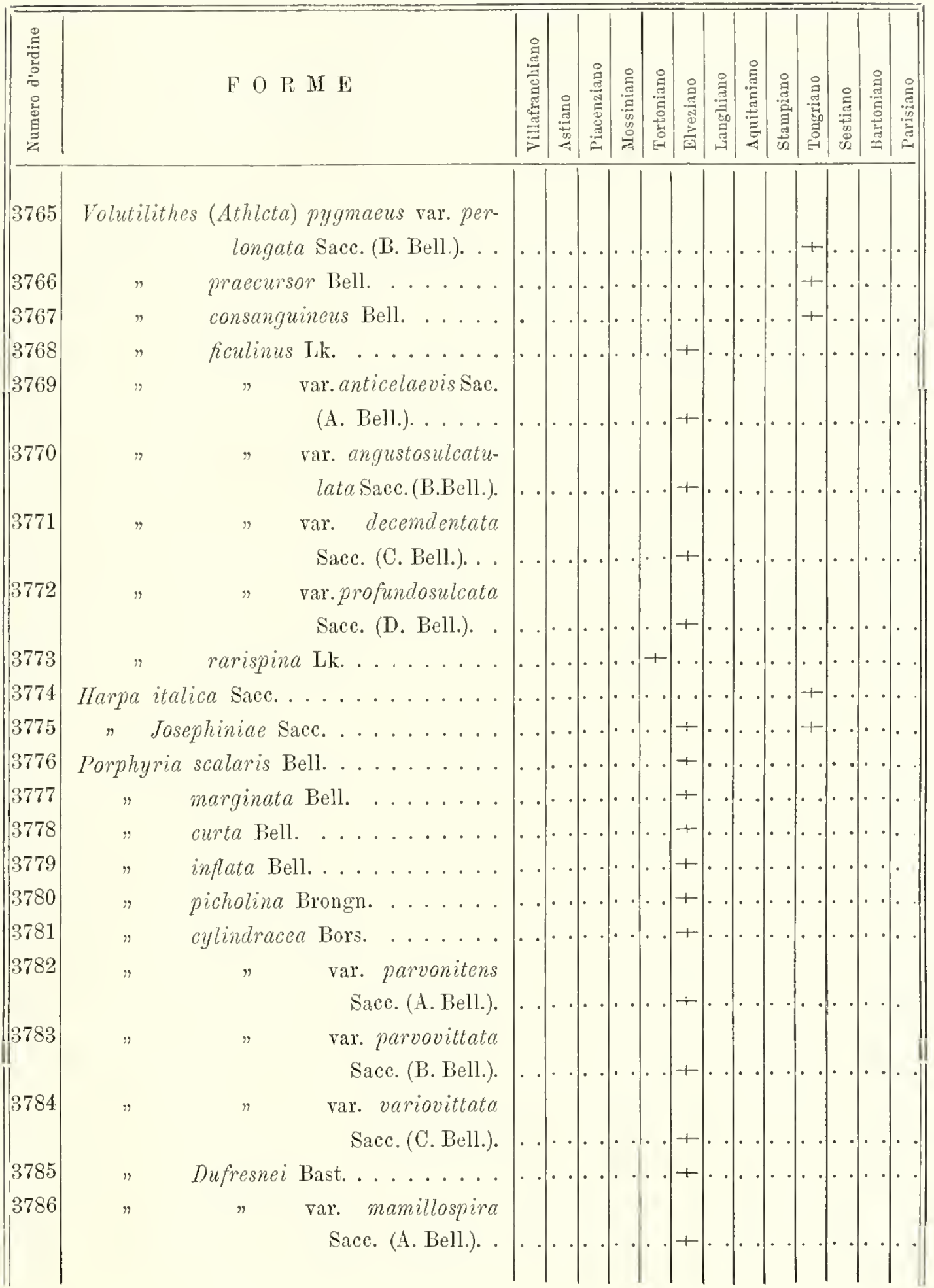




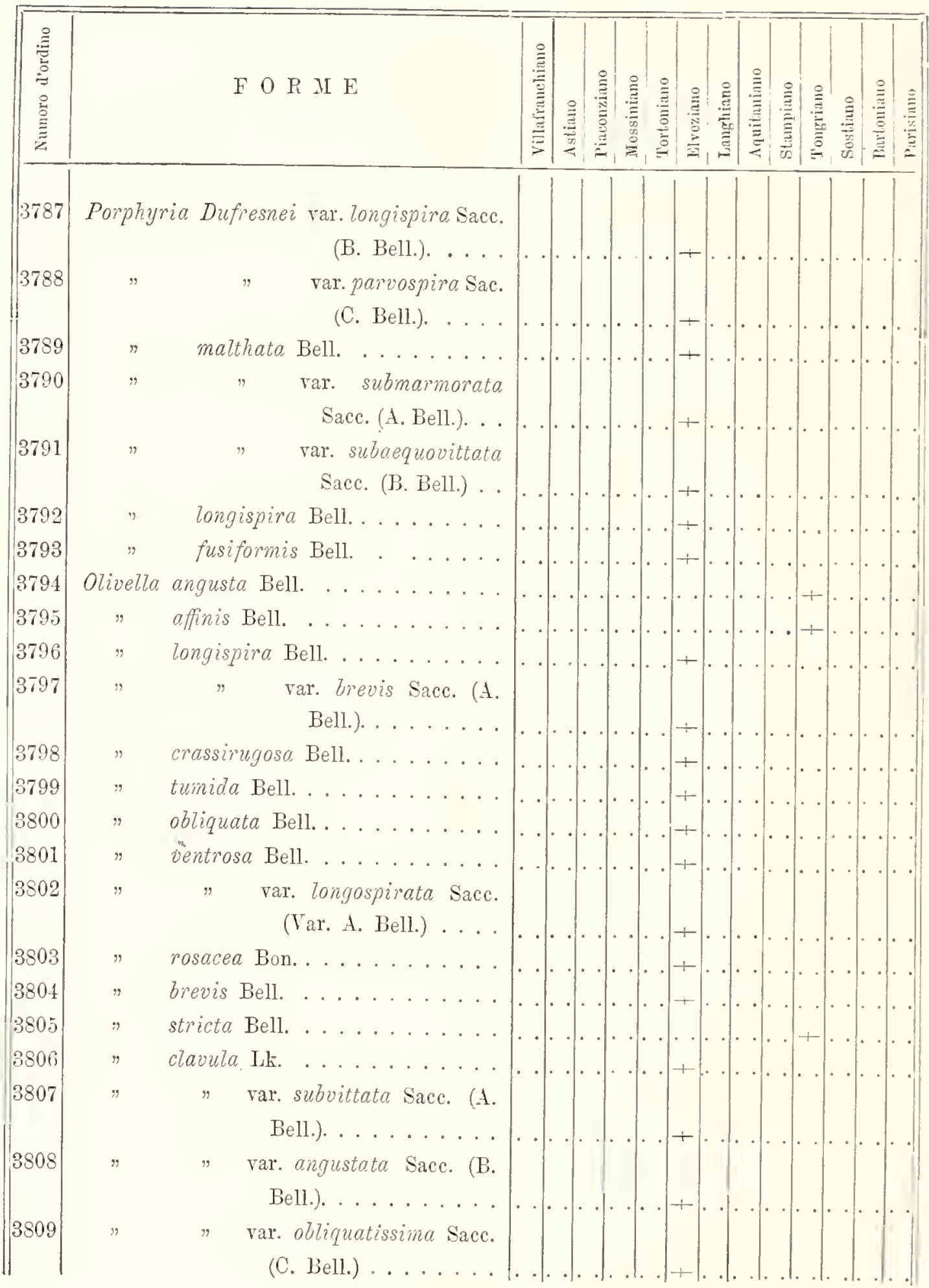




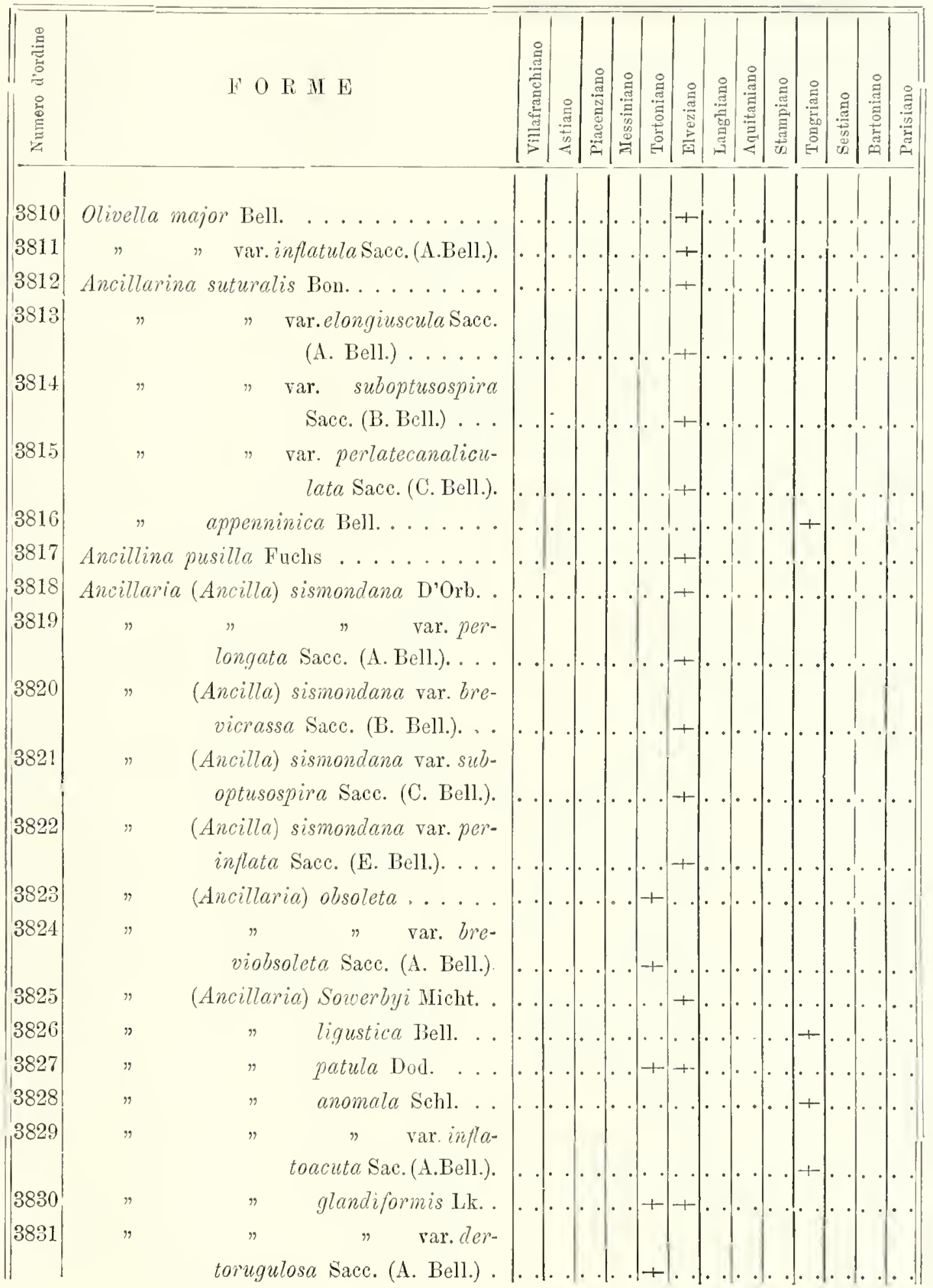




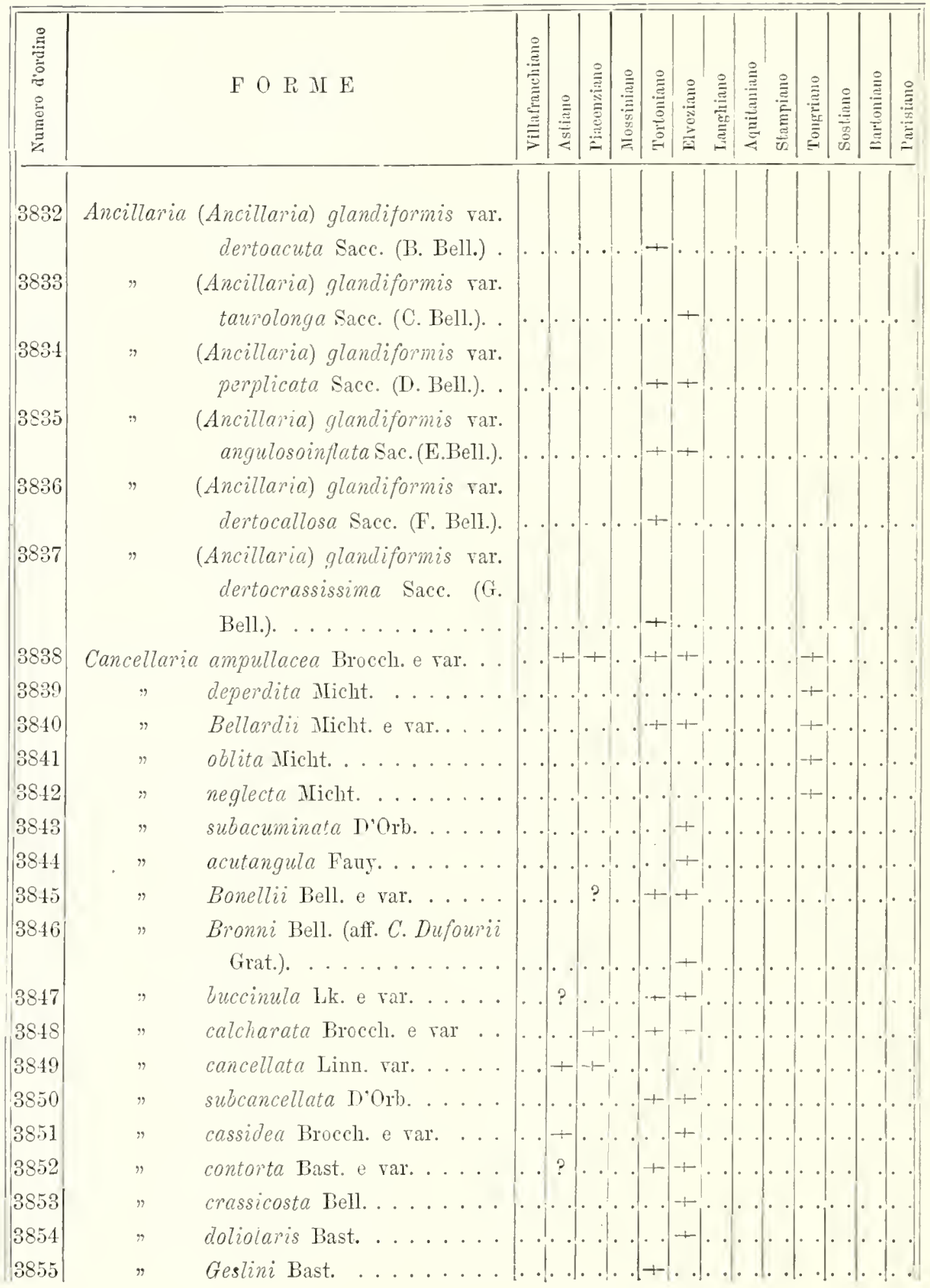




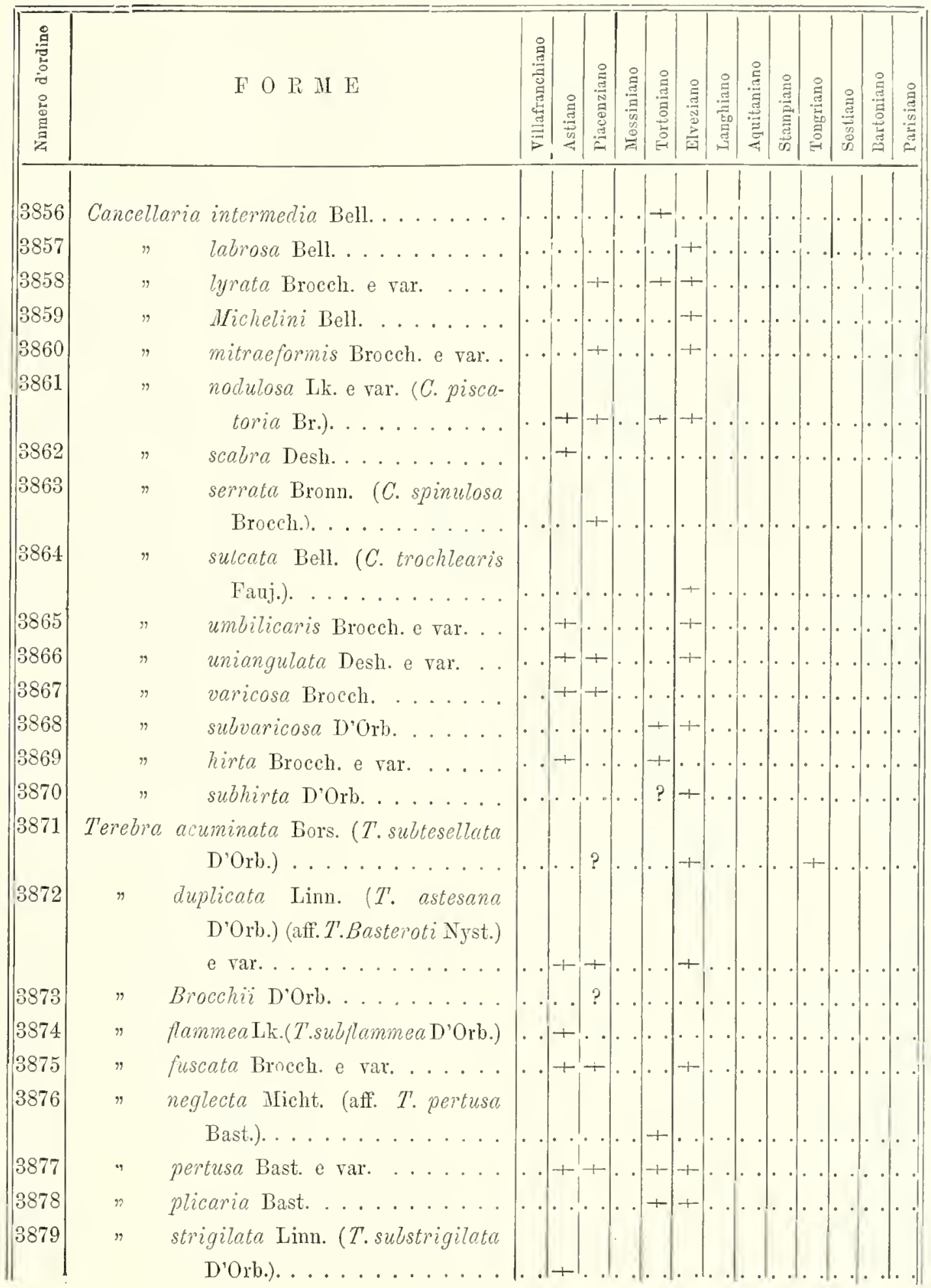




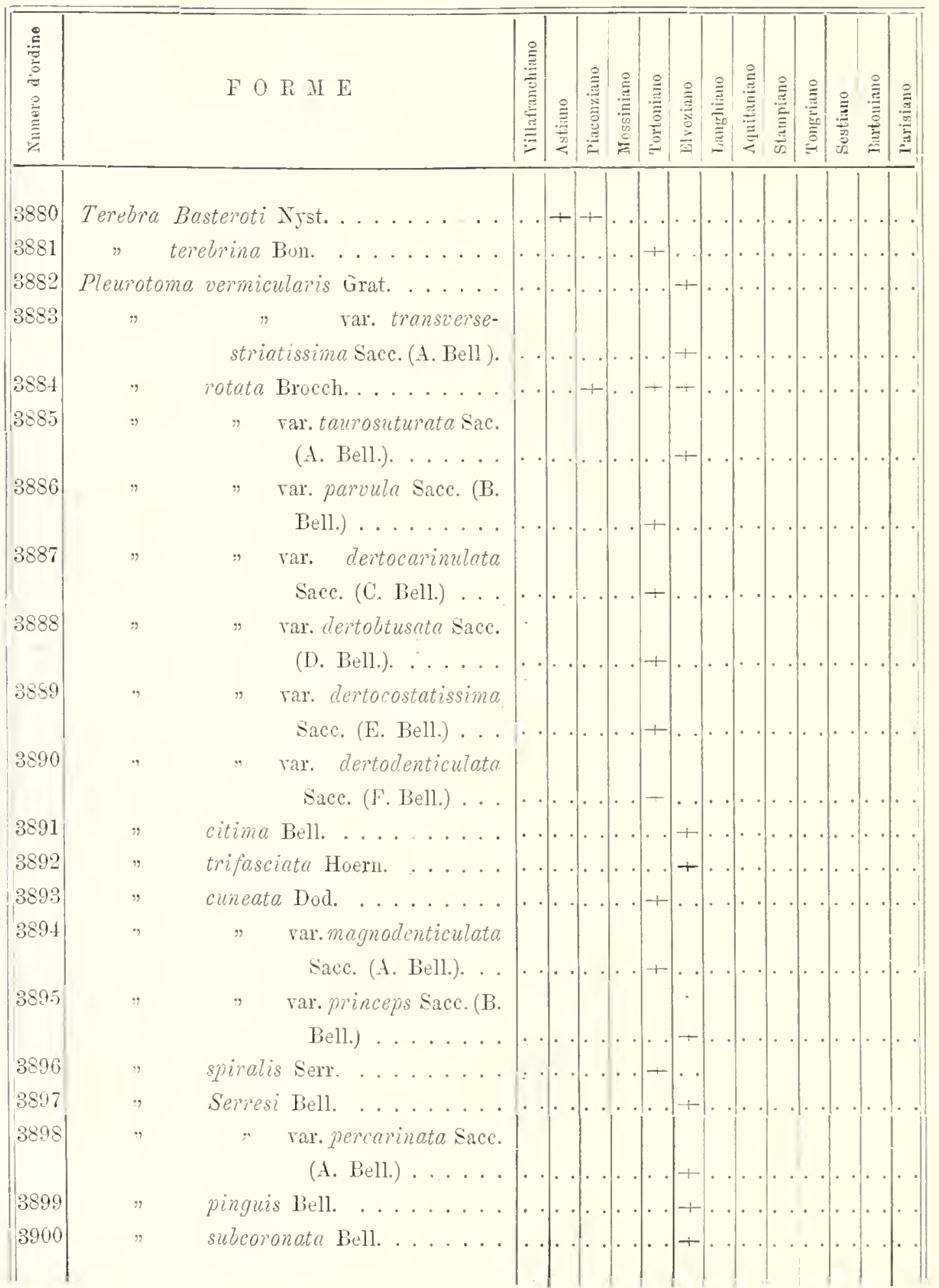




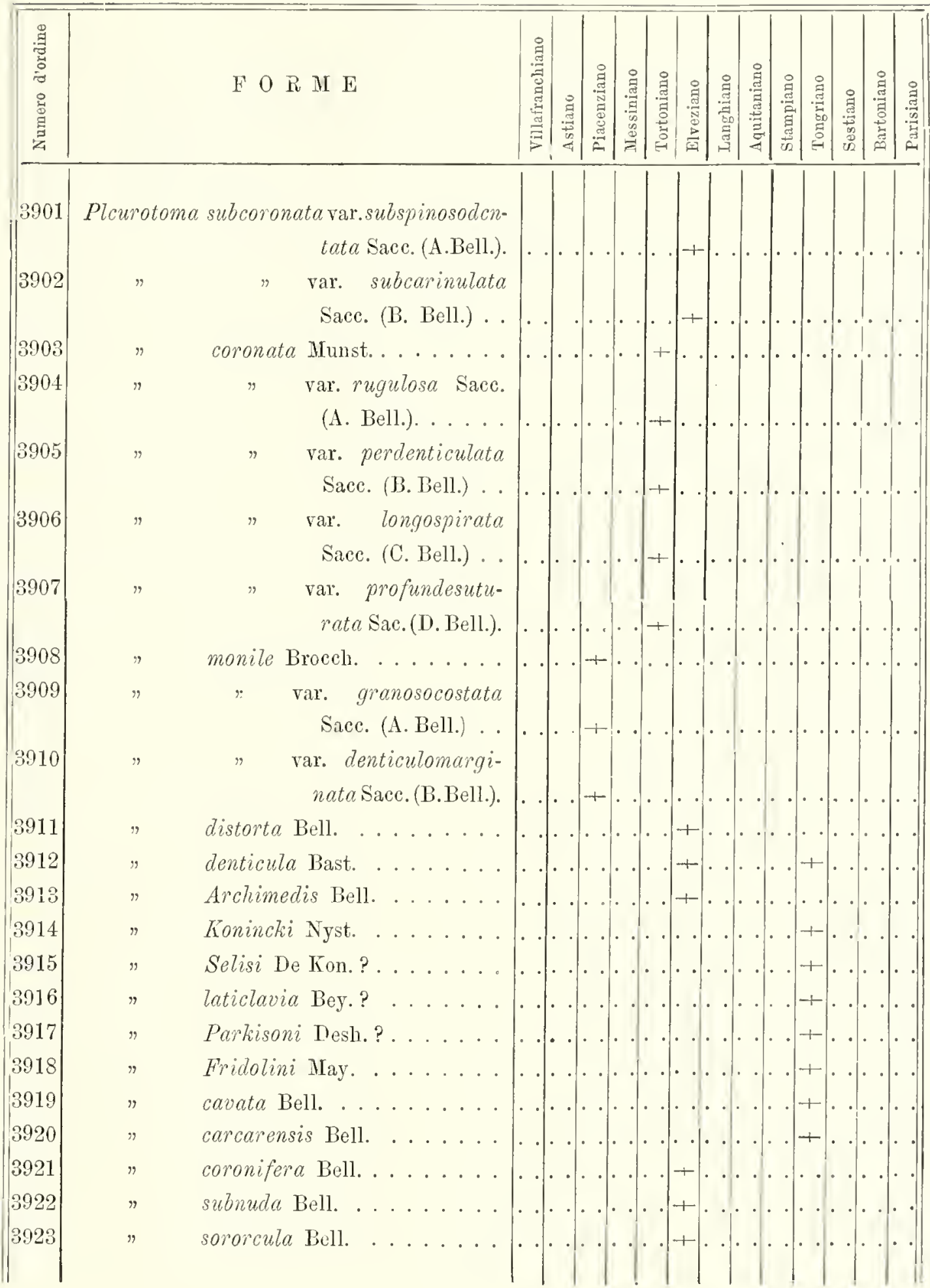




\begin{tabular}{|c|c|c|c|c|c|c|c|c|c|c|c|c|c|c|}
\hline 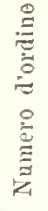 & $\mathrm{F} O \mathrm{P} \mathrm{M} \mathrm{E}$ & 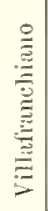 & 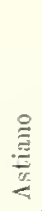 & 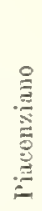 & 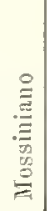 & 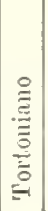 & 号 & 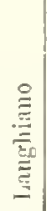 & 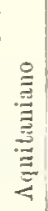 & $\mid \frac{0}{.}$ & 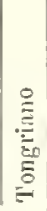 & 总 & 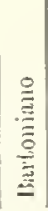 & | \\
\hline
\end{tabular}

3924 Pleurotoma sororcula rar. longoconcava

Sace. (A. Bell ).

$$
3
$$


Catalogo paleontologico del bacino teraiario del Picmontc

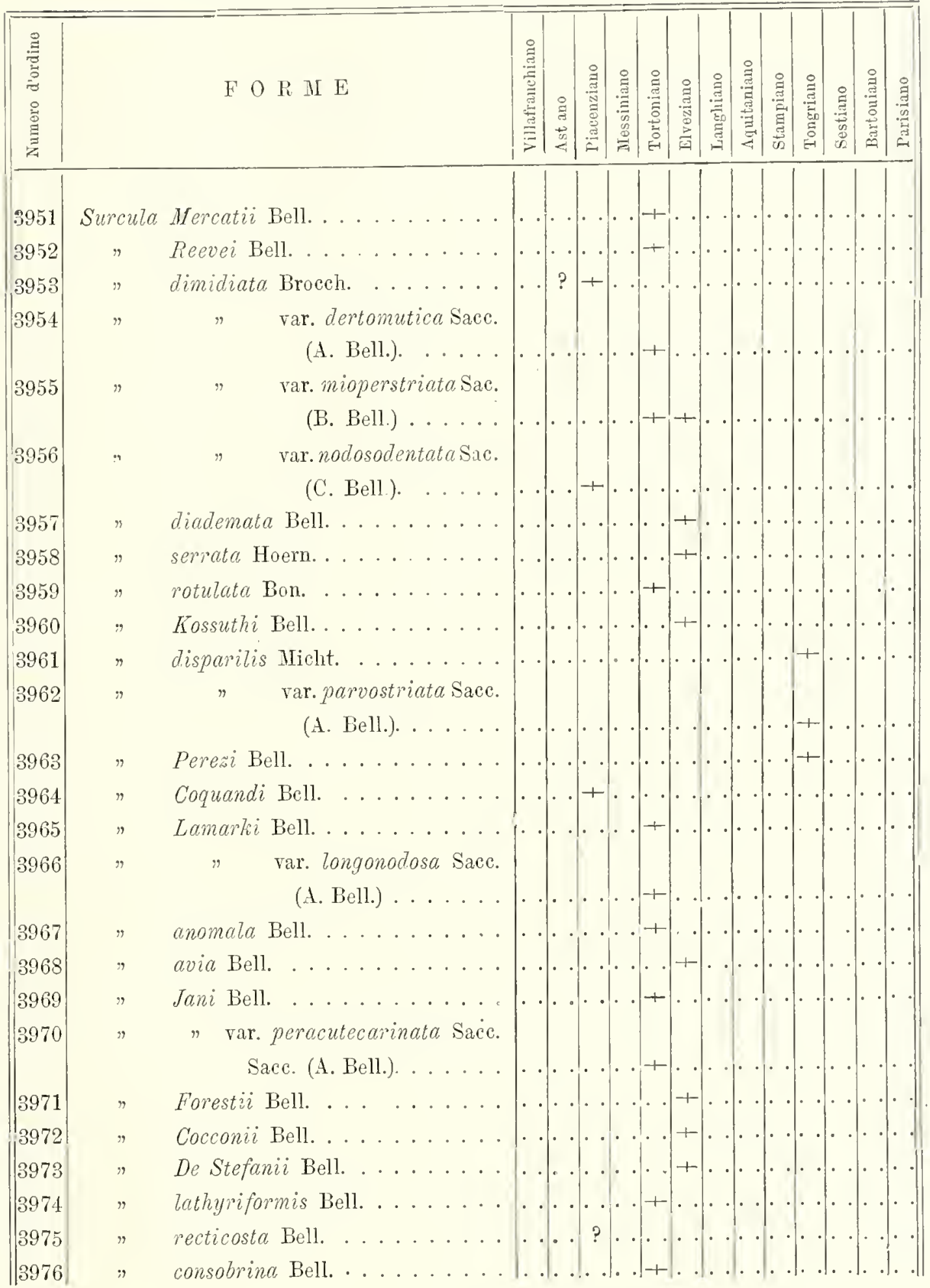




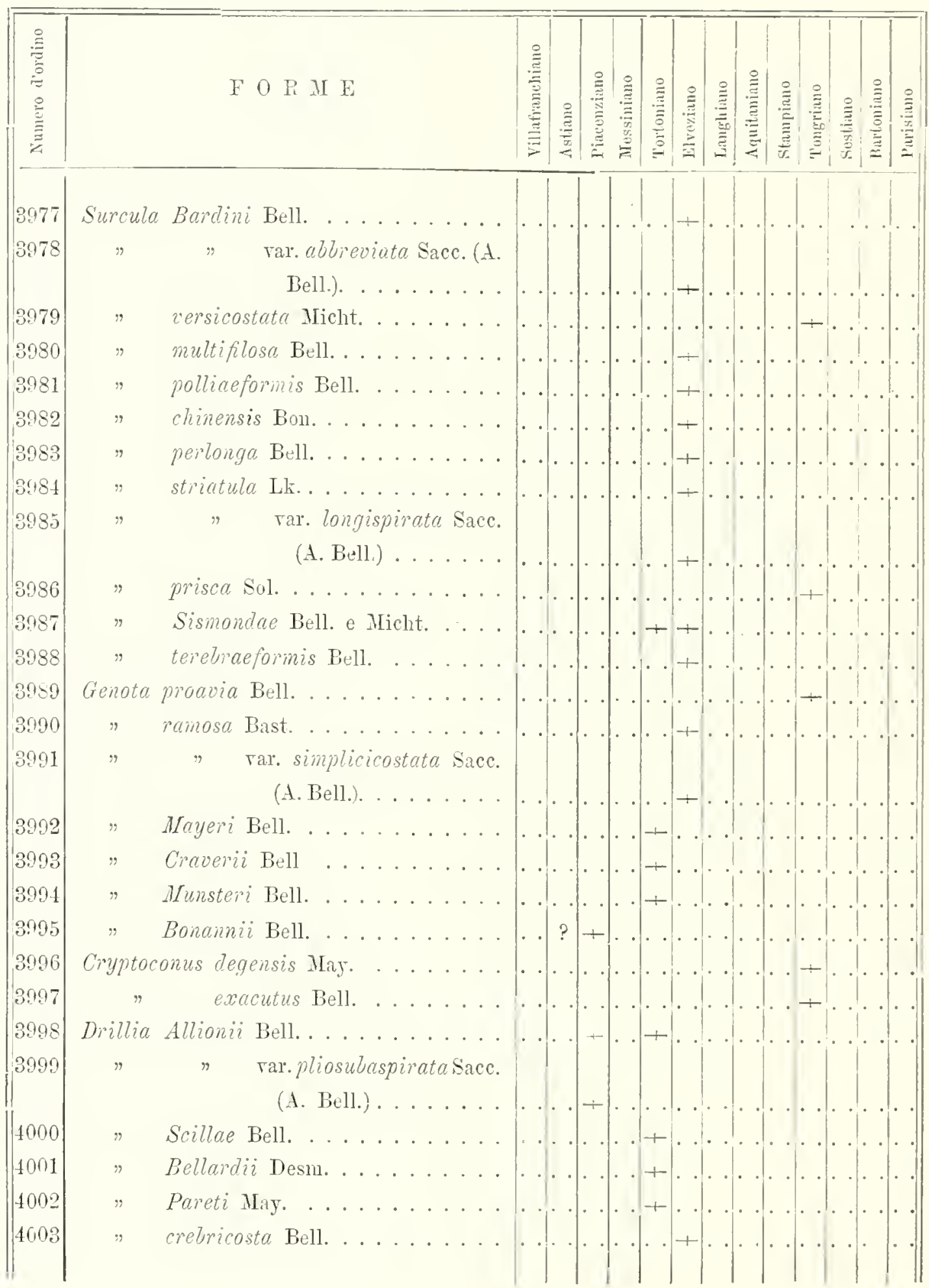




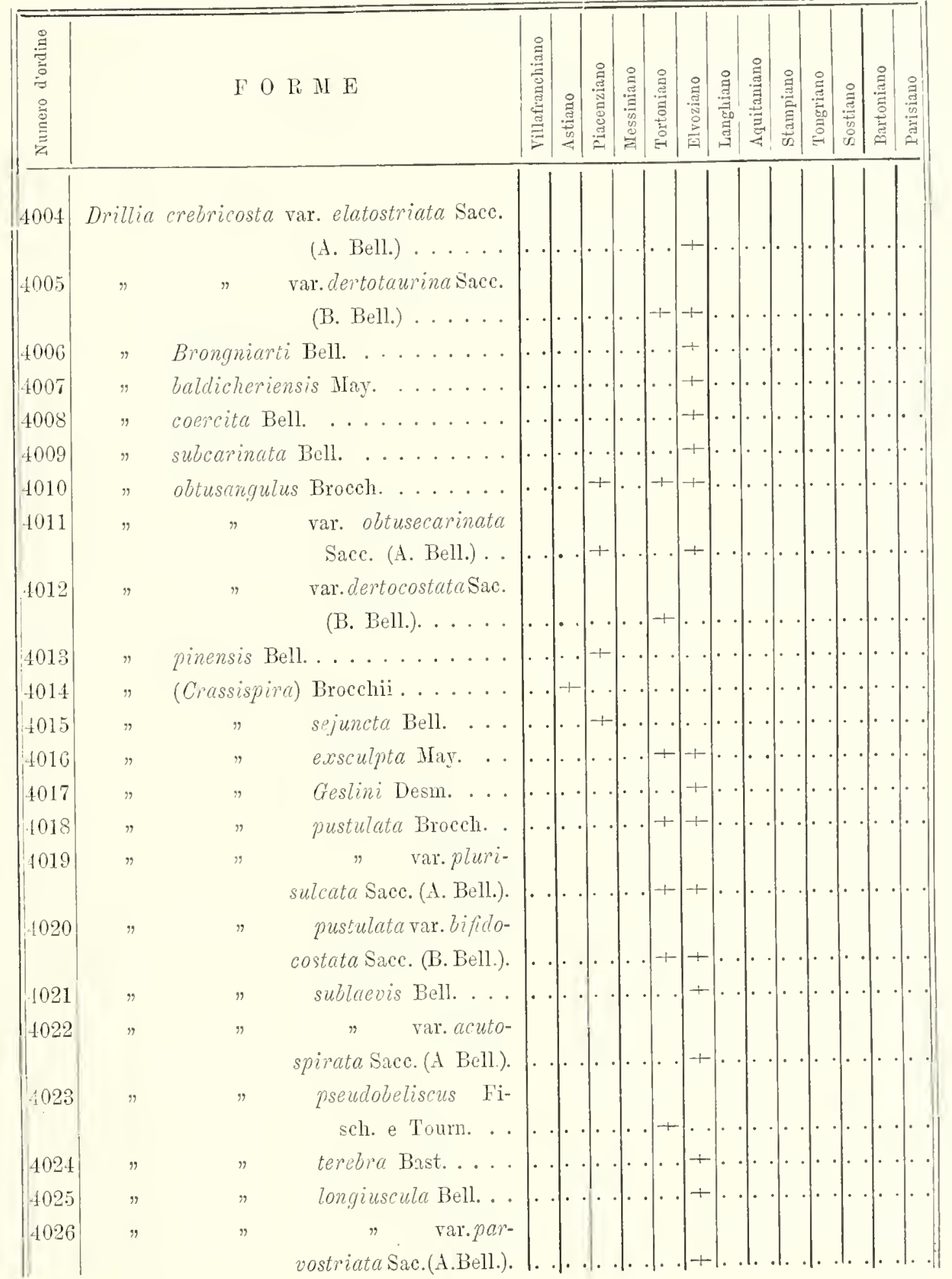




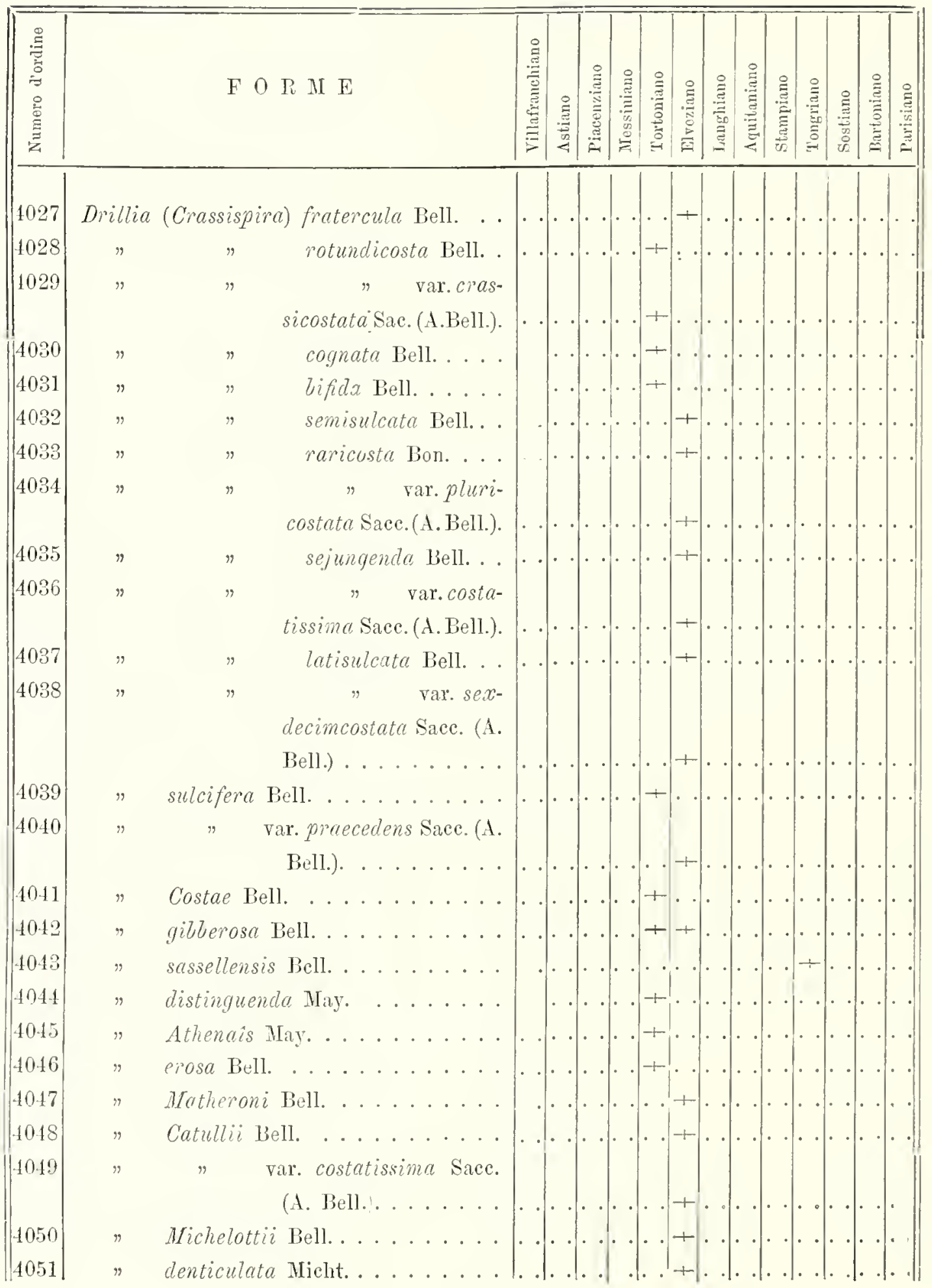




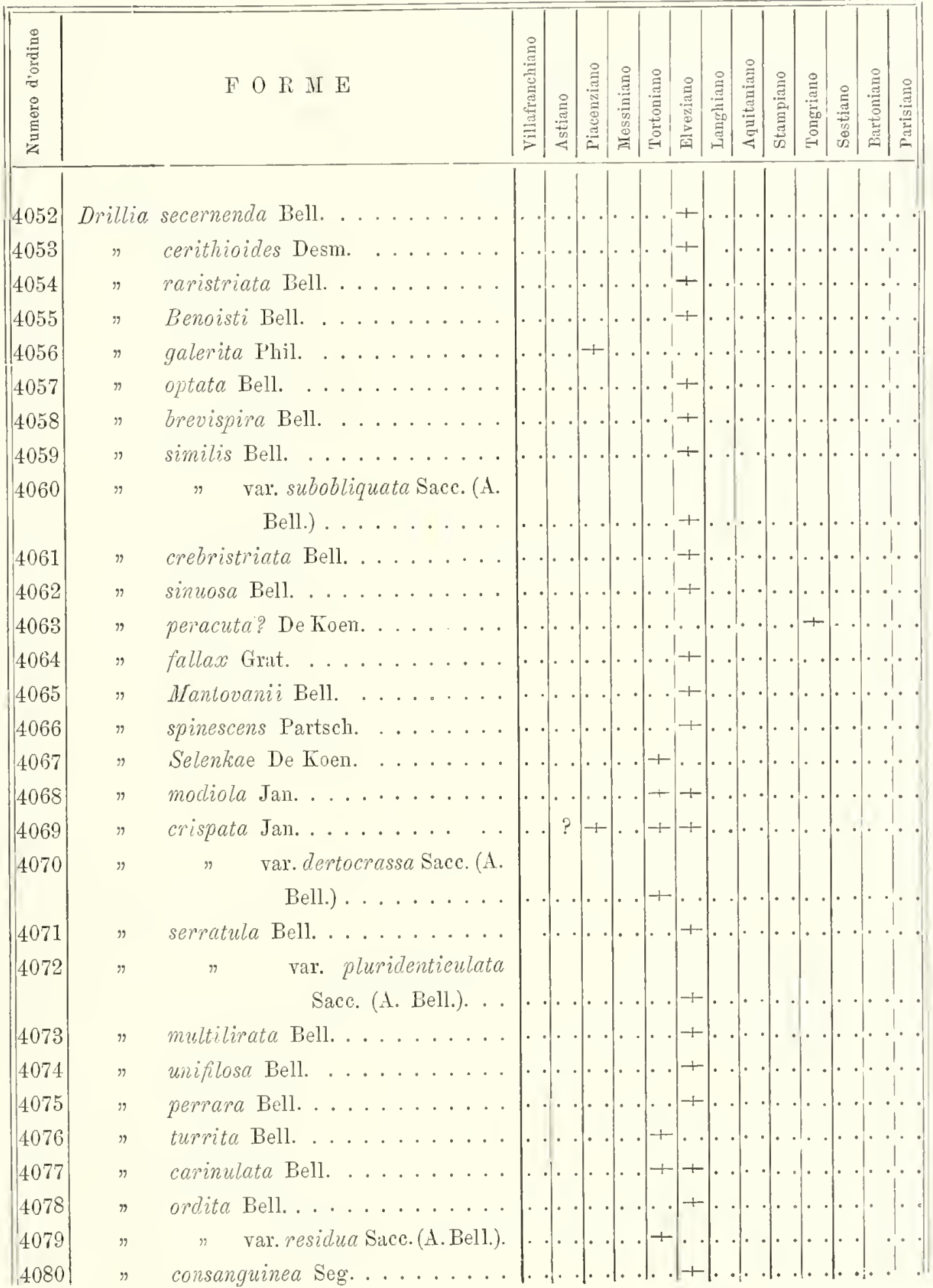




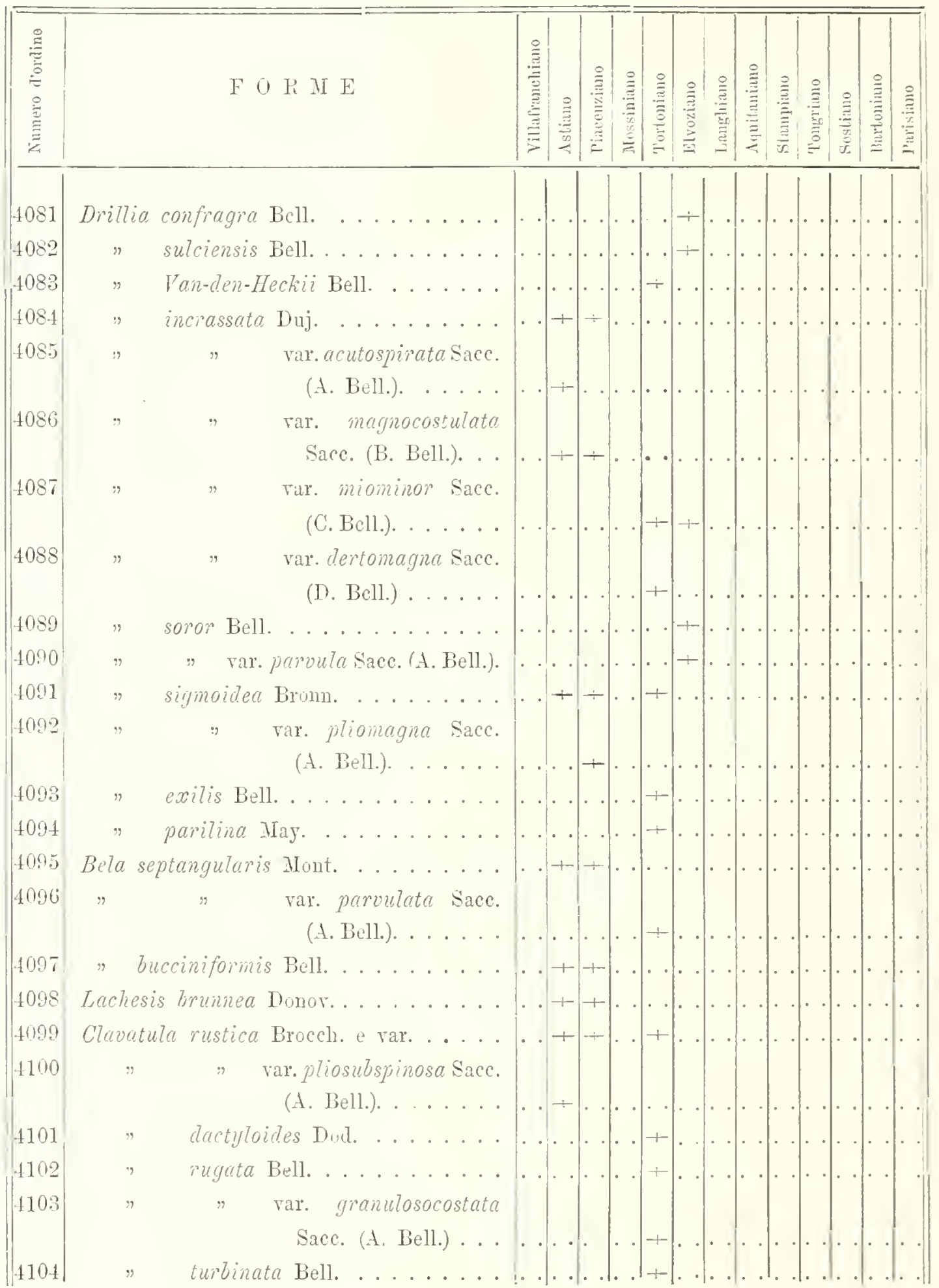




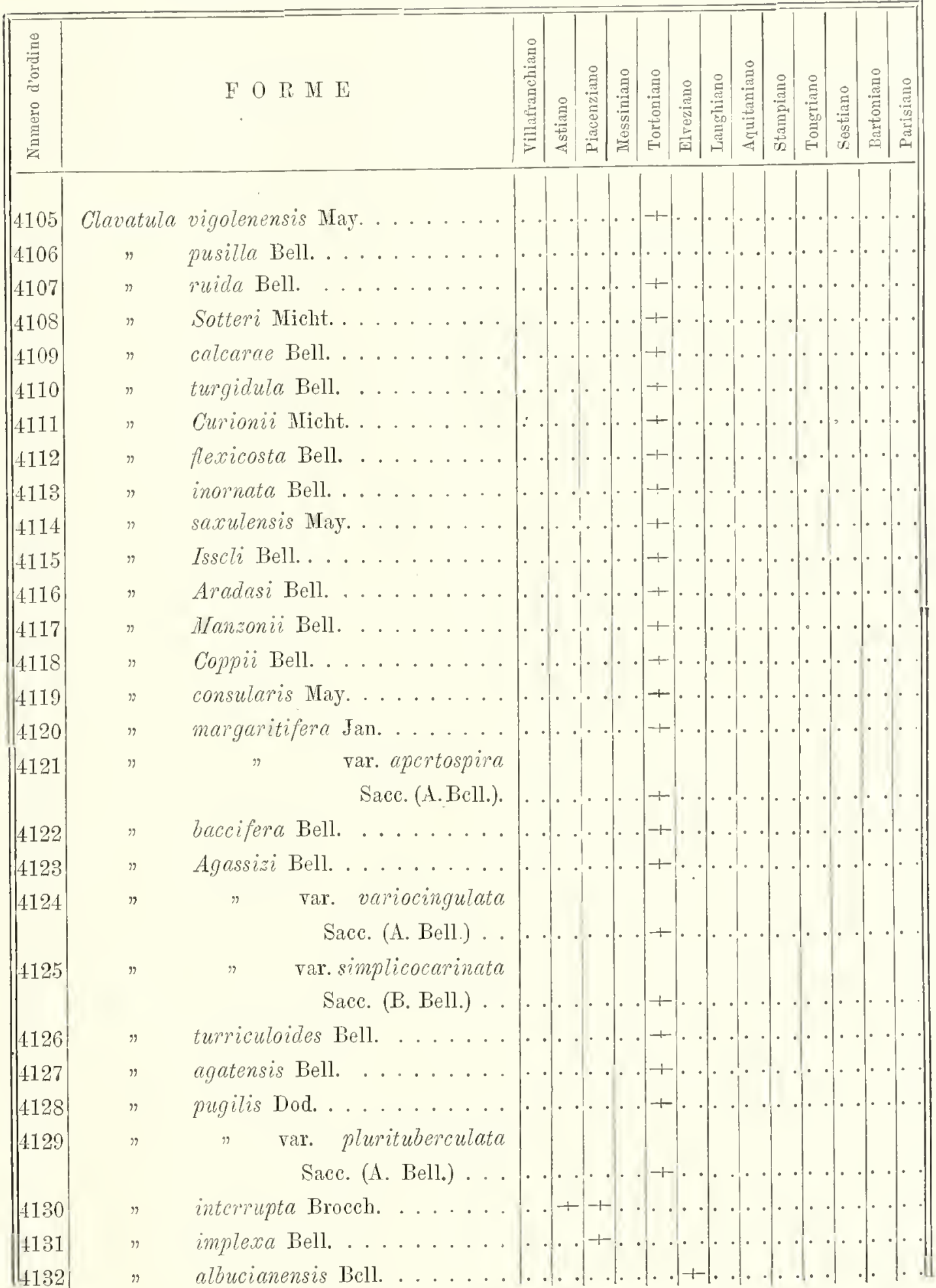




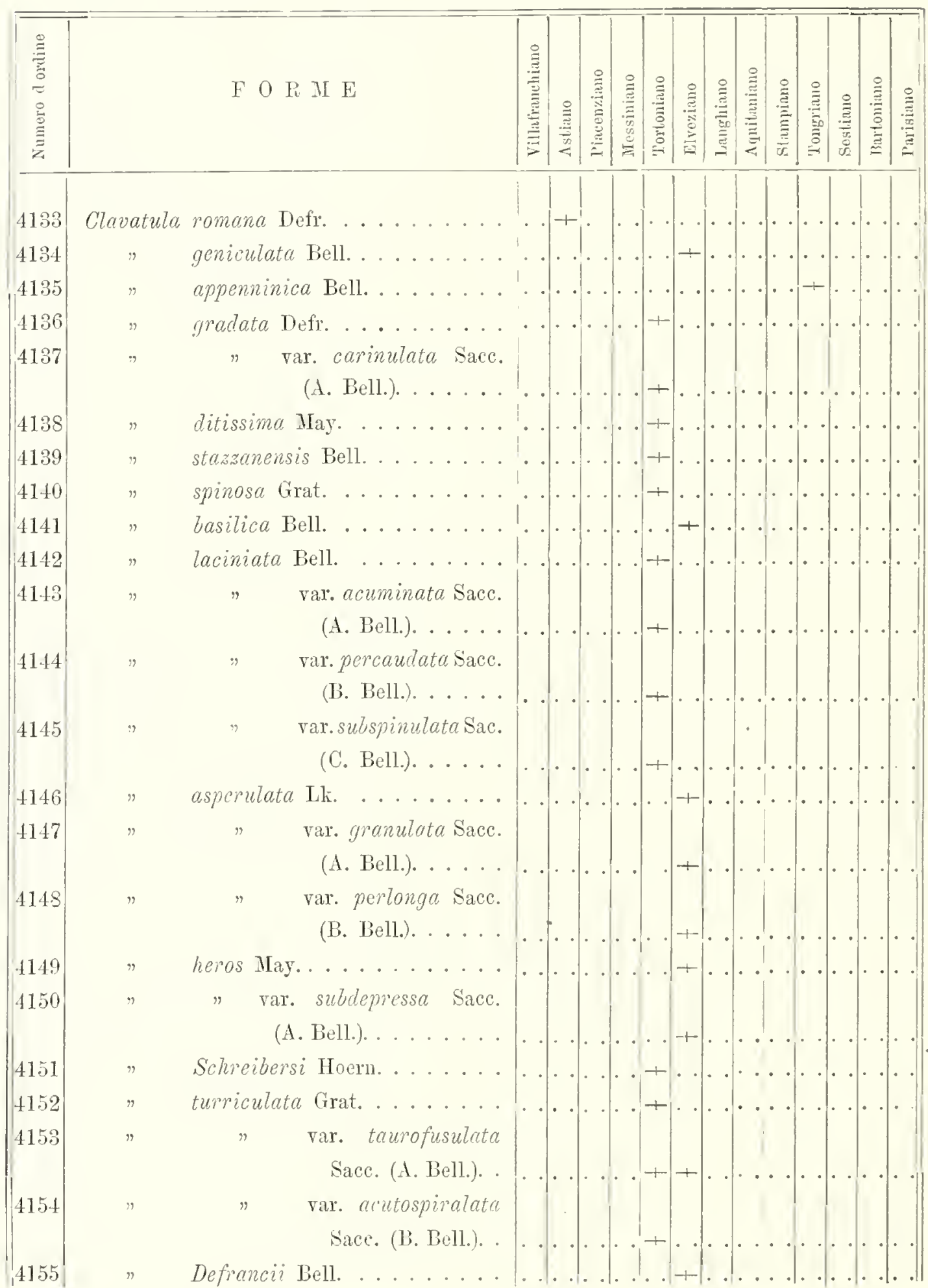




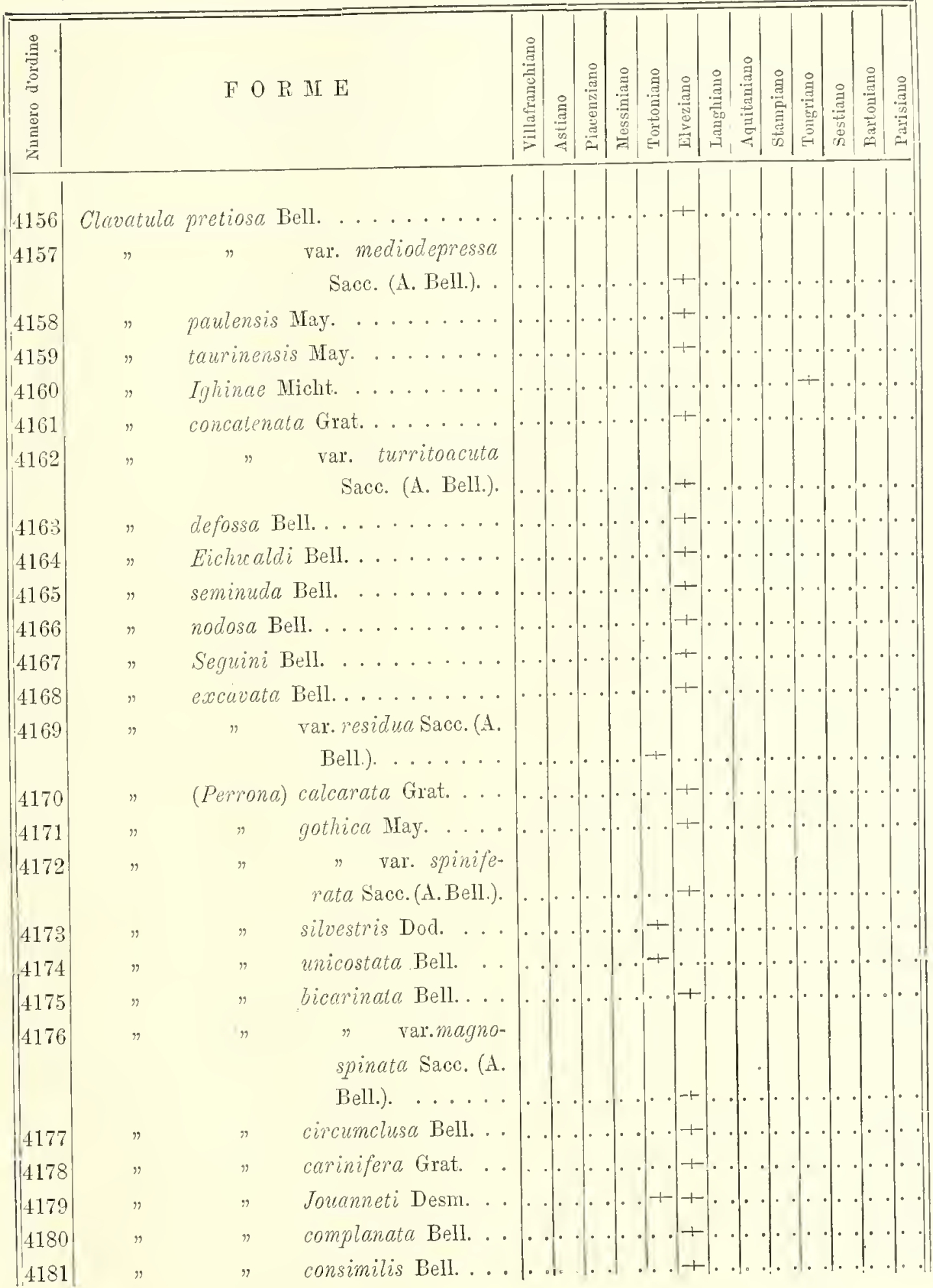




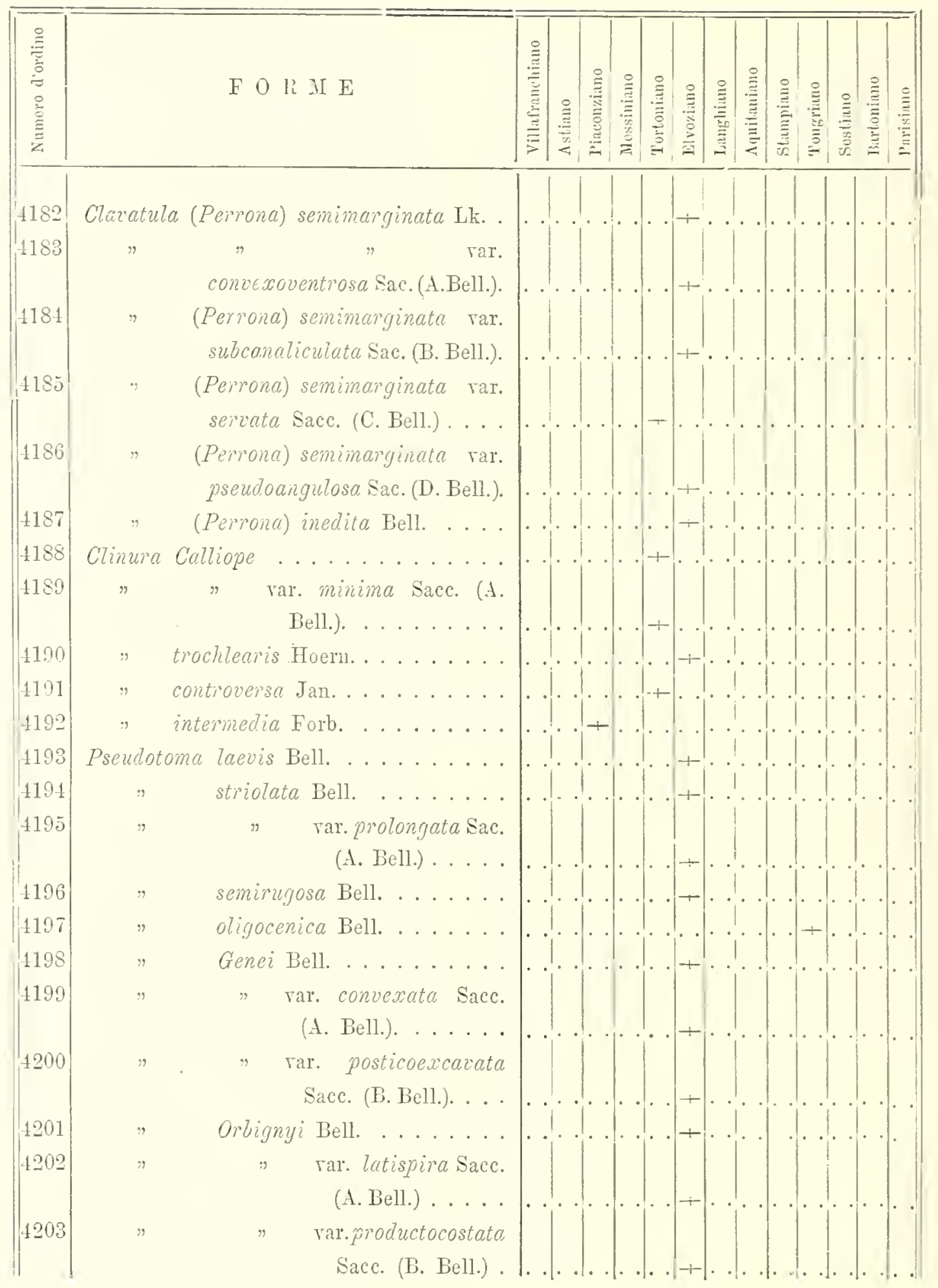




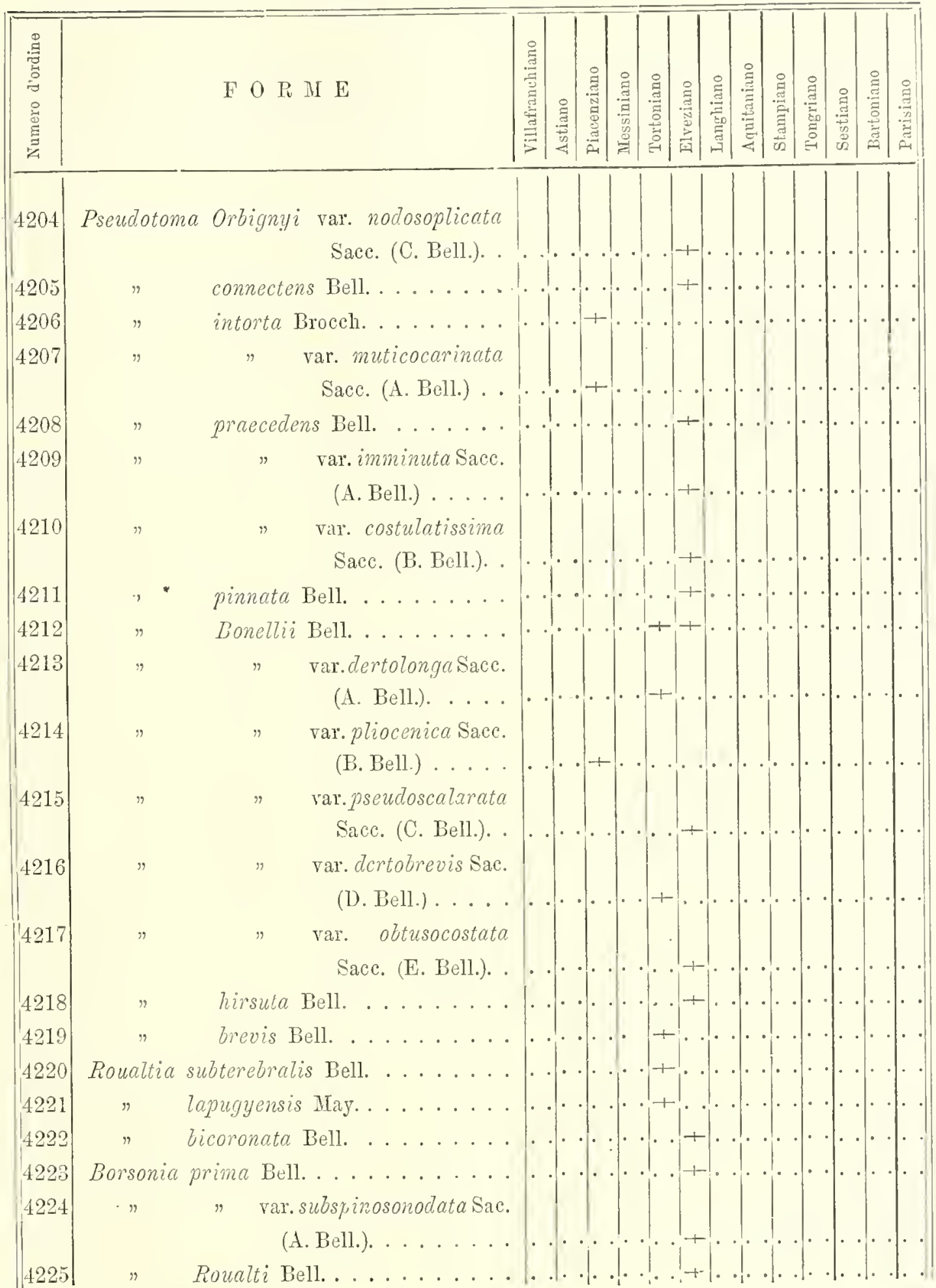




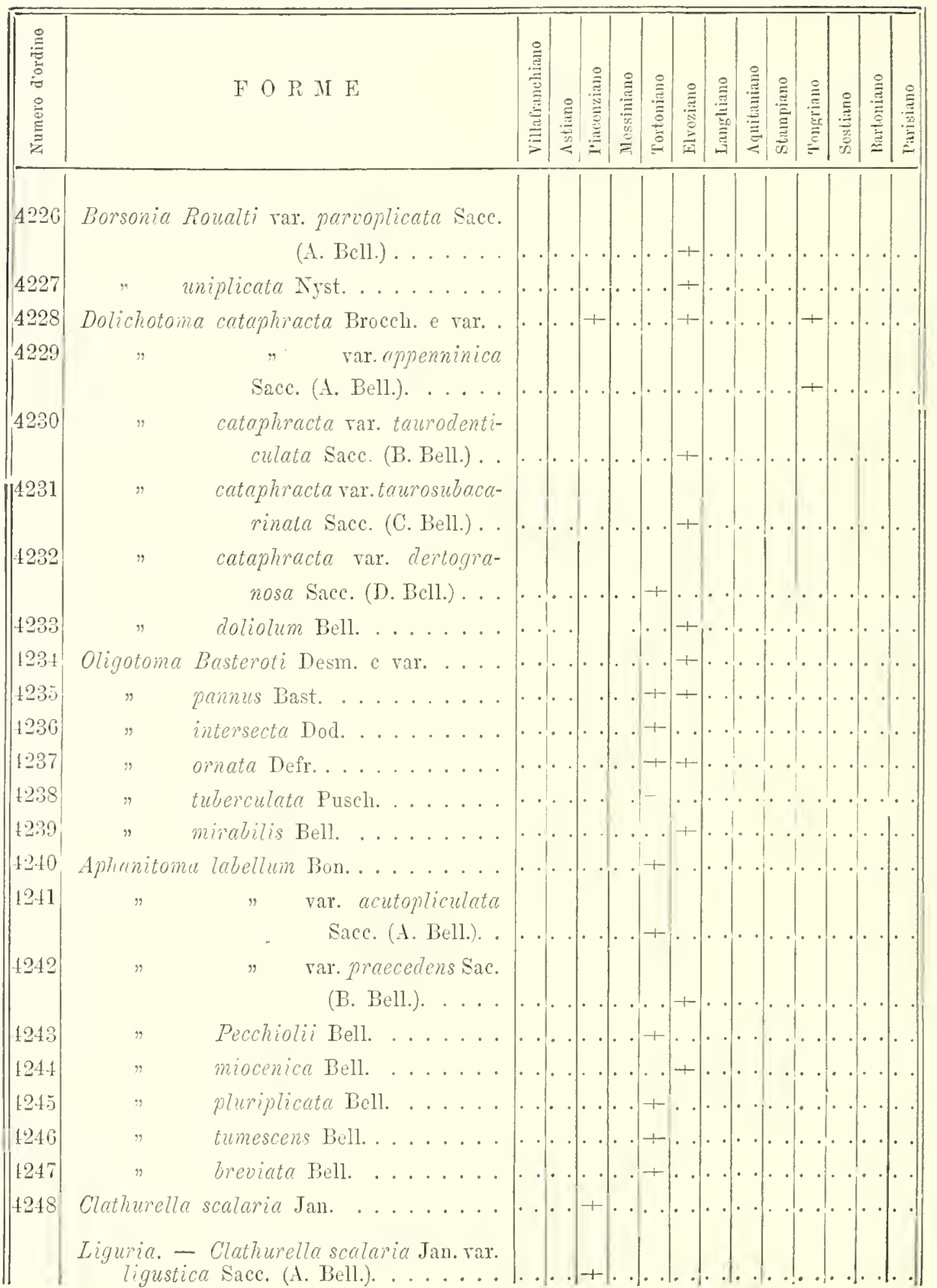


Catalogo paleontologico del Zacino terziario del Piemonte

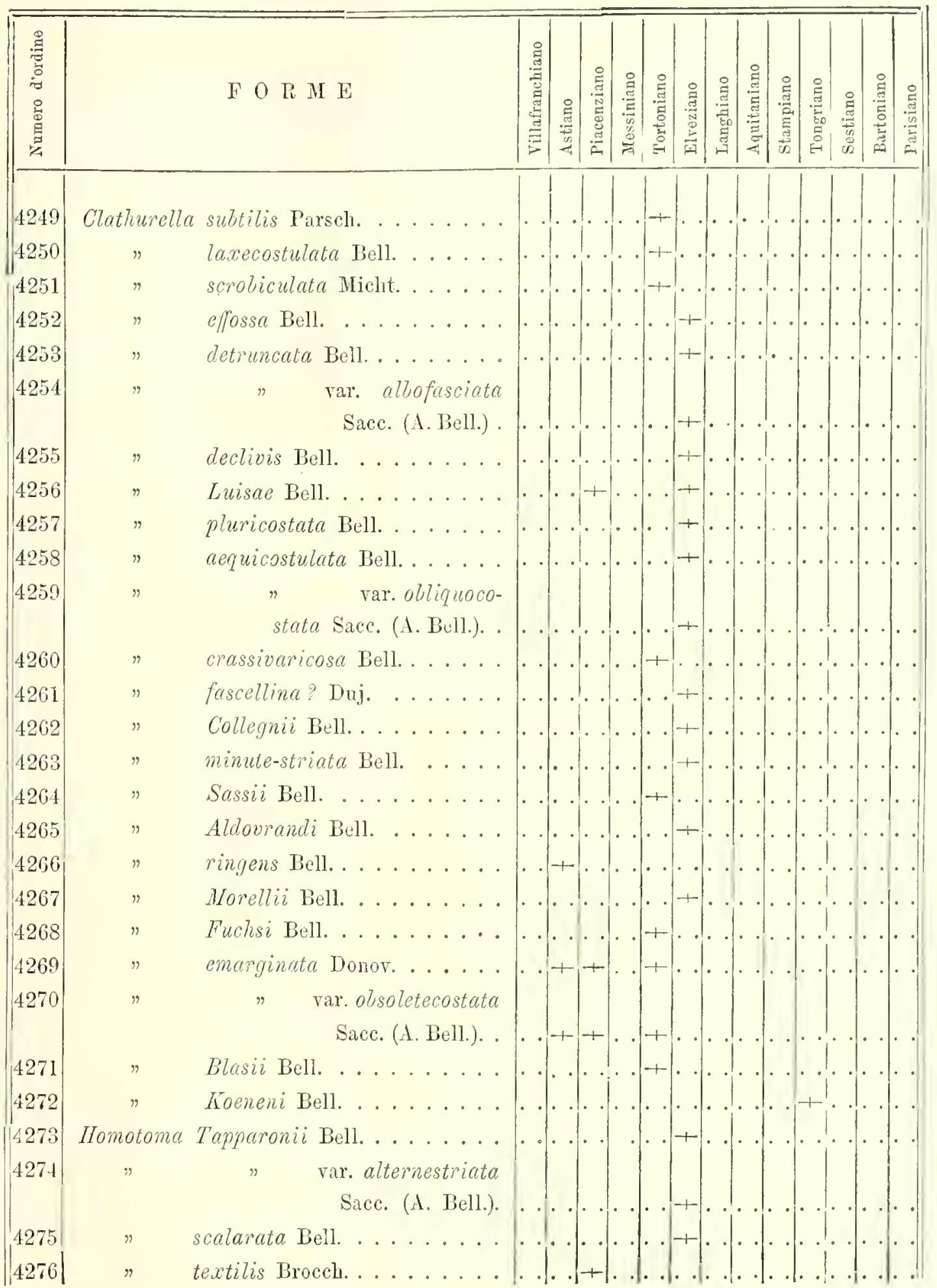




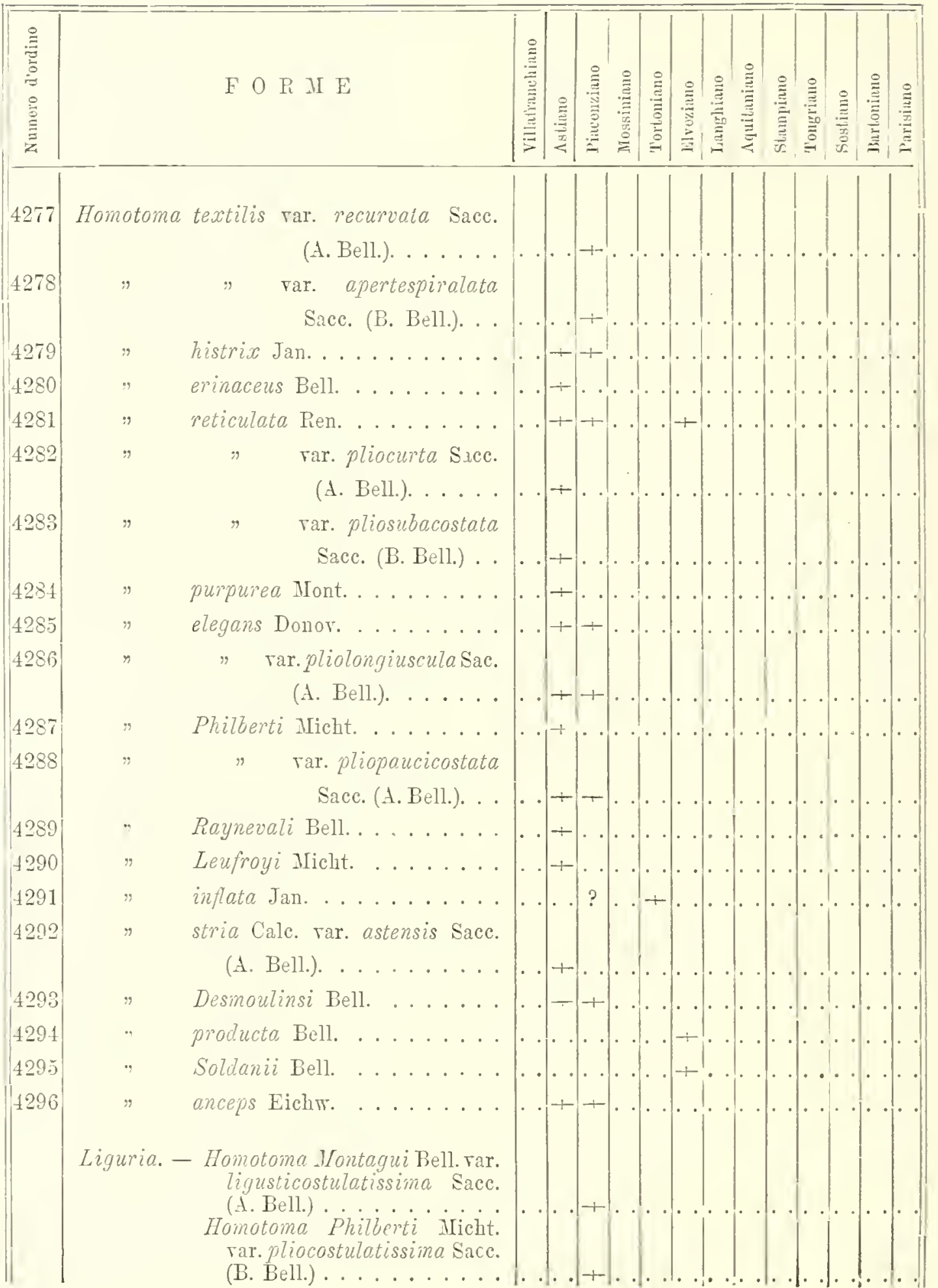




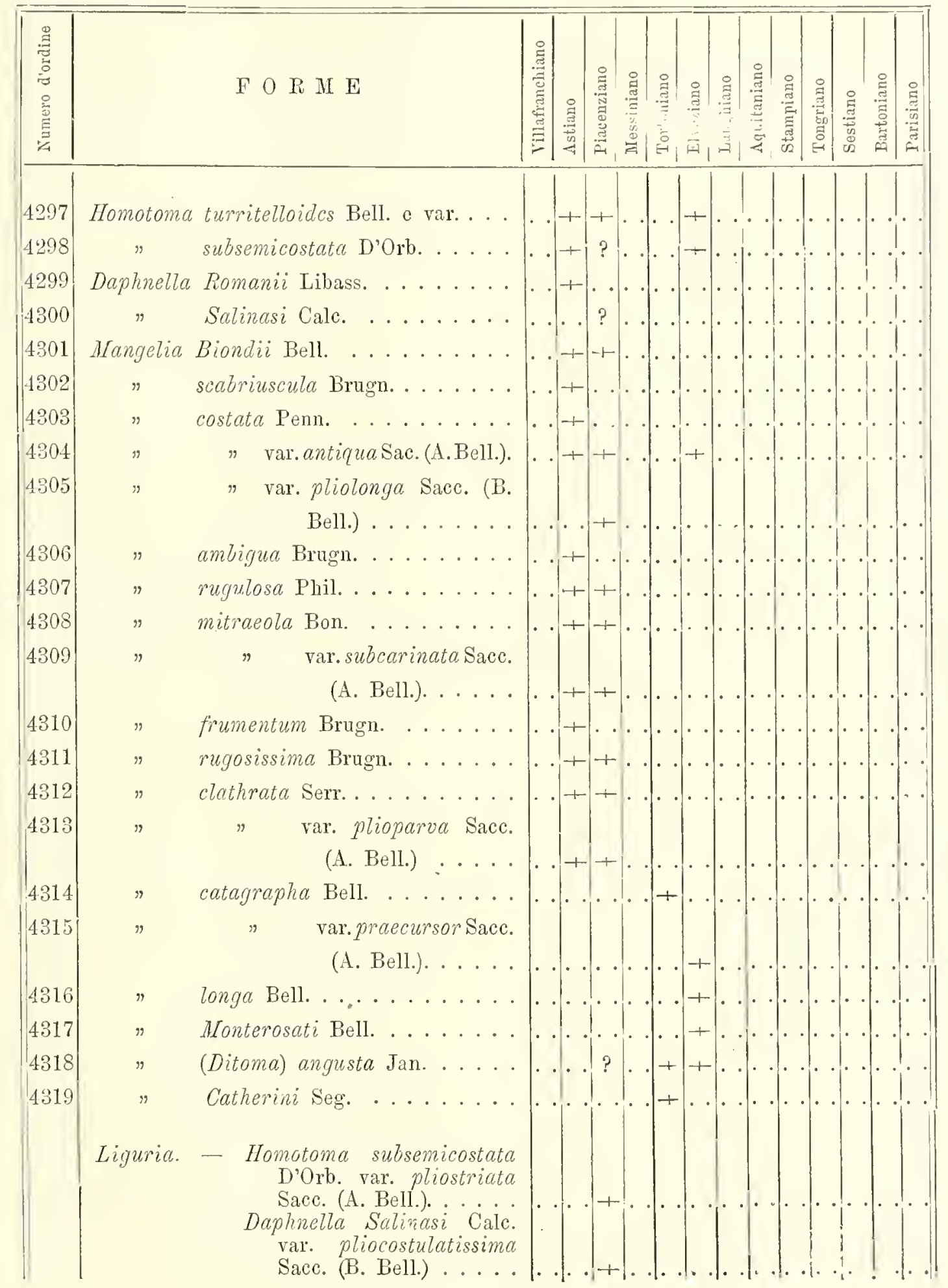




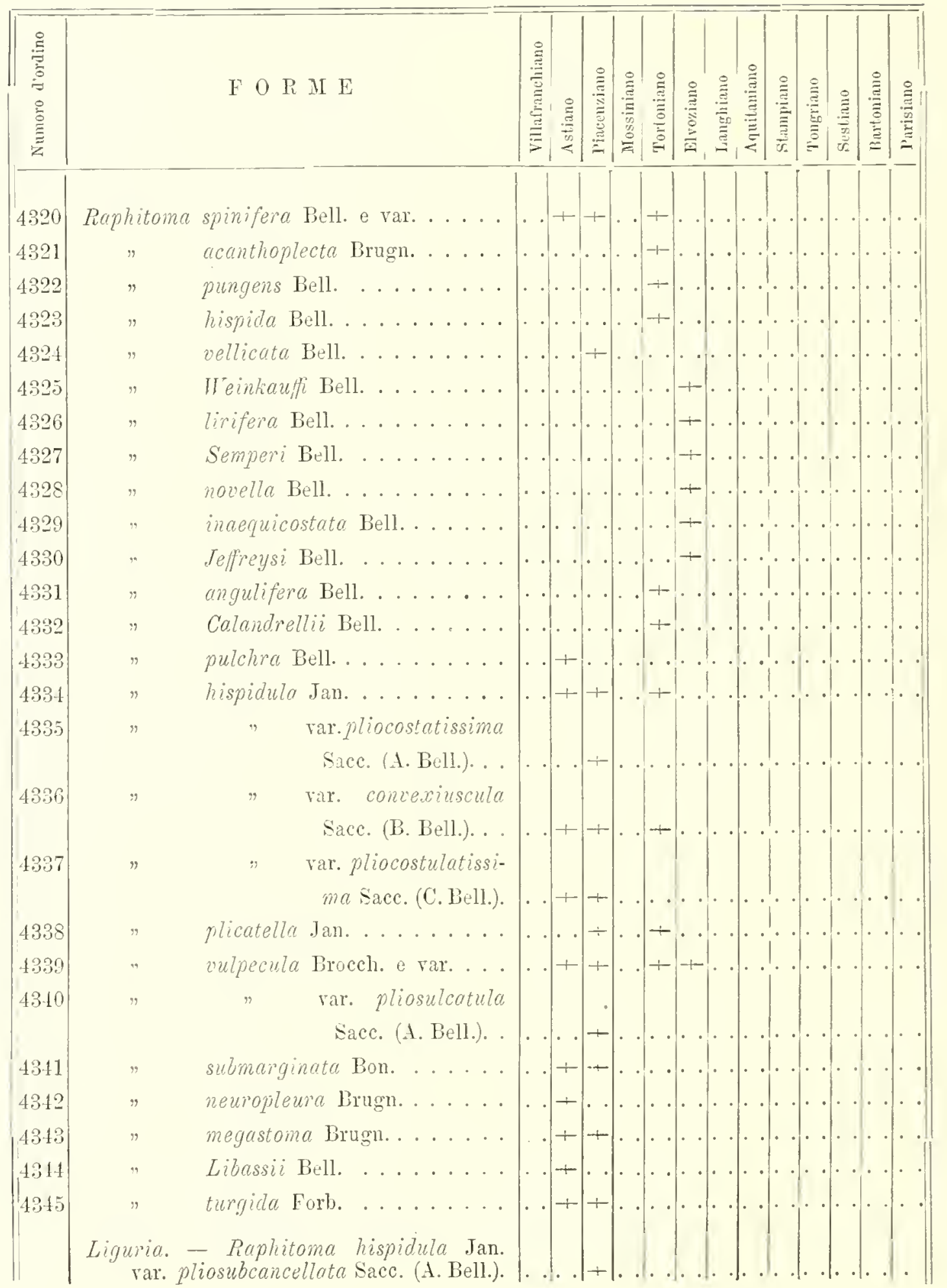




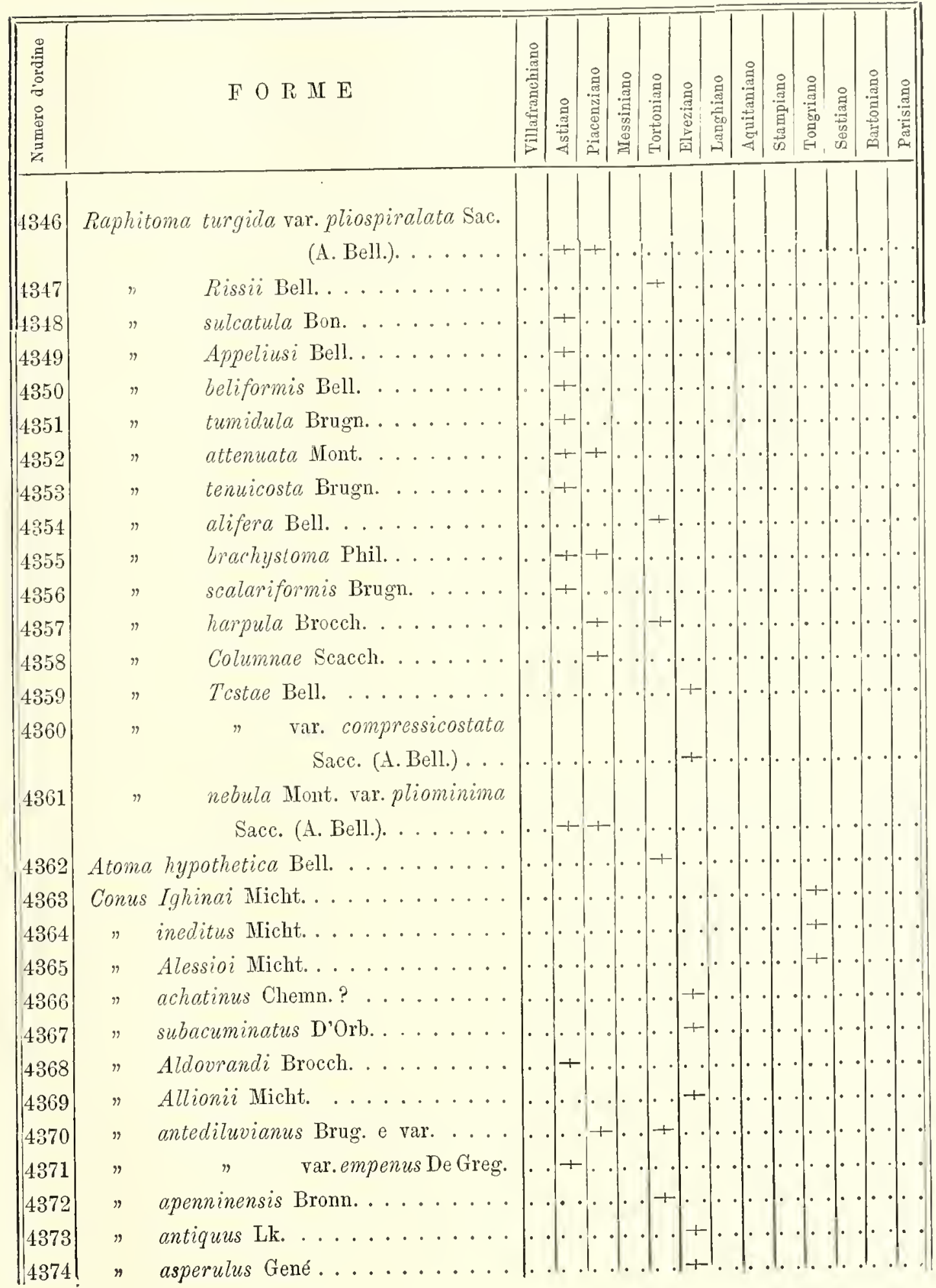




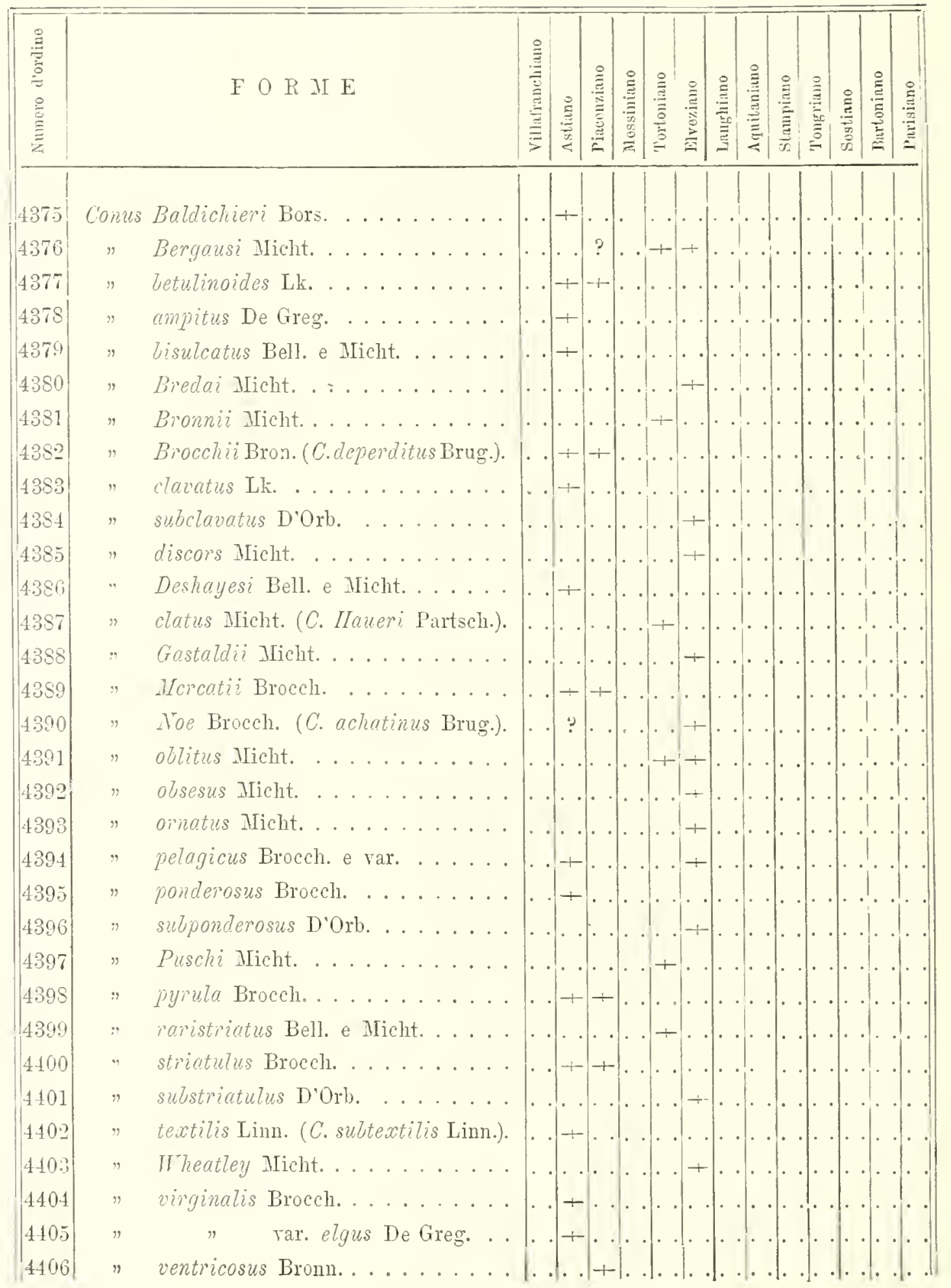


Catalogo paleontologico del bacino terziario del Piemonte

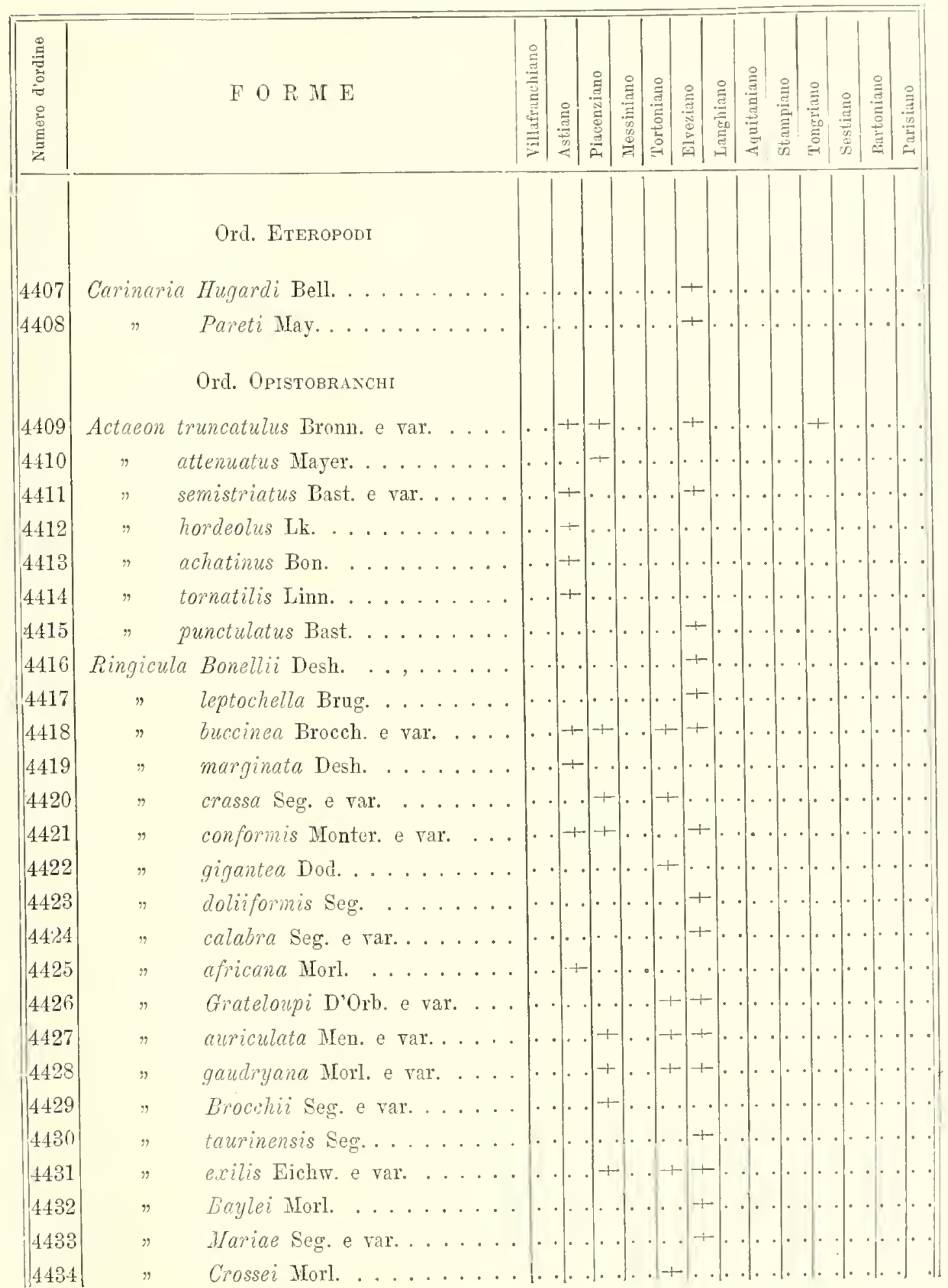




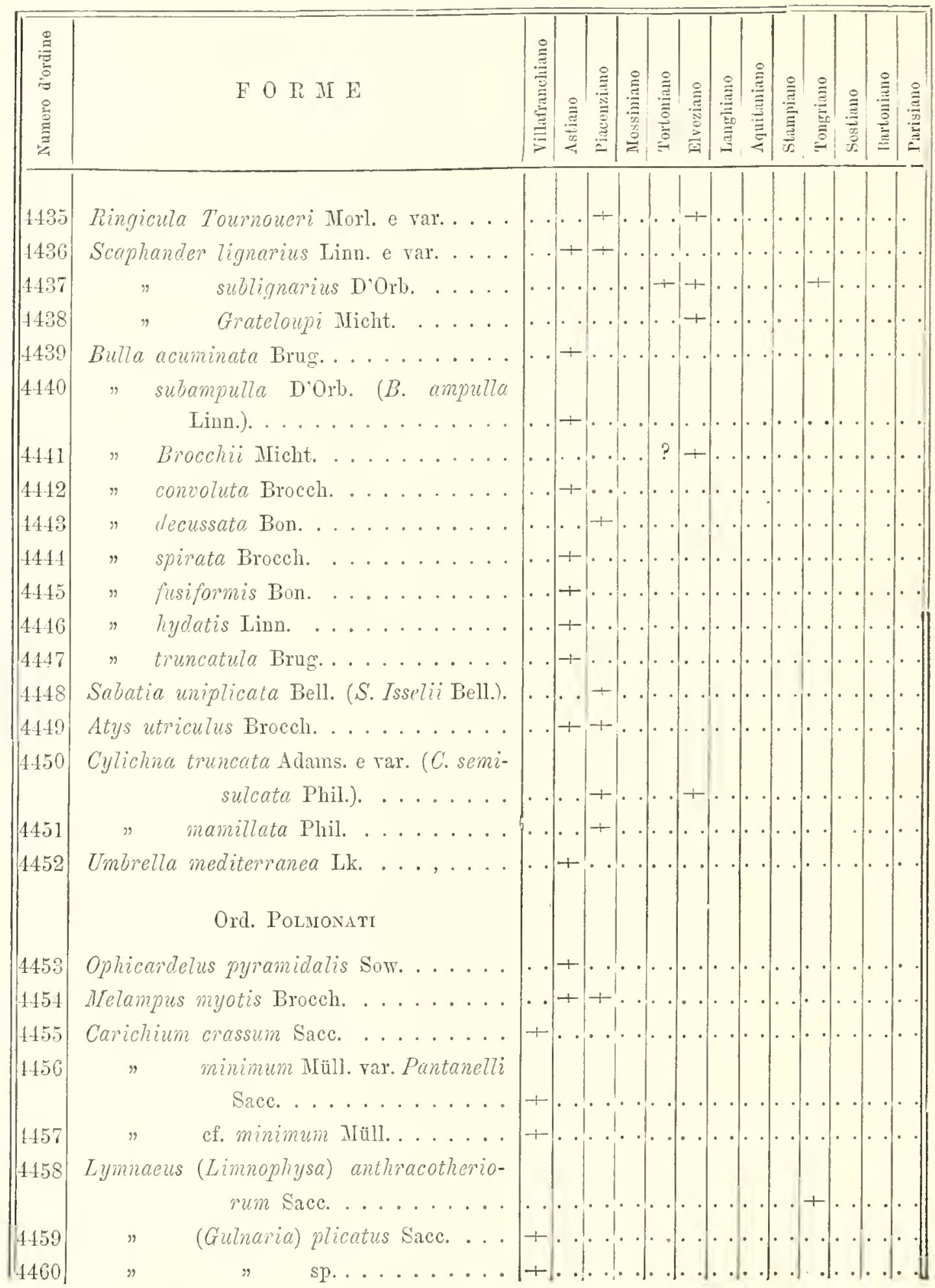


Catalogo paleontologico del bacino terziario del Piemonte

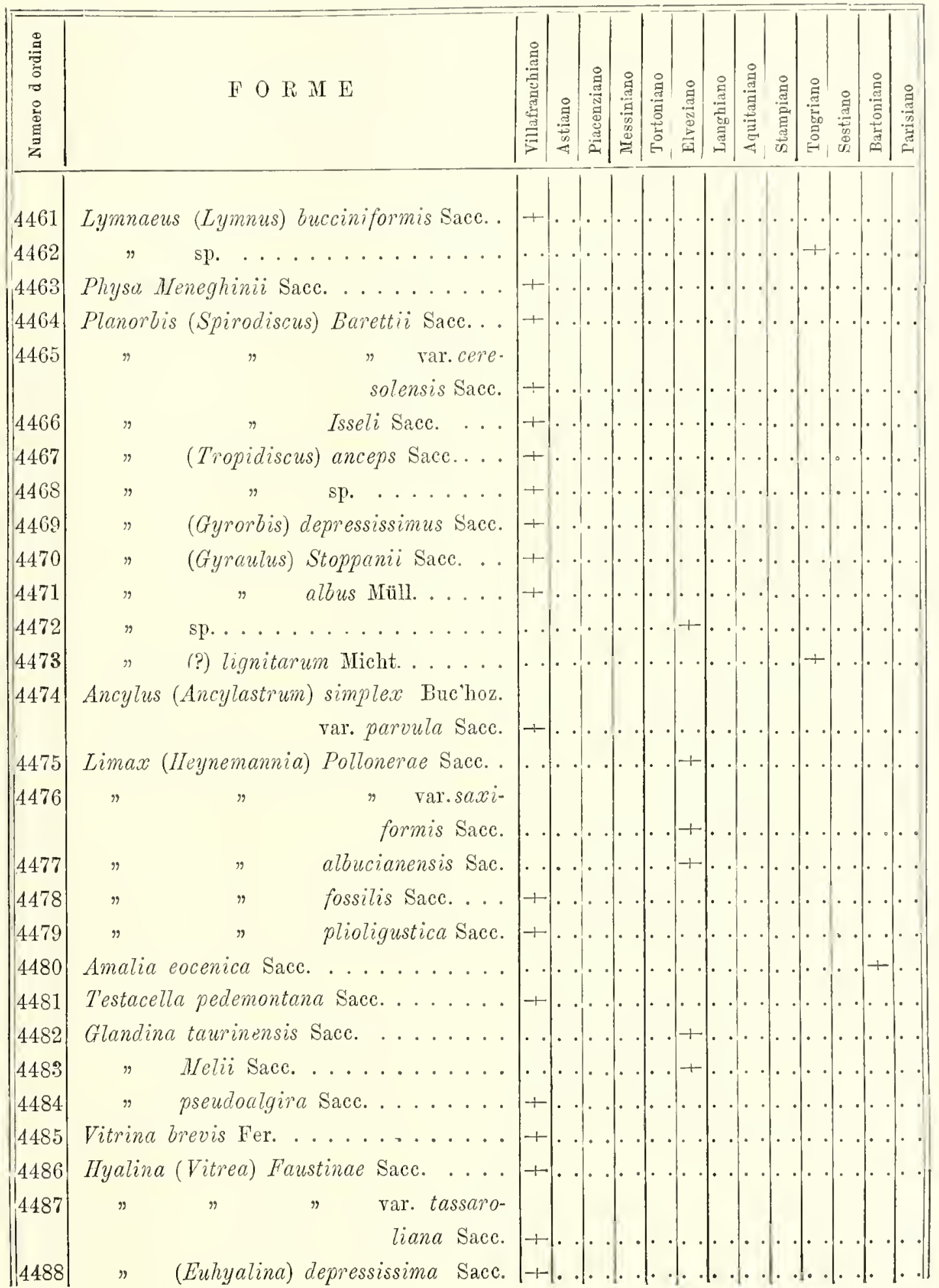




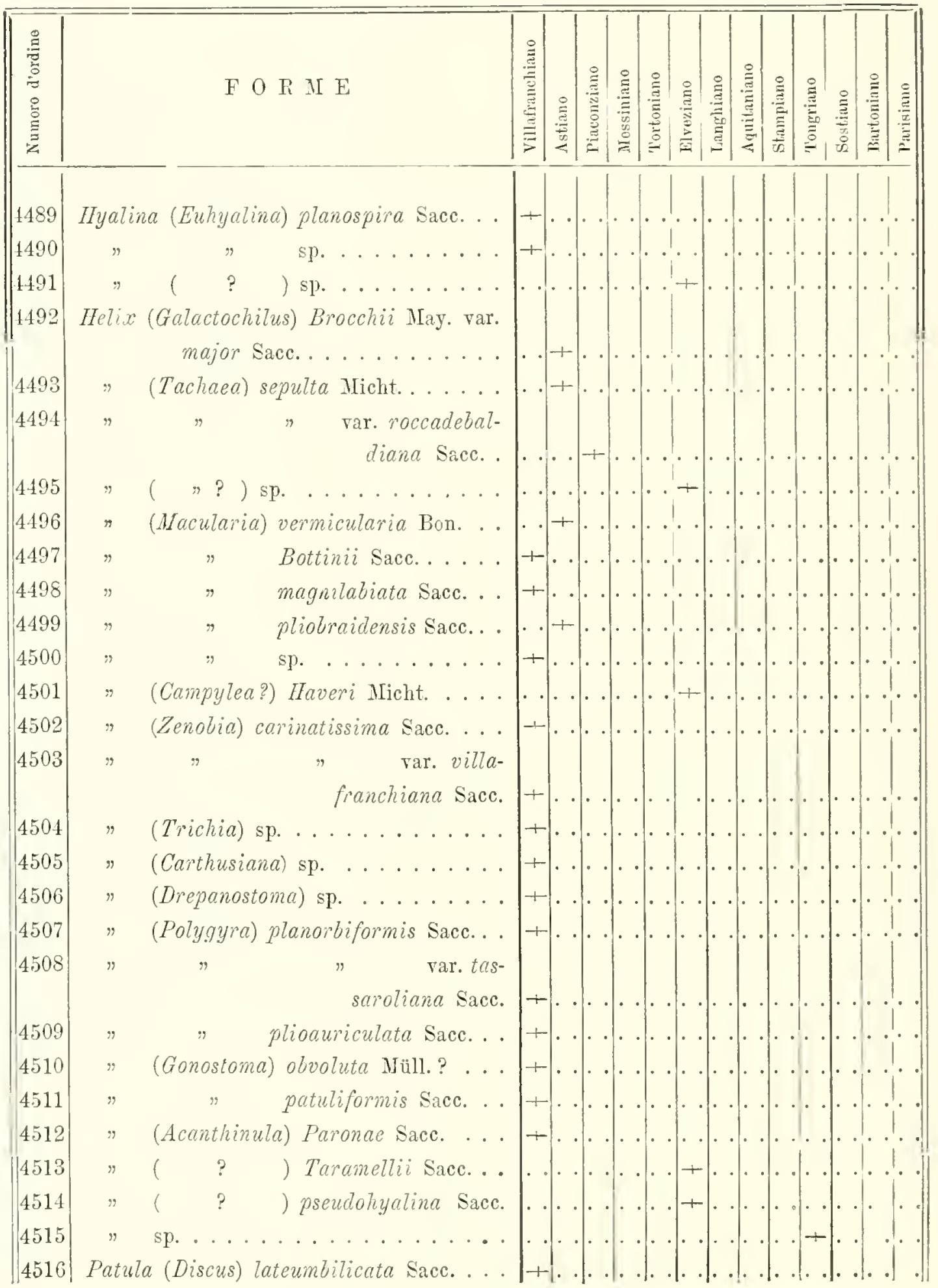




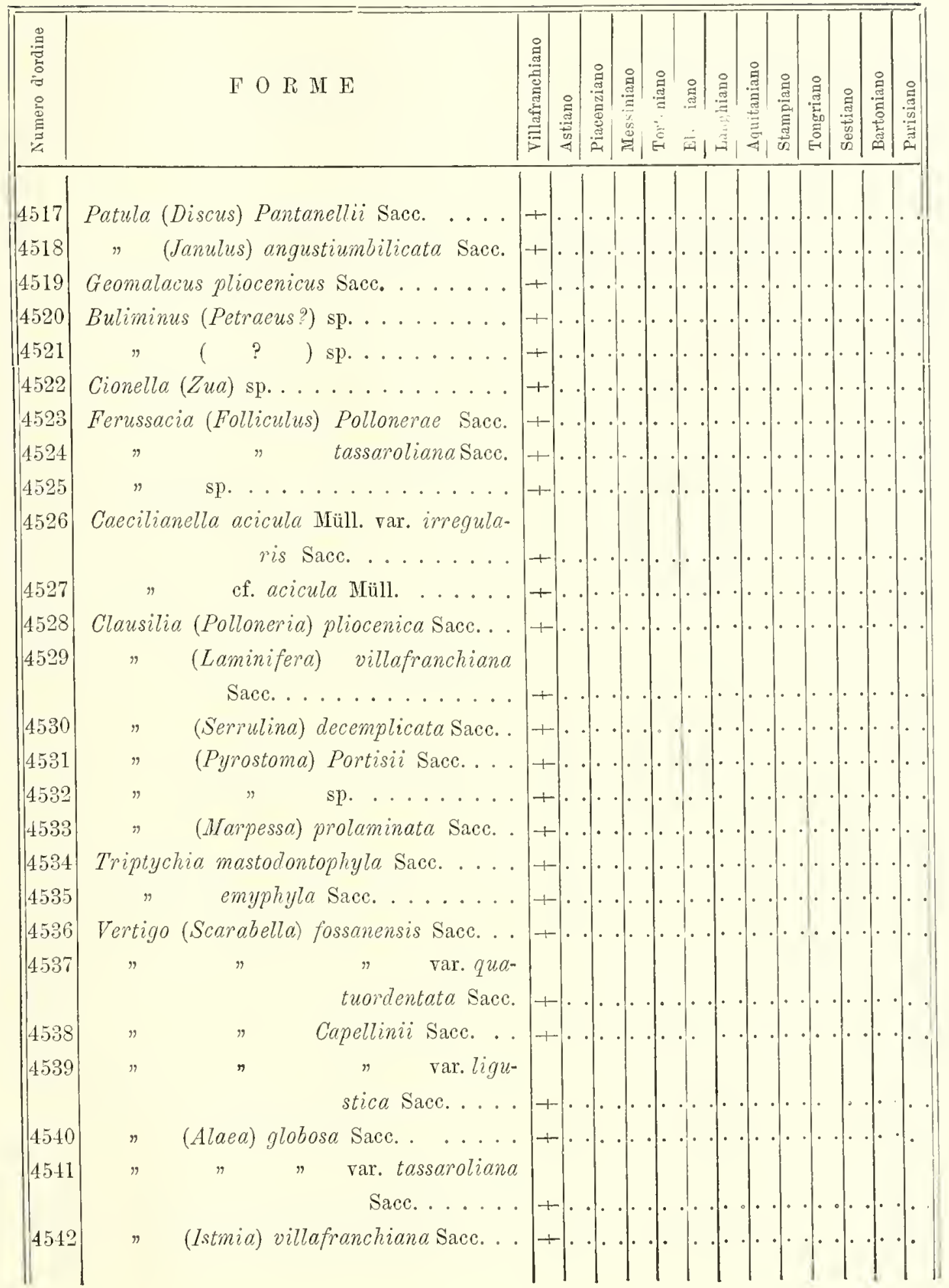




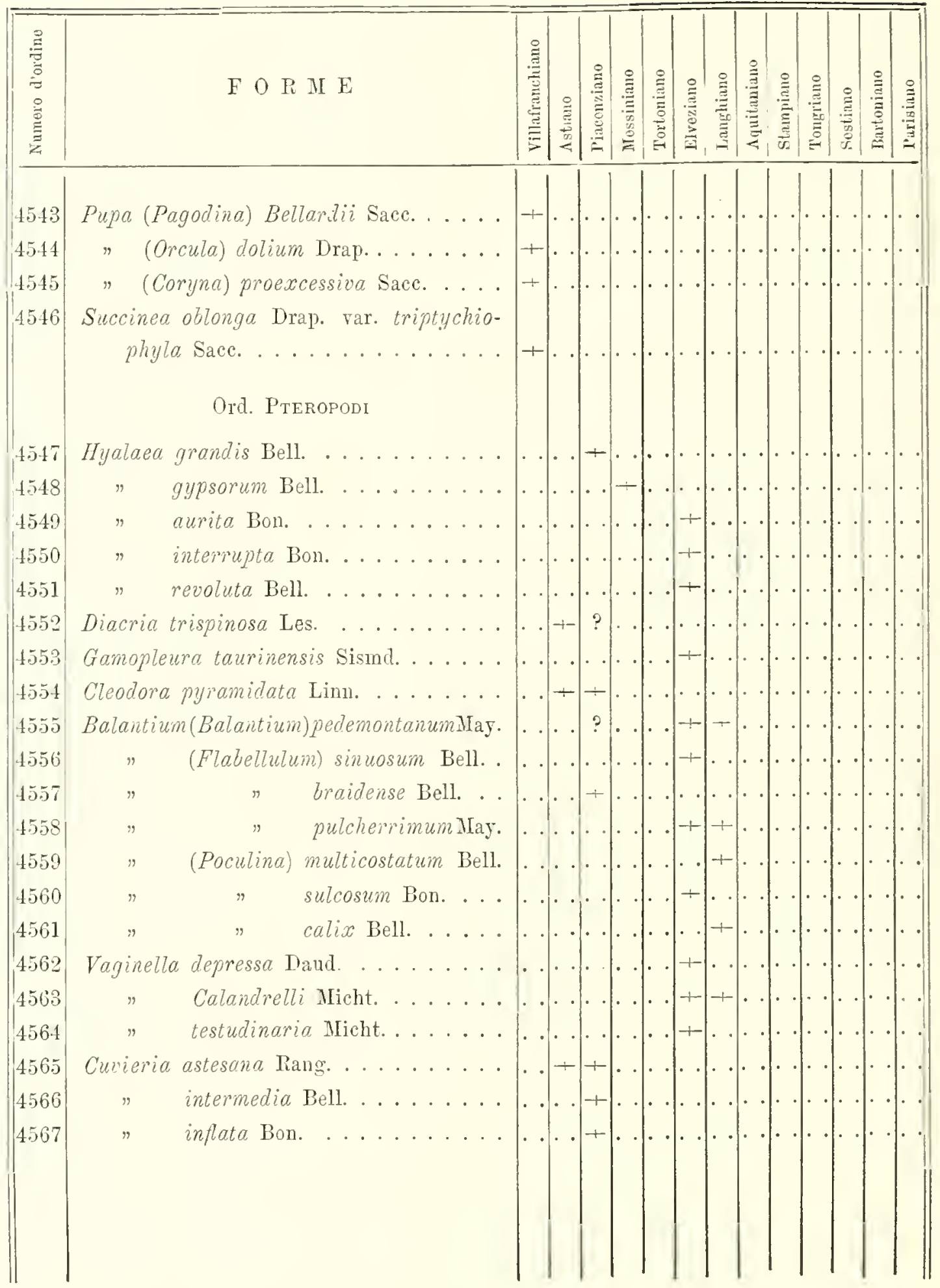




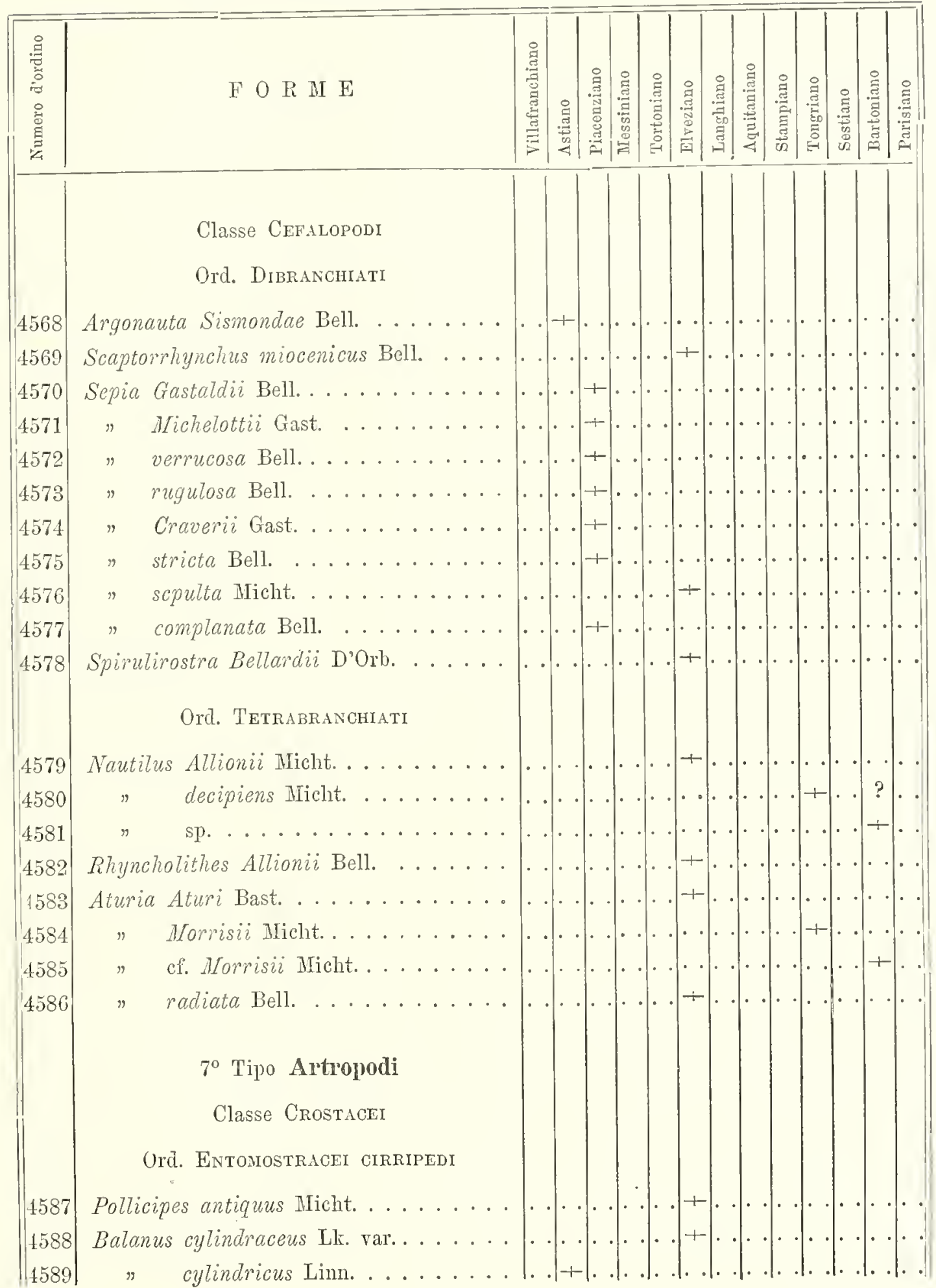




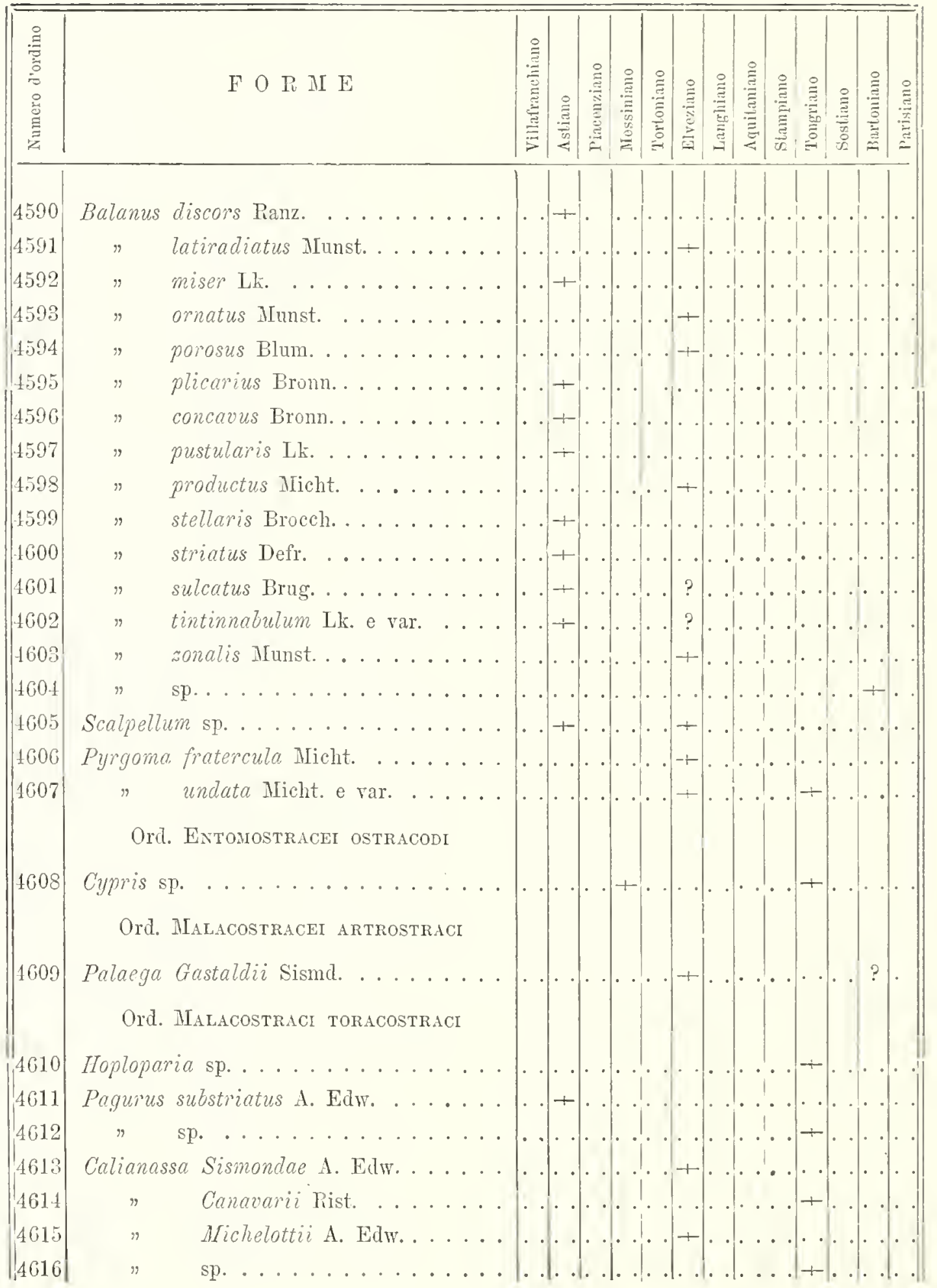




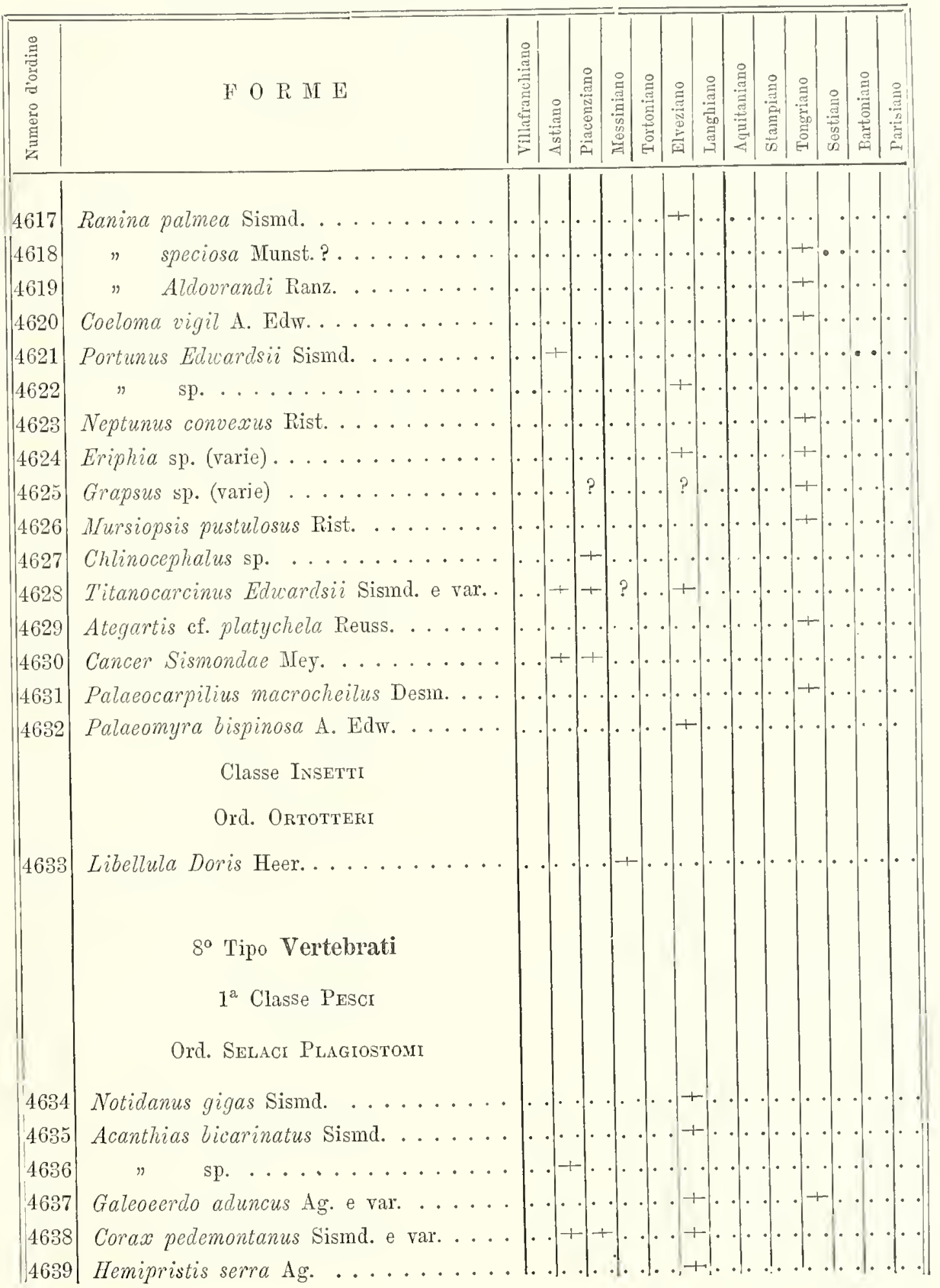




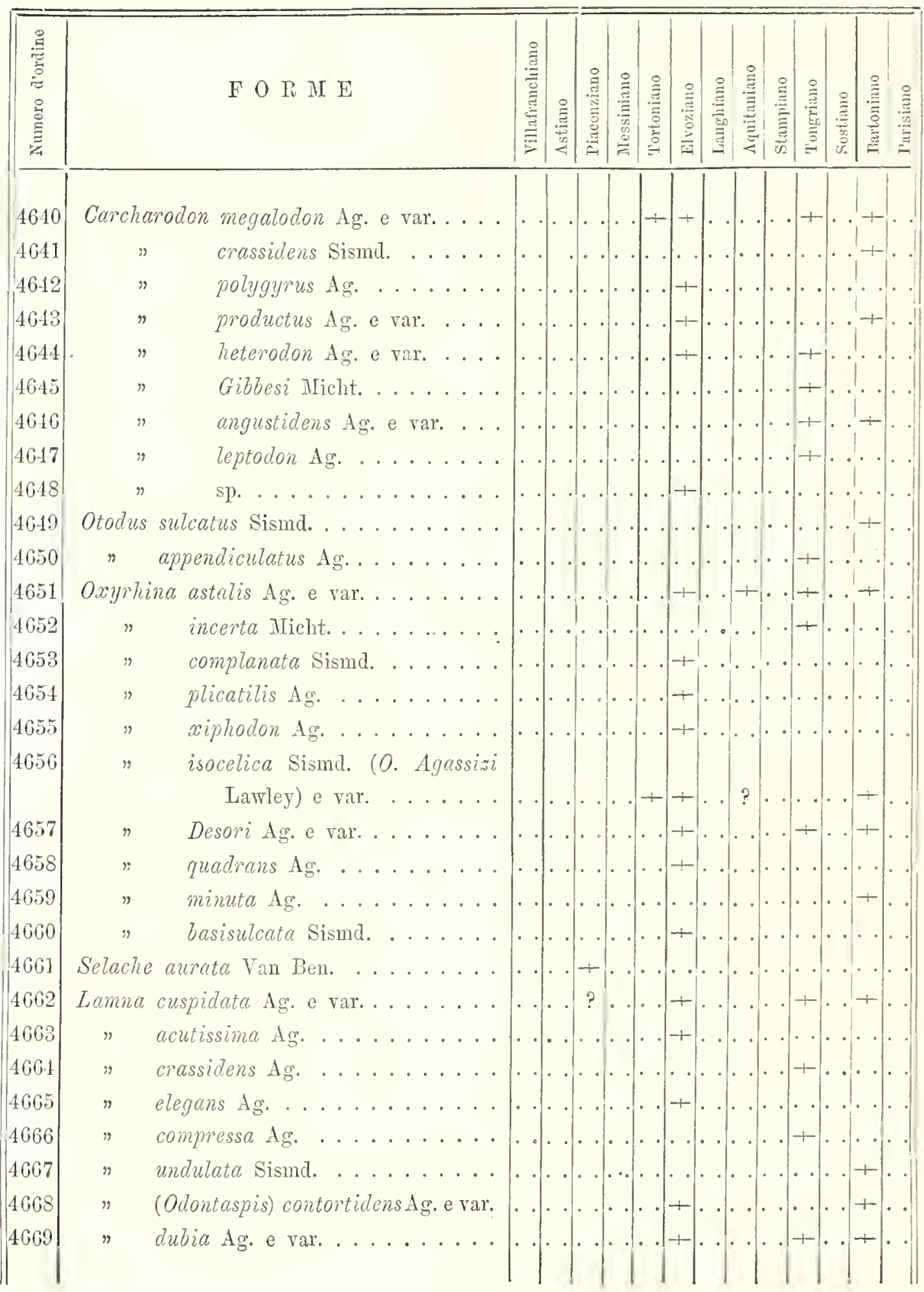




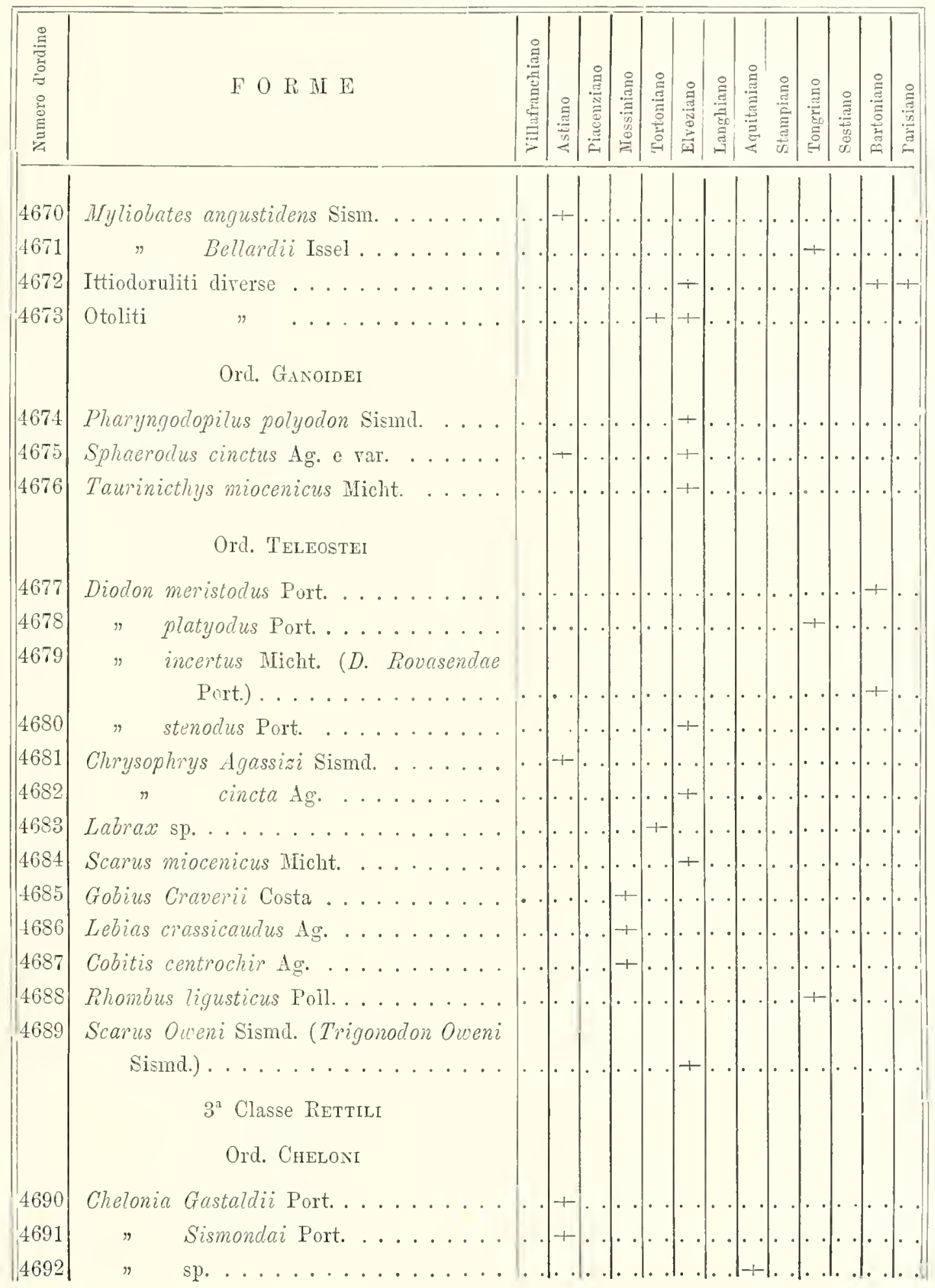




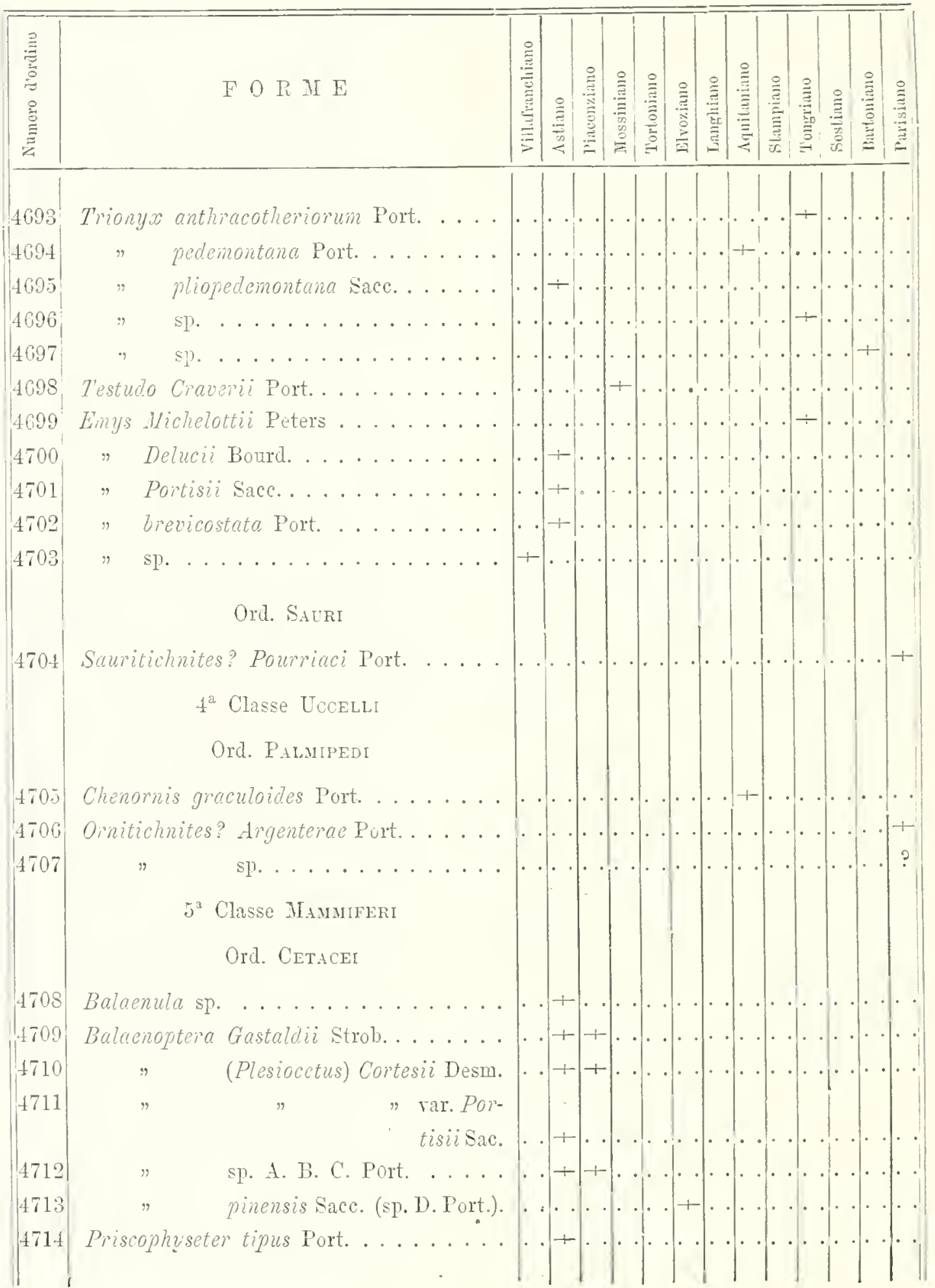




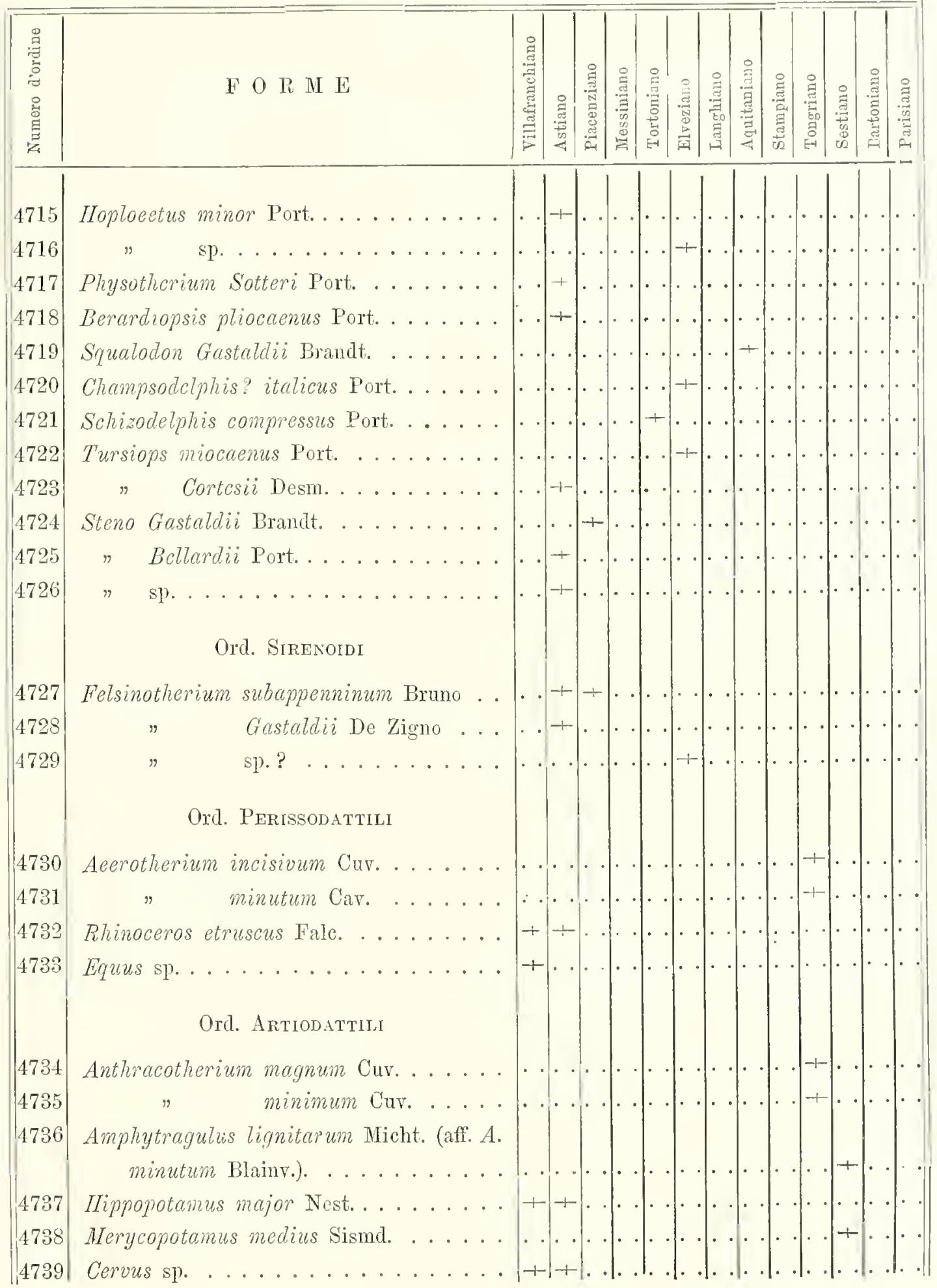




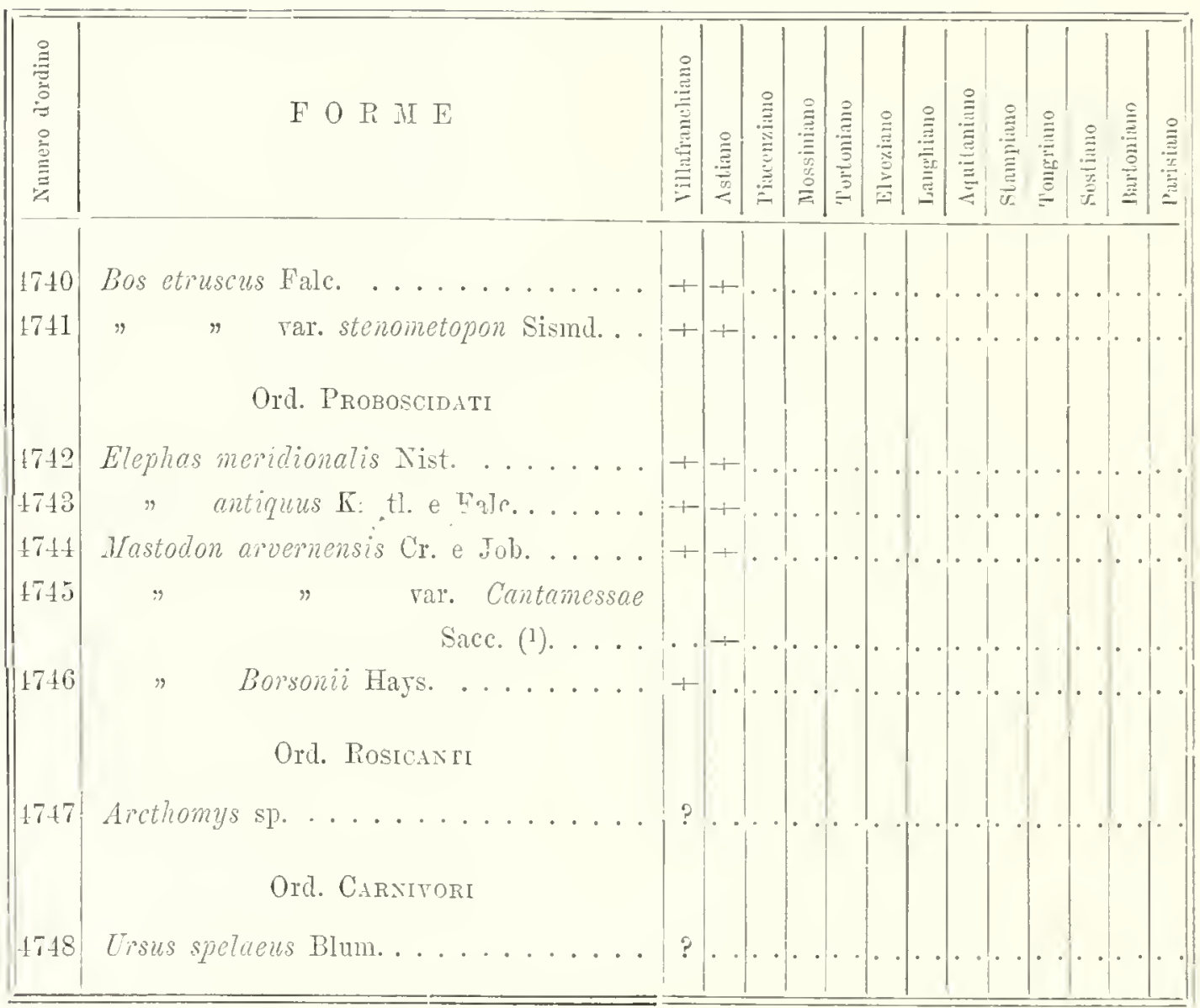

(1) Distinguesi dal tipo per: dimensioni gigantesche; ulimo molare con jo 6 gioghi oltre i 2 talloni; sinfisi del mento sviluppatissima, protratta crizontalmente, antcriormente espansa e con 2 alveoli (di incisivi inferiori) separati da un riliero osseo. Forma di passaggio ai Pentalophodonti, e di collegamento al H. ohioticus ler gli incisivi infcriori, ed al $M$. sivalensis per l'ultimo molare. 
AGGIUNTE E CORREZIONI

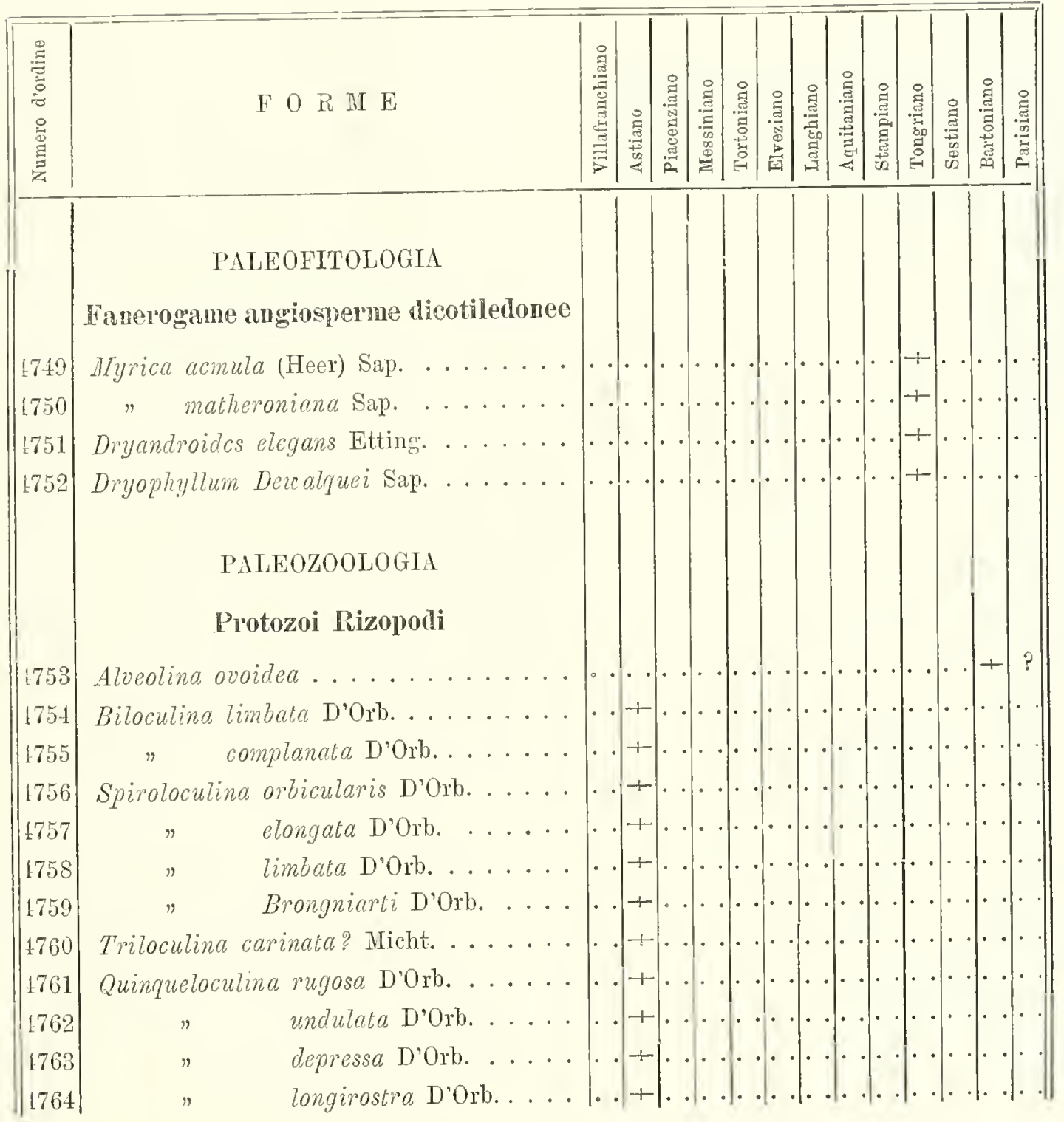




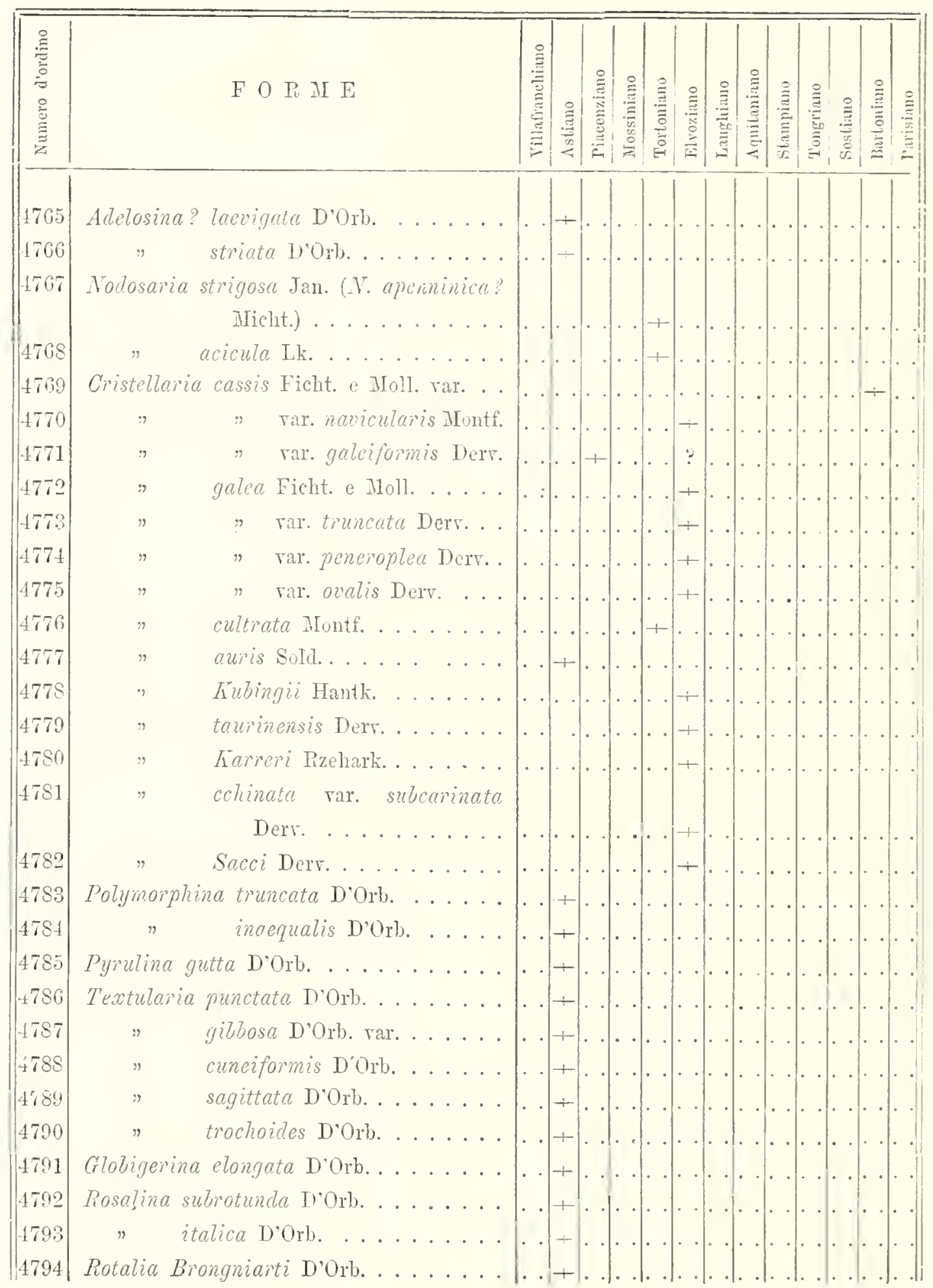




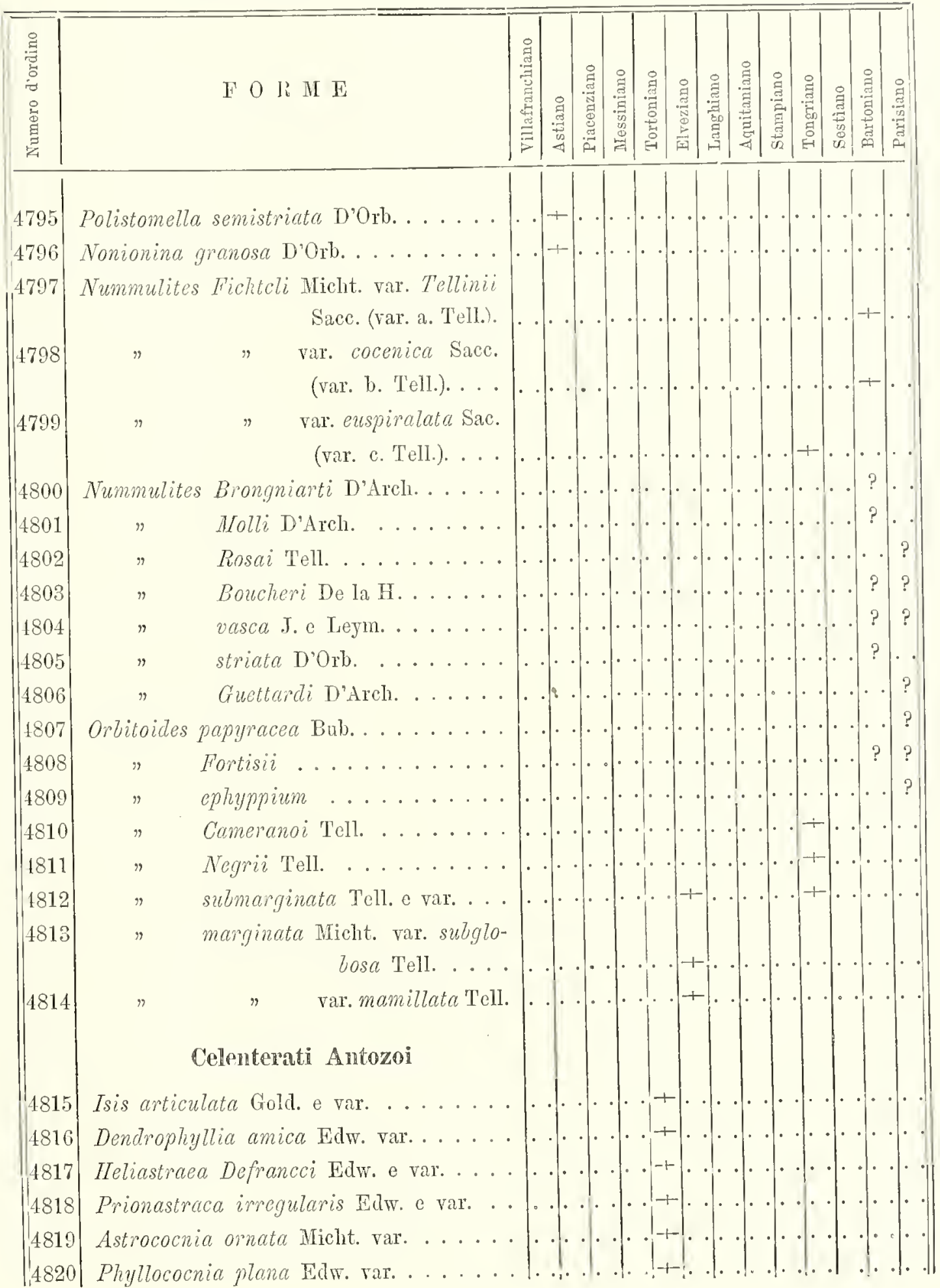




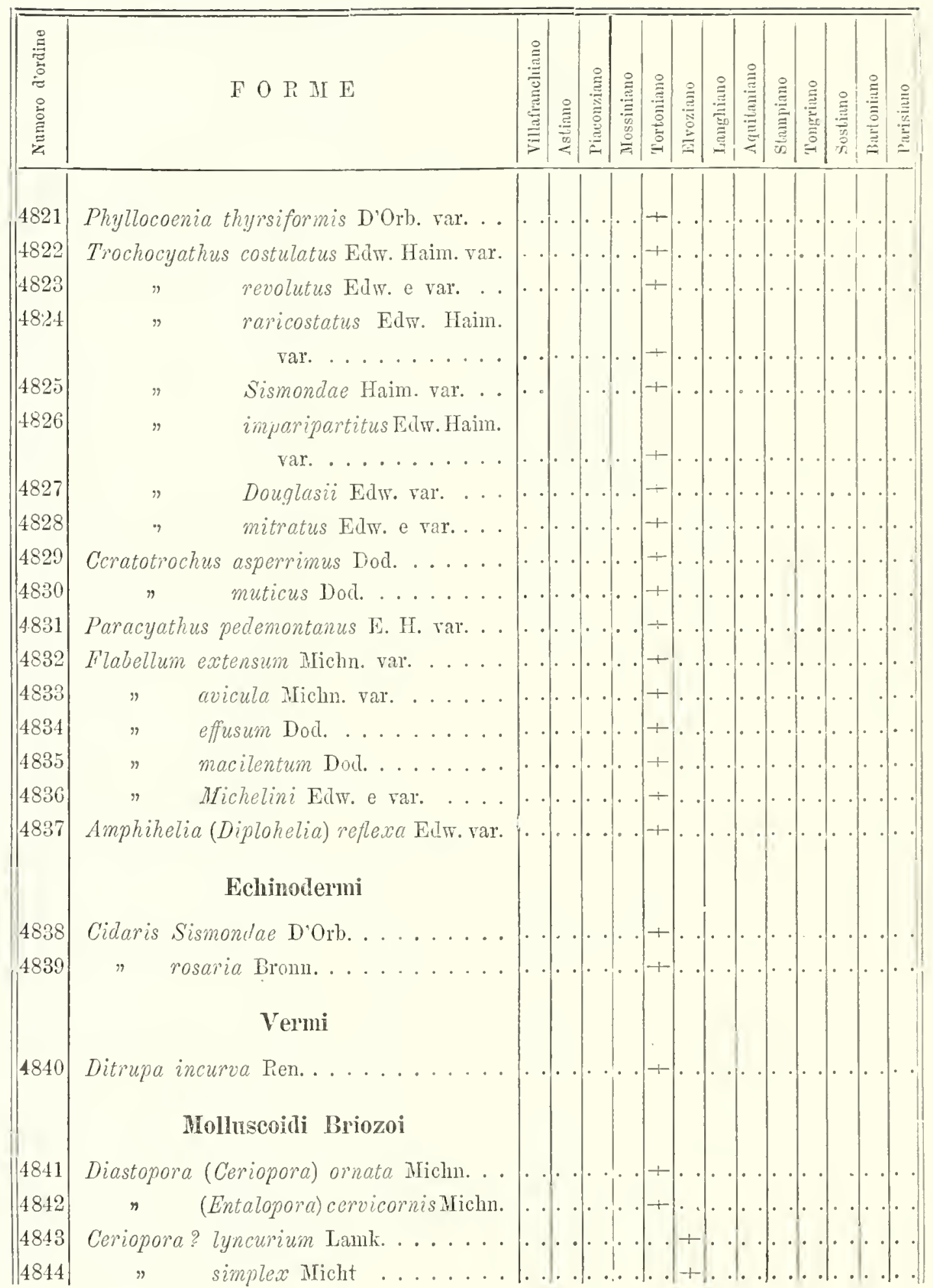




\begin{tabular}{|c|c|c|c|c|c|c|c|c|c|c|c|c|}
\hline 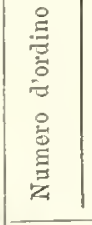 & F O P N E & 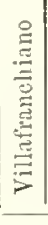 & 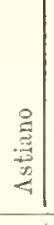 & 竎 & 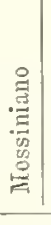 & 总 & 量 & 总 & 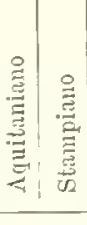 & 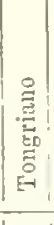 & & 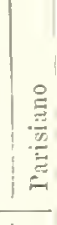 \\
\hline 4845 & Cupularia (Discoporella) umbellata Defr. & & & & & + & & & & & & \\
\hline 4846 & $\begin{array}{l}\text { Lunutites androsaces \&ll. ........ } \\
\text { Molmechi Lamelihmnchiat }\end{array}$ & & & & & + & & & & & & \\
\hline 4847 & 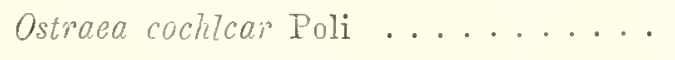 & . & & & & + & & & & - & & \\
\hline 4818 & " denticulata Chemn. var. .... & . & & & & + & & . & & & & \\
\hline 4819 & " corrugata Br. rar. ...... & . & & & & + & & - & & - & & \\
\hline 4850 & plicatula Lk. var. ....... & . & & & & $\div$ & & . & - & • & & . \\
\hline 4851 & " pedemontana Mas. ....... &. & & + & & . & . & - & & - & & \\
\hline 4852 & Anonia clectrica Linu. var. ....... & . & & & & + & . & . & & & & . \\
\hline 4853 & $"$ potinorpha Phil. var. ..... & & & & & $1+1$ & & & & & & - \\
\hline 4851 & " scabrolla Phil. var......... & . & & & & $\left.\right|_{+} ^{+}$ & & & & & & \\
\hline 4855 & Spontylus eximius Dod......... & & & & & + & & & & & & \\
\hline $\begin{array}{l}4856 \\
48.57\end{array} \mid$ & $\begin{array}{l}" \text { Deshaycsi Micht. rar. .... } \\
" \quad \text { crassicosta Lk. var. ...... }\end{array}$ & & & & & + & & & & & & \\
\hline 4858 & Pecten latissimus Brocch. rar. . . . . . & . & & & & + & & & & & &. \\
\hline 4859 & " Bcudanti Bast. var. ....... & . & & & & + & & . & & . & & \\
\hline 4860 & " flobelliformis Defr. var. ...... & . & . & & & + & & & & . & & \\
\hline 4861 & " varius Lk. var. . . . . . . . & • & & & & + & & . & & . & & . \\
\hline 4862 & " scabrellus Lk. var. ........ & . & & & & + & & & & & & \\
\hline 4863 & $"$ pusio Lk. var............ & . & & & & + & & 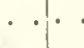 & - & & & \\
\hline 4864 & " cristatus Bronn. var. . . . . . . & 1. & & & & + & & . & • & & & \\
\hline 4865 & Acicula phalaenacea Lk. var. . . . . . . & . & & & & + & & & . & - & & \\
\hline 4866 & Perna Soldanii Desh. rar......... & & & & & + & & & & & & \\
\hline 4867 & Pinna Brocchii D'Orb. ? var. ...... & . & & & & 1 & & & & & & \\
\hline 4868 & Arca navicularis Brag. (A.tetragona Poli) & & & & & & & & & & & \\
\hline 4869 & $\begin{array}{l}\text { rar. } \ldots \ldots t i t o i d e s \text { Brocch. var. uniopsis De } \\
\text { Greg. . . . . . . . . . . . }\end{array}$ & & & & & 1 & & & & & & \\
\hline 4870 & " Diluvii Lk. e var. ........ & • & & & & 1 & & & & & & \\
\hline 4871 & 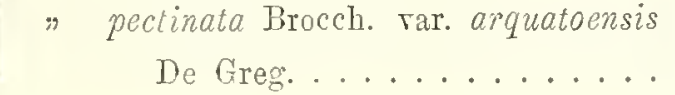 & & & & & & & & & & & \\
\hline
\end{tabular}




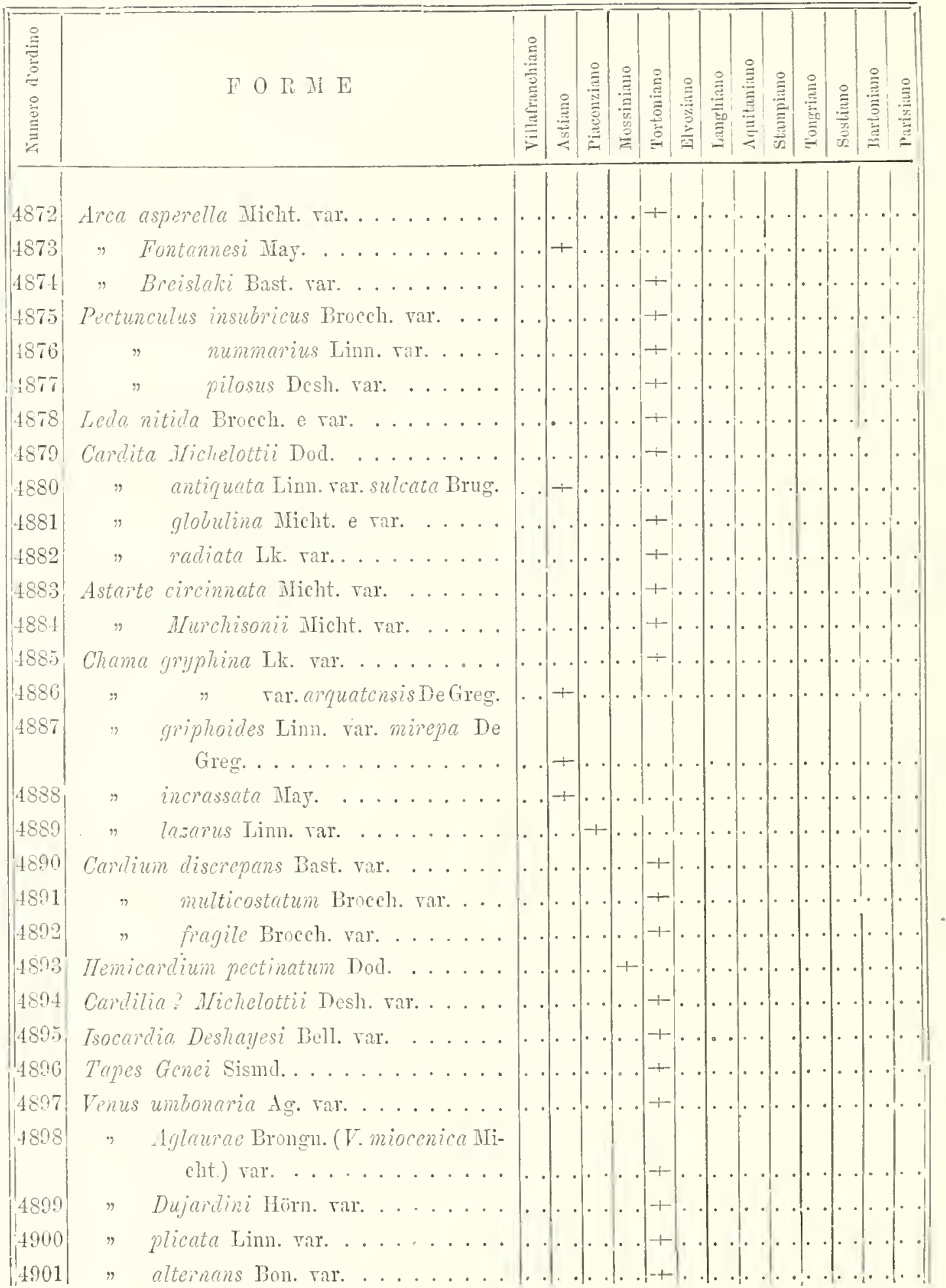




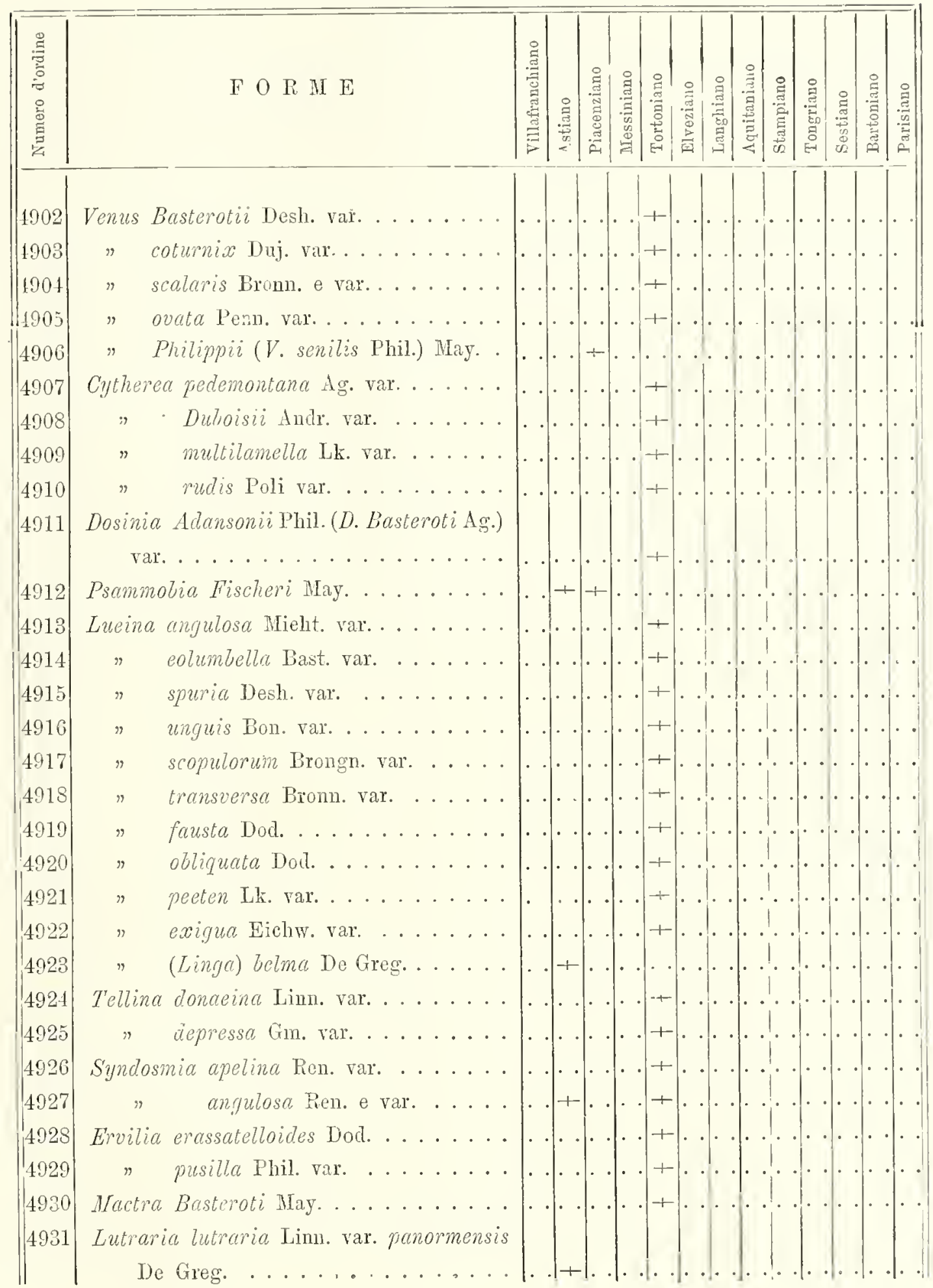




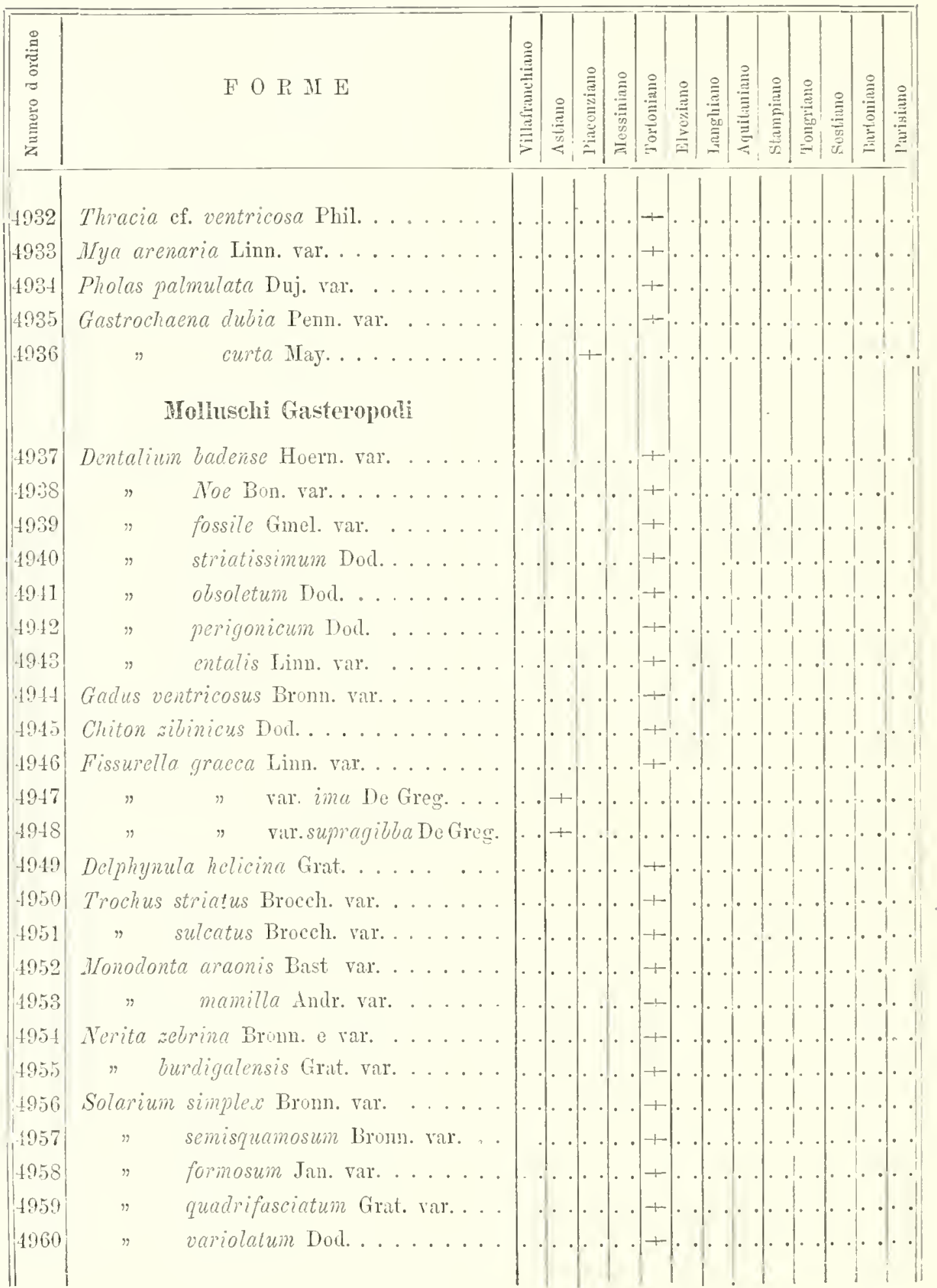


Catalogo paleontologico del bacino torziario del Picmonte

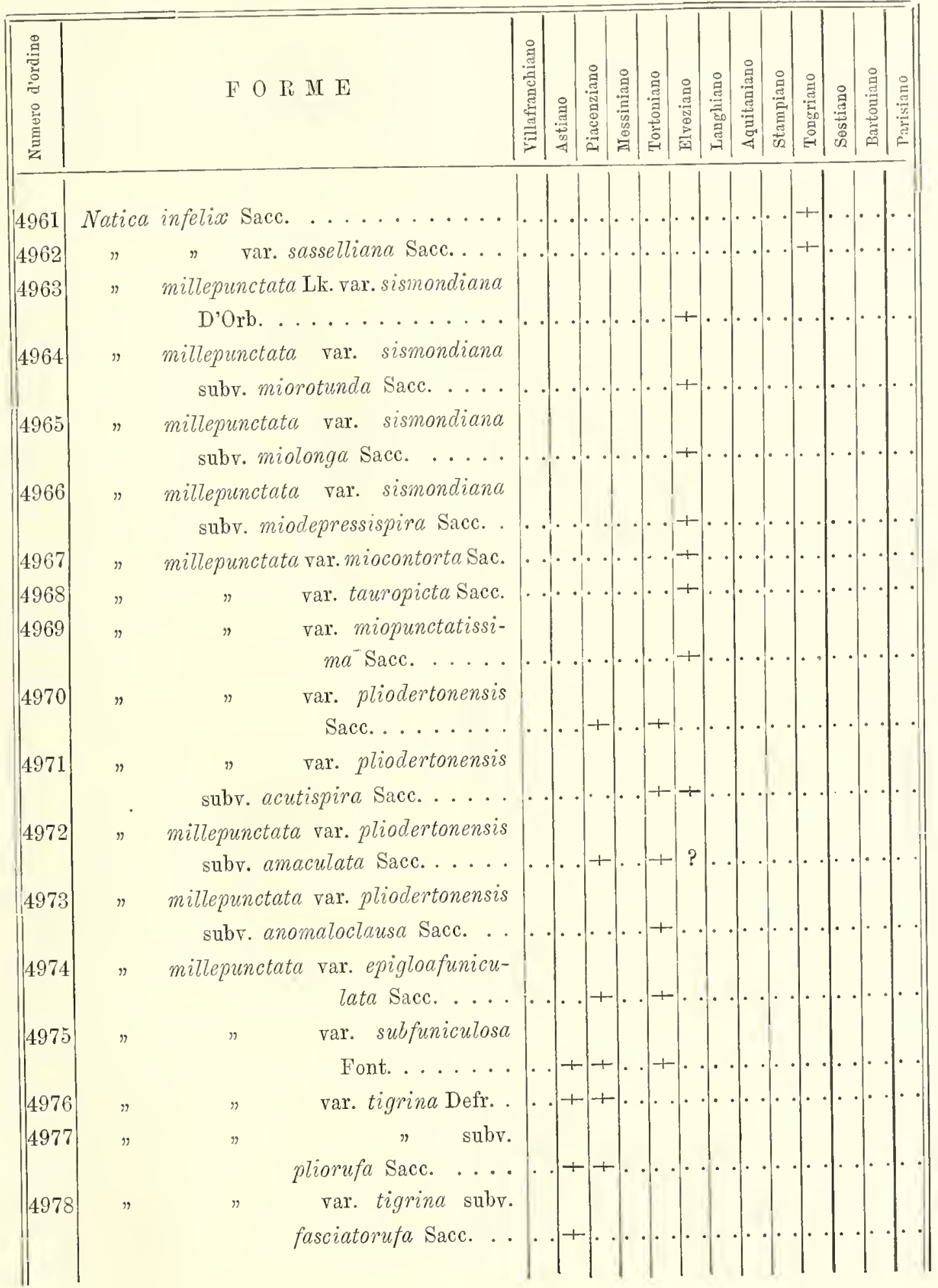




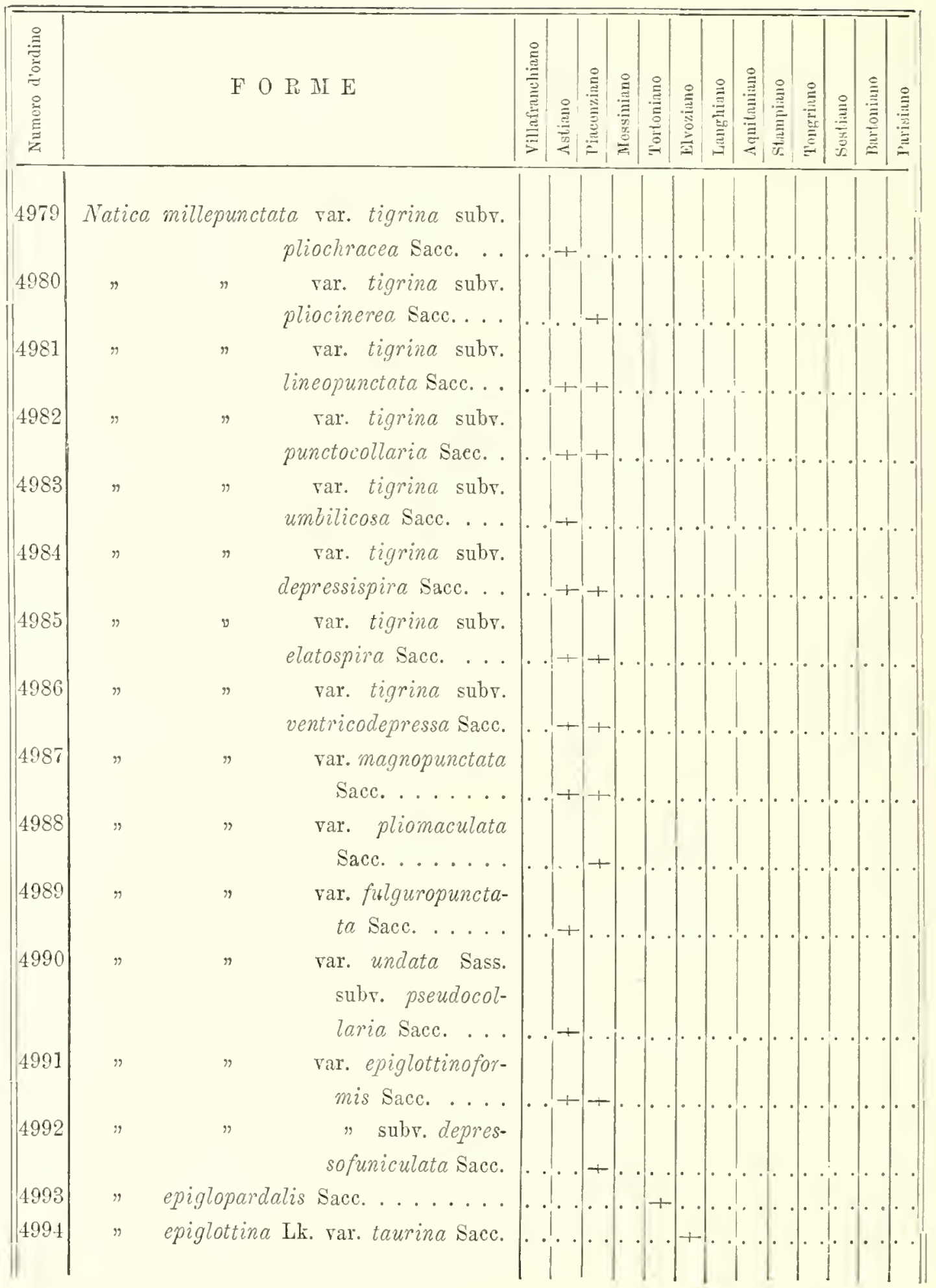




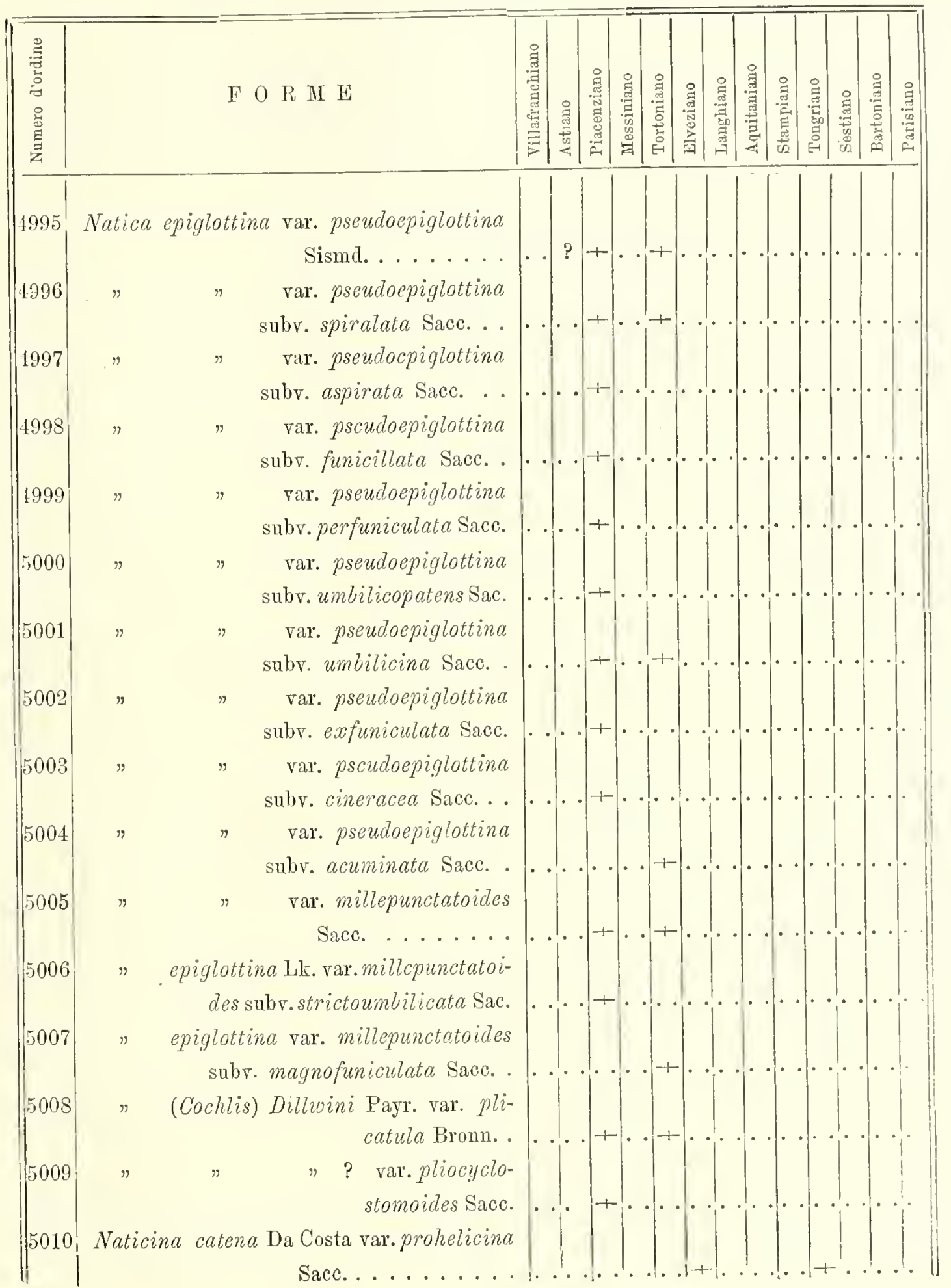




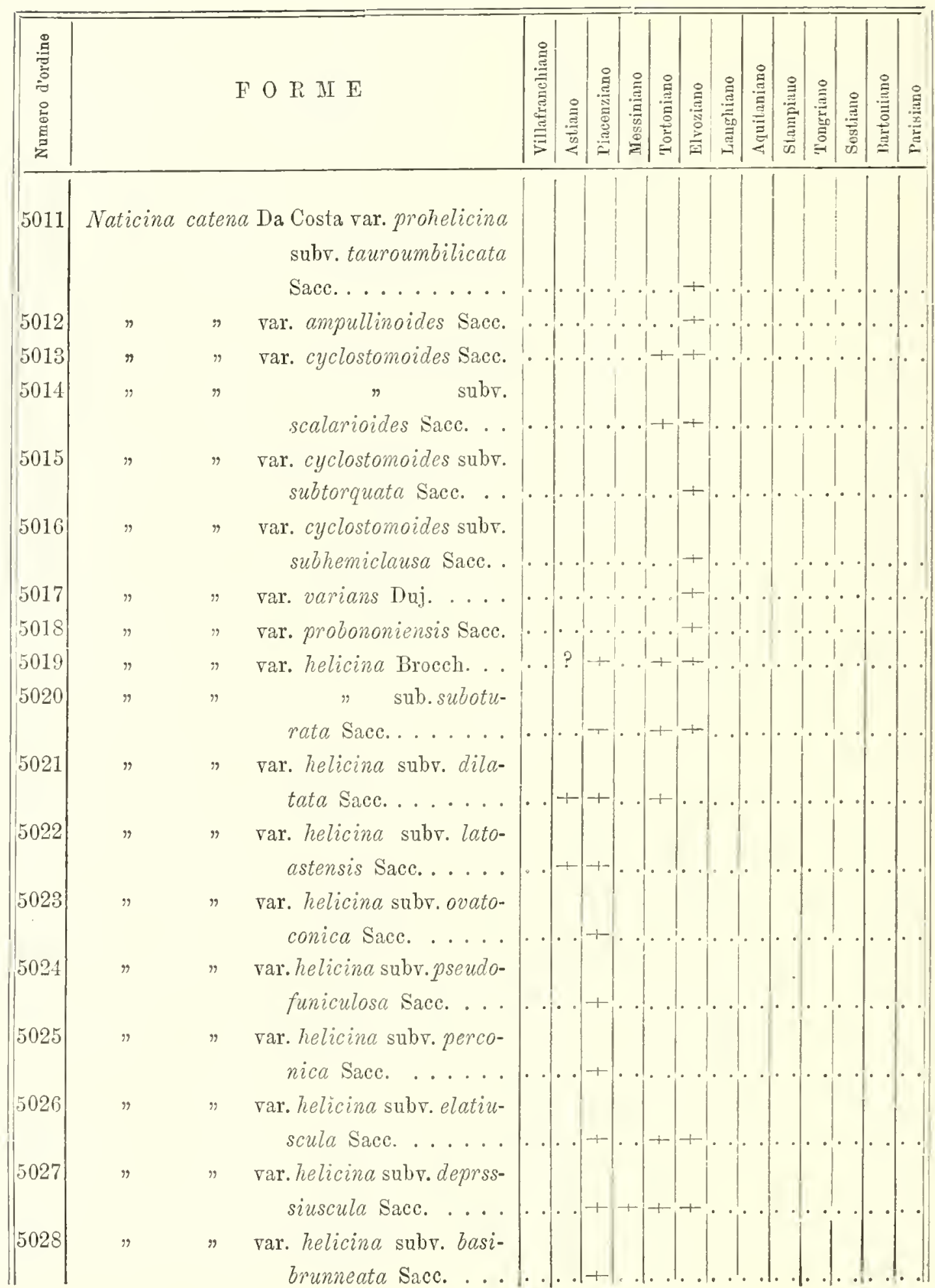




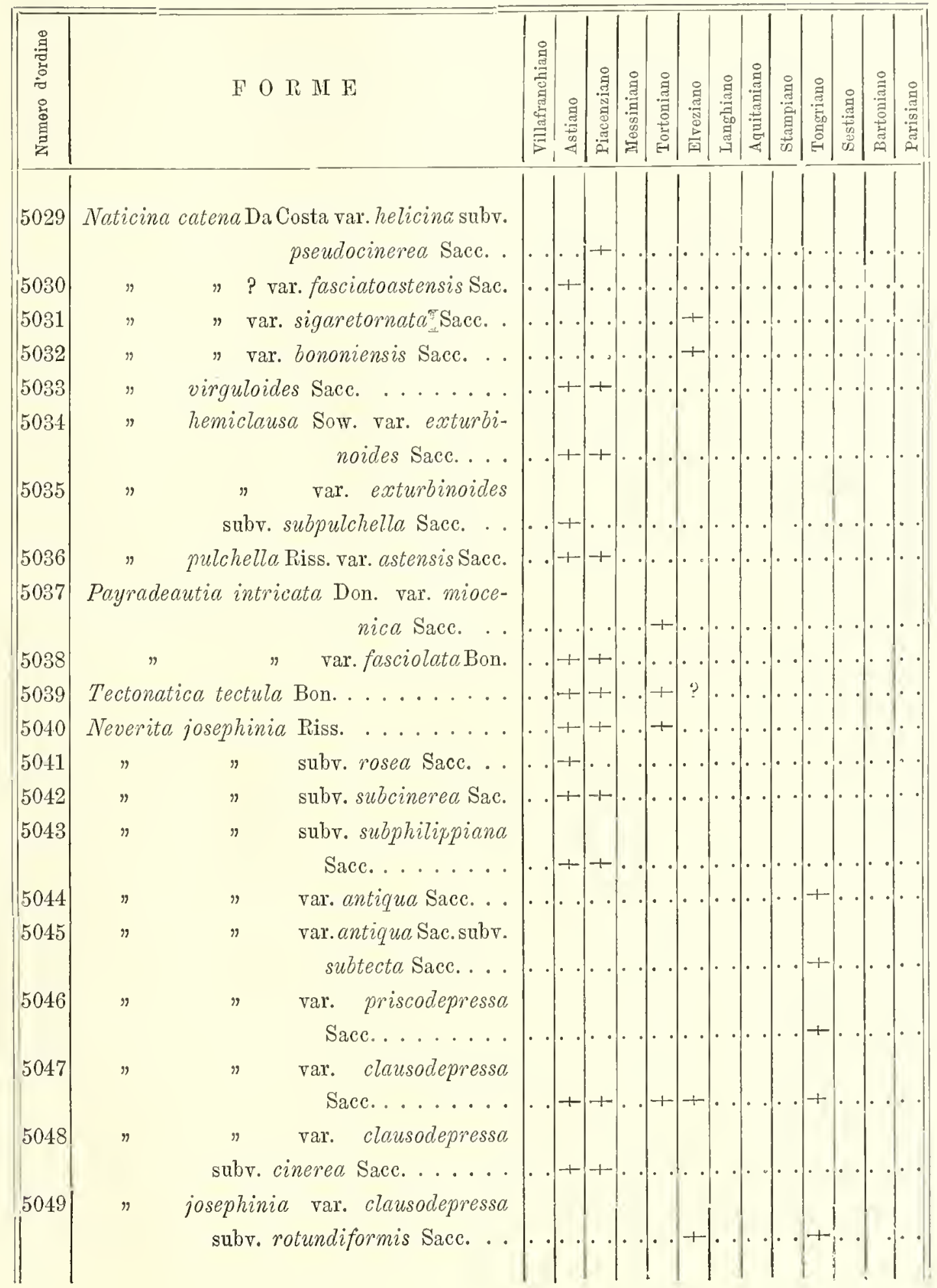




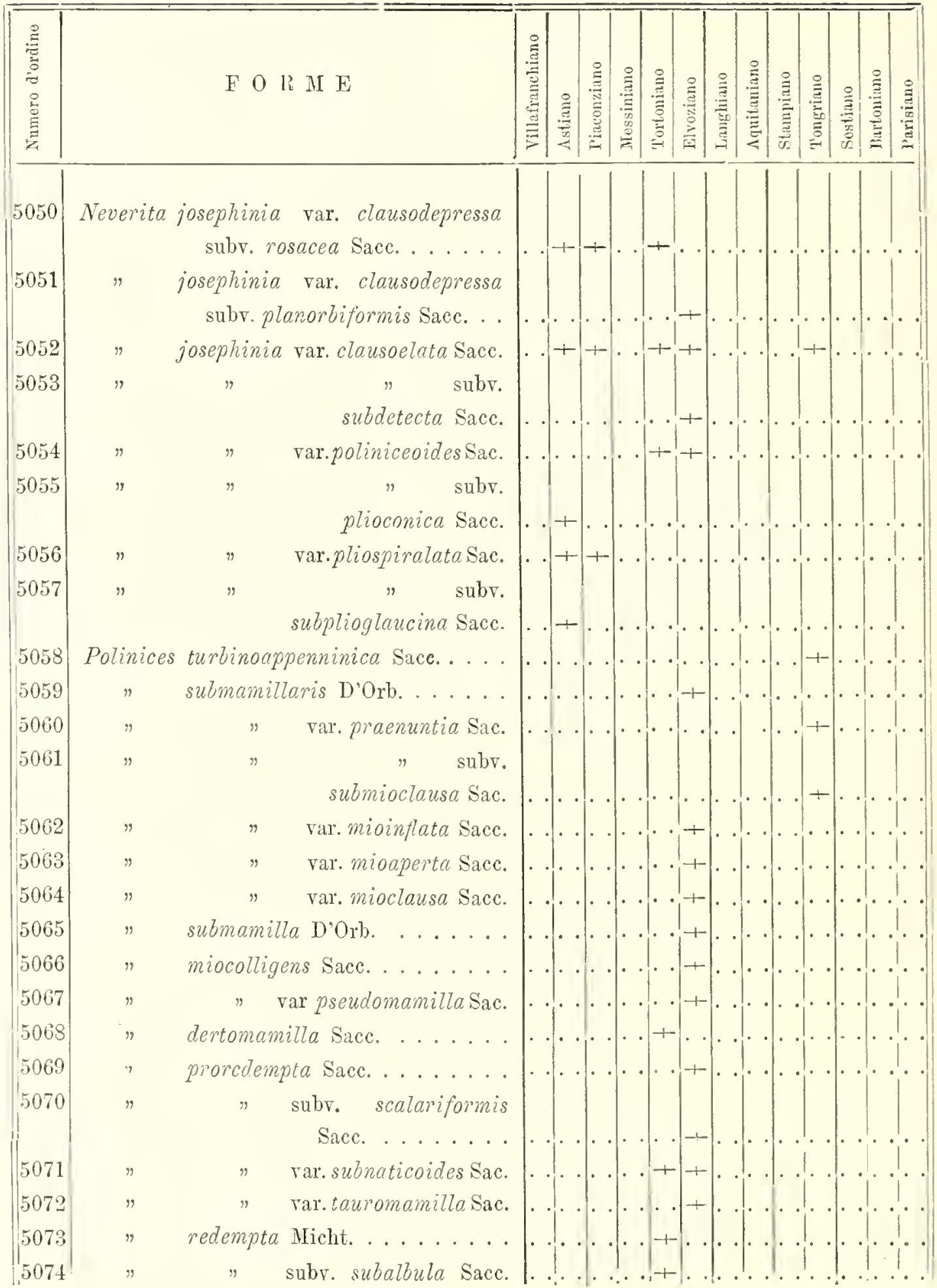




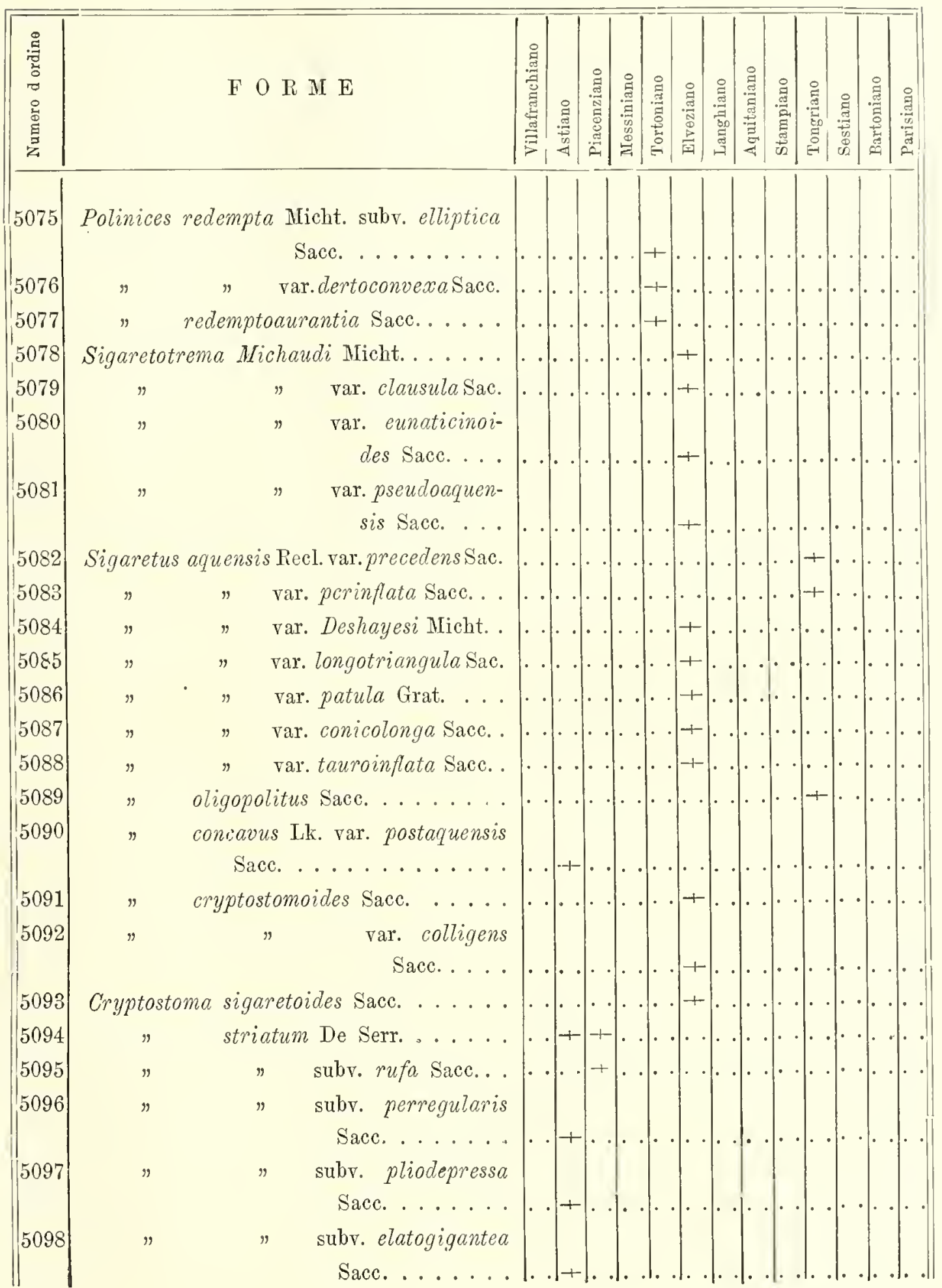




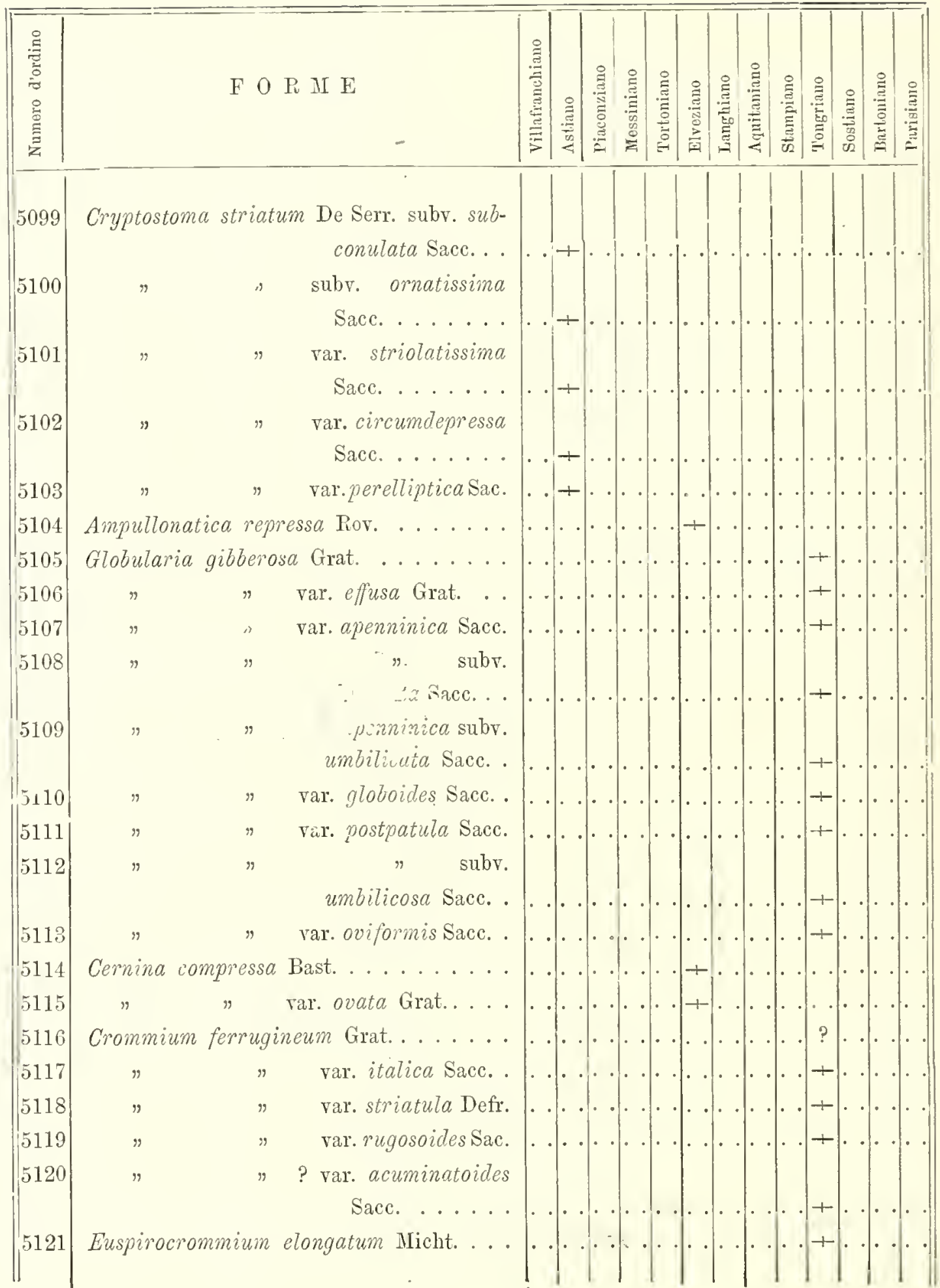




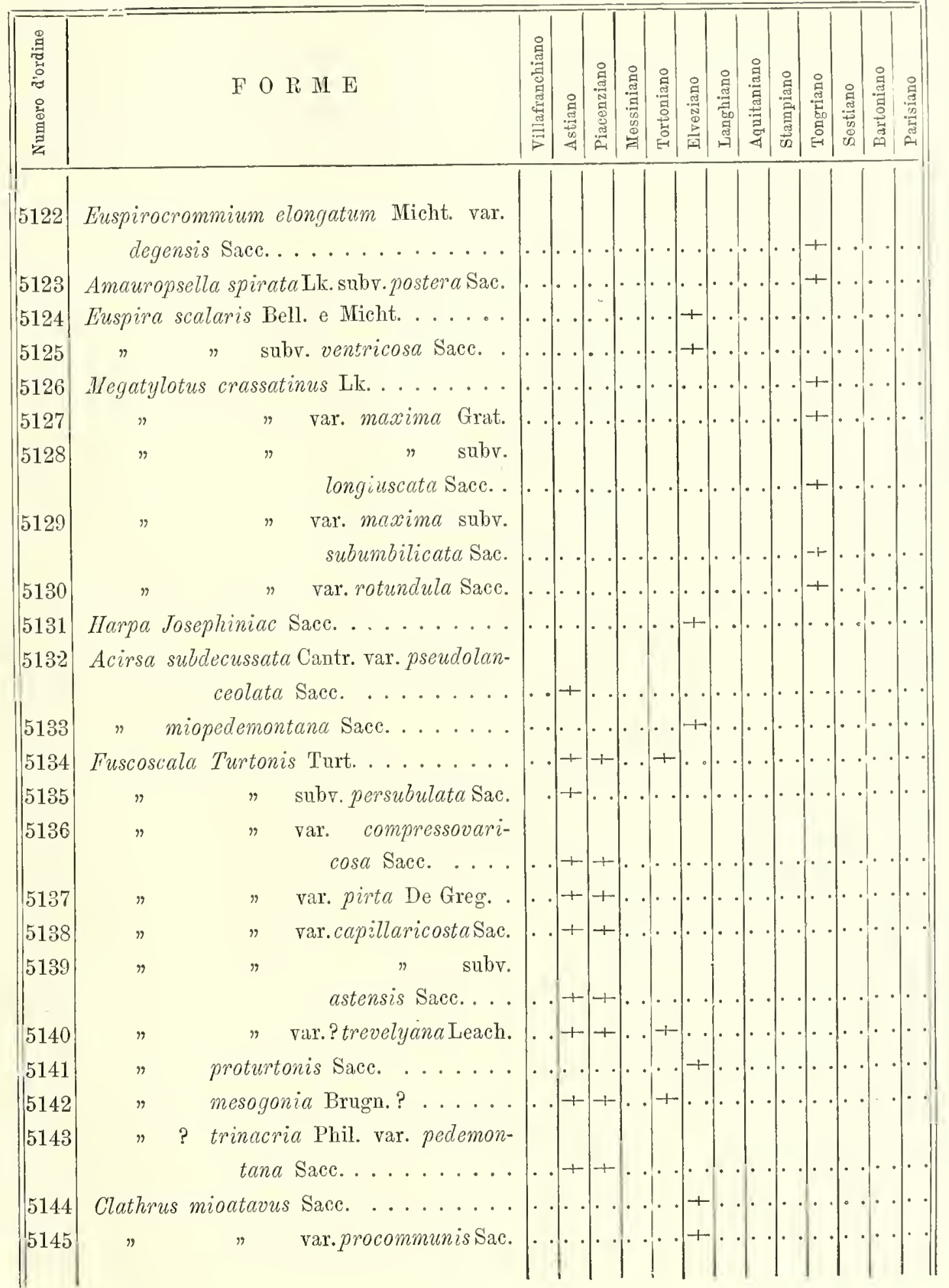




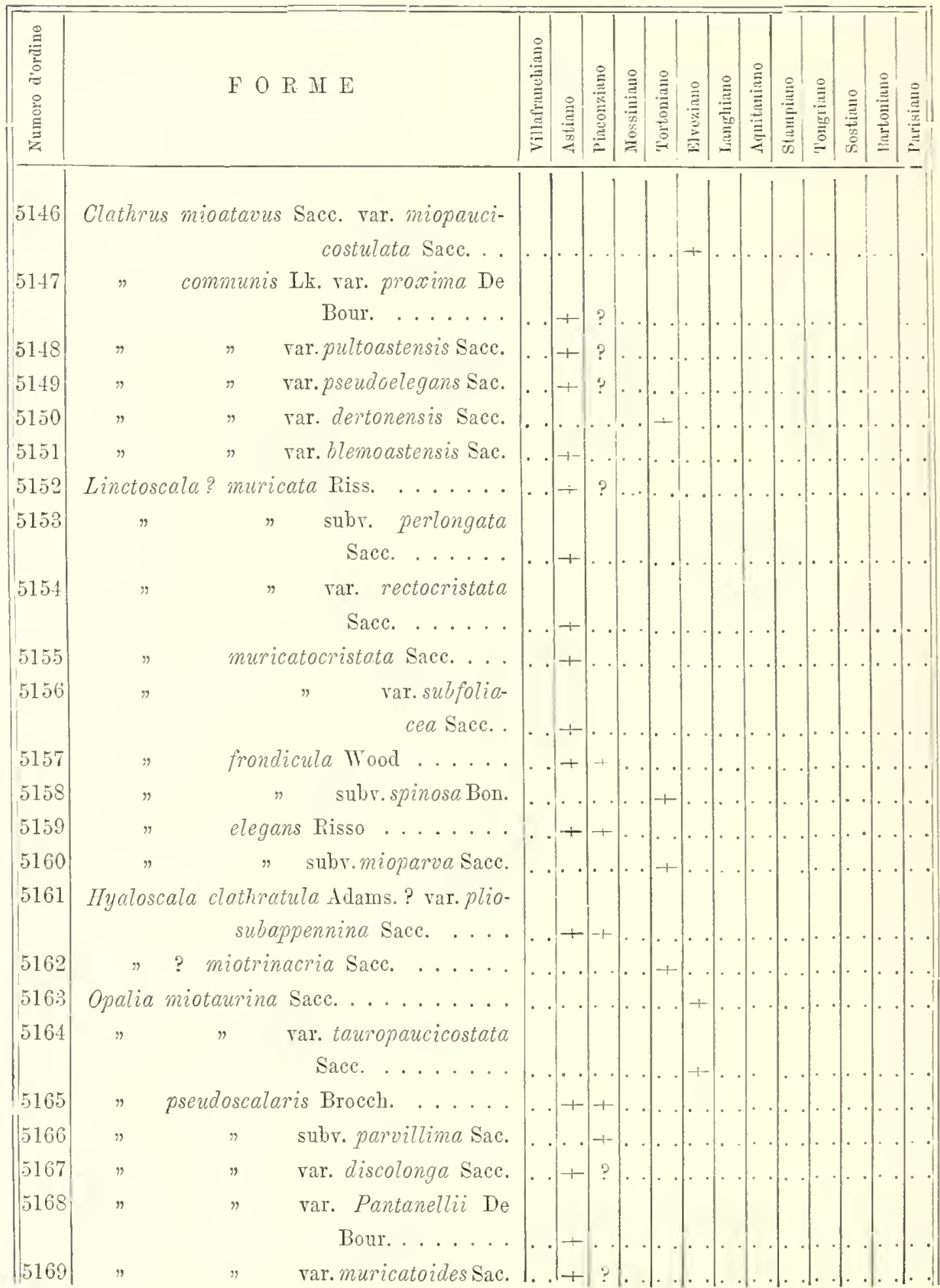


Catalogo paleontologico del bacino tersiario del Piemonte

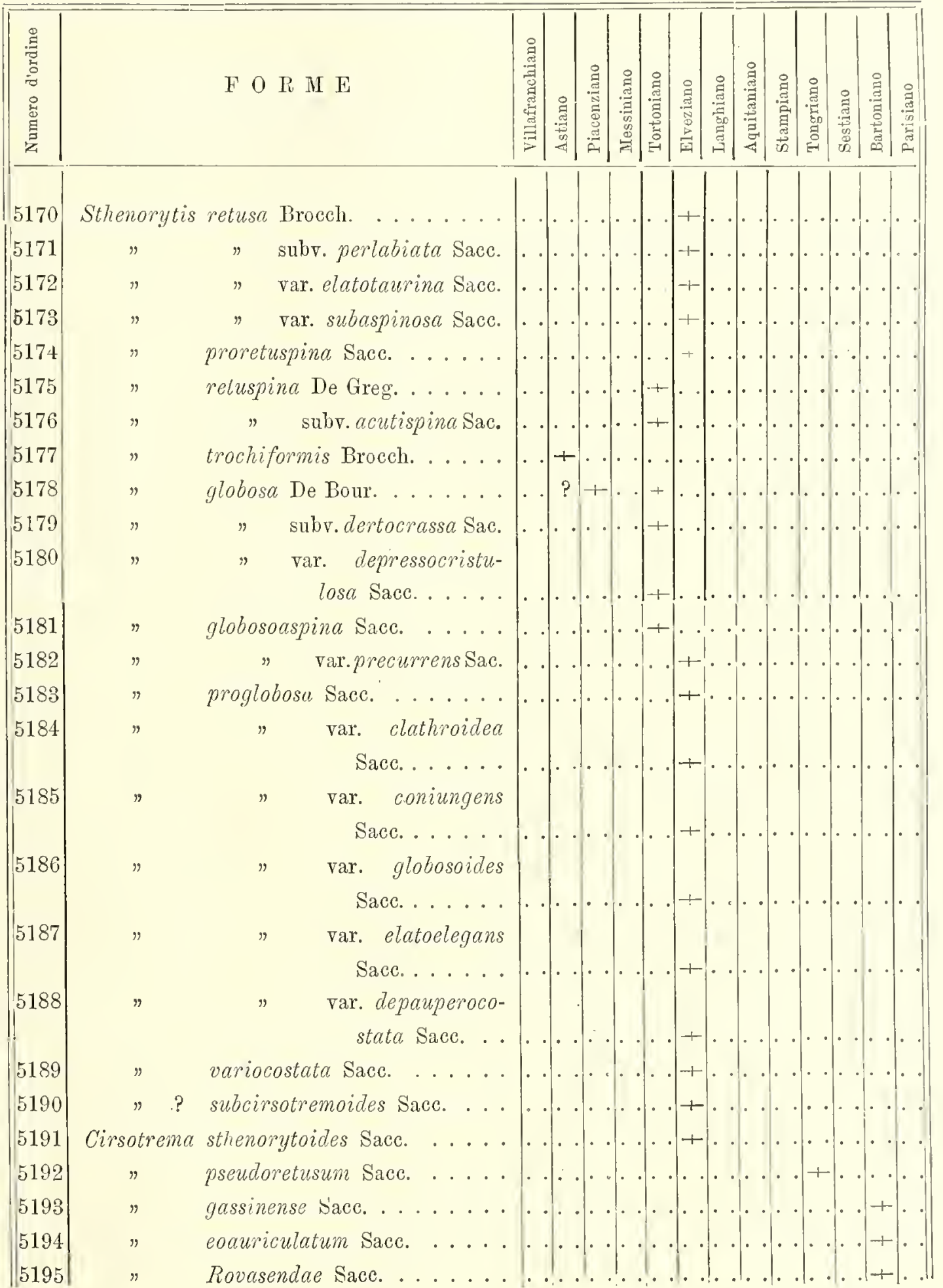




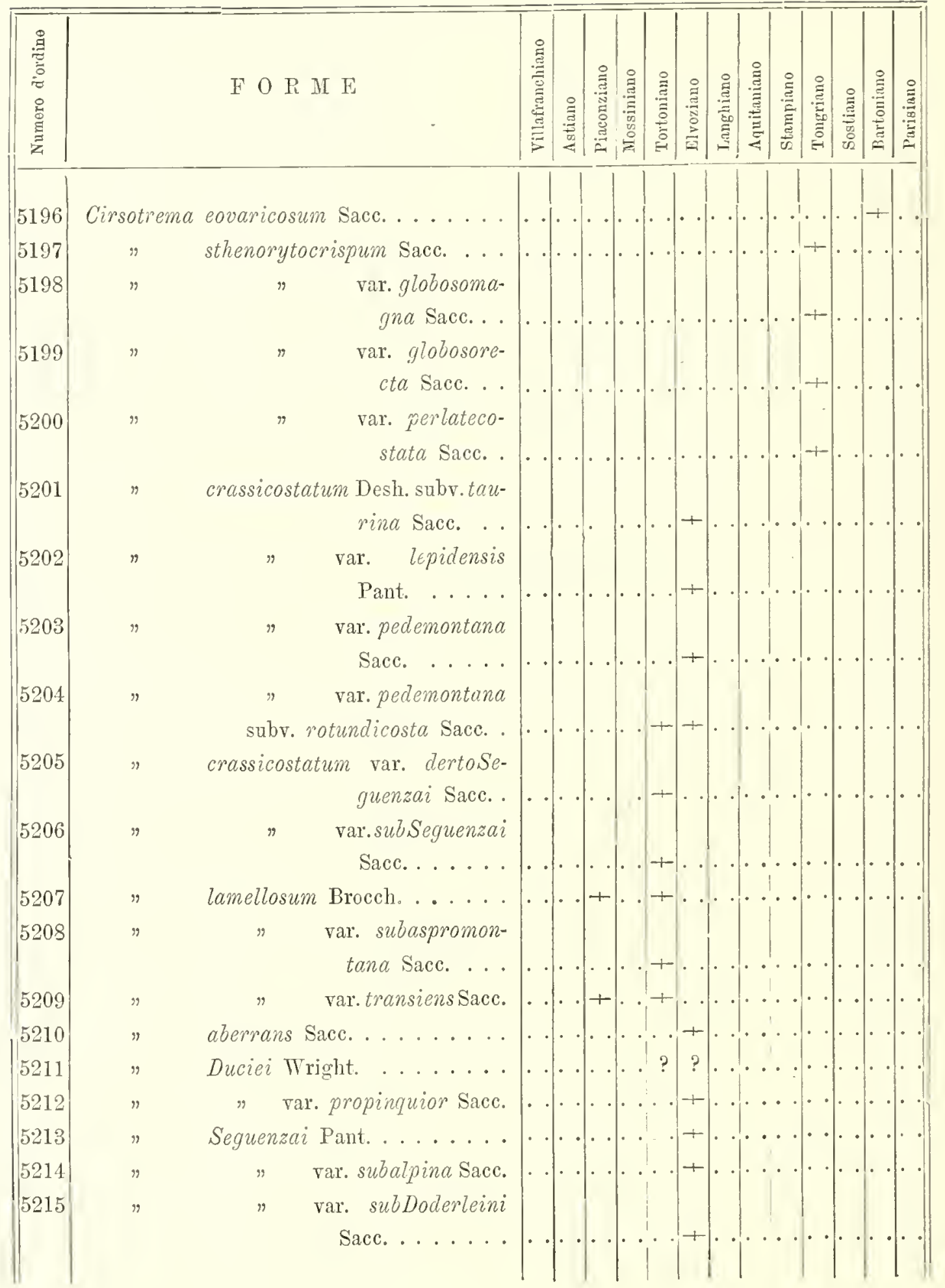


Catalogo paleontologico del bacino terziario del Piemonte

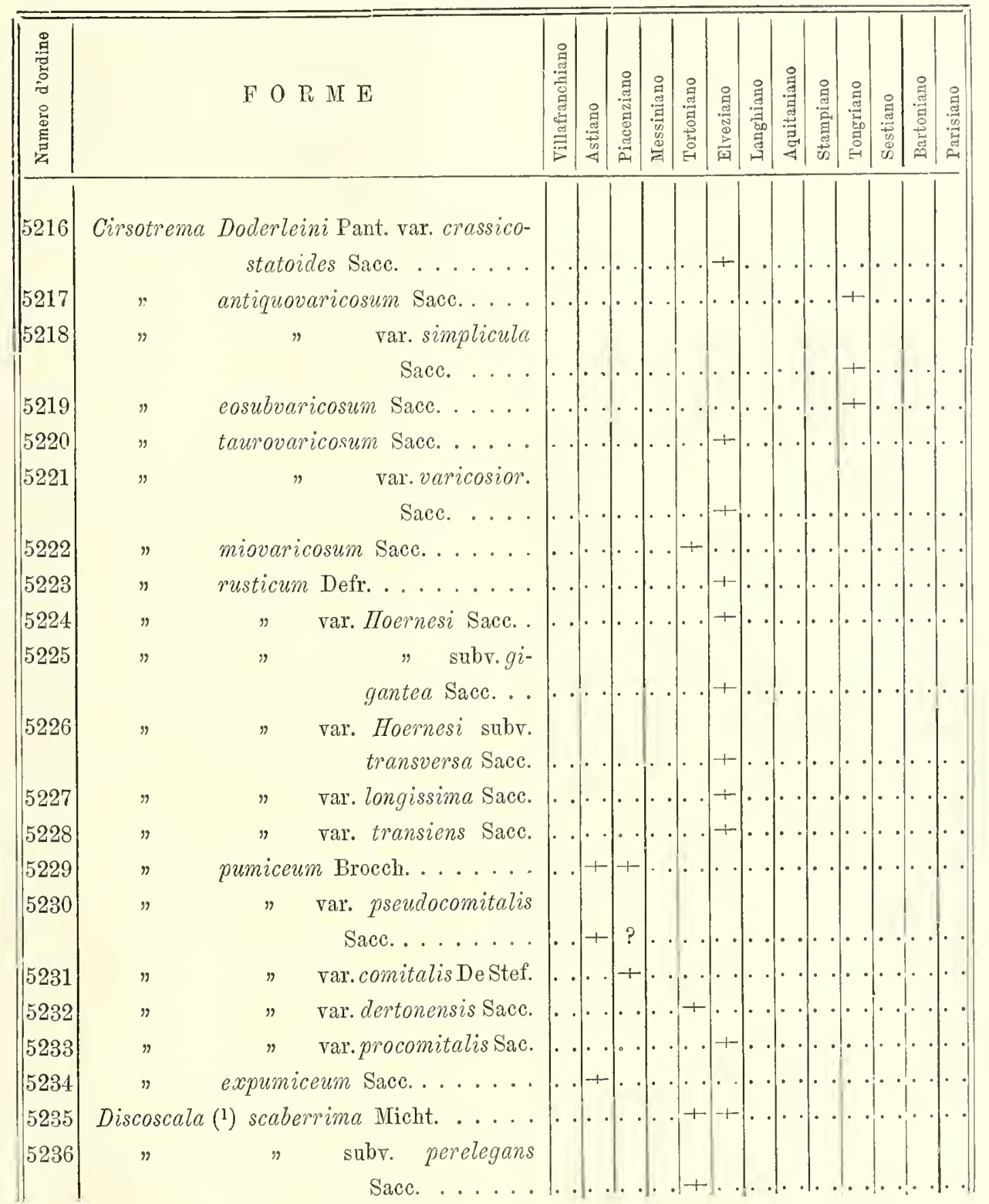

(1) Sottog. Discoscala Sacc. 1890 (Forme alquanto affini alle Cirsotrema, ma con disco basale, numerose lamelle longitudinali, cristate, non varicose. Tipo D. scaberrima). 


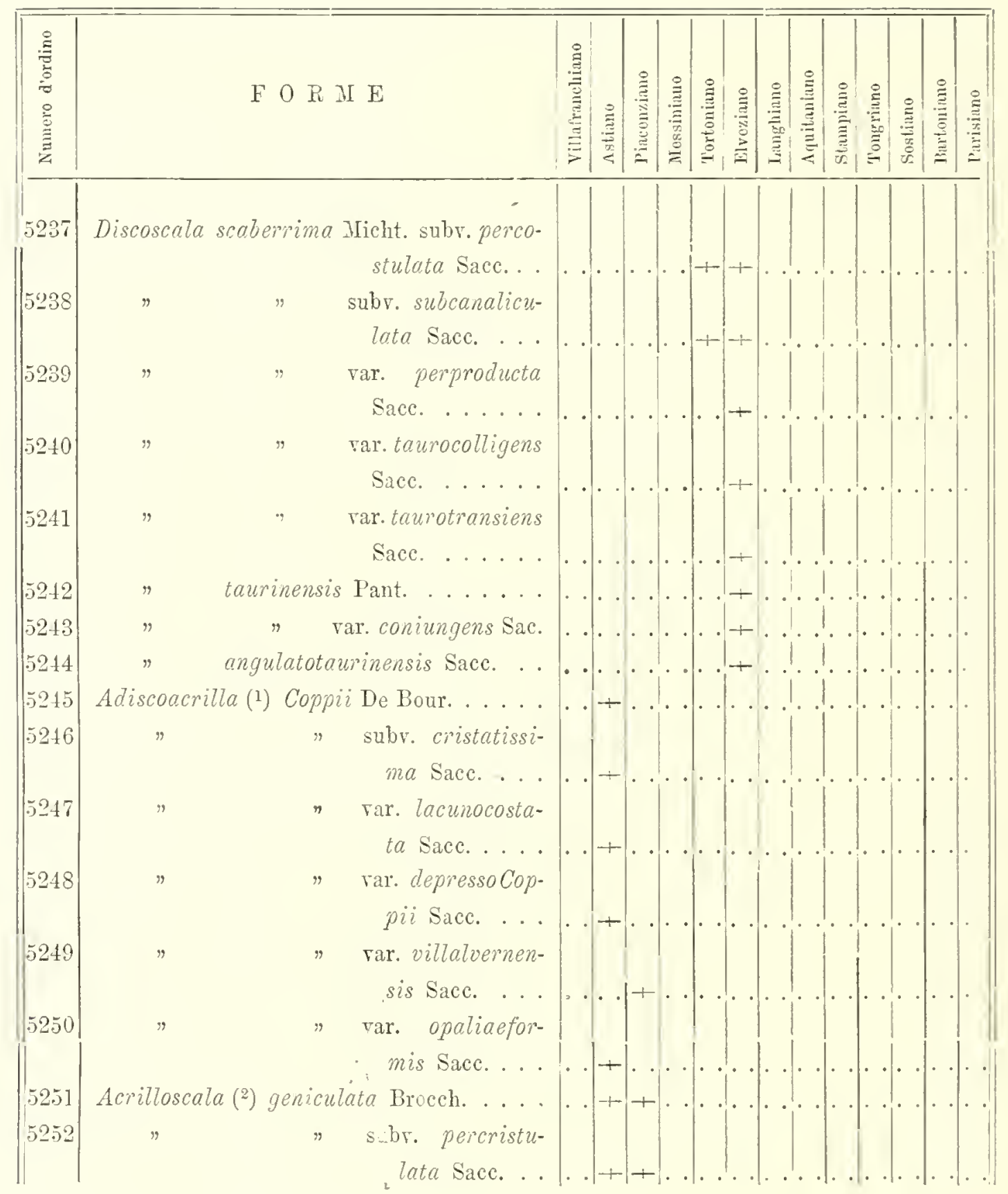

(1) Sottog. Adiscoacrilla Sacc. 1890 (Forme affini alle Acrilla, ma senza rero disco basale; le coste longitudinali alla base non presentano quasi inflessione).

() Sottog. Acrilloscala Sacc. 1890 (Forme affini alle Acrilla ed alle Clathroscala; ne è tipo la Scalaria geniculata Br.). 
Catalogo paleontologico del bacino terziario del Piemonte

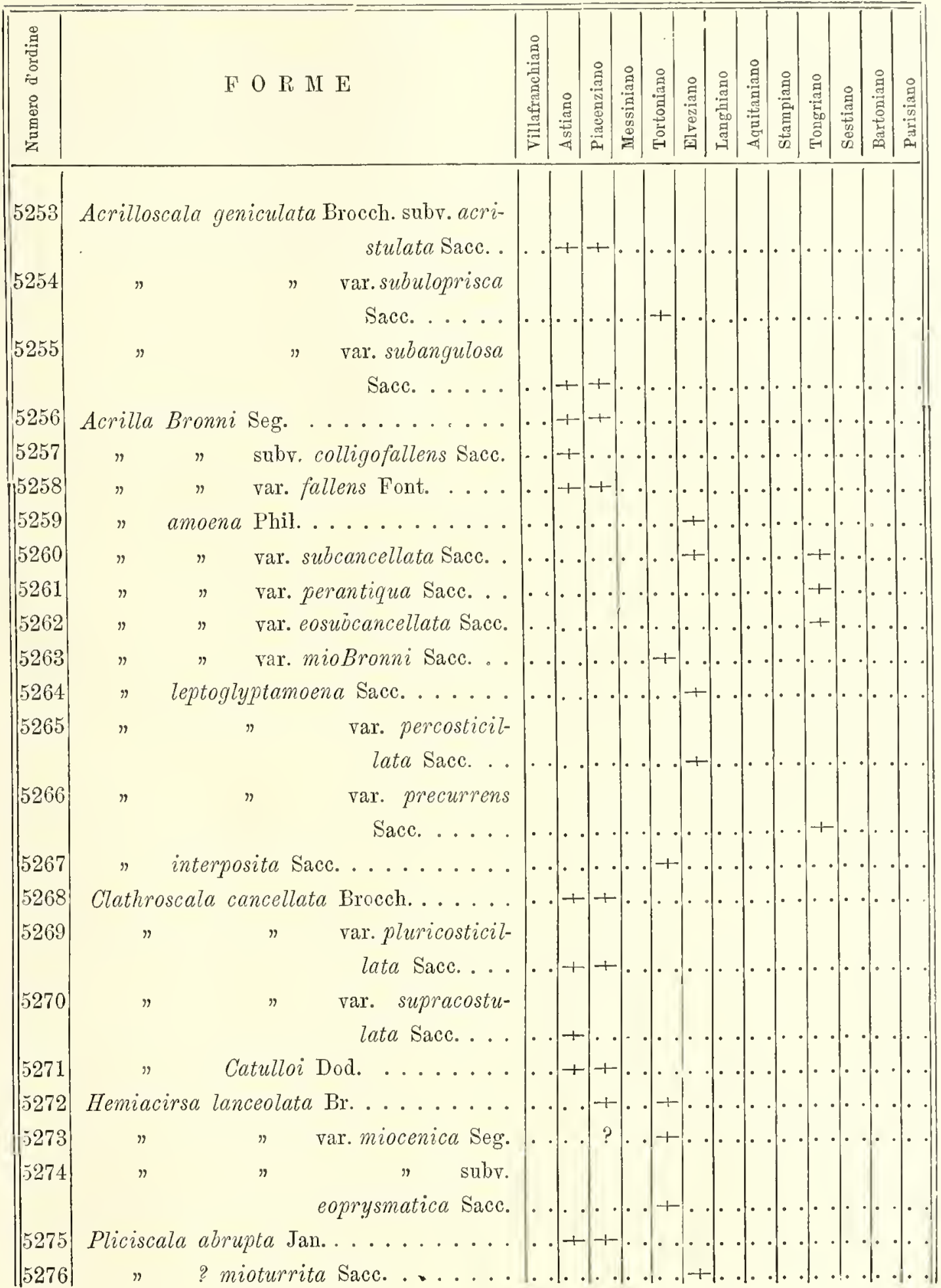




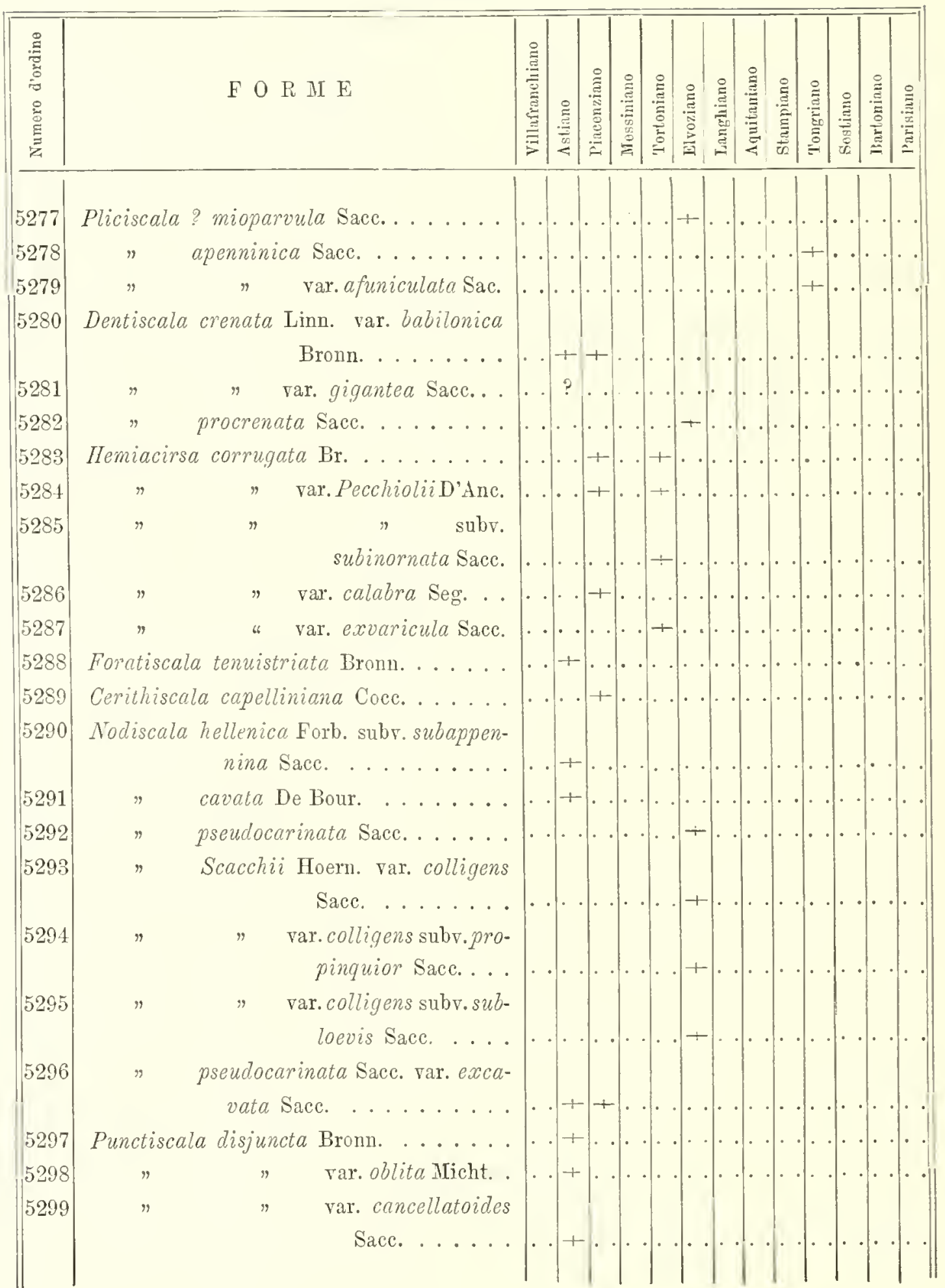




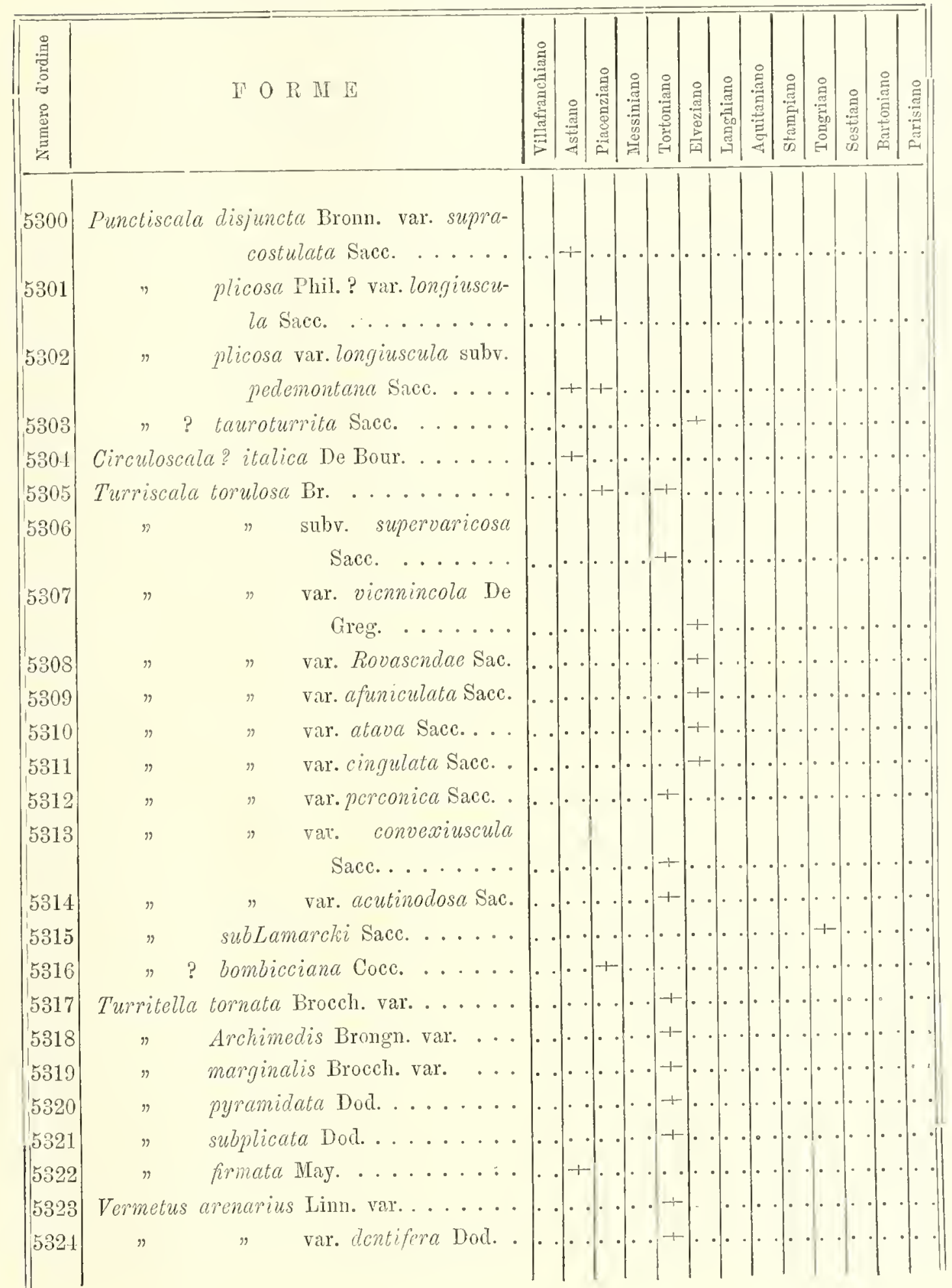




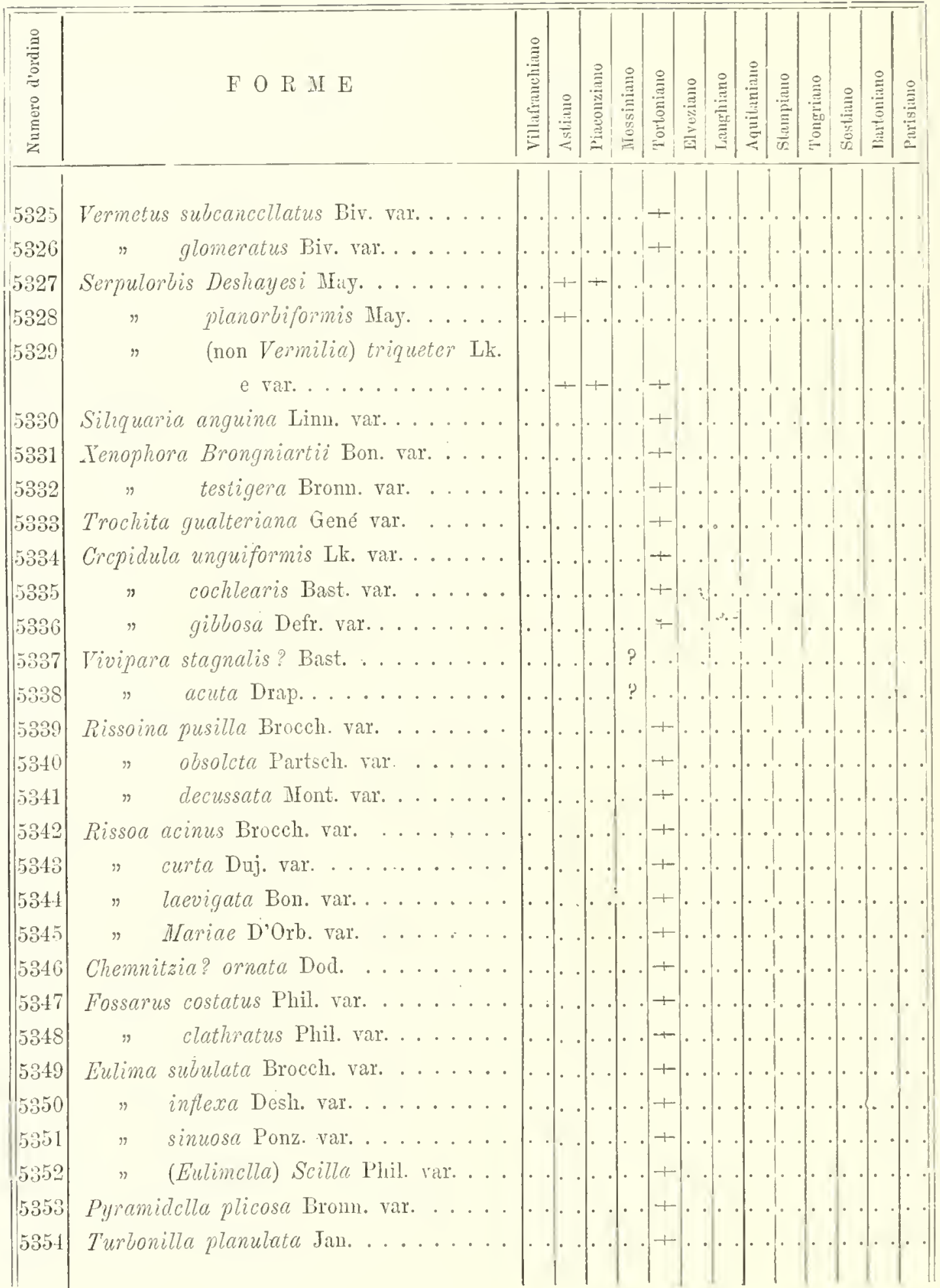




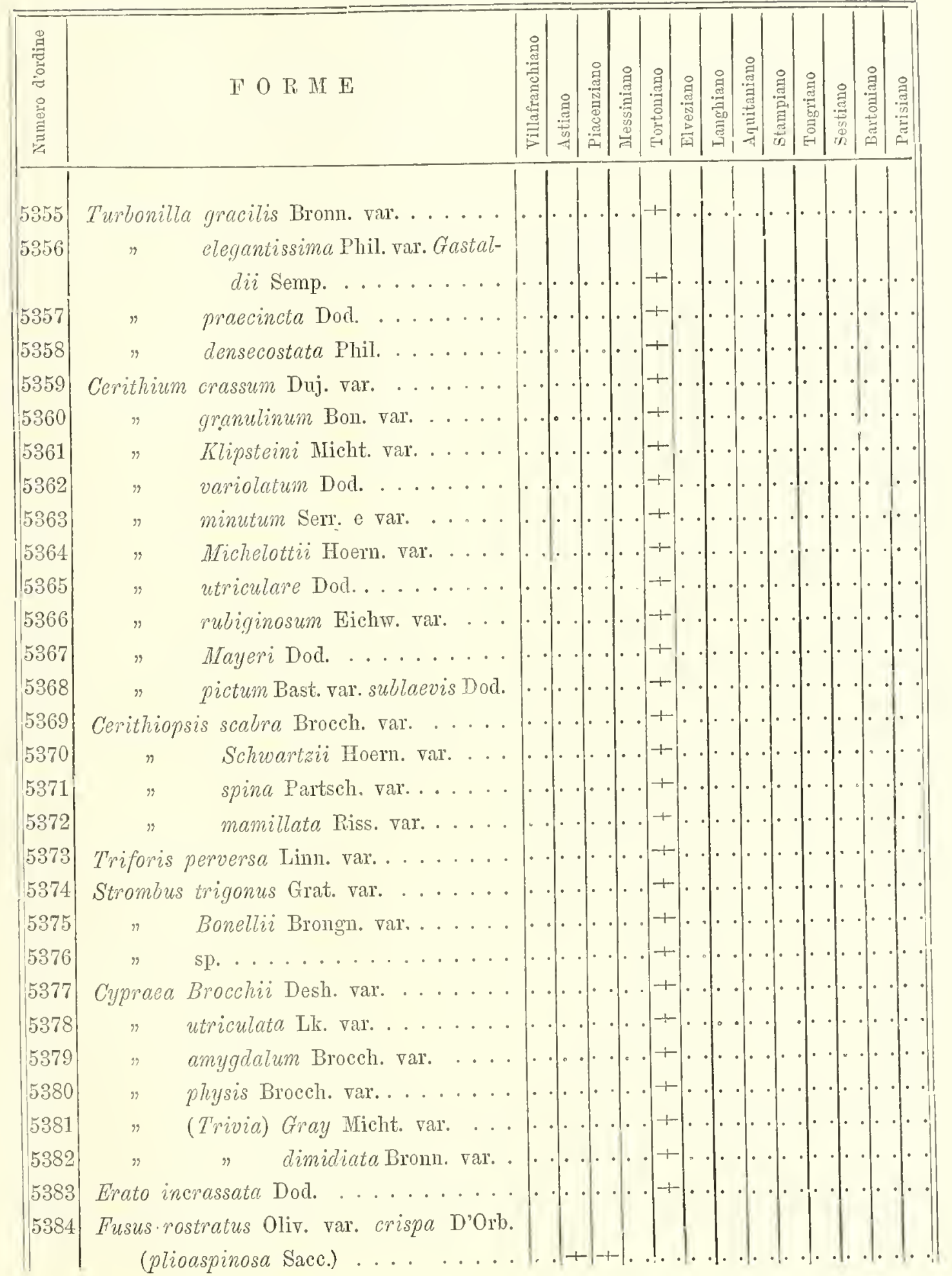




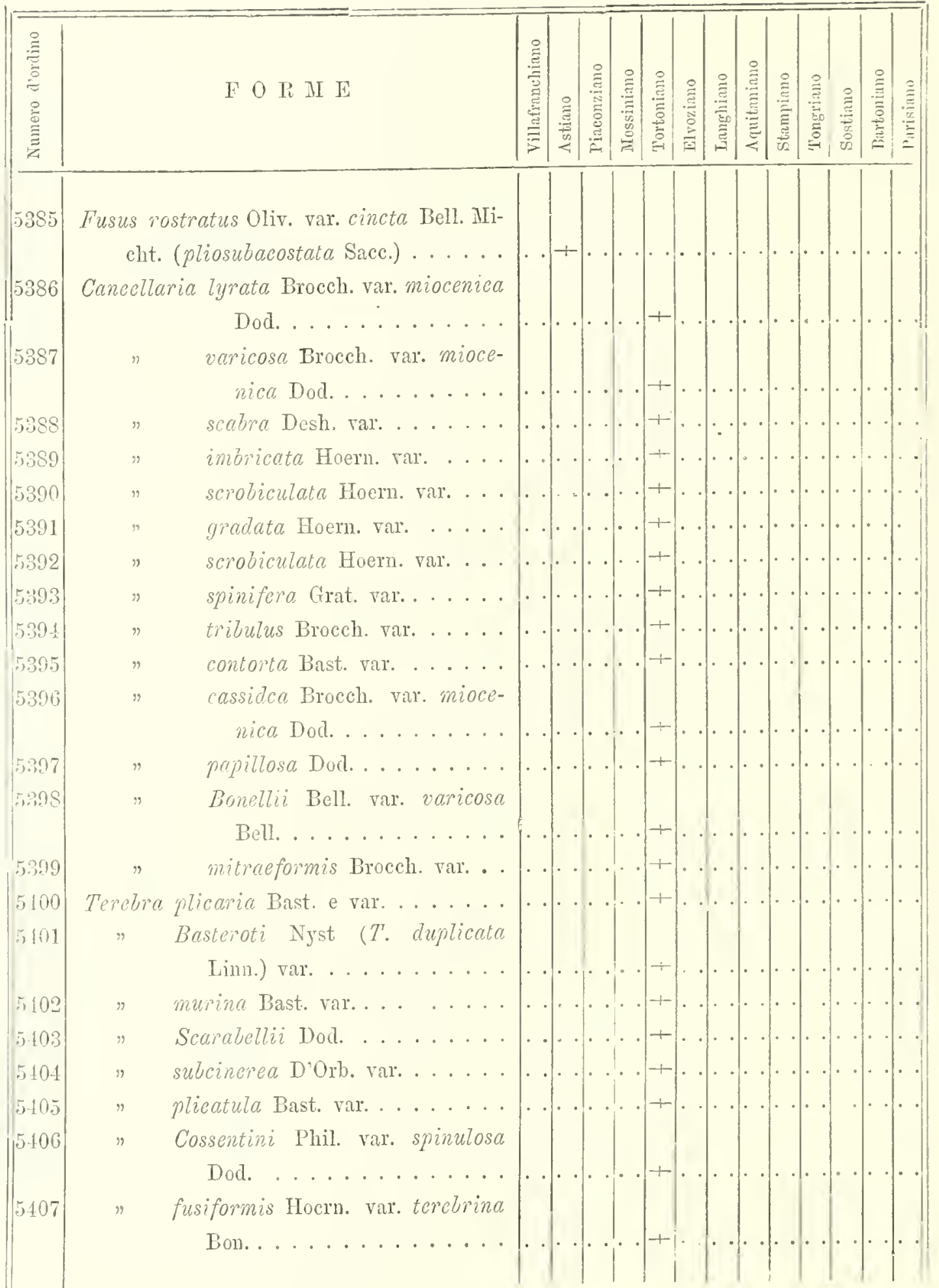




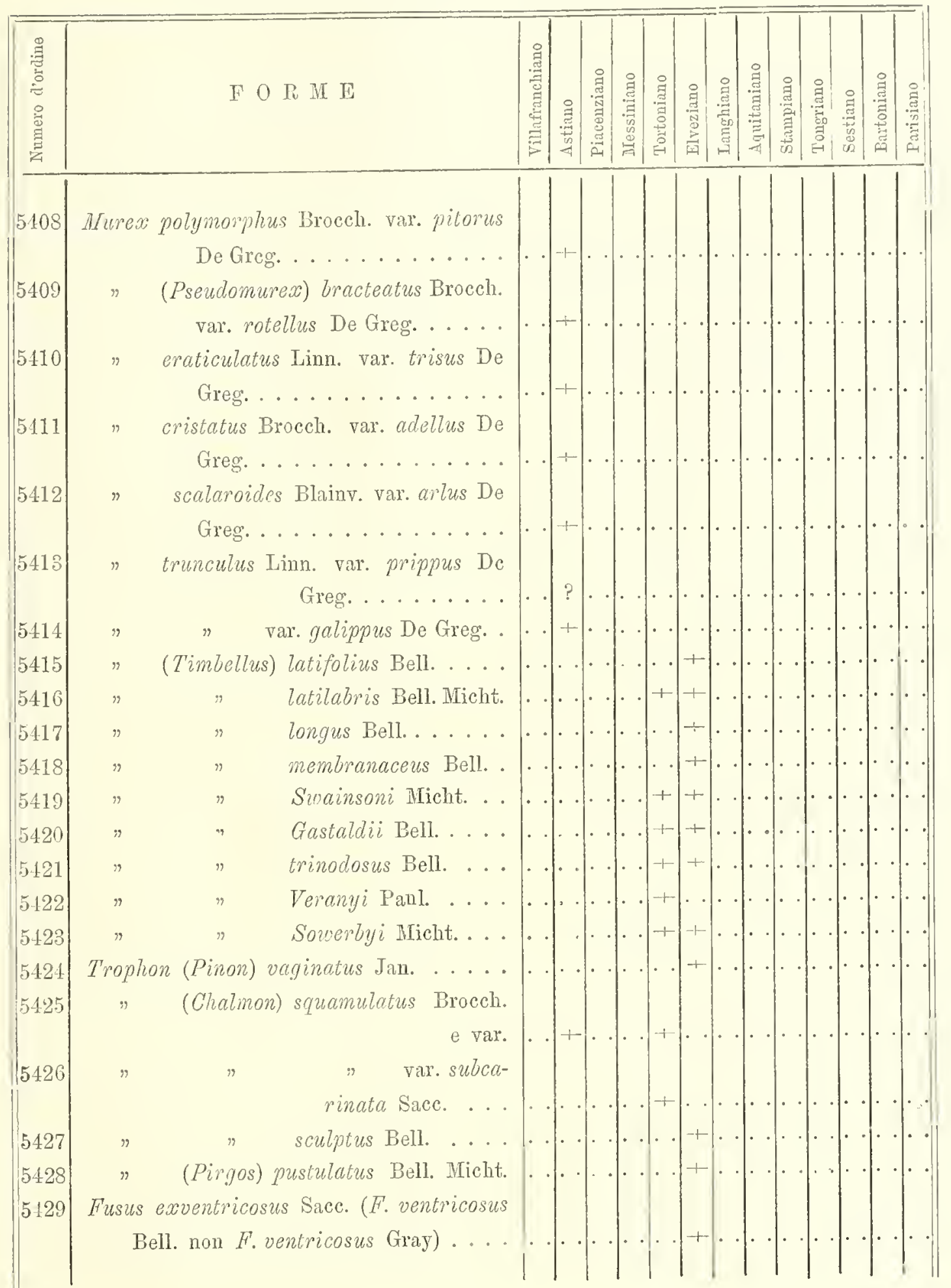




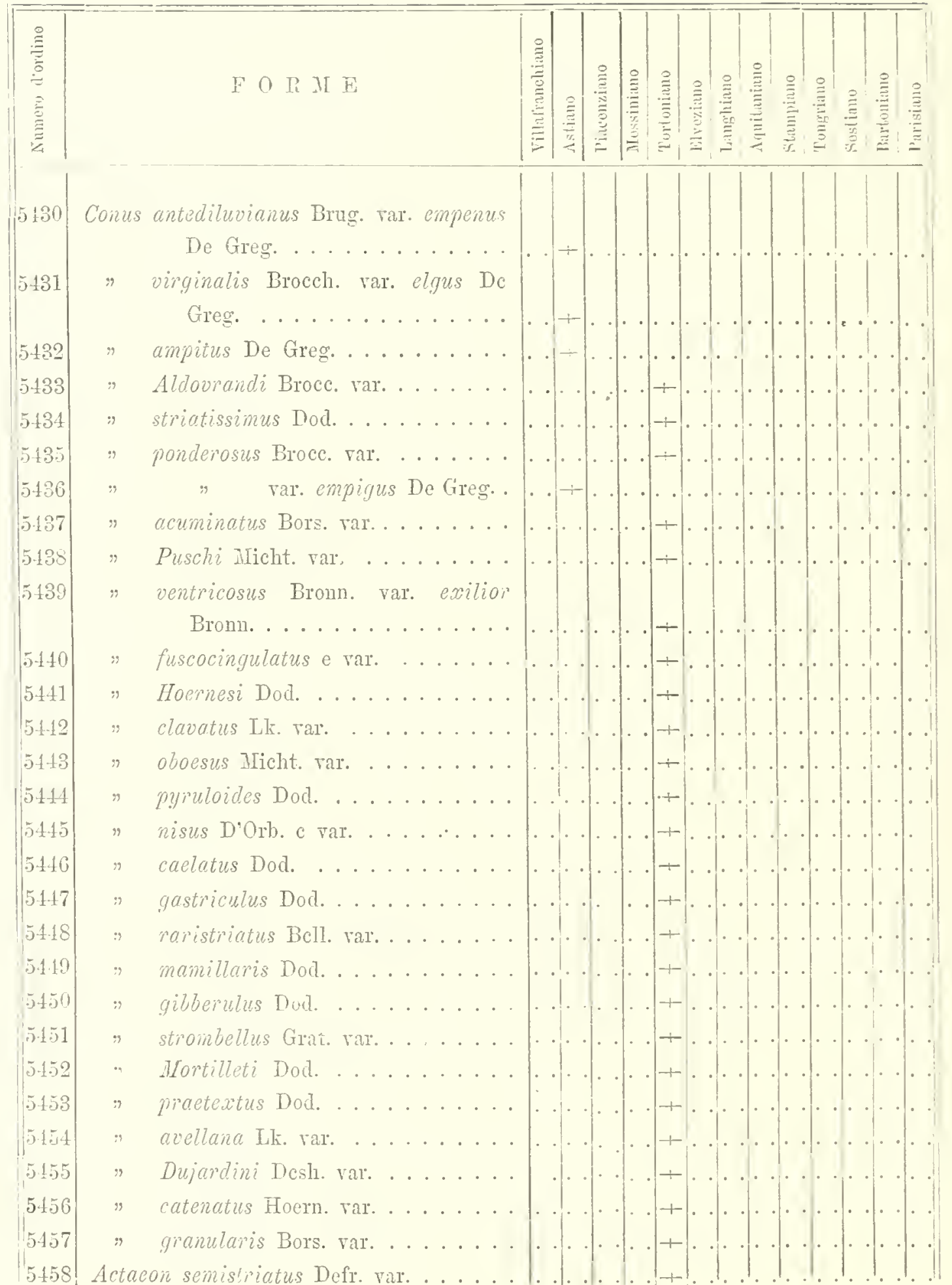




\begin{tabular}{|c|c|c|c|c|c|c|c|c|c|c|c|c|c|c|}
\hline 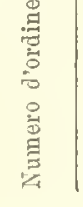 & $\mathrm{F} O \mathrm{P} \mathrm{M}$ & 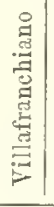 & 苞 & 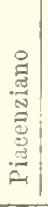 & 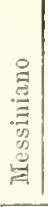 & 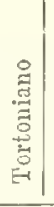 & 量 & 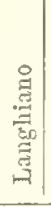 & 总 & 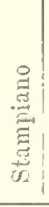 & 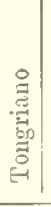 & 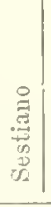 & : & 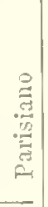 \\
\hline 5459 & Scaphander Grateloupi Micht. var..... & . & & • & • & + & & & & & & & & \\
\hline $5+60$ & Bulla utriculus Brocch. var........ & . & & & & + & & - & • & . & - & . & & \\
\hline $5+61$ & " burgidatensis D'Orb. var....... & . & . & • & • & + & . & - & . & . & . & . & & \\
\hline $5 \frac{1}{1} 62$ & " elongata Bronn. var. ....... & . & • & • & 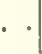 & + & & . & & . & . & . & . & \\
\hline 5463 & 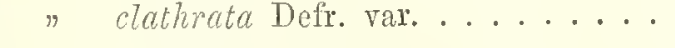 & . & - & . & • & + & & . & & - & . & . & & \\
\hline 5164 & $"$ radians Dod............ & . & . & & • & + & $\cdot$ & . & · & - & 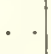 & 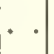 & . & \\
\hline 5465 & $"$ subconulus D'Orb. var. ...... & . & $\cdot$ & & & + & - & . & . & . & . & $\left.\right|^{\circ}$ & • & \\
\hline 5466 & $"$ truncata Phil. var. . . . . . . & 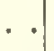 & . & • & 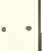 & + & . & . & . & . & . & . & & • \\
\hline $5+67$ & $" \quad$ acuminata Brag. var. ........ & . & . & . & 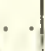 & +1. & . & • & - & $\cdot$ & . & . & . & \\
\hline $5 \pm 68$ & Bullina? (vel Cylichna) lajonkaireana Bast. & & & & & & & & & & & & & \\
\hline & 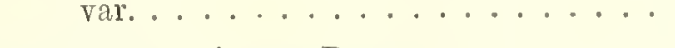 & • & • & & & + & & & & & & & • & \\
\hline 5469 & Lymnaeus minutus Drap. var....... & . & - & 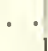 & $?$ & $?$ & & & $\cdot$ & & & · & - & \\
\hline 5470 & $\begin{array}{c}\text { Cuvieria astesana Rang. var. ...... } \\
\text { Artropodi Crostacei }\end{array}$ & & & & • & $-i$ & . & . & & & & & . & \\
\hline $5+71$ & Balanus cylindsaceus Lk. var. ...... & 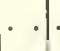 & & 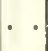 & 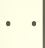 & + & & & & & & - & & \\
\hline 5472 & " latiradiatus Münst. var. . . . . & & & 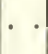 & . & + & & & & & • & & & \\
\hline
\end{tabular}




\section{INDICE DEI GENERI E DEI SOTTOGENERI}

A

Acacia 351.

Acanthias 4635.

Acanthinula 4512.

Acanthocyathus 963 .

Acer 284.

Acerotherium 4730.

Achanthina 2977.

Acirsa 5182.

Acmaea 1752.

Acme 2001.

Acrilla 5256.

Acrilloscala 5251

Actaeon 4409.5458.

Actinacis 712.

Adachna 1558.

Adelosina 4705

Adeorbis 1785 .

Adiantun 62 .

Adiscoacrilla 5245 .

Alaea 4540.

Alectryonia 1219.

Almus 146.

Alveolina 4753.

Alveopora 701.

Amalia 1480.

Amauropsella 5123.

Amphihelia 1008. 4837.

Amphimelania 2028.

Amphistegina 617.

Amphytragulus 4736.

Ampullonatica 5104.

Anachis 2928.

Ancilla 3818.

Ancillaria 3818, 3825.

Ancillarina 3812.

Ancillina 3817.

Aneylastrum 4474.

Ancylus $4+7 t$.

Andromeda 879.

Anonia 1220. 4850

Antenoclon 1099.

Anthracotherium 4734 .
Anura 315.

Apeibopsis 280 .

djhanitoma 4240.

Aphrastroea 815 .

Apocynophilluın 368.

Apollon 2493.

Aporrhais 2130 .

Araeacis 930.

Arancarites 99.

Arbacia 1053.

Area 1330. 4868.

Arcopagia 1645.

Aretomys 1717.

Ardisia 572 .

Areiole 1179.

Aroonauta 4568 .

Artocarpus 215.

Ascolatirus 3235.

Asimina 271.

Aspa 2496.

Aspidium 80

Asplenium 7:.

Assilina 656 .

Astarte 1459. 4883 .

Asterimina 573 .

Astraca 879.

Astraeopora 714.

Astrangia 893 .

Astrocoenia 918. 4819.

Astrohelia 931.

Ateoartis 4699 .

Athleta 3762.

Atoma 1362.

Aturia 4583.

Atys 4449 .

Aviculie 1305. 4865.

Axinus 1493 .

\section{$\mathbb{B}$}

bialanucochlis 2039 .

Biulanopleyllia $7: 0$.

Bizlantium 455. 
Balaenopteira 4709 .

Balaenula 4708.

Balanus 4588. 5471.

Bambusa 121.

Banksia 230.

Bela 4095.

Benizia 89.

Benzoin 252.

Berardiopsis 4718 .

Berchemia 319.

Betula 151.

Bigenerina 556.

Biloculina 394. 4754 .

Bitinia 1974.

Bittium 2123.

Blechnum 63, 70.

Bolivina 558.

Borsonia 4223.

Bos 4740

Boscia 277.

Bourgueticrinus 1026.

Brachelixella 2863.

Brachyphyllia 853.

Brissopsis 1085.

Bufonaria 2478.

Bulimina 565.

Bulininus 4520 .

Bulla 4439. 5160 .

Bullina 5468.

Bumelia 373.

Byrsonima 295.

\section{C}

Caecilianella 4526.

Calamophyllia 782.

Calianassa 4613.

Callitrites 95.

Calyptraea 1925.

Campylea 4501.

Cancellaria 3838. 5386 .

Cancer 4630.

Caprulus 1937.

Carcharodon 4640.

Cardilia 1700. 4894.

Cardita 1442. 4879

Cardium 1534. 4890.

Carichium 4455.

Carinaria 4407.

Carpinus 190.

Carthusiana 4505.

Carya 227

Caryophyllia 937.

Casmaria 2203.

Cassia 352.
Cassidca 2190.

Cassidulina 574.

Cassis 2178.

Castanea 185.

Caulinites 138.

Celastrophyllum 308.

Celastrus 303.

Cellepora 1161.

Ceratisolen 1660.

Ceratocyathus 943.

Ceratotrochus $986.482 !$.

Cercis 292.

Ceriopora 1154. 4841. 4843.

Cerithiopsis 2129. 5369.

Cerithiscala 5289.

Cerithium 2055. 5359.

Cernina 5114.

Cervus 4739.

Chalmon 5425.

Chanı 1473. 4885.

Champsodelphis 4720 .

Chara 49.

Chelonia 4690.

Chemnitzia 2023. 5346 .

Chenornis 4705.

Chicoreus 3302.

Chinconidium 360.

Chiton 1742. 4945.

Chlinocephalus 4627.

Chondrites 34.

Chrisodium 58.

Chrrsorlomus 3041.

Chrysophrys 4681.

Chyphastraea 857.

Cidaris 1032. 4838.

Cinammomum 256.

Cincinna 1972.

Cionella 4522.

Circe 1626.

Circophyllia 776.

Circuloscala 5304.

Cirsotrema 5191.

Cissus 267.

Cithara 2365.

Cladangia 899.

Cladocora 885.

Clanculus 1822.

Clavagella 1713.

Clavella 3119.

Clathroscala 5268.

Clathrus 5144.

Clathurella 4248.

Clausilia 4528.

Clavatula 4099.

Cleodora 4554.

Clinomitra 3733. 
Clinura 4188.

Clinurella 2895.

Cliona 682.

Clypeaster 1058 .

Cobitis 4687.

Coeloma 4620 .

Cnelosmilia 904.

Coenocrathus 961 .

Cocsalpinia 350 .

Columbella 2856.

Colutea 341.

Combretum 329.

Cominella 2499.

Comoseris 756 .

Confusastraea 855.

Conidea 2864.

Conoclypus 1055.

Conocrinus 1025 .

Conocyathus 935.

Conotrochus 991.

Conus 4363. 5430.

Coptosoma 1049.

Curalliophila 2981.

Corallium 697.

Corax 4638.

Corbula 1703.

Cornus 270.

Cornuspira 390.

Corylus 178.

Corjna 4545.

Crania 1176

Craspedopoma 2052.

Crassatella 1465.

Crassispira 4014.

Crepidula 1931. 5334.

Cristellaria 479. 4769.

Crommium 5116.

Cryptangia 892.

Crsptoconus 3996.

Cryptostoma 5093.

Cuma 2980.

Cupanoides 302.

Cupularia 1172. 4815.

Cuvieria 4565. 5470.

Cyathoseris 760 .

Cyclas 1573.

Cyclolina 616.

C5clolithes 753 .

Cyclonassa 2855.

Cyclostoma 2018 .

Crlichna 4450. 5468.

Cyllene 2830.

Cyllenina 2834.

Cynodonta 3256.

Cyperites 126.

Cyperus 124.
Crphosoma 1049.

Cypraea 2146. 5377.

Cypris 4608 .

Cjrena 1569.

Cystoseirites 31.

Cytherea 4907.

\section{D}

Dafne 216

Dalbergia 343.

Daphnella 4299.

Daphnogene 265

Dasiphyllia 777.

Defrancia 1130.

Deltocyathus 978.

Delphinula 1788. 4949.

Dendracis 717.

Dendrogyra 909.

Dendrophyllia 740. 4816.

Dendrosmilia 912.

Dentalina 443.

Dentalium 1719. 4937.

Dentiscala 5280.

Dertonia 3253.

Desmopliyllum 1011.

Diacria 4552.

Diastopora 4841 .

Dimorphastraea 755.

Dimorphina 532.

Diodon 4677.

Diosprros 376.

Diplodonta 1486.

Diplohelia 4837.

Diploria 798.

Diptychomitra 3734.

Discohelix 1862.

Discoscala 5235 .

Discoporella 1129. 4815.

Discorbina 592.

Discotrochus 992.

Discus 4516.

Ditoma 4318.

Ditrupa 1128. 4840.

Ditypodon 1569.

Dolicholatirus $32: 1$.

Dolichotoma 4228.

Dombeyopsis 275.

Donax 1629.

Dosinia 1627. 4911.

Dreissena 1324.

Drepanostoma 4506.

Drillia 3998.

Dryandroides 232. 4751.

Dryophyllum 189. 4752. 
Durvillides 24 .

Dyctioastraea 860 .

\section{E}

Eastonia 1686.

Eburna 2509.

Echinanthus 1069.

Echinocyamus 1057.

Echinolampas 1071.

Echinophoria 2249.

Echinus 1050.

Echitonium 367.

Elaeodendron 310.

Elephas 4744.

Fllasmoastraea 813.

Emarginula 1759.

Emmericia 1975.

Emys 4699.

Enallopsammia 739.

Engelhardtia 229.

Engina 3114.

Entalophora 1151. 4842.

Eoclathrus 23.

Eolatirus 3184.

Ephedrites 117.

Epidromus 2471.

Equisetum 91.

Equus 4733.

Erato 2177.5383.

Eriplia 4624.

Ervilia 4928.

Erycina 1481.

Erytroxylon 296.

Eschara 1152.

Eucaliptus 331.

Eudolium 2366.

Eugenia 334.

Euhyalina 4488.

Enlima 2004. 5349.

Eulimella 5352.

Eupatagus 1114.

Euphyllia 906.

Eupsammia 734.

Euspira 5124.

Euspirocrommium 5121 .

Euthria 3124.

Eronyinus 309.

\section{F}

Fagus 180.

Fasciculipora 11:5.

Fasciolaria 3175.
Favia 830.

Felsinotherium 4727 .

Ferussacia 4523.

Ficula 2412.

Ficus 206.

Fissurella 1754. 4946 .

Flakellulum 4556.

Flabellum 994. 4832.

Folliculus 4523,

Foratiscala 5288.

Fossarus 2003. 5347.

Fracastoria 283.

Fragaria 338.

Frondicularia 520.

Fulguroficus 2447.

Fuscoscala. 5134.

Fusoficula 2446.

Fusus 3001. 5384. 5429.

\section{G}

Gadus 4944.

Galactochilus 4492 .

Galeocerdo 4637.

Galeodea 2283.

Galeodocassis 2187.

Galeodosconsia 2344.

Gamopleura 4553.

Gardenia 361.

Gari 1650.

Gastrana 1649.

Gastrochoena 1711. 4935.

Genea 3165.

Genota 3989.

Geomalacus 4519.

Gibberula 3421.

Glabella 3395.

Glandina 4482.

Glandulina 516 .

Gleditschia 349.

Globigerina 579. 4791.

Globularia 5105 .

Glycimeris 1664

Glycrne 312 .

Glyptostrobus 93.

Gobius 4685.

Goniastraea 817.

Goniopteris 77.

Gonostoma 4510.

Gorgonella 690 .

Grapsus 4625.

Grewia 282

Gujera 330.

Gulnaria 4459.

Guttulina 530. 
Gutturnium 2469.

Grraulus 4470

Gyrorbis 1971. 4469.

\section{H}

Halia 2142.

Haliotis 1766.

Halysiastraea 862.

Harpa 3774. 5131.

Hauerina 392.

Haustellum 3269.

Helcion 1750.

Heliastraen 833. 4817.

Helicia 236.

Helicteres 278.

Heliopora 700 ,

Helix 4492.

Helminthoida 16.

Helminthopsis 15

Hemiacirsa 5272. 5283.

Hemiaster 1080.

Hemicardium 4893.

Hemicidaris 1048.

Hemifusus 3061.

Hemipristis 4639 .

Heterostegina 667.

Hexastraea 920.

Heynemannia 4475.

Hiatula 1653.

Himnites 1254.

Hipponyx 1935.

Hippopotamus 4737 .

Homotoma 4273.

Hoplocetus 4715 .

Hoploparia 4610.

Hyalina 4486.

Hyaloea 4547.

Hyaloscala 5161.

Hydractinia 1022.

Hydrobia 1976.

Hydrophora 799.

Hymenophyllum 87.

Hypolepis 76 .

\section{I}

Iania 3034.

Ianulus 4518.

Ierea 686 .

Ilex 313.

Iopas 2976.

Jouannetia 1716 .
Isis 692. 4815

Isocardia 1577. 4895.

Ittiodoruliti 4672.

Iuglans 218.

Iupiteria 1125.

Istmia 4542 .

\section{L}

Labatia 317.

Labrax 4683.

Lachesis 4098.

Lacuna 2002.

Lagena 810.

Laminarites 22.

Laminifera 4529.

Lamna 4662.

Lampas 2482.

Larix 115.

Lastrea 56.

Latiaxis 3000 .

Latirus 3184.

Laurophyllum 217.

Laurus 237.

Lebias 4686.

Leda 1417. 4878.

Leiopathes 690 .

Leiostoma 3054 .

Lembulus 1418.

Lenzites 55 .

Lepralia 1145.

Leptastraea 863.

Leptomussa 775.

Leucotlioe 380.

Libellula 4633.

Lima 1244.

Iimax 4475 .

Limea 1253.

Limopsis 1396.

Linctoscala 5152 .

Linga 4923.

Lingulina 511.

Linthia 1073.

Liquidambar 254.

Liriodendron 273.

Litliaroea 705.

Lithodomus 1321.

Lithophyllia 774.

Lithothanmium 50 .

Litsoea 253.

Lituola 389.

Lobopsammia 752 .

Loripes 1533.

Lucina 1494. 4913.

Lunulites 11694846 . 
Lutraria 1693. 4931.

Lymreus 4458. 5469.

Lymnophysa 4458.

Jymnus 4461.

Iyria 3741.

\section{M}

IIachaerium 346.

Hacrurella 2902.

Iactra 1687. 4930.

ITacularia 4496.

Nadrepora 718.

IIagnolia 272.

Malea 2400.

Malletia 1433.

Malpighiastrum 293.

Mangelia 4301.

Manicina 796.

Maretia 1118.

Margaritana 1439.

Marginella 3395.

Narginulina 467.

Margovoluta 2365.

Marpessa 4583.

Mastodon 4744.

Hayeria 3056.

Keandrina 797.

Megatylotus 5126.

Negerlea 1182.

Trelampus 4454.

Melania 2026.

Melanopsis 2031.

ILembranipora 1137.

Merycopotanis 4738 .

Metastraea 876 .

Metrosideros 333.

Metula 3067.

Micromitra 3722

Vicropocrinus 1030 .

Microtropis 312.

Millepora 1023.

Miocardia 1576.

Miocenia 2498.

Nitra 3423.

Vitraefusus 3164.

Mitrella 2866.

Modiola 1320.

Moltlivaultia 767.

Monodonta 1823. 4952.

Monticulopora 1$] 60$.

Montipora 724.

Morionassa 2350.

Münsteria 8.

Murex 3263. is 108.
Muricidea 3290.

Mursiopsis 4626 .

Mya 1701. 4933.

Nycetophyllia 787.

Myliobates 4670 .

Myrica 141. 4749.

Myriozoon 1166.

Nyristica 3057.

Myrsine 371.

Mytilus 1310.

\section{$\mathbf{N}$}

Najadopsis 130 .

Nassa 2516.

Natica 1950. 4961.

Naticina 5010.

Nautilus 4579.

Neaera 1710

Neilo 1434.

Nemertilites 25.

Neoathleta 3756 .

Neolatirus 3233.

Neptunus 4623.

Nerita 1826. 4954.

Neritinium 365.

Neritodonta 1835.

Neverita 5040 .

Nipadites 138.

Niso 2012.

Nodiscala 5290.

Nodessaria 420. 4767.

Nonionina 660. 4796.

Notidanus 4634.

Nucula 1404.

Nulliporites 6.

Nummulites 623. 4797.

\section{0}

Ocinebra 3351.

Odnstomia 2025.

Olea 364

Oligotoma 4234

Olivella 3794.

Oniscidia 2351

Opalia 5163.

Operculina 620.

Ophicardelus 4453.

Orbitoides 668. 4807.

Orbulina 577.

Oreula 4544.

Oreodaphne $26 t$.

Ornitichnites 4706 . 
Orthocerina 464.

Orthurella 2916.

Ostraea 1202. 4847.

Otodus 4619.

Otoliti 4673.

Opula 2175.

Oxyrhina 4651 .

Pagodina 4543.

Pagurus 4611.

Palaeocarpilius 4681.

Palaeolobium 294. 347.

Palaeomyra 4632.

Paleodictyon 1.

Paliurus 318

Palaega 4609

Paracyathus 981. 4831.

Parasmilia 905.

Patula 4516.

Patella 1745.

P'aronia 524.

Payradeartia 5037.

Pecchiolia 1479.

Pectell 1257. 4858.

Pectunculus 1378. 4875.

Pelloea, 61.

Pentacrinus 1027.

Pericosmus 1109.

Peringia 1983.

Peristeruia 3238.

Perna 1307. 4866.

Perrona 4170.

Persaea 250.

Persicula 3417.

Persona 2476.

Petraeus 4520 .

Petricola 1580.

Phaenicites 137.

Pharyngodrpilus 1674.

Phasianella 1769.

Pholadumya 1675.

Pholas 1717. 4934 .

Phos 2500

Phragmites 118.

Phyllangia 895.

Phyllites 384.

Phillocaenia 921. 4820.

Pliyllonotus 3317.

Physa 4463.

Physotherium 4717.

Pinna 1326. 4867.

Pinon 5424.

Pinus 101.

Pirgos 5428.

Pirus $3: 36$.

Pisania 3069

Pisidium 1574.

Planera 200.

Planorbis 4464.

Planorbụlina 595.

Platanus 153.

Plenasirm 75.

Plerastraea 877.

Plesiastraea 851.

Plesiocetus 4710.

Plesiolatirus 3225.

Plesiopliyllia 805.

Pleurocora 891.

Pleurotoma 3882.

Plicatula 1227.

Pliciscala 5275.

Poacites 120.

Pocillopora 725.

Poculiua 4559.

Podabacia 759.

Polinices 5058.

Polipodium 60.

Polistigmites 53.

Pollia 3082.

Pollicipes 4587.

Polloneria 4528.

Polygona 3227.

Polygyra 4507

Polymorphina 525. 4783 .

Polystomella 657. 4795.

Pimatias 2051.

Populus 192.

Porites 703.

Porocidaris 1047.

Porpliyria 3776.

Portunus 4621.

Potamides 2091.

Primnoa 689.

Prionastraea S67. 4818.

Priscophyseter 4714.

Proprlidium 1753.

Protoseris 758.

Prunus 339.

Psammechinus 1054

Psammobia 4912.

Pseudolatirus 2243.

Pseudonurer 5409.

Pseudotoma 4193.

Pteris 64.

Pterocar. 228.

Pterocera 2133.

Pteronotus 3274.

Pullenia 586.

Pulvinulina 603. 
Punctiscala 5297.

Pupa 4543.

Pnrpura 2941.

Pusia 3719

Pyramidella 2014. 5353.

Pyrgoma 4606.

Pyrgulina 2024.

Pyrostoma 4531.

Pyrulina 4785.

\section{Q}

Quereus 155.

Quinqueloculina 403. 4761.

\section{R}

Rabdophyllia 783 .

Radiopora 1136.

Ranella 2478.

Ranina 4617.

Raphitoma 4320.

Retepora 1157.

Rhammns 321.

Rhinoceros 4732.

Rhipidogyra 911.

Rhizotroeus 1007.

Rhombus 4688 .

Rhynchonella 1199.

Phyncolithes 4582 .

Rhynocantha 3278.

Rhytisma 54.

Ringicula 4416.

Rissoa 1984. 5342.

Rissoina 2000. 5339.

Robulina 504.

Rosalina 1792.

Rostellaria 2143.

Rotalia 608. 4794.

Rotularia 1125.

Roualtia 4220.

Runa 1068.

Sabal 136

Sabatia 4448.

Sagrina 540.

Salicornaria 1143.

Salisburia 116.

Salix 197.

Sapindus 297.

Sapotacites 374 .
Sassafras 248.

Sassia 2161.

Sauritichnites 4704 .

Saxicava 1670.

Scabrella 1924.

Sealaria 1864.

Scalpellum 4605.

Scaphander 4486. 5459.

Scaptorrhynchus 4569 .

Searabella 4536.

Searus 4684. 4689.

Sehizaster 1095 .

Schizodelphis 4721.

Sconsia 2347.

Serupocellaria 1144.

Seutella 1067.

Scutum 1765.

Selache 4661.

Semicassis 2204.

Sepia 4570.

Septastraea 808.

Sequoia 97.

Serpula 1122.

Serpulorbis 5327.

Serrulina 4530.

Sigaretotrema 5078.

Sigaretus 1947. 5082.

Siliquaria 1916. 5330.

Simplicotaurasia 3081.

Simpulum 2453.

Smilax 139.

Smilotrochus 984.

Solarium 1841. 4956.

Solecurtus 1657.

Solen 166L

Solenastraca 864.

Solenomya 1441.

Sophora 348.

Sparganium 131.

Spatangus 1120.

Sphaerites 52.

Sphaerodus 4675.

Sphaeroidina 588.

Sphenopteris 88 .

Spirillina 591.

Spirodiseus 4464.

Spiroloculina 401. 4756.

Spiropteris 90.

Spirorbis 1127.

Spirulirostra 4578.

Spondylus 1234. 4855.

Squalodon 4719.

Stazzania 3411.

Steno 47?4.

Stephanocacnia 919.

Stephanophyllia 737. 
Sthenorytis 51:0.

Stomatophora 1133.

Strepsidura 3055.

Strombus 2134. 5374.

Strophostoma 2053.

Stylaster 1024.

Stylocaenia 914.

Stylophora 925.

Stylotrochus 993.

Succinea 4546.

Surcula 3948.

Symphyllia 786 .

Syndosmya 1655. 4926.

Syringa 366.

\section{1}

Tachaea 1193.

Tapes 1586. 4896.

Taphrhelminthopsis 11 .

Taurasia 3075.

'Taurinicthys 4676.

Taxodium 114.

'Tecosmilia 784.

Tectonatica 5039.

Tellina 1633. 4924.

Terebra 3871. 5400.

Terebratula 1189.

Terebratulina 1184.

'Teredo 1718.

Terminalia 327.

Testacella 4481.

Testudo 4698.

Tethia 687.

Tetrastomella 2884.

Textularia 541. 1786.

Thamnastraea 754 .

Thecidea 1178.

Thegioastraea 852.

Thiarella 2919.

Thiarinella 2927.

Thliacia 1684. 4932.

Thrichomanes 86 .

Thuia 96.

Tilia 279

Timbellus 5415.

Tindaria 1436.

Titanocarcinus 4628 .

T'oxobrissus 1092.

Trichia 4504.

Tridacnophyllia 794.

Triforis 2128. 5373.

Trigonodon 4689.

'Triloculina 408. 1760 .

Trionyx 4693.
Triptychia 4534.

Triton 2449.

Tritonium 2449.

Tritonofusus 3053 .

Trivia 5881.

Trochita 1927. 5393.

Trochocyathus 961. 4822.

Trochoseris 764 .

Trochosmilia 902.

Trochus 1791. 4950 .

Trophon 3848. 5424.

Tropidiscus 4467.

Truncatulina 597.

Trymohelia 934.

Tubulipora 1134.

Tudicla 3166.

Turbinaria 709.

Turbinella 3254.

Turbo 1771.

Turbonilla 201อั. 535ั4. 5355.

Turricula 3716.

Turriscala 5305.

Turritella 1888. 5317.

Tursiops 4722.

Typhis 3258.

$\mathrm{U}$

Ulangia 898.

Ulastraea 861.

Ulophyllia 792.

Ulmus 202.

Umbonium 1786.

Umbrella 1452.

Unio 1437.

Urohelminthoida 21.

Urolnitra 3643.

Ursus 1748.

Urigerina 534.

\section{V}

Taccinium 383.

Taginella 1562 .

Taginulina 465

Talrata 1971.

$\checkmark$ alrulina 562.

Tenerupis 1582.

Venus 1589. 4897.

Termetus 1911. 5323.

Vermilia 1126. 5329.

Verneuilina 557.

Vertigo 4536.

Viburnum 362. 
Vioa 682.

Vitis 268

Vitrea 4486.

Vitrina 4485.

Vitularia 3394.

Vivipara 1973. 5337.

Volutilithes 3750 .

Volvarina 3413.

W

Woodwardia 72 .

$\mathbf{X}$

Yoldia 1427

Z

Zenobia 4502

Zingiberites 140

Zizipluus 320.

Zonarites 33.

Zoophycos 44.

Zosterites $] 32$.

Zua 4522

Xenophora 1919. 5331. 



\title{
GEOLOGIA APPLICATA
}

\author{
"x \\ BACINO TERZIARI0 E QUATERNARIO \\ DEL \\ PIEMONTE
}

Memoria del Dott. FEDERICO SACCO.

(Con una tavola)

ROMA

TIPOGRAFIA NAZIONALE

$1 \overline{890}$ 


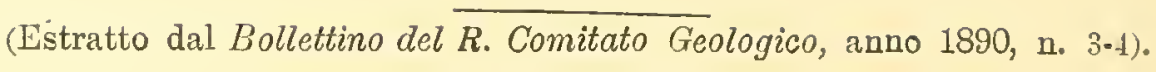




\section{GEOLOGIA APPLICATA}

Allorquando di una regione si è compiuto l'esame geologico generale, riesce opportuno di trattare eziandio dei diversi ed importantissimi rapporti che in tale regione esistono tra la costituzione geologica e l'uomo, la configurazione del terreno, il regime acqueo, ecc.

Nelle pagine seguenti cercherò appunto di fare tale esame di geologia applicata al bacino terziario del Piemonte, che è tipico affatto dal lato geologico e paleontologico e che presentasi pure assai interessante sotto il punto di vista utilitario.

Onde procedere con chiarezza maggiore divisi questo esance applicativo in diversi capitoli riguardanti l'orografia, l'idrografia, l'agricoltura, l'industria, l'igiene e gli argomenti affni, indicando per ciascun capitolo ciò che di piu interessante offre ognuno degli orizzonti geologici in cui divisi la serie terziaria piemontese. 



\section{Capitolo 1.}

\section{$O x^{\circ}$ og $I^{\prime}$ ia.}

E ben noto quanto stretto sia il nesso che esiste tra la costituzione geologica di una data regione e l'orografia della regione stessa e quindi indire:tamente colla distribuzione dei centri abitati, ecc.; perció, tralasciando considerazioni generali in proposito, possiamo passare senza altro all'esame dei singoli terreni rispetto ai fenomeni orografici a cui essi dànno origine.

Liguriano. - Siccome il Parisiano tipico, nummulitifero, appare solo come sottile zona nelle Alpi marittime, cosi non abbiamo quasi a trattarne: indichiamo solo come esso sia costituito per lo più da banchi calcarei abbastanza resistenti che lungo le pareti montuose sporgono quindi spesso a guisa di cornice frammezzo agli argilloschisti fra cui sono inglobati.

La formazione liguriana, che dicemmo rappresentare in Piemonte quasi tutto l'Eocene, per essere costituita di terreni molto diversi, presenta pure esternamente diversi aspetti orografici; le zone arenacee (macigno) costituiscono nelle Alpi marittime e nell'Appennino ligure regioni aspre ed a creste elevate, acute, irregolari. Invece gli argilloschisti formano pendii dolci, bassi colli (Colle della Maddalena nell'alta Valle della Stura di Cuneo, Colle dei Giovi nell'Appennino, ecc.) e talora anche regioni pianeggianti. Dove compaiono lenti ofiolitiche, là si verifica quasi sempre un rilievo ben spiccato, nerastro, aspro, caratterisco.

Dove le formazioni ofiolitiche terziaric si appoggiano a quelle antiche, come tra Voltaggio e la riviera ligure, si vede che le prime costituiscnno generalmente rilievi molto meno accentuati che non le seconde. 
Nella stessa regione si vede che talora la serpentina si presenta compatta e forma creste, talora invece è poco resistente costituendo quindi piccoli colli.

Ma ció che è più interessante, riguardo al bacino terziario studiato, si è la facies delle argille scagliose, giacchè queste, per la poca compattezza, per la facile stemprabilità, per i movimenti in grande scala a cui vanno soggetti, costituiscono regioni affatto caratteristiche, leggermente ondulate o pianeggianti, piuttosto basse riguardo a quelle circostanti costituite di altri terreni, spesso intersecate da burroni di forma mutevole, fangose al sommo in tempo di pioggia, aride, screpolate, indurite in tempo di siccità; ne risulta quindi un paesaggio deso. lato che fortunatamente nel Piemonte appare solo in piccole zone, per lo più verso il fondo di alcune valli, ma che diventa poi predominante nella regione appenninica di gran parte d'Italia.

In conseguenza di tutto ciò facilmente si comprende come su queste zone liguriane non esistano in generale centri d'abitazione e che anzi si cerchi, anche per le abitazioni rurali, di €vitäre per quanto è possibile le aree costituite di argille scagliose, poichè quivi succedono spesso screpolature, scoscendimenti, ecc.; da questi spostamenti di terreno talora vengono originate conche più o meno ampie che si convertono in stagni o laghetti.

La tettonica par lo più molto tormentata delle formazioni liguriane influisce anche molto sulla orografia, che ne risulta naturalmente assai irregolare.

Bartoniano. - La predominanza delle marne grigie friabili, che in Piemonte costituiscono gran parte della formazione bartoniana, la si che le regioni collinose dove essa appare si mustrano quasi sempre intersecate in tutti i sensi da ampi e profondi burroni, piuttosto aridi, continuamente in via di trasformazione; solo qua e là dove appaiono lenti calcaree quivi si presentano creste rilevate, $m a$ in generale mai molto spiccate. Naturalmente non sorsero centri d'abitazione su tali regioni bartoniane.

Sestiano. - Questo sottile orizzonte geologico non presenta generalmente fenomeni orografici proprii, ma per lo più invece quasi simili a quelli del Tongriano che esamineremo ora.

Tongriano. - Per la natura eminentemonte conglomeratica ed 
arenacea che presenta l'orizzonte tongriano, e per la forte inclinazione che hanno i suoi banchi, verificasi che le regioni costituite di questo terreno sono quasi sempre assai rilevate, spesso aspre, per modo da presentarsi con un paesaggio alpestre, talora arido e dirupato, con valloni profondissimi, a pareti turrite, con fr əquenti salti che formano belle cascate, ecc.; sovente tali placche tong iane costituiscono sull'alto delle colline grandiosi monoliti.

Nelle regioni montuose la formazione tongridna costituisce quasi sempre, sopra le rovine antiche, regioni pianeggianti, veri altipiani poco undulati su cui sorsero sovente centri abitati, come Battifollo, Scagnello, Cimaferle, Sassello, ecc.

In seguito ad erosioni si verifica spesso che la formazione tongriana si presenta solo piu in placche sul Liguriano, come ad esempio verificasi in parte delle colline tortonesi; tali placche spiccano da lungi pei i loro pendii dirupati che cessano di tratto sul dorso ondulato costituito dalla zona liguriana.

Naturalmente le zone marnose del Tongriano originano regioni collinose diverse da quelle sovraindicate come tipiche in generale dell'orizzonte in questione.

L'abbondanza di ciottoloni in certi banchi tongriani fa si che talora la regione tongriana prende un aspetto quasi di terreno morenico, tanto piu quando per denudazione i ciottoloni trovansi sparsi sulla superficie del suolo a guisa di erranti.

Stampiano. - Al contrario di ciò che verificasi nell'orizzonte sottostante, la formazione stampiana, essenzialmente marnosa, costituisce regioni collinose poco elevate ma caratterizzate in modo spiccatissimo per essere intersecate in tutti i sensi da burroni profondissimi, di forma variabilissima per i facili scoscendimenti e per la facile erodibilitá delle marne farinose; nel complesso quindi questo orizzonte rassomiglia assai dal lato orografico a quello bartoniano. Anche in questo caso non troviamo che rarissimamente centri d'abitazione sopra le marne in questione ed anzi si può constatare che paesi fondati sullo Stampiano ruinarono completamente (Rocchetta di Spigno ad esempio) appunto per la franosità del terreno.

I torrentelli, generalmente asciutti, che intersecano le regioni stampiane sono per lo più di andamento molto tortuoso, per modo da 
originare talvolta curiose regioni labirintiformi, dando al paesaggio un aspetto di aridità, di franosità, direi, molto caratterisco.

Dove le correnti acquee agirono potentemente sulle formazioni stampiane, là vediamo come le regioni collinose basse sono sostituite da ampie valli e da ampie pianure tanto che sovente si delinea anche di lontano a larghi tratti la zona stampiana solo considerando l'orografia della regione.

Notiamo però che talora colle marne stampiane si alternano banchi, anche abbastanza notevoli, di arenarie, specialmente nella parte superiore dell'orizzonte; quindi viò altẹra alquanto la sovraccennata facies tipica del piano geologico in questione e ne deriva che, per fenomeni di erosione e di denudazione, talvolta questi banchi arenacei rimangono ampiamente allo scoperto e costituiscono vasti altipiani leggermente inclinati verso il centro del bacino terziario, come verificasi ad esempio nelle vicinanze di Cengio, di Cosseria, ecc., nell'alta Val Bormida; in queste regioni talora si verifica che i banchi arenacei spaccandosi e venendo erosi dagli agenti atmosferici costituiscono grandiosi monoliti torreggianti, come vediamo, ad esempio, al Bric della Pongia, al Bric della Marca, ecc., presso Millesimo.

Aquitaniano. - Si è visto come molto varia sia la natura litologica di questa formazione, per cui non è possibile indicare in generale i caratteri orografici delle regioni che ne sono costituite; in complesso peró si può dire che siccome colle sabbie e colle marne aquitaniane si alternano frequentemente banchi arenacei assai consitenti, spesso fortemente inclinati, cosi le regioni collinose che ne risultano sono piuttosto elevate, ripide, grigio-giallastre, a contorni irregolari, oppure complessivamente quasi piramidali, ciò che contrasta sovente coi vicini colli langhiani rotondeggianti grigiastri; spesso vediamole grandi vallate restringersi assai nell'attraversare le zone aquitaniane; talora in queste specie di forre nelle valli trovansi paeselli, ad esempio quello di Ponti in Val Bormida.

Talvolta le colline aquitaniane sono foggiate da un versante ad ampi piani inclinati, colla pendenza nel senso dell'inclinazione degii strati, come vediamo ad esempio a Montezemolo, presso Bubbio, presso Ar. quata Scrivia, ecc., ecc. Sovente abbondano molto nelle regioni aquitaniane i frammenti arenacei sparsi sul dorso delle colline. 
Siccome sovente l'A quitaniano è costituito alla base da un grosso banco arenaceo, cosi quivi si forma spesso o una gradinata od una specie di cornicione caratteristico, sporgente lungo i pendii collinosi; anzi questo carattere orogralico sovente è di aiuto al geologo per fare una distinzione complessiva degli orizzonti geologici, tanto più quando si tratta di lembi aquitaniani o placche isolate sullo Stampiano, come quelle di Monte Castello in Val Bormida.

Ma nelle colline 'Torino-Casale l'A quitaniano essendo specialmente rappresentato da marne poco resistenti, naturalmente l'aspetto del suo paesaggio cangia assai; vi osserviamo cioè colline poco elevate ed a morbidi pendii; è solo nelle colline torinesi che, alle marne aggiungendosi potenti banchi arenacei e conglomeratici, il rilievo dei colli aquitaniani diventa nuovamente più accentuato e più aspro.

Da quanto si è detto rispetto alla formazione aquitaniana della parte meridionale del bacino piemontese risulta facile il comprendere come moltissimi paesi siano situati su di questo terreno che, per le elevazioni che raggiunge e per i ripidi pendii delle sue colline, si dovette prestare assai bene alla difesa nel periodo medioevale; ne siano esempi Ponzone, Montechiaro d'Acqui, ecc.

Langhiano. - Nella parte meridionale del bacino terziario piemontese la formazione langhiana essendo costituita per massima parte da marne, dà origine a colline biancheggianti, poco elevate, rotondeggianti e con pendii spesso assai dolci; le vallate che l'intaccano vi si presentano notevolissimamente allargate, come ad esempio osservasi nella Val Bormida presso Acqui; lungo le creste collinose, là dove esse sono attraversate dalla zona langhiana, si nota una depressione abbastanza marcata. Talora anzi si possono utilizzare tali fenomeni. orografici per segnare in complesso l' andamento della zona langhiana attraverso una data regione. Naturalmente anche in questo orizzonte compaiono più o meno potenti ed estesi banchi di arenarie che alterano alquanto la tipica orografia sovraccennata.

Nelle colline Torino-Casale le marne langhiane, per la compressione subita, si indurirono in modo che ora costituiscono sovente creste di colline, tanto più che spesso colle marne calcaree indurite si alternano eziandio banchi arenacei.

Sulla zona langhiana del bacino meridionale del Piemonte troviamo 
diversi importanti e prosperosi centri di abitazione, ció che è in rap. porto colla facile viabilità e coltura che essa presenta. Invece nelle colline Torino-Casale vediamo sul Langhiano esistere pochi e piuttosto meschini centri d'abitazione che debbono la loro ubicazione specialmente all'idea della difesa che non a quella dell'industria e del commercio.

L'esame dell'andamento stratigrafico dei terreni langhiani ci spiega molti fenomeni orografici che non credo però necessario passare ora in esame poichè risultano chiaramente dal semplice esame delle carte geologiche.

Elveziano. - La natura eminentemente sabbiosa ed arenacea di questo orizzonte influisce molto sulla orografia delle vastissime regioni che ne sono costituite; esse infatti per la resistenza abbastanza notevole della formazione elveziana formano per lo più colline assai elerate (tanto da raggiungere i 900 metri a Mombarcaro) ed a pendii alquanto scoscesi; anzi là duve le arenarie prendono un grande sopravvento, come ad esempio dalla Val Bornida al tortonese, la regione elveziana acquista spesso una facies di paesaggio alpestre con pendii dirupati, cascatelle, creste ardite, ecc.

In conseguenza di questa conformazione orografica notiamo che molti centri d'abitazione si trovano sull'alto delle colline elveziane per la sulita causa della facile difesa di dette posizioni; ma mutate oggi le condizioni delle cose questi paesi situati sulle cime elveziane non sono generalmente suscettibili di progresso e sono destinate invece per lo più a graduale decadimento.

'Tra l'Elveziano e il sottostante Langhiano esiste sovente un'irre. golare gradinata causata dalla diversità di natura litologica e quindi dal vario grado di erosione delle due formazioni geologiche; questo fatto osservasi abbastanza generalmente attraverso le colline dell'alto Monferrato fino ai colli tortonesi.

Le valli che intagliano le regioni elveziane sono per lo piu strette e profonde; anzi osservando il percorso delle principali vallate si nota che generalmente, dove esse attraversano la zona elvesiana, là esse si restringono rapidamente, per di nuovo allargarsi nella zona tortoniana; ne sia esempio la valle della Bormida tra Orsara e Strevi. Talora in queste forre delle vallate sorsero paeselli di commercio, ad esempio Serravalle in Val Scrivia. 
L'esame stratigrafico della formazione elveziana ci spiega molti fenomeni orografici, come gradinate in grande ed in piccola scala, valli con una sponda ripidissima e quella opposta a dolcissimo pendio, rapide deviazioni di corsi d'acqua, ecc., ecc.

Talora per fenomeni di erosione nelle regioni a banchi arenaceo-marnosi questi sono ridotti a pilastri quasi isolati; si presenta tipica a questo riguardo la cosi detta regione diroccata presso Cigliè nelle Langhe.

Nelle Langhe e nell'alto Monferrato ed in parte sulle colline più ad Est si osserva che colli elveziani presentano burroni molto piu numerosi e più profondi (spesso a pareti quasi verticali) che ron nelle colline tortoniane; tale carattere secondario può quindi servire talora per separare complessivamente una regione dall'altra.

Nelle colline monregalesi e torinesi l'abbondanza di ciottoli e ciottoloni fra le marne e le sabbie fa si che, per lenta denudazione, spesso le regi ni elveziane assumono la facies di terreno glaciale, cioè del cosi detto paesaggio morenico.

Tortoniano. - In quasi tutto il Piemonte la zona tortoniana, costituita essenzialmente da banchi marnosi, si presenta sotto forma di colline basse, biancastre, rotondeggianti, a dolci pendii, attraversate da ampie vallate d'erosione (ad esempio la Val Tanaro presso Alba); là dove l'erosione acquea fu molto potente le formazioni tortoniane furono in parte esportate per modo che ne risultarono ampie regioni pianeggianti coperte da un velo alluvionale.

Nella delimitazione grossolana del Tortoniano dall'Elveziano è appunto molto utile l'esame orografico, poichè fra i due orizzonti esiste quasi sempre una specie di irregolare gradino causato dalla differenza nella costituzione geologica e quindi nei fenomeni d'erosione.

Raramente osservansi potenti banchi arenacei fra le marne tortoniane, ma in questo caso (che verificasi per esempio a Novello nelle Langhe) tali banchi costituiscono spesso altipiani ben spiccati.

Il paesaggio delle regioni tortoniane è in generale un po' monotono ed uniforme. Su questa zona esistono diversi centri d'abitazione in causa della facile viabilità e della sviluppata agricoltura che vi si trova.

Messiniano. - Sovente le regioni messiniane presentano una configurazione orografica ben spiccata fiammezzo alle zone vicine; in- 
fatti siccome sovente in questo orizzonte geologico sriluppansi ampie formazioni arenacee, sabbiose, conglomeratiche, calcaree e gessifere, cioè formazioni che resistono assai all'erosione, cosil le cclline messiniane per lo piủ presentano pendii dirupati e pareti quasi a picco, grandiose e ripetute gradinate, profondi valloni, cime elevate, monoliti torreggianti (Val Scrivia), ecc.

Le vallate che attraversano una zona messiniana sovente vi si restringono molto, come vediamo ad esempio in Val Tanaro ad Est di Alba.

Nella sovrapposizione del Messiniano al Tortoniano esiste generalmente una specie di gradino causato appunto dalla diversità nella compattezza e quindi nella erosione dei due orizzonti geologici; ne siano esempio le colline della Morra, di Ricaldone, ecc.

Molte colline messiniane sono di una tinta generale rossiccia per decomposizione chimica di certi elementi litologici, che talora vengono a far parte di questo orizzonte.

Là dove esistono lenti gessifere, oltre ai ripidi gradini già accennati, osservansi spesso fenomeni orografici assai curiosi, dovuti alla dissoluzione del gesso, cioè imbuti a forma di anfiteatro, caverne e condotti sotterranei, monoliti gessosi isolati sull'alto delle colline, ecc., come osservasi specialmente nelle colline della Morra, presso S. Biagio nel Tortonese, ed altrove; ciò è in relazione col grande sviluppo e colla speciale stratigrafia della zona gessifera.

Per la solita causa della difesa, ed in parte anche della maggior salubrità, sull'alto delle colline messiniane esistono spesso centri d'abitazione, che però ora di rado sriluppansi ulteriormente, tanto più che la ripidità di detti rilievi rende sovente poco facile sia la viabilita di queste regioni, sia l'estendersi regolare degli abitati.

Piacenziano. - La formazione piacenziana per la sua natura essenzialmene marnoso-argillosa costituisce basse colline rotondeggianti ma per lo più fondi di vallate, piuttosto ampie per essere valli di erosione; infatti le correnti acquee, mentre erod no facilmente le sabbie astiane più difficilmente intaccano le argille piacensiane, scorrendovi invece sopra, per modo che poco a poco la valle si allarga senza approfondarsi molto. Per tal modo ci spieghiamo il rapilo allargarsi di certe valli, ad esempio, di Val Tanaro tra Asti e Castello Annone. 
Per la suddetta orografia delle regioni piacenziane molti ed importanti sono i centri di abitazione, generalmente in via di accrescimento, che trovansi su questa zona, però coll'intermezzo di un velo di loess.

Astiano. - La prevalenza delle sabbie nella costituzione della formazione astiana e la loro facile erosione fanno si che la zona che ne è costituita si presenta generalmente ridotta ora ad una regione collinosa assai complicata, frastagliata in tutti i sensi, labirintiforme, come è appunto la tipica regione dell'Astigiano.

Inoltre il colore prevalentemente giallastro e la facile permeabilitå delle sabbie astiane ci spiega come il paesaggio astiano sia per lo più di una tinta giallognola in generale e piuttosto arido. La facilità di erosione e di scoscendimento delle incoerenti sabbie astiane ci spiega pure come le colline che ne sono costituite presentino ben sovente i loro fianchi ripidi, talora a picco, spesso franosi; inoltre ci spiega pure alcuni curiosi mutamenti orografici e l'allargarsi di certi orizzonti visuali, la formazione di guglie isolate singolarissime, ecc.; tali fenomeni osservansi specialmente nelle colline tra Brà e Montà.

I profondi burroni franosi dell'Astiano terminarı spesso in duri, cementatissimi banchi arenacei che resistono notevolissimamente alla erosione; nel qual caso costituiscono spesso spiccati rilievi collinosi, come sovente si osserva nella parte settentrionale dell'Astigiano. In questo caso, come di solito, su tali altirilievi si costituirono, specialmente in epoca medioevale, centri d'abitazione stretti ed allungati nel senso della cresta collinosa, per lo più dominati da un grandioso castello che serve assai bene a spiegarci il perchè dello sviluppo di tali paesi; ne siano esempio Piano d'Asti, Passerano, Moncalvo, Altavilla, ecc., ecc.

Giova poi notare che molti paesi costrutti sopra le sabbie astiane sono inesorabilmente destinati alla distruzione in un avvenire più 0 meno lontano, a causa della lenta ma continua esportazione naturale di dette sabbie per mezzo degli agenti atmosferici; trovansi ad esempio in questa posizione precaria i paesi di Moriondo, Montà, Monteu Roeru, Montaldo Roero, S. Stefano Roero, Baldissero d'Alba, Sommariva Perno, Pocapaglia, ecc.

Fossaniano. - Le regioni fossaniane presentano generalmente quasi la stessa facies orografica di quelle astiane; solo vi sono generalmente più comuni e più ripidi i burroni, molto mutevoli di forma; 
le colline si presentano spesso di color rossiccio. Pero in molti punti l'orografia fossaniana si avvicina già a quella oillafranchiana, in causa specialmente di potenti banchi marnoso-argillosi che si alternano talora colle sabbie e colle ghiaie

In causa della non grande estensione di questo terreno pochi sono $\mathrm{i}$ centri d'abitazione che vi sono fondati, quasi sempre sull' alto delle colline; cosi Mombercelli.

Villafranchiano. - Quantunque sia molto varia la natura della formazione villafranchiana tuttavia in generale si può dire che, per il grande sviluppo dei banchi marnoso-argillosi, le regioni villafranchiane in seguito alle trasformazioni operate dagli agenti esterni sono ora ridotte a colline basse, rotondeggianti, a fianchi morbidissimi, di colore giallo-verdognolo; è tipica a questo riguardo la regione collinosa tra Villafranca d'Asti e l'altipiano di Villanova.

Dove però l'erosione non potè agire tanto intensamente là rediamo che le regioni villafranchiane conservarono ancora in parte l'originarı disposizione pianeggiante, solo che esse snno ora ridotte ad altipiani ondulati, come vediamo, ad esempio, presso Cellarengo, nel centro dell'Astigiano, presso Bergamasco, ecc.

Notisi però che il Villafranchiano subalpino è spesso conglomeratico, resistentissimo, per modo che le erosioni acquee vi costituiscono talora balze dirupate lungo il corso dei fiumi.

In generale le formazioni oillafranchiane non dànno direttamente ricetto a grandi centri d'abitazione in parte per la natura stessa del terreno, in parte perchè non presentano generalmente nè la comoditá dei bassipiani nè i vantaggi, relativi, dei siti molto elevati; tanto più che le vie di comunicazione che corrono sul Villafranchiano, sovente sono poco comode perchè spesso fangose o, nei tempi di siccitá, dure e poco piane.

Sahariano. - Non è il caso di insistere sulla configurazione per lo più pianeggiante che presentano le formazioni sahariane diluriali; solo è a notarsi che per le potenti erosioni rerificatesi dopo questo primo periodo del Quaternario, tali pianure furono quasi tutte ridotte ad altipiani alquanto ondulati, più o meno vasti, più o meno elevati sulie circostanti pianure terrazziane.

Il paesaggio di questi altipiani diluviali (barragyie, brughiere, 
oaude, ecc.) è piuttosto triste e monotono, di tinta giallo-rossiccia, ed a scarsa vegetazione; anche la viabilità è spesso resa poco comoda dalle argille del loess che cangiansi facilmente in fanghiglia appiccicaticcia.

Malgrado ciò i pianori diluviali, per la loro poca elevazione sulle fertili pianure terrazziane, presentano spesso centri di abitazione abbastanza importanti, specialmente verso il loro margine; per lo più si verifica in tal caso che la parte antica e meno frequentata di questi paesi si trovi sul ciglione della terrazza diluviale, mentre la parte recente ed animata si stende al piede di detto ciglione.

Quanto alla orografia delle formazioni moreniche, essa è troppo nota perchè ci dobbiamo fermare sopra, tant'è che il nome di paesaggio morenico è ormai entrato nell'uso comune per indicare le regioni collinose od appena ondulate costituite di terreno glaciale; spesso vi si incontrano piccole conche lacustri, causate dall'irregolare formazione del deposito.

Per la loro amenità e fertilità, molti centri d'abitazione si stabilirono poco a poco su queste regioni moreniche.

Terrazziano. - Questa formazione è caratterizzata da regioni piane quasi sempre amplissime; essa costituisce generalmente l'imbasamento diretto dei grandi centri popolati del Piemonte, come d'altronde anche altrove. 


\section{Capitolo II.}

\section{Idrogra fia.}

Nello stesso modo che i fenomeni orografici, anche ruelli idrografici sono in strettissima relazione colla natura del terreno e quindi, in complesso, cogli orizzonti geologici; di più non solo l'idrografia superficiale ma anche e specialmente, anzi, quella sotterranea è-strettamente in rapporto colla natura geologica di una data regione; si nota poi in generale che i veli acquei sotterranei trovansi per lo più nella zona di sovrapposizione di un orizzonte geologico all'altro, a causa sia di leggiere trasgressioni, sia di differenze litologiche che quivi si verificano.

Liguriano. - Nelle Alpi marittime e nell' Appennino settentrionale dove questa formazione geologica è molto sviluppata essa non presenta particolari fenomeni idrografici; vi sono piuttosto scarse le sorgenti acquee.

Lo stesso verificasi ad un dipresso nelle zone liguriane dei culli tortonesi e di Torino-Valenza, poichè quivi i banchi, specialmente argillosi, nelle epoche di pioggia si imbevono d'acqua solo superficial. mente formando fanghiglia, ma asciugano poi tosto, per modo che ne risultano regioni piuttosto aride, a terreno screpolato.

Talora per scorrimenti avviene che si formino nelle regioni liguriane piccole conche che cangiansi tosto in stagni o laghetti.

sestiano. - Dal lato idrografico le ristrette formazioni sestiane si comportano ad un dipresso come quelle tongriane.

Tongriano. - In generale le regioni in cui sviluppasi il Tongriano si presentano piuttosto aride in causa della sua natura prevalentemente sabbiosa e ciottolosa; peró siccome alla sua costituzione sorente 
prend no anche parte estesi e potenti banchi conglomeratici, molto cementati, alternati con marne o poggiati direttamente sulla roccia in posto, cosi essi formano talora veli acquei che originano sorgenti anche abbondanti (ad esempio quella di Madonna del Deserto, presso Millesimo).

Dove la formazione tongriana costituisce placche sopra al Liguriano, ad esempio nelle colline tortonesi, là si vede che queste placche arenacee agiscono quasi da spugna, assorbendo l'acqua di pioggia che poi gemono poco a poco in basso; se ne originano piccoli veli acquei i quali alimentano diverse sorgenti; questo fenomeno idrografico, semplice in sè, influi notevolissimamente sulla distribuzione dei centri d'abitazione, che infatti spesso trovansi situati presso queste sorgenti acquee, tanto più che piuttosto aride si presentano le circostanti regioni liguriane.

Stampiano. - Caratteristiche sono in complesso le zone stampiane per la loro aridità, poichè, le marne un po' sabbiose che le costituiscono non si imbevono molto d'acqua ed invece per gli agenti acquei si disaggregano facilmente e formano gli aridi burroni già menzionati sopra.

Aquitaniano. - Come il Tongriano anche la formazione aquitaniana si presentu piuttosto povera d'acqua; ma tuttavia qua e là fra i suoi banchi arenacei più compatti appaiono sorgenti acquee anche sull'alto delle colline, come, ad esempio, a S. Giulia (presso Cairo), a Ponzone, ecc.

Nelle colline Torino-Casale la prevalenza delle marne nella costituzione dell'Aquitaniano rende ancora più scarse le sorgenti acquee, eccetto che nelle colline torinesi dove esistono pure sviluppate zone arenacee.

Ianghiano. - Le marne langhiane sono anch'esse per lo più poco atte ad originare veli acquei, e quindi formano pure generalmente regioni povere d'acqua, eccetto là dove compaiono compatti banchi arenacei.

Elveziano. - Come in generale quasi tutte le formazioni terziarie di mare basso, quella elveziana costituisce regioni amplissime in cui scarseggiano le sorgenti, a causa della facile permeabilità delle sabbie e delle marne sabbiose che rappresentano in massima parte questo orizzonte geologico. 
Peró siccome in certe regioni sviluppansi pure nell'Elveziano potenti banchi arenacei od anche conglomeratici compattissimi, quivi compaiono copiose e spesso abbondantissime sorgenti acquee, come in diversi punti presso il Santuario di Mondovi, presso S. Michele Mondovi, presso Ticoforte, sulle colline ad Ovest di Alba, nelle vicinanze di Barolo, di Monforte, ecc., cosi pure fra le potenti arenarie eloeziane che sviluppansi dalla Val Bormida alle colline tortonesi.

Tortoniano. - Le marne un po' argillose di questo orizzonte geologico si imberono al juanto di acqua per modo che nel complesso costituiscono regioni non tante aride, quantunque non diano quasi mai origine a veli acquei costanti e perciò raramente a sorgenti acquee notevoli, eccetto che in quelle pochissime regioni, come a Norello, dove compaiono banchi arenacei.

Messiniano. - Questa formazione si presenta assai interessante dal lato idrografico; infatti siccome in generale essa è costituita in parte di marne ed in parte di arenarie, di conglomerati e di banchi ca'carei spesso assai compatti, ne deriva che vi si costituiscono spesso parziali veli acquei i quali originano copiose sorgenti o alimentano vaste cisterne.

Questo fatto lo possiamo verificare comunissimamente, in special modo nell'alto e basso Monferrato (sorgenti del Borbore, Ricaldone, ecc.).

Là, poi dove esistono zone gessifere. non di rado si rerifica che per dissoluzione del gesso si costituiscono piccole correnti acquee sotterranee, come in alcuni punti delle colline tra la Morra el il Tanaro.

Piacenziano. - L'assoluta prevalenza delle marne argillose nella costituzione di questo orizzonte geologico fa si che esso forma :egioni piuttosto umide, ricche sia in sorgenti, sia in acque superficiali.

L'impermeabilità di questa formazione è poi molto importante perche, qual'inque sia il terreno che la ricopre, alla sua superficie superiore si costituisce quasi sempre un relo acqueo rero, costante, regolare, come osservasi per regioni estesissime in ogni parte del Piemonte. La regolarità di ta!e falda acquea sotterranea diventa poi grandissima quando la formazione piacensiana per fenomeni di erosione trovasi direttamentè ricoperta da un velo di allurione terraziana.

In causa di questo costante velo acqueo esistente sul Piacenziano non è improbabile che con fori opportuni in certe conche stratigrafiche se ne possano ricavare sorgenti artesiane. 
Astiano. - Al contrario di quella piacenziana la formazione astiana è sommamente permeabile, per modo che l'acqua di piogria l'attraversa senza fermarvisi; è perciò che le regioni astiane sono molto aride e l'uomo che vi abita è costretto a raccogliere l'acqua di pioggia nelle cisterne per uso alimentare.

É solo verso la base dell'Astiano che compaiono strati marnosi che s'inzuppano d'acqua ed originano qualche scarsa sorgente

Alla base affatto della formazione astiana esiste il tipico velo acqueo che scorre sul Piacenziano e che si rivela con una serie di sorgenti, come si può tipicamente osservare al fondo di una gran parte delle valli dell'Astigiano.

Fossaniano. - Anche questo orizzonte si presenta piuttosto arido, per la facile permeabilità delle sue sabbie e delle sue ghiaie; siccome però vi compaiono pure strati ed́ ampie lenti marnoso-argillose, cosi non è raro nelle regioni fossaniane di incontrare scarse e temporanee sorgenti acquee, come ad esempio si può osservare nelle colline tra Bra e Ceresole d'Alba.

villafranchiano. - L'abbondanza di strati marnoso-argillosi, che alternansi colle sabbie e colle ghiaie villafranchiane, fa sì che questo terreno si presenta quasi ovunque ricchissimo in veli acquei e quindi in sorgenti, anzi è spesso questo un carattere secondario che serve talora a riconoscere in complesso tale formazione; cosl, per esempio, Jungo certe vallette che attraversano terreni pliocenici superiori, l'apparizione del corso d'acqua nell'alveo del torrente segna sovente, in epoca di siccità, l'inizio della zona villafranchiana; così pure le numerose sorgenti che sgorgano frammezzo a banchi conglomeratici servono talora a distinguere in complesso il Villafranchiano da consimili depositi quaternarii; ciò dicasi specialmente pel Villafranchiano subalpino.

Abbastanza esteso in certe regioni si presenta un velo acqueo verso la base del Villafranchiano (ad esempio presso Redabue, Masio, ecc.); ciò ci spiega come su certe colline villafranchiane esistano pozzi profondi, talora anche oltre 30,40 e più metri.

Sahariano. - In gran parte le formazioni alluvionali del Sahariano sono permeabili, ma siccome per lo più basano su orizzonti permeabili, così sovente troviamo che alla loro base ścorre un velo acqueo potente e relativamente regolare. 
'Talora poi coi banchi sabbioso-ghiaiosi alternansi pure banchi o lenti di marne oppure di conglomerati cementatissini, costituendosi in ambi i casi veli acquei più o meno ampì che alimentano pozzi ed originano anche qualche sorgente acquea.

É poi notevole il fatto che per la profonda alterazione chimicofisica che sovente hanno subito le formazioni diluviali sahariane, e specialmente per una profonda argillificazione verificasi che esse diventarono generalmente impermeabili, come osservasi comunemente nel cono di deiezione della Stura di Lanzo.

Anche il velo superiore di loess ê spesso talmente argilloso che diventa quasi impermeabile, costituendosi allora sovente pozzanghere piu o meno vaste alla superficie delle regioni sahariane.

In generale l'aridità dei terreni diluviali sahariani è un grave ostacolo all'agricoltura di queste ampie regioni pianeggianti.

Le formazioni moreniche del Sahariano sono invece per lo più quasi impermeabili per la loro compattezza e pel materiale marnosnargilloso che connette gli elementi rocciosi; si comprende quindi l'abbondanza delle piccole conche lacustri delle regioni moreniche ad orografia tanto complicata.

Dove esiste un velo più o meno potente di terreno glaciale poggiante sul Diluvium là si osserva sovente una falda acquea abbastanza abbondante tra le due formazioni.

Terrazziano. - Di per sè la formazione terrazziana che è una semplice alluvione sabbioso-ghiaiosa, si presenta piuttosto arida; ma riesce invece assai importante idrograficamente, sia perchè il sottile velo di loess che la ricopre non è completamente permeabile e quindi s'imbeve d'acqua e la conserva per un dato tempo rendendo cosi umido il terreno vegetale, sia perchè sotto al deposito terrazziano, per lo più di soli 2 o 3 metri di spessore, esiste quasi sempre un velo acqueo abbastanza costante el abbondante che scorre sul Diluvium oppure, assai più comunemente, sui terreni terziarii.

Ne consegue che le vastissime pianure terpazsiane si presentano piuttosto fertili ed atte allo sviluppo delle popolazioni. 


\section{Capitolo III.}

\section{Agricoltura.}

Non è il caso di indicare particolareggiatamente il nesso strettissimo esistente fra la costituzione del terreno e l'agricoltura, questa non essendo altro che un'applicazione di quella; solo è a notarsi che siccome la parte coltivabile è soltanto quella che trovași alla superficie del terreno, essa si presenta già alterata chimicamente e fisicamente in modo che la sua natura è quasi sempre ben diversa da quella originaria; ciò ad ogni modo non toglie importanza alla studio geologico applicato all'agricoltura poichè col variare della costituzione degli orizzonti geologici varia anche naturalmente la costituzione del terreno superficiale che ne rappresenta il prodotto diretto.

Iiguriano. - Nelle Alpi marittime e nell'Appennino settentrionale la formazione liguriana si presenta specialmente costituita diarenarie (macigno) e di argilloschisti; nel primo caso la natura rocciosa del terreno si oppone quasi ad ogni sorta di coltivazione; nel secondo caso invece incontriamo estese regioni a dolce pendio, coperte o da foreste o da amplissime praterie; anzi nelle regioni meno elevate veggonsi eziandio pendii liguriani coltivati a frumento.

Nelle colline tortonesi e di Torino-Valenza gli affioramenti liguriani (quantunque l'uomo li utilizzi quasi per ogni sorta di coltura) non si presentano generalmente molto fertili, anzi dove abbondano le argille scagliose lá sovente per la natura del terreno e per la sua instabilità la vegetazione è magra, scarsa; talora anzi per aree abbastanza vaste si vede il suolo screpolato, arido, senza coltura regolare.

Sestiano. - I.a strettezza della zona sestiana in Piemonte non ci porge occasione ad osservazioni speciali dal lato agricolo; in complesso questo terreno presenta fenomeni simili a quelli del Tongriano. 
Tongrizno. - La nalura essenzialmente arenaceo-conglomeratica di questo orizzonte fa si che in generale esso si mostra poco atto alla coltura; sovente si presenta piıttosto arido, quasi denudato di vagetazione, talora invece è coperto di regatazione forestale; le sue zone marnose e marnoso-sabbiose vengono n tturalmente utilizzate specialmente per la coltivazione della vite.

Stampiano. - Le marne più o meno sabbiose di questo orizzonte geologico si prestano assai bene alla coltivazione della vite, ma in molte regioni a questa coltur $九$ si oppons la instabilita del suolo, fatto a cui già accennammo nel capitolo sull'orografia. Oltre che la vite anche altre sorta di coltura allignano assai bene sulle marne stampiane là dove esse costituiscono regioni a dolce pendio.

Aquitariazo, - Questa formazione, là dove l'orografia od il clima non è contrario, si mostra piuttosto atta alla viticoltura; ne sono chiari esempi le estesissime regioni aquitaniane delle Langhe e dell'alto e basso M-nterrato, che contribuiscono per notevole parte alla produzione viticola del Piemonte.

Molte regioni pianeggianti ed a dolce pendio, il cui substratum è costituito di terreno aquitaniano, sono molto utilmente coltivate a campi o, più di rado, a prati, a quest'ultima coltura opfonendosi la relativa ariditả del terreno.

Langhiano. - Nella parte meridionale del bacino terziario piemontese la estesa zona marnosa langhiana, per la natura sua propria e per le morbide colline a cui dà origine, presentasi favorevolissima allo sviluppo ed alla prosperità della vite; i pendii poco rapidi delle colline langhiane e loro relativa regolarità orografica fanno si che questa zona terziaria puó essere utilizzata quasi completamente per l'agricoltura ed è quindi preziosissima sotto questo punto di vista.

Certi depositi marnosi del Langhiano possono essere utilizzati in certe regioni speciali per correggere zone vicine troppo sabbiose.

Ma nelle colline tortonesi, casalesi e torinesi le marne langhiane, per la potente compressione subita e per una certa ricchezza in calcare, sono ora cosi compatte che non si prestano in generale molto facilmente al dissodamento, e quindi alla coltura; di più esse, per la loro durezza relativa costituiscono sovente le parti alte e scoscese delle colline, per cui sovente reggonsi tuttora ricoperte di regetazione arbore a. 
Elveziano. - Quantunque di costituzione alquanto simile a quella dell'Aquitaniano, la formazione elveziana si presenta molto più atta alla viticoltura, sia perchè coi banchi sabbiosi alternansi più comunemente estese zone marnose o marnoso-sabbiose, sia perchè le colline elveziane sono generalmente meno elevate di quelle aquitaniane e, nel Piemonte, trovansi in un clima quasi sempre più dolce.

亡े perciò che la grande zona elveziana delle Langhe costituisce, con quella astiana, la più importante regione viticola del Piemonte; zona importante non solo per la quantità ma anche sovente per la qualità del vino che produce, come, ad esempio, il Barolo, il Nebiolo, ecc.

Nelle colline torinesi esistono estese regioni elveziane che, per la loro elevazione e fer i ciottoloni che vi si trovano sparsi, sono coperte quasi solo da vegetazione cespugliosa.

Naturalmente è pure assai estesa la coltivazione pratense e del frumento là dove le regioni elveziane si presentano a dolce pendio o pianeggianti.

Tortoniano. - La sua natura eminentemente marnosa, talora anzi alquanto argillosa, e quindi la conformazione a colline basse e rotondeggianti, rendono questo orizzonte geologico stupendamente adatto alla coltivazione della vite, più ancora che l'orizzonte langhiano, il quale generalmente si trova in regioni più elevate e di clima meno dolce che non il Tortoniano.

Si comprende quindi come la formazione tortoniana segni attraverso al Piemonte una zona, se non molto ampia, certo fra le più fertili dal lato viticolo.

La prevalenza del materiale marnoso dà ai vini úna costituzione chimica e quinti un aroma alquanto diverso da quelli che, in condizioni esterne identiche, produconsi nelle zone sabbiose dello Elveziano.

Chiunque percorra un po' attentamente la regione piemontese rimane colpito da queste colline rotondeg@ianti, a forma di cupole regolari, ricoperte da un infinito numero di filari di viti, disposti in ordine concentrico regolarissimo.

La morbidezza dei pendii e le ampie vallate che esistono nella zona tortoniana rendono detta zona pure favorevolissima alla coltura dei cereali, nonchè alla costituzione di belle praterie.

Messiniano. - Per la presenza di banchi duri arenacei e calcarei 
spesso le colline messiniane presentano irregolarità orografiche che ostacolano la coltivazione; inoltre certi elementi ghiaioso-conglomeratici, che entrano spesso nella costituzione di questa zona, la rendono poco atta ad una coltura regolare, per cui non di rado le regioni messiniane si presentano coperte per ampî tratti soltanto di vegetazione arbustacea.

Peró la grande abbondanza di marne che s'alternano coi conglomerati rende sovente assai fertile la zona messiniana per una gran parte del Piemonte, specialmente sul lato settentrionale della conca piemontese.

Vedremo più avanti come l'abbondanza di lenti gessose nella formazione messiniana debba essere considerata come importante, indirettamente, anche dal lato agricolo, poichè il gesso puó essere utilizzato quale efficace correttivo per certi terreni.

Piacenziano. - Questa formazione deve essere considerata nella serie terziaria come una delle più acquifere e quindi delle più atte alla coltura pratense, tanto più che le marne argillose del Piacenziano costituiscono o colline basse ed a pendio morbidissimo oppure, più comunemente, fondi di vallata, per cui tutto concorre alla costituzione di vaste e belle praterie, nonchè di zone coltivabili anche a frumento; di piủ le colline piacenziane si prestano pure alla coltura viticola quando l'elemento argilloso non è trop! o abbondante.

Astiano. - La natura sabbiosa di questa formazione geologica ed il costituire essa colline non molto elevate e situate per lo più nelle regioni più calde del Piemonte, sono condizioni tali che la rendono molto atta alla viticoltura, che infatti vi si sviluppa amplissimamente e con grande profitto.

Famosa sotto questo punto di vista è l'Astigiano in generale e di. verse regioni astiane situate alle falde alpine, come ad esempio nel Biellese, Valdengo, (Vuaregna, Lessona, ecc.

Però sul lato settentrionale delle colline astiane, come d'altronde in generale anche delle altre colline terziarie sinora menzionate, trovasi specialmente sviluppata la vegetazione arborea od arbustacea. Sopra i piccoli pianori astiani si coltivano i cereali pure con profitto.

Fossaniano. - In causa della comparsa di letti ghiaiosi, di banchi argillosi e di una relativa abbondanza di sali minerali la formazione fos- 
saniana è assai meno atta che non quella astiana alla coltivazione della vite; quindi sovente essa è ricoperta da boschi o da vegetazione cespugliosa, per quanto non vi manchino neppure le solite colture a frumento e specialmerte a vite; anzi è prevedibile che col tempo si miglioreranno assai dal lato agricolo le ampie regioni fossaniane che si estendono dai colli braidesi verso Nord, per modo che esse diventeranno pure assai più coltivate e abitate che non lo siano ora; ad esempio il gruppo di cascine di S. Lorenzo è destinato forse a cangiarsi in paesello.

villafranchiano. - In questa formazione accentuandosi ancor più fortemente l'abbondanza di banchi argillosi e di banchi ghiaiosi, la coltura della vite vi è naturalmente ancor meno adatta, quantunque le colline villafranchiane vengano in gran parte utilizzate per tale coltivazione.

Molto ricche sono invece le praterie che esistono sulle regioni villafranchiane a causa della grande umidita che esse presentano per i loro banchi argillosi. Sugli altipiani villafranchiani prosperano abbastanza bene i cereali.

Sahariano. - Le formazioni sahariane, per costituire amplissime regioni pianeggianti, pare che dovrebbero presentarsi attissime alla coltura dei cereali ed a trasformarsi in vaste praterie; in realtà però si vede, al contrario, che queste regioni sono piuttosto aride, coperte di vegetazione cespugliosa o boschiva, difficilmente riducibili ad una coltivazione razionale produttiva. Ciò dipende da due cause principali; anzitutto che le formazioni sahariane sono ora in generale ridotte, per erosione, a costituire altipiani molto difficilmente irrigabili e quindi piuttosto aridi; inoltre spesso i materiali che le costituiscono sono o elementi ciottolosi sovente argillificati oppure argille molto ric. che in sali minerali per cui ne sisultano terreni compatti, poco permeabili, e con elementi chimici in parte contrari a molti dei vegetali più comunemente coltivati; ne siano esempi le vaude del cono di deiezione di Lanzo, le barraggie del biellese, le brughiere, le groane della Lombardia, ecc.

Talora poi l'infertilità di queste pianure diluviali è accresciuta dalla presenza di lenti d'ossidi di ferro e di manganese, commisti a terra argillosa impura, lenti che trovansi quasi alla superficie del ter- 
reno; volgarmente queste speciali formazioni appellansi mürs, gherloun, ecc., e vengono a ragione paventate dall'agricoltore.

Lungo i pendii delle terrazze diluviali si coltiva abbastanza utilmente la vite.

Il loess sahariano, che copre spesso le falde collinose è specialmente favorevole alla coltura dei cereali.

Le colline moreniche si prestano spesso assai bene alla viticoltura ed alla frutticoltura; talora però per l'abbondanza degli elementi rocciosi che entrano a far parte del terreno morenico esso si presenta tuttora coperto di vegetazione cespugliosa.

I depositi glaciali hanno poi, dal lato agricolo, un'importanza capitale entro Ie regioni alpine poichè quivi essi costituiscono sui terreni rocciosi placche di terreno fertile ed adatto ad un gran numero di colture, anche della vite là dove il clima lo permette.

Terrazziano. - Questa formazione per costituire amplissime regioni pianeggianti, per il velo di loess che quasi ovunque la ricopre e per la sua relativa umidità, si presta mirabilmente alla coltivazione dei cereali ed alia coltura pratense, per modo che tale formazione fra tutti i terreni sin qui menzionati, è certamente il migliore dal lato agricolo; fortunatamente esso è anche il più esteso, poichè non costituisce solo la superficie dell'ampia pianura padana ed alessandrina, ma penetra entro tutte le regioni collinose e montuose formando sia il fondo delle valli, sia talora anche regioni pianeggianti o poco inclinate lungo i fianchi delle colline.

Solo le alluvioni attuali, per non essere generalmente coperte da un velo terroso e per essere ancora poco decomposte superficialmente, in modo che presentano uno scarsissimo velo di humus, sono per lo più pochissimo fertili. 
Capitolo IV.

\section{Industria, Igiene, eec.}

Quasi tutti i terreni terziari presentano, in scala più o meno vasta, materiali utili all'uomo, sia per costruzione, sia per ornamento, sia per combustione, sia come medicina, ecc.; inoltre la costituzione di ciascun orizzonte geologico è interessante molto a conoscersi per diversi lavori di ingegneria; di più anche dal lato igienico è sovente importantissima la conoscenza del sottosuolo di una data regione, in causa dei veli acquei, della varia natura del terreno, ecc. È perciò che credo opportuno esaminare in un capitolo a parte queste applicazioni della geologia all'uomo.

Liguriano. - Nelle Alpi marittime i banchi arenaceo-calcarei nummulitiferi del Parisiano sono talora utilizzati come materiale da costruzione; gli esempi migliori di ciò si osservano lungo la riviera ligure presso la Palarea.

Quanto al Liguriano vero delle regioni montuose sono specialmente da menzionarsi gli argilloschisti o ardesie utilizzate in diversi punti onde estrarne lastre per coperture di tetti, lavagne per uso scolastico, ecc.

Riguardo alle lenti ofiolitiche, talora sviluppatissime, dobbiamo accennare cone esse siano importanti sia perchè talora offrono un materiale eccellente per pietrisco e per costruzione, sia perchè talora, , quando la roccia s:rpentinosa si presenta fratturata e rilegata da calcare, essa costituisce un'oficalce che colla pulitura forma una bellissima pietra ornamentale, sia infine perchè non di rado esistono in questa formazione filoni minerali, specialmente di pirite, calcopirite, magnetite, ecc.

Come materiale da costruzione vengono pure usate le arenarie 
(macigno) ed i calcari impuri che compaiono, spesso già frantumati, nelle zone liguriane.

Importantissini sono poi i calcari più o méno argillosi (calcari alberesi, marmorins a grana fina, bastardello a grana grossolana, ecc.) che accompagnano quasi sempre le formazioni liguriane nelle colline tortonesi, casalesi e torinesi; infatti tali calcari vengono escavati quasi ovunque su vasta scala, poichè se ne ricava un' eccellente materiale per calce idraulica e per cementi idraulici; famosa è ad esempio la calce di Casale, poichè nelle vicinanze di questa città esiste appunto una vastissima area d'affioramento liguriano.

Certe speciali lenti di calcare breccioso, come ad esempio quelle che osservansi in punti limitati presso Lauriano: danno invece una calce dolce di qualia non molto pregiata.

Dal lato dell'ingegneria si deve pure tenere molto conto della formazione liguriana, quando si vogliano fare costruzioni sia sotterranee, sia superficiali. Nel primo caso è sempre a ricordarsi come gli argilloschisti e le argille scagliose sono di grande ostacolo alla costruzione e manutenzione dei tunnel, delle trincee, ecc., perchè fasilmente si alterano, si imbevono d'acqua, cangiandosi in fanghiglia colante e presentano quindi pochissima resistenza alle potenti pressioni laterali, pressioni talora disuguali nei diversi punti, per quelle irregolarita stratigrafiche e litologiche che per lo più esistono nel Flyseh; ne consegue che i rivestimenti delle gallerie fatte entro questi terreni debbono essere robustissimi, e che ad ogni modo non sempre possono resistere alle enormi ed irregolari spinte che debbono sopportare. Di ciò sono sgraziatamente tristissimo esempio le gallerie ferroviarie dei Giovi.

Anche nelle costruzioni stradali sovente la formazione liguriana presenta gravi difficoltà lá dove predominano le argille scagliose, instabili, screpolabili, facilmente tramutabili in poltiglia e che quindi costituiscono strade pessime per quanto si cerchi di correggerle con potenti depositi di pietrisco; ne sono esempi, per citare un caso, quelle delle colline liguriane tra Casale e Val Stura.

Per le stesse ragioni anche gli edificii fondati sulle argille scagliose liguriane spesso hanno a soffrire grandemente essendo soggett i facilmente a screpolarsi ed a spostarsi alquants pei movimenti del terreno sottostante; è perció che soventi vediamo tali costruzioni presen- 
tare numerose fenditure o pendere leggermente da un lato, tanto che non di rado esse debbono essere abbandonate perchè divenute troppo pericolose come avvenne recentemente per esempio presso Monteu da Po.

Le sorgenti acquee che sgorgono dalla formazione liguriana talora sono alquanto mineralizzate; ne sia esempio la fontana sulfurea di Voltaggio usata su larga scala come medicinale sia per bevanda, sia per bagni, quantunque a mio parere tale cura, tanto qui come altrove in generale, sia specialmente efficace perchè coadiuvata dal clima, dall'ambiente e dal modo di vivere un pò meno antigienico di quello che si ha nelle città.

Talora colle formazioni liguriane sono in stretta relazione locali sorgenti di petrolio, come verificasi nel Vogherese, nel Piacentino, nel Parmigiano, ecc.

Bartoniano. - Nelle colline Torino-Casale è molto importante la formazione bartoniana come quella che fornisce sia un buon calcare da calce (calce dolce), sia specialmente un calcare da costruzione ed ornamentazione abbastanza pregevole; ben noto a questo riguardo è il cosidetto calcare di Gassino, che venne usato per la facciata della Basilica di Superga, per le colonne dell'Università, dei portici di Piazza S. Carlo, del Palazzo di città, ecc., in Torino; peró ora l'uso di questo calcare venne alquanto tralasciato, perchè esso non resiste molto agli agenti atmosferici ma si sfalda facilmente alla superficie, la qua!e diventa quindi presto irregolare. Calcari simili osservansi nel Bartoniano subalpino lombardo.

Le marne friabili della zona bartoniana si prestano poco alla viabilità appunto per essere piuttosto soggette a franare, alterando l'orografia della regione e dando poca presa ad opere d'arte. Si comprende quindi come scarseggino gli edifizi sulle colline bartoniane che non offrono sufficiente sicurezza. Rarissime incontransi le sorgenti sulfuree nella zona bartoniana, così presso Verrua Savoia.

Sestiano. - È solo a notarsi come fra le sabbie marnose di questa formazione si incontrano talora sottili lenti di lignite compattissima ma in quantità assolutamente troppo scarsa per meritare un lavoro di estrazione; spesso le sabbie inglobanti tali lenti lignitiche si presentano giallastre per depositi sulfurei, cosi presso Cocconato.

Tongriano. - Molti ed assai svariati sono i materiali che l'uomo 
puó trarre dalla formazione tongriana. Dove i conglomenti si presentano fortemente cementati essi vengono escavali in monoliti per materiale da costruzione, per dighe, per pietre da macina, ecc., come, per esempio, a Pietrabissara in Val Scrivia, a Millesimo, ecc.; dove invece gli ele. menti ciottolosi sono incoerenti o quasi, essi vengono utilizzati come materiale da costruzione, come pietrisco, ecc.

Anche le sabbie e le arenarie tongriane, specialmente nei colli Torino-Valenza, vengono comunemente usate come materiale incoerente da costruzione, tanto che in certe regioni le aree tongriane sono segnalate complessivamente dall'abbondanza di cave di sabbia.

Fra le regioni in cui i banchi arenacei del Tongriano superiore sono largamente escavati, notiamo come più famose le vicinanze di Dego in Val Bormida, a causa della posizione facile per il trasporto; lo stesso rerificasi pel Tongriano subalpino lombardo.

Alcuni banchi di compattissima e fine arenaria tongriana trovansi pure in alcuni punti delle colline Torino-Valenza, specialmente nell'anticliuale Villadeati-Alfiano dove essi sono escavati per pietrisco e per materiale da costruzione.

Certi schisti arenacei biancastri vengono pure utilizzati come lastre per materiale da costruzione, ad esempio nella conca tongriana di Bagnasco, ma detto rnateriale si sfalda facilmente quando è esposto agli agenti esterni e quindi non ne è consigliabile l'escavazione.

In certe regioni si usa fare il lavaggio delle ghiaie tungriane per ricerche aurifere, ma senza śrande profitto.

In punti speciali molto limitati della zona tongriana appenninica, presso C. Biscaelli (Voltaggio), ecc., esistono banchi o lenti di breccie calcaree, derivate dalla demolizione, a poca distanza, di zone di calcare triasico ora scomparso; tali lenti vengono utilizzate qua e lá per materiale da calce.

Ma le formazioni più interessanti nella zona tongriana sono le frequenti lenti di lignite nera, compatta, assai buona per combustione, poichè in generale dà oltre 1000 calorie e contiene meno del 9,00 di ceneri; ne offrono esempio le famose regioni lignitifere di Nuceto, di Bagnasco, di Cadibona, di Roccaforte e quelle assai meno ricche, di Scagnello, di Mombasiglio, di Ponzone, di Pareto, di Morbello, dei colli tortonesi e casalesi, ecc. 
E anzi notevole che nelle colline Torino-Valenza (Oddalengo, Alfiano, ecc.), la comparsa di lenti lignitiche serve spesso come carattere secondario per riconoscere certi affioramenti tongriani frammezzo a terreni più recenti.

Colle ligniti spesso incontransi cristallini di pirite e traccie sulfuree di poca importanza.

Straordinariamente numerose sono poi le sorgenti minerali nella zona tongriqna; specialmente comuni sono quelle sulfuree, tanto che anch'esse sovente servono come carattere accessorio nella determinazione del terreno tongriano, là dove scarseggiano $\mathrm{i}$ fossili, come ad esempio nelle colline tortonesi e di Torino-Valenza; sonvi anche sorgenti salso-iodiche, cosi quelle di S. Lorenzo presso Vignale. Queste sorgenti minerali sono spesso utilizzate come medicinali ció che si verifica specialmente nelle colline casalesi.

Stampiano. - Questo orizzonte non fornisce molti materiali utili all'uomo; talora gli stratelli'arenacei, che alternansi colle marne, vengono usati localmente come materiale da costruzione; vi si trovano rarissimamente (alla base nel passaggio al Tongriano) lenti calcaree, da cui si ricava calce dolce, come ad esempio presso Marzapiede; la poca consistenza di questo terreno forma sovente gravi difficoltà all'ingegneria stradale ed anche alla costruzione degli edifizi.

Aquitaniano. - Come la formazione tongriana, anche quella aquitaniana fornisce sovente sabbie, ghiaie e ciottoli, utilizzati sia per costruzione, sia per pietrisco; ció specialmente si verifica nella parte meridionale del bacino piemontese, poichè nelle colline casalesi predominano le marne nella zona aquitaniana.

Nelle colline tortonesi e casalesi, essendo la formazione aquitaniana in gran parte marnosa, in alcuni punti essa viene utilizzata per ottenerne materiali da laterizi, cosi ad esempio, sotto Camino sulla destra del Po.

Sono interessanti certi regolari banchi arenacei dell Aquitaniano inferiore perchè costituiscono un'eccellente pietra da costruzione; ne esistono diverse cave, per esempio, presso Arquata Scrivia, presso Cortemiglia, ecc.

In certe regioni i banchi basali dell'Aquitaniano si presentano costituiti essenzialmente di calcare utilizzato come pietra da calce; ne è 
esempio il calcare di Ponzone, di Visone, ecc. Oltre che alla base, incontransi pure lenti calcaree ad altri livelli della serie aquitaniana, come ne è esempio la bellissima formazione calcarea che esiste presso Acqui, sulla destra delia Bormida.

Riguardo al calcare è ancora a notarsi come nelle colline torinesi la zona aquitaniana fornisca anche un'eccellente calce idraulica, in causa della grande quantità di ciottoli e ciottoloni di calcare alberese che trovansi frammisti agli altri elementi rocciosi nei conglomerati aquitaniani; ha precisamente tale origine il cosi detto ealeare di Superga.

Certi durissimi banchi arenacei dell'A quitaniano nella parte meridionale del bacino terziario piemontese sono utilizzati come fondo naturale delle strade di collina per tratti assai lunghi, ciò che produce un effetto assai strano, specialmente per le screpolature dei banchi arenacei, dando alla strada l'aspetto di una via romana a lastroni; ve ne sono bellissimi esempi specialmente presso Garbagna.

Non sono rare le sorgenti minerali, quasi sempre solfuree, come quella presso Ponti in Val Bormida. Presso Visone e presso Acqui sgorgano dal terreno aquitaniano diverse sorgenti solfureo-termali nella valle della Bormida; queste famose sorgenti credo peró trovinsi solo in rapporto secondario colle formazioni aquitaniane; ed invece in rapporto assai più interessante coi terreni preterziari sottostanti; sonvi pure sorgenti solfuree in Val Ravanasco, ecc.

Le sorgenti solfuree di S. Genesio, nei colli torinesi, sgorgano dall'Aquitaniano, ma forse sono in rapporto diretto con terreni più antichi.

Ianghiano. - Quantunque in generale scarseggino i materiali arenacei nella zona langhiana tuttavia la compattezza delle marne calcaree è tale, specialmente nelle colline Torino-Casale, che esse vengono in molii casi utilizzate come pietrisco e come materiale da costruzione.

Piuttosto rare sono le sorgenti solfuree in questo terreno.

È bensi nella zona langhiana che viene a giorno la famosa sorgente solforosa termale (la bollente), nonchè altre vicine di Acqui, ma credo che questo fenomeno sia legato con fenomeni tettonici riguardanti terreni preterziari e che la venuta a giorno di tali acque calde nel Langhiano non sia che un fatto accessorio di poca importanza. 
Elveziano. - In causa della sua natura prevalentemente grossolana questo orizzonte è ampiamente utilizzato per escavarne materiale da costruzione, sia sabbie, sia arenarie, sia ciottoli; quest'ultimo caso peró si verifica solo nei colli torinesi e monregalesi.

Per regioni molto estese, specialmente nel tortonese e nel casalese, le marne più o meno arenacee dell'Elveziano sono cosiffattamente ricche in materiale calcareo cementante che esse vengono escavate su vasta scala in parallelepipedi (cantoni) che costituiscono un solido ed elegantissimo materiale da costruzione; l'escavazione ne è abbastanza facile in causa dell'acqua di cava che si elimina poi gradatamente a contatto dell'aria atmosferica, per modo che il materiale diventa poco a poco compatto e durissimo. Però, a seconda delle varie regioni e dei vari livelli della serie elveziana, queste marne calcaree presentano varia resistenza agli agenti atmosferici, poichè talune si conservano a lungo compatte, altre si sfaldano facilmente alla superficie, per modo che col tempo si sfacelano, con grave danno dell'edifizio che ne è costituito; siccome fra questi agenti demolitori ha una grande importanza l'acqua del terreno, cosi, sovente si usa di fabbricare la base degli edifizi con laterizi (che agiscono in parte come isolanti contro l'umidità del suolo) mentre il resto dell' edifizio vien costituito di cantoni.

Esistono intieri paesi, ad esempio Vignale, le cui case sono formate in massima parte di questo materiale, ciò che dà agli edifizi un'architettura severa e caratteristica.

Talora il materiale calcareo è talmente abbondante ed a grana fina che fornisce anche lastre di marmo abbastanza pregevole come si osserva nella zona elveziana di Rosignano.

Qua e là l'abbondanza del calcare fra le marne elveziane fa sì che esse possonsi utilizzare come materiale da calce, generalmente peró di qualità poco pregiata.

Nelle colline monregalesi si incontrano, nella parte inferiore della formazione elveziana, banchi marnosi, argillosi, grigio-biancastri che forniscono un materiale assai buono per fabbricazione di maiolica; ciò osservasi ad esempio nel rio Groglio, prco a Nord del Santuario di Vicoforte, ecc. Queste argille figuline biancastre, untuose al tatto perchè assai magnesiache, trovansi in lenti frammezzo a marne sabbiose grigioazzurrognole con traccie sulfuree (per decomposizione di solfuri di ferro che talora veggonsi ancora allo stato di piccoli cristallini). 
In alcune regioni, specialmente presso le Alpi, non sono neppur rarc le lenti lignitiche frammezzo ai depositi elveziani, ma trattasi quasi sempre di lenti sottili, di poca importanza ed assolutamente immeritevoli di escavazione; ne troviamo gli esemplari migliori presso il Santuario di Mondovi e S. Michele Mondovi, ma d'altronde se ne incontrano frequentissindmente anche altrove, nelle Langhe, nelle colline torinesi, ecc.

Fra le sabbie e le marne dell'Elveziano, specialmente dell'Elveziano inferiore, trovansi talora lenticelle solfuree, come in diversi punti dci colli monregalesi, ma esse non possono assolutamente porgere campo ad una escavazione speciale.

Fra le sorgenti acquee che sgorgano dalle arenarie elveziane sonvene parechie mineralizzate, specialmente sulfuree o solfureo-ferruginose, come presso Cassinasco in Val Moja sotto C. Albezzano, presso Marmorito, presso Castelletto d'Orba, presso Serravalle Sesia, presso Treville di Casale, presso Murisengo (Piemonte), presso il Santuario di Mondovi, ecc., ecc; in quest'ultima regione però sonvi eziandio polle ferruginose e magnesiache, ciò che d'oltronde si incontra non raramente anche altrove. Tali mineralizzazioni sono dovute al fatto che queste acque attraversano marne argilloso-talcose o piritose. Le acque magnesiache del Santuario di Mondovi gemono dalle marne talcose e sono raccolte in un pozzo artificiale.

In alcune colline elveziane si usa di fare piccole escavazioni entro i banchi sabbioso-arenacei, ottenendone vasche d'acqua, grotte ad uso di cantina, ecc. In certe regioni poi, là dove fra le sabbie elveziane trovansi grossi accentramenti arenacei vuoti all' interno, questi sono talora utilizzati come grossolani recipienti ad uso rurale.

Tortoniano. - Le marne di questo orizzonte geologico spesso possono venire utilizzate per fabbrica di laterizi, tanto più se già alquanto alterate superficialmente dagli agenti atmosferici. Nel passaggio tra questa zona e quella messiniana si incontrano talora, come presso S. Agata Fossili, alcune lenti calcaree da cui si trae una mediocre calce dolce.

Fra le sorgenti che sgorgono dalla formazione tortoniana è notevole che molte sono salate, come verificasi presso Vignale, presso Agliano in Tal di Nizza, presso Barbaresco d'Alba, presso C. Salera 
di Castagnole-Lanze, presso Castelnuovo d'Asti, ecc. Queste acquc saline possono csserc utilizzate per l'estrazione del sale, oppure per cure terapeutiche.

Alcune sorgenti minerali del Tortonians sono anche solfuree, cosi quella famosa solfurea (forsc però già in rapporto col terreno messiniano) di Castelnuovo à'Asti, situata poco a valle della sorgente salina sovraccennata; altre sorgenti sono solfurco-iodurate, come quelle di Agliano.

Per la loro natura marnosa le formazioni tortoniane talora si presentano franose, smottabili, cce.; quindi è sempre preferibile, quando si può, di evitare di costruirvi grandi opere d'arte, gallerie, ecc.; triste esempio in proposito ne sono le gallcrie ferroviarie tra Neive ed Alba continuamentc in riparazione. Sovente anche le strade che percorrono le regioni tortoniane divengono facilmente fangose, infossate, e sono di difficile manutenzione.

Messiniano. - Fra i terreni terziari questo è certamente uno dei più ricchi in materiali industriali, specialmente per la presenza dei depositi gessosi. Non è il caso qui di fermarci sopra questa speciale formazione geologica che abbiamo già esaminato minutamente nella parte geologica del lavoro; le lenti gessilere trovansi per lo più verso la base della serie messiniana, quantunque se ne incontrino anche più in alto. Il gesso si presenta o in grossi cristalli costituenti veri banchi, oppure in piccoli cristallini frammischiati abbondantissimamente alla marna; talora poi tali cristalli trovansi solo sparsi irregolarmente ed in piccola quantità.

La cottura e la triturazione del gesso, per portarlo allo stato polverulento quale mettesi in commercio, si compiono quasi sempre in modo abbastanza primitivo nelle immediate vicinanze delle cave di estrazione.

L'escavazione del gesso esiste in quasi tutte le regioni messiniane del Piemonte; questo materiale si usa quasi solo per costruzione ed imbiancamento; ma si potrebbe pure utilizzare efficacemente a correggere chimicamente certi terreni per alcune speciali colture.

Assieme alle lenti gessifere, specialmente in quelle più estese e potenti, si trovano pure sottilissime lenticelle sulfuree, per lo più direttamente frammischiate ai cristalli di gesso; cosi, per esempio, nelle colline della Morra, di Alice Belcolle, di Castellania, ecc.; ma, ad ogni 
modo, la quantità di zolfo è sempre cosi scarsa che non credo affatto consigliabile la sua estrazione.

Ben sovente, in modo speciale nella parte meridionale del bacino piemontese, compaiono nel Messiniano vere zone nerastre, carboniose, bituminose; neppure queste credo siano utilizzabili.

Invece degne di nota sono le formazioni calcaree che spesso appaiono nella zona messiniana solto forma di lenti od anche di banchi abbastanza estesi; di questo materiale si ebbe giả a trattare, con molti particolari, nel corso del lavoro, quindi non è il caso di ritornarci sopra; si tratta per lo più di un calcare grunuloso, leggiero, impuro, che viene utilizzato per estrarne calce di qualità però non molto buona.

Rare e poco importanti sono le lenticelle lignitiche che ưua e là incontransi fra $i$ banchi messiniani.

Siccome nella serie messiniana esistono spesso banchi di materiali grossolani, sabbie, arenarie più o meno compatte e calcaree, ciottoli sparsi, conglomerati, ecc., cosi sovente vediamo che in questa zona terziaria sonvi cave per diversi materiali da costruzione, per pietrisco, per pietre da macina (come alla Morra), ecc. Talvolta le zone marnoso-argillose sono anche utilizzate per fabbrica di laterizi.

In causa della speciale natura del terreno sovente si osserva che nella zona messiniana le strade si presentano incassate ed a fondo compatto; spesso poi nei banchi arenacei e sabbiosi del Messiniano l'uomo si è scavato piccole grotte per vari usi, sovente solo per raccogliere acqua.

Frequentissimamente le sorgenti acquee che sgorgono nella zona messiniana si presentano mineralizzate, ciò che si comprende facilmente da quanto si è detto precedentemente; per lo più si tratta di sorgenti solfuree od anche di gusto amarognolo per avere attraversato depositi inglobanti solfato di magnesio, di sodio, ecc.; quasi sempre tali acque vengono usate come medicinali. Ma quando invece le acque hanno attraversato depositi gessosi esse vengono a giorno molto cariche di solfato di calce, cioè molto gessate; in tal caso esse sono dannose alla salute e devono quindi essere proscritte.

Piacenziano. - Le marne argillose di questo orizzonte geologico vengono utilizate in diversi punti del Piemonte come materiale per 
laterizi o per maiolica grossolana, tanto piil che in certe regioni piacenziane la ricchezza in argilla è tale che se ne puó ottenere un'argilla figulina abbastanza buona.

Le marne, piacenziane possono anche venir utilizzate, dal lato agricolo, come correttivo per certi terreni.

In alcune regioni piacenziane trovansi traccie di olio minerale, così presso Chcrasco; ma finora non ne venne mai trovato in quantità sufficiente da meritarne l'estrazione.

Siccome questo terreno, per quanto in generale sia costituito di materiale assai fine, presenta, in alcune speciali regioni, zone arenaceocalcaree, come a Verrua Savoia ed in parecchi punti dell'Astigiano settentrionale, o zone marnoso-calcaree, come in alcuni punti dei colli casalesi, cosi anche dalla zona piacenziana si estraggono qua e là materiali grossolani da costruzione, rarissimamente da calce, e persino quei cantoni che ascannammo estrarsi tanto comunemente dall' Elveziano; ma i cantoni piacenziani che, ad esempio, vediamo usati in qualche regione presso Occimiano, resistono molto meno agli agenti atmosferici che non quelli elveziani per cui la loro escavazione è limitatissima.

Dal lato igienico bisogna tener conto speciale del velo acqueo che quasi sempre scorre regolare e costante sulla zona piacenziana; ciò è importantissimo per l'ubicazione dei fabbricati, dei cimiteri, per i pozzi, ecc.

Fra le molte sorgenti che incontransi nella zona piacenziana alcune sono solfuree, ad esempio quella presso Montafia, presso Chieri (S. Balermo), ecc.

"Rispetto a lavori d'ingegneria bisogna sempre fare attenzione alla natura speciale del terreno piacenziano, piuttosto argilloso, acquifero, trasformabile facilmente in fanghiglia scorrevole; è quindi consigliabile di evitare il più che possibile di costrurre strade, canali, fabbricati, ecc., lungo pendii piacenziani, e di attraversare questi terreni con gallerie; tristissimi esempi in proposito si potrebbero citare di regioni piemontesi presso Mondovi, presso Bra, ecc.

Soventissimo nei terreni piacenziani incontransi lenti lignitiche, ma in generale esse sono cosi strette e sottili che ron meritano affatto un lavoro di escavazione, tanto più poi che tale lignite non è molto compatta, ne ricca di potere calorifero. 
Astiano. - Le sabbie astiane sono largamente usate come mate. riale da costruzione, lo stesso dicasi di quelle lenti arenacee che si formarono là dove abbonda l'elemento calcareo cementante; talora anzi il calcare organico diventa cosi abbondante che costituisce quasi da solo ampie lenti utilizzate per costruzione, per pietrisco ed anche per ottenerne calce dolce, come ad esempio, si verifica presso S. Bartolomeo d'Alessandria.

Le colline astiane, per la loro grande permeabilitả, sono piuttosto salubri; i loro centri d'abitazione trovansi quindi per lo piủ lontani dai veli acquei, che sono sovente il veicolo di malattie infettive.

Nei lavori a'ingegneria è opportuno tener conto della poca stabilità che presentano spesso le sabbie astiane.

Per lo più le strade nella zona astiana sono alquanto incassate sull'alto della collina ed invece talora rilevate e molto sabbiose al fondo delle valli per modo da rendere talvolta assai faticoso il percorrerle; ne siano esempio Val Casetta, Val Piana, ecc., presso Ferrere d'Asti.

E comune in tutto l'Astigiano l'uso di escavare grotte più o meno profonde entro i banchi sabbioso-marnosi, specialmente per uso di cantina, per ripararvi oggetti rurali, ecc.

Fra i terreni astiani di certe regioni incontrasi solfato di magnesia - epsomite disseminata, cosi presso Canale (sal canale), presso Cisterna d'Asti, ecc., peró quasi sempre esso trovasi solo allo stato di eftlorescenza non solo nell'Astiano ma anche nelle marne piacenziane.

Fossaniano. - Oltre a materiali sabbiosi questa formazione geologica fornisce pure sovente materiali ghiaiosi e ciottolosi più o meno grossolani, che servono per costruzione e per pietrisco.

In alcune poche località, dove la formazione fossaniana fa passaggio a quella villafranchiana, compaiono già lenticelle lignitiche, come, ad esempio presso Castellamonte.

E noterole come in certe regioni, specialmente subalpine, nella serie fossanima trovansi banchi argilloso-sabbiosi che servono per'́abbrica sia di laterizi, sia di materiali refrattari di vario genere; ne sono esempio le famose regioni di Castellamonte, nonchè altre del Canarese, del Biellese, ecc.

Villafranchiano. -- Questo terreno fornisce materiali da costruzione, come sabbia e ciottoli, di cui alcuni di mole noterolissima; talora questi 
elementi sono uniti assieme in arenarie e conglomerati cementatissimi (eeppo) utilizzabili anch'essi quale materiale da costruzione, come specialmente osservasi in Lombardia. Fra le argille villafranchiane trovai talora traccie di tosfati, come ad esempio presso Fossano, ma sempre soltanto in quantità minima e che non offre quindi speranze di escavazioni proficue.

Il fatto più interessante che verificasi nella formazione villafranchiana è la comparsa, specialmente presso monte, di lenti lignitiche abbastanza notevoli, cosi presso Mommello, presso Front, lungo il Ticino, ecc., ecc.; però è raramente consigliabile l'intraprendere lavori un po' costosi per l'estrazione di questo combustibile che non è di qualità molto buona nè trovasi in banchi potenti e continui.

Dal punto di vista dell'ingegneria devesi tenere gran conto della natura argillosa che spesso prevale nella costituzione del Villafranchiano lungi dalle Alpi, rendendolo allora un terreno acquifero, fangoso, smottabile, instabile al sommo, per modo che difficilmente vi fanno presa le opere d'arte; ne è esempio, sgraziatamente ben famoso, il tratto di linea ferroviaria Torino Genova che taglia la formazione villafranchiana tra Villanova e Villafranca d'Asti. Anche le strade nelle regioni villafranchiane sono spesso di difficile manutenzione, fangose, a fondo irregolare, ecc.

Sahariano. - Sotto forma di Diluvium questo orizzonte geologico offre abbondantissimi ed usitatissimi materiali da costruzione, come sabbie, ghiaie e ciottoli. Talora questi ciottoli sono cementati in durissimi conglomerati, ad esempio nel cono di deiezione della Dora Riparia, in quello di Val Maira, di Val Stura di Cuneo in parte, ecc.; in questi casi talora i conglomerati sahariani vengono utilizzati come grossolani materiali da costruzione, il che però verificasi assai di rado.

Nella parte superiore del Diluvium esiste quasi sempre un velo più o meno potente di loess, escavato in tutte le parti del Piemonte quale eccellente materiale per laterizi. Nel loess delle colline si usa sovente di escavare piccole grotte per uso di cantina, per deposito di oggetti rurali, ecc.

Le strade che percorrono le regioni ammantate di loess sono per lo piì di difficile manutenzione perchè fangose, talora incassate, con facili smottamenti laterali, ecc. 
Certe lenti arenacee ferrifere o manganesifere (gherloun) che osserransi talora nella parte superiore del Diluoium, rengono utilizzate in alcune località come colore grossolano, cioè come terra d'ombra.

Anche le concentrazioni lentiforme calcareo-arenacee impure, che osservansi talora in Jenti alla supreficie del Diluvium, e sono note col nome volgare di mürs vengono spesso escavate, oltre che per migliorare il terreno, anche per utilizzarle come materiale da costruzione per fabbricati di campagna, argini di strade, ecc.

In certe regioni le sabbie e le ghiaie diluviali sono abbastanza aurifere per meritare ed aver meritato il lavoro di lavaggio, come fecero ad esempio i Romani nella famosa regione della Bessa nel Biellese, riducendola a quella strana configurazione e costituzione che essa ora ci presenta.

Riguardo al terreno morenico i materiali più utilmente escavabili sono le argille, specialmente per laterizi, ed i ciottoloni erratici; questi infatti, provenendo per lo piủ dalla parte centrale delle Alpi, sono geleralmente costituiti di roccie cristalline che danno un materiale eccellente per costruzione ed anche per ornamentazione; da ciò la distruzione che si va facendo continuamente dei blocchi erratici facienti parte delle morene terminali dei ghiacciai sahariani.

Le regioni costituite di Diluvium sahariano sono piuttusto salubri in generale, sia per la loro posizione elevata, sia perchè il relo acqueo assai profondo, furnisce un'acqua pura non inquinata da infiltrazioni locali.

Terrazziano. - Questa formazione, per quanto generalmente più sottile di quella sahariana, si presenta generalmente assai piu atta di quella all'escarazione dei materiali da costruzione e da pietrisco (sabbie, ghiaie e ciottoli), sia per la sua posizione quasi sempre più favorerole a tale scavazione, sia perchè le alluvioni del Terrazziano presentano i loro materiali generalmente assai meno decomposti che non quelle del Sahariano e quindi molto più durevoli.

Anche il velo di loess che copre generalmente le alluvioni terrazsiane è utilizzato ovunque su larga scala per fabbrica di laterizi.

Riguardo all'epoca di loro formazione appartengono al Terraziano i depositi torbosi che incontransi sovente nelle regioni moreniche, cosi negli anfiteatri morenici della Dora Riparia, della Dora Baltea, del 
Lago d'Orto, del Lago Maggiore, ecc.; anche nei bassipiani si formano talora depositi torbosi ma per lo più molto sottili e poco importanti. A dire il vero anche le conche torbose inframoreniche sono poco estese e di pochi metri di spessore; infatti esse vennero già quasi tutte completamente escavate per modo che fra pochi anni non esisteranno più in Piemonte importanti giacimenti torbosi.

Le alluvioni terraziane ed attuali deposte da certi corsi d'acqua, come il Malone, l’Orco, la Dora Baltea, il Cerro, l'Orba, ecc., sono aurifere e talora perciò escavate e lavate.

Dal lato igienico sovente le regioni terraziane si presentano meno salubri di quelle sahariane sia per trovarsi per lo più in posizione bassa, sia perchè il velo acqueo che scorre sotto le alluvioni del Ter. razziano è quasi sempre poco profondo; quindi non è raro che esso venga inquinato dall'esterno per infiltrazioni.

Di questo fatto si deve tener molto conto nell'alimentazione acquea dei centri abitati, nella ubicazione dei cimiteri, ecc.

Dalle poche considerazioni generali fatte nelle pagine precedenti risulta chiarissimamente la stretta relazione esistente fra il terreno e l'uomo che vive di esso e su di esso, e quindi l'importanza grande degli studi geologici non solo dal punto di vista scientifico ma anche sotto l'aspetto applicativo. 



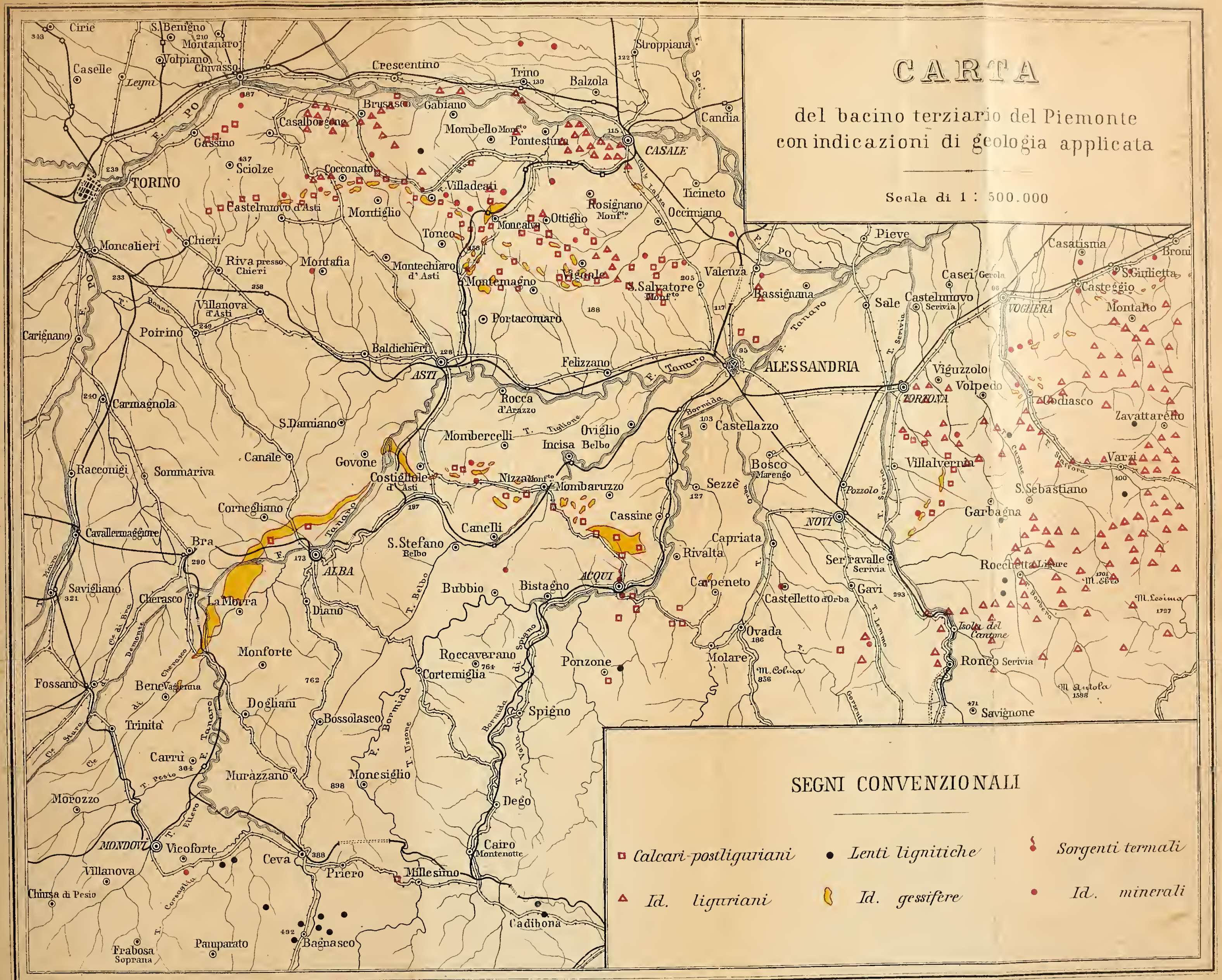

Lit Brumor Saloururue , Bam 


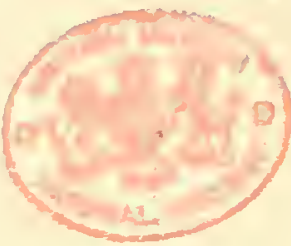

$$
\text { • }
$$




\section{A P P E N D I E}

Lo studio geologico del Bacino terziario e quaternario del Picmonte venne condotto a termine nel 1888 e se ne intraprese la pubblicazione sul principio del 1889 negli Atti della Soc. It. di Sc. Nat. In causa però della grande lentezza di tale modo di pubblicazione credetti opportuno di terminare privatamente la pubblicazione della parte deserittiva del tcrziario e di far inserire nei Bollettini della Soc. geol. it. e del R. Com. Geol. it. quelle parti che potevano esistere isolate, eioè: la descrizione del Bacino quaternario, il Catalogo palcontologico del Bacino terziario, c la parte riguardante la Geologia applicata.

Ed ora che tale pubblicazione è terminata non mi resta che porre in appendice quelle aggiunte, correzioni, ece. che sono rese necessarie o da dimenticanze, o da crrori, o dalla comparsa di nuovi lavori, o da nuove osservazioni fatte in questi ultimi due anni.

La classificazione dei terreni terziari, quale venne proposta nella Prefazione del presente lavoro, dere essere alquanto modificata riguardo all'Eocene, sia perchè il Gassiniano non è probabilmente altro ehe il Bartoniano, sia perchè il Liguriano, in parte, rappresenta solo una facies del Parisiano.

Il catalogo paleontologico, malgrado i numcrosi errori inerenti alli sua stessa natura, ha l'importanza: anzitutto di indicarei il preciso orizzonte di ritrovamento di ogni fossile finora linvenuto nei terreni terziarii del Piemonte: inoltre di racchiudere i nuovi nomi (oltre 500) delle varictì di Molluschi descritte dal Bellardi e finora indicate solo con lettere d'alfabeto: infine di lasciarci abbracciare in breve la straordinaria ricehezza paleontologica del bacino terziario Piemontese ehe raceliudeva, secondo il catalogo del Sismonda, circa 1000 forme, incntrc ora colle nuove riecrehe e sccondo i recenti studi analitici, esse sommano a quasi 5500.

Non credetti opportuno di porre in questo Catalogo paleontologico anche le forme del Quaternario, poichè esse consistono quasi unicamente in Molluschi, di cui presentai già un elenco completo nei lavori indicati nella Bibliografia ai numeri 468 e 506. 


\section{BIBLIOGRAFIA}

1816-30. 520. Defrance, Dictionnaire des sciences naturelles, en- $8^{\circ}$. Paris. 1825. 521. Basterot (De), Descript. géolog. du Bassin tert. du S. O. de la France. - Mém. Soc. Hist. nat., 3e série. Paris.

1825-? 529. Bonelli, Catalogo manoscritto del Museo Zoologico delI"Universitá di Torino.

1829. 523. De Serres H., Géogn. des terrains tert. du midi de la France. Montpellier.

1834-40. 524. Milne-Ełwards, Histoire naturelle des Crustacés.

1835-45. 525. Lamark, Hist. Nat. des animaux sans vertëbres (2e édition revue par MM. Deshayes et Milne-Edwards). Paris.

1837. 526. Brom, Lethæa geognosticil. Stüttgart.

1840. 527. Grateloup, Conchyliologie fussile des terrains tert. du Rassin de l'Adour. Bordeaux.

1813. 528. Michelotti G., in Malacolog. and conchiolog. Mag., conduct. by G. Sowerby. Parte 11.

1843-45. 529. Brocehi G., Conchiol. foss. subuppennina (2 ediz.). Milano. 1814. 530. P. H. Nyst, Description des Coquilles et des Polypiers fossiles des terrains tert. de la Belgique. Bruxelles.

1816. 5:31. Michelotti G., Neues Jahrb. Leohn. und Bronn.

1848. 532. Bronn, Index paleontologicus. Stûttgart.

1818-50-53. 533. 0. G. Costa, Paleontologia del Regno di Napuli. Atti Acc. Pontan. Vol. V, VI, VIl.

1851. 594. Sismonda E. (non A.), Osteografia di un Mastodonte, ecc.

1853. 505. Gastaldi B., Appunti sulla Geologia del Piemonte. Tor'ino, tipngrafia Marzorati.

1857. 536. Faleoner H., On the species of Nastodon an Elephant occurring in the fossil state in Great Britain. Proc. Zool. Soc. London.

1859. 537. Lartet, Sur la dentition des Proboscidiens fossiles et sur la distribution géographique et stratigraph. de leurs debris en Europe. Bull. Soc. gẻol. de France. $2^{e}$ série, tome XVl.

1862. 588. Gaudry A., Animanx fossiles et géologie de l'Attique. Paris, T. Savy édit.

1864. 539. Coechi I., Monografia dei Pharyngodopilidae, nucva filmiglia di Pesci labroidi. Firenze, $4^{\circ}$.

1867-68. 540. Weinkanfe C., Die conchylien des Mittelmeeres, ecc. Cassel.

1867-70. 541. Meyer (H. V.), Studien über Gellus Mastodon. Paleontograplica. Cassel.

1869-72. 542. Schimper W. Th., Traité de Paléontologie végétale. Paris.

1873. 543. Coceoni, Enumerazione sistematica dei Molluschi miocenici e pliocenici delle prov. di Parma e Piacenza. Mem. Acc. Sc. Istituto di Bologna. Serie 1ll, tomo 111.

1875. 544. Manzoni A., I Briozoi del Pliocene antico di Castrocaro. Bologna, $4^{\circ}$. 
1876-80. 545. De Stefani C., Molluschi continentali pliocenici d'ltalia. Atti Soc. tosc. sc. nat. Vol. III.

18:9. 546. Tiberi N., Céphalopodes, Pteropodes, Héteropodes, vivants de la Méditerranée et fossiles du terrain tertiaire d'Italie. - Ann. Soc. Malac. de Belgique, tome Xili.

1878-81. 547. Nyst P. H., Conchyliologie des terrains tert. de la Belgique. - Ann. Mus. R. Hist. nat., tome Ill. Bruxelles.

1880. 548. Tiheri N., Cefalopodi, Pteropodi ed Etcropodi, viventi nel Mediterraneo e fossili nel terreno terziario italiano. - Boll. Soc. MaIac. it., vol. VI.

1881. 548bis - Bibliographie géologique et paléontologique de l'Italie (Bologna).

519. Bagatti 0., Aggiuntc all'Enumer. sist. dei Moll. mioc. e plioc. delle prov, di Parma e Piacenza. Parma, Tipogr. Ghelfi. $4^{\circ}$.

5ă0. Gahntti G., Memolie sulle antichità di Dogliani. Torino, $8^{\circ}$.

1883. 551. Hantken, 11 piano a Clavulina Szaboi nella regione degli Euganci e delle Alpi marittime, ccc. Pest, Verhandl.k. k. geol. Reichst., n. 11 .

552. De Bonry, Description d'espèces nouvelles de Mathilda du Bassin de Paris et revision du genre. Journ. de Conchyl.

1884-85. อ็ว3. De Gregorio A., Studi su talune conchiglie mediterranee viventi e fossili. Boll. Soc. malac. it. Vol. X e Xl.

1885. 554. Pantanelli D., Sopra alcune Scalarie terziarie. Boll. Soc. malac. it. Vol. Xl.

1857. 555. Pantanelli D., Spccic nuove di Molluschi del Miocene medio. Boll. Soc. malac. it. Vol. XII.

556. Pantauelli D. e Mazzetti F., Ccnno monografico intorno alla fiuna fossile di Montese. Atti Soc. Nat. di Modena, serie III, vol. VI.

5.57. Trabuceo, La petrificazione. Pavia.

1888. 558. Minoglio G., Scoperta di un fossile (Mastodon longirostris) in Valle Andona (Asti). Torino.

559. Pantanelli, Melanopsis Matheroni e 1. narzolina. Bollett. Soc. malac. it. Vol. XIII.

560. Ristori G., Alcuni Crostacei del Miocene medio ital. Mem. Soc. tosc. Sc. Nat. VoI. IX.

561. Trabuceo A., Fossili del Bacino pliocenico di Rio Orsecco (Carpencto). Como.

562. Taramelli T. e Mercalli G., Alcuni risultati di uno studio sul terremoto ligure del 23 febbraio 1887. Rendic. Accad. Lincei, serie IV, vol. IV.

563. Taramelli T. e Mercalli G., II terremoto ligure del 23 fabbraio 1887 (Ann. uffic. centr. di Meteor. e Geol, vol. Vil'). Roma, $4^{\circ}$.

1889. 564. The Gregorio, Studi sul genere Scalaria. Ann. de Géologie et Paléont., 6e livraison. Palermo.

505. Hayer-Eymar C.g Tableau des terrains tertiaires de sédiment. Societas historico-naturalis croatica. Zagreb. 
1889. 666 . Hayer-Eymar C., Descript. des coquilles fossiles des terrains tertiaires sup. Journ. de ConcliyI. Série III, tome XXIX.

567. Pollini C.g Sopra alcuni avanzi di Pesci fossili terziarii conservatı nel Míseo geol. della R. Università di Genova. - Milano.

568. Portis A., Di alcuni Gimnodonti fossili italiani. Boll. R. Comit. geol. ital.

569. $\mathbb{R}$. Ufieio Geologico, Carta geologica d"Italia alla scala di 1/1000000. Roma.

5:0. Saceo F., Le Ligurien. Bullet. Soc. géol. de France. $3^{\circ}$ série, tome XVI.

581. Saceo 5 Sopra due tracciati per un tronco della linea ferroviaria Torino-Chieri-Piovi-Casale. Osservazioni geol. Torino.

5\%2. Saceo $\mathbb{F}$. Sopra un progetto di serbatoio in Valle Usseglia presso Torino. Osservazioni geologiche. Torino.

578. Saceo F., I colli monregalesi. Boll. Soc. geol. it. Vol. VIIl.

$5 \mathbf{5}$. Sacco $\mathbb{F}$.g Il seno terziario di Moncalvo. Atti R. Accc. delle Scienze di Torino, vol. XXIV.

575. Sacco î. Les conglomerats du Flysch. - Mém. Soc. belge de Géologie, Paléontologie, ete. Tome III.

556. Saceo $\mathbb{P}$.g La conca terziaria di Varzi - S. Sebastiano Curone. Boll. R. Comit. geol. italiano.

3\%:. Sacen F., La caverna ossifera lel Bandito in Valle del Gesso. Boll. Club Alp. it. Vol. XXXiII, n. 56.

5.8. Sucen F.g I Cheloni astiani deI Piemonte. Mem. R. Accad. delle Scienze di Turino, serie II, tomo XXXIX.

559. Sareo $\mathbf{r}$.g Catalogo paleontologico del Bacino terziario del Piemonte. Boll. Soc. geol. it. Vol. VIII.

5\$o. Saceo F., Il Bacino terziario del Piemonte. - Parte I: Bibliografia. - Parte Il: Geologia pura (Suessoniano e Parisiano, Liguriano, Bartoniaro, Sestiano, Tongriano, Stampiano). Atti Soc. it. Sc. Nat. Vol. XXXI e XXXll.

581. Saceo $\mathbb{E}$.g Carta geologica dei colli torinesi alla scala di $1 / 25000-$ ( $2^{\mathrm{a}}$ ediz. corretta). Torino.

552. Squimabol \$., Contribuzione alIa Flora fossile dei terreni ter. ziarii della Liguria - II (Caracee e Felci). Genova.

583. Squinabol \$., Saggio bibliografico delle opere di Paleontologia vegetale italiana del secolo presente. Genova.

584. Bellar 3 i 1. e Sacco F., I Moluschi dei terreni terziari del Piemonte e della Liguria. - Pirte VI (Volutidae, Iarginellidae e Columbellidae). Mem. R. Acc. Sc. di Torino, serie II, t. XL.

5\$5. Cantamessa F., ll Mastodonte di Cinaglio ed il Mastodon (Tetralophodon) arrernensis. Boll. Musel Zool. ed Anat. comparata di Torino, vol. $\mathrm{V}$.

586. De Boury L.g Revision des Scalidae miocènes et pliocènes de l'Italie. Boll. Soc. malac. it., vol. XIV.

587. Dervieux H., Crislellaria cassis e C. galea. Boll. Musei Zool. ed Anat. comp. di Torino, vol. V.

588. Issel A. e Squinahol S., Carta geologica della Liguria (in 2 fogli). 
1890. 589. Rcid 0., The Pliocene deposits of Britain. Mem. of. the Geol. Survey.

590. Saceo $\mathbb{P}$. Geologia applicata del Bacino quatemario del Piemonte. Boll. R. Comit. geol. italiano.

591. Saceo F., Catalogo paleontologico del Bacino terziario del Piemonte (ine). Boll. Soc. geol. it., vol. IX.

592. Saceo $\mathbb{F}$. Il Bacino quaternario del Piemonte. Boll. R. Comit. geol. italiano.

593. Sacco $\mathbb{E}$. e Bellardi $\mathbb{Z}$.g I Molluschi dei terreni terziarii del Piemonte, ecc. - Parte VI (Vedi Bellardi).

594. Sacco Fi., Relazione geologica sopra un progetto di derivazione d'acqua dal torrente Giandone. Municipio di Torino.

595. Sareo $\mathbb{F}$. I Molluschi dei terreni terziarii del Piemonte a della Liguria. Parte VII (Harpidae e Cassidiclae). Nota preventiva. Boll. Musei di Zoologia ed Anatomia comparata, vol. V, n. 82.

596. Sacea T. Louis Bellardi (Biographie de), avec portr. - Mém. Soc. belge de Géol., Paléont., etc., tome IlI.

597. Face $\mathbf{H}$. I Molluschi dei terreni terziarii del Piemonte e della Liguria. Parte VIII (Galeodoliidae, Doliidae, Ficulidae, Nalicidae). - Nota preventiva. - Boll. Mus. Zool. ed Anat. comparata di Torino. Vol. V, n. 86.

598. Saceo $\mathbb{F}$. . Sur la position stratigraphique des charbons fossiles du.Piémont. Bull. Soc. géol. de France, 3e série, tome XVIII.

999. Sareo $\mathbb{F}$., Sopra una mandibola di Bataenoptera dell'Astigiana. Atti R. Acc. Sc. Torino, vol. XXV.

600. Sacco If., La geéo-tectonique de la Haute Italie occidentale. Mém. Soc. belge de Géologie, Paléontologie, etc. Tome IV.

B01. Saceo F.g I Molluschi dei terreni terziarii del Piemonte e della Liguria. Parte VII (Harpidae e Cassididae). Mem. R. Acc. Sc. di Torino, serie Il, tomo XL.

602. Sace F.g I Molluschi dei terreni terziarii del Piemonte e della Liguria. Parte VIlI (Galeodoliidae, Doliidae, Ficulidae e $\mathrm{Na}$ ticidae). Mem. R. Accad. Sc. di Torino, serie II, tomo XLI.

603. Sreco F., Il Bacino terziario del Piemonte. Parte II: Feologia pura (Aquitaniano). Atti Soc. it. Sc. Nat., vol. XXXI.

604. Sacco F.g ll Bacino terziario del Piemonte. Parte 11: Geologia pura (Langliano, Elveziano, Tortoniano, Messiniano, Piacenziano, Astiano, Fossaniano, Villafranchiano). Torino, Tipografia Guadagnini e Candellero.

605. Squinabol S., Cenni preliminari sopra un cranio ed altre ossa di Anthracotherium magnum di Cadibona. Atti Soc. ligust. di Sc. Nat. e Geogr., vol. I.

606. Squinabol S.g Di un tipo paleocenico di Quercinea ritrovato nel Miocene inferiore di S. Giustina e di alcune altre piante rare del medesimo giacimento. Atti Soc. ligust. di Sc. Nat. e Geogr., vol. 1.

607. Tarmelli T., Carta geologica della Lombardia alla scala di $1 / 250000$ (con opuscolo esplicativo). Milano. 


\section{GEOLOGIA PURA}

Capitolo 1. - Cerchia preterziaria. - Riguardo a questo argomento si potrá consultare la recente mia nota "La géo-tectonique de l'haute ltalie occidentale ", in cui esso é svolto con più larghe vedute e meglio chiarito per mezzo di una carta geologica d'assieme e di una compreensiva sezione geologica.

Capitolo 1l. - Suessoniano e Parisiano. - Tanto l'uno come l'altro orizzonte vennero finora, nella regione in esame, inglobati in quel grande complesso che ricevette il nome di Liguriano; essi peró sono poco sviluppati e difficilmente delimitabili, sia per le contorsioni che spesso presentano i loro strati, sia per il graduale loro passaggio agli orizzonti sottostanti, sil perché spesso vi scarseggiano i fossili caratteristici. Riscontrai peró in qualche punto alcune Assiline, specialmente I'Assitira mamillata (cosi presso Borgata Curone a Sud di Narmorito), alcune Nummuliti li facies parisiana (cosi presse C. Cappone presso il Po nel Casalese, ed altrove), alcuni esemplari di Alveolina ovoidea (cosi presso C. Cappone nel Casalese), ecc. Ė certo quindi che l'orizzonte parisiano è rappresentato anche nel centro del bacino terziario piemontese, solo che esso è difficilmente delimitabile; liesciranno quindi utili ulteriori ricerche in proposito.

Capitolo 11I. - Liguriano. - In apposita Nota "Le Ligurien - B. S, G. F. - 1890 », indicata nella Bibliografia col numero 570, cercai di dimostrare come questo nome, corrispondendo ad una facies litologica e comprendendo orizzonti geologici diversi (dal Giura al Tongriano), dovrebbe venire abbandonato od essere solo piu conservato per indicare una facies speciale. Osservazioni fatte ulteriormente nel Piemonte e fuori, l'incontro di fossili caratteristici, alcuni fenomeni stratigrafici, ecc. mi fanno abbracciare l'ipotesi che gran parte delle argille scagliose e di altre formazioni incluse nel Liguriano e credute eoceniche, appartengano invece già al Cretaceo. Ė seguendo questo criterio in linea generale che nella carta geologica del bacino quaternario del Piemonte segnai complessivamente in bianco (terreni preterziarii) quasi tutte le formazioni liguriane dell'interno del bacino terziario piemontese; ma è certo ad ogni modo che in dette aree sono pure compresi affioramenti più o meno notevoli di Eocene; cosi, ad esempio, nelle colline casalesi, dove in parecchi punti ebbi a riscontrare calcari nummulitici (presso C. Lissandrina, C. Coppone, ecc.), nelle colline di Brusaschetto, specialmente a N. E. di questo paese, dove osservai esistere banchi arenacei con Orbitoides stella, O. tenuicostata, piccole Nummuliti, ecc. Ma mentre finora da tali ritrovamenti io deducevo la eocenicita di tutta la complessa formazione indicata col nome di Liguriano, invece ora ritengo che in parte essa 
debba pure attribuirsi al Cretaceo, pur mantenendo nell'Eocene estesi affioramenti liguriani, quelli specialmente clie prescntano fossili nummulitici. Credo siano specialmente da riferirsi al Cretaceo le zone di argille scagliose a tinte varicgate; di esse sono tipo, per es., nelle colline Torino-Casale: le regioni dove si estrae il calcare di calce, presso Lauriano e presso borgata La Pietra: le vicinanze di Marcorengo e di Quarlasco presso Brusasco, ecc, ecc. Invece riguardo alle formazioni marnosocalcareo-arenacee che sovrappongonsi alle tipiclie argille scagliose rimane talora incerto se esse debbansi ancora attribuire al Cretaceo o se in par'te siano gia da riferirsi all'Eocene inferiore; e tale delimitazione è assai difficile in causa della stratigrafia disturbata, della rarita dei fossili, della sviluppata vegetazione, ecc. Talora i resti fossili sono cosi scarsi da non permettere una netta decisione sull'età dei terreni che li racchiudono. Cosi, ad esempio, nelle colline casalesi, salendo da C. Monsasco a C. Rossa, trovai, frammezzo a marne nerastre piủ o meno argillose, sottili banclii calcarei zeppi di fossili mal conservati, spccialmente piccole Nummuliti, numerosissime Globigerine, alcune Orbitoidi del sottogenere Lepidociclina, ecc.; trattasi probabilmente in questo caso di terreni appartenenti all'Eocene inferiore, ma non sarebbe neppure impossibile che per il loro assieme già dovessero attribuirsi al Cretaceo. Ulteriori studi in proposito, sia nella regione piemontese, sia specialmente altrove, saranno necessari per meglio chiarire la questione. $\dot{\mathrm{E}}$ certo peró ad ogni modo clie nelle regioni alpine le formazioni costituite di Macigno, Flysch, argilloschisti, ecc., sovrap. poste a strati nummulitici, e generalmente conosciute col nome di Liguriano, rappresentano veramente l'Eocene, specialmente l'orizzonte parisiano.

Capitolo IV. - Formazioni ofiolitiche del Liguriano. - Se complessa è l.l questione riguardante l'origine delle formazioni ofiolitiche, invece quasi tutti i geologi sono ora d'accordo nel ritenerle eocenichc; orbene, astrazion fatta delle serpentine prepaleozoiclie, quantunque possano naturalmente ammettersi formazioni oficlitiche di diverse età, sino all'Eocene, i miei recenti studi mi porterebbero inrece a collocare nel cretaceo quasi tutte le cosidette serpentine eoceniche, come cercheró di dimostrare in una prossima pubblicazione.

Capitolo V. - Bartoniano. - Le recenti osservazioni mi lianno sempre più provato come, sia litologicamente che paleontologicamente, non esista sempre una netta delimitazione fri l'orizzone bartoniano e quello parisiano. Ad esempio, nella regione settcntrionale delle colline casalesi in alcuni banchi calcarei presso C. Lissandrina incontrai Nummulites Fichteli var., N. Rosai, N. Boucheri, orbitoides papyracea, ecc., cioè fossili a facies bartoniana, mentre poco lungi presso C. Coppone, oltre a $N$. Boucheri, N. vasca, N. striata, N. Guettardi, O. papyracea, 
o. Forlisii, O. ephyppium, ecc., riscontrai Alreolina oroidea e piccoli Nummuliti di facies parisiana. Fenomeni consimili osservai presso borgata Curone attorno all'affioramento liguriano di Cocconato, cosi pure nel lato settentrionale dell'affioramento liguriano di Lauriano-Brusasco, specialmente poco a Sud di Monteu da Po, ed altrove. Noto a questo proposito come l'incontro che talora ho fatto di Assitine in alcune delle prenominate regioni, provi maggiormente come quivi afiorino piú o meno estese zone parisiane collegantisi insensibilmente a quelle barloniane. ̇̀ quindi probabile che in questo laroro e nella carta geologica all: $1 / 100000$ io abbia talvolta inglobato nel Barloniano formazioni che invece debbono attribuirsi in parte al Purisiano, cosi, per esempio, nel Tortonese tra Costa Vescovado e Brignano Curone, ed altrore; cio spiega come io abbia in alcuni punti osservato graduale passaggio dal Barloniano tipico alle argille scagliose. Quanto al nome di Gassiniano. esso, quando meglio siano chiariti i rapporti cronologici dei terreni che lo l'appresentano. dorrá probabilmente renir abolito el essere posto in sinonimia del Barloniano.

Capitolo Vll. - Tongriano. - Nella delimitazione delle formazioni tongriane, specialmente nell:A ppennino settentrionale, mi arrenne di dimenticare lembi sparsi, cosi quello tipico, conglomeratico, cementatissimo, di Montecanue (lsola del Cantone), ecc.

Capitolo X. - Aquilaniano. - In causil della grande scarsità di fossili e della loro natura litologica poco caratteristica, le formazioni aquilaniane non possono talora essere nettamente limitate; cosi nelle colline casalesi $l^{*}$ Aquitan ?ano è probabilmente alquanto più sviluppato a N. N. E. di S. Giorgio Monferrato di quanto sia stuto indicato nella carta geologica all\%1/100000; debbo in proposito sempre piu far notare la straordinaria ricchezza paleontologica del lembo elveziano del Cimitero di S. Giorgio, tanto più che vi si incontrano comunemente fossili assai rari in altre regioni del Piemonte, cosi grosse Orbitoidi, Cidariti, denti di sphcrodus e d'altri pesci, ecc.

Capitolo XV. - Astiano. - Recenti osservazioni mi fanno ritenere che una parte della placca pliocenica di Verrua Savola, e piu precisamente la parte superiore occidentale su cui basa direttamente il Castello, debba attribuirsi all'Astiano, passante peró grałuillissimamente al Piacenziano; tale piccolissimo lembo astiano consta di banchi sabbioso-arenacei, giallastri, assai fossiliferi, inclinati alquanto fortemente verso il Nord circa. Pel" quanto sia piccolo questo lembo asliano, esso è assai interessante, essendo l'unico lembo che appaia sul lato settentrionale del corrugamento Torino-Casale. 


\title{
CORREZIONI ALLE CARTE GEOLOGICHE
}

\author{
IN G R A DE SCALA
}

Delle più interessanti regioni del Bacino terziario picmontcse credetti opportuno pubblicarc le carte geologiche in grande scala, cioè all'1/50000 quelle di Spigno Monferrato, Voltaggio Nord, Ovada Nord, Ceva Sud e Garessio Nord, Cairo Montenotle Orest, e all'1'23000 quelle di Serravalle Scrivia, Gavi, Villavernia e Garbagna Ovest, Acqui, Capriala d'Orba, Fossano, Nizza Monferrato e Sezzè Ovest, Mombercelli e Canelli Nord, Canale e Nonteu Roero Est, Calamandrana, Costigliole d'Asti, Colli torinesi (diametro centim. $90 \times 110$ ), Cherasco e Cervere.

Tali carte, che lasciano molto da desiderare dal lato estctico, furono pubblicate in modo alquanto economico, specialmentc allo scopo che esse servissero di guida a chi vuol impratichirsi nella conoscenza dei diversi orizzonti terziarii, a chi vuol raccogliere fossili in modo razionale ed a chi vuol visitarc con profitto c con comodita le piu classiche regioni del tipico bacino terziario del Piemonte.

Naturalmente, trattandosi quasi sempre di orizzonti geologici succedentisi regolarmente l'un l'altro, le loro delimitazioni riescono sovente alquanto arbitrarie e quindi soggette talora ai criteri individuali ed alle oscillazioni derivanti dai diversi punti di vista litologico, paleontologico ou orografico, da cui tali formazioni sono considèratc. Ne consegue che molte discrepanze di opinione possono sorgerc all'atto pratico nella delimitazione degli orizzonti geologici; oltrecciò é probabile clıe osservazioni ulteriori provino come in molti punti io abbia realmente errato; anzi di questi errori, in parte derivanti da me cl in parte dil litografo, voglio accennare alcuni che fin d'ora ebbi gia a riconoscerc.

Nella carta di Splgno Monferrato la tinta dell'Aquitaniano fu troppo poco estesa al limite di contatto colla carta di Cairo-Montenotte, risultandovi troppo cstesa invece la tinta dello stampiano. Nella cirta di HoMBEriCELLu il Fossaniano fu indicato solo con puntini blen, invece cle con puntini rerdi sul giallo. Nella cirta di Nuzza Monferkato venne dimenticata la placea fossaniana, costitucnte la parte superiore del Bric C. Barattera. Nella carta di Gavi, sotto C. Poggio, devesi estendere alquanto piu a Sud la tinta del Piacensiano, invece di quella del Messiniano. Nella carta di Villavernia tra Costa Vescovado e le colline di Avolasca-Pallanzana venne indicato un grande sviluppo di Langhiano, mentrc al suo posto devesi in parte far apparire una zona di Eocenc assai vasta ed cstesa. Nella carta di Vortaggio sono da riferirsi al Trias diversi affioramenti di calcari dolomitici (utilizzati su larga scala come calcare di calce), che credetti dapprima poter attribuire ancora al Liguriano. Nella carta di Ovas. venne 
dimenticata una placca aquitaniana presso C. Losio (Ponzone), e pure fu dimenticato uno spuntone serpentinoso che esiste presso Poggio a S. O. di Grognardo; d'altronde qui, come altrove, simili dimenticanze possono essermi sfuggite assai facilmente. Nella carta geologica dei CoLLI TORINesI le diverse correzioni fatte, riguardo specialmente al Tortoniano, al Tongriano, allo Stampiano, ecc., mi obbligarono a pubblicarne una seconda edizione; venne peró ancora in questa tralasciato un piccolo affioramento liguriano, circondato da una zona bartoniana, nella parte Sud-Est di detta carta tra Moriondo e Colombano.

Quanto alla carta generale a $1 / 1000000$, oltre ad alcune delle correzioni giả indicate per le carte in grande scala, è specialmente a notarsi che una parte delle zone indicate come liguriane sono probabilmente da riferirsi al Cretaceo; qualche parte di alcune zone bartoniane dovrá forse riferirsi al $\mathrm{Pa}$ risiano; cosi pure dovià forse segnarsi qualche striscia bartoniana nella parte settentrionale dei colli casalesi; venne dimenticata la placca tongriana di Montecanne (Isola del Cantone); deve estendersi alquanto la tinta dell'Aquitaniano a Nord-Est di S. Giorgio Monferrato; è da aggiungersi la piccola placchetti astiana del Castello di Verrua, ecc., ecc.

Ma oltre a questi ed altri varii errori, molti se ne formarono (tanto nelle carte a grande come in quelle a piccolil scala) per spostamento di colori durante la loro stampa, per dimenticanze del coloritore, ecc. Raccomando la correzione di questi errori alla benevolenza ed alla intelligenza dei geologi che avranno ad esaminare dette carte. 


\section{N D I G E}

BACINYO TERZIARIO Introduzione

PARTE 1.

Hibliogradia.

Elenco cronologico.

Elenco alfabetico

PARTE 11.

\section{Geologial pura.}

Capitolo I. - Cerchia preterziaria

Stessoniano e Parisiano

1II. - Liguriano . • • • • • • • 》 53

1V. - Formazioni offolitiche Lel Liguriano . • . » 87

V. - Barloniano (Gassiniano?). . . . . » 94

VI. - Sestiano . . . . . . . » 11 ?

Vll. - Tongriano . . . . . . . . \ $126^{\circ}$

V111. - Stampiano . . . . . . . . \ 225

1X. - Aquilaniano . . . . . . . \ 261

X. - Langhiano . . . . . . . . " 321

XI. - Elve iano . . . . . . . \$348

XII. - Tortoniano . . . . . . . . 》 4 I6

XII. - Messiniano . . . . . . . . " 440

XIV. - Piacenziano . . . . . . . » 474

XV. - Astiano . . . . . . . . 501

XVI. - Fossaniano . . . . . . . 5523

XVll. - Villafranchiano . . . . . . . 》 544

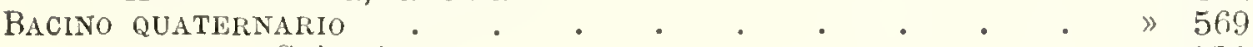

Sahariano . . . . . . . .

Diluvium . . . . . . . . \ 577

Terreno morenico . . . . . . $\$ 607$

Terraziano . . . . . . . . .

Allurioni recenti . . . . . . . \ 632

Palroetnologia . . . . . . . . . $\quad$. 633

PARTE 1II.

Catalogo palcontologico del bacino terziario. Pag. I (648)

Paleoicnologia

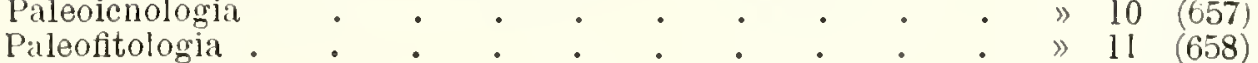

Paleozologia $\quad \cdot \quad \cdot \quad \cdot \quad \cdot \quad \cdot \quad \cdot \quad \cdot \quad \cdot \quad \cdot \quad$ • $\quad \cdot \quad 24(671)$

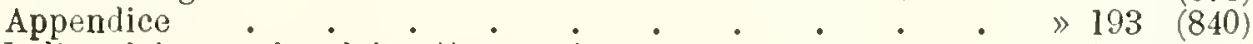

Indice lei generi e dei sottogeneri . . . . . . $\quad$. 224 (871)

PARTE IV.

Geologia applicata. $\quad$ 》 1 (882)

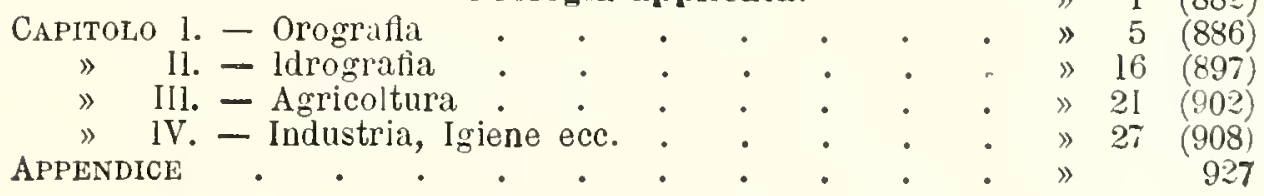





\section{IL BACINO TERZIARIO E QUATERNARIO DEL PIEMONTE}

Dopo circa 10 anni di studio venne ora condotta a termine e pubblicata la descrizizione del Bacino terziario e quaternario del Piemonte; questo Bacino, gia ben famoso paleontologicamente per la riccliezza in fossili terziari, specialmente di quelli tongriani dell'Appentino settentrionale, di quelli elveziani dei colli di Torino, di quelli tortoniani delle vicinanze di Tortona, di quelli astiani dell'Astigiana, ecc., diventera ora, dopo questo lavoro, un bacino pure affatto tipico dal lato geologico, presentando esso completa, graduale, bellissima Ia serie dei diversi orizzonti geologici, quasi tutti fossiliferi, dall'Eocene al Quaternario.

Il volume, di 940 pagine, è diviso in quattro parti, cioè:

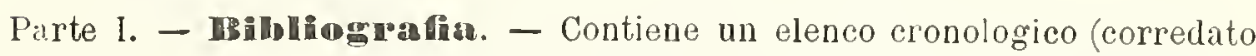
da un indice alfabetico) di oltre 600 opere trattanti, esclusivamente o parzialmente, della geologia o della paleontologia del Bacino terziario del Piemonte.

Parte II. - Geologia pura. - Contiene la descrizione geologica del Bacino piemontese el è divisa nei seguenti capitoli : Cerchia preterzi:ıria, Snessoniano e Parisiano, Liguríno, Formazioni ofiolitiche del Liguriano, Bartonino, Sestiano, Tongriano, Stanpiano, Aquitaniano, Ianghiano, Elveziano, Tortoniano, Messiniano, Piaccnziano, Astiano, Fossaniano, Villafranchiano, Sahariano (Diluvium, Terreno morenico), Terrazziano (Alluvioni recenti), Paleoetnologia.

Ciascun capitolo è a sua volta suddiviso nei seguenti paragrafi:

Studi anteriori, Generalití, Caratteri paleontologici, Distribuzione gecgrafica, Tettonica, Potensa, Altimetria, Rapporto coi terreni sotto e soprastanti, Località fossilifere, Descrizione geologica regionale, Riassunto.

Partc III. - Catalogo paleontologico. - $\dot{E}$ un elenco sistematico di circa 5500 forme terziarie, di ciascuna delle quali é indicato il preciso orizzonte geologico di ritrovamento. Tale catalogo è diviso in tre parti, cioé: Paleoicnologia, Paleofitologia c Paleozoologia; esso termina con un Indice generale dei generi e dei sottogeneri.

Parte IV. - Geologia applicata. - In quest'ultima parte si tratta della geologia terziaria e quaternaria del bacino piemontese in rapporto colla orografia, coll'Idrografia (sia superficiale che sotterranea), coll'Agricoltura, coll'Industria, Igienc, ecc. Riguardo a ciascuna di queste parti, costituenti altrettanti capitoli, è esaminato singolarmente ognuno degli orizzonti geologici descritti nella parte II. 
Al lavoro vanno unite diverse carte geologiche, cioè: $1^{\circ}$, Carta geologica del Bacino terziario hel Piemonte (scala di l : 100.000, dimensioni centim. $100 \times 120$, con 16 colori, legata su-tela, entro astuccio); - $2^{\circ}$ Carta geologica del Bacino quaternario dcl Piemonte (scala di 1:500.000); $-3^{\circ}$, Carta geologica applicata (scala di 1:500.000); - 4"19 Carte geologiche, in grande scala, delle più interessanti regioni del Bacino terziario, cioè: ad 1:50.000, Spigno Monferrato, Voltaggio, Ovada, Ceva e Garessio, Cairo Montenotte; ad l:25.000, Serravalle Scrivia, Gavi, Villalvernia e Garbagna, Anfiteatro morenico di Rivoli (centim. $110 \times 100$ ), Acqui, Capriata d'Orba, Fossano, Nizza Monferrato e Sezzè, Mombercelli e Canelli, Canale e Monteu Roero, Calımandrana, Costigliole d'Asti, 1 Colli torinesi (centim. $110 \times 100$, 12 colori), Cherasco e Cervere.

N. B. Numerose altre carte speciali del Bacino piemontese ranno unite a speciali lavori, recenti, indicati nella Bibliografia.

PREZZI :

1 Volume (legato in telia) colle 3 prime carte geologiche: in $-4^{\circ}$ L. 40 ; in $-8^{\circ}$ L. 3i) " 》 " 》 $\gg$ ma senza il

Catalogo paleontologico (pubblicato nel Boll. Soc. geol. it.), in- $8^{\circ}$ L. 20 Le 19 carte geol. in grande scali L. 30; ciascuna (eccetto 2 gr.) L. 1,50-2,50 La sola $1^{\text {a }}$ Carta geologica del Bacino terziario (leg. in tela, entro astuccio) L. 10

\section{MOLLUSGII \\ dei terreni Terziarii del Piemonte e della Liguria}

Questa opera grandiosa, ben nota ai Paleontologi, venne iniziata nel 1872 dal Prof. Luigi Bellardi che ne pubblico le prime 5 parti, comprendenti i Cefalopodi, gli Eteropodi, i Pteropodi e dei Gasteropodi le seguenti famiglie: Muricidae, Tritonidae, Pleurotomidae, Buccinidae, Cyclopsidae, Purpuridae, Coralliophilidae, Olividae, Fasciolaridae, Turbinellidae e Milvidae.

ll Prof. Saceo, allievo ed amico del Bellardi, dietro incarico avuto dalia R. Accademia delle Scienze di Torino, condusse a termine la parte $6^{\text {, giá }}$ iniziata dal Bellardi, e quindi intraprese la continuazione dell"opera, che ora trovasi a questo punto:

Parte Vl. - Volutidae, Manoginellidae e Columbellidae con l 10 figure.

Parte VIl. - Harpidae e Cassididae - con 120 fig.

Parte Vlll. - Eudlolidae, Doliidae, Ficulidac Maticidae con oltre $200 \mathrm{fig}$.

Parte IX. - Scalaniidace (in corso di stampi).

Parte X. - Terebuidae, Dusionellidac, Pyramidellidue,

thingiculidac, Eulimidac e Solaridac (in preparuzione). 


\author{
OPERE DELLO STESSO AUTORE \\ in deposito presso la Libreria Loescher (C. Clausen) - Torino
}

\title{
G E O L G I A
}

1. L'alta Valle Padana durante l'epoca delle terrazze in relazione col contemporaneo sollevamento della circ. cat. alpino-apenninica (l cart. geol.).

2. Nuove caverne ossifere e non ossifere nelle Alpi marit. ed osservazioni geol. fatte durante un'ascensione al Mongioie ( 2 tav. ed l carta geol.).

3. Sull'origine delle vallate e dei lagh alpini in rapporto coi sollevamenti delle Alpi e coi terreni pliocenici e quaternari della Valle Padana (1 cart. geol.).

4. Sopra alcuni fenomeni stratigrafici osservati nei terreni pliocenici dell'alta Valle Padana ( 1 tav.).

5. Massima elevazione del Pliocene al piede delle Alpi (l carta geol.).

6. Studio geo-paleontologico del territorio di Bene-Vagienna (l gr. carta geol.).

7. La valle della Stura di Cuneo dal ponte d'Olla a Bra e cherasco (l tav.).

8. Massima elevazione dell'Eocene nelle Alpi occ. italiane (1 carta geol.).

9. Sulla costituzione geolica degli altipiani isolati di Fossano, Salmour e Banale (l grande carta geol).

10. II piano Messiniano nel Piemionte. Parte l.

11. 》" 》 $" 11$ (l tav.).

12. Des phénomènes altimétriques observés dans l'intérieur des continents.

13. Il Villafranchiano al piede delle Alpi (l tav.).

14. 11 terrazzamento dei littorali e delle vallate ( 1 tav.).

15. I Bacini torbiferi di Trana e di Avigliana (l carta geol.).

16. Le Fossanien: nouvel étage du Pliocène d'ltalie.

17. I terreni terziari del Piemonte e della Liguria (foglietto d'annunzio).

18. l terreni quaternari della collina di Torino (l grande carta geol.).

19. 1 terreni terziari e quaternari del Biellese (1 grande carta geol.).

20. Le tremblement de terre du 23 février 1887.

21. I Colli torinesi (foglietto esplicativo).

22. Studio geologico dei dintorni di Voltaggio (l carta geol.).

23. On the origin of the Great Alpine Lakes.

24. L'anfiteatro morenico di Rivoli (l carta geol.).

25. Studio geologico dei dintorni di Guarene d'Alba (1 carta geol.).

20. Il passaggio tra il Liguriano ed il Tongriano (l grande carta geol).

27. Classification des terrains tertiaires conforme à leur facies.

28. Sur l'origine du Loess en Piémont.

29. Il cono di deiezione della Stura di Lanzo (l carta geol.).

30. Studio geologico delle colline di Cherasco e della Morra in Piemonte (l grande carta geol.).

31. Il Pliocene entroalpino di Valsesia (l grande carta geol.).

32. Les terrains tertiaires de la Suisse.

33. l Colli braidesi (l grande carta geol.).

34. Le Ligurien.

35. Sopra due tracciati per un tronco della linea Torino-Chieri-Piovà-Casale.

36. Sopra un progetto di serbatoio in Valle Usseglia.

37. Un coin intéressant du tertiaire d'Italie (1 grande carta geol.).

38. I Colli monregalesi (1 grande carta geol.).

39. 11 seno terziario di Moncalvo (l carta geol.).

40. Les conglomérats du Flysch (2 tav.).

41. La conca terziaria di Varzi-S. Sebastiano (l grande carta geol.).

42. La caverna ossifera del Bandito in Val Gesso (l tav.).

43. Relazione geologica sopra un progetto di derivazione d'acqua dal torrente Giandone (l carta geol.). 
44. Sur la position stratigraplique des charbons fossiles du Piémont.

45. La géotectonique de la Haute ltalie septentrionale (l carta geol).

46. Il Bacino terziario e quaternario del Piemonte (Bibliografia - Geolologia pura - Paleontologia - Geologia applicata). Volume di 940 pagine (3 grandi carte geol.).

47. Con M. Baretti - Il Margozzolo (2 carte geol. e 3 tav.).

\section{PALEONTOLOGIA}

48. Nuove specie di Molluschi lacustri e terrestri del Piemonte (1 tav.).

49. Fauna macologica delle alluvioni plioc. del Piemonte (2 tav.).

50. Nuove specie terziarie di Molluschi terrestri, d'acqua dolce e salmastra del Piemonte ( 2 tav.).

51. Studio geo-paleontologico sul Lias'dell"alta Valle della Stura di Cuneo.

52. Sopra una nuova specie di Discohelix Dunker (1 tav.).

53. Sur quelques restes fossiles du Pliocene du Piémont (con fig.).

54. Rivisti della Fauna malacologica fossile terrestre, lacustre e salmastra del Piemonte.

55. Aggiunte alla Fauna malacologica estramarina fossile del Piemonte e della Liguria (2 tav.).

56. Sovra aleuni Potamides del Bacino terziario del Piemonte (4 tav.).

57. Note di Paleoicnologia italiana (2 grandi tav.).

58. 1 Cheloni astiani del Piemonte (2 tav.).

59. Sopria una mandibola di Balaenoptera dell"Astigiana (l tav.).

60. I Molluschi dei terreni terziari del Piemonte e della Liguria. Parte VIl (Harpidae e Cassididae.) - (Nota preventira).

61. I Molluschi dei terreni terziari del Piemonte e della Liguria. Pirte Vil (Harpidae e Cassididae (120 figure).

62. I Molluschi dei terreni terziari del Piemonte e della Liguria. Parte r'lli (Galeodoliidae. Doliidae, Ficulirlae e Naticidae). - (Notil preventiral.

63. I Molluschi dei terreni terziari del Piemonte e della Liguria. Parte Vill (Galeodoliidae, Doliidae, Ficulidae e Naticidae) - (oltre 20 figure).

64. I Molluschi dei terreni terziari del Piemonte e della Liguria. Parte IX (Scalaridae) - (in corso di stampa).

65. I Molluschi dei terreni terziari del Piemonte e della Liguria. P.nte X (Terebridae, Pusionellidae, Pyramidellidae, Ringiculidae, Eulimidae e Solariidae - (in preparazione).

66. Con L. Bellardi - I Nolluschi dei terreni terziari del Piemonte e iella Liguria. Parte Vl (Volutidae, Columbelliclae e Marginellidae) - (con 140 rigure).

\section{CARTE GEOLOGICHE.}

Alla scala di l : 50.000: - 67. Spigno MIonferrato - 68. Voltaggio N. - 69. Orada N. - 70. Ceva S. e Garessio N. - 71. Cairo Montenotte O. Alla scala di 1:25.000 - 72. Serravalle Serivia - 73. Gavi - 74. Villavernia e Garbagna 0. - 75. Acqui - 76. Capriata d Orba - 77. Fussano - 78. Nizzia IIonferrato e Sezzè 0. - 79. Mombercelli e Canelli N. - 80. Canale e Mlonten Roero E. - 81. Calamandrana - 82. Costigliole d'Asti - 83. Cherasco e Cervere - 84. Colli torinesi (12 colori ; diametro centim. $100 \times 110$ ) -85 . Anfiteatro morenico di Rivoli (diametro centim. $100 \times 110$ ).

\section{BIOGRAFIE.}

86. Luigi Bellardi (Biografia di) - (con ritratto).

87. Louis Bellardi (Biographie de) - (con ritratto).

\section{ZOOLOGIA.}

88. Sulla presenza dello Spelerpes fuscus (Bonap.) in Piemonte. 



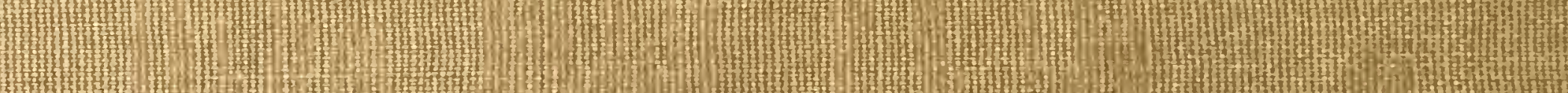

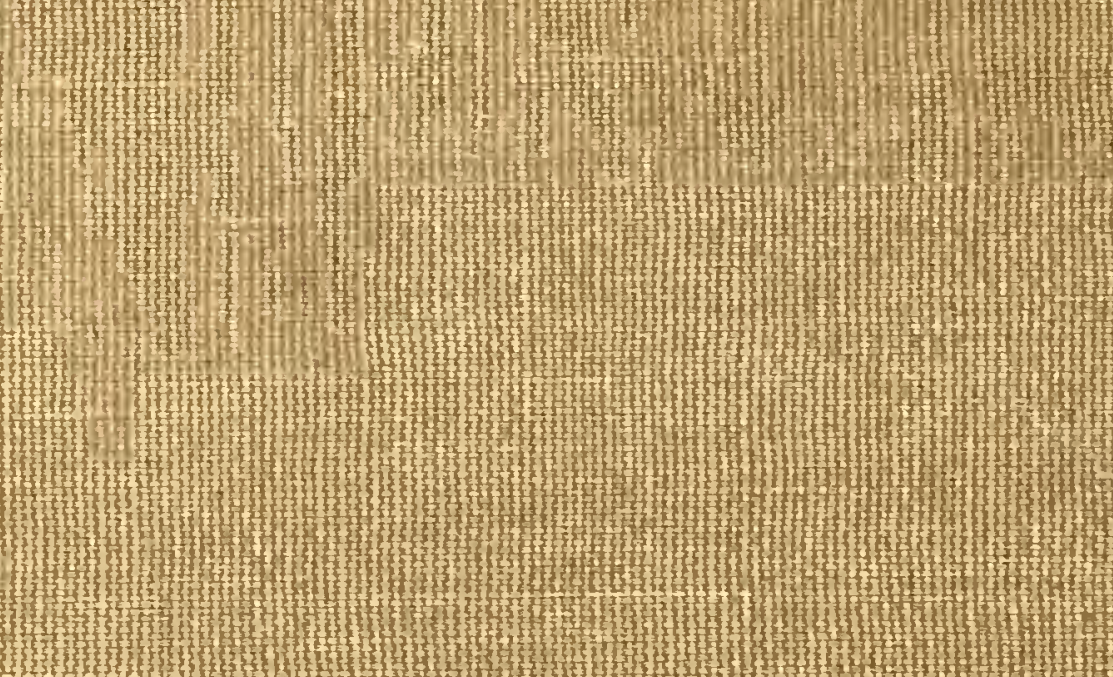

$$
\begin{aligned}
& m \\
& m
\end{aligned}
$$

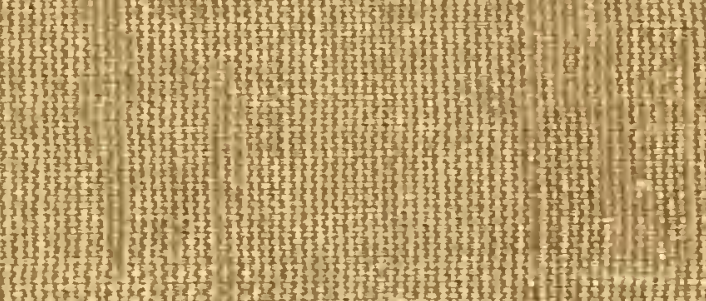

mWm

Whth

mith

Why

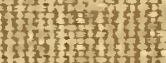

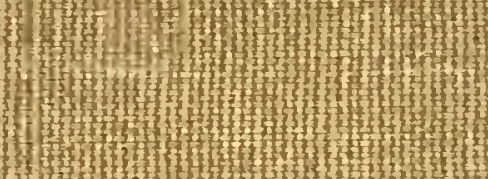

Mmb

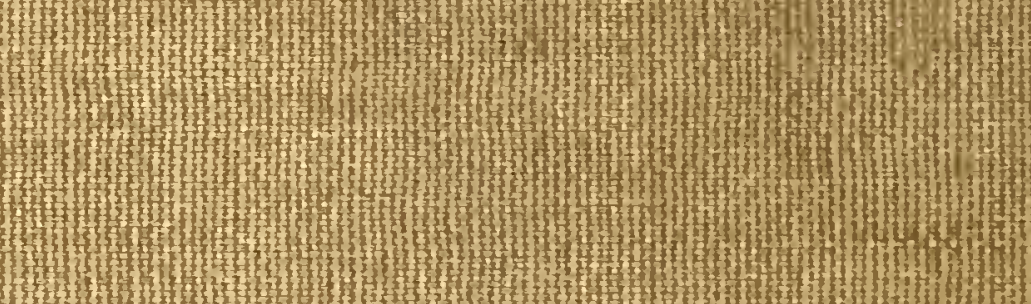

Em

mum

m

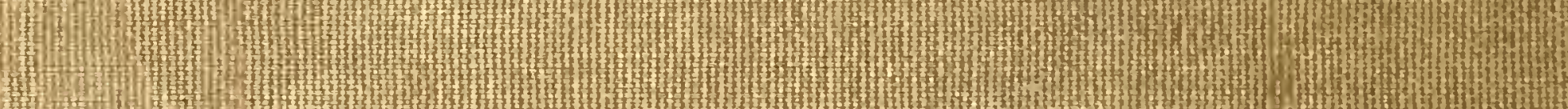
m)

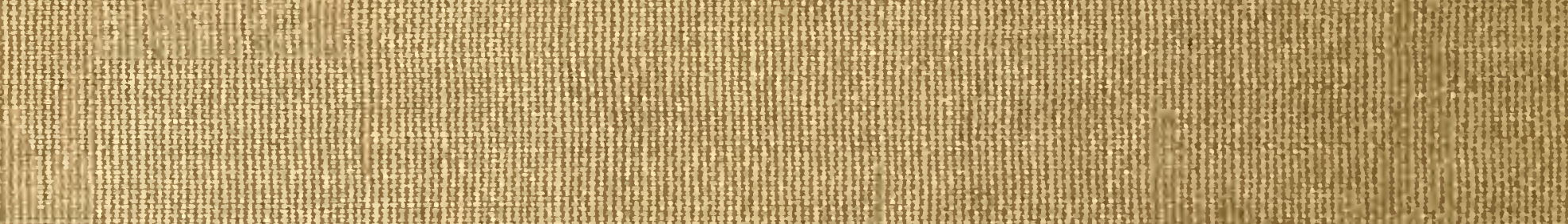

(1)

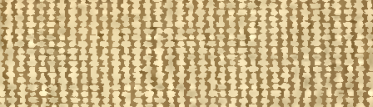

